Fall 2002

\title{
2002 Miracle Yearbook
}

Cedarville University

Follow this and additional works at: https://digitalcommons.cedarville.edu/yearbooks

Part of the Higher Education Commons, Organizational Communication Commons, and the Public Relations and Advertising Commons

\section{Recommended Citation}

Cedarville University, "2002 Miracle Yearbook" (2002). Yearbooks. 6.

https://digitalcommons.cedarville.edu/yearbooks/6

This Book is brought to you for free and open access by DigitalCommons@Cedarville, a service of the Centennial Library. It has been accepted for inclusion in Yearbooks by an authorized administrator of DigitalCommons@Cedarville. For more information, please contact digitalcommons@cedarville.edu. 


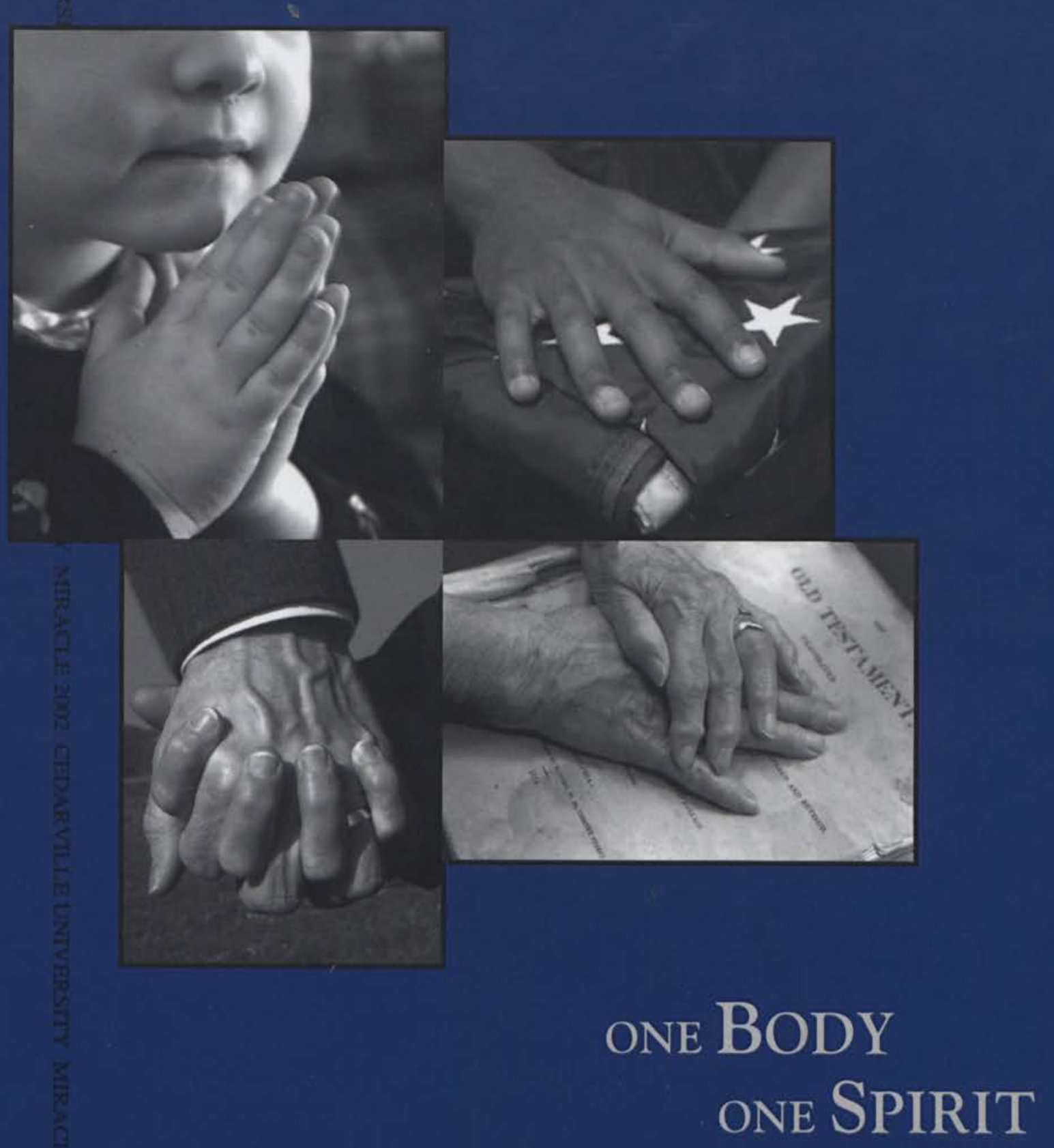







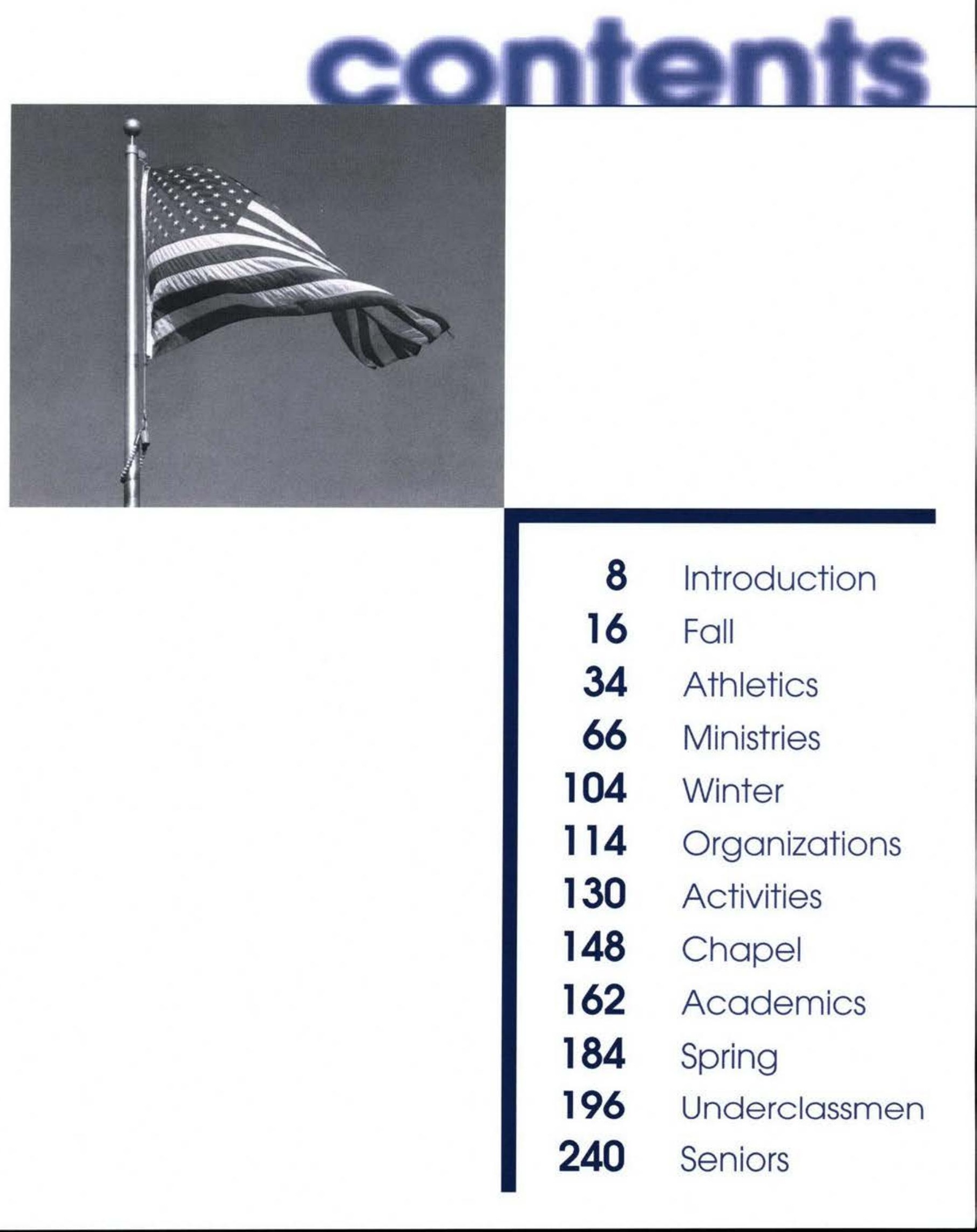




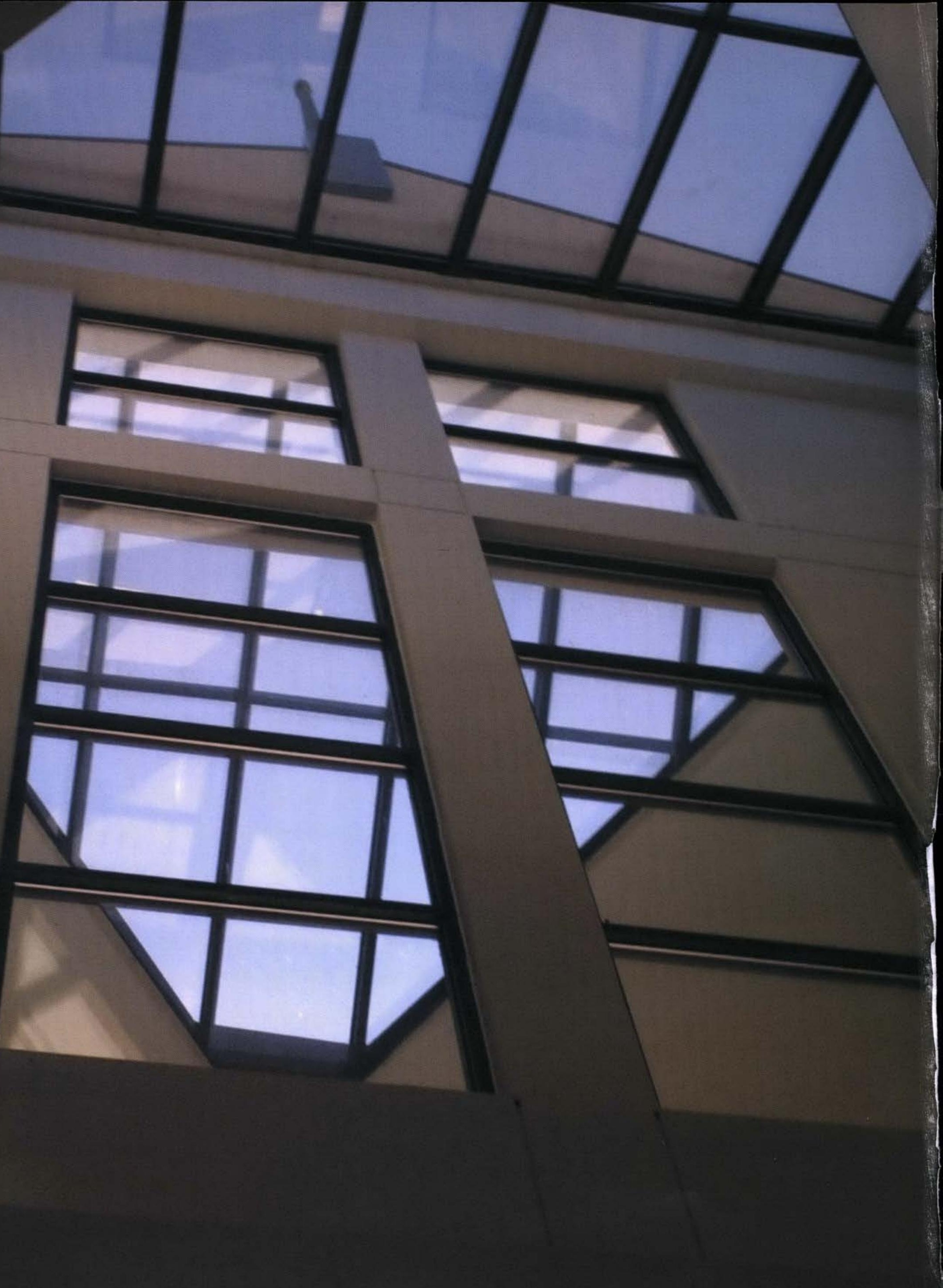




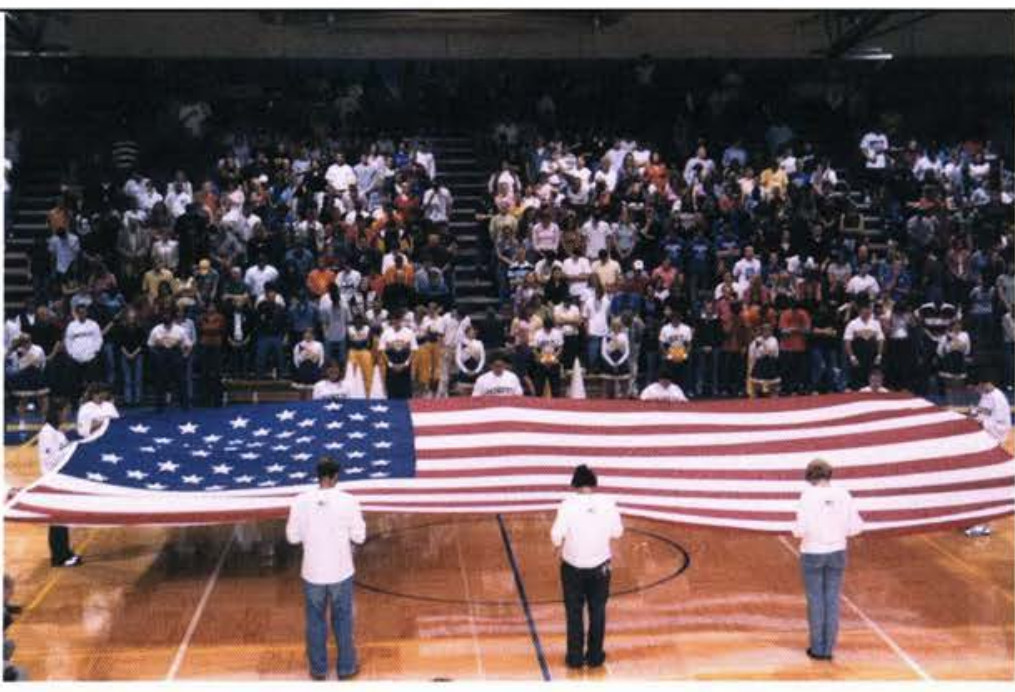

Father, we come to you in spirit and truth with our

heart and our mind. Father, I want to keep the unity

of the spirit in the bond of peace. One body,

One spirit. One hope of our call. One faith and

one baptism. One Father of all, Who is above all and

through all and in us all. Oh, Lord, let forgiveness rain

down. Let your unity resound in our heart. Oh, Lord,

let us learn to forgive. Let your children learn to live as

one Body. 


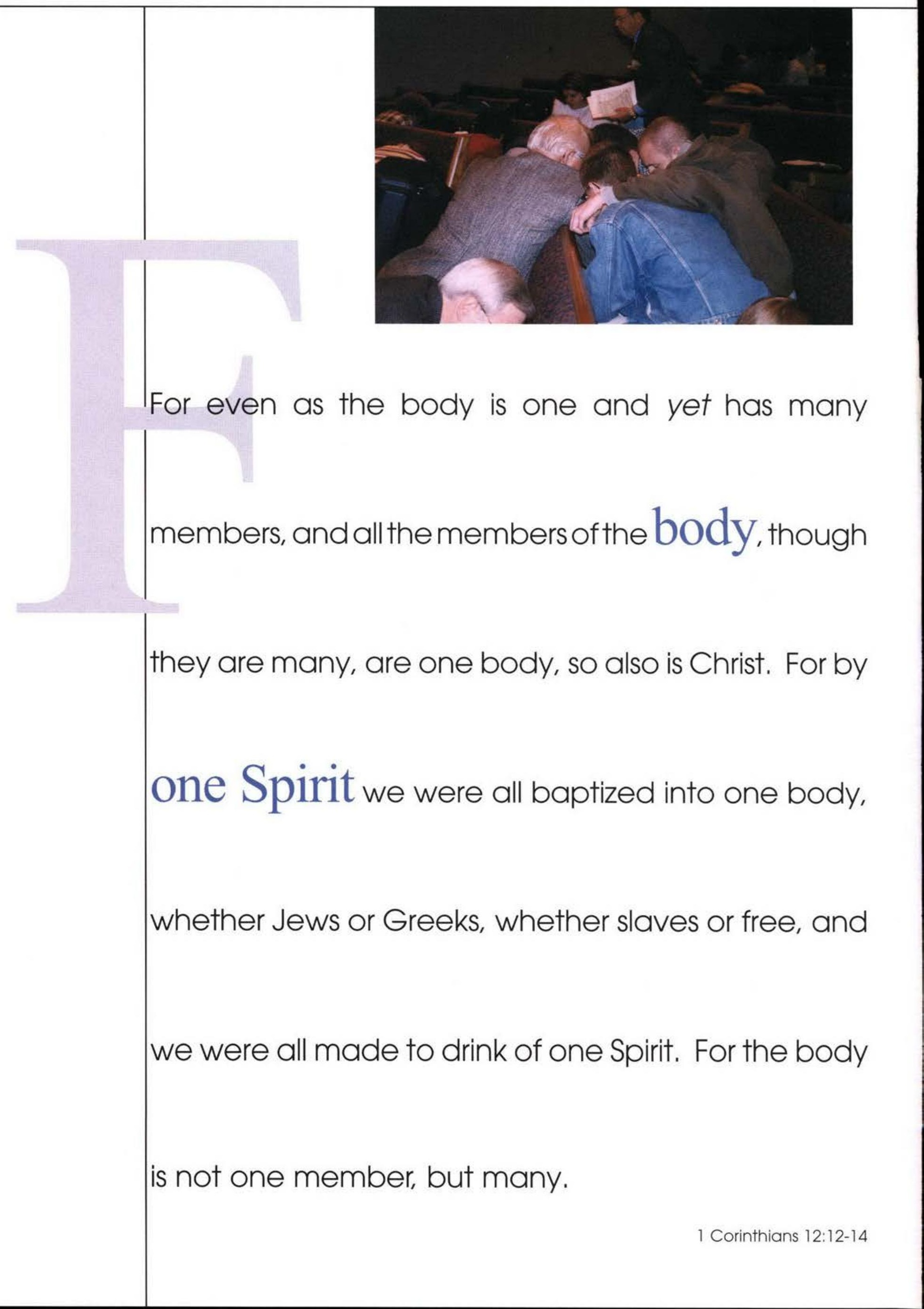





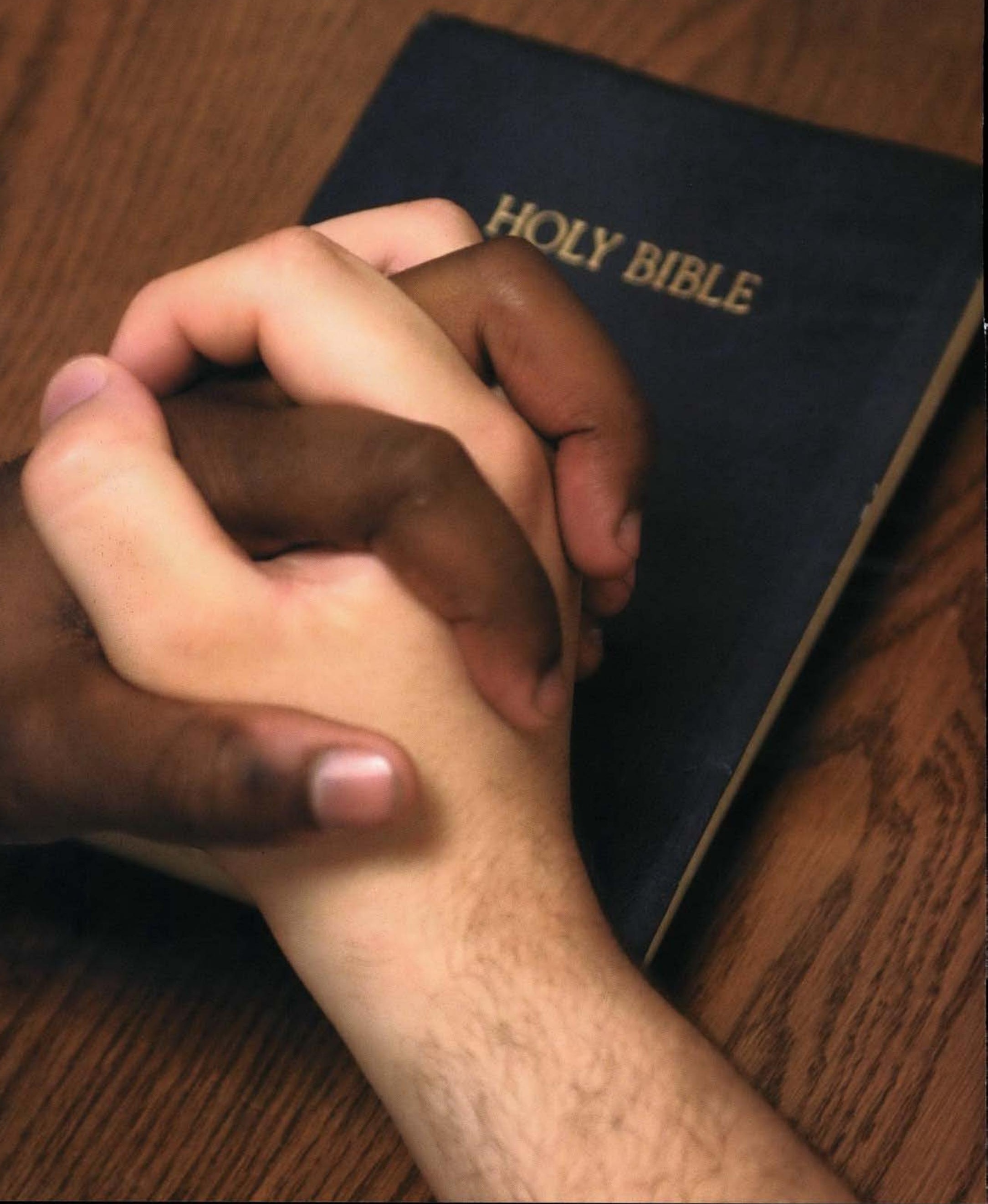




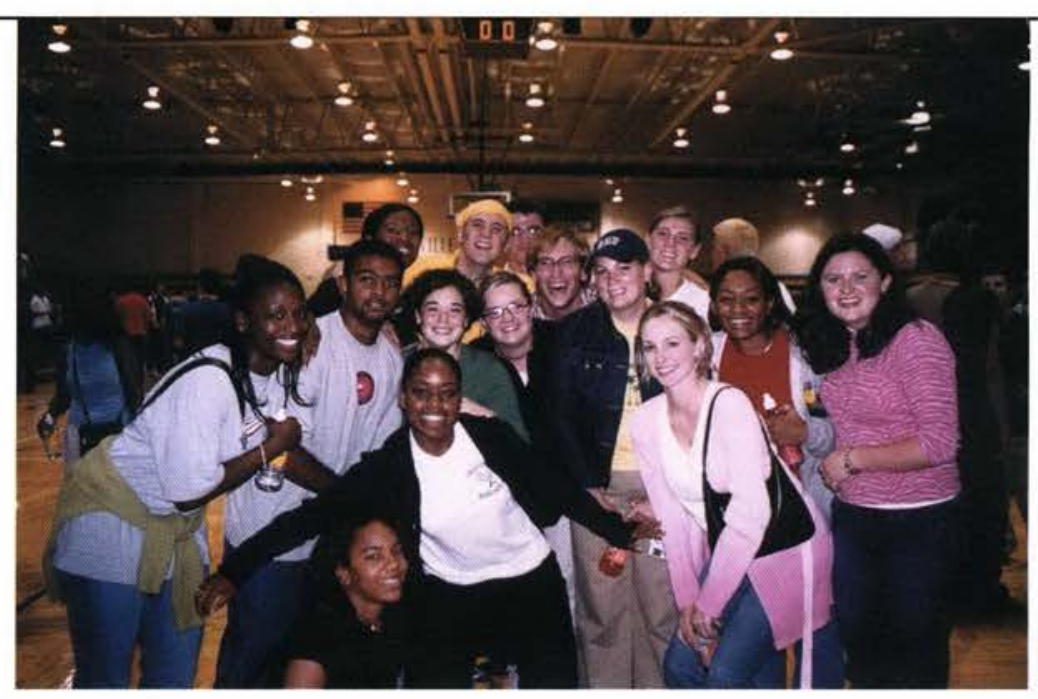

Since its establishment, the purpose of the University

has remained unchanged: to offer an education

consistent with Biblical truth. One way to acheive this

purpose is by building a student body that better reflects the diversity of the body of Christ (Acts

10:35) in ways that benefit all members of the

Cedarville family. 


\section{faithful servant}

\section{Dr. Danald Baumann}

A friend to students and a respected colleague in the Department of Science and Mathematics, Dr. Donald Baumann was a faithful servant to his Savior and Cedarville for thirty-six years.

$\mathrm{He}$ and his wife, Carol, have been married for 38 years and enjoy spending quality time with each other. When he was not busy in the ENS, he enjoyed spending time gardening fruit and vegetables.

Dr. Baumann received his B.S. (1960), M.S. (1962), and Ph.D. (1964)

from Iowa State University.

After coming to Cedarville in 1964, he served as the Chairman of the

Department of Science and Mathematics for over twenty years and also served as

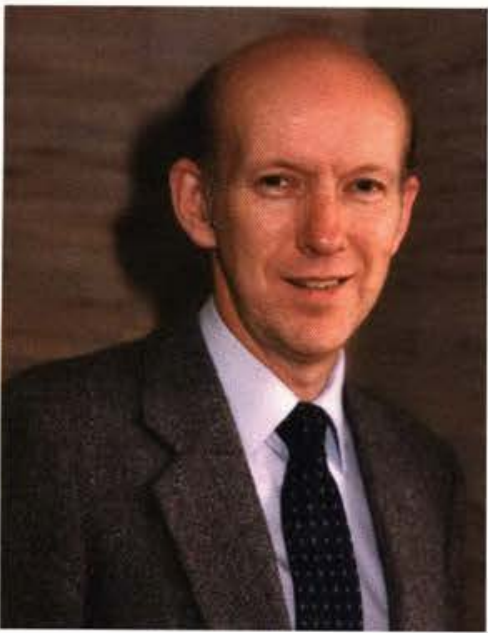

of students in chemistry and biology is a testimony to his commitment to the University and to his students. He loves his students and provides many opportunities for them to be successful in his classes. He spends hours in biochemistry and microbiology labs so that the students get the maximum benefit from their experience," said Dr. Dennis Flentge.

Dr. Larry S. Helmick said, "When he spoke, people listened because what he said was always important and well thought out. Academically, he has taught a broad range of courses in chemistry and biology over the years and has always been well liked by students."

Dr. Baumann maintained an amazing testimony to the Cedarville family

Professor of Biology and Chemistry. His insight contributed to the construction of the Engineering, Nursing, Science facility in 1973.

Baumann impacted the world by joining a number of professional organizations, including the American Institute of Biological Sciences and the Society for Industrial Microbiology.

"I have known Don for twenty-one years and have found him to be an excellent example of a godly servant. His faithfulness in meeting his responsibilities as a department chair for more than 20 years and in teaching large numbers throughout his life, even during his bout with cancer. While battling his sickness, he still remained committed to students and made their needs a priority. He was an example to faculty, staff, and students of a man who was devoted to truth and the service of Jesus Christ, despite difficult circumstances.

Dr. John Silvius said, two decades, I would describe him as a quiet man with a warm heart, a genuine servant spirit, and a testimony that is one of a steady faith in the midst of trial." "Having worked with Don for over
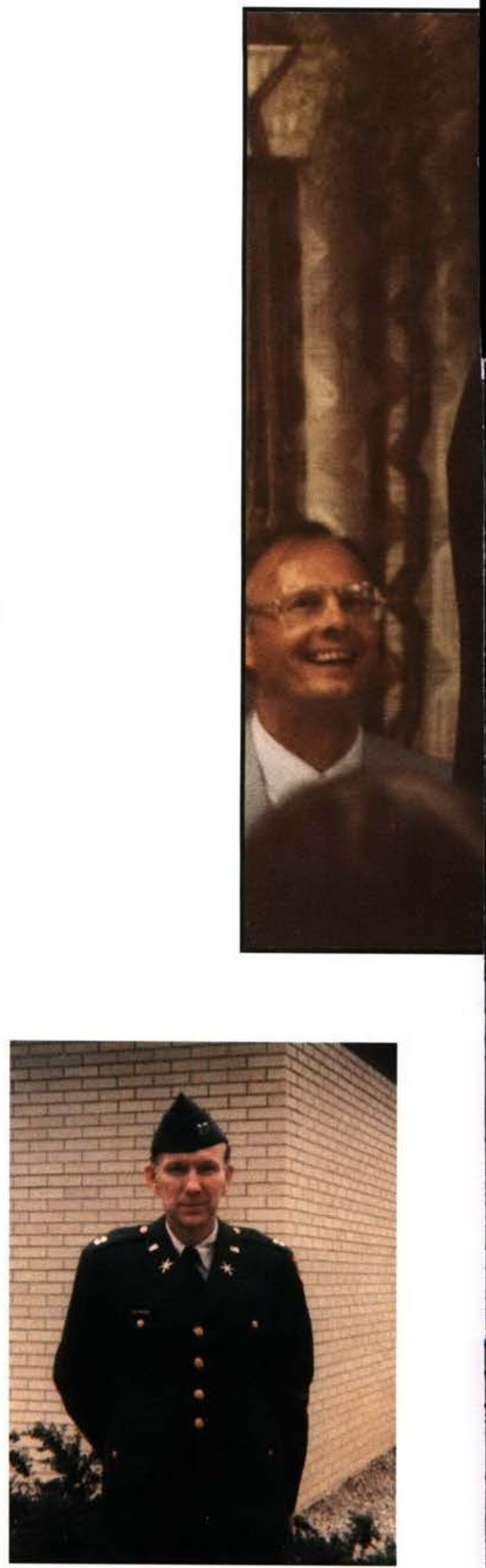
$3-3$

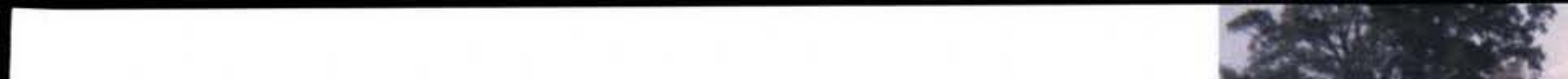

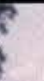

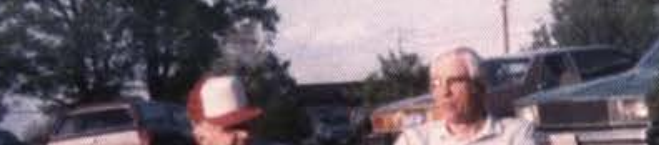

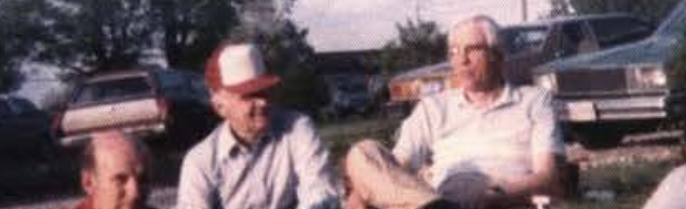

15

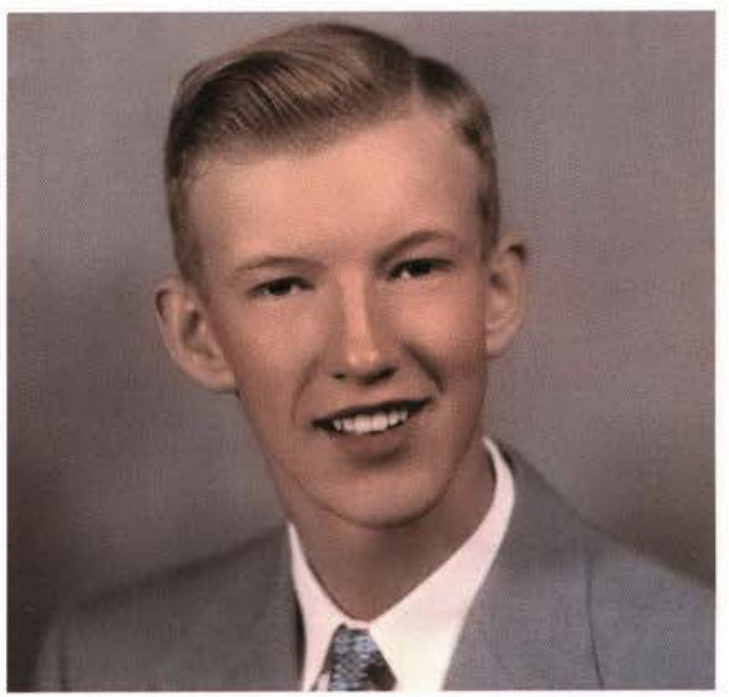

i

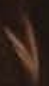

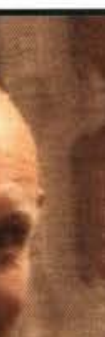

${ }^{20}$

MPC 1
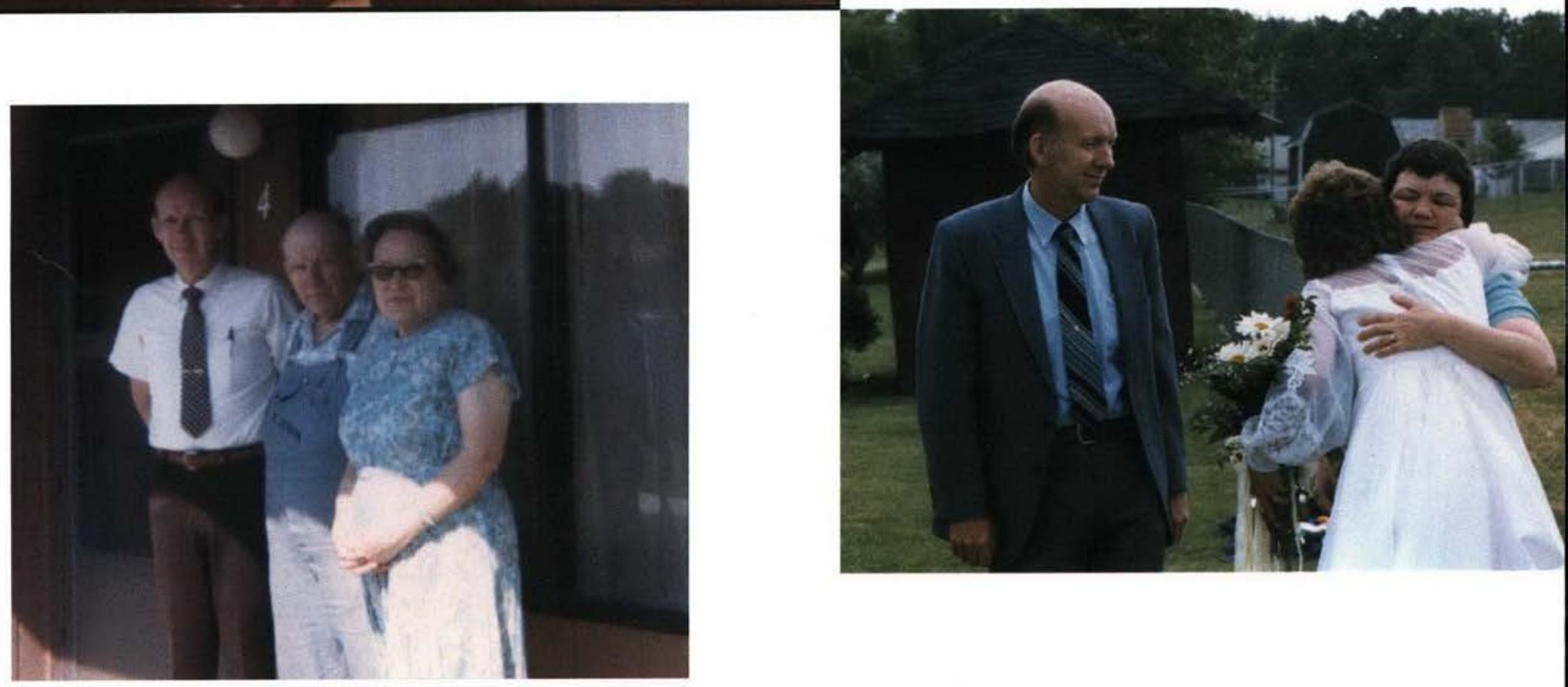


\section{n loving memory of...}

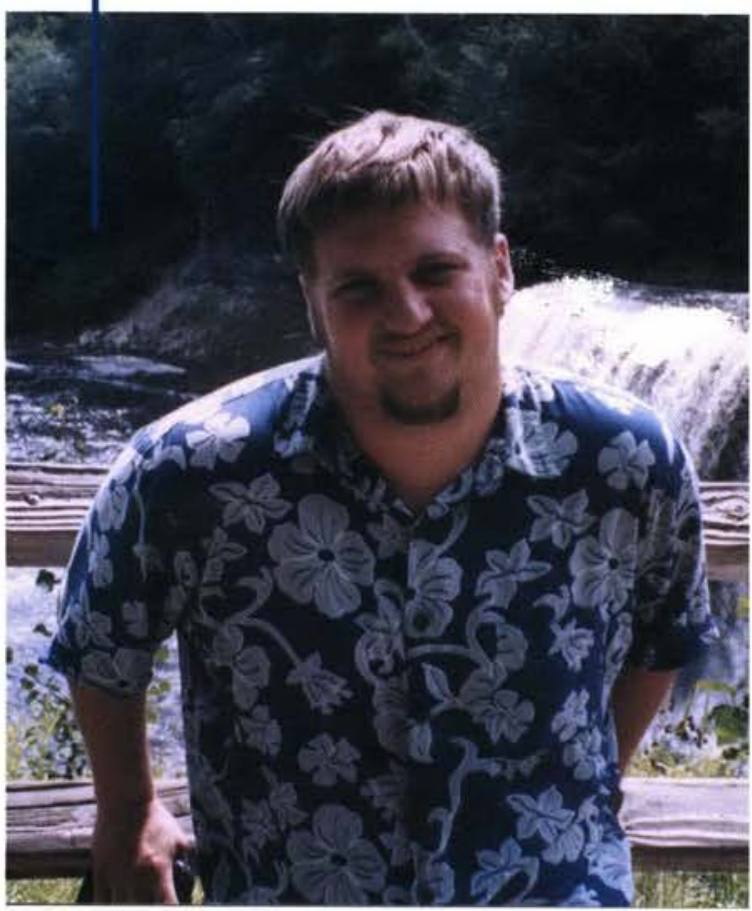

Randall g. Bamwens
Randall J. Bouwens, a mechanical engineering major from Wayland, Michigan, "strived and yearned to be like Jesus during his life on earth," friend Susan Martin said. Known as R.J. to his friends, he was preparing to return to Cedarville for his junior year when a sudden brain aneurysm took him home to be with the Lord. His friends now rejoice that R.J. is in heaven and fondly remember the time they had with him.

"I remember R.J. as an incredibly intelligent, giving and friendly person. He cared about so many people and wanted nothing more than to serve his King. There is so much I could say about a guy who left such an impression on me, but in the end he ran the race and persevered to the end." -Ariel Starbuck

"RJ is the first Christian friend I think I could truly call a brother. We always had a great time together, but the things I'll always remember most are when we would just talk about life, especially our relationship with God. He made me a better Christian, and I loved him as a brother." -Ben Harreld
Mrs. Donna Purple went home to be with the Lord in September of 2001 after a long bout with lung cancer. She used her trial as a platform to share God's Word through speaking opportunities, appearances in magazines, and personal encouragement to other cancer patients and their families. Her husband Jon and daughter Jessica, along with friends and family, grieved her passing but rejoiced that she was free of pain and in the presence of her Master.

"Donna fought for life up until the end, trusted in God's goodness, looked for opportunities in the most negative circumstances, never gave up, and kept on serving God." - Dr. Phil Bassett

"Donna's personality was always upbeat and positive. That doesn't mean she wasn't honest with how she was feeling... What a model she was of selflessness." - Dr. Timothy Heaton

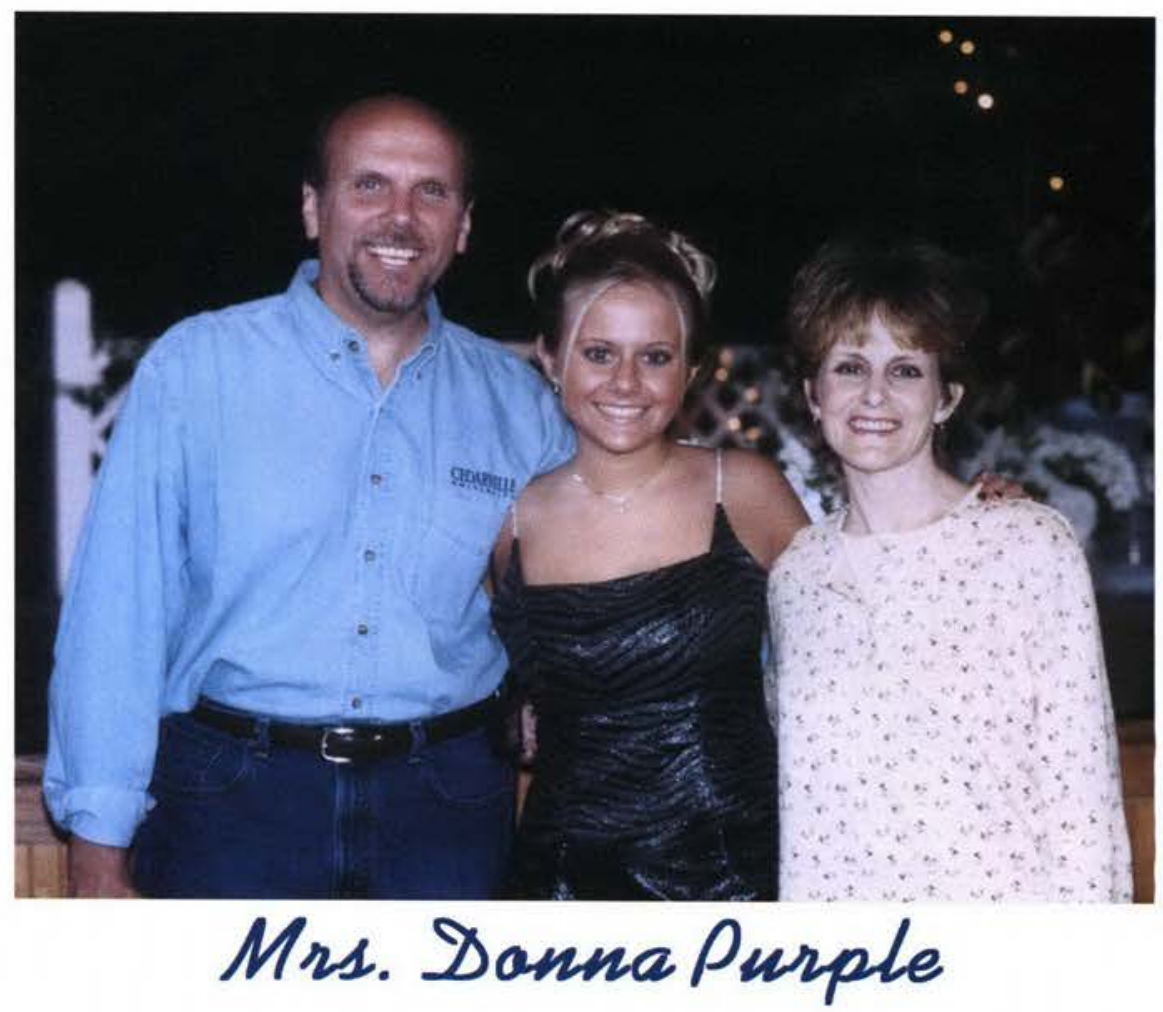




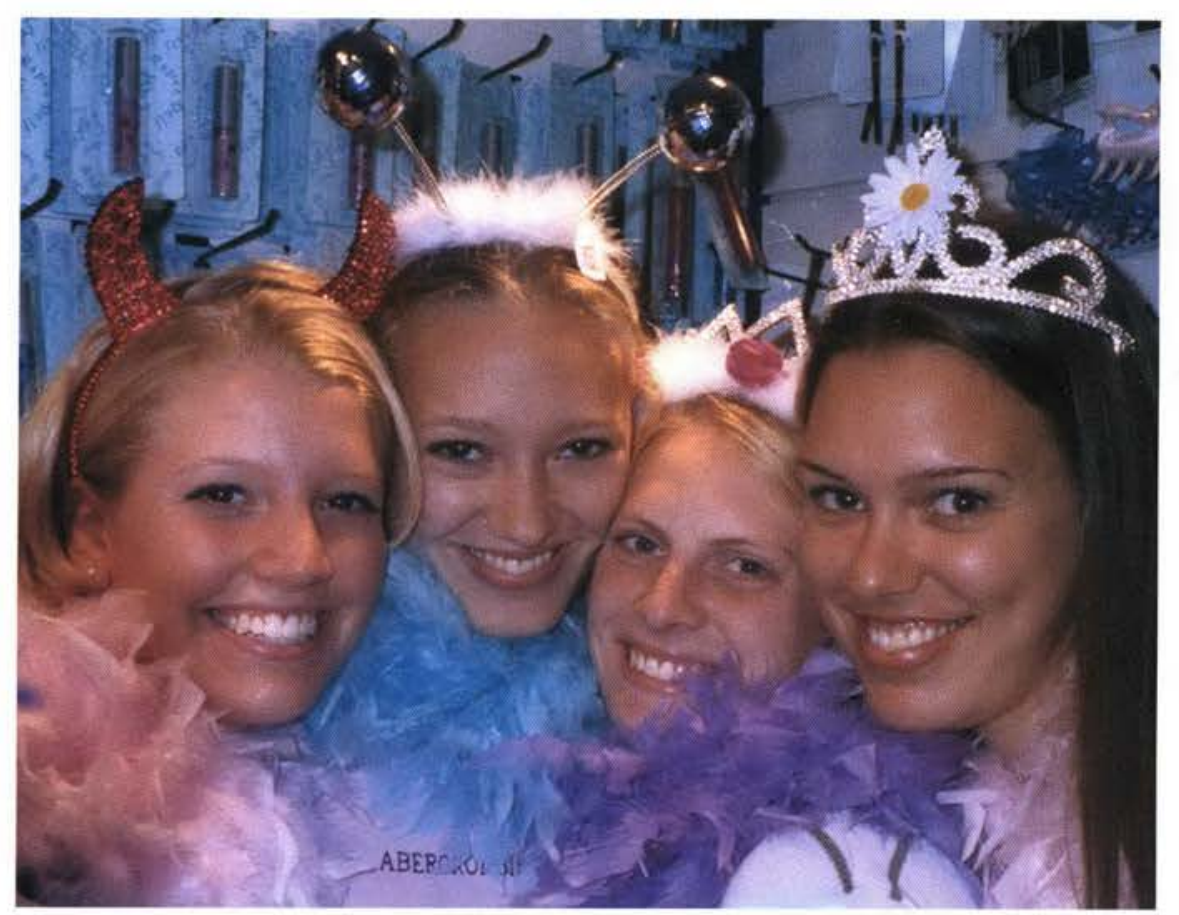

Lisa Herman

Professor Morley Halsmith went home to be with Jesus on February 12, 2002, after serving at Cedarville for a little more than five months. Despite the brevity of his time at the university, students and faculty loved this man of God and learned from his testimony. After he came to Cedarville to serve as Assistant Professor of Church Music and the director of Jubilate, Professor Halsmith learned that his cancer had returned. However, he continued to mentor his church music majors and used this opportunity to impact the lives of his students.

"Professor Halsmith was a man with the proper perspective. $\mathrm{He}$ didn't focus on cancer and death, but on God, family, others, and life. Mr. Halsmith was truly an inspiration to me." - Ben DeLong

"Morley Halsmith was only with us for less than a year. In that short time, however, he became a good friend. The physical trials that he faced gave him an extraordinary understanding of the meaning of an intimate relationship with God and of trusting God with his entire life. His friendship and leadership will be greatly missed." - Dr. James Colman
Lisa Herman, a freshman nursing major from Cleveland, Ohio, passed away on Monday, April 8, 2002. Herman went to the doctor for a routine check up and found that she had a cancerous tumor in her chest. After a difficult and heartbreaking battle, Lisa left behind her mother and father, a or. Ciıristy, who was a junior at Cedarville, and four brothers John, Joel, Paul, and Peter. During her brief time at Cedarville, Lisa was able to make a deep impact on her friends and unitmates.

"Lisa was a very godly woman. She was definitely an example that all of us can look to. She was a genuine, on-fire Christian." - Nicole Jewell

"God truly blessed me by giving me such a beautiful, loving, and passionate sister. I believe that she blessed each life that she touched." - Christy Herman

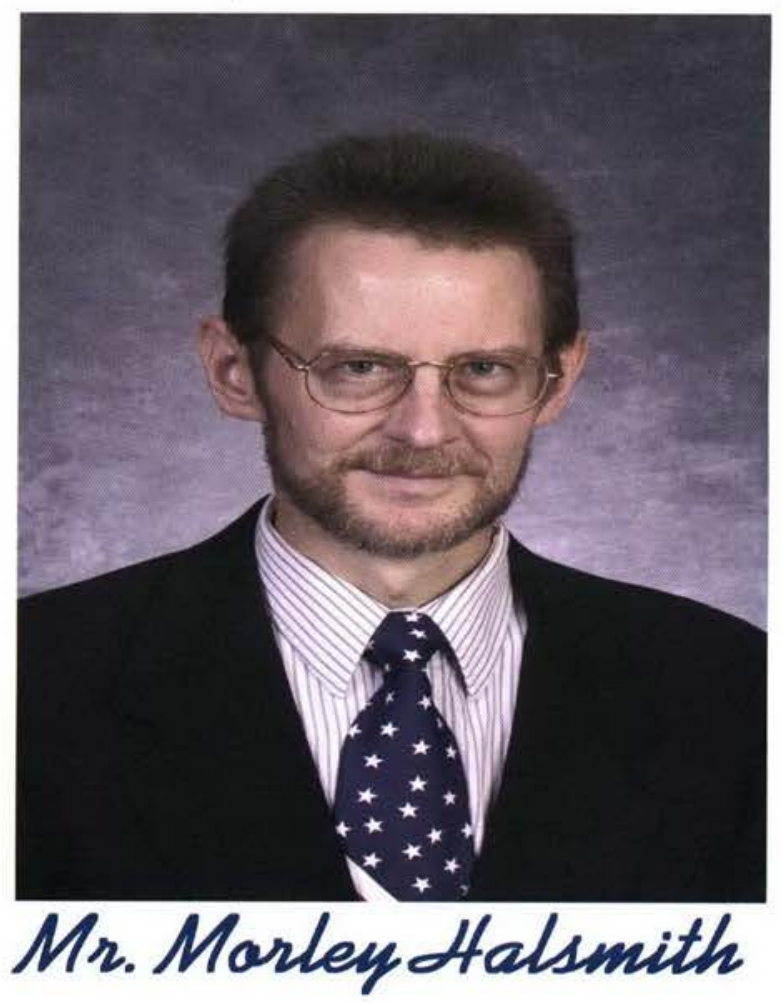




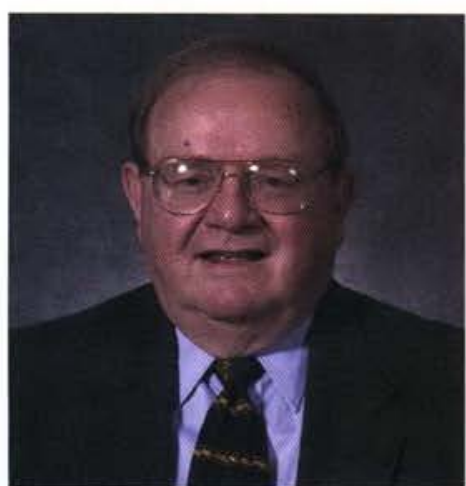

Eugene Apple

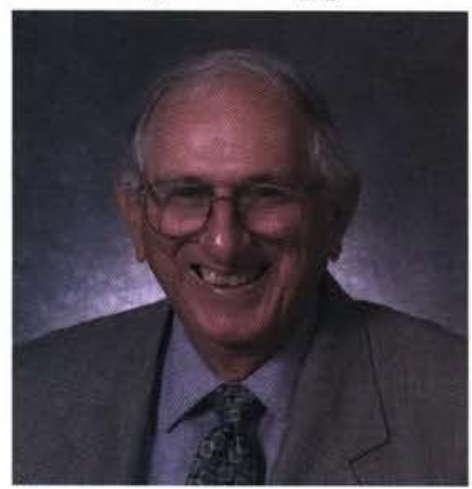

Francis Bresson

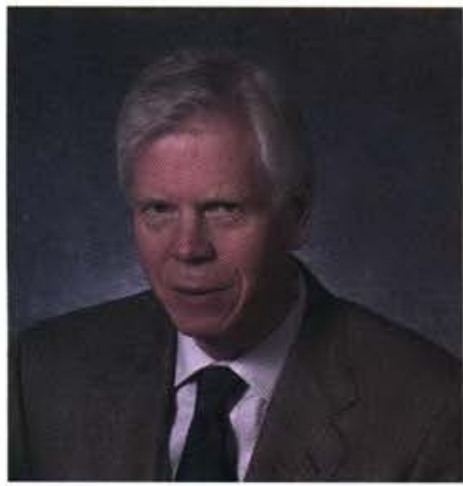

James DeVries

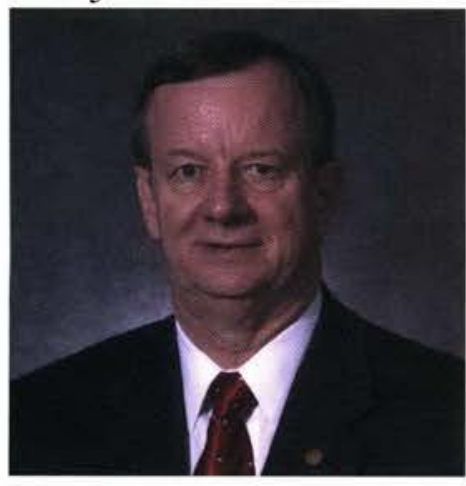

David Gower

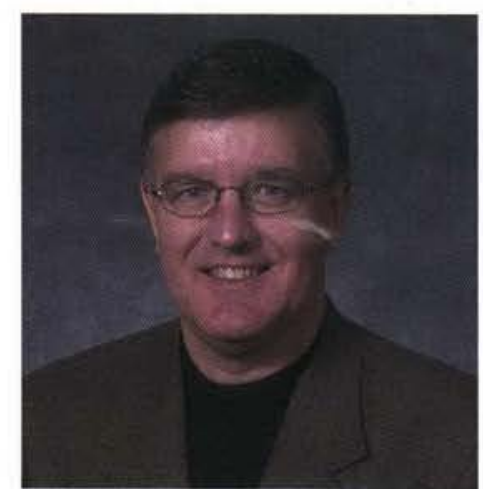

William Bernhard

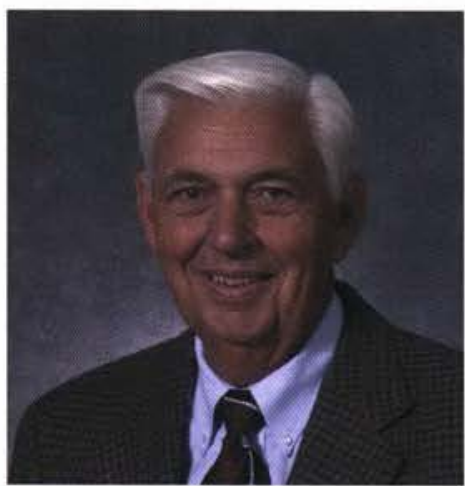

Gilbert Bruekner

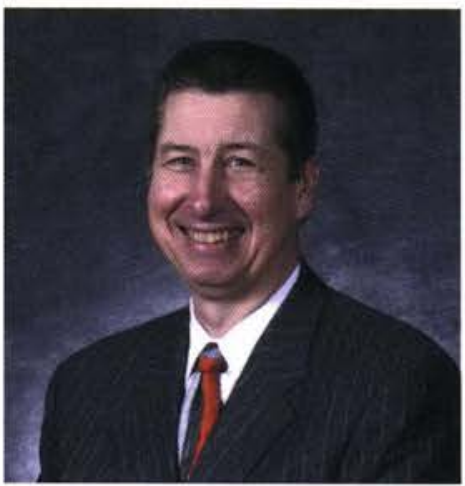

Daryle Doden

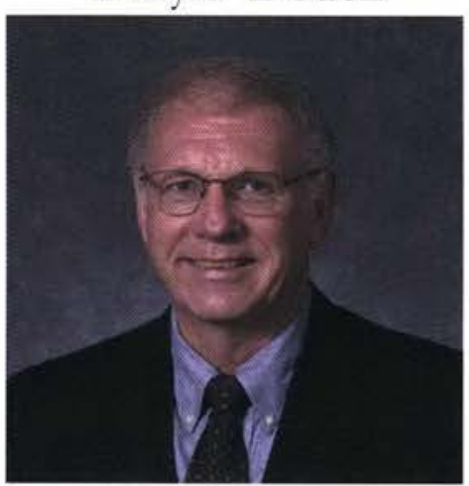

David Graham

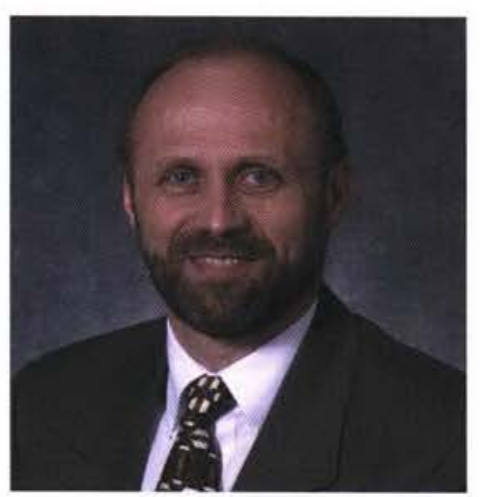

John Blodgett

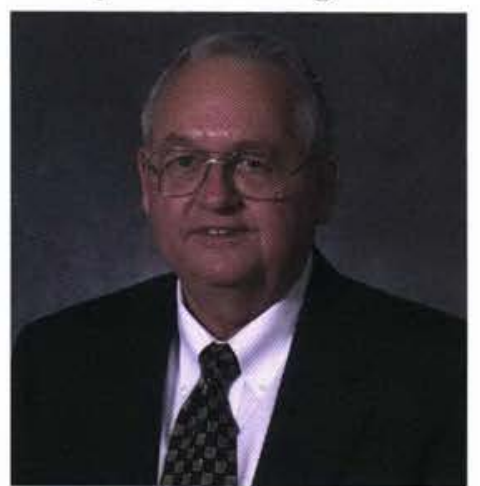

James Carraher

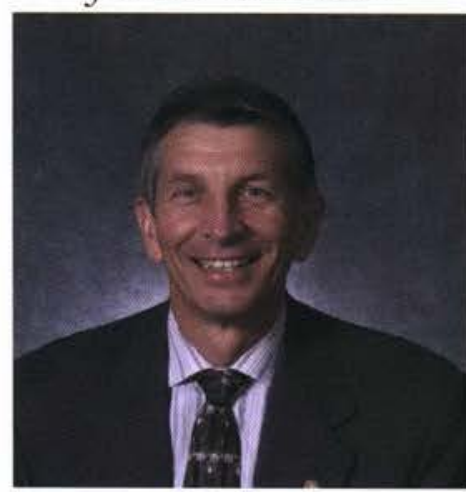

James Englemann

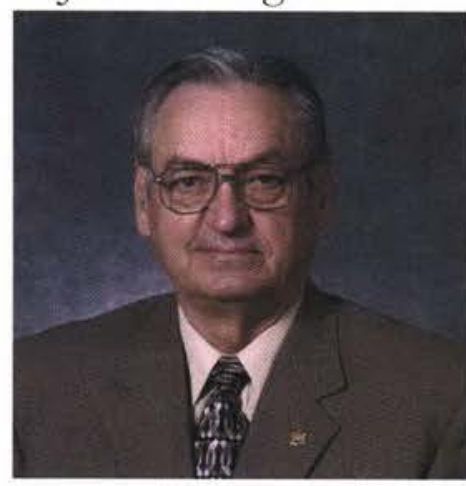

Roy Guenin

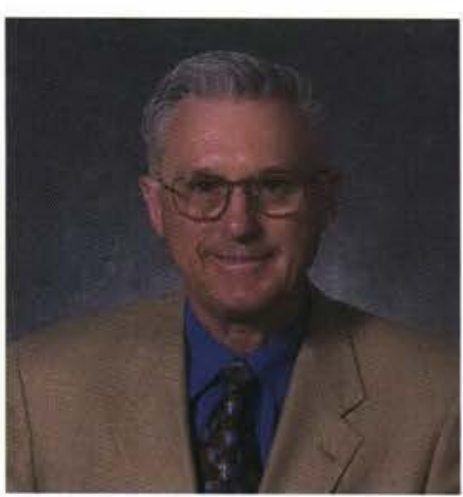

William Bolthouse

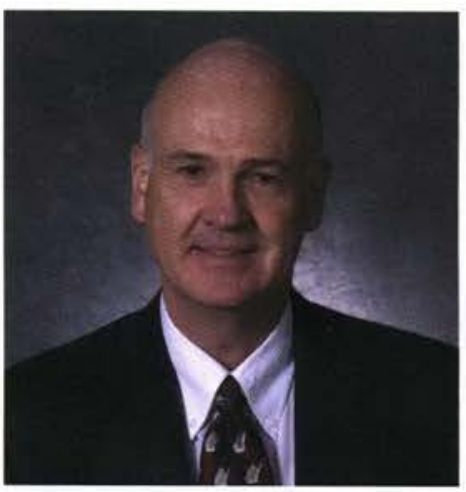

William Commons

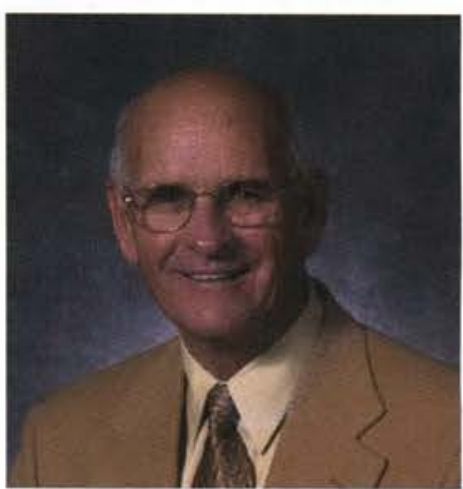

Joeseph Godwin

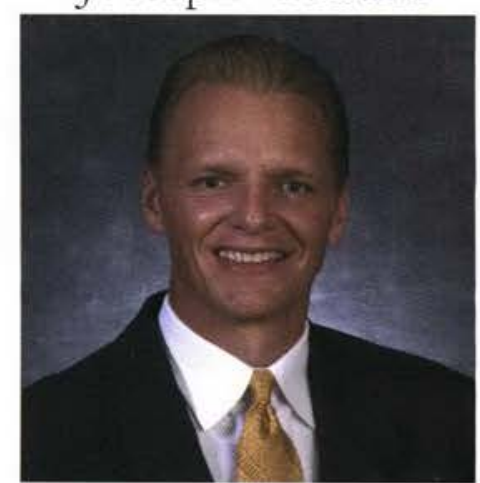

John Haynes 


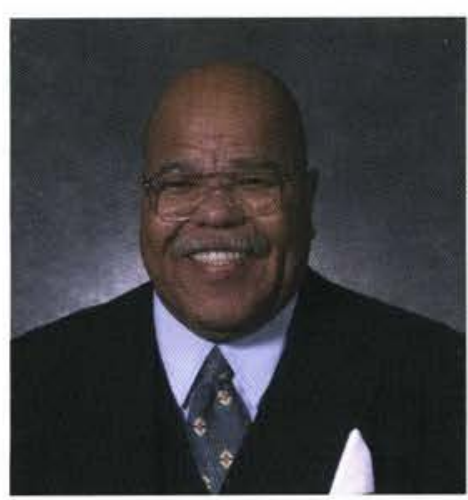

E. L Hawkins

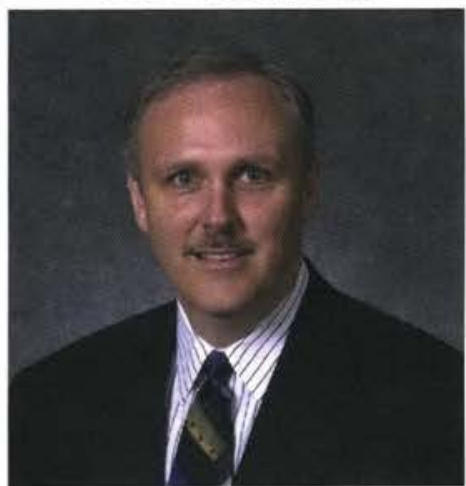

Donald Moran

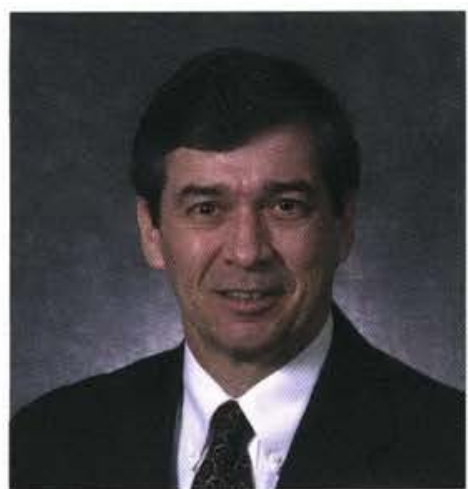

William Rudd

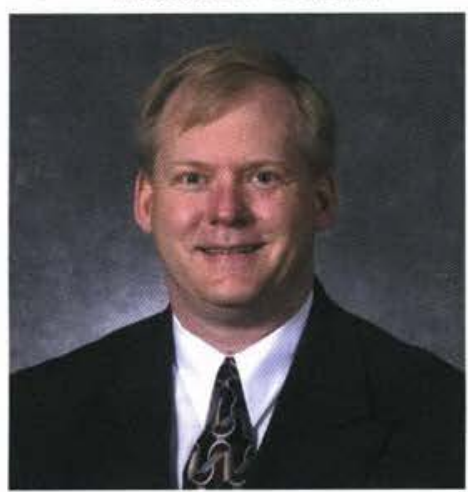

Bruce Sparks

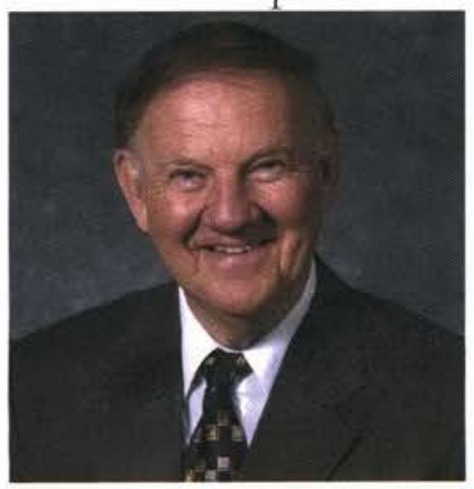

Donald Tyler

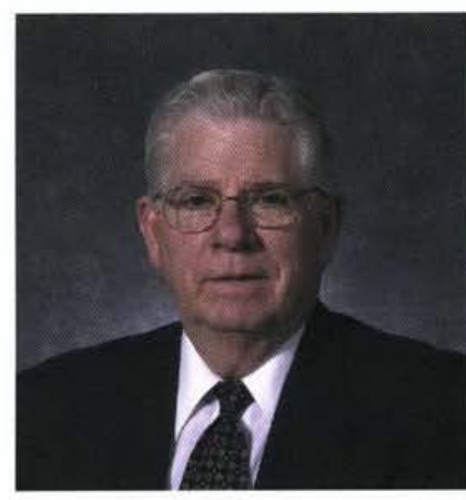

Jack Jacobs

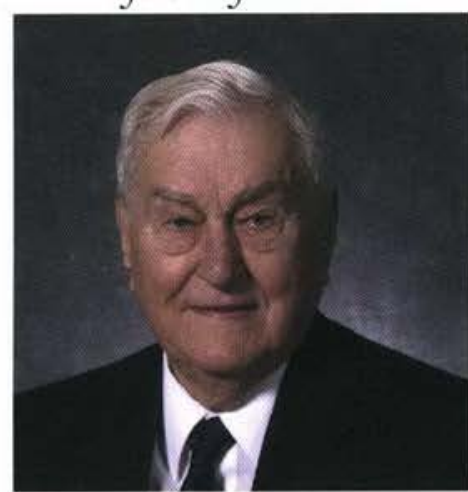

J. Dale Murphy

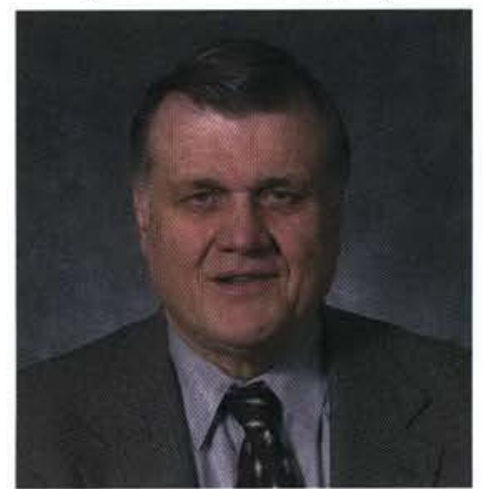

Lorne Scharnberg

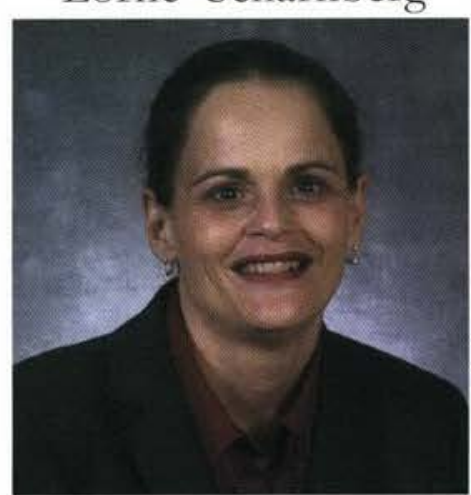

Debby Stephens

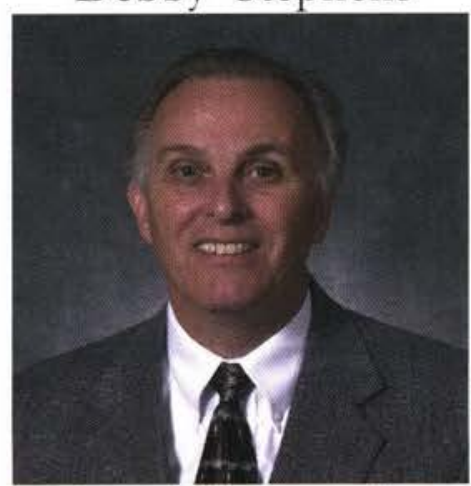

David Warren

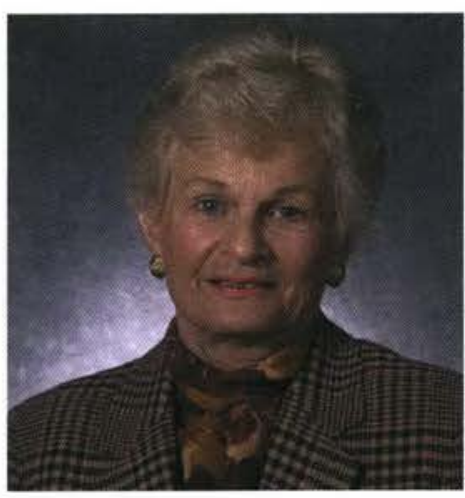

Ruth Kempton

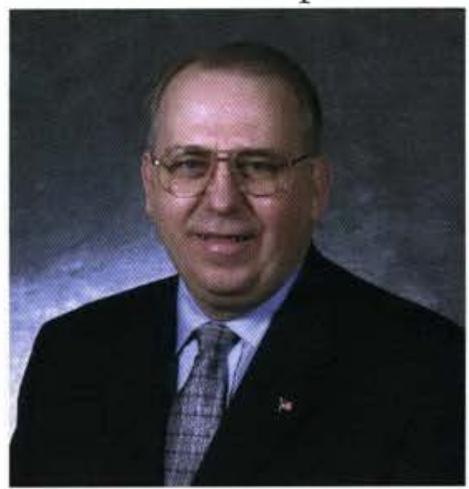

Randy Patten

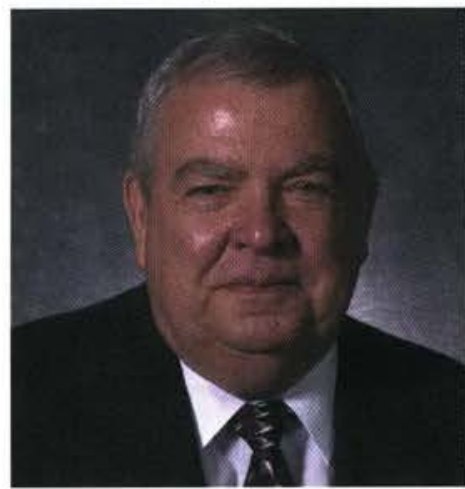

Bill Smith

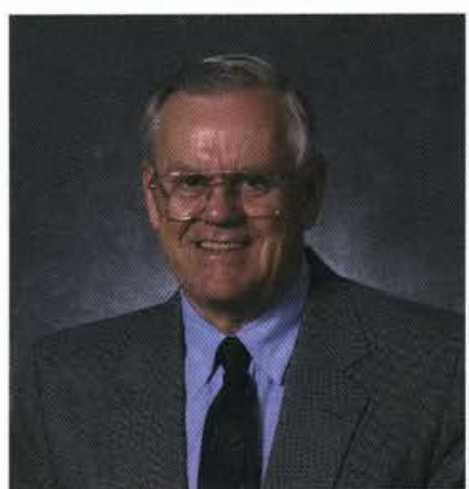

Albert Stevens

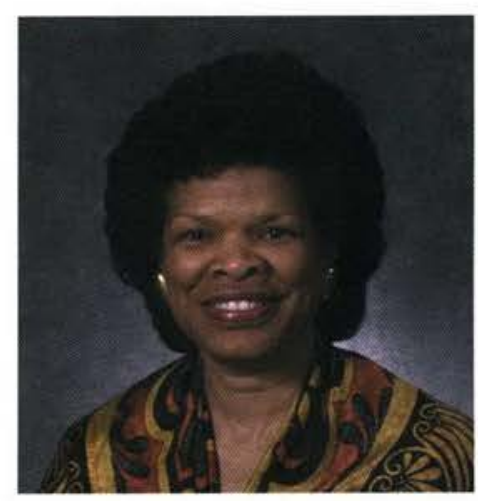

Deforia Lane

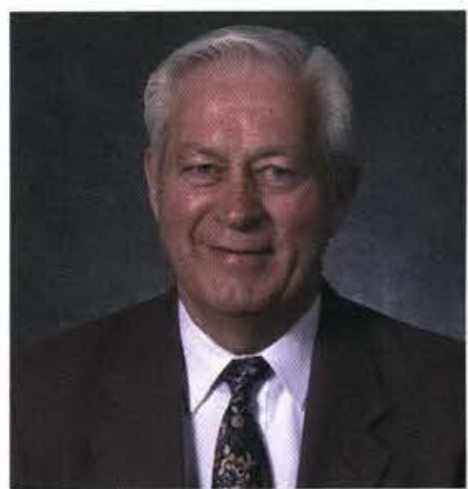

Lynn Rogers

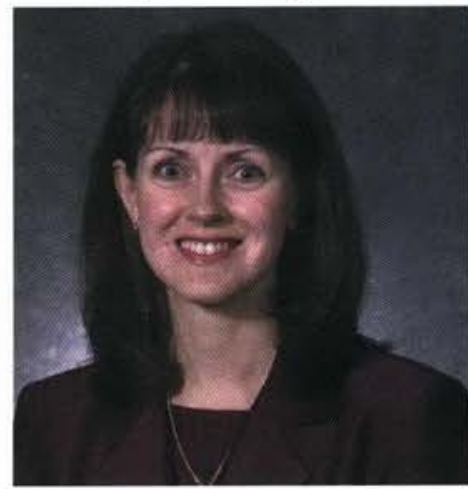

Sherri Smith

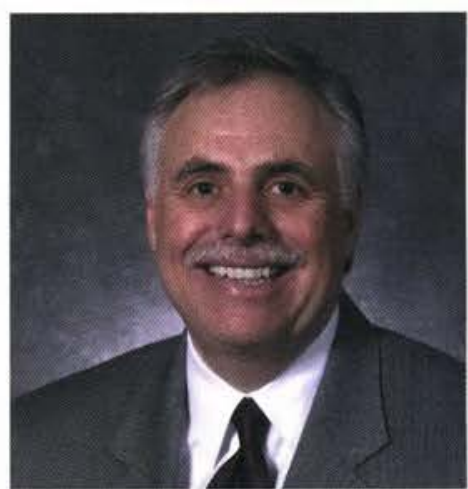

Robert Thomas 


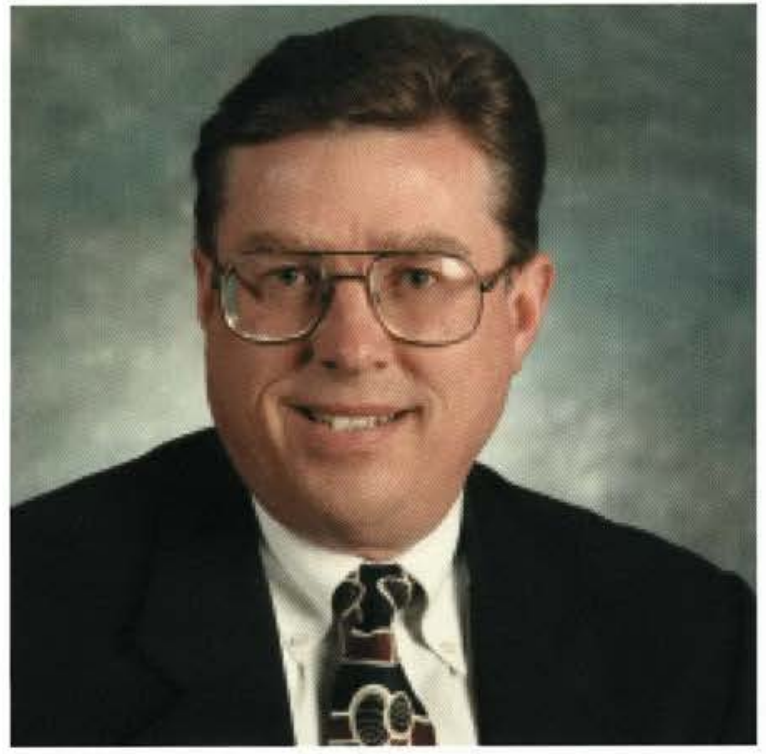

Mr. John Anglea

VICE PRESIDENT of BUSINESS

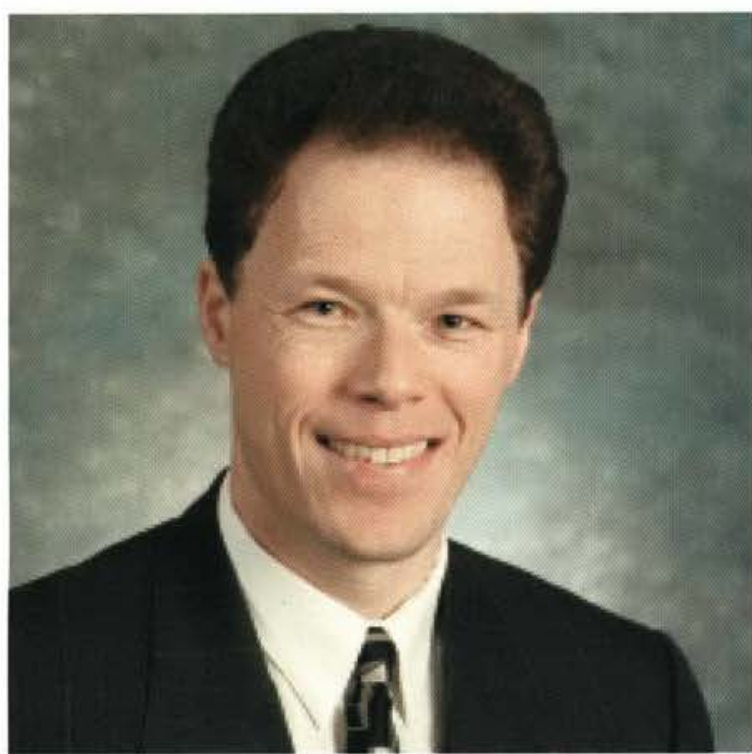

Mr. David Ormsbee

VICE PRESIDENT of ENROLLMENT

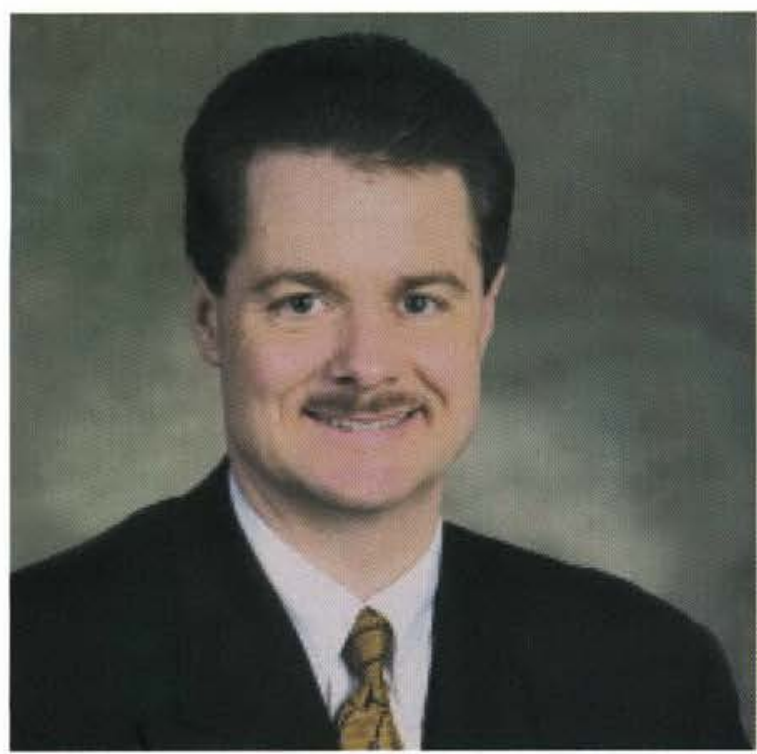

Dr. Carl Ruby

VICE PRESIDENT of STUDENT SERVICES

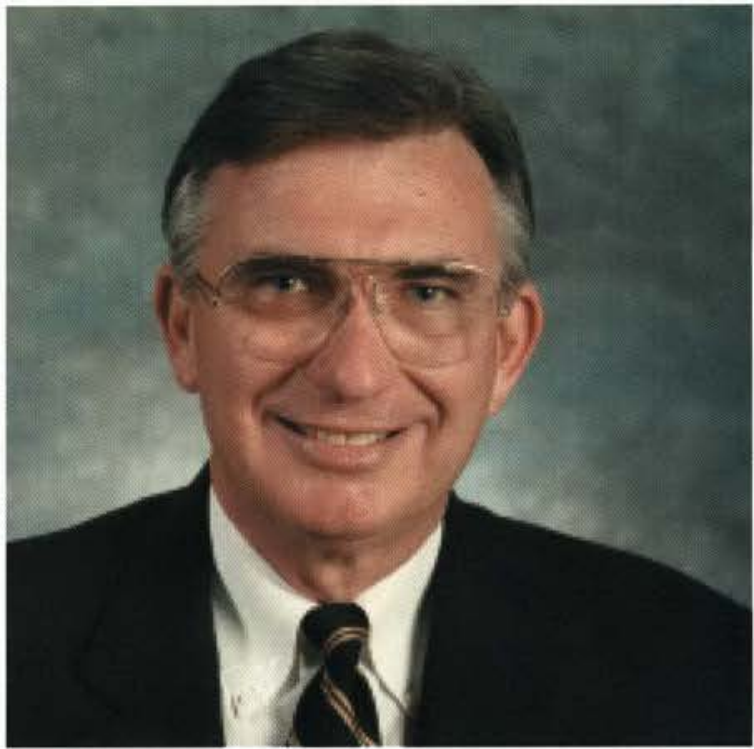

Dr. Martin Clark

VICE PRESIDENT of DEVELOPMENT

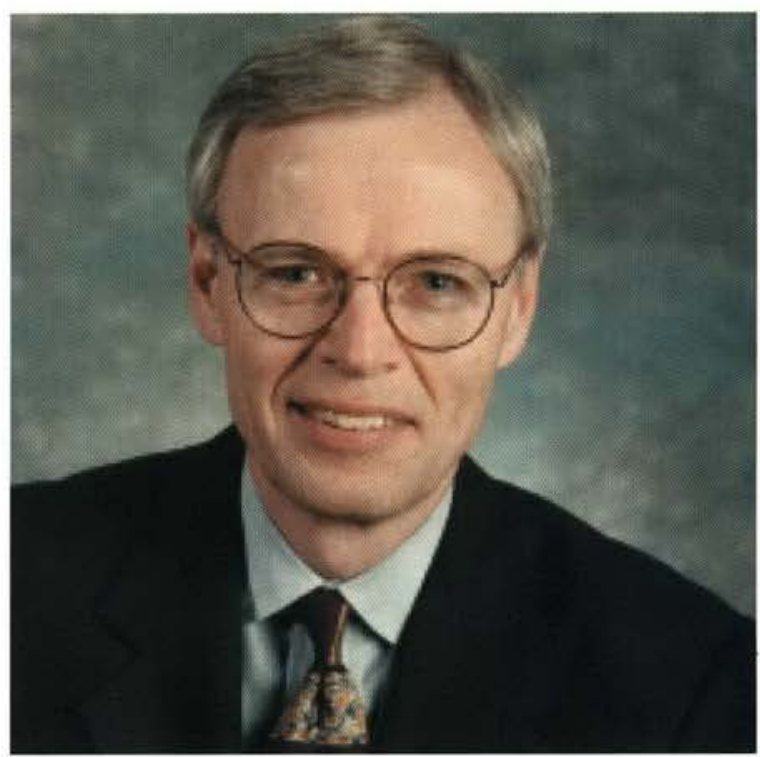

Pastor Robert Rohm

VICE PRESIDENT of CHRISTIAN MINISTRIES

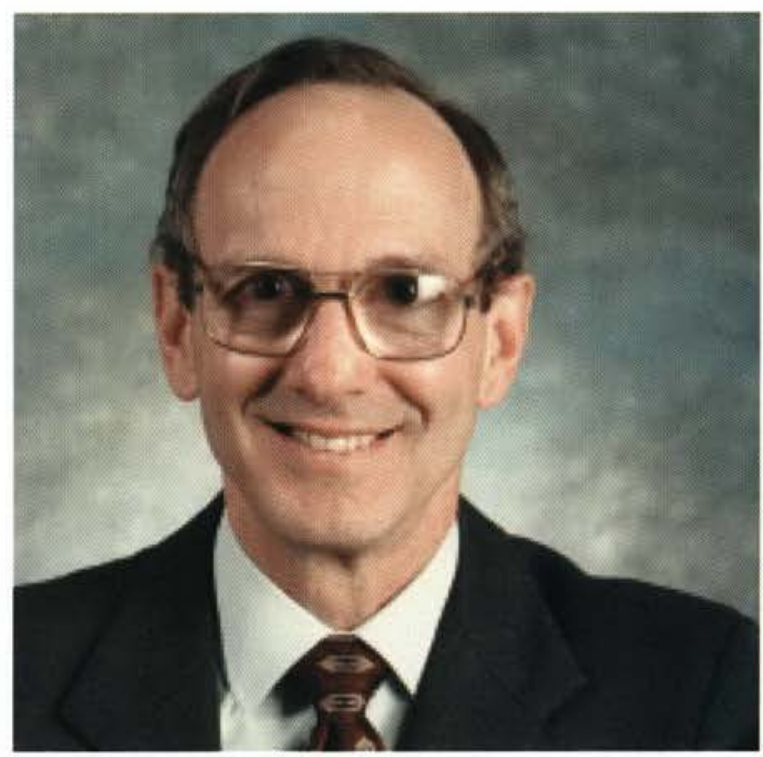

Dr. Duane Wood

VICE PRESIDENT of ACADEMICS 


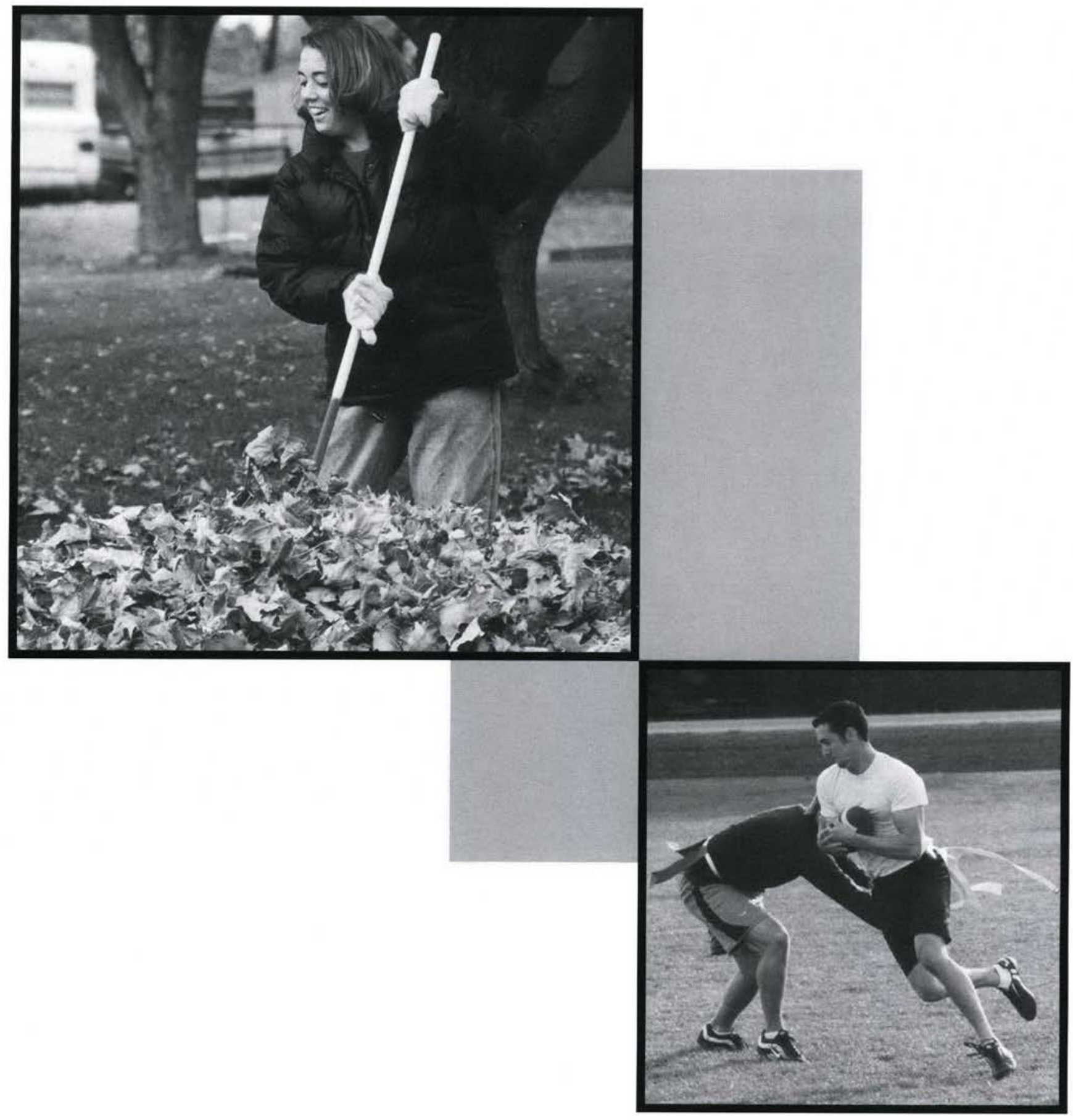




\section{neV ac Ven getting started}

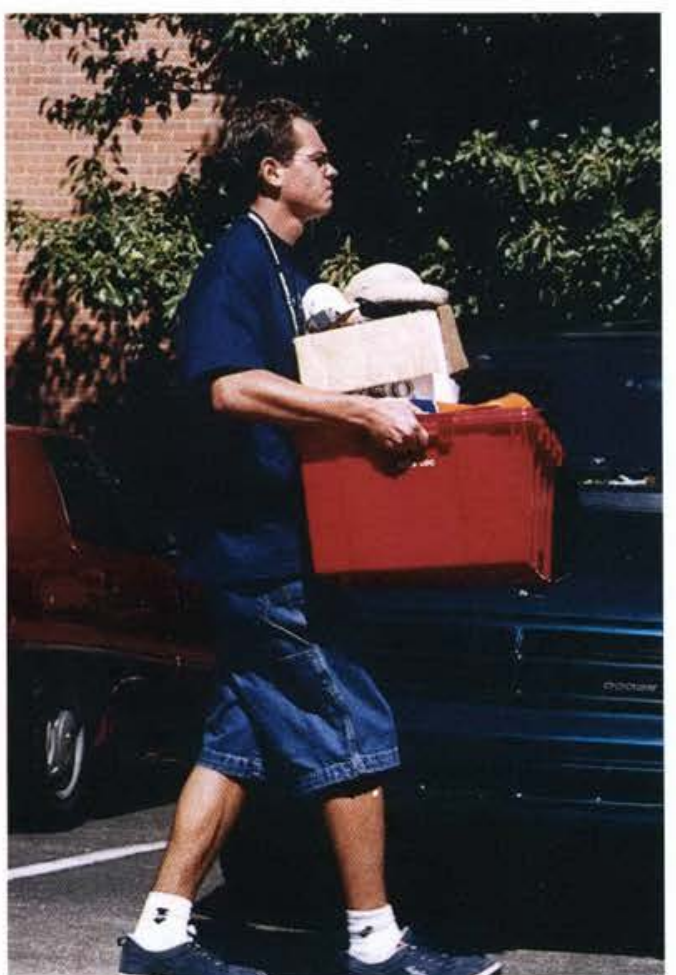

Getting Started

Staff help fresh-

man and transfers

move into their

new homes.
The Cedarville adventure, which began for most new students last fall as they started looking at colleges, came to what they thought was a conclusion during Getting Started 2001. These freshmen and transfers counted down weeks, days, and finally hours until their arrival at Cedarville. It didn't take long for them to figure out that their adventure had not ended; rather, it had just begun.

A whirlwind of activities greeted the freshmen. After months of waiting, they finally met their roommates; for many of them, this was the first time. They attended parties and seminars; they unpacked their belongings and decorated their dorms. They will never forget the party their first night: groups of strangers bonding over conversations and inflatable games. The most asked questions of the weekend involved names, dorms, majors, and home states. They made many trips to WalMart, looking for shelving units, storage containers, and those many forgotten personal items.

Amid this whirlwind, they could only glimpse what waited for them in the next few months. During those moments, they did not know which expectations would reach fulfillment and which would wither away into oblivion, yet they stood on the brink of change with optimism.

The tearful goodbyes came too quickly for most. With hugs and last minute advice, parents packed their cars and drove back into the world the freshmen had left behind. As the parents drove out of sight, the students waved goodbye one last time. Their lives would never be the same; the adventure truly began that moment.

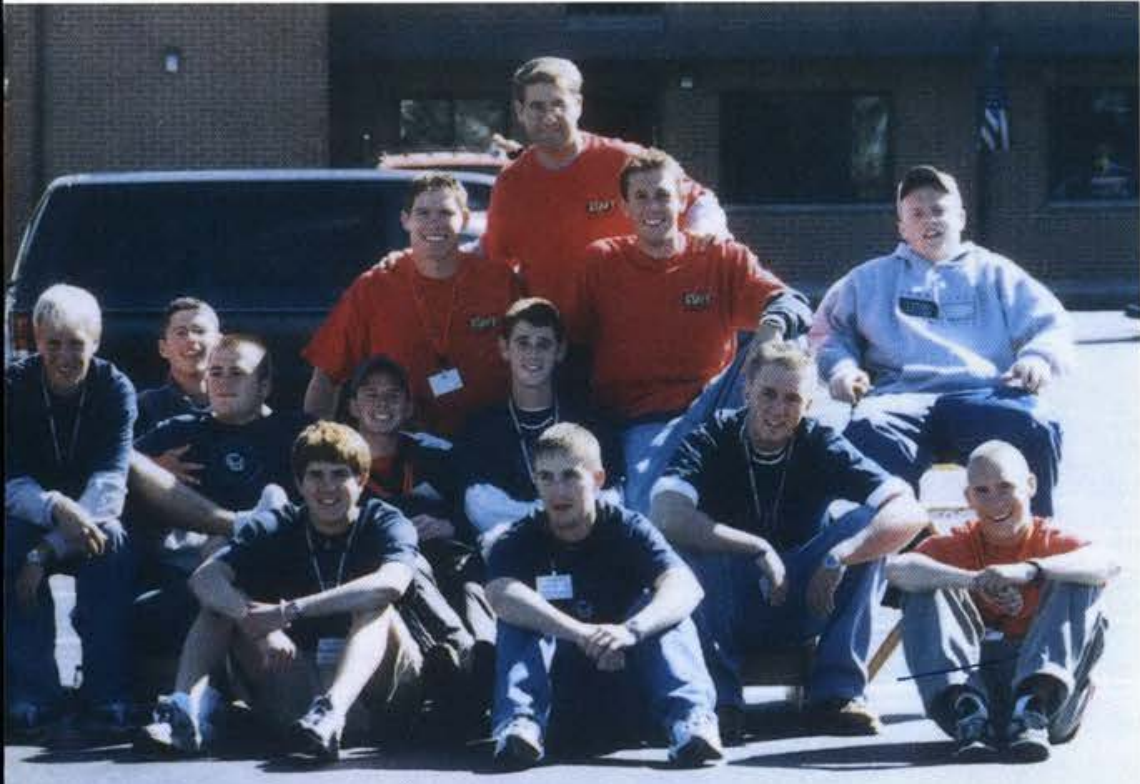

The Lawlor guys take it easy on the couch, attempting to make college life feel just like home.

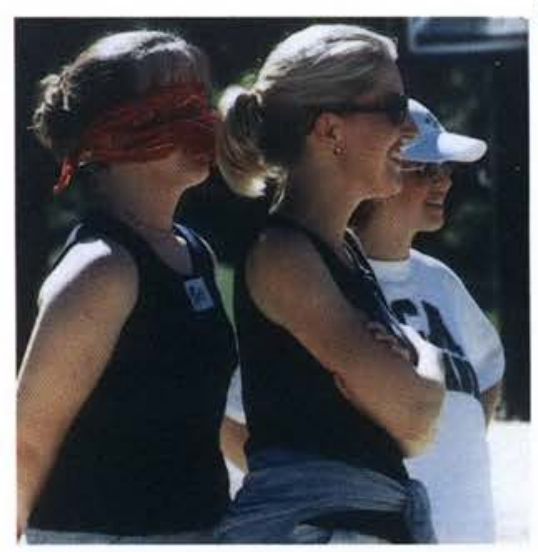

Beth Brown and Courtenay Atwell watch the events of Getting Started from a distance. 


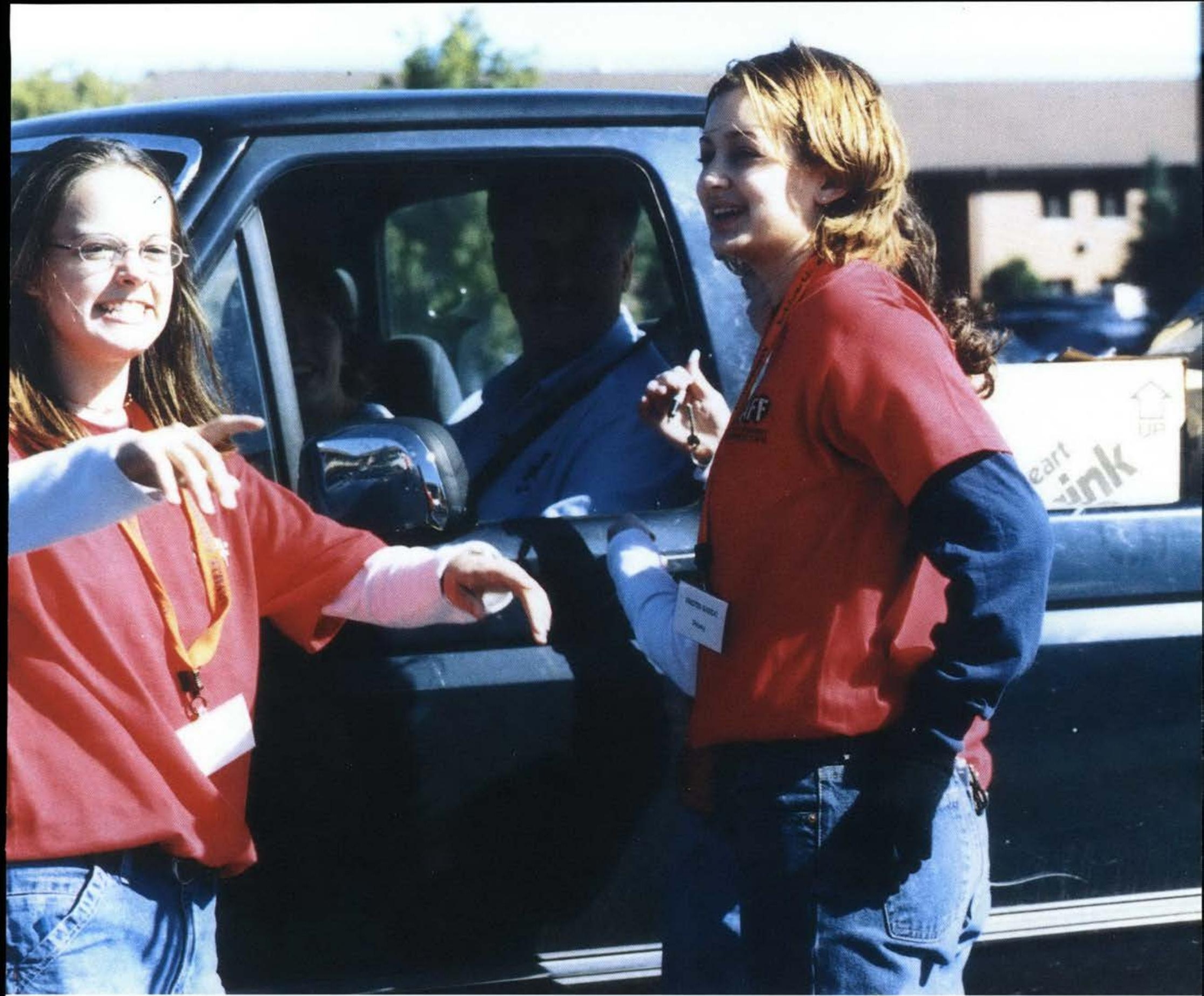

R.A.s Julie

Offerman and

Kristin Sando

point parents in
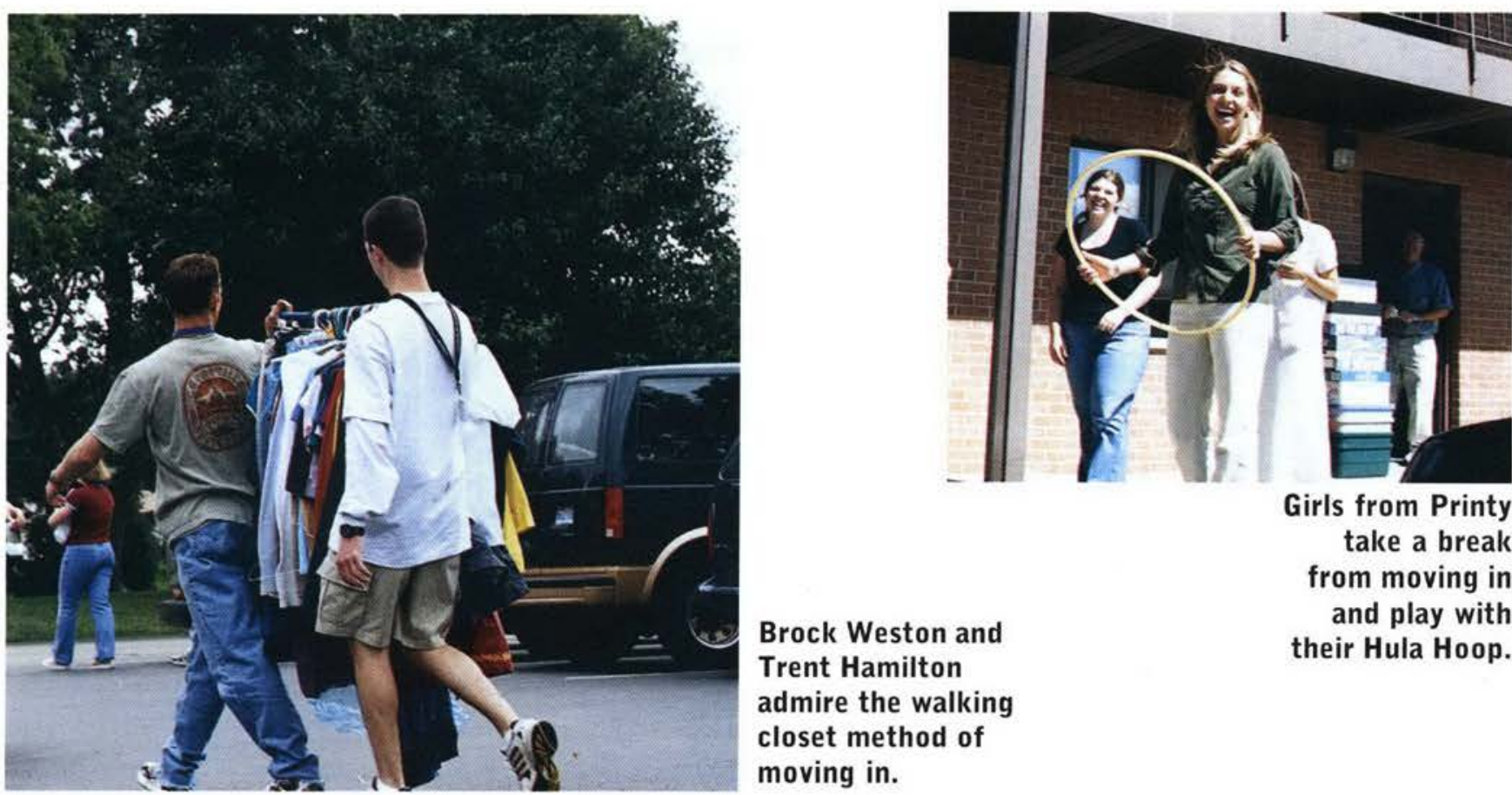

the right direc-

tion for unloading

luggage and their

anxious children.

Girls from Printy

take a break

from moving in

and play with

Brock Weston and

Trent Hamilton

their Hula Hoop.

admire the walking

closet method of

moving in. 


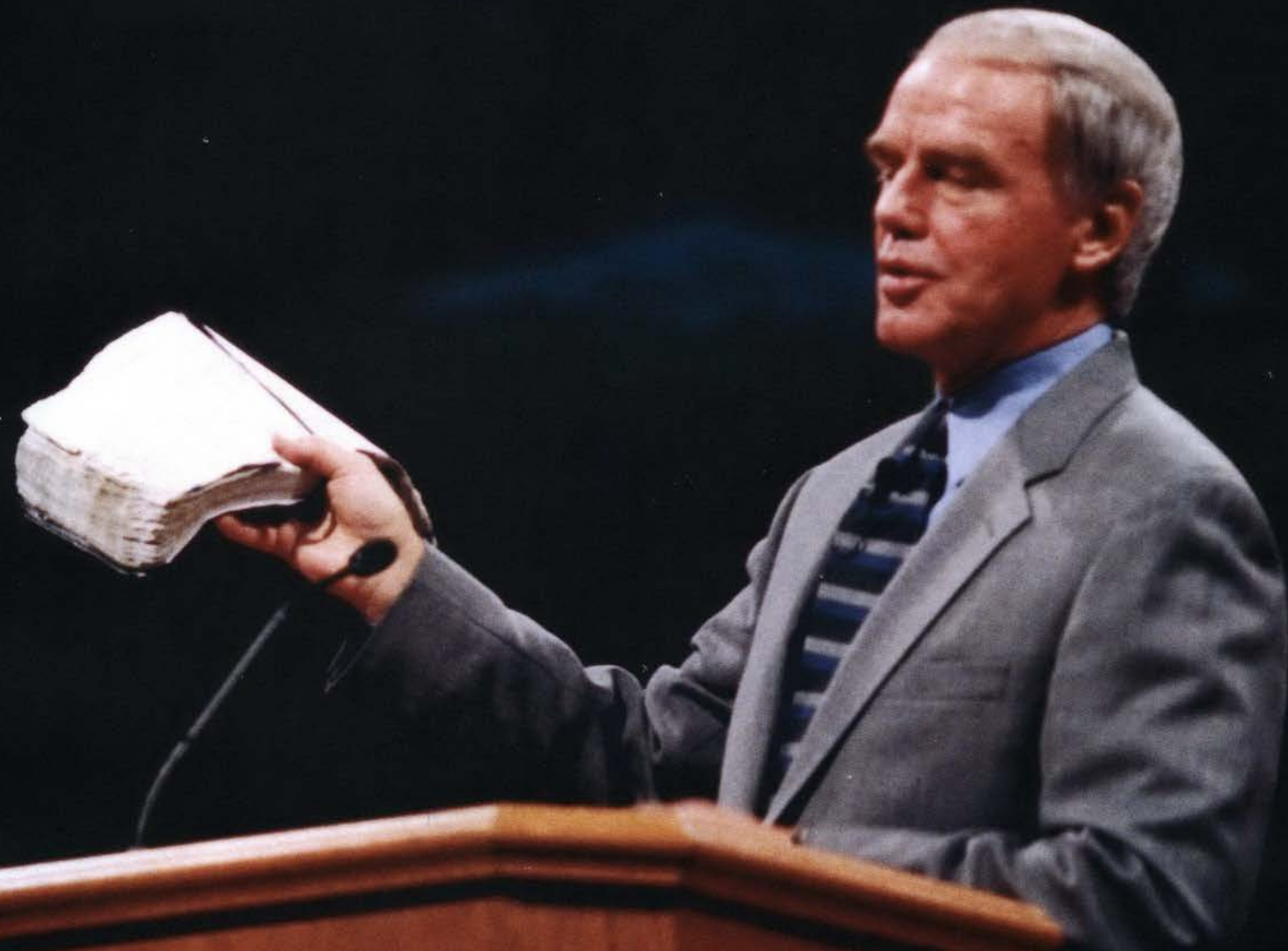

\section{Knute Larson, pastor of Akron}

Chapel, challenges the student body to show compassion to others, amidst this time of crisis in our world.
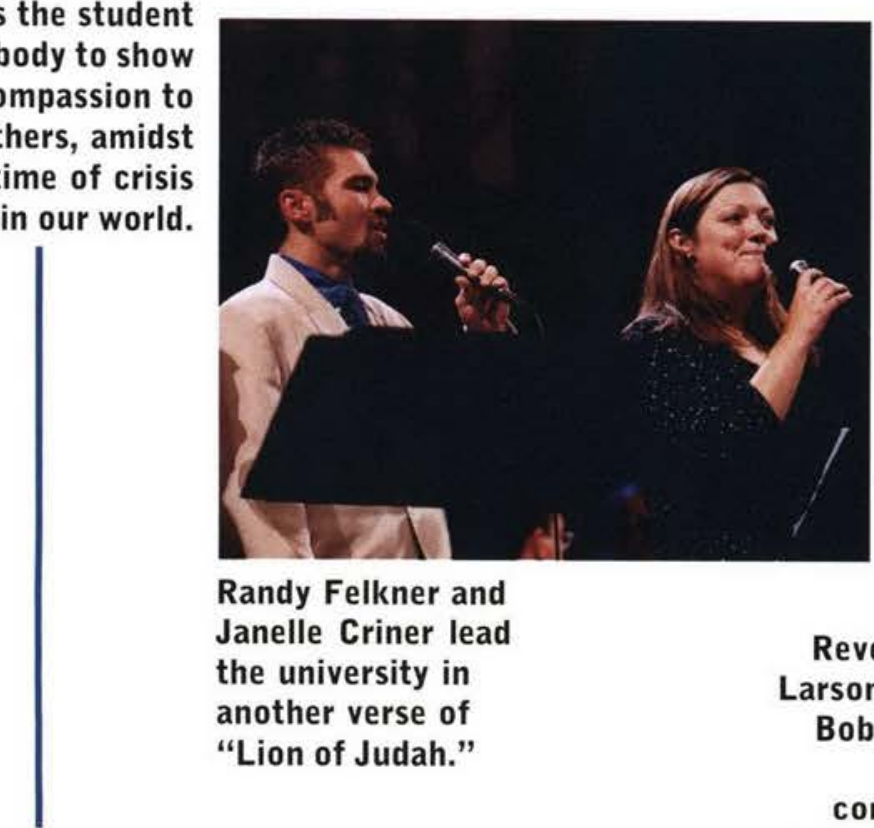

Randy Felkner and Janelle Criner lead the university in another verse of "Lion of Judah."

Reverend Knute Larson and Pastor Bob Rohm swap jokes after conference for upcoming sermon material.

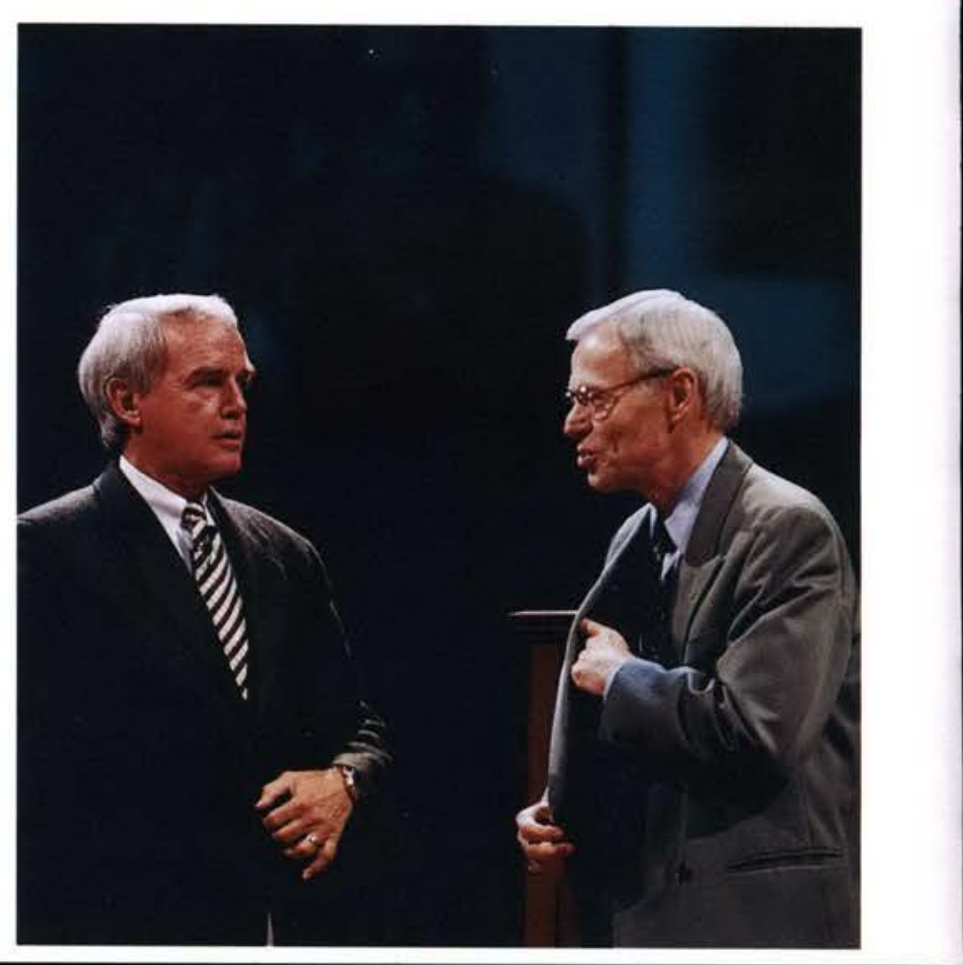


Getting Started Week again hosted the 2001 Fall Bible

Conference. Students raised their voices to "Lion of Judah" as the bass drum thundered along with their vocals, and the upperclassmen once again learned that some things just don't change.

The Chapel in Akron lent Reverend Knute Larson to be the keynote speaker at Dr. Dixon's invitation. His messages came from different angles but focused on the Attack on America, when planes hijacked by terrorists had crashed into the World Trade Center and the Pentagon the week before on September 11. The terrorist attacks hit home with the students and penetrated the messages deep into their hearts.

The Prayer of Paul from Colossians 1 served as the topic for the morning meetings. As the conference moved forward, the

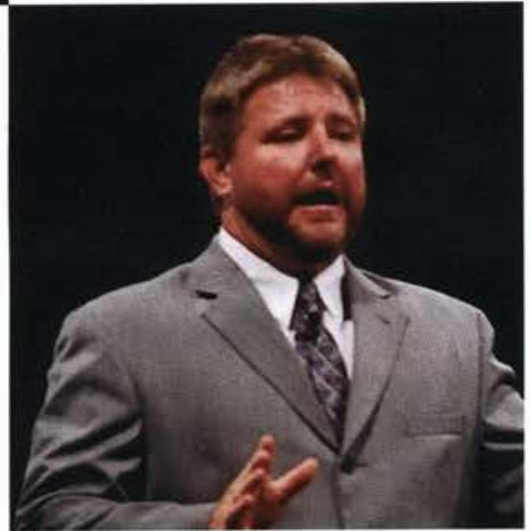

Youth Pastor of

The Chapel, Jodie

Bowers, captures

the students'

attention with his

animated person-

ality and dramatic

life experiences. students responded well to Larson's daily challenges. However, the subject soon affected the conference outside of its messages. Larson's hometown asked for his presence at several municipal meetings as a spiritual leader.

The normality of the week and conference were thrown for a spin as Larson sent Jodie Bowers, youth pastor at The Chapel, to finish the conference.

The unusual change didn't affect Bowers or the Cedarville student body. He moved on with Larson's theme and managed to keep the students in tune to God's Word.

\section{Students enjoyed both} speakers, and the conference was again a success. This success was one tradition that the University was pleased to see in the commotion of the first week of school.

\section{The Kingsmen Quartet entertain the University with their great vocal talent and variety of music.}

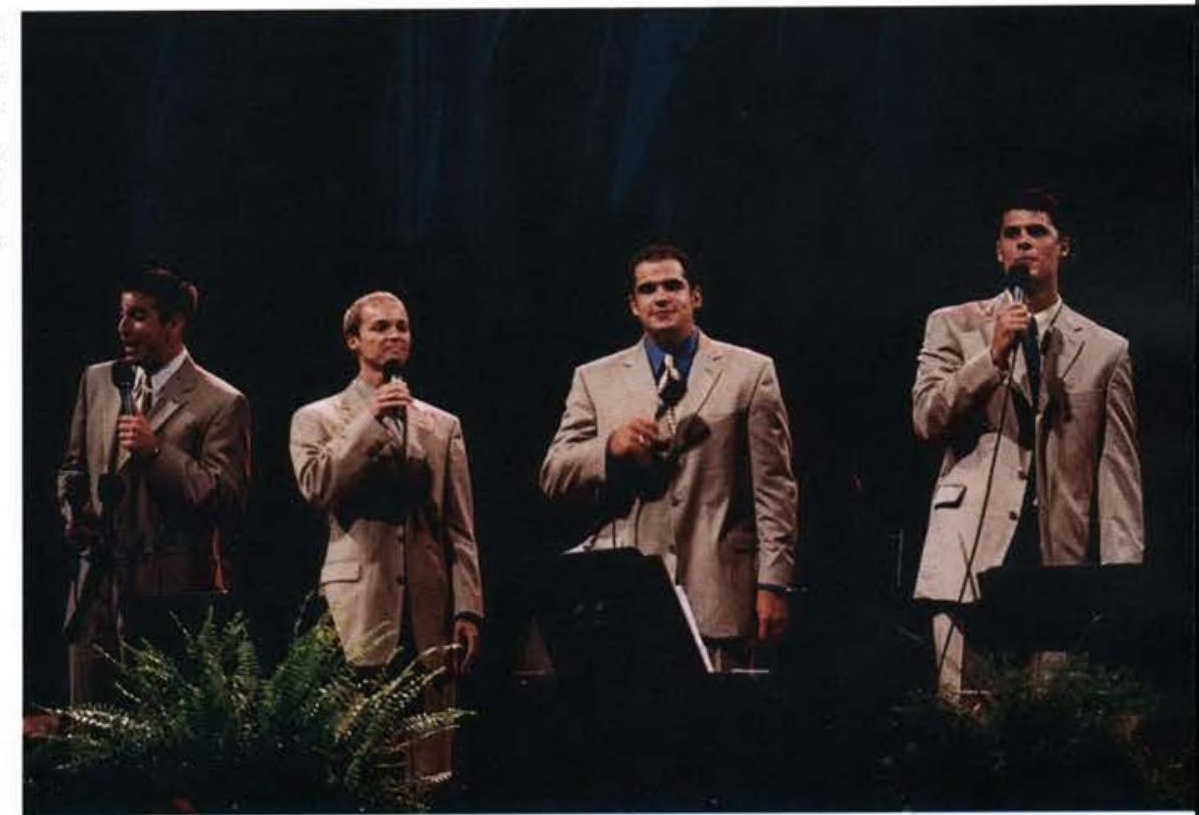

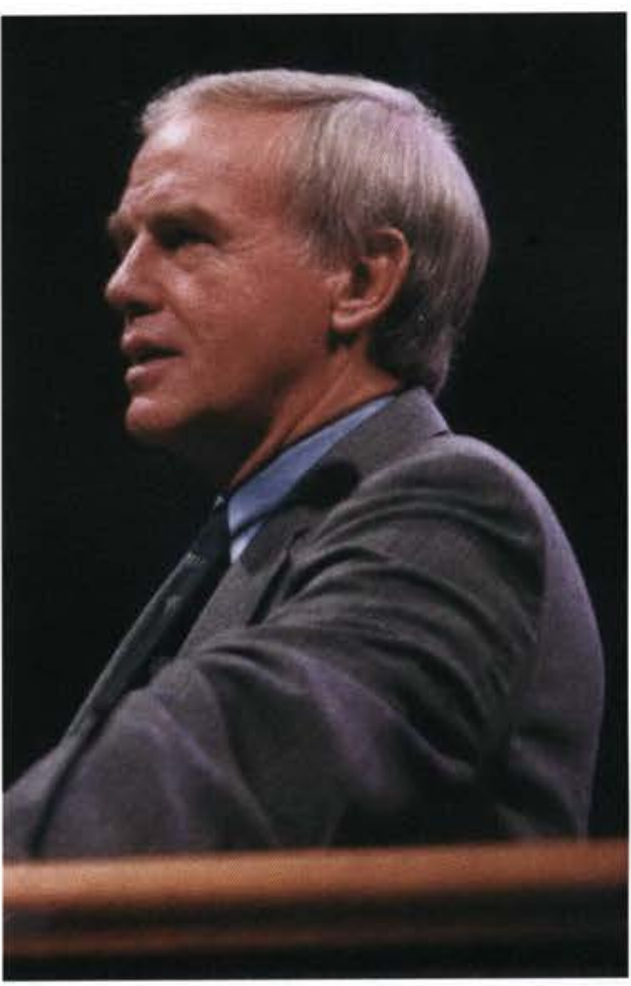

Reverend Knute Larson uses the present crisis of the nation to share with us from God's Word how to show Christ-like compassion . 


\section{nilat 0 homecoming banquet}

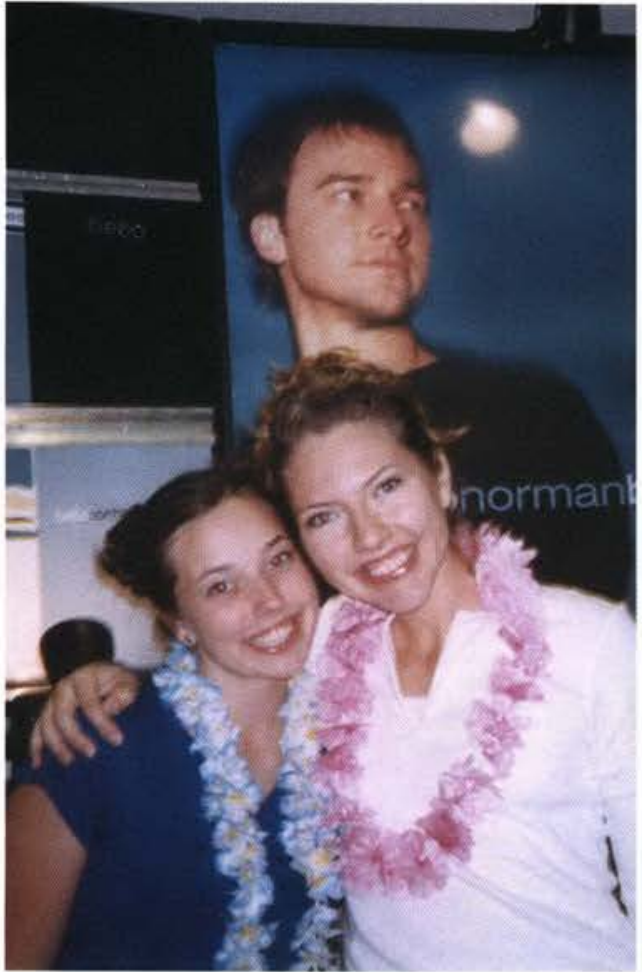

Stacy Rasmussen and Heidi Everett share a moment together in front of their hero, Bebo Norman.
Despite the weather, the Homecoming Bash on Friday, October 5 took the form of a Luau, complete with tiki torches, Beach Boys music, and a truckload of tropical fruit. During the banquet, the Homecoming Queen, Julia Roberts, was crowned, followed by authentic Polynesian Dancers.

After students dined, they relocated to the Jeremiah Chapel where they heard Katy Hudson, Shaun Groves, and Bebo Norman, who was on his Big Blue Sky tour. Hudson, a talented 16 year old, charmed the crowd with her funky tunes, and Groves encouraged students to go beyond the music and make their lives an act of worship.

When Bebo took the stage, he sang some of his hits such as "Sons and Daughters," "All that I have Sown," and "Big Blue Sky," as well as cracking jokes about his single life and experiences.

After the concert, students were treated to the first ever $\mathrm{CU}$ fireworks show over Cedar Lake as they made their way back to the Stevens Student Center. Inside they found elaborate desserts, smoothies, coffee, karaoke, a classic movie, great live music in the Hive, tons of games, and, oh yeah, a goldfish eating contest.

Junior Hattie Majka and her friends took advantage of Katy Hudson's musical abilities and sang "Jesus is Still Alright" by DC Talk on the karaoke stage. Majka said, "It was going to be great, because we all thought we knew the song pretty well. But when we got up on stage, they had a glitch, and we had to do the whole song without the monitor...It was cool though."

The bash ended at 2 a.m. when SGA locked down and rebuilt the SSC to its familiar form.

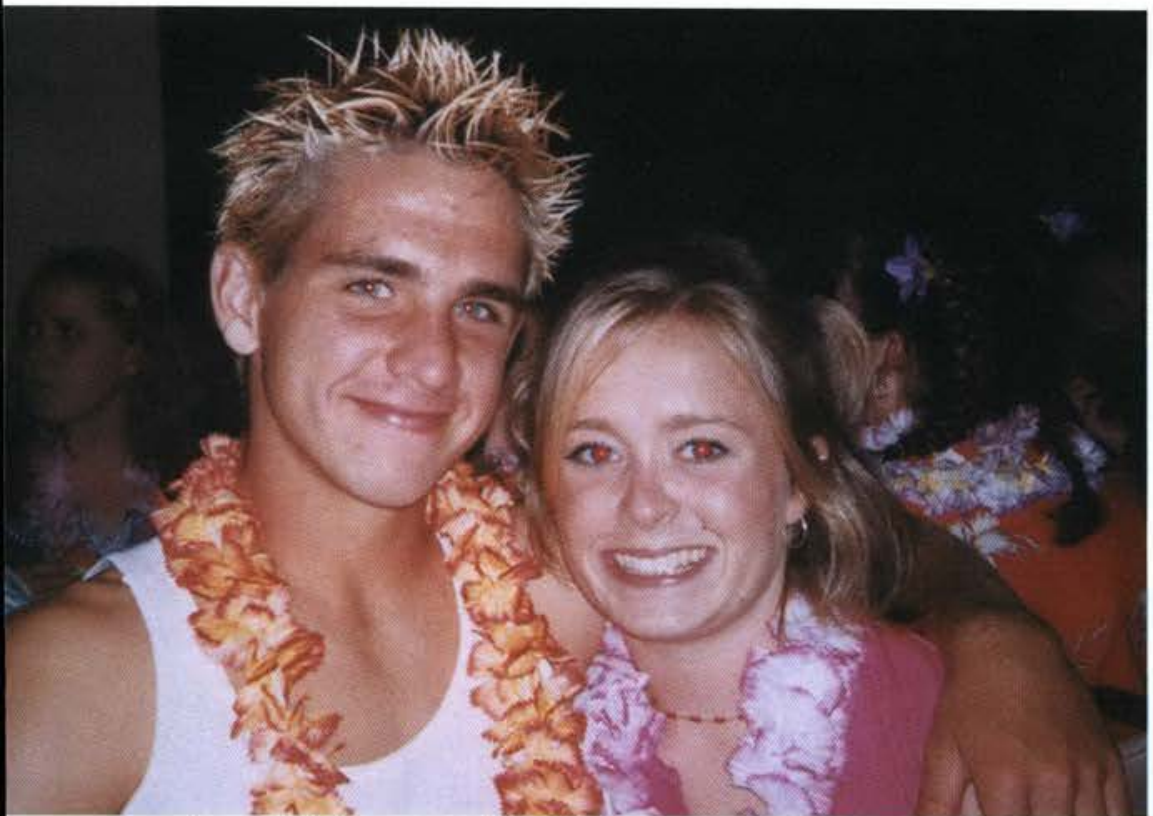

Steve Palmer and Abby Brown enjoy each other's company during the Hawaiin festivities.

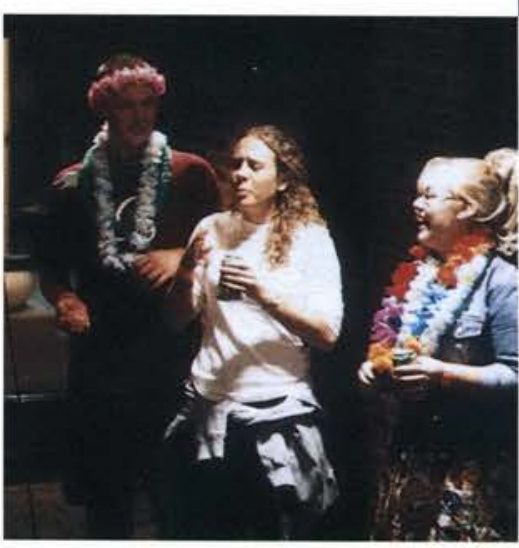

Eating the fish is just one of the many activities available in a Hawaiin Homecoming. 


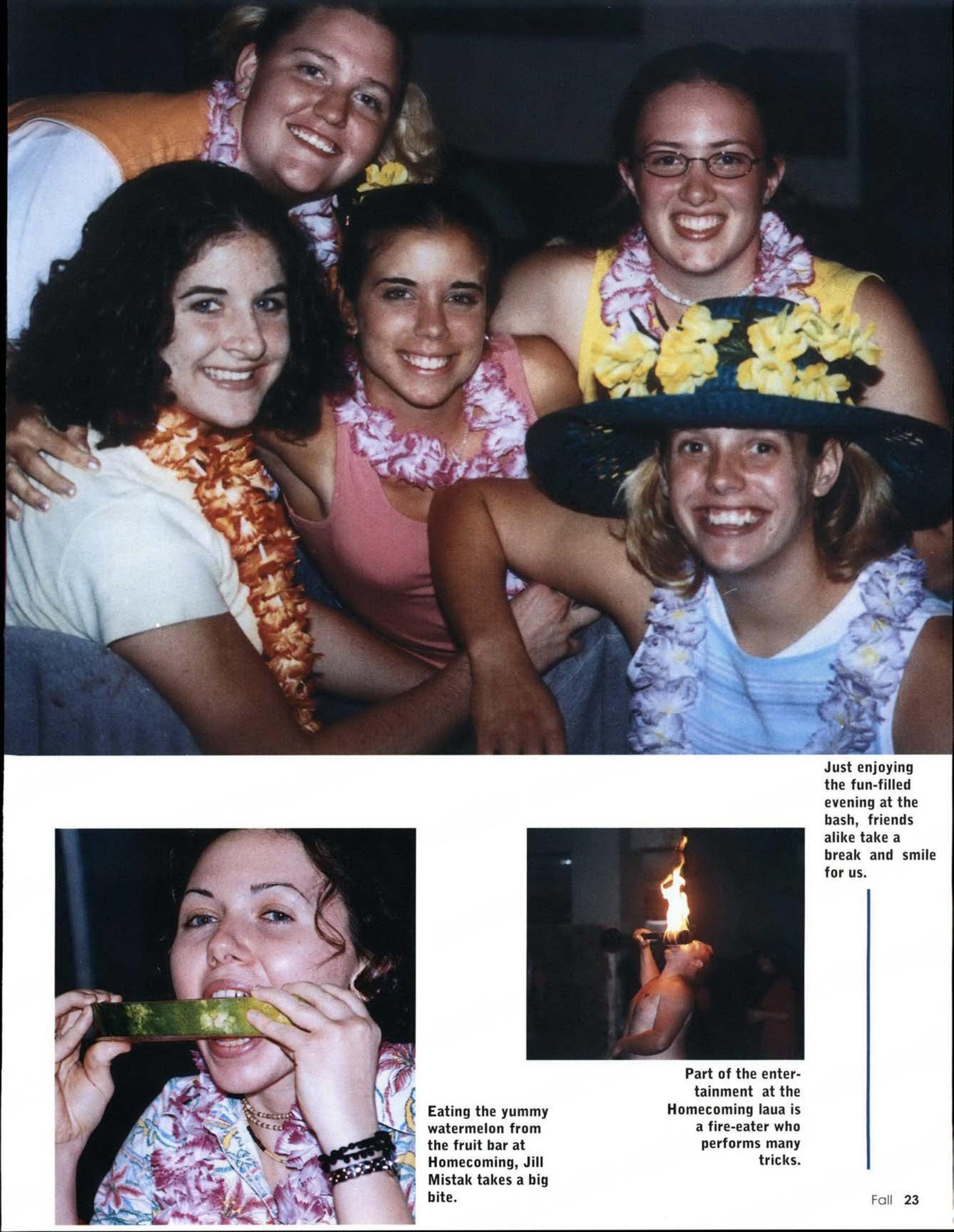




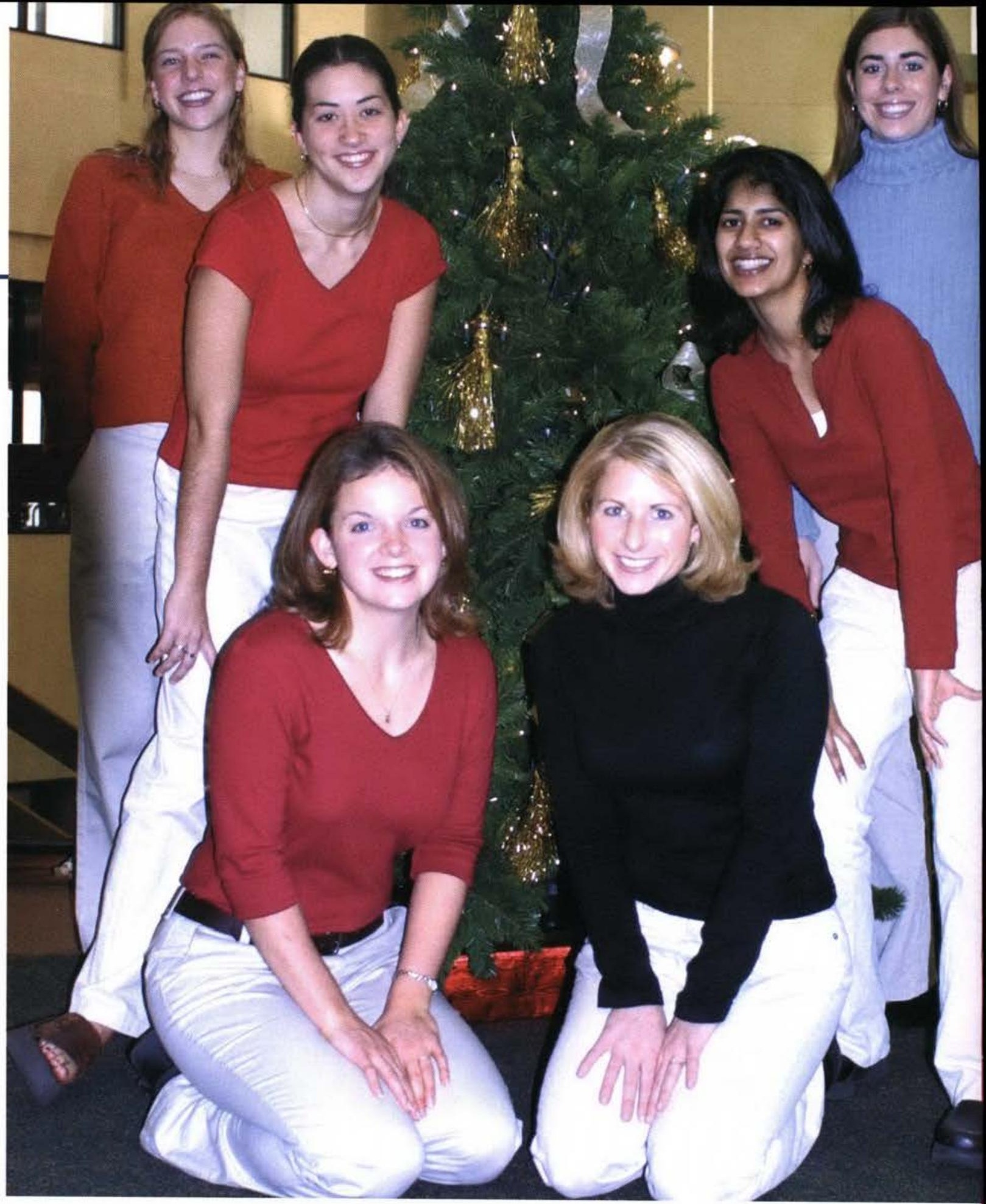

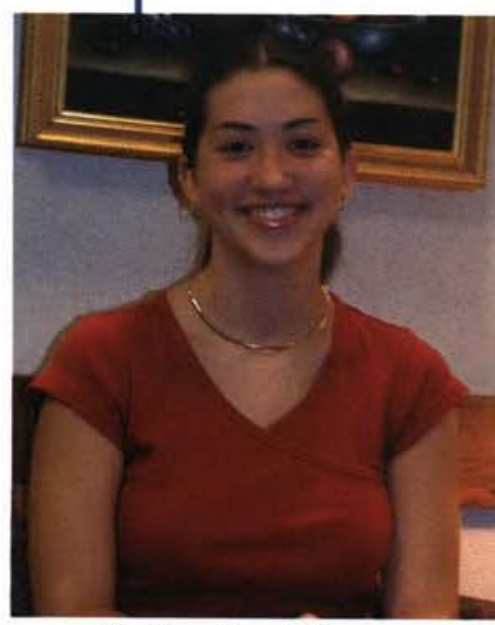

Katherine Meyer Freshman Attendant

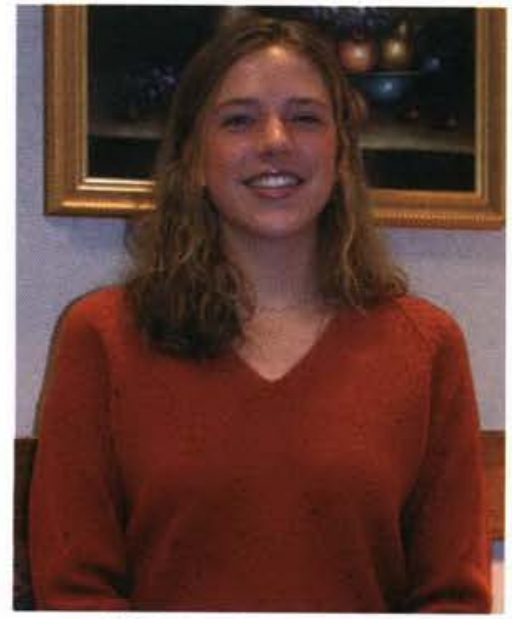

Krista Augustine Sophomore Attendant

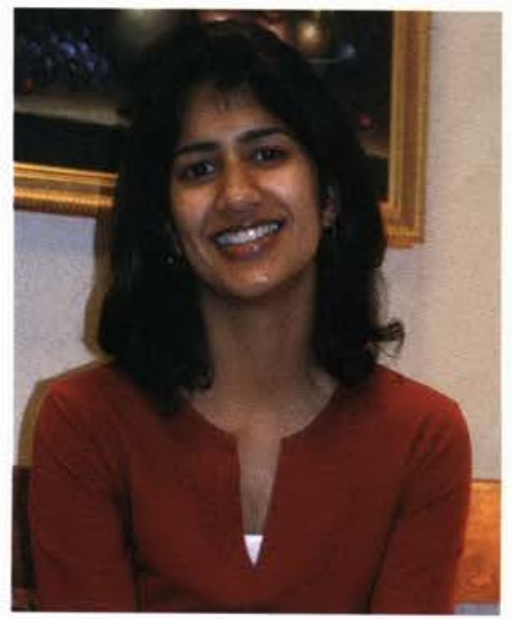

Jyoti Philip Junior Attendant

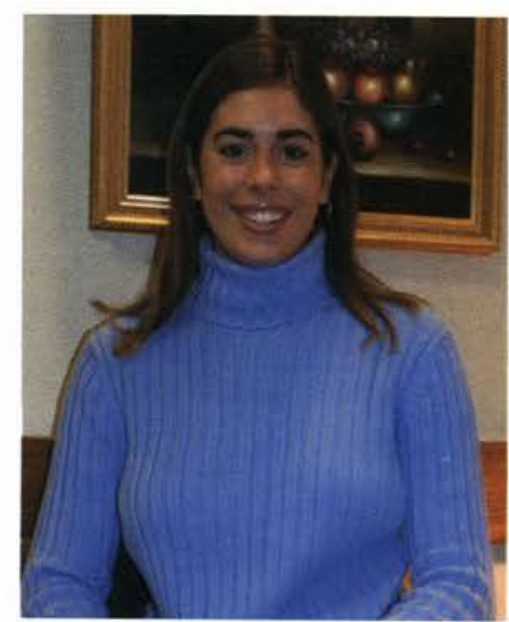

Emily McQuinn Senior Attendant 
The Homecoming Court enjoyed the first ever Hawaiian Homecoming Luau where Julia Roberts received her crown as the 2001 Homecoming Queen. Her court celebrated with her, trading in their formal gowns, traditionally worn to the Homecoming Banquet, for their fun Hawaiian apparel.

Julia Roberts, known for her sweet personality and celebrity name, was a middle childhood education major from Milton, Vermont. She said she loved spending time with her family and was especially excited that her sisters could be present when she received her honor.

Julia also enjoyed the opportunity to spend time with the other attendants. "I knew all the girls on the court at least a little. I think that they are all beautiful girls, both inside and out. It was fun to get to do this with them, since we were all a little nervous and didn't really know what to expect," she said.

She was accompanied by freshman Katie Meyer, sophomore Krista Augustine, junior Jyoti Philip, and senior attendants Shana Barba, Carolyn Dizer, Erin Ewig, April Lucas, and Emily McQuinn. They were all excellent representatives of their class and Cedarville University.

Barba, a native of Medford, New Jersey and a middle childhood education major, said she loved "the guy twirling the fire stick at the banquet!" She appreciated the décor as well - goldfish on every table.

The excited spirit of Julia and her attendants was contagious during the Homecoming Bash, as their prospective classes cheered heartedly for these special girls.

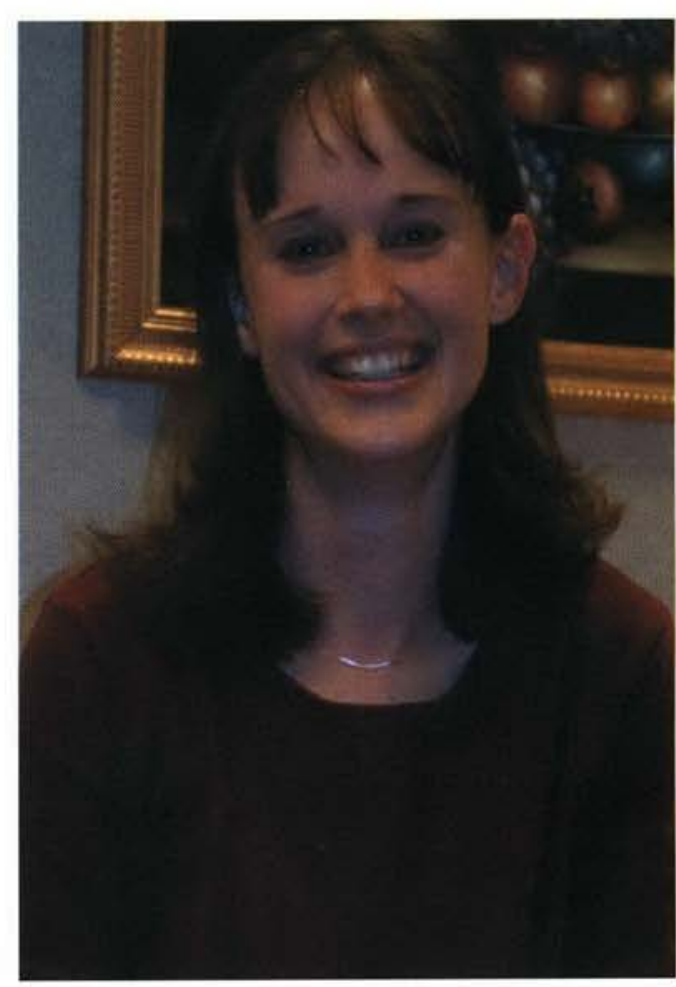

Julia Roberts Homecoming Queen

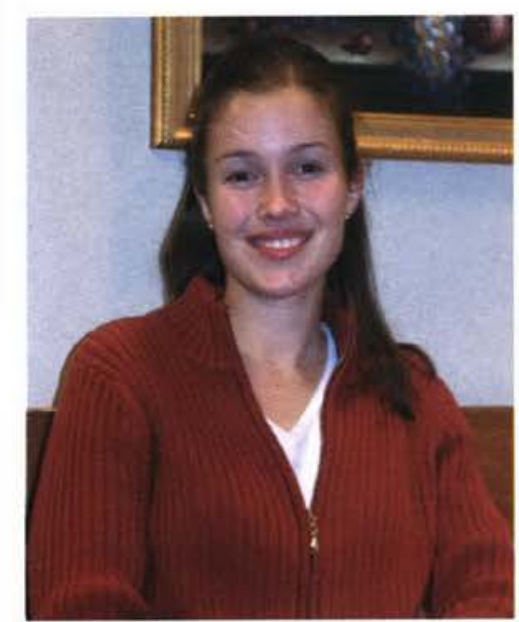

Shanna Barba Senior Attendant

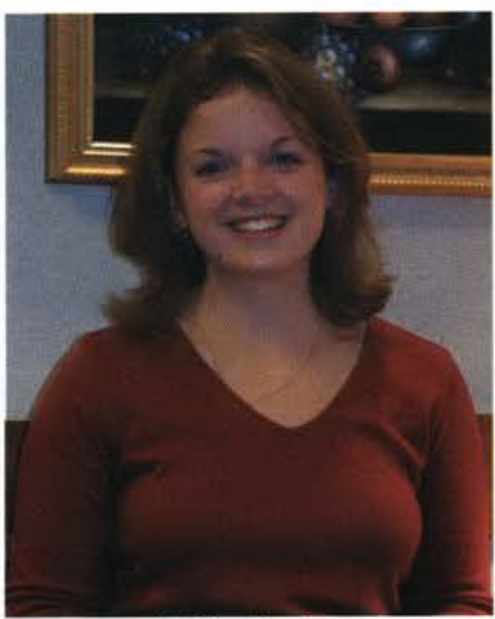

Erin Ewig Senior Attendant

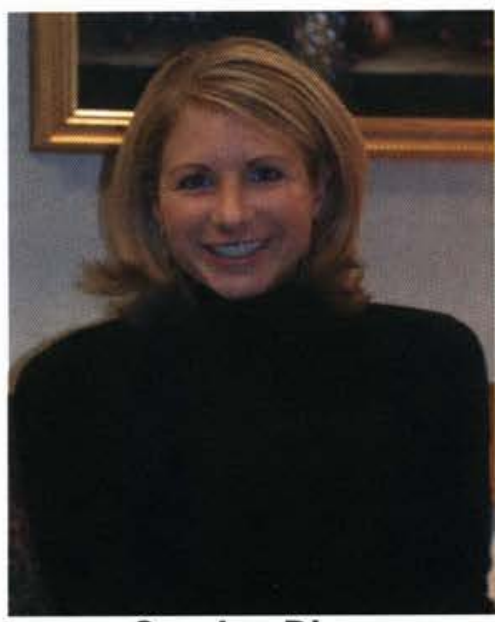

Carolyn Dizer Senior Attendant

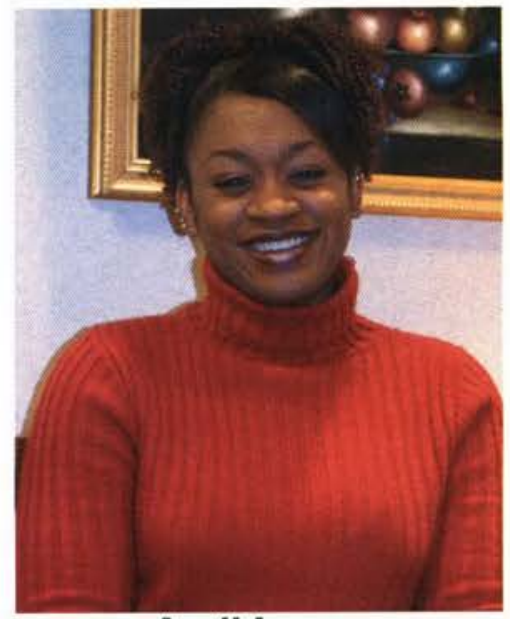

April Lucas Senior Attendant 


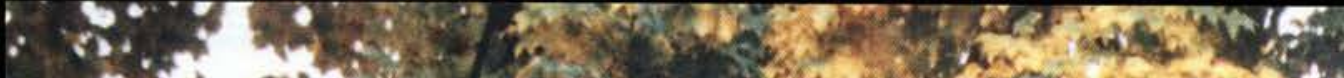

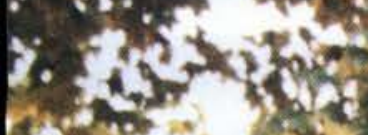

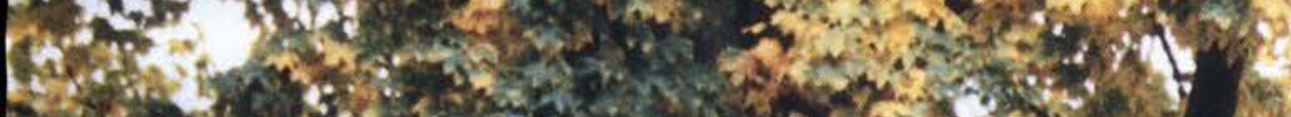
*.

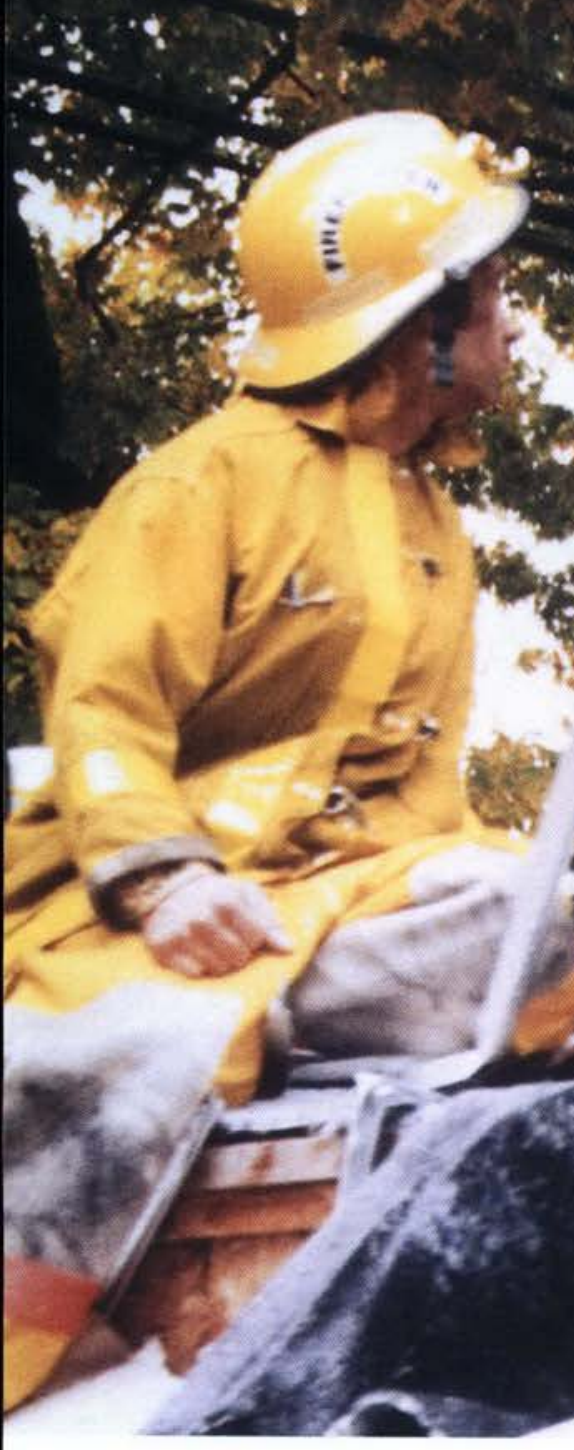

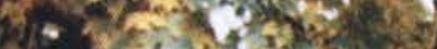

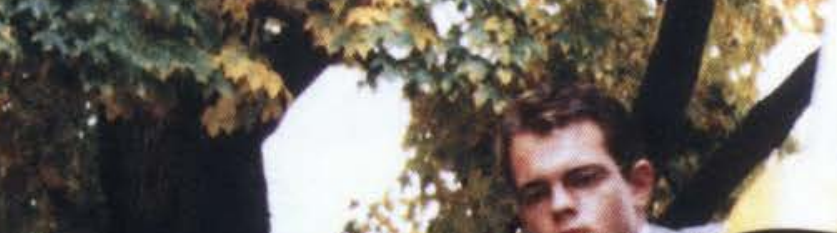

8

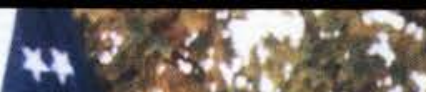

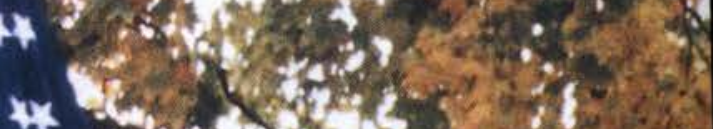

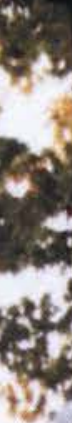

The sophmore

float reenacts

what happened on

September 11th,

showing what's really important.

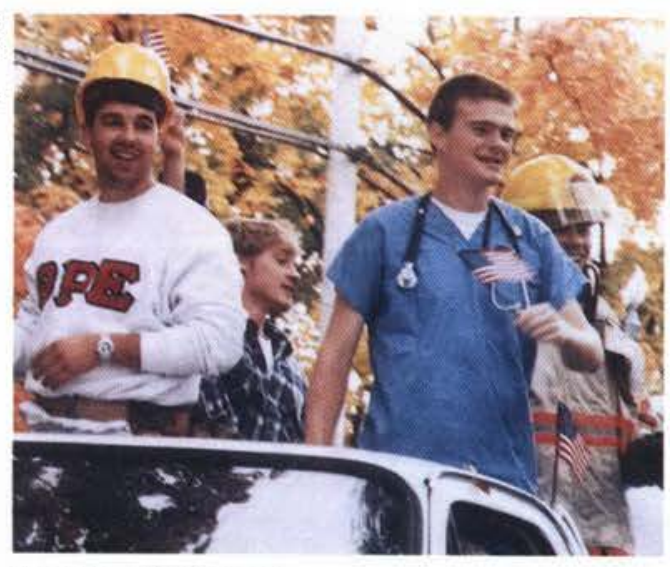

On the OPE float, Josh McKinney,

Dave Black, and Jeremy Hudson are showing their patriotic spirit.
Pi Gamma Pi join hands with one another as they walk down the street during the

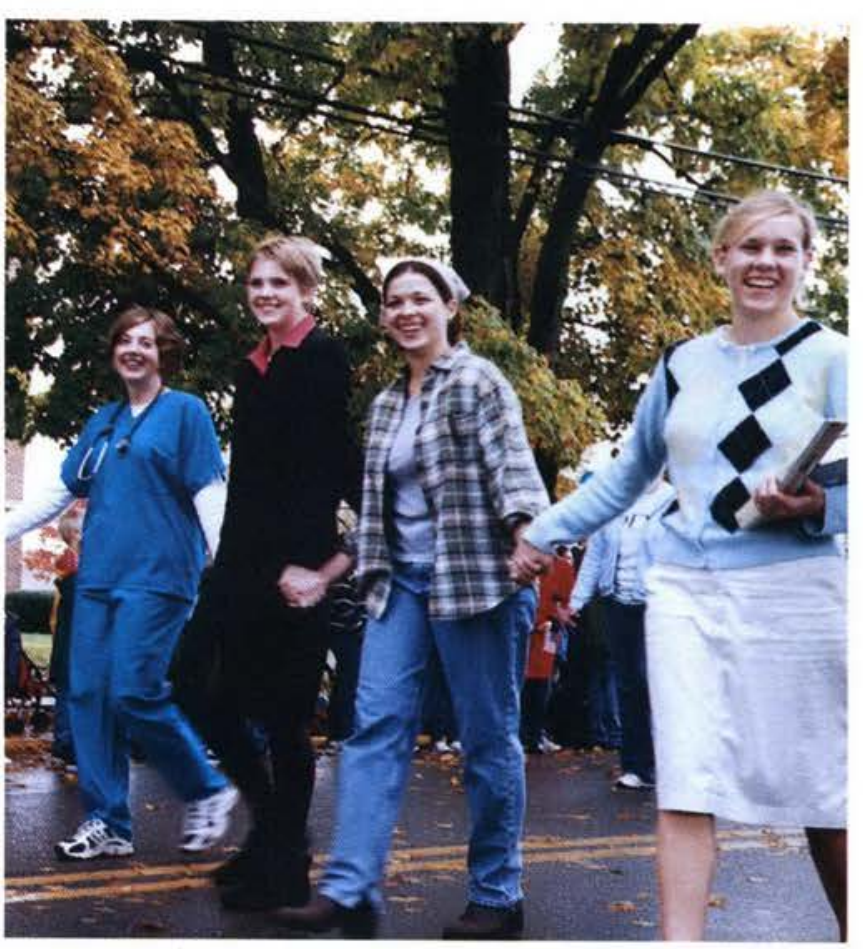

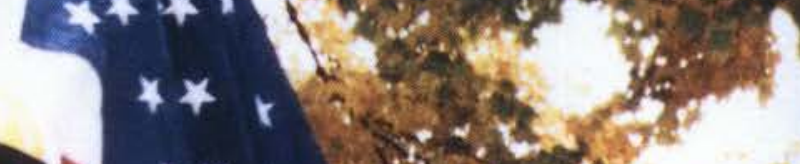

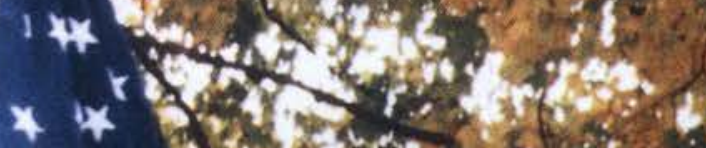

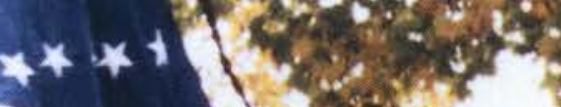

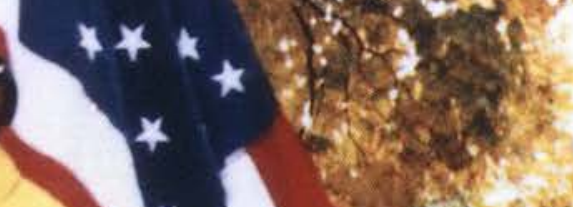




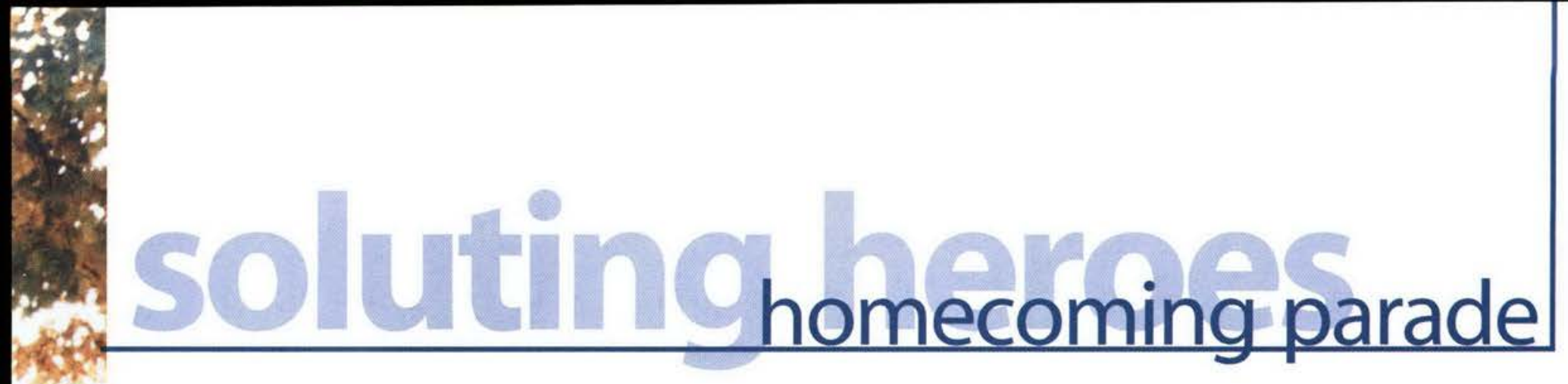

For most students, it was just another lazy, dreary Saturday morning tailor-made for hours of peaceful slumber, but for some, the October $13^{\text {th }}$ morning was anything but dreary.

A few select girls, representatives from classes dating back to the sixties, and numerous organizations lined up for their glorious march down Main Street. Large drops of cool rain slithered through the overhanging trees and met the crowd as they eagerly waited for a hero, a mentor, a best friend, or a shiny red fire truck.

Grand Marshals, Mr. and Mrs. Galen Smith, rode by in their carriage, starting the festivities. Junior, sophomore, and freshman attendants, Jyoti Phillips, Krista Augustine, and Katie Meyer passed in their Corvette escorts, and the 2001 Homecoming Queen, Julia Roberts, adorned with a crown and flowers, quickly followed.

Class floats proceeded by

the judges, and for the third consecutive year, the class of 2003 took the crown in the interclass contest. Themes of unity and patriotism dominated the organizational floats with many depicting the New York City tragedy as well as the emergency personnel who became heroes on September 11.

Dr. and Mrs. Dixon slowly advanced in an elegant carriage, and as they rode past on a hay wagon, the class of 1961 proudly waved their aged hands with more energy than any other college representatives. Various bands marched down Main Street, playing patriotic tunes until finally, the grand finale came blazing by, and little boys rose to their feet to salute the long-awaited bright red fire engines.

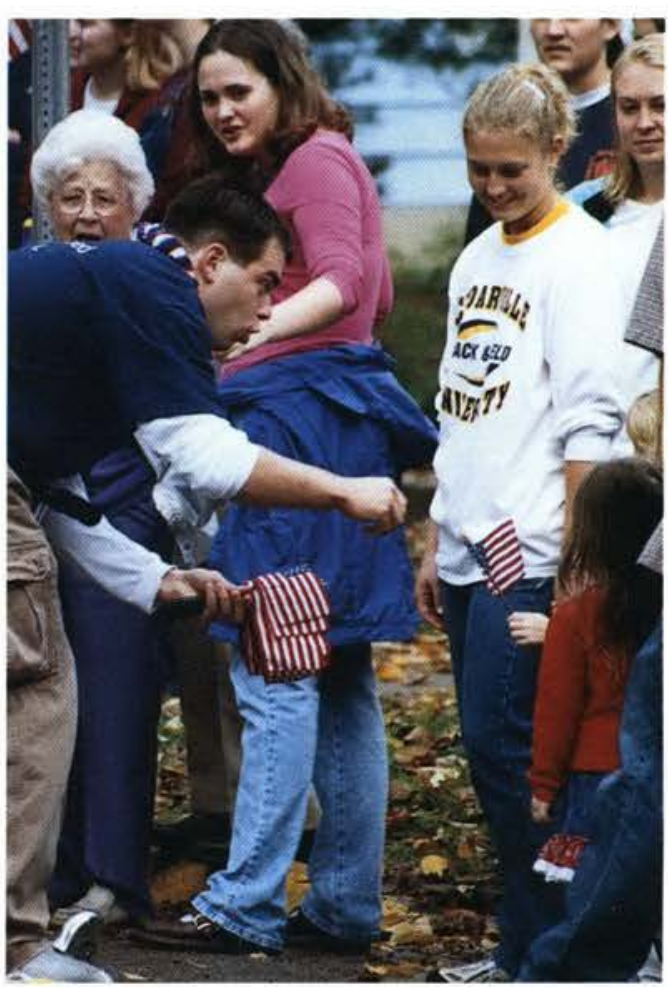

Graig Bantle bends down to give flags to the little ones who came to see the parade.

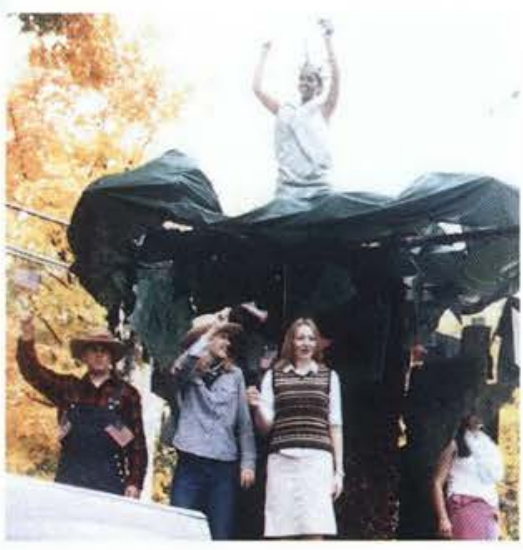

Showing their

creativity, the

freshman class

float has the

banner, "Rooted in

God, United We

Stand."

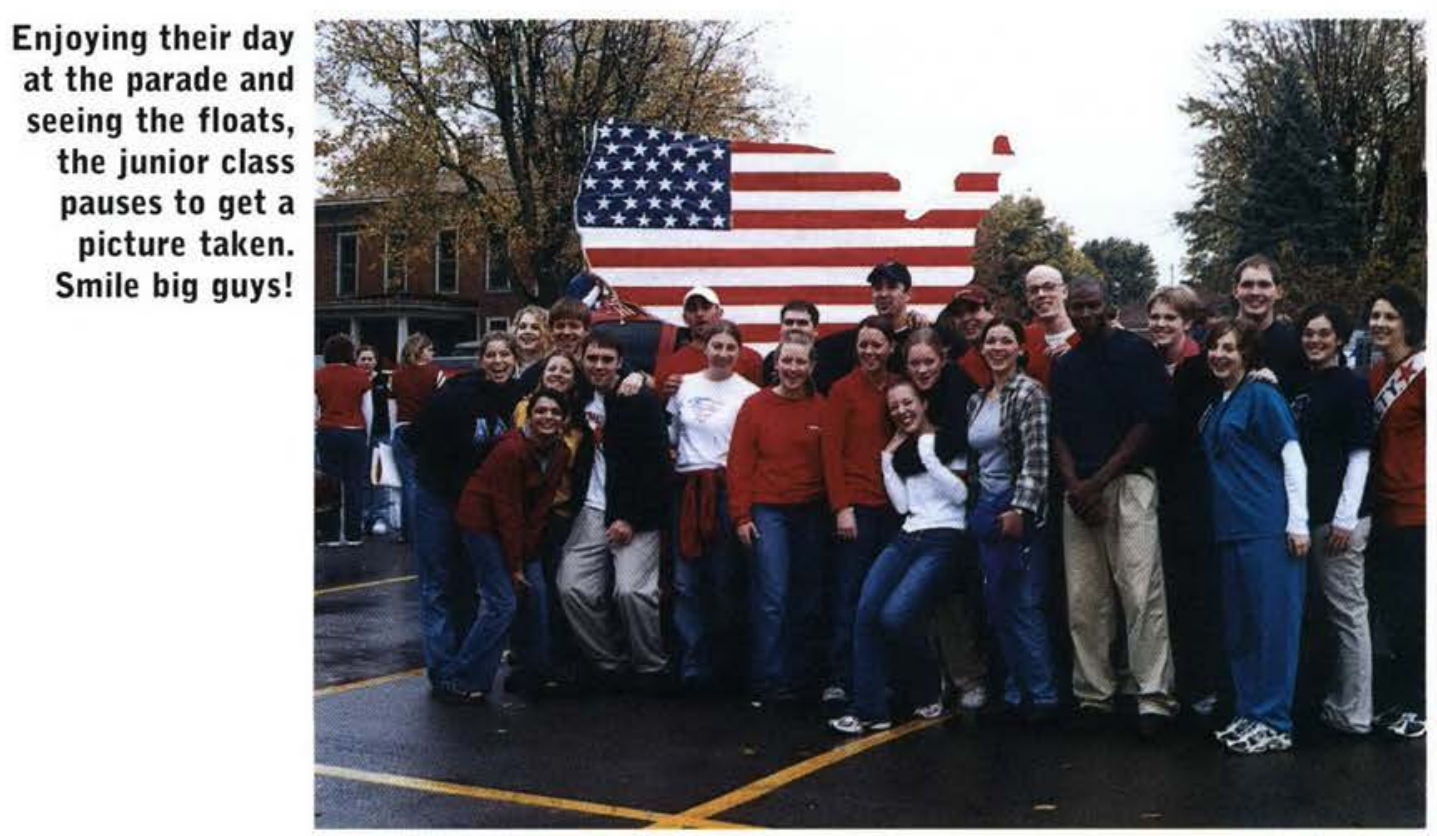

Fall 27 


\section{canoe race}

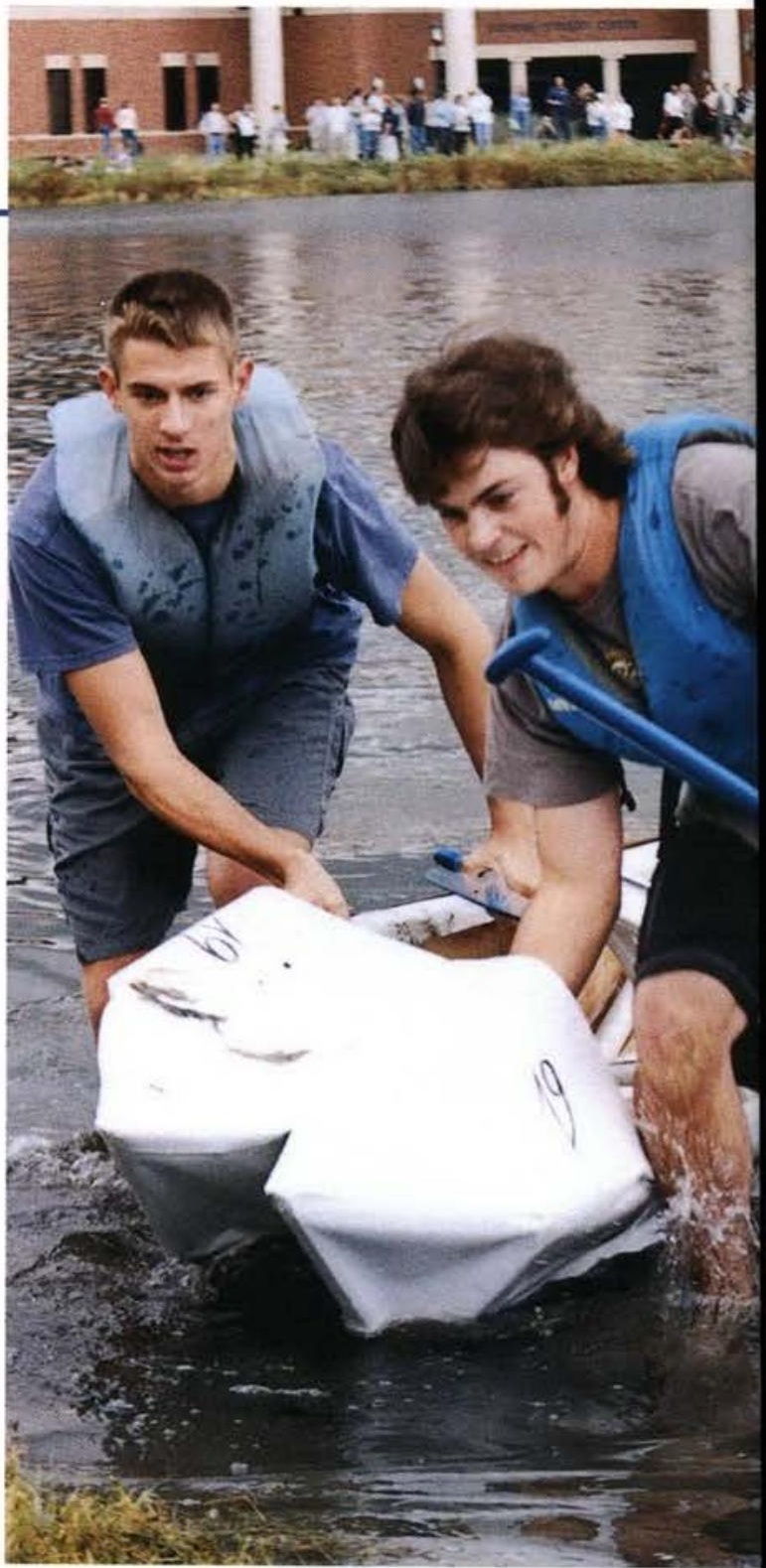

Freshman engineer majors race their home-made canoe to the finish line.

The crew of Moby Dixon take the canoe race challenge seriously, out paddling the other contestants.
The canoe race challenges engineers to build a canoe and get it successfully across Cedar Lake.

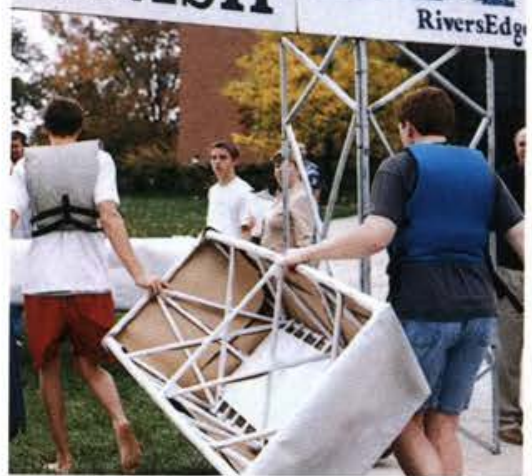




\section{farm liffall play}

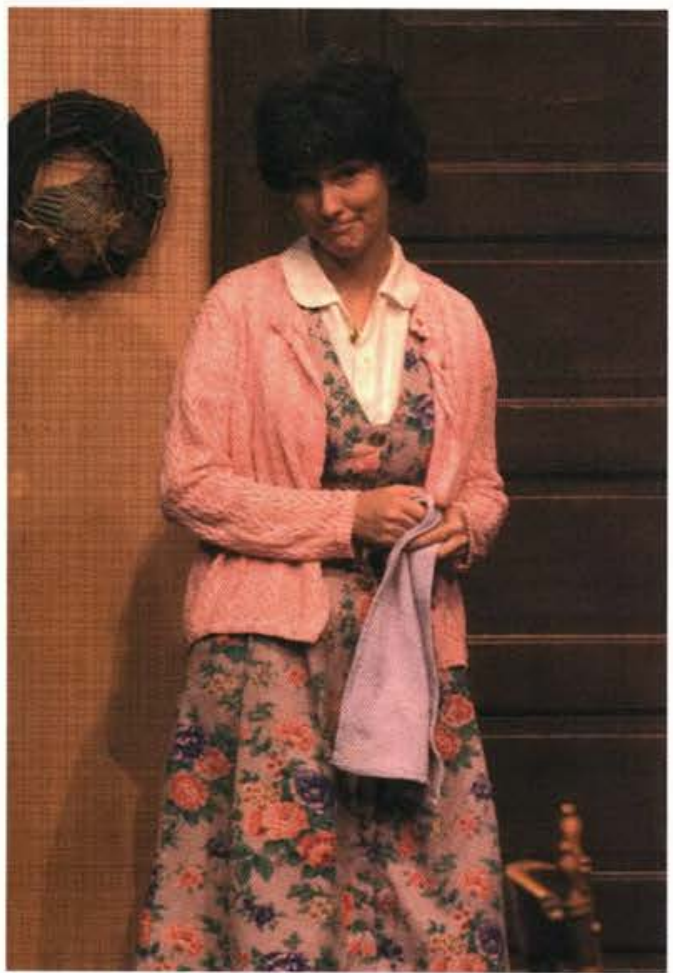

Susan Brown

potrays the

demanding,

realistic mother

in the play

Husbandry.
The fall play Husbandry by Patrick Tovatt, focused on the hard times of a farmer in the midst of rising technology and economic problems in the farming industry. Mischelle L. McIntosh directed the play and cast with Susan Brown, Ryan Culpepper, Julie Van Winkle, and Scott Ryan as main characters.

Senior Cristina Miller said, "It was a realistic depiction of farm life. I really enjoyed it." The play revolved around one family struggling to keep their farm. Their son was faced with the problem of choosing to please his parents and take over the farm or to please his wife and remain where they were in the city. Although the problem was never resolved in the play, it left the audience with an emotional depiction of conflict in the family.

Michael Minahan, both

Dramaturg and Scenic Charge, said, "An interesting fact is that the playwright, Patrick Tovatt, lived in Kentucky for 17 years and continued the family tradition of raising cattle. Husbandry can certainly be seen as a somewhat autobiographical piece."

Minahan also said, "The themes that are dealt with in the play are real and had a significant impact on the Greene County farmers who were able to see this drama." During two of the performances, some farmers from the community shared some of their life experiences with the audience.

The theme centered on the importance of carrying on family tradition and keeping the farm within the family. Senior Jodi Crawford said, "It was interesting to see how the problems in the farming industry affect individual people and families. I have never looked at farming in that way."

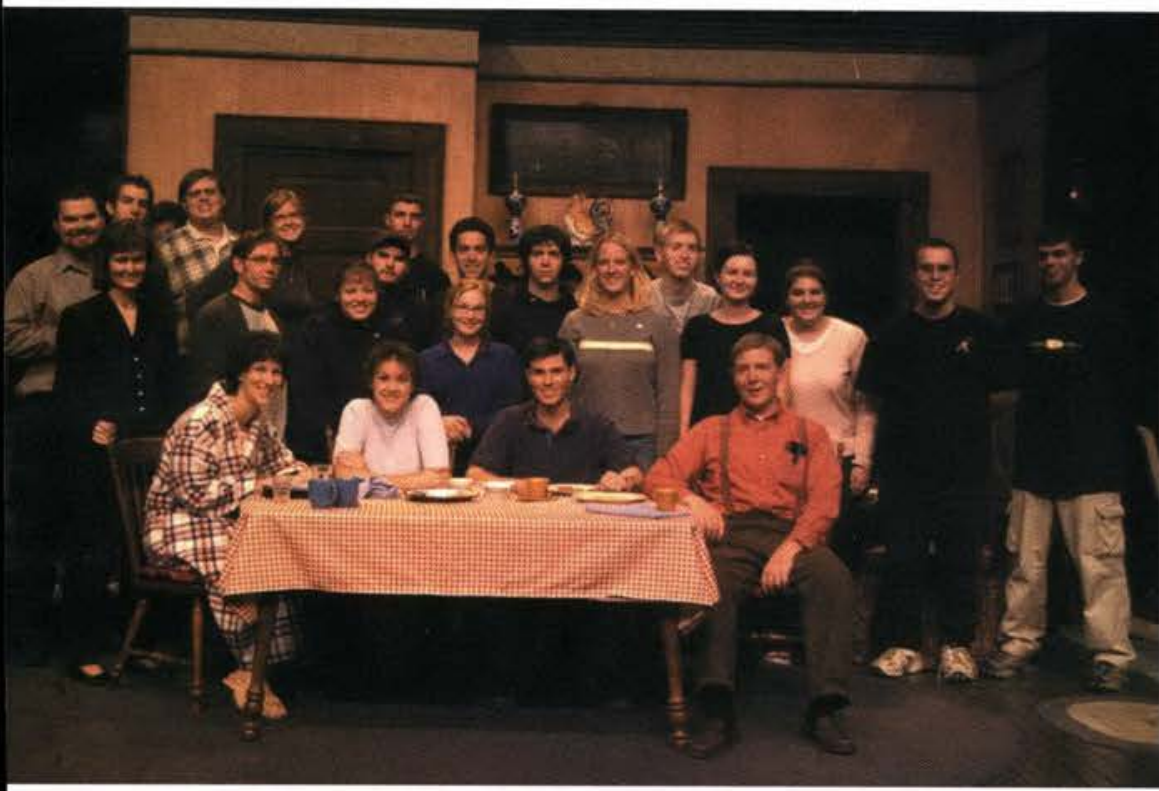

The entire Husbandry cast poses for a picture so that they can be known for their excellent performance.

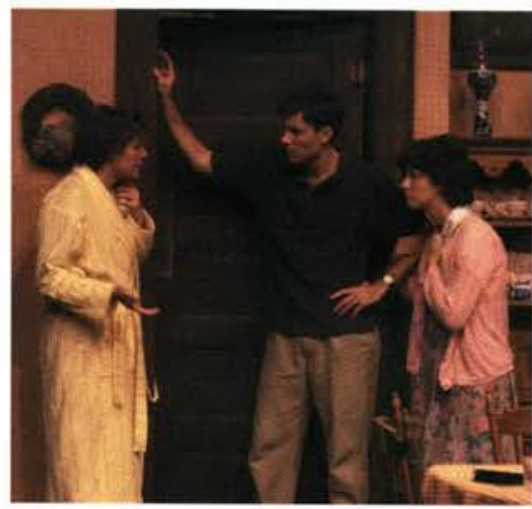

Julie Van Winkle, Scott Ryan, and Susan Brown get into a heated arguement over the farm. 


Open house gave Cedarville students an ample opportunity to get into the Christmas spirit. Christmas lights were hung, and mistletoe dangled above the doorways, ready to capture the unsuspecting. The themes this year covered a wide range from "Christmas Across America" in Johnson to "An Eighties' Christmas" in Printy.

One of the units in Lawlor chose to experiment with a cross between Santa and his twelve reindeer and Luke Skywalker and the Millennium Falcon. While in a light-saber duel with Santa Claus, Darth Vader was sure to point out that, "The season is strong with this one."

\section{Some of the women of}

Willets rolled up their sleeves and tightened their boots. While caped in camouflage, they put their unsuspecting visitors through basic training. With shouts and grunts, matching a general's drilling of his

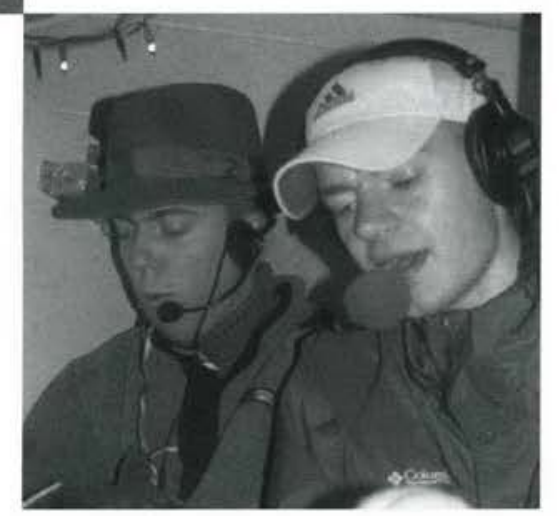

Brian Davis and

Dan Dunham give

a live broadcast of

the Christmas

parade in

McChesney. troops, ringing in their ears from the Willets women, the involuntary enlistees crawled, ran, and leaped through a challenging obstacle course.

Sophomore Dan Cobb thought, "St. Clair's 'Santa Crashed in the Congo' theme was very impressive...I would definitely date the gorilla."

Freshman Wendy Curtis loved her first chance to pass the stop sign in the Lawlor parking lot legally. "Open house was really fun; it was great to be able to have my guy friends over and see their rooms all decorated for the holidays."

The creativity and hours of work of two halls were rewarded with gift certificates. The women's top winner was the Sesame Street gang in McKinney Hall. Harriman captured the men's crown with their interpretation of the one gift on every girl's Christmas list, the "ideal man."

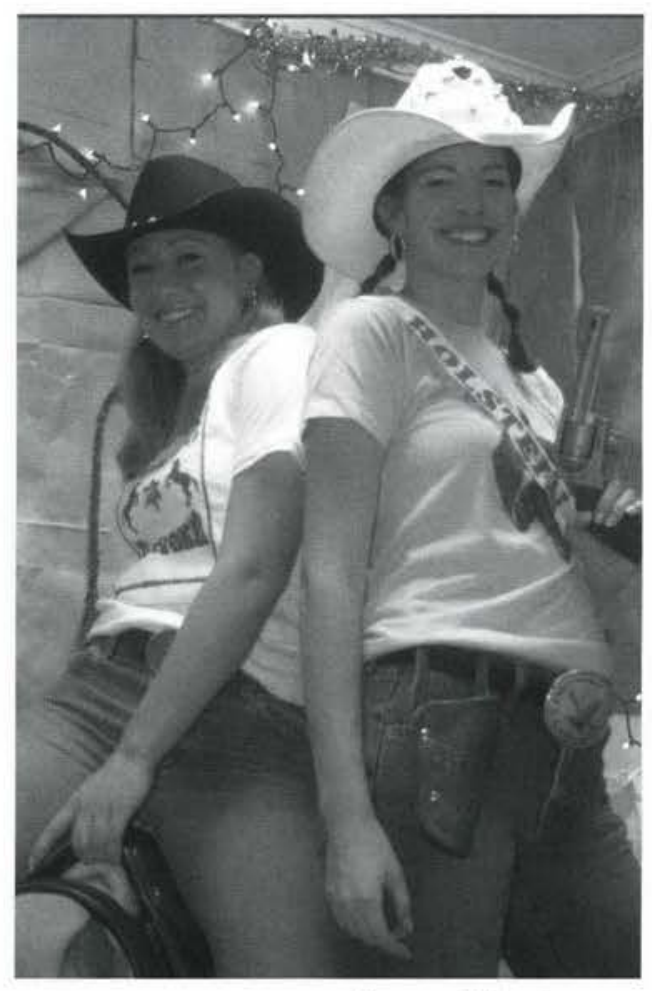

Some girls choose to break out the Wranglers, hats, and big buckles for their CowGirl Christmas.

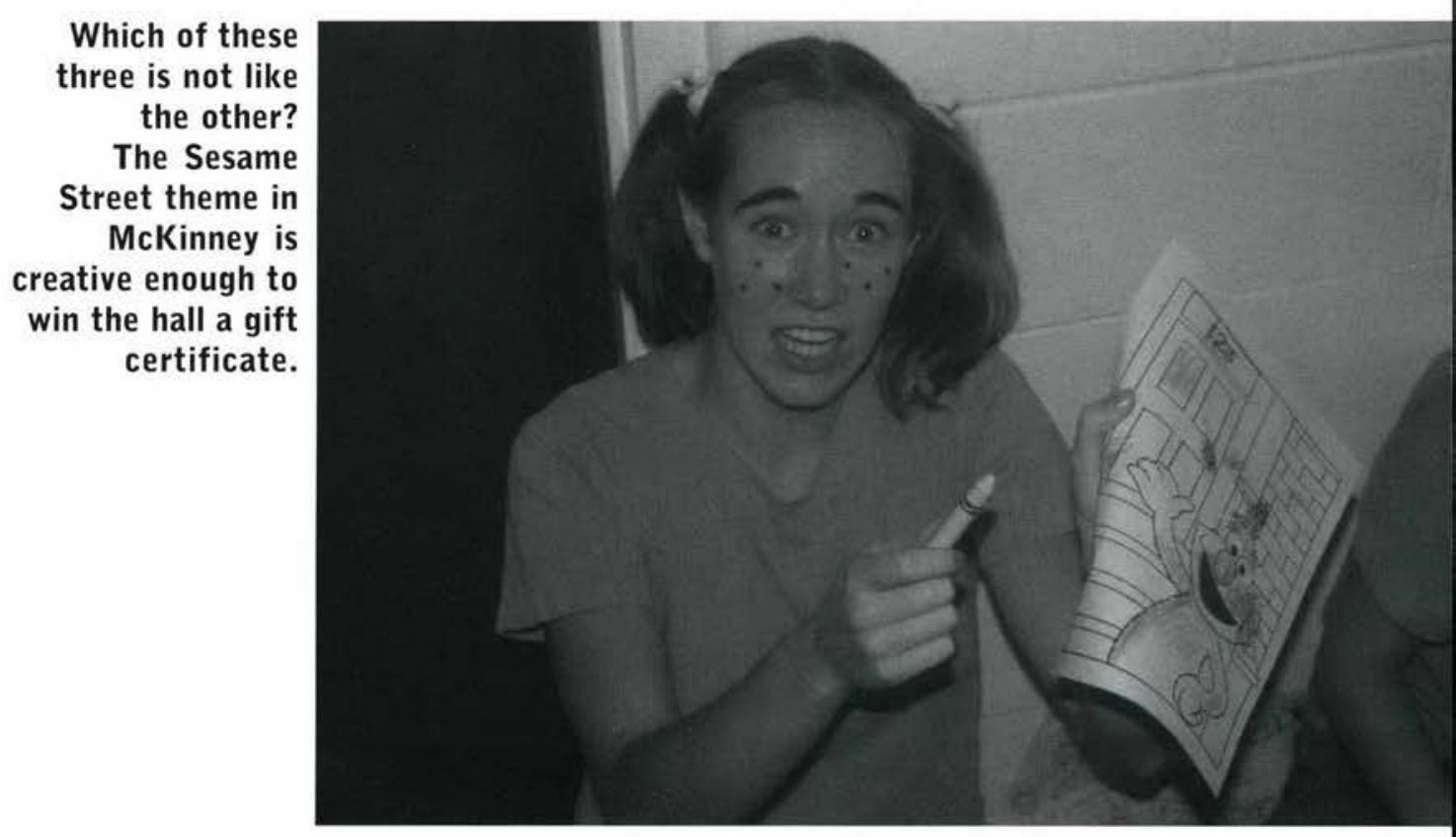




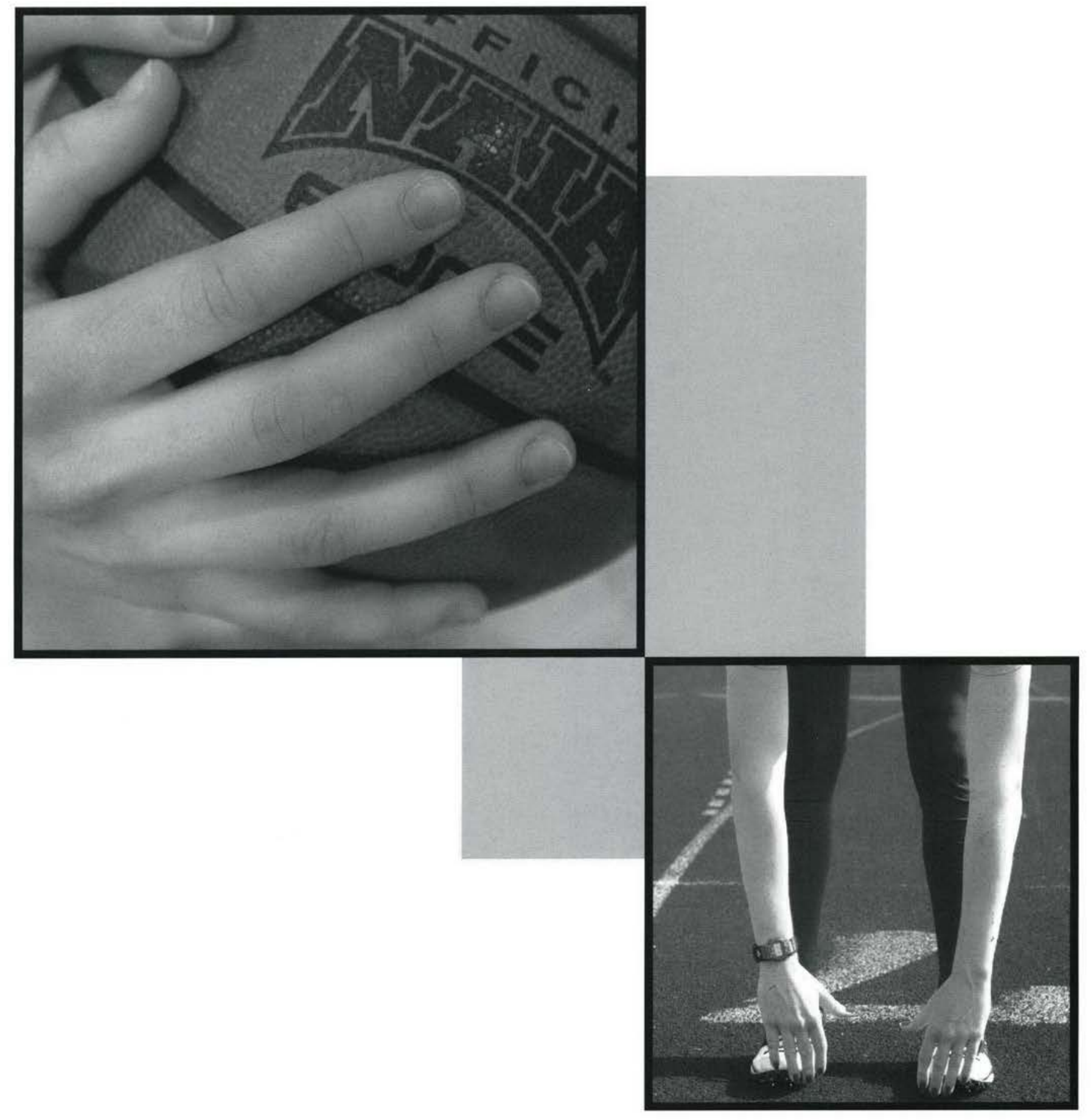

ATHLETIGS 

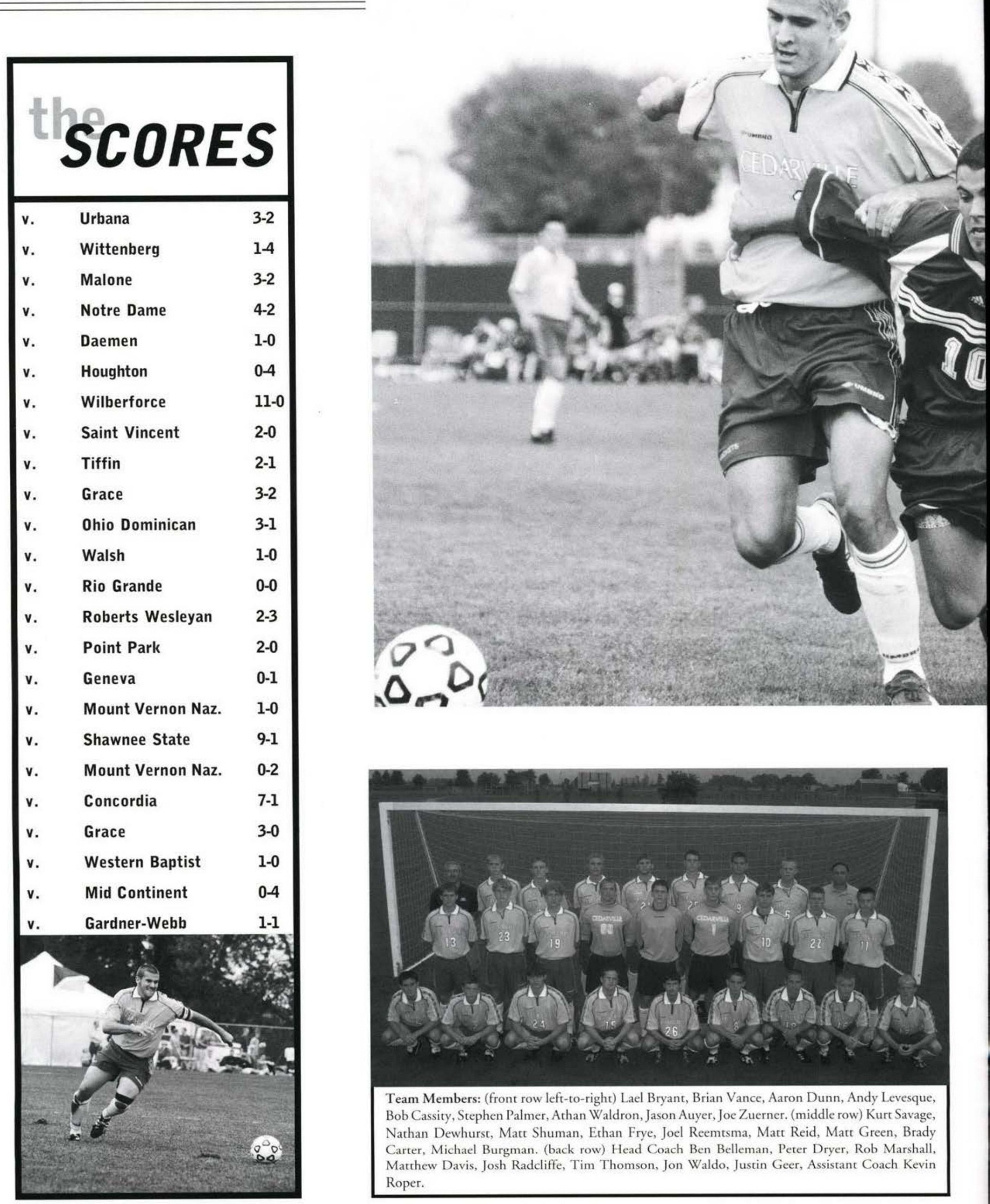


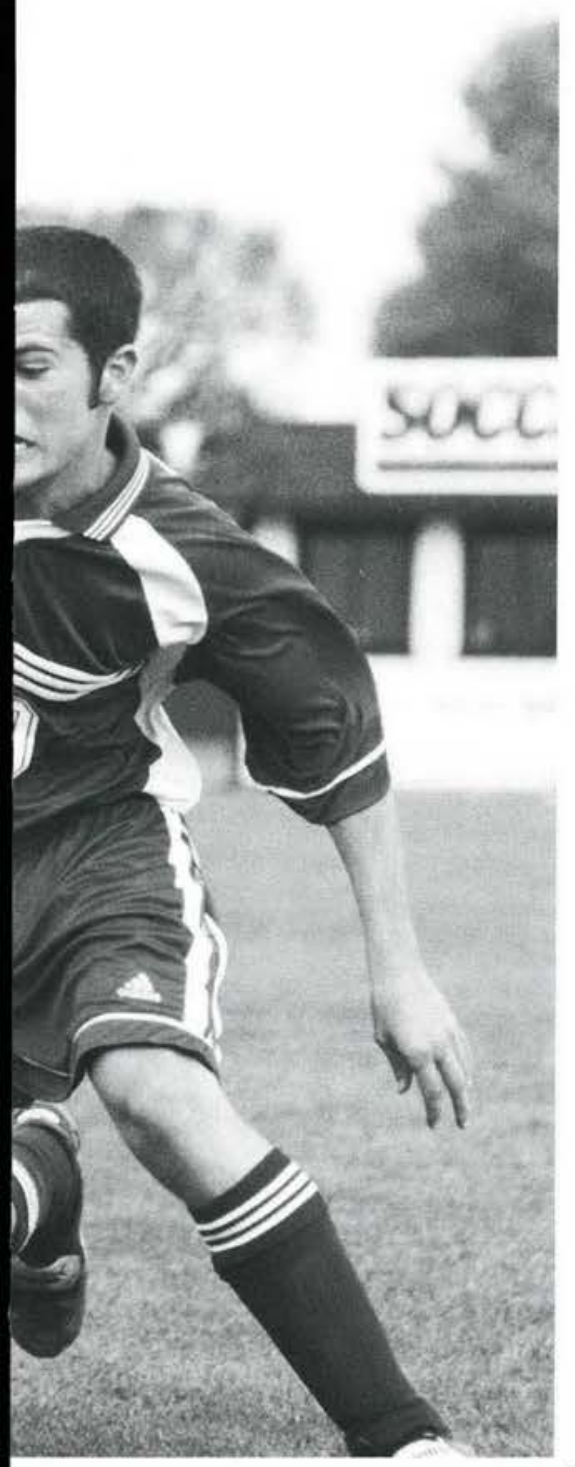

John Waldo, leading scorer on the men's soccer team, fights for possession of the ball. $\mathrm{n}$ a cold, windy November Saturday afternoon, the Cedarville faithful trooped out to the frigid soccer field armed with blankets, parkas, and scalding coffee to watch the Cedarville University Soccer team battle rival Grace for a birth in the NCCAA championships.

Behind Jon Waldo's three goals and two assists, the Jackets slaughtered Concordia 7-1 to set up this match with Grace. Most fans remembered the 3-2 overtime win with Grace earlier in the season and expected a close fight. As balls found posts and cross bars, the match remained scoreless for most of the first half. In the $35^{\text {th }}$ minute, Waldo collected a rebound in front of the net and scored his $21^{\text {st }}$ goal of the season. Grace attempted to rally with a number of offensive charges, but goalkeeper Matt Reid made some key saves. Peter Dryer finished the scoring, earning the Jackets a 3-0 shutout and a trip to the NCCAA nationals in Florida. At the national tournament, the men's soccer team completed their season finishing third.

Captains Lael Bryant and Justin Greer led the team to a 16-6-2 record overall and a 12-3-1 record in the AMC. Waldo also contributed a Cedarville University Record of 14 assists, becoming the fourth player in Cedarville history to notch more than 20 goals. Senior Michael Burgman anchored an outstanding defense in front of Junior Matt Reid. Reid collected eight and a half shutouts on the season while accumulating an astounding 1.23 goals against average.

Coach Benson Bellemen said, "It has not just been the captains displaying good character, but all the seniors. I have been impressed and encouraged by their leadership. Their leadership has been instrumental in our success this year."
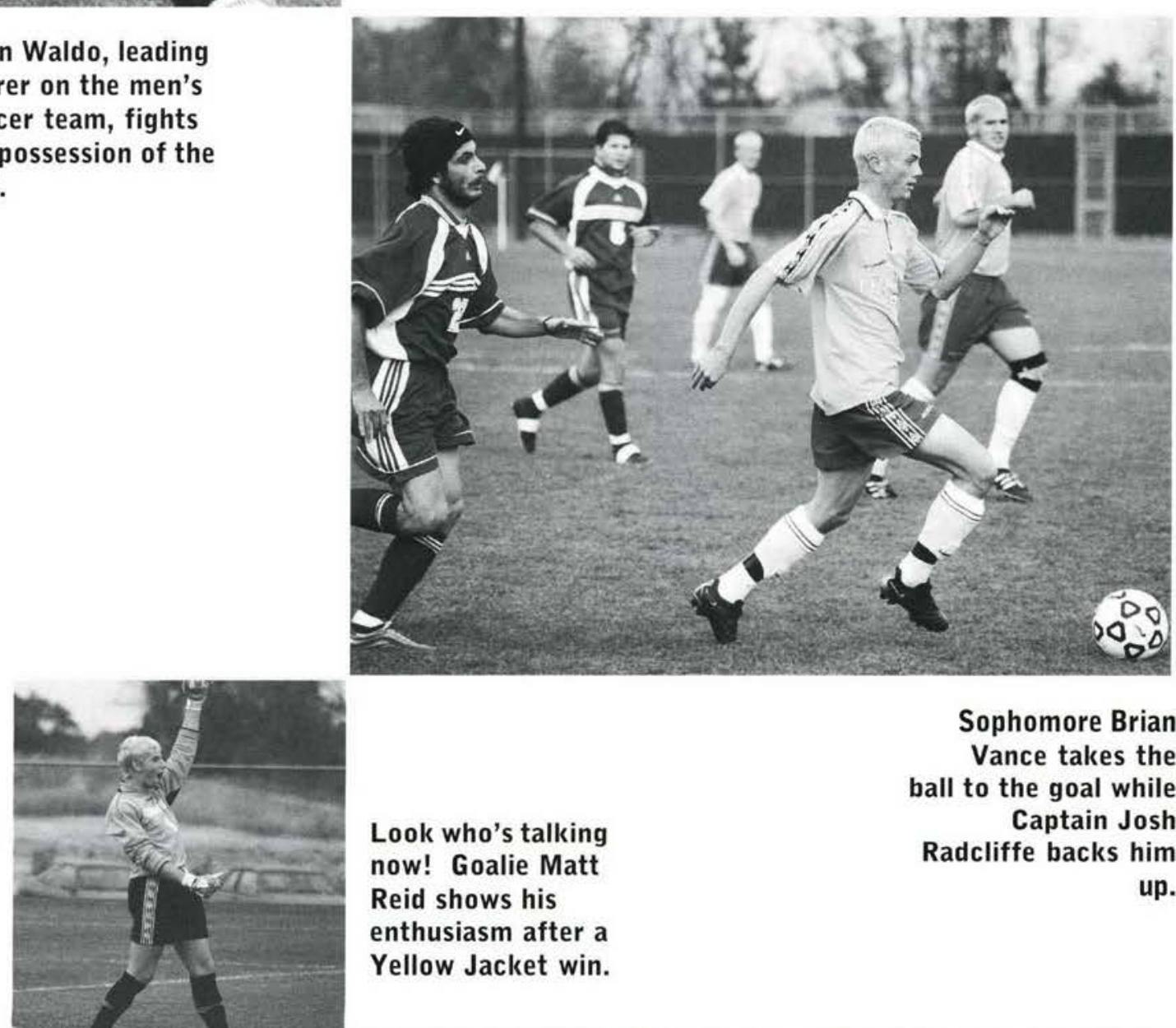

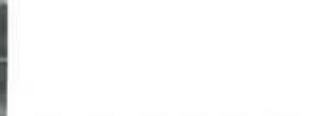

Look who's talking now! Goalie Matt Reid shows his enthusiasm after a Yellow Jacket win.
First year player Matt Green is all "hands off"as Captain Lael Bryant comes to the rescue.

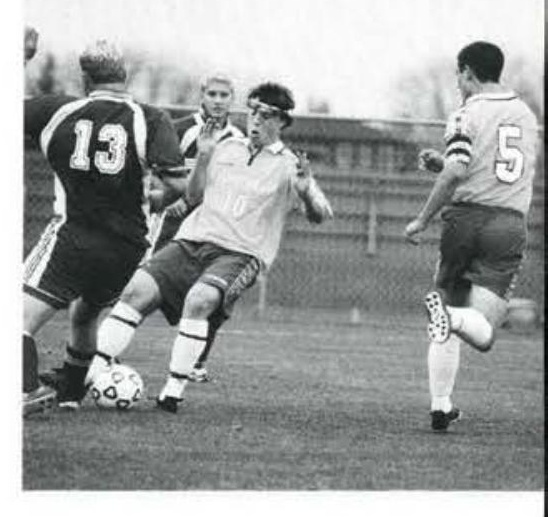

Athletics 37 
Led by co-captains Michelle Ruhlman and Danielle Davidson, the Cedarville University Yellow Jacket Women's Soccer team completed an excellent season, placing second in the NCCAA Midwest Region finals.

As the top women's soccer player in Cedarville University's history, Senior co-captain Michelle Ruhlman finished her career strongly. She was second on the team in goals and points, despite playing in only 12 games. Following this season, Ruhlman held Cedarville University

Women's soccer records for most career points with 95 and most career goals with 34.

Additionally, seven seniors provided the team with an immense amount of depth as Jessica Alexander, Lisa Hockenberry, and Jenny Walker completed their fourth years as Lady Yellow Jackets.

Building upon her freshman year, Jane Adams was one of five sophomores to make outstanding contributions. She led the team in goals and assists, finishing with 35 points, which is second on the career scoring list for Cedarville University.

Junior co-captain Danielle

Davidson anchored a solid defense in front of sophomore goalkeeper Melissa Fawcett. With a 1.66 goals against average and a school-record, seven shutouts, Fawcett carried on the torch of excellent goaltending. Only Malone, Wittenberg, and Tiffin scored more than 2 goals against her.

At the beginning of the season, a tough schedule stared the Lady Jackets in the face with games against defending champion Tiffin and new rival Houghton College. Despite the tough schedule, they represented the school well with a double overtime tie to NAIA powerhouse Houghton and an exciting 1-0 overtime victory over AMC rival Shawnee State. They completed the season 11-9-2 overall and $9-5-2$ in the AMC.

\section{Jane Adams}

protects the ball

as she takes it up

the field

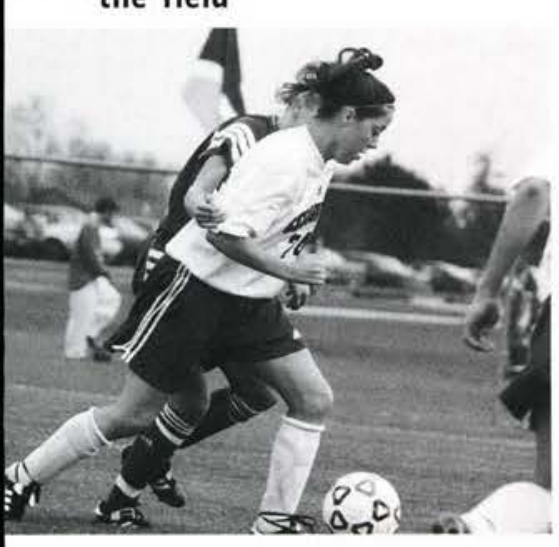

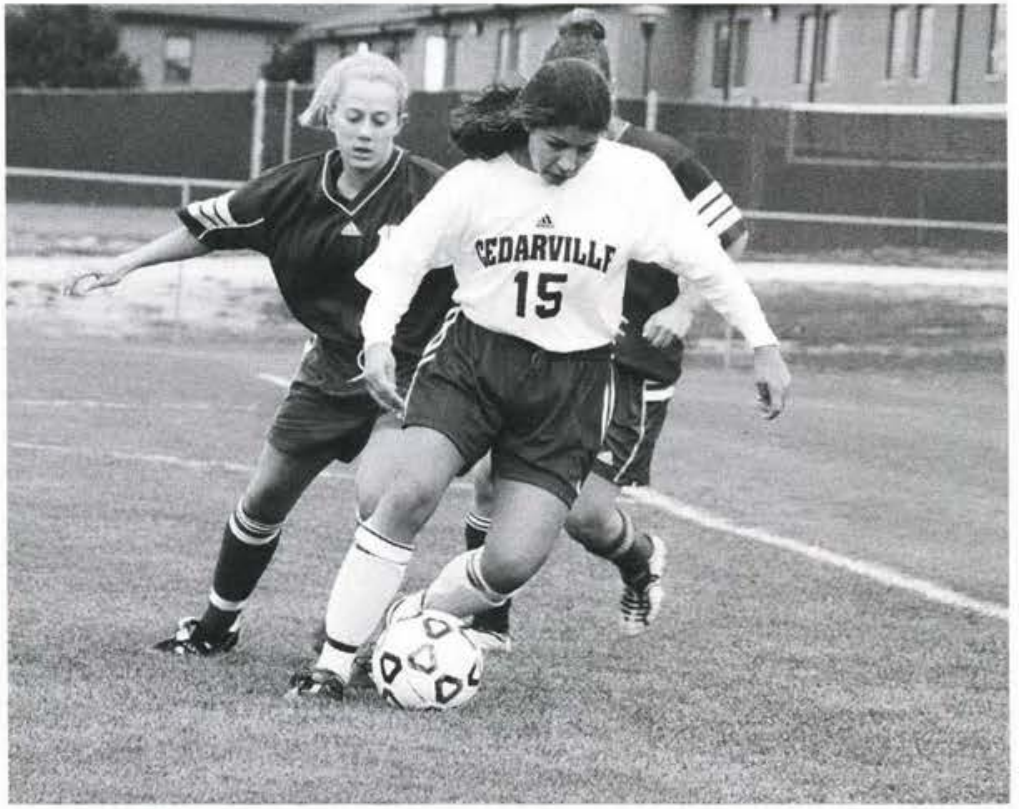

Jen Rock shows her freshman talent as she keeps the ball from the opposing double team strategy.

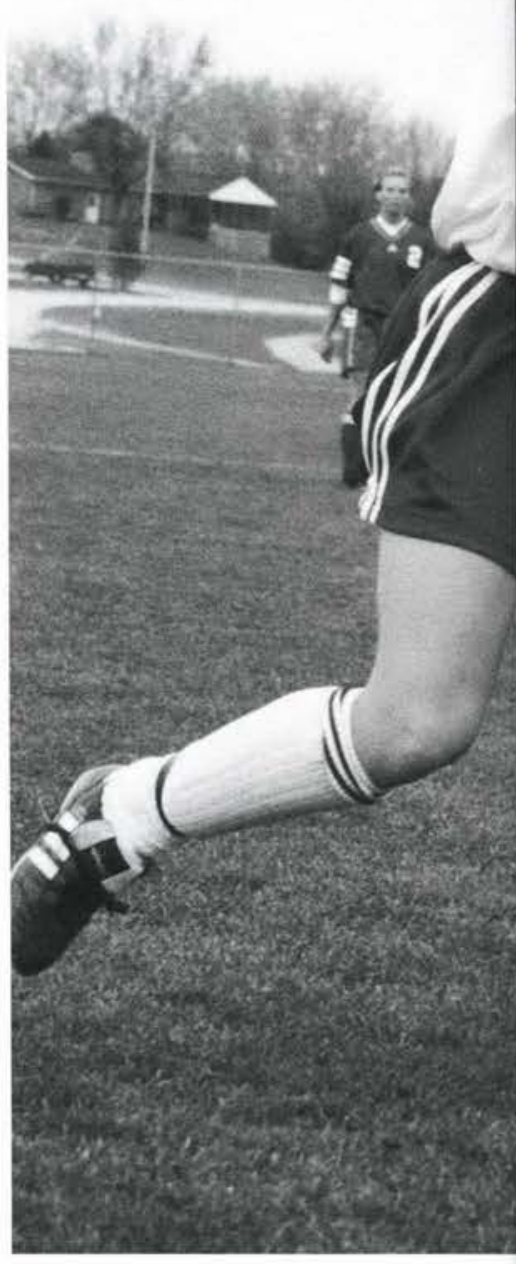

Senior Alicia Anderson fights her opponent for control of the ball.

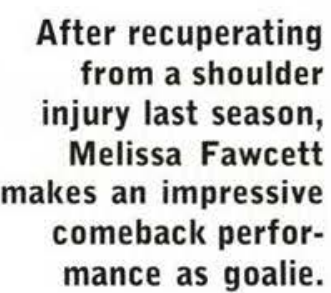



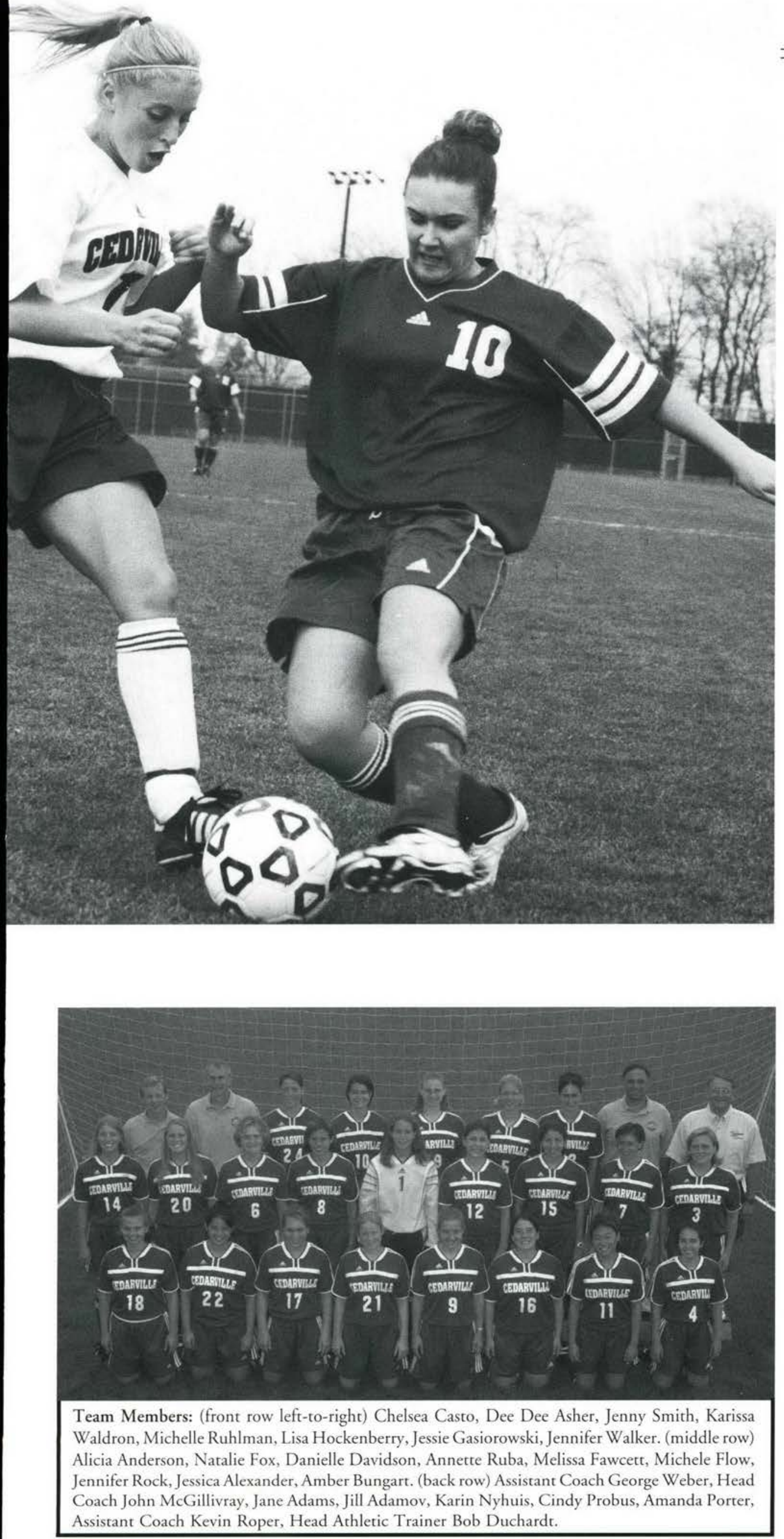


\section{'ISCORES}

Rio Grande Invitational

2nd of 2

Midwest Collegiate Championship

13th of 28

11th Annual Friendship Invitational

4th of 12

Greensboro Invitational

3rd of 15

All-Ohio Championship

15th of 33

Wilmington Classic

1st of 12

\section{NCCAA Nationals}

4th of 20

\section{NAIA Ranking}

25th

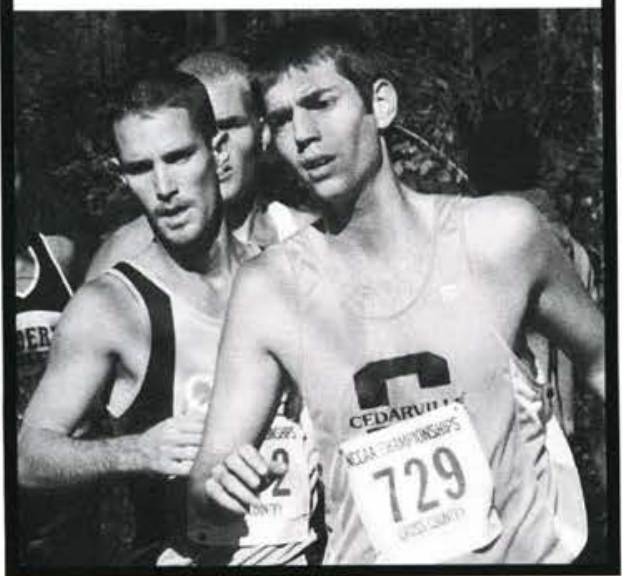


For the first time in Cedarville University's history, an athletic team earned first place in the NAIA National tournament. Led by Junior All-American Erin Nehus, the Women's Cross Country team edged second place Concordia NE by 22 points to bring home the trophy. Nehus placed third overall, and fellow AllAmericans Jennifer Tetrick and Heidi Wright earned $12^{\text {th }}$ and $29^{\text {th }}$ respectively. Sarah Roberts, Kim McNeilance, Abigail Winburn, and Jen Roman rounded out the top seven for the Lady Jackets.

Excitingly, all top seven Jacket runners will be returning next year.

Before the race, Coach Elvin King said, "We want God to be honored by our effort and how we handle the success or failure in reaching the goal [of finishing in the top four]." His team succeeded by taking first place and earning Coach King his first NAIA Coach of the Year award.

During the entire season, the Lady Jackets battled for the first-place ranking in the NAIA. Before the American
Mideast Conference Tournament, NAIA ranked them first in the country, but despite winning the tournament behind Nehus' first place finish, they fell to second in the rankings. They entered the NAIA tournament still ranked second following an impressive victory in the NCCAA championships hosted at John Bryan State Park. Nehus won the women's title, and Tetrick, Wright, and Roberts joined her in earning NCCAA All-American Honors by placing fourth, fifth, and eighth respectively.

\section{Additionally, the NCCAA} named Coach King the Cross Country Coach of the Year for the conference. Cedarville University welcomed them back proudly at a chapel service where they presented their first-place banner, and Coach King received his NAIA Coach of the Year Award.

Team member Jen Roman summarized the year by saying, "Our desire is to go out and glorify God."
Student manager Julia DeHart bends down for a picture with her little sister while the team is on the run.

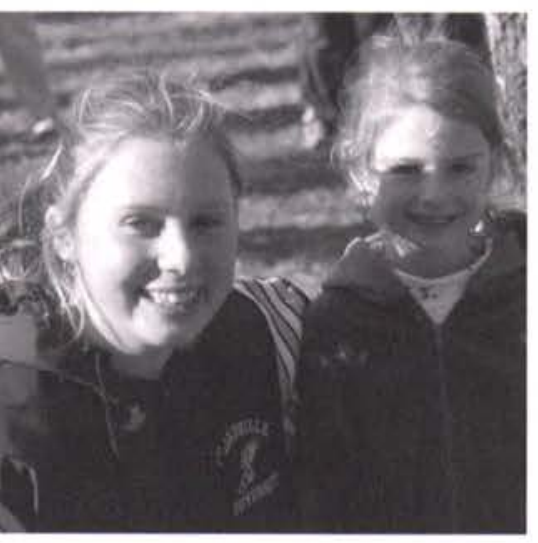

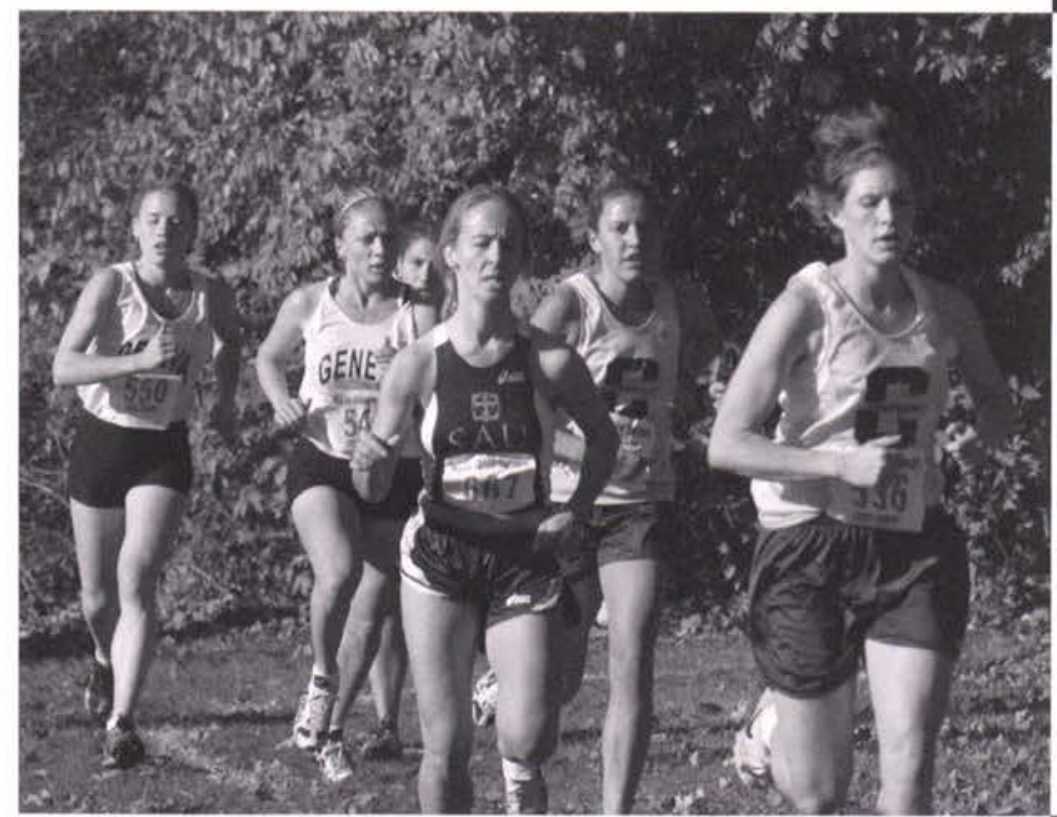

The competition among Christian schools keeps the women's team on their toes.
The Cedarville pack, Jen, Erin, Heidi, and Corrie take off strong and stick together for a big win. 


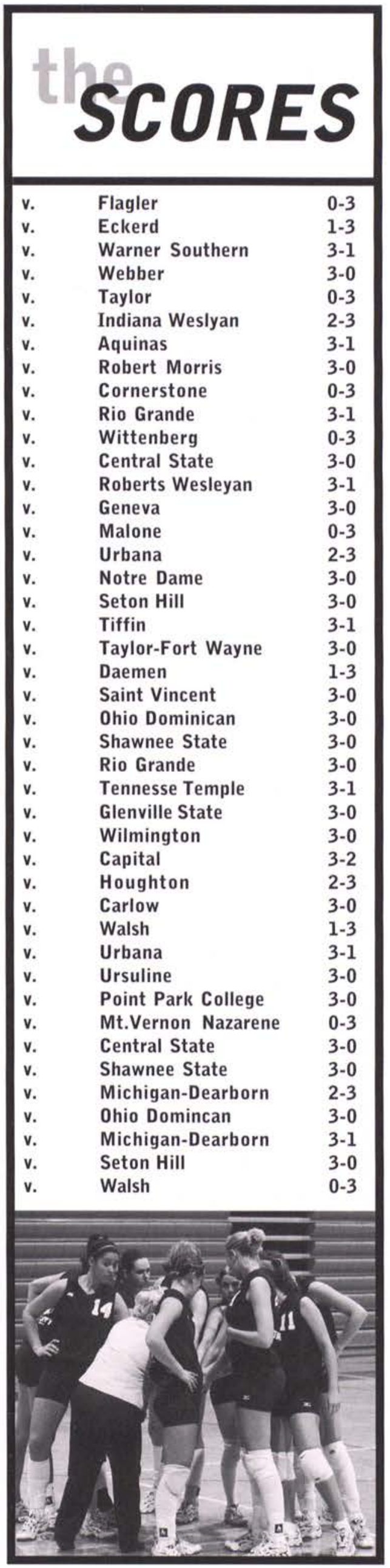
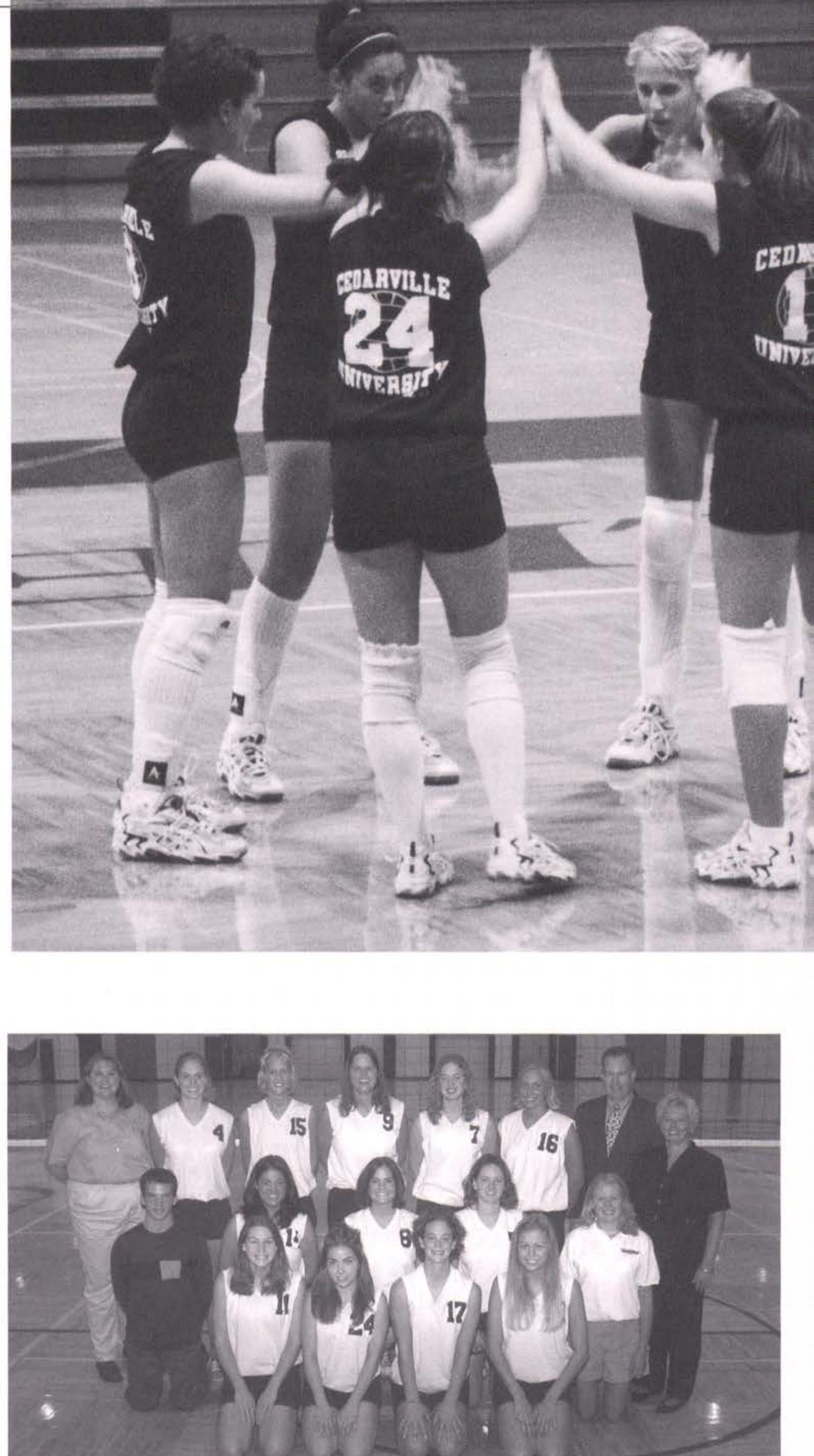

Team Members: (front row left-to-right) Cheryl Meyer, Courtney Williams, Carrie Hartman, Andrea Hilliker. (middle row) Student Assistant Matt Kaufman, Richelle Clem, Paula Thompson, Charissa Winburg, Student Trainer Julia Wolters. (back row) Assistant Athletic Trainer Lisa Martin, Amy Martin, Heather van der Aa, Melissa Holland, Julie Rhoads, Sarah Oleszczuk, Assistant Coach Jim Clark, Head Coach Teresa Clark. 


\section{CUwomens volleyball \|}

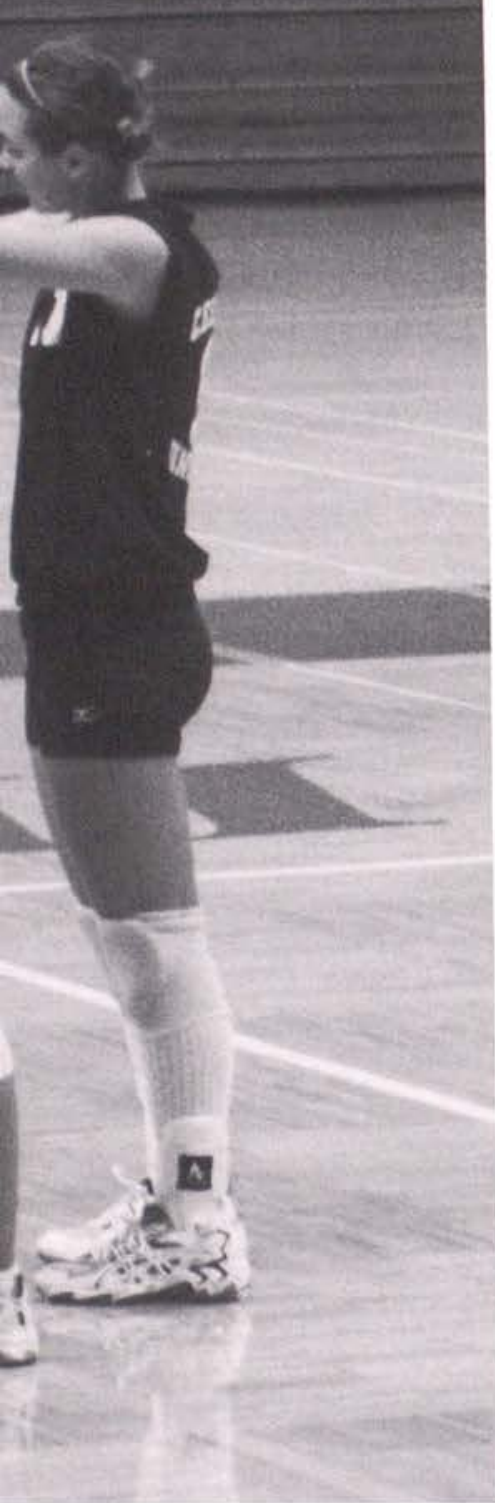

New and old members of the Women's Volleyball team pep each other up before a match.

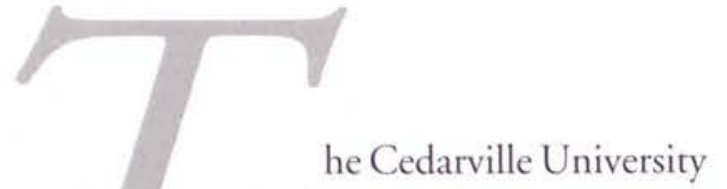

Volleyball team had another winning season last year, led by Senior Heather van der $\mathrm{Aa}$, who completed her volleyball career as the all-time kills leader with an astounding 2390.

Adding to a host of accolades including NCCAA All-American AllTournament team honors and NAIA First Team Honors, the American Mideast Conference named van der Aa the Player of the Year. She was the first player in Cedarville University history to earn this honor in volleyball. In response to van der Aa's excellent play, teammate Sarah Oleszczuk said, "She is a smart player who knows how to hit in the holes." Additionally, Senior Amy Martin earned Second Team honors, while Carrie Hartman and Melissa Holland received honorable mention.

During the season, Student Assistant Matt Kaufman said, "We're getting good all around play and solid contributions from everyone. After a lot of hard work, the desired system is

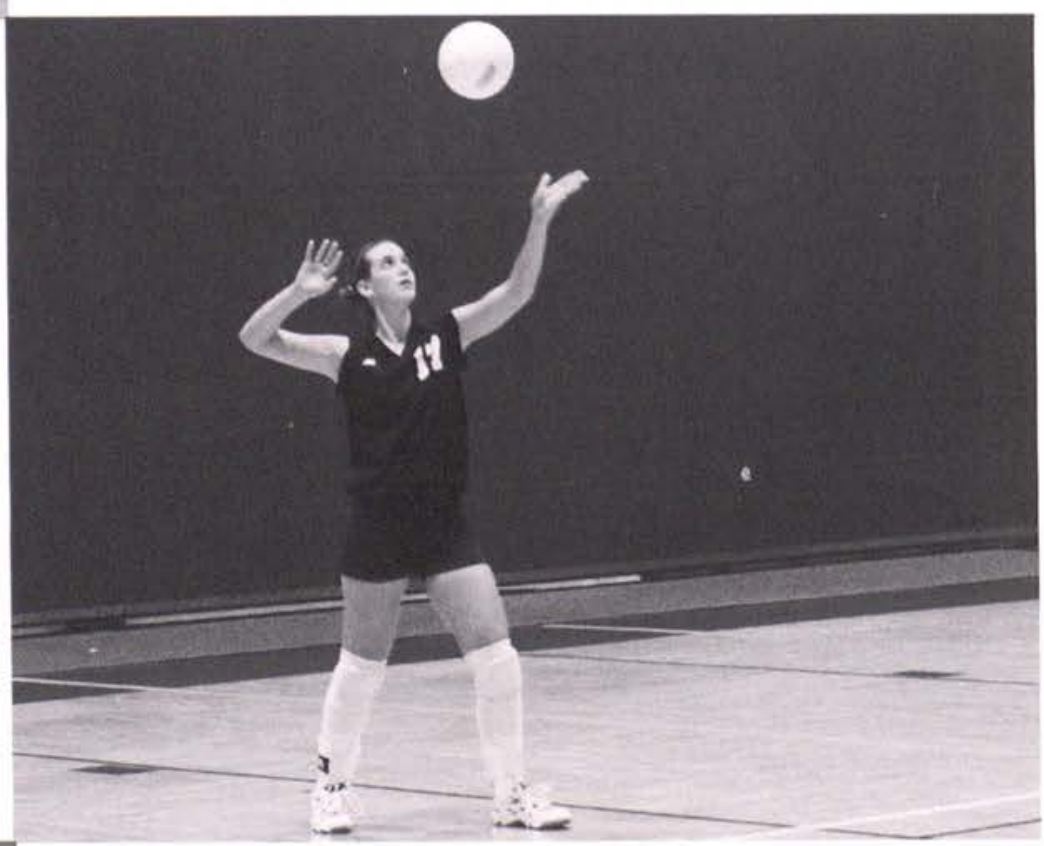

\section{Sophomore setter Carrie Hartman times her serve perfectly to send it over the net.}

starting to mold. The team is communicating well, and we are all starting to gel." At the end of the season, he remarked that he was pleased with the unity the team developed over the long season, pointing to the Jackets' eight game winning streak as evidence.

Seniors Amy Martin, Cheryl Meyer, and Heather van der Aa contributed to this unity as they led the team throughout the season. Van der Aa and Martin led the team in kills and blocks, while Meyer was second on the team in serves and led the Lady Jackets with her verbal encouragement.

In the first round of the season the Lady Jackets defeated Seton Hill soundly, but Walsh proved too strong in a 3 match battle. Winning 17 of the final 22 games, the team finished strong, compiling a 29-14 record and a 176 record in the AMC.

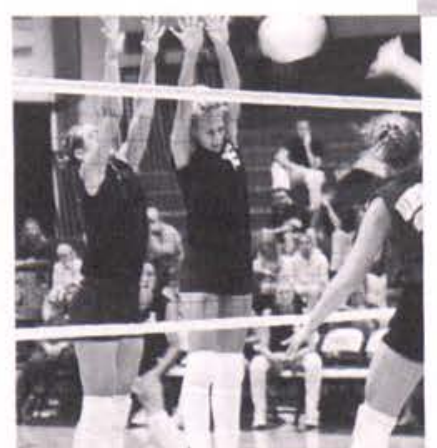

Two Lady Jackets are all hands as they block their opponent's shot.
Freshman Paula Thompson goes for the bump as Cheryl Meyer watches intently.

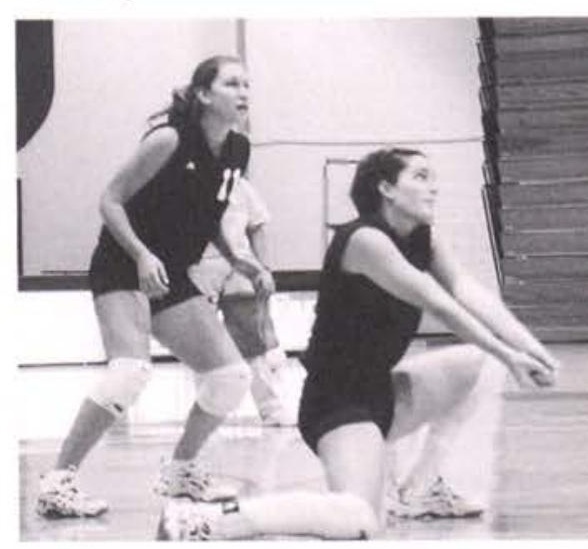


The purpose of the Cheerleading squad was to bring glory to God and support the players, coaches, and fans, and that is what they did. The Cedarville University cheerleaders encouraged school spirit and honored God through the 2001-2002 school year. They strived through many injuries while taking their Christian testimonies to many home and away games. They also encouraged the basketball players through notes, gifts, and verbal reinforcement. Through their acrobatic talent, they showed their support for both the Men's and Women's basketball teams and sought to glorify God in everything they did.

The Cheerleading squad worked extremely hard over the season. Tough practices and many injuries contributed to a difficult year, but the team grew closer together and pushed through the difficulty. According to freshman cheerleader Sarah Spracklen, "The team really worked hard throughout the entire season. I was proud of what we were able to accomplish. We overcame lots of obstacles and many injuries." Despite the struggles, she added, "The team had a blast."

They pushed themselves to achieve greater physical levels and encouraged record-setting crowds during Li'l Sibs weekend. Li'l sib, Adam Fernandes said, "The flips and cheers the cheerleaders did were amazing."

For the first time, the cheerleading squad was large enough to divide into two teams. One cheered for the Men's Basketball team, while the others supported the Women's team by cheering during the women's home games, as well giving out prizes to the crowds who came. The squad enjoyed this addition and looks forward to cheering next season.

\section{Gold Squad:}

Kristie Tate, Beth

Boyne, Sarah

Spracklin, Jennifer

Presley, Amy

Zeppenfeld

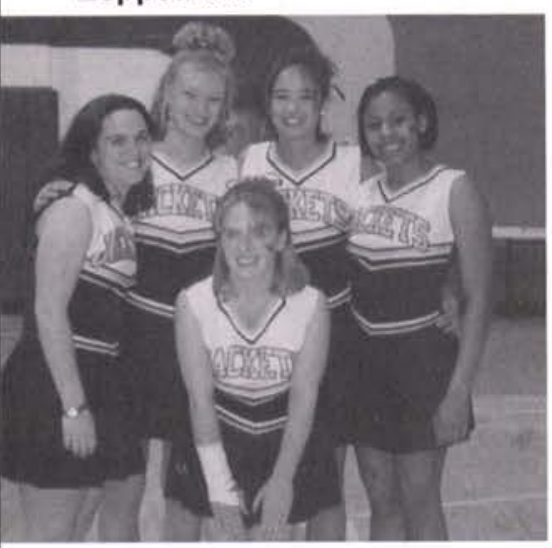

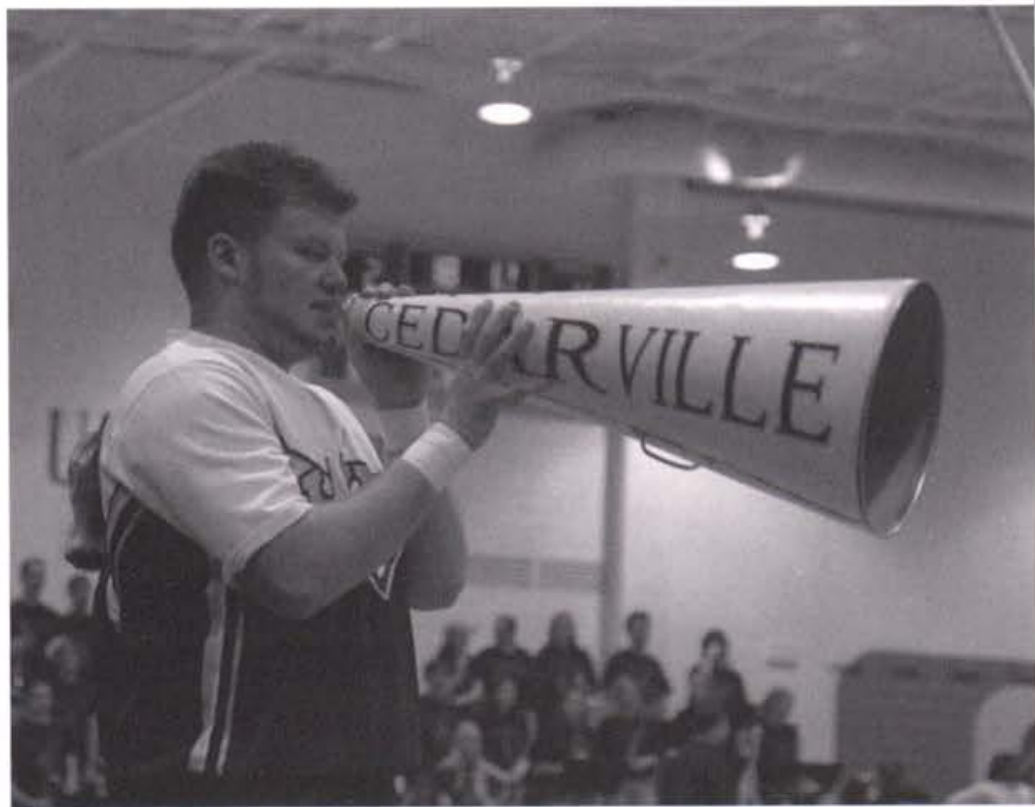

Josh Knorr does his part to get the crowd rowdy and the team spirit up!
Who says bees can't cheer? The Yellow Jacket jumps into the action for some crowd entertain-
The Cedarville cheerleaders move in sync during a basketball time out. 

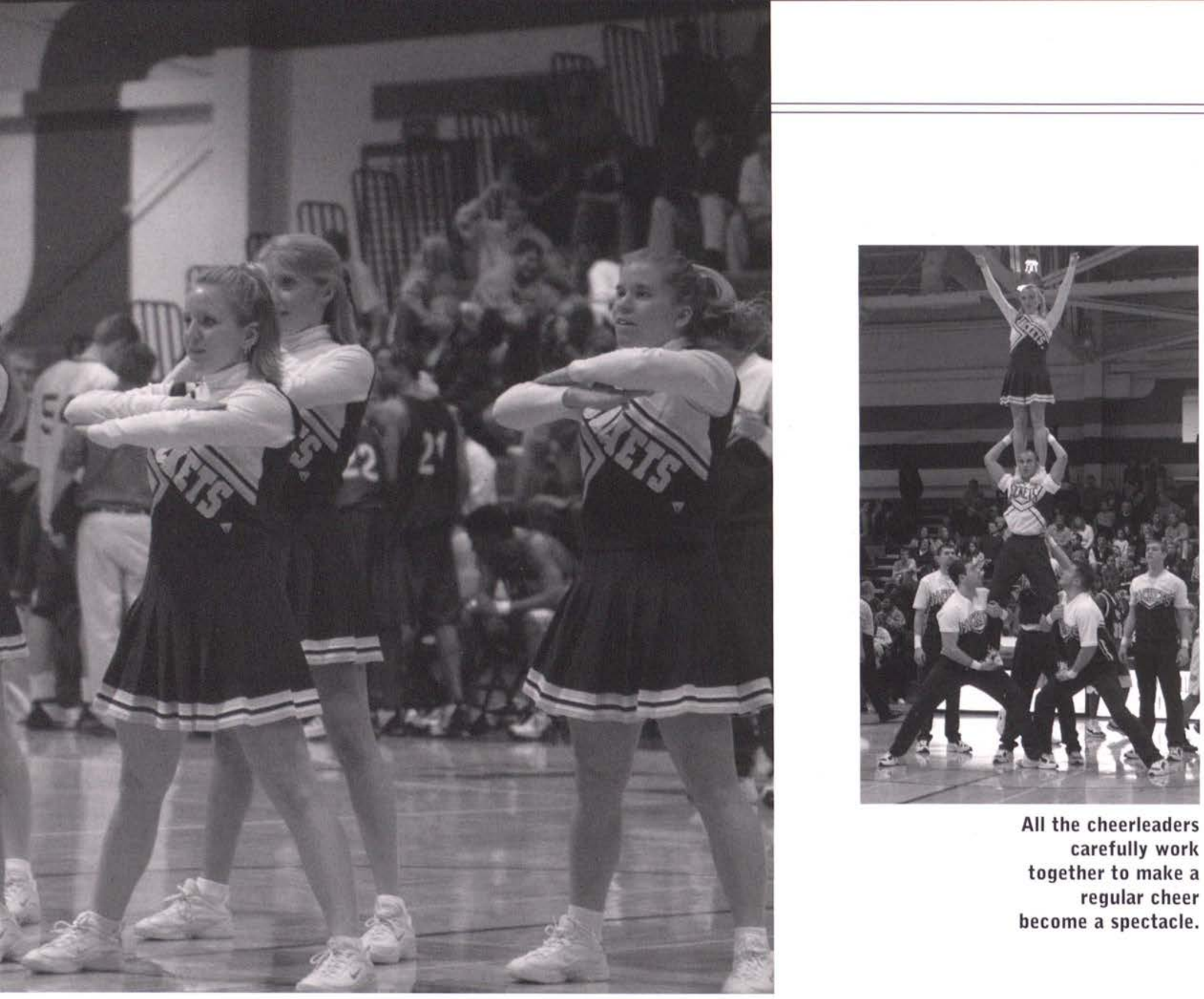

All the cheerleaders carefully work together to make a regular cheer become a spectacle.

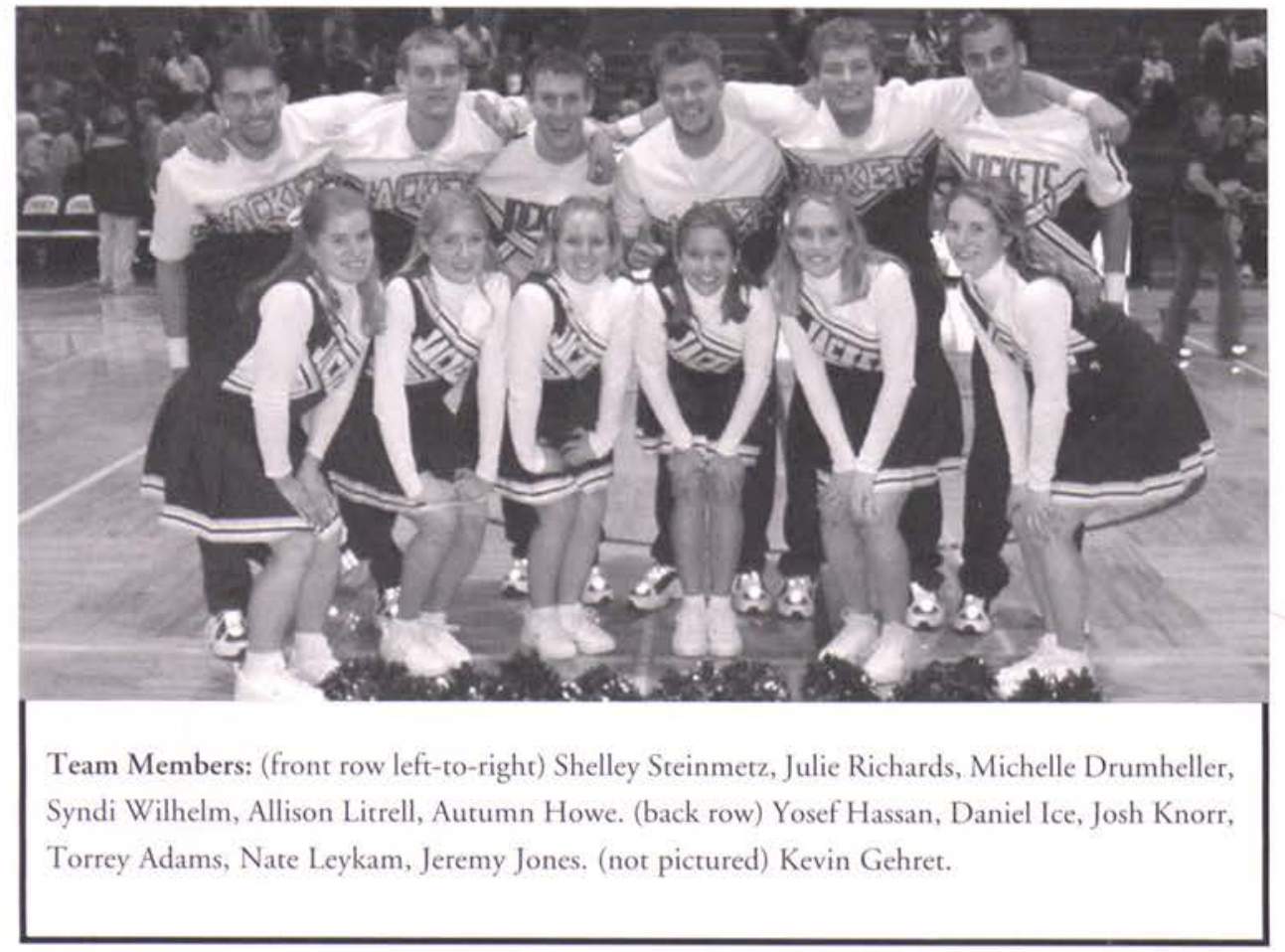

Who says that

cheeleaders have it

easy? These cheer-

leaders work hard

to make a strong

triangle. Talk about

strength!

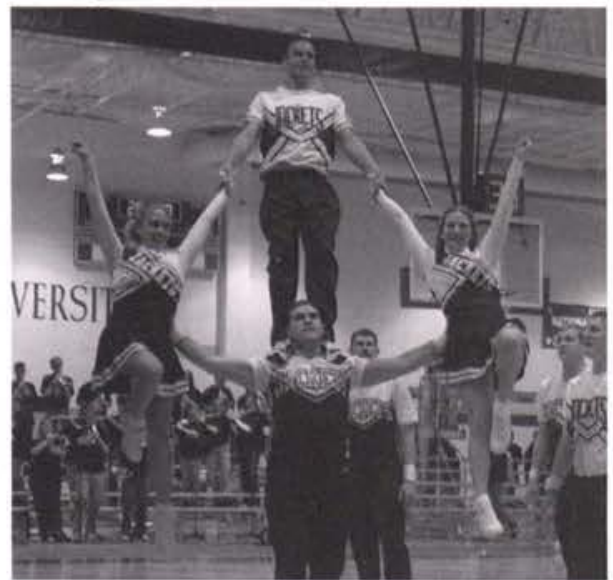


When the Cedarville University Women's Basketball team took the court for the first time on a cool November evening, expectations were not too high for the team with a new coach. Not even the Lady Jacket players expected to compile a 20 win season, but in the first year of Kirk Martin's collegiate coaching career they set a school record with 23 wins. Coach Martin came from Southeastern High School where he notched 297 wins and a state title in thirteen years of coaching. The Lady Jackets adjusted well to his coaching style and put together a tremendous year.

The Lady Jackets finished the season with a 23-10 record (15-5 in the AMC). They slaughtered Notre Dame of Ohio 97-51 to win their 20th game for the first time in Cedarville Women's Basketball history. Led by posts Kirsten Rossotti (19.6 points per game) and Molly Earley ( 9.2 points per game), the Lady Jackets went 16-3 in their last 19 games and 12-2 in their final 14 conference matches. They responded well to a slow start as their interior game developed and began to dominate.

Kirsten Rossotti earned American MidEast Conference Player of the Year and NAIA Division II AllAmerican Second Team honors. Additionally, freshman Kari Flunker (13.6 points per game) and sophomore Julie Stauffer (14.5 points per game) played well from the guard positions. Stauffer received NCCAA All-

American Second Team honors.

The Lady Jackets hosted rival Saint Vincent and beat them for their first playoff win but fell to top seeded Shawnee State in overtime. In the NCCAA playoffs, they fell in a semifinal match to Spring Arbor.

The team grew throughout the season and looks to continue their winning play next season. "Our team has incredible chemistry and really came together, which made the season a true success," Earley said.
Kari Flunker fights

hard to keep possession of the ball.

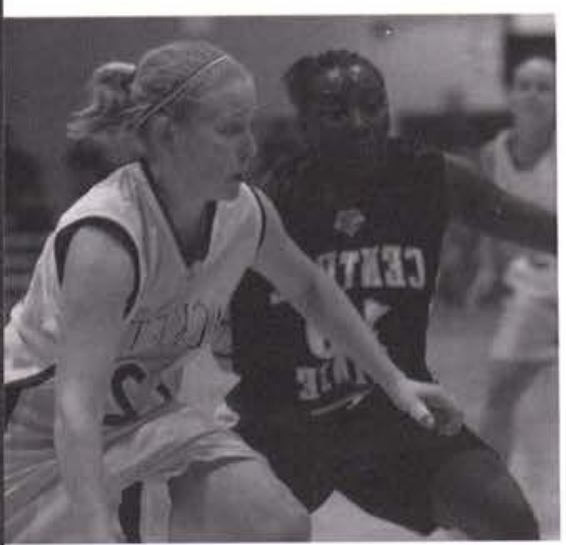

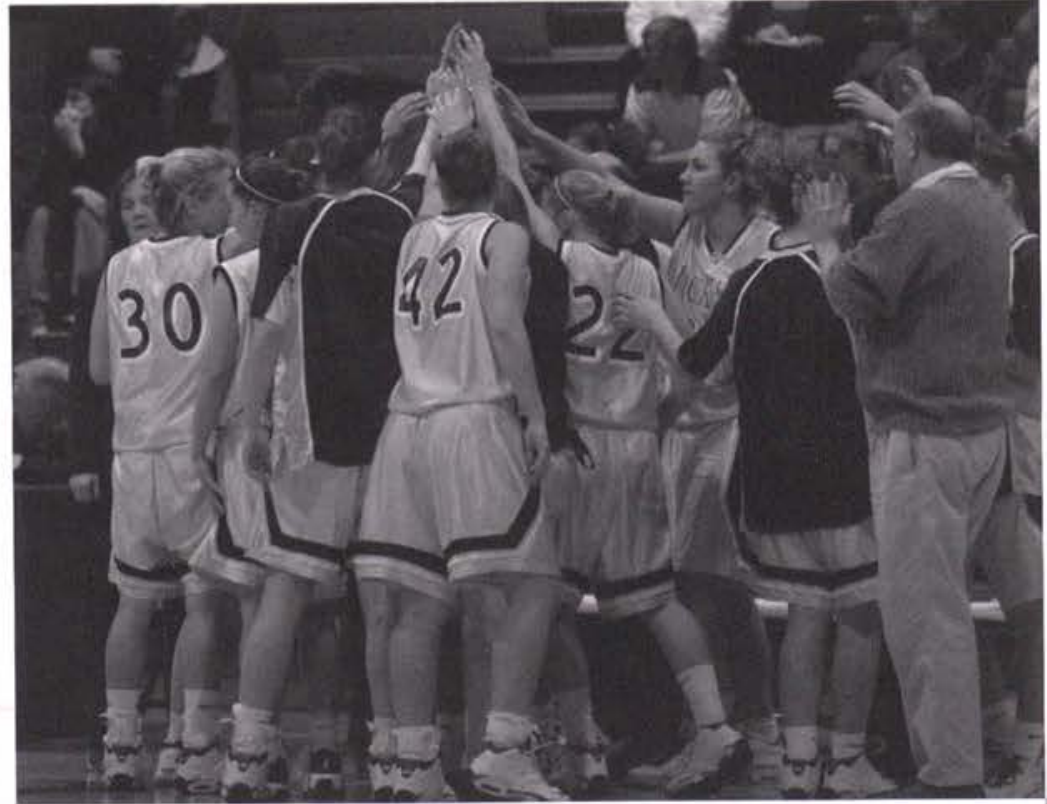

The team joins together to regroup and refocus before heading back on the court.
The Yellow Jackets play a tough conference schedule, so they are constantly challenged to work hard for the win.

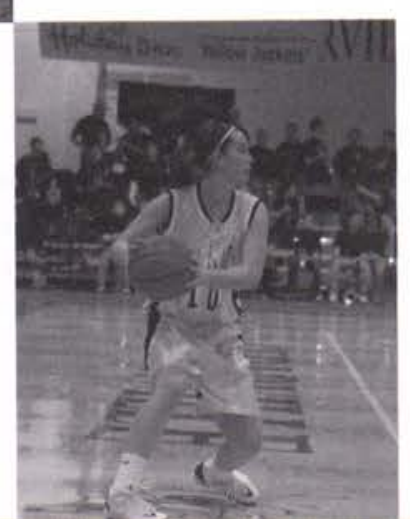




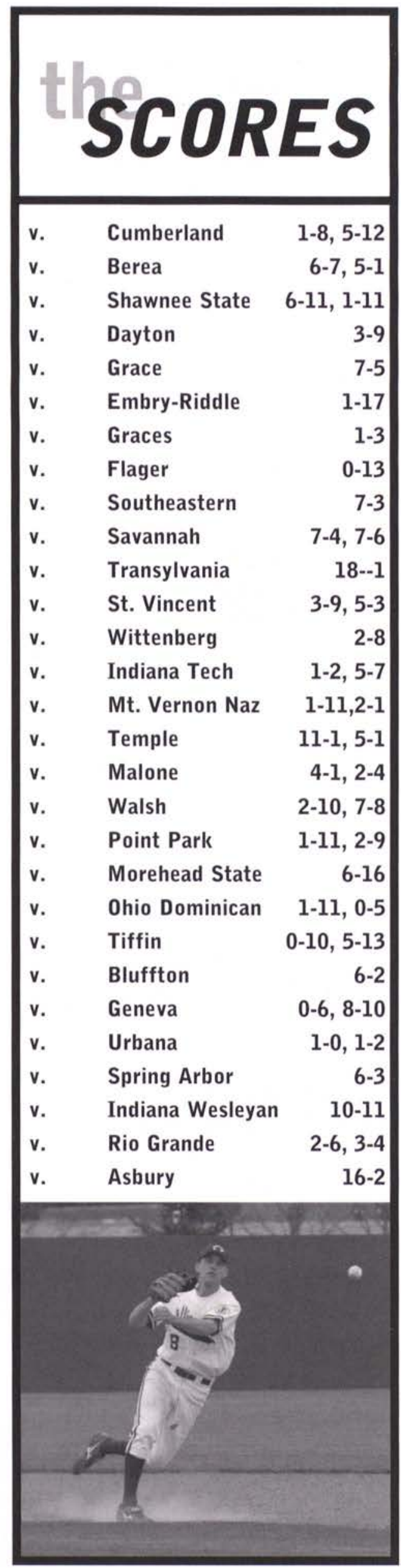
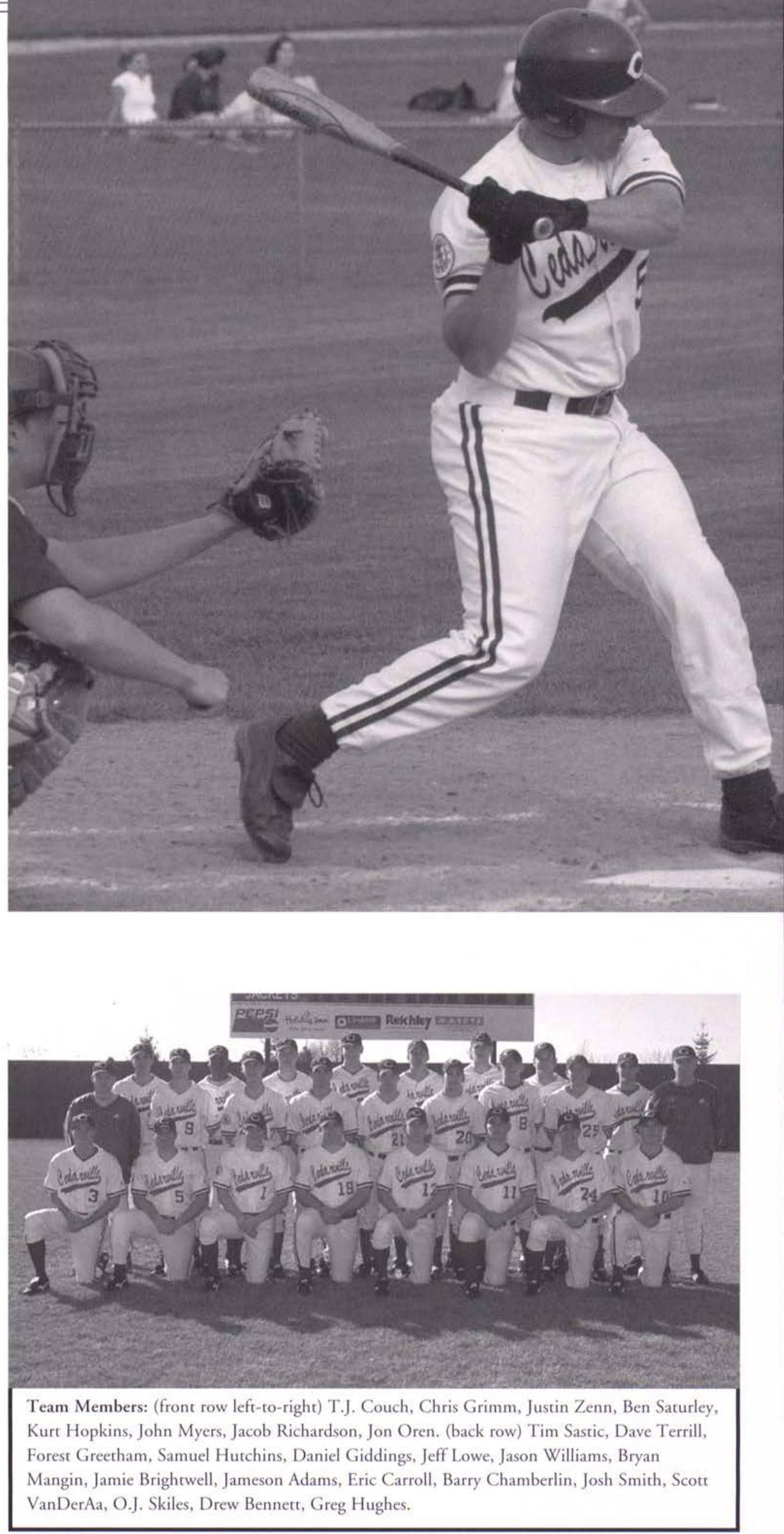


\section{CUmens baseball II}

he outfield flags whipped against their poles as Chris Grimm belted a 2-0 fastball over the 383 sign in left field and gave Cedarville a two run lead against visiting Bluffton. They went on to win 62. After the game, Sam Hutchins commented, "We are definitely headed in the right direction."

The Jackets managed 15 wins on the season, defeating Spring Arbor in the NCCAA Midwest Regional Tournament and beating sixteenth ranked Mount Vernon Nazarene in April.

Ryan Zenn contributed as a freshman with a 3-2 record and an impressive 2.97 ERA. He led the Jackets over Spring Arbor in the Regional Tournament, giving up only four hits and belting a two run homer. Zenn crushed five homeruns and knocked in 19 runs on the season. Senior Bryan Mangin finished his record-setting career as a .328 hitter. He was a valuable asset to the team, playing shortstop, outfield, and catcher. Senior catcher Ben Saturley and junior pinch hitter Jameson Adams led the team with .338 batting averages. Junior transfer Chris Grimm led the team with 29 RBI's hitting two home runs on the season. Senior pitcher Scott VanDerAa finished the season at 54. He leaves the program with the most innings pitched in Cedarville baseball history.

Their final record was 15 30, 4-18 in the AMC. They strung together a four game winning streak in early April, but faltered midmonth due to injuries. Chad Hofstetter hit for a .318 average but only managed to play in 13 games after having a career junior season. With only five seniors leaving and many experienced sophomores and freshmen, the team looks poised to improve next year.
It takes a good eye and serious focus for Chris Grimm to put the ball where he wants it.

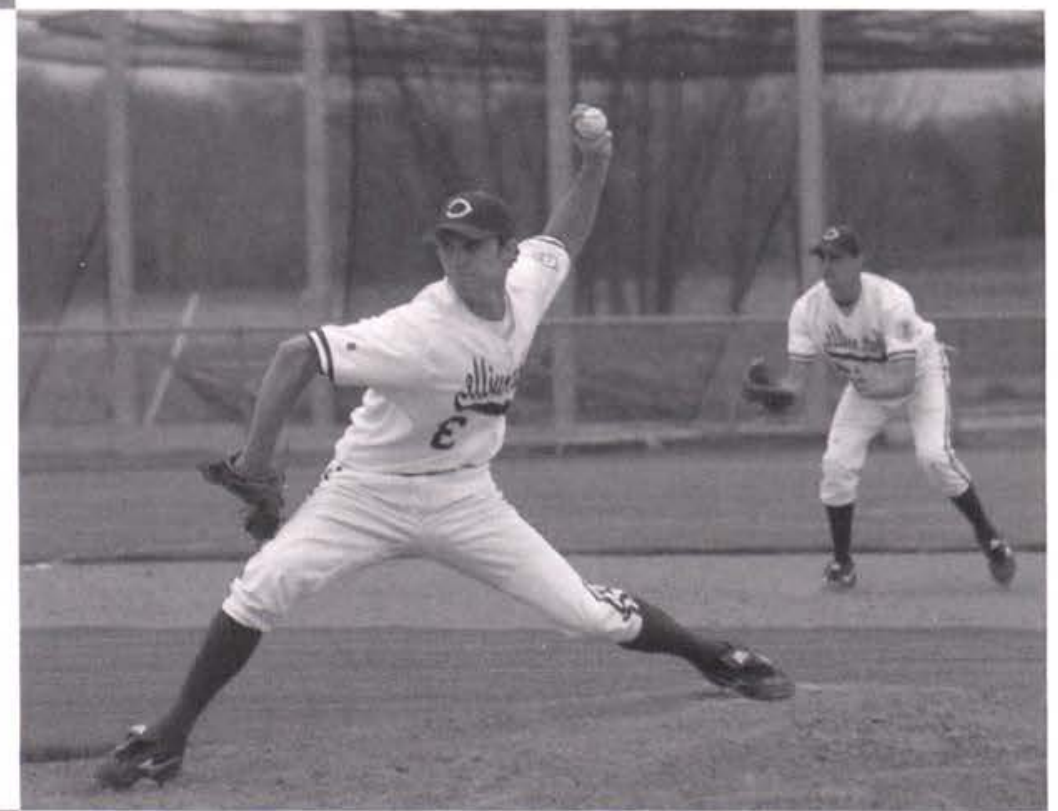

T.J. Couch makes a giant leap from the mound to home plate as he winds up for the pitch.
Senior Brian Mangin, both an infielder and pitcher for the team, does a little infield practice before the inning begins.

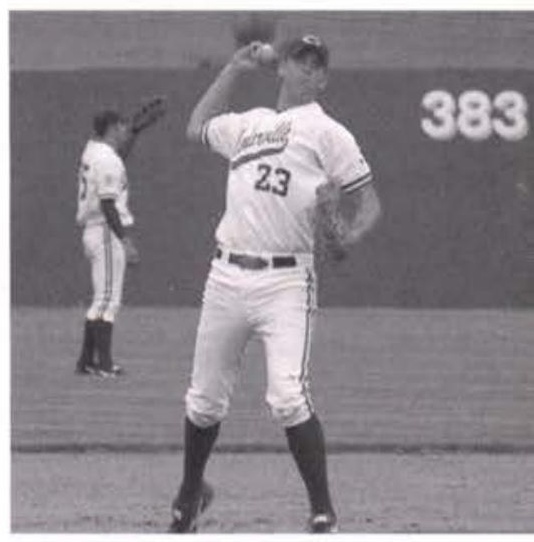





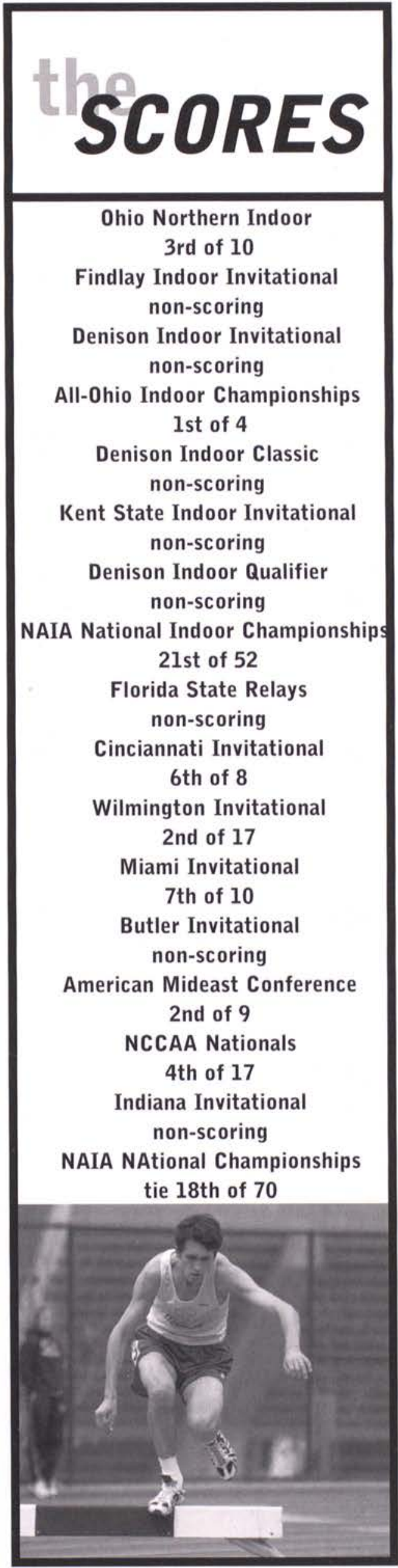
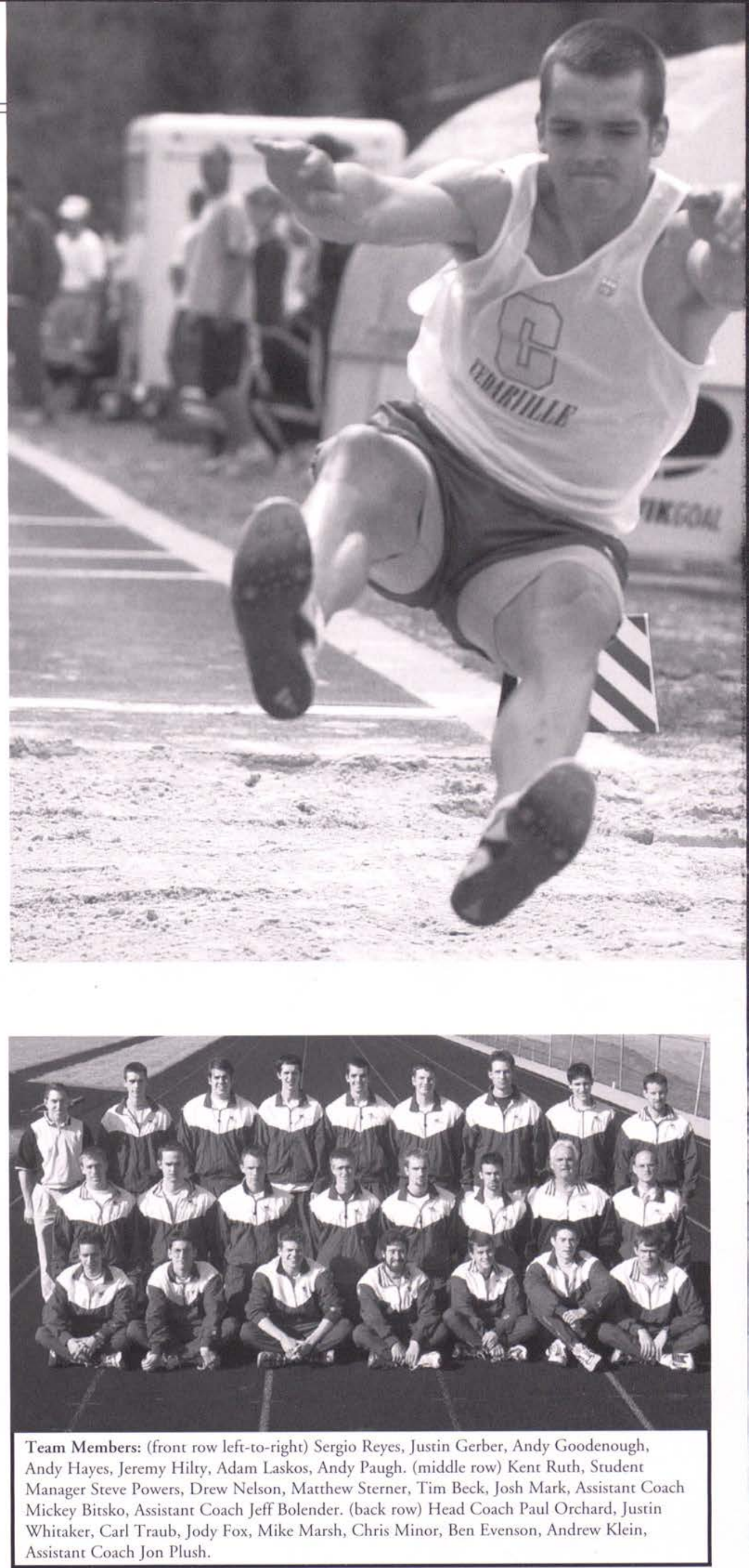


\section{CUmens track and field \|}

ll-American Sergio Reyes ran the Cedarville University Track team to an $18^{\text {th }}$ place finish at the NAIA tournament. Then senior Reyes won the 10000-meter race and finished third in the 5000meter run, which won him a pair of NAIA All-American honors.

With the win, he became the second NAIA champion in Cedarville Track history.

In early May, the Track team headed to Marion Indiana to compete in the NCCAA National Tournament. Josh Mark, Mike Marsh, and Carl Traub placed second in the 3000-meter steeplechase, the long jump, and the hammer throw respectively. Reyes earned Outstanding Performer of the Meet honors by setting records in the 5000-meter and 10000-meter runs. The teamed placed fourth with 90.5 points. Reyes said, "The NCCAA meet was our last meet as a team,

\section{Senior Mike Marsh picks up as much speed as possible down the run way to increase the length of his jump.}

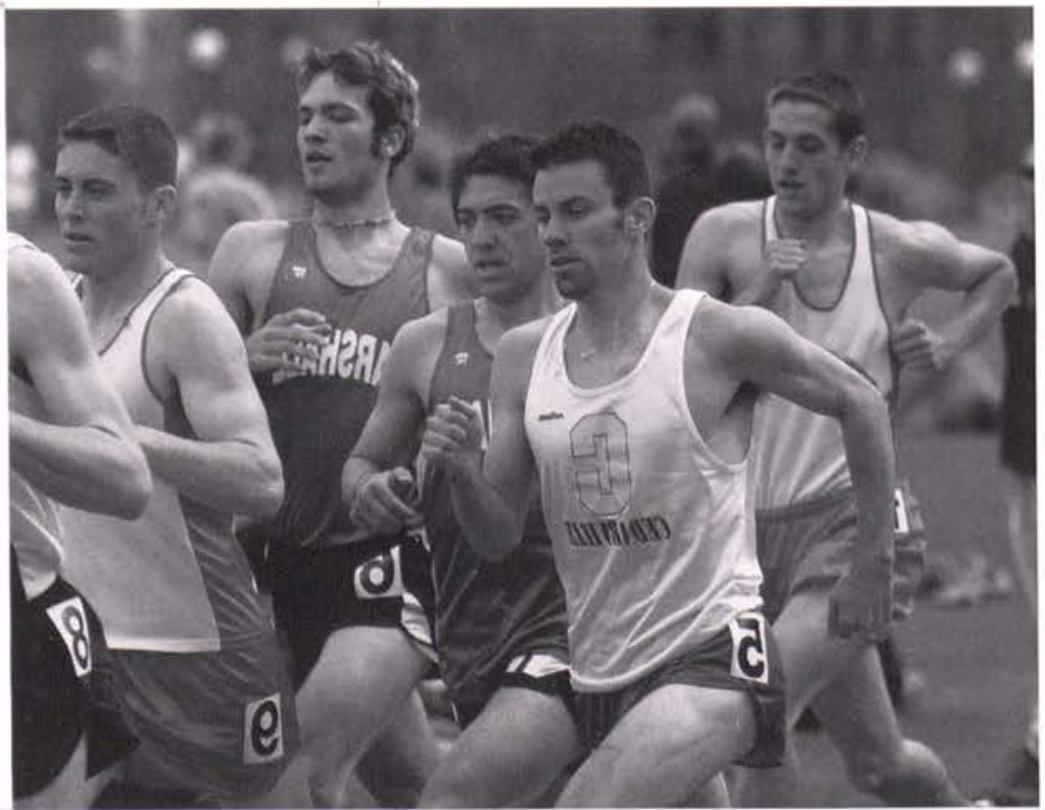

Josh Mark takes the opportunity to move ahead around a corner. and I felt we ended the season there on a good note. There are too many names to mention, but overall, our season was successful in the fact that we peaked in our training right on time for this meet."

At the Indiana University Meet, Senior Andy Paugh set two personal records in the hurdles, and at the AMC Championships, he won the high jump. The Jackets fell in second, five points behind Malone at the AMC

Championship. Reyes defended his victories from previous years as he won the 1500-meter and the 5000-meter runs, and Traub, Mike Marsh, Drew Nelson, and Jody Fox placed second in their events to earn points for the team.

Overall, the season went exceptionally well. "We set a lot of personal records this year and a couple of school records as well," junior Brittian Bollenbacher said.
These guys definitely manage to have some fun amidst a busy season.

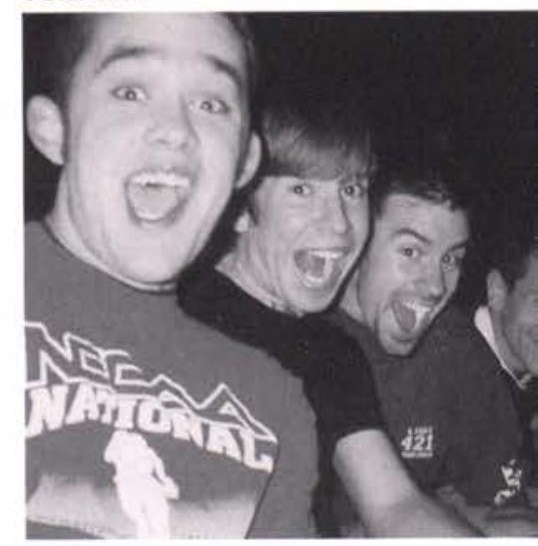

Senior Eric Yearley, the team's lone hurdler, takes his event seriously. 
In late April, the Cedarville University Women's Track and Field team traveled to Houghton, New York for the American MidEast Conference Championships and came home with a second place finish. Michalina Gluckowski shattered a meet and school record with her hammer throw of 165-5 feet while Erin Nehus continued to dominate the AMC championships. Nehus won her third 1500-meter championship and captured the 3000-meter title. Kate Beatty joined Nehus by winning her third straight high jump title, and she additionally placed first in the 100 meter hurdles. Jennifer Tetrick also won her second 10000-meter title, and outstanding freshman, Rachael Castro took the pole vault title.

With the strong second place finish at the AMC Championship, the Lady Jackets went into the NCCAA Championships intending to perform well. Once again, Erin Nehus carried the team as she posted meet records in the 3000-meter and 5000-meter races. This was the second time the Junior Nehus has won both races at the NCCAA championships. Kate Beatty also won the 100-meter hurdles and again won the high jump. Rachael Castro also broke her own school record in the pole vault, and Jen Tetrick placed second in the 10000 meter race as the team placed third overall.

\section{In the NAIA outdoor}

championships, the women's team placed eighth overall, which was a school record. Nehus placed second in the two races, and Castro completed an outstanding rookie season with a second place finish in the pole vault. Sarah Roberts, Tetrick, and Gluchowski joined Nehus and Castro as All-Americans for the Lady Jackets. With all their All-Americans returning and only three seniors graduating, the Lady Jackets will look to take the AMC and place high in the NAIA next year.

\section{Heidi Wright,Sarah \\ Roberts, and Erin \\ Nehus take some \\ time out of their \\ schedule to relax \\ and have fun.}

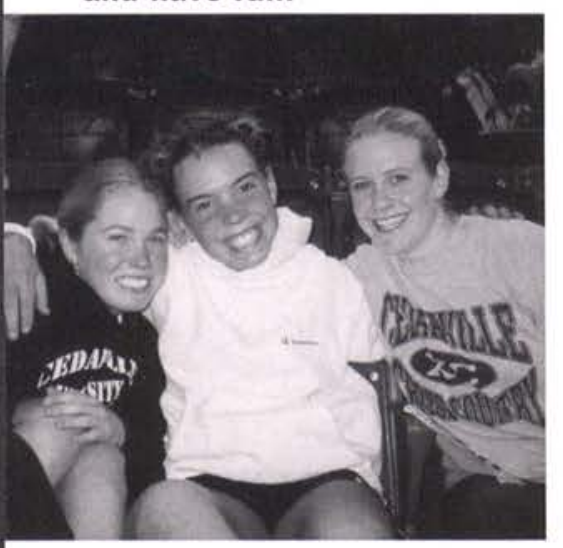

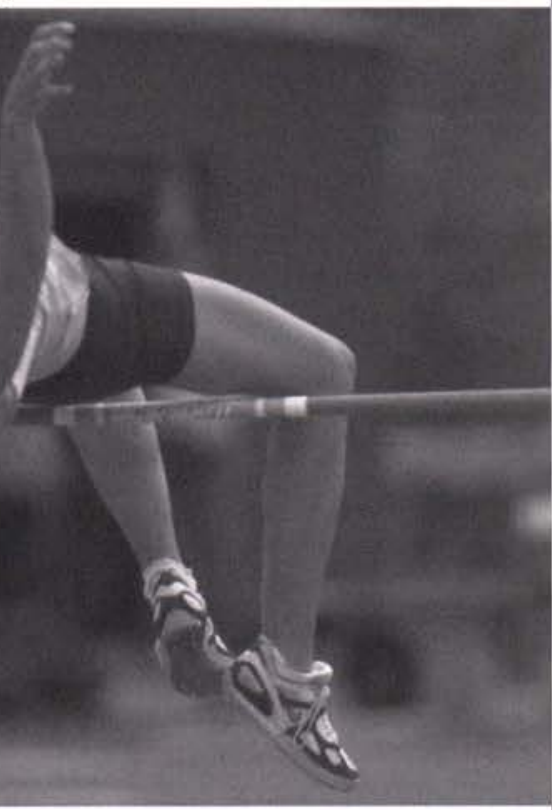

Kate Beatty uses her

height to her

advantage for the

high jump event.
Senior Kate Beatty takes a giant leap over the hurdle to edge out her opponent. 

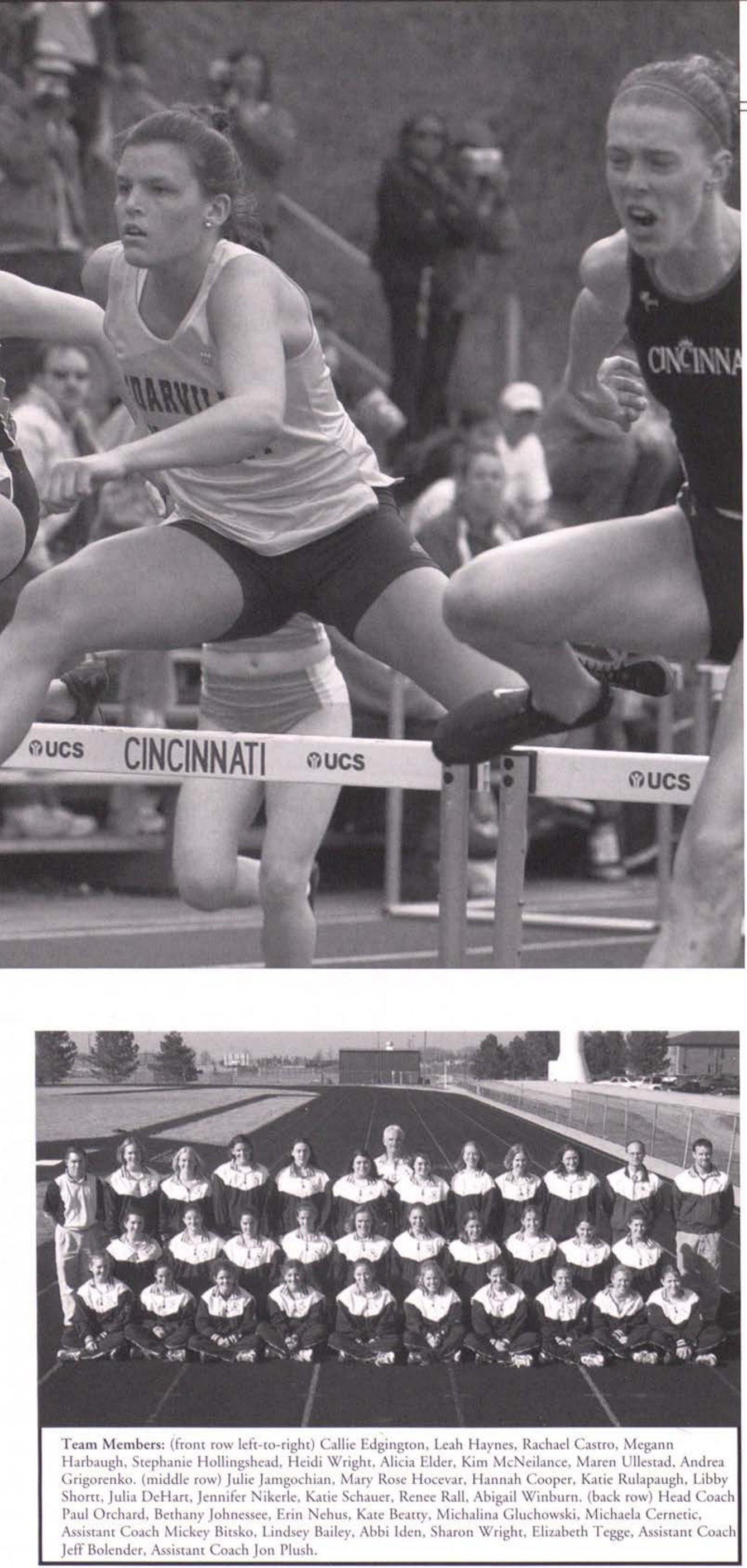

Ohio Northern Indoor

3rd of 9

Findlay Indoor Invitational non-scoring

Denison Indoor Invitational non-scoring

All-Ohio Indoor Championships 1st of 3

Denison Indoor Classic non-scoring

Kent State Indoor Invitational non-scoring

Denison Indoor Qualifier non-scoring

NAIA National Indoor Championships tied 33rd of 42

Florida State Relays non-scoring

Cincinnati Invitational 6th of 8

Wilmington Invitational 3rd of 15

Miami Invitational 8th of 12

Butler Invitational non-scoring

American Mideast Conference 2nd of 9

Indiana Invitational non-scoring NAIA National Championships 8 th of 58

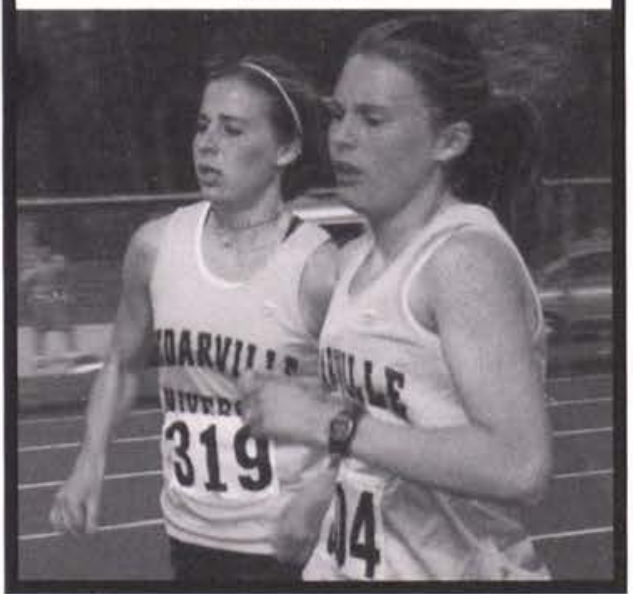




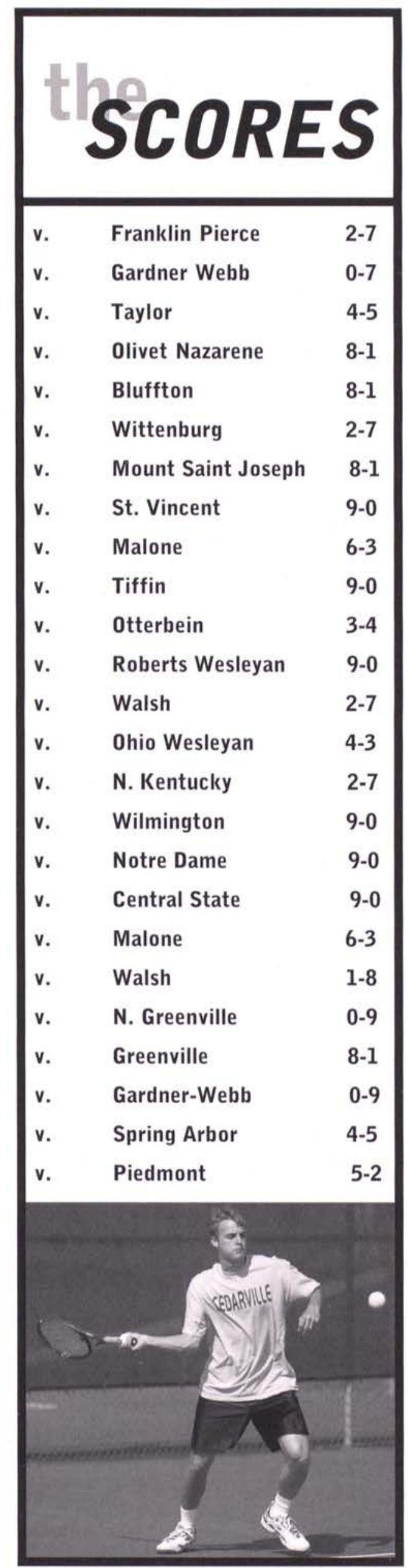
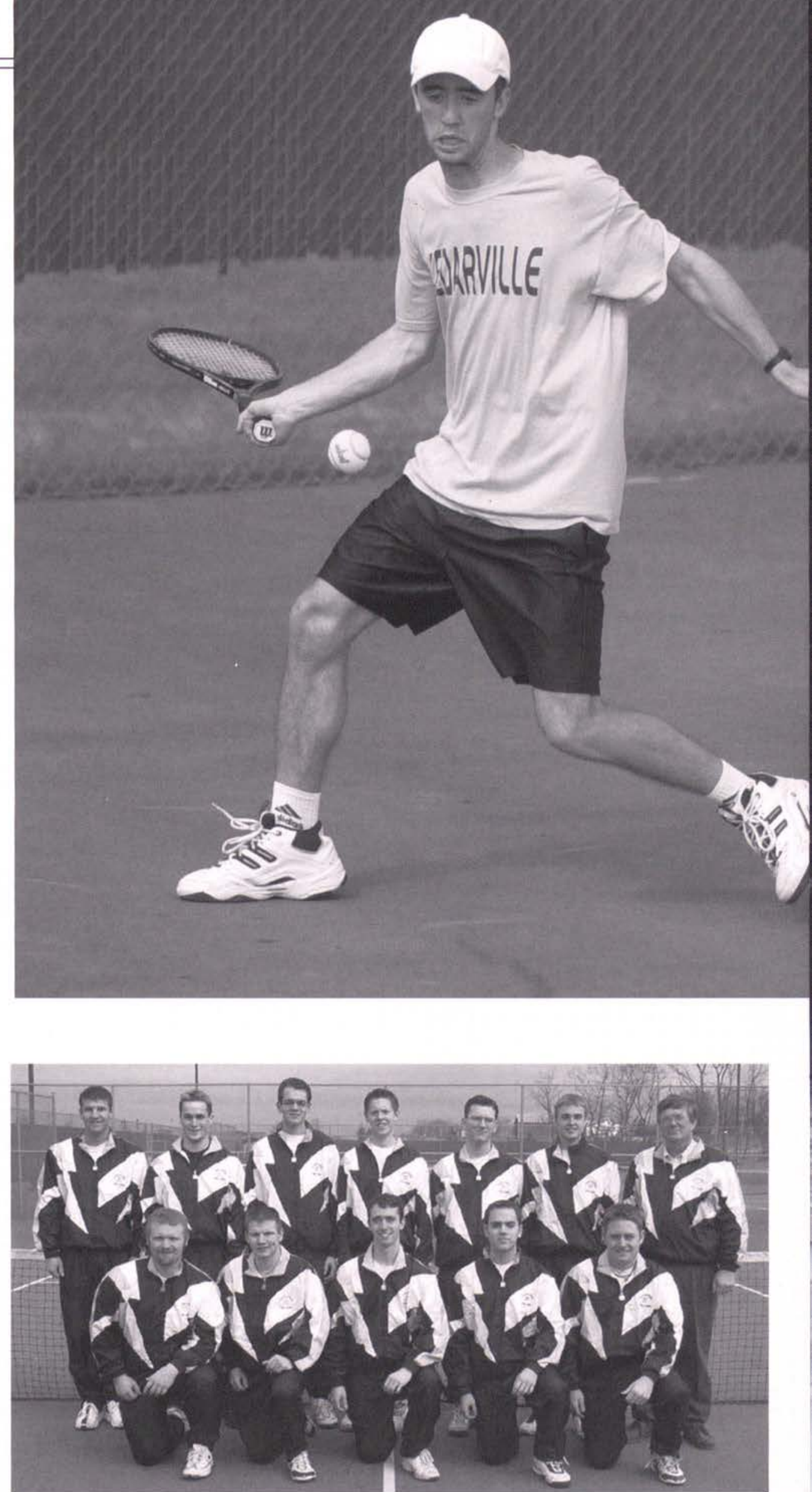

Team Members: (front row left-to-right) Scott Kinniburgh, Pete Springirth, Victor Puhy,

Nathan Vitatoe, Aaron Franke.(back row) Dave Dice, Dan DeHaan, Gertjan Flickweert, Matt

Michonski, Ben Herreld, John Bailey, Head Coach Alan Edlund. 


\section{$\mathbf{C U}$ mens tennis $\|$}

he hot sun beat down on a warm day in North Carolina as Cedarville University Tennis team rallied over Piedmont to a fourth place finish at the NCCAA National Tournament. Senior John Bailey and Junior Victor Puhy took singles wins for the Jackets, and the combinations of Bailey/Puhy and Gertjan Flikweert/ Aaron Franke posted doubles wins as well.

Although the Jackets faced a tough schedule at the beginning of the year with stronger opponents including Division I and Division II teams, the tennis team cruised to 14-11 record. They posted a 5-1

American Mideast Conference record losing only to Walsh during the season. The Jackets tallied 9-0 shutouts over Saint Vincent, Tiffin, Roberts Wesleyan, Wilmington, Notre Dame, and Central State.

Flikweert, a sophomore from the Netherlands, stepped up his play and moved from playing in the sixth spot last season to number two this year where he had a 13-10 record. Facing many of the opponents' top players, Dice played well from his number one position and Junior Aaron Franke accumulated a 14-4 record from the sixth position. Senior John Bailey, the number three player, finished his career with 49 total victories.

The team will undoubtedly miss the leadership of Bailey and Springirth as they head into next season, but with eight returning players, the men's tennis team should improve. Dice emphasized the team's goal of winning the regional title and going to the NAIA tournament next year. With Cedarville's strong set of returnees, the team looks poised to dominate in the future. Flikweert commented, "We should be at the top of our game next year."
Victor Puhy takes a stride and hits the ball back to his opponent.

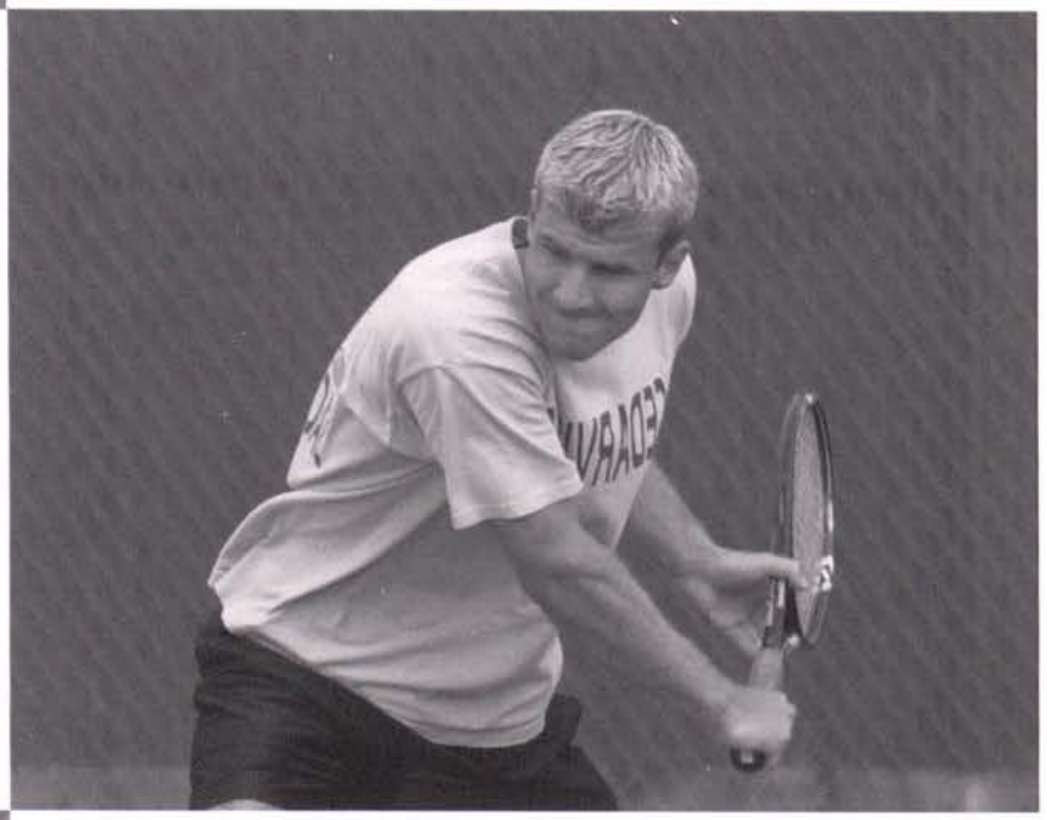

Sophomore Dave Dice gets his game face on as he shows his opponent who owns the court.
Senior John Bailey focuses on the spot where he wants his serve to land.

\section{John Bailey waits in anticipation for the coming back- hand.}

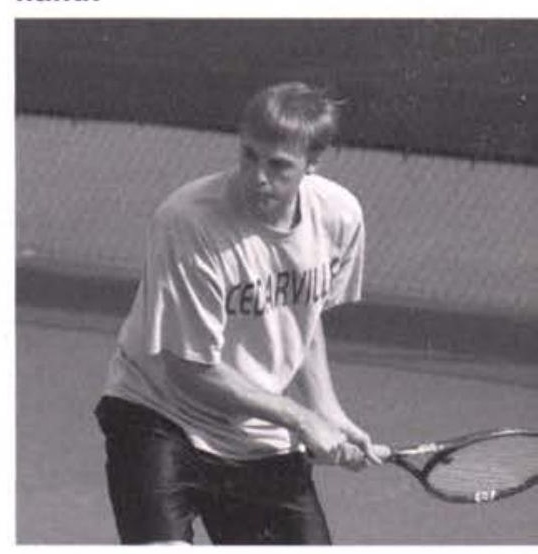




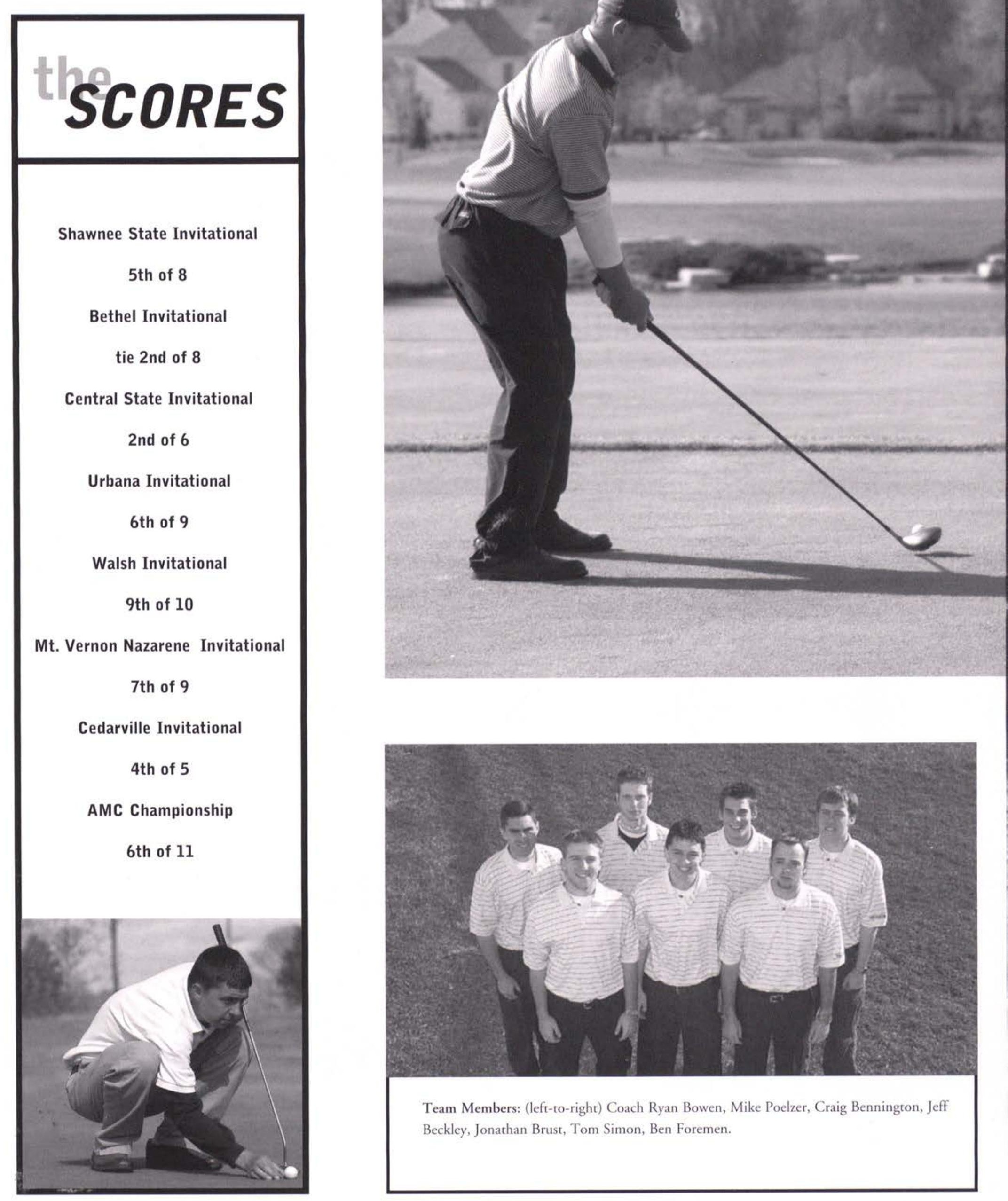




\section{CU mens golf ||}

slow drizzle beat down on a humid May afternoon as the Cedarville golf team prepared to compete in the AMC championship at the classic Apple Valley Golf Club. The Cedarville golf team completed a positive season, which saw them fight through snow, wind, and rain.

Senior Mike Poelzer sought to finish his outstanding career at Cedarville that saw him earn four letters and average almost 82 strokes per 18 holes. Craig Bennington, Cedarville's number one player, looked to better his 2001 season's finish of fifteenth in the AMC championship while fellow underclassmen Ben Foreman and Tom Simon looked to post low scores.

The Cedarville University Golf team found success in the 2002 season under first year coach Ryan Bowen. Bowen won numerous accolades while playing
Mike Poelzer takes a second to focus and set up his perfect shot.

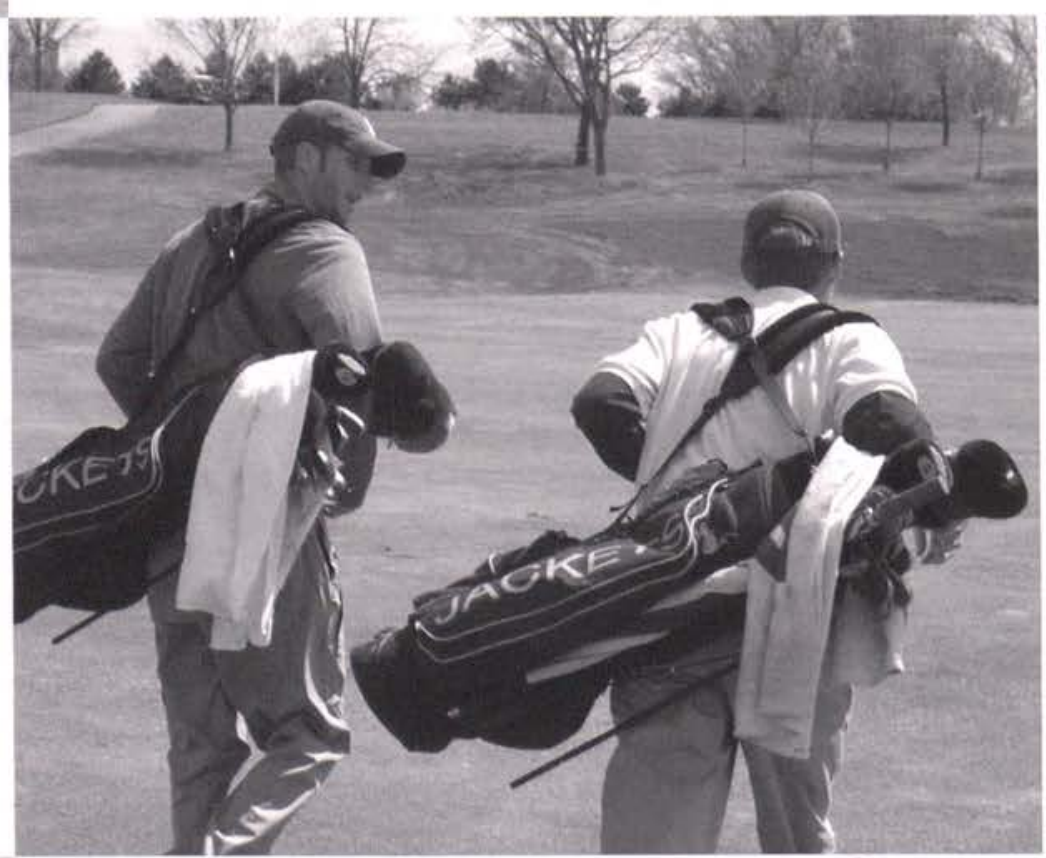

There's always time for fun and joking with teammates as Craig Bennington and Ben Foreman walk from green to green. for Cedarville and looked to lead the team to new heights.

The team finished second at the Bethel invitational, and also placed second at the Central State Invitational as Tom Simon posted his lowest score of the year, 74 . They broke 600 at the Urbana Invitational and posted low scores at the Mount Vernon Nazarene Invitational, the Walsh Invitational, and the Cedarville Invitational.

At the American MidEast Conference Championships, Bennington shot a final round 73 for a three round total of 226 to finish fourth and earn All-AMC Honors. He is the first Cedarville All-AMC golfer since 1990. Simon and Poelzer each hit 247 while sophomore transfer Jonathon Brust and Foreman hit 252 and 253 respectively. Cedarville placed sixth, and with 6 returning golfers, they look to improve even more next year.

\section{Jonathan Brust makes the intense and serious sport look easy.}

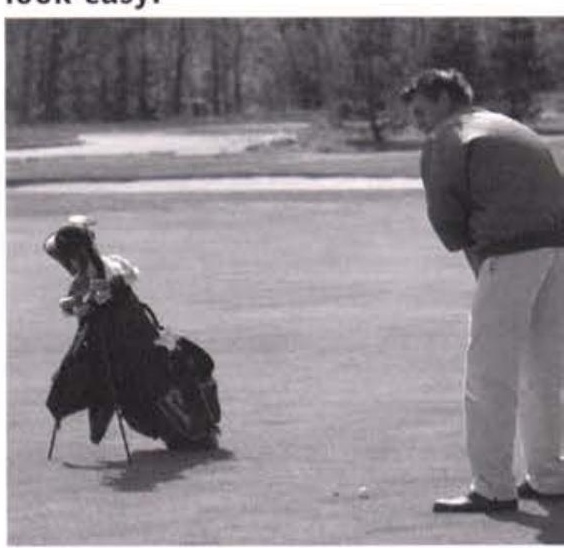




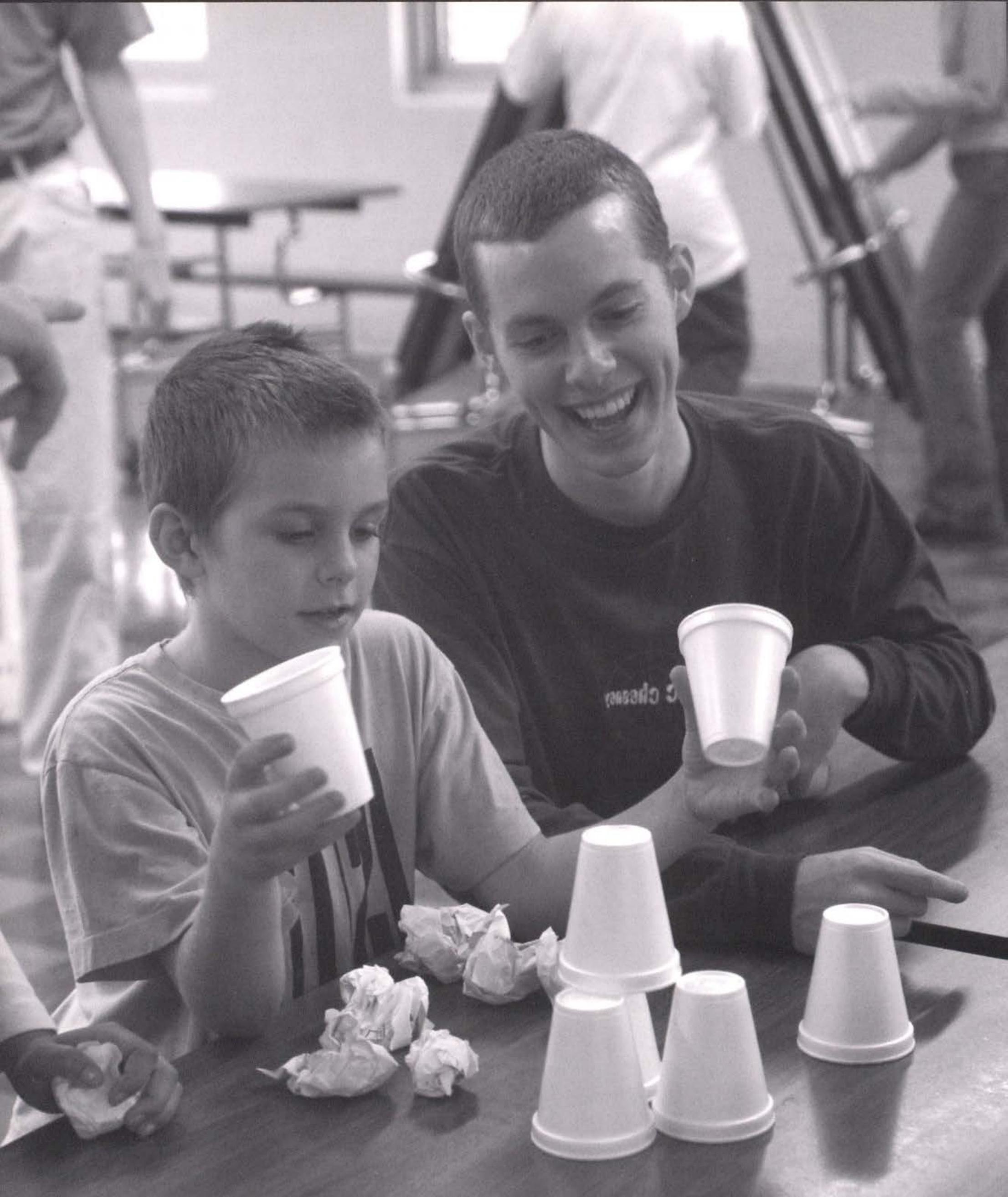




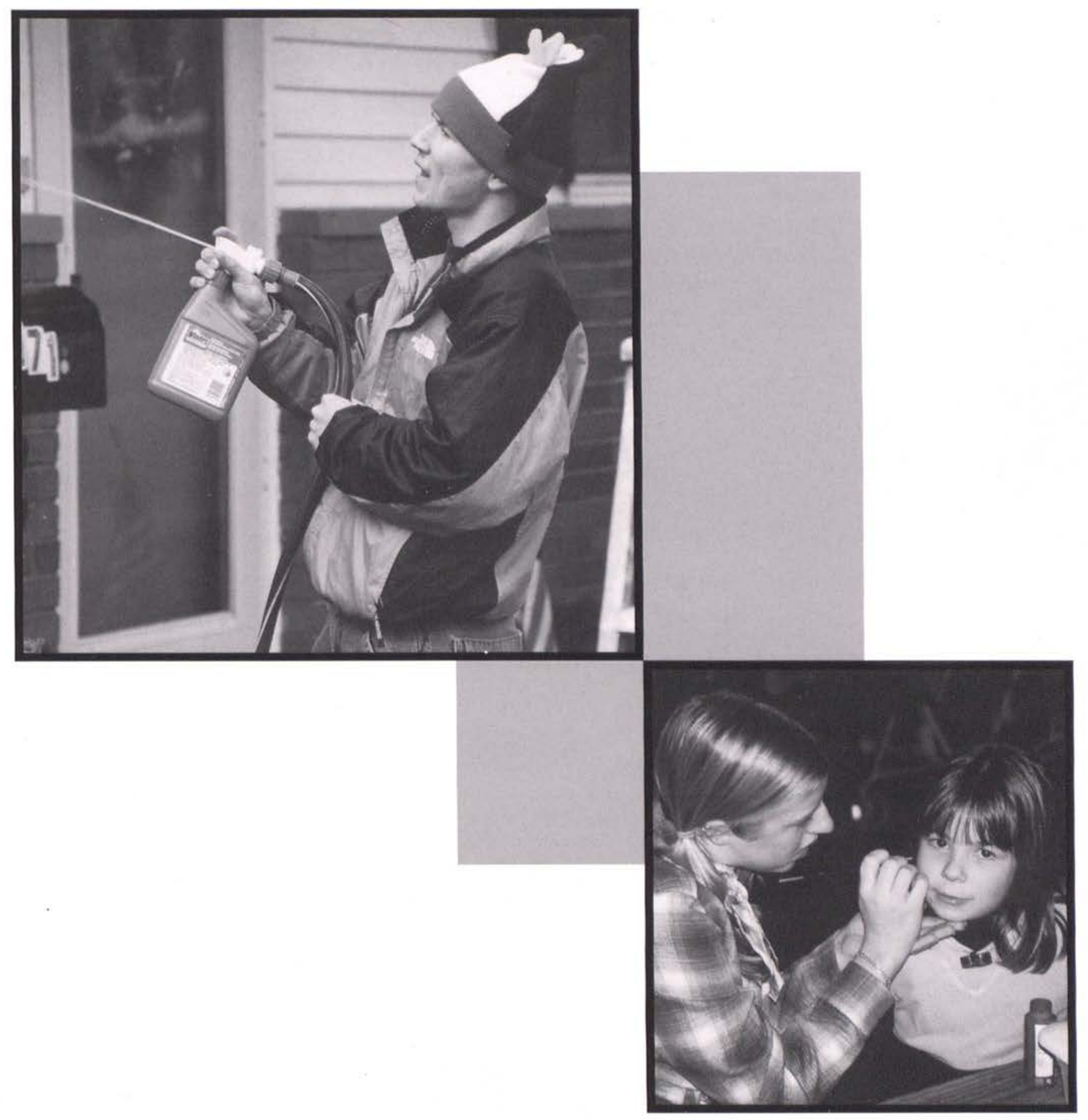

MINISTRIES 

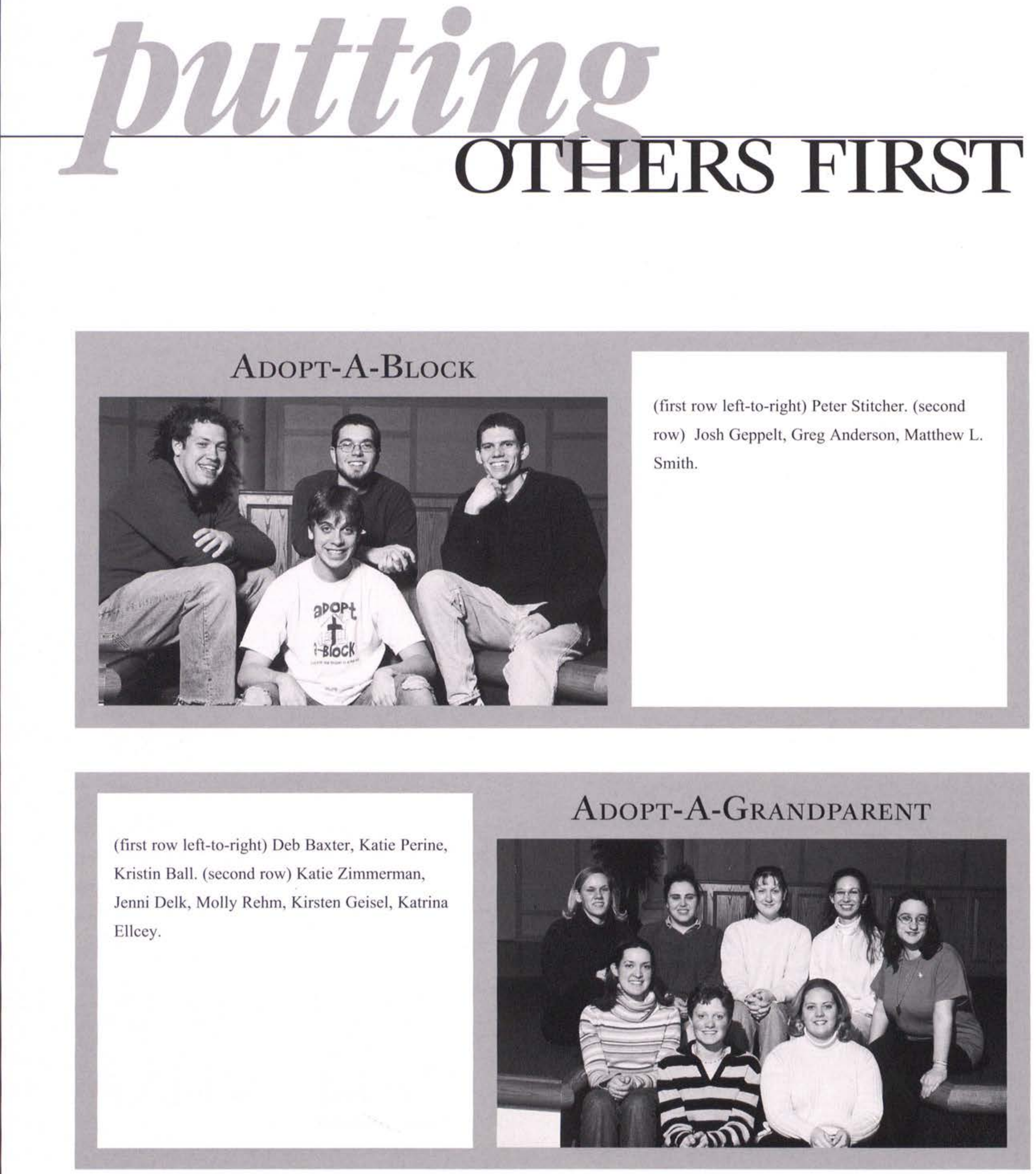
(first row left-to-right) Ray Green, Trent

Hamilton. (second row) Barrett Craig, Adam

Henker, Matt Garrett. (third row) Ryan Flunker,

Tristan Mason.

\section{Advisory 7}

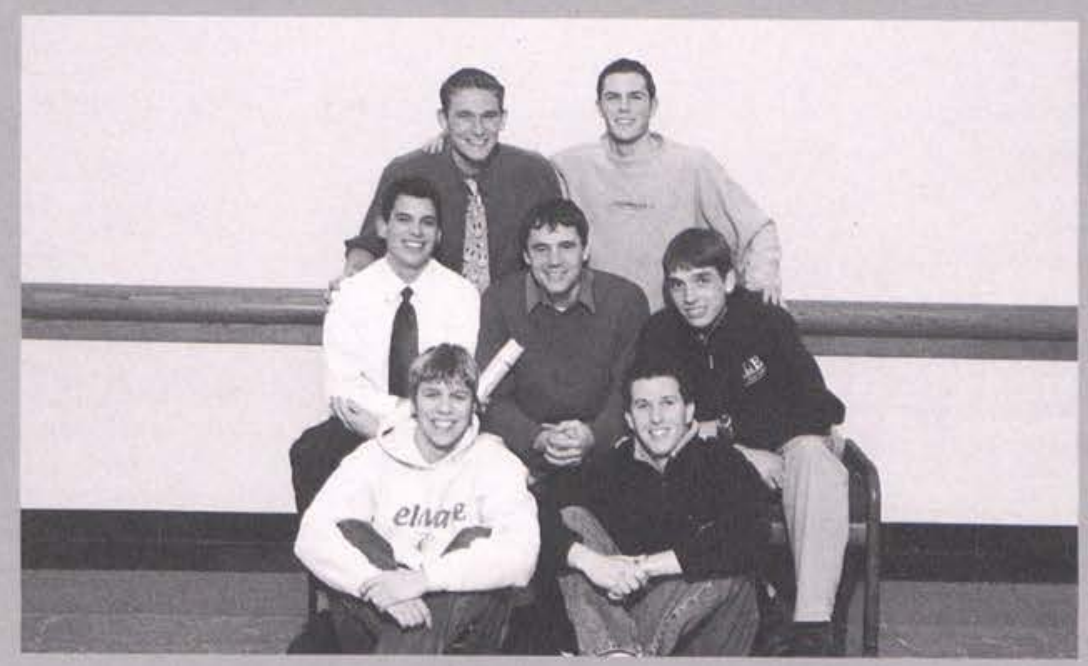

\section{The Ark}

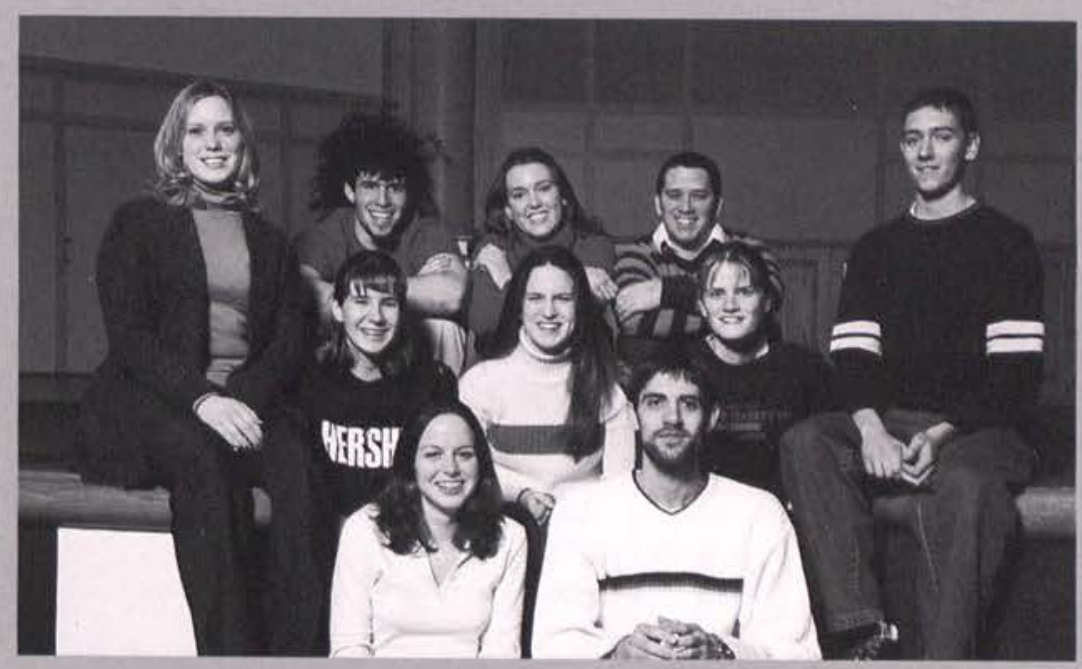

(first row left-to-right) Bethany Walden, Christopher Freeman. (second row) Marcy Abildness, Holly Seace, Anna Mied, Ricki Stumpf, Benjamin Rodak. (third row) Paul Milby, Erika Love, Mark McDaniel. (not pictured) Kimber Porter, Terra Posten, Beth Stone, Katie Roggie, Anne-Marie Gaynier.

\section{BACK 2 BACK}

(first row left-to-right) Sarah J. Boillat, Susan R. Eggebeen. (second row) William Cliff, Christina Nofziger, Megann Harbaugh, Tana Adams,

Tammy McCall. (third row) Ryan Husband, Anna Faulkner, Nathan Hedger, Jenn McKee, Mary Lyle.

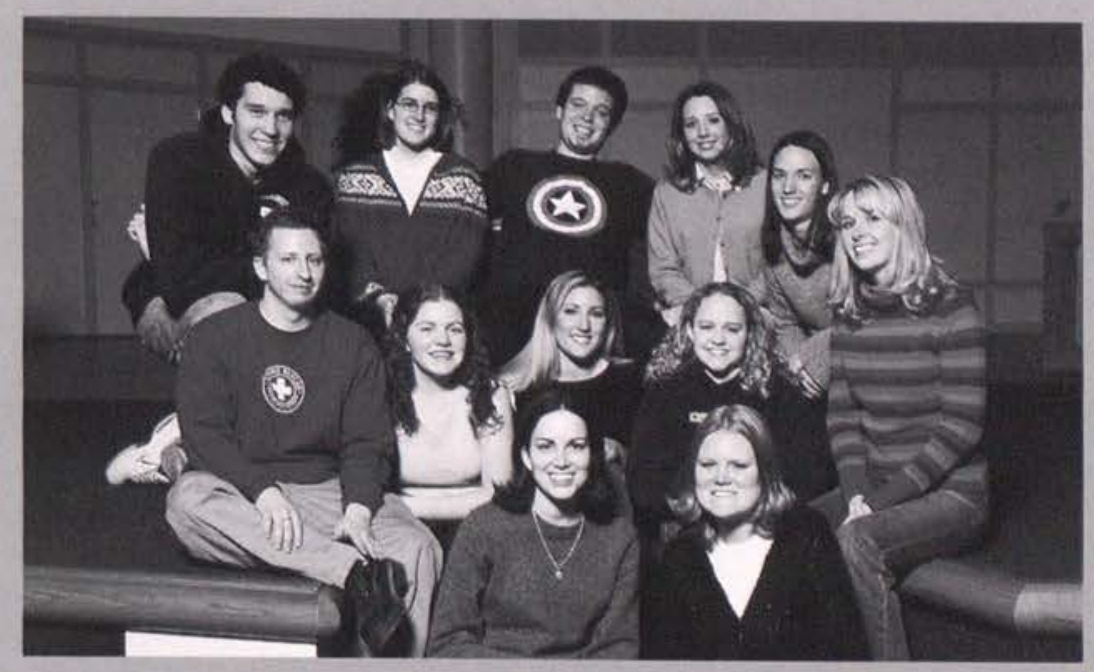


(first row left-to-right) Ariel Starbuck, Laura Jolly, Becky Baxter, Tiffany Landau, Gregory Roth. (second row) Erin Kuyper, Ivan Davis, Sarah Robertson, Matt Stevens. (third row) Juliann Kooy, Elizabeth Dudick, Shelby Keyser, Eric Sullenberger, Airynn Adams. (fourth row) J.T Rowland, Kathryn Mowrey, Dawn Cazier, Sarah McDivitt. (fifth row) Amanda Flenar, Bethany Keilman, Alison Edwards, Chip Mundy, Josh Paulick, David Drye, Chancy Persons, Leslie Maxey, Ben Haas, Andrea Nelson, Dan Dunham.

\section{The BARN}

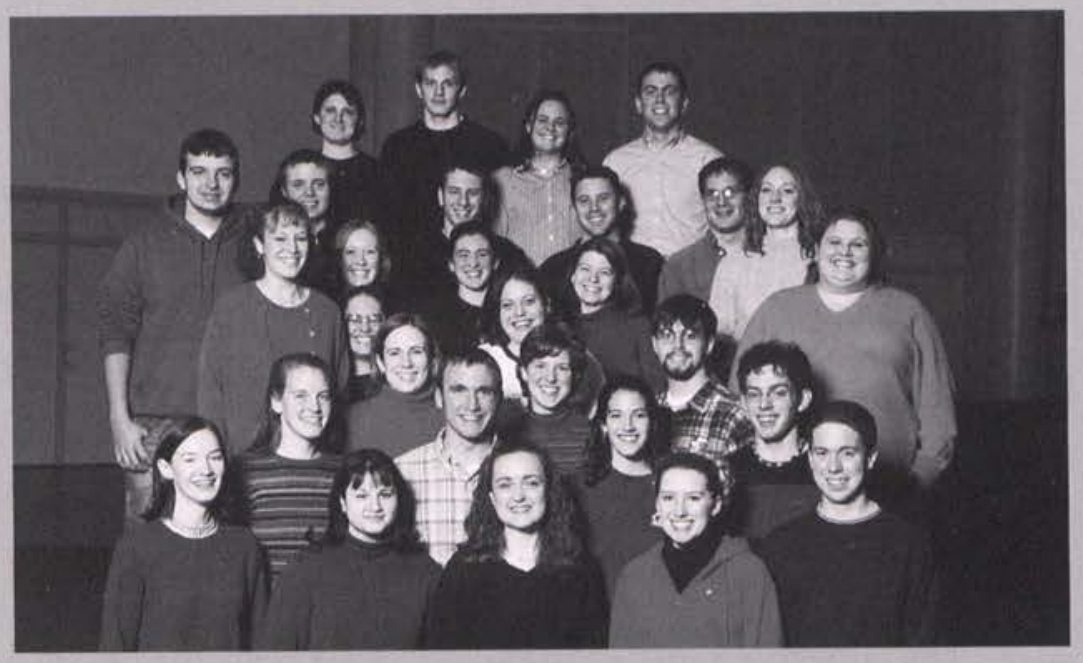

\section{BeAVERCREeK BAPtist}

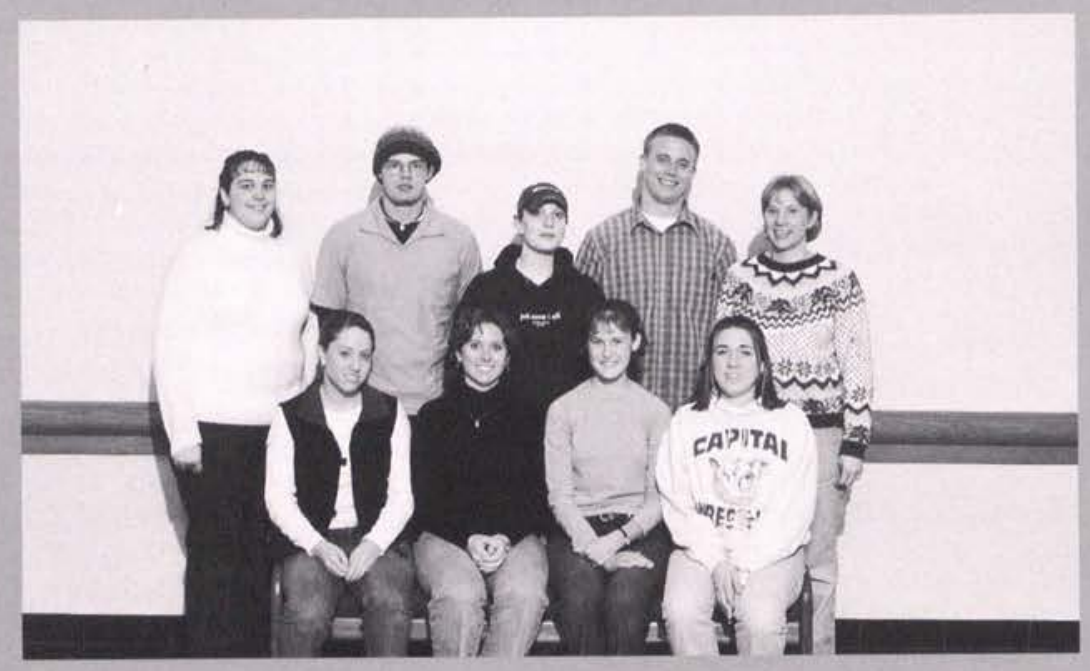

(first row left-to-right) Alyssa Rost, Andrea Johnson, Rachel Shellenbarger, Amy Elliot. (second row) Tammy Mikel, Justin Hughen, Sarah Woodstock, Ron Mason, Becca Jensen.

\section{Berea Bible}

(first row left-to-right) Andrew Jarvis, Tim

Eichner, Lisa Bleikamp, James Love. 

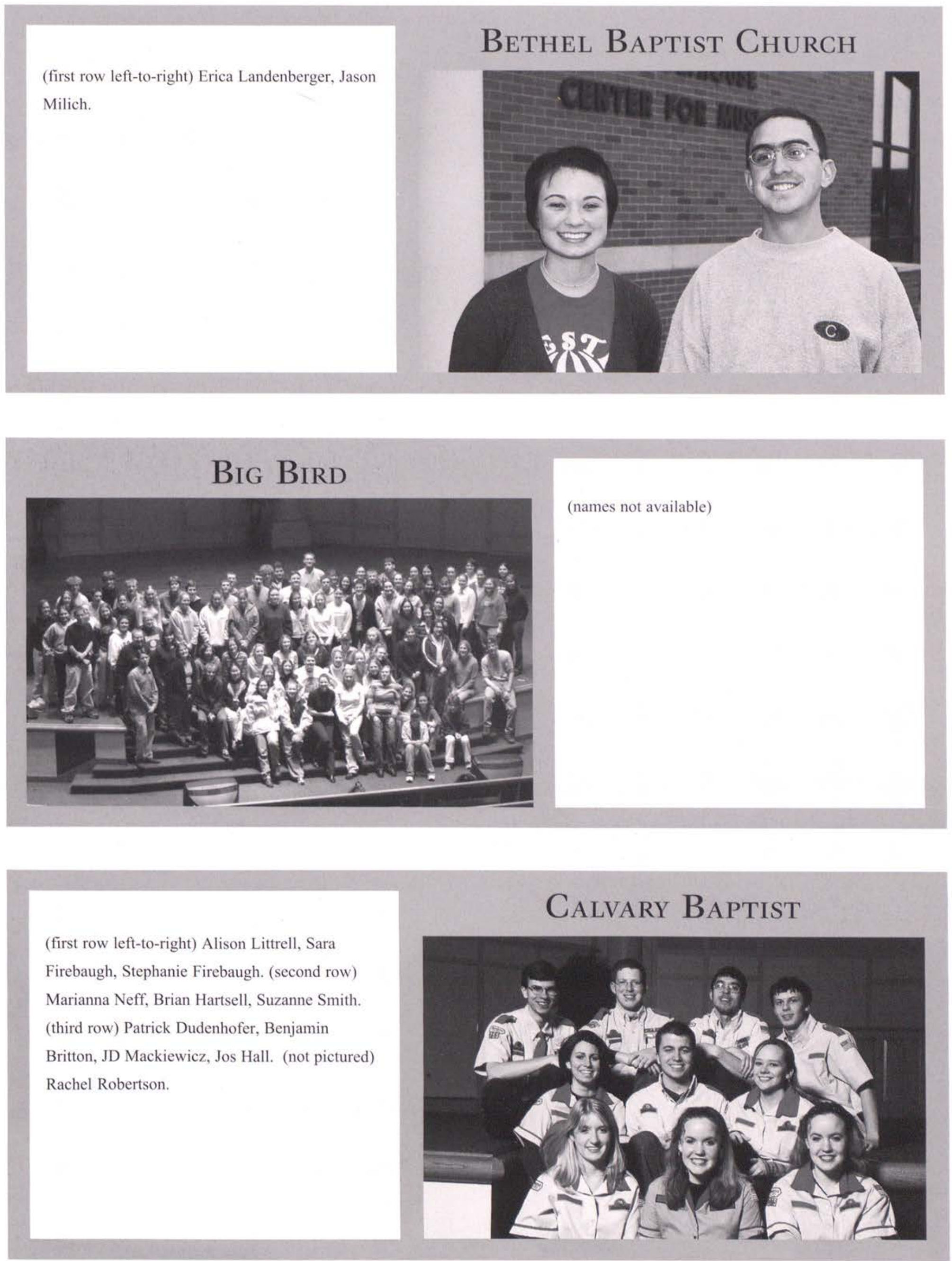
(first row left-to-right) Mike Webster, Katie McGunnigal, JoAnne Willett. (second row) Heidi Yehnert, Rubie Maybury, Corrie Porter, Shannon Little. (third row) Angie Reninger, Rachel

Moyer, Hannah Livingston, Christina Papke. (not pictured) Beth Uitti, Kate Schriemer, Lisa Culver.

\section{Castle Knoll}

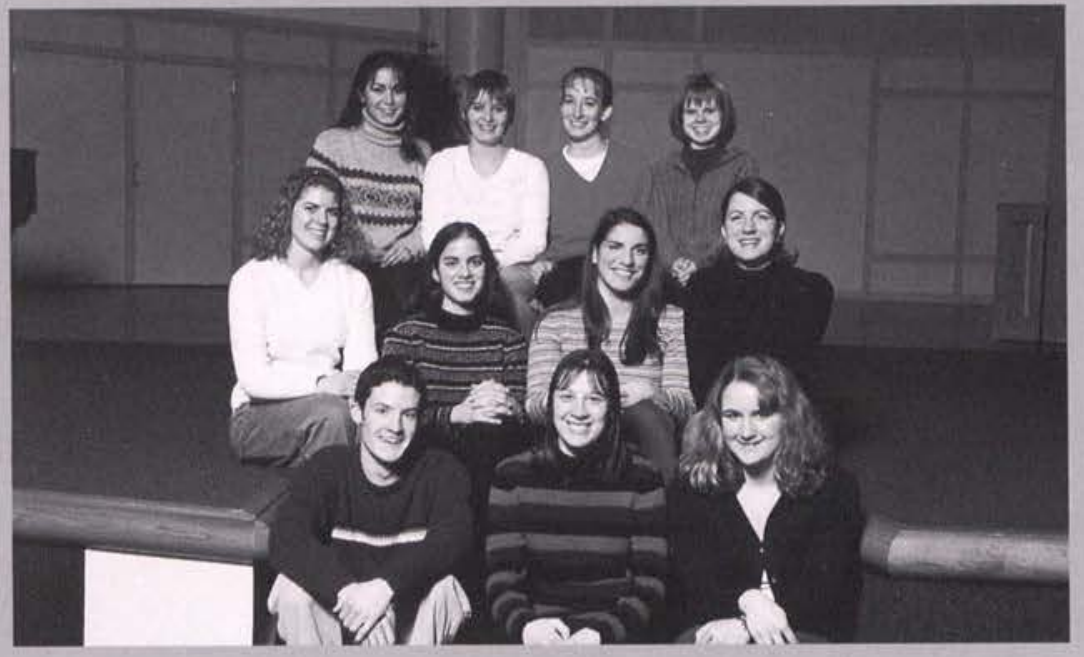

\section{Cedarcliff Elderly Apartments}

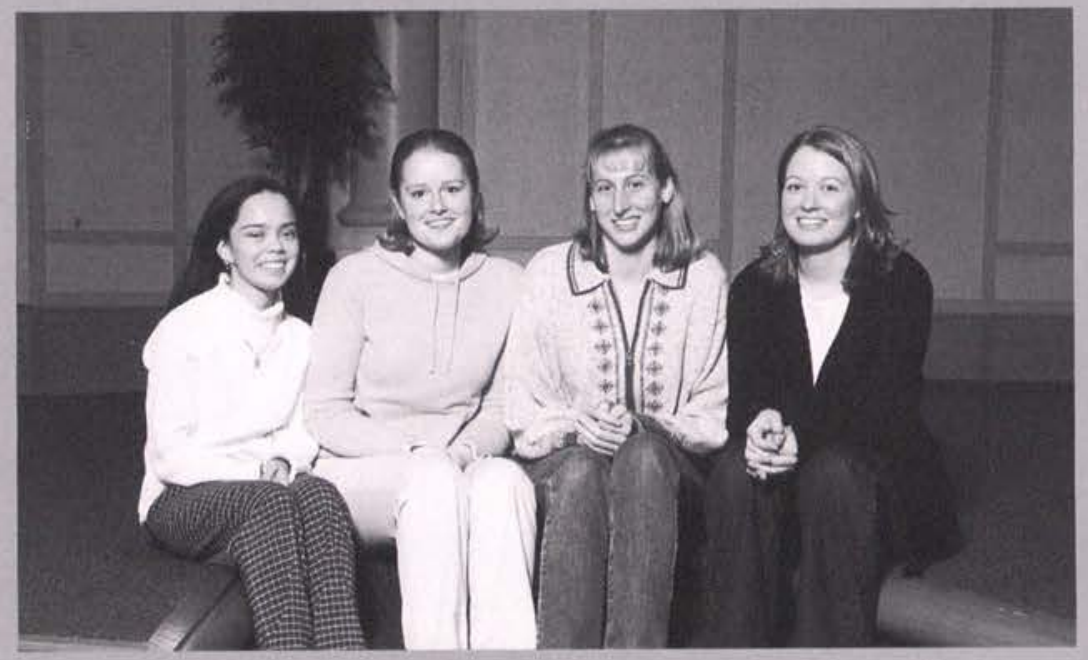

(first row left-to-right) Brook Colon, Sherri

Burger, Graceann Pearce, Angie Otto. (not

pictured) Marcella McCumber, Althea Beachy,

Esther Mace.

\section{Cedarcliff Elementary Tutoring}

(first row left-to-right) Matt Braun, Stephanie

Vanderhoof, Rachel Shaw, Davina Murray,

Jennifer Sparling. (second row) Blair Anderson,

David Drye, Kristin Jones, Stephen Moseley,

Gregory Roth.

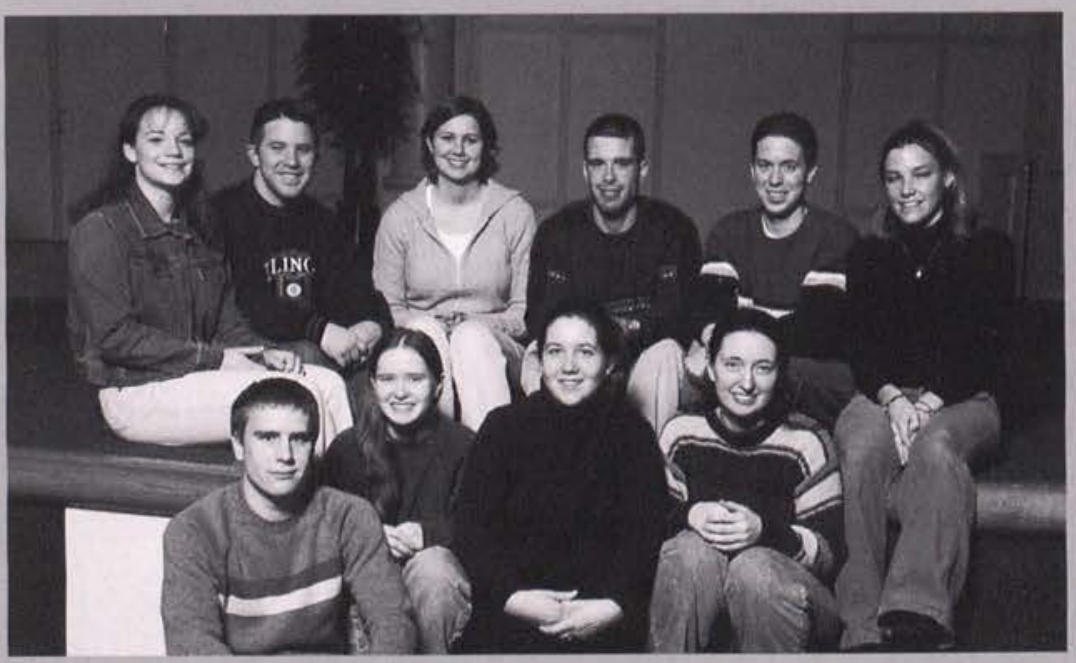


(first row left-to-right) Josh Fenton, Stefanie Clarke. (second row) Katie Bledsoe, Emily

Thompson, Leann Wolgemuth, Krystle Rossbach. (third row) Justin Bahorik, Kari Calhoun, Kari Sue Eaves, Beth Wright, Gretchen Bigley, Ryan Flunker.

\section{CEDARKIDS}

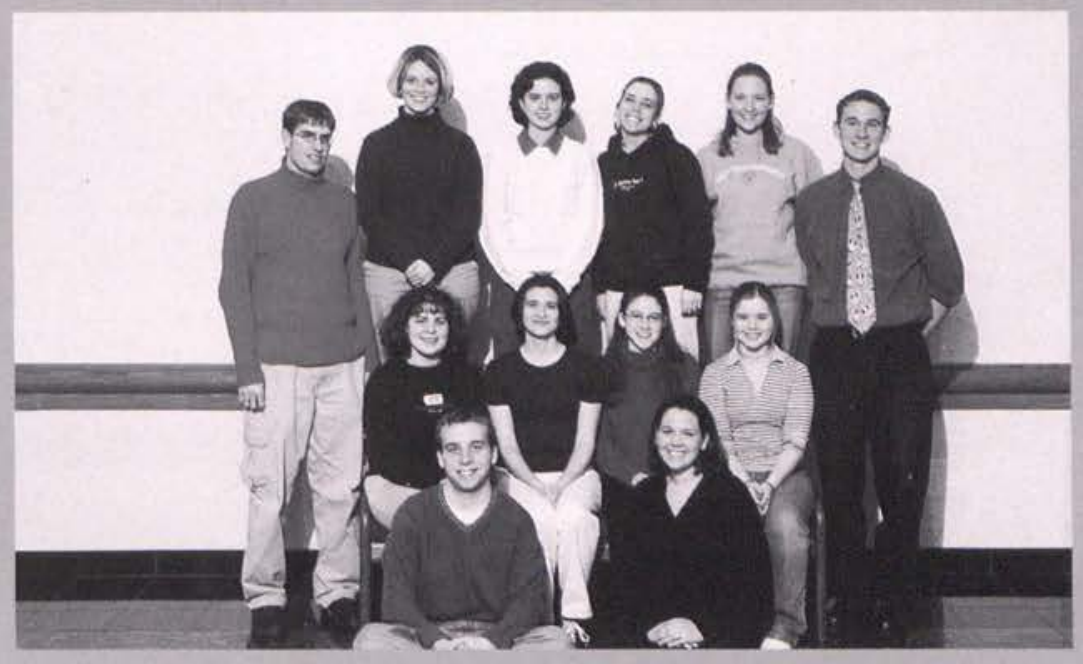

\section{Cedarville Tutoring}

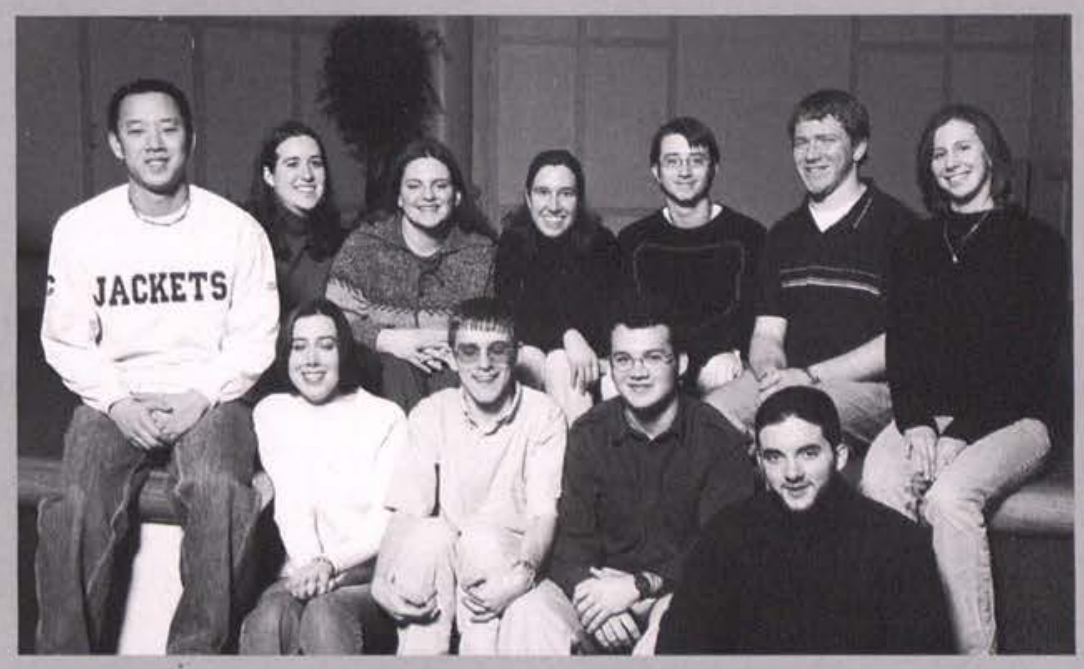

(first row left-to-right) Jonathan Begg, Lisa Wendl, Nathan Kibelbek, Seth Ritchie, Andy Young. (second row) Sarah Gaynier, Sarah Greene, Kimberly Eridon, Shawn Steele, Aaron Briggs, Emily Dyer. (not pictured) Ethan Hodge, Caleb Schnake, Stephen Satterthwaite, David Ross, Alan Ference, Jill Eikhoff, Rebecca Brown, Anjel Stough, Rachel Robertson, Beth Secor, Allyson Gilbert.

(first row left-to-right) Melissa Stark, Stephanie Kreuder-Crowell, Adria Combs, Lari Mead, Jennifer Thompson. (second row) Tim Cochrell, Amanda Slagle, Julia Parobek, Emily Pfeister, Ashlee Gallaugher. (third row) Katie Conant, Susan Magin, Becca Kane, Sarah Strobridge, Jessica Busch, Beth Jelsma, Ryan Bucher, Victor Puhy, Bethany McCloskey. (fourth row) Jonathan Oren, Philip Attard, Joshua Wyse, Andrew Becker, Jeremy Doot, Tracy Geiser. (not pictured) Brittian Bollenbacher.

\section{Cedarville Partners}

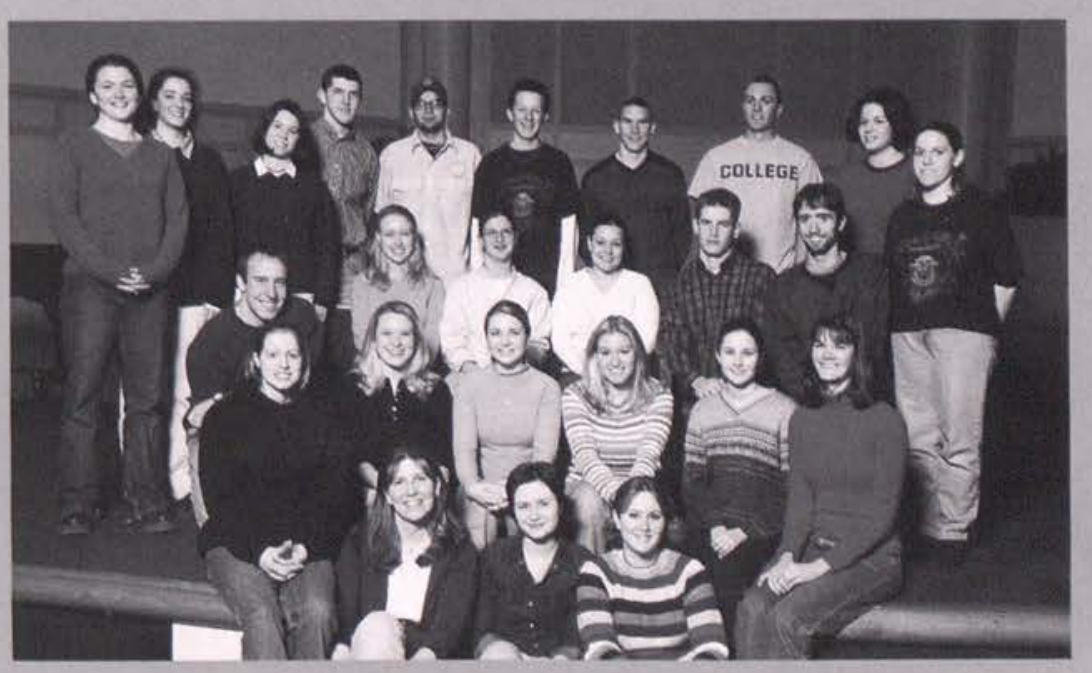


(first row left-to-right) David Zelenka, Kikelomo Kolawole, Lydia Baker. (second row) Sarah Weaver, Kathryn Mowrey, Rob Marshall, Nisha Strauch, Matthew Smith, Krystal Sellars, Elizabeth Proemmel. (not pictured) Gretchen Sproul.

\section{Central State Aia}

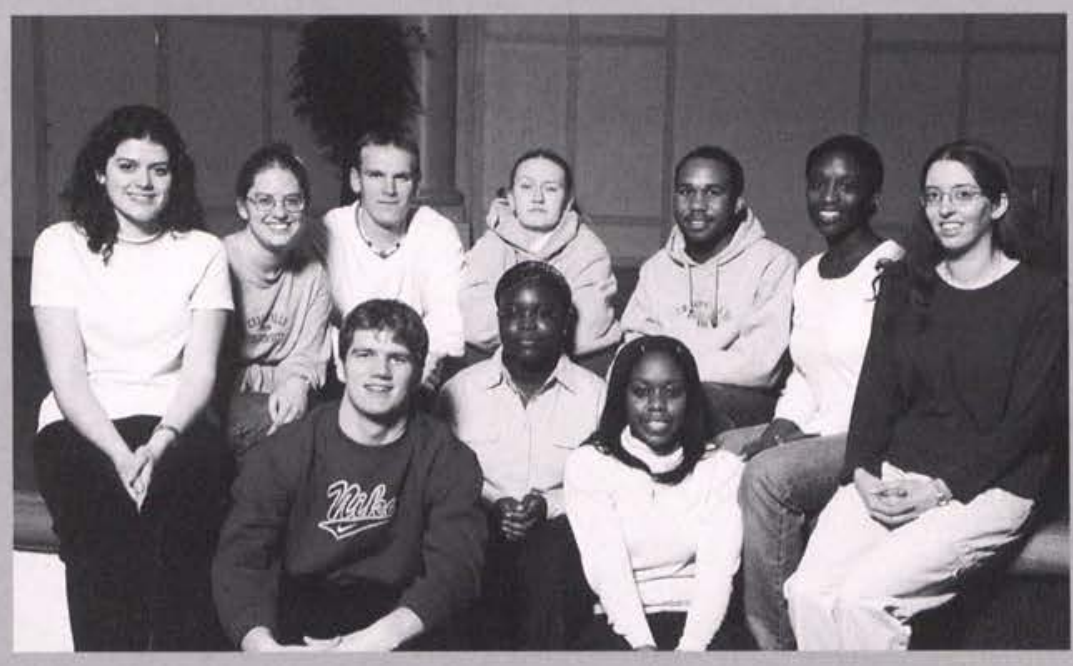

\section{Children's Medical Center}

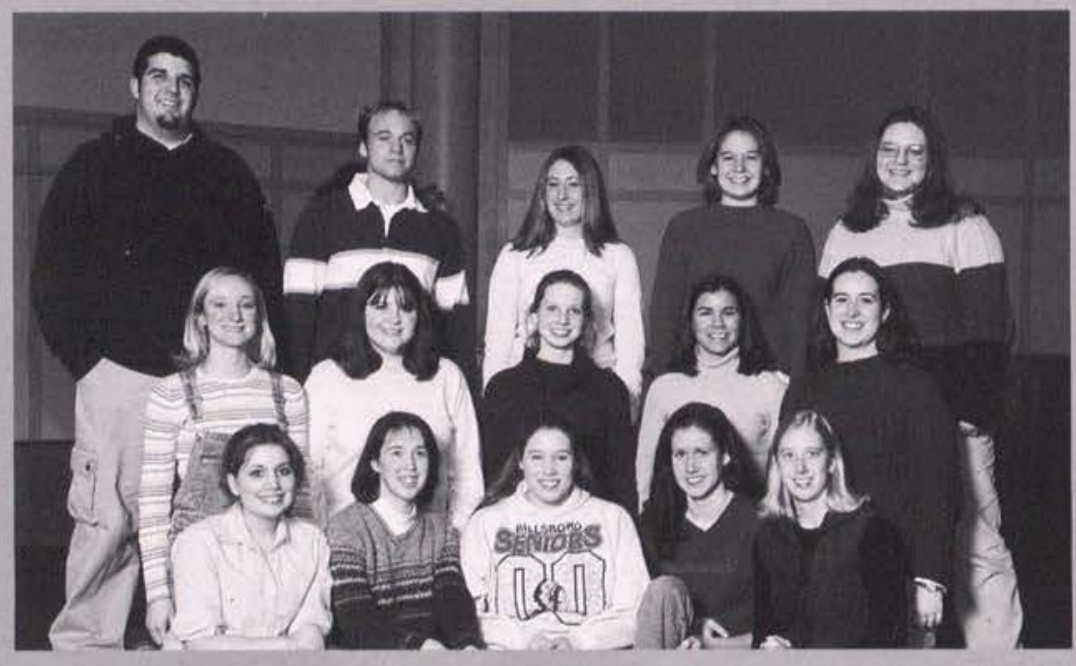

(first row left-to-right) Sheena Chalvners, Sarah Sanders, Stephanie Lengefeld, Bethany Hochstaetter, Kristi Warndahl. (second row) April Bauman, Pam Mercer, Anna Woodhams, Christi Thompson, Sarah Gaynier. (third row) Matthew Myers, Dave Nickell, Jennifer Dennis, Ruthanne Gough, Sarah Greene. (not pictured) Grayden Schafer, Jesse Fredrick, Christine Davlantes, Sara Faith, Heather Osborn, Carrie Weaver, Greg Schwab, Jonathan Coleman, Susan Fultz, Rachel Johnson.

(first row left-to-right) Sarah Reed, Kimberly Harbison, Elisabeth Keim, Pam Salmons, Michael Burgman, Gertjan Flikweert, Keith Dougherty, Richard Brewer.

\section{Clowns for Christ}

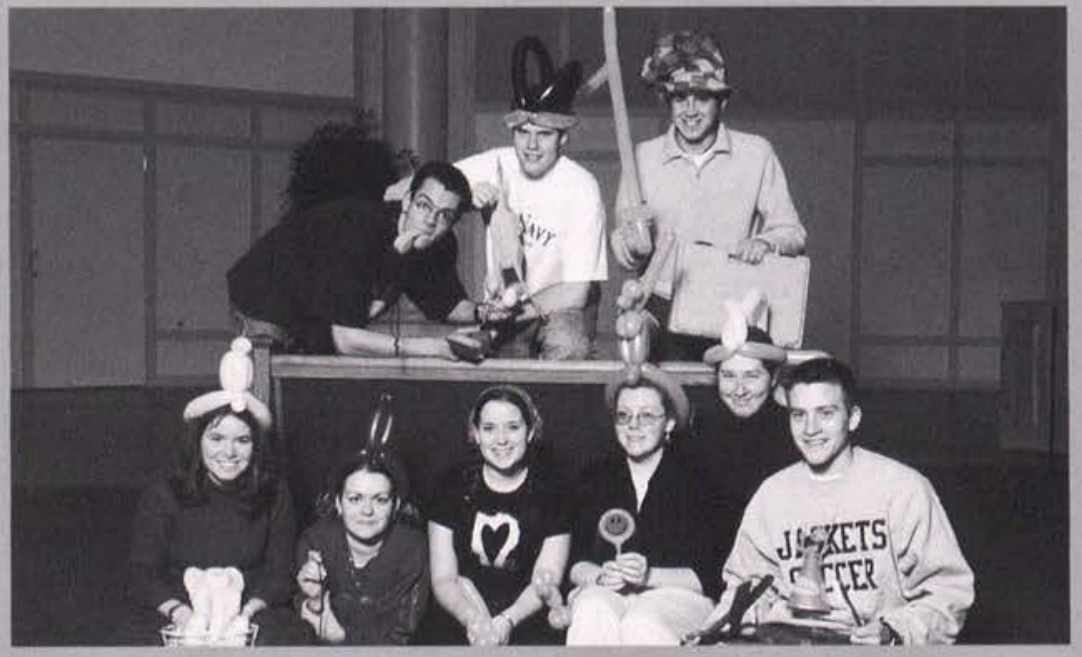




\section{Colonial Baptist}

(first row left-to-right) Anne Wilson, Holly

Seace, Emily Macdonald. (second row) Joshua

Foster, Shannon Grimm.

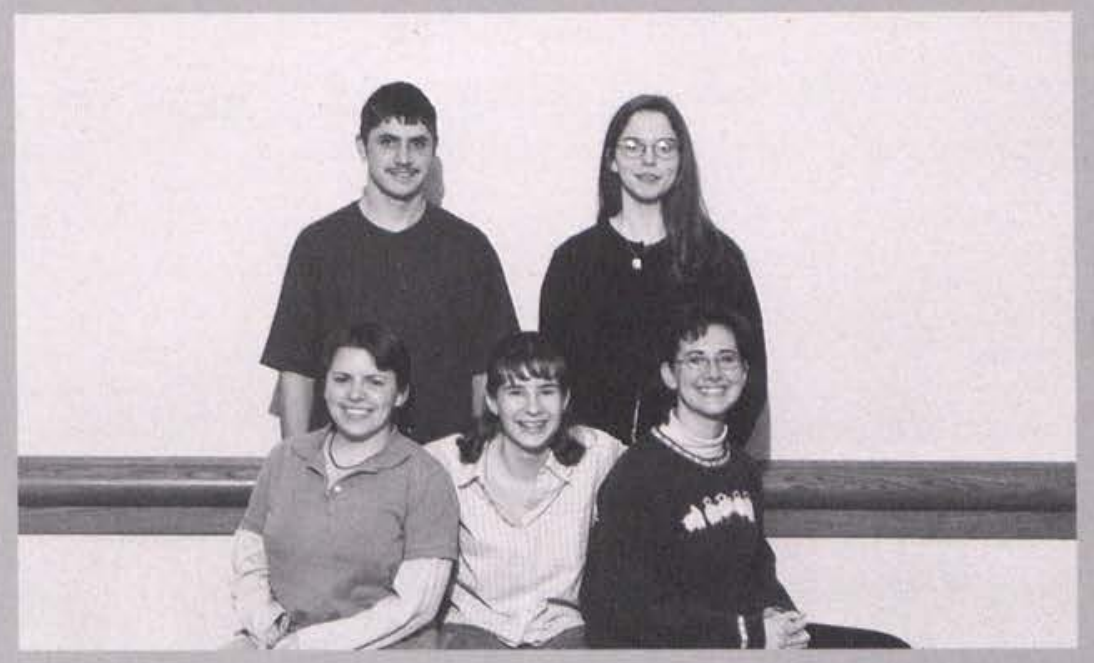

\section{Cornerstone Baptist}

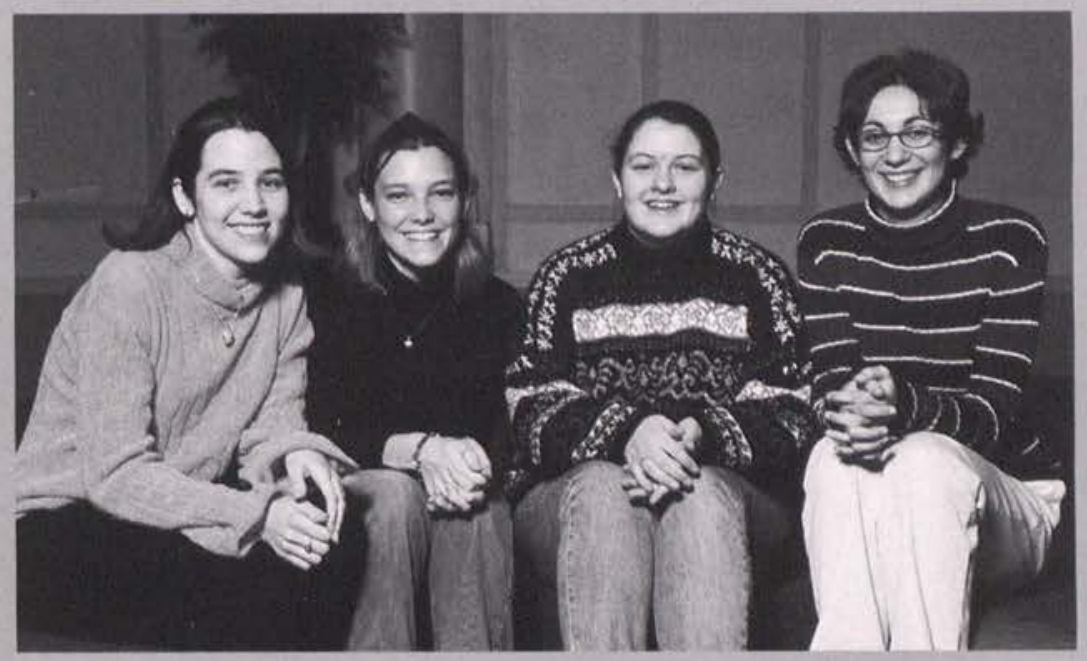

(first row left-to-right) Eileen Hopkins, Jennifer

Sparling, Rebekah Manwiller, Melissa Weirich.

\section{Cornerstone, Triple C}

(first row left-to-right) Jon Nelson, Rebekah

Manwiller, Adrienne Ruegg.

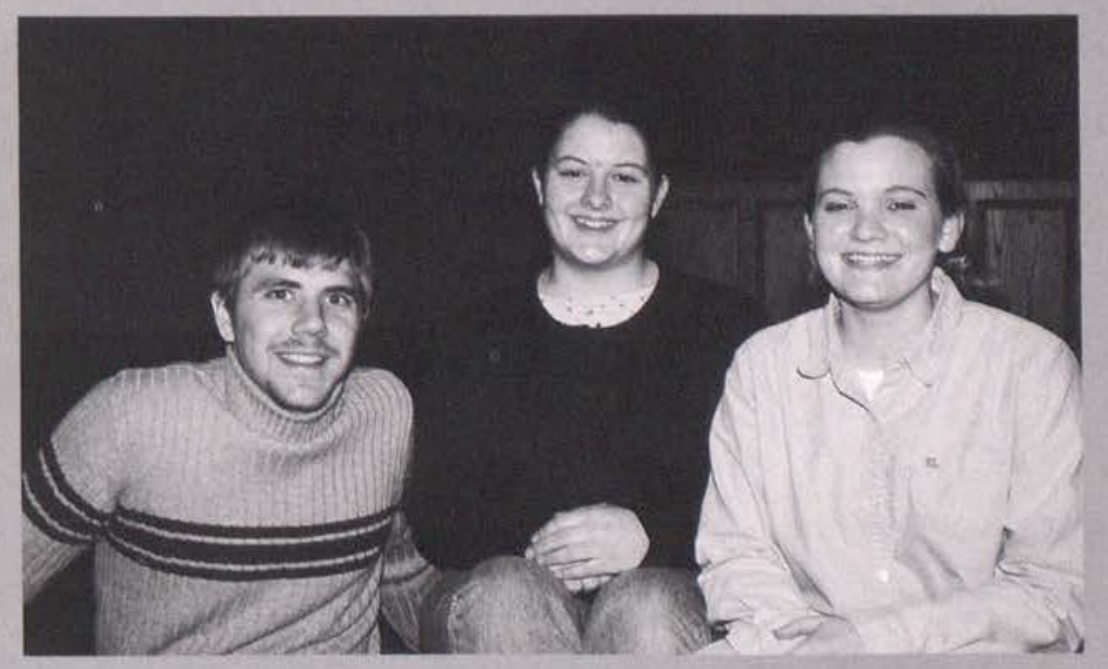



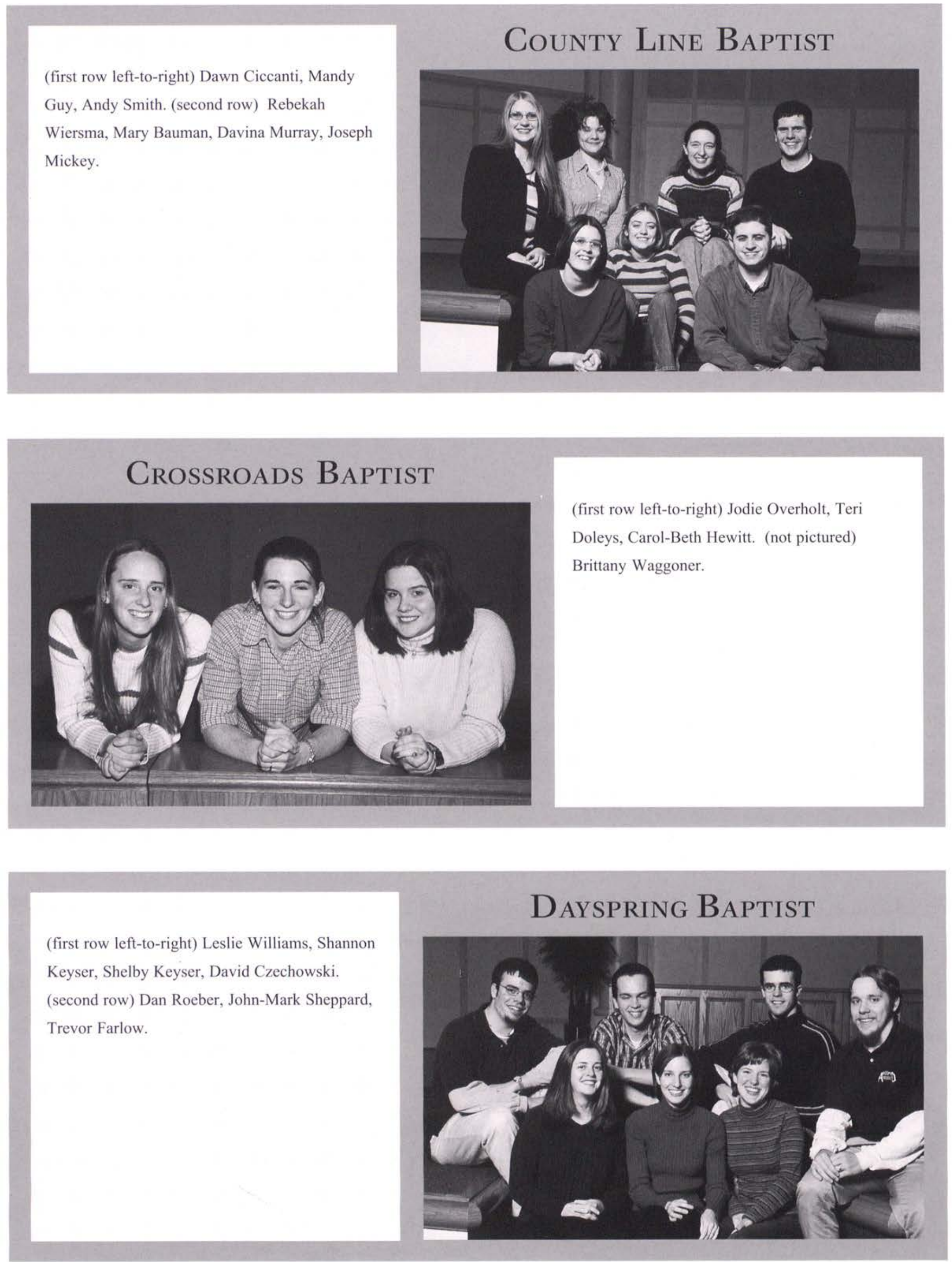
(first row left-to-right) Kristyn McKenna, Andrea Winship. (second row) Ben Mitchell, Steve Storer, Greg Vruggink, Becky Gross.

\section{Dayton Chinese Church}

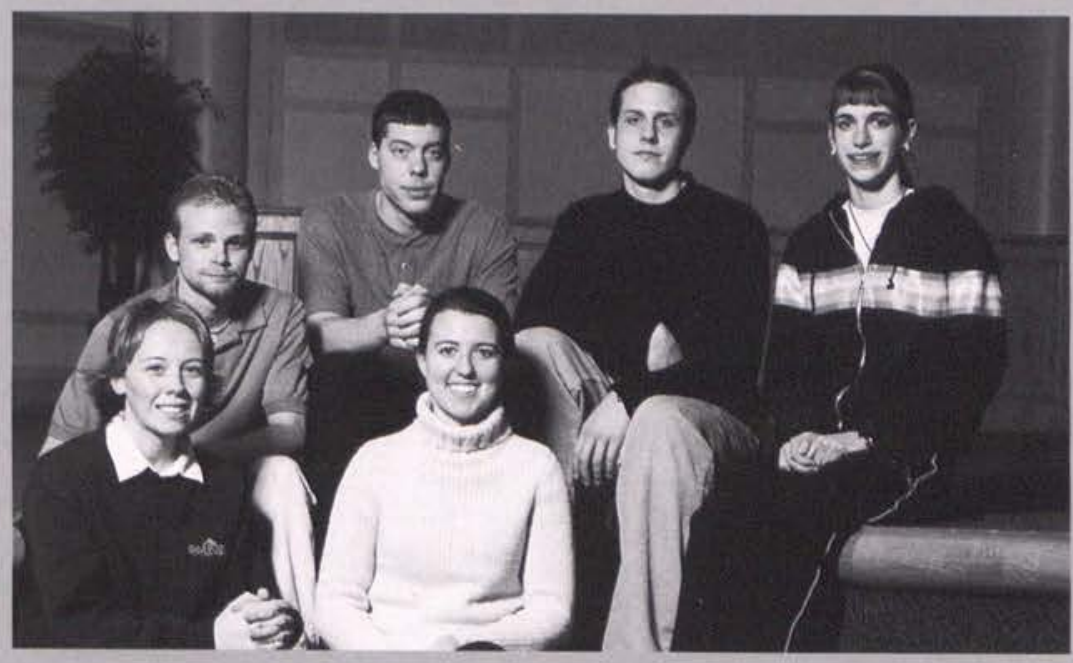

\section{Dayton Detention Home}

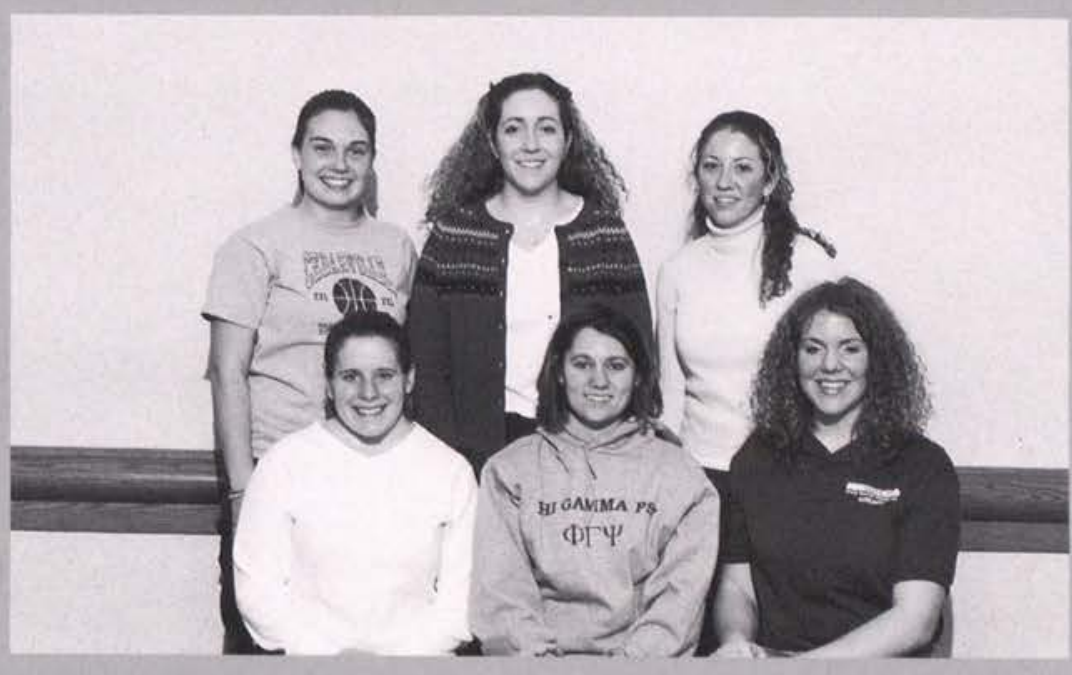

(first row left-to-right) Silas Gibbs, Lavinia

Vanderven, Karen Snyder. (second row) Leah

Nielson, Devon McCarty, Kikelomo Kolawole.

\section{Dayton Gospel Mission}

(first row left-to-right) Kristi Schutter, Stephanie O’Hara, Mellissa Zurakowski, Abby Dixon. (second row) Katie Krumeich, Rebecca Reich, Courtney Cox, Kenna Stark. (third row) Lindsay Prowitz, Geny Chipe, Mary Beth Haug, Paul Abraham, Robyn Pitman, Chris Bartlett, Jon Schutter.

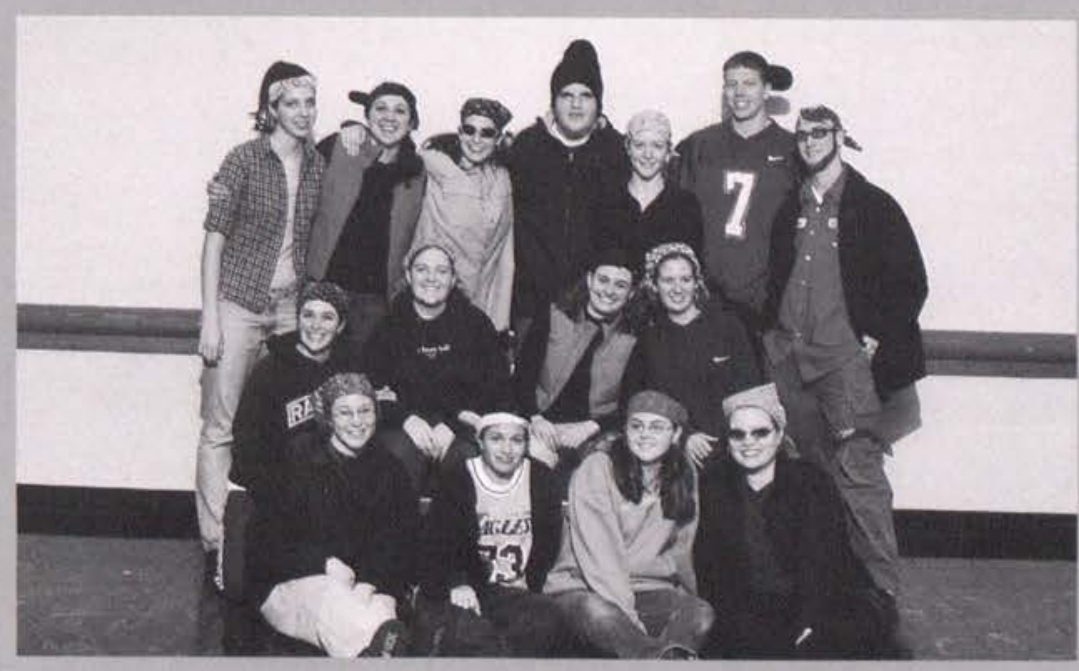




\section{Echoing Valley Resident Center}

(first row left-to-right) Kaley Johnson, Kathy

Steingass, Rebekah Wagner, Anna Bolser. (not pictured) Joy Shustack.

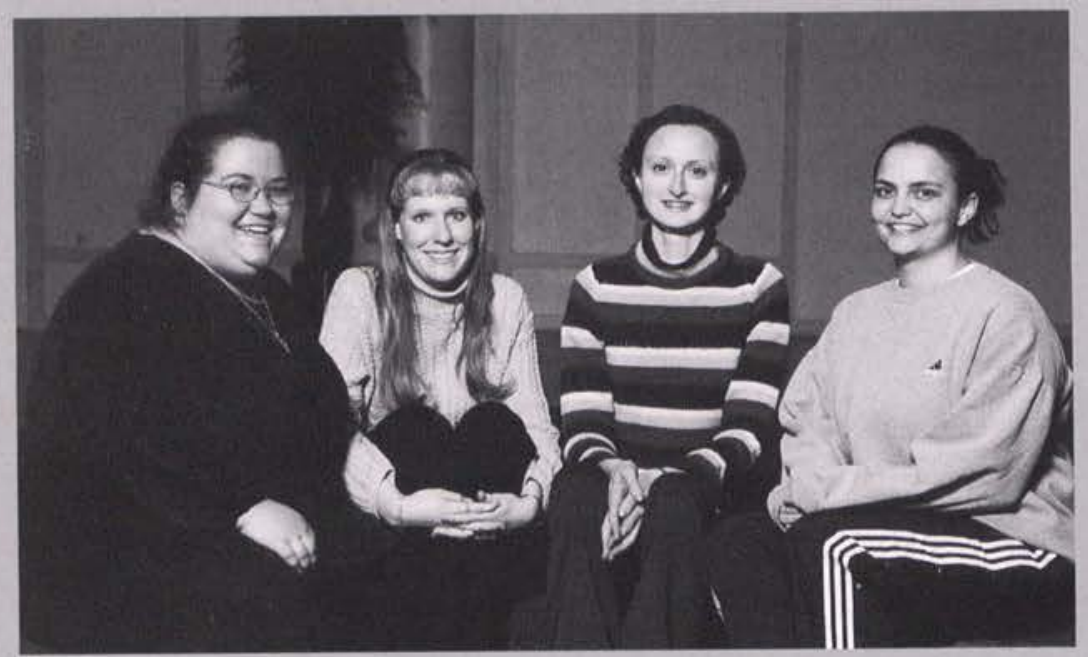

\section{Emerson Bible Club}

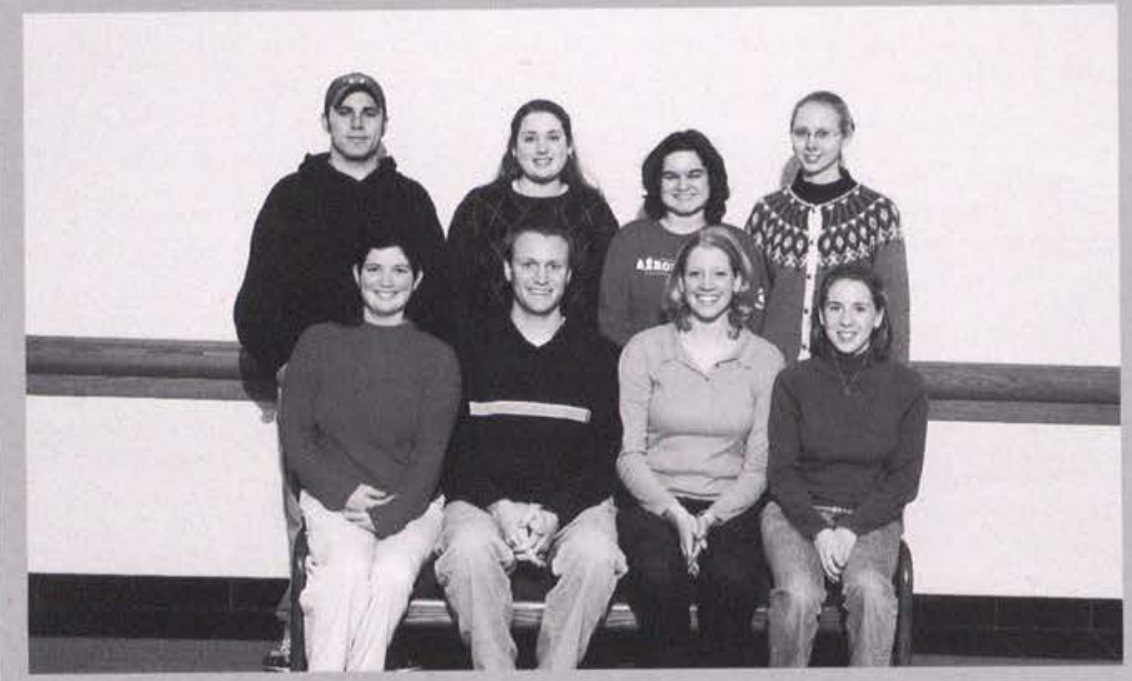

(first row left-to-right) Stephanie Vantuyl,

Nicholas Walton, Kelly Schriemer, Bethany

Kinley. (second row) T.J. Freeman, Melissa

Joubert, Candi Hutcheson, Rebecca Christenson.

\section{EMMANUEL BAPTIST}

(first row left-to-right) Jeremy Spence, Debbie Compton, Michael Cosgrove, Shawna Smith, Nathan Williams, Tammy Moore. (second row) Erin Seeloff, Amanda Allen, Allison Krizo, Dawn Abney.

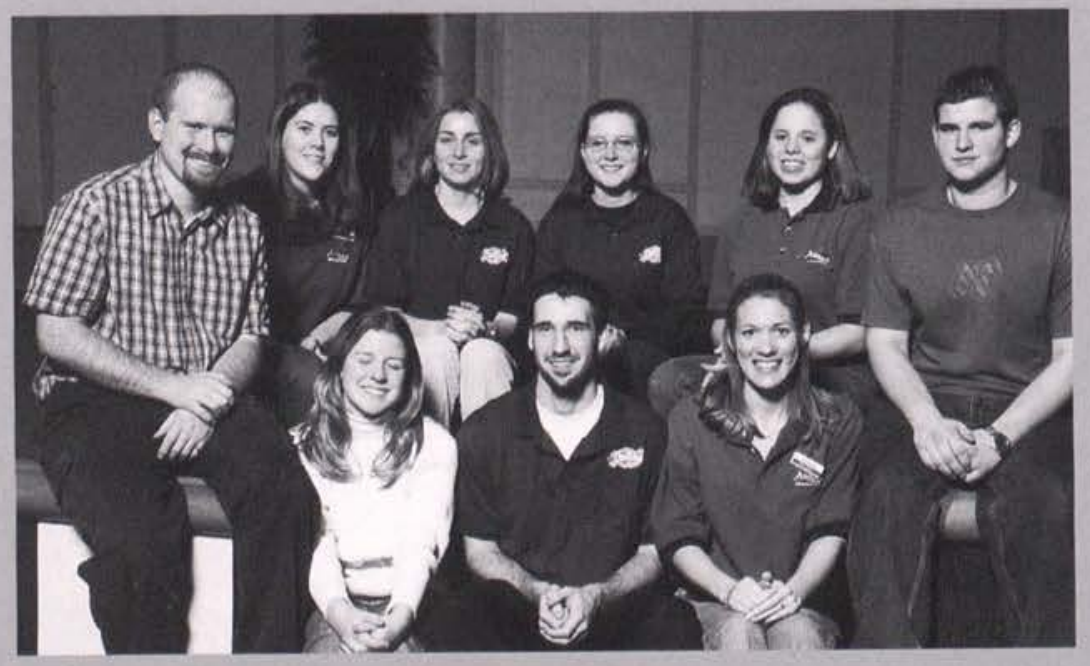


(first row left-to-right) Amanda Elliott, Sarah Mackenzie, Lindsay Engelmann, Carrie Sorensen, Matthew Bigelow. (second row) Elizabeth Gwilt, Jess Wallace, Katie Sparks, Carissa Smith, Teresa Myers, Alicia Marsh. (third row) Jeanette Calo, Kristen Detwiler, Sharon Wright, Callie

Edgington, Mindi Sparks, Michelle Koziol, Beth Brown. (fourth row) David Williams, Brian Huster, Jared Lamb. (not pictured) Julie Jamgochian, Kristen Roberts, Adam Bartlett, Benjamin Nesbit, Tyler Brumback.

\section{Extra Mile}

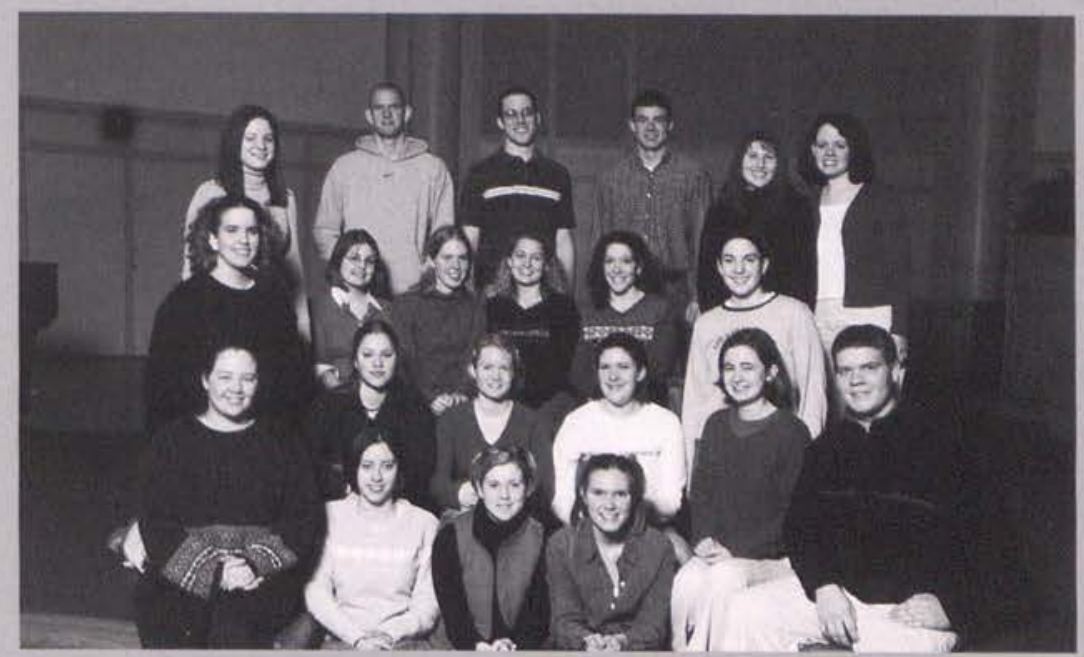

\section{Fairhaven Kids Club}

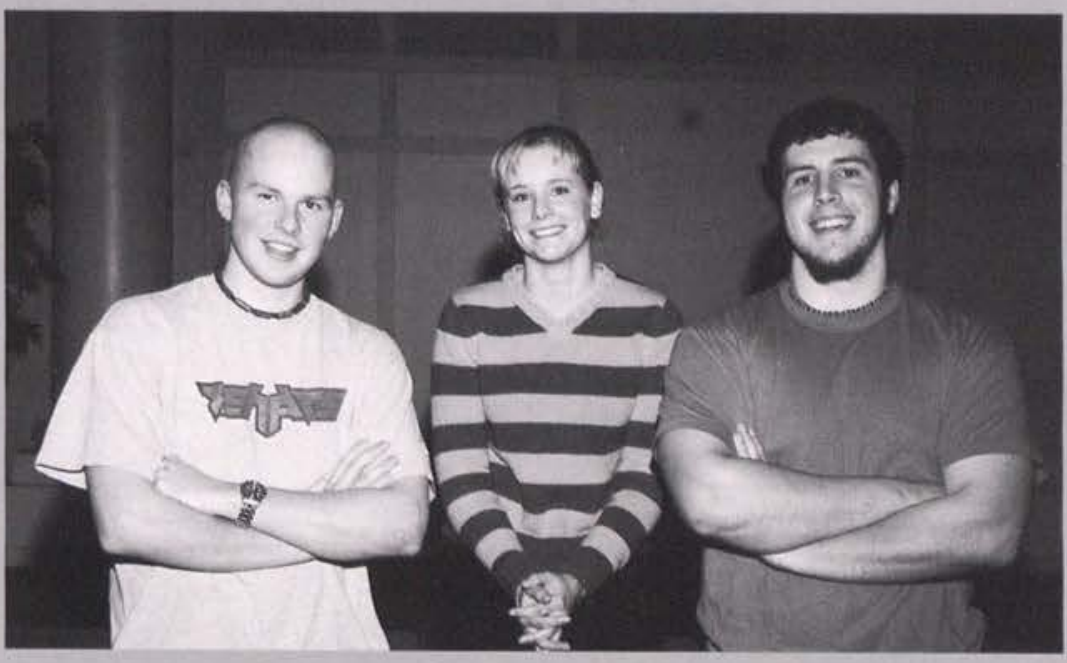

(first row left-to-right) Ted Norris, Monica Thomas, Matt McCracken.

\section{Faith Baptist Willmington}

(first row left-to-right) Mark Erikson, Jennifer Ingersoll, Adam Bartlett.

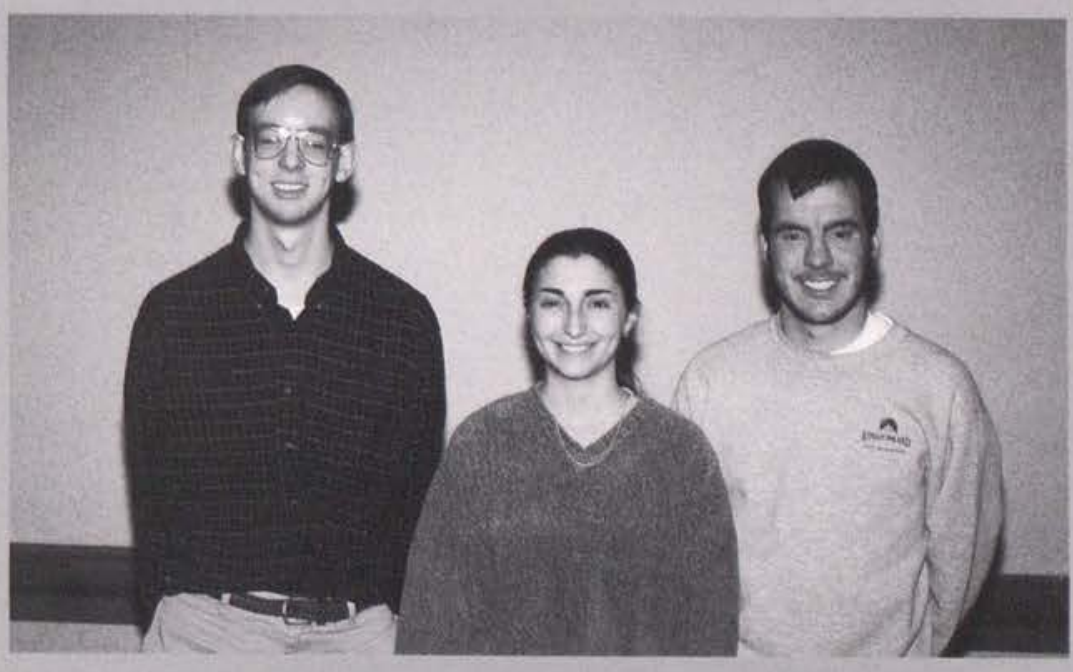


(first row left-to-right) Kelley Goldsby, Rachel Jodry, Julie Marshall. (second row) Nate Hill,

Ruthina Northcutt, Ben Rosner, Mark Emmons. (not pictured) Melissa Stauffer, Karen Mowrer, Steve High, Mike Proudfoot.

\section{Far Hills Baptist}

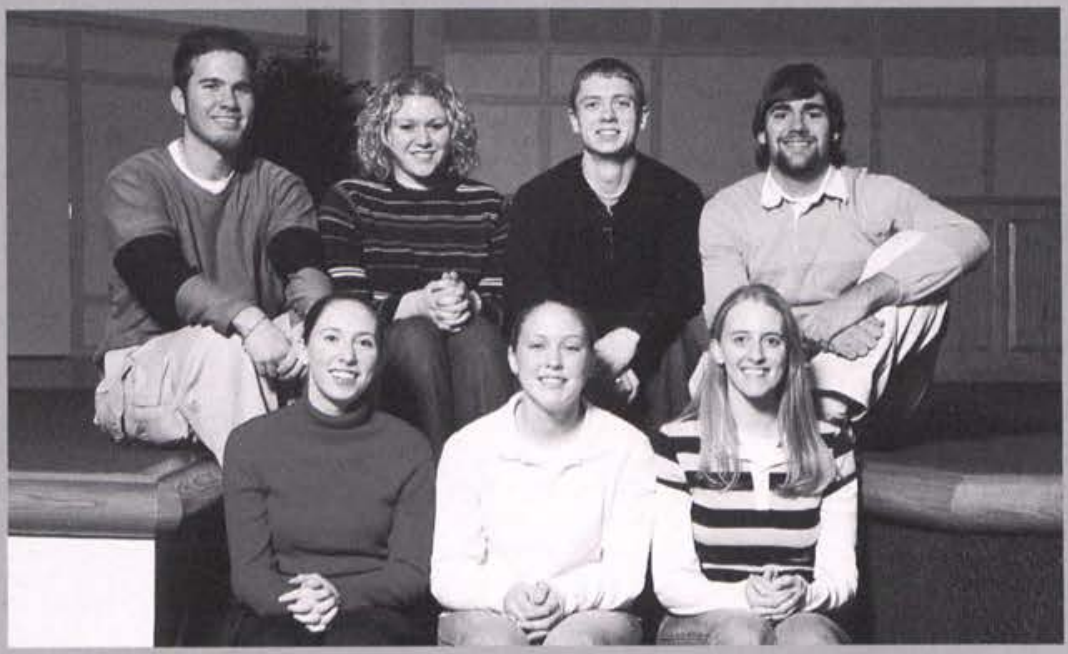

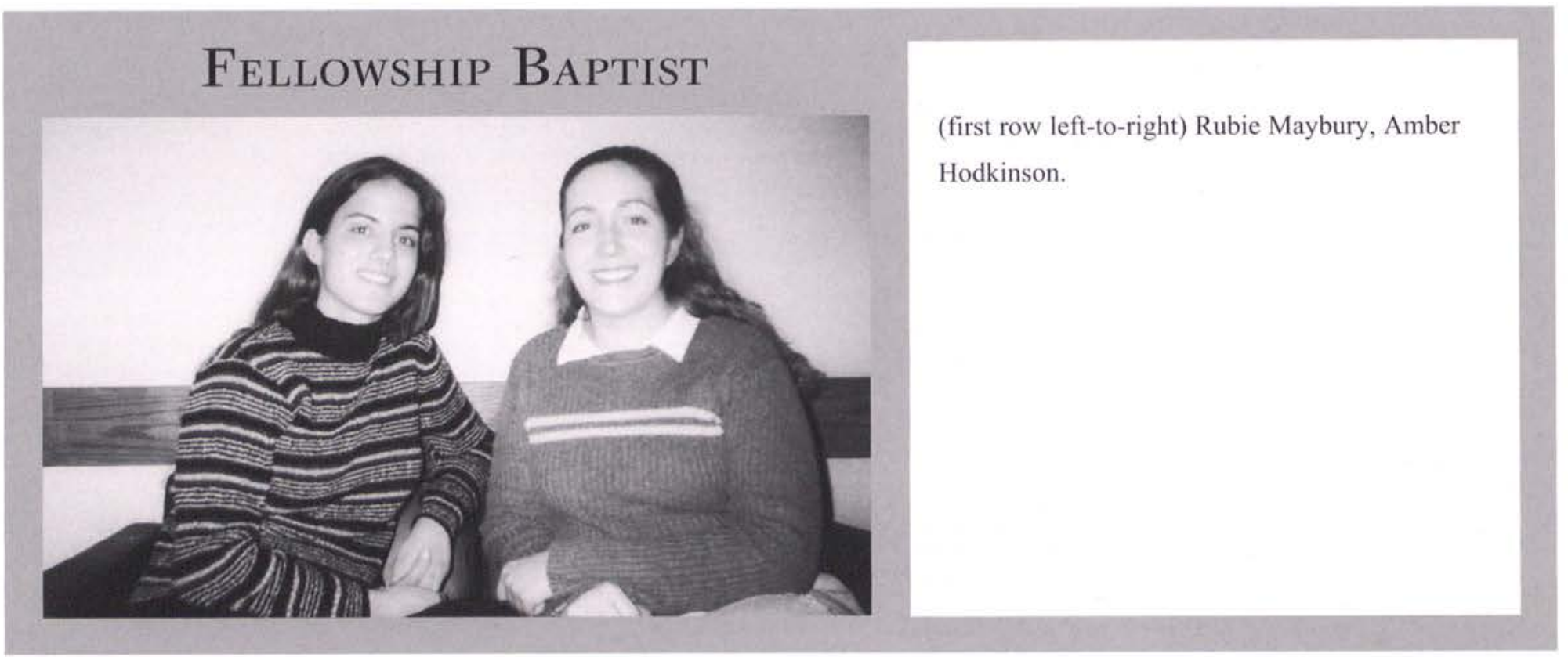

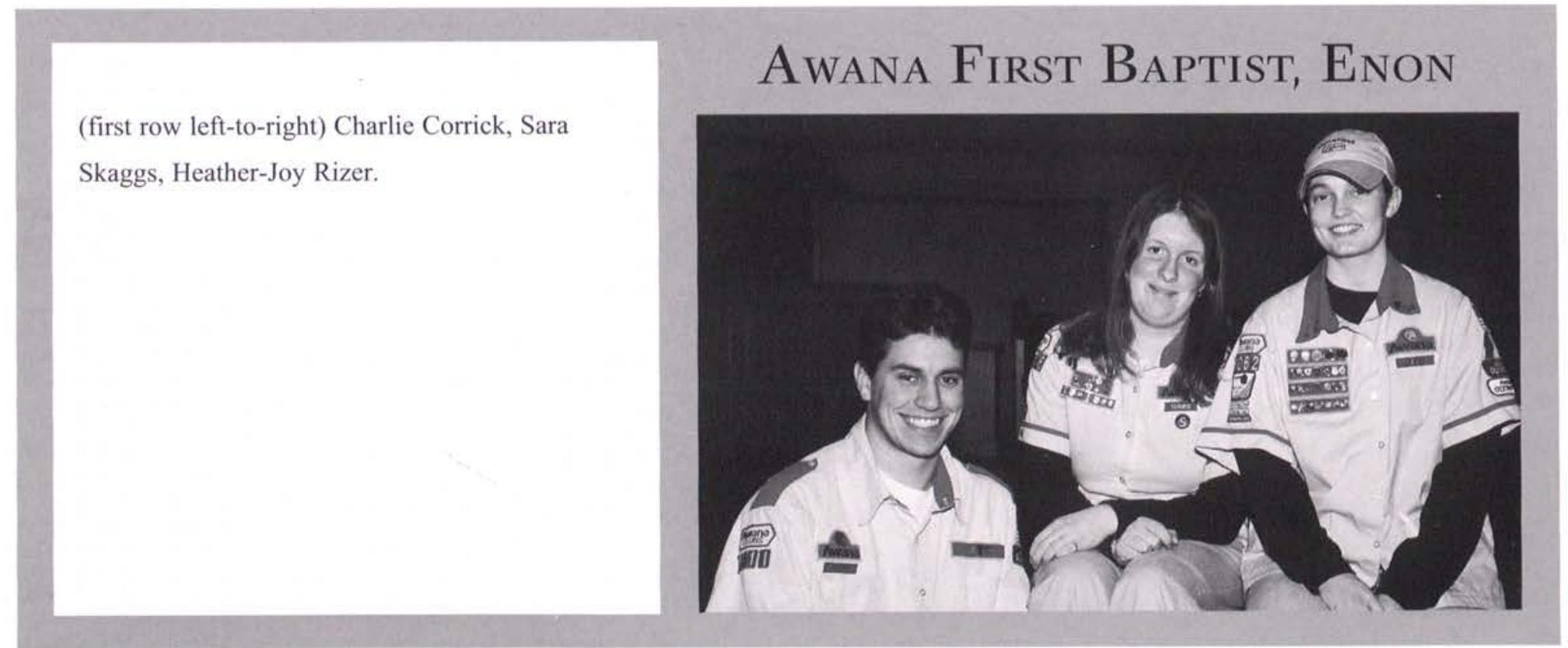


(first row left-to-right) Rachel Roberts, Kara

Burks. (second row) Chris Reyes, Mark

Underkofler.

\section{First Baptist, Tipp City}

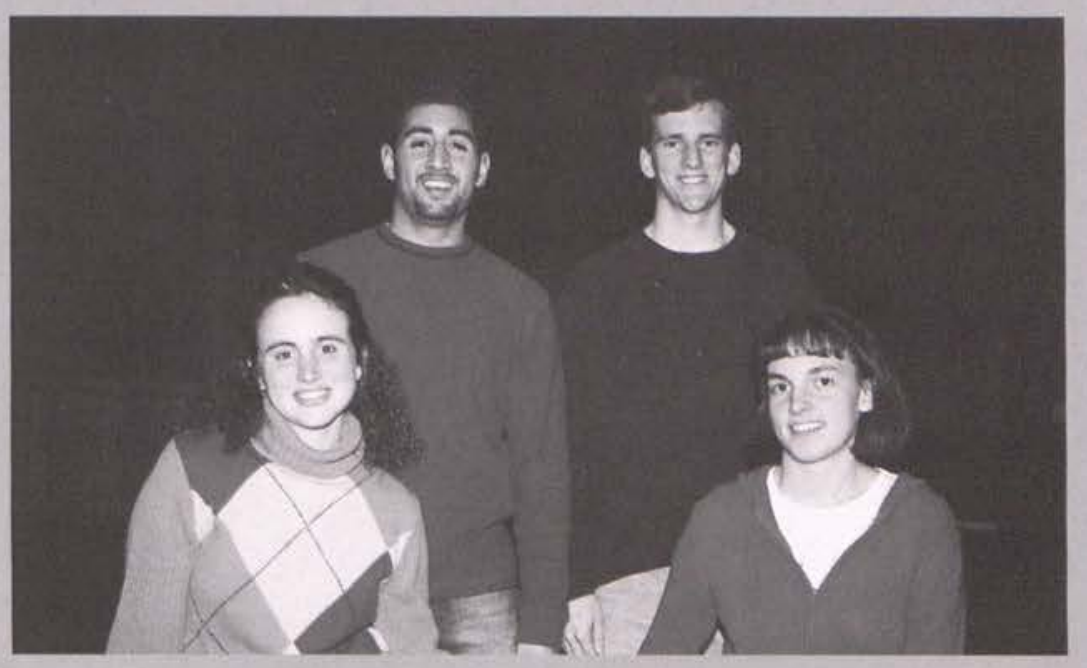

\section{First Reformed Church}

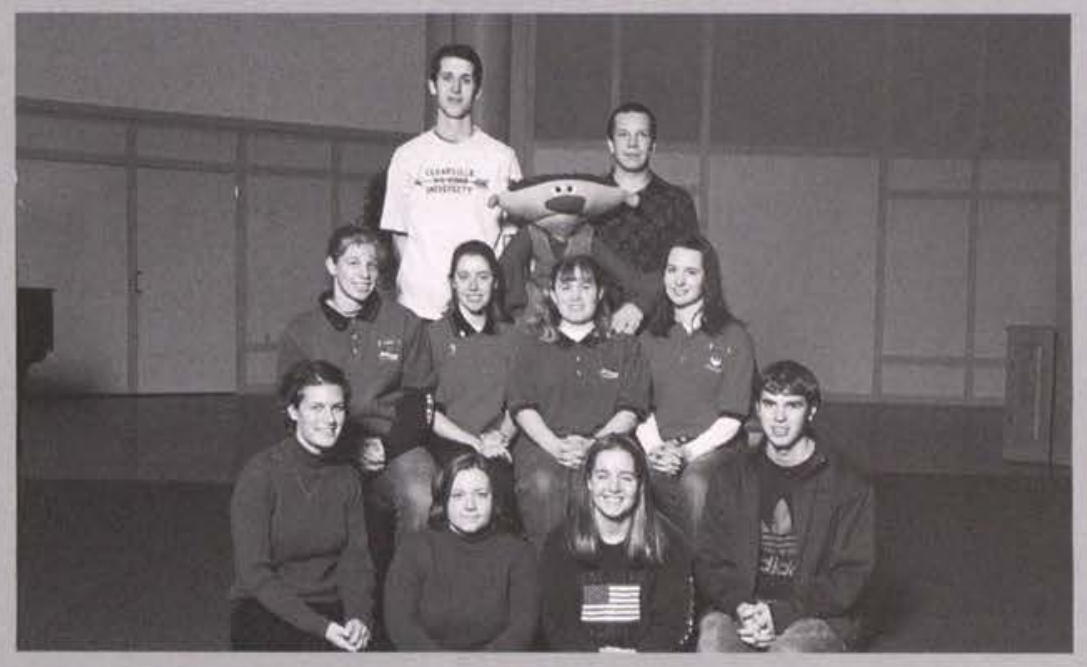

(first row left-to-right) Robin Acheson, Adelle Schanely, Michelle Ruhlman, Jason Miller. (second row) Kailin Acheson, Annie Kerns, Christine Newhard, Emily Plate. (third row) Jody Fox, Ralph, Nathan P. Hay. (not pictured) Jonas

Kibelbek, Nathan Kibelbek, Heidi Wright.

\section{Forest Ridge Baptst}

(first row left-to-right) Kristina Seace, David Bates, Julie Landau. (not pictured) Gwen Oatman, Ashley Walton.

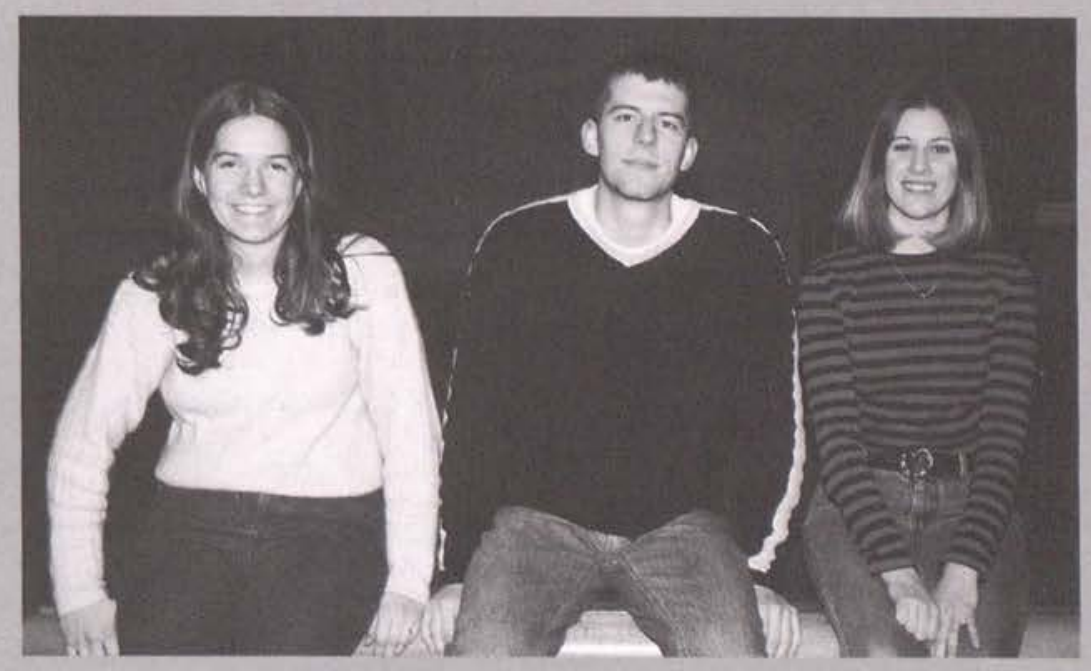


(first row left-to-right) Seth Crowder, Andrew Courser, Eileen Hopkins, Matt Blosser. (second row) Ben Saturley, Jennifer Chmielewski, Julia Christner, Angie Reninger, Kristen Hilsher, Melissa Miller

\section{FosTERING FRIENDSHIPS}

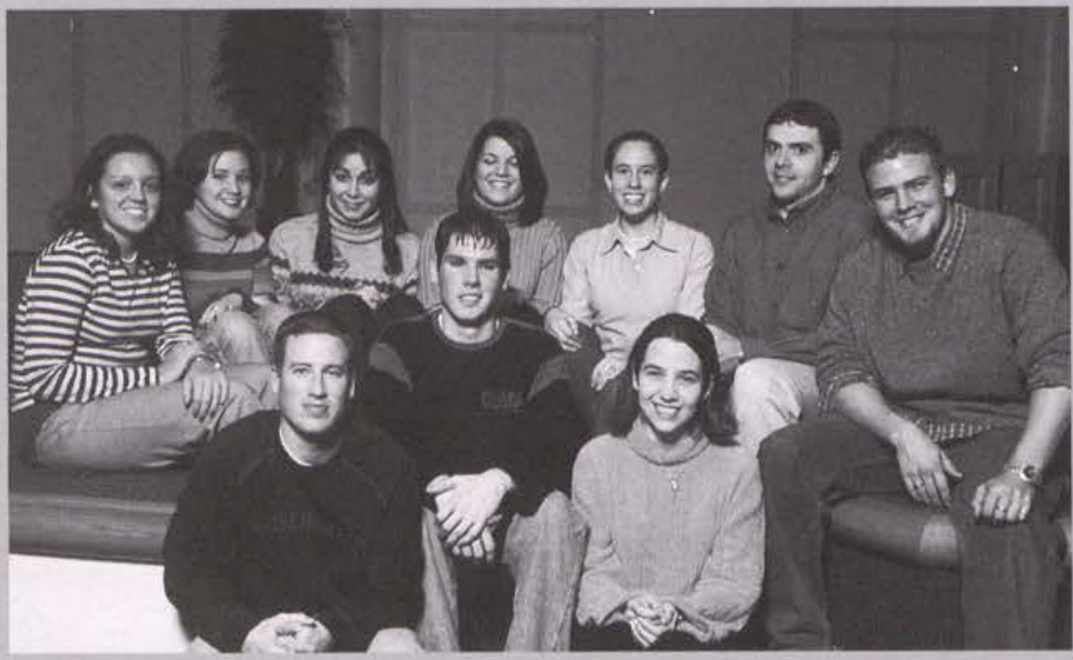

\section{FRIENDSHIP BAPTIST}

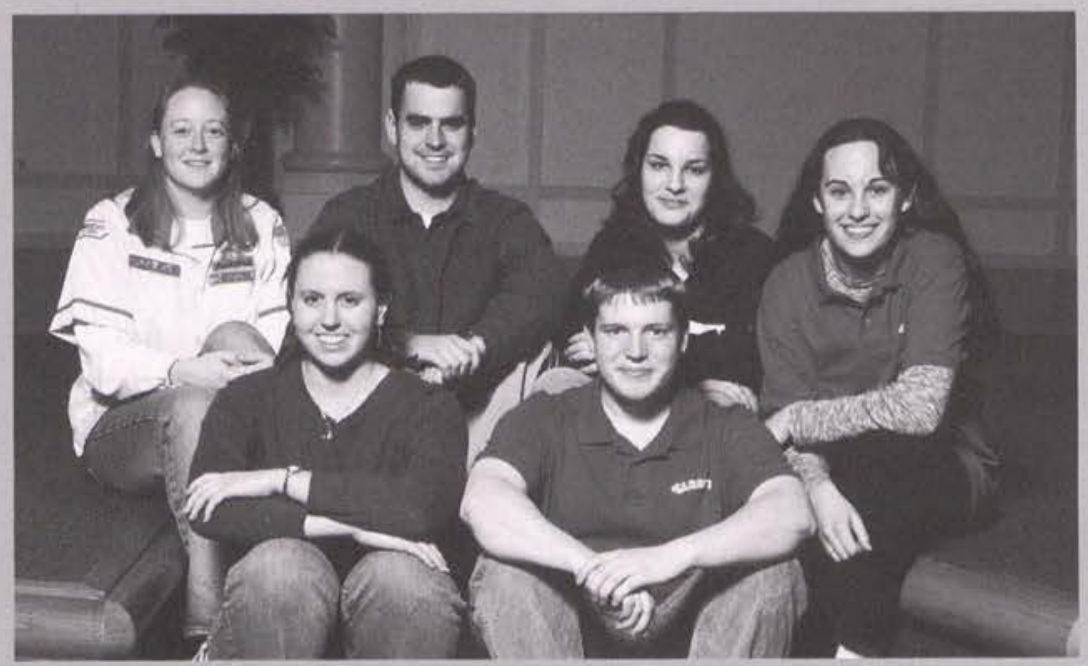

(first row left-to-right) Christine Fairchild, Jeremy Bossard. (second row) Christina Barrons, John Bolinger, Megan Mate, Liz Zeron. (not pictured) Russel Pierpont.

\section{Grace Baptist Church}

(first row left-to-right) Lauren Crissman, Shannon Stowers, Megan Smith, Melissa Howland, Rachel Althaus, Jennifer Barham, Sarah Parker. (second row) Morgan Price, Lena Fischer, Erin Tubbs, Amanda Nelson, Erica Johnson, Traci Weiss, Laureann Osenni. (third row) Kevin Kickbusch, Joe Marshall, Jonathan Estes, Brian Montague, Bryan Horton, Joshua Krupka, Emily Furler, Stacy Rosser. (fourth row) Justin Ohlinger, Jacob Hummitzsch, Matthew Tabbut, Alan Bruder, Patrick Noonan, Aaron Handley.

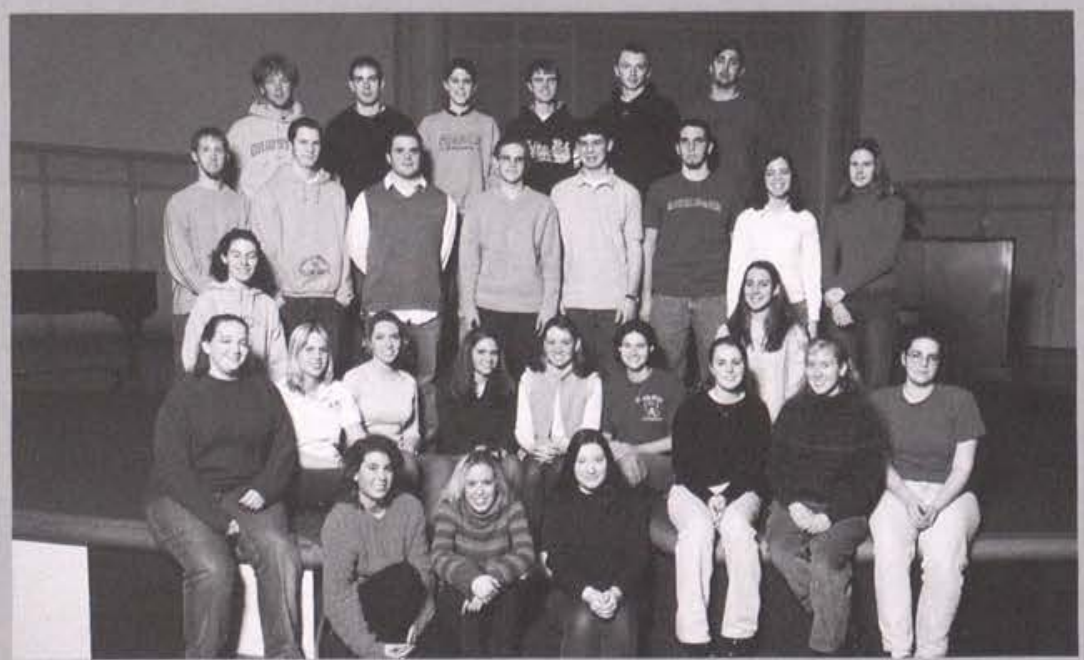




\section{Grand Heights Baptist}

(first row left-to-right) Heather Roth, Sara Allen, Susan Magin. (second row) Peter Romaine, Melissa Mattner, Pete Springirth.

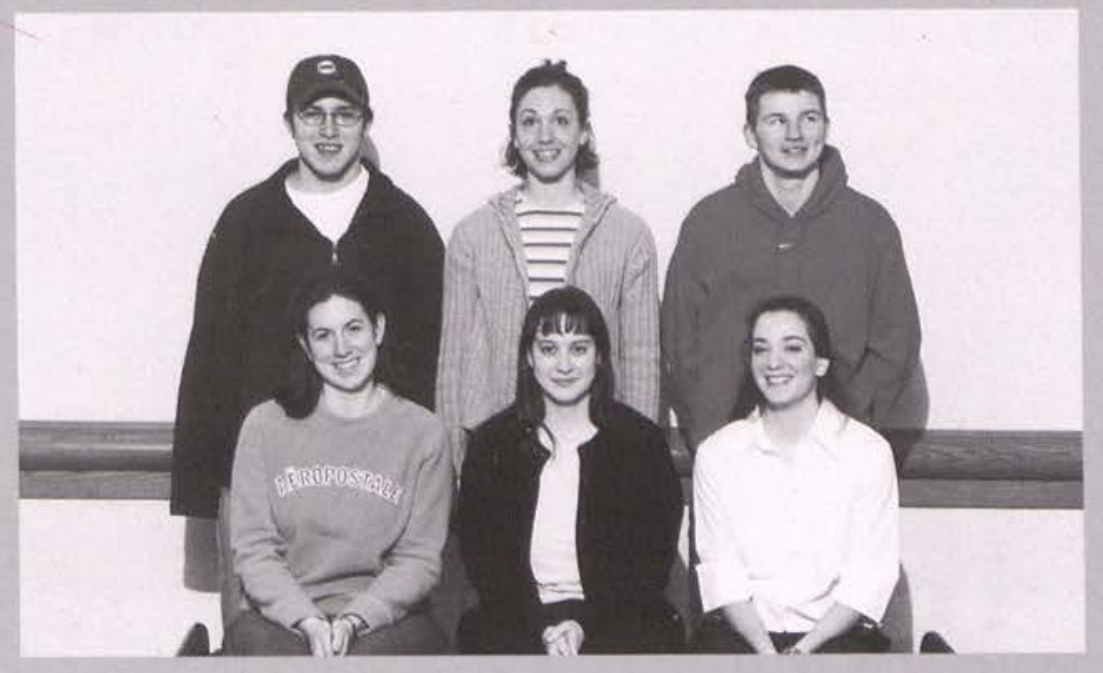

\section{Greene County JaIL}

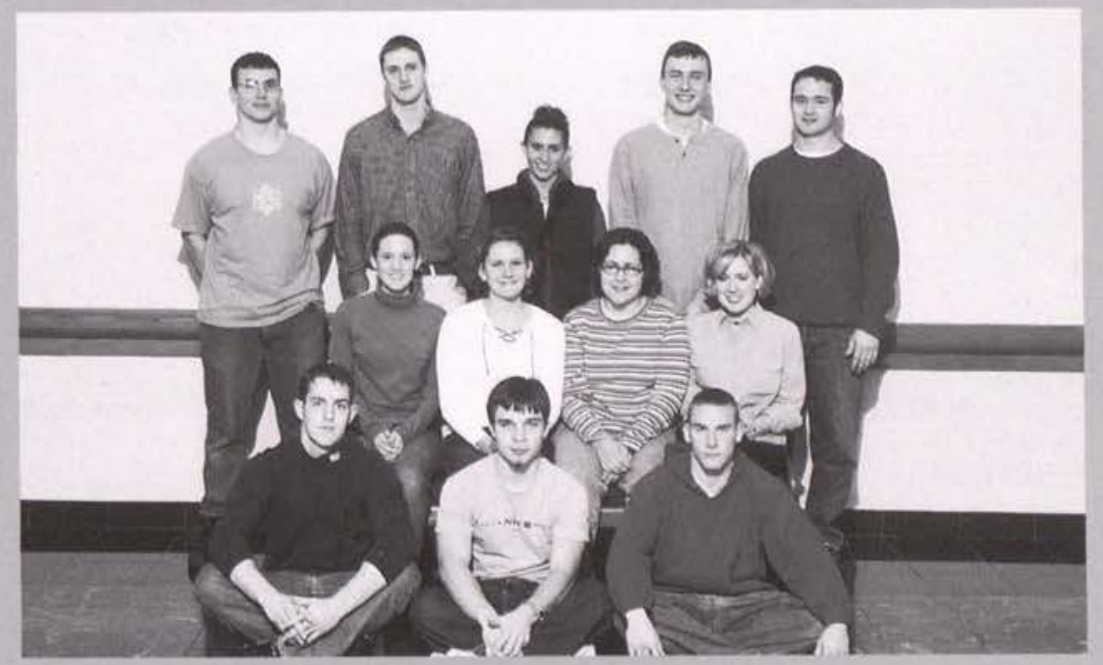

(first row left-to-right) Jason McDaniel, Jonathan D. Brown, Andrew Becker. (second row) Cherith Payne, Danielle Davidson, Jenny Hime, Rhianna Hickey. (third row) Matthew Miklacic, Joe Schneider, Jessica Alexander, Daniel Kennedy, James Miller.

\section{Greene County Juvenile Detention}

(first row left-to-right) Jennifer Smith, Kate

Miller, Julie Miller. (second row) Jennifer Tuttle, Melissa Wagner, Patty Wilson, Denaye Hilty. (third row) Paul Laborde, Mark Yorgey, Ryan Ruff, Jeffrey Cassano.

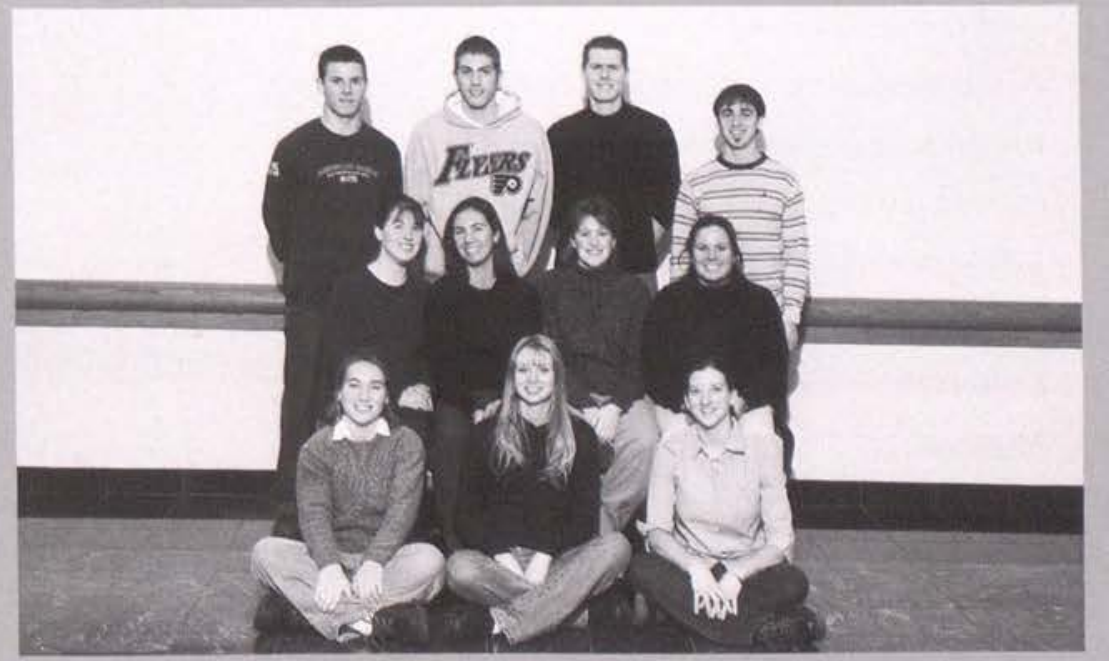




\section{Greene County Treatment Center}

(first row left-to-right) Rob Marshall, Ross

Gilfillen. (second row) Nate Gilbert, Ian Ellis,

Matthew T. Davis, Kyle McCarrell.

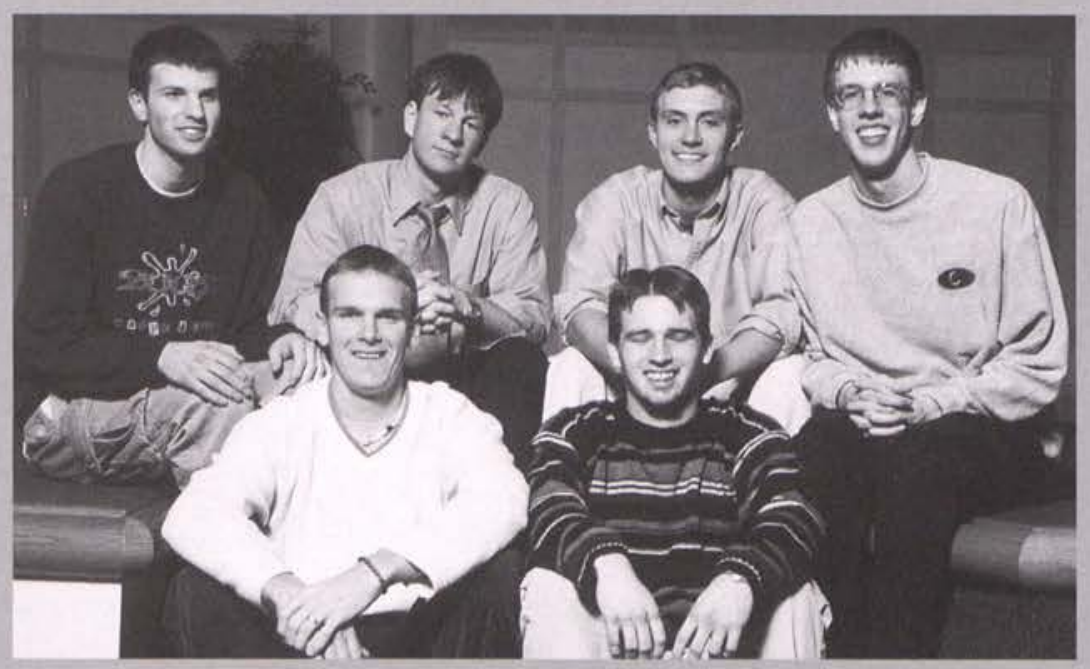

\section{Greene County Treatment Center}

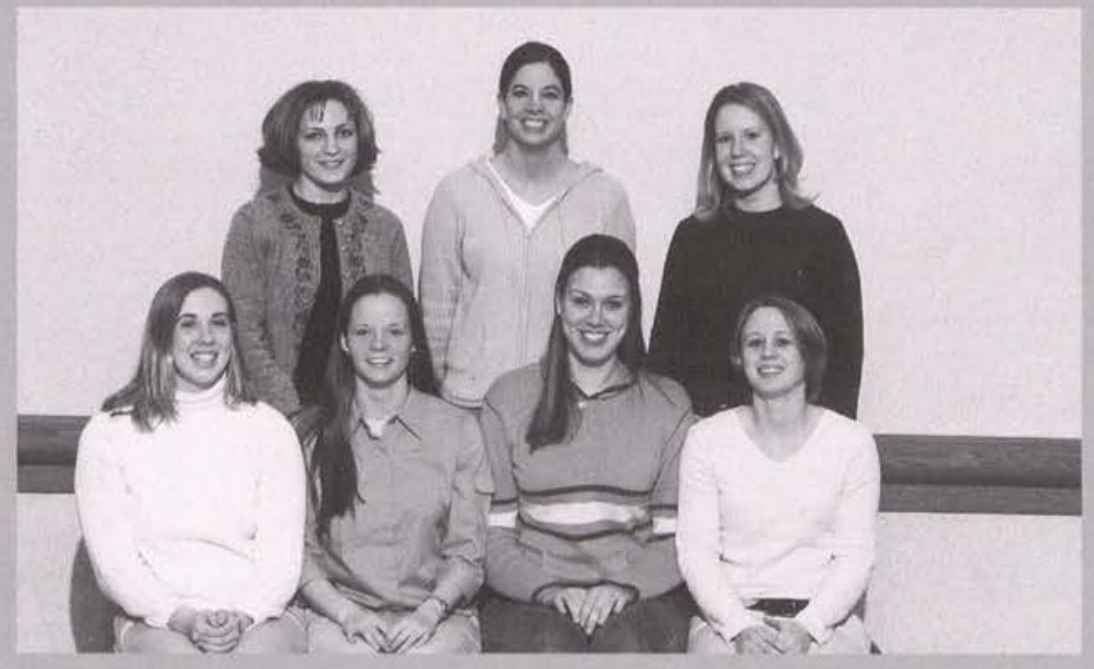

(first row left-to-right) Anjel Stough, Marcee

Hart, Christy Herman, Heather Stark. (second row) Tricia Wilkens, Meg Copella, Jessica Ells. (not pictured) Amanda Dye.

\section{Greene Memorial Hospital}

(first row left-to-right) Julie Ackerman, Kristi

Haring, Shere Brisendine. (second row) Amanda Lucarini, Sharon Foley, Kathy Colgain, Rachel Goldston. (third row) Crystal Stuckey, Andrea Galehouse, Alana Merritt, Daniel Rasbach, Nichole Sabine. (fourth row) Sigrid Myers, Thomas Leach, Josh McKinney, Stephen Sandlund.

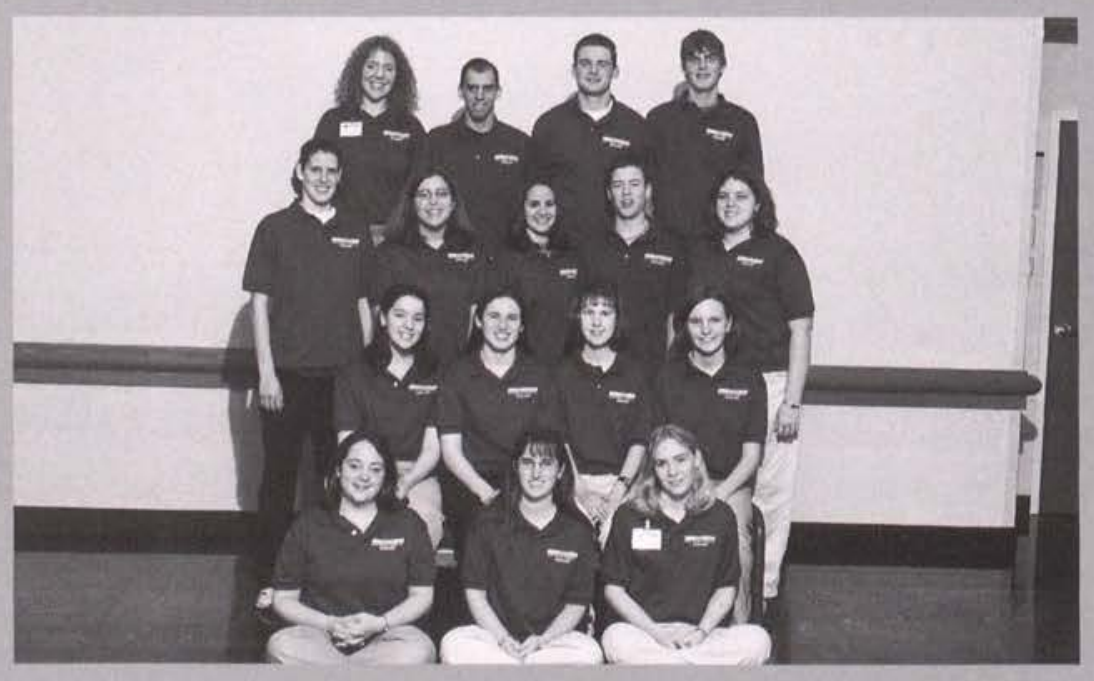


(first row left-to-right) Amber Bostic, Katie Chouinard, Andrew N. Jenkins. (second row) Andrew Raymond, Andrea Howell, Cheryl Elliott, Allison Mapes, Tom Chiavetta.

\section{Greennewood Manor}

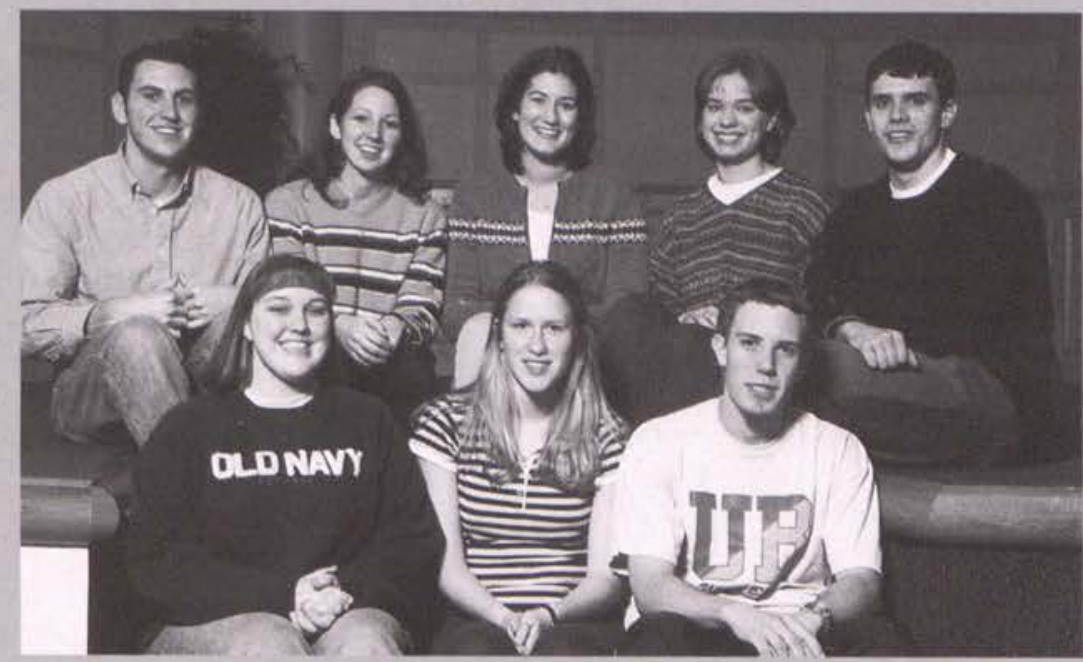

\section{Hannah House}

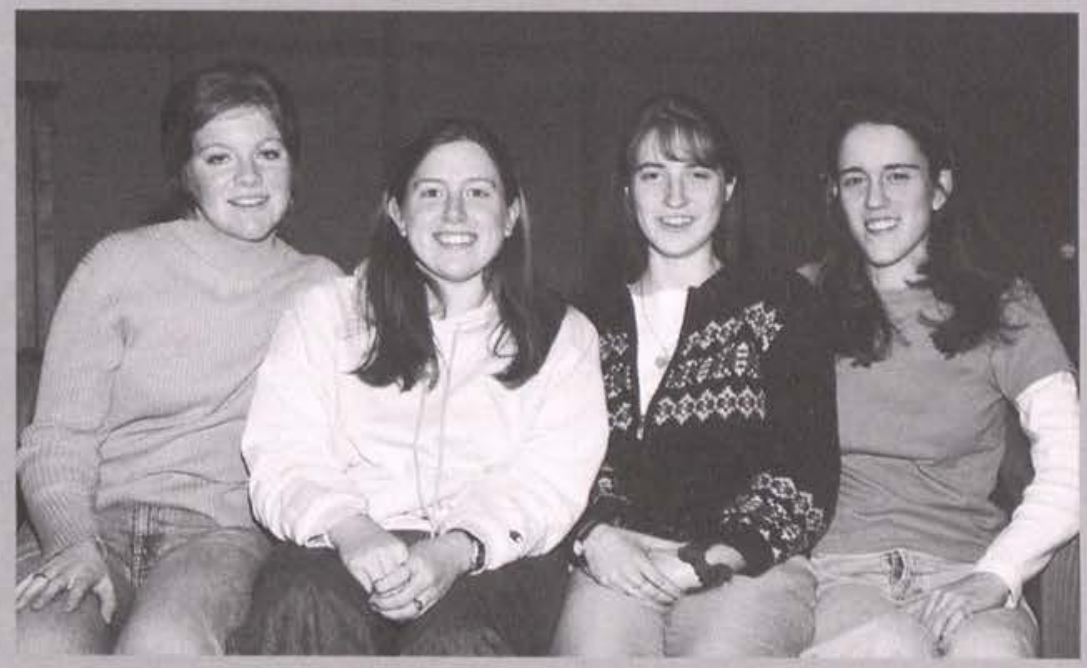

(first row left-to-right) Sharon Girouard, Emily Stokes, Amy Kennard, Kendra Cassidy

(first row left-to-right) Jessica Spears, Jennifer Sullivan, Adrienne Ruegg. (second row) Lavinia Vander Ven, Kevin Craig, Philip Kirby, Jessi vonder Mehden, Beth Elaine Seachrist, Sara Skaggs. (third row) Emily McQuinn, Melissa Koch, Amy Miloch, Mark Riddle, Rebecca Lietzow, Rachel Herring, Christi Flick. (not pictured) Caleb Halulko, Andy Kirby, Don Alburger, David Nickerson, Sarah Buckner, Mark Tedford, Julie Jamgochian, Jenn Williams, Dorothy Blake.

\section{Hayward Tutoring}

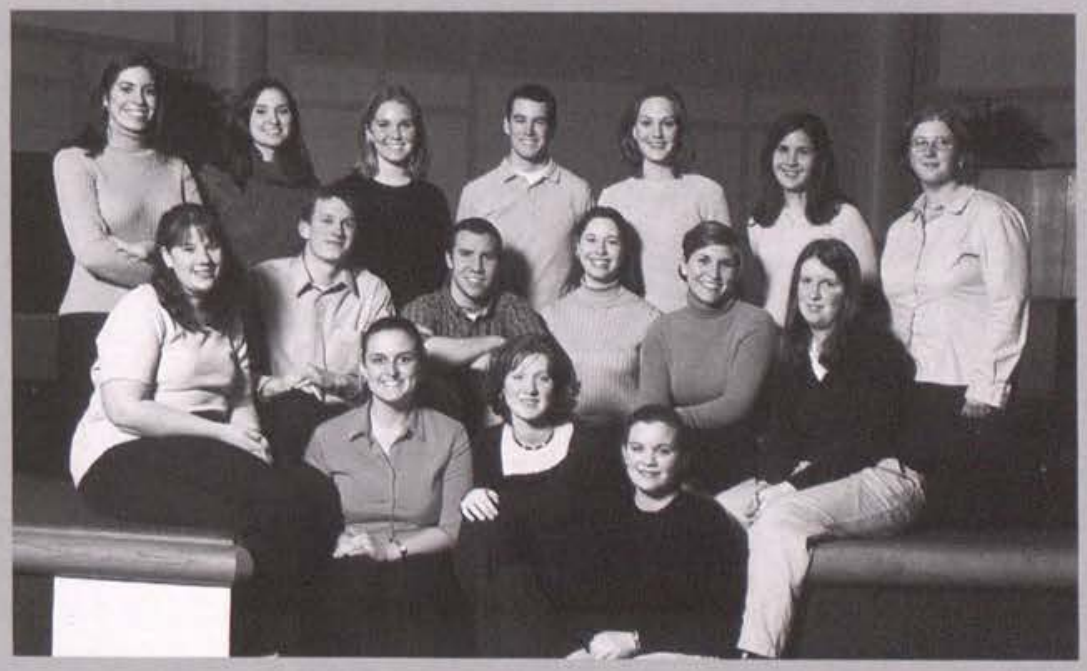




\section{Hillside Retirement}

(first row left-to-right) Kate Nelson, Ed

VanderBush, April Price. (second row) Desiree De Penning, John Evenson, Elizabeth Clawson.

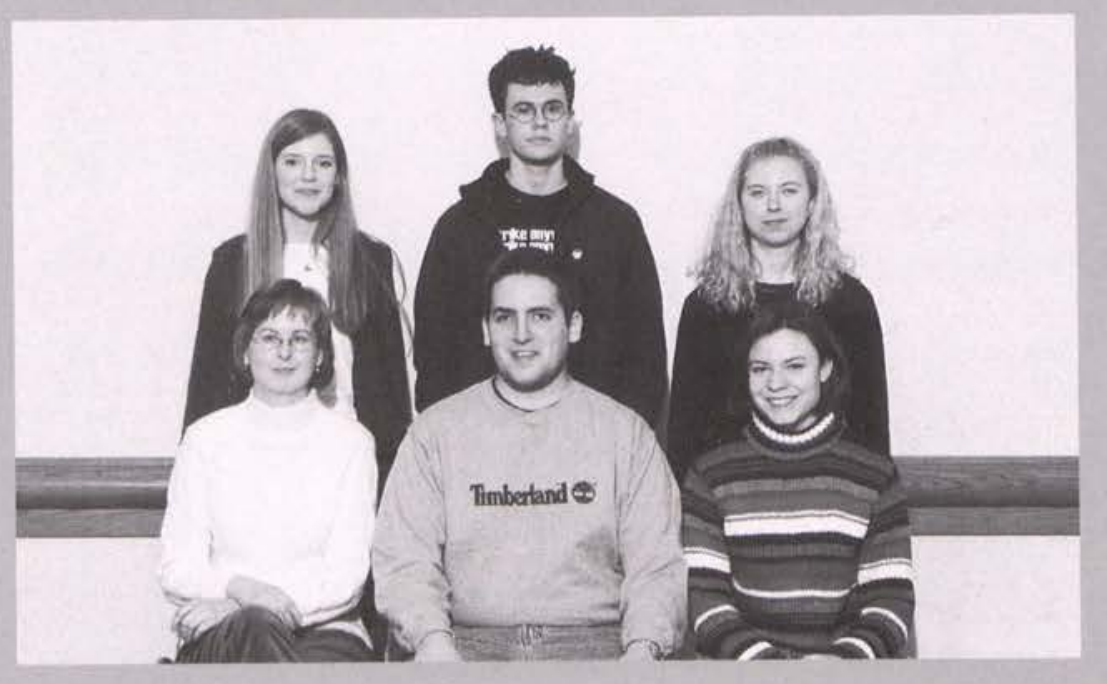

Homes For L.I.F.E.

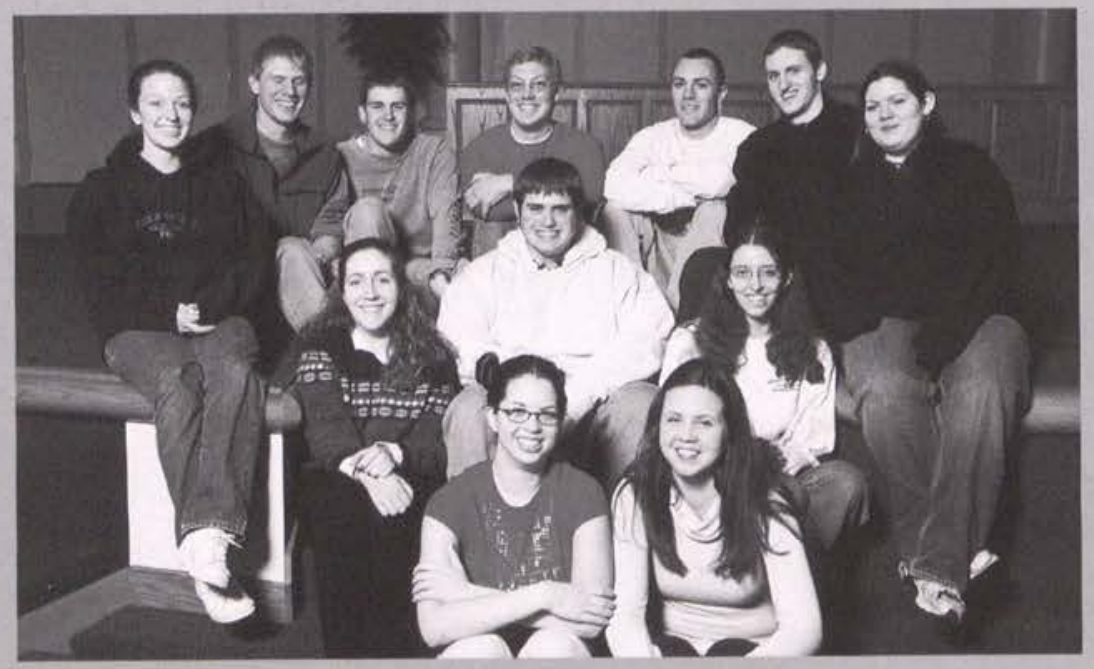

(first row left-to-right) Christi Babcock, Melanie Reber. (second row) Amber Hodkinson, Jason Holmes, Elizabeth Proemmel. (third row) Monica Lilley, Jesse Frederick, Tim Groff, Andrew W. Smith, Jeremy Doot, Joe Schneider, Becky Johnson. (first row left-to-right) Billy Petite. (second row) Kristi Beckett, Rebekah Huffman, Matthew McCloskey, Amy Estes, Motoi Ishikawa, Dana Hook. (not pictured) Charis Nims, Johnathan Hood, Shelley Hansen, Katherine Reed, Kikelomo Kolawole.

\section{INTERNATIONAL FRIENDSHIPS}

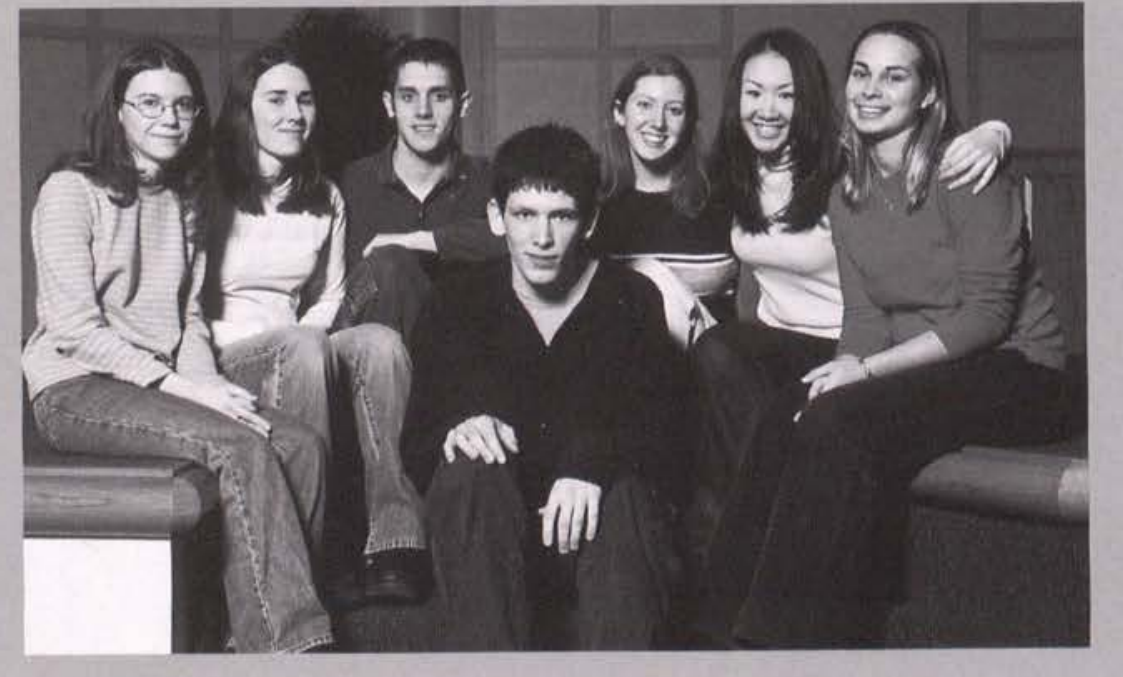




\section{InTERnATIONAL ORdER OF OdD FELLOWS}

(first row left-to-right) Megan Hause, Jyoti

Philip, Dan Spanagel. (second row) Tim

Schierloh, Ryan Sharp, Chris Freeman, Chris

Antigas, Jessi vonder Mehden, Daren Norris, Jessica Mao.

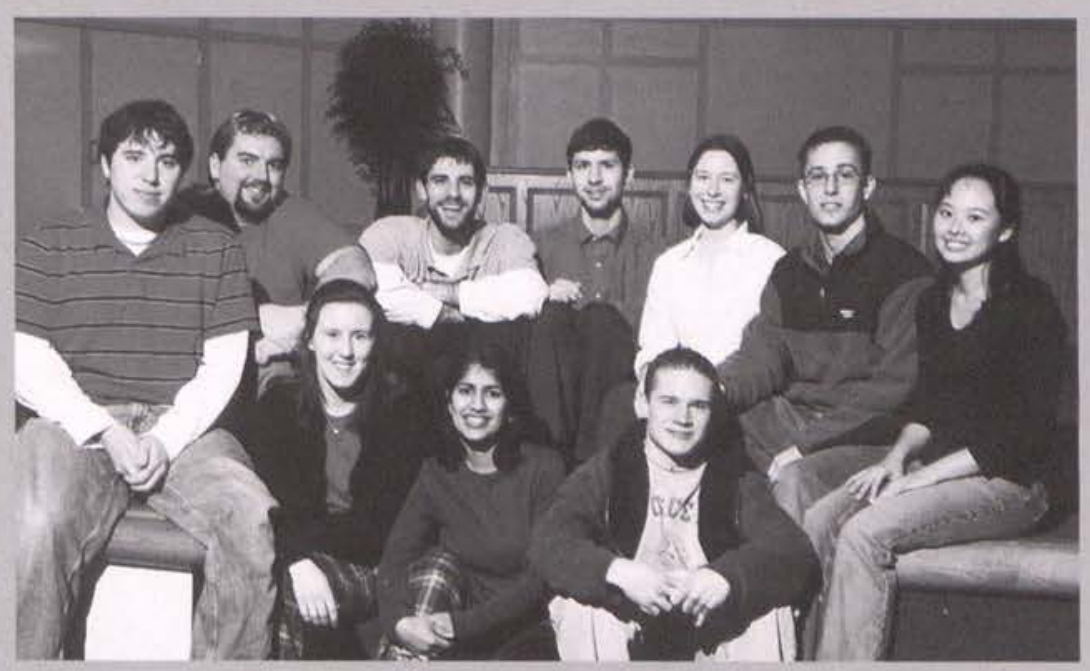

\section{Liberty Nursing Center I}

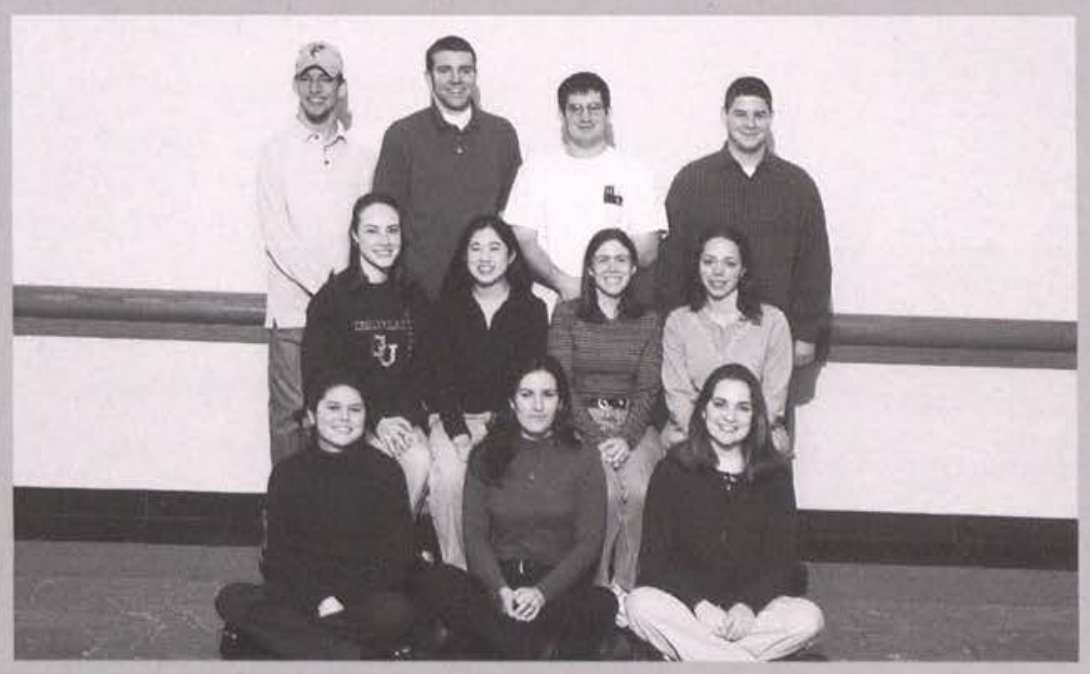

(first row left-to-right) Kristin Ohman, Julie

Taylor, Angela Rudd. (second row) Allison

Siddall, Mandy Chandler, Lauren Stewart,

Abigail Sanborn. (third row) Matt Gibble, Chris

Stokes, Chris Calo, David Hancock.

\section{Liberty Nursing OF JAMESTOWN}

(first row left-to-right) Eric Kramer, Markis

Taylor. (second row) Charli Brown, Abby Iden,

Becky Stewart, Andy Hayes.

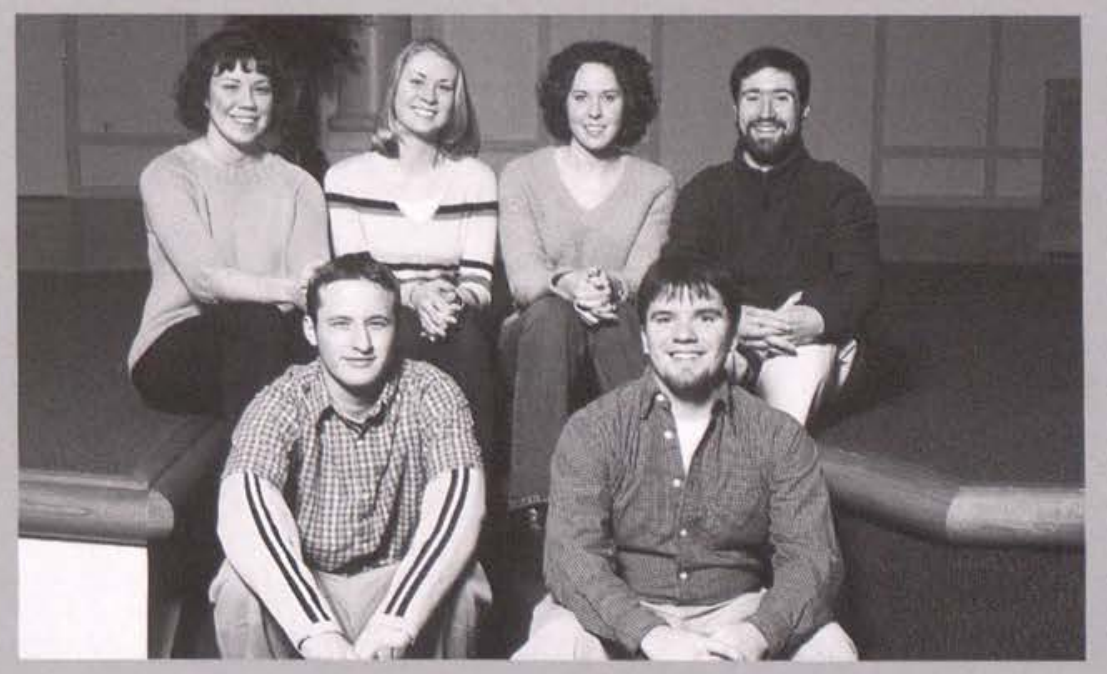


(first row left-to-right) Sarah Weist, Bethany

Butters, Sigrid Myers. (second row) Julie

Thompson, Amber Hodkinson, Lisa Alligood.

\section{Mercy Medical Center}

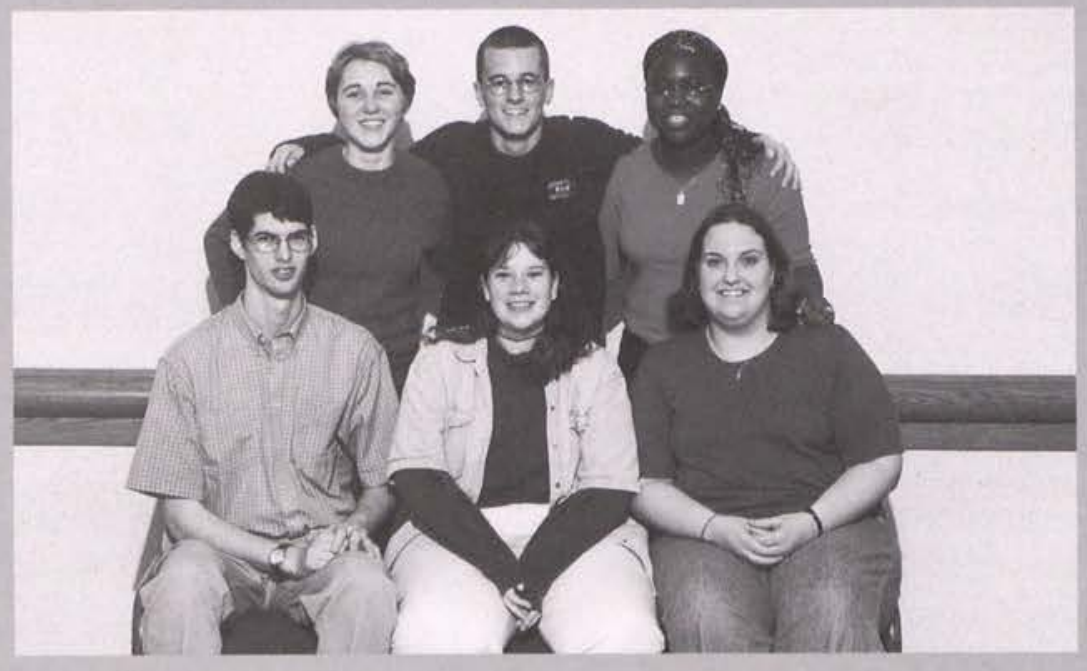

\section{Miami Valley Women's Center}

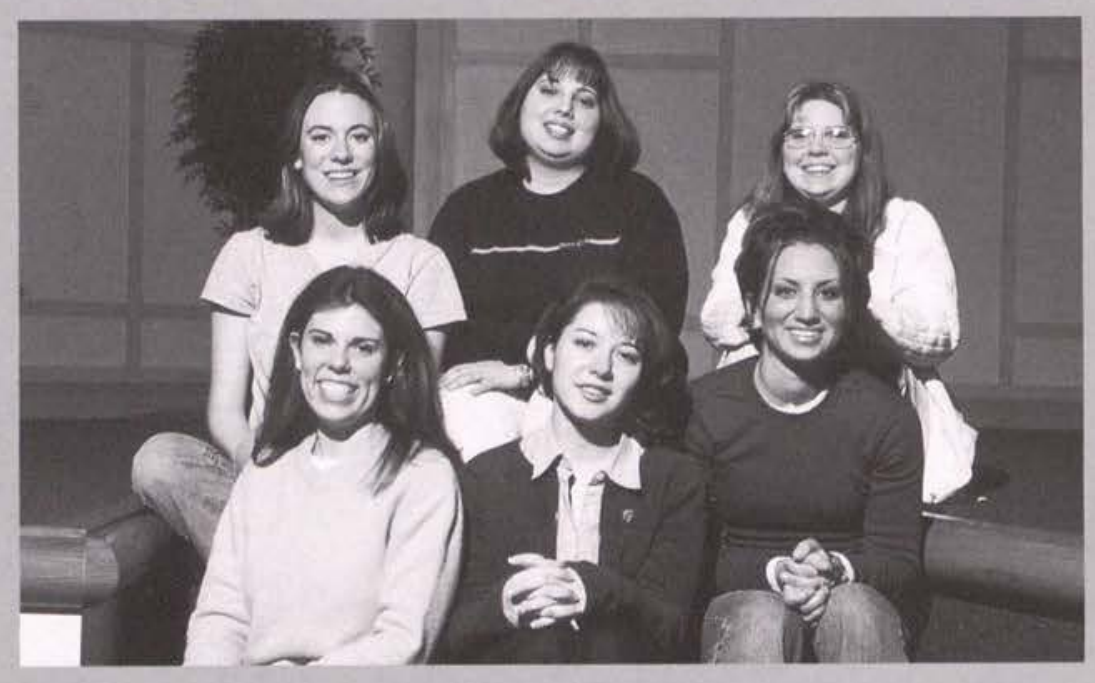

(first row left-to-right) Natalie Newfield,

Christianna Ransom, Casey Claypool. (second row) Elizabeth Byers, Jen Castellani, Andrea Gensel.

\section{Mueller Center}

(first row left-to-right) Jacquelyn Recktenwald,

Sam Naik, Aubrey Furlong. (second row) Angela

Courtade, Anna May, Kirsten Larson. (third row) JD O'Neal, Sharon Hershey. (not pictured)

Melissa Cassidy, Kristen Ross.

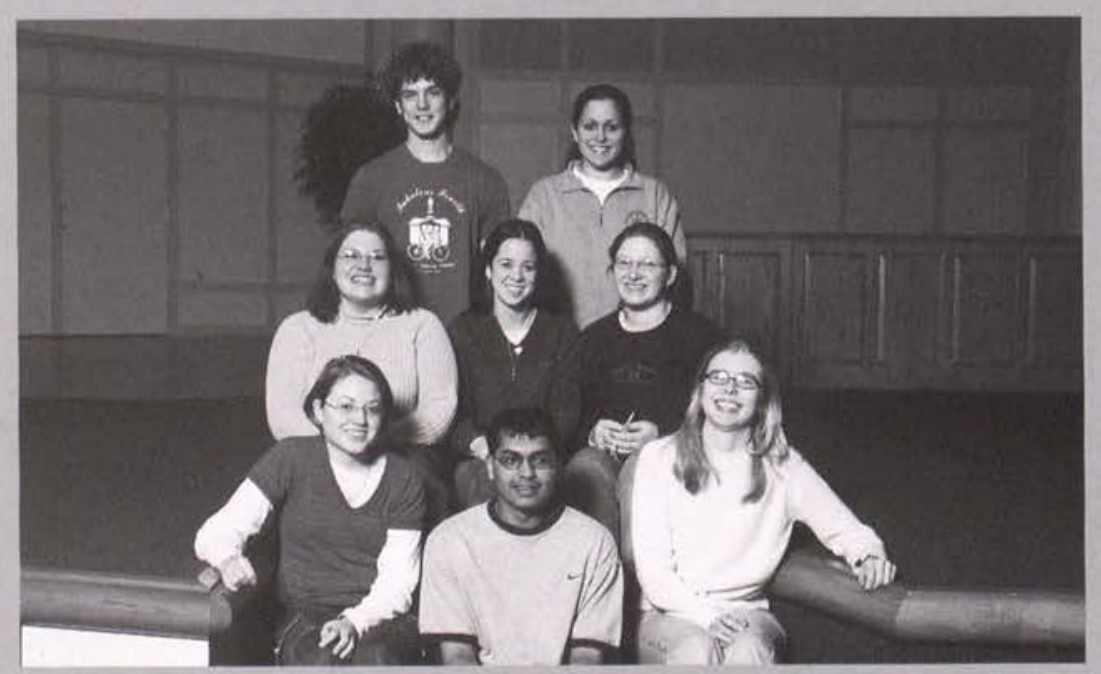


(first row left-to-right) Mark Kirby, Adam

Townsend. (second row) Ben Burnet, Nick

Grisco, Erin Taylor, Leslie Shamblin, Leah

Cooper, Andy Bolton, Melissa Stinson.

\section{Northside Baptist Awana}

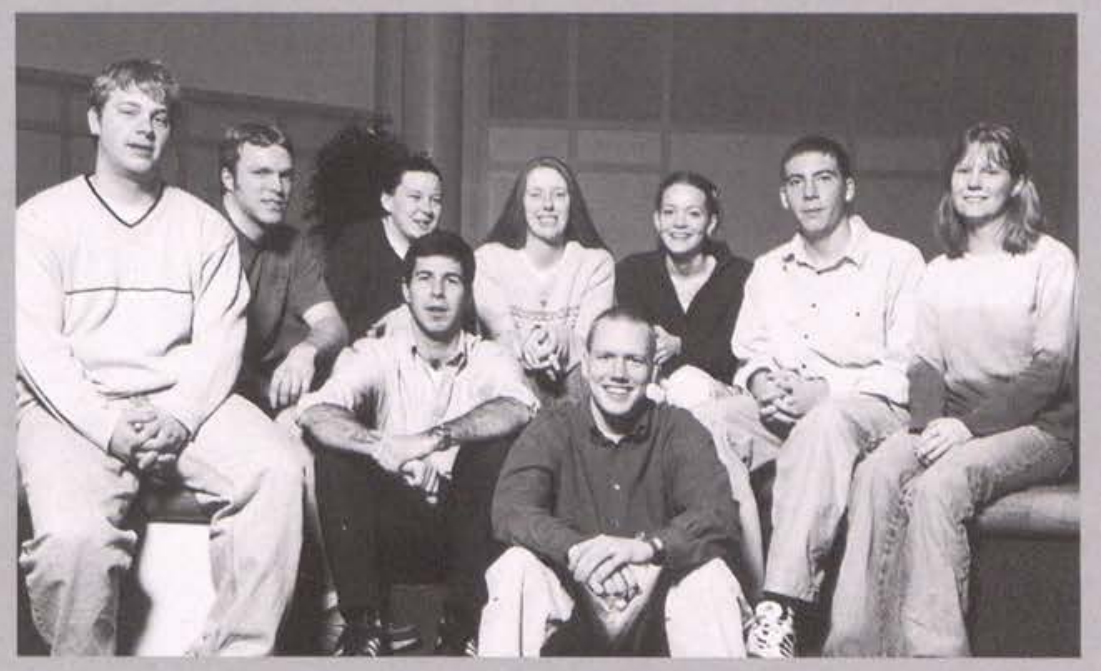

Northside Baptist Sunday SchoOl

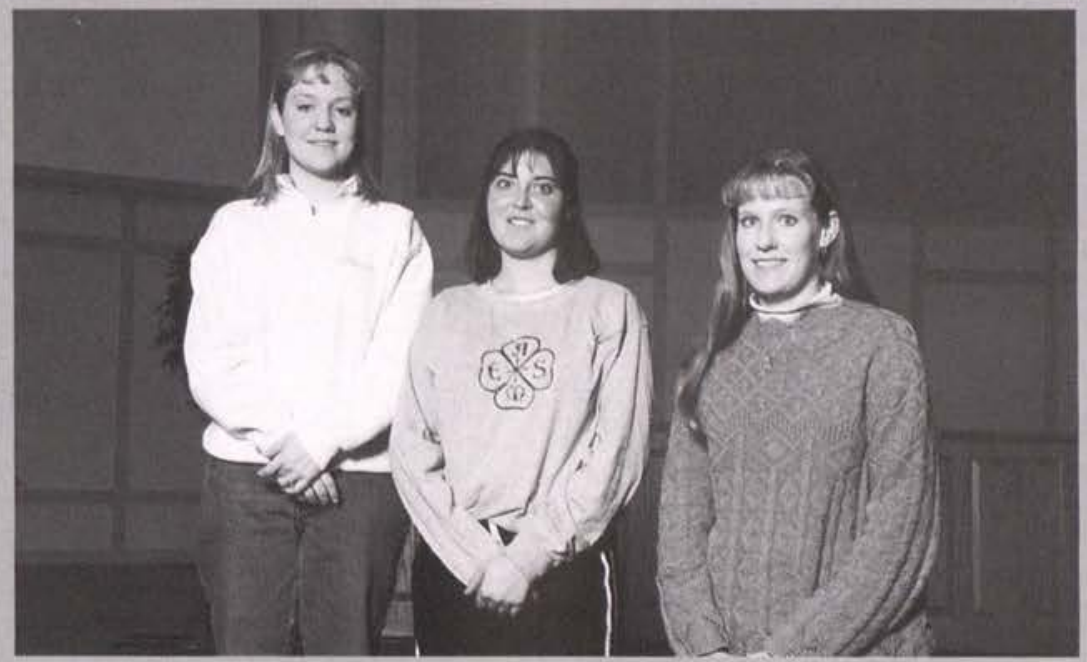

(first row left-to-right) Krista Steingass, Kristy

Mandigo, Kathy Steingass.

\section{Northside Baptist Jr. High}

(first row left-to-right) Sarah Rogers, Tim

Cochrell, Dana Schiavo. (second row) Carissa

Smith, Joan Endicott, Jeremy Hudson, Matt

Hofmann, Sarah Thengvall, Jeff Westlake. (not

pictured) Mike Call, Jason Siemer, Mike

Goodwin.

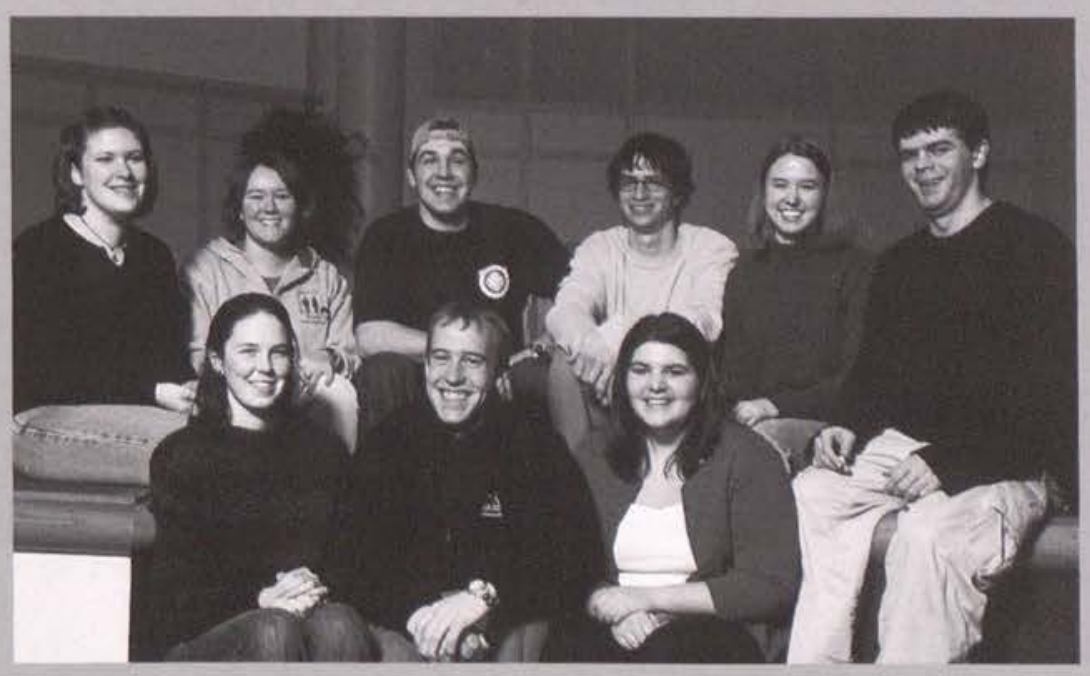


(first row left-to-right) Courtney O'Connell, Rachel Marely, Veronica Lawton, Angie Guntry, Michelle Parrish, Rebecca Schmidt, Rubie Maybury, Joelle Marquardt, Melissa Wagner, Christine Newhard, Laura Volpe. (second row) Sherri Cha, Julie Ackerman, Charity Crosley, Sara Grosskopf, Liz Tucker, Amy Kennard, Karen Dimatteo, Emily Wiedemann, Jennifer Wooldridge, Kristina Seace, Elizabeth Earnhardt. (third row) Rachel Moyer, Andrew Tatham, Jesse Magnuson, Kellen Blythe, Aaron Dieringer, Clive Staples Lewis, Matthew Nelson, Brian Dennert, Stan Mistak, Brent Schumacher, John-Mark Sheppard, Lauren Crissman. (fourth row) Melissa Pinkerton, Angela Rosseau, Ryan Bondreau, John Murray, Mike Webster, Jeremy Williamson, Benjamin Valice, Yosef Hassan, Jack Curran, Adam Craig, Bonnie Hammond, Hannah Livingston, Sarah Wiegand. (fifth row) Dan Roeber, Jordan Long, Greg Vruggink, Michael Lyons, Eli Werner, Evan Day, Jeff Mitchell, Andy Klein, Dan Sudlow. (not pictured) Amy Salmon.

\section{Open Heirs}

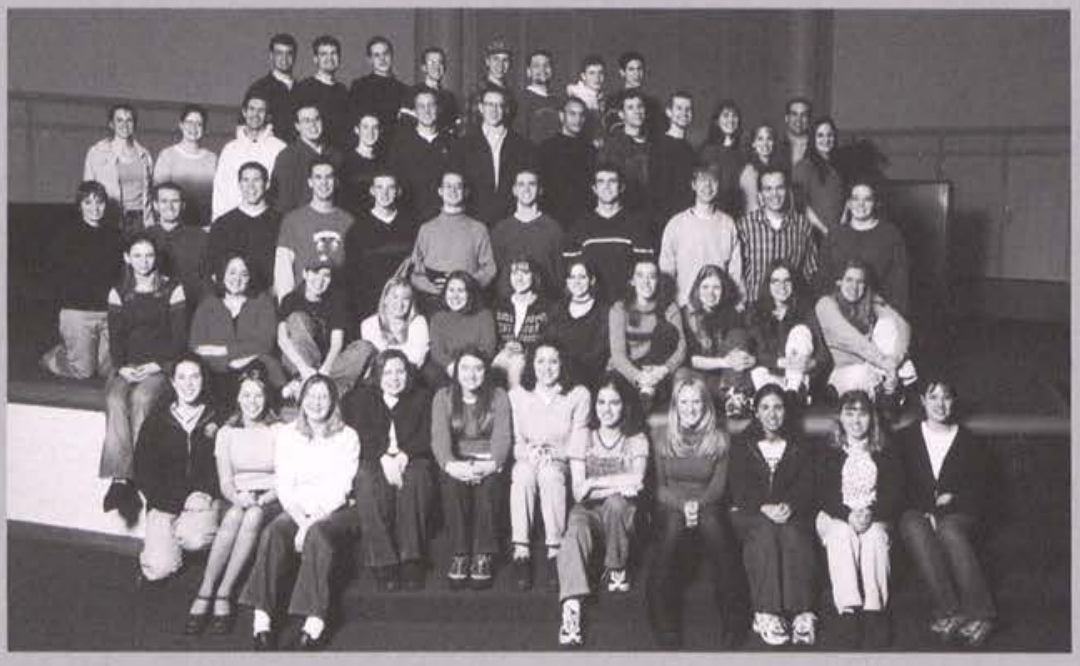

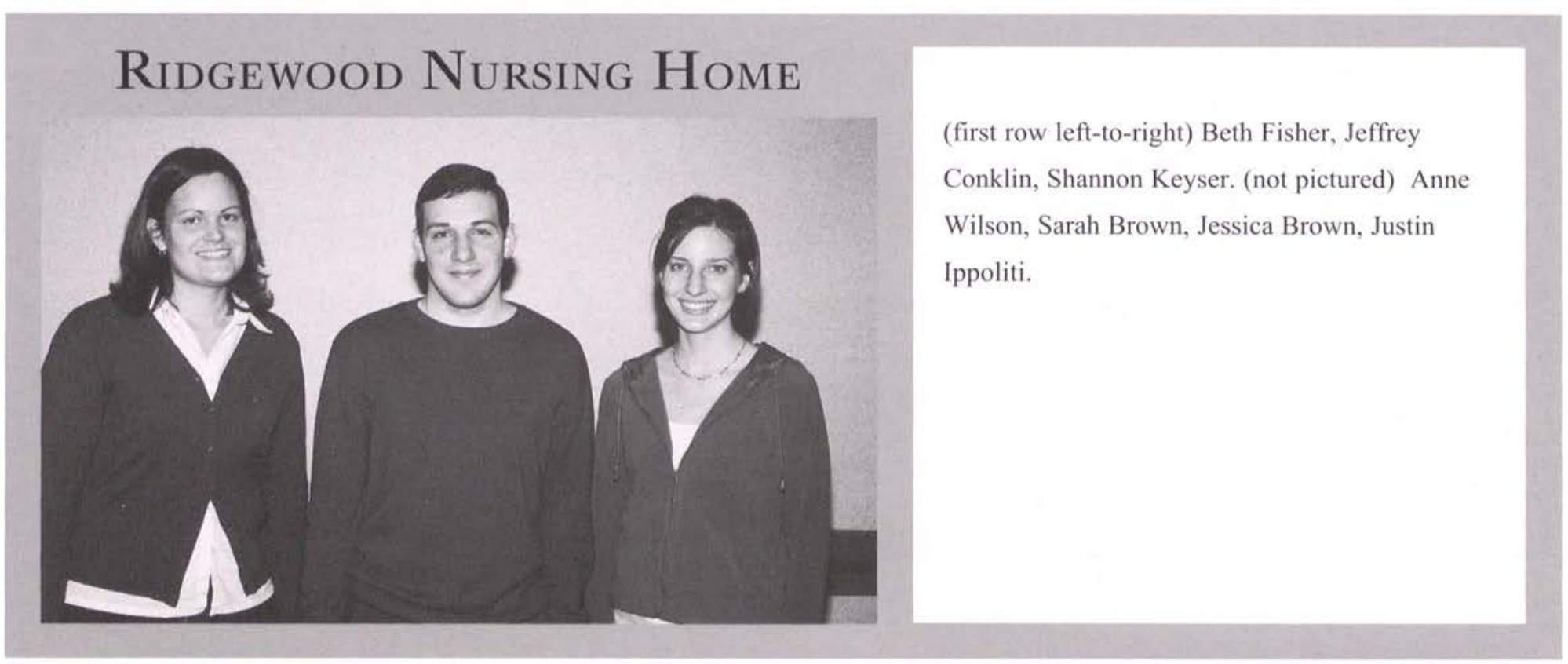

(first row left-to-right) Emily Baldwin, Bethany Bockmann. (second row) Elizabeth Tegge, Kristen Lapp, Ashli Nelson, Libby Reep. (third row) Sarah Sharp, Diana Harris, Celia Shortt, Anthony Gianettino.

\section{Ronald McDonald House}

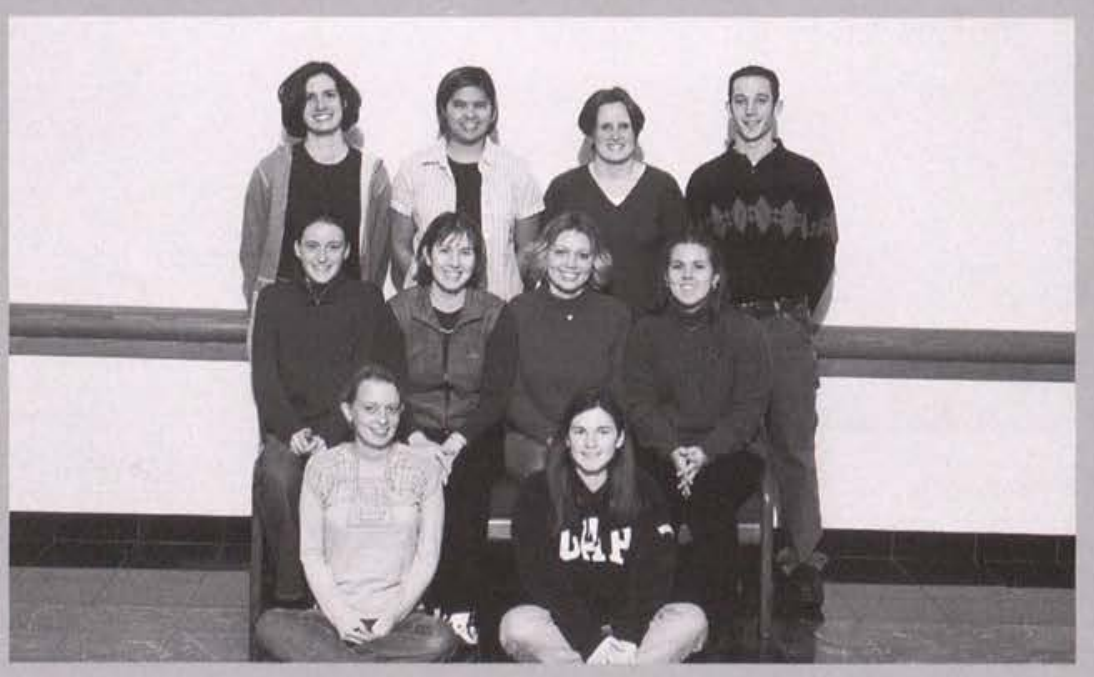


(first row left-to-right) Jessica Baratta, Melissa

Knaus, Lindsey Johnson. (second row) Leslie

Finn, Lisa Wendl, Amanda Flenar, Nicole Tracy,

Sarah McDivitt. (third row) Chancy Persons, Ben

Walsh, Andrew Williams, Melinda Chord.

\section{Shawnee Hills Baptist}

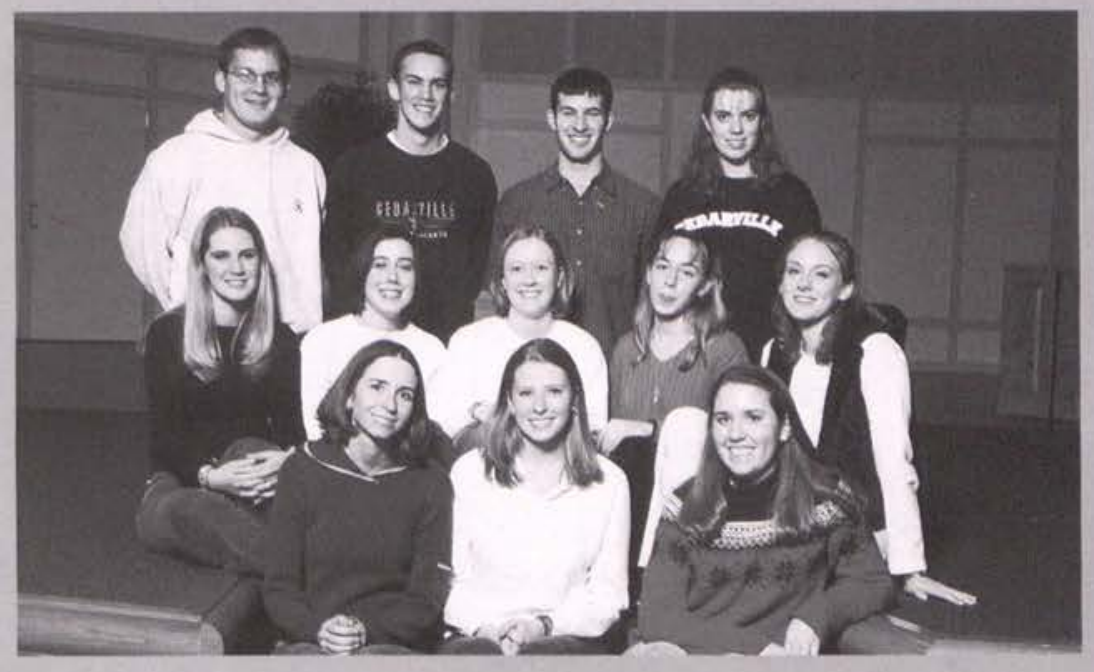

\section{Sonshine Bible Club}

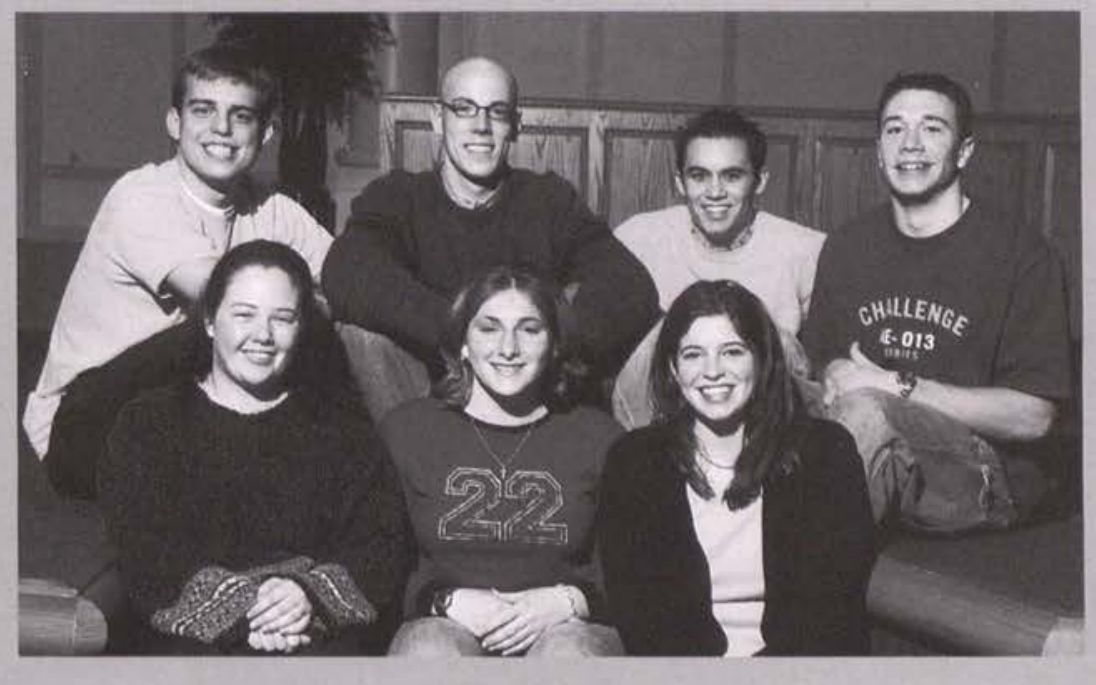

(first row left-to-right) Amanda Elliott, Katy Dellicarpini, Emily Gayer. (second row) Todd Pellowe, Jacob Abbs, Shawn Alexander, Brett Johnson.

\section{Southbrook Care Center}

(first row left-to-right) Josh Johnson, Benjamin Borich. (second row) Devon McCarty, Mandie Smithmier, Lisa Lauritzen. (third row) Kimberly Nikitin, Gillian Boucher, Kristen Claeys, Jonathan Hunsberger.

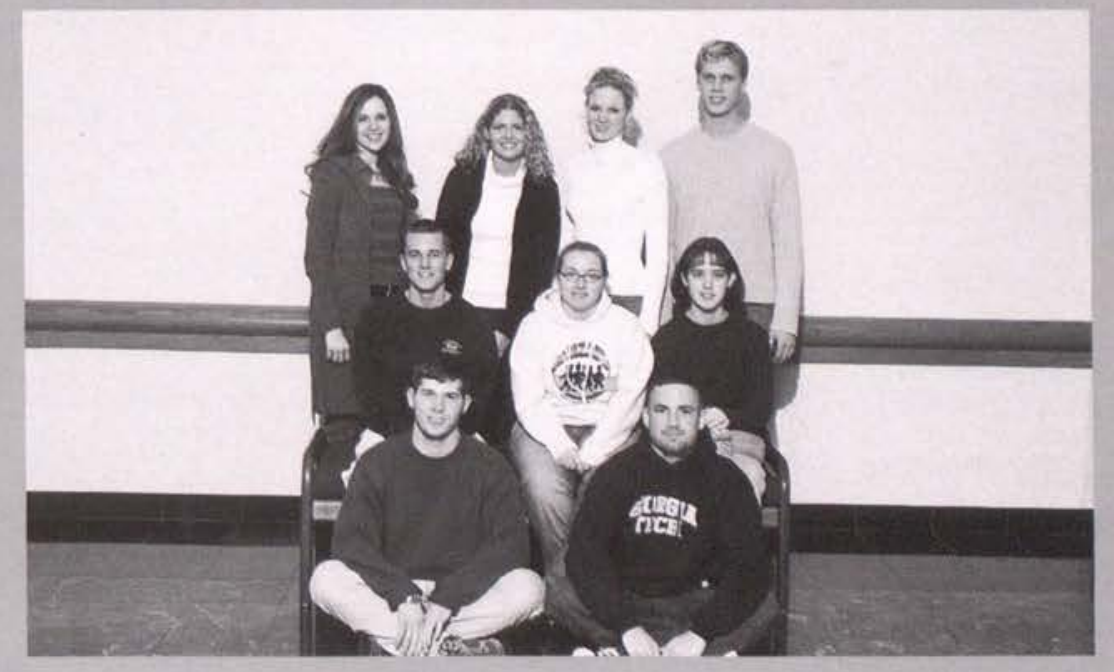


(first row left-to-right) Erica Taldo, Heidi Neuhart, Rachael Mohler, Jessica Kaiser. (second row) Mike Forrer, Christine Fairchild, Jodi Strychalski, Joelle Marquardt, Amy Cullip, Joanna Estes, Jonathan Mohr, Jaime Hawkins, Drew Carroll, Mark Erikson, Chris Macklin. (not pictured) Dave Terrill, Matt Ozinga, Kelsie Steiner, Brian Schildroth, Jenna Miller.

\section{Southgate Baptist}

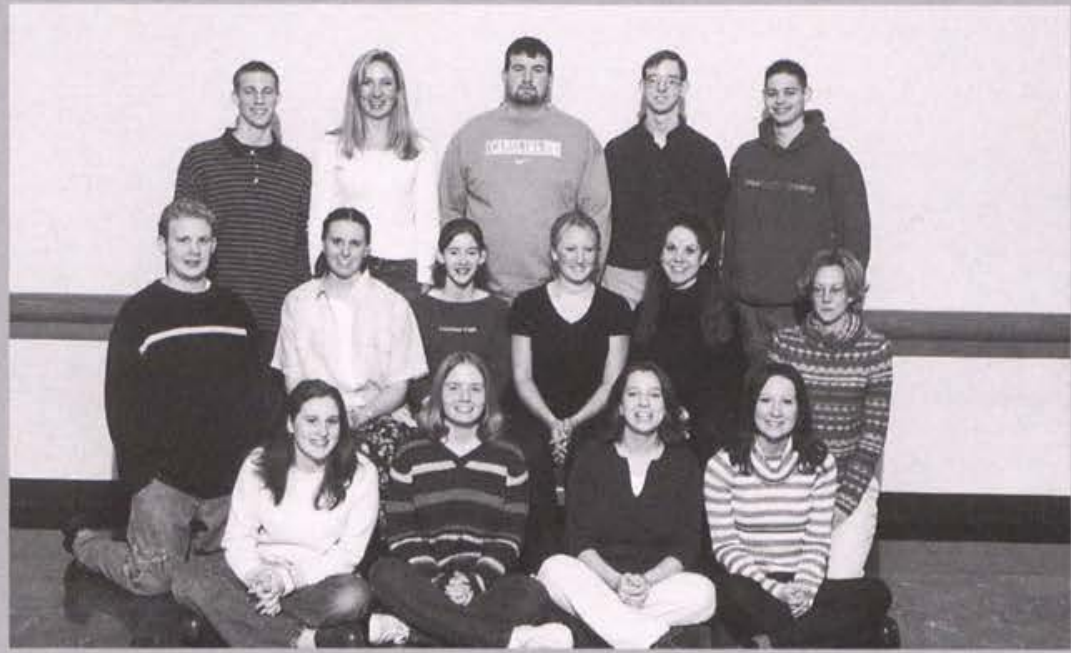

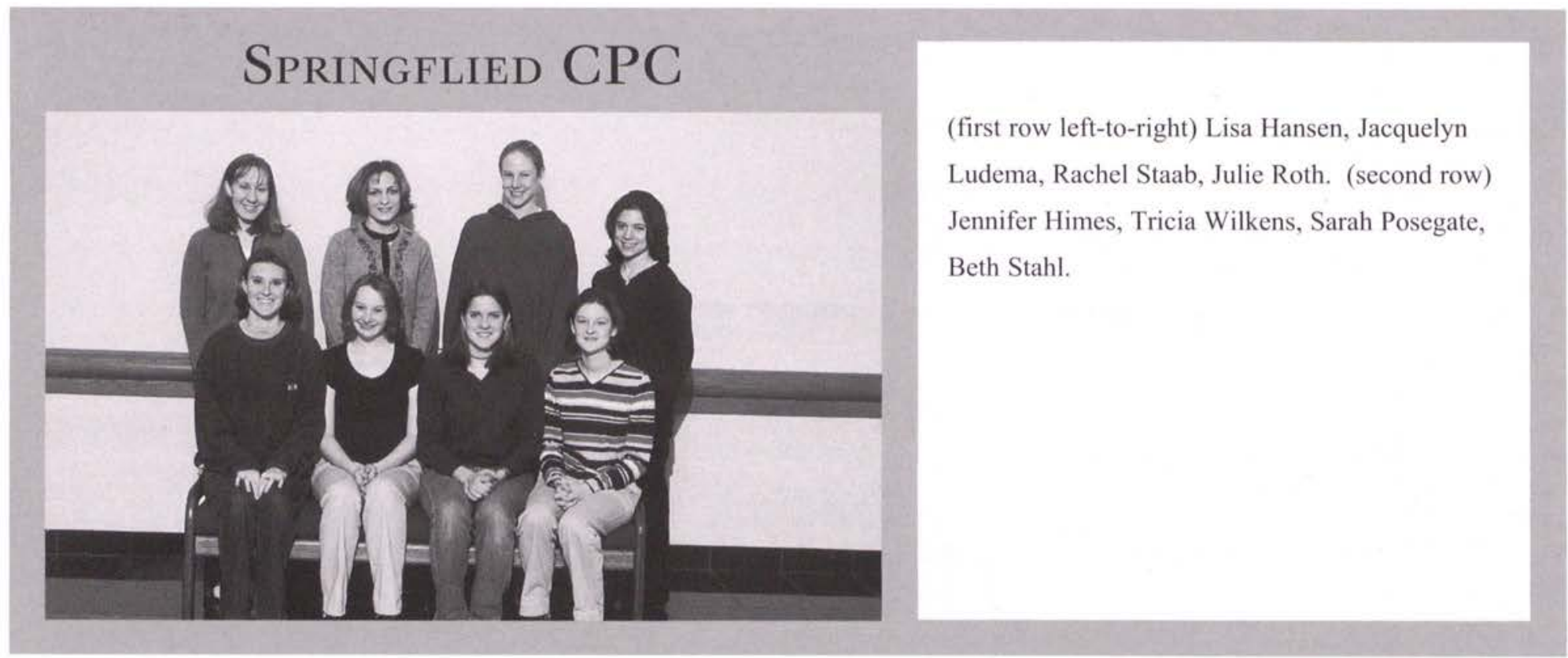

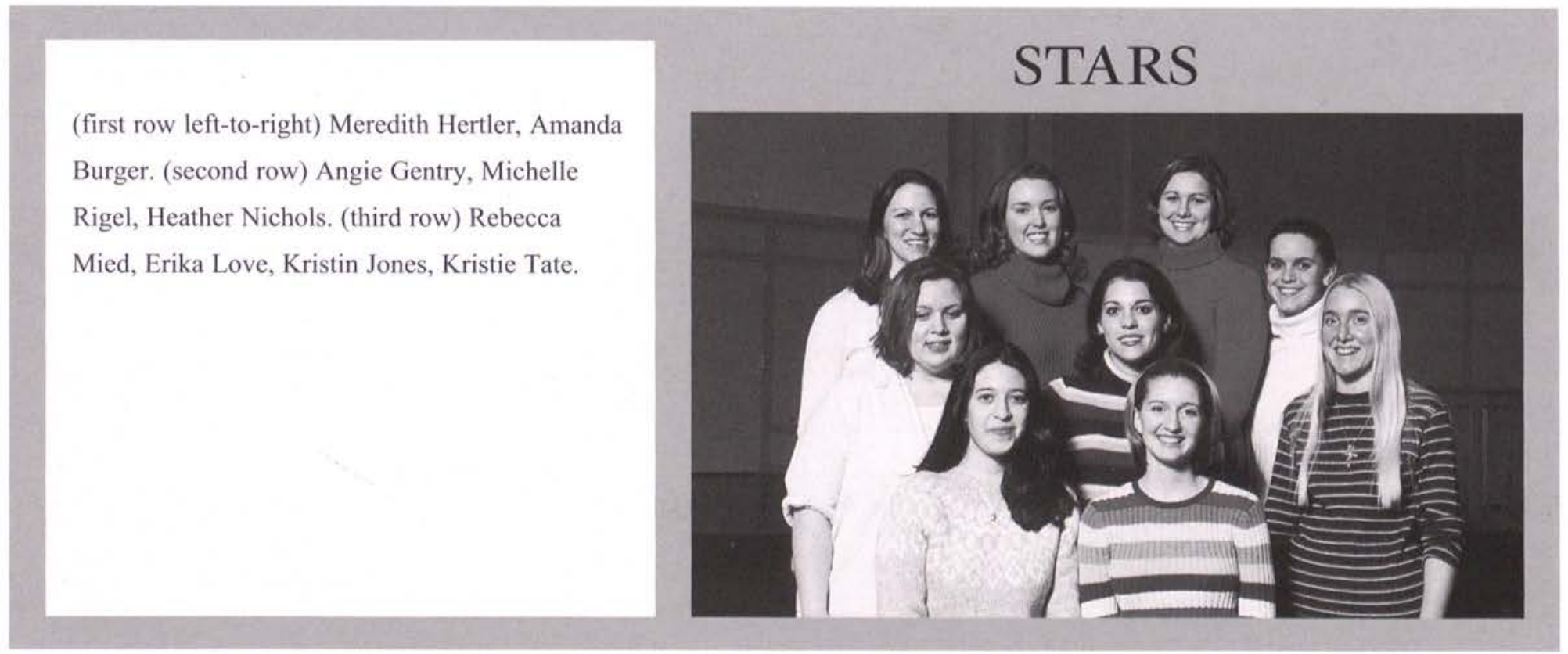




\section{Twin Valley Psychiatric System}

(first row left-to-right) Jim Stitzel, Heather Eger,

Aaron Vaughn. (second row) Kelly O'Connell,

Leslie Scadding, Lindsay Burman.

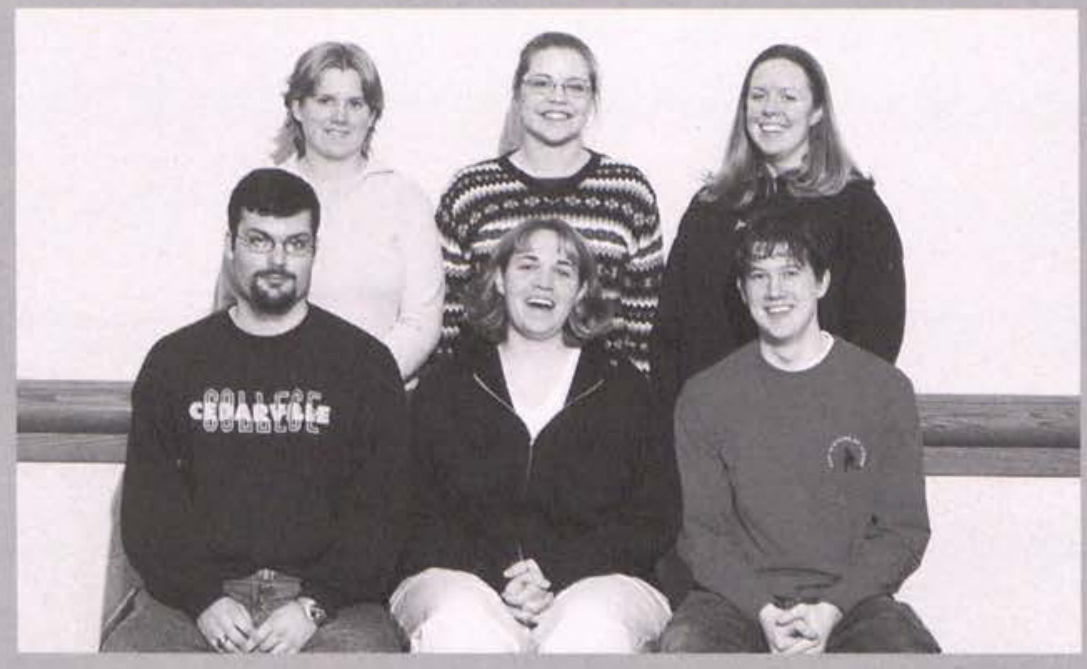

\section{UNION BAPtist Church}

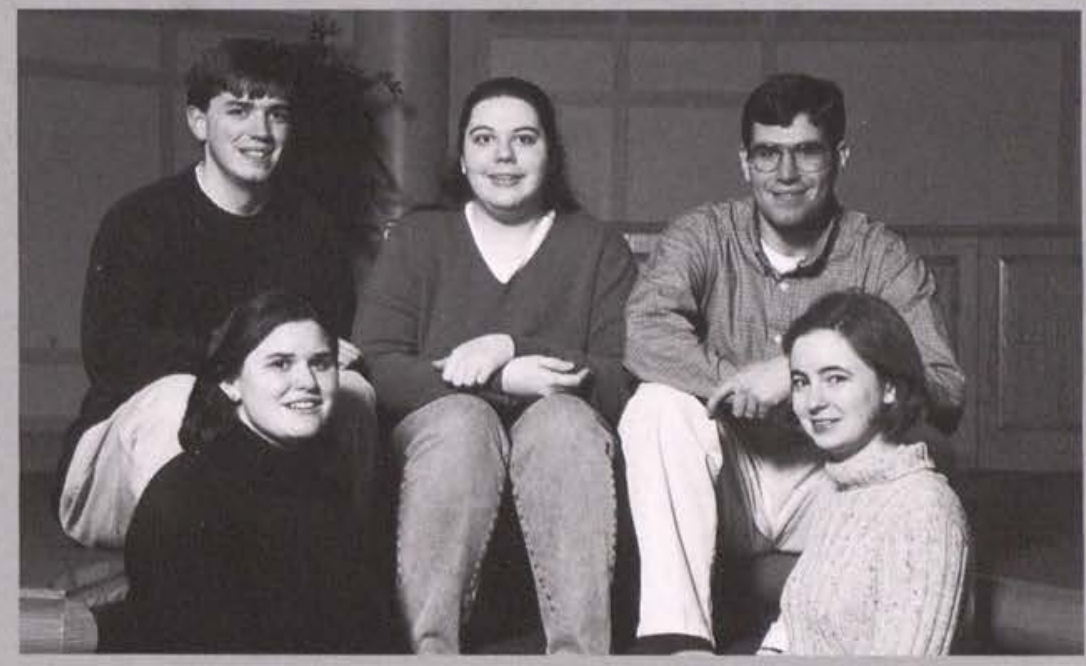

(first row left-to-right) Heather Worth, Alicia Marsh. (second row) Daniel T. Price, Jennifer Hensley, Jeremy Maller.

\section{Yellow Springs Riding Center}

(first row left-to-right) Joel Lansford, Dana

Litchfield, Eric C. Nielsen. (second row)

Catherine Mills, Karis Bissett, LeeAnn Senseney. (not pictured) Sarah Posegate, Traci Weiss, Kara Syversen.

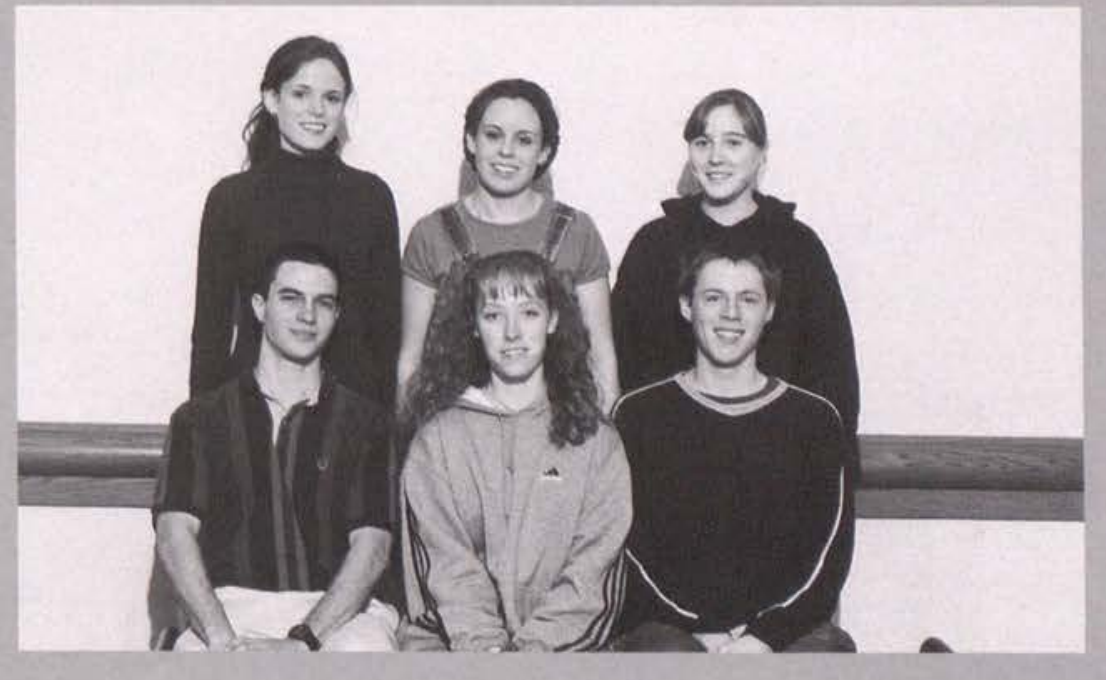



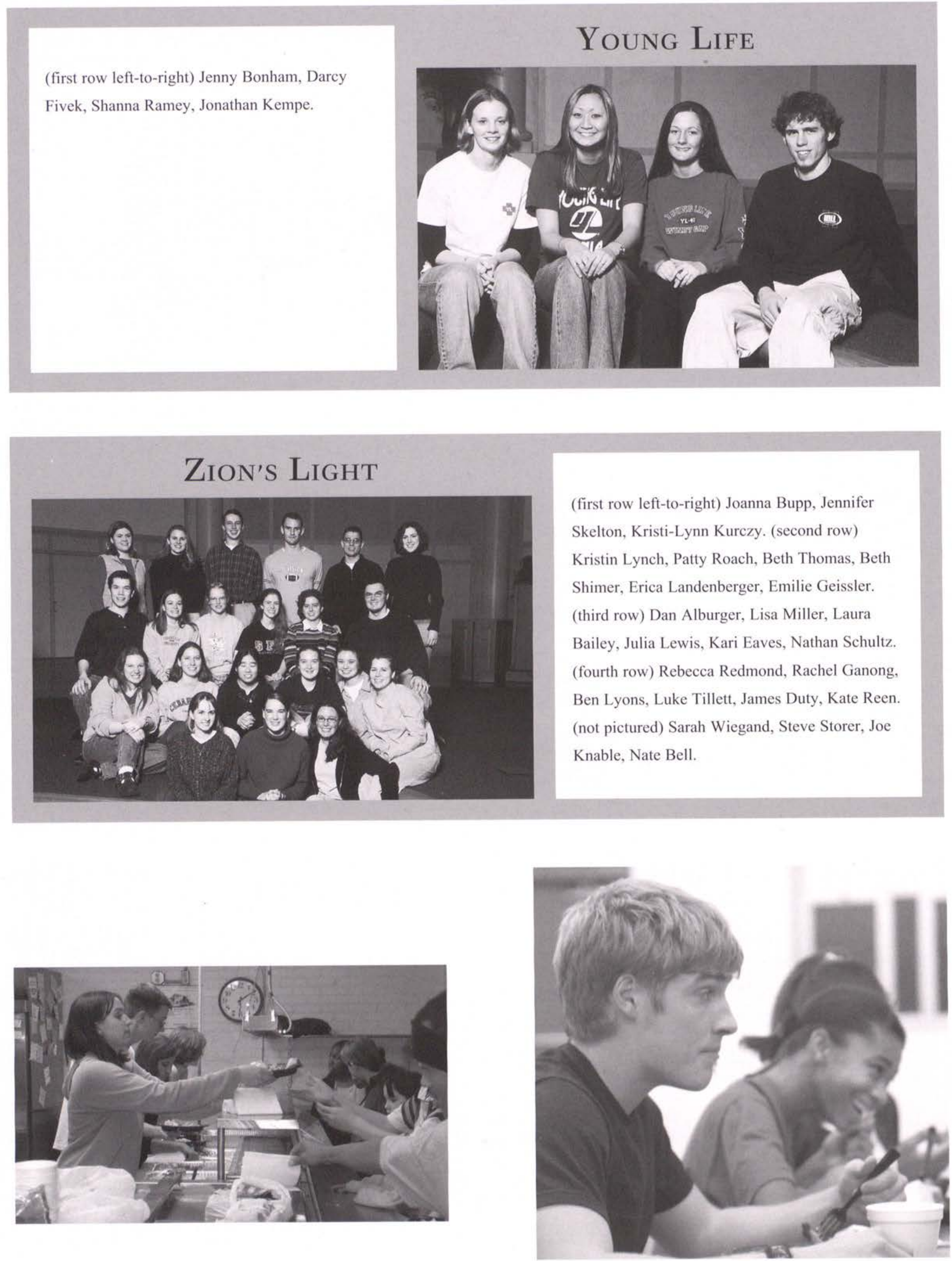

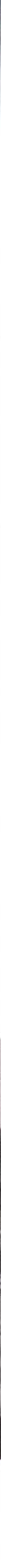

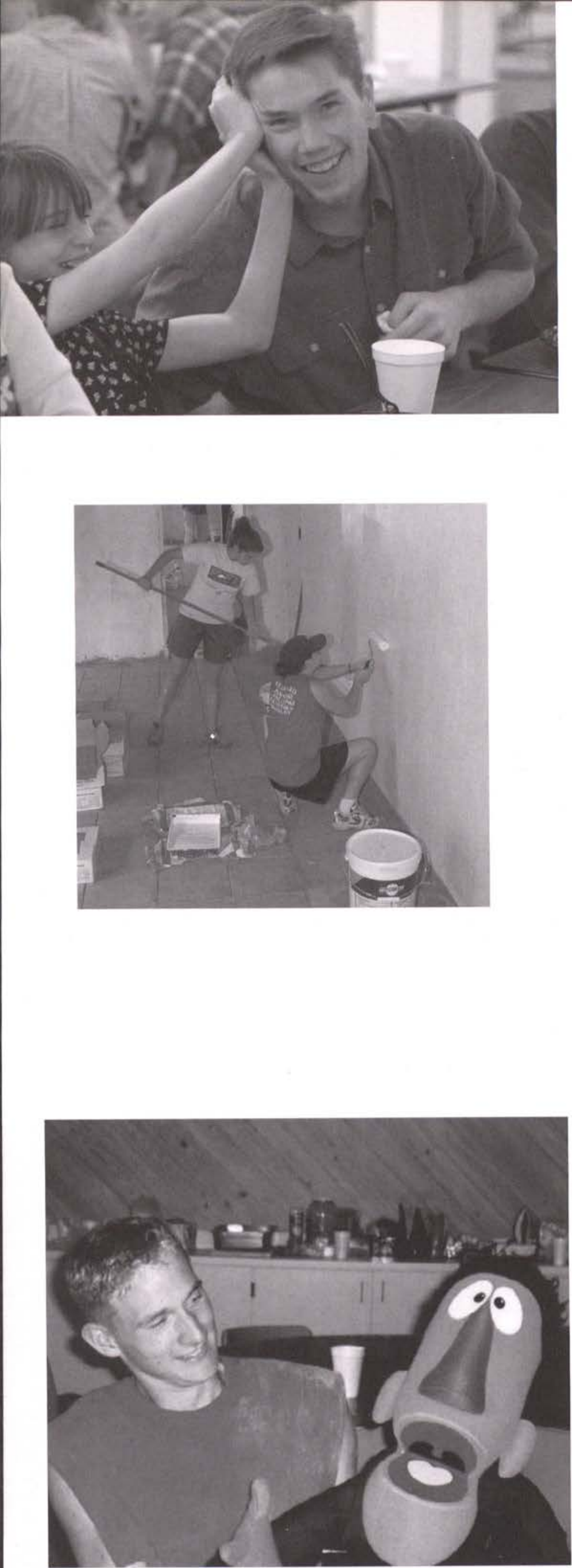
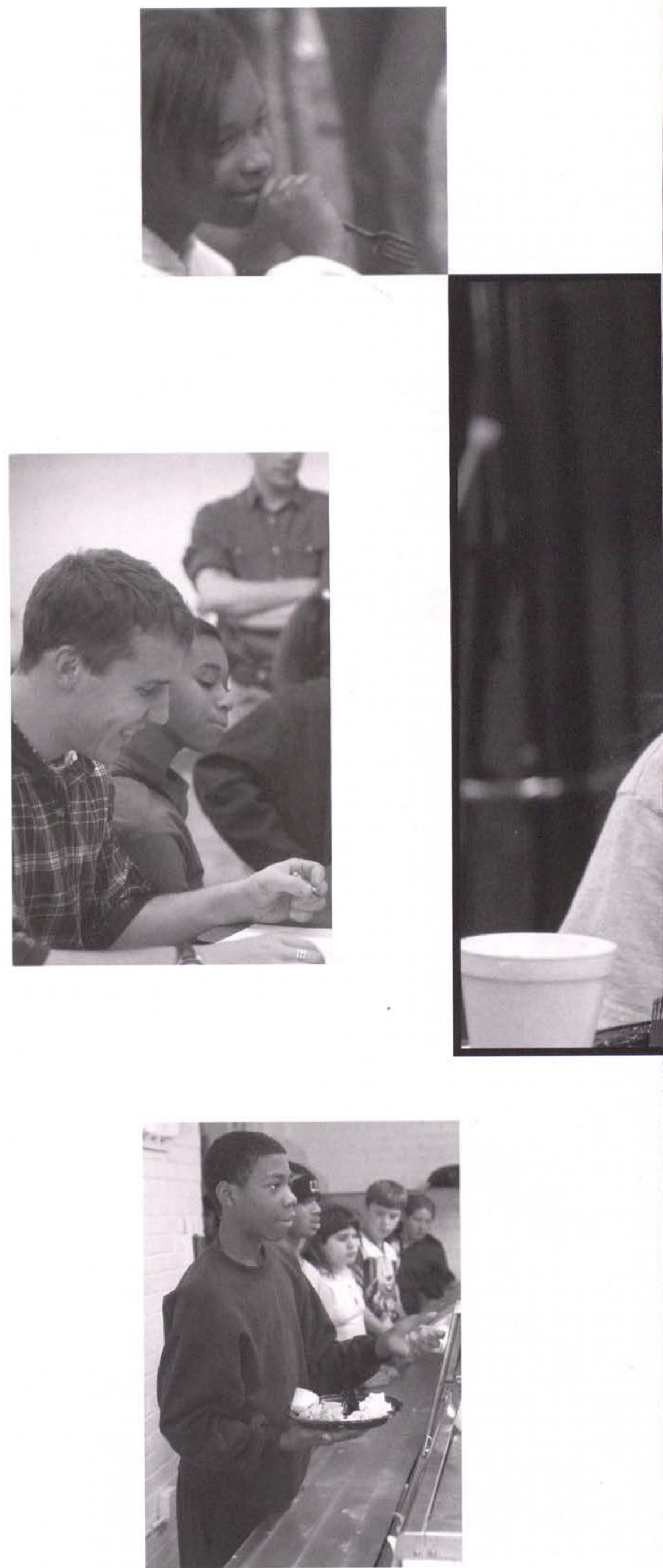


\section{tourine TEAMS}

\section{Abundant Life Singers 1}

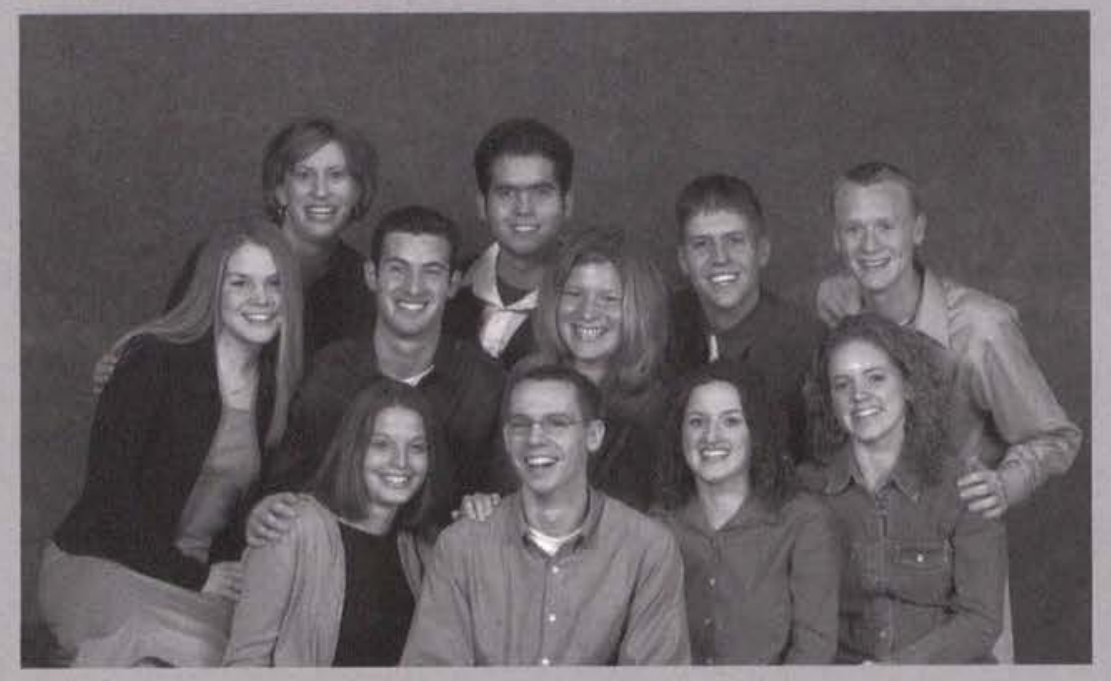

(first row left-to-right) Jodi Slagle, Jason

Bradshaw, Kara Davis, Janet Kishpaugh. (second row) Alisha Hunter, Andrew Williams, Laura Bowen. (third row) Heidi Sproul, Filip Quina, Wayne Altstaetter, Josh Canfield.

\section{Abundant Life Singers 2}

(first row left-to-right) LaRissa Bales, Joel Estes, Sara Yackey, Lindsey Johnson. (second row) April Lucas, Aaron Kreider, Bonnie Burrage, Zach Trimble. (third row) Tim Cary, Joel Tomkinson, Willy Shelton .

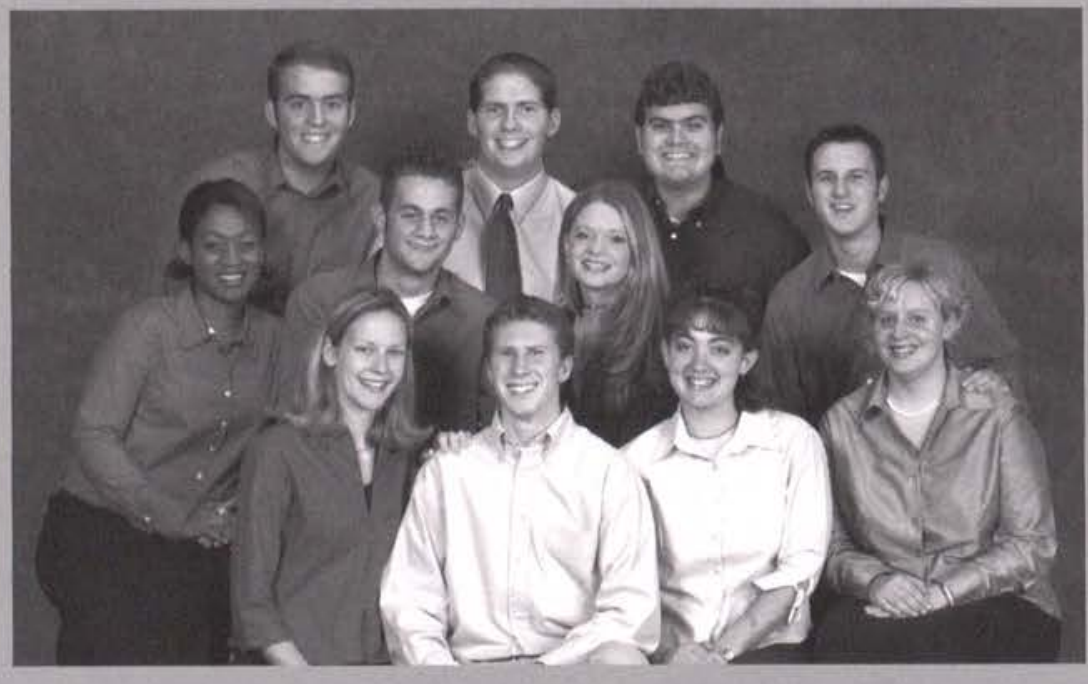


(first row left-to-right) Adam Dennis, Justin Tubbs, Nathan Shev. (second row) Phillip Winfield, Eric Marler, David Beres.

\section{Kingsmen QuARTET}

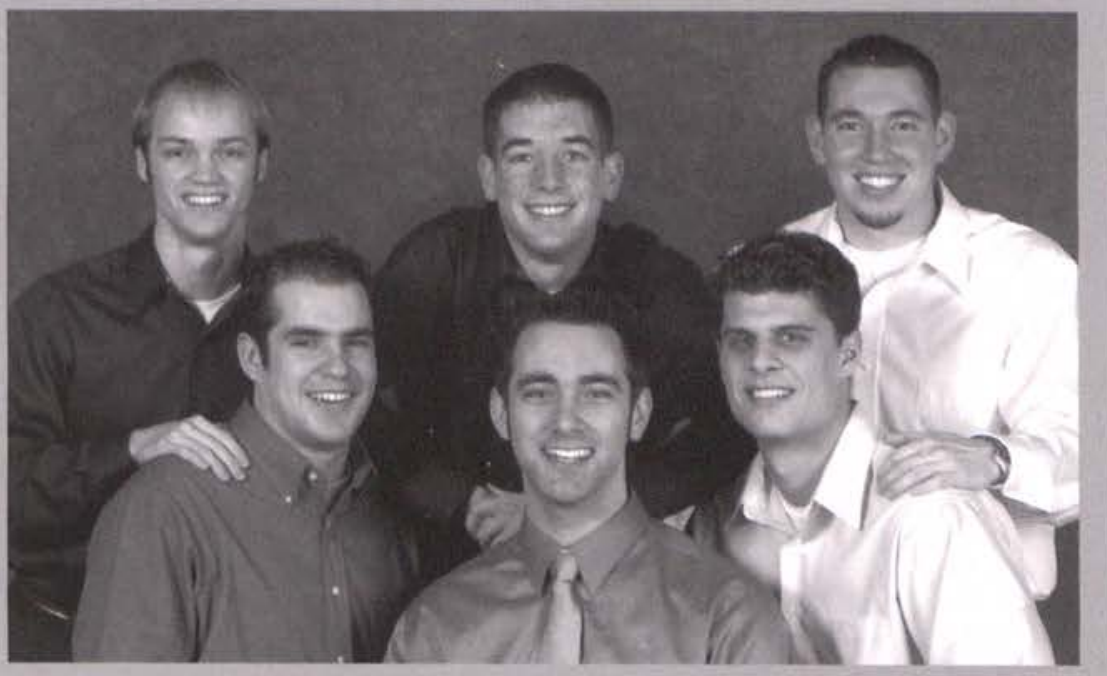

\section{Masters Puppets 1}

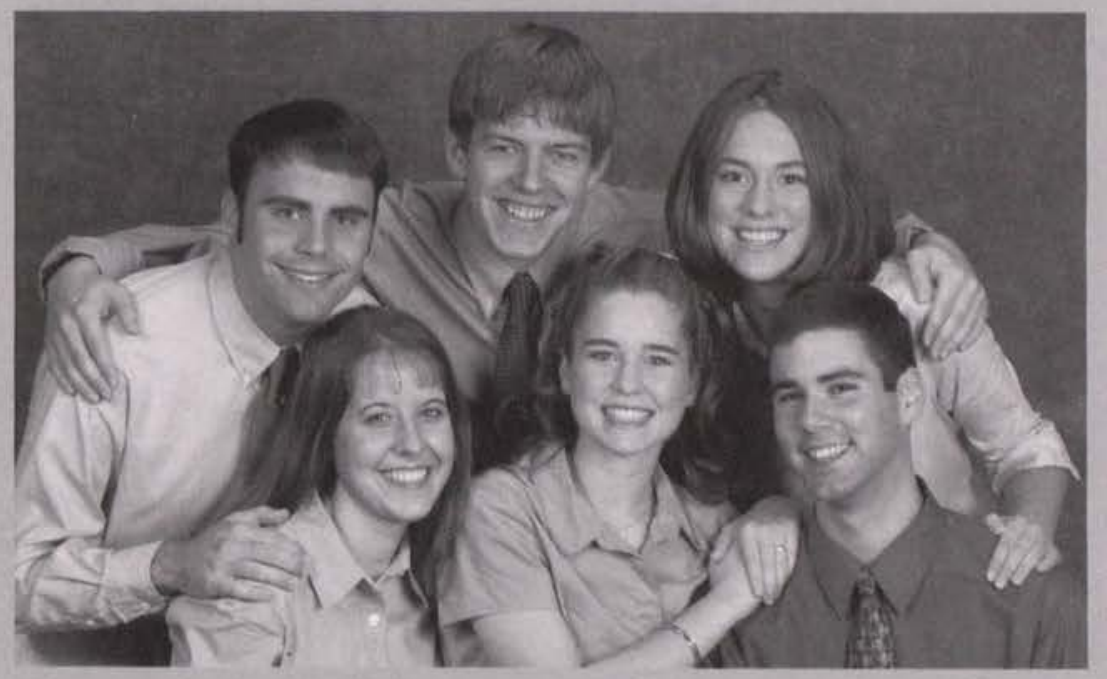

(first row left-to-right) Rebekah Read, Anna Farwell, David Mead. (second row) Nathan Boone, Brian Schildroth, Elizabeth Byers.

(first row left-to-right) Jennifer Steely, Holly Forsberg, Brian Antes. (second row) Nathan Gilbert, Chad Jackson, Erica Johnson.

\section{Masters Puppets 2}

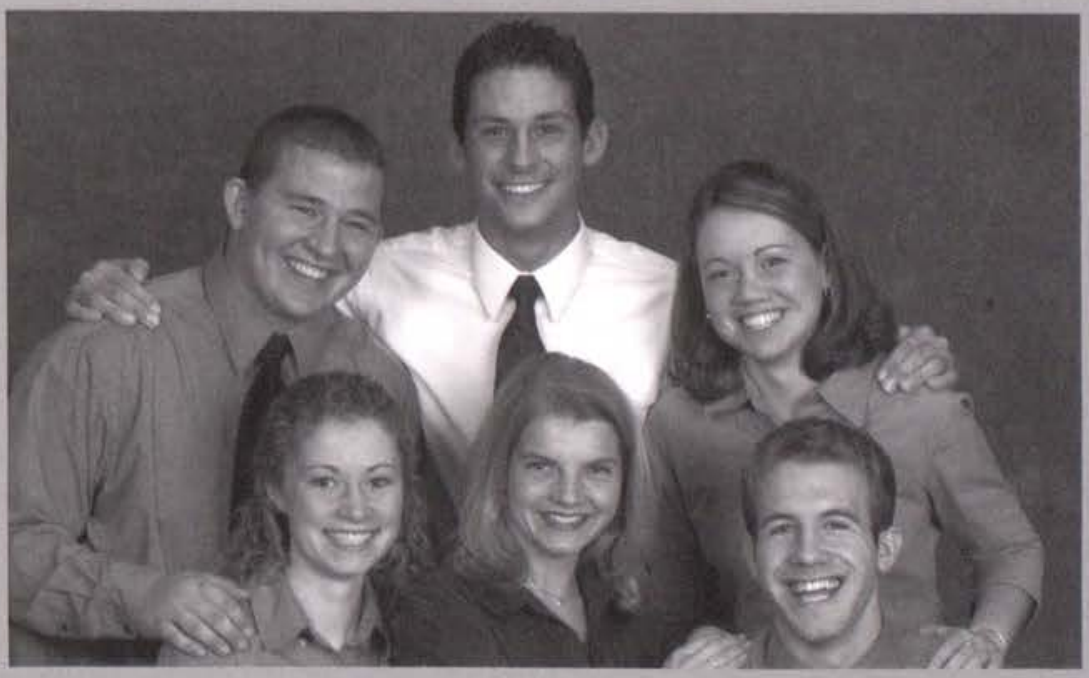



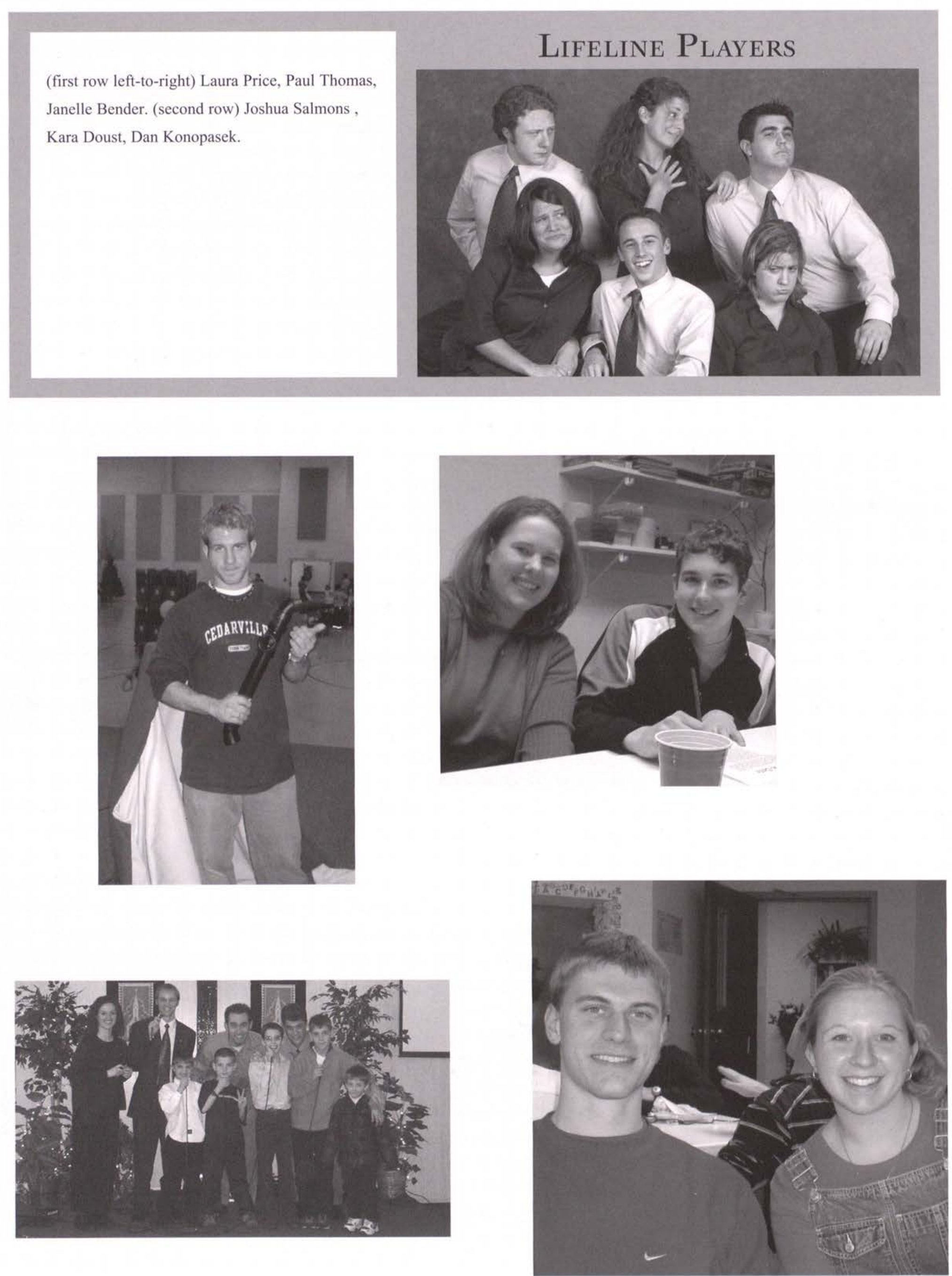

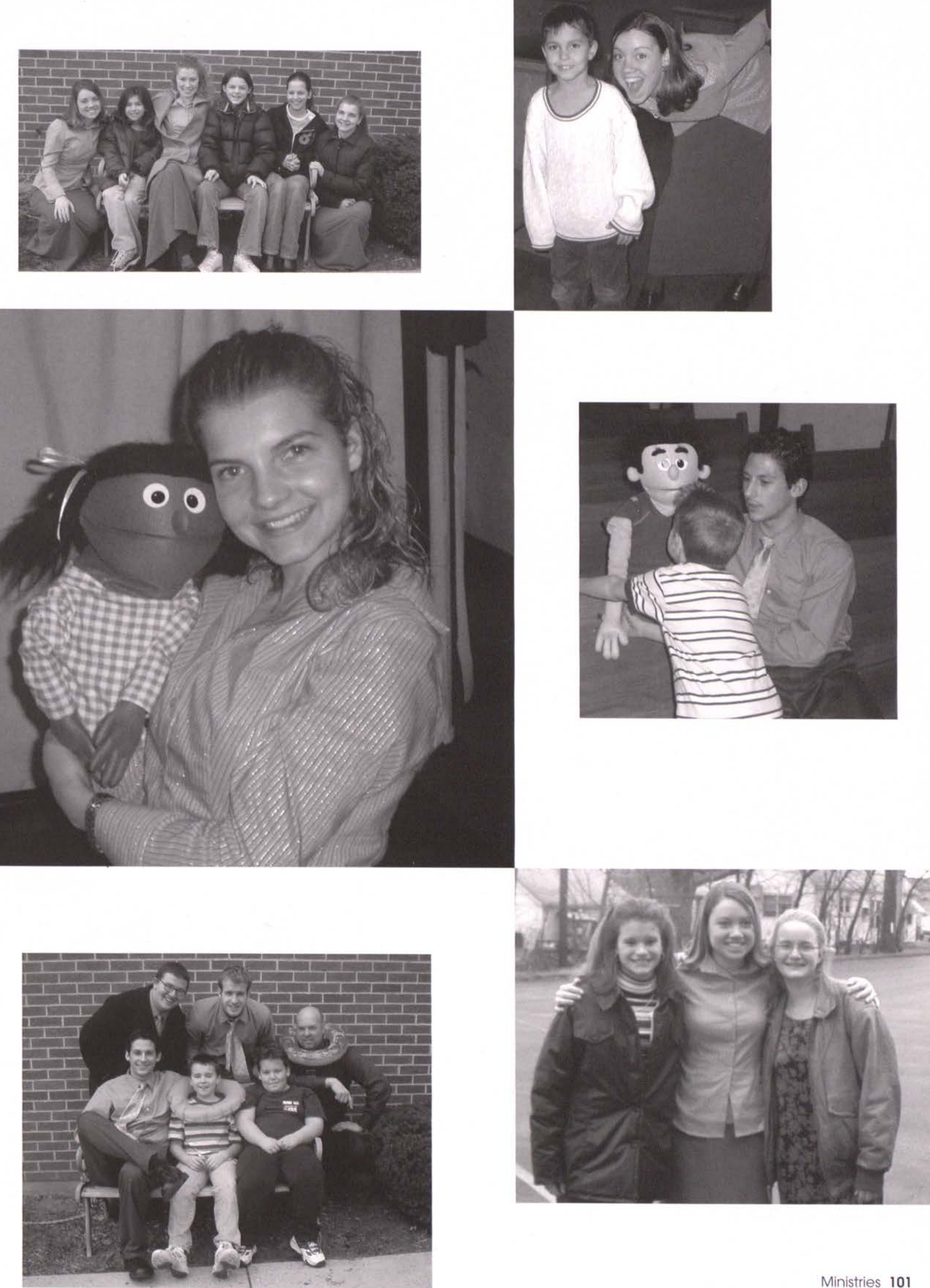


\section{se ser SP
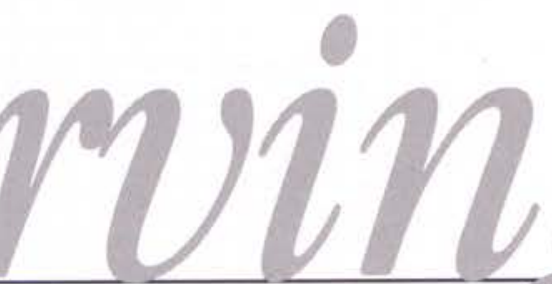

The University's Missions Involvement Services sent out scores of short-term missionaries from the student body this year. Students, burdened with a passion to be ambassadors for Christ, traveled during their Christmas, spring, and summer breaks all over the globe with the message of hope. They enlarged their vision of world evangelism by serving in just about every venue... from playing basketball in the Dominican Republic to ministering through nursing in Thailand.

Jonathan Plush led a construction team to Jamaica over spring break where they worked at the Caribbean Christian Center for the Deaf. He said, "The thing I appreciated most about the team was the unique differences in our personalities, and yet, we came together as a team because we all had one thing in common - Christ and a heart for doing His work."
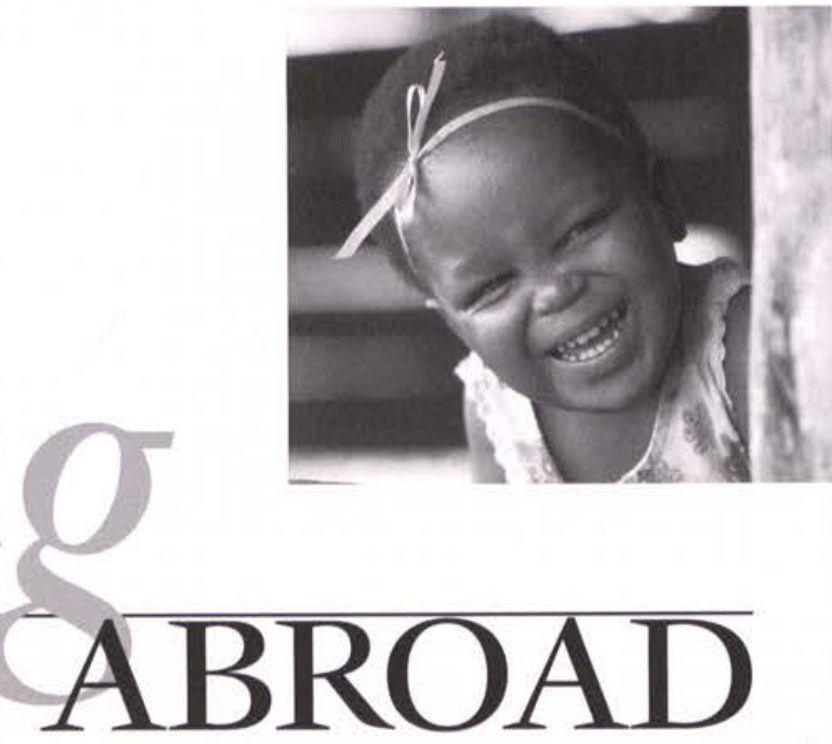

Jeff Beste led the spring break trip to Mexico. Their purpose was to provide camps for MKs. They had the opportunity of being at a church service and seeing a young teenager get baptized. "I appreciated the willingness everyone had to be so flexible, as well as the way each one took every opportunity possible to build into the lives of the campers," said Beste.

Peter Burban led a team to Utah for evangelism to Mormons. He said, "God opened doors to the lives of several Mormon people so that we could plant the seeds of His Gospel.”

Caleb Halulko, who led a young man to Christ during his MIS trip, said, "It is so awesome to see God work and be able to witness it." And when asked if he would want to return next year to minister with MIS, he replied, "Of course. In a heartbeat."
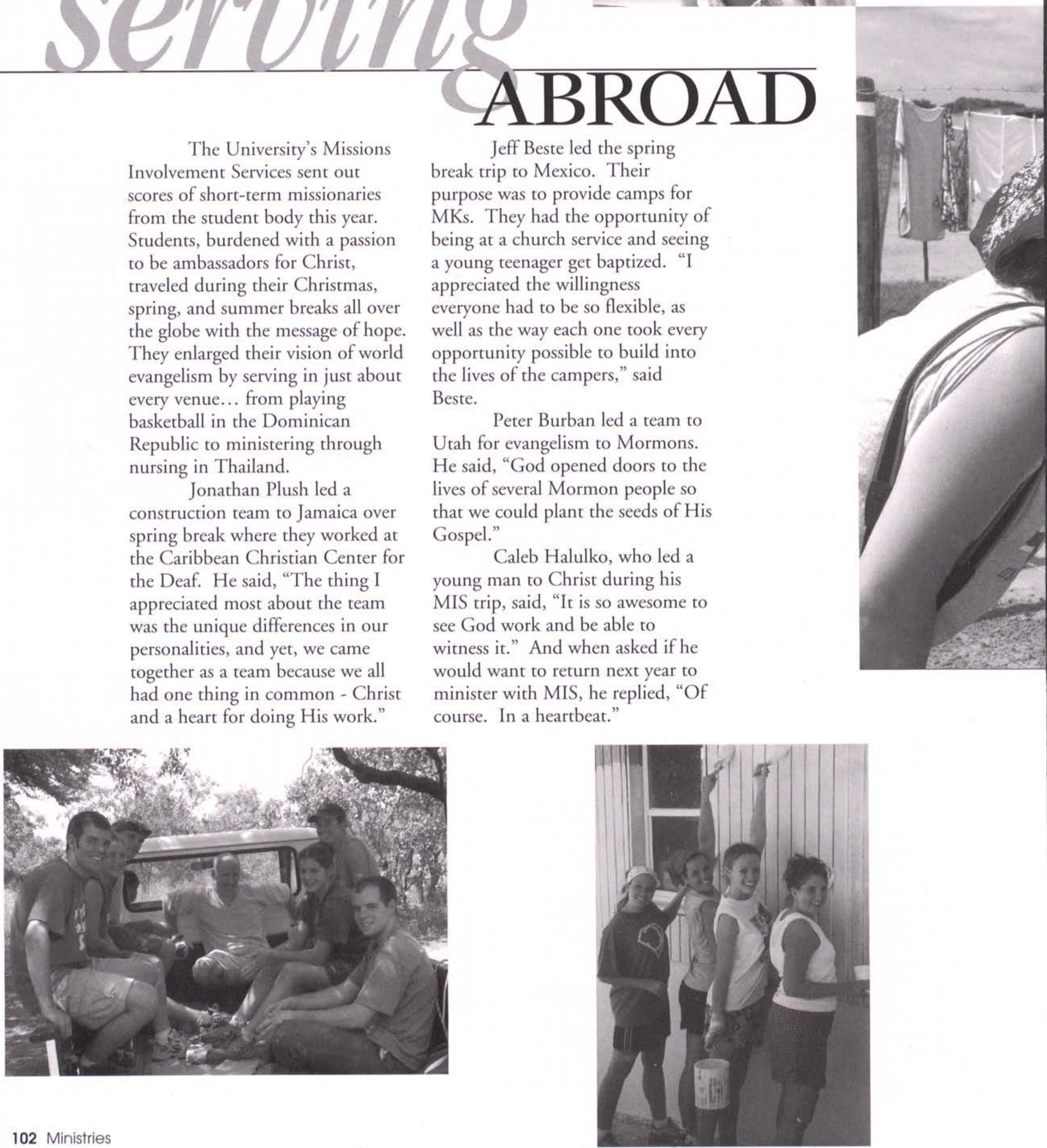

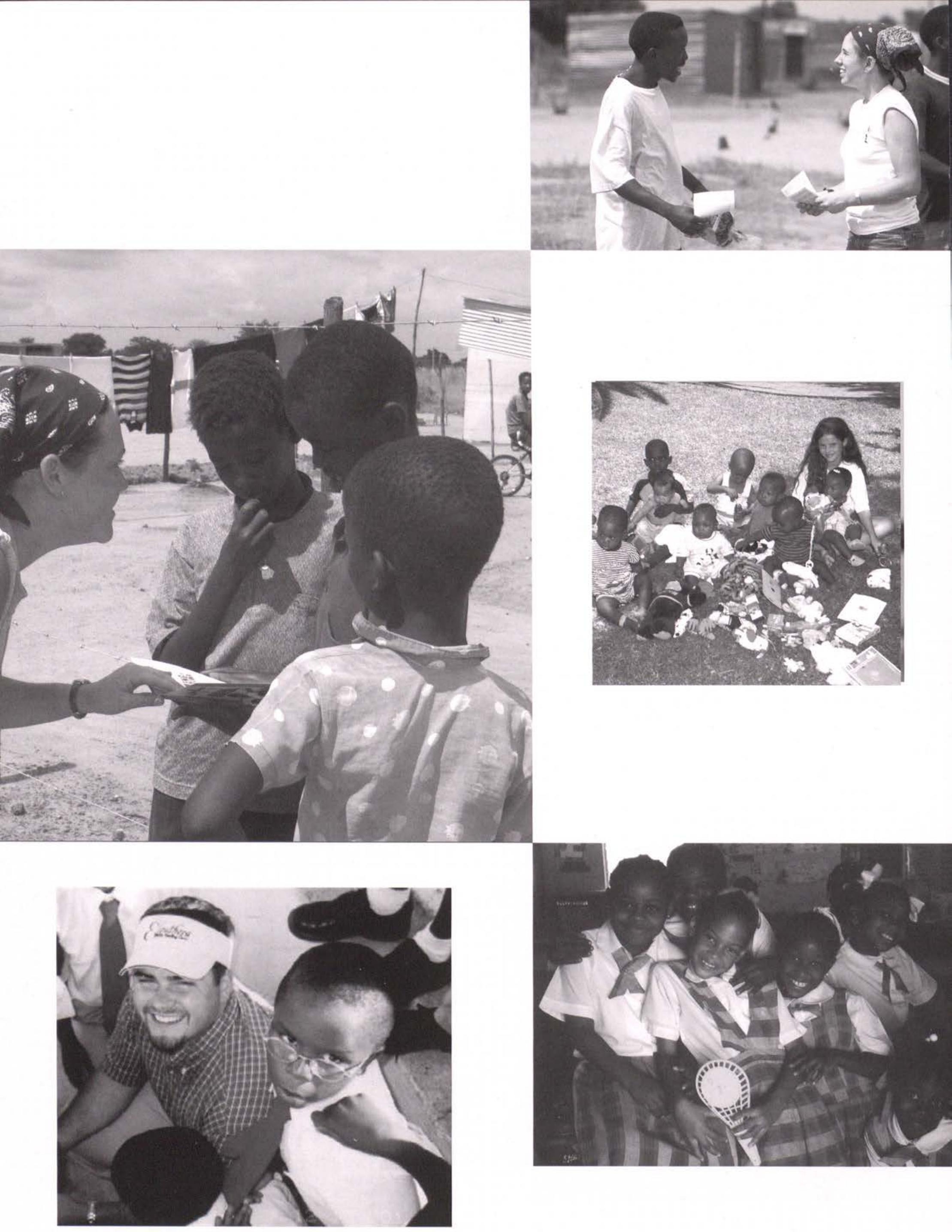


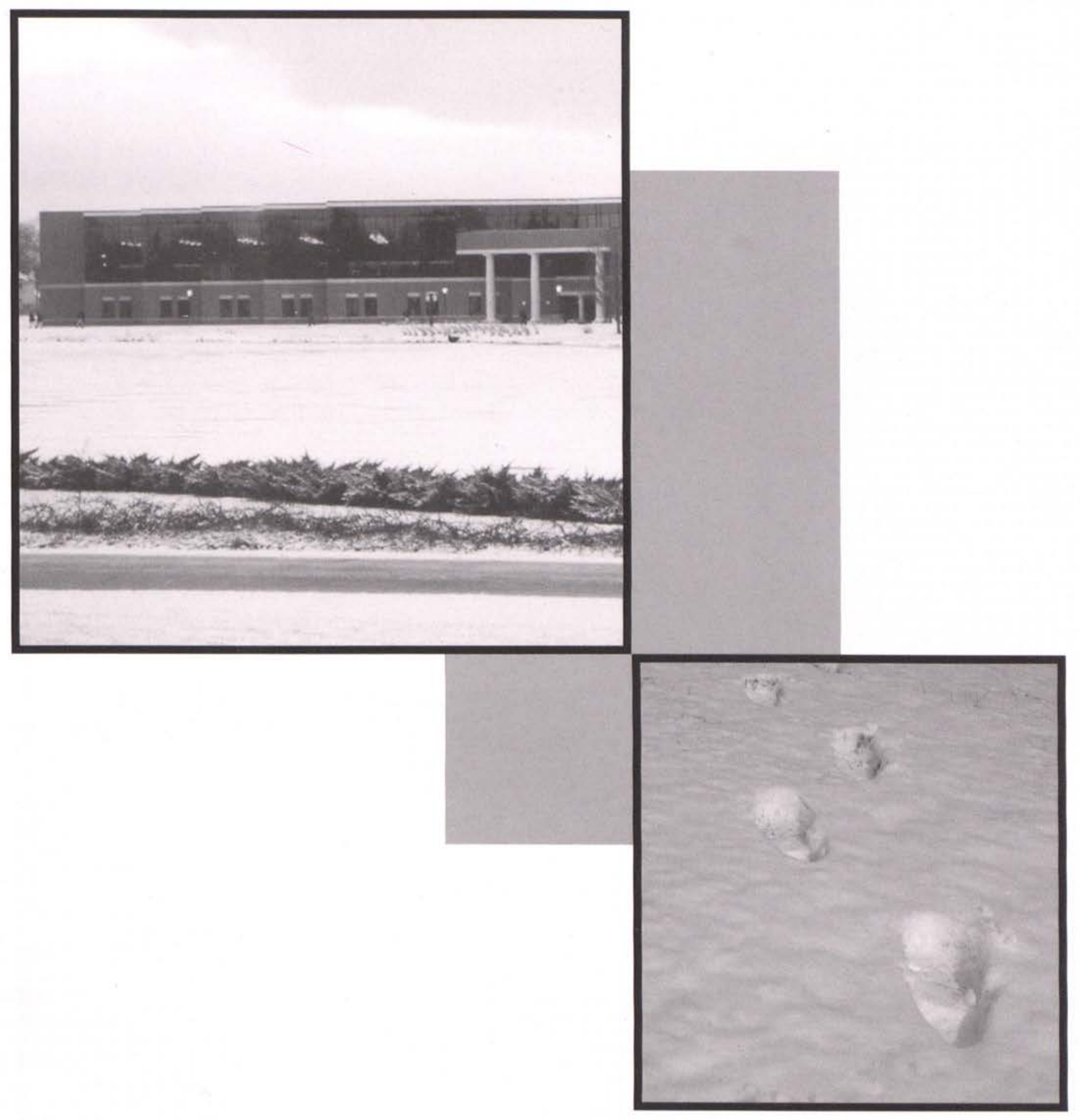




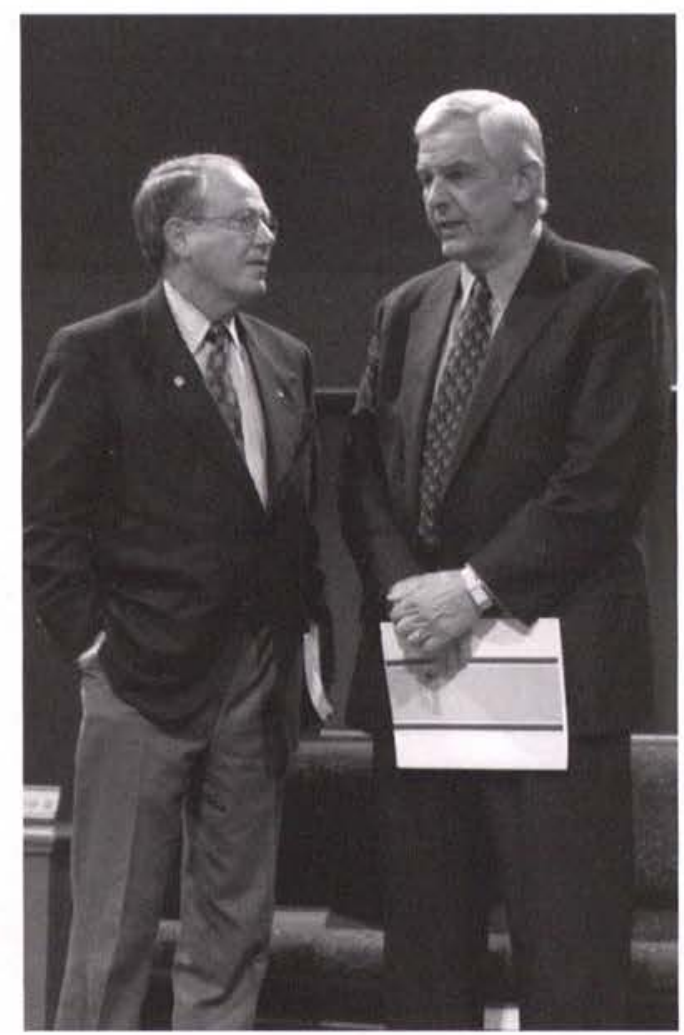

Dr. Dixon and Dr.

Jeremiah take

some time to

reflect after the

conference.
As ritual and habit go, the third week of winter quarter comes, and it is time for the annual Winter Enrichment Conference. This year the conference speaker was Dr. David Jeremiah, an alumnus of Cedarville and the son of former chancellor, Dr. James T. Jeremiah. Dr. Jeremiah was the senior pastor of Shadow Mountain Community Church, in El Cajon, California; he also had a radio program called "Turning Point" which was broadcast nationwide.

Each of the conference sessions began with lively music. Led by Professor Mike DiCuirci and his entourage, it was always an enjoyable experience.

Dr. Jeremiah started many of his messages telling amusing stories or jokes that he said "had nothing to do with his sermon." It was a great technique to get the students awake in the morning and after a long day of classes, as well as interested in what he was going to be speaking on. His topics came from a recent survey taken at his church, where his church members wrote down their greatest fears.

The series of messages was very practical and applicable to the entire Cedarville family. Monday night Dr. Jeremiah spoke about Fear and how the opposite of fear is love, not courage. Tuesday morning chapel was about Temptation, and Tuesday evening was about the Fear of Failure. Wednesday morning he spoke about Doubt, and in closing on Wednesday evening, he spoke on the topic of Worry.

Senior Elementary Education major Rachel Frey stated, "I really enjoyed Dr. Jeremiah; his messages were thought out, and he gave a lot of scripture for every example. I also liked the way he gave suggestions of how to counter the problems with a lot of Scripture."

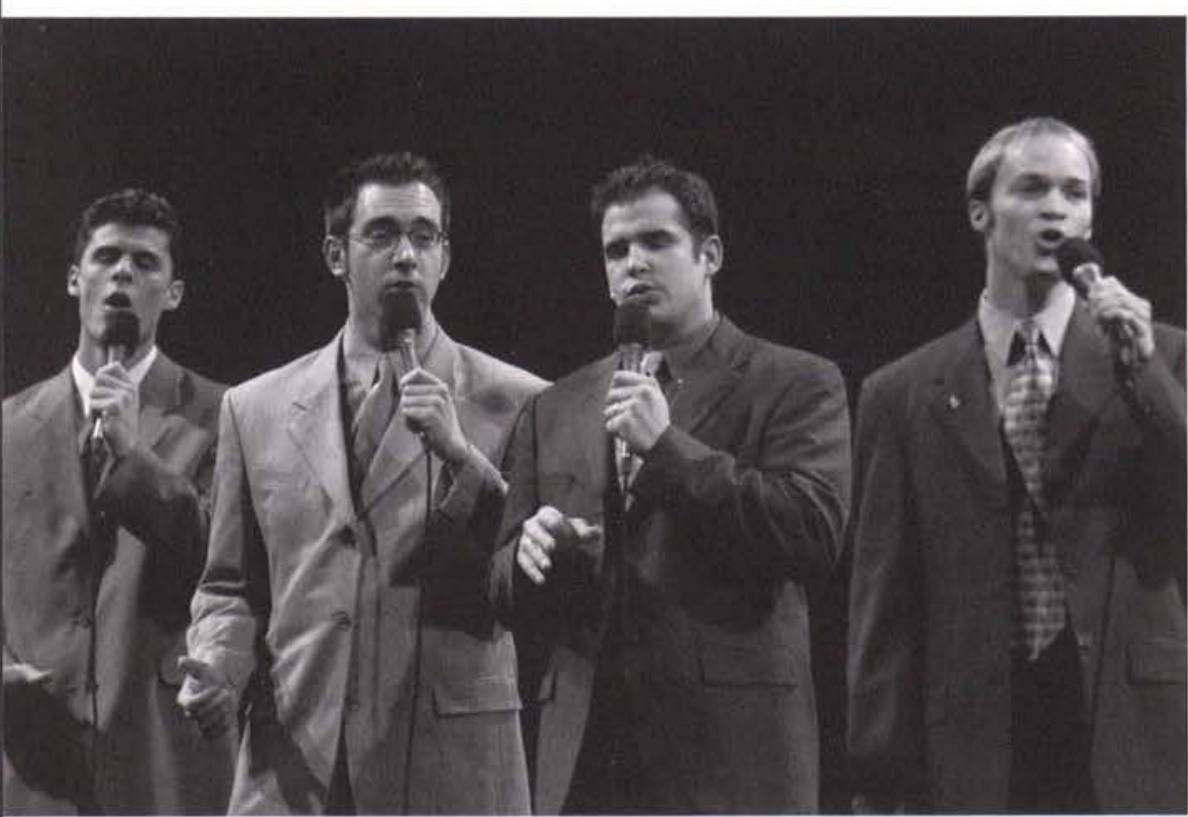

The Kingsmen

Quartet, always a favorite, perform for special music.

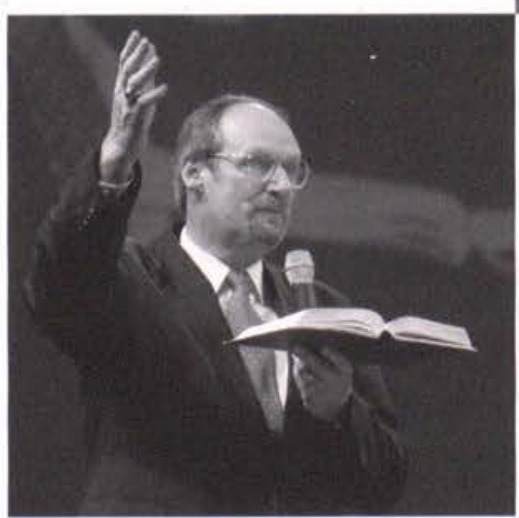

That's right! It's definitely time for "Lion of Judah." 


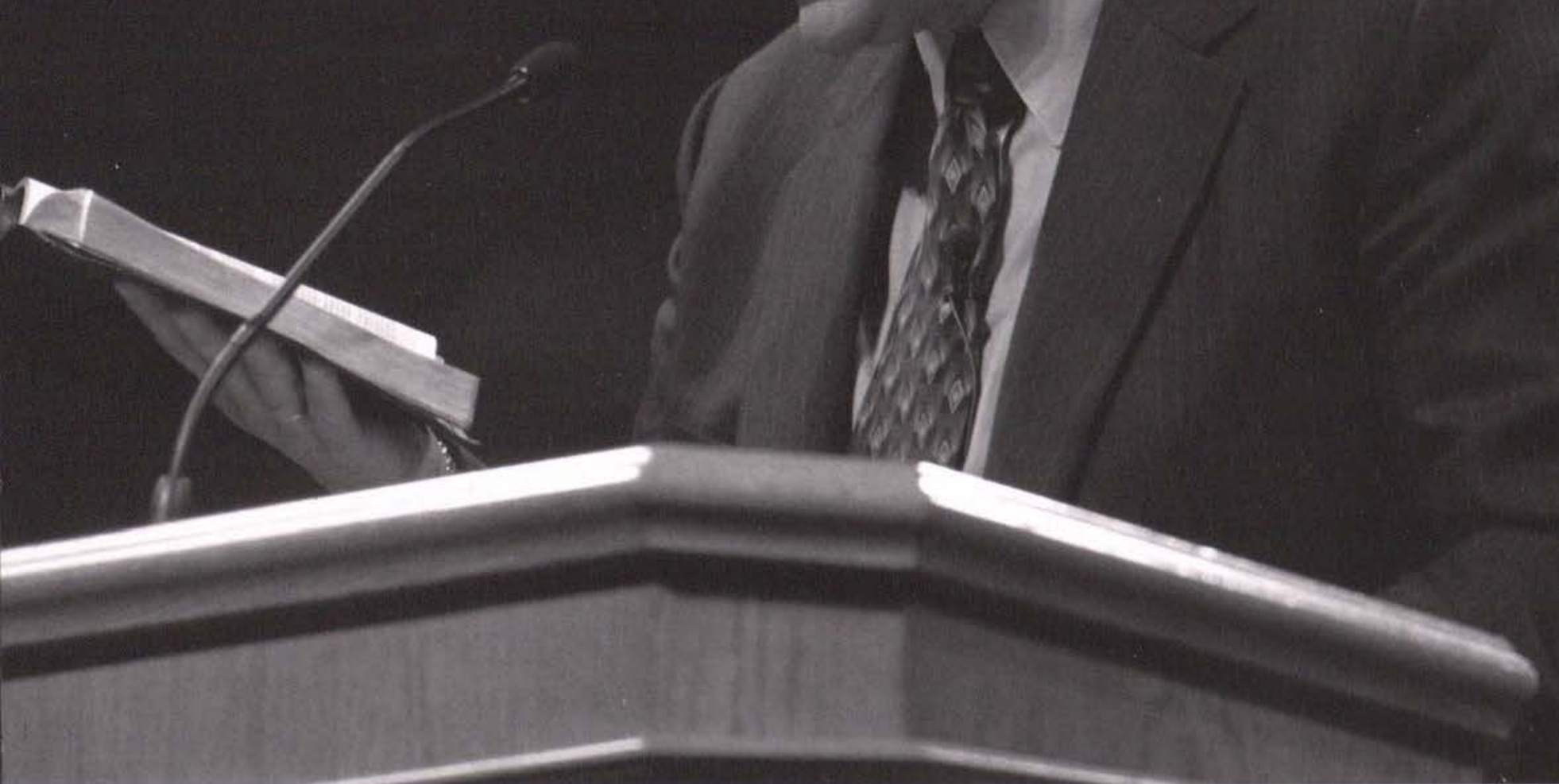

David Jeremiah shares his heart
with the students,
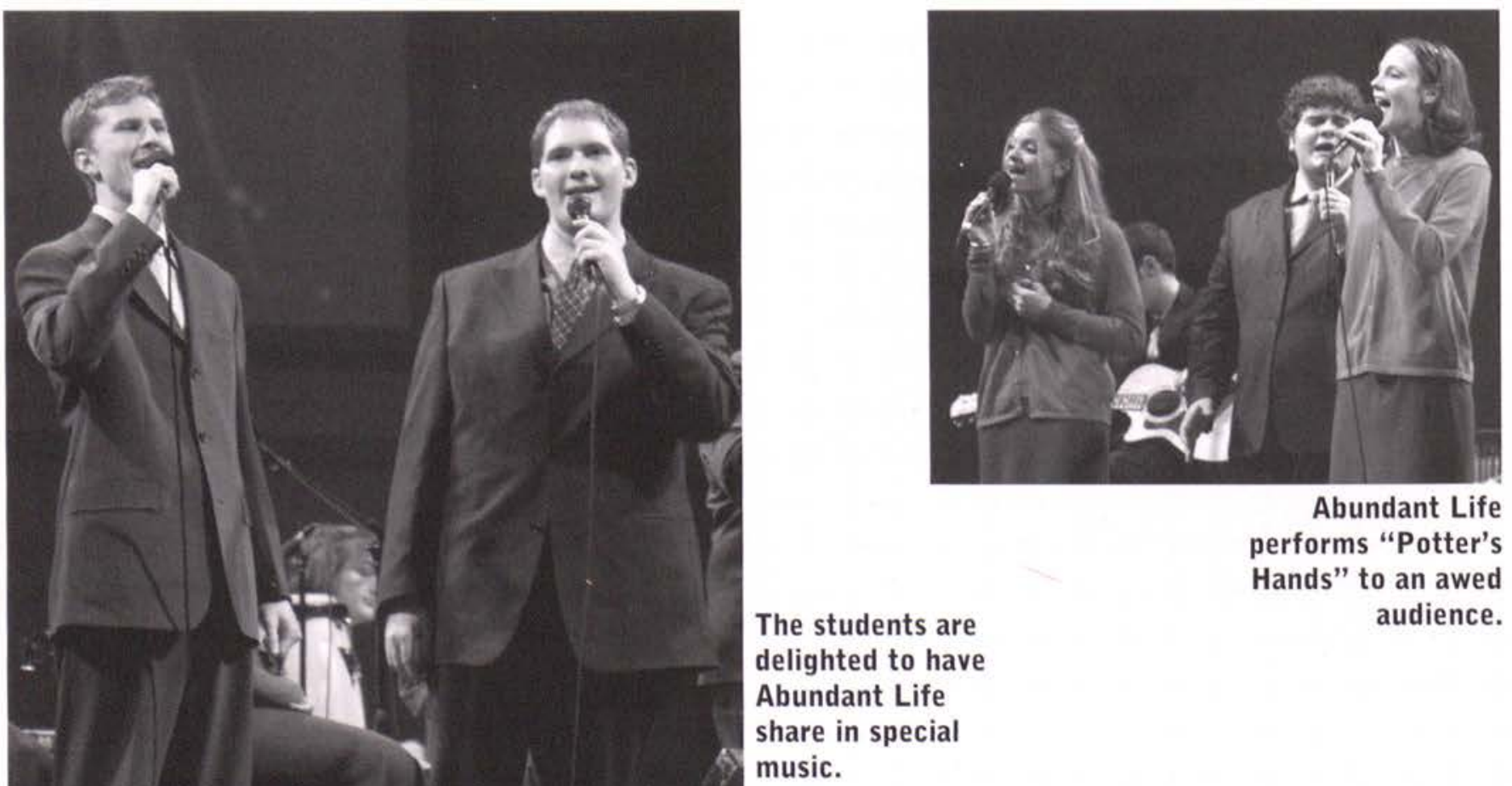
straight from the

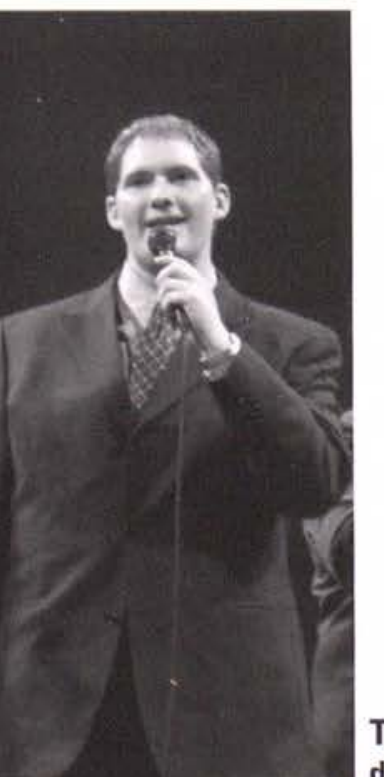

The students are

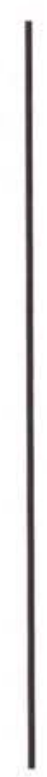

delighted to have

Abundant Life

share in special

music. 


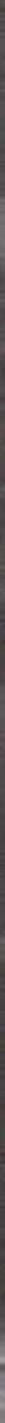

The winning act,

the Skittlelickers,

show their music

and fasion skills.

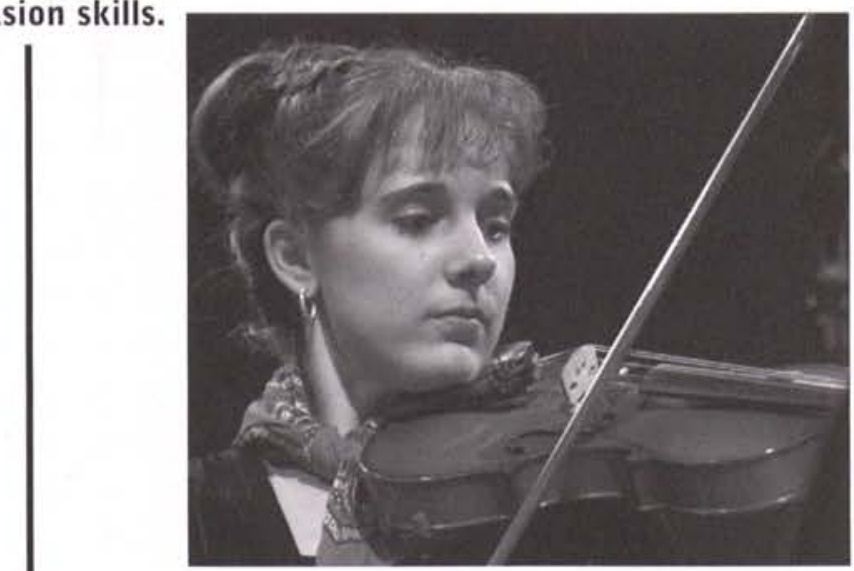

Some sing, some

tap, some rap,

some show, and

some play.

Tim Nester intrigues the crowd with his

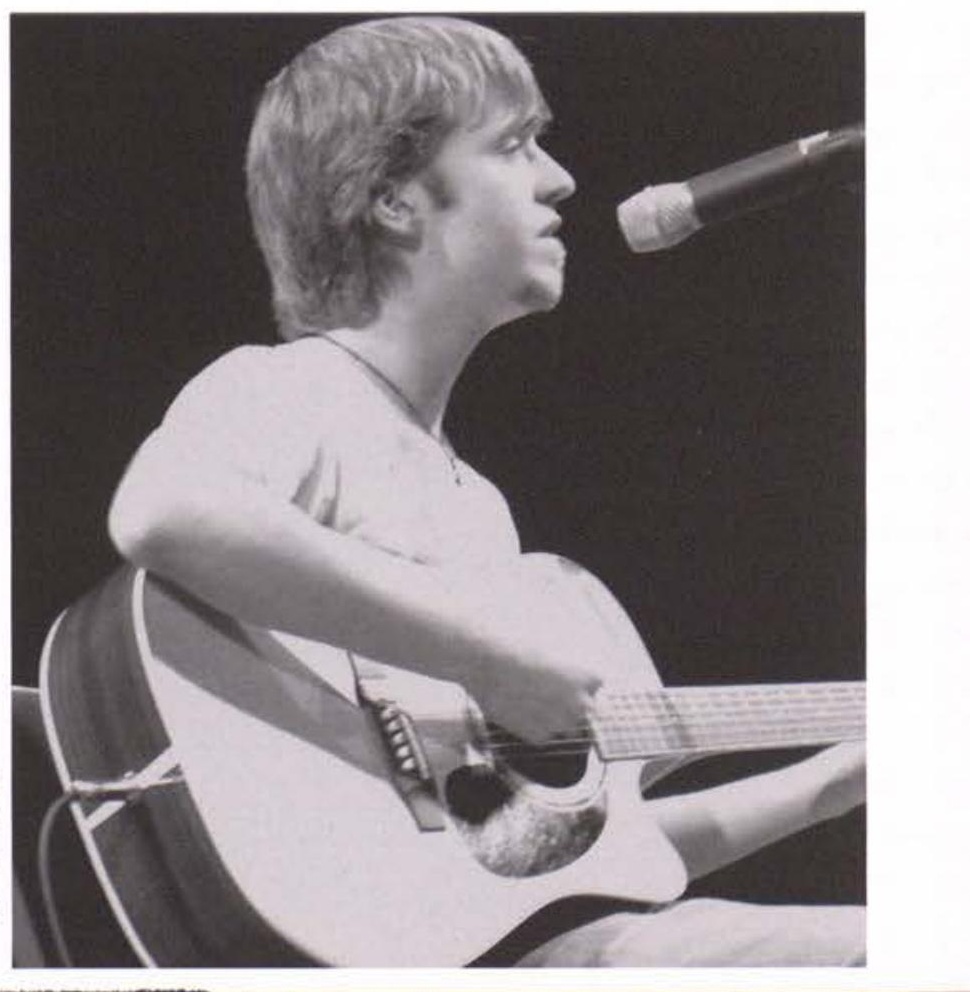


The Alpha Chi Talent Show, held on February 9, 2002,

entertained and wowed the crowd as always, bringing new talent to the stage and celebrating the returning performers.

Hosts Andrea Endicott and Michael Dorsey spiced up the time during set changes with prize giveaways from local restaurants, hair salons, and stores. They also recounted funny tales of past talent shows and performed some of their previously hidden talents.

Smallskat and the

Skittlelickers, winners of the evening's competition, returned to the stage for a second year to perform their "Stomp"-style percussion act. They implemented electric fans and laundry detergent jugs into their routine. One Skittlelicker beat drumsticks on his helmet-clad head, and the group ended their rhythmic sensation with the smashing of a guitar.

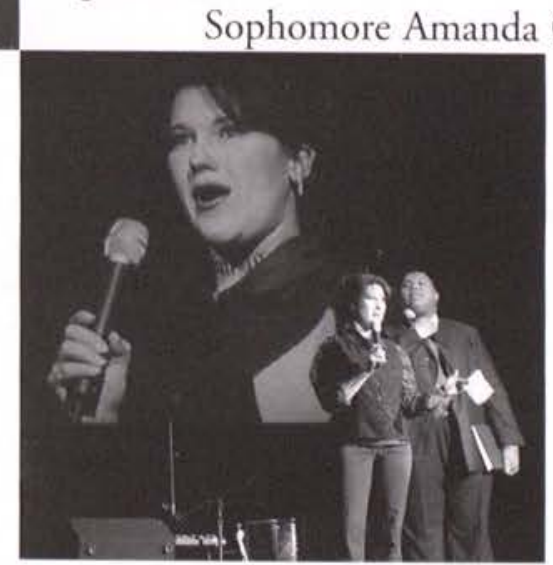

Once again Andrea

Endicott and

Michael Dorsey

team up to run the

show. took second place with a comical ballad, "Taylor." The song spoke of her fictitious love interest, a Starbucks employee named Taylor. The song of devotion and true love discovered over a triple latte had the audience laughing hysterically. Senior Matt Hofmann, under the pseudonym of Mayfield Brown, impressed the crowd with a funky bass solo entitled "Trevor's Fugue Newton" and took home third place.

Senior Tim Cochrell,

President of Alpha Chi, was pleased with the way the evening turned out, planned by Vice-President Richard Brewer. "I was glad to see youth groups and others from the community there. We really wanted to reach out to the lost in a way that was fun and not intimidating, yet still effective in the preaching of the Gospel. The acts were great, and the atmosphere was lively; it was just a great show!"

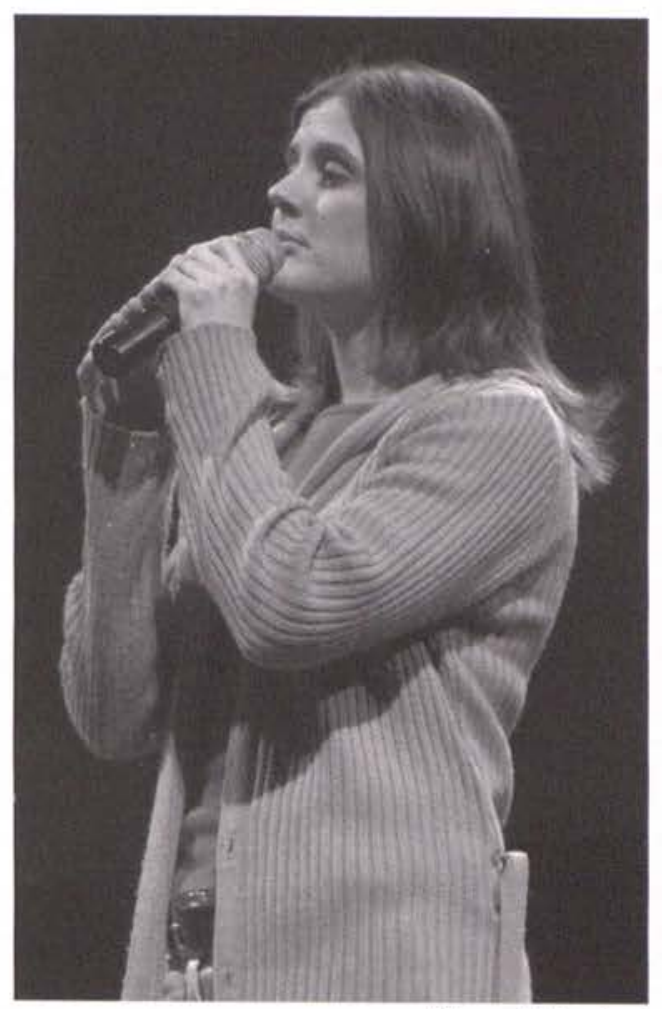

Many talented singers captivated the crowd of university students.

\section{Matt Hofman struts his stuff for his talent.}

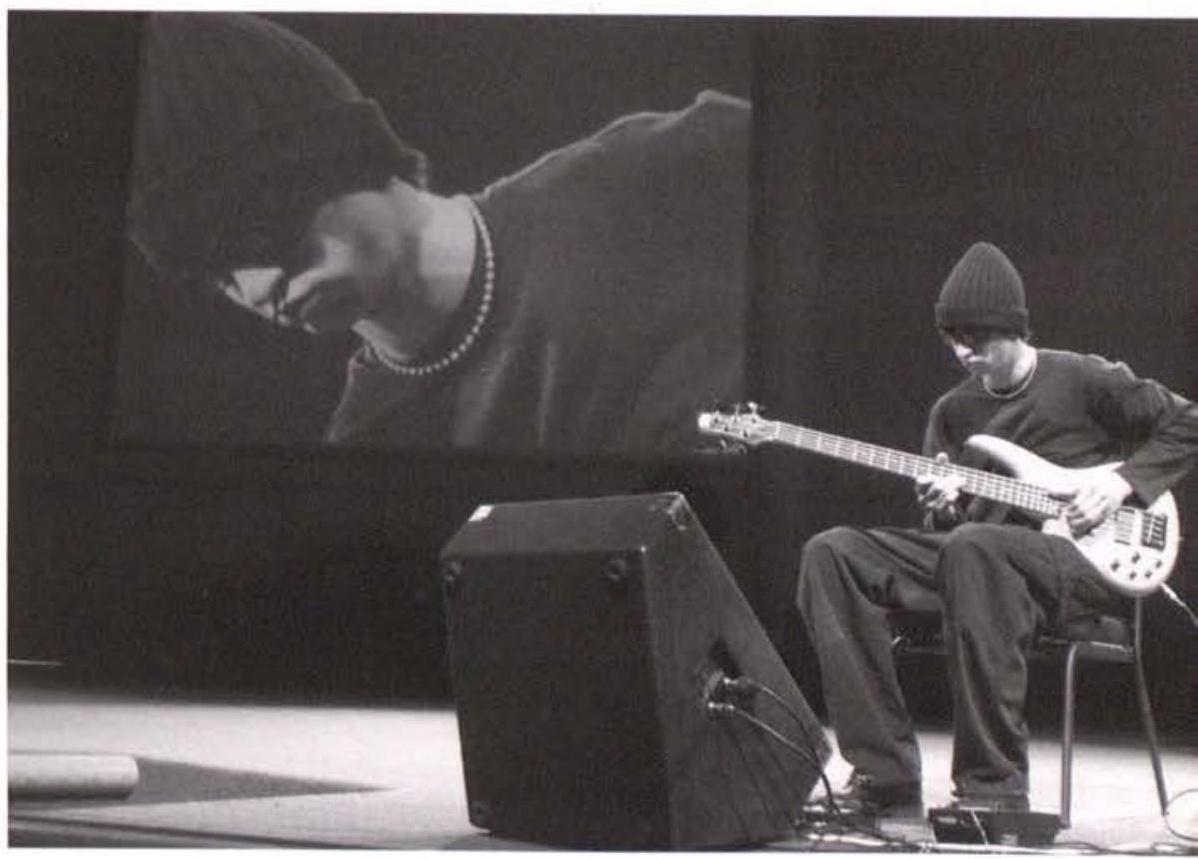




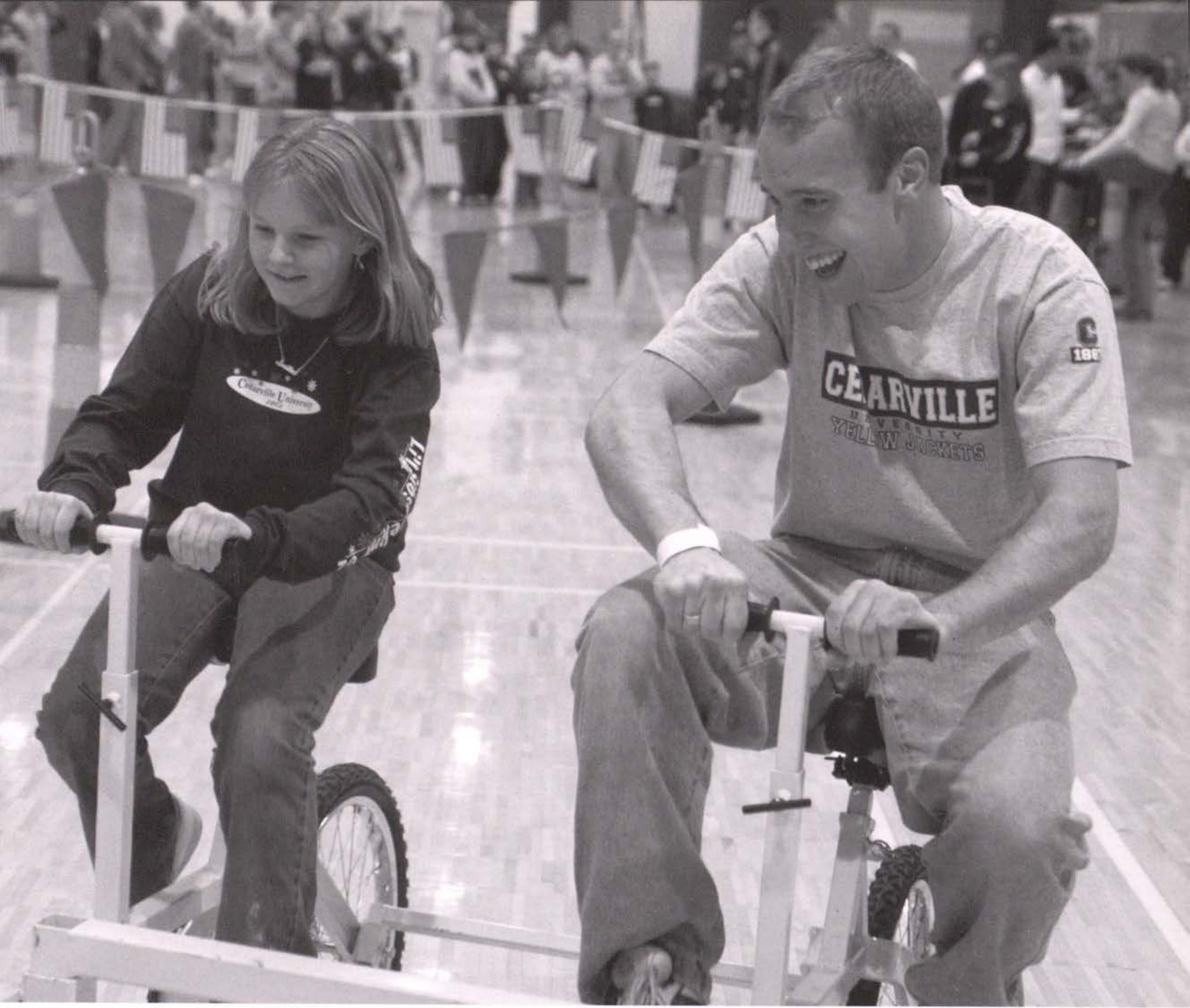




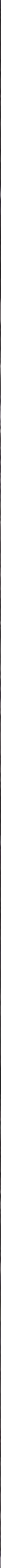

The cast of "Steel Magnolias" lights up the stage.

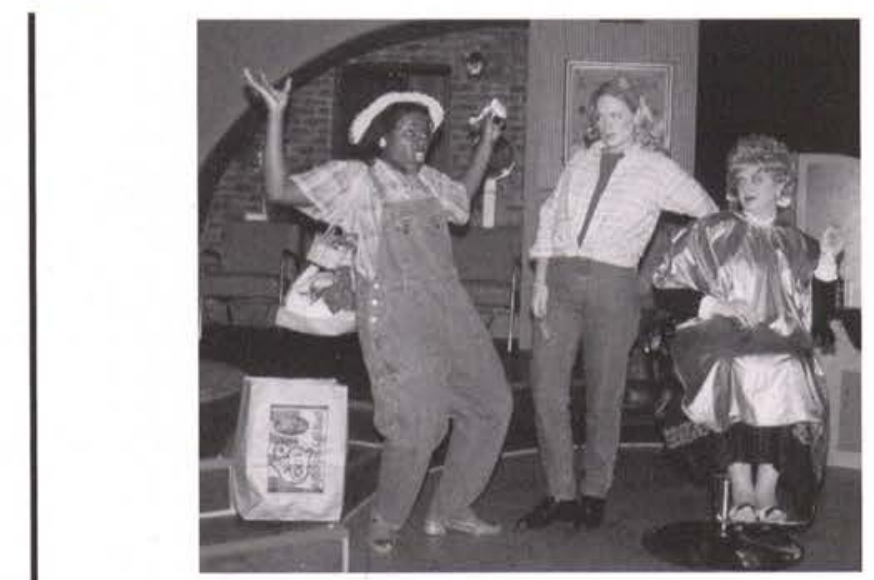

Ouiser, Julianne

Howe, rages as

Annette and

Clairee take in the

spectacle.

"Oops, I see a

hole!" exclaims

Annette. 


\section{winter play}

As you stepped into the theater, you were transported to a brightly coloured beauty salon where there was "no such thing as natural beauty." The winter play Steel Magnolias told the story of six women who stood beside each other through laughter and hardship.

The cast consisted of Katie Masterson, as Clairee, Shae Elam as Annelle, Rebecca DeGarmo as Shelby, Megan Koons as M'lynn, Amy Hollins as Truvy, and Julianne Howe as Ouiser. Rebecca Baker, Assistant Professor of Communication Arts, directed the play.

The play was set in Louisiana during the 1980's and written by Robert Hartling. He based the play on the real-life situations of his sister Susan, his mother, and his mother's friends. When he originally wrote the play,

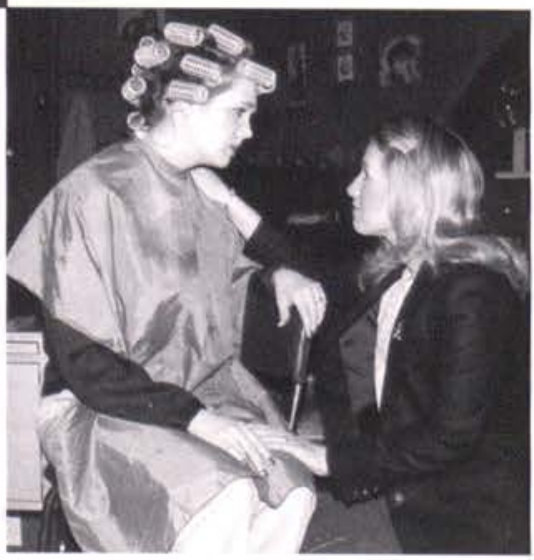

Shelby, Becky

DiGarmo, reas-

sures her con-

cerned mother, Meagan Koons. he intended it to simply be a story, but it later turned into a play and then a movie.

Baker said, "It's so much fun having a play with six great roles for women. It's an awesome cast - they all shine." The play was a very real-life drama, and Masterson said that one of the biggest challenges was to separate her personality from the characters. The play was a great mixture of intense drama with a dash of comedy at just the right moments. Hollins said, "You will really find yourself laughing a lot, and then crying a few moments later. It's funny and sad, but has a good ending that just makes you feel good about life."

Masterson summed it up when she stated that any female audience member would identify with at least one of the women on stage.

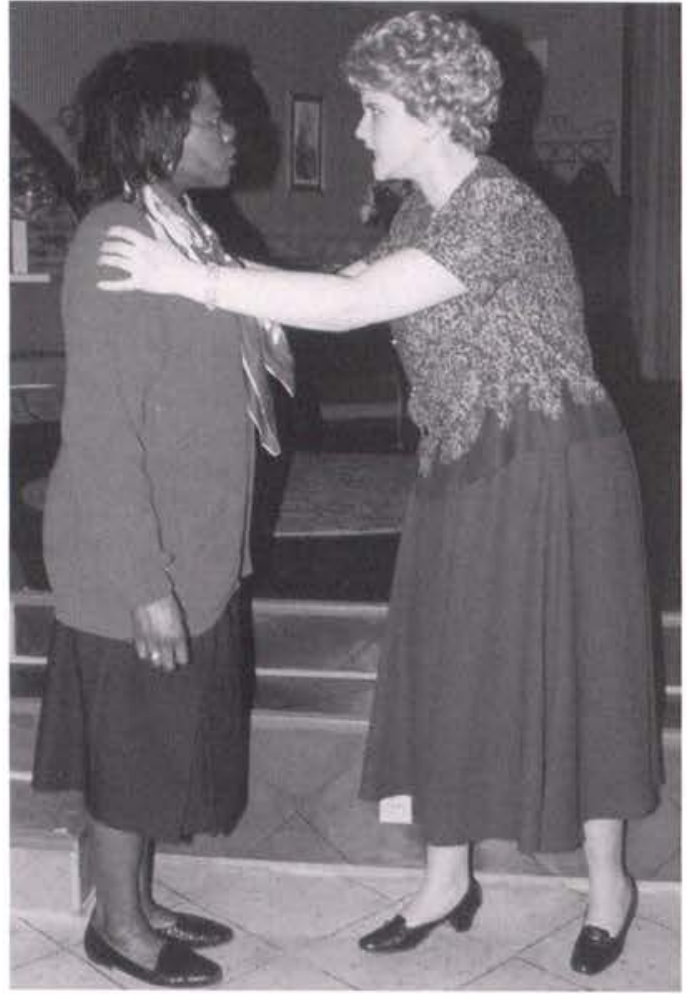

The tension rises as Ouiser and Clairee, Katie Masterson, cope with Shelby's death.

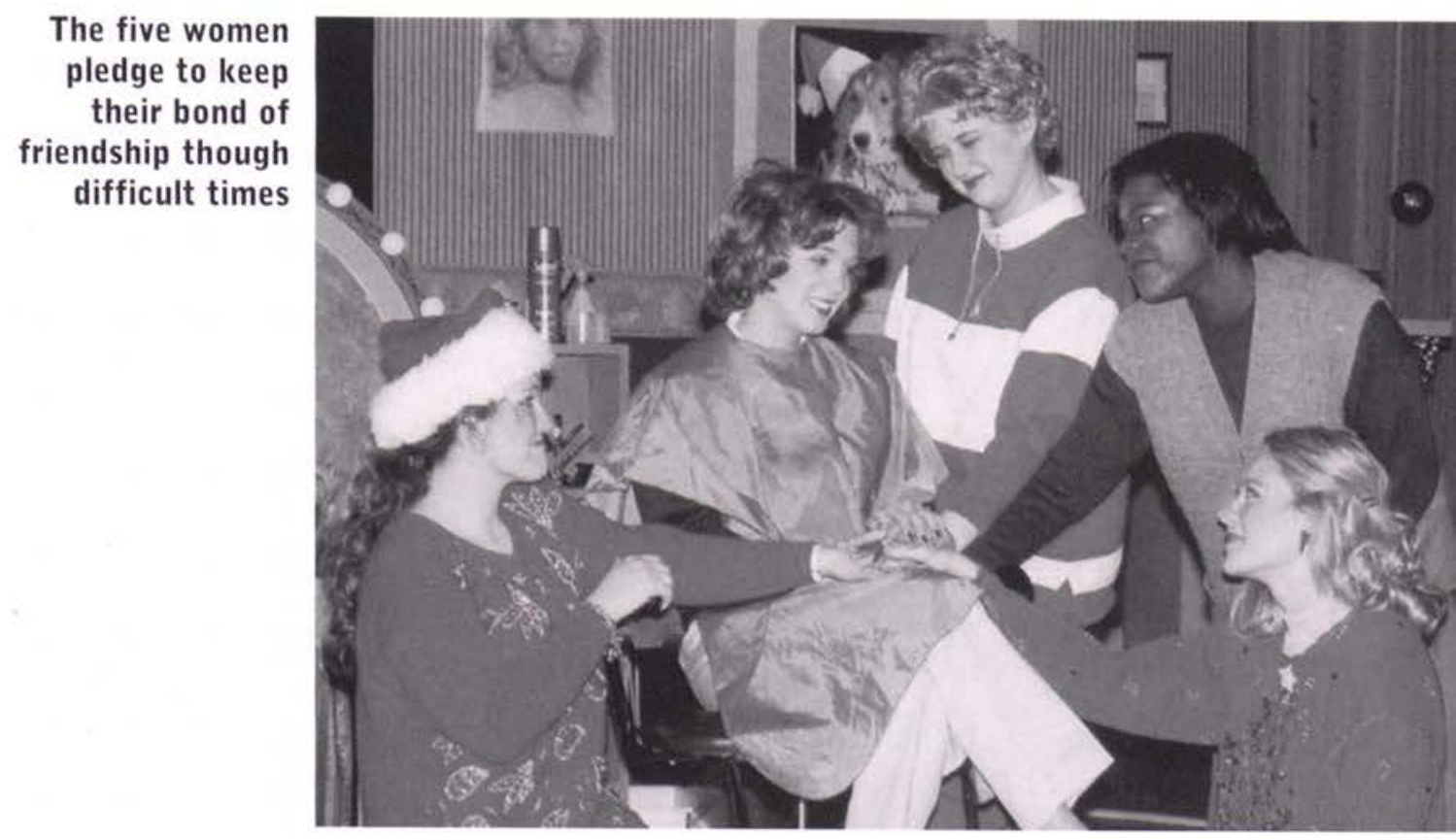




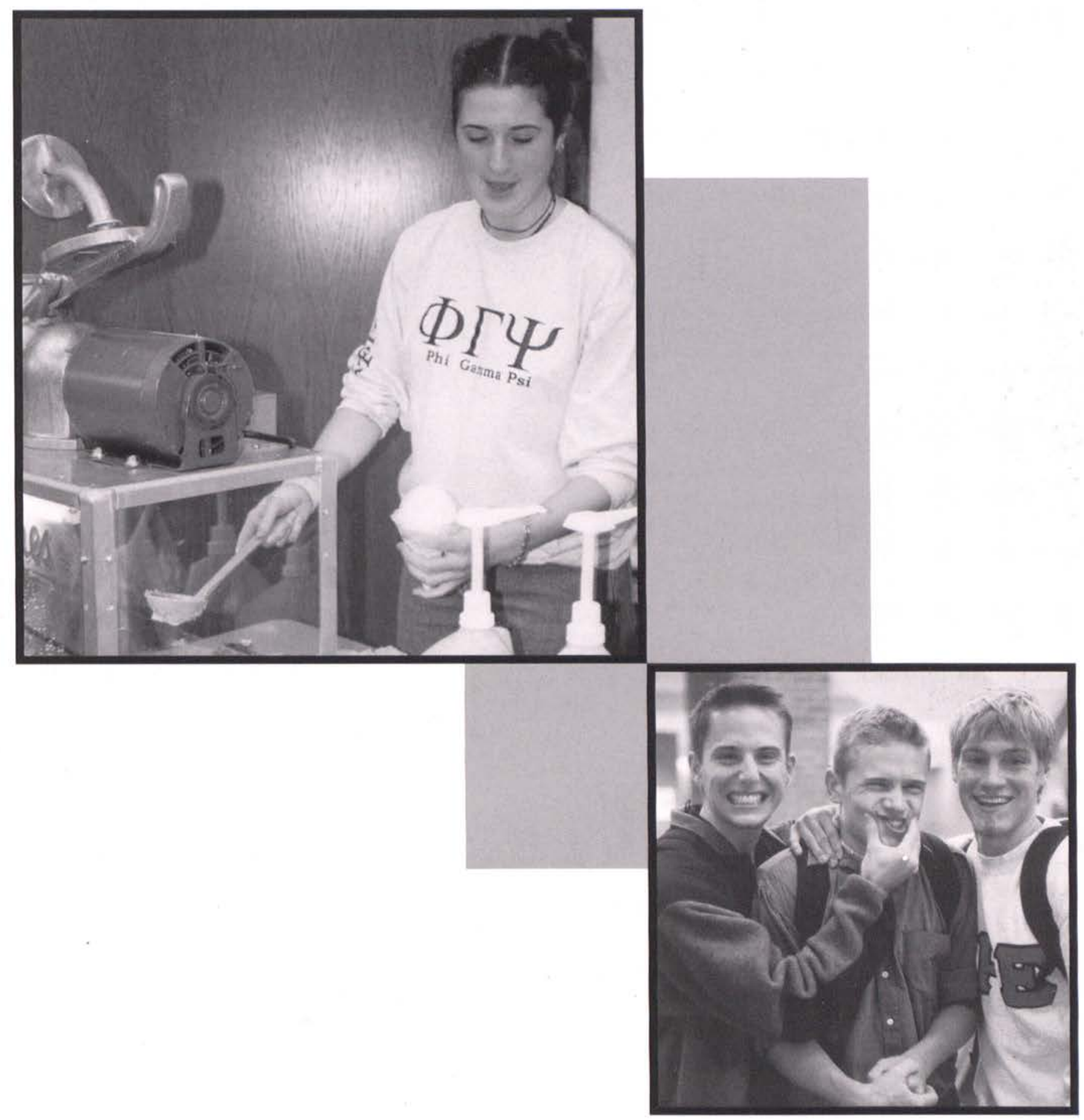



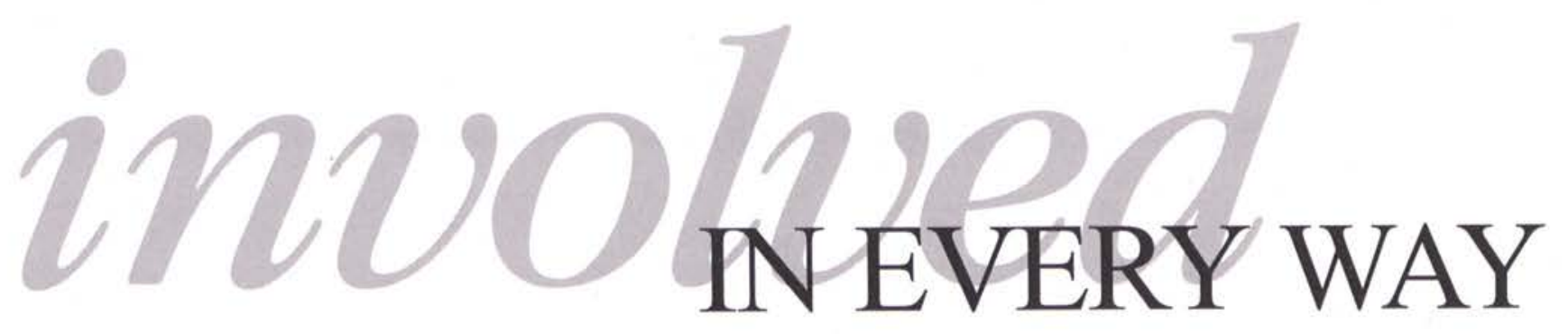

AIR FORCE RESERVE OFFICER TRAINING CORPS

(first row left-to-right) Cherith Payne, Megan Ellis. (second row) Leah Nielson, Jeanette Brogan, Pete Springirth. (third row) Jesse Hornback, John Glett, Joseph Knable, Jeffrey Conklin, Joshua Daniel, Brandon Foss, Eric Babson, Sam de la Rosa. (fourth row) Daniel Shellenbarger, David Colao, Joshua Houk, Eric Peschell, Joseph Schneider, Justin Colon, Brian Allen, Joshua Carter. (not pictured) Athan Waldron, David Raubach, Joel Roberts, Tristan Fries, Cory Henwood, John Groth.

\section{ROTC}

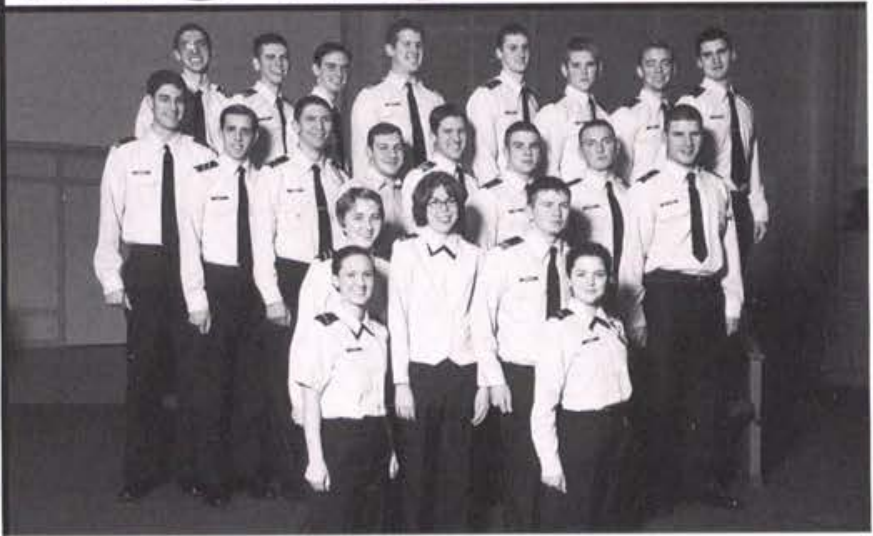

\section{ROTC}

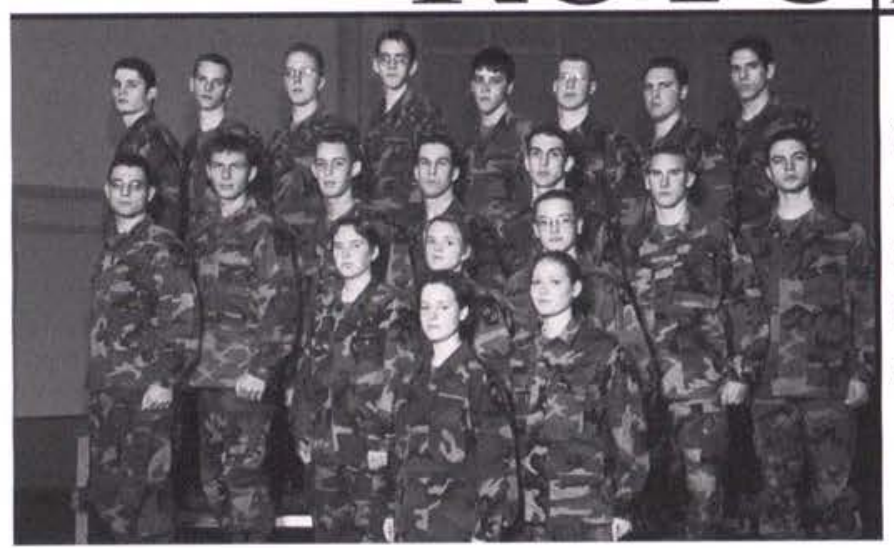

ARMY RESERVE OFFICER TRAINING CORPS

(first row left-to-right) Laura Stevenson, Erin McGarry. (second row) Erin Avery, Anna Avery, Jesse Divine. (third row) Jim Duty, Matt Skidmore, Justin Henry, Kellen Blythe, Mark Hayes, Andrew Becker, Joel Lansford. (fourth row) Andrew Merchant, Jared Jensen, John Erickson, Michael Cramer, Daniel Congrove, John Compton, Kevin Hamilton, Josh May. (not pictured) Paul Laborde, Brandon Brown.

ALPHA BETA PHI

(first row left-to-right) Lauren Bizzoco, Jessie Jacobowitz, Laura Livingston. (second row) Summer Allison, Rebecca Gapinski, Julie Van Winkle, Holly Kuhn, Diane Merchant. (third row) Dan Konopasek, Michael Minahan, Susan Brown, Ryan Culpepper, Brian Coon. (not pictured) Katie Masterson, Nathan Loftis, David Gedney.

\section{$\mathrm{AB} \Phi$}

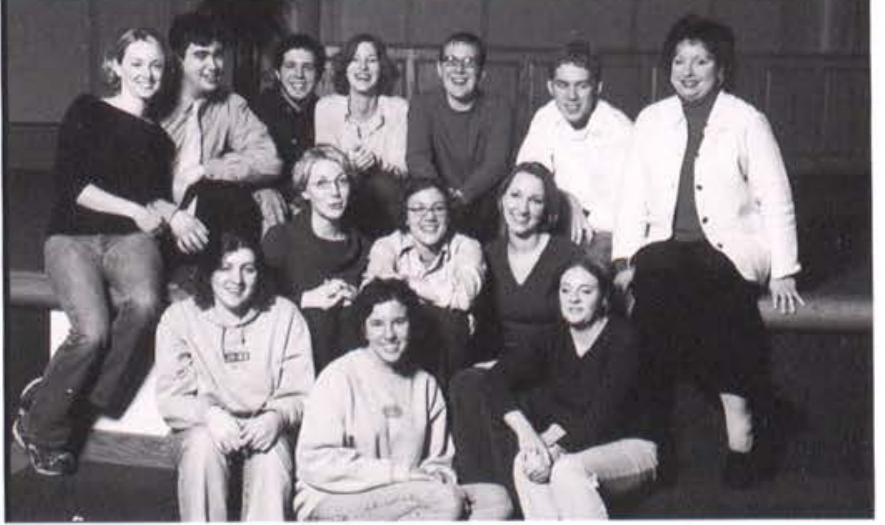




\section{$\mathrm{A} \Sigma \Lambda$}

ALPHA SIGMA LAMBDA

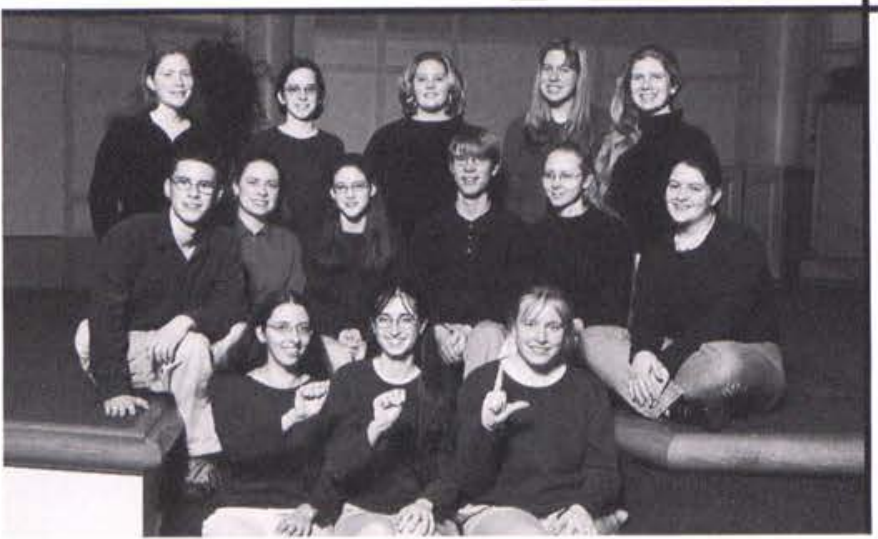

(first row left-to-right) Elizabeth Proemmel, Lana Christensen, Bethany Sears. (second row) Tim Holzmann, Katie Roberts, Leann Wolgemuth, Brent Schumacher, Rebecca Christenson, Rebekah Manwiller. (third row) Karen Robinson, Karen Holloway, Kristin Ball, Elizabeth Earnhardt, Jennifer Wooldridge.

\section{AMERICAN SOCIETY OF MECHANICAL ENGINEEERS}

(first row left-to-right) Emilee Fairbanks, Kristy Mandigo. (second row) Joshua Root, Dave Marshall, Jeremy Estes, Adam Yingling. (third row) Jonathan Mattson, David Rench, Mark Ross

\section{AITP}

\section{ASME}

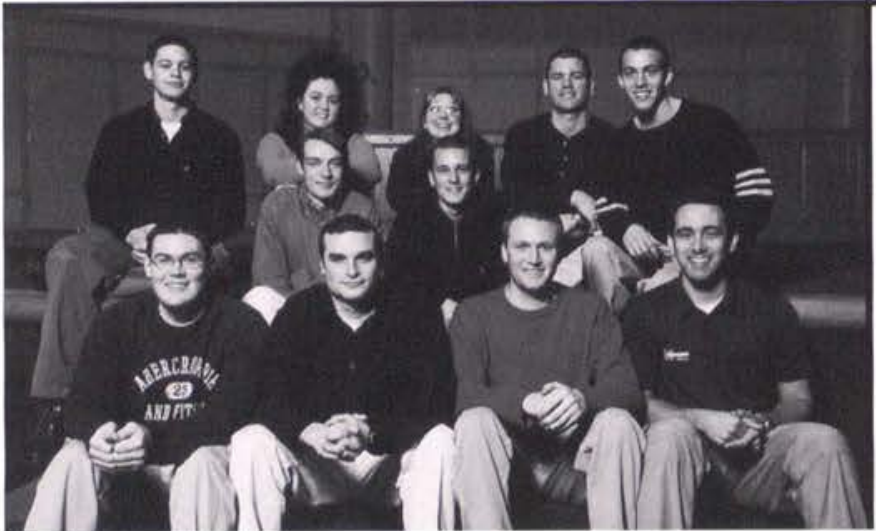

ASSOCIATION OF INFORMATION TECHNOLOGY PROFESSIONALS

(first row left-to-right) Marshall Lyons, Ben Vlug, Nicholas Walton, Justin Tubbs. (second row) Chris Macklin, Jason Hohertz, Devon McCarty, Adam Beres (third row) Erin Hamrick, Andrea Gensel, Kevin Carmichael.

\section{CAMPUS ACTIVITY BOARD}

(first row left-to-right) Sarah Grimme, Ken Mansfield, Alicia Ayers, Brett Buckingham, David Wolf, Dick Walker. (second row) Brock Weston, Katie Hofert, Brian Davis, Scott VanLoo, Jennifer Gration. (third row) Leah Gombis, Emily Gayer, Rebecca Mied, Todd Kocher, Adam Barger, Jeff Olin. (fourth row) Val Wubbena, Amanda Herd, Erin Ewig, Trent Hamilton, Natasha Boyce, Kate Schriemer, Alicia Rambikur. (fifth row) Jeff Beste, Sarah Clark, Dan Dunham, Joseph Reno, Jonathan Christman, Collin Sutherland.

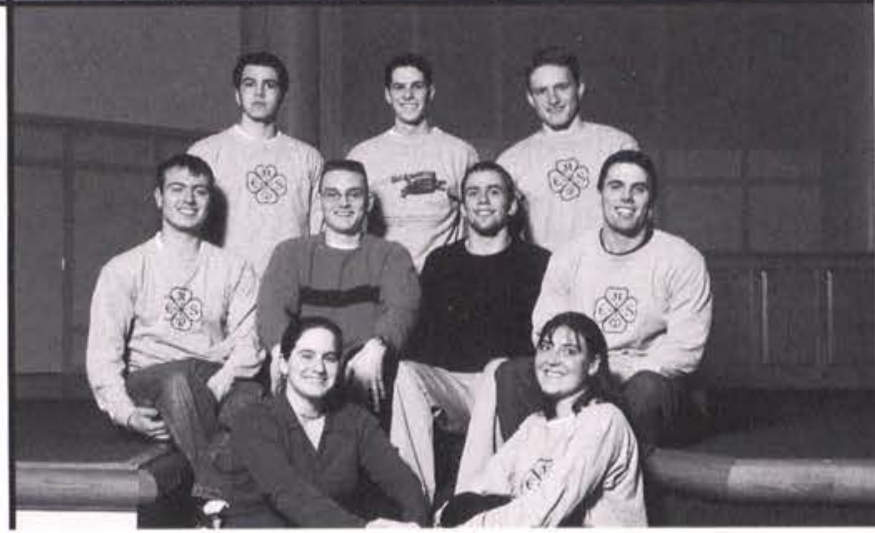




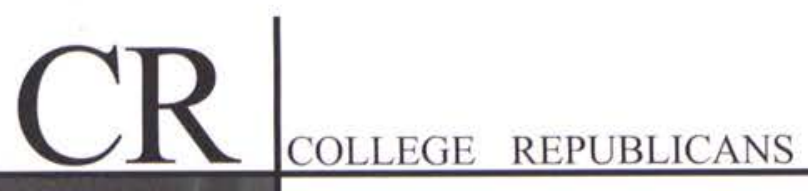

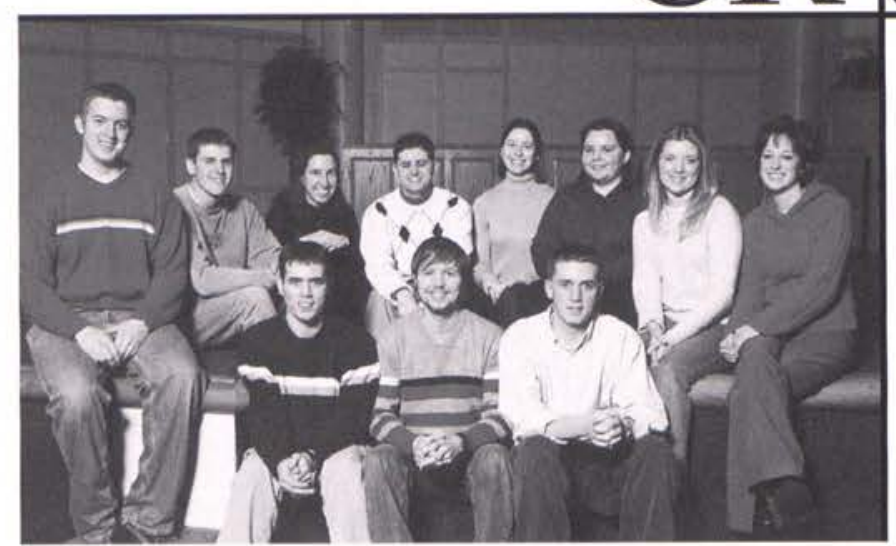

(first row left-to-right) Jonathan Mizer, Colby Mathews, Joshua Bailey. (second row) Matt Dunn, Tim Groff, Kimberly Eridon, Andy Smith, Jessi van der Mehden, Danielle Rogers, Amanda Dye, Katie Carlson.

DEBATE TEAM

(first row left-to-right) Rachel Marley, Rachel Williams, Jennifer Thompson, John Bolinger. (second row) Michael Daiello, Dawn Vargo, Mark Bentley, J.C. Heiden, Lena Fischer.
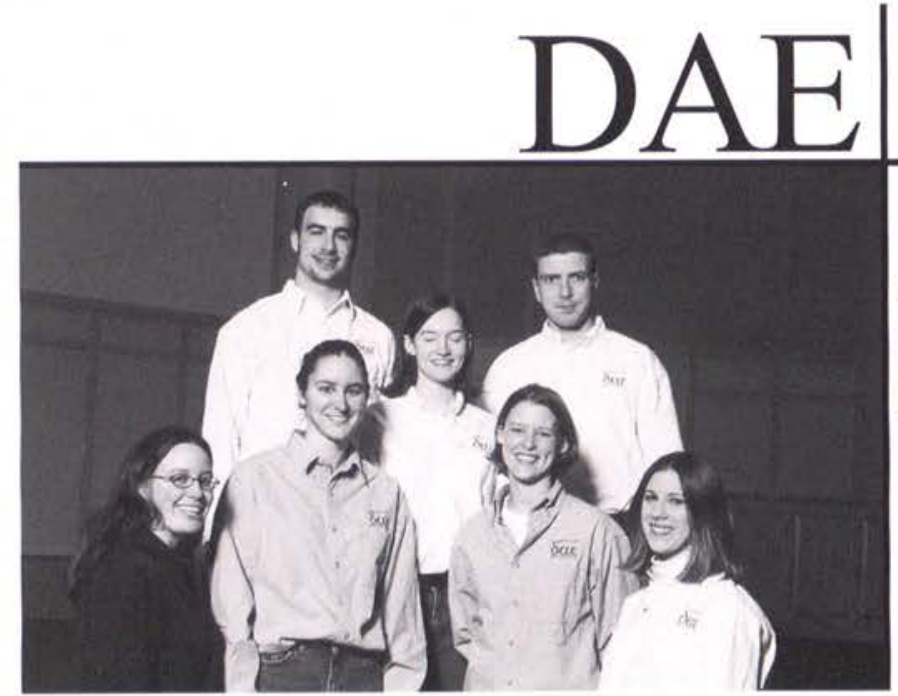

\section{DELTA ALPHA EPSI-}

LON

(first row left-to-right) Kristi-Lynn Kurczy, Julie Driessnack, Erica Linafelter, Julie Landau. (second row) Jason Holland, Ariel Starbuck, Nate Olin. (not pictured) Kate Davies, Dan Hasty, Abby Dixon.

(first row left-to-right) Michael DiCuirci, Jacob Dickinson, Jack Thomas, Dave Emerson, Brent Frazier, Michael Burgman, Matt Garrett, Nick Schlappi, Steve Zarrilli, Scott Vanloo. (second row) John Bailey, Lance Ferguson, Jesse Leightenheimer, Todd Kocher, Brandon Buckingham, Jason Howard, Matt Lowstetter, Micah Russell.

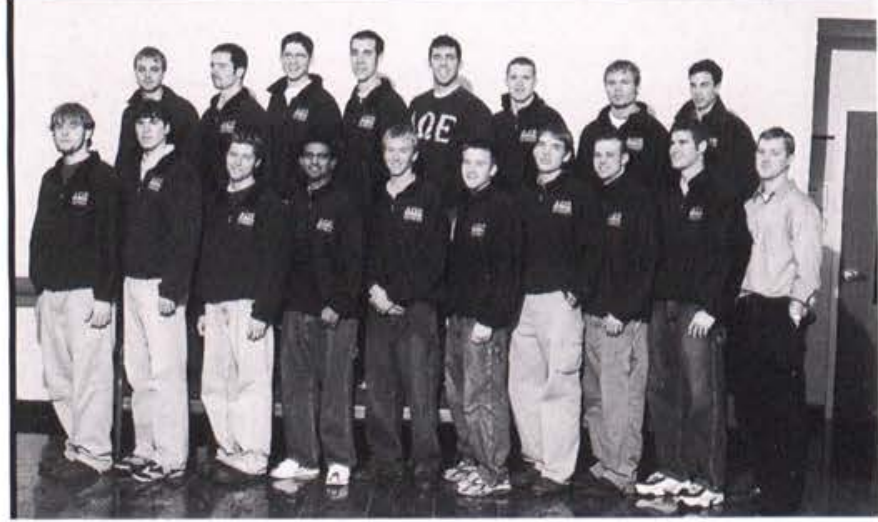



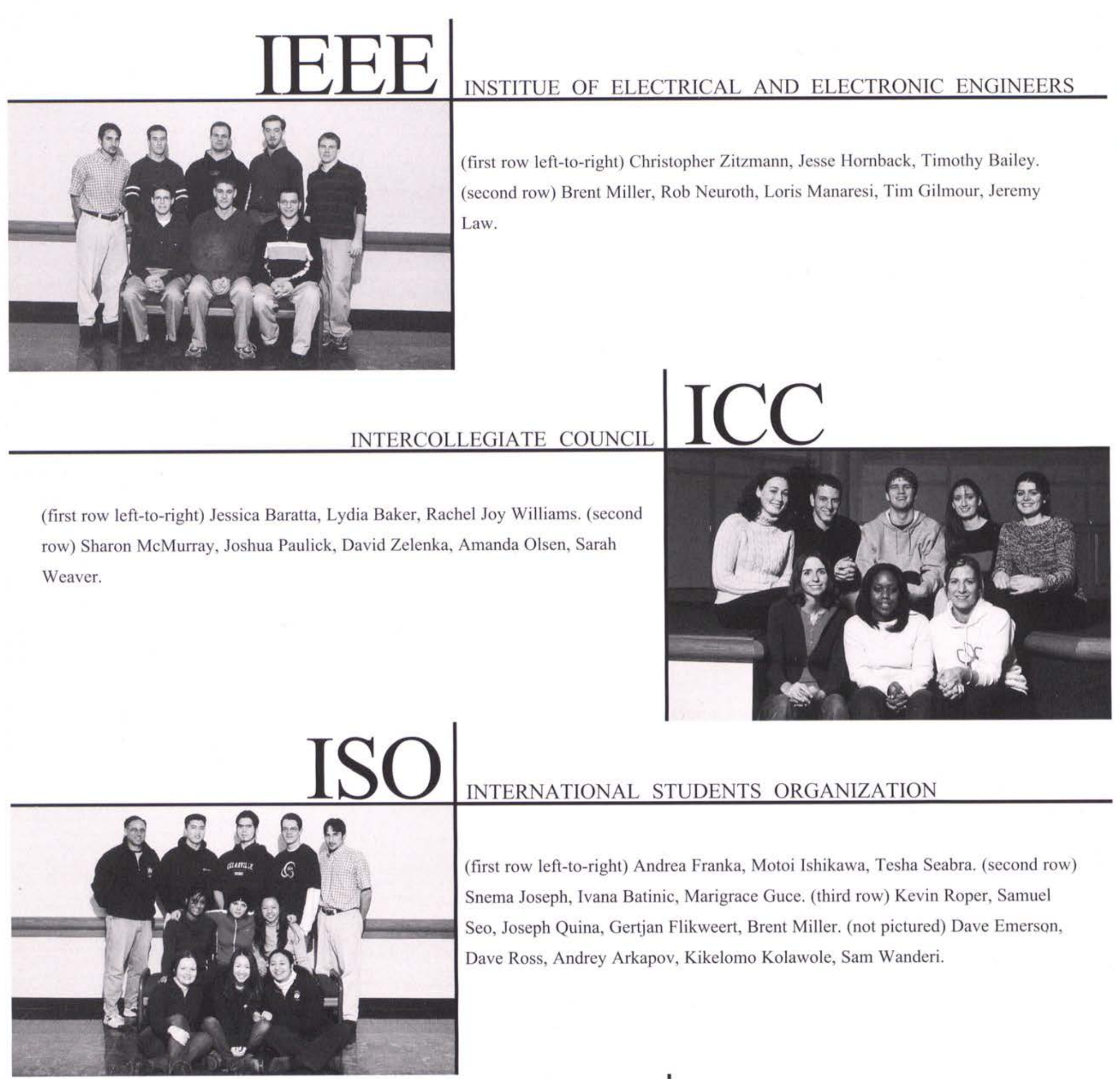

KAPPA EPSILON ALPHA 1

(first row left-to-right) Kristen Spurlock, Abby Iden, Becky Stewart, Katie

McGunnigal, Alyssa Rost. (second row) Andrew Smith, Lena Fischer, Mandy Herd,

Amanda Bartholomew, Lisa Bleikamp, Allen Rager. (third row) Ryan McCormick,

Erika Love, Shaun Hanna, Greg Hamilton, Rob O'Brien, Michelle Smith, Seth

Crowder. (not pictured) Jessica Baratta, Katie Carlson, Courtney Cox, Chris Davis,

Michelle Fowler, Becky Hart, Jenny Hummel, Julie Jamgochian, Stephanie Lewis,

Kristen Pierce, Diamond Redmond, Holly Seace, Kara Syversen.

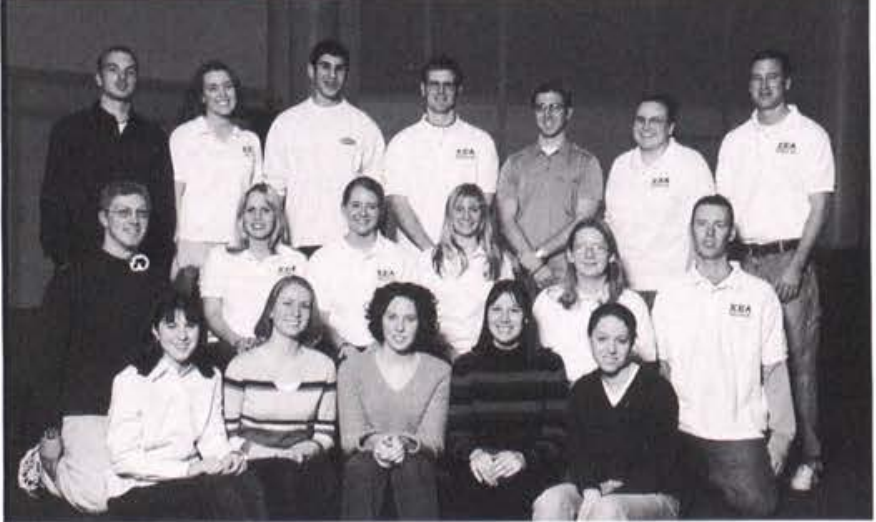



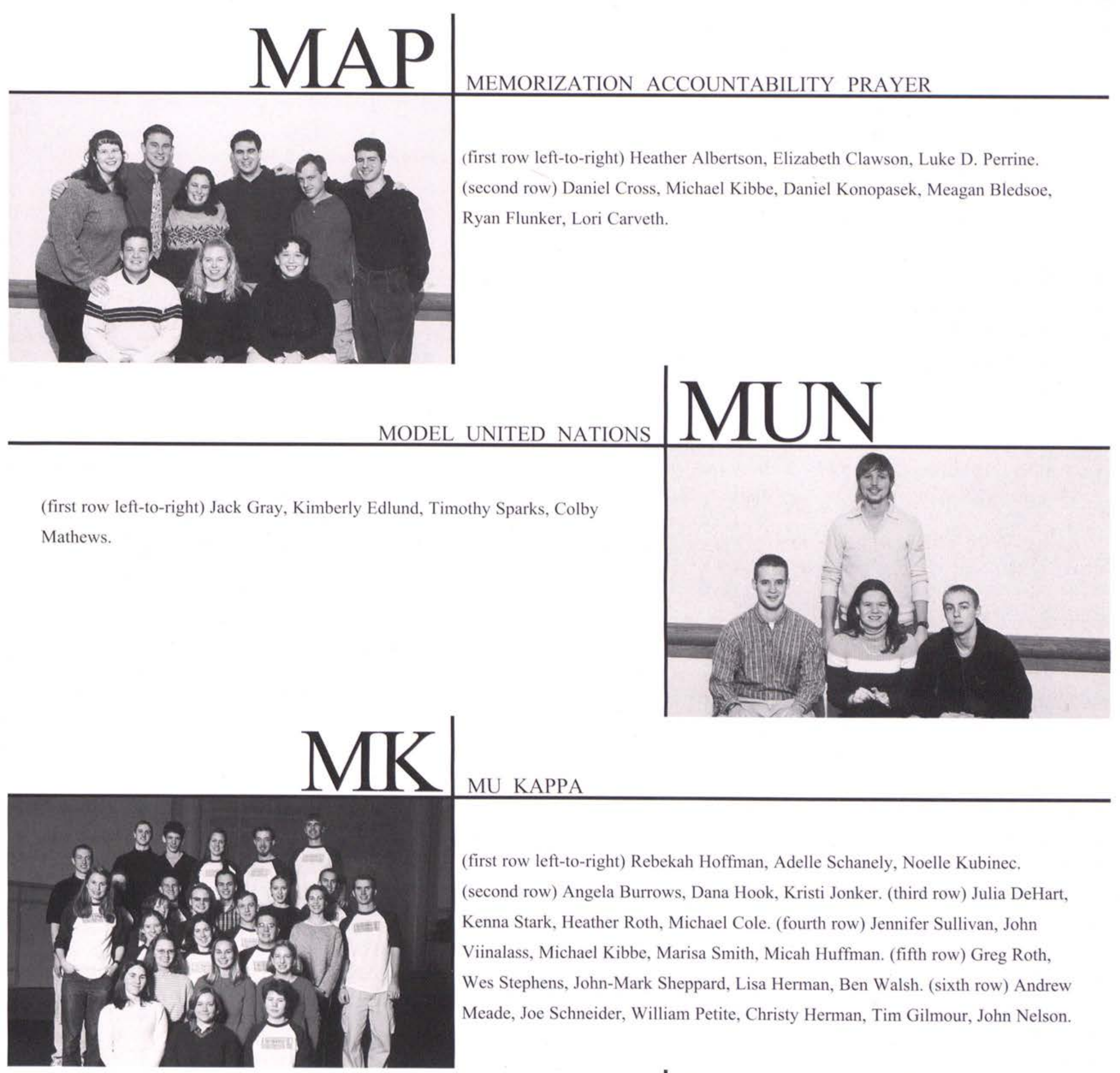

(first row left-to-right) Rebekah Hoffman, Adelle Schanely, Noelle Kubinec, (second row) Angela Burrows, Dana Hook, Kristi Jonker. (third row) Julia DeHart, Kenna Stark, Heather Roth, Michael Cole. (fourth row) Jennifer Sullivan, John Viinalass, Michael Kibbe, Marisa Smith, Micah Huffman. (fifth row) Greg Roth, Wes Stephens, John-Mark Sheppard, Lisa Herman, Ben Walsh. (sixth row) Andrew Meade, Joe Schneider, William Petite, Christy Herman, Tim Gilmour, John Nelson.

\section{MUSIC EDUCATION NATIONAL CONFERENCE}

(first row left-to-right) Lana Christensen, Mark McDaniel. (second row) Stephanie Firebaugh, Miriam Grossman, Katie Roberts, Elizabeth Dudick, Katie Buehner. (third row) Amanda Lucarini, Daylyn Warren, Debbie Compton, Natalie Nicholl, Brandon Moses. (fourth row) Rebecca Christenson, Rachel Bojczuk, Jonathan Estes, Benjamin Haas, Michael Clutz, Kyle McCarrell, Jenn Weaver, Lynn Wagner.
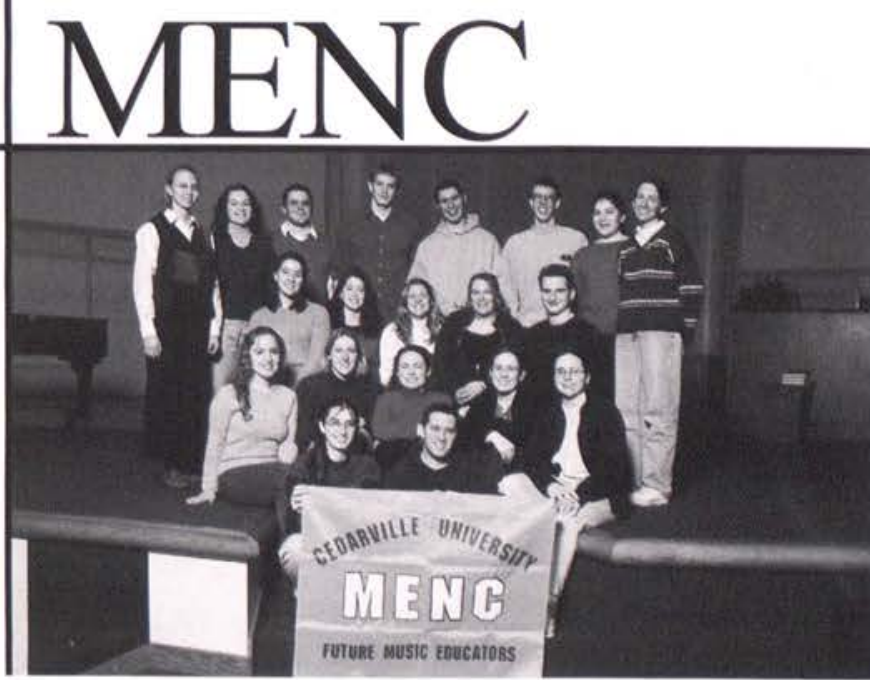


\section{OCF}

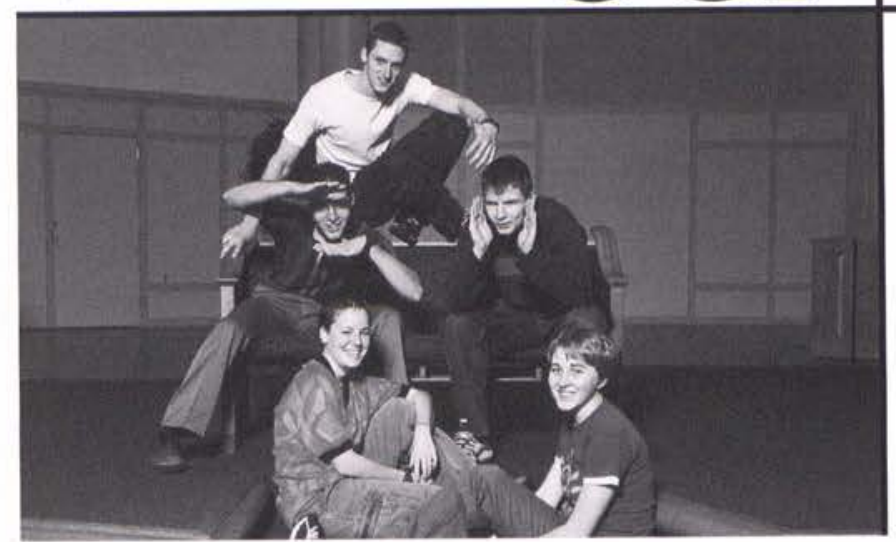

\section{OFFICERS CHRISTIAN FELLOWSHIP}

(first row left-to-right) Laura Stevenson, Leah Nielson. (second row) Joel Lansford, Pete Springirth. (third row) Joe Schneider.

\section{oneco vu $\Omega M$}

(first row left-to-right) Keith Peters, Andrew Smith. (second row) Ethan Hodge, Gerson Moreno-Riano. (not pictured) Jennifer TeTrick, Andrew Johnson.

\section{$\Phi \mathrm{EB}$}
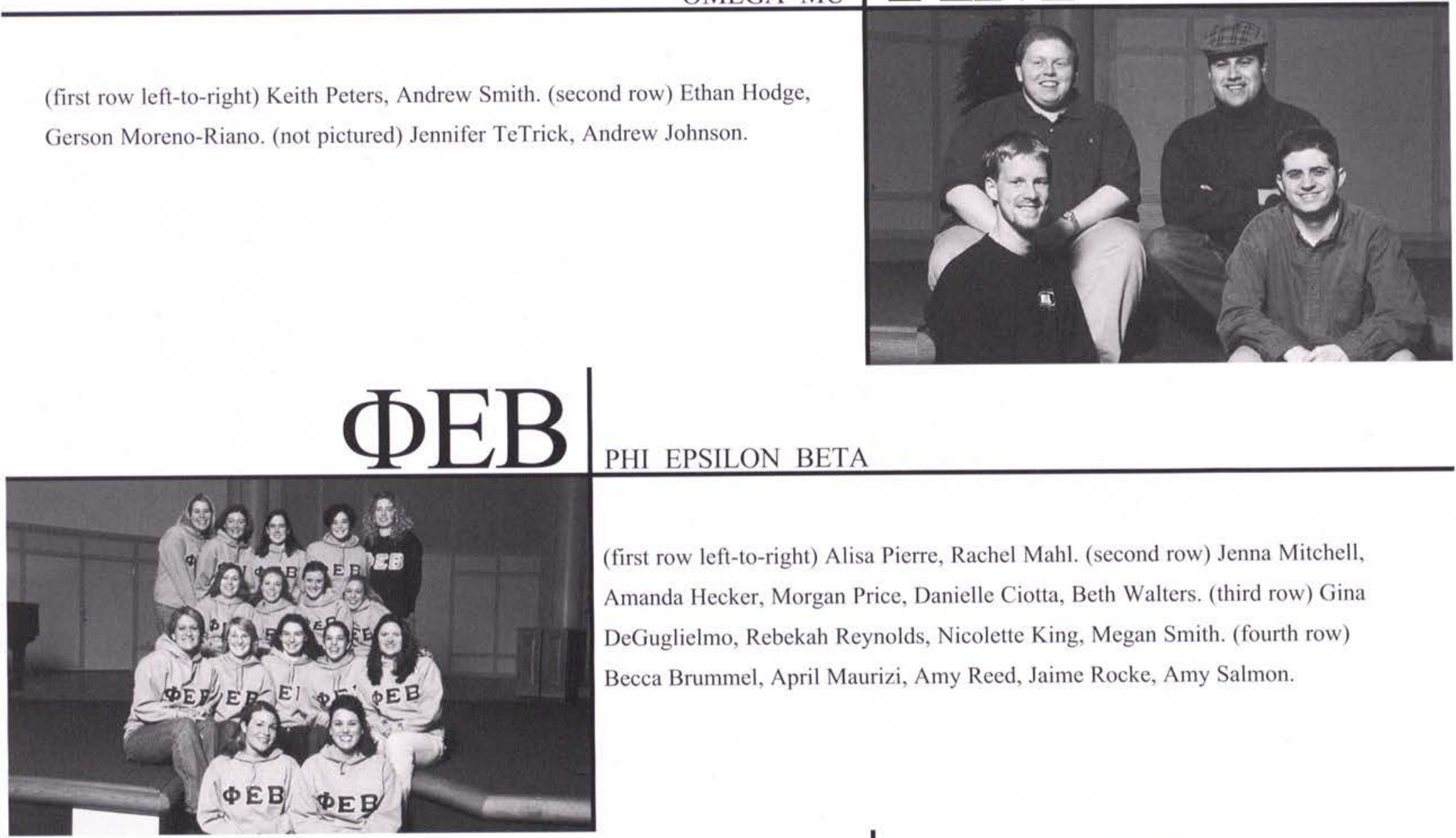

PHI EPSILON BETA

(first row left-to-right) Alisa Pierre, Rachel Mahl. (second row) Jenna Mitchell, Amanda Hecker, Morgan Price, Danielle Ciotta, Beth Walters. (third row) Gina DeGuglielmo, Rebekah Reynolds, Nicolette King, Megan Smith. (fourth row) Becca Brummel, April Maurizi, Amy Reed, Jaime Rocke, Amy Salmon.

PHI ALPHA EPSILON OMEGA

(first row left-to-right) Jenna Caron, Erin Knowles, Dr. Nelson Henning, Tracy Loudermilk. (not pictured) Shannon Grimm, Ben Nesbitt, Janelle Muoio, Christine Trago.

\section{$\Phi A E \Omega$}

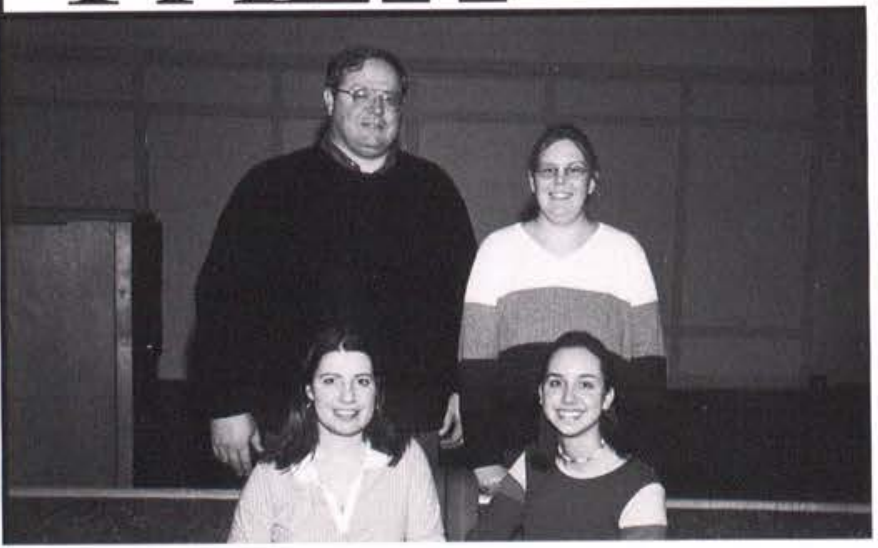



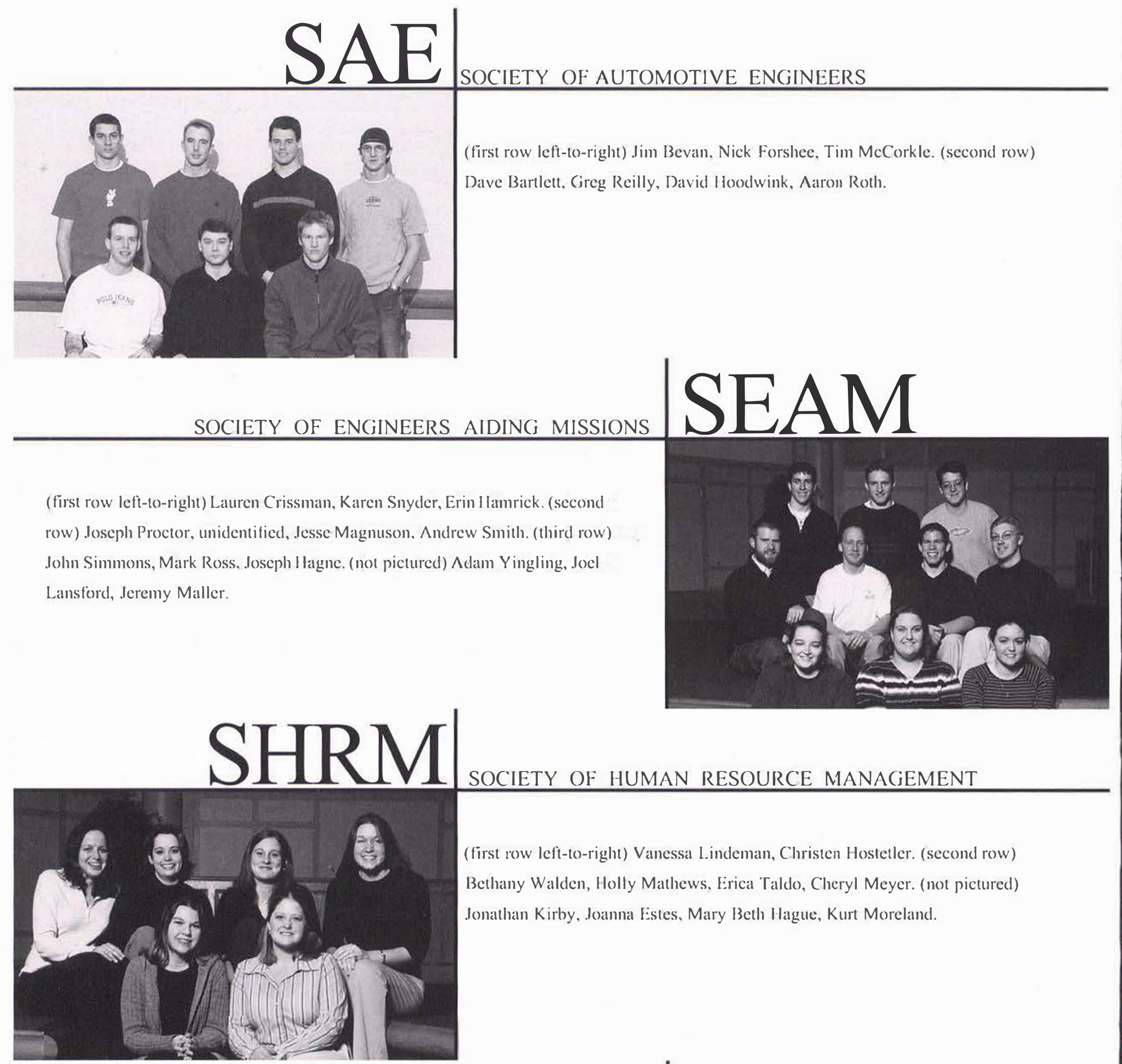

(first row left-to-right) Vanessa Lindeman, Christen Hostetler. (second row) Bethany Walden, Holly Mathews, Erica Taldo, Cheryl Meyer. (not pictured) Jonathan Kirby, Joanna Estes, Mary Beth Hague, Kurt Moreland.

SOCIETY FOR TECHNICAL COMMUNICATIONS

(first row left-to-right) Amanda Olsen, Jo^nne Willett, Rachel Shaver, Jenny Bonham, Jillian Mistak. (second row) Katy Hult, Laura Jolly, Kimberly Eridon, Rachel Mitchell, Alissa Black, Lisa Marie Ables. (third row) Ashley Vitaliti, Jen Castellani, Leah Cooper, Jessica Sobonya, Jemnifer Walker.

\section{STC}

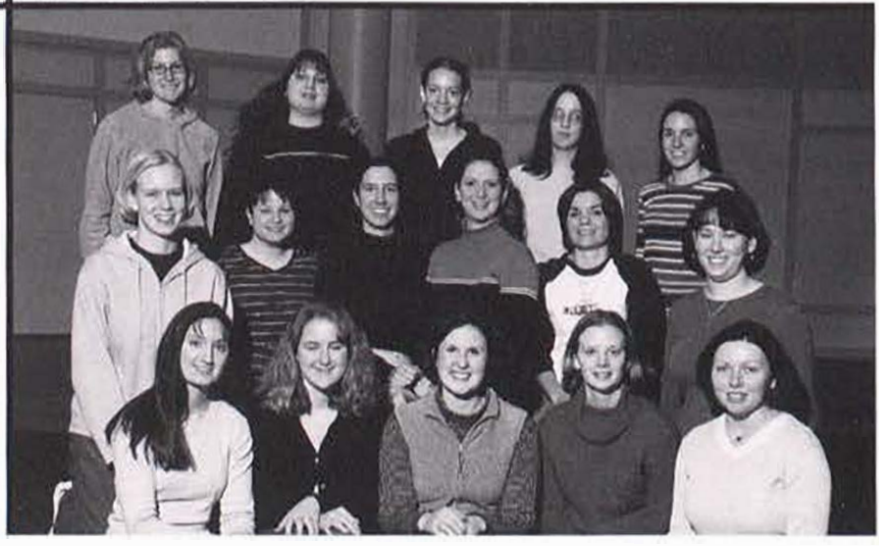



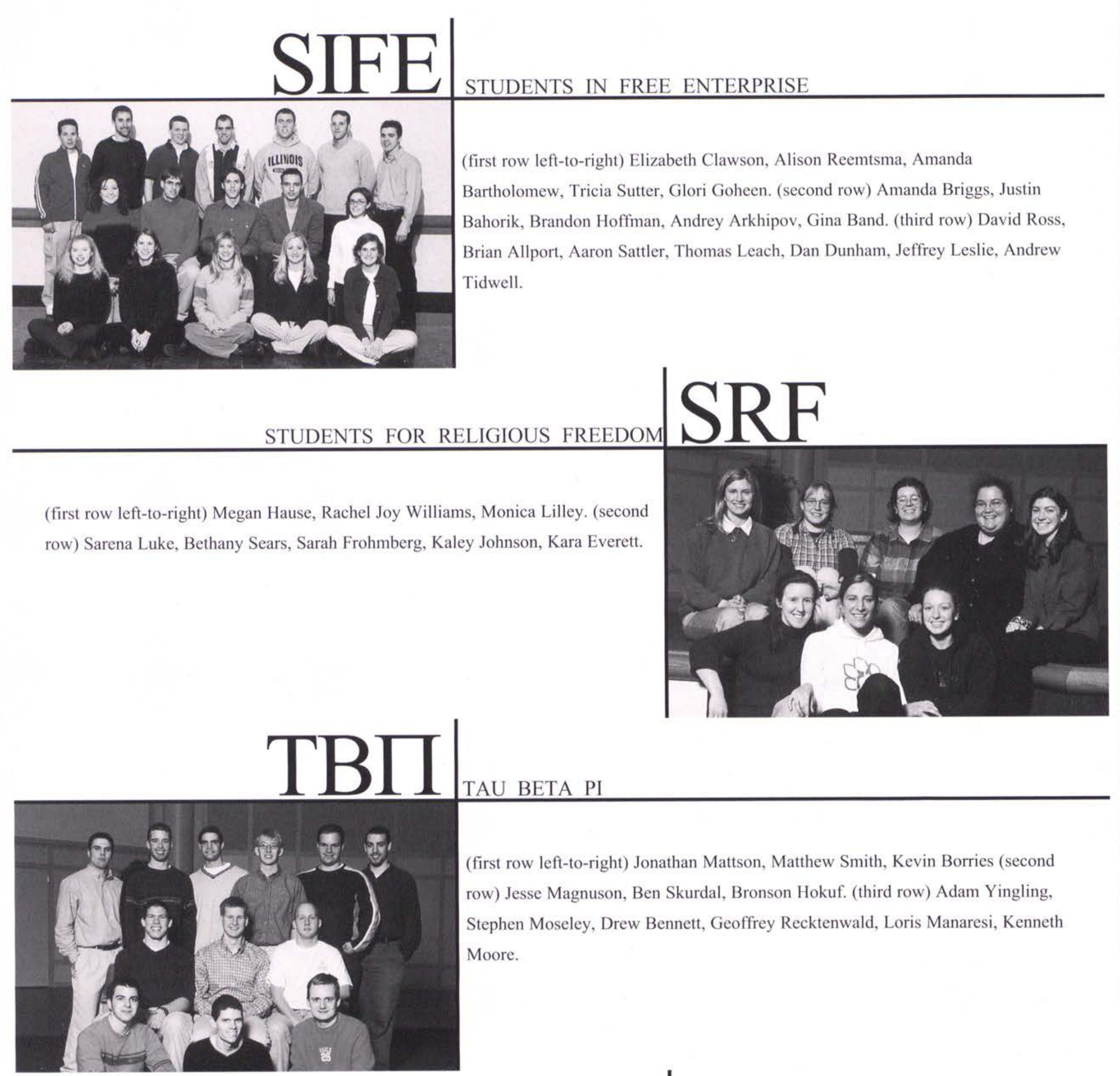

(first row left-to-right) Jonathan Mattson, Matthew Smith, Kevin Borries (second row) Jesse Magnuson, Ben Skurdal, Bronson Hokuf. (third row) Adam Yingling, Stephen Moseley, Drew Bennett, Geoffrey Recktenwald, Loris Manaresi, Kenneth Moore.

TAU DELTA KAPPA

(first row left-to-right) Lisa Wendl, Allison Krizo, Kimberly Eridon. (second row) Sharon Foley, Christine Fairchild, Sara Firebaugh. (third row) Melissa Stinson, Liz Zeron, Charis Nims, Daniel Cross, Jeremy B. Pooh, Alicia Marsh, Christina Papke. (not pictured) Josh Wallace, Diamond Redmond, Tim Gilmour, Dave Nickerson, Sarah Bowman, Alyson Perry, Rubie Maybury.

\section{$\mathrm{T} \Delta \mathrm{K}$}

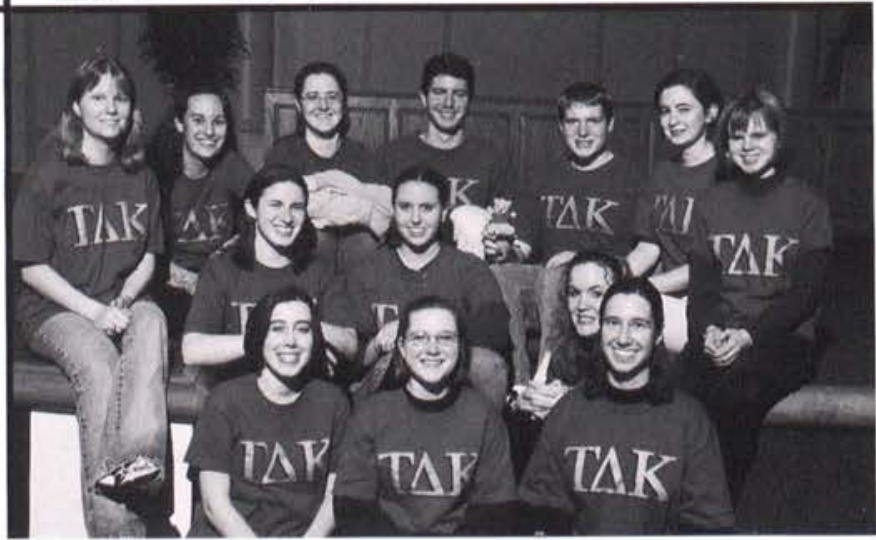




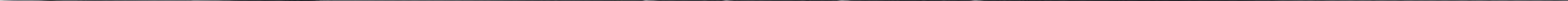




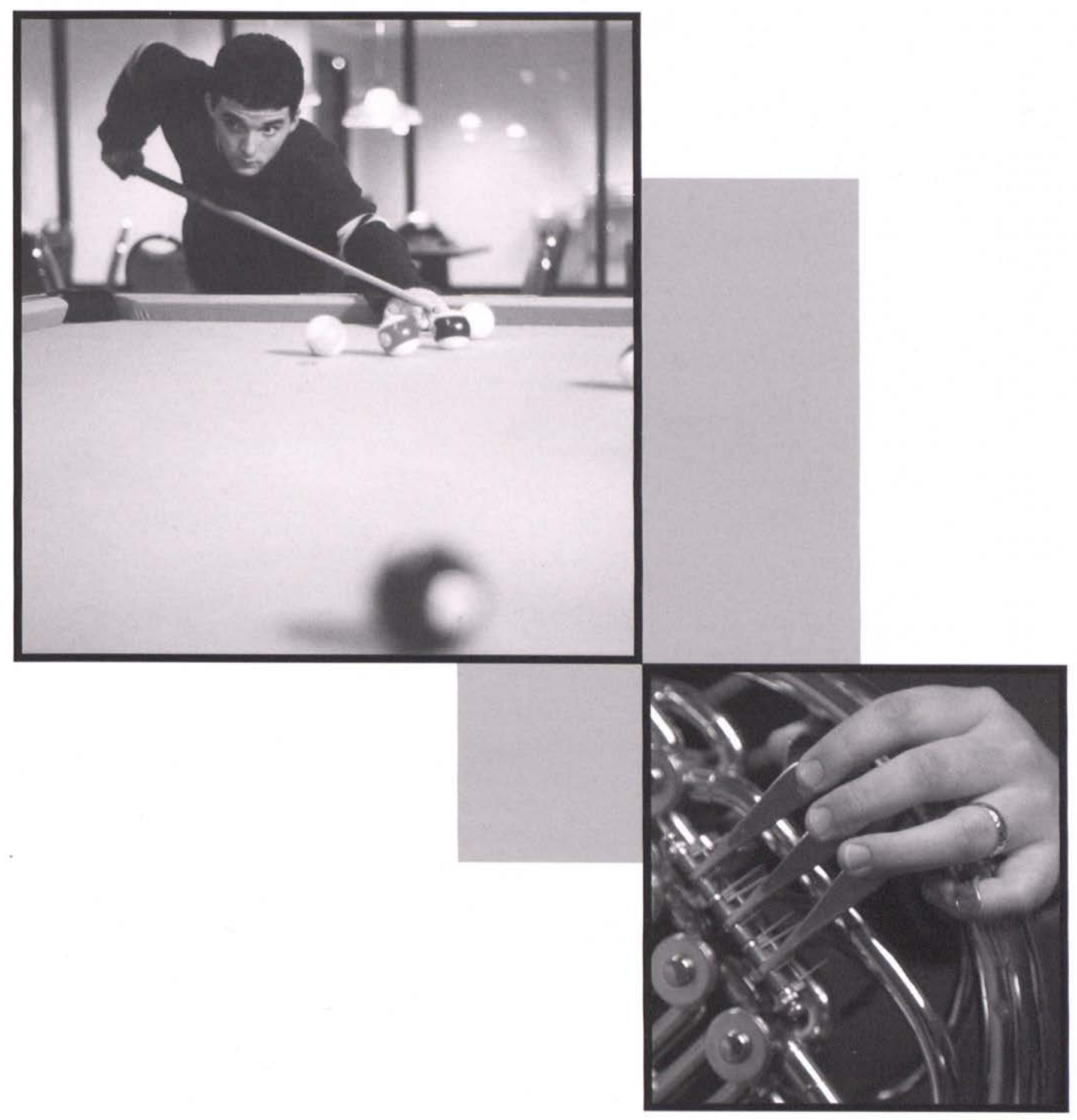

AGTIVITIES 

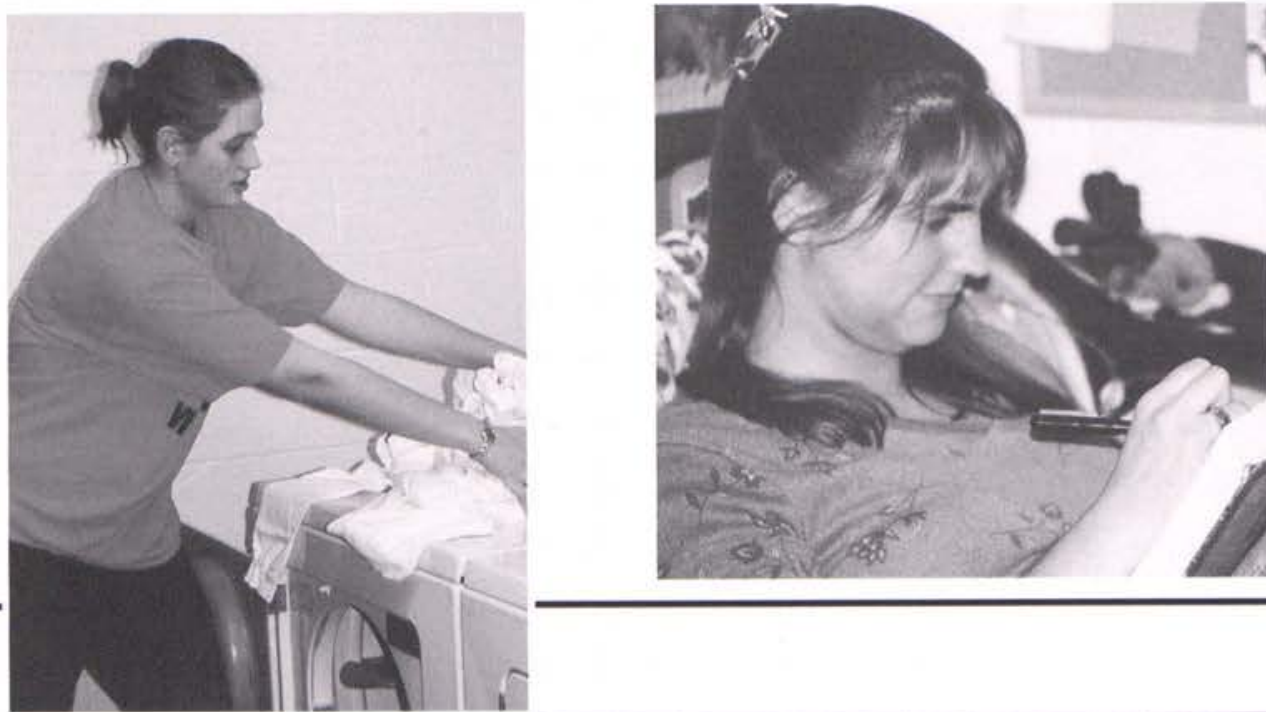

Kimberly Edlund, a junior, looks excited after a mad dive across

the ping pong table to save her game.

Although it feels like a waste of time and money, that $\$ 1.75$ for a load of wash is necessary every couple of weeks.

Roommates check their new make. overs once more before heading out the door for their pick-a-date.

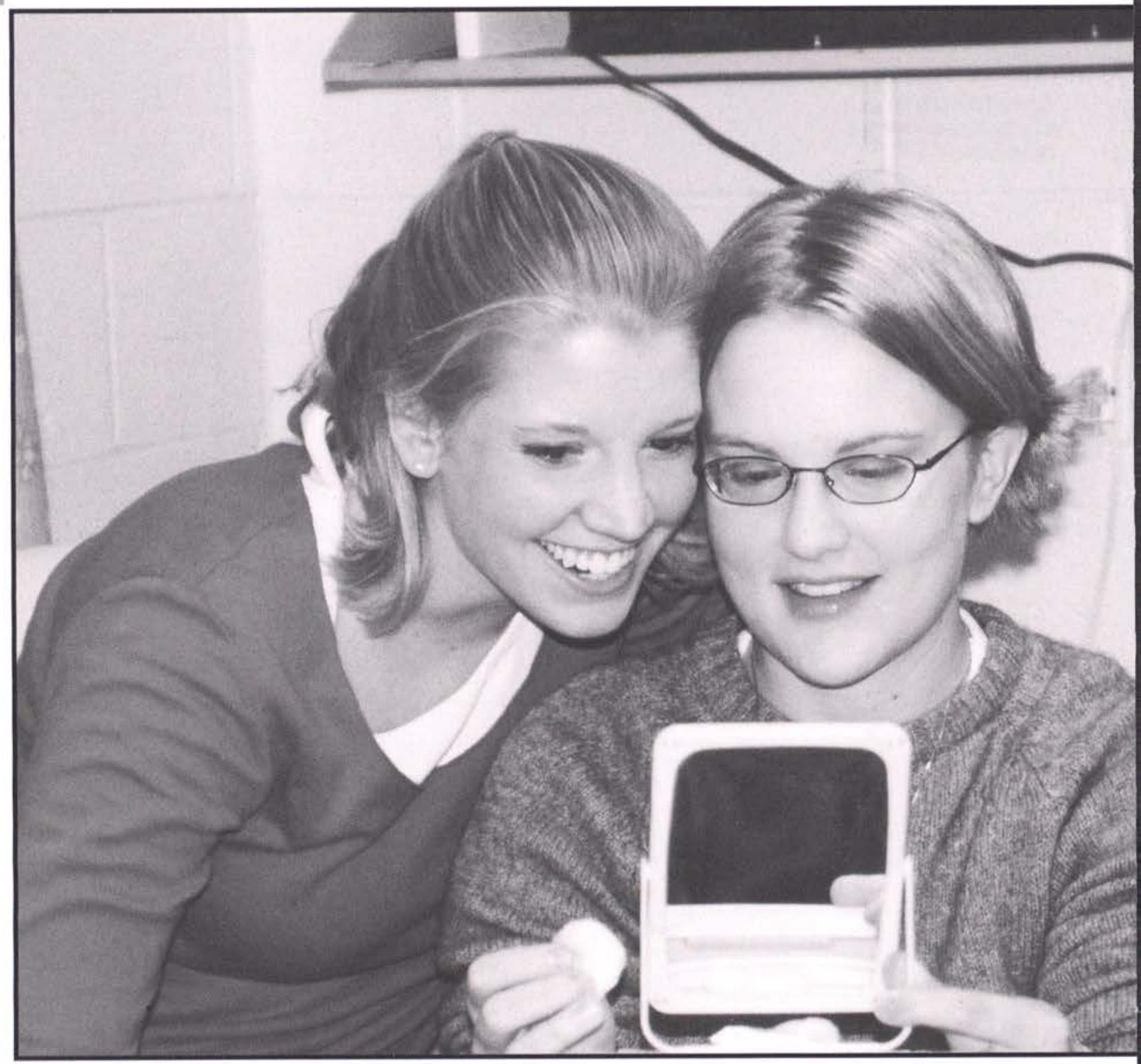

some time

out of her busy

day to pray and read her Bible.

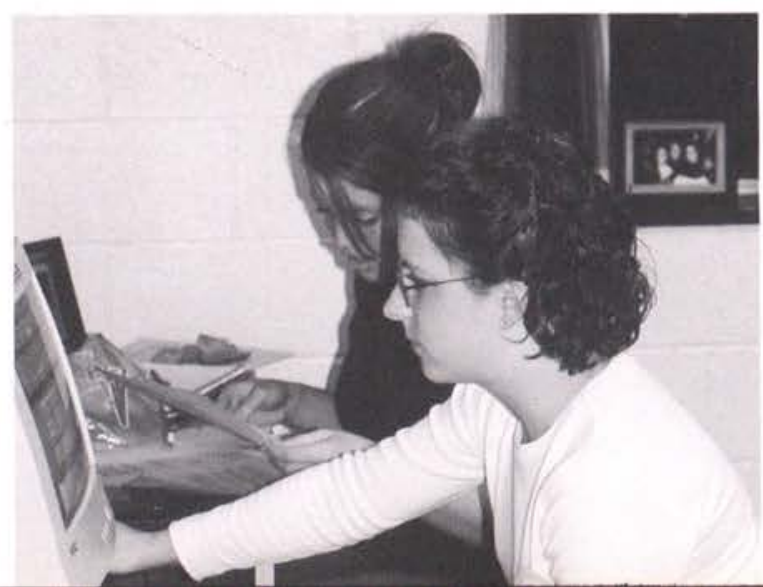

Girls spend most of their time in the dorms doing homework, talking with one another, or checking their e-mail every 10 seconds. 


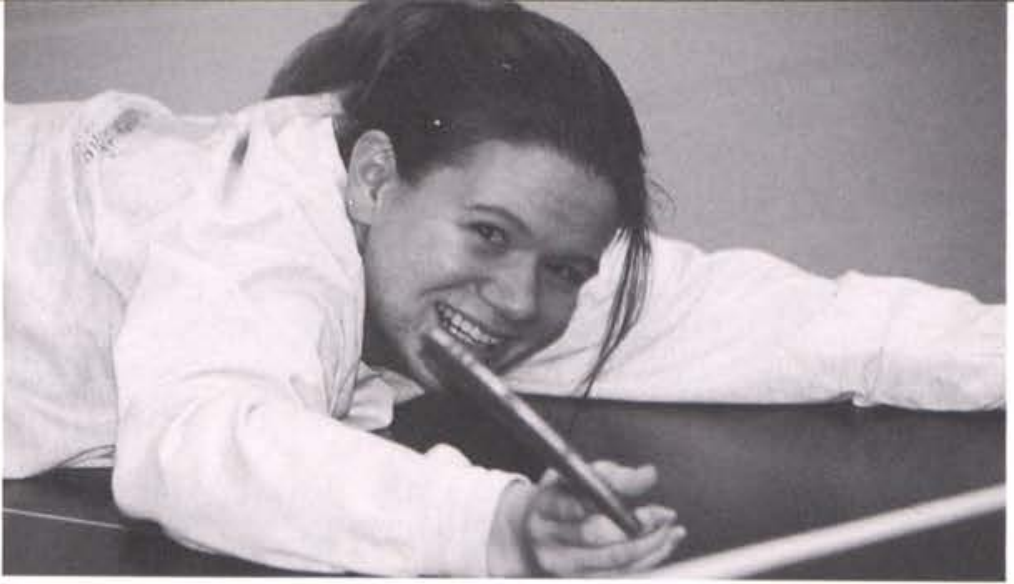

Women's Residential Life

\section{Close to Home}

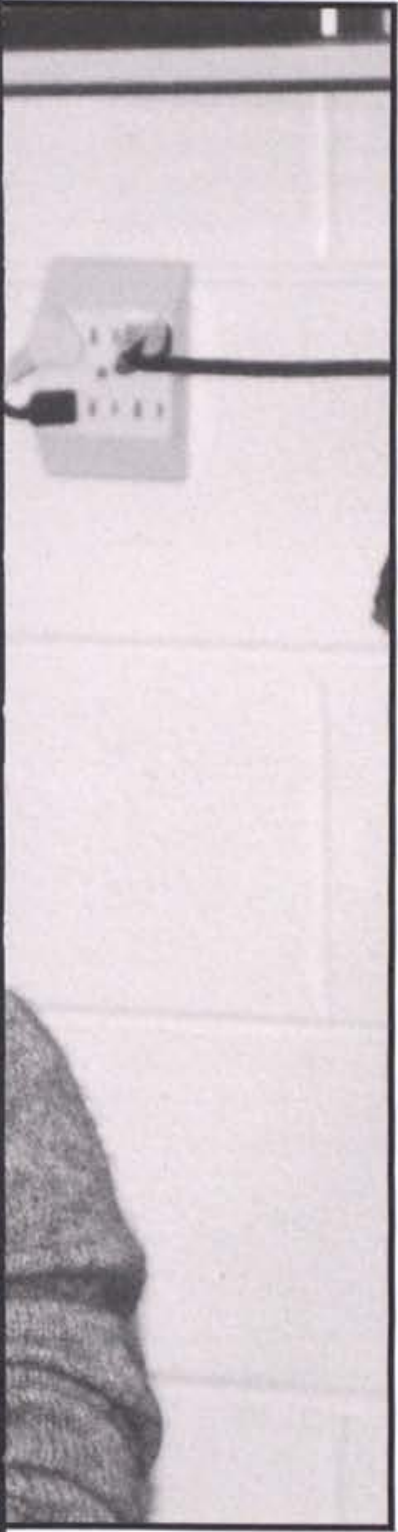

Maddox lounges offer enough space for girls to bring their keyboards to freshen up their musical talents.
Dorm living is close to the heart of nearly every student of the Cedarville campus. Late nights, snack food, giggles, squeals, ring downs, the soft music of Delilah, and the loud sounds of N'Sync are some characteristics of women's dorm life that have trickled down through the ages and through the halls.

Residence Life is constantly changing, and new members of the staff this year were Courtney Atwell, RD of Printy, and Amy Dirr, RD of Maddox.

The Residence Life theme for Resident Assistant training week was "Life Means so Much" taken from a song written by Chris Rice. Angela Rudd, a Resident Assistant in Johnson, commented that the theme helped her not to be distracted by the details and to make every day valuable. She was taking advantage of the theme in her hall meetings and said, "We talk about living a purposeful life and just the way that God has created and chosen and gifted us for His purpose, and I think the two concepts are closely related."

While many students looked forward to moving off campus, others liked the unity and family-like atmosphere of the dorm. Cheryl Gumprecht, a senior of Johnson, said, "I like the way the dorm keeps you connected with the campus. It's also convenient and close to classes. Living with 100 girls, there is always someone who you can talk to and help or receive help from."

Cedarville University liked having its students on campus, and building the new dorm behind the track will allow for that. The new residence hall will be completed by fall of 2002 and will add many additional spaces for women to enjoy residence life in the new year.
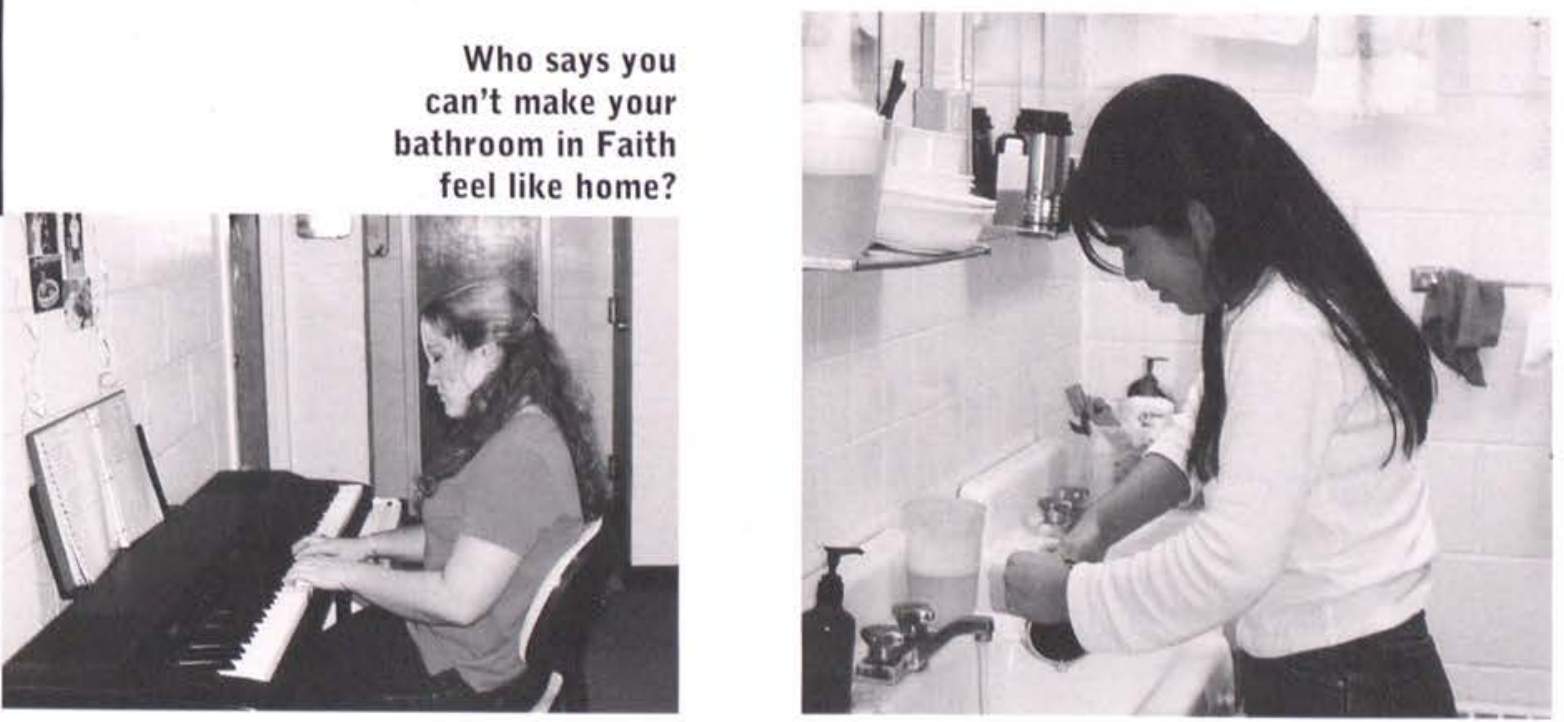


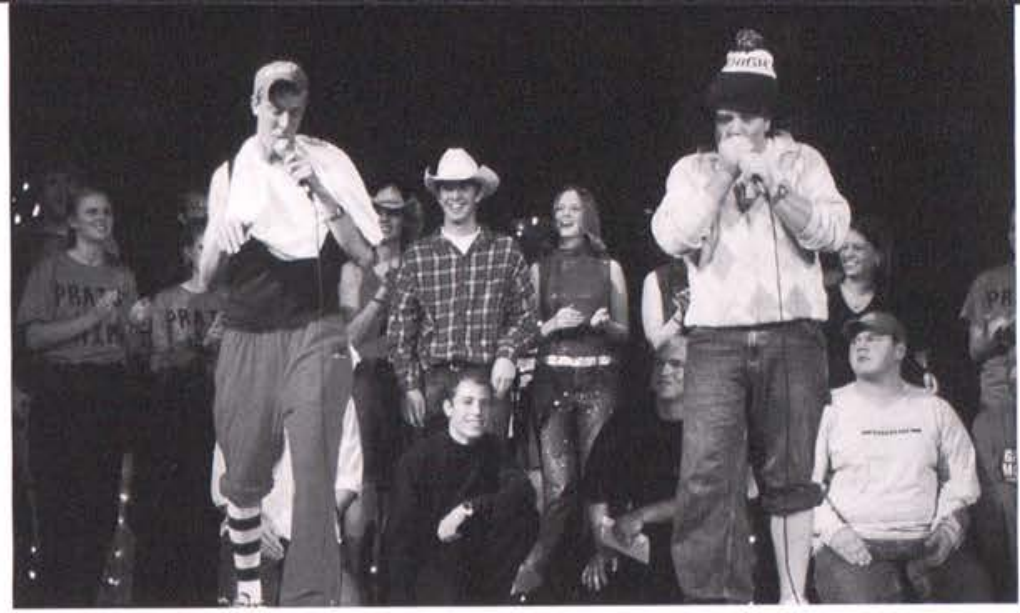

Homecoming, the New Student Talent Show, Rock the Vote, Art Week, Elliv, and Alpha Film Festival were a handful of the spectacular events of the 20012002 school year planned by the Student Government Association that put a little twist on the "traditional" activities.

SGA president Seth Martin said, "SGA seeks to serve the entire student body. We try not to focus on one particular set of students but rather the various groups of students we have on this campus." In line with this goal,

Homecoming, instead of the usual banquet in Alumni Hall, was a Hawaiian festival complete with leis, hula dancers, and many colorful outfits.

Art Week and the Alpha Film Festival were also an added change to the list of SGAsponsored events for the year. Art
Week included a performance of the drama Art and students' art on display in the lower level of the Steven's Student Center. Students got a chance to see studentproduced videos during the Alpha Film Festival.

Martin explained, "We wanted in everything we desired to challenge students to live out their faith as the relationship with Christ that God intended for us to have void of rules, rituals, and indifference. Going hand in hand with that is challenging the student body to think."

The servanthood of the SGA leaders made all these events happen. Vice President Lisa Pederson said, "We were here to serve the students in any way that we could. We tried to be an open door for them. We had an awesome group that sought to serve and sacrifice."

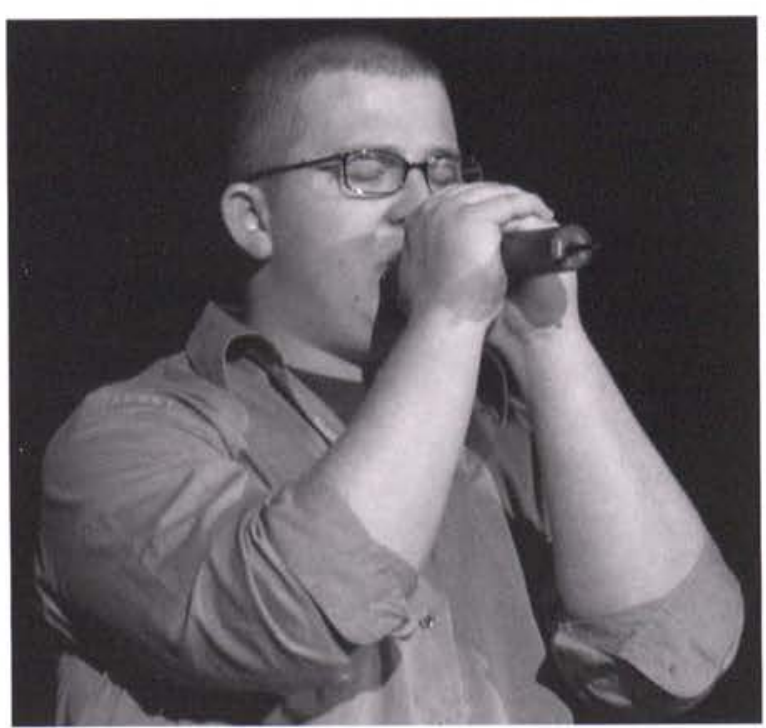

\section{A band performs \\ "Ants are March- ing" live to an excited audience.}

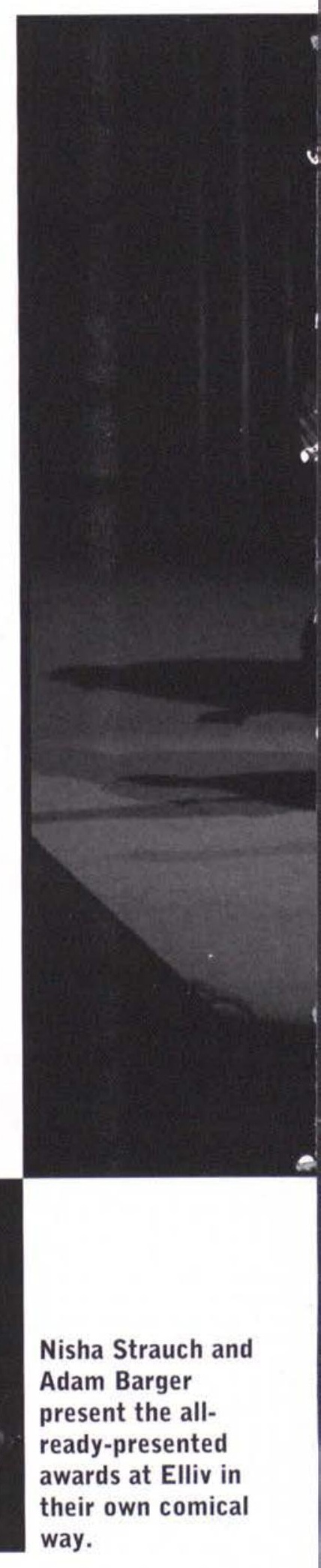



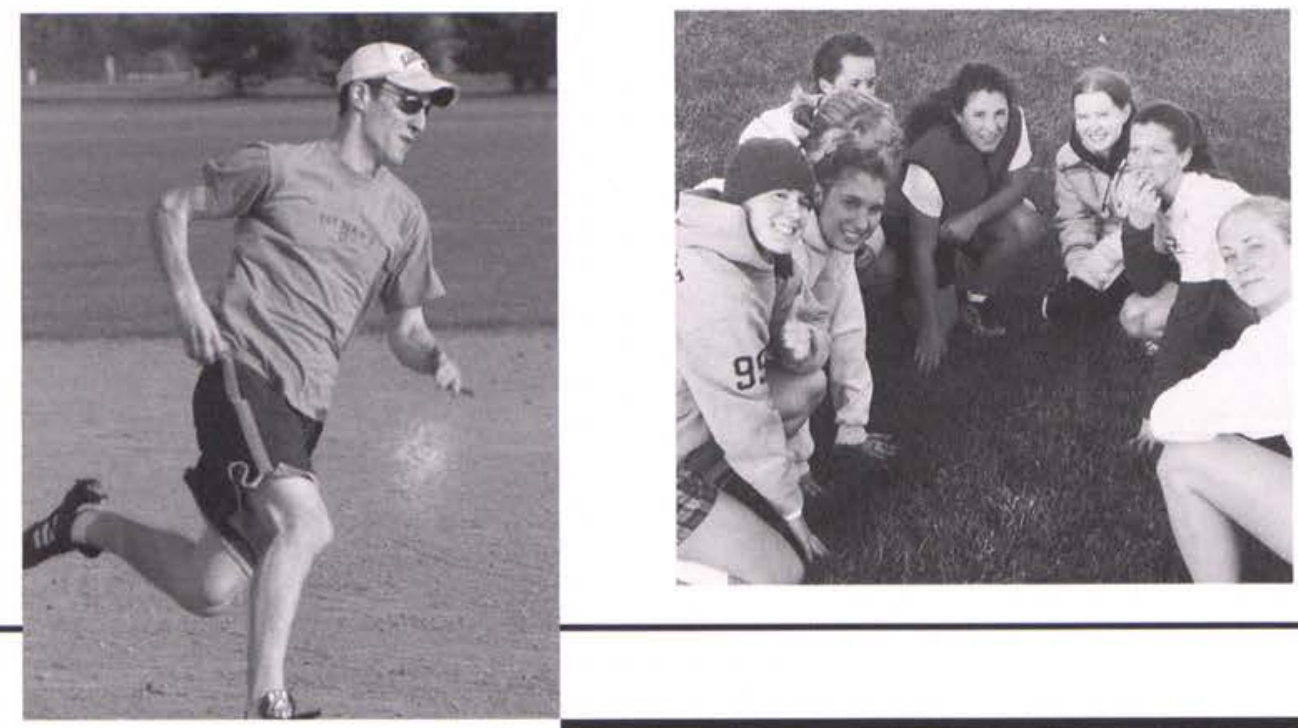

Real men wear sweatbands to play basketball.

"Bring it on!"

This hard core

intramural team huddles up to strategize before the game.

Charles Kirby rounds the bases quite satisfied with his homerun.

Beth Walters and Leah Gombis team up to work their magic and win the intramural t-shirt.
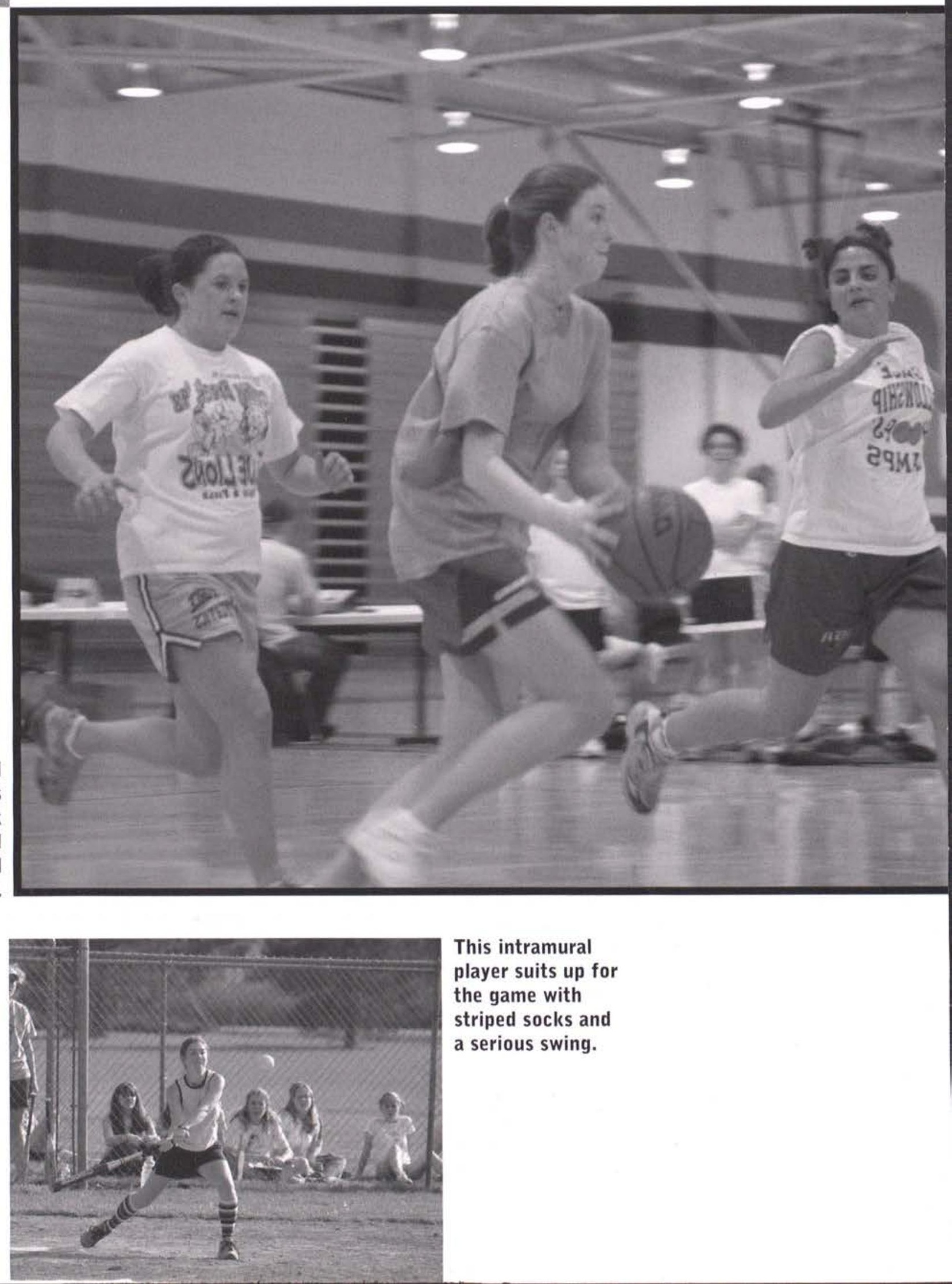

This intramural player suits up for the game with striped socks and a serious swing. 
Cedarville's Pep

Band adds energy

and excitement to

the atmosphere of the basketball

games.

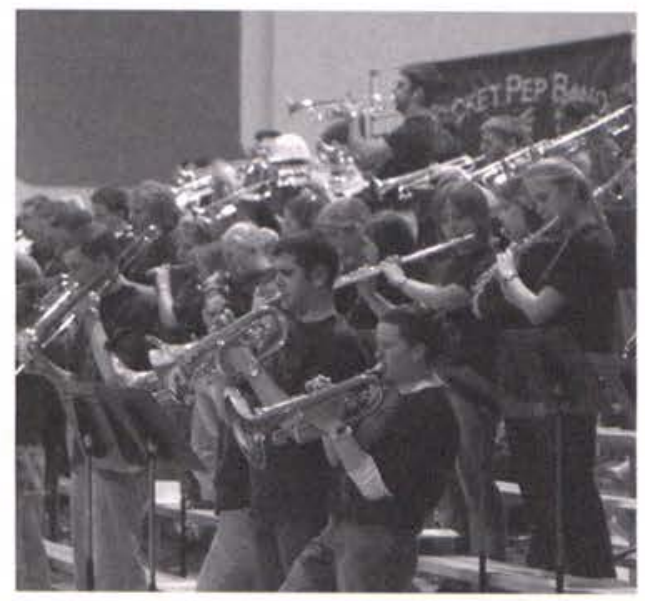

Cedarville's Pep

Band provides

lively tunes at the basketball games.

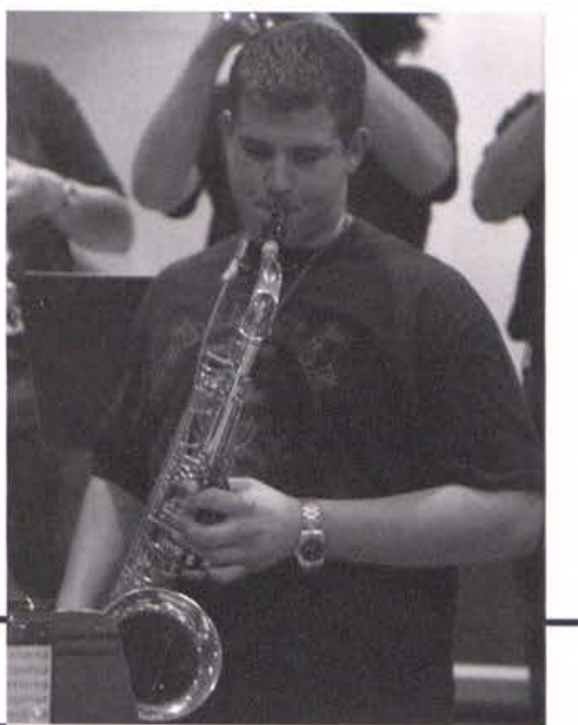

This Pep Band member is putting forth all he has playing the saxaphone.
To help make the game start out right, Cedarville proudly displays its flag as the fans go wild at the Cedarville Jacket basketball game.

The frenzied bee takes a break from

buzzing around the gym to strike a pose.

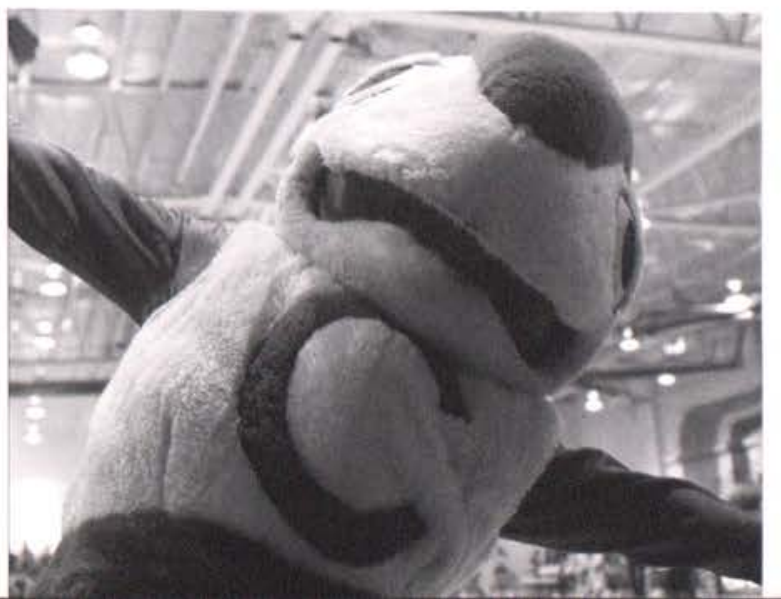




\section{Concert Chorale}

The Concert Chorale has a membership of almost 100 voices selected by auditions in September and May. Repertoire is chosen from a wide spectrum of musical styles including choral masterpieces, sacred classics, anthems, spirituals, and contemporary works. Numerous performances are presented each year on campus as well as in churches, schools, and other venues. In recent years the Chorale has toured in the Czech Republic, Austria, Puerto Rico, and England.

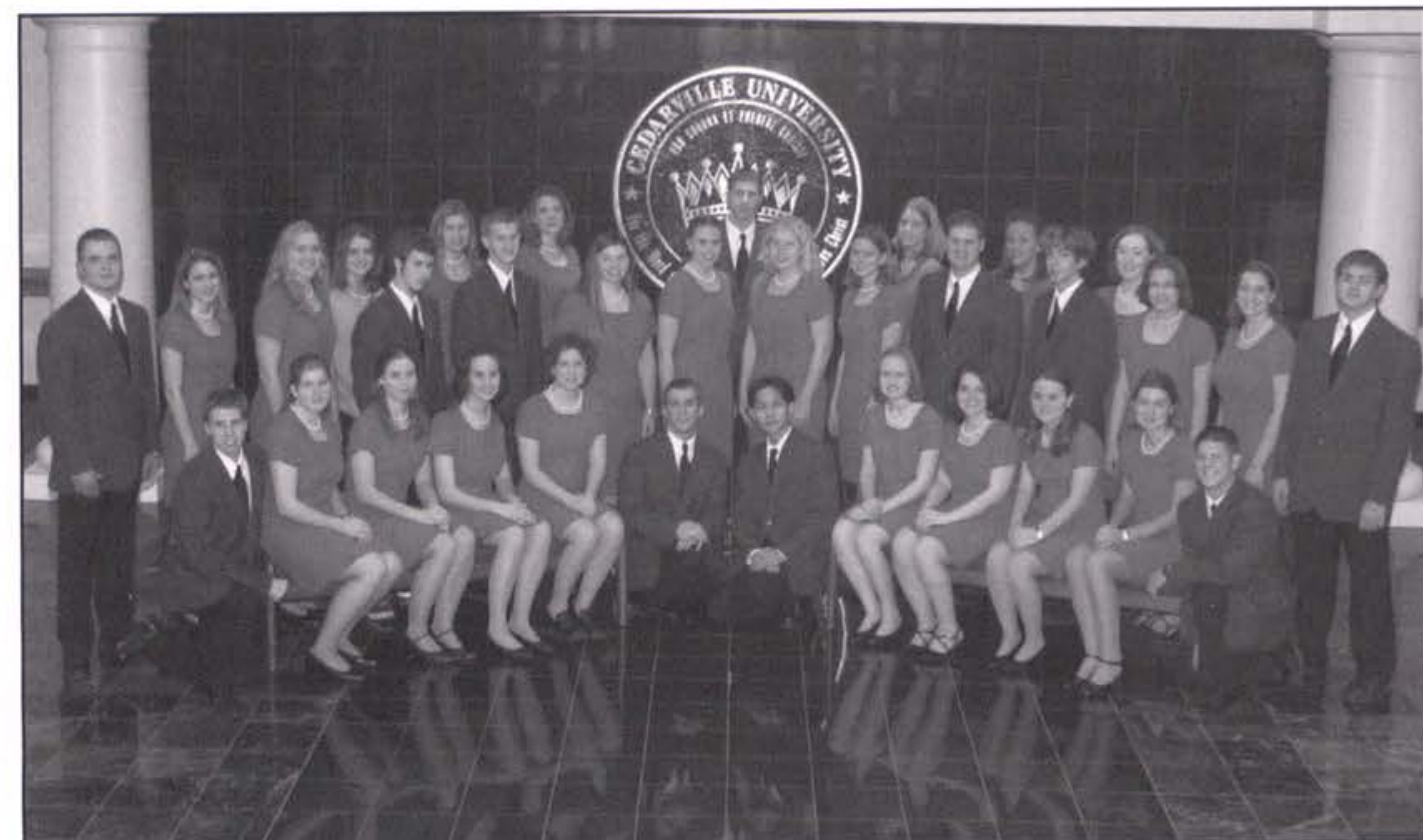

\section{Jubilaté}

Jubilaté is a ministry team of approximately 40 vocalists and instrumentalists selected by audition. Repertoire is selected from a wide spectrum of musical styles representative of the various evangelical traditions. Numerous concerts are presented on campus and in churches with special application to weekend music ministry workshops and "event-oriented presentations." Jubilaté meets twice each week and takes an annual tour during the Spring quarter.

\section{Men's Glee Club}

The Men's Glee Club has a membership of 50 voices selected by auditions in September and May. Traditional repertoire is performed on and off campus throughout the school year including spirituals, hymns, contemporary Christian, occasional classical, and popular music. Tours to surrounding states are scheduled annually.

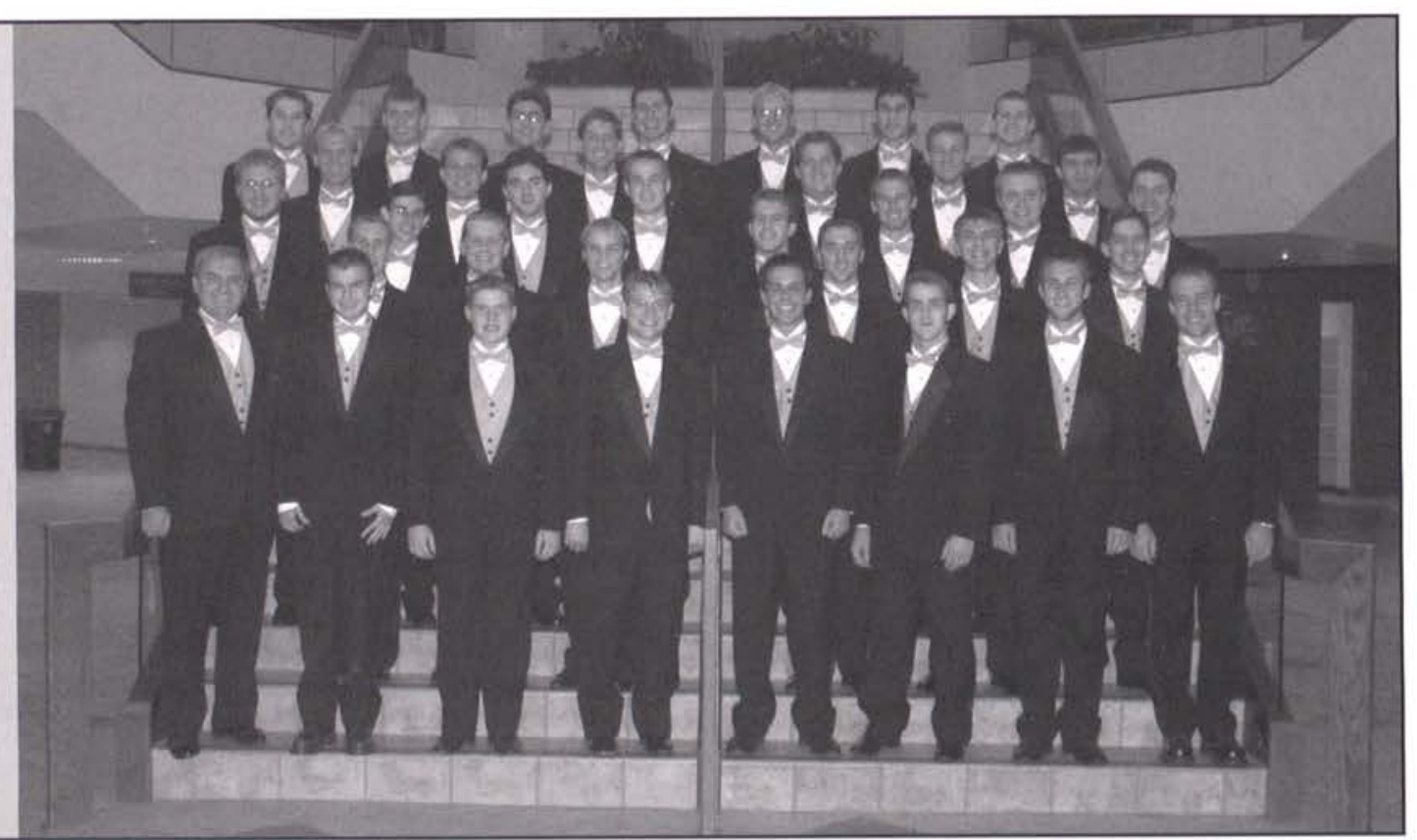




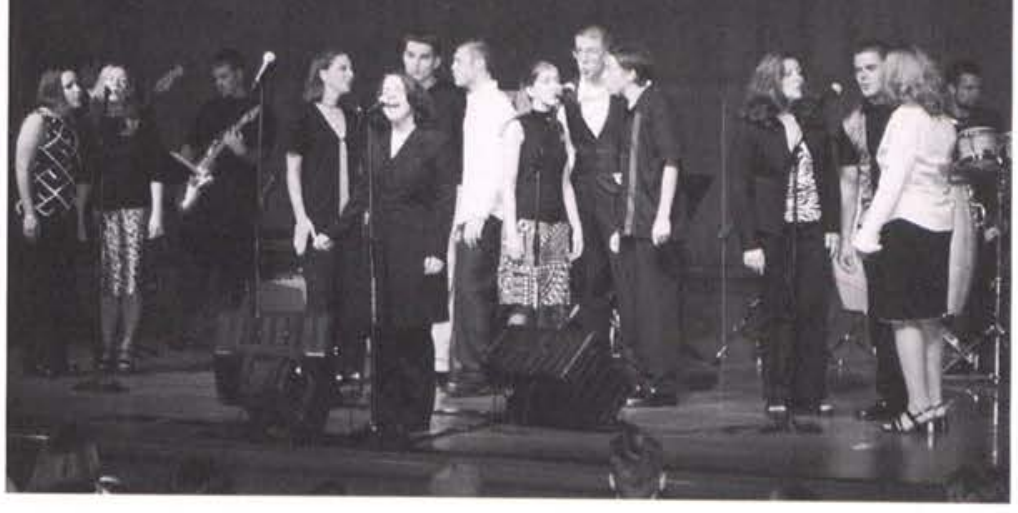

Music Groups

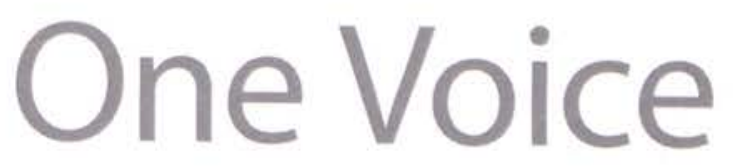

The Cedarville University music department offered numerous opportunities for students and many others to see and hear the various music groups perform. These performances came in the forms of community concerts, chapel presentations, and tours. In beautifully coordinated concerts, combining the various vocal and instrument talent, the music department delivered a wonderful display of their musical talent for the community to enjoy along with the student body.

Chapel performances offered the music groups a chance to perform for the student body. Men's Glee Club, Concert Chorale, Women's Choir, and Jubilaté added their own personal flair to numerous chapels. Symphonic Band participated as

special music for many of the formal occasion chapels. Each group brought its own unique flair and an exciting change of pace to fellow classmates.

While all the groups offered opportunities to perform on the Cedarville campus and locally, some also offered their performers a chance to travel. Jubilaté, Men's Glee Club, and Women's Choir received the opportunity to share the ministry of their music with people outside the state of Ohio. Concert Chorale enjoyed the experience of touring in China.

The music department had the distinctive opportunity of witnessing to many people through the use of music. Using the talents God gave many students, the music groups have excelled in their numerous performances.

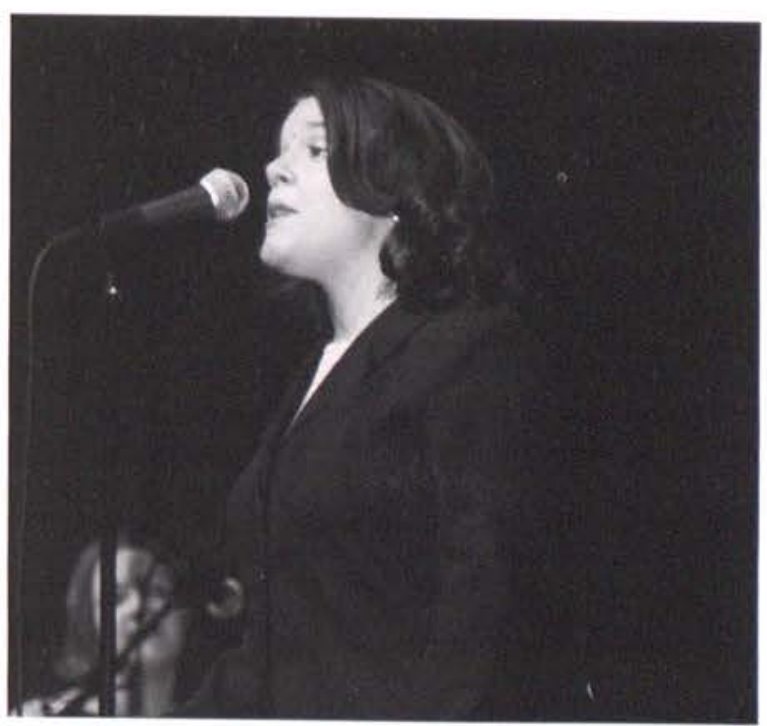




\section{-Sound of Music mincraum}

The musically inclined Cedarville students had the opportunity to participate in a myriad of musical opportunities.

The music department offered the students a selection of nine performance groups, covering a wide assortment of musical genres, from jazz to classical, from hymns to contemporary. Almost all students on campus could find an appropriate style to satisfy their assorted tastes.

The University Jazz

Singers, a new group for the 2001/ 2002 year, gave an excellent performance during fall quarter. The response to this new group was overwhelming, shown by people sitting in the aisles because the chapel was overcrowded. The Symphonic Band and Orchestra gave several concerts throughout the year. Lana Christensen, a freshman music major and member of Symphonic Band, recalled,
"Theater Music, one of ourwinter concert selections, was one of the more challenging pieces that really pushed us, but in the end, it was one of our most improved and well played pieces at the concert."

These groups encouraged both vocal and instrumental talents in their participants, offering a challenge for excellence in all musical areas. Their many performances throughout the year gave the students an excellent opportunity to display their Godgiven talents in music. Such performances included travel to different states, chapel performances, concerts, and festival participation.

Due to the events on September 11, 2001, a patriotic theme was included in the year's performances beyond that of the annual Memorial Day Concert. God Bless America became a theme for the music department.

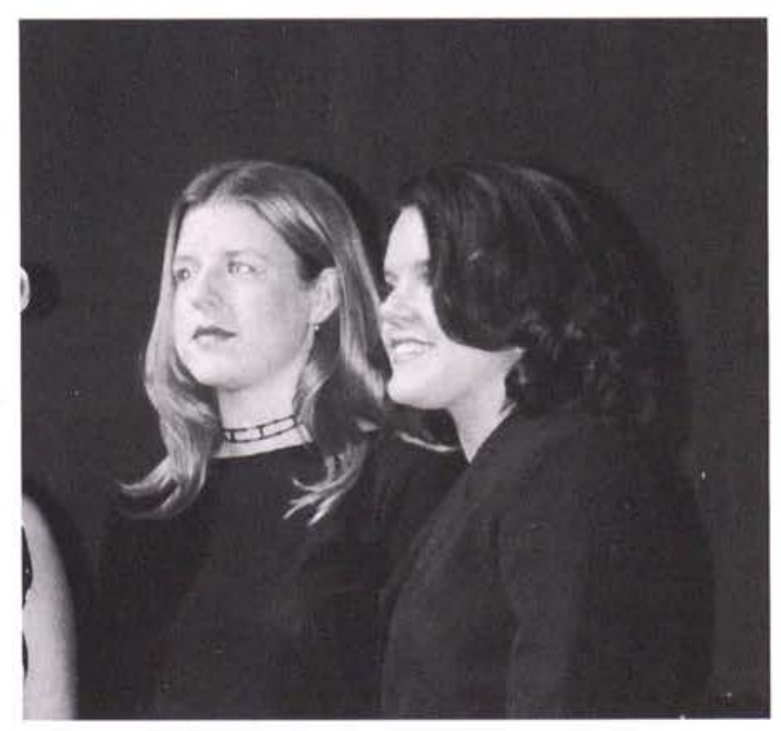

Team members 


\section{Symphonic Band}

The Symphonic Band is composed of approximately 90 members selected by audition. Performing quality band literature, the band has appeared before state and national conferences and in concert under the baton of such guest conductors as Jim Curnow, George Strombeck, and George Wilson. Several concerts are presented each year on campus, in churches, and schools.

\section{Jazz Band}

The Jazz Band has 15-20 members selected by audition. The group performs music ranging from the Big Band era of the 30 's and 40's through contemporary jazz arrangements. The band is active in both campus and off-campus events.

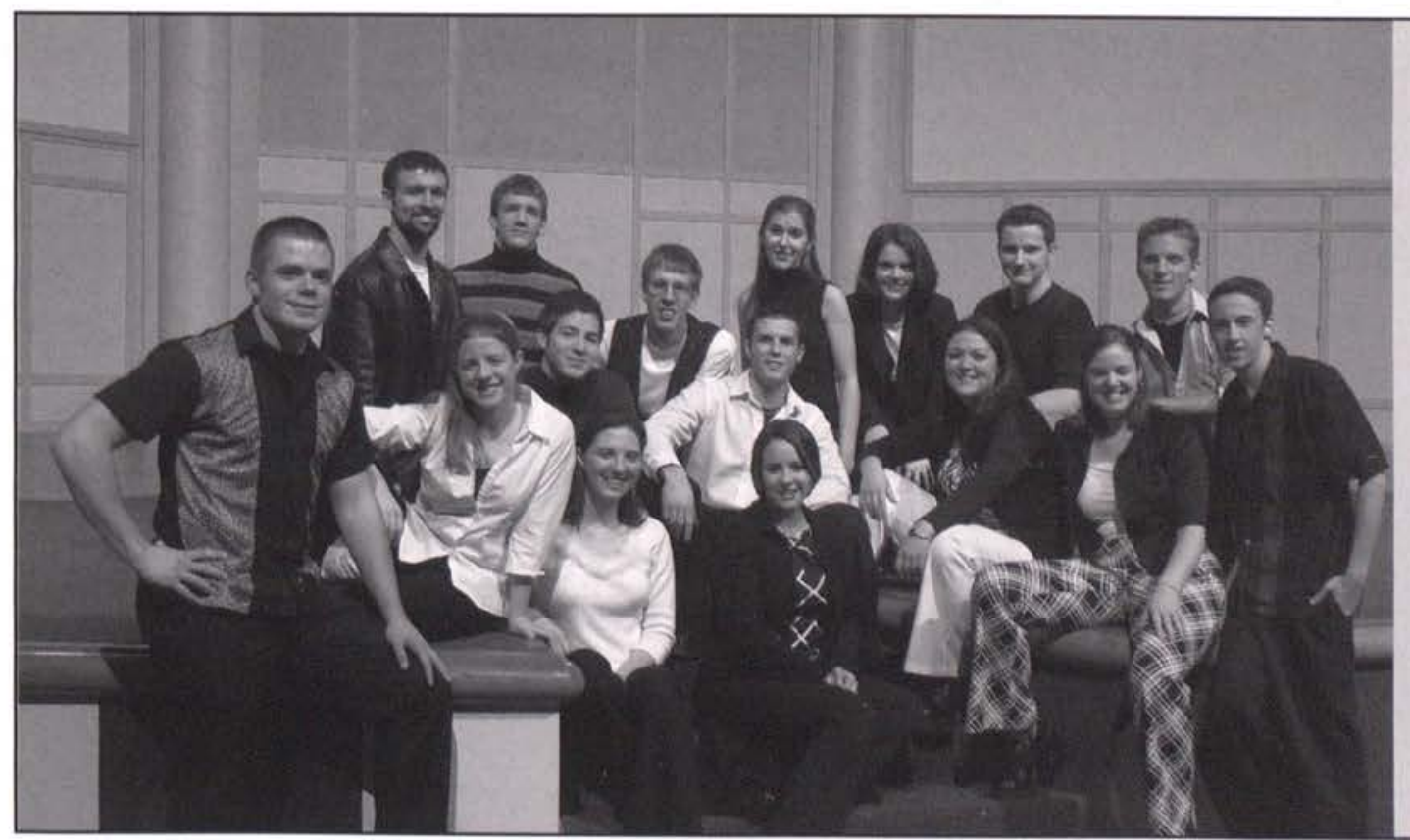

\section{University Jazz Singers}

The University Jazz Singers is a chamber group made up of 12-14 select voices, accompanied by an auditioned rhythm section of piano, bass, drums, guitar and percussion. Repertoire is selected from representative styles and eras of American jazz, as well as from other ethnic jazz traditions. The development of improvisational skill within the literature is emphasized among participants. Numerous concerts and festival participation are planned each year 

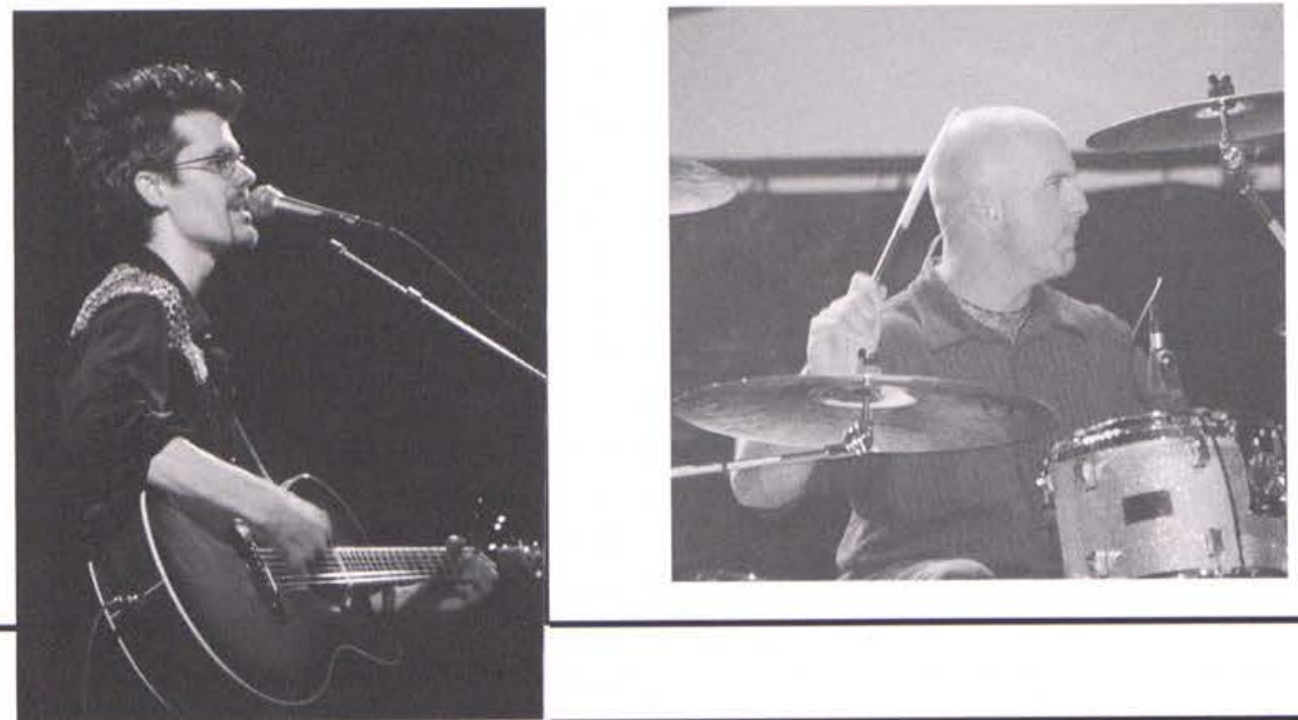

Solomon's Wish returns to Cedarville for the Youth Blowout Event.

Shawn Groves kicks off a concert with his award winning song "Coming Home."

FFH impresses an excited Cedarville crowd with their blend of worship and humor.

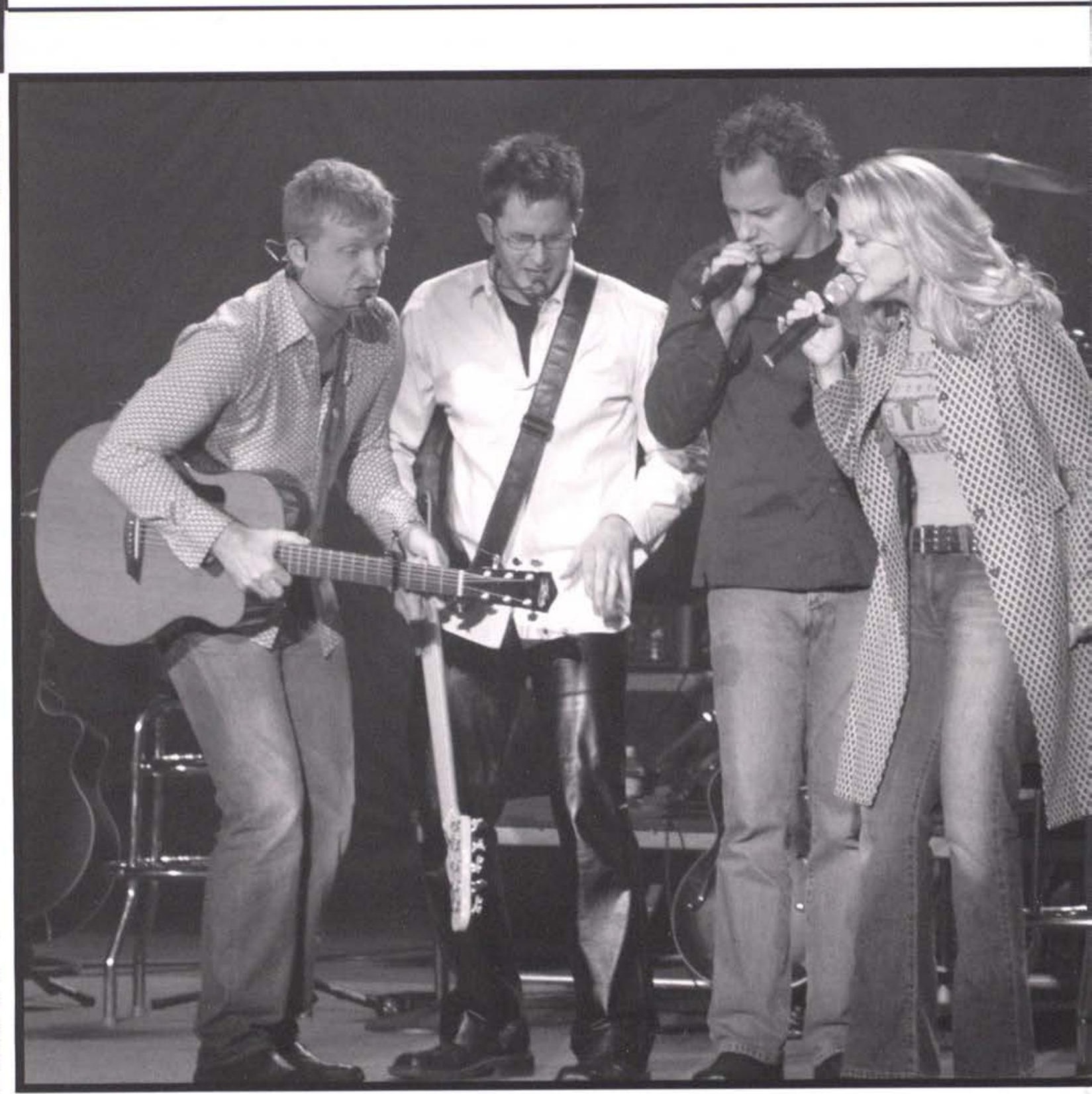

This drummer

plays to his heart's

content by back-

ing up Bebo

Norman.

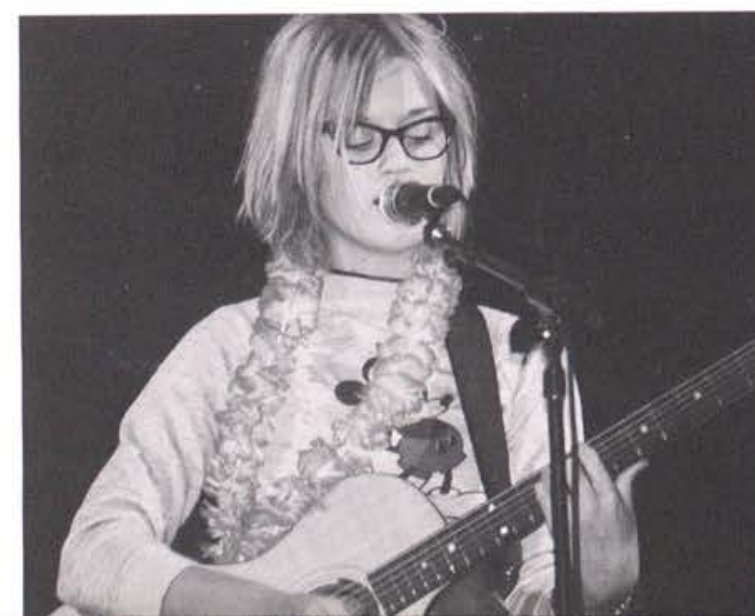

Kate Hudson

shows off her

young musical

talent and jokes

openly with the

audience. 


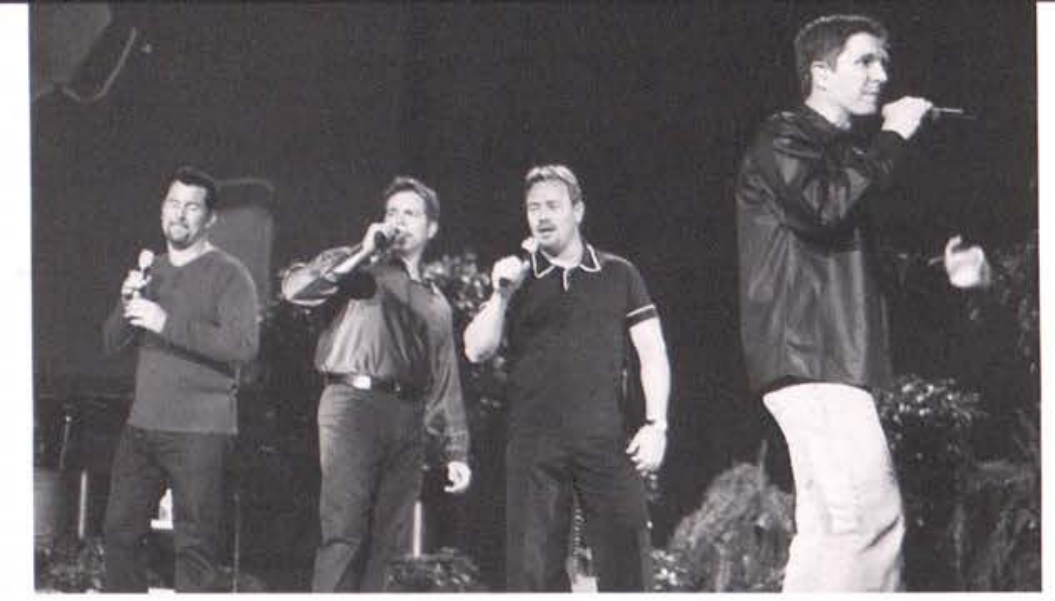

\section{Guest Concerts}

\section{New}

Cedarville University brought big musical names to the Dixon Ministry Center to entertain and edify students, faculty, staff and the community this school year. Special contemporary Christian music returnees such as $\mathrm{FFH}$ and Avalon gave concerts on the Cedarville stage drawing an increased number of fans.

For the SGA Homecoming Banquet/Luau on October 5, Bebo Norman came to the University as part of his Big Blue Sky Tour. He entertained the crowd with songs from his recent "Big Blue Sky" album and older favorites.

Norman's visit to campus was a huge hit, complete with female students screaming out marriage proposals from the massive crowd. $4 \mathrm{HIM}$ sang for returning alumni on October 13. Ten Shekel Shirt made an appearance at the Stevens Student Center Theatre on
February 23, and Avalon visited for Parents' Weekend on May 4. Freshman Eric Jingst said,

"I went to the Bebo Norman concert...[He] is my favorite Christian artist. I thought his concert was awesome. He is a great guitar player and a great singer.

Whoever scheduled him to come to Cedarville made a good choice."

Sophomore early childhood education major Elizabeth Weaver was pleased with the concert schedule as well. She said, "I went to the FFH concert. I really enjoyed how they got the audience to participate and be involved. It was also nice that they were willing to take time and do a gospel message saying why they were there singing in the first place. Most groups do not tell you how they got where they are today during the concert."
The band members are just as excited to be at Cedarville as the students.

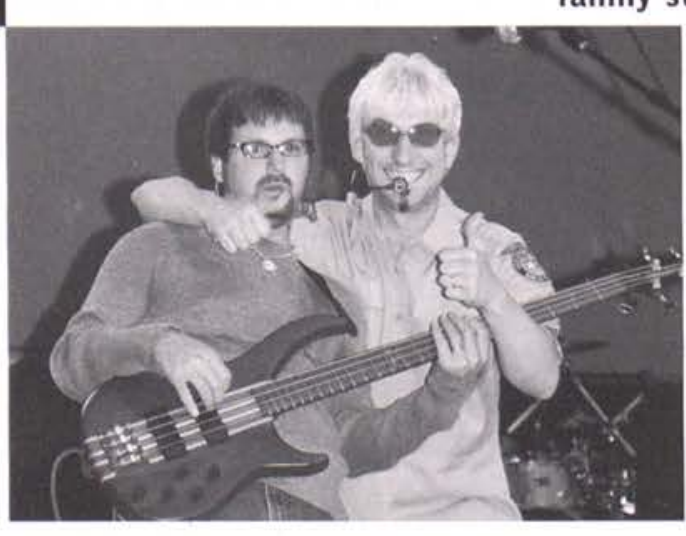

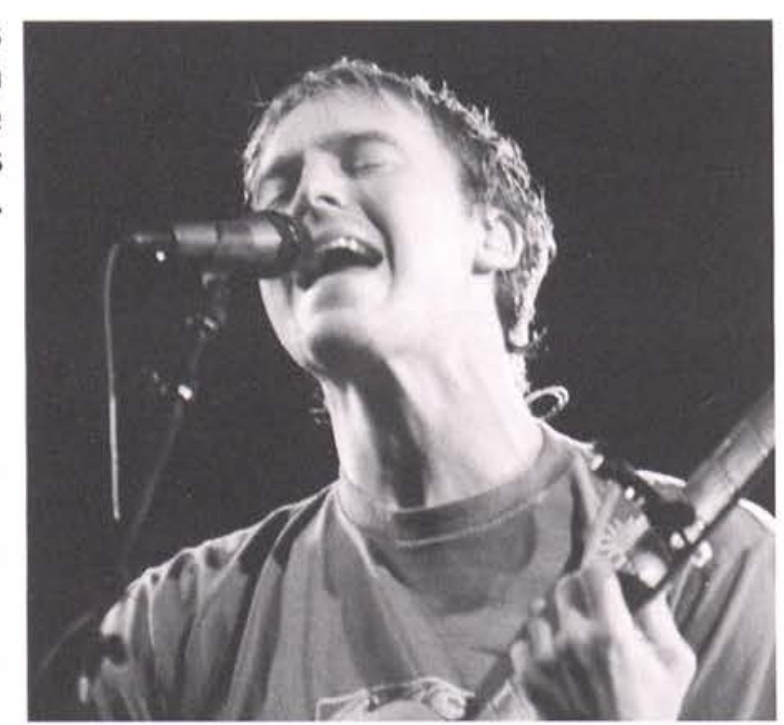




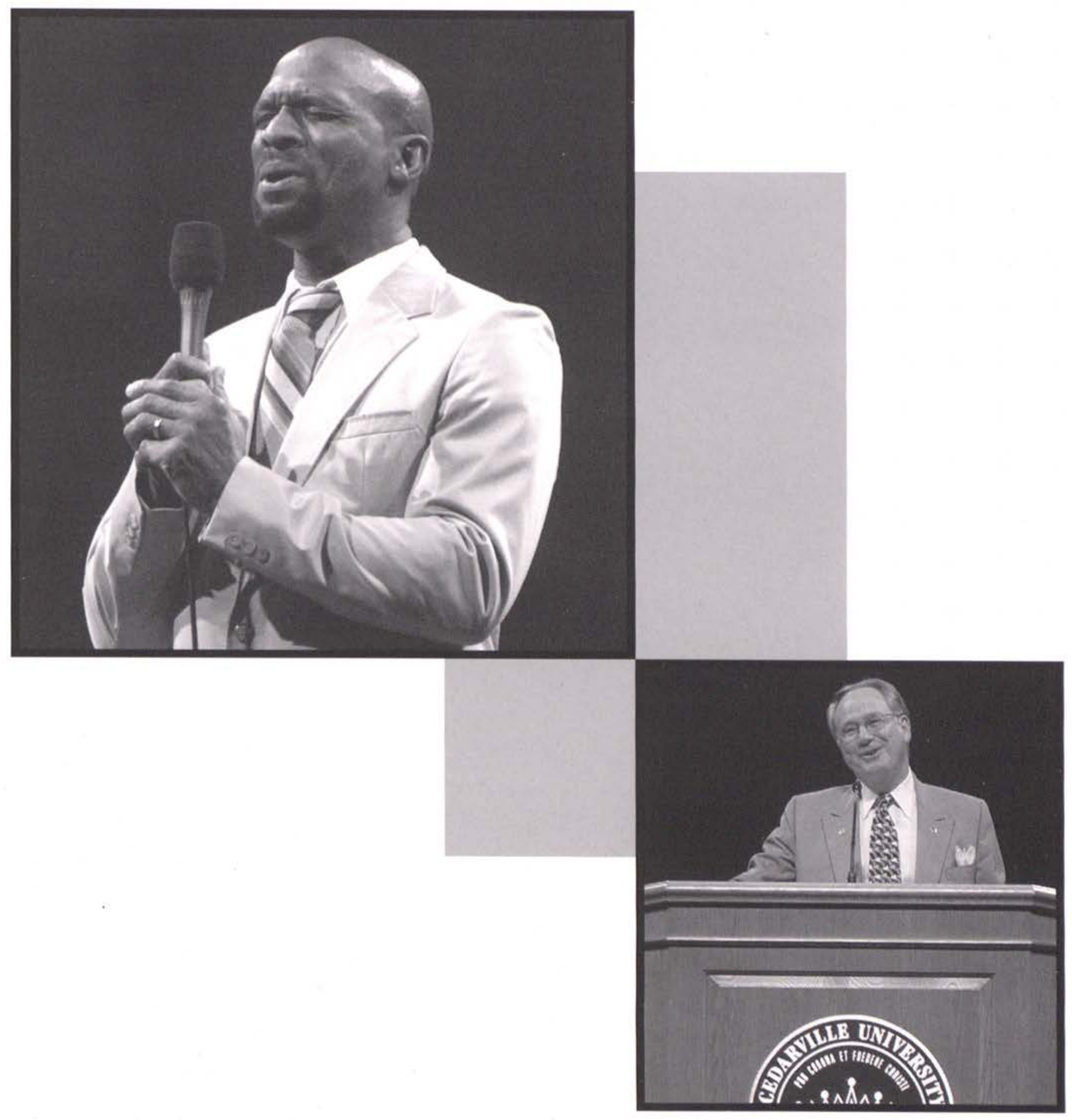

BHAPEL 
This year SGA upheld its reputation for presenting the most student-focused chapels of the year, making each Friday unique, entertaining, and spiritually encouraging. SGA Chaplain Kevin Batista shared his heart and God's Word with the student body, lifting them up in their daily Christian walks with his down-to-earth, caring personality. Speaking on topics such as watching what is said and the real love found in Christ, he provided solid biblical teaching and funny stories from his real-life experience. Batista said, "I have loved working with my team for SGA chapels and also with the SGA executive council. Being chaplain is an incredible opportunity to let God work through you, but most importantly in you."

Senior Ray Green led the worship team. His band, made up of Joe Strychalski, Adam McCune,
Matt Hofmann, Ivan Batista, Crystal Cripe, and Adam Dennis, gave the student body energetic praise music and an opportunity to worship corporately. Some favorite new songs among students were "Everyday" and "Give Me One Pure and Holy Passion.” Green said, "The opportunity to lead the student body in worship was an incredible privilege I will never forget. Ultimately though, working with close friends in preparation and execution of chapel were some of the most rewarding moments of the year."

\section{Of course, SGA chapels} were filled with videos, skits, games, and an abundance of laughter. Not only did students appreciate the action-packed entertainment, they found they were challenged to be more intimate with God as a result of attending.

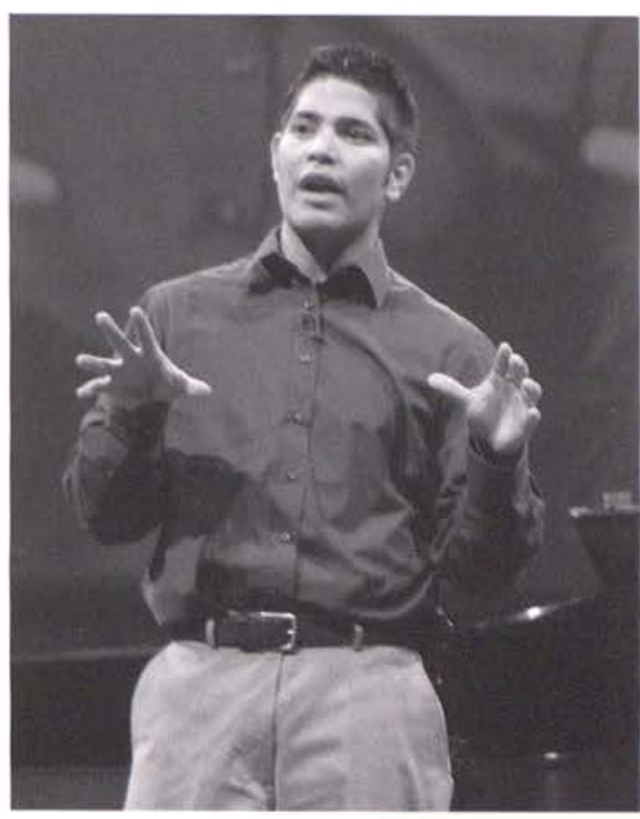

Kevin Batista challenges his classmates about their daily lives.

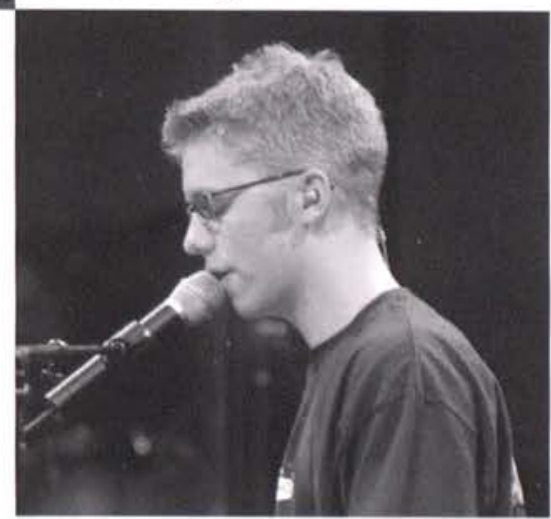

Ray Green leads

the students in

God-centered worship.

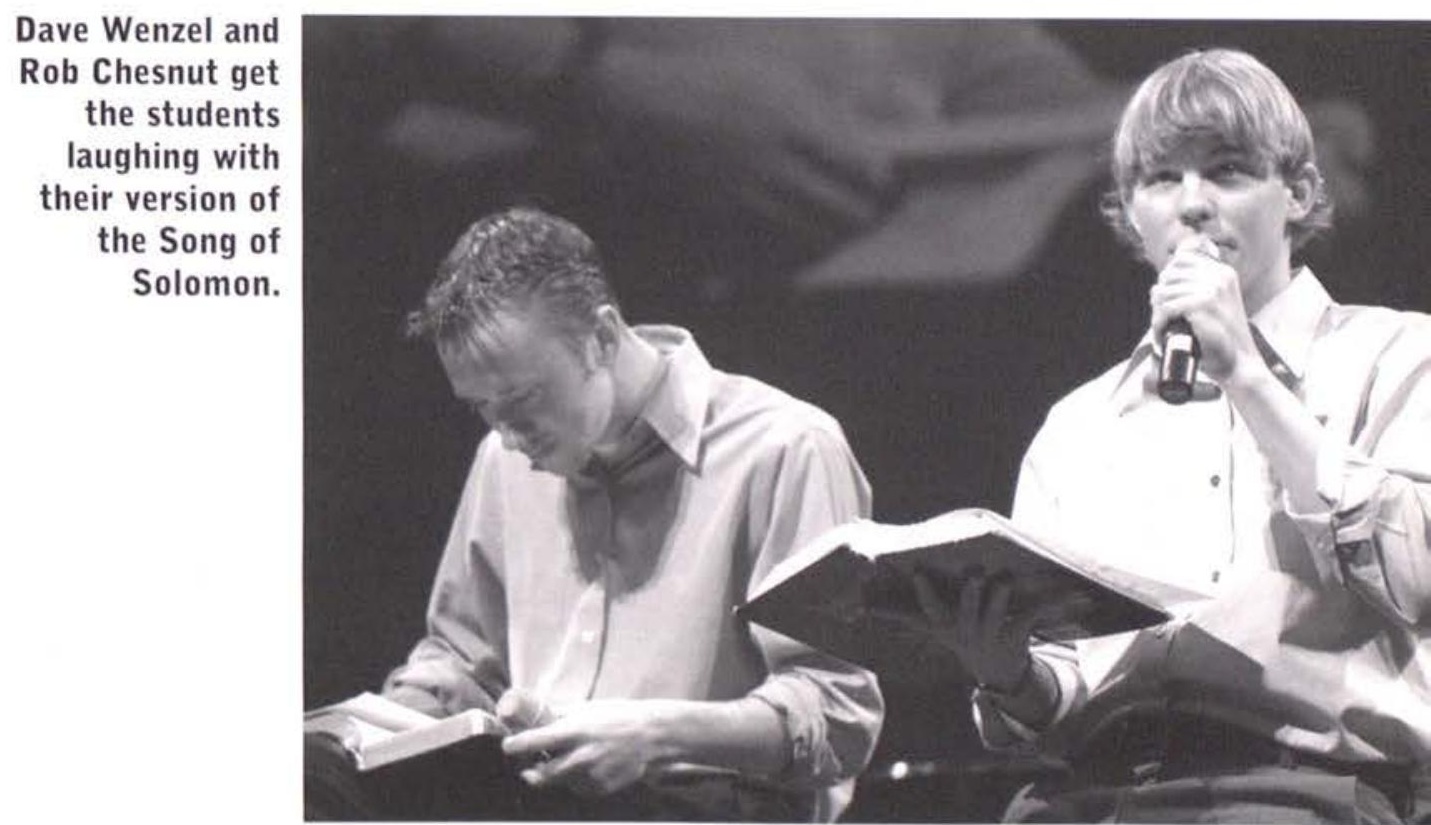




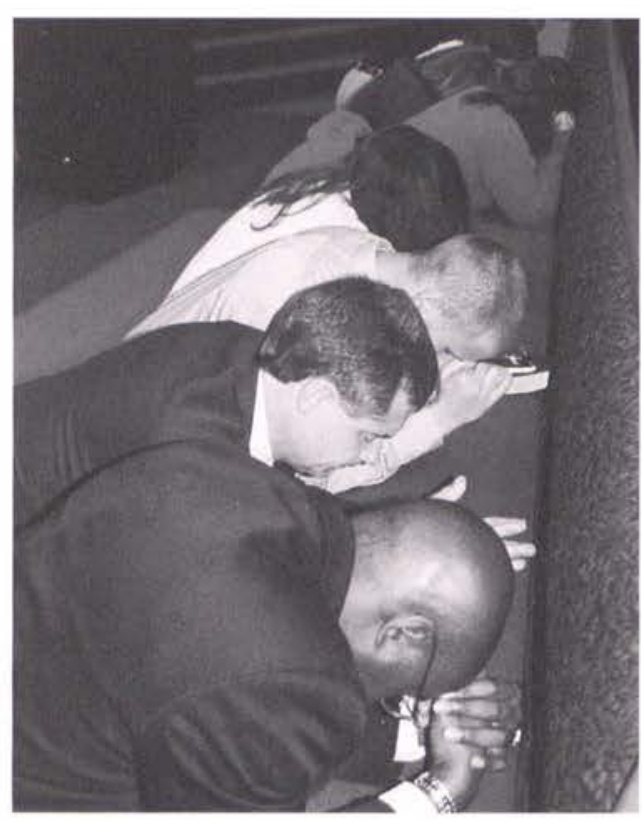

Faculty and students offer prayer requests together on their knees.
Cedarville's Day of Prayer on October 31 found students presenting their requests to God on behalf of their friends, their family, and their country.

During chapel, Drs. Colman and Clevenger led the student body in praise choruses and responsive readings, focusing on the holiness and goodness of God. Guest speaker Reese Kauffman, President of Child Evangelism Fellowship, not only encouraged students to be avid in their prayer lives, but he also cast a vision for the hurting children of the world particularly those in what he called the " $4-14$ Window" (between the ages of 4 and 14) and the children of prisoners.

After Kauffman spoke, faculty members prayed for specific needs, including direction for the seniors and salvation for unsaved parents and grandparents. Students then split up into small groups to pray.

Following chapel, students had the option to attend "In Prayer with the Psalms" led by Wade Harris of Elijah's Fire and other prayer gatherings.

Students enjoyed the opportunity to step back from their academic pressures and devote the morning to prayer.

Sophomore Leanne Jones said, “This year's day of prayer was very encouraging and uplifting... I have several family members that I have a lot of spiritual burden for, and today, God reminded me about patience and trusting in Him... I really enjoyed the speaker and what he had to say about the importance of prayer in every day life."

Jones put it plainly, stating the purpose of the Day of Prayer: "Overall, today really helped me to focus once again on how important prayer is - every day."

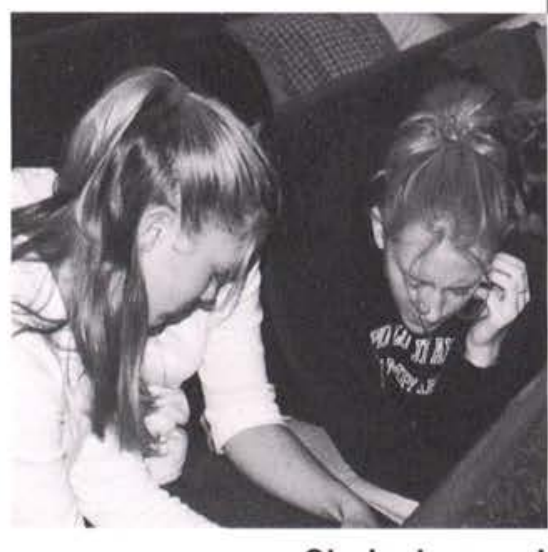

Students spend the uninterrupted hour praising God for His goodness.
Together in a circle of prayer, students lift their needs to God on this special day of prayer. 


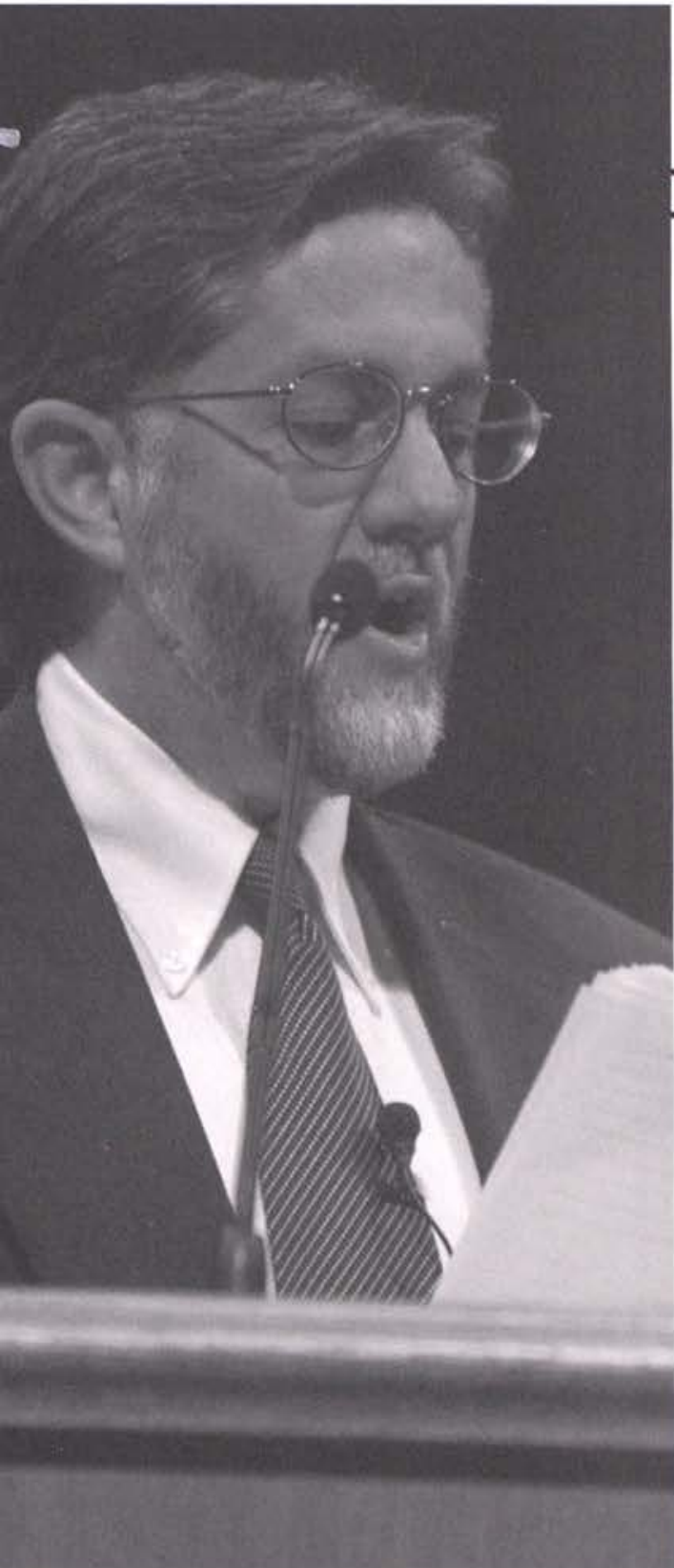

Dr. Ware informs the student body with lectures about Open Theism vs. Theology.

Dr. Ware shakes

hands with $\mathrm{Dr}$. Miller, who had given him an

introduction before his lecture series.

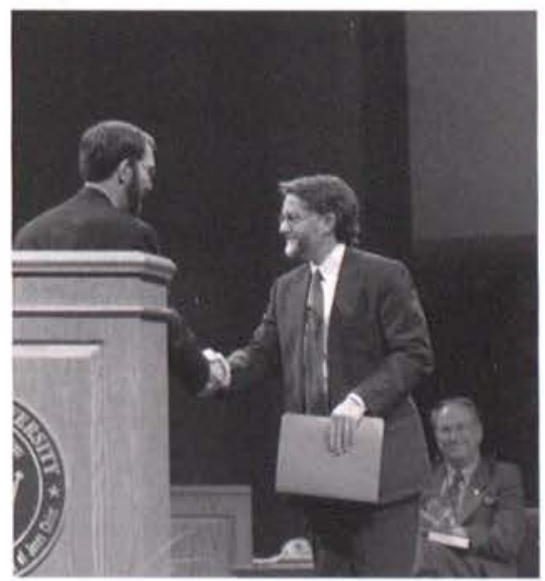

\section{- Staley Lecture}

The Staley Distinguished Christian Scholar Lecture Program, sponsored by the Thomas F. Staley Foundation, brought Dr. Bruce Ware to the University campus for the annual lecture.

Dr. Ware, a graduate of Whitworth College, Western Conservative Baptist Seminary, the University of Washington, and Fuller Theological Seminary, was a professor of Christian theology at Southern Baptist Theological Seminary. As well as teaching, Dr. Ware was also the Associate Dean of the School of Theology and Associate Dean of the Theology and Tradition Division.

Dr. Ware's lectureship series titled his lectures "My Glory I Will Not Give to Another: The God of Open Theism vs. the God of the Bible." Tuesday's chapel, "A God Who Guesses and Makes Mistakes? Open Theism's View of God," was a general overview stating how open theists view God when He seemed to "change His mind" in the Bible. Wednesday's lecture, "What's Wrong with This Picture? Open Theism's Denial of Exhaustive Divine

Foreknowledge," and Thursday's lecture, "What's Wrong with This Picture? Open Theism's Doctrine of a God Who Risks," developed the ideas of the first day of the lecture.

Besides the lectureship, Dr. Ware also spoke in various Bible classes and in fellowship on

Wednesday evening about Biblical Personhood, another area in which he is well known for his work.

Senior English major Gina Band said, "I found Dr. Ware to be very informative on the topic of Open Theism. He brought forth some good points about that philosophy I had never thought of before."
Justin Geer spends time talking with Dr. Ware.

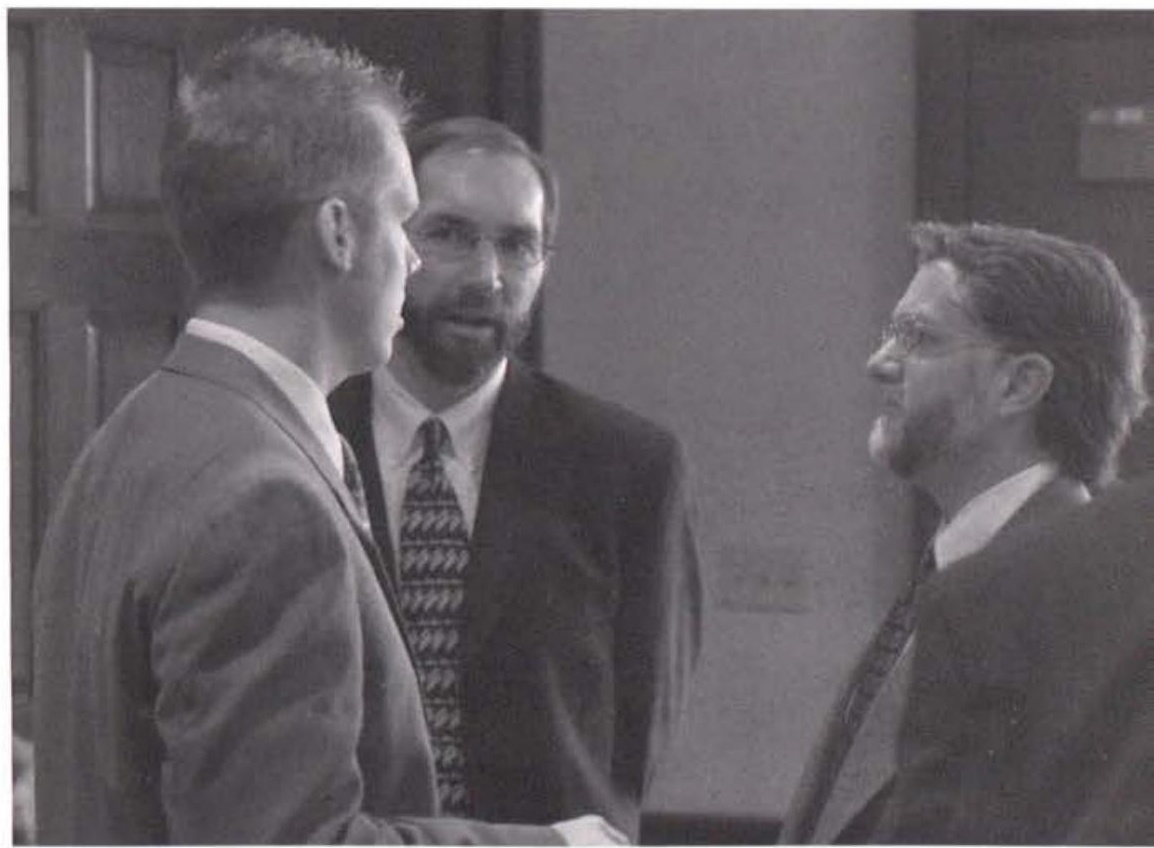


The New Faculty chapel allowed students to become familiar with new faces seen in the front of classrooms. The hour began with bagpipes and a processional of the new faculty.

The Sharps, both in the Nursing Department, shared their story with students to begin chapel, speaking on the theme, "Although we are many, we are one."

A professor from the Engineering Department surprised students when he rode in on his unicycle. He shared a few words while juggling in order to reflect the idea that all of the students and faculty of the University have to "juggle responsibilities."

The chapel continued with remarks and a video from various professors. Rebecca Reich said, "Since I usually only get to see the Math and Science professors, it was good to see other professors and hear some of their beliefs, talents, and thoughts."

\section{Another special chapel for} the year was Staff Chapel. "This is a staff that serves GOD and serves us," introduced this chapel, involving almost 340 staff members who work at Cedarville University.

The chapel began with their chosen theme, "We have chosen to come to you with a message of hope, as fellow believers we know beyond doubt our hope is in Christ...Christ is the hope in all of our lives."

In a reader's theater style, several staff members told the story of a 1990 alumnus, who took the opportunity after September 11 to become a "Jesus Freak" to rescue workers.

This was followed by the message "Share the Hope" from Mark Irving, Director of

Discipleship Ministries. He said, "Through chaos in our world we have a rock, a solid foundation," and we should share that with other people.

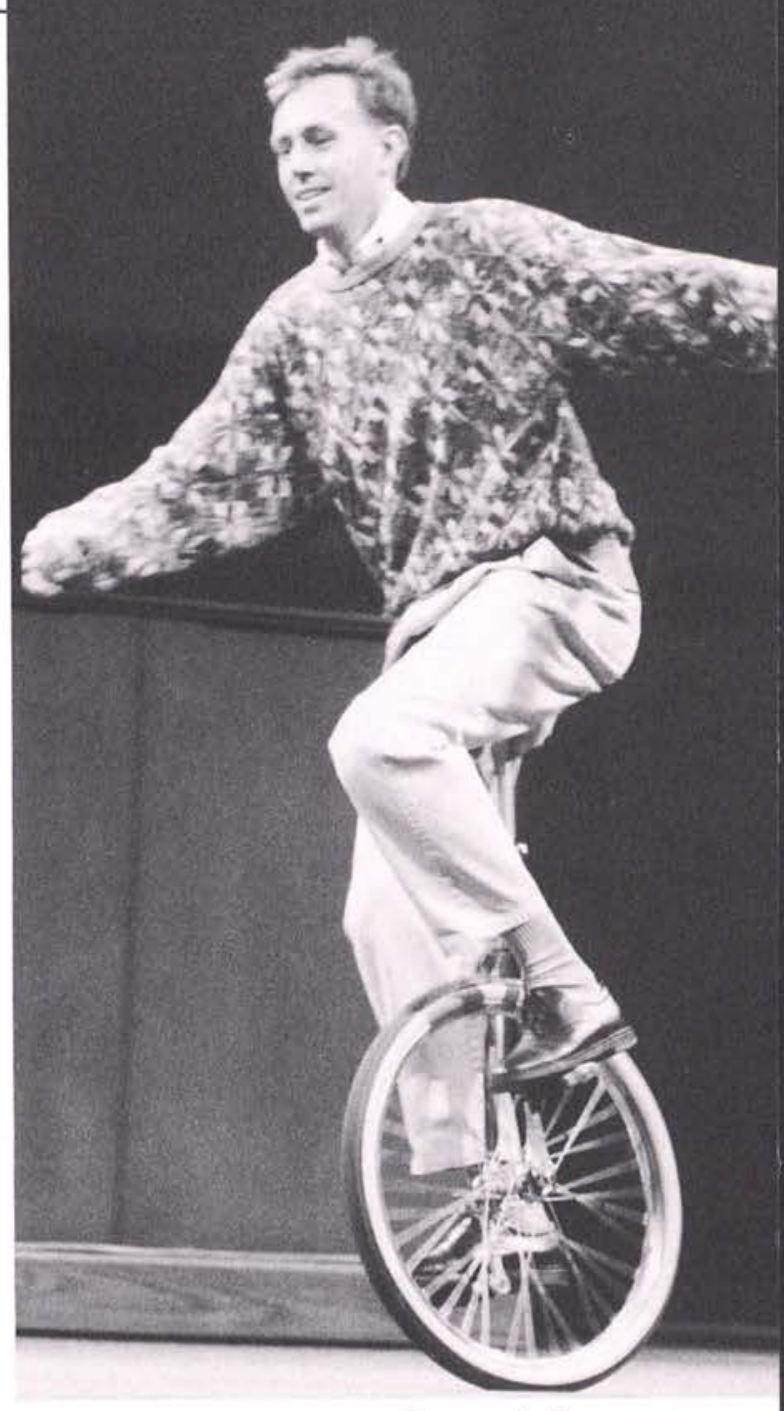

Some of the new faculty make students wonder why they are

teaching and not in the circus!

The Sharps, a new couple in the Nursing Department, interject humor into the story of their Scottish background.
The new music professor shares his bagpipe talent to an interested audience.

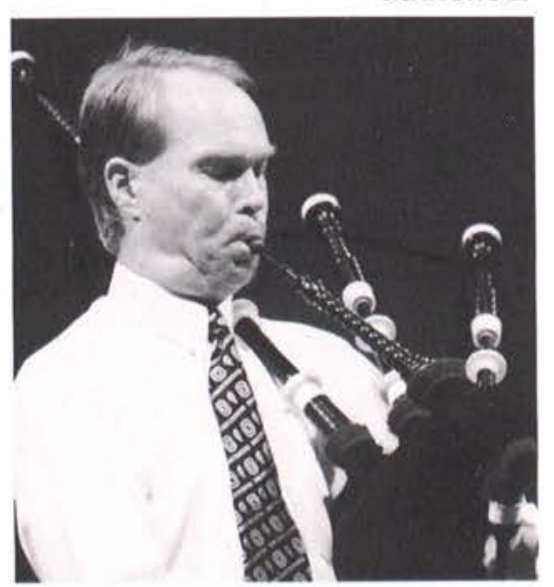




\section{Faculty and Staff Awards}

The Faculty Member of the Year for 2002 was Dr. Charles Clevenger of the Music

Department. Dr. Clevenger had been at Cedarville University since 1982, having served as Professor of Music and chair of the music department. He participated in Fit to be Tied, Jubilate, and

Symphonic Band. Dr. Clevenger also kept a full concert schedule while exhibiting his paintings and drawings throughout the area.

One student stated, "He not only passes on his love for music, but his love of life to everyone he comes in contact with."

Dr. Clevenger said, "To me the most significant thing about this award is that it comes from the students. My wife and I have decided to put our lives into people, especially students, and so I'm honored beyond words by this vote of confidence."

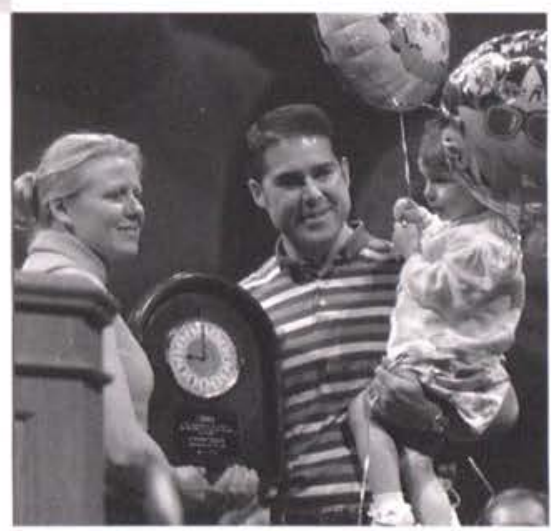

Jeff Beste, Staff Member of the Year, receives a clock as recognition of his hard work.
The Staff Member of the

Year was Jeff Beste, Assistant

Director of Campus Activities \&

Director of Leadership

Development. On campus he was the OPE advisor, headed up the Leadership Institute, and participated in numerous MIS trips, Campus Activities Board, and the Presidential Search Committee.

Among nomination

comments, one person stated, "His love for the Lord shines through all he does. I appreciate his compassion and vision."

Beste said, "I am totally honored and humbled by receiving this award. I am especially thankful for a wonderful wife who does not mind the many hours I end up being away from home due to student things on campus, and two beautiful girls who share their daddy with so many college students."

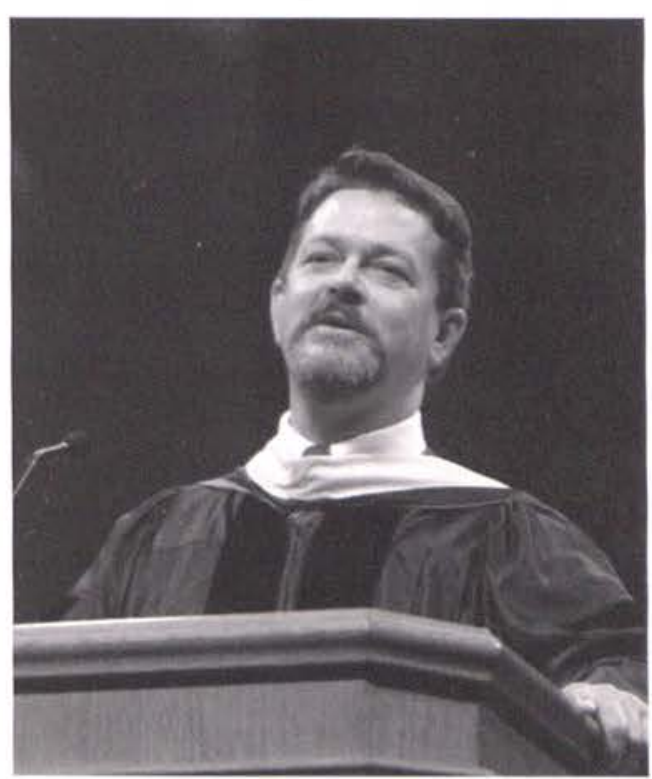

Dr. Charles

Clevenger, recongnized as a humble, selfless faculty leader, gives a thank- you speech to the student body.

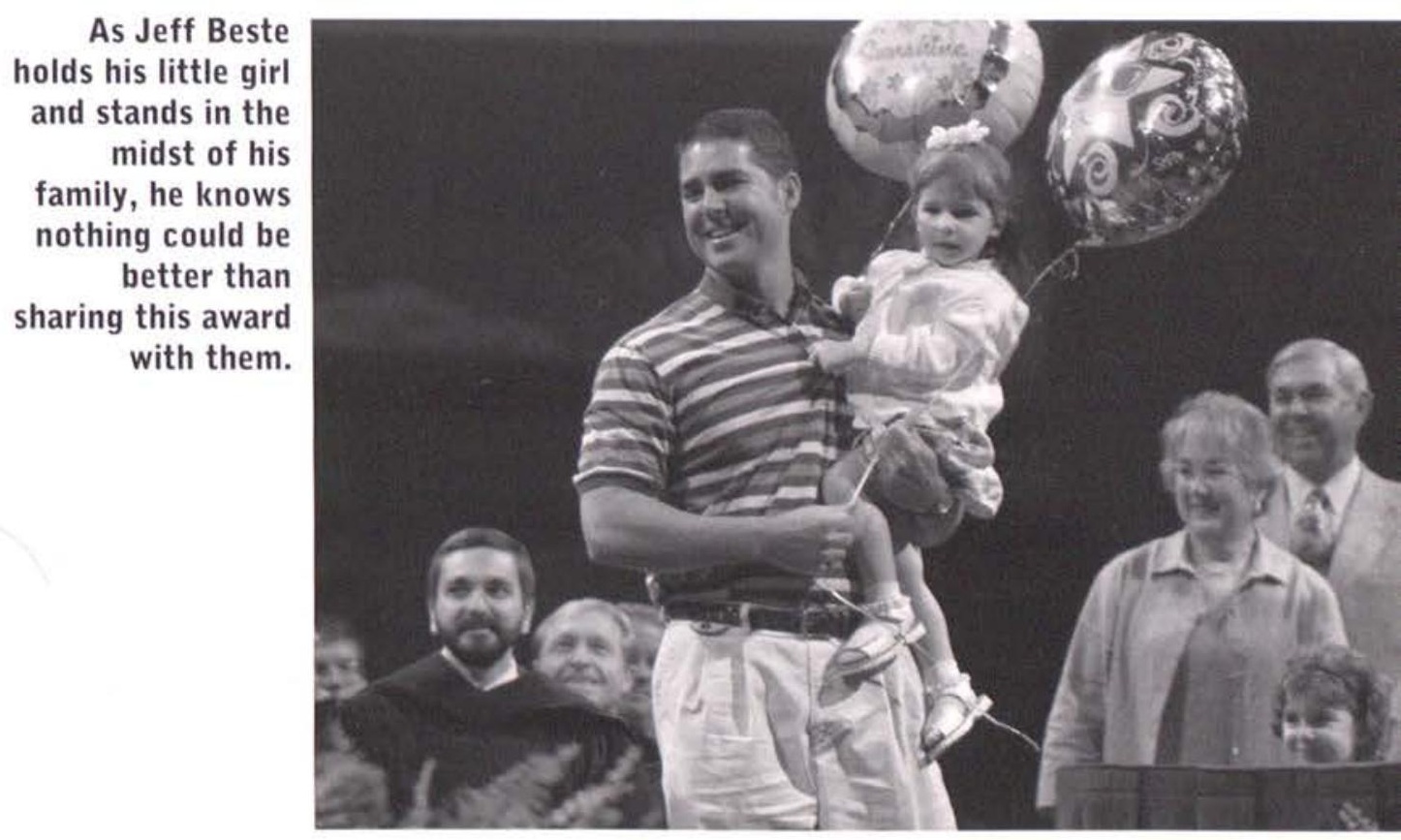




\section{Memorial DaY}

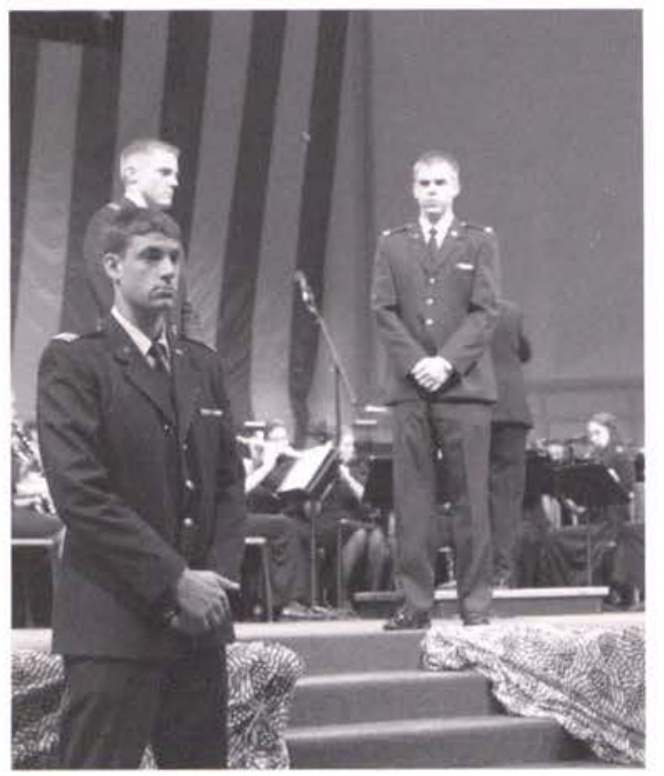

Cedarville

University's ROTC

proudly welcomes

those who were in

any military ser-

vices to join in

Memorial chapel.
On May 27, 2002, in the twenty-second annual Memorial Day Chapel, the student body and surrounding community gathered to honor all those who fought and served for America's freedom.

A large American flag dominated the background of the stage. Flags representing the Marines, Navy, Air Force, Army, and Coast Guard reminded all the people present why they had gathered. Through music, pictures, and oratories, those present remembered all people serving in the armed forces and the civilians who died to bring and keep freedom in America.

Chapel began with the Symphonic Band playing a rousing rendition of Stars and Stripes

Forever. The audience thoroughly enjoyed the performance and clapped along in enthusiasm. The Symphonic Band, under the direction of Dr. Mike DiCuirci, performed the patriotic favorites of God Bless America and America the Beautiful.

In the middle of chapel service, time was set aside to honor all the men and women present who had served in the past or were presently serving in some aspect of the Armed Forces. Representatives from the First World War to the conflict in Afghanistan joined together on the stage. Men and women from the Army, Coast Guard, Marines, Air Force, and Navy led the entire auditorium in the Pledge of Allegiance to the Flag.

Throughout the Memorial Day Chapel, those attending were reminded that this country was built on the shoulders of giants, both those who framed the constitution and started this country, as well as men and women who served at home and abroad.

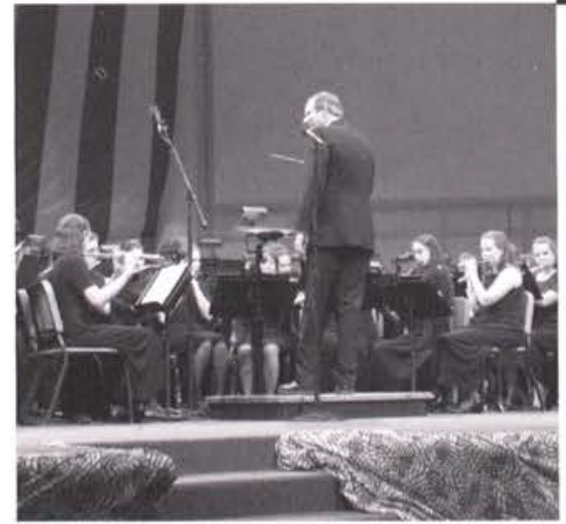

Mike DiCuirci leads the Symphonic Band in patriotic musical numbers to stir the "PROUD to Men and women of every military be AMERICAN" hearts

service stand to the enthusiastic applause congratulating their efforts. 
More than fifty students gathered on the stage while Dr. Paul Dixon congratulated a special group of seniors on their

achievements on recieivng the Who's Who award. The University chose the students on the basis of academics, extracurricular activities, and ministries. Each Who's Who student influenced the culture of the university he or she attended.

The chapel, which contained skits, monologues, personal testimonies, and a time of praise, centered on a message taken from Jeremiah 2:13. The verse states, "My people have committed two sins: they have forsaken me, the spring of living water, and have dug their own cisterns, broken cisterns that cannot hold water."

Senior English major

Grayden Schafer said, "I feel that the concept of broken cisterns applies to everyone at any stage in life. Whether it is grades, career, relationships, sports, or even entertainment, all too often Christians unknowingly allow other things to become central in their lives."

The seniors encouraged students to identify the "broken cisterns" in their lives and give them to God, so they would be open to allow "living water" to fill them. Senior Engineering major John Bailey said, "I really enjoyed the time I spent reflecting on my own life. The Scripture and testimonies from my brothers and sisters challenged me to make sure my significance is only in Him."

The chapel gave these seniors an opportunity to share their hearts with the student body. Their sincerity and desire to help others grow in their relationship with the Lord allowed the chapel to be a touching and memorable experience for everyone involved.

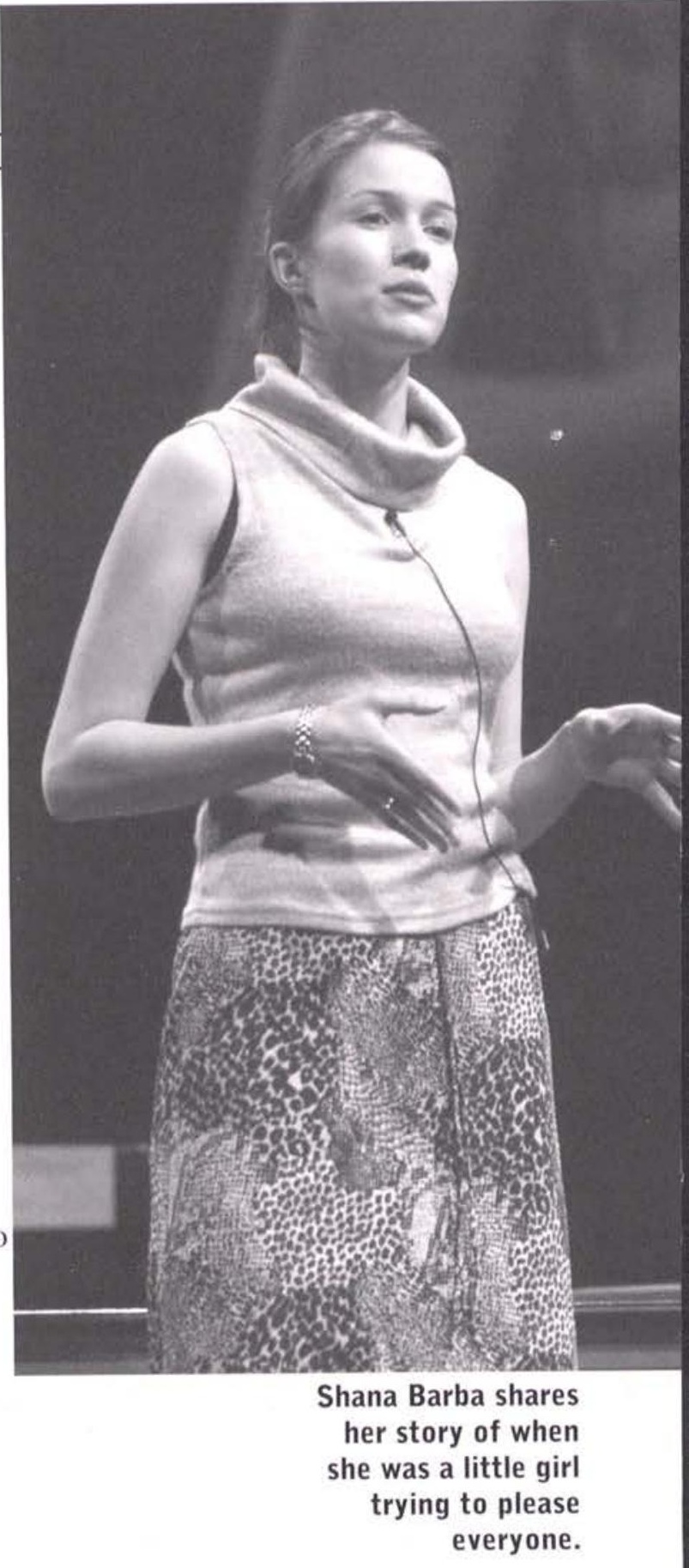

Todd Pellowe and Brock Weston take the time to slow down during Who's Who chapel to reflect on our compassionate Savior with their fellow classmates
In a skit preformed in Who's Who chapel, Graig Bantle and Eric have a conversation underlining the importance of students.

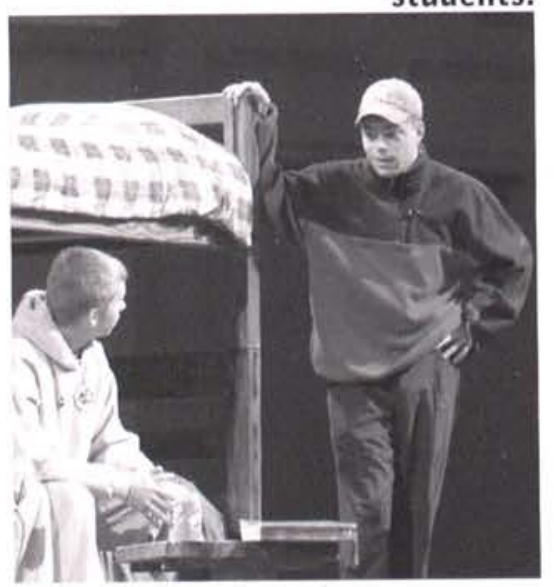




\section{Senior Chapel}

Senior class chaplain Brian Davis organized the annual Senior Chapel, a special chapel presented by the graduating class to the rest of the student body. The chapel took place on Thursday, May $23^{\text {rd }}$, and it included humorous sketches, performed by graduating seniors. The sketches maintained the theme that Davis later spoke briefly on the difficulties of being seniors and trusting their futures in God's hands.

The class presented a long time-line, showing what had happened during their time at Cedarville, and at one point, while the auditorium was quiet, a recording of Alistair Begg played over the sound system. He spoke the prayer he had prayed when the seniors were freshmen in 1998. In this prayer, he recognized the pain of starting something new, the loneliness experienced when one

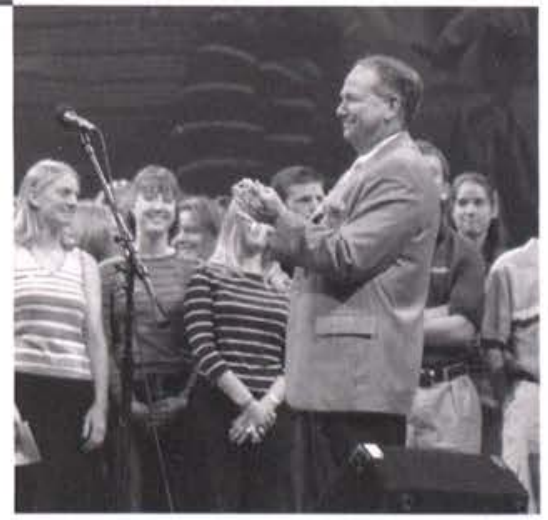

Dr. Dixon congratulates the senior class for all their efforts contributed throughout the four years toward Cedarville. goes out on his or her own, and testified the comforting reminder that "our times are in His hands."

To close the chapel, senior worship leader Matt Bell played the guitar and sang the worship chorus "The Potter's Hand." The seniors chose this song because it expressed their desire to let God take their lives, mold them into His plan, and use them for His eternal glory. Meanwhile, seniors left their seats in the audience to crowd onstage and join him.

Dr. Dixon, moved by the event, ended the chapel service with a few words expressing his appreciation for the graduating seniors, thanking them for choosing to come to Cedarville, on behalf of himself and the Board of Trustees. He challenged the graduating seniors to continue on the path of godliness, taking the testimony of Christ with them.

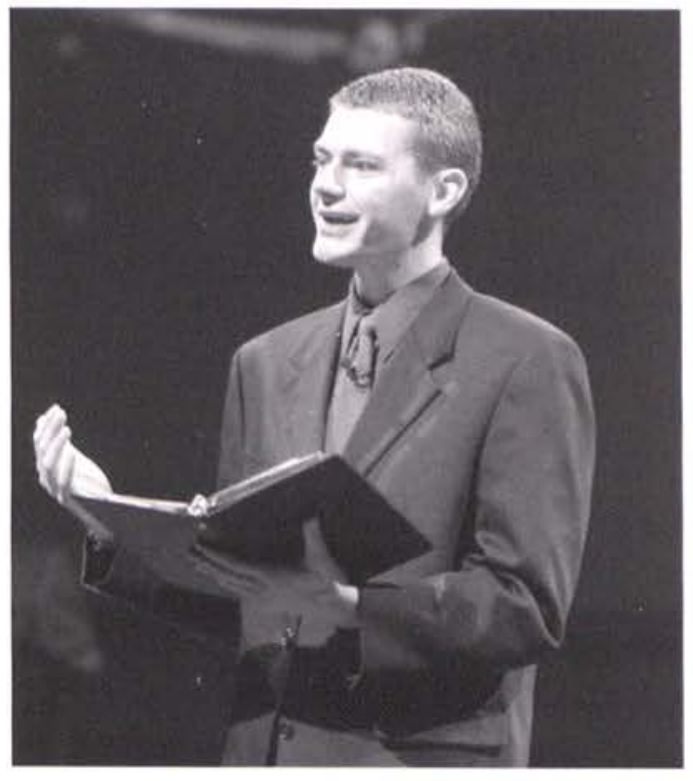

A graduating senior Brian Davis shares with his fellow classmates and the student body on how to trust God with their future no matter where the road may lead.

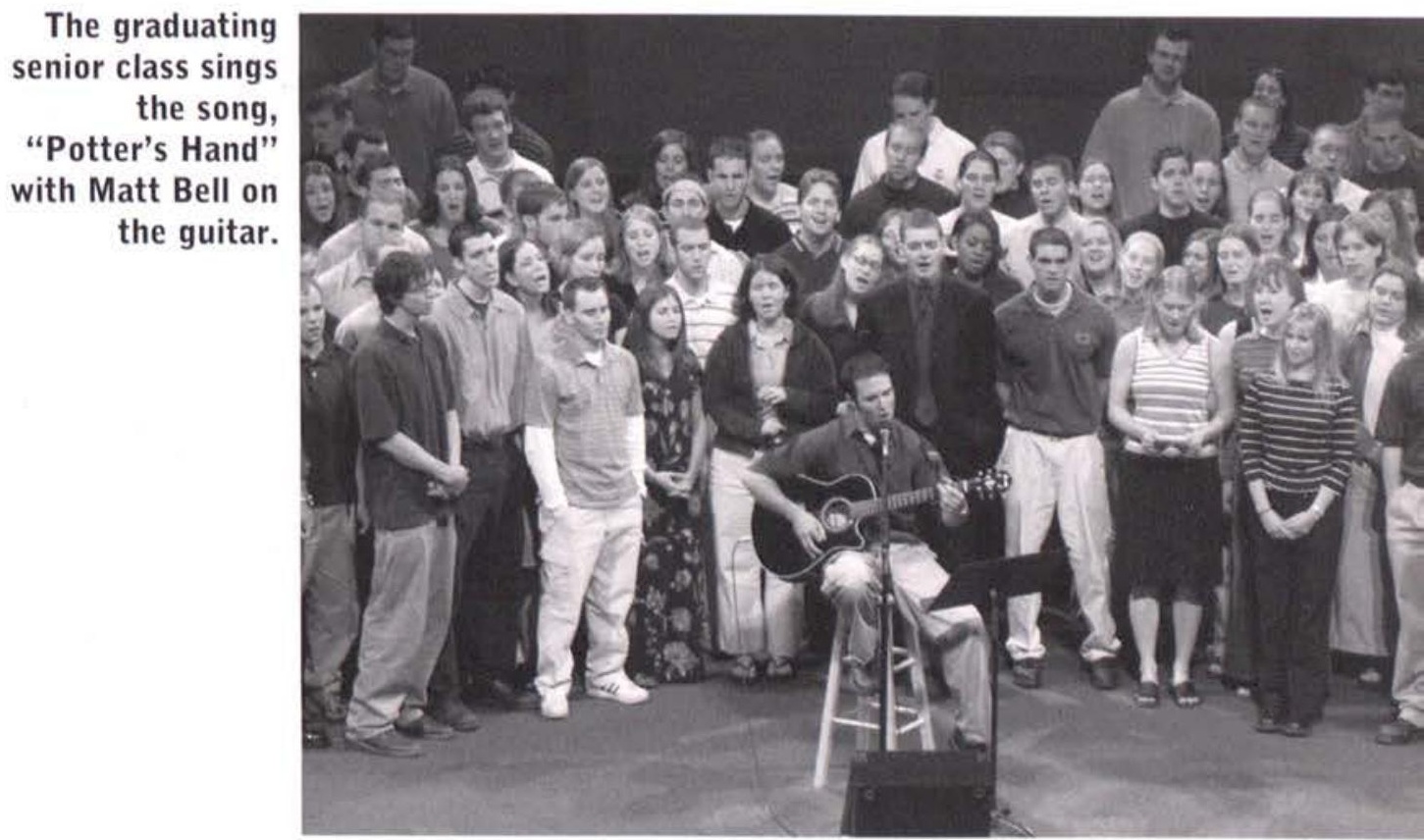




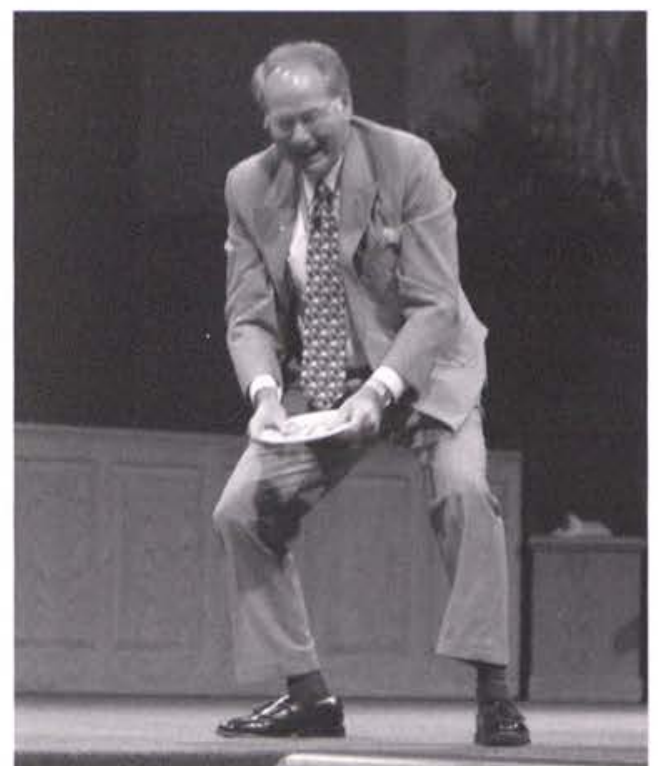

Dr. Dixon, showing

his love towrd

dandelions, gets

ready to brake a

dandelion plate in

chapel.
"All I want to do is get rid of the dandelions!" was President Dixon's battle cry. Dixon transformed Monday morning chapel into his platform for one of his most outrageous calls for dandelion genocide. The annual dandelion chapel entertained students and most likely scared any dandelions in the state of Ohio.

While presenting 4.0 mugs, Dixon found himself crowned with bright yellow flowers after a young lady's headgear was transported to his head. Dixon, with astounding response time, threw the headpiece into the fourth row of pews.

Dixon defined what he believed his presidential successor should be. After downplaying the importance of "looks," in which he believed no future president will ever be able to match his own, he said, "I don't even care if he doesn't go to church!" Dixon made it clear he wanted a president who would not rest until the dandelion extermination met its conclusion.

Dixon next unmasked many of his enemies, including Pat Dixon, the president's spouse of 41 years, who challenged the milestone of 42 by wearing dandelion apparel.

The dandelion movie placed Cedarville faces in the front lines. Professor DiCuirci, portrayed by the Klingon, Worf from Star Trek, and Professor Spencer, reprising his role as Yoda, furthered the cause for dandelion destruction in the film. Dr. Scott Dixon, played by the young Jedi, Anakin Skywalker, took up the sword against the yellow beasts of the field. "I might not be old enough to be a college professor or fight the dandelions, but my dad's the president, so it's okay."

The dandelion chapel proved once again that "The war on dandelions has begun."

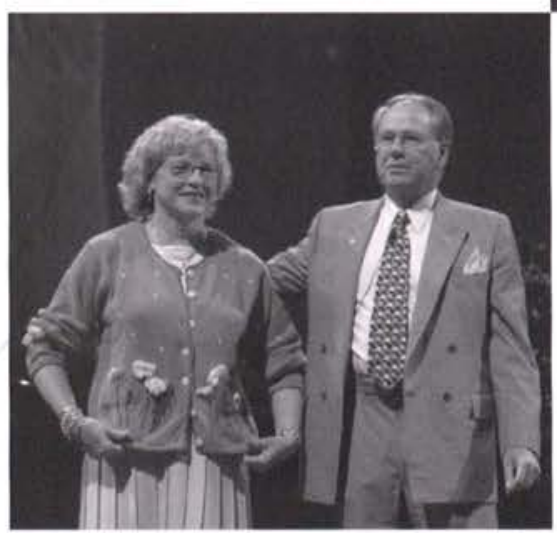

Mrs. Dixon proudly displays her dandelion sweater that a student gave her.
Dixon can only smile as he holds the dandelion headband after it was placed on his head by a 4.0 student. 


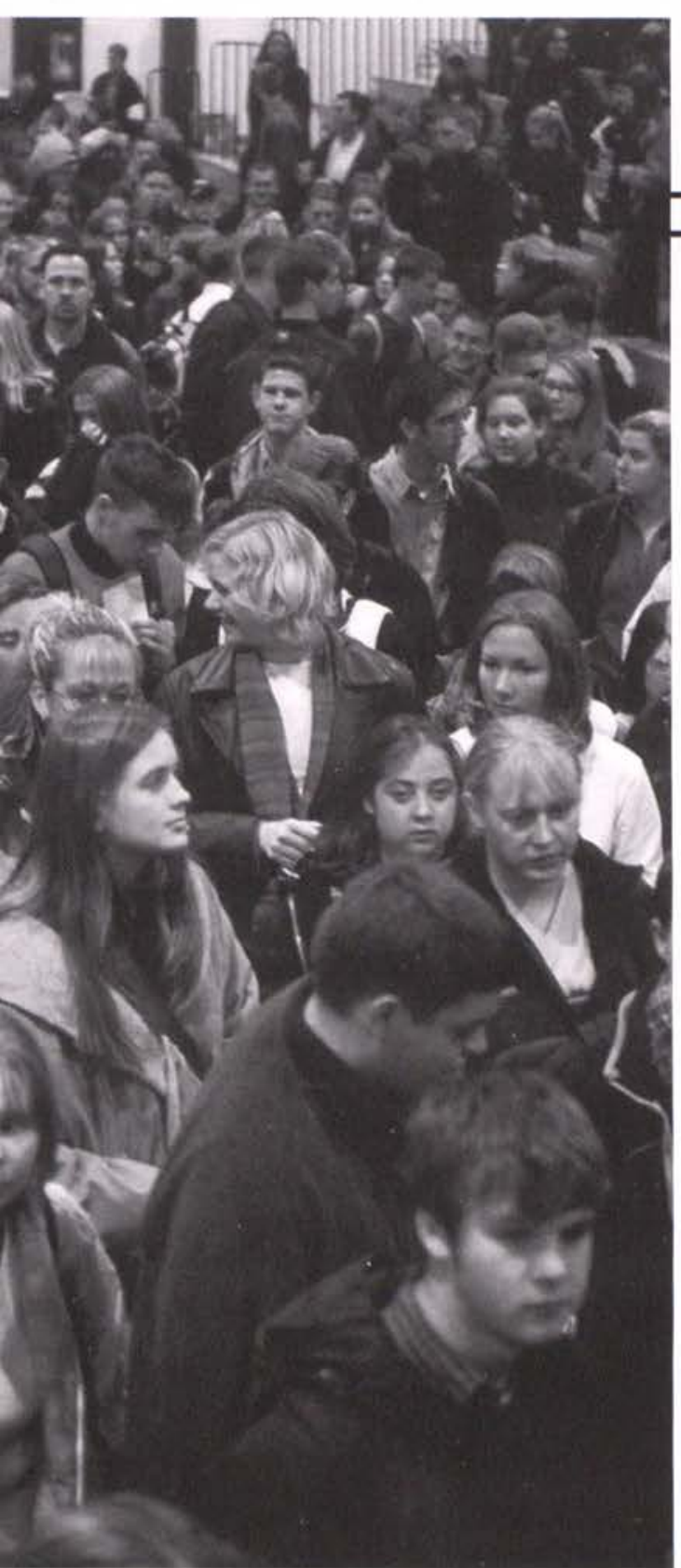

\section{Class Chapel}

Class Chapels provided a monthly highlight on the chapel schedule. Led by the elected class chaplains, these student-led chapels catered to the specific needs of each class by being entertaining and encouraging.

Brian Davis, the class of 2002's chaplain for the last three years, gave away prized t-shirts from Goodwill, as well as gift certificates to the Montgomery Inn during some of his chapels. His messages also drew the seniors to the SSC Theatre once a month because of his honest and caring approach. He challenged the seniors with topics such as living with an eternal perspective and looking forward to the Lord's coming. Matt Bell taught the seniors a variety of new songs as he led them in musical worship.

The junior class chaplain, Dan Konopasek, in his first year as chaplain, worked around the theme of Philippians 1:27 - behaving in a manner "worthy of the Gospel of Christ" - for his class chapels.

Konopasek aimed to get as many class members involved as possible, to make it truly a class experience. Jason Bradshaw led the junior class members in praise and worship.

Sophomore chaplain

Donald Mathias and freshman chaplain Daniel Rasbach led their classes in spiritual growth and unity as well. Rasbach said that he enjoyed "getting to grow in [his] walk with God through preparing messages." His theme was "The Cedarville Sinner and..." $\mathrm{He}$ hoped that by choosing this theme, he would have the opportunity to remind his classmates to remain humble and rely on God's grace.

Overall, class chapels were a great opportunity to bond as a class and grow spiritually as well.
The crowd of students bump into each other before going to class chapel.
Randy Felker leads the worship for the sophomore class chapel with praise songs focusing on God's soveriegnty.

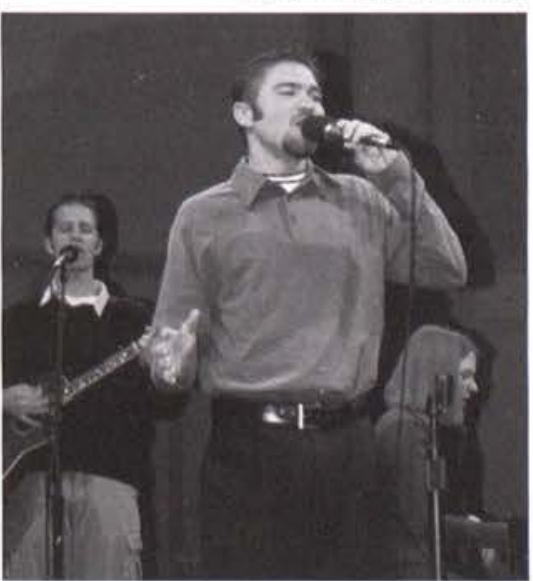

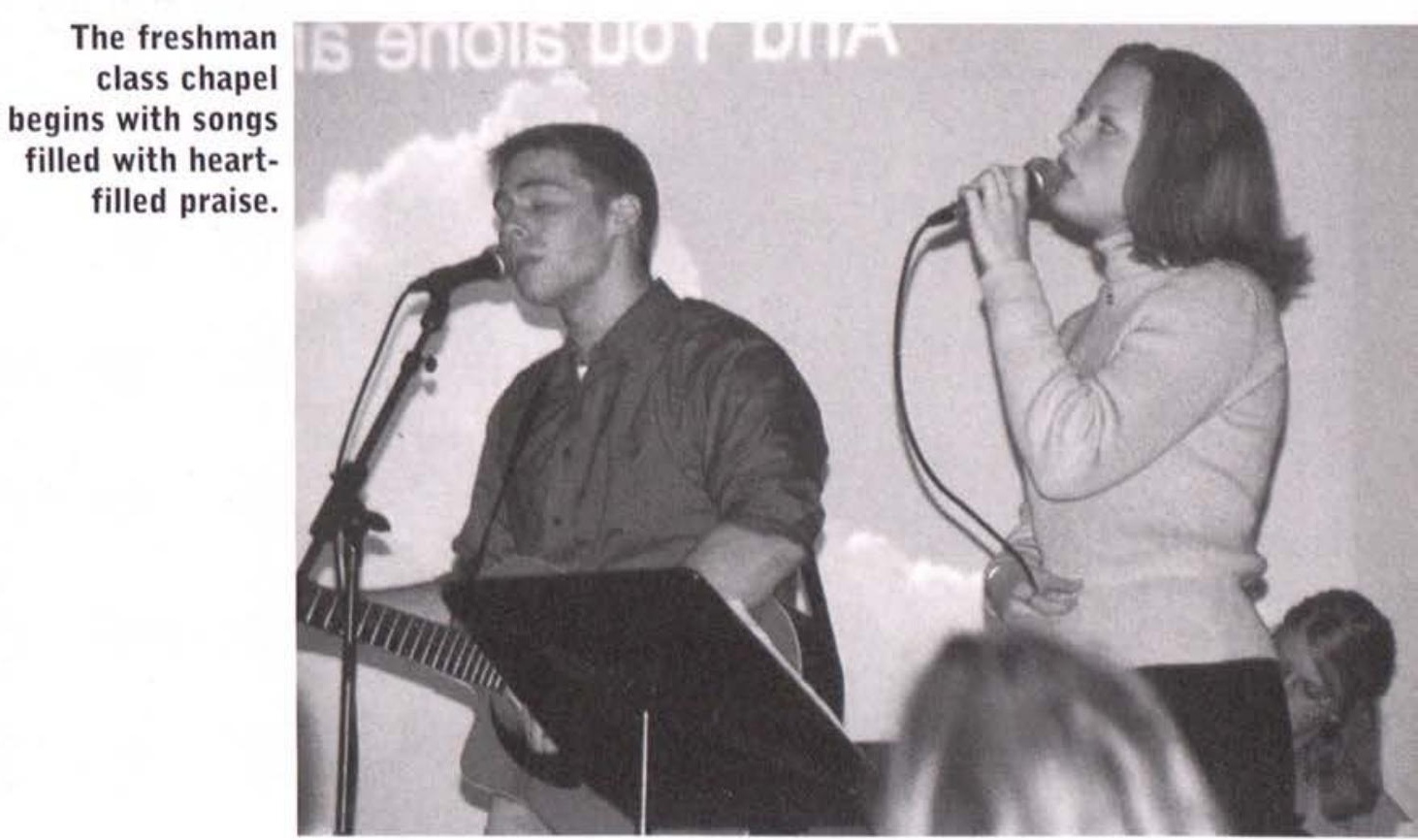




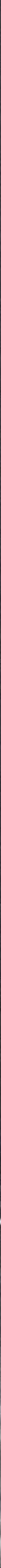



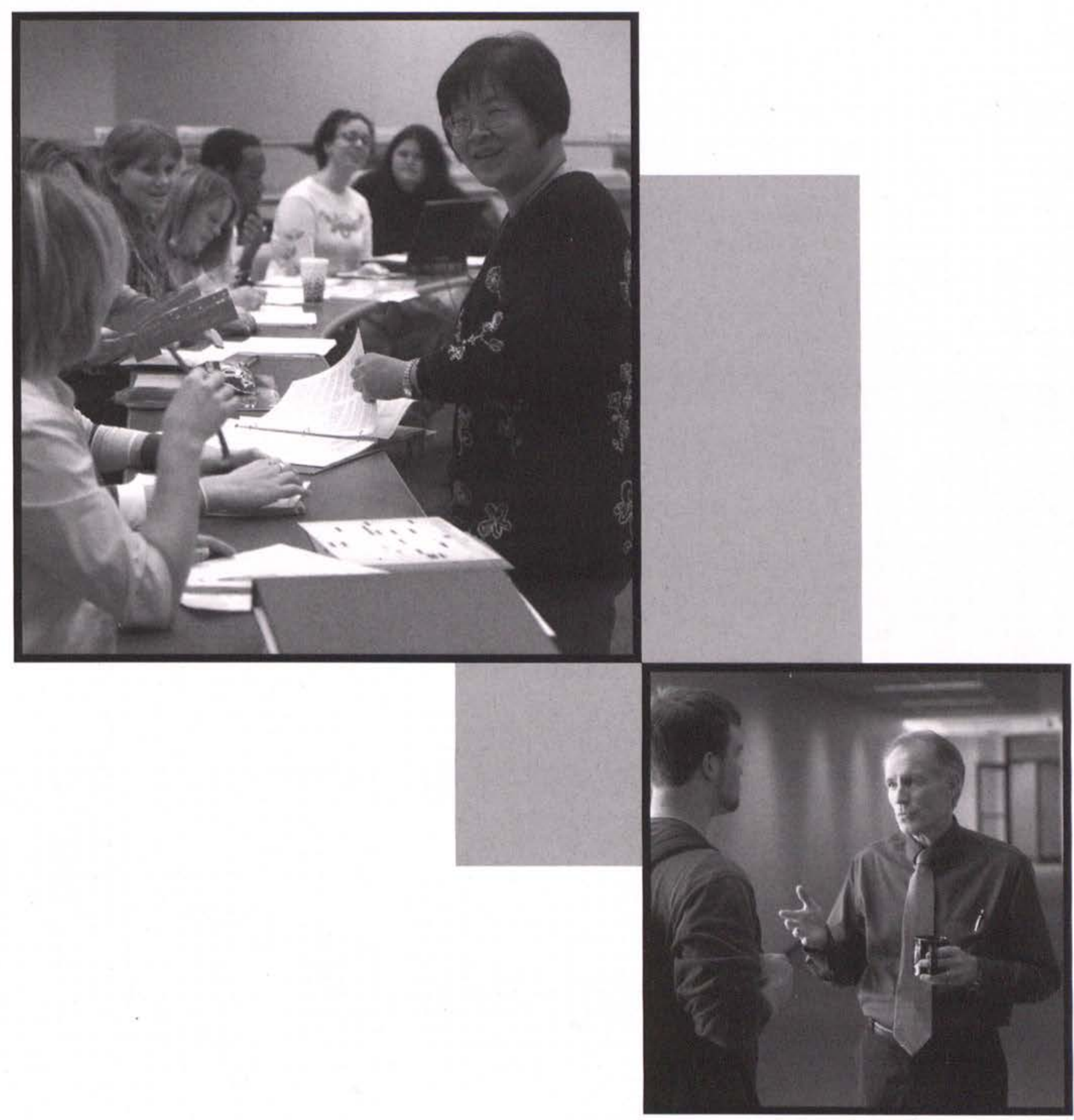

AGADEMIBS 


\section{aculty}

School of Humanities, Fine Arts \& Bible

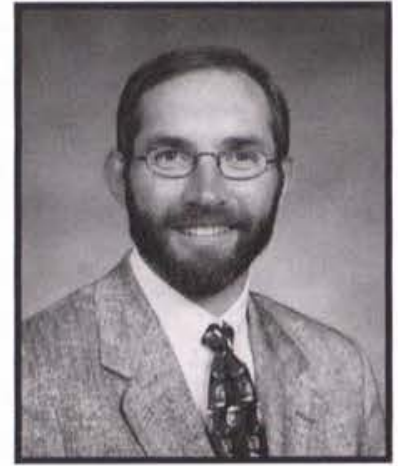

Dr. Chris Miller Chair of Bible

Professor

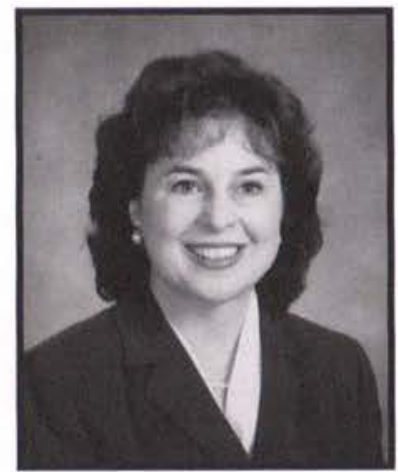

Rebecca Baker Assistant Professor

Communication Arts

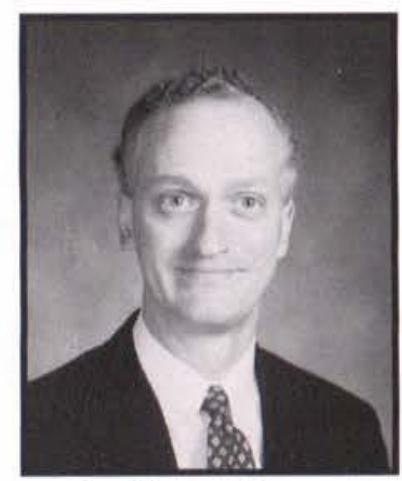

Dr. Thomas Cragoe Associate Professor Bible

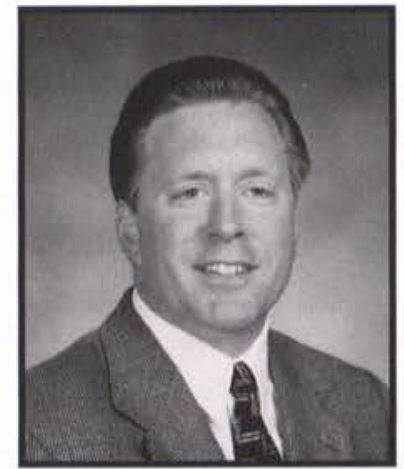

Dr. James Colman Chair of Music Professor

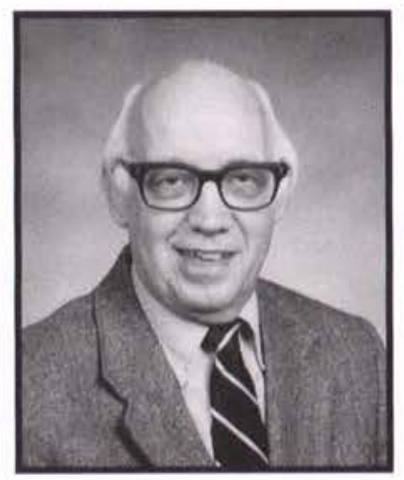

Dr. Ray Bartholomew Professor Emeritus English

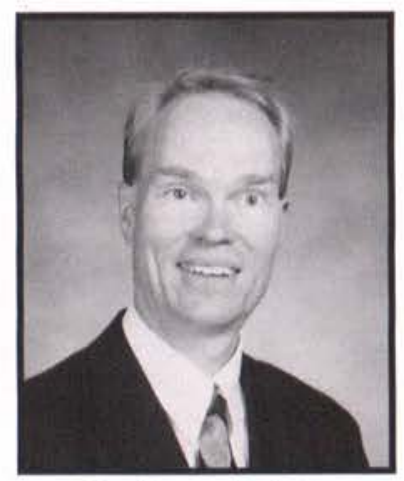

Dr. Bruce Curlette Associate Professor Music

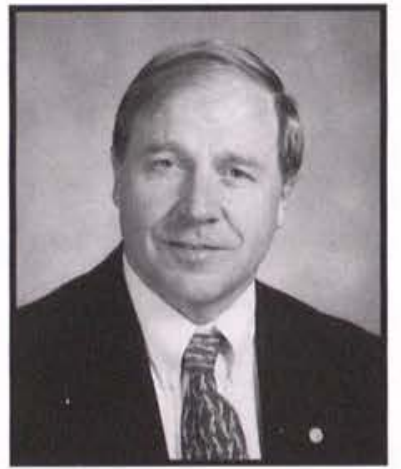

Dr. James Phipps

Chair of Comm. Arts Professor

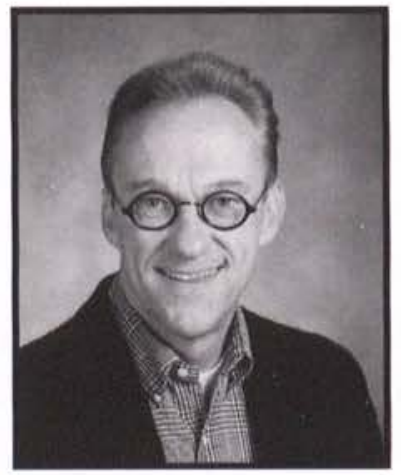

Terry Chamberlain Assistant Professor Art

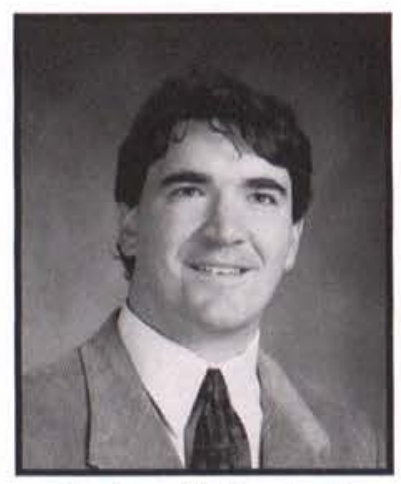

Dr. Donald Deardorff Associate Professor English

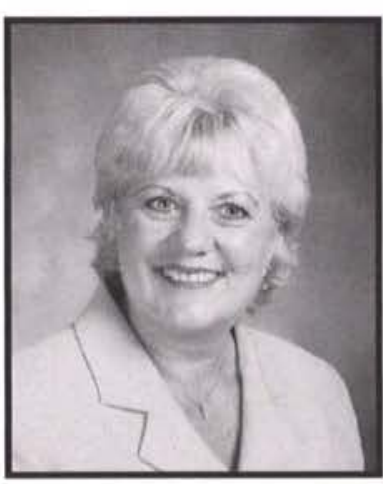

Connie Anderson

Assistant Professor Music

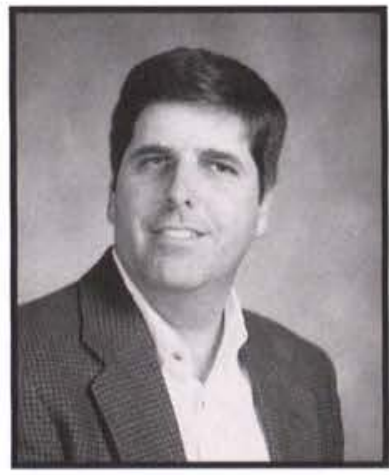

Daniel Clark Assistant Professor English

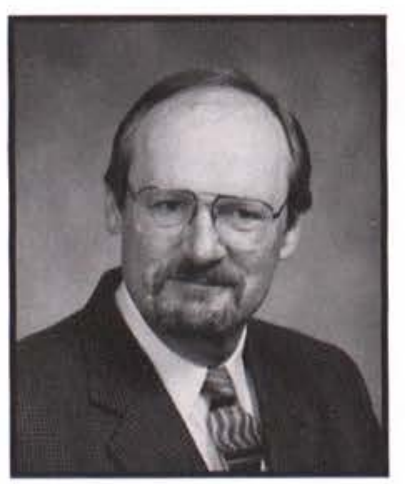

Michael DiCuirci Professor Music
Dr. Jack Riggs

Dean

Professor of Bible

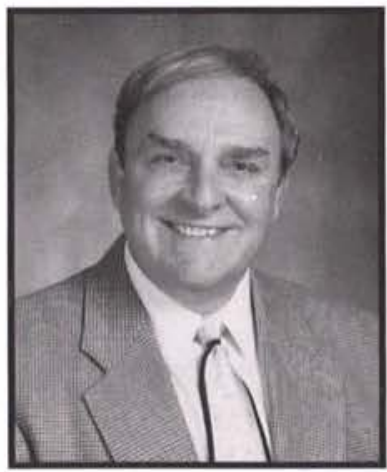

Dr. Lyle Anderson Professor Music

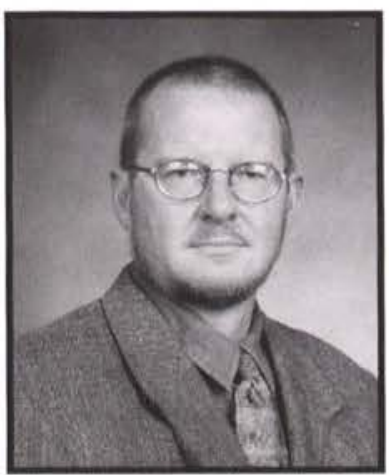

Dr. Jeffrey Cook Assistant Professor Bible

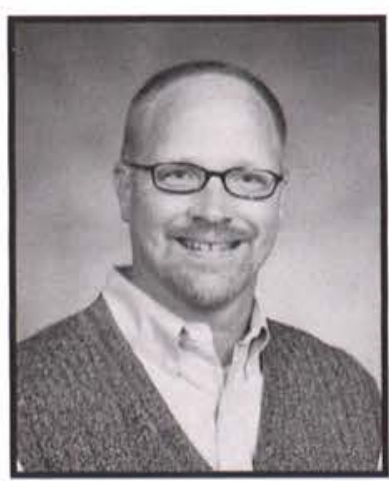

Dr. Scott Dixon Assistant Professor Bible 


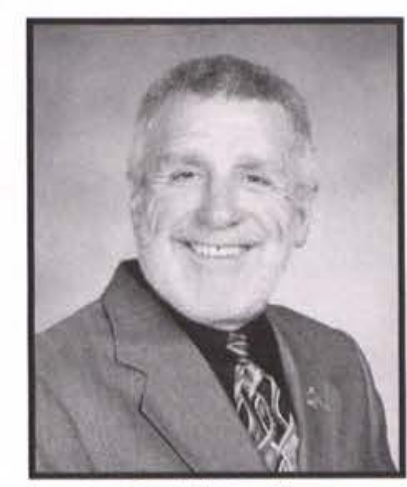

Dr. David Drullinger Professor

Bible

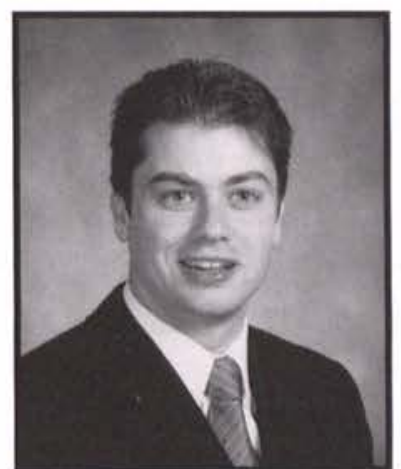

Dr. David Hoffeditz Assistant Professor Bible

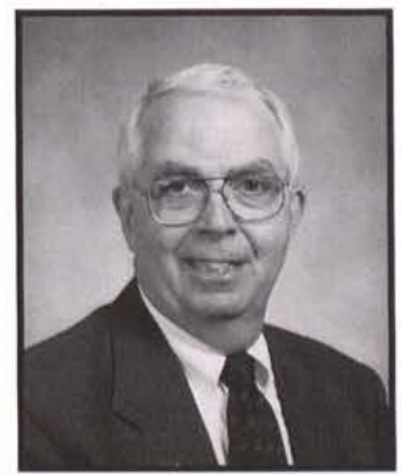

Dr. David Matson

Professor

Music

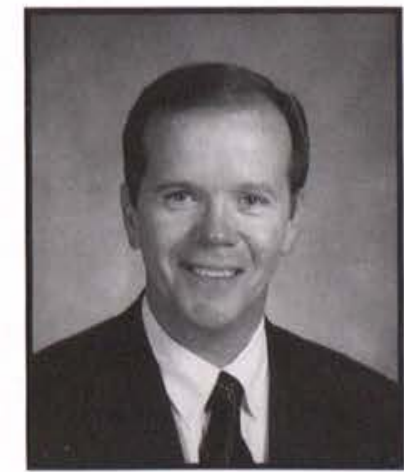

Dr. David Robey

Professor

Comm. Arts and Theatre

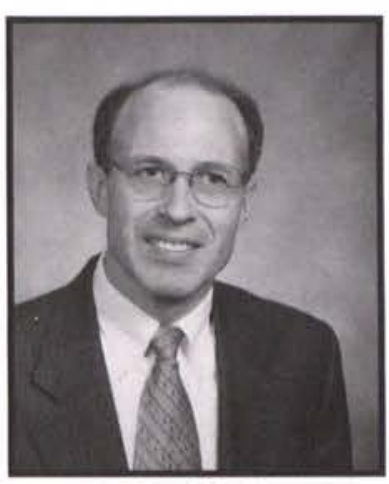

Dr. Daniel Estes Professor

Bible

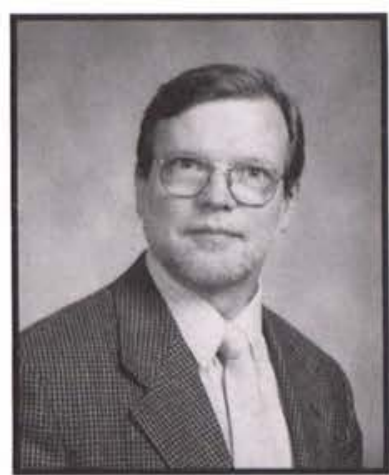

Michael Holt

Assistant Professor Bible

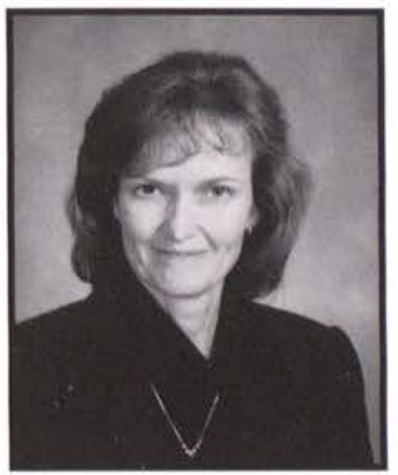

Mischelle McIntosh

Assistant Professor

Communication Arts

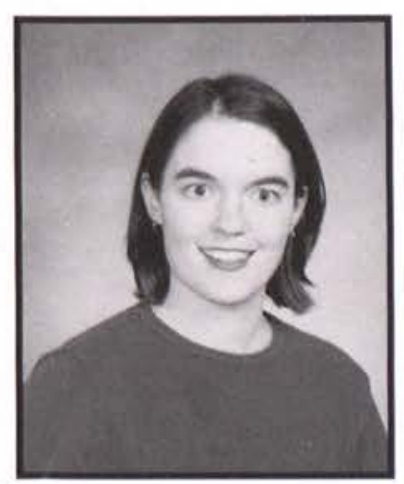

Jennifer Shaw

Adjunct Professor Voice

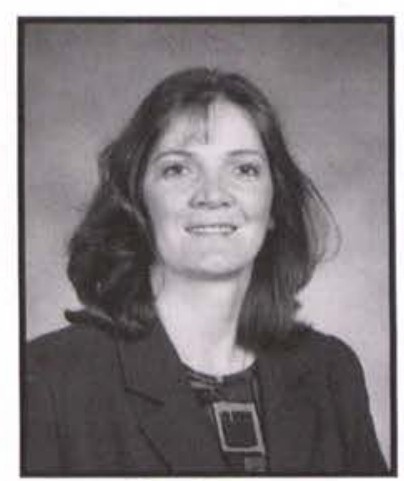

Joy Fagan

Assistant Professor

Bible

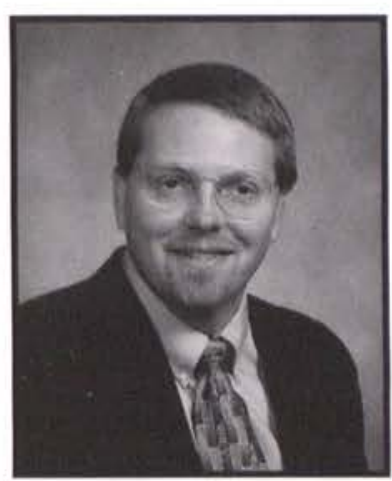

Dr. Thomas Hutchison

Associate Professor Bible

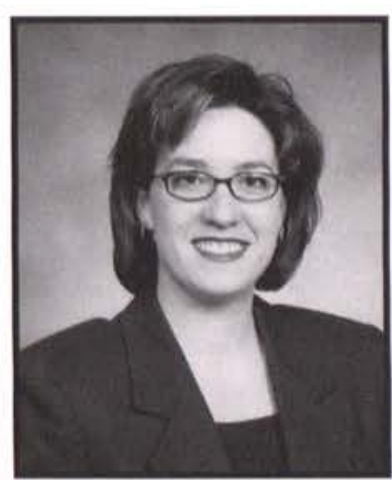

Cynthia Messer

Assistant Professor English

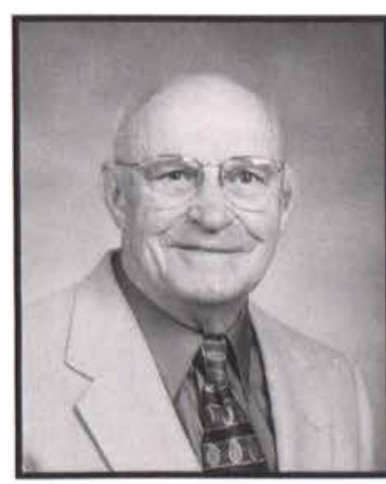

Dr. Edward Spencer Professor English

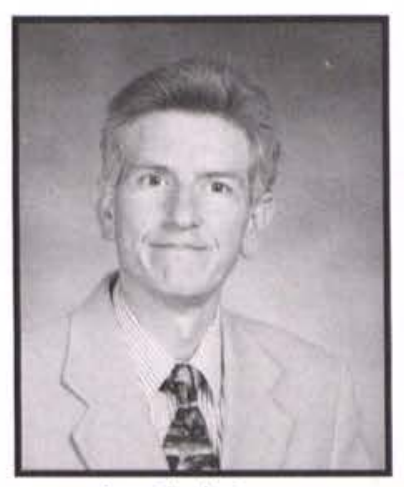

Dr. Clark Greer

Assistant Professor

Communication Arts

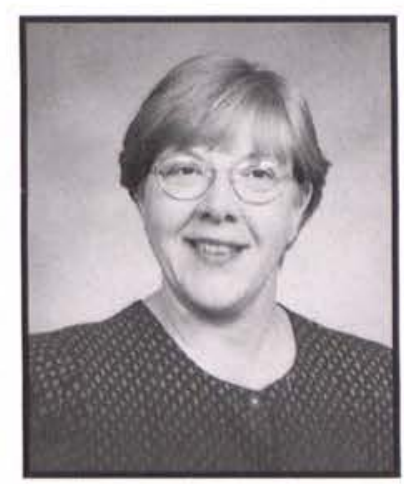

Dr. Barbara Loach

Professor

Spanish

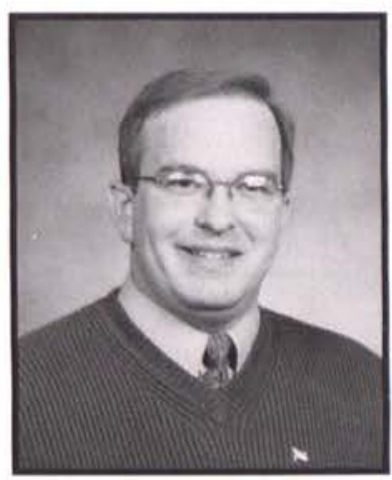

Matt Moore

Assistant Professor

Communication Arts

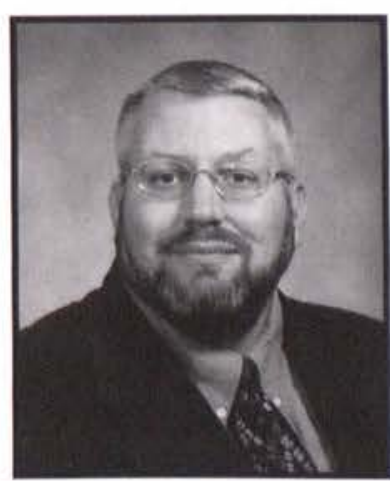

Daniel Stiernsher

Assistant Professor

Technical Communication

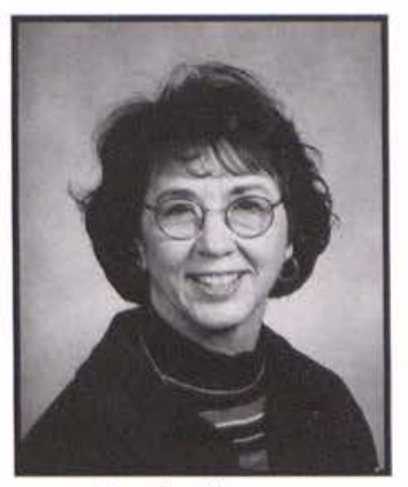

Sandra Harner Professor

Technical Communications

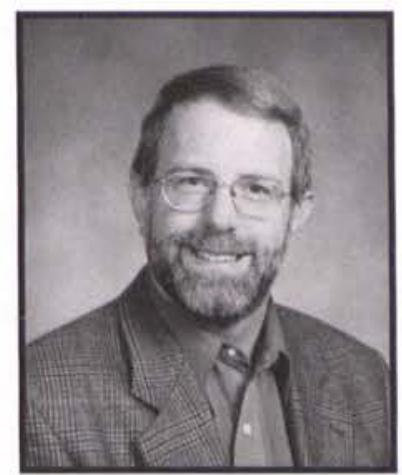

Dr. David Mappes

Assistant Professor Bible

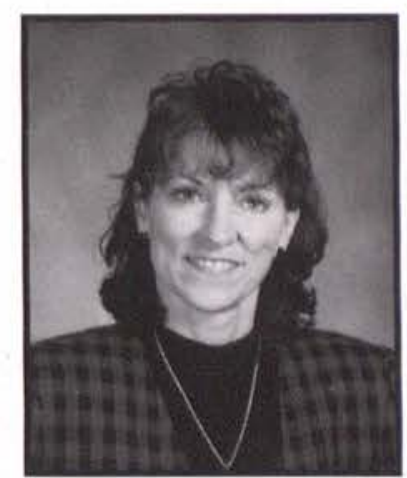

Karen Power

Assistant Professor English

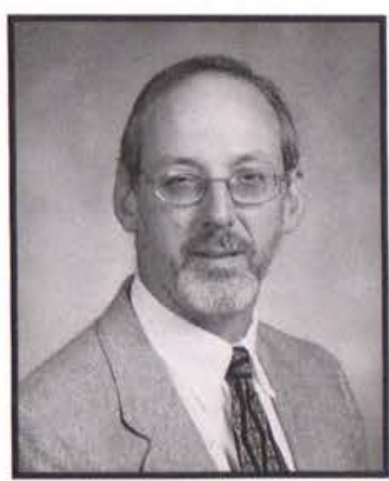

Dr. Michael J. Lopez Professor

Communication Arts 


\section{aculty \\ School of Health \& Human Performance}

"What a great place to work, where God and prayer are always the focus. It is a pleasure to see leaders stick to those principles all the time. The students have a similar heart for the Lord and have been great to work with." With these words, Professor and Coach Ben Belleman was referring to his work as a member of the faculty at Cedarville University in the school of Health and Human Performance.

The faculty of this school deserved the same praise that $\mathrm{Mr}$. Belleman awarded the leaders and students. They shared their hearts that yearned for the Lord, reinforcing the school's Godhonoring reputation, using their abilities both in the classroom and on the field. Their leadership and teaching gave the students the ability to master their area of study and graduate as professionals ready to take their knowledge and education into the world.

Professor and Coach Teresa

Clark enforced the claims in favor

of the school with her statement:

"Integrating Biblical truth and principles in the classroom and on the volleyball court is why I love my position. Using a sport to further the gospel and training future educators to stand firm on Biblical concepts is so rewarding."

The University's Yellow

Jacket Sports teams saw great success under the leadership of these professor and coaches. An NAIA national championship was even rewarded to the women's crosscountry under the guidance of Coach and Associate Professor Elvin King.

Jeff Bolender, an assistant track and field coach, said, "It is not always the best team or athlete who wins, but rather the one who competes the best on the given day."

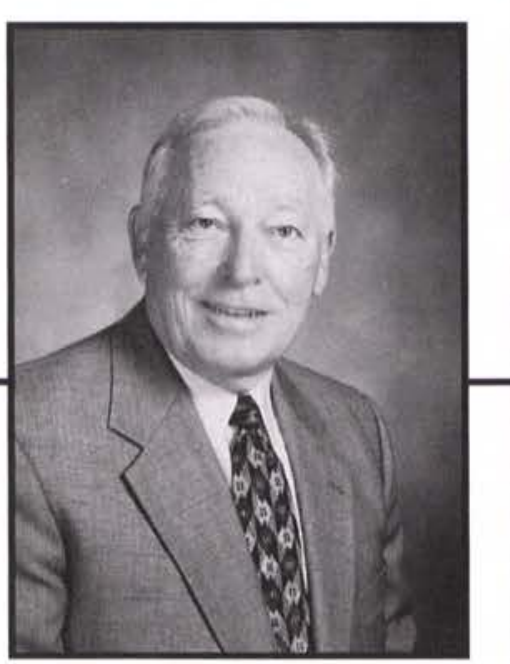

Dr. Don Callan

Dean

Professor of Physical Education

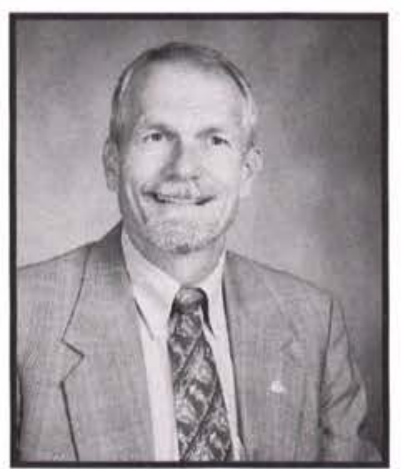

John McGillivray

Chair of Exercise and

Sport Science

\section{Coach John McGillivraytakes a break from coaching to catch up on his email.}

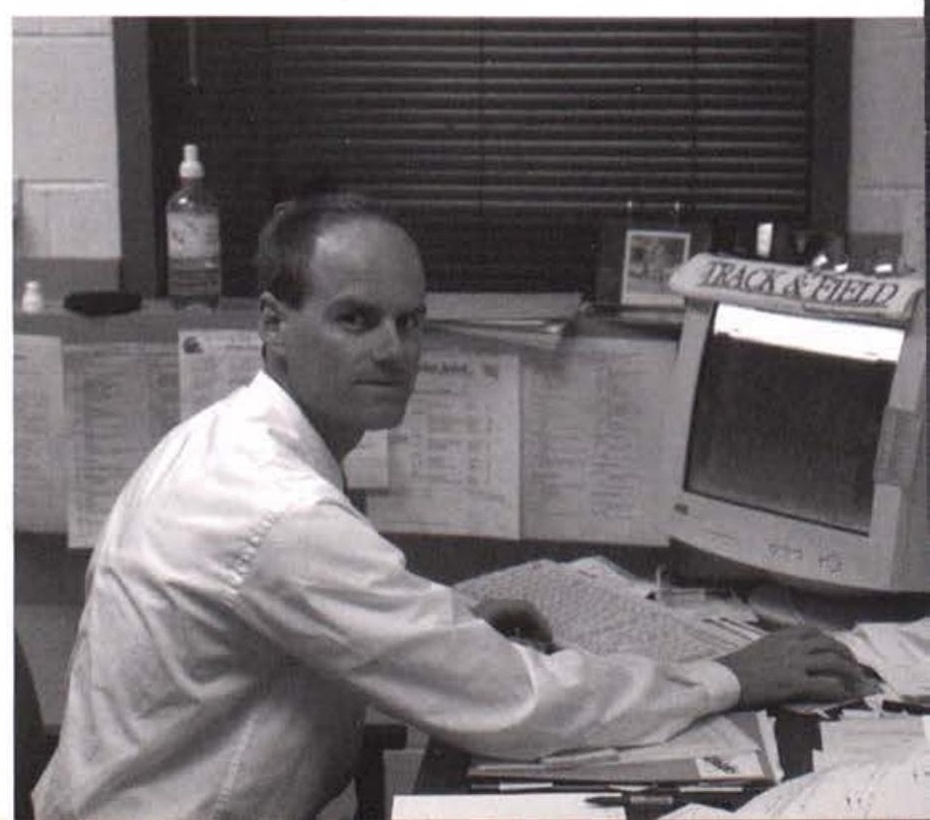




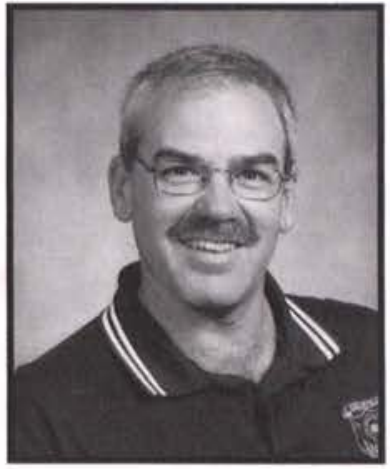

Ben Belleman Assistant Professor Physical Education

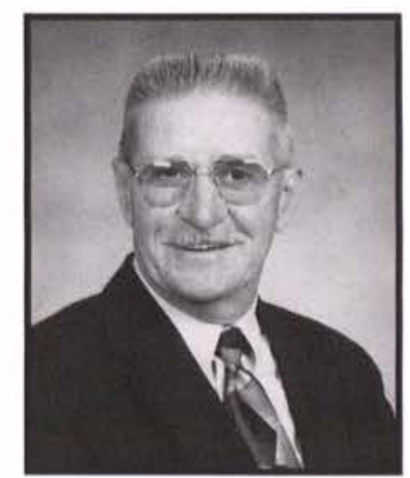

Elvin King

Assistant Professor Physical Education

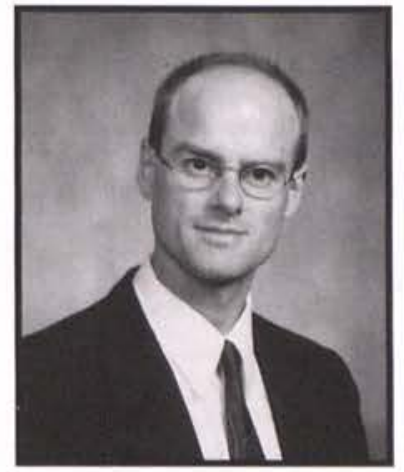

Jeff Bolender Assistant Professor Physical Education

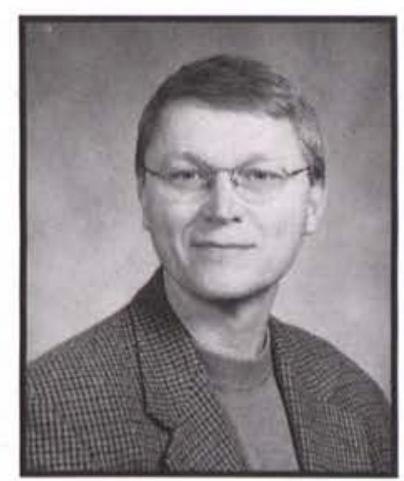

Kirk Martin Assistant Professor Physical Education

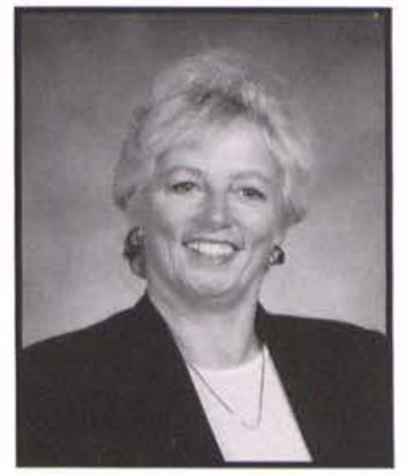

Teresa Clark Assistant Professor Physical Education

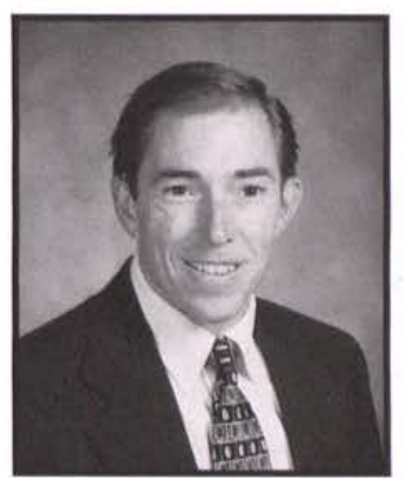

Paul Orchard Assistant Professor Physical Education

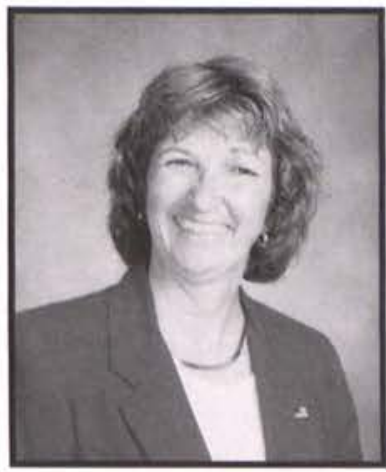

Kathy Freese Assistant Professor Physical Education

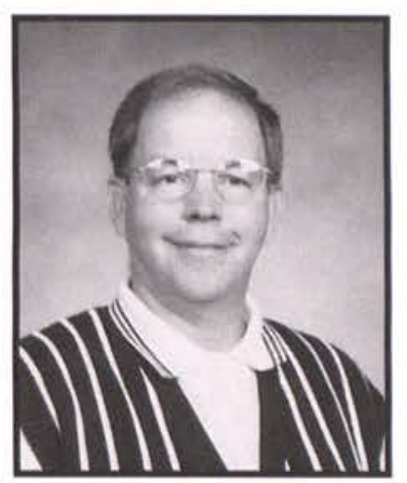

Ray Slagle

Assistant Professor

Physical Education

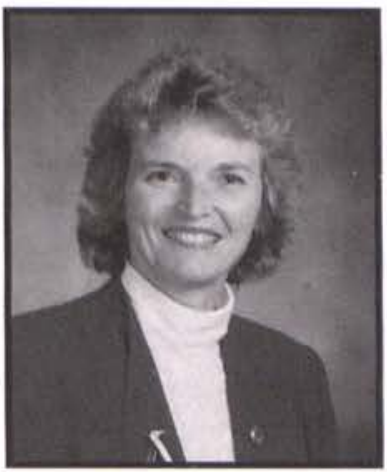

Dr. Pamela Johnson Professor

Physical Education

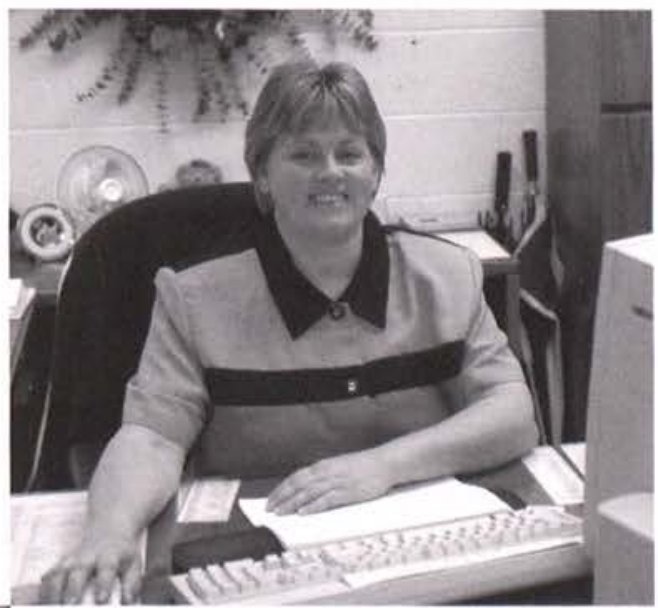

Merilee Shank helps keep the office organized.

Track and Field

Coach Jeff

Bolender hurdles his daily office

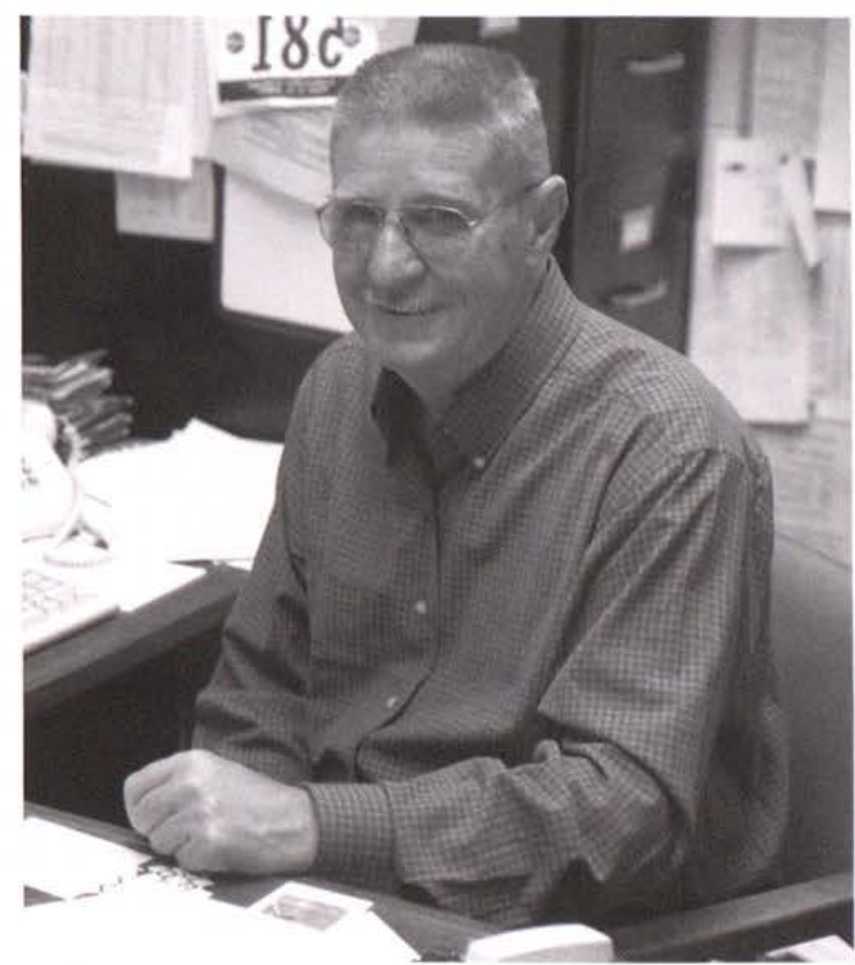

Cross Country Coach of the Year Elvin King stops running around to smile for the camera. tasks. 


\section{aculty}

School of Social Science \& Professional Studies

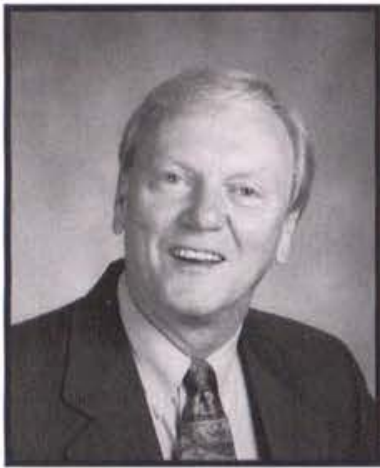

Dr. Robert Abbas

Professor

Psychology

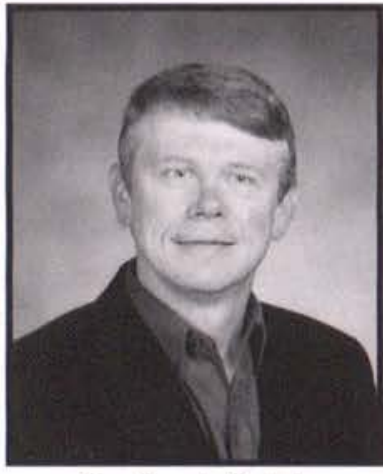

Dr. Chuck Dolph

Professor

Psychology

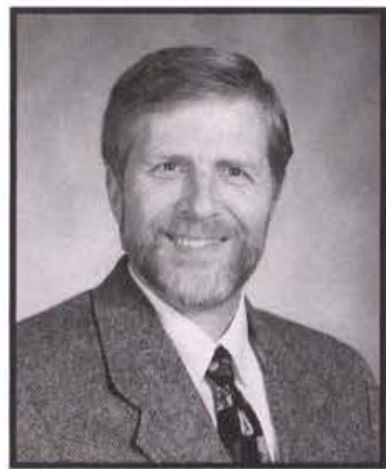

Dr. Phil Bassett

Chair of Education

Associate Professor

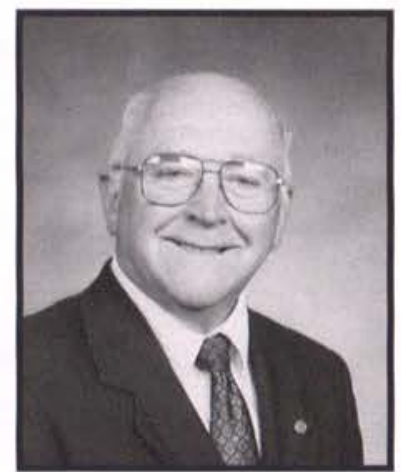

Dr. Richard Baldwin

Professor

Mang. \& Int. Business

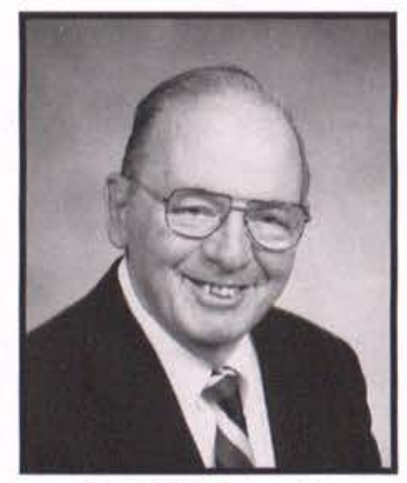

Dr. C.W. Fawcett

Professor Emeritus Management

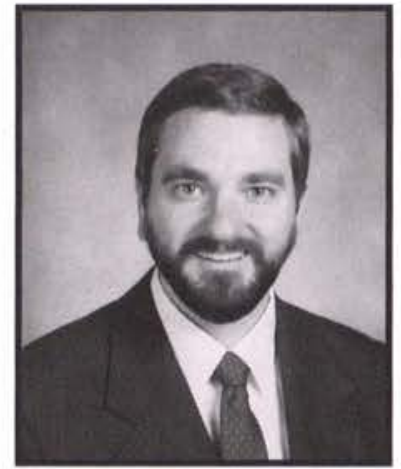

Dr. Michael Firmin

Chair of Psychology Professor

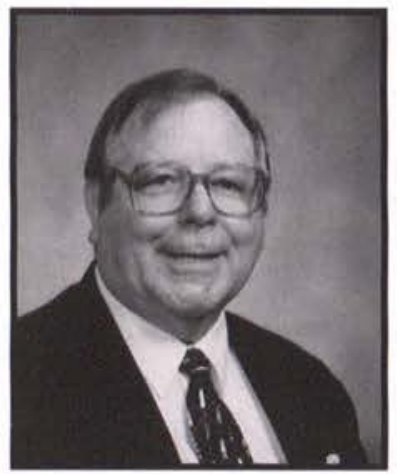

Dr. Omer Bonenberger Associate Professor Education

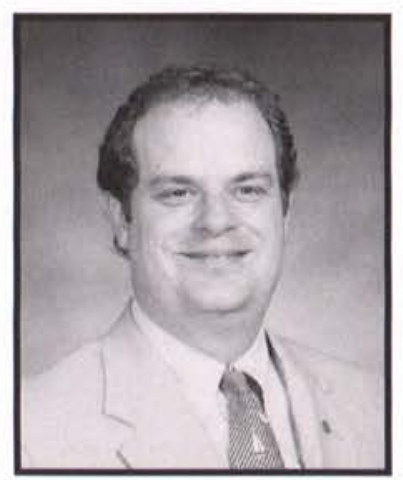

Dr. Jeffery Fawcett Associate Professor Marketing

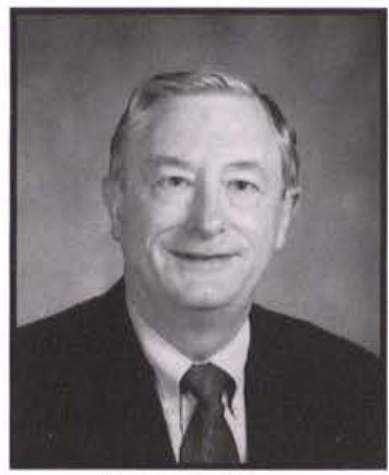

Marinus Hazen

Chair of Business Adm. Associate Professor

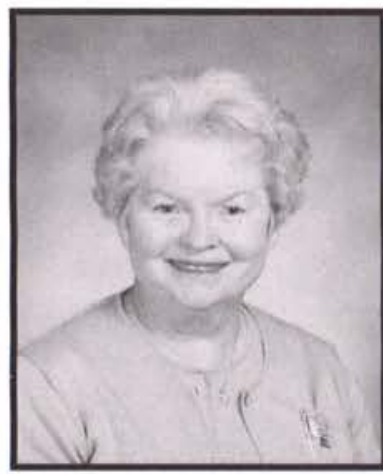

Dr. Sally Castle

Associate Professor Education

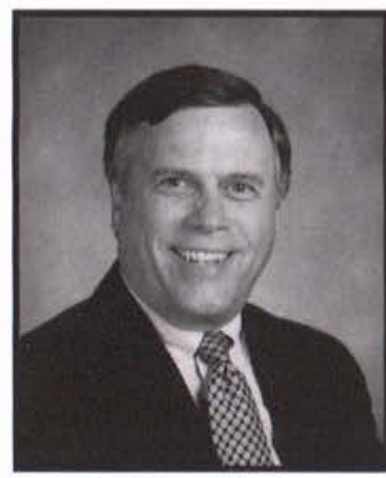

Dr. Steve Gruber Assistant Professor Education

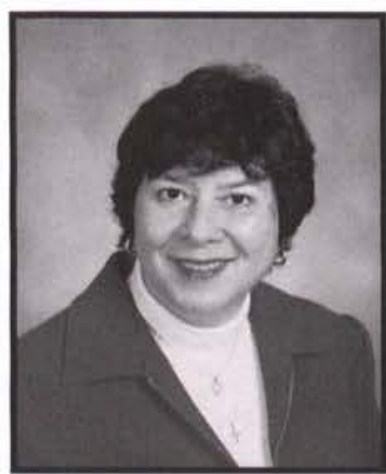

Barbara Chilton Assistant Professor Education

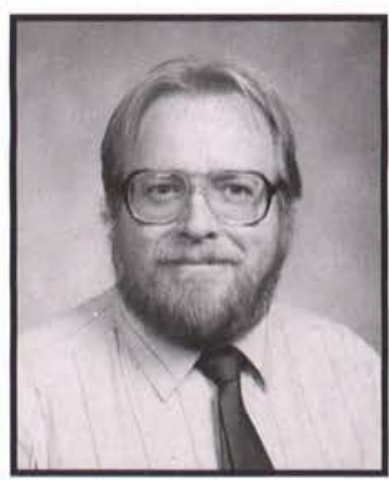

Timothy Hansell Assistant Professor Mang. Information System 


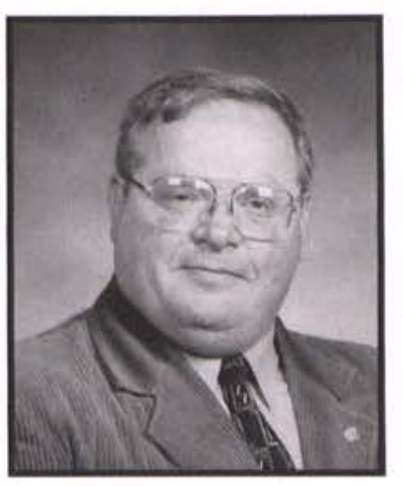

Dr. Nelson Henning Associate Professor Social Work

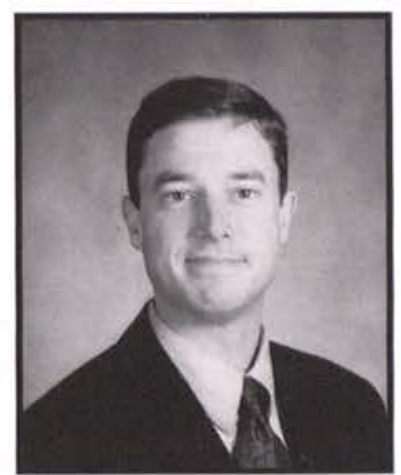

Dr. Thomas Mach Associate Professor History

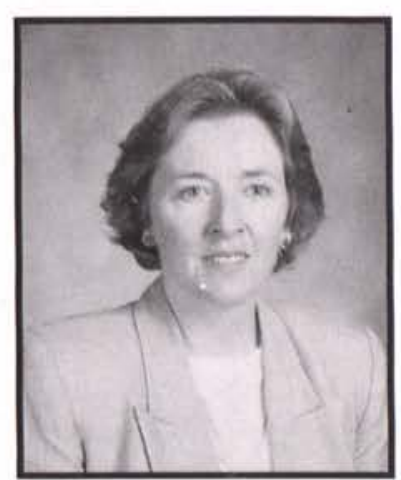

Anne Rich

Associate Professor Accounting

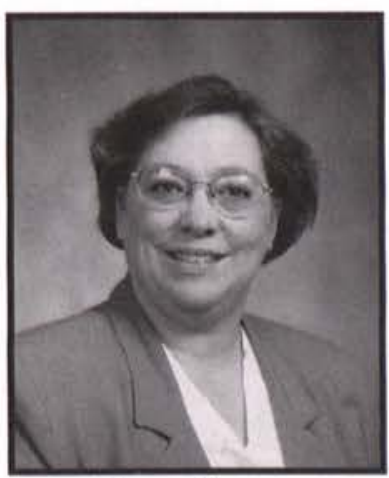

Susan Warner Assistant Professor Social Work

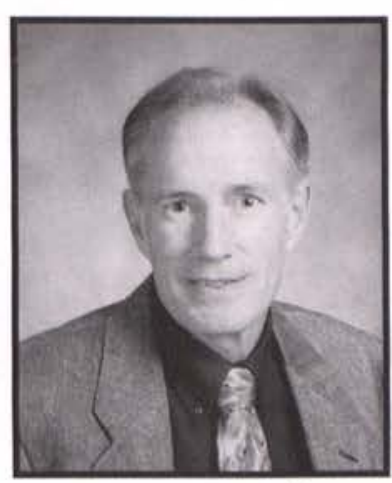

George E. Huff Assistant Professor Social Work

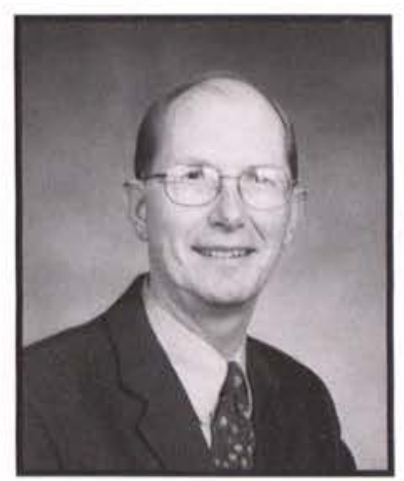

Dr. Donald Meissner Assistant Professor Education

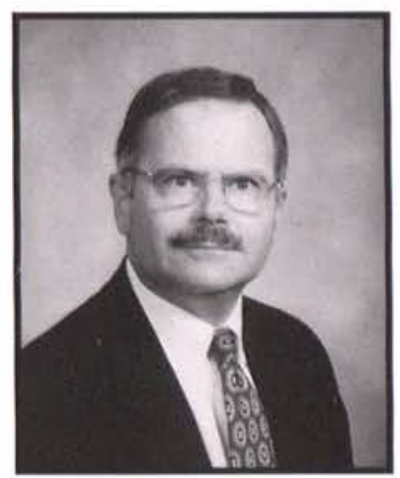

Dr. Kevin Sims

Associate Professor

Political Science

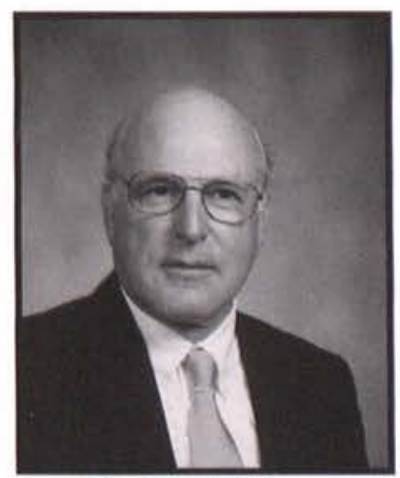

Dr. Ron Walker

Professor

Management Science

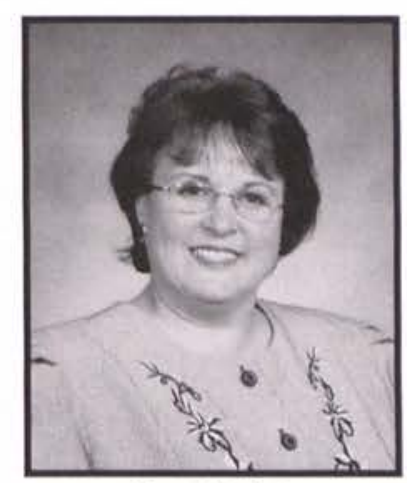

Cheryl Irish

Assistant Professor

Education

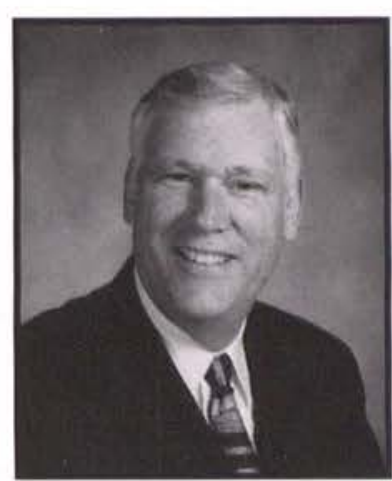

Dr. Robert Parr

Professor

Sociology

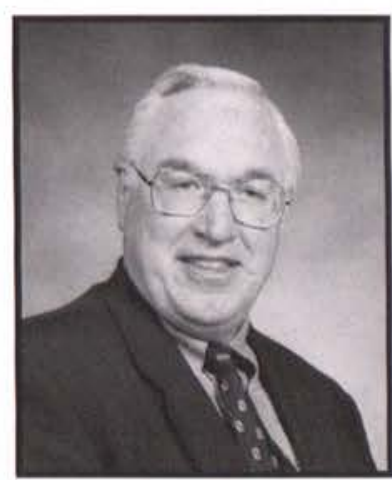

Dr. Galen Smith

Professor

Economics

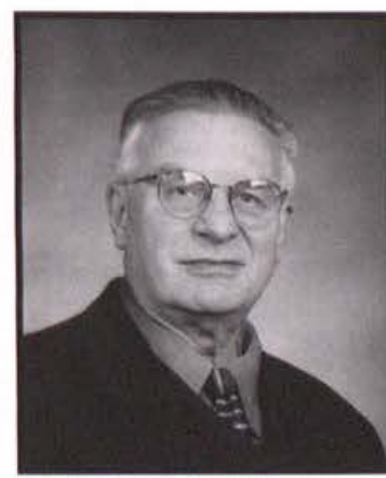

Dr. Robert Wiggins Professor

Criminal Justice

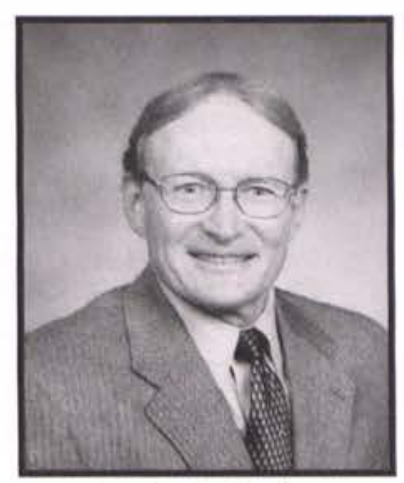

Dr. Frank Jenista Professor

International Studies

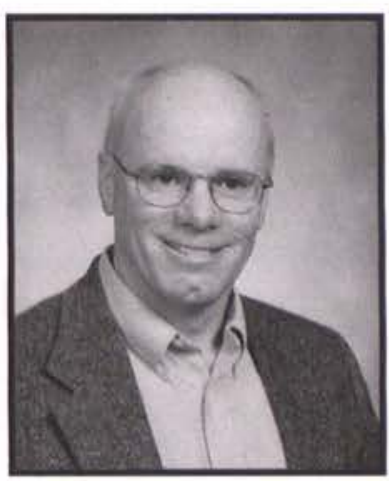

Dr. William Ragle

Assistant Professor Finance

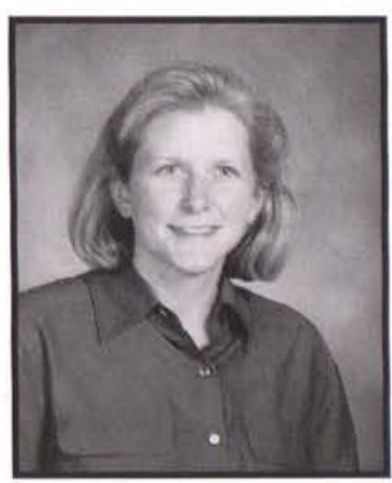

Susan Terkelsen Assistant Professor Office Communication

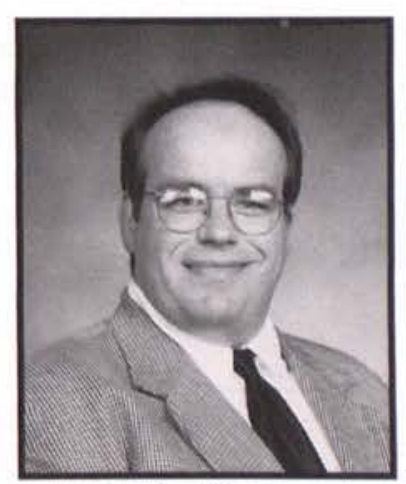

Kevin Winslow Assistant Professor Education

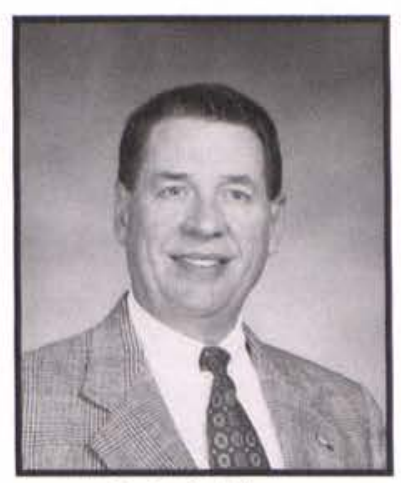

John Leblanc Associate Professor Management

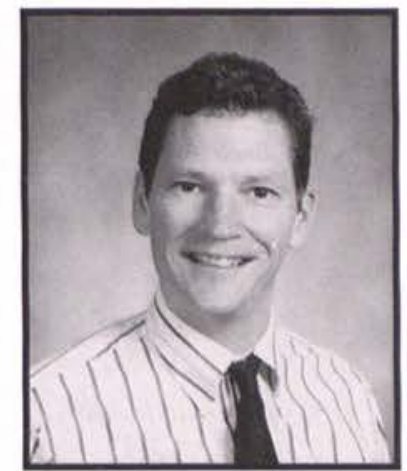

Dr. Lance Revenaugh Associate Professor Mang. Information System

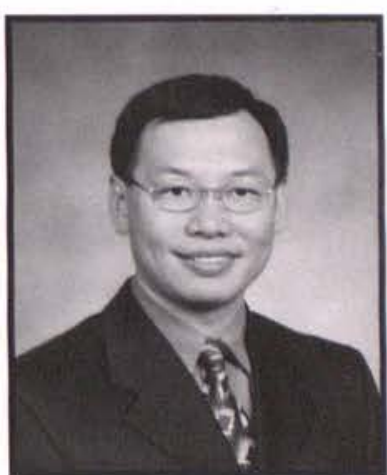

Dr. Luke Tse

Assistant Professor Psychology 


\section{aculty

Towering shelves laden with books offered resources for many projects. The computer lab and resource center provided a place to work on projects for those with a creative flair. Tables scattered throughout the building gave the students a place to study away from their room or with their friends and classmates. These features helped make the Centennial Library a wonderful place, but the staff's passion and love for the students enhanced the effectiveness of the library.

The staff worked hard to provide the materials needed for all the classes on campus. They offered a wide variety of books, magazines, journal writings, and internet connections. If the Centennial Library did not own the needed material, they would send out to get it; often in a few days, the pertinent material arrived.
Besides offering excellent technology and a myriad of resources, the library also provided a warm atmosphere to work.

Students could find a place away from the distractions of dorm rooms and roommates. With large windows, open spaces, and peaceful views from the windows, the library contained the aura of learning and study.

The library faculty and staff held the desire to serve students in a multitude of ways. Librarians aided the students in their various

projects. With specialties in many areas, librarians could assist students with using a computer, researching a topic, or finding a book. The staff gave of their talents in different divisions-from collection services to media services. Through their diligent work and care for the students, the library prospered.

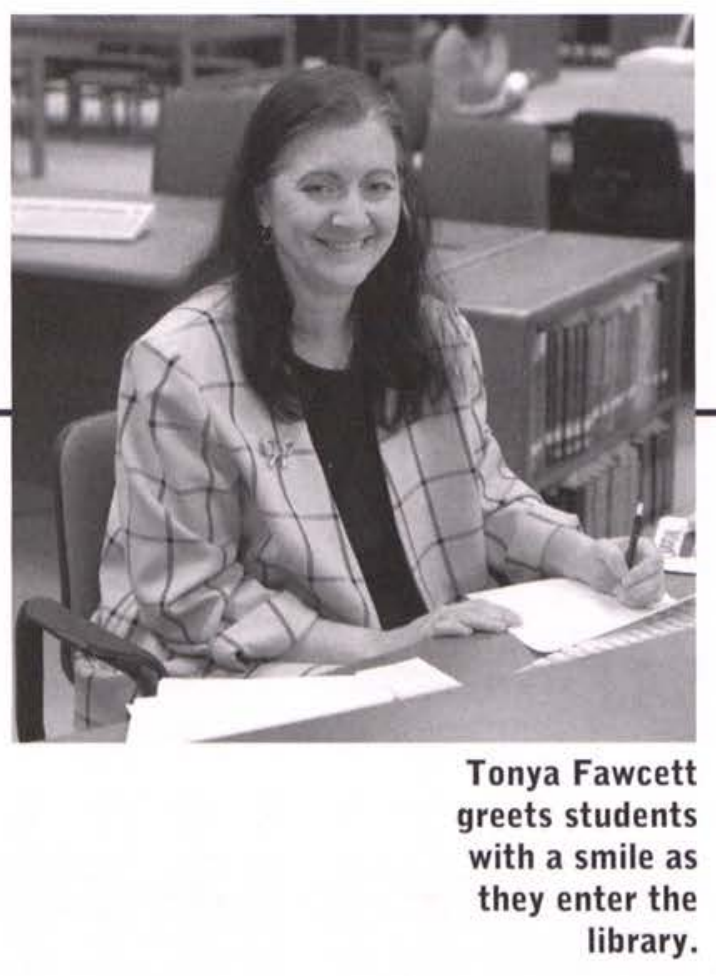

library.

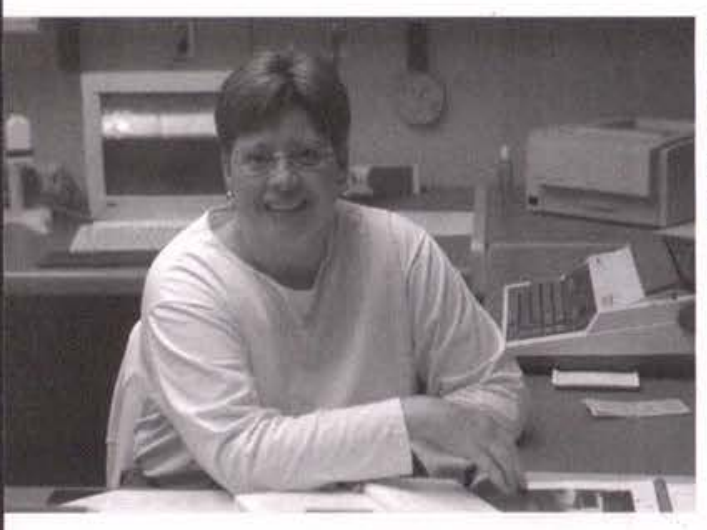

Interrupted from work, Melinda Howard gladly smiles for a picture.

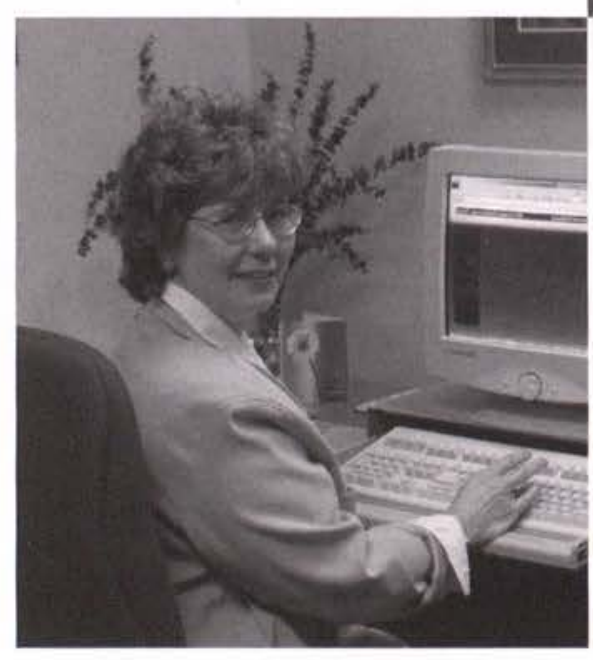

Not only does Lynne Funtik work hard in her office, but she helps students find library resources. 


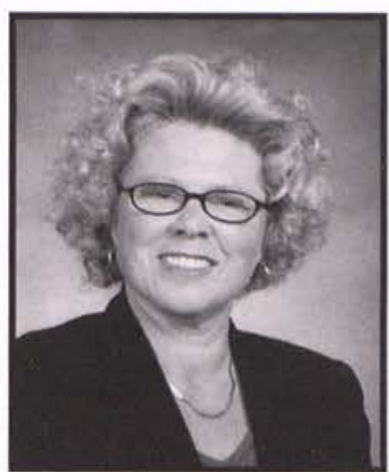

Jance Bosma

Associate Director

Library Services

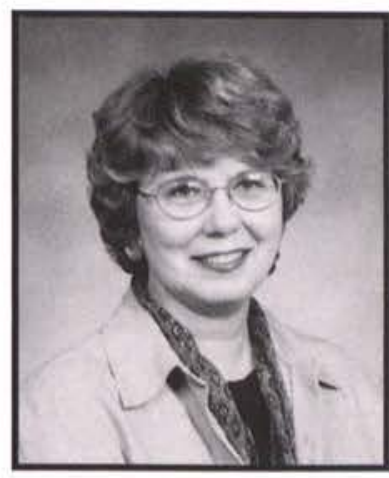

Lynne Funtik

Senior Reference

Librarian

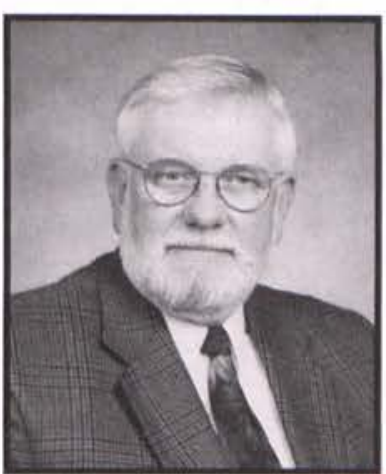

Carl Brandon

Assistant Director

Media Services

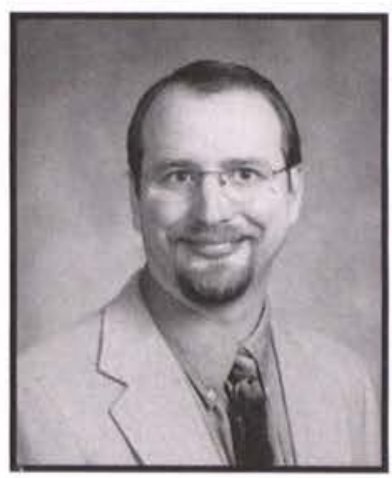

Rory Patterson

User Education Librarian

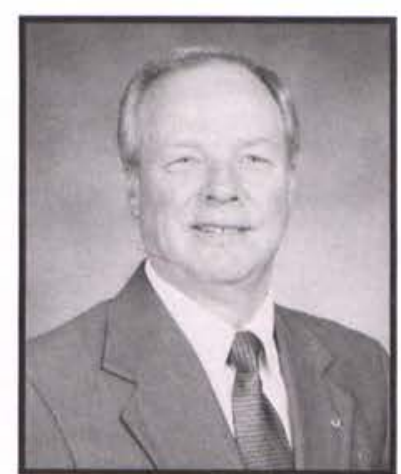

Lynn Brock

Director

Library Services

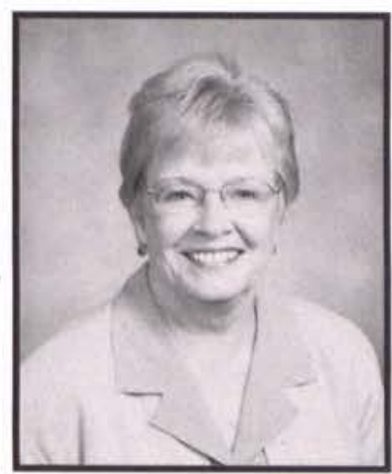

Joyce Riggs

Curriculum Materials

Center Librarian

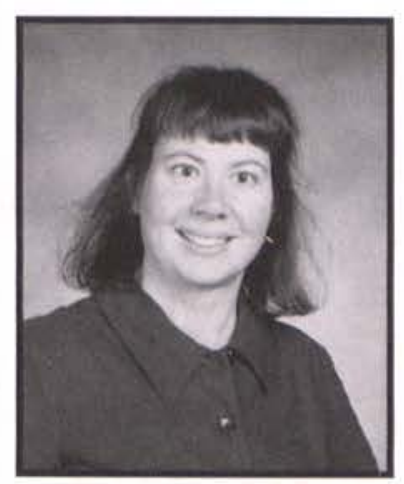

Julie Deardorff

Assistant Library Director Collection Services

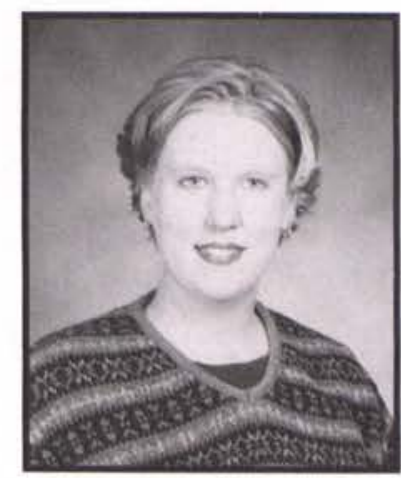

Susan Winn

Reference

Librarian

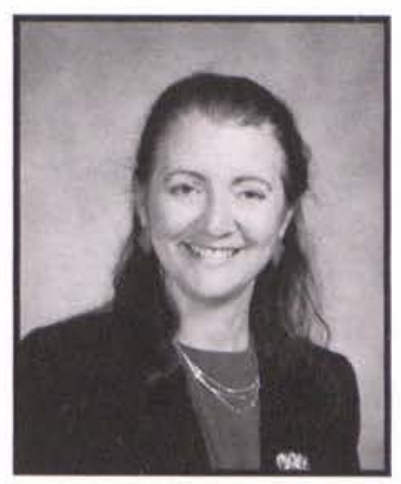

Tonya Fawcett Assistant Library Director Reader Services

\section{Centenial Library StafF}

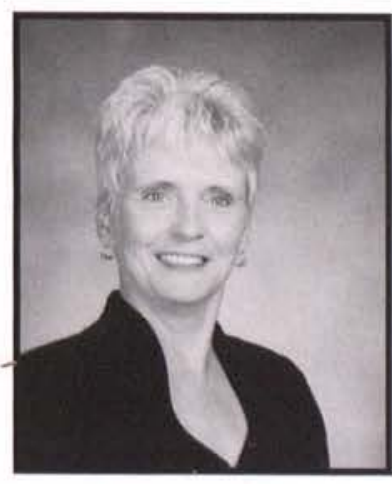

Patty Stutes

Manager

Media Research Center

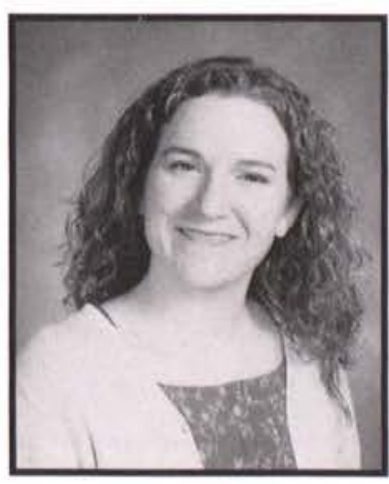

Jennifer Myers

Manager

Circulation Services

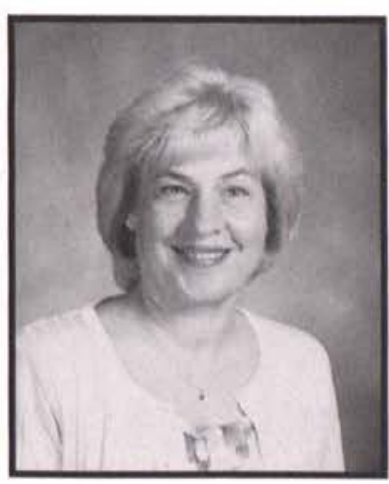

Dianne Gottwals Assistant MRC Graphics

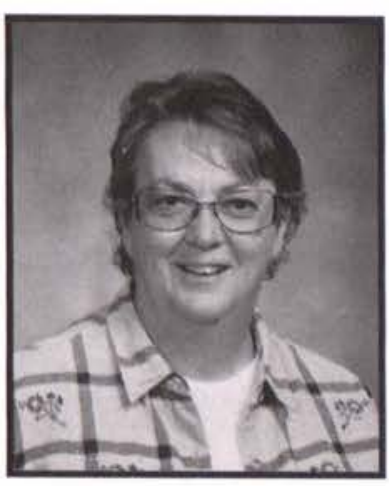

Margaret Dillon Assistant

Serials Technician

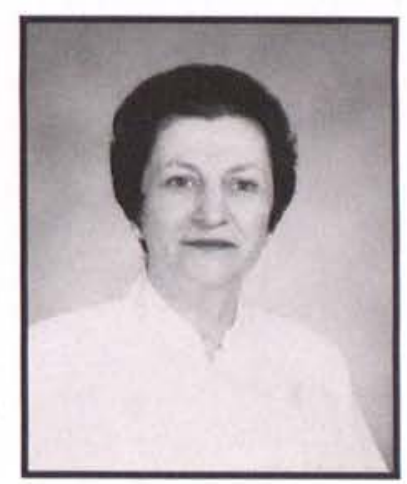

Fran Andrews Manager Library Office 


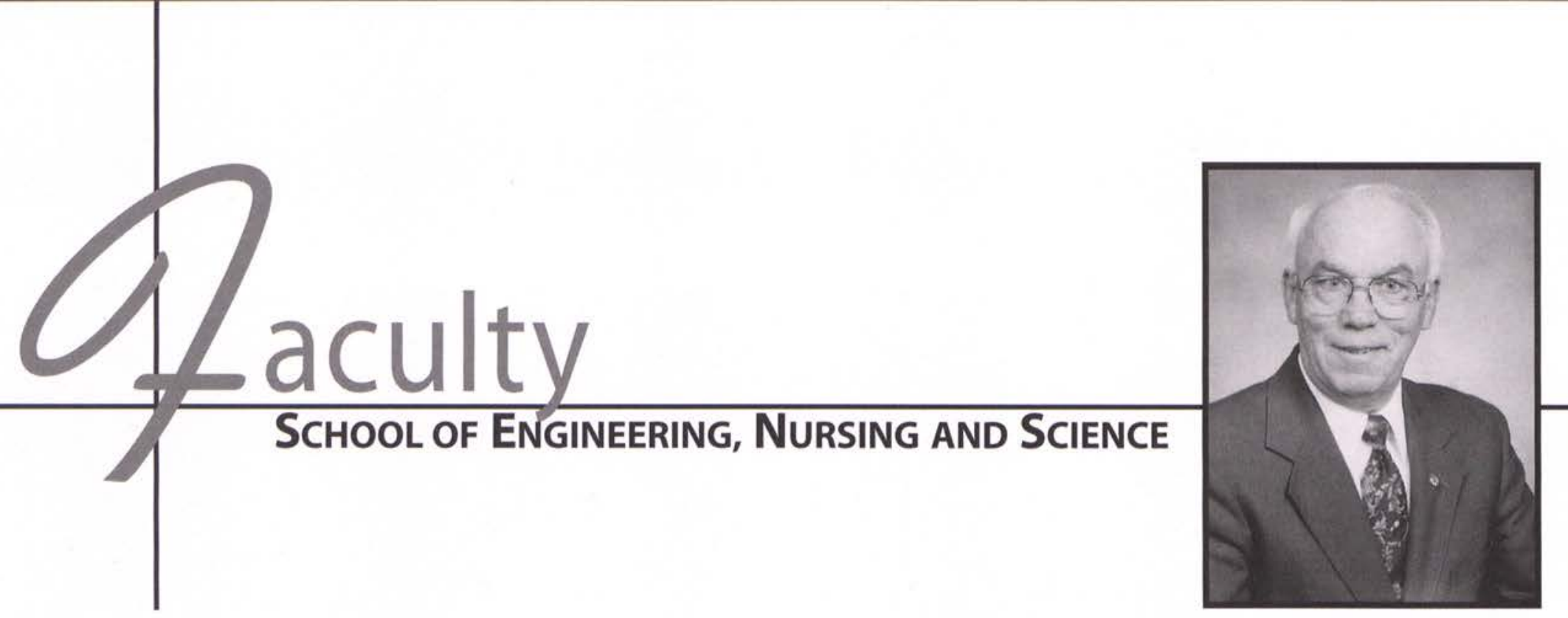

Dr. Daniel Wetzel

Dean

Professor of Physics \& Math

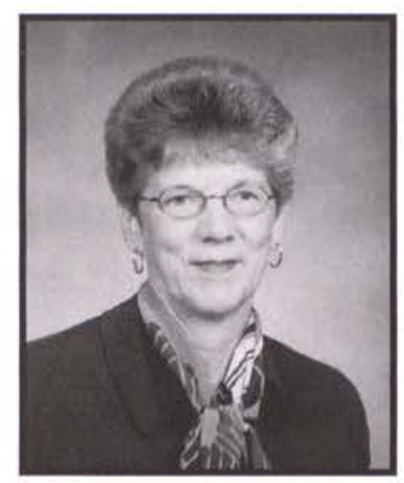

Dr. Irene B. Alyn Chair of Nursing Professor

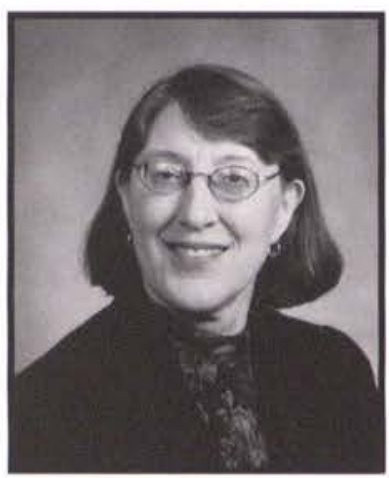

Dr. Lois Baker Professor Nursing

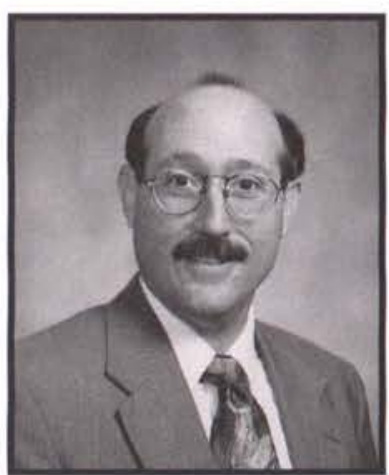

Dr. Robert Chasnov

Professor

Engineering

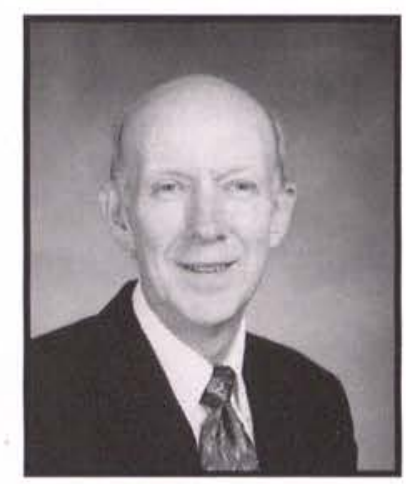

Dr. Donald Baumann Professor

Biology \& Chemistry

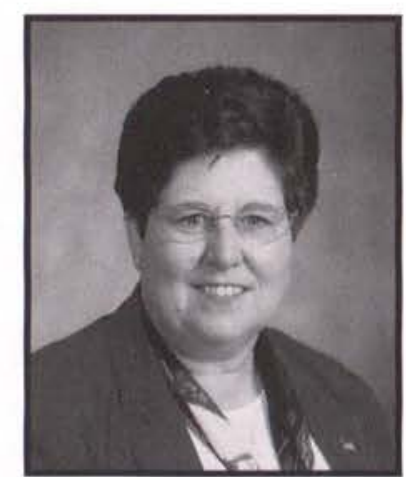

Dr. Janet Conway Professor Nursing

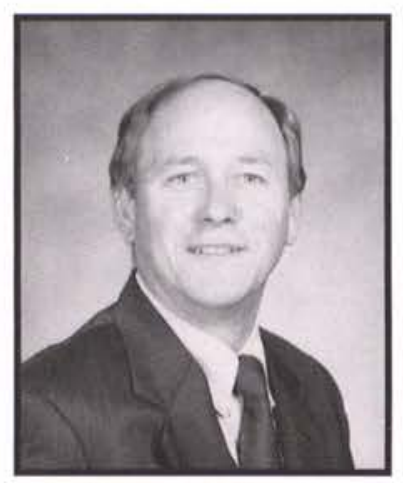

Dr. Lawrence Zavodney Chair of Engineering Professor

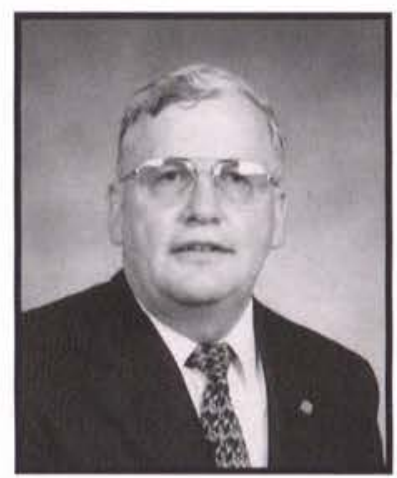

Dr. Edwin Braithwaite Professor

Mathematics

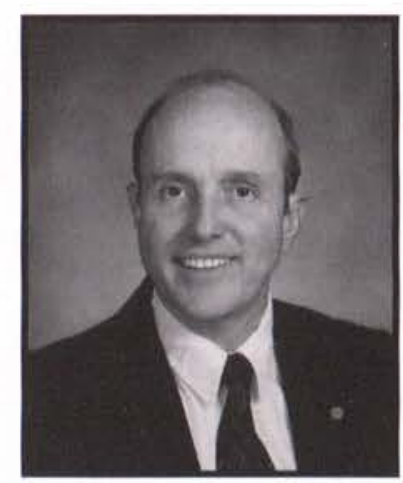

Dr. Keith Francis Associate Professor Biology

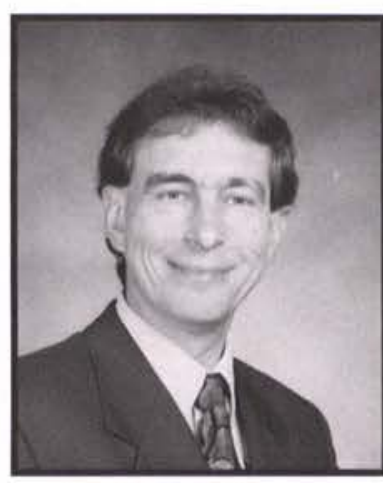

Dr. Dennis Flentge Chair of Science \& Math Professor

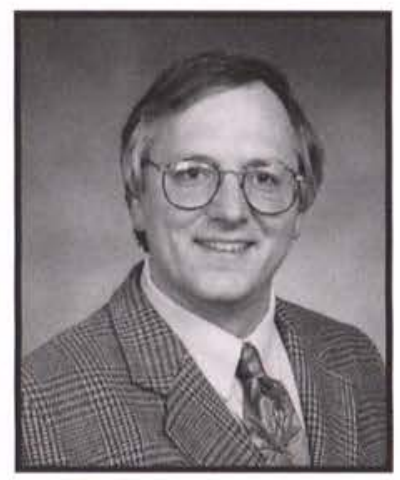

Dr. Peter Burban Associate Professor Mechanical Engineering

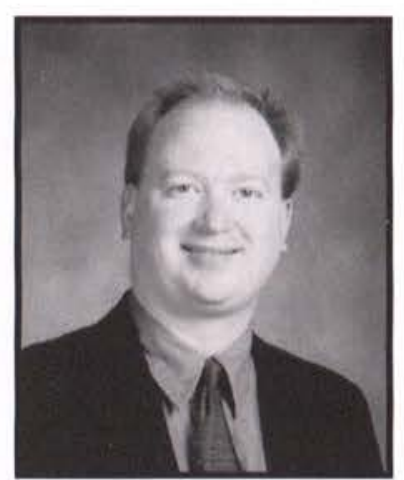

Dr. Darrin Frey Assistant Professor Mathematics

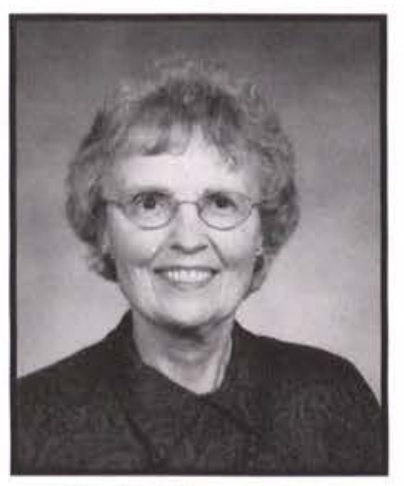

Dr. Carolyn Carlson Professor Nursing

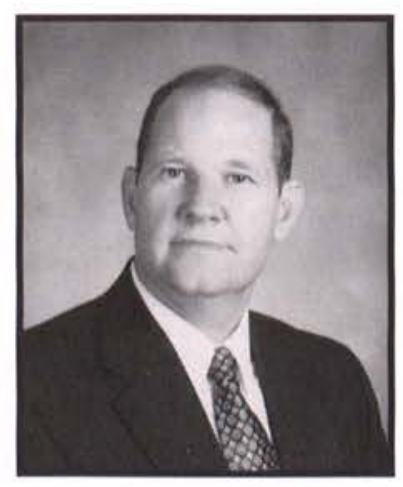

Dr. Dave Gallagher Associate Professor Computer Science 


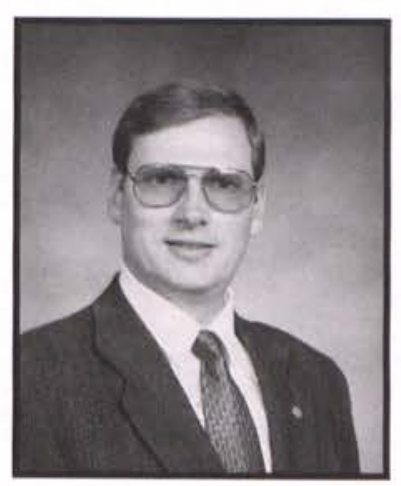

Dr. Steven Gollmer Associate Professor Physics

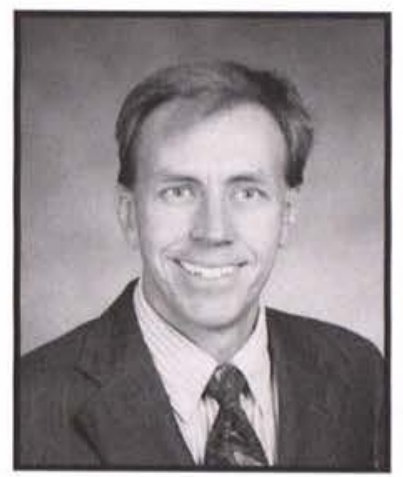

Jay Kinsinger Assistant Professor Mechanical Engineering

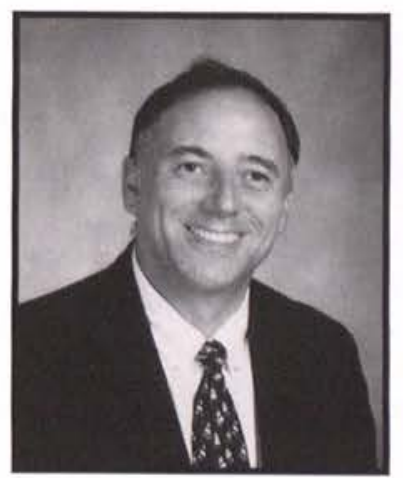

Dr. Kevin Roper Assistant Professor

Mathematics

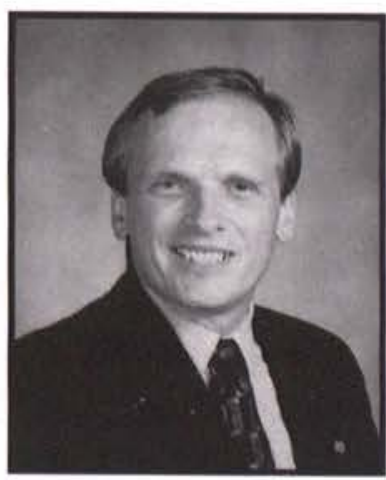

Dr. D. Jeffrey Shortt Associate Professor Electrical Engineering

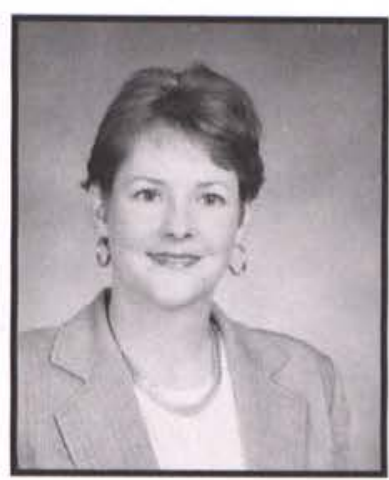

Sandra Hayward Assistant Professor Nursing

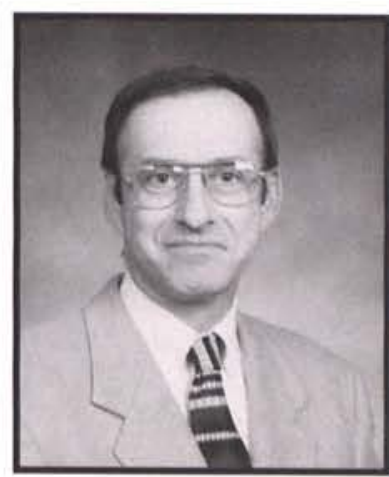

Robert Laramore Associate Professor Electrical Engineering

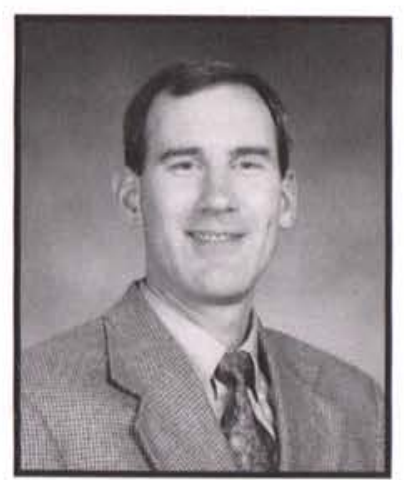

Dr. Sam SanGregory Associate Professor Electrical Engineering

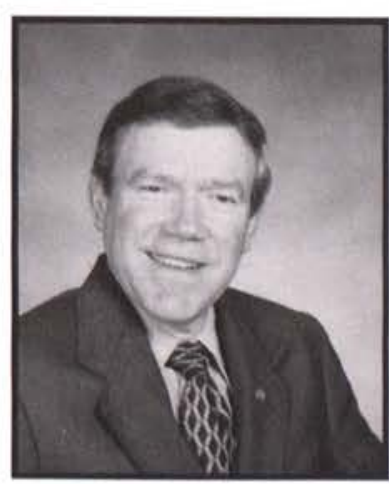

Dr. John Silvius Professor Biology

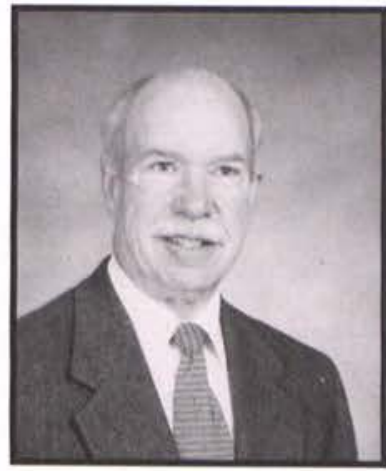

Dr. Larry Helmick Professor Chemistry

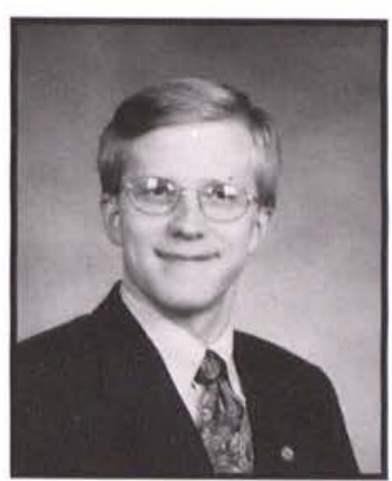

Dr. Mark McClain

Assistant Professor Chemistry

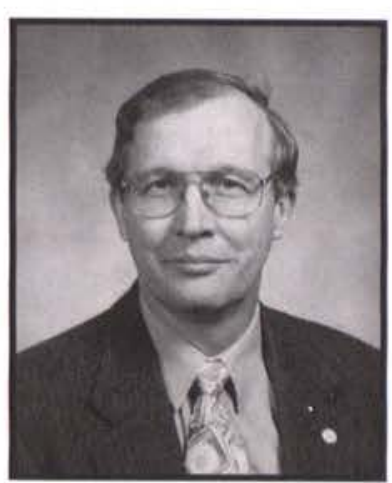

Robert Schumacher

Assistant Professor Science

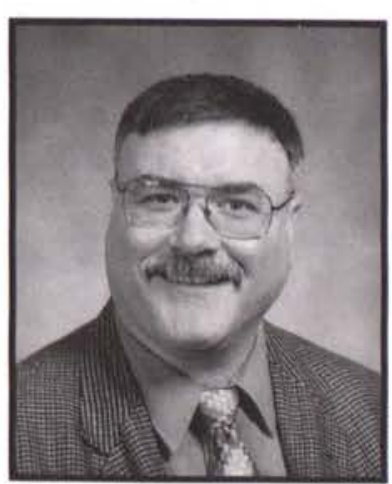

Dr. Dennis Sullivan Associate Professor Biology

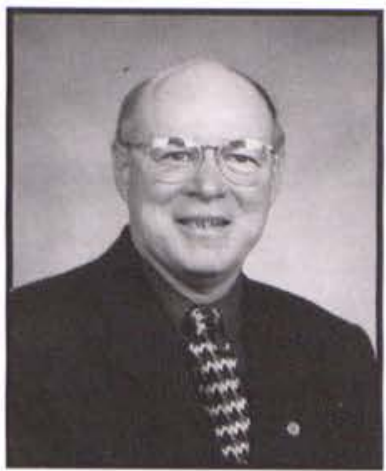

Dr. Harwood Hegna

Professor

Mechanical Engineering

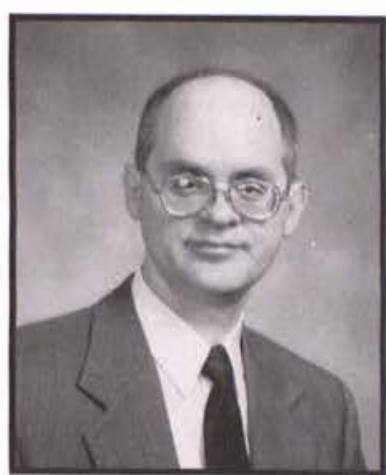

Dr. Douglas Miller

Professor

Chemistry

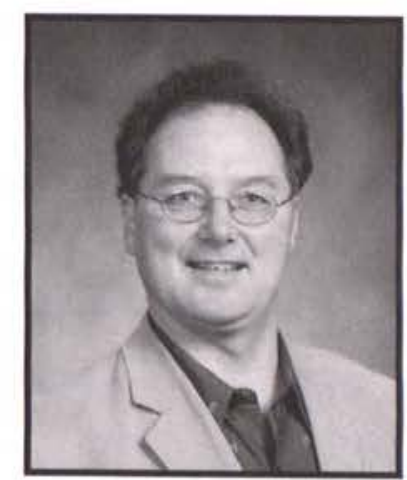

Dr. David Sharp

Associate Professor Nursing

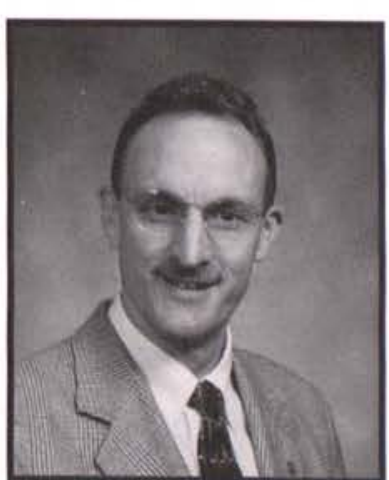

Dr. Thomas Thompson Associate Professor Mechanical Engineering

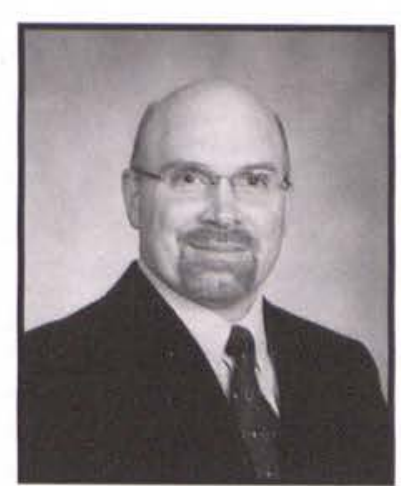

William Jones

Assistant Professor Biology

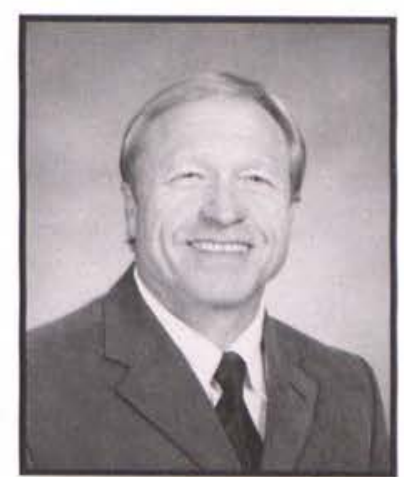

Dr. Terry Phipps Professsor Biology

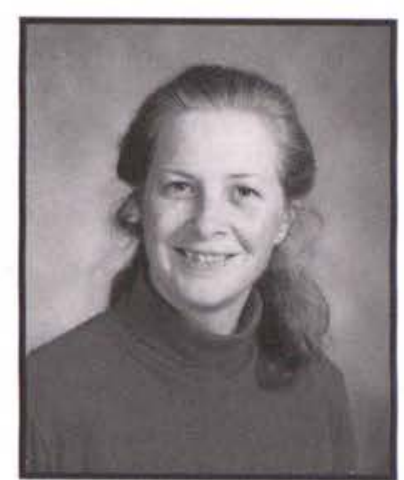

Dr. Kimberly Sharp Associate Professor Nursing

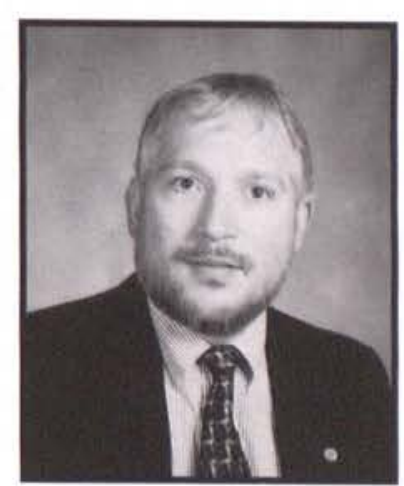

John Whitmore Assistant Professor Geology 


\section{Student Services Division}

There were a plethora of activities, organizations, conferences, and meetings for students to be involved in at Cedarville. The driving force behind all of these was the Student Services Division, the people who did their best to meet the needs of students on and off campus.

Vice President for Student Services Carl Ruby headed the Division of Student Services, and under his leadership were several other departments: Campus Activities, Career Services, the Counseling Center, and Patterson Clinic.

There were also smaller divisions of student leaders who took positions under the Student Services name. Included were the Student Government Association, the Resident Directors, Resident Assistants, and the Campus Activities Board.

For the 2001-2002 school year, a series of leadership conferences was instituted. This workshop explored the importance of character and integrity in the lives of Christian leaders. The Career Services Department aided the students in composing resumés and hosted Career Link days, inviting numerous employers to campus.

This year, VP Ruby

decided to undertake a comprehensive evaluation of the University's progress by preparing an audit team to come in and assess the effectiveness of the various groups on campus.

Looking toward the future, Ruby said, "Our highest strategic priorities as a division include the ongoing development of our leadership program, the completion of the fitness/recreation facility, and the expansion of our counseling resources."

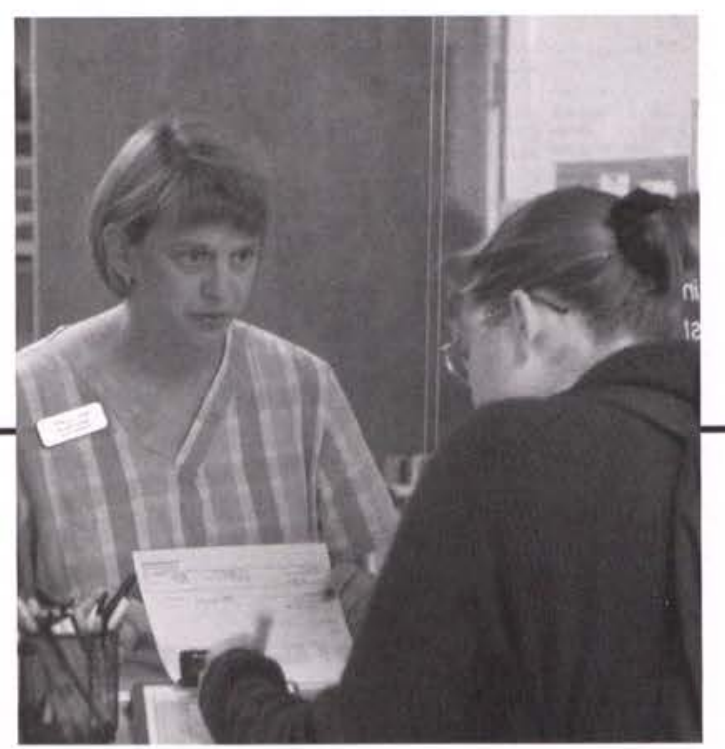

Kay Clark helps a student in

Patterson Clinic.

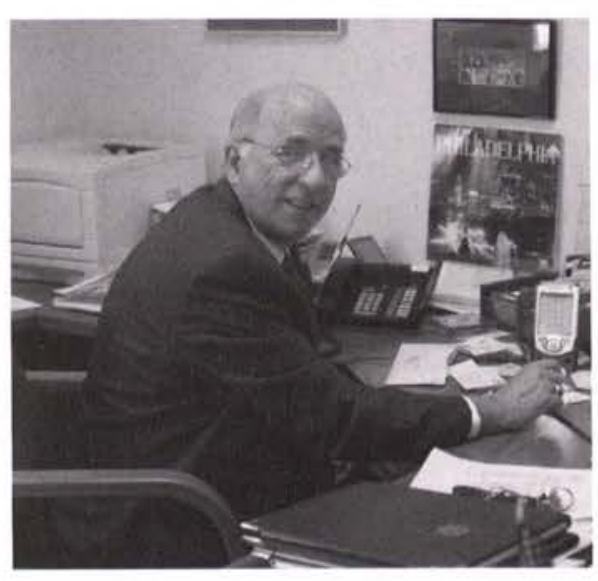

Lew Gibbs helps students prepare for the future in Career Services.

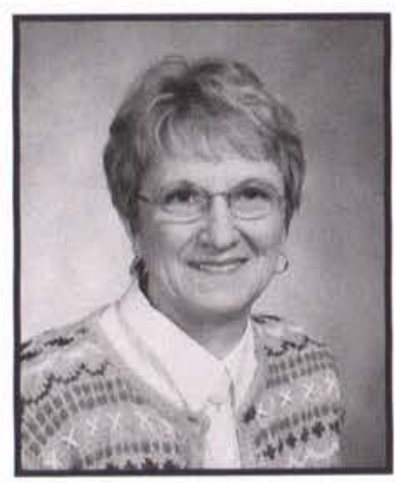

Ruth Ager

Exec. Secretary for VP Student Services

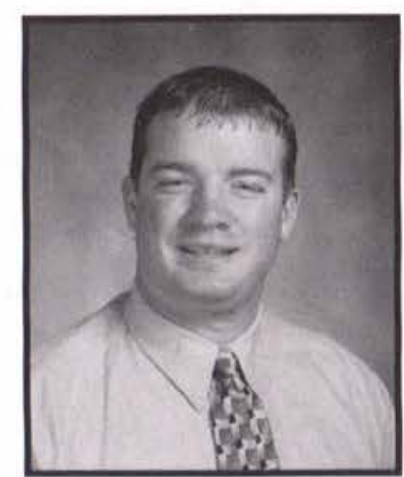

Jim Amstutz Resident Director The Hill

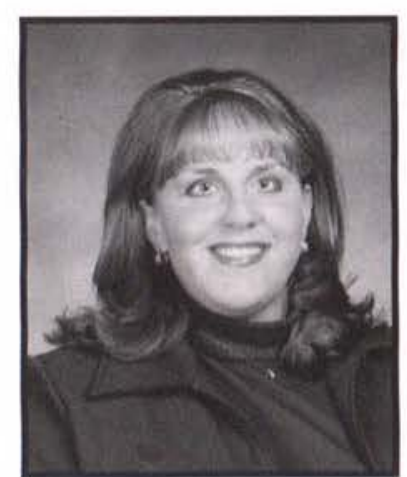

Lori Anderson Counselor Counseling Services

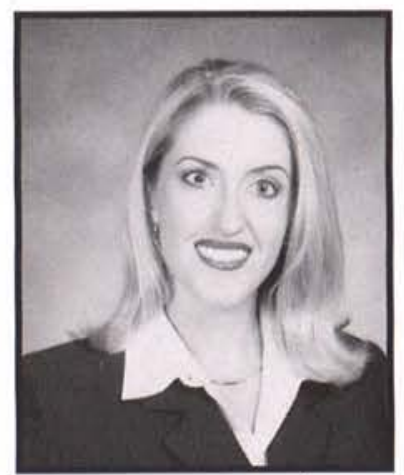

Courtney Atwell Resident Director Printy

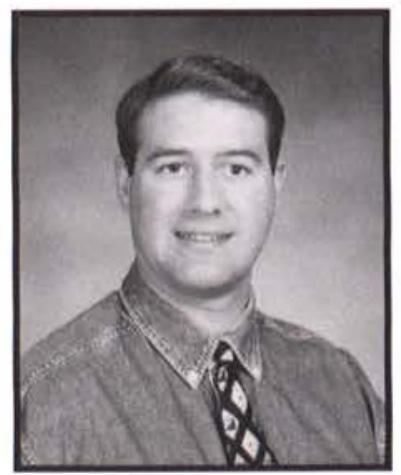

Jonathan Basner Resident Director Lawlor 


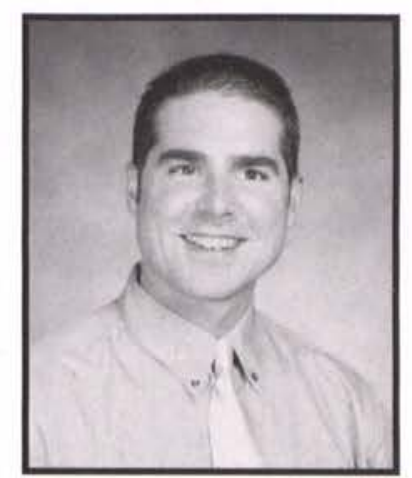

Jeff Beste

Assistant Director

Campus Activities

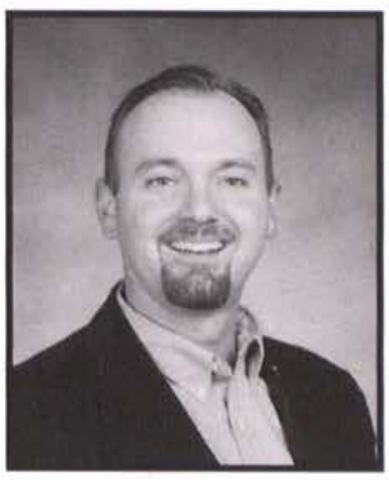

Paul Isaacs

Resident Director Brock

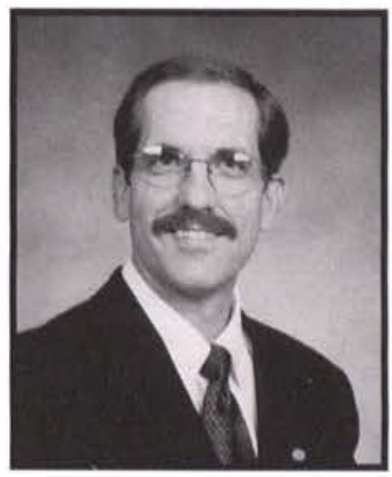

Mark Mathews Director

Recreational Activities

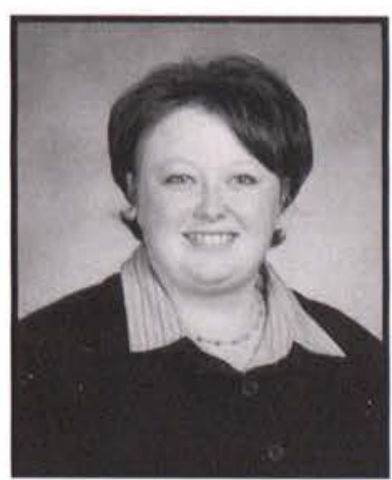

Lyndell Rising

Resident Director Johnson

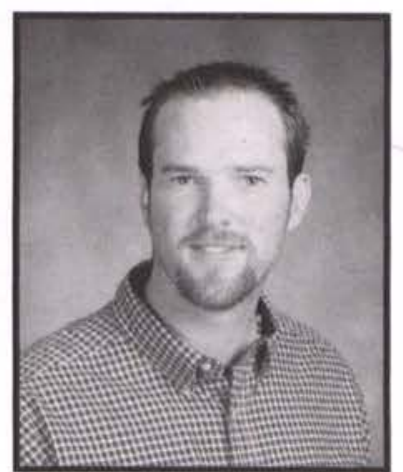

Tracy Commons

Resident Director

McChesney

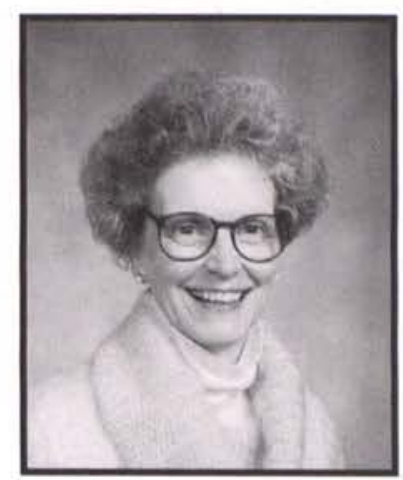

Murtha Kaercher Insurance Coordinator Patterson Clinic

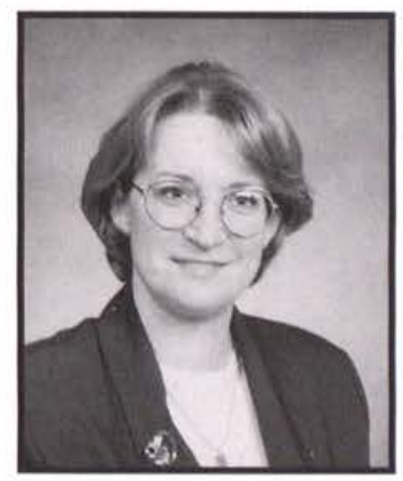

Deb McDonald Director

Patterson Clinic

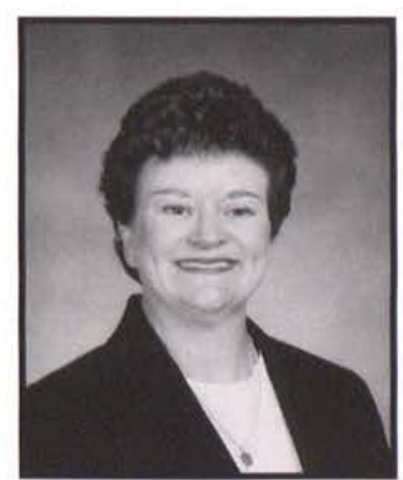

Beverly Robey Supervisor

Patterson Clinic

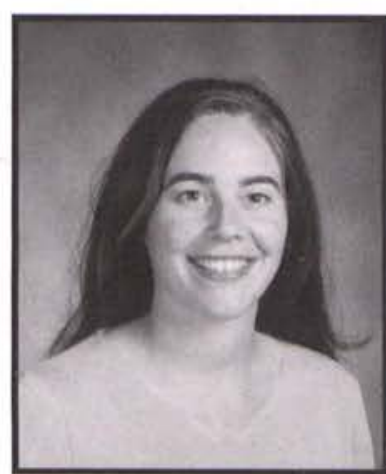

Amy Dirr

Resident Director

Maddox

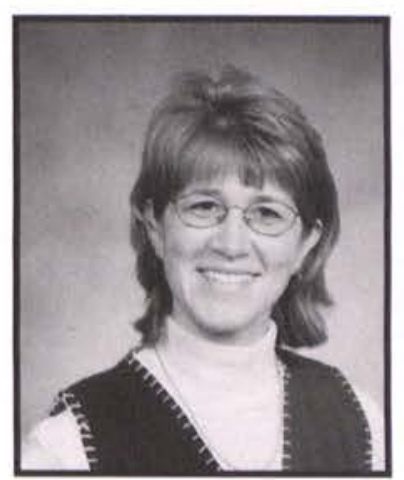

Elaine Keller

Secretary

Campus Activities

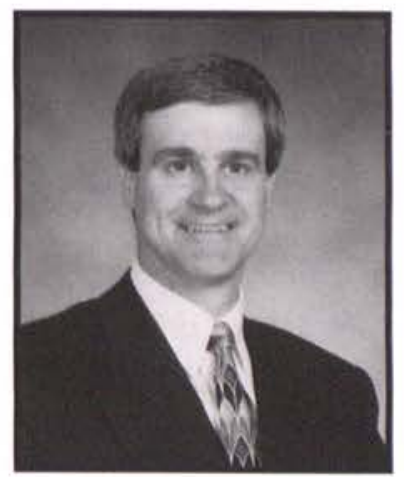

John Potter

Director

Counseling Office

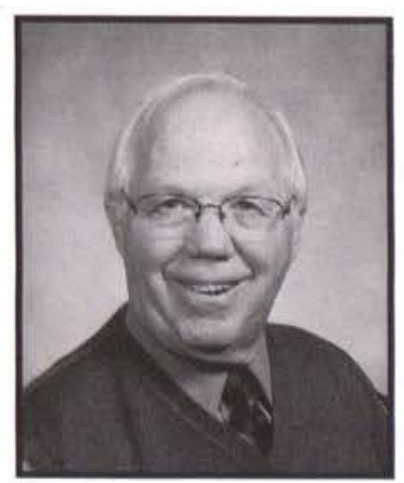

Marvin Troyer

Coordinator

Off Campus Living

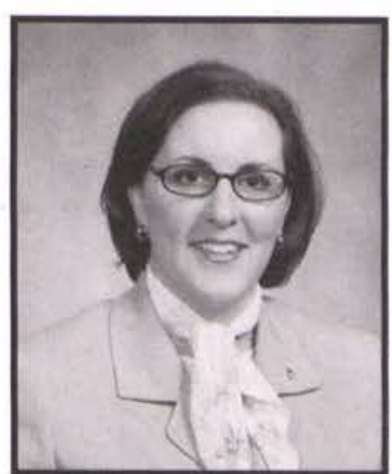

Kirsten Gibbs

Associate Dean

Student Services

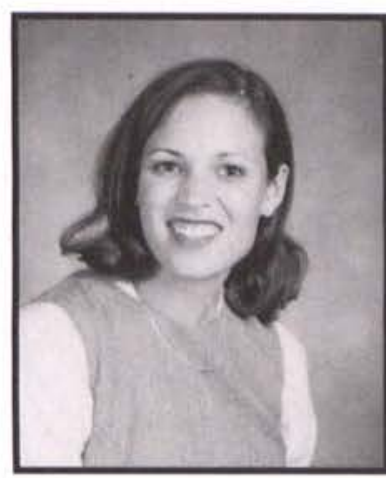

Noella Kleis

Administrative Assistant

Career Services

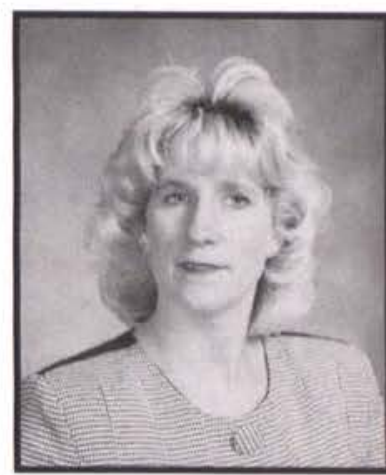

Dawn Scott

Information Center

Coordinator

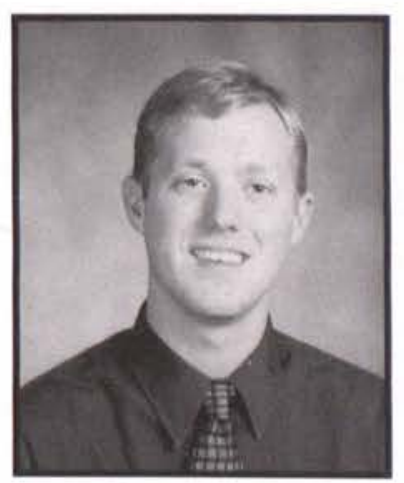

Scott VanLoo

Director

Stevens Student Center

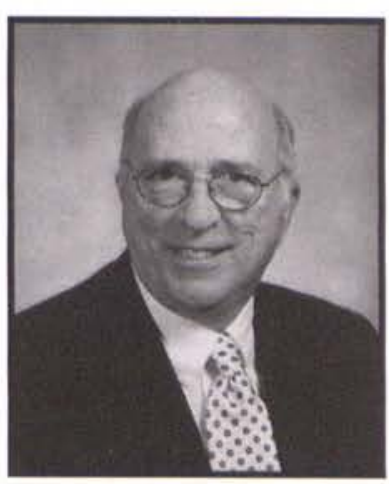

Lew Gibbs

Director

Career Services

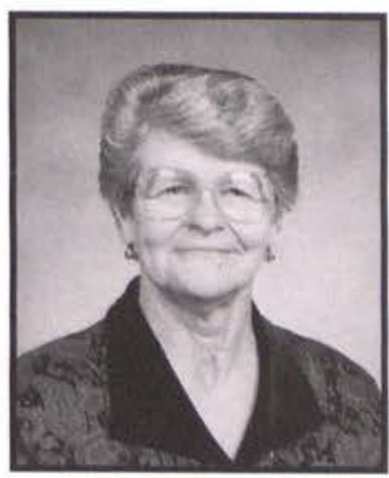

Nancy Knauff

Secretary

Student Services

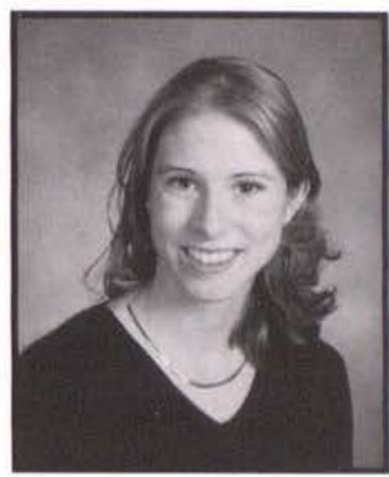

Alison Reemtsma

Office Manager

Career Services

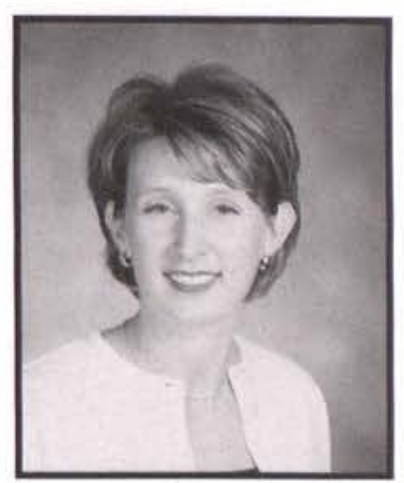

Susan West

Resident Director

McKinney 
Mark Womack

keeps fans in-

formed of Jacket

sporting events.

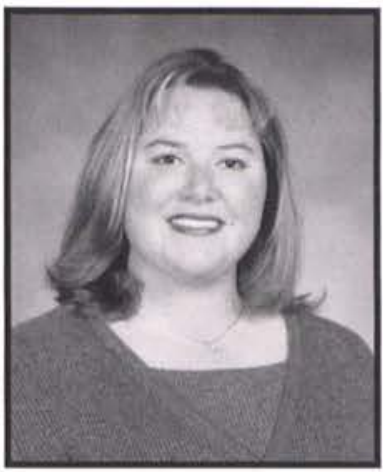

Lisa Martin

Athletic Trainer

Exercise \& Sport Science

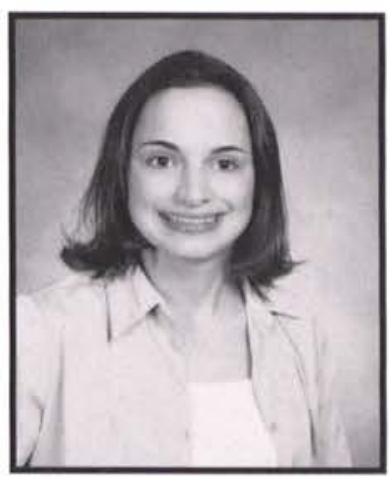

Amanda Pilgrim

Administrative Assistant Education

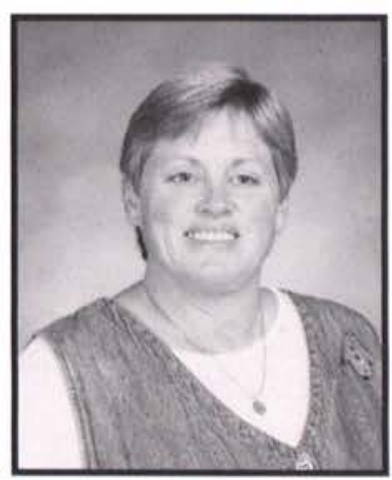

Merilee Shank

Administrative Assistant Exercise \& Sport Science

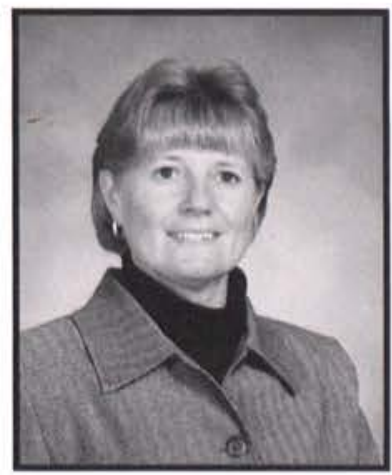

Joy Williams

Administrative Assistant Assistant VP Office

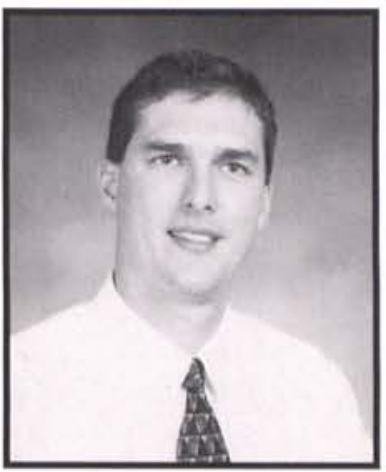

Mark Mazelin

Assitistant Coordinator

Computer Services

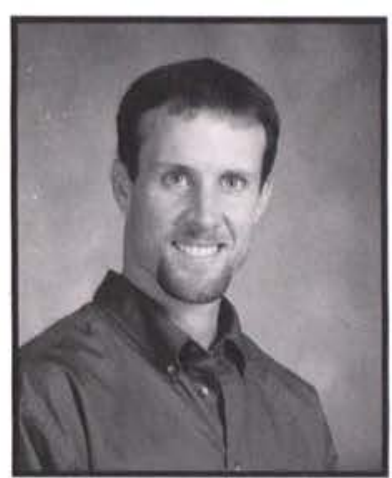

Jon Plush

Athletic Trainer

Exercise \& Sport Science

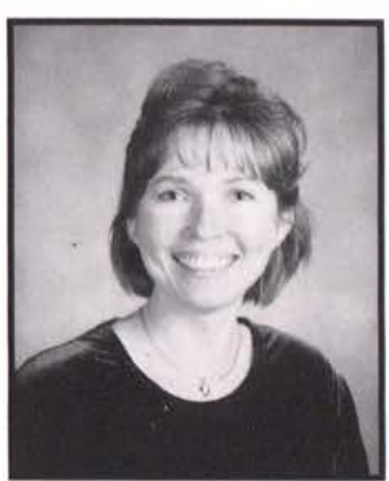

Tammy Slone

Administrative Assistant Athletics

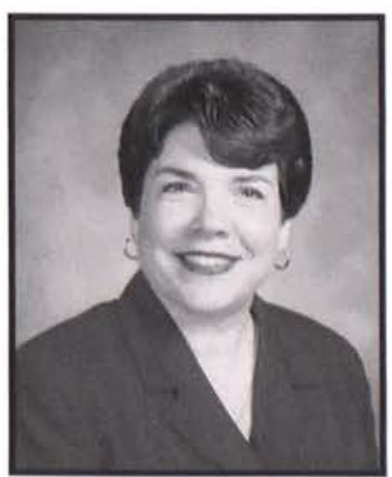

Sherrie Wood

Dean's Assistant Humanities, Arts \& Bible

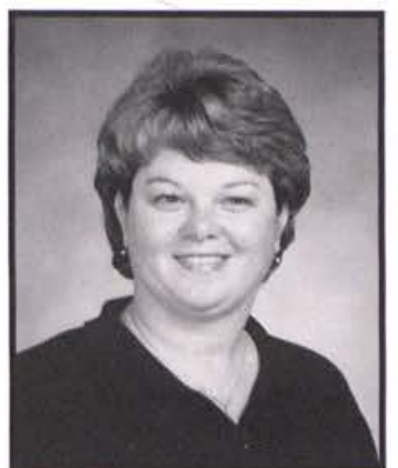

Pam Miller

Administrative Assistant Music

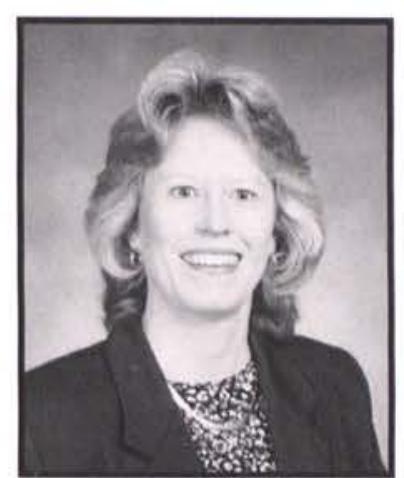

Nancy Ranger Dean's Assistant

Health \& Human Performance

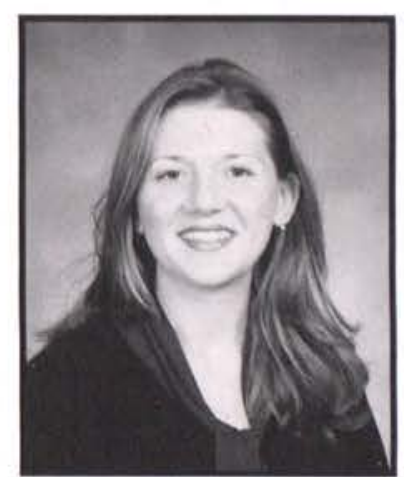

Rebekah Thompson Secretary

Summer School

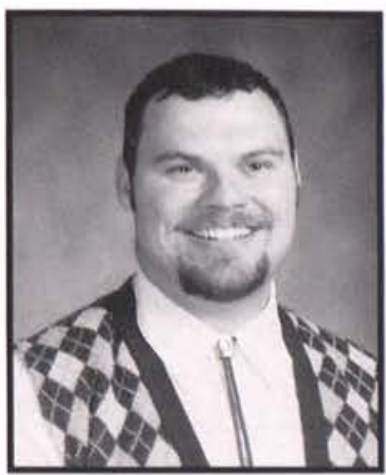

Steve Wood

Assistant Technical Director Theatre

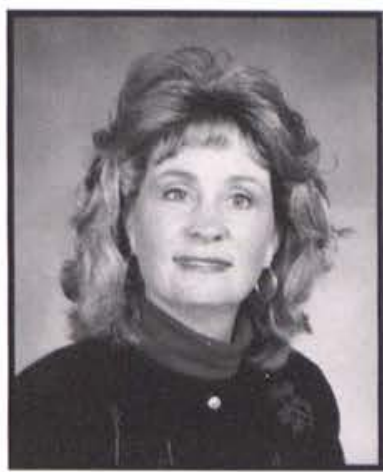

Shelly Nutter

Administrative Assistant Science \& Math

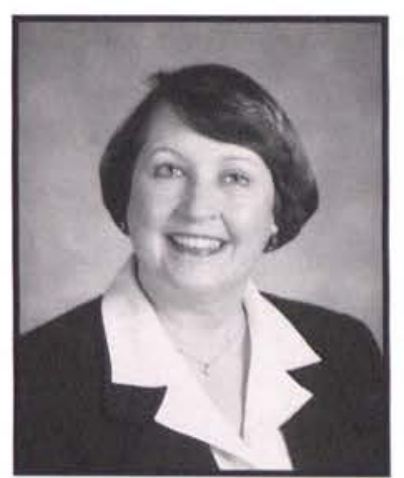

Lynn Rohm

Administrative Assistant to President

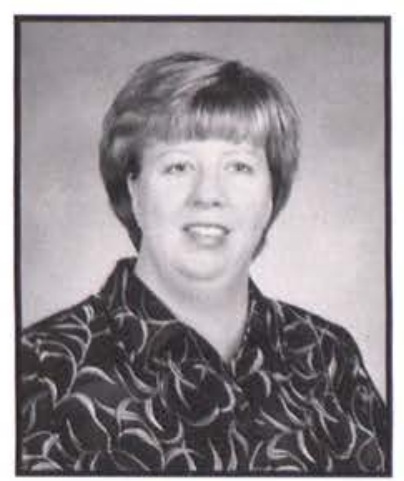

Linda Tse

Administrative Assistant Engineering

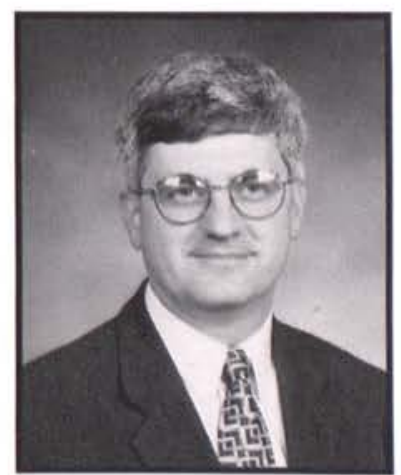

Mark Womack

Director

Sports Information

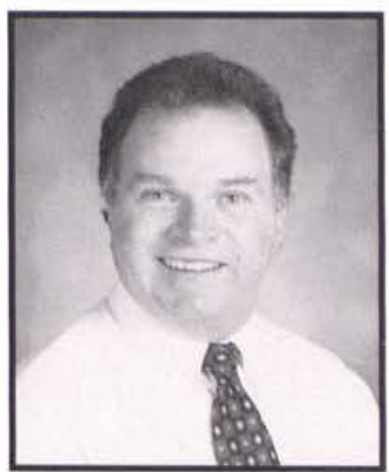

Gary Olin

Software Specialist

Computer Services

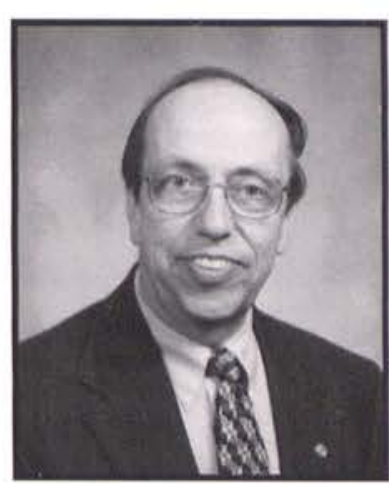

David Rotman Director

Computer Services

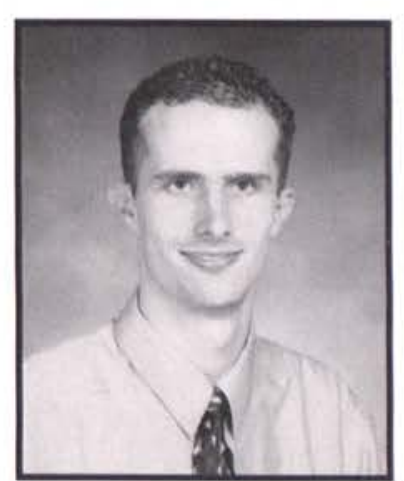

Bradley Voumard Programmer

Computer Services 


\section{taff \\ EnROLlment MANAGEMENT Division}

In the lower level of the Stevens Student Center, amidst the catacombs of hallways, hid the Enrollment Management offices. Prospective students met this staff when they visited the campus for the first time. Grateful graduating students observed its work when they attended graduation.

Financial Aid, External Relations, Academic Services, and Admissions all helped carry out the responsibilities of this division.

A main part of Enrollment Management's job on campus was to maintain a dynamic enrollment on campus. This means they helped the university to grow moderately-fifty to one hundred students per year. In doing this, they hoped not only to maintain the student body, but also to enhance it. Their work, though, did not cease at this; they worked at retaining current students and recruiting future students as well.

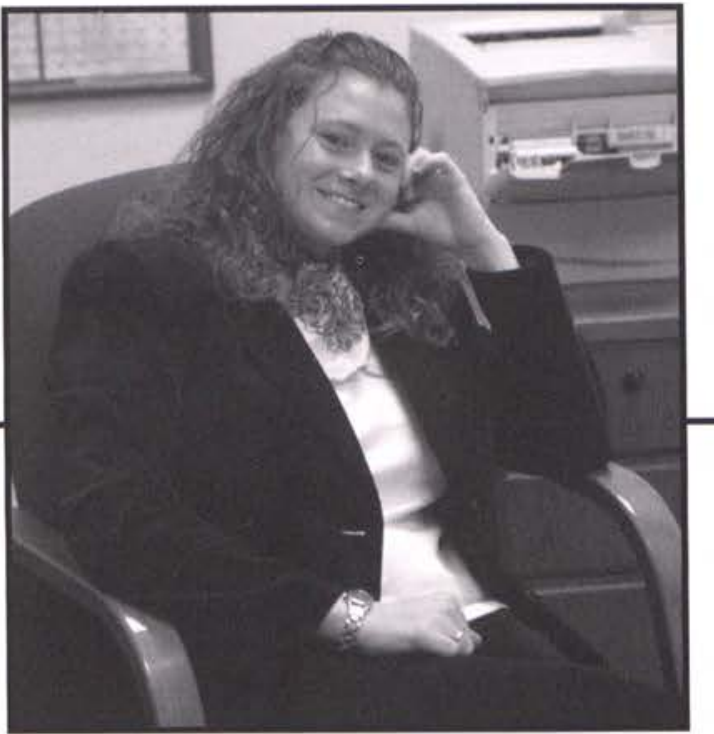

The student involvement was not just limited to employment and enrollment, but also many specific activities. These activities included Youth Blowout and Junior Jam through External Relations. Enrollment Management found students on campus to help with programs such as Link2CU and the Thanksgiving calling program. They used the students to make a personal contact with those in their home area. Dave Ormsbee, Vice President of Enrollment

Management, stated that he and his division are "vitally interested in students" and were here to serve them however they could.

This division wanted to maintain the reputation of being the nicest and most helpful people on campus. They truly cared about the students and wanted them to feel comfortable around Enrollment Management.
In External Relations, Chrissy Faulkner helps plan events for prospective students.

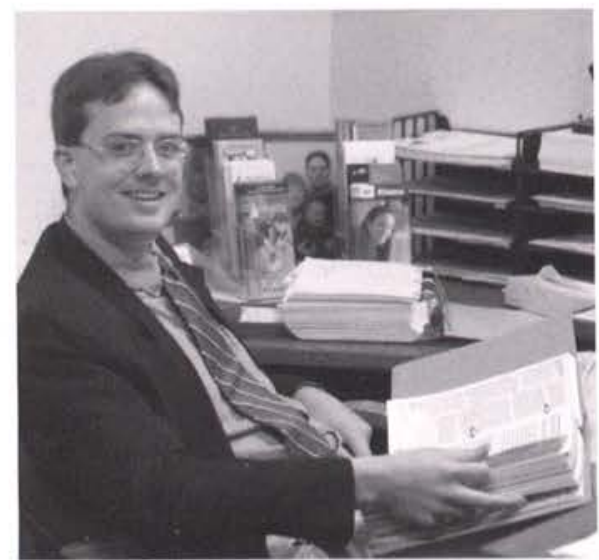

Tim Hewitt works with students as they plan funding for the school year.

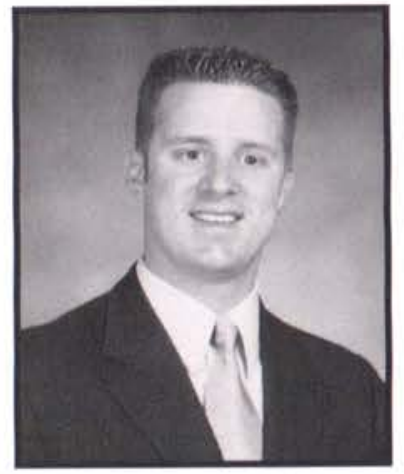

Jason Atwell Assistant Director Admissions

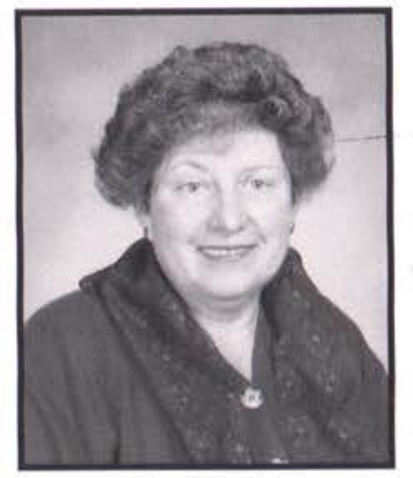

Judy Awabdy

Correspondence Coordinator Admissions

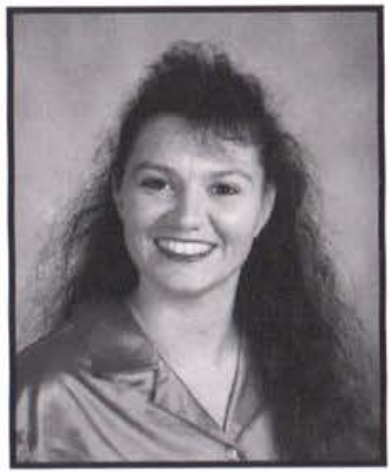

Tonya Bailey Compliance Manager Financial Aid

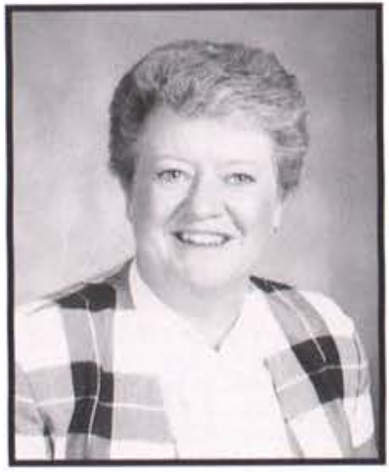

Fran Campbell Registrar Academic Services

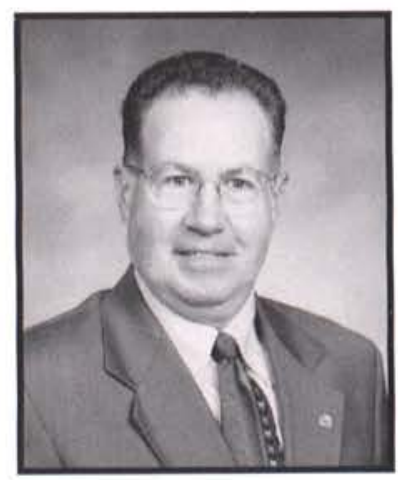

Jim Clark

Production Coordinator Admissions 


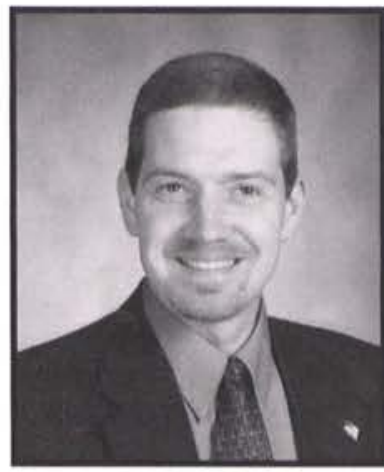

Curtis Cline

Relations Coordinator

Church \& School

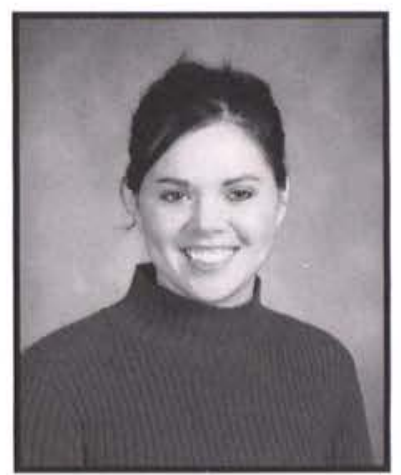

Micah Howdyshell

Records \& Testing

Academic Services

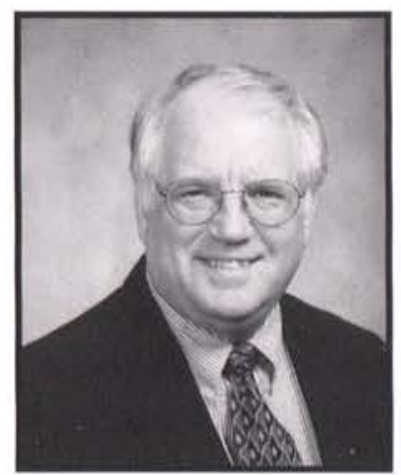

Fred Merritt

Director

Financial Aid

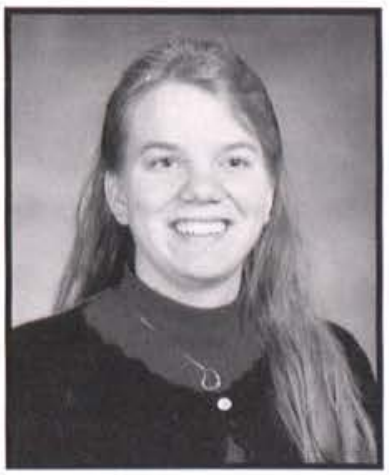

Erin Tuinstra

Correspondence Assistant Admissions

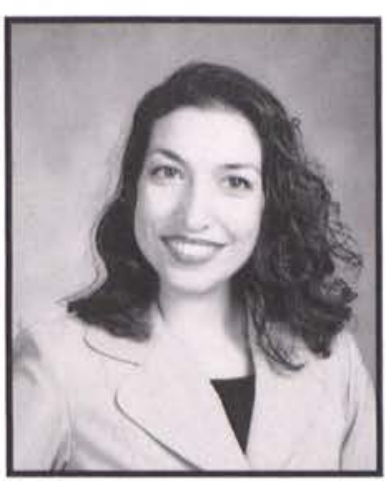

Jennifer Deal

Student Loan Coordinator Financial Aid

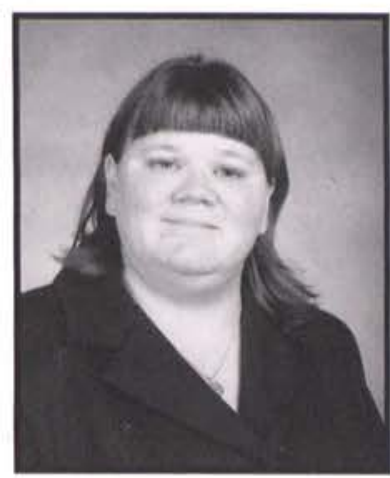

Kristy Lester

Senior Assistant

Admissions

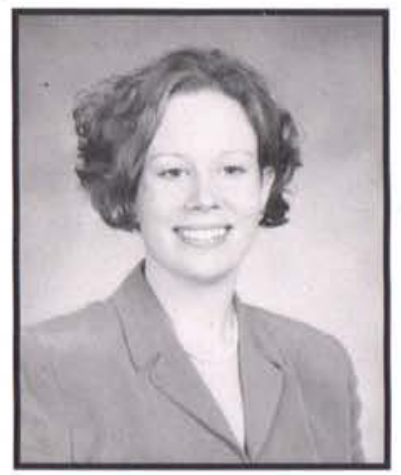

Nicole Neu

Administrative Assistant

Financial Aid

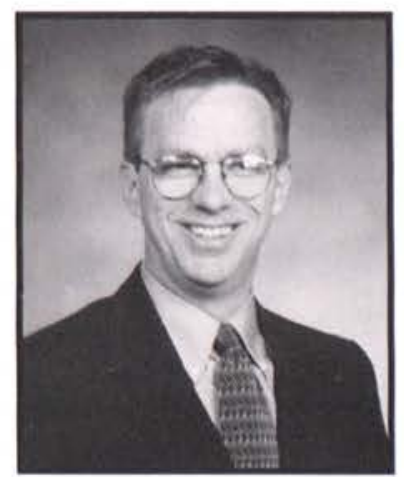

Steven Winey

Assistant Registrar

Academic Services

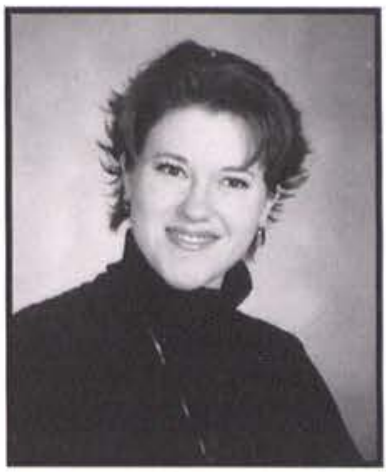

Andrea Endicott

Relations Assistant

Church \& School

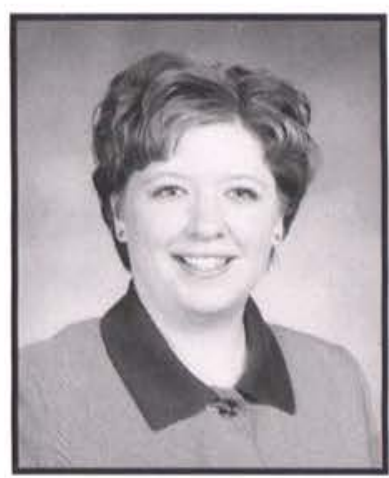

Karisa Linafelter

Assistant Registrar

Academic Progress

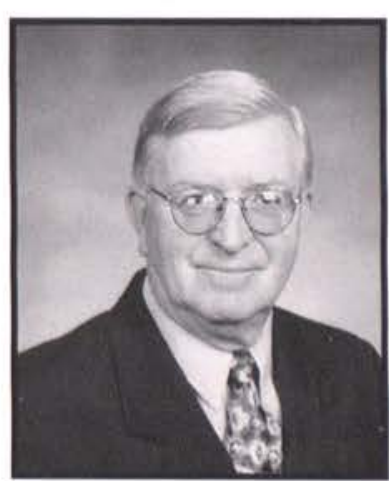

Ken Rotroff

Administrator

Financial Aid

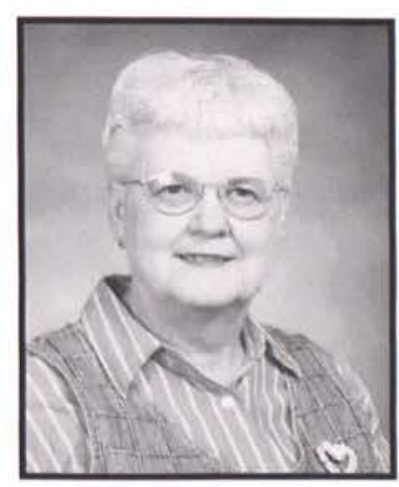

Glenda Womack

Correspondence Assistant Admissions

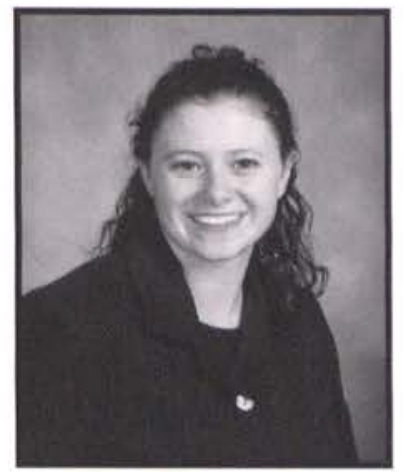

Chrissy Faulkner

Event Assistant

External Relations

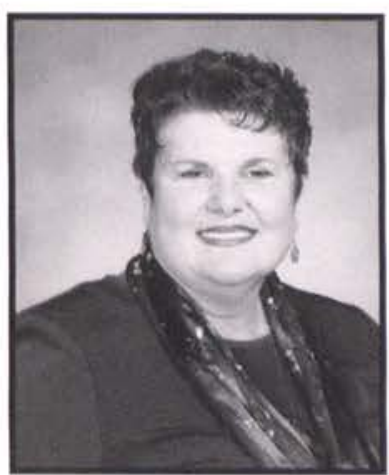

Carol Marshall

Testing \& Advising

Academic Services

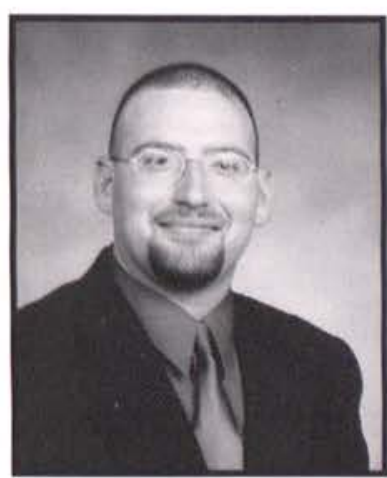

Christopher Straits Applications Coordinator Admissions

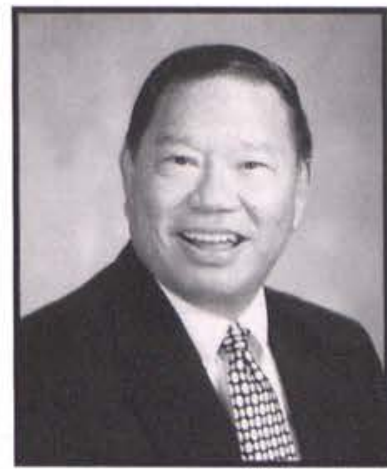

Bert Fujishige

Assistant Director

Financial Aid

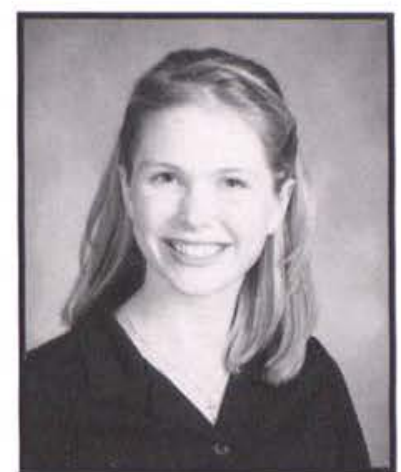

Grace Marshall

Records and Registrations Academic Services

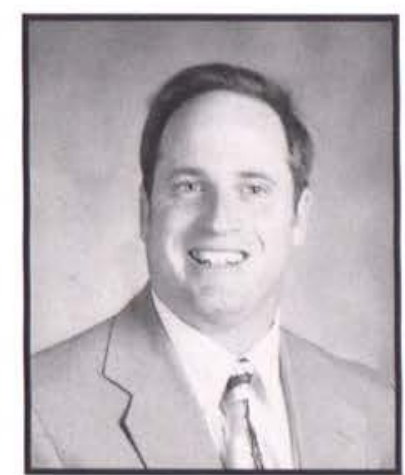

Steven Thompson Associate Director

Financial Aid 


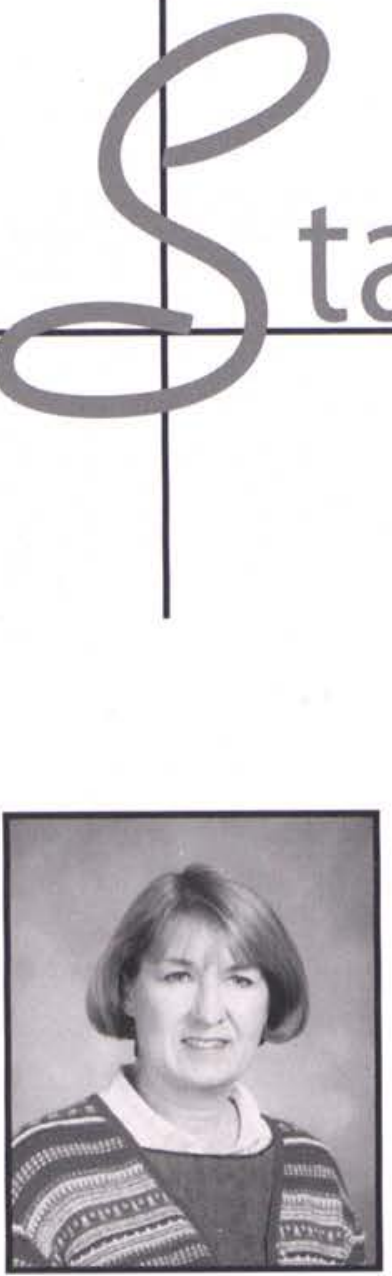

Carrin Battaglia

Secretary

Building Services

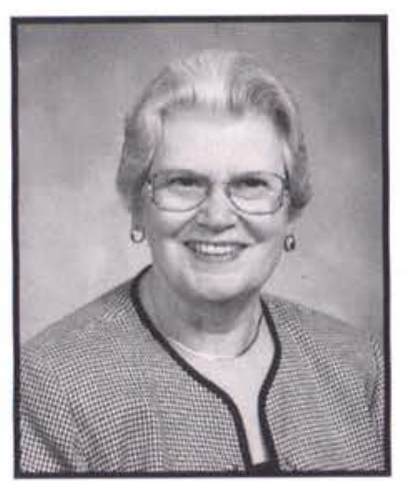

Alberta Carr

Textbook Buyer

Bookstore

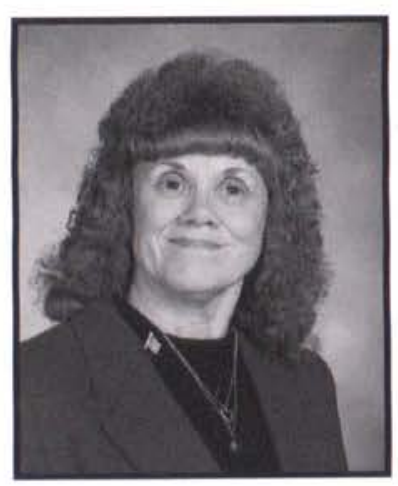

Sharon Ewing

Cashier

Business Offices

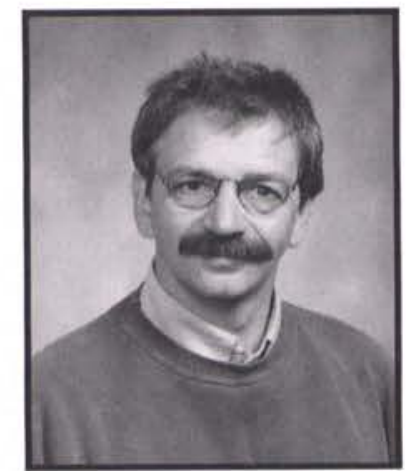

Robert Bielek

CAD Technician

Building Services

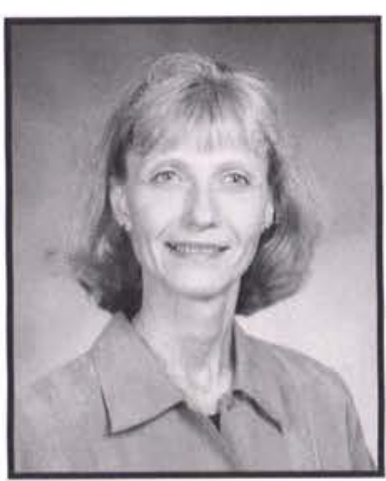

Melody Cato

Postal Clerk \& Adjunct Prof.

Exercise and Sports Science

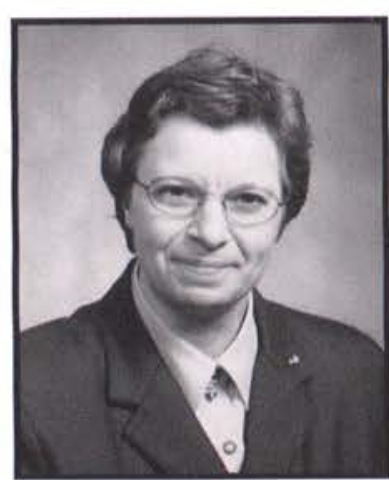

Kathy Gallagher

Administrative Assistant Business Offices

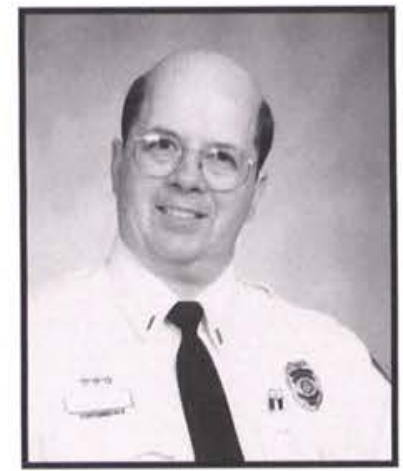

LT. J. Bowersox

Operations Manager

Campus Safety

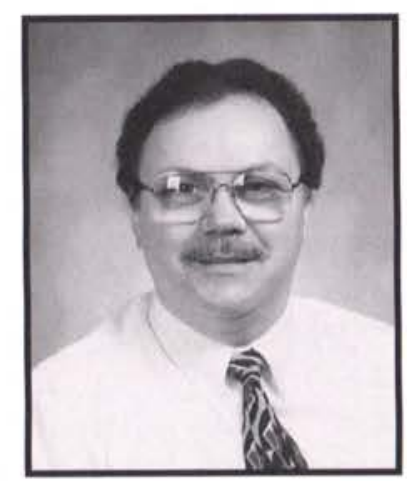

Chris V. Chrystal

Textbook Buyer

Bookstore

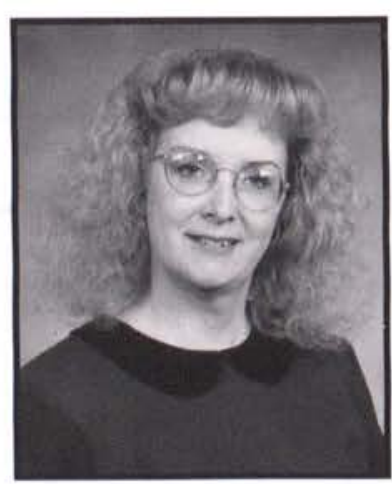

Georgia Greer

Cashier

Business Offices

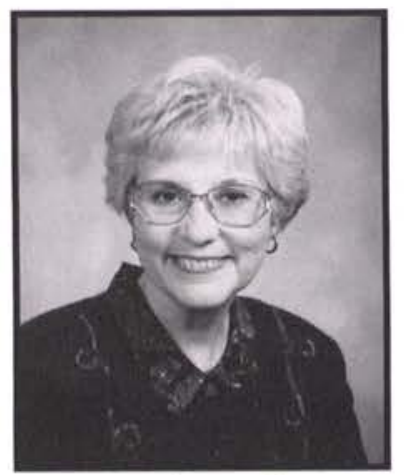

Connie Bradds Supervisor Post Office

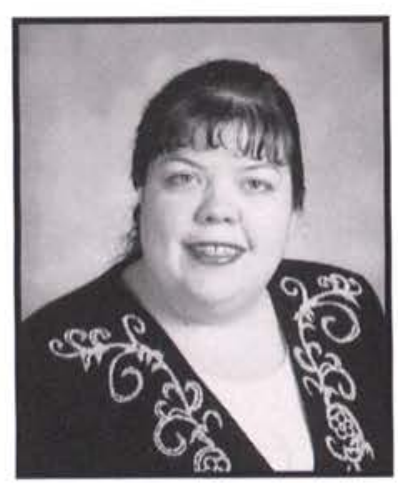

Jane Dean

Cashier

Business Offices

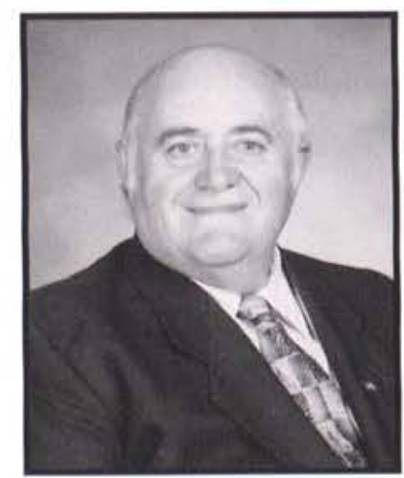

Leigh Hunt

Director

New Construction

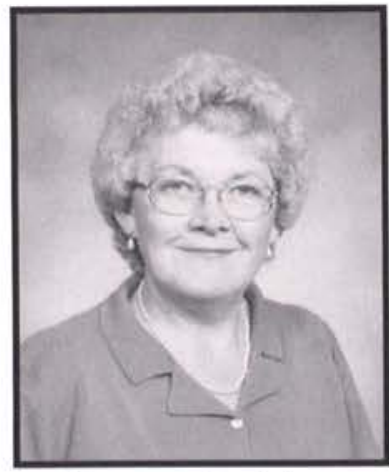

Margaret Burrichter Cashier

Business Offices

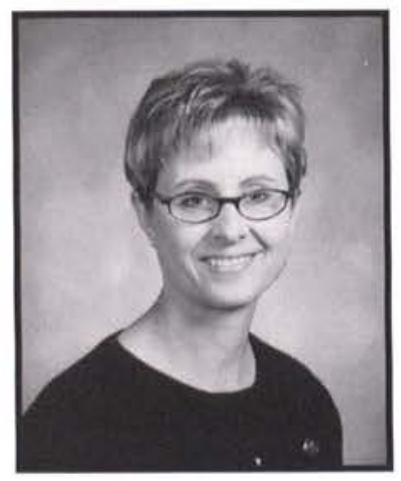

Ann DeLange

Music/Sportswear Buyer Bookstore

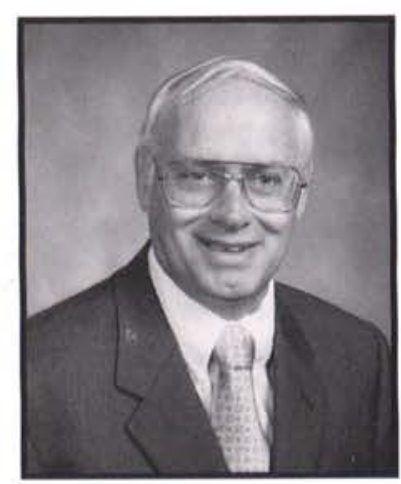

Timothy Johnson Purchasing Building Services 


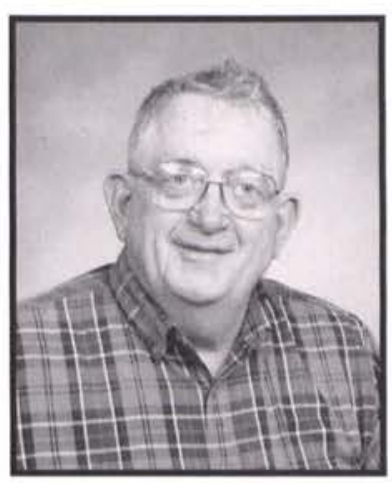

Glenn Knauff

Groundsman

Landscape Development

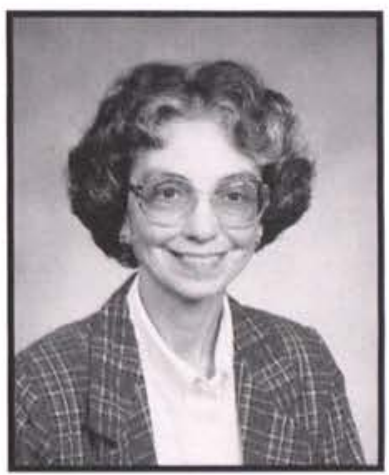

Bonnie McGillivray

Postal Clerk

Post Office

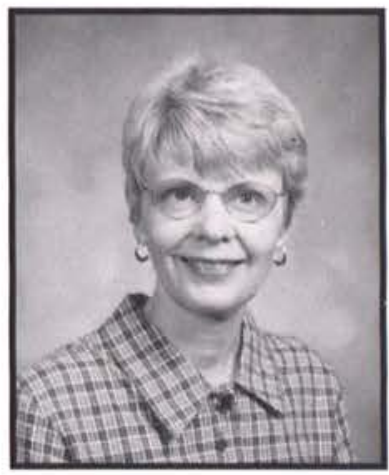

Julie Olin

Cashier \& Card Buyer

Bookstore

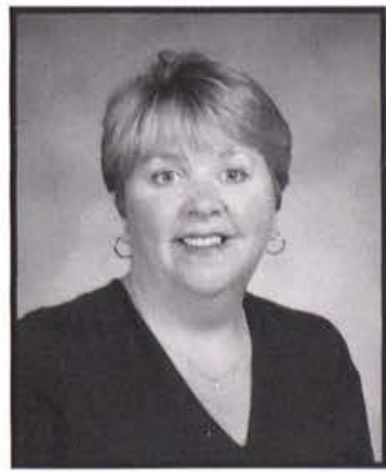

Nellie West

Assistant to Supervisor Bookstore

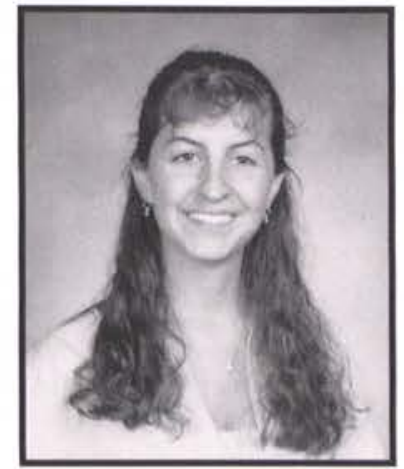

Kristie Koerbel Secretary

Maintenance

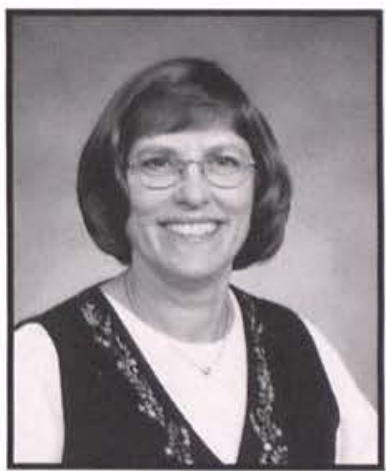

Diane Mitchell Office Manager Building Services

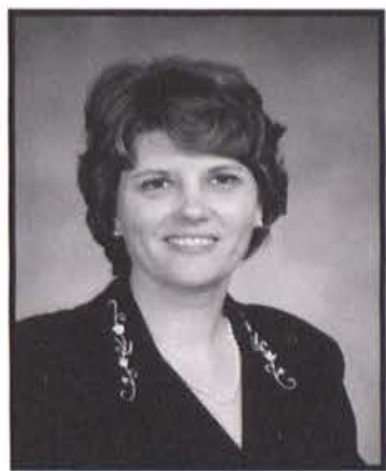

Ruth Prugh

Payroll Clerk

Business Offices

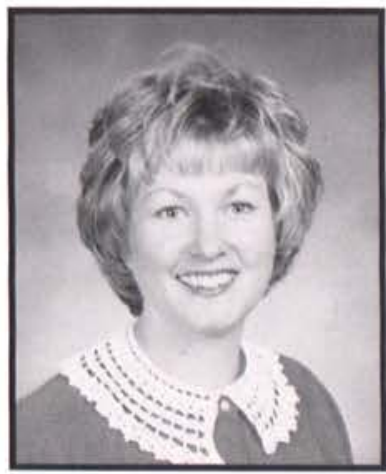

Sarah Young

Assistant Textbook Buyer Bookstore

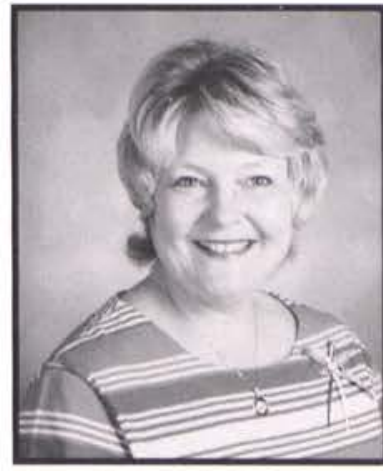

Jeanie Leblanc Gift and Book Buyer Bookstore

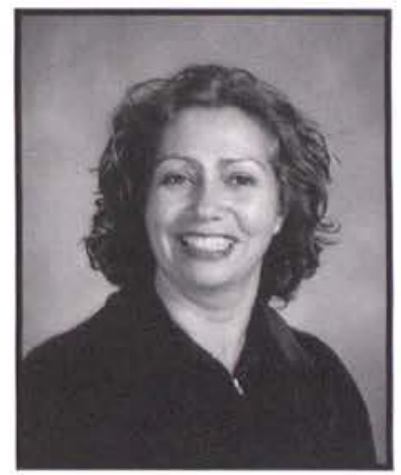

Ruby Moreno

Customer Service

Public Relations

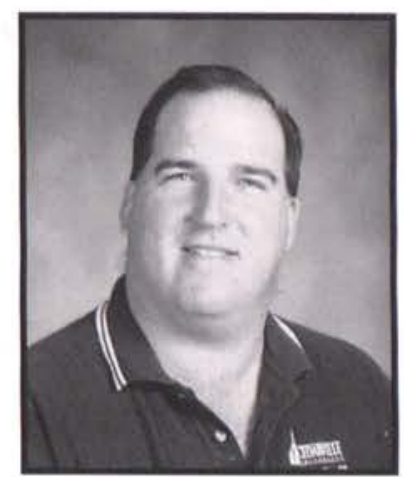

Dan Shirk

Key Technician

Building Services

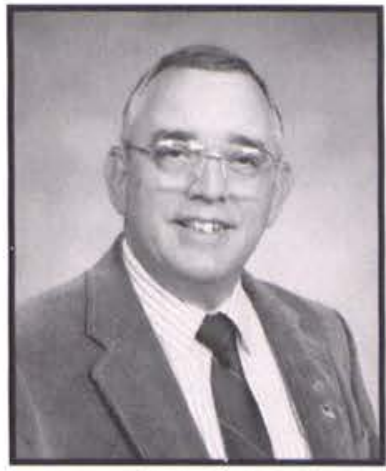

Tom Leightenheimer Inventory Coordinator Maintenance

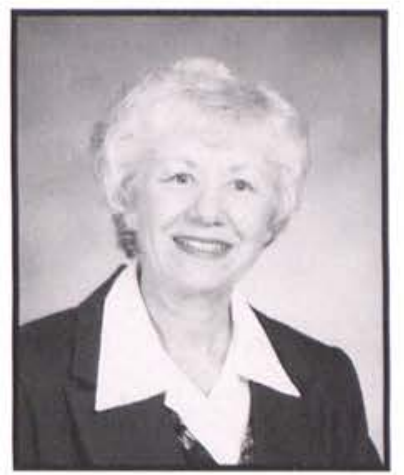

Phyllis Morris

Postal Coordinator Post Office

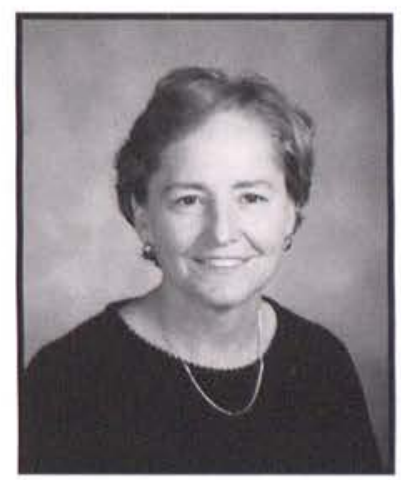

Matis Slagle

Postal Clerk

Post Office

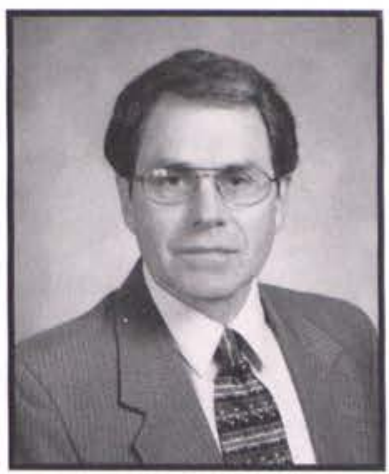

Lee Mattson

Supervisor

Bookstore

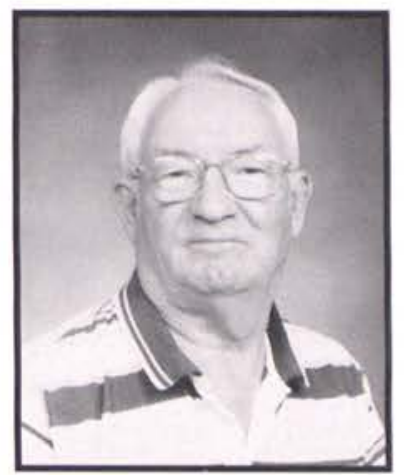

Lavern Musselman

Customer Services

Public Relations

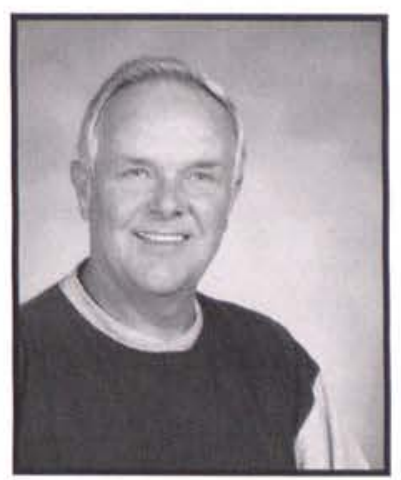

Cooley Turner Custodian Building Services 


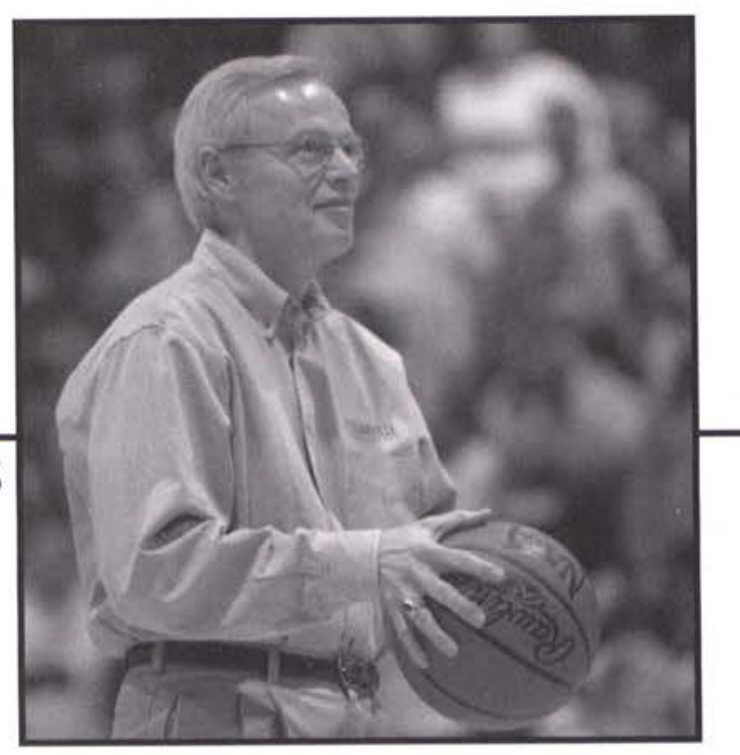

The Christian Ministries Division of Cedarville University held Mark 10:45 as the purpose of their department. They believed service to others and God was an important factor in students' lives. While serving others, students learned to develop the Christ-like attitude described in Mark 10:45. Pastor Bob Rohm, Vice President of Christian Ministries, stated he hoped that students "no matter their vocation," will be "servants of the living God."

Students had the opportunity to serve in many ways. They could find many ministries that suited their talents and interests. Christian Ministries expected service to become a natural part of students' lives, hoping that students would continue serving throughout their lives.

\section{Christian Ministry also} worked with pastoral counseling

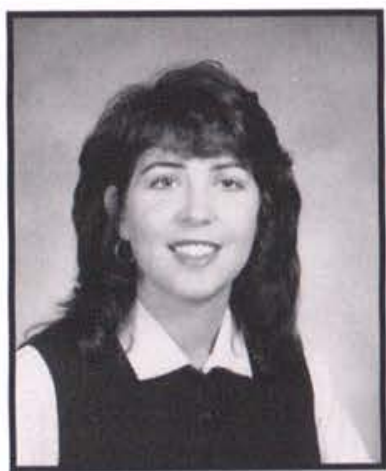

Sharon Eckstein Secretary to the Director Music Teams

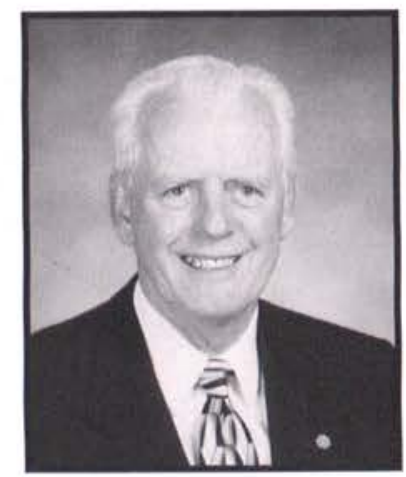

Harold Green

Director

Church Relations

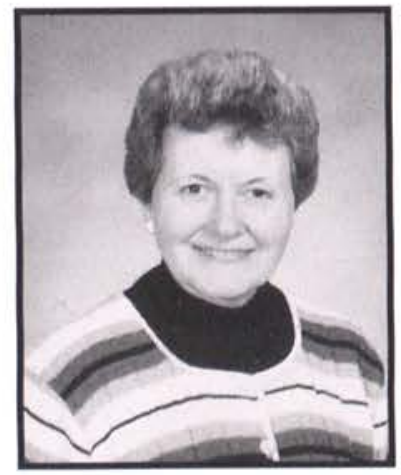

Margaret Green Secretary Church Relations

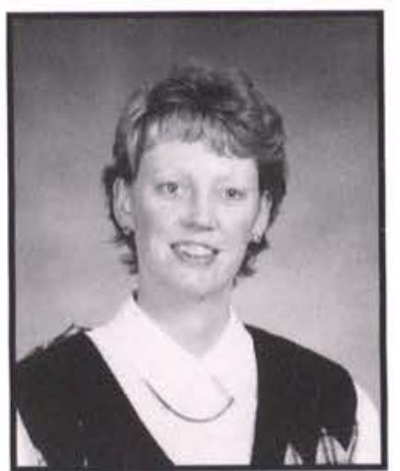

Carol Bliss Secretary to the Director Drama Teams

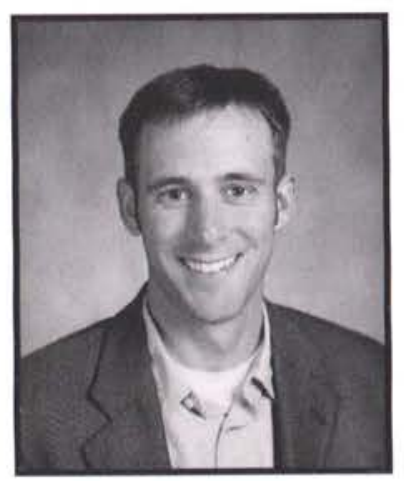

Mark Irving Director Discipleship Ministries

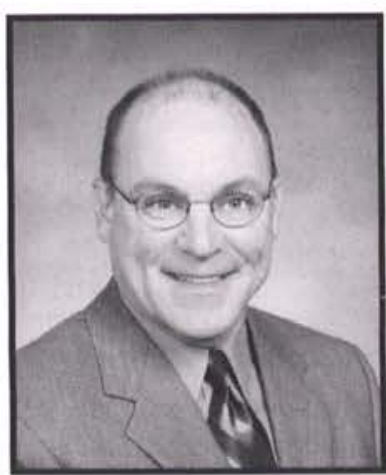

Jim Cato Director Music Teams

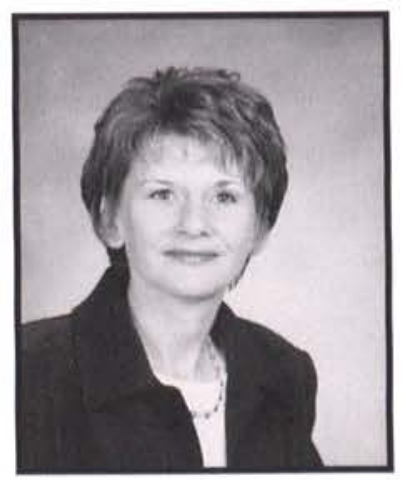

Paula Kordic Secretary Biblical Education 


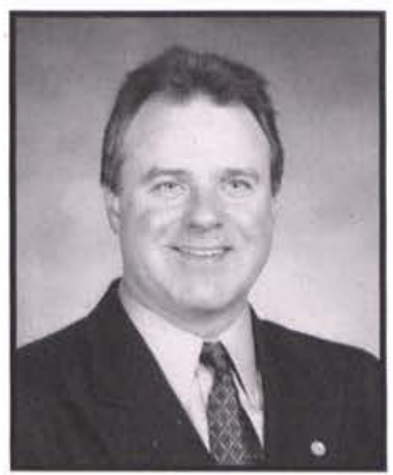

Brian Nester

Director

Mission Inv. Services

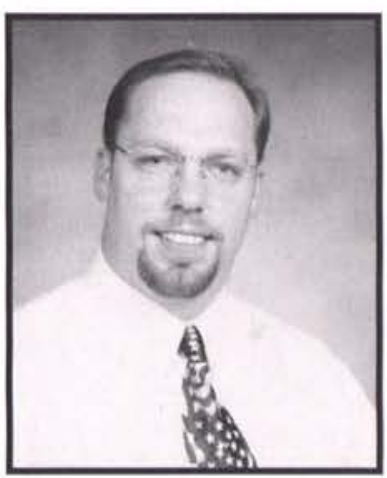

Mike Bieniek

Senior Graphic Designer

Public Relations

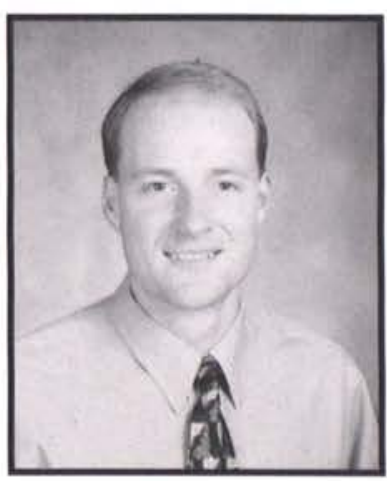

David Hoecke

Production Services

CDR Radio Network

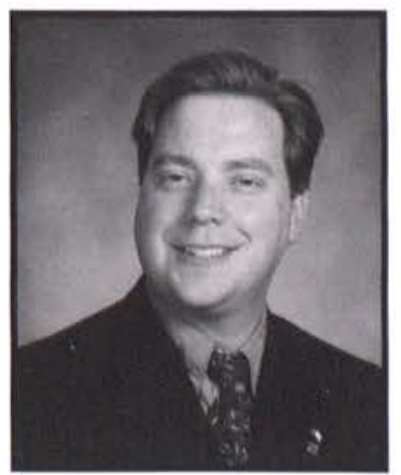

Benjamin Smith

Director

Donor Accounting

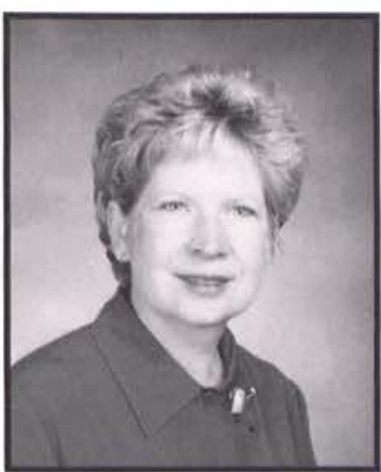

Jackie Pyles

Receptionist

Christian Ministries

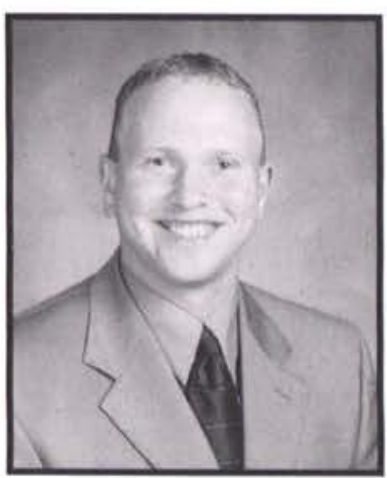

Brian Burns

Grant Coordinator

Development

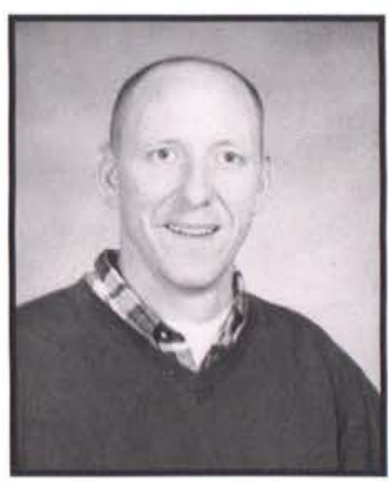

Scott Huck

Photographer

Public Relatons

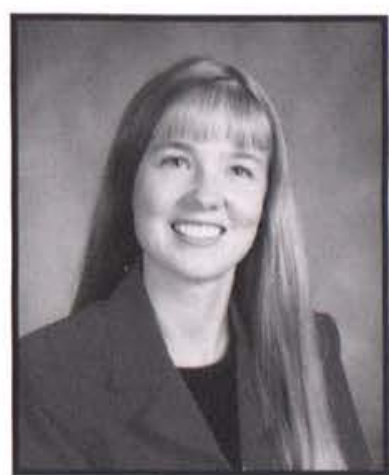

Kara Steinman Assistant Director Public Relations

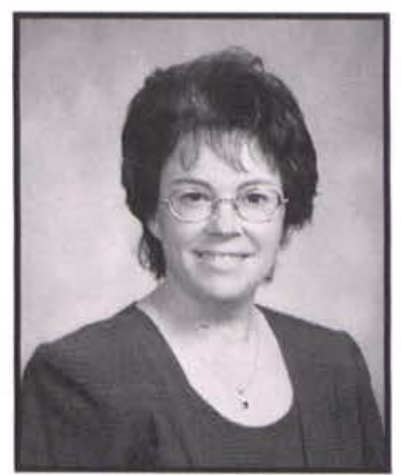

Cheryl Shupe

Executive Secretary for VP

Christian Ministries

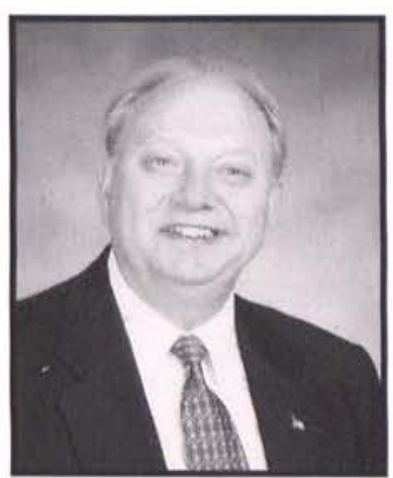

Paul Gathany

General Manager

CDR Radio Network

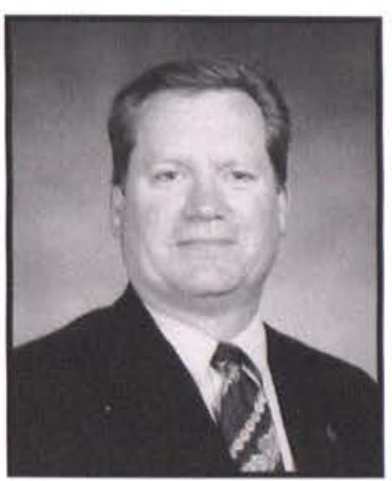

Roger Overturf Director

Public Relations

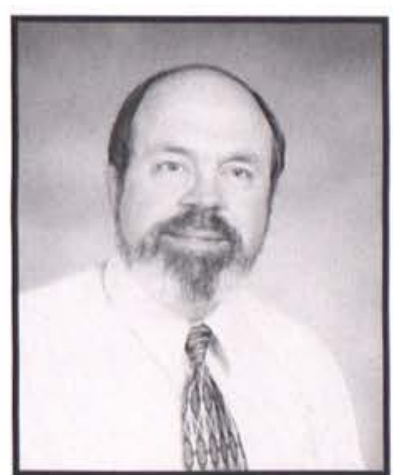

John Tocknell

Engineer

CDR Radio Network

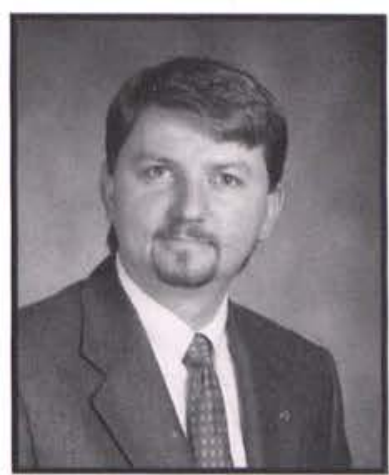

Brandon Waltz

Director

Drama Teams

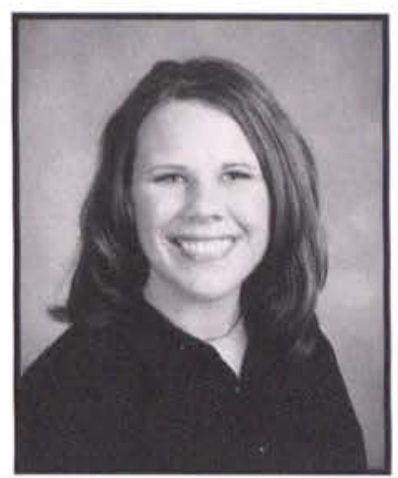

Kristi Gleason

Administrative Assistant

Public Relations

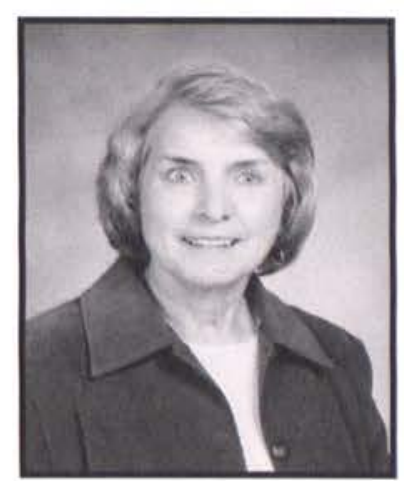

Joyce Reese

Operations Assistant

Development Services

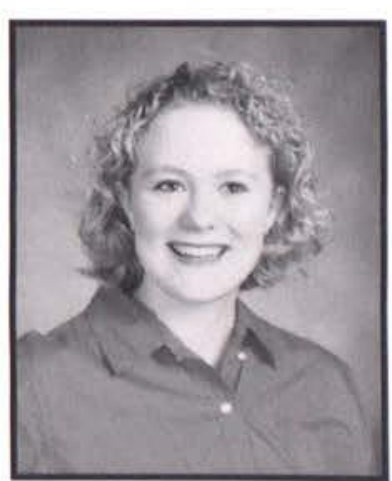

Rebecca Van Loon

Impact News Assistant

CDR Radio Network

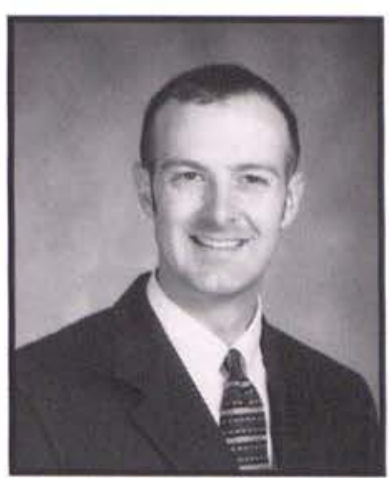

John Wambold

Director

Community Ministries

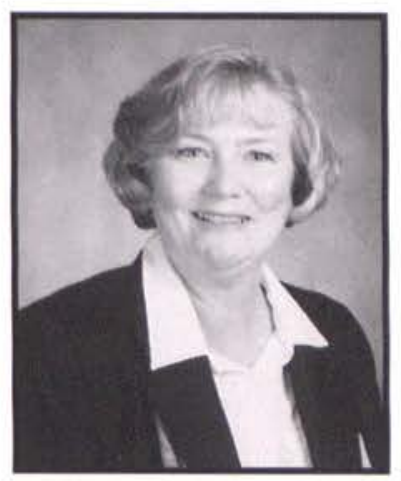

Jan Greenwood

Operations Assistant

Development Services

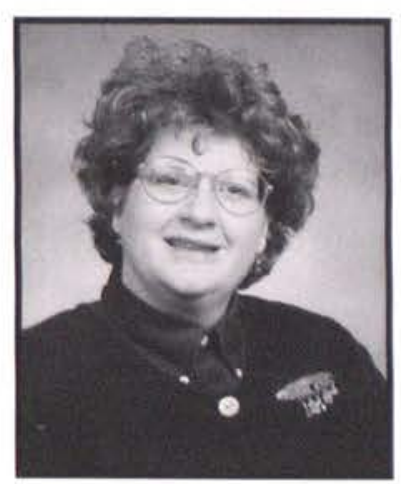

Melanie Scheerschmidt Event Coordinator

Development Services

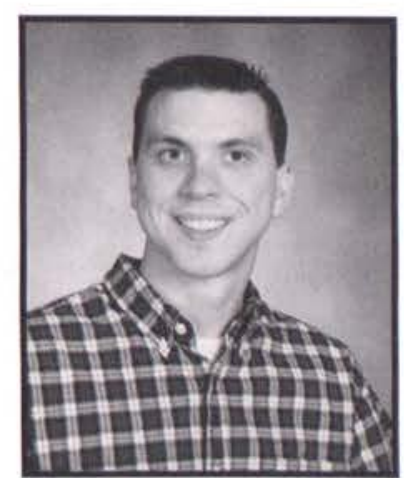

Mark Zuiderveen

Production Coordinator

CDR Radio Network 



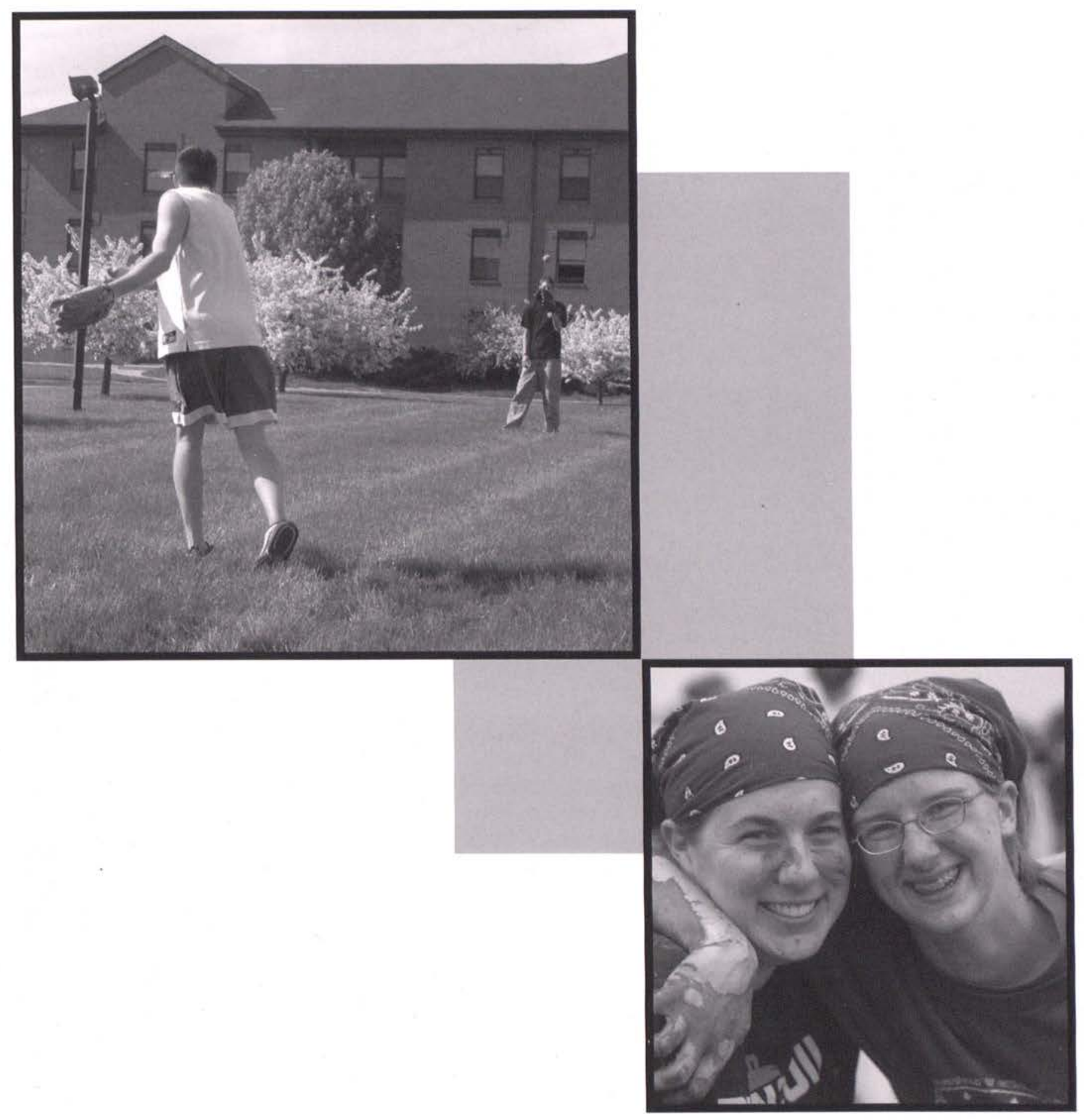

SPRING 


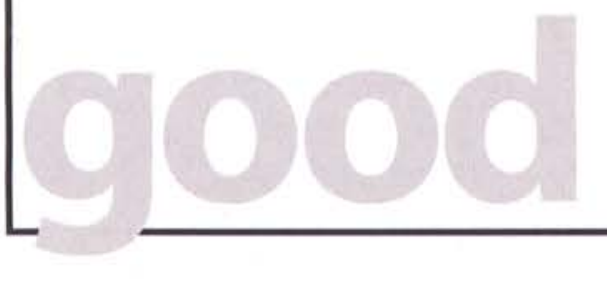

neVspring conference

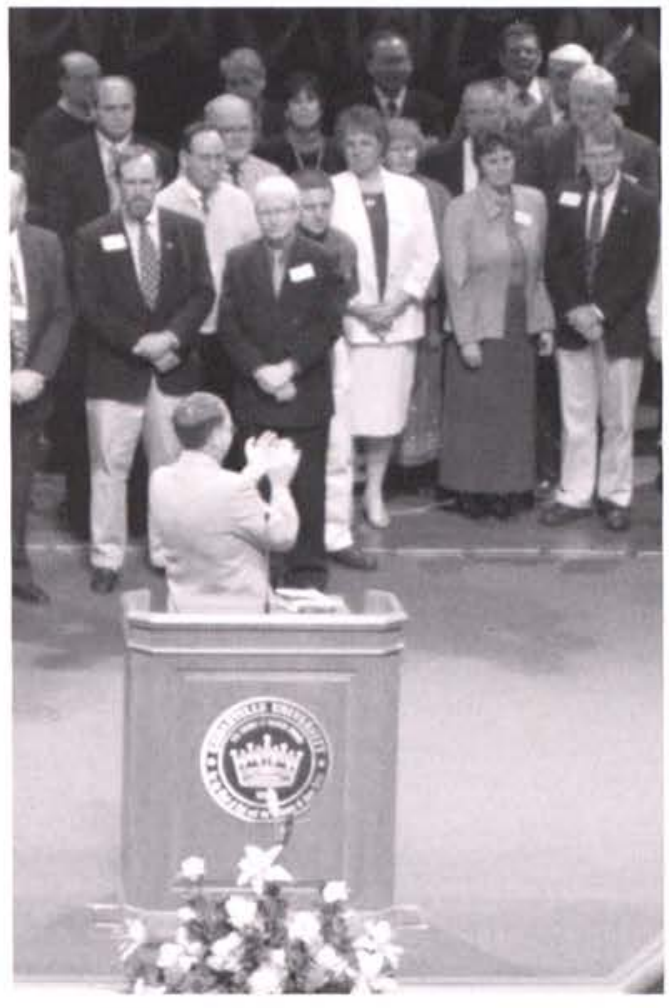

Paul Dixon and the student body honor the people who have dedicated their lives to living overseas as missionaries.
Displays and missionaries filled the Alumni Hall of the Dixon Ministry Center spring quarter. Worship permeated the chapel with the theme chorus, "Our Heart's Our Desire." The annual Missions Conference consisted of various chapel speakers including Dr. Paul Nyquist in the evenings speaking of "extreme missions."

Two of the most memorable chapel speakers were Jim Bowers and Tania Rich who spoke about their experiences of losing a spouse on the mission field. Both Bowers and Rich spoke of God's faithfulness and thanked the school for its prayer support.

Junior Stephanie Kline said, "It was amazing to hear the testimonies of Jim Bowers and Tania Rich. Seeing them in person and hearing them share from their hearts about how our prayers had helped made me think about how powerful prayer really is."

Students also heard messages from Grady Toland of Network of International Christian Schools and Dr. Daniel Fountain, a King College faculty member. Dr. Fountain encouraged students with a message from Matthew 16, stating, "We have the key to the good news."

The evening conference speaker was Dr. Paul Nyquist, whose messages were centered on his assertion that "an extreme world calls for extreme missions." They were organized into four requirements of extreme missions: God, Motivation, Goal, and Commitment.

Nyquist's powerful teachings prompted students to be disciples and to commit their lives to following Jesus wherever $\mathrm{He}$ leads, which was the main focus of the conference. Nyquist encouraged students to allow Jesus to lead them and to follow bravely and wholeheartedly.

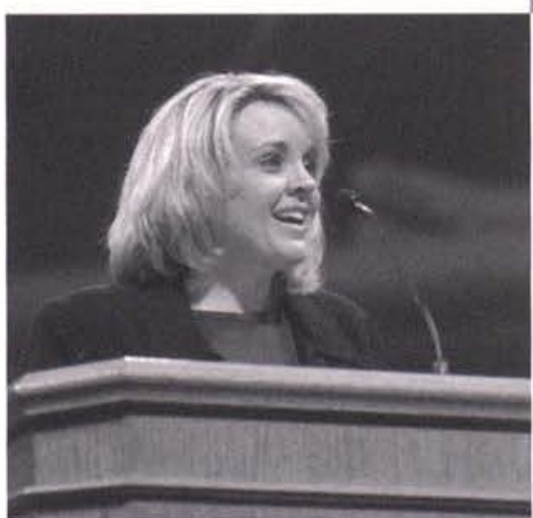

Tania Rich, wife of

Mark Rich, a martyred New Tribes missionary, shares her touching personal story of the years of waiting and wondering. 


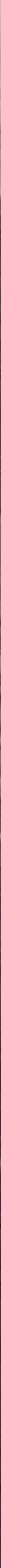

As the winning juniors dominated the Class Clash, they celebrated with smiles all around.

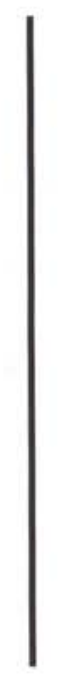

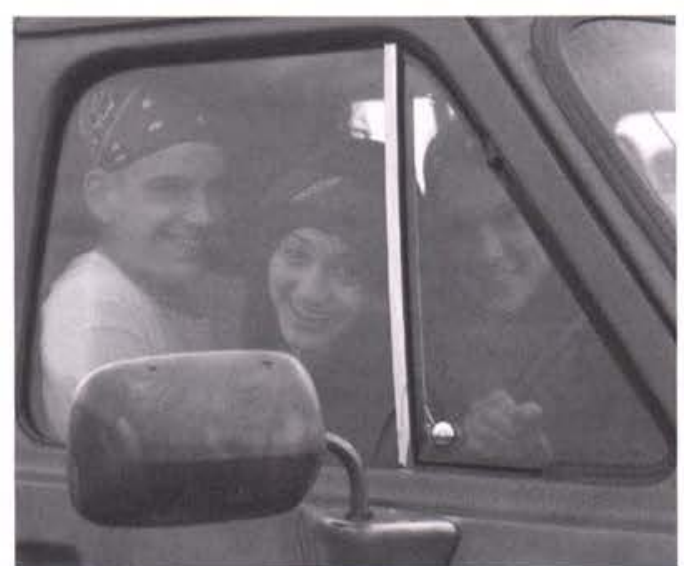

Tyson Herald,

Kristin Sando, and

Carrie Sorensen

will soon find out

you can't drive with three people in the driver's seat.
Who says trees aren't good for anything? These girls know they are good to balance on.

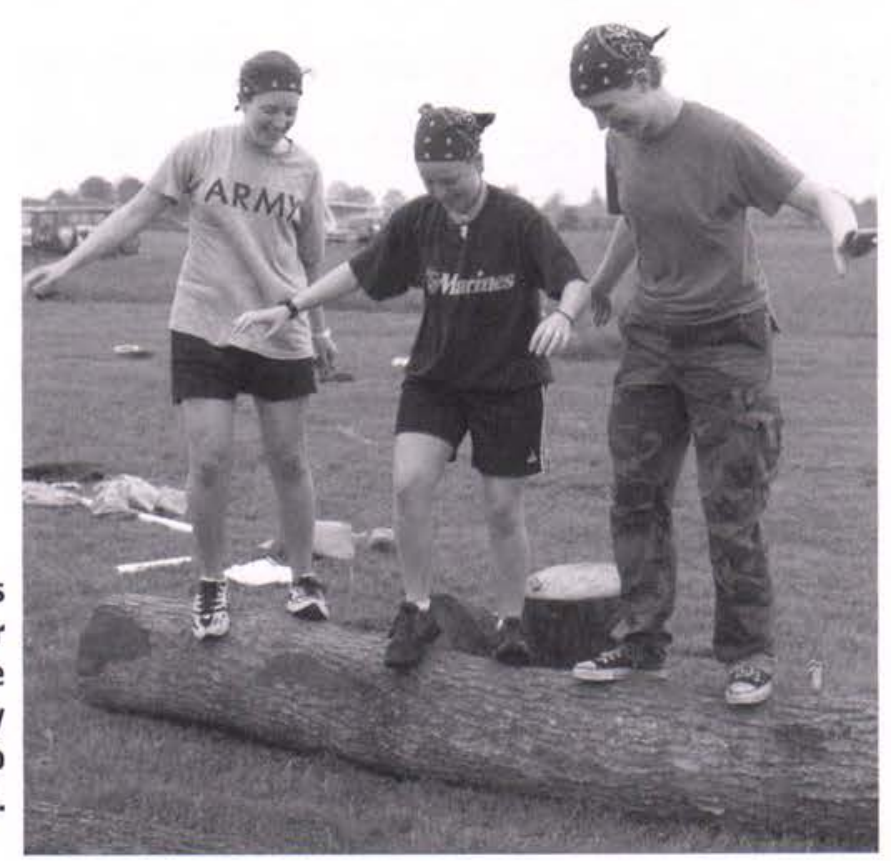




\section{Visting 10 family weekends}

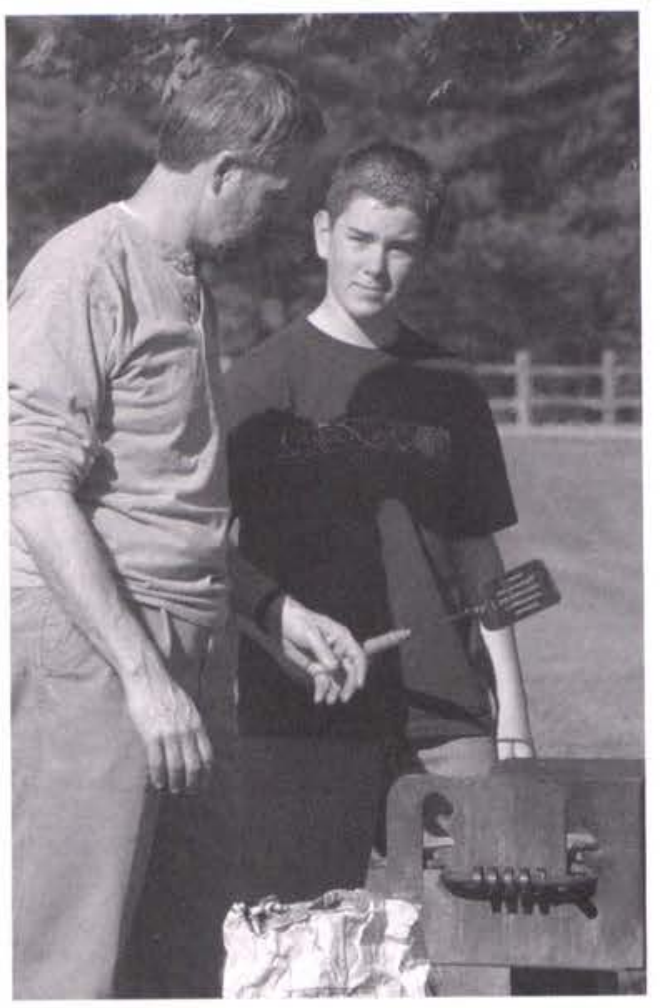

A Cedarville

student takes

some time to

catch up with his

family at John

Bryan Park.
Grandparents came to campus on a November weekend to spend quality time with their grandkids. They were honored in chapel for their long-lasting marriages, impressive longevity, and military service. Evening activities included a concert from Cedarville's musical ensembles and a women's basketball game.

Throughout the weekend, students escorted their grandparents to the fall play, Husbandry, watched sports teams, and took trips to the Clifton Mill.

Senior Grayden Schafer's grandparents from New York had been coming to Grandparent's

Weekend for seven years, ever since his sister was a freshman. Schafer said, "I really enjoyed just the quiet moments. We played Jenga in the Snack Shop for a while and were just able to have some great conversation."
In May parents visited the Cedarville campus during Parent's Weekend. Parents had the opportunity to see the spring play, Inherit the Wind, throughout the weekend. On Friday evening the music department offered a pops concert and a Late Night Jazz Band Jam session.

Friday's events began with the Academic Honors Day Chapel. During the rest of the day, parents followed their children to classes and explored the town of Cedarville and surrounding areas.

On Saturday morning, parents met with Dr. Dixon over coffee to pray for their children and the school. This weekend for parents and students ended Saturday evening with the Christian music group Avalon. The concert challenged attendees to trust God and to depend fully on Him.
Rachel and her family try the Snack Shop for lunch together.

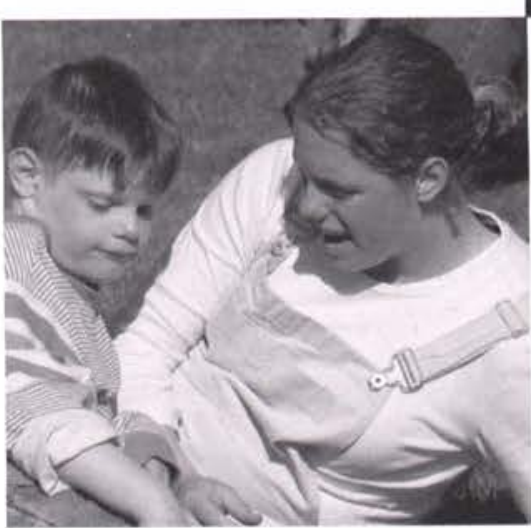

For Jessica Balser, little siblings are always a highlight of parents' weekend. 


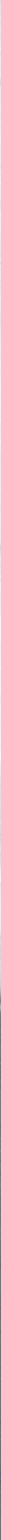

We now know where Brock

Weston got his
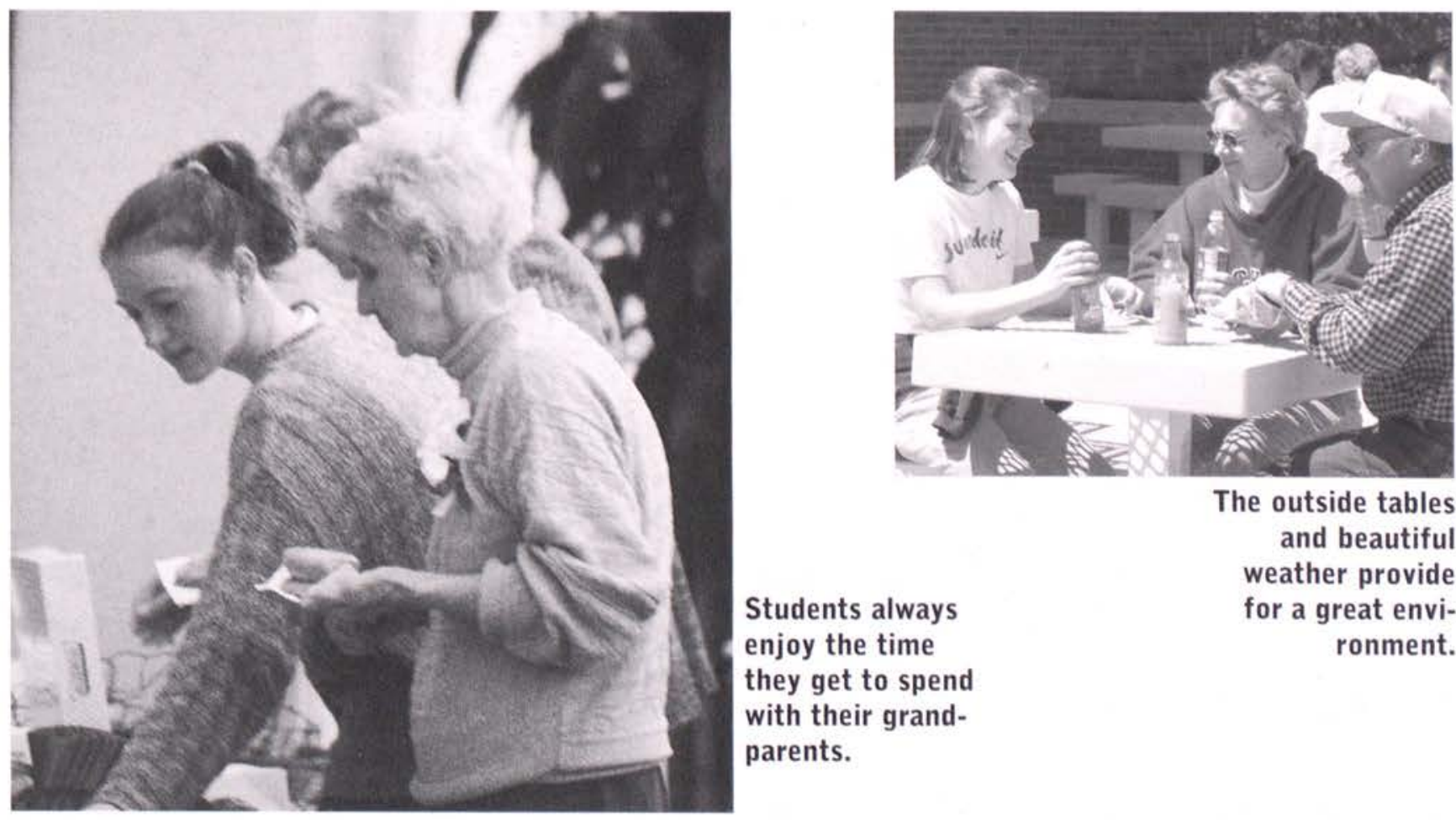
fabulous smile.

Students always

enjoy the time

they get to spend with their grand-

parents.
The outside tables and beautiful weather provide for a great environment.

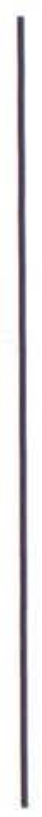




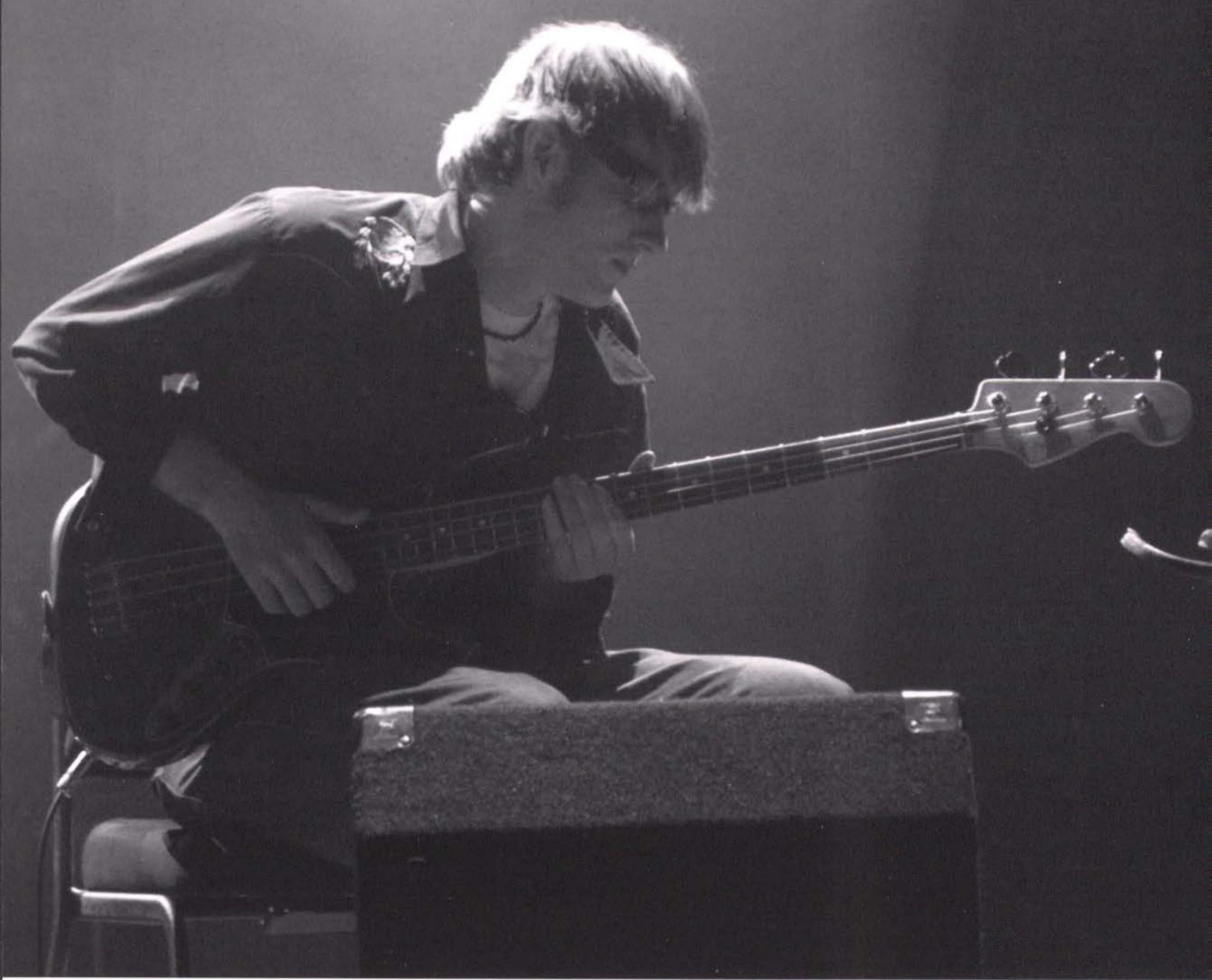

\section{Sophomore}

Michael DiCuirci

plays in his band

for Rock the Vote.
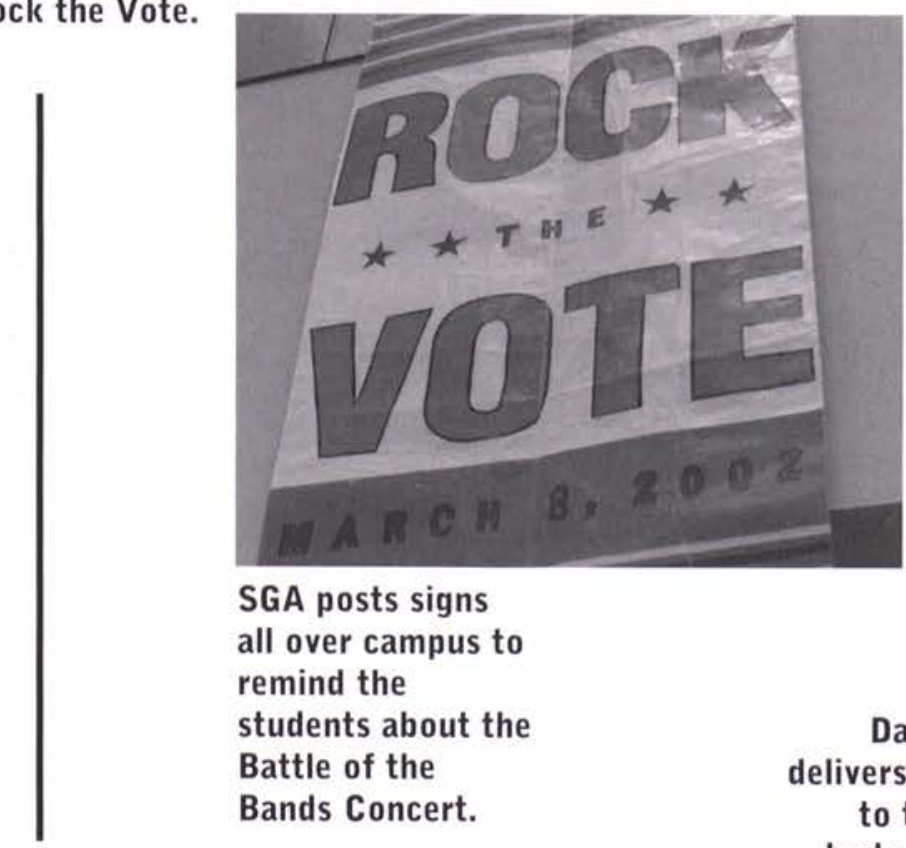

SGA posts signs

all over campus to

remind the

students about the

Battle of the

Bands Concert.

David Wenzel delivers his speech

to the student body at the SGA elections.

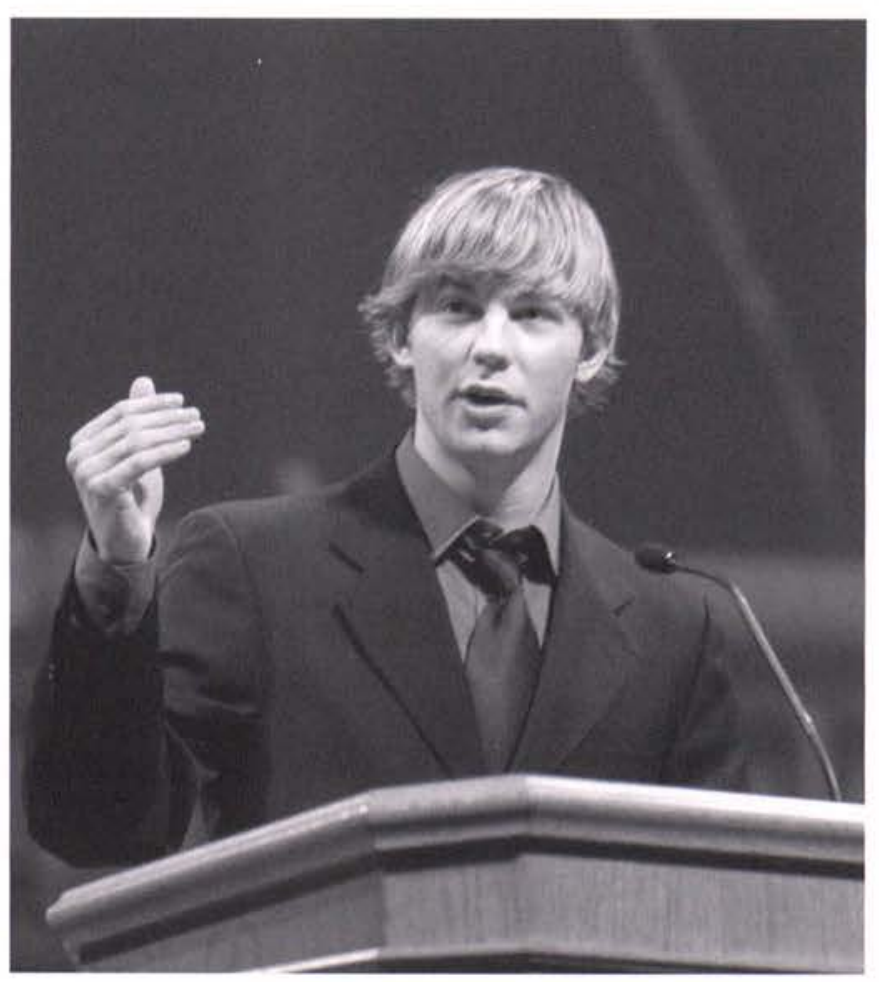


Prayer and an informal meeting on January 28 started the year's process for next year's Student Government Association leaders. One month later, February 25 , the announcement was made of the three pairs running for President/Vice-President, three candidates for Secretary, six men considering Chaplain, and one ostensible winner for Treasurer.

$$
\text { After Fellowship on }
$$

February 27, each of the candidates shared their platform with the student body. Three days later, primaries were held, narrowing down the choice for future leadership.

During chapel on March 8 th, Seth Martin, this year's Student Government President began the chapel by showing the student body exactly what the Student Government can do for the students. Martin invited Dean
Jonathan Purple to the stage, who was standing in for Vice-President for Student Services, Dr. Carl Ruby. Dean Purple then announced a few changes being made to the student handbook; the first change was that men no longer had to wear socks with sandals; the second change brought slacks for women year-round.

\section{Elections took a new} approach to announcing the winners of the election by this year's SGA hosting "Rock the Vote." This event included a battle of the bands with stage show effects. The leaders of tomorrow, selected by the student body were David Wenzel and Jaime Rocke as President/Vice-President, Jonathan Farrell as Chaplain, Jeremy Wickler as Secretary, and Brian Schildroth as Treasurer. These students have found that their main goal is to encourage the students.

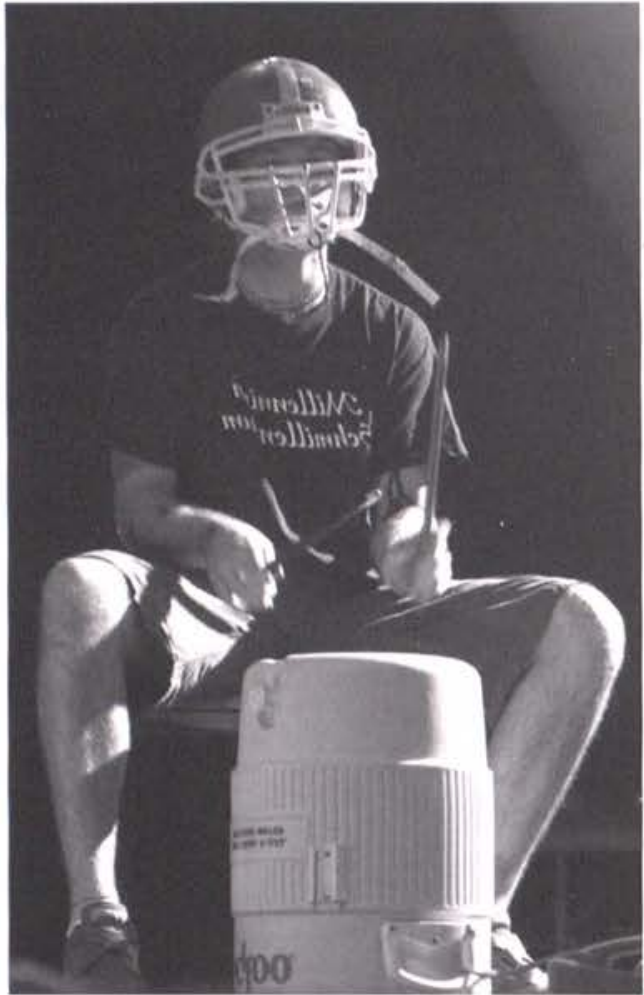

Music comes in many forms for the Battle of the Bands; even water coolers can make music.

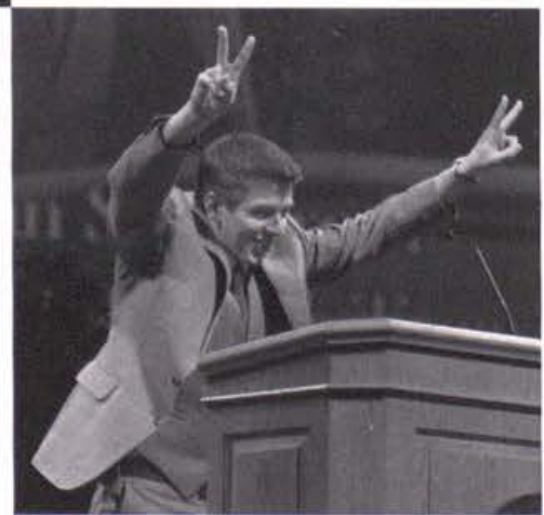

Brian Schildroth shows his victory sign as the new SGA treasurer.

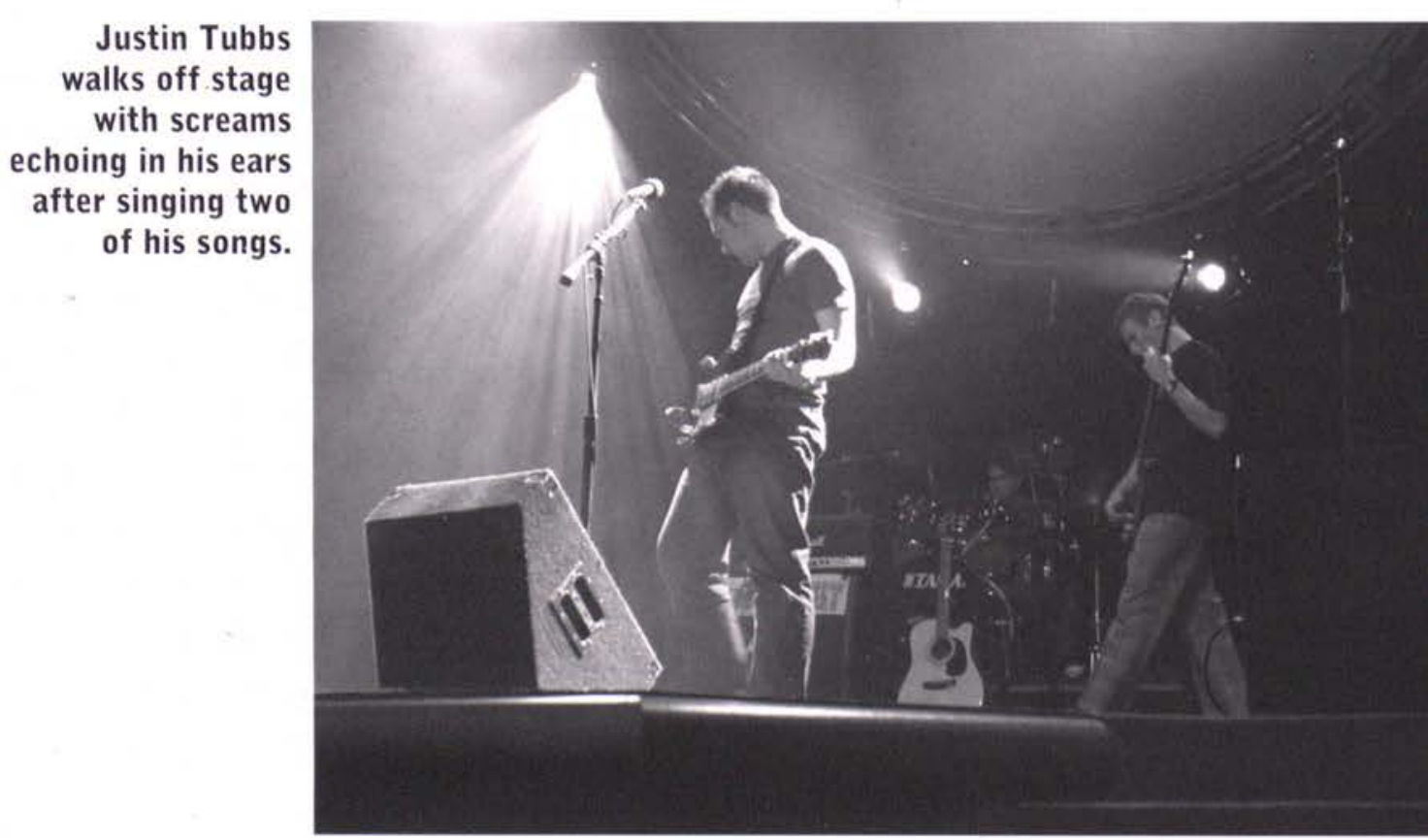




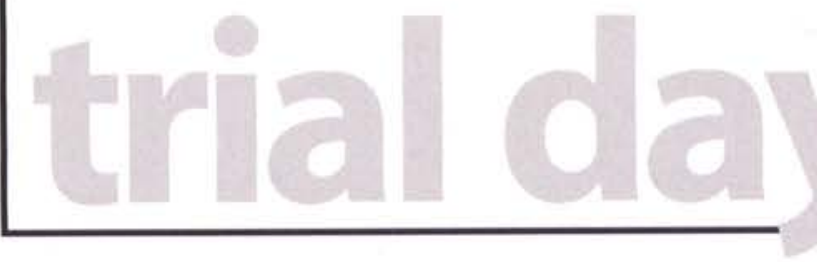

spring play

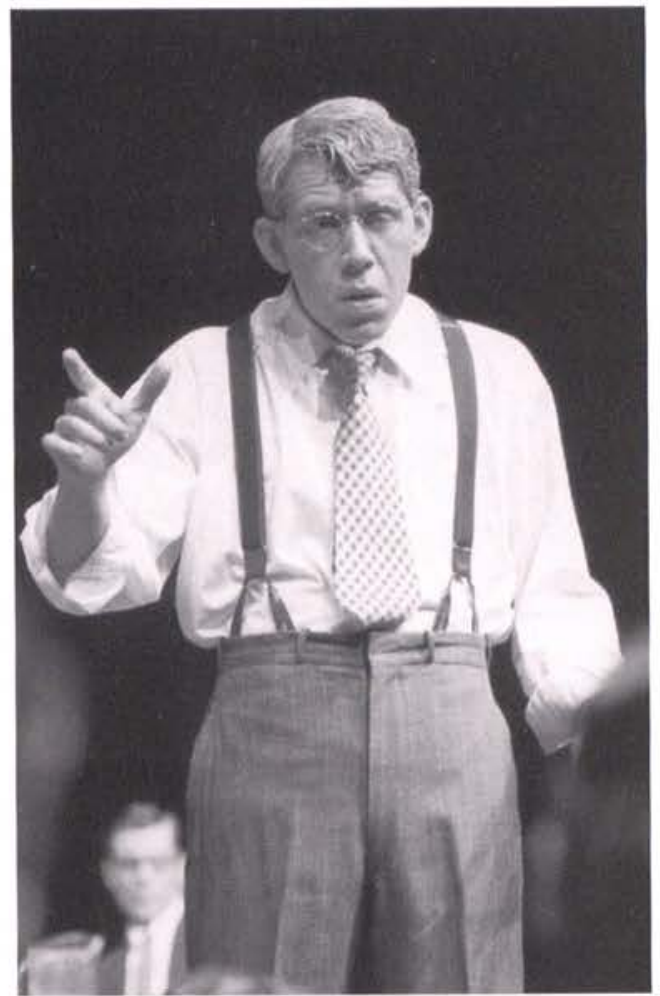

Brian Coon as Mr. Drummond tries to make his point in the trial scene of Inherit the Wind.
Inherit the Wind was

Cedarville University's dramatic challenge for the spring of 2002 .

Between April 25 and May 4, more than 40 thespians took over the stage under the direction of Dr. David H. Robey. This particular play was controversial in nature because of the play's message, "the supremacy of the individual mind," according to Robey.

Robey worked alongside Dr. Richard Cornelius, professor emeritus of English at Bryan University and the leading scholar in the nation on the Scopes trial, to understand better the factual information of the Scopes trial. Because of the nature of the play, chapel on April 15 and 16 were dedicated to discussing the philosophical, ethical, and spiritual issues of the drama. Robey's hope was that the play would move the audience toward a deeper understanding of God's Word.

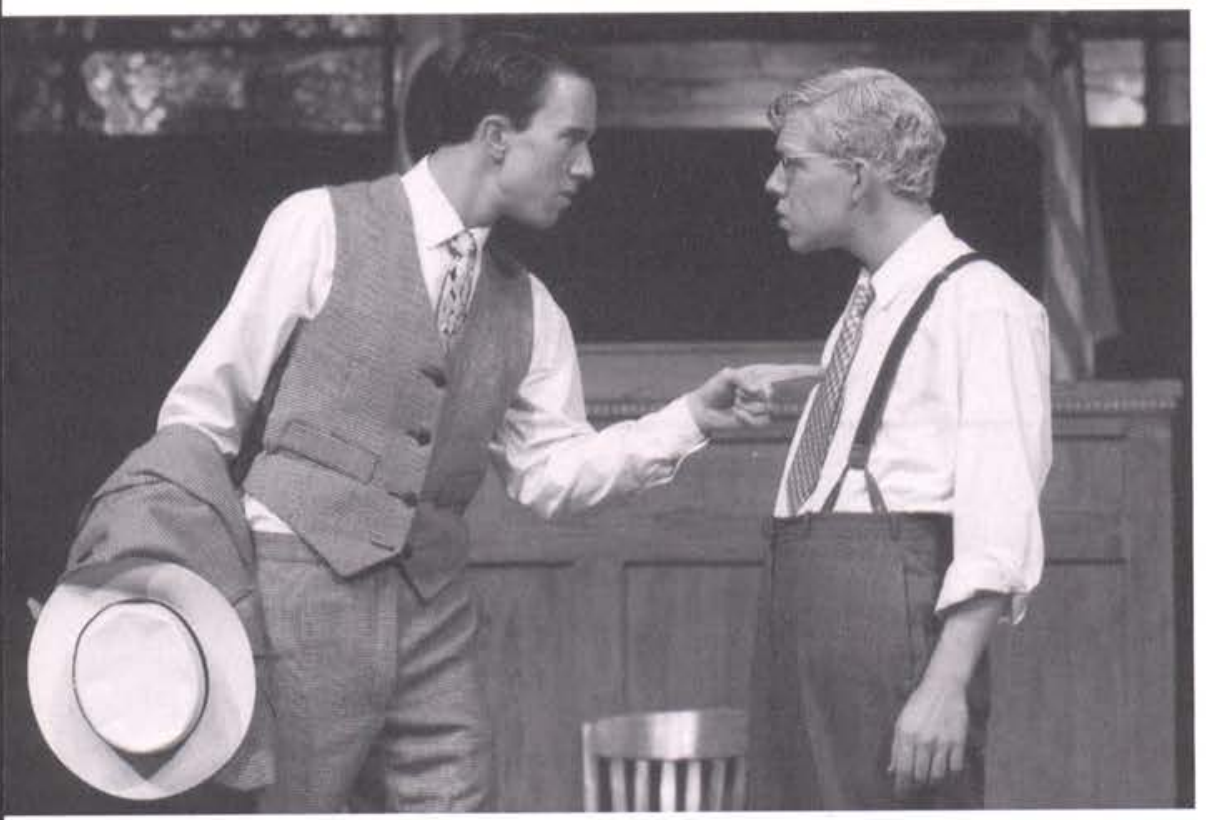

On issues of faith, Valerie Wubbena, one of the women in the play's choir, stated, "It has been a privilege for me to be a part of a production that encourages us as believers to be prepared to give an answer for the faith we hold on to. Since it is my senior year, it has been a blast being a part of this production, and it has also encouraged me to never stop learning so that my faith can truly become my own."

Debbie Compton, a student and audience member, said, "I thought it was excellent. It was a very interesting perspective on the evolution because it showed a very non-biased view of the conflict. You could never tell which side the author supported. It also challenged me and reminded me that sometimes we can't have all the answers, and faith has to be enough for this life."

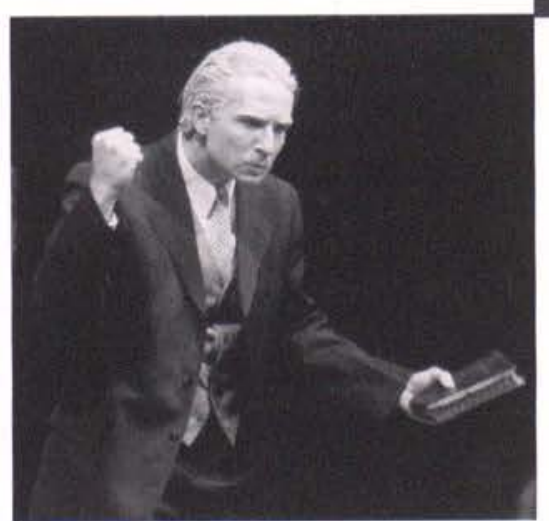

Showing the vigor and robust attitude of Matthew Harrison Brady, Matt Olson brought the character to life. 



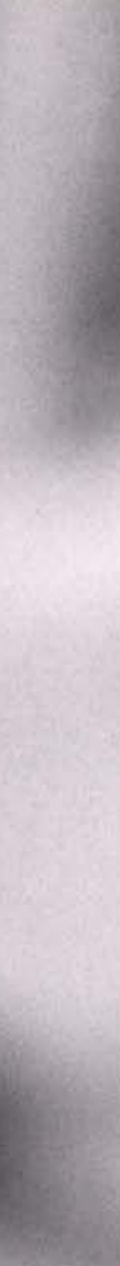

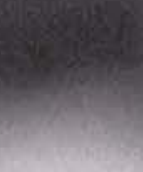

(1900)

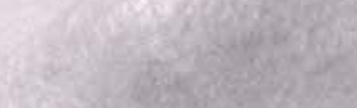

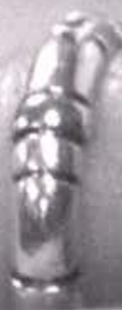

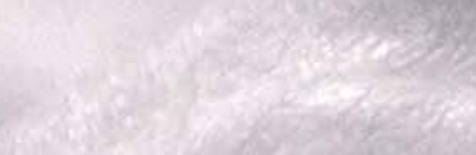

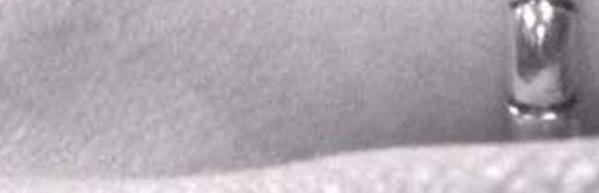



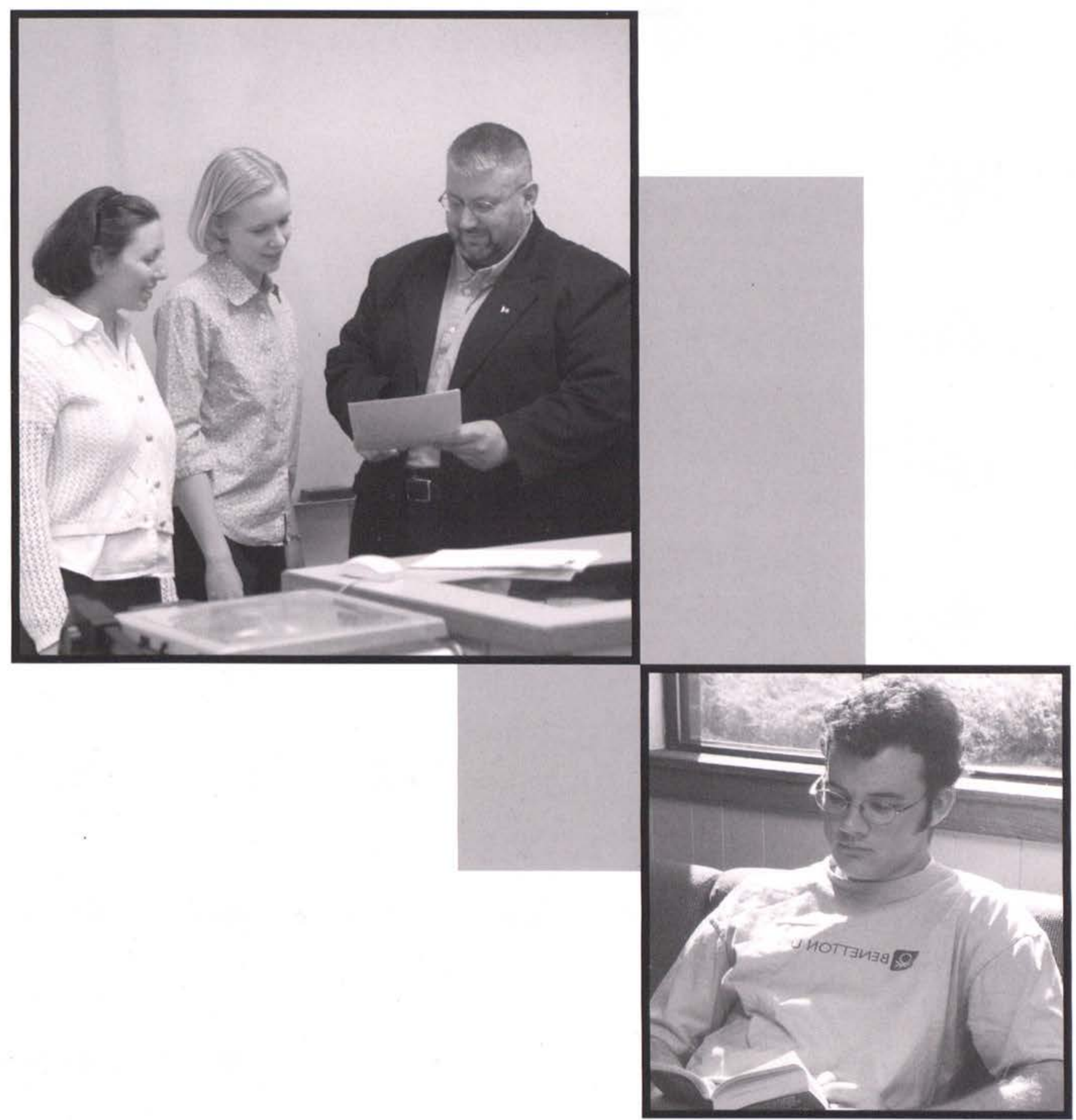


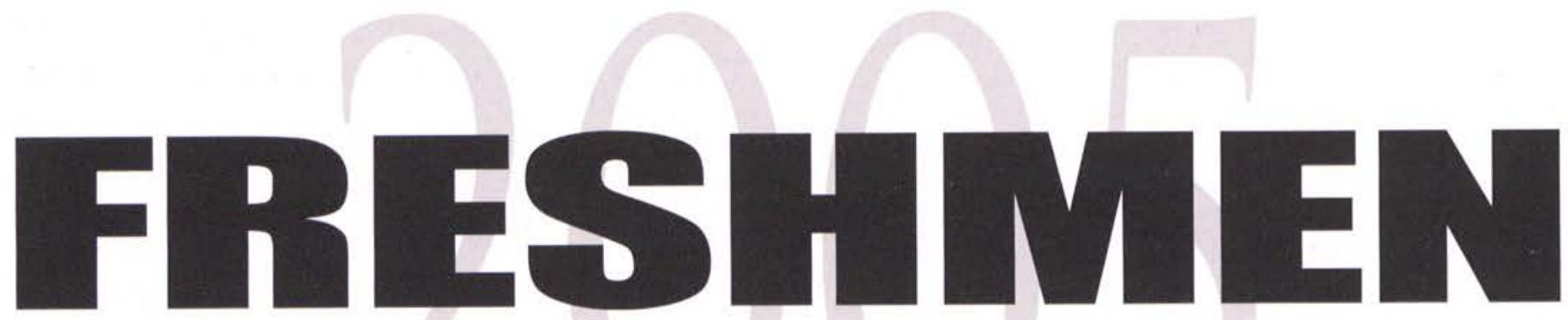

Elizabeth Abney Kailin Acheson Juliet Ackerman Daniel Alburger David Aleuskis Shawn Alexander

Amanda Allen

Brian Allen

John Ament

Kristin Armitage

Nathan Arnold

Deanna Austin

Jason Auyer Lindsey Bailey Lydia Baker Michael Baker Nathan Baker Ryan Ballard

Ruth Ballou Kristen Banas Jennifer Barham Ivan Batista Tim Beck Lindsey Bender

Brandon Bennett Mark Bentley Karl Bernhard Tyler Bethel Amy Betts Rani Bird
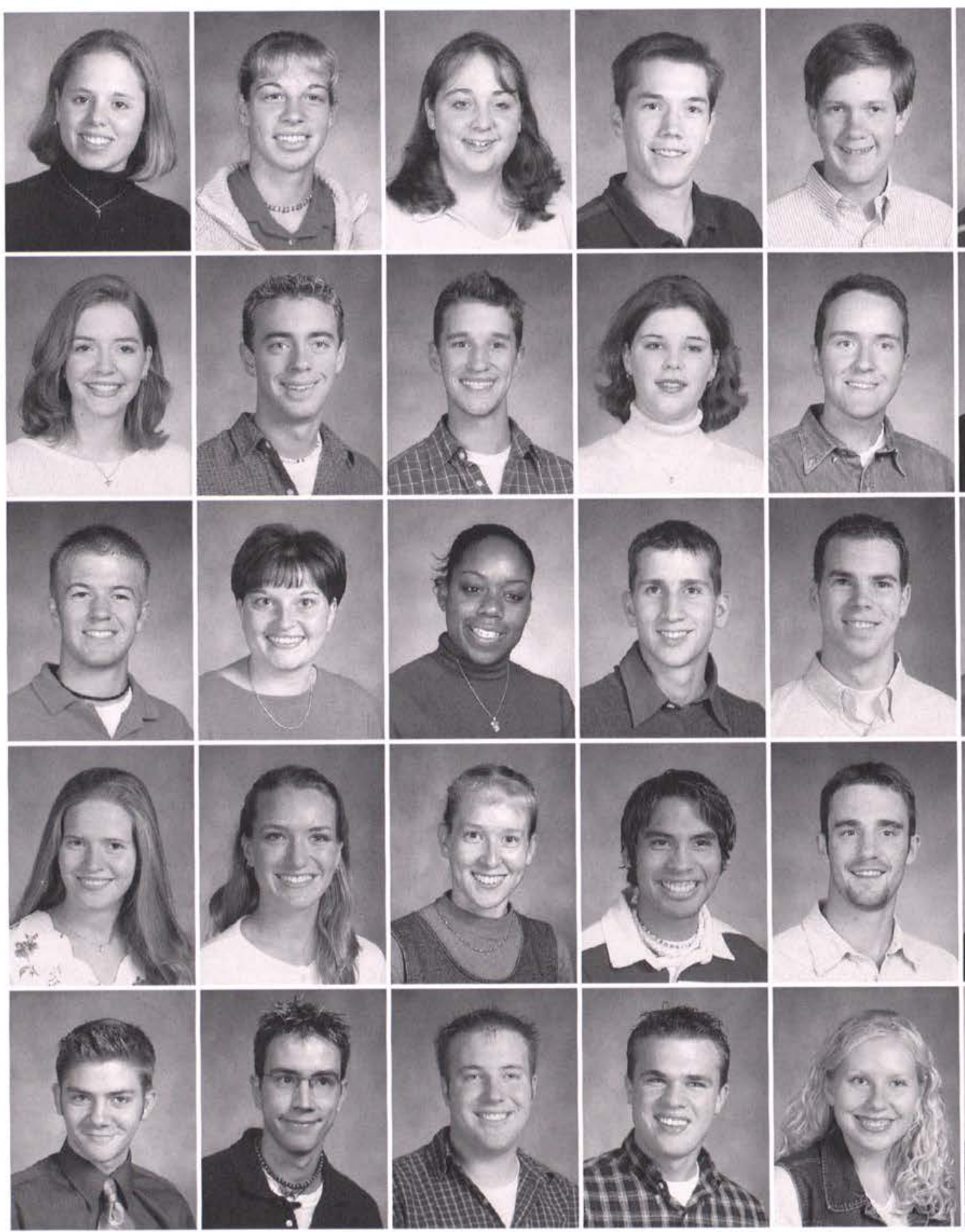
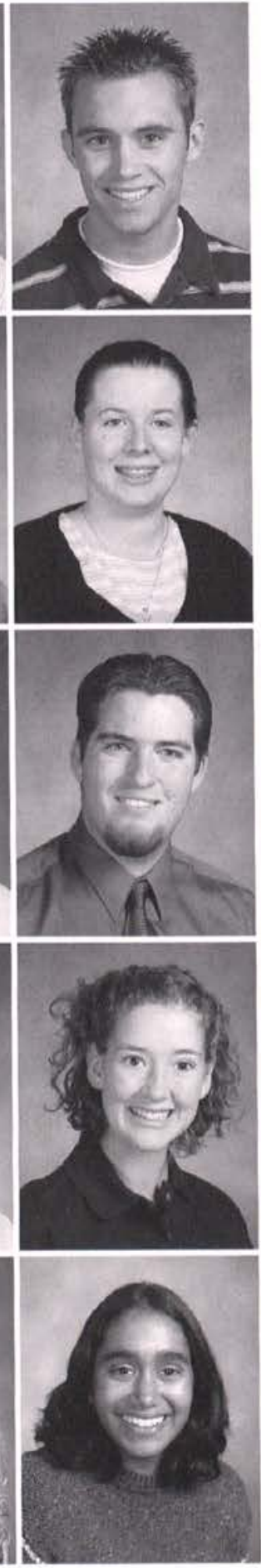
Rebekah Clark

Andrew Clauson

Richelle Clem

Michael John Clutz

Jonathan Coleman

Justin Colon

Angie Combs

Paul Compton

Daniel Congrove

Jeffrey Conklin

Heather Coon

Kristi Corder

Andrew Courser

Angela Courtade

Michael Cramer

Jason Culpepper

Laura Cummings

Jack Curran

Wendy Curtis

Cameron Daigle

Laura Davis

Jennifer Delk

Kathryn Dellicarpini

Richard Denius

Jennifer Dennis

Nathanael Dewhurst

Melissa DeYoung

Karen Dimatteo

Jesse Divine

Kelly Dixon

Valerie Dolby

Jeffrey R. Doub

Keith Dougherty

Matthew Douglas

Jim Dowd

Dustin Doyle

Adam Drent

Amber Drummond

Megan Dulin

Meredith Eckburg

Lindsey Edlund

Amy Eggleston
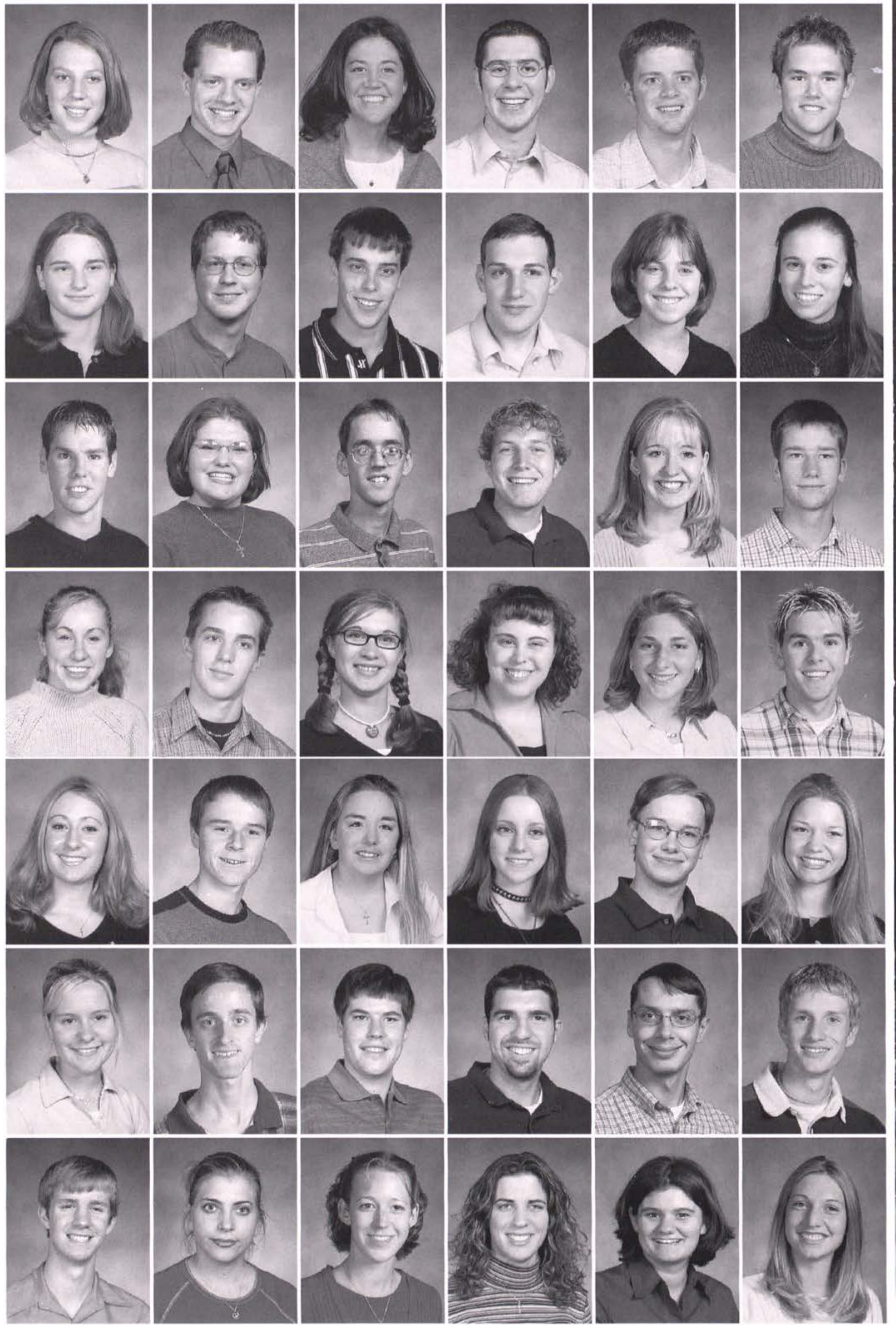


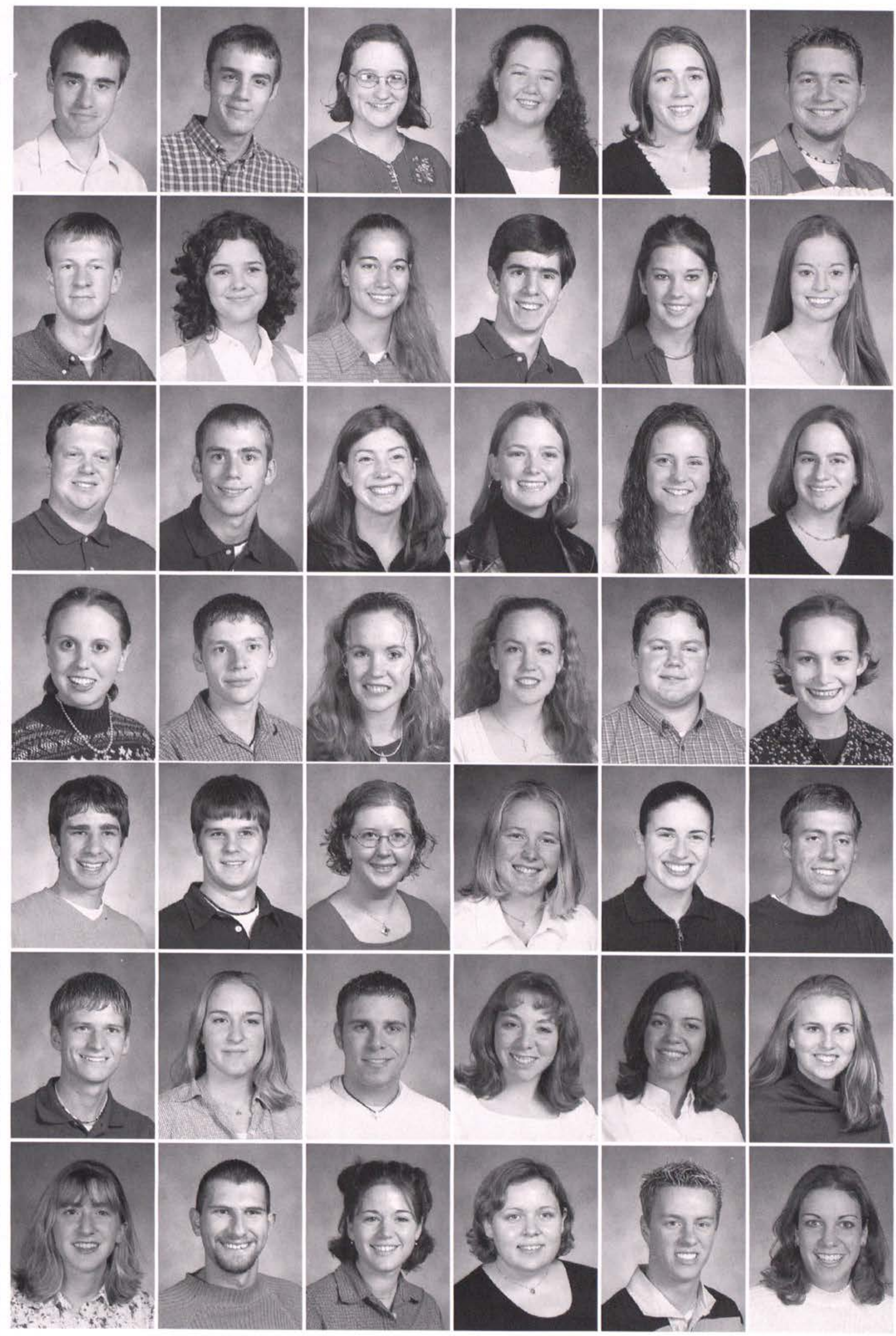

Timothy Eichner Mark Eisentrager Katrina Ellcey Amanda Elliott Amy Elliott David Ellis

Ian Ellis

Megan Ellis Kelly Elshoff Michael Ensslen Kayleanne Epp Kristen Erikson

Seth Erskine Jeremy Estes Kara Everett Lindsey Everswick Sandra Ewerth Emilee Fairbanks

Christine Fairchild D. Wayne Fannon Sara Firebaugh Stephanie Firebaugh Brett Fisher Colleen Fitzsimmons

Andrew Flamm David Fleetwood Christi Flick Kari Flunker Sharon Foley Ben Foreman

Dustin Foster Christen Fowler Thomas Freeman Susan Fultz Emily Furler Rachel Ganong

Anne Gaynier Kevin Gehret Tracy Geiser Angela Gentry Adam George Tami Gheen 
Melissa Gibb

Sarah Gibson

Daniel Giddings

Zach Gifford

Sharon Girouard

Matthew Gish

Kelley Goldsby

Andy Goodenough

Jessica Goodrich

Ruthanne Gough

Nick Graff

Karen Green

Matt Green

Andrew Greene

William Grimme

Sara Grosskopf

Elizabeth Gwilt

Benjamin Haas

Jennifer Hake

Benjamin Halladay

Rachel Hamilton

Timothy Hamilton

Doug Hammond

Erin Hamrick

Shaun Hanna

Marguerite Hansell

Lisa Hansen

Megann Harbaugh

Kristi Haring

Dan Harkleroad

Amy Harlan

Ben Hart

Marcee Hart

Elizabeth Hartman

Yosef Hassan

Ross Hauswald

Robby Haynes

Sarah Haynes

Janine Helmick

Karla Herdzik

Lisa Herman

Hannah Hermiz
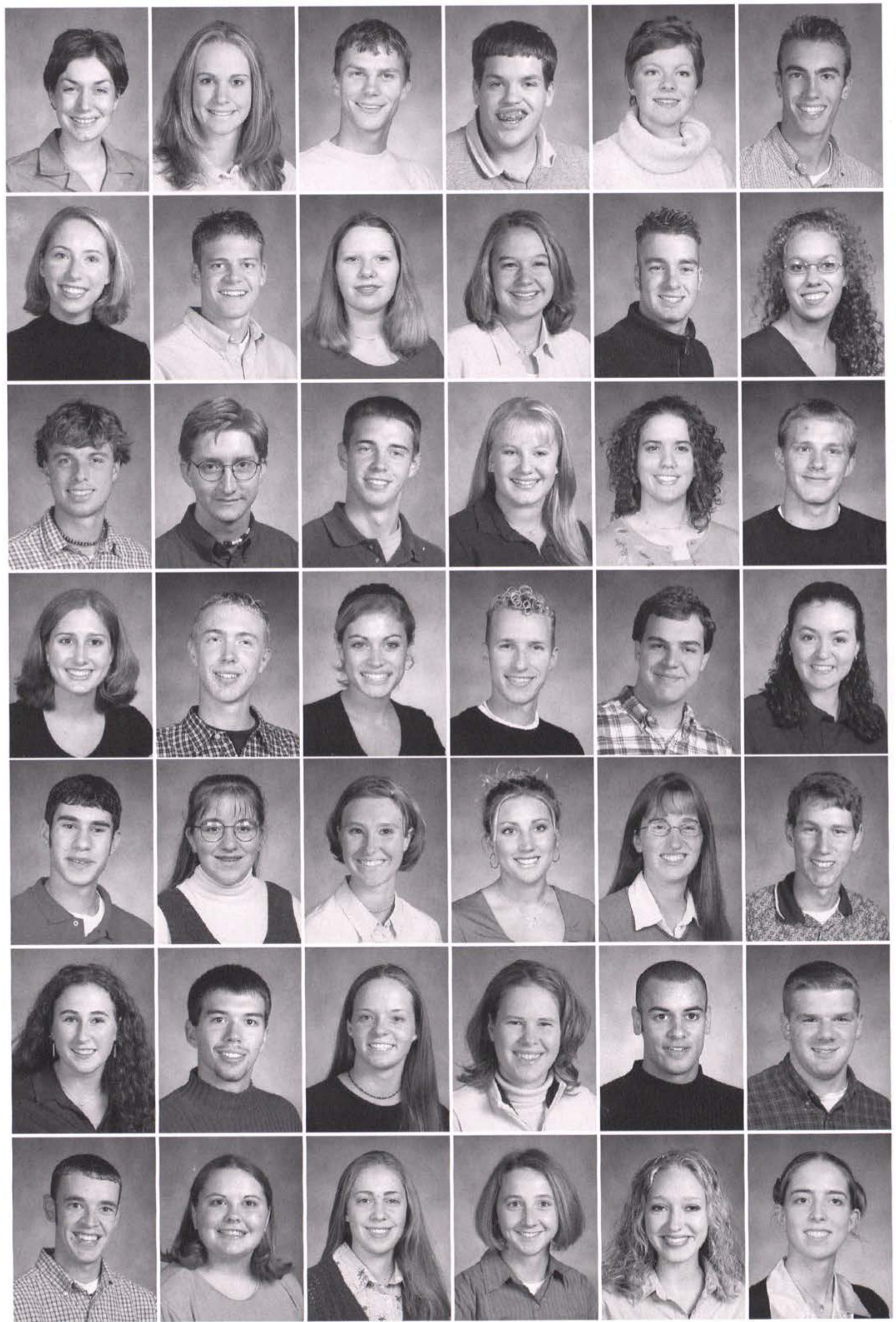

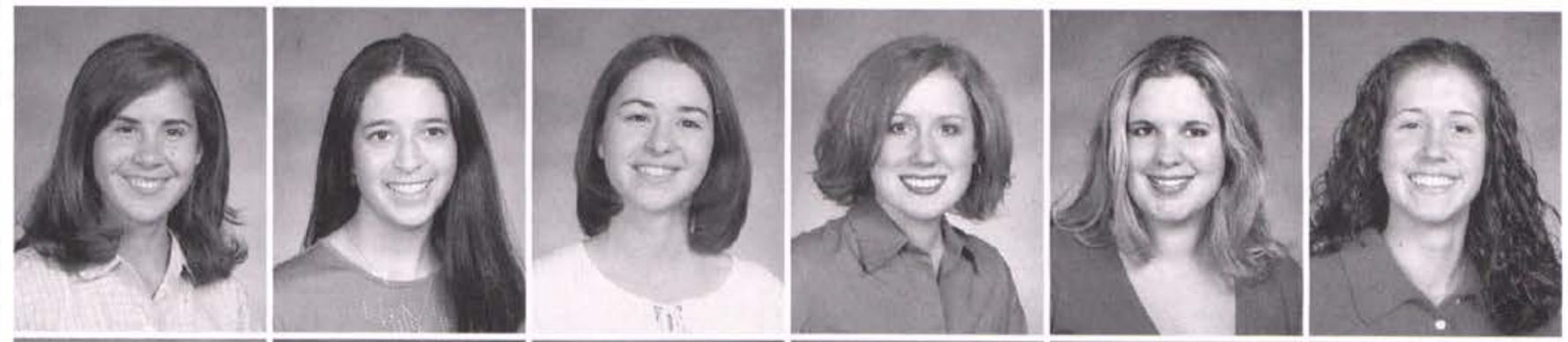

Rachel Herring Meredith Hertler Mary Heslop

Rhianna Hickey

Erin Higley

Bethany Hochstaetter
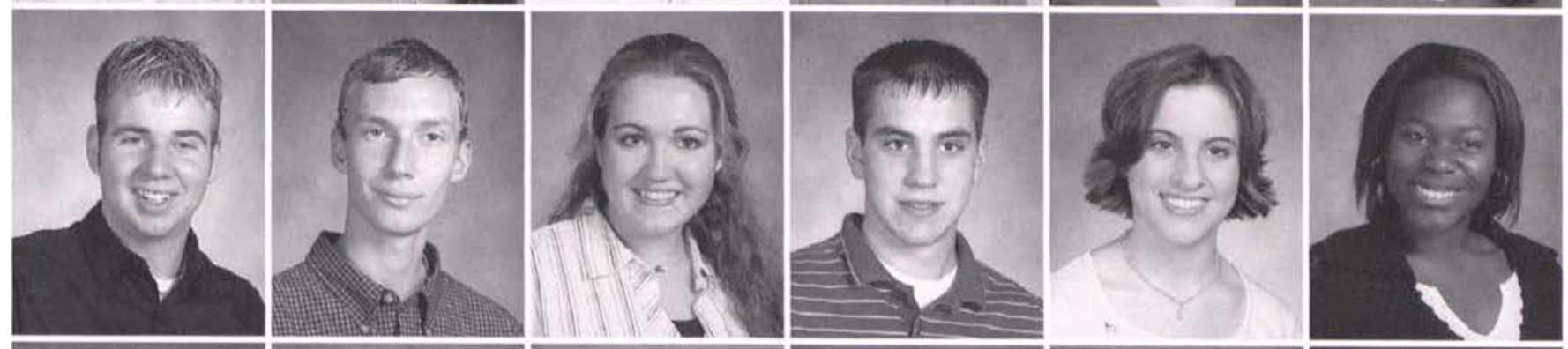

Kyle Hoff

Aaron Hofner

Amy Hollins

Steven Hop

Noel Hoskins

Julianne Howe
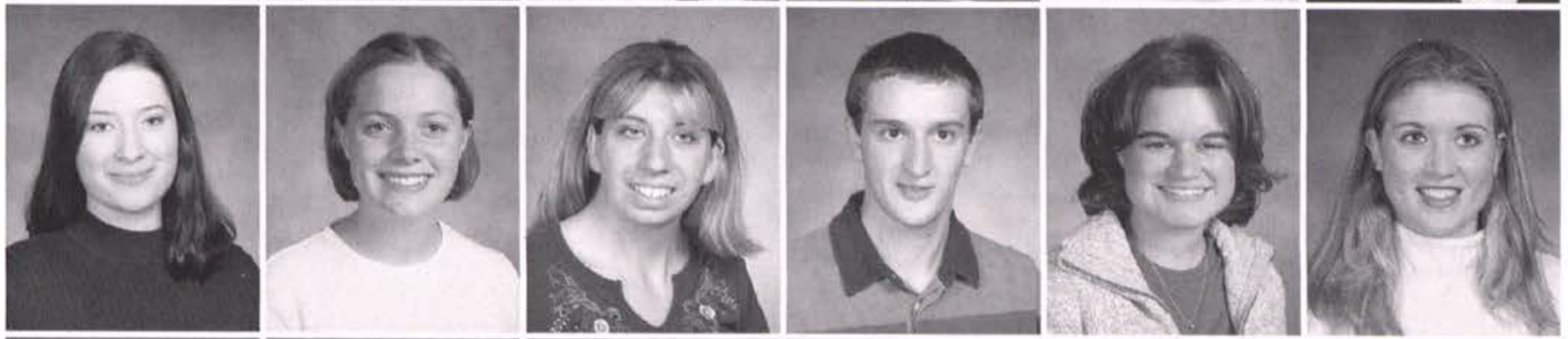

Melissa Howland

Katie Joy Huizinga

Jennifer Hummel

Bret Hurlbut

Candice Hutcheson

Cassandra Ingram
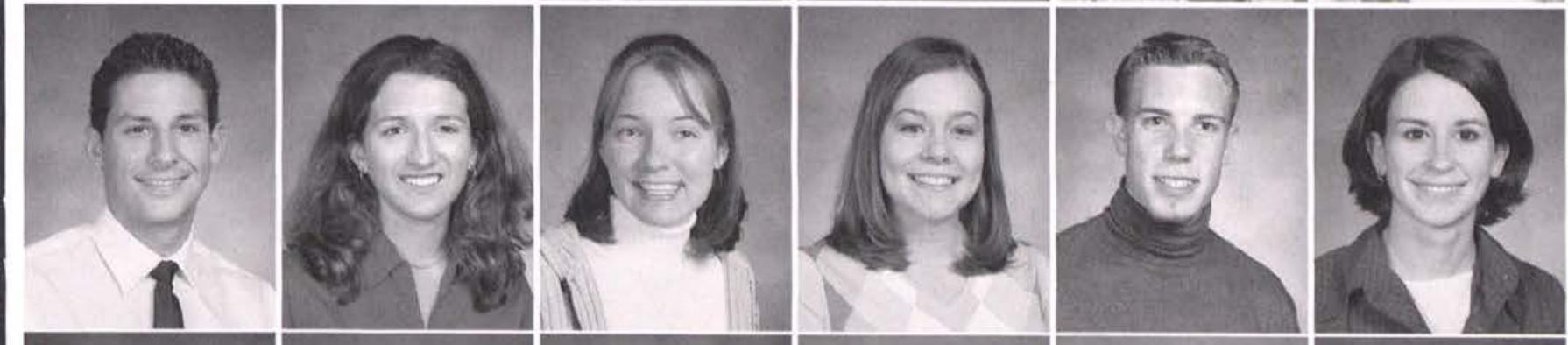

Chad Jackson

Julie Jamgochian

Rachel Janssen

Elizabeth Jelsma

Andrew Jenkins

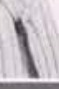

Nicole Jewell
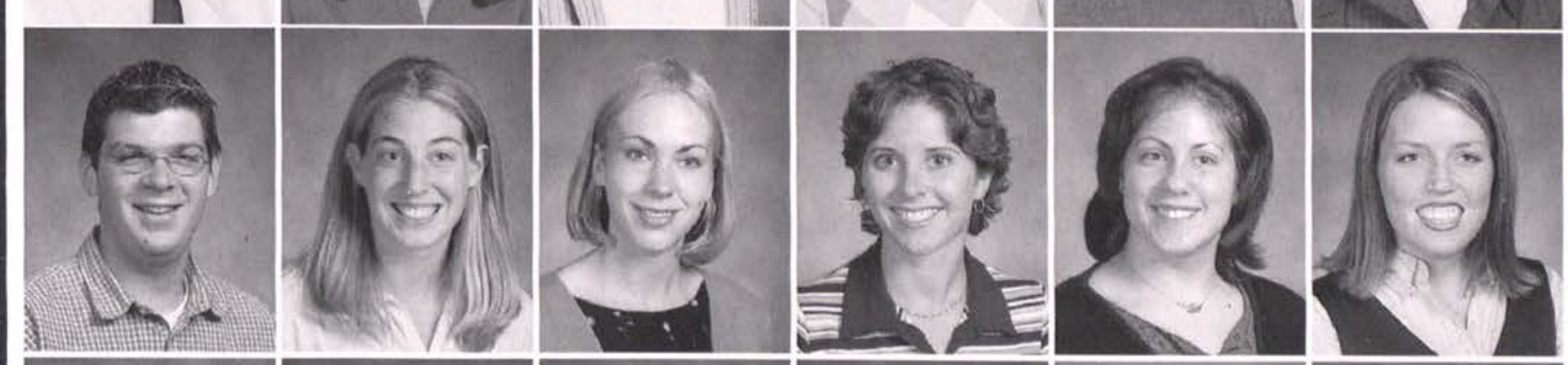

Eric Jingst

Kara Jodry

Bethany Johnessee

Andrea Johnson

Arielle Johnson

Bethany Johnson
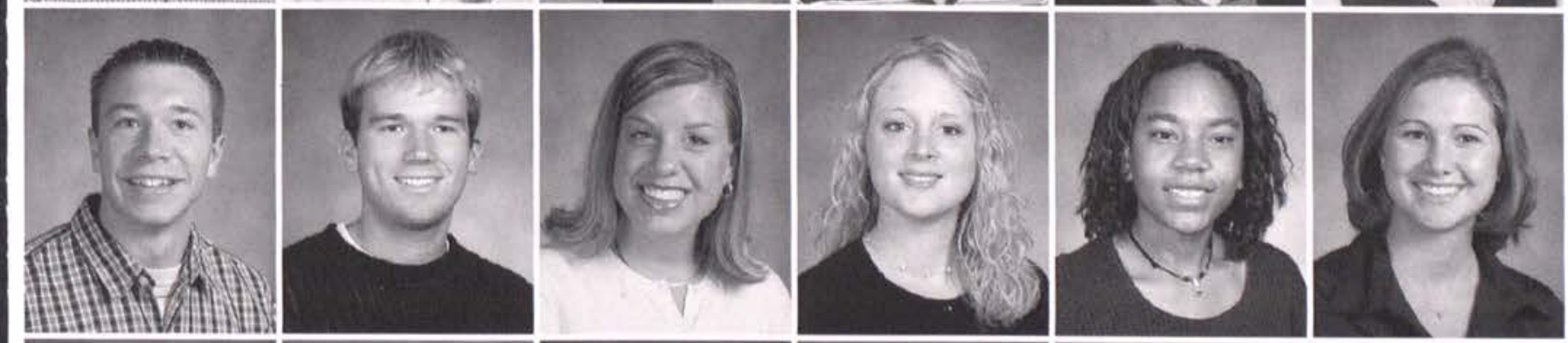

Brett Johnson

Derek Johnson

Rachel Johnson

Rebecca Johnson

Amanda Jolly

Kristin Jones
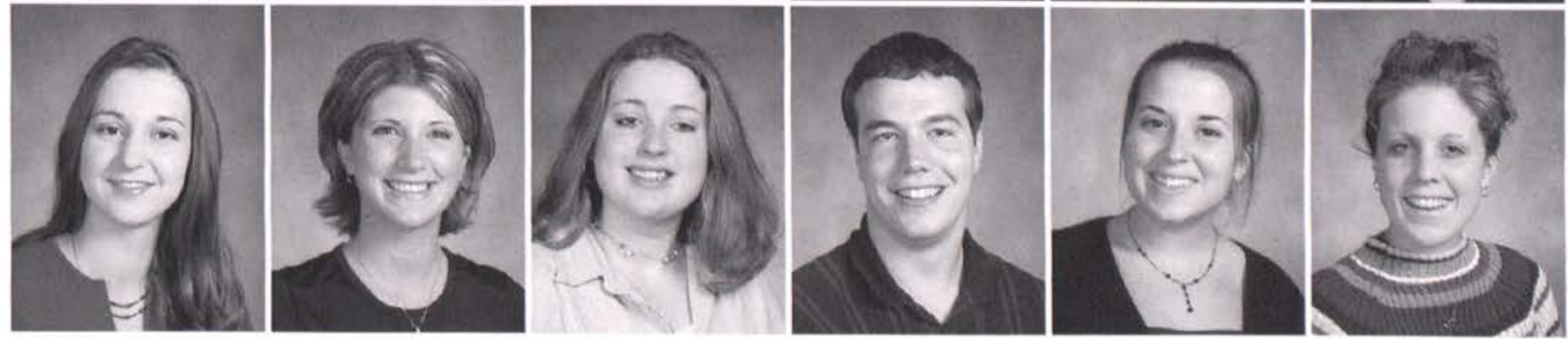

Leslie Jones

Melissa Jones

Melissa Joubert

Timothy Kaminsky

Elisabeth Keim

Kassondra Keller 
Jamie Kelly Justin Kemmerer

Amy Kennard

Shelby Keyser

Adam King

Stephanie King

Andrew Kirby

Philip Kirby

Andrew Klein

Jennifer Klimek

Megan Koons

Michelle Koziol
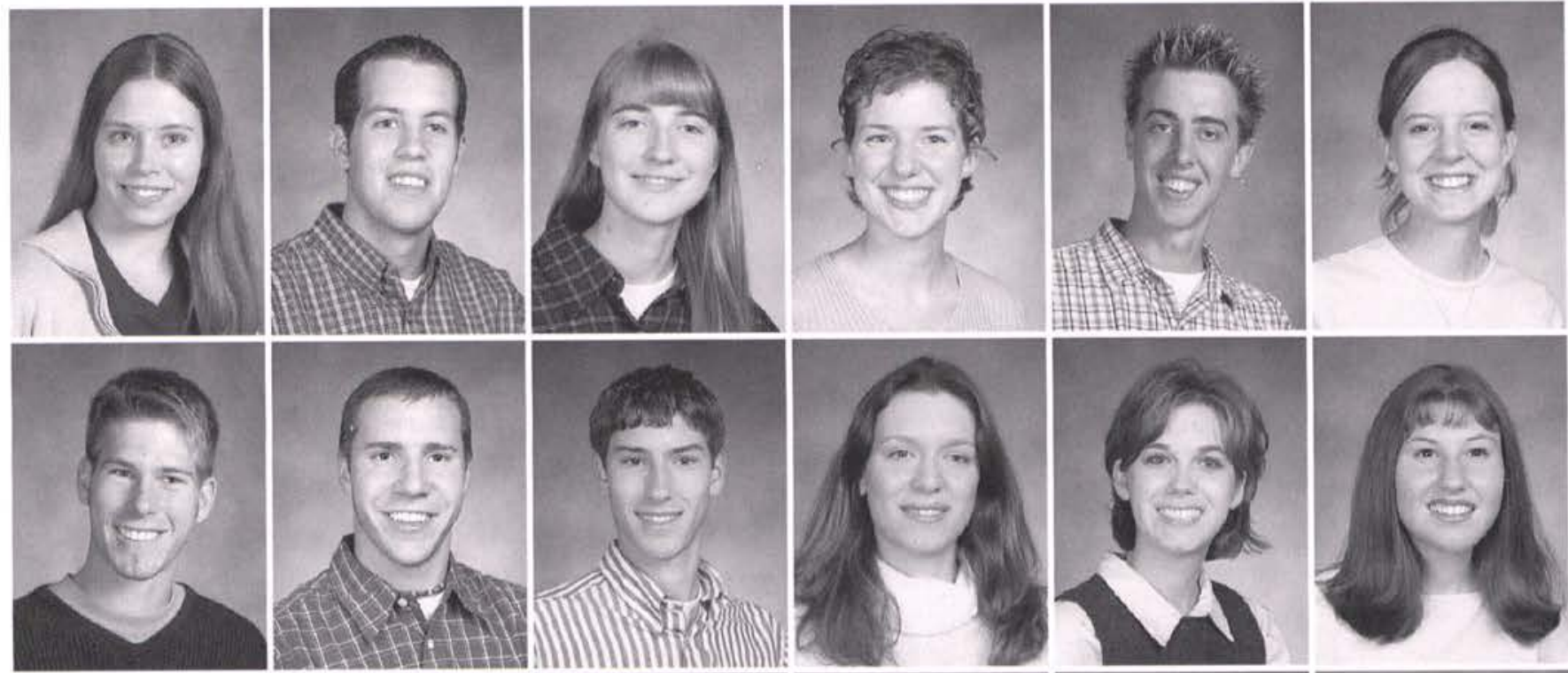

Jeff Kraker

Eric Kramer

Matthew Krizo

Katie Krumeich

Joshua Krupka

Paul Kushnir

Amber Lane

Joel Lansford

Richard Lanz

Adam Laskos

Erin Leach

Tim Leasure
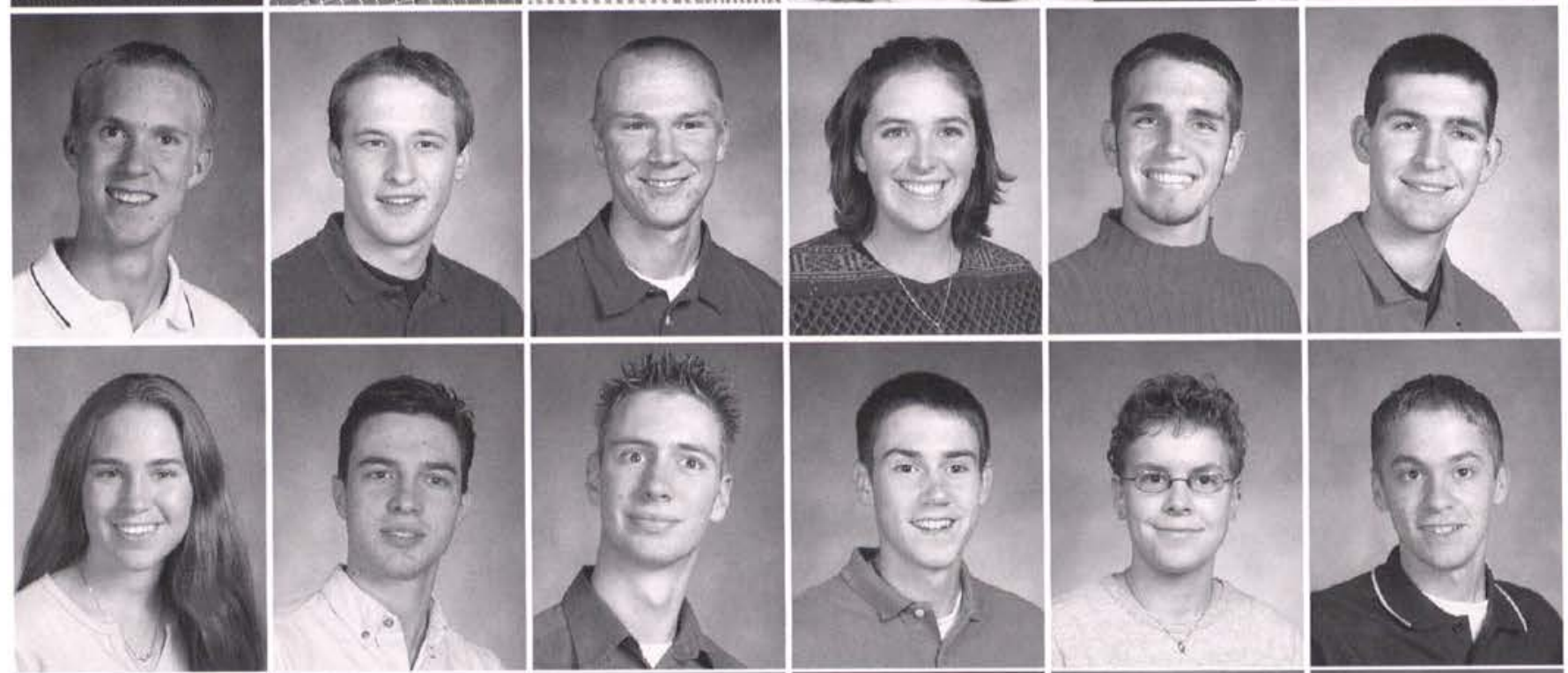

Elizabeth Lemmel

Jennifer Lewellyn

Julia Lewis

Michael Lewis

Stephanie Lewis

Joseph Leykam

Justin Linderman

Stephanie LoDico

Sarah Lorence

Cheri Loughran

Erika Love

Jeffrey Lowe
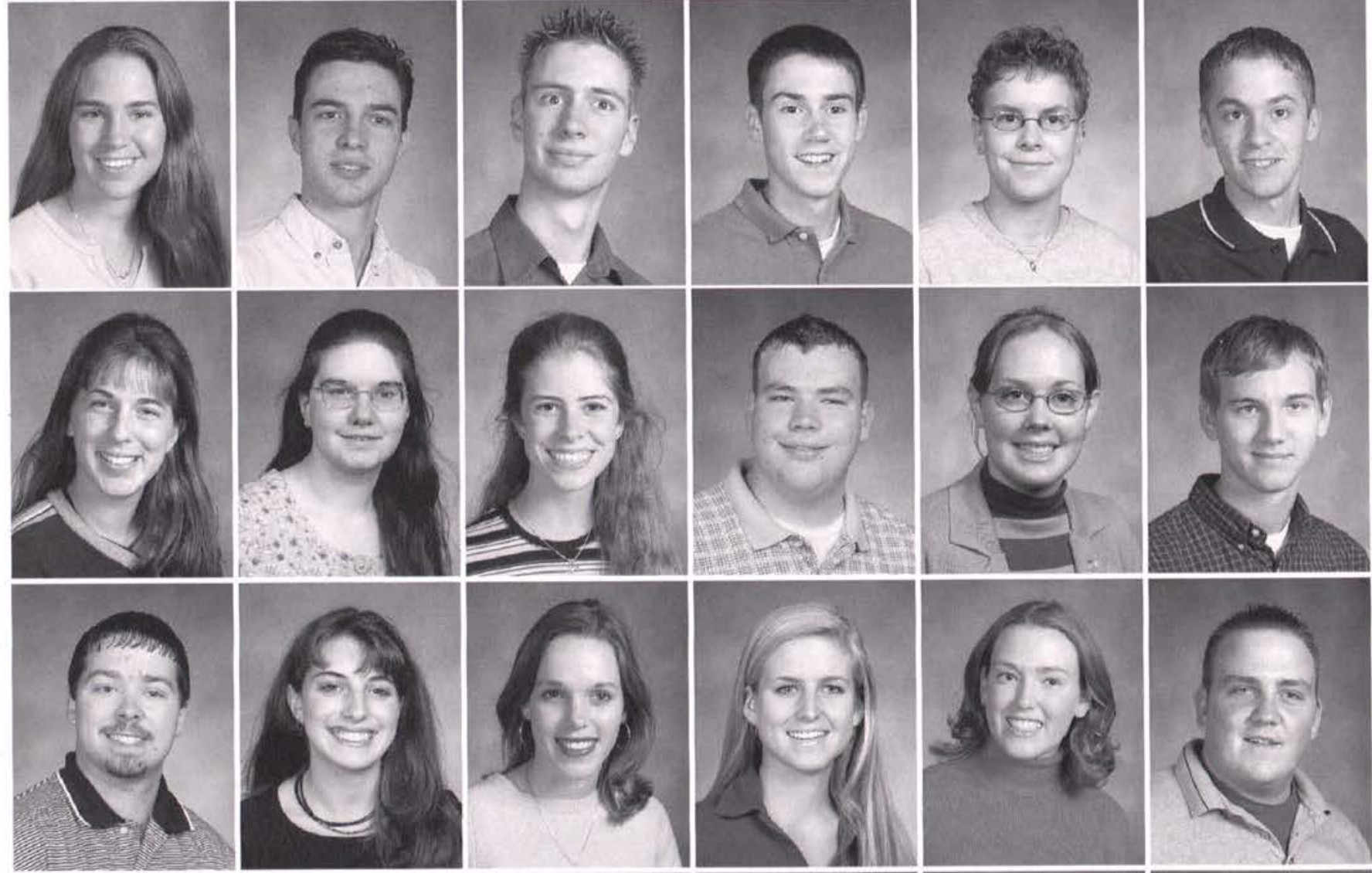

Jeffrey Lowe Justin Lower
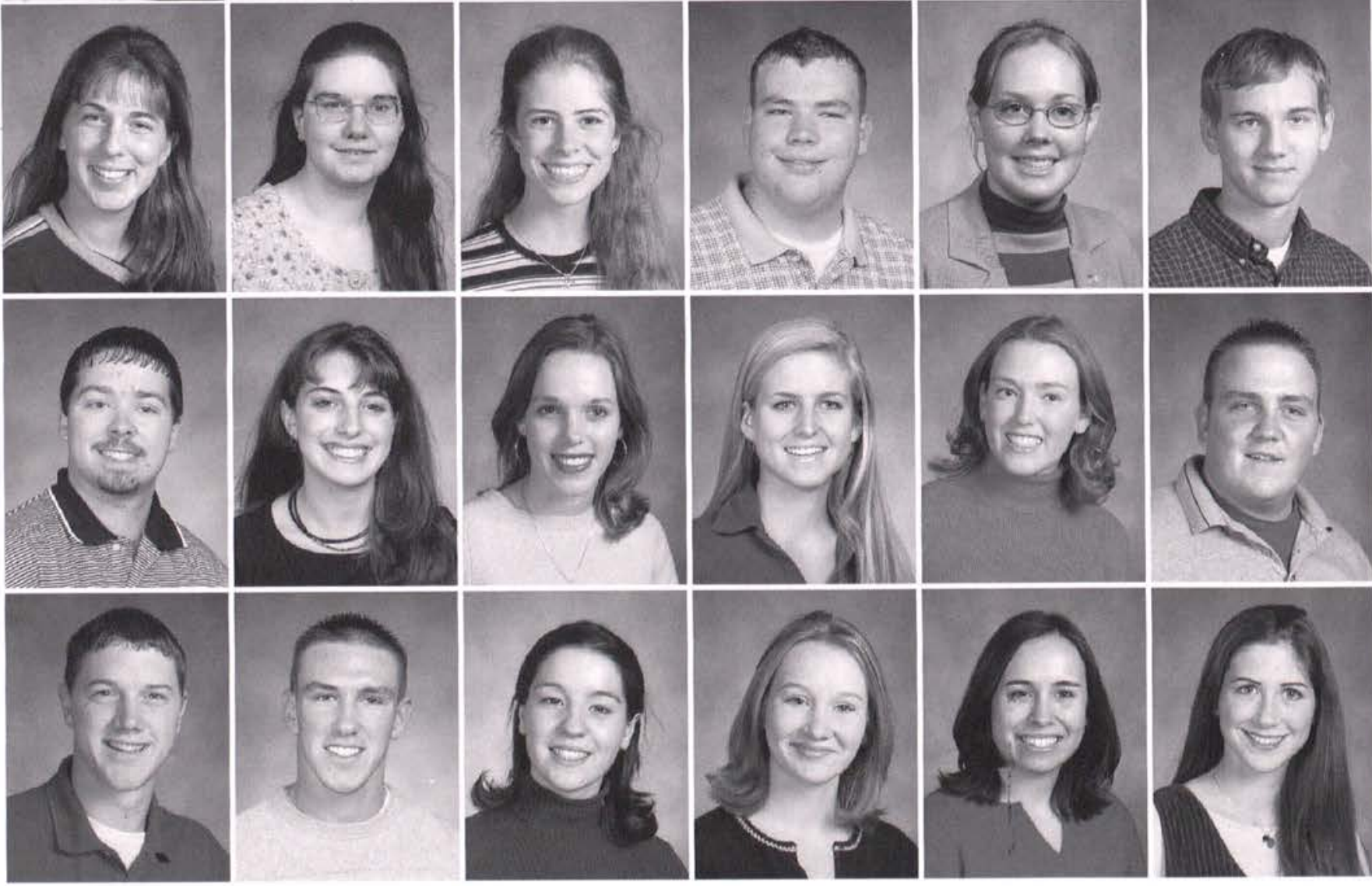

Amanda Lucarin

Jacquelyn Ludema

Emily Mace

Meghan MacLean 

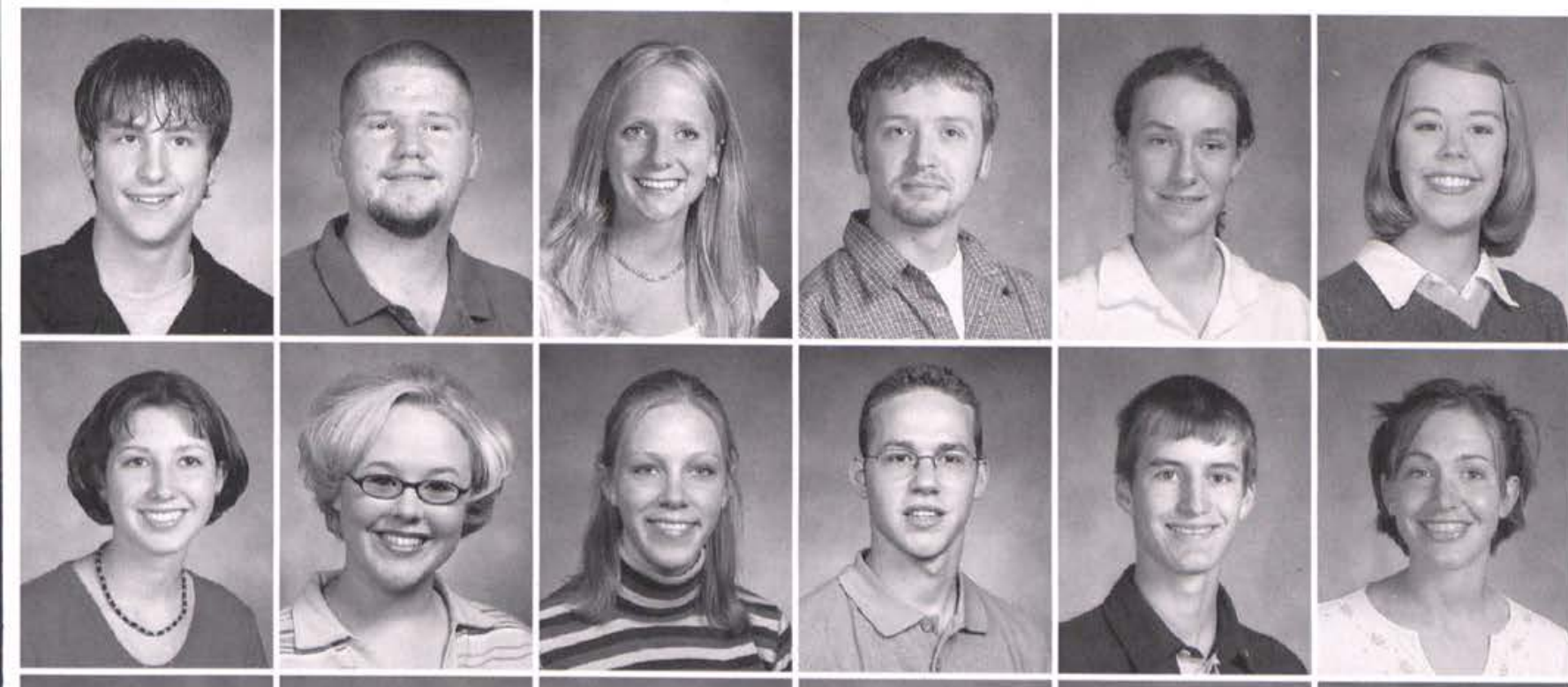

(2)
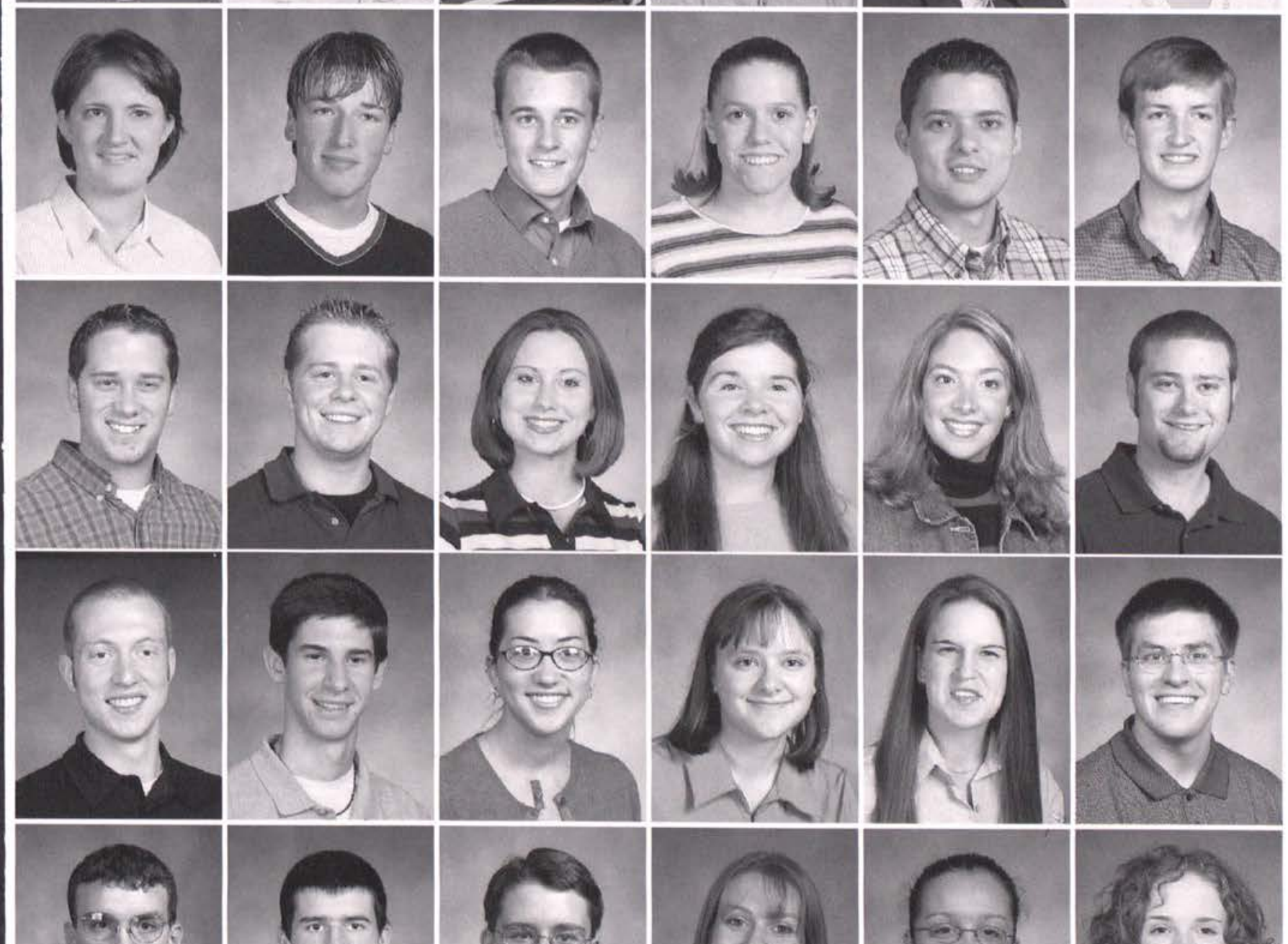

(10)

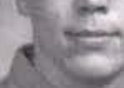

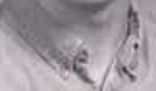
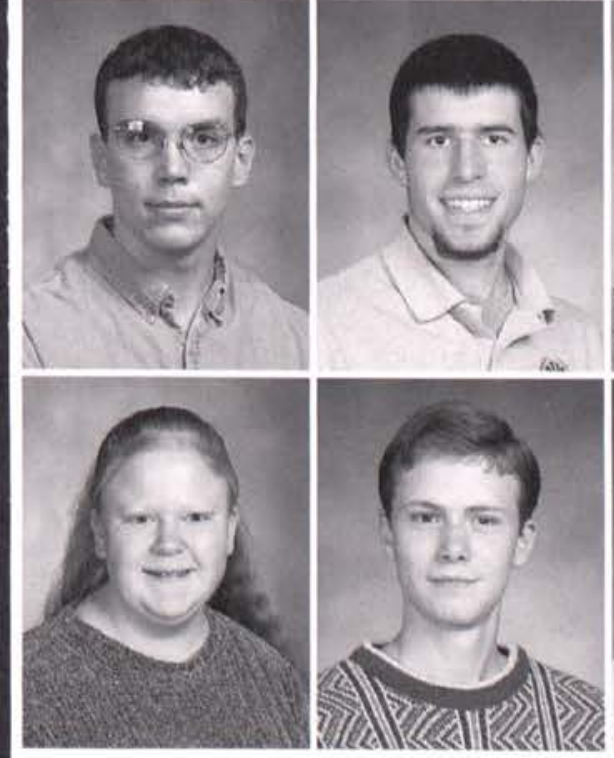
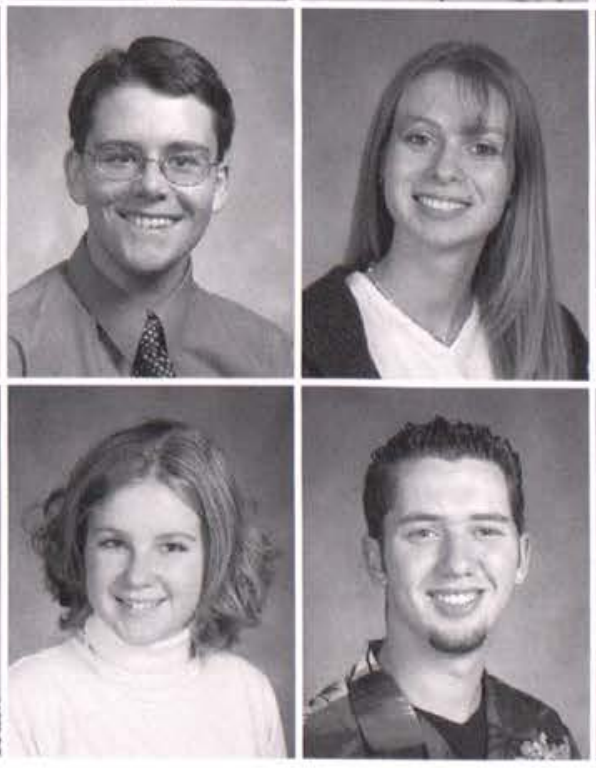

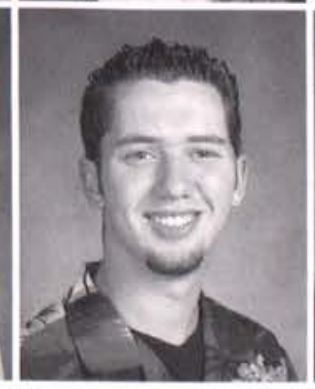

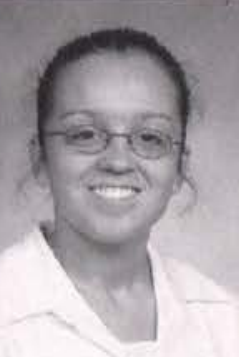

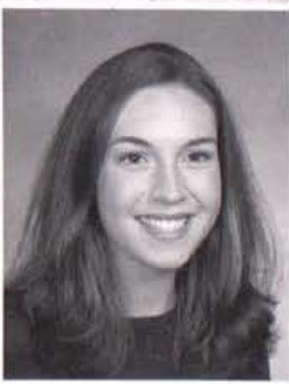

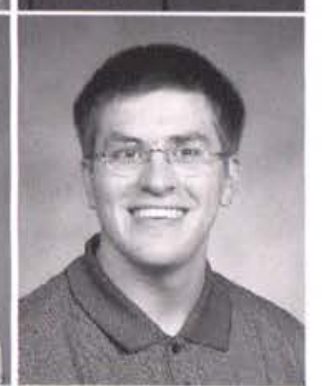
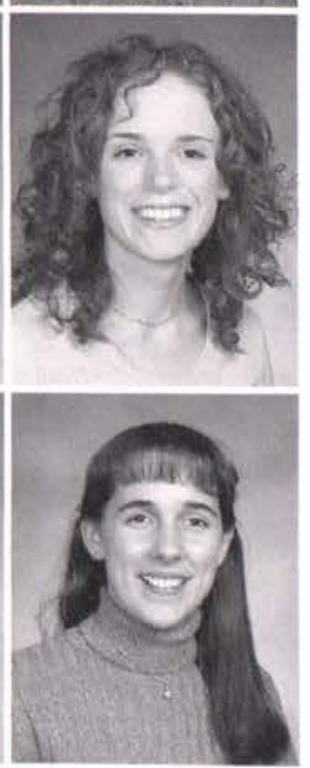

Matt Malone

Matthew Malpas

Allison Malpass

Micah Maltsberger

Sarah Markas

Rachel Marley

Julia Martin

Kate Martin

Kelly Martin

Brian Masser

Jason Mattern

Melissa Mattner

Leslie Maxey

Jarid Mayo

Devon McCarty

Bethany McCloskey

Ryan McClure

Philip McCune

Mark McDaniel

Matthew McDonald

Kelly McGrath

Kathryn McKallagat

Stephanie McNeilance

David Mead

Andrew Meade

Ethan Merck

Katherine Meyer

Laura Michaels

Anna Mied

David Miedema

Matthew Miklacic

Paul Milby

Jonathan Miller

Kate Miller

Melissa Miller

Catherine Mills

Crystal Missler

Jeffrey Mitchell

Gillian Mocas

Matt Molby

Sharon Mooney

Marie Morris 
Emily Morton

Michael Mossop

Tara Munson

Sigrid Myers

Kasey Neff

Marianna Neff

Amanda Nelson

Andrea Nelson

Ashli Nelson

Mike Nelson

Tim Nester

Heidi Neuhart

Andrew Nicholl

Heather Nichols

Benjamin Nickum

Edward Norris

Ruthina Northcutt

Josh Northeimer

Jolene Nourse

Gwendolyn Oatman

Courtney O'Connell

Natalie Ogden

Kristin Ohman

J.D. O'Neal

Laureann Osenni

Rachel Osterman

Jodie Overholt

Jeremy Owens

Josh Owens

Morgan Packard

Christina Papke

Michael Parr

Aimee Partch

Craig Pascute

Cherith Payne

Emilee Pearce

Grace Ann Pearce Kathryn Perine

Kristin Perry

Lance Peterson

Amanda Petz

Brianne Pfaffle
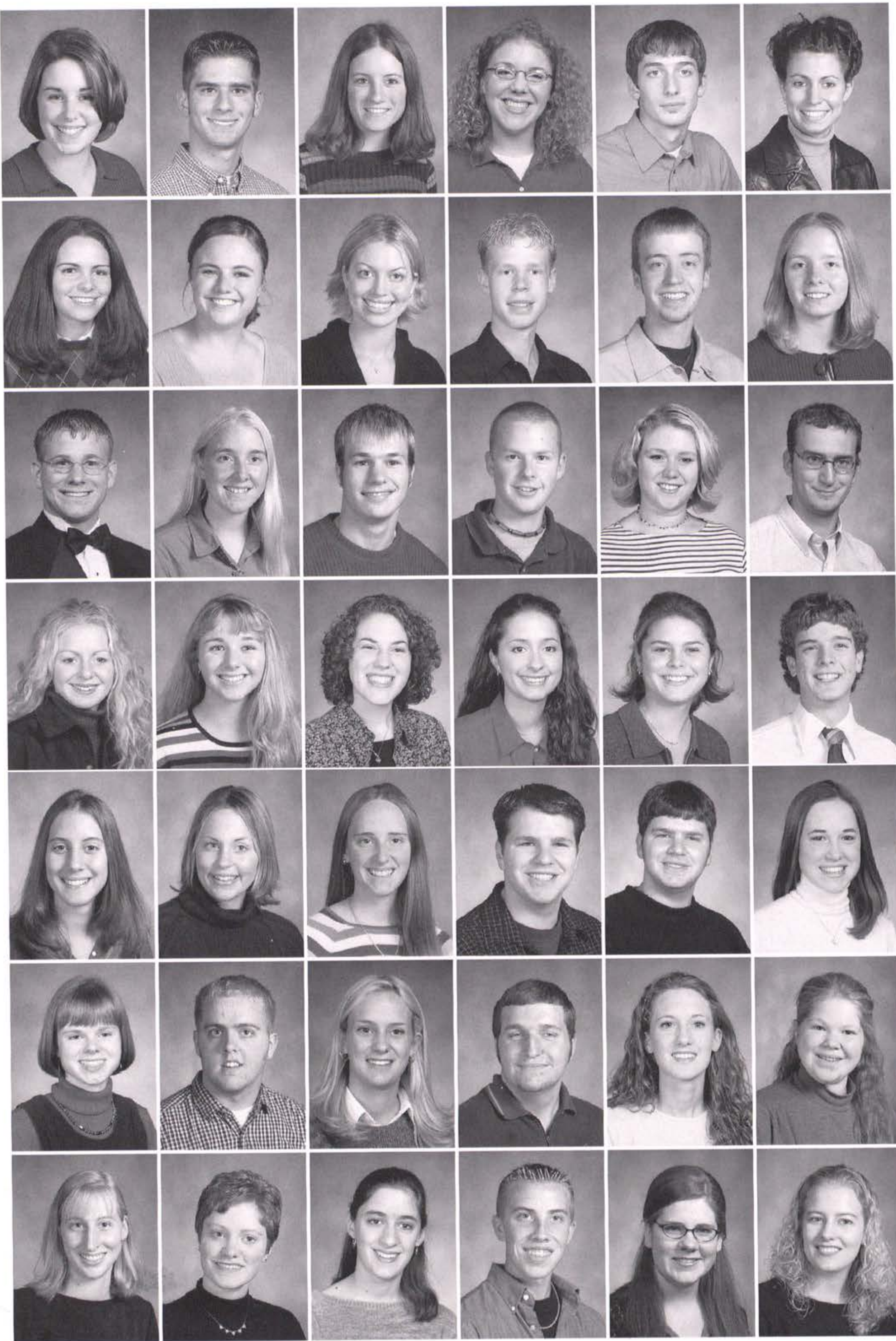
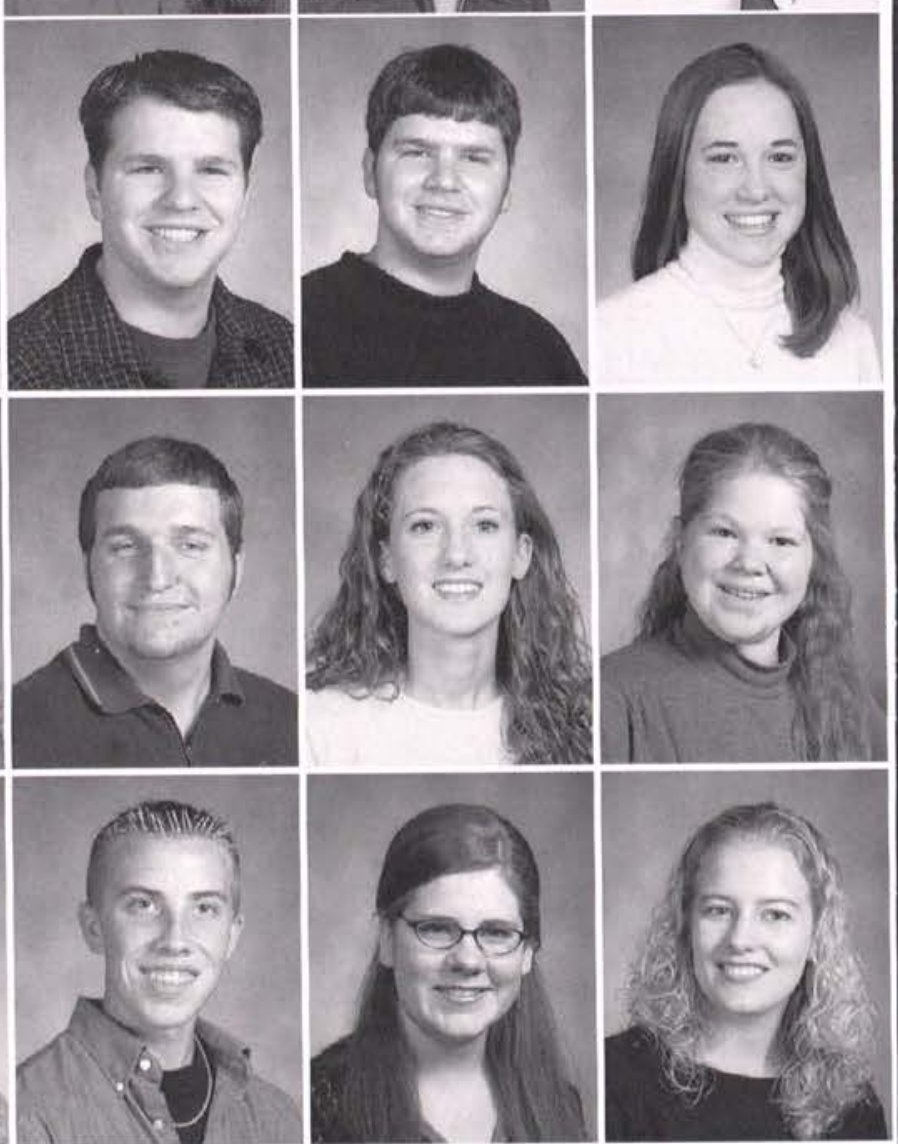


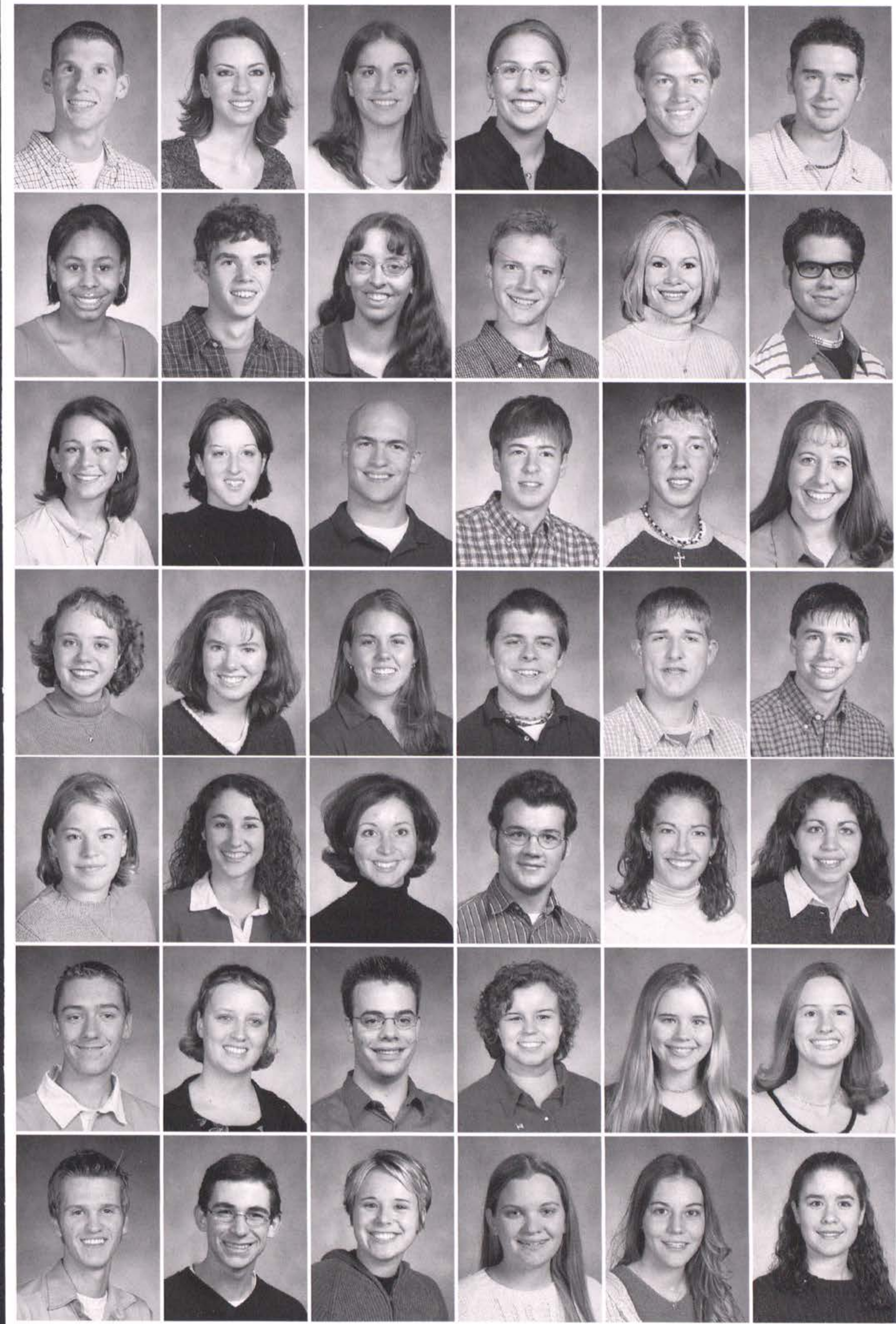

Jason Pichea

Melissa Pinkerton

Corinne Porter

Kimber Porter

Matt Porter

Nathan Pratt

Jennifer Presley

Ty Price

Elizabeth Proemmel

Brian Pursley

Abbey Pyles

Joseph Quina

Joy Raimondo

Lisa Rainsberger

Ethan Ransom

Daniel Rasbach

David Raubach

Rebekah Read

Kate Reed

Sarah Reed

Elizabeth Reep

Brett Register

Matthew Reichartz

Matt Reno

Sarah Rhoads

Sarah Richardson

Amanda Richert

Seth Ritchie

Sarah Robertson

Jennifer Rock

Ben Rodak

Leslie Roe

Daniel Roeber

Kimberly Ross

Krystle Rossbach

Stacy Rosser

Paul Rothhaar

Paul Round

Jennie Rowell

Adrienne Ruegg

Courtney Ruffin

Leigh Ann Rutrough 
Christopher Ryan Erin Sagraves

Pamela Salmons

Joshua Sanborn

Stephen Sandlund

Jason Sandrof

Rebekah Sartori Stephen Satterthwaite Carrie Schaeffer

Katherine Schauer

Jesse Schlicher Tiffany Schmoyer

Megan Schmuck Joseph Schneider

Denise Schoen

Jon Schutter

Gregory Schwab

Holly Seace

Bethany Sears

Bethany Secor

Daniel Selvey

Haley Semer

Samuel Seo

Lauren Shackelford

Leslie Shamblin

Stephen Sharp

Rachel Shaw

John-Mark Sheppard

Jenni Sherwood

Krista Shifflett

Beth Shimer

Erika Short

Elizabeth Shortt

John Simmons

Elizabeth Sims

Leanne Sims

Sara Skaggs

Jason Skidmore

David Skillings

Steve Slotterback

Mike Slusher

Jennifer Smith
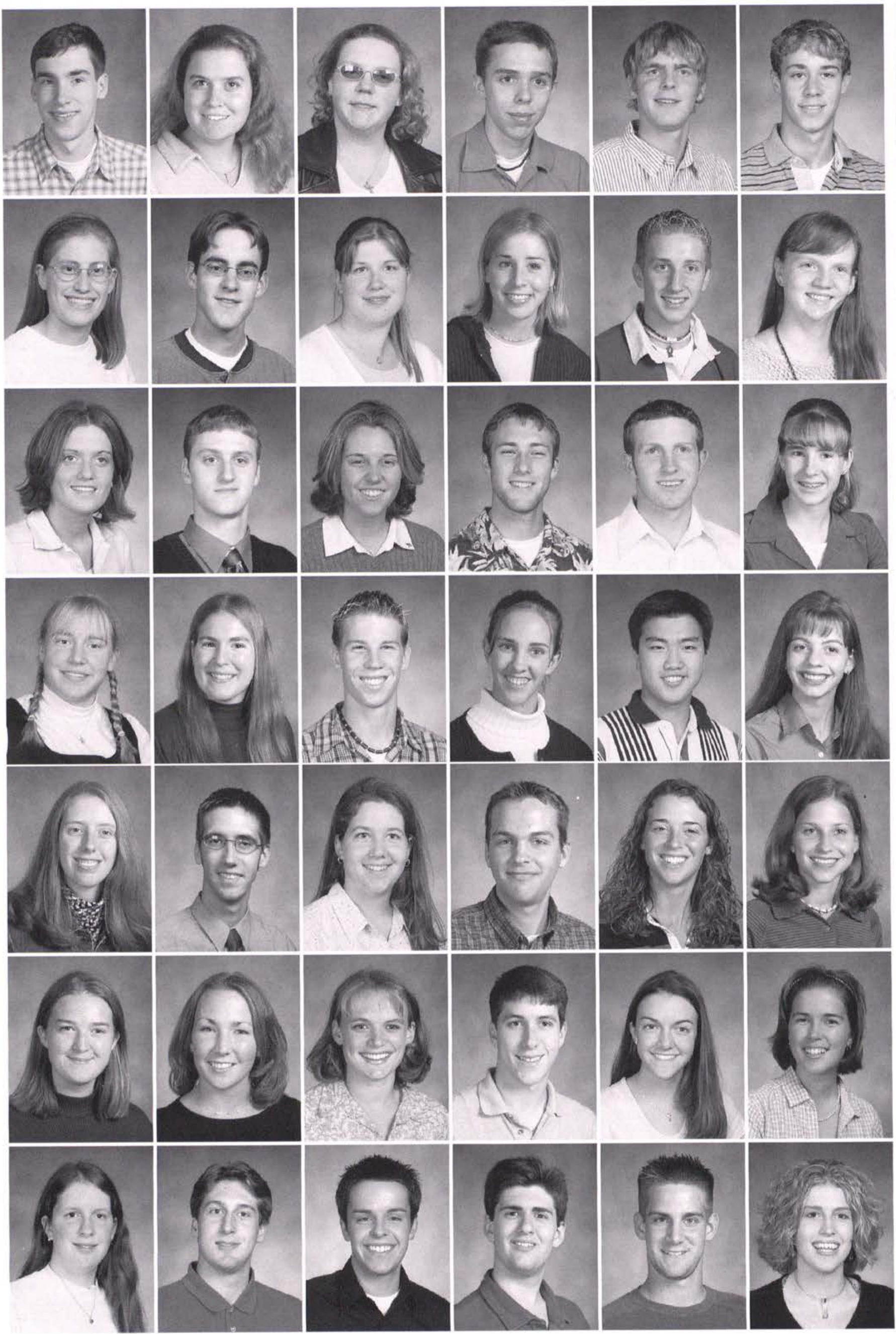


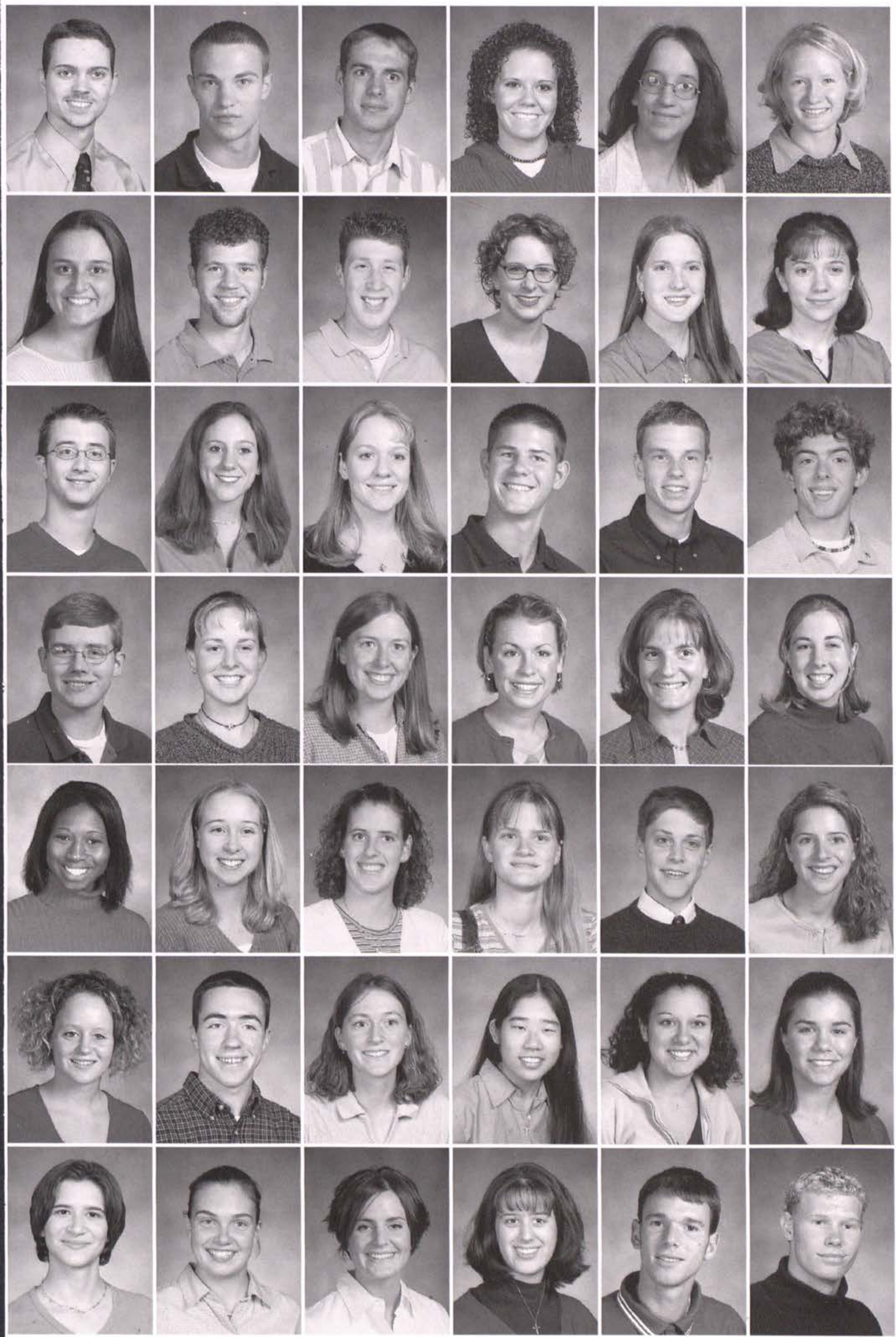

Nathaniel Smith William Smith Ben Snyder Melissa Snyder Jessica Sobonya Katie Sparks

Jessica Spears Matt Spena Nathanael Spencer Gretchen Sproul Rachel Staab Elizabeth Stahl

Shawn Steele Katie Steiner Krista Steingass Jason Stephens Jonathan Stevens Matthew Stevens

Jeff Stevenson Laura Stevenson Emily Stokes Carly Stoltzfus Renell Stoltzfus Anjel Stough

Tiffaney Strickland Sarah Strobridge Crystal Stuckey Ricki Stumpf Matthew Tabbut Mary Taylor

Kylee Teboda Mark Tedford Elizabeth Tegge Beth Thomas Kelly Thomas Christina Thompson

Emily Thompson Julie Thompson Paula Thompson Sara Thompson Timothy Thomson Hank Tippins 
Adam Townsend

Sheri Trennepohl Emily Trevino Ben Trotter

Elizabeth Tucker Philip Tucker

Jennifer Tuttle Joshua Urban Lavinia VanderVen Amanda Van Hooser Valerie Van Wingerden John Viinalass

Daniel Vogel Jessica Waggoner Athan Waldron Joshua Wallace Steve Walters Ashley Walton

Megan Ward Daylyn Warren Tyler Wasson Carrie Weaver Michael Webster Adam Weiss

Sarah Weist Aaron Welty Lisa Wendl Jeff Westlake Julie Westrick Jeremy Wheeler

Kaylene Whitaker Lauren White Susannah White Elizabeth Wickert Joseph Wiles Daniel Wilkins

Ryan Willaman Jennifer Williams Nathan Williams Jeremy Williamson Jennifer Wilson Patty Wilson
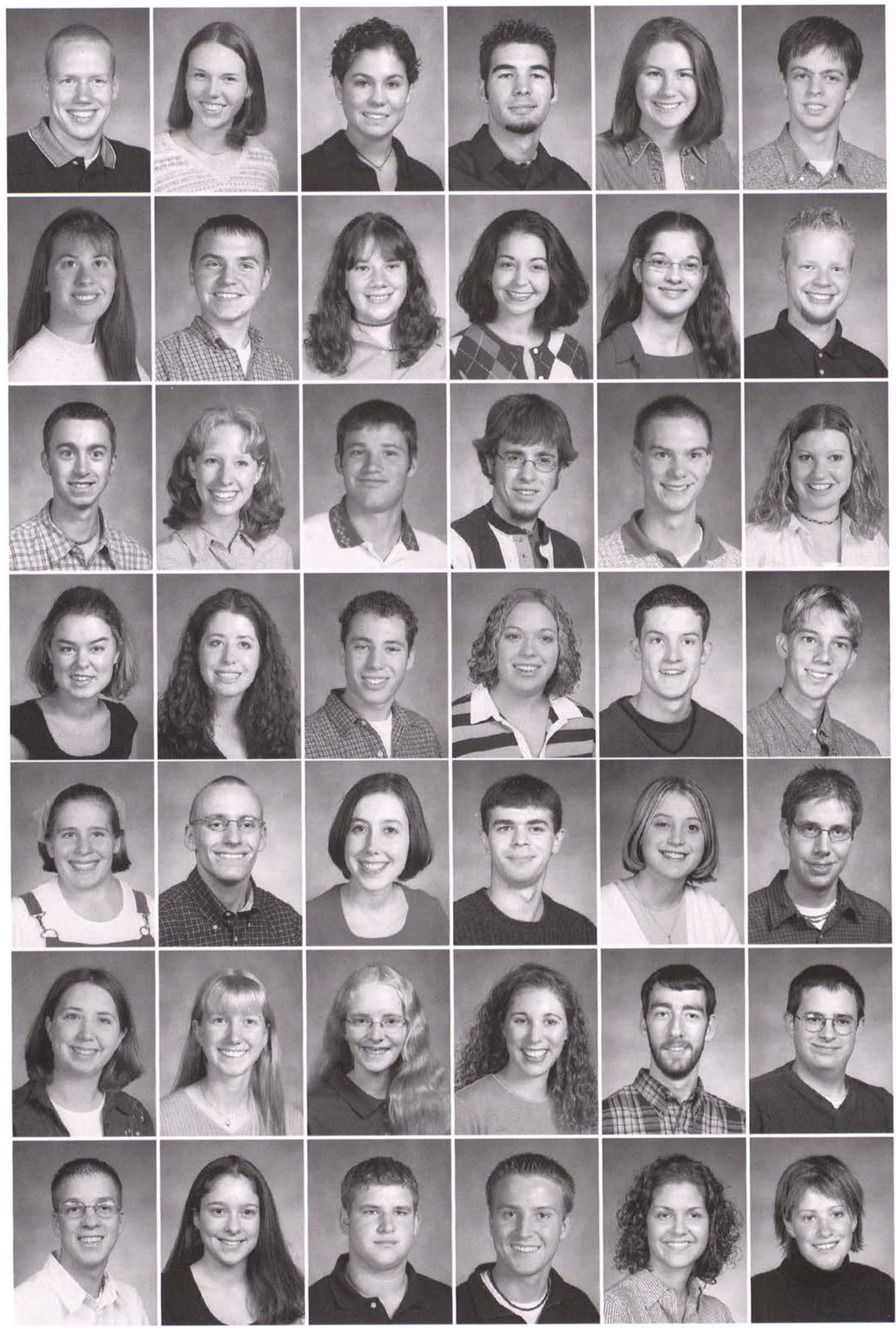

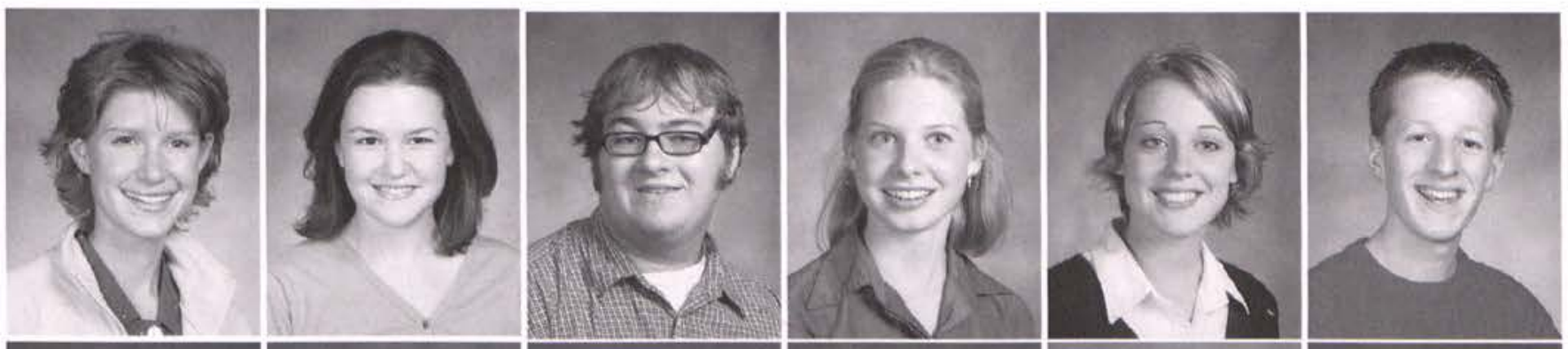

Abigail Winburn

Lacey Wiseman

Daniel Wood

Anna Woodhams

Kelly Woodruff

Joshua Wyse
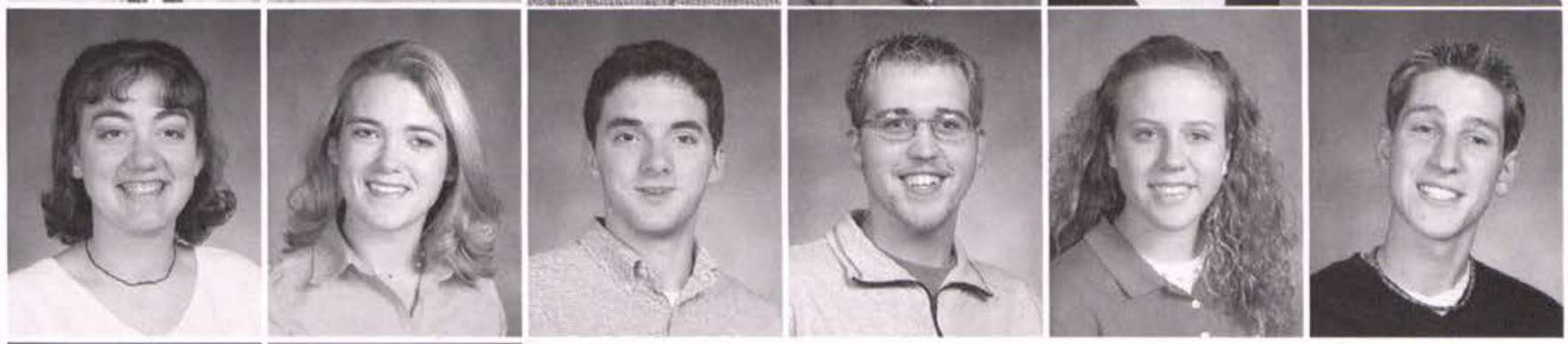

Sara Yackey

Stephanie Yonker

Andrew Young

Jonathan Young

Christie Zimmerman

Justin Zimmerman

Christopher Zitzmann

Mellissa Zurakowski

\section{CLASS OFFIGERS}

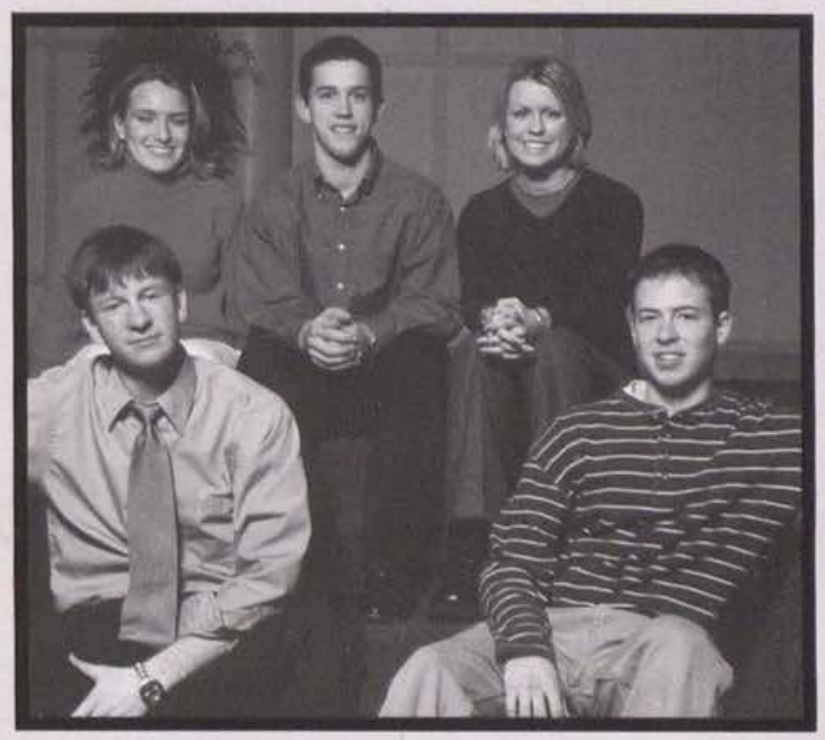

President: Ethan Bolvi (center-back)

Vice-President: Carly Stoltzfus (right-back)

Treasurer: Ian Ellis (left-front)

Secretary: Kristen Banas (left-back)

Chaplain: Dan Rasbach (right-front) 


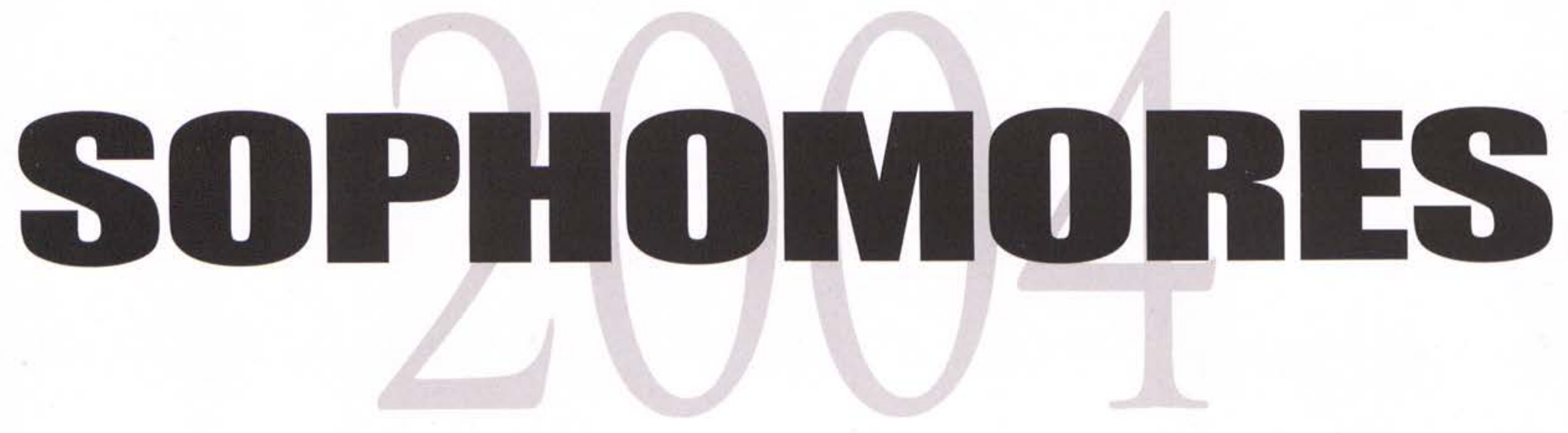

Marcy Abildness Rich Abraham

Robin Acheson

Chris Acorn

Jane Adams

Tana Adams

Teressa Adams Kristen Ahtila

Travis Allen

Rachel Althaus

Jenny Anderson

Jennifer Asbury

Dee Dee Asher

Ryan Atkinson

Philip Attard

Krista Augustine

Anna Avery

Erin Avery

Mark Awabdy

Brock Bahler

Joshua Bailey

Emily Baldwin

Rochelle Bales

Priscilla Band

Stephanie Barron Janine Bartholomew Ivana Batinic' Mary Bauman Marybeth Baustian Lucas Beagle
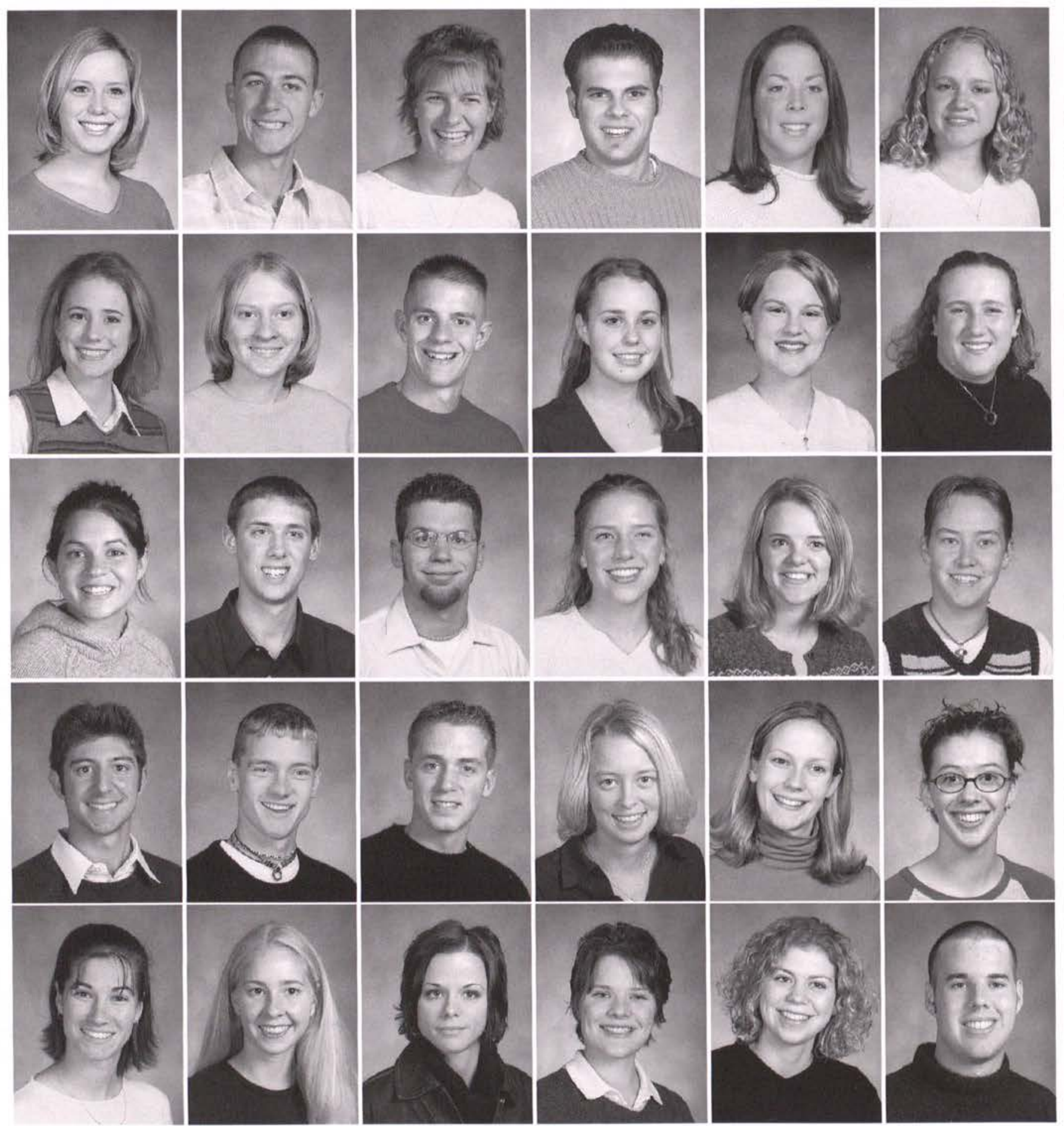
Konnie Caldwell Joshua Call Jeanette Calo Benjamin Carhart Michael Caron Joshua Carter

Jeffrey Cassano Jonathan Cassell Kristen Caudill Melanie Chance Mandy Chandler Kenneth Charpie

Joey Chen Tom Chiavetta Danielle Ciotta Stefanie Clarke Elizabeth Clawson K. Michael Cole

Sarah Coleman Kathy Colgain Jessica Cook Michael Cook Amy Cullip Susan Davis

Evan Day

Rachel DeArmon Jonathan DeHart Erin Delp

Bethany Denton Desiree DePenning

Kathryn Detwiler Rebekah DiazPons David Dice Amy Dickey Michael DiCuirci Matthew Dobbins

Jeremy Doot Kara Doust Patrick Dudenhofer Christen Dudick Ashley Duff Sara Dull
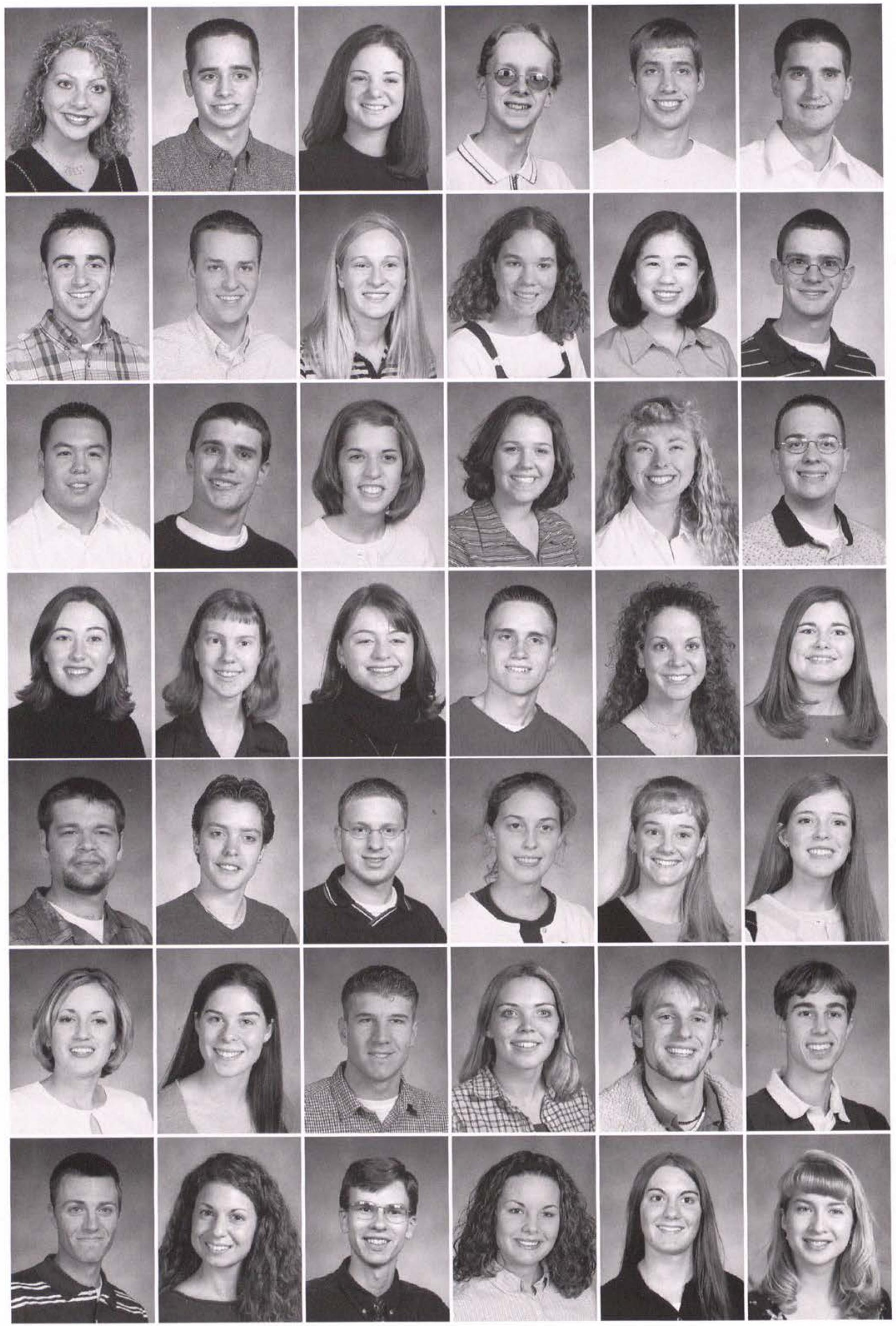
Jonathan Gallagher Ashlee Gallaugher

Andrew Garrett

Anna Gebert

Kirsten Geisel

Emilie Geissler

Deanna Genesi

Matt Gibble

Allyson Gilbert

Ross Gilfillen

Andrea Gillenwater

Eric Gilmore

Kristyn Gledhill Abbey Gochenaur

Rachel Goldston

Jack Gray

Paige Greenwood

Forest Greetham

Rebecca Gross

Miriam Grossman

Sara Gruber

Marigrace Guce

Amanda Guy

Alexandria Gyurik

Elizabeth Hacker

Jennifer Hale

Greg Hamilton

Lizabeth Hamlin

Bonnie Hammond

Justin Handley

cole Hanson

Joel Harris

Kelly Harrison

Amy Harshbarger

Carrie Hartman

Nathan Hay

Kathryn Hayes

Nathan Hedger

Marcie Hefner

J.C. Heiden

Luke Heinz

Stephanie Heldreth
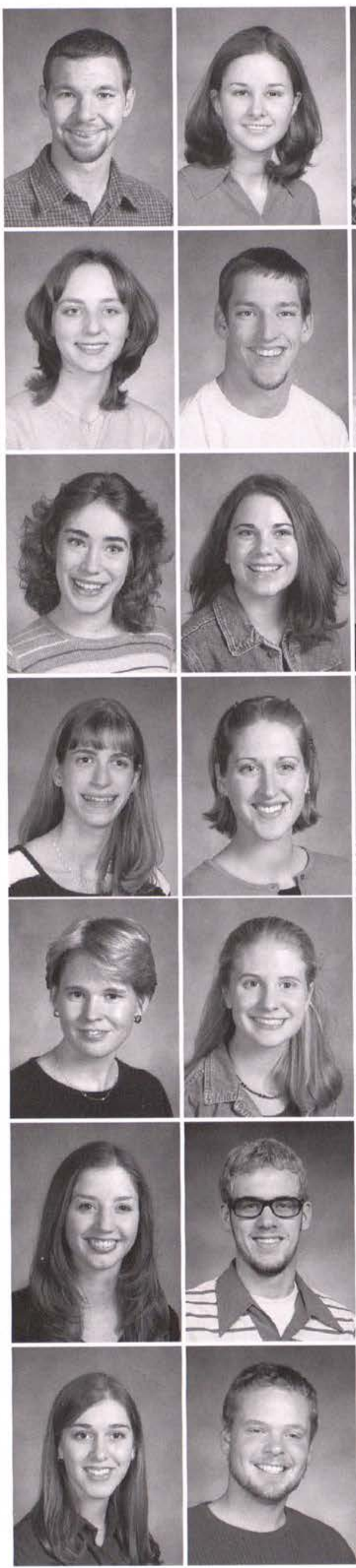
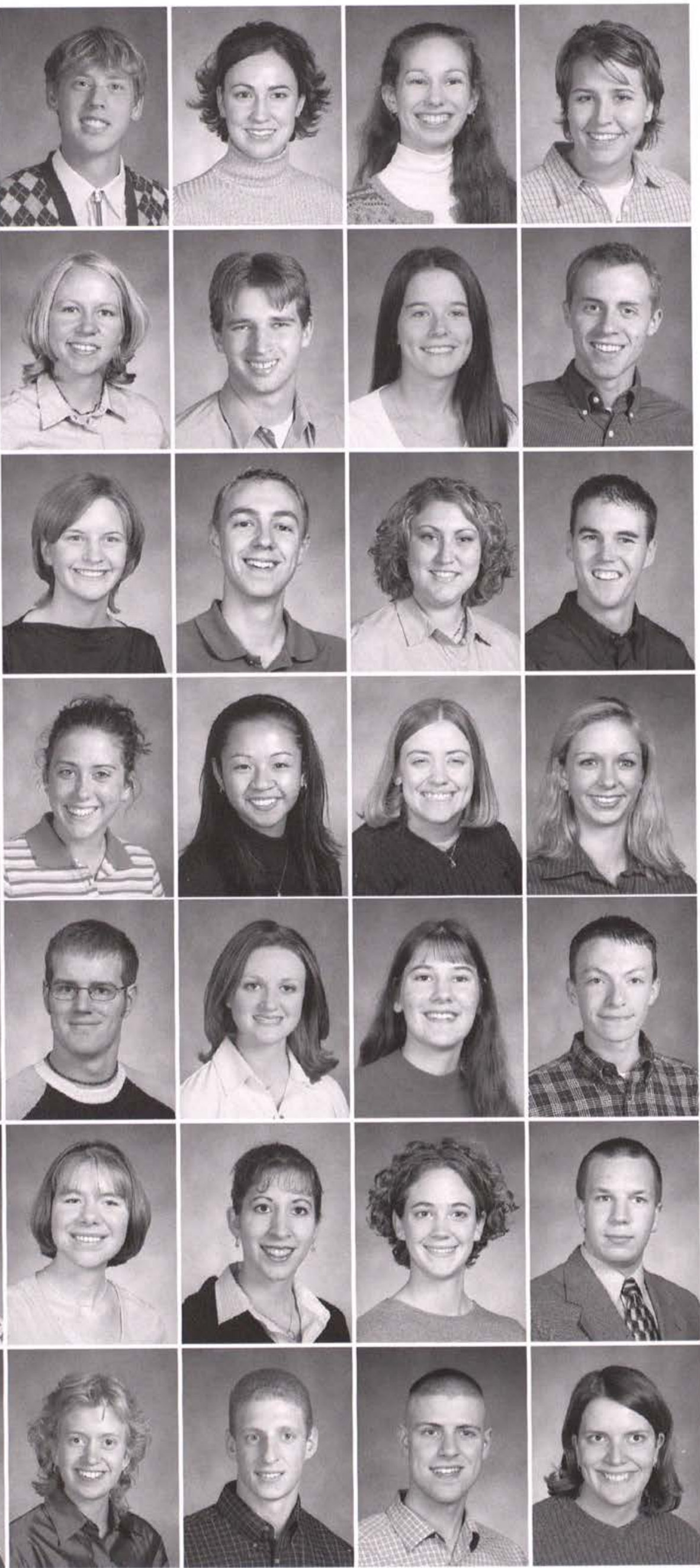
Jennifer Keller Jonathan Kempe Joel Kennard

Daniel Kennedy

Korie Kerber

Kenneth Keslar II

Shannon Keyser Jonas Kibelbek Sara King

Erin Kinnell

Scott Kinniburgh Kelly Kish

Janet Kishpaugh

Rachel Klawer

Doug Klein

Dustin Knoedler Josh Knorr Katharine Kochis

Heather Konop Andrew Koury Aaron Kreider Noelle Kubinec Melanie Kurzen Jeremiah Kwast

Paul Laborde Sara Lambers Shauna Lao Kristen Lapp Rachel Larrabee Kirsten Larson

William Lawler Chuck Lawrence Tasha Lawson Thomas Leach Jesse Leightenheimer Natalie Leitch

Stephanie Lengefeld Monica Lilley Amie Linamen Andrea Link Shannon Little Alison Littrell
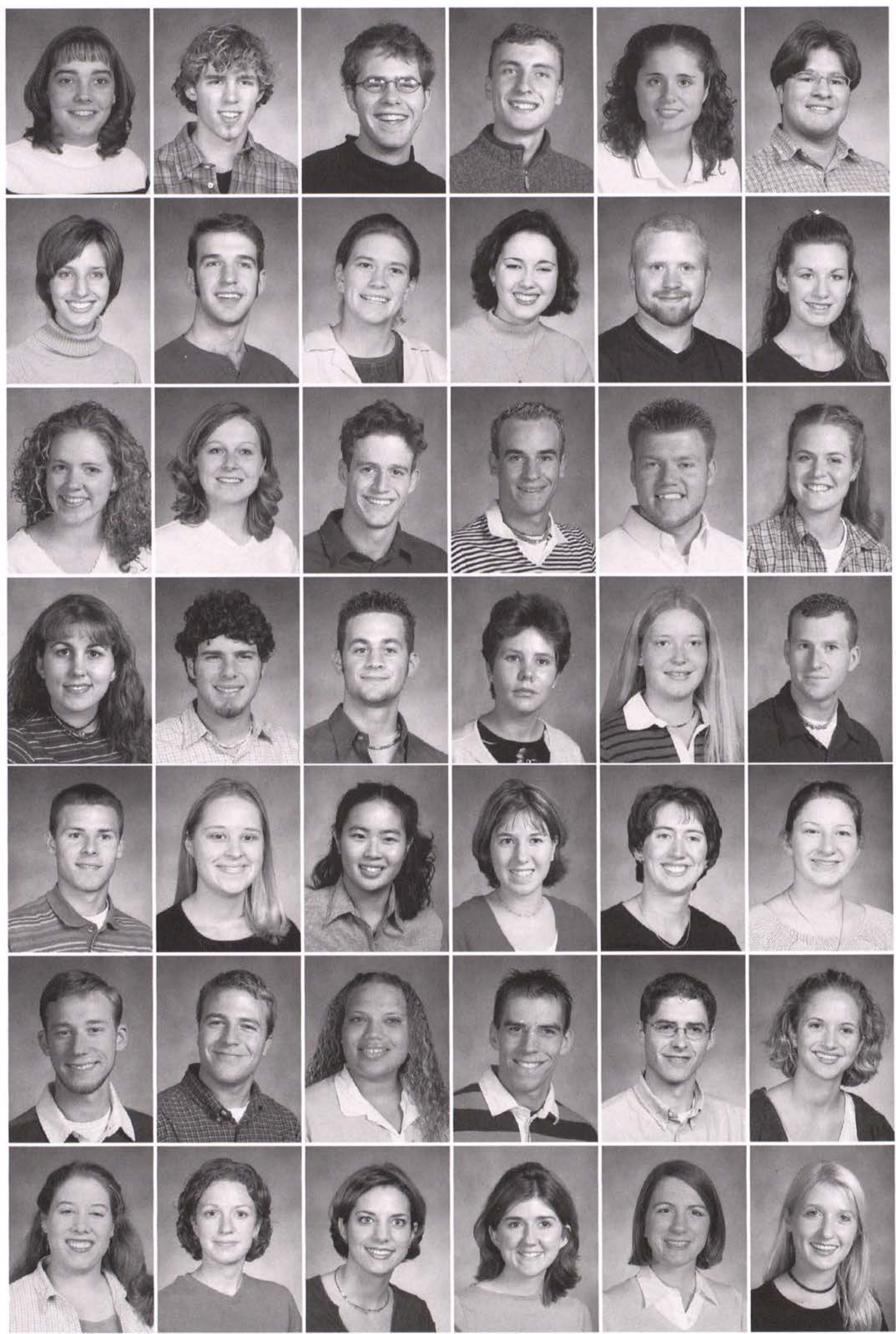
Adam Miller

Brent Miller

Daniel Miller

Julie Miller

Philip Miller

Rebekah Miller

Rebecca Mills

Carole Mings

Chris Minor

Stan Mistak

Jenna Mitchell

Jonathan Mohr

Sam Monroe

Brian Montague

David Moore

Mandy Morrell

Kevin Morris

Leah Morris

Brandon Moses

Karen Mowrer

Kathryn Mowrey

Rachel Moyer

Tracy Mrowca

Jennifer Muka

John Murray

K.C. Myers

Matthew Myers

Teresa Myers

Amanda Nale

Karl Napekoski

Christine Newhard

Dave Nickell

Eric Nielsen

Leah Nielson

Kimberly Nikitin

Josh Nissley

Christina Nofziger

Patrick Noonan

Karin Nyhuis

Stephanie O'Hara

Jonathan Oren

Bethany Painter
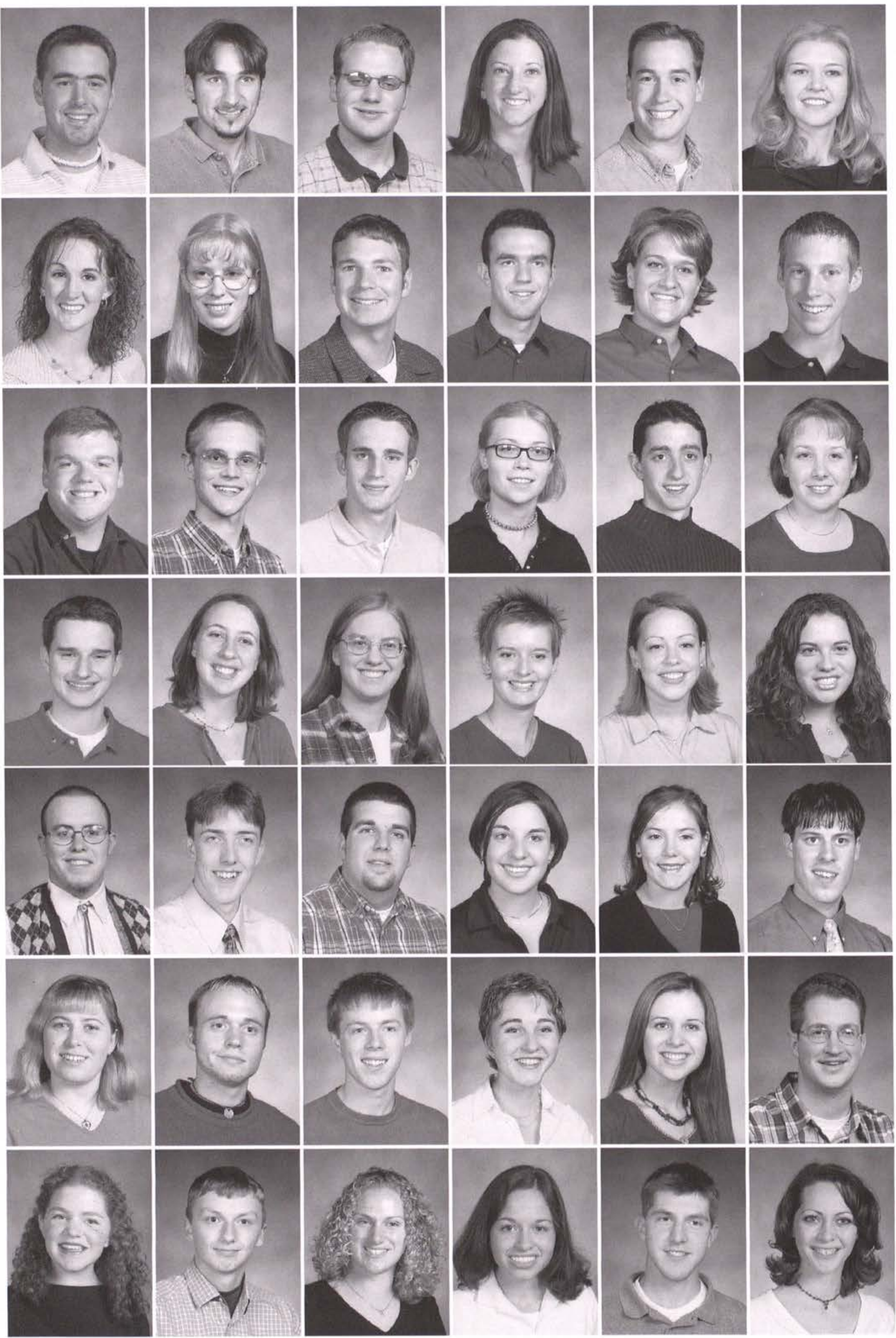
Rachel Roberts

Rachel Robertson

Timothy Rodabaugh

Joshua Rogers

Sarah Rogers

Katie Roggie
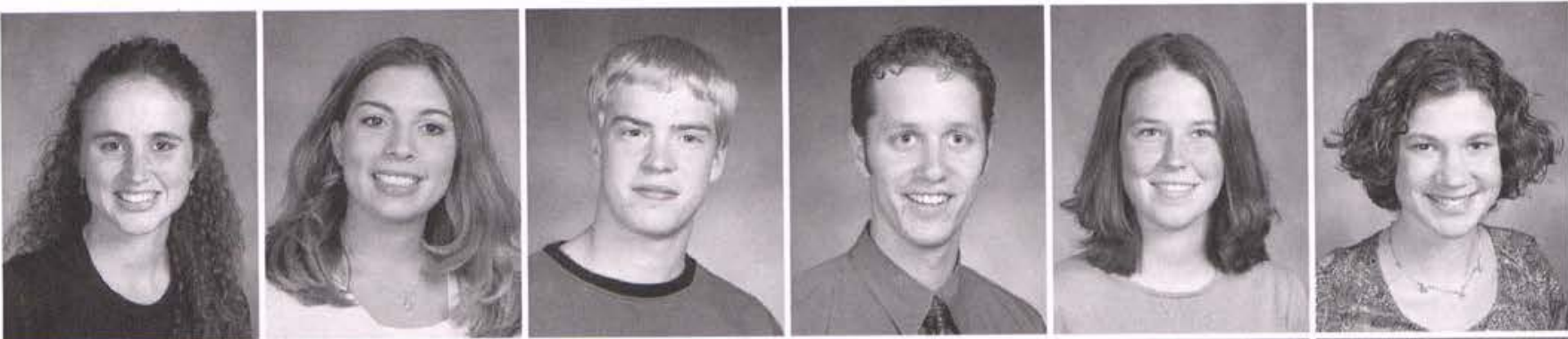

Rachelle Roller

Peter Romaine

David Ross

Mark Ross

Julie Roth

Katherine Roy

Scott Ryan

Nichole Sabine

Amy Salmon

David Sampson

Sarah Sanders

Kristin Sando
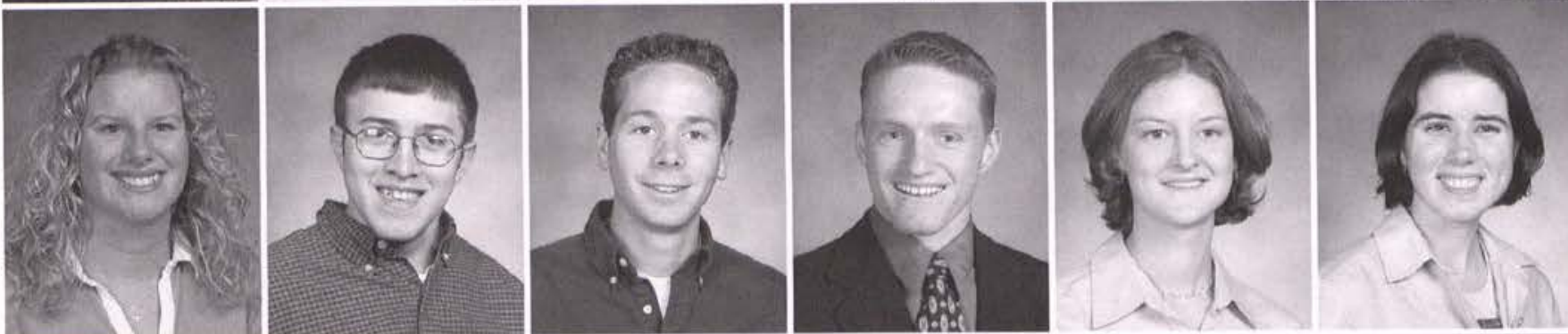

Jessica Sarver

Adella Schanely

Kelly Schriemer

Eric Schroeder

Nathan Schultz

Brent Schumacher
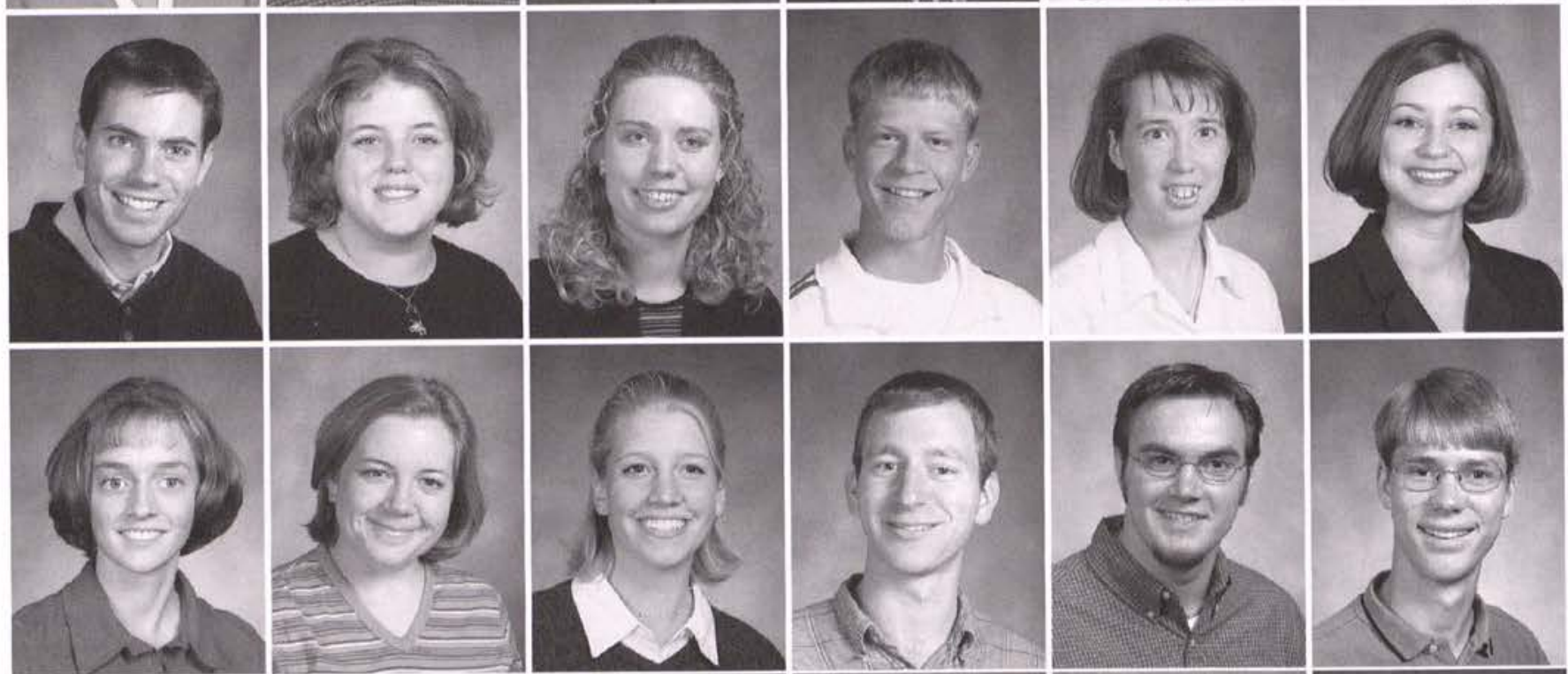

Sarah Scott

Erin Seeloff

Eric Shadle

Rachel Shaver

Kerri Sheldon

Daniel Shellenbarger
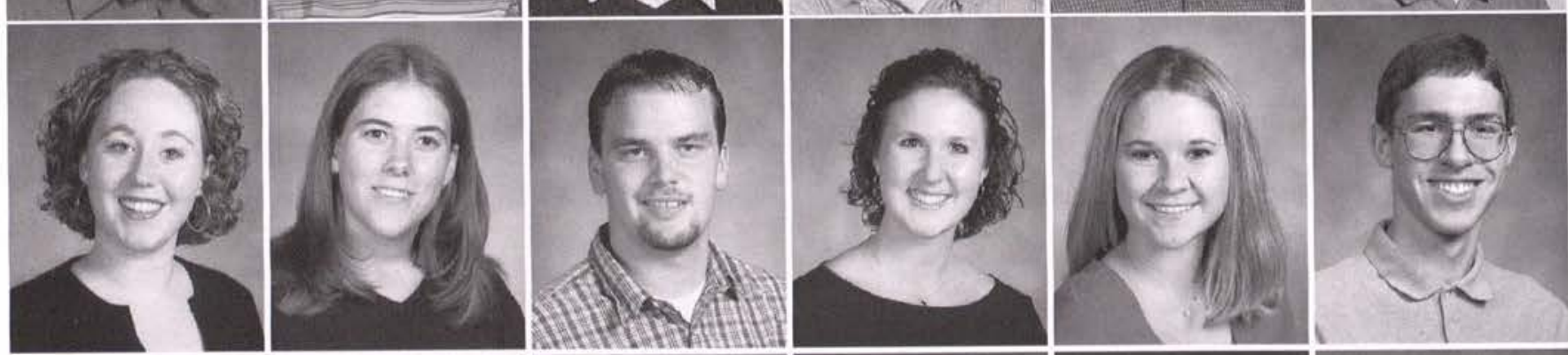

Rachel Shellenbarger

Angela Shuff

Miranda Simmons

Jordan Sipes

Kevin Sisco

Jennifer Skelton
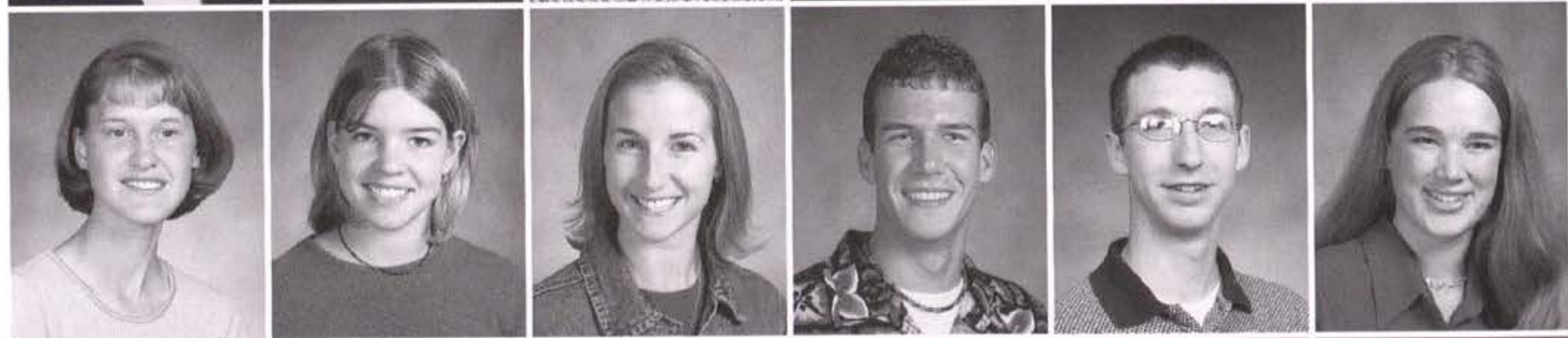

0.J. Skiles

Rachel Slade

Amanda Slagle

Isaac Slone

Andrew W. Smith

Michelle Smith
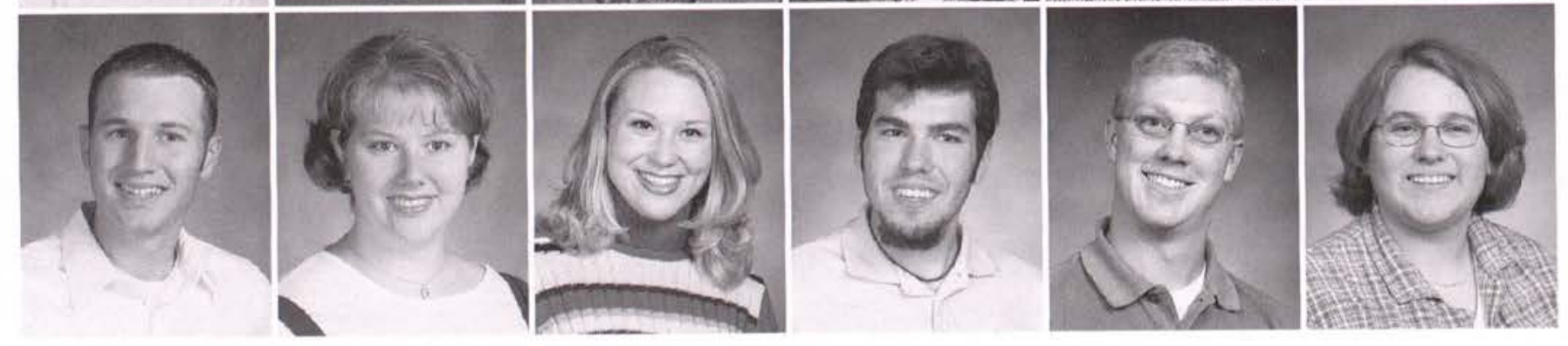


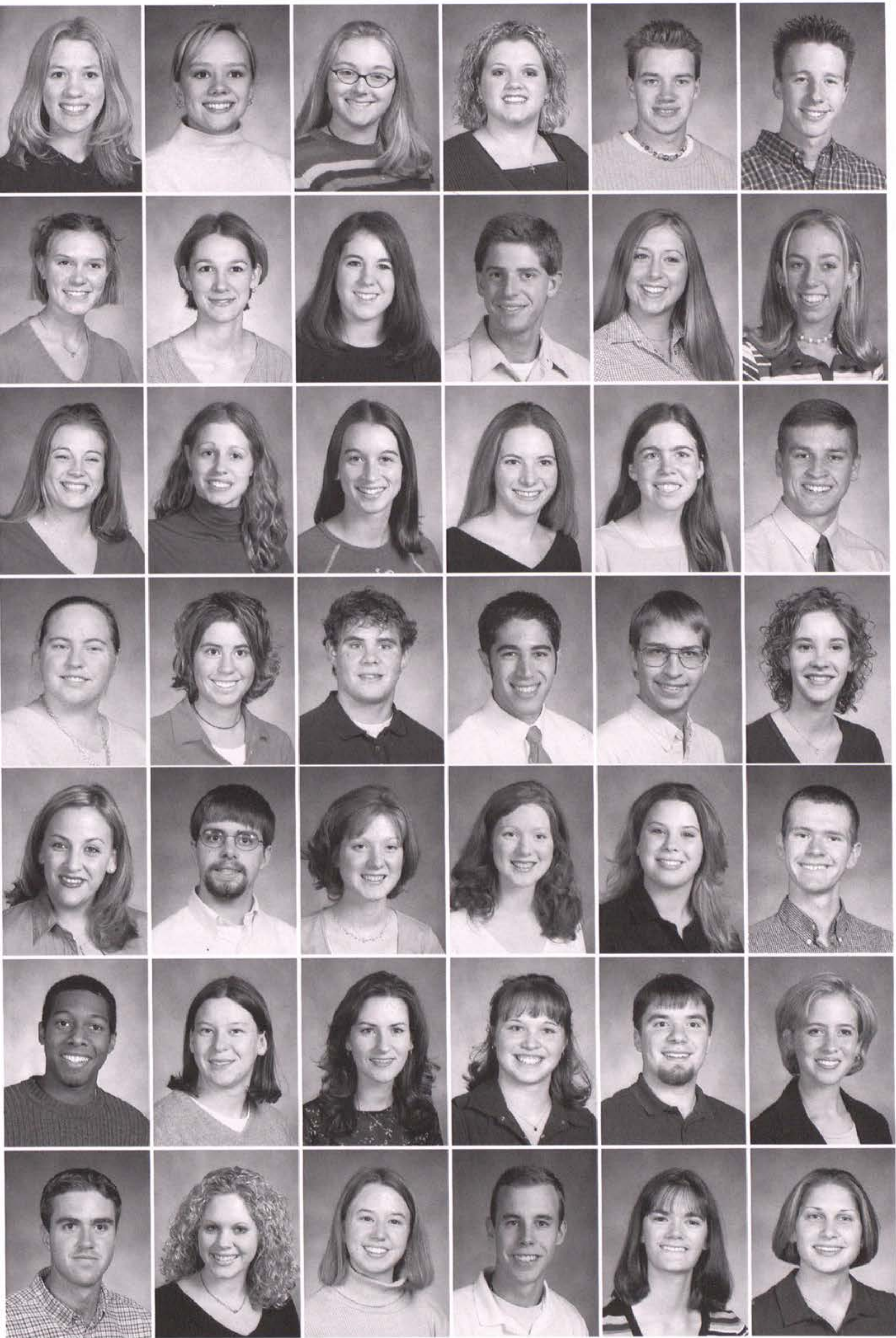

Shawna Smith

Suzanne Smith

Amanda Smithmier

Megan Smyth

Erik Snell

Aaron Snyder

Carrie Sorensen

Amanda Spence

Sarah Spurlock

Jesse St. John

Gaelyn Staab

Annie Stafford

Christa Stanford

Melissa Stark

Julie Stauffer

Shelley Steinmetz

Lauren Stewart

Ben Stickle

Stephanie Stiles

Shannon Stowers

John Stranzin

Matthew Strife

Jonathan Struebel

Jodi Strychalski

Carrie Stuenzi

Eric Sullenberger

Jennifer Sullivan

Julia Sullivan

April Tate

Andrew Tatham

David Taylor

Erin Taylor

Julie Taylor

Laura Taylor

Markis Taylor

Stephanie Taylor

David Terrill

Milinda Tharp

Sarah Thengvall

Brendan Thomas

Jennifer Thompson

Melissa Thompson 
Andrew Tidwell Candace Townsend Matthew Toyer Nicole Tracy

Zachary Trimble Erin Tubbs

Tim VandeKopple Stephanie Vanderhoof Andy Van Valkenburg Mikala Varney Amber Vawser Nathan Vitatoe

Daniel Volpe Bryan Wagner Melissa Wagner Rebekah Wagner Matthew Wailes Nathan Walden

Jon Waldo Kristin Waligorski Michael Walker Jessica Wallace Rob Wallace Ben Walsh Charissa Warsavage

Jason Weakley Cassie Weaver Elizabeth Weaver Christine Webber

Nate Weir

Traci Weiss

Seth Wiebe

Katy Wiggers Jeremiah Wikler David Williams

Jason Williams Leslie Williams Melissa Williams Anne Wilson Kelly Wilson Steven Wires
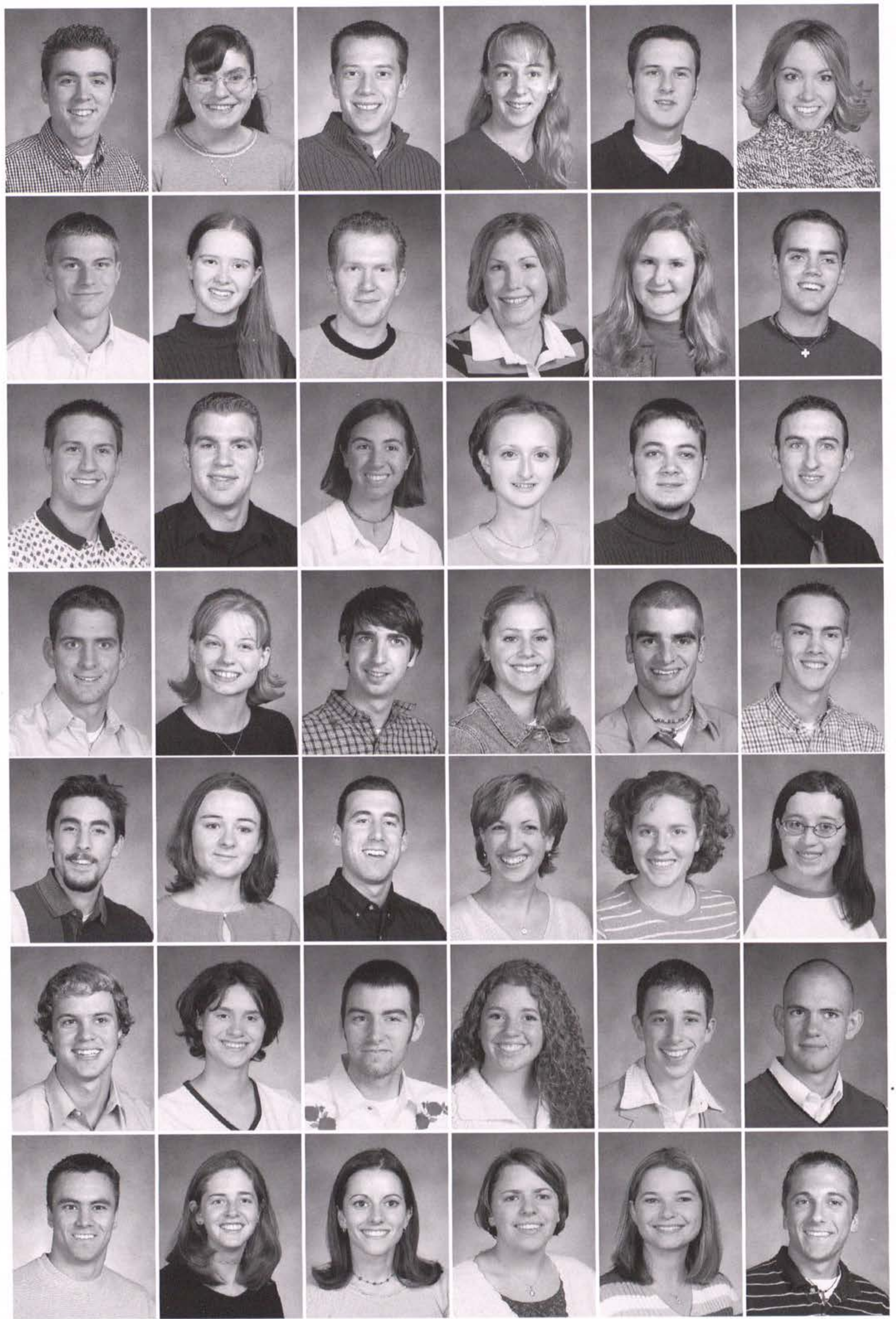

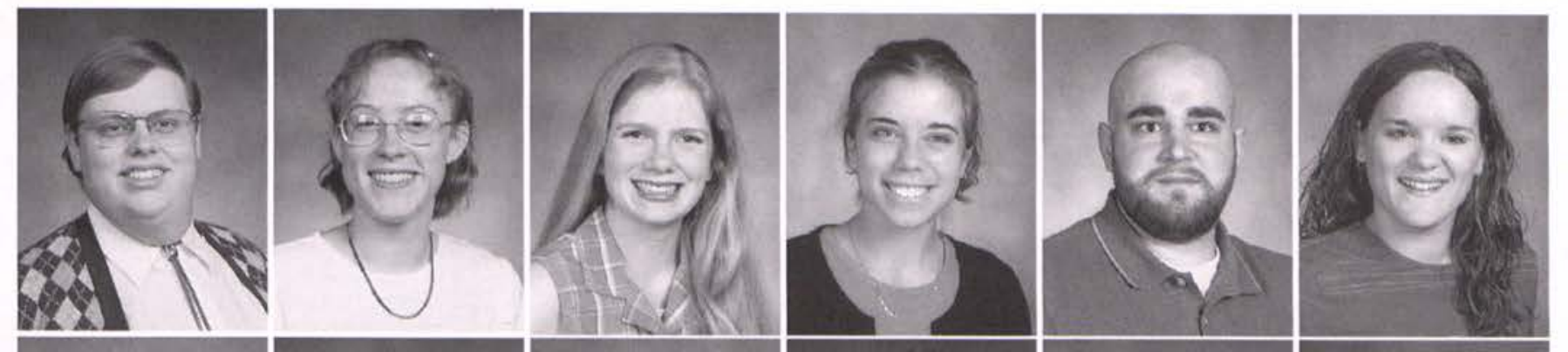

James Wolfe

Stephanie Wood Jennifer Wooldridge Bethany Wright James Yahara Marcia Yamarino
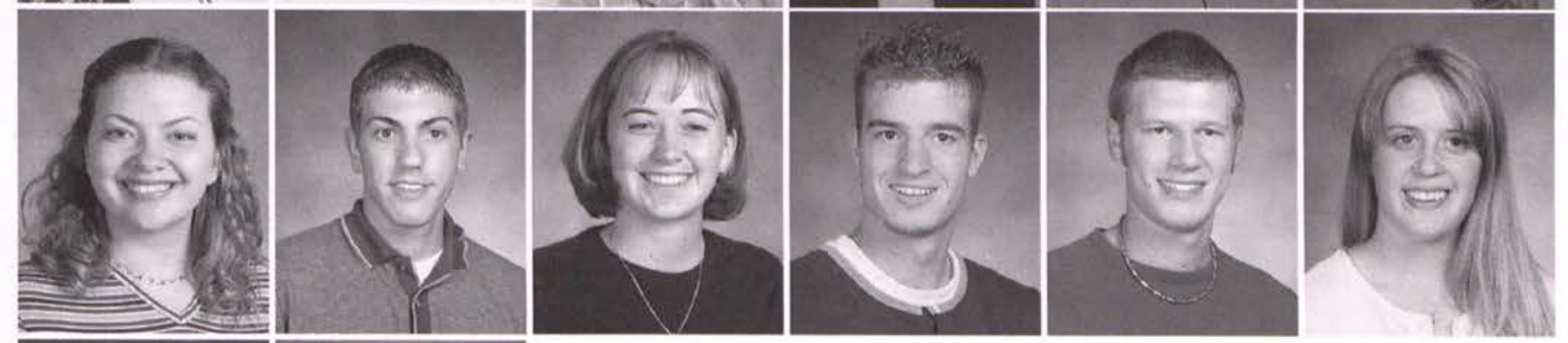

Erin Yarnell Mark Yorgey

Ruth Young Joshua Zarrilli Justin Zenn Amy Zeppenfeld

Carrie Ziegenfuss

Jill Zwyghuizen

\section{GLASS OFFICERS}

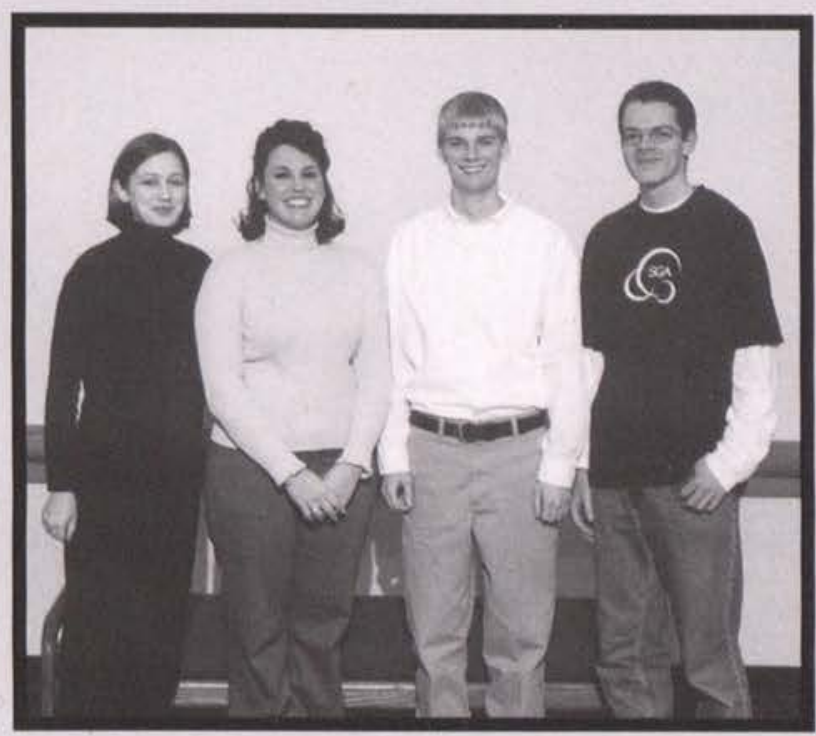

President: Tyson Herald (third)

Vice-President: Kristin Sando (first)

Treasurer: Gertjan Flikweert (fourth)

Secretary: Rachel Mahl (second)

Chaplain: Dony Mathias (not pictured) 


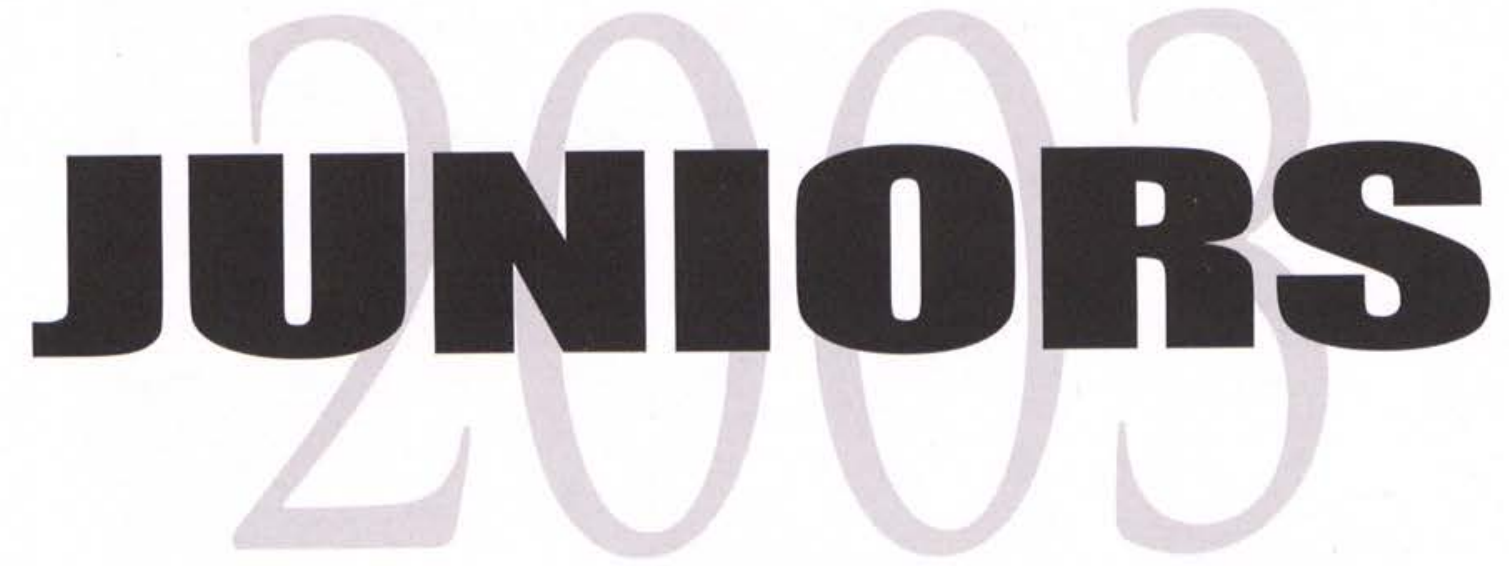

Jacob Abbs

Tim Abernathy

Mark Acker

Jillian Adams

Heather Albertson

Brenda Allen

Summer Allison Blair Anderson Desiree Anderson

Greg Anderson Jill Andras

Sarah Arnstein

Christina Babcock Eric Babson Laura Bailey Timothy Bailey Anelise Baits Krista Baker

Margaret Bales Hannah Ballou Adam Barger Rebecca Barr Adam Bartlett Chris Bartlett

David Bates Ryan Battaglia Deborah Baxter Rachel Beach Althea Beachy Kristi Beckett
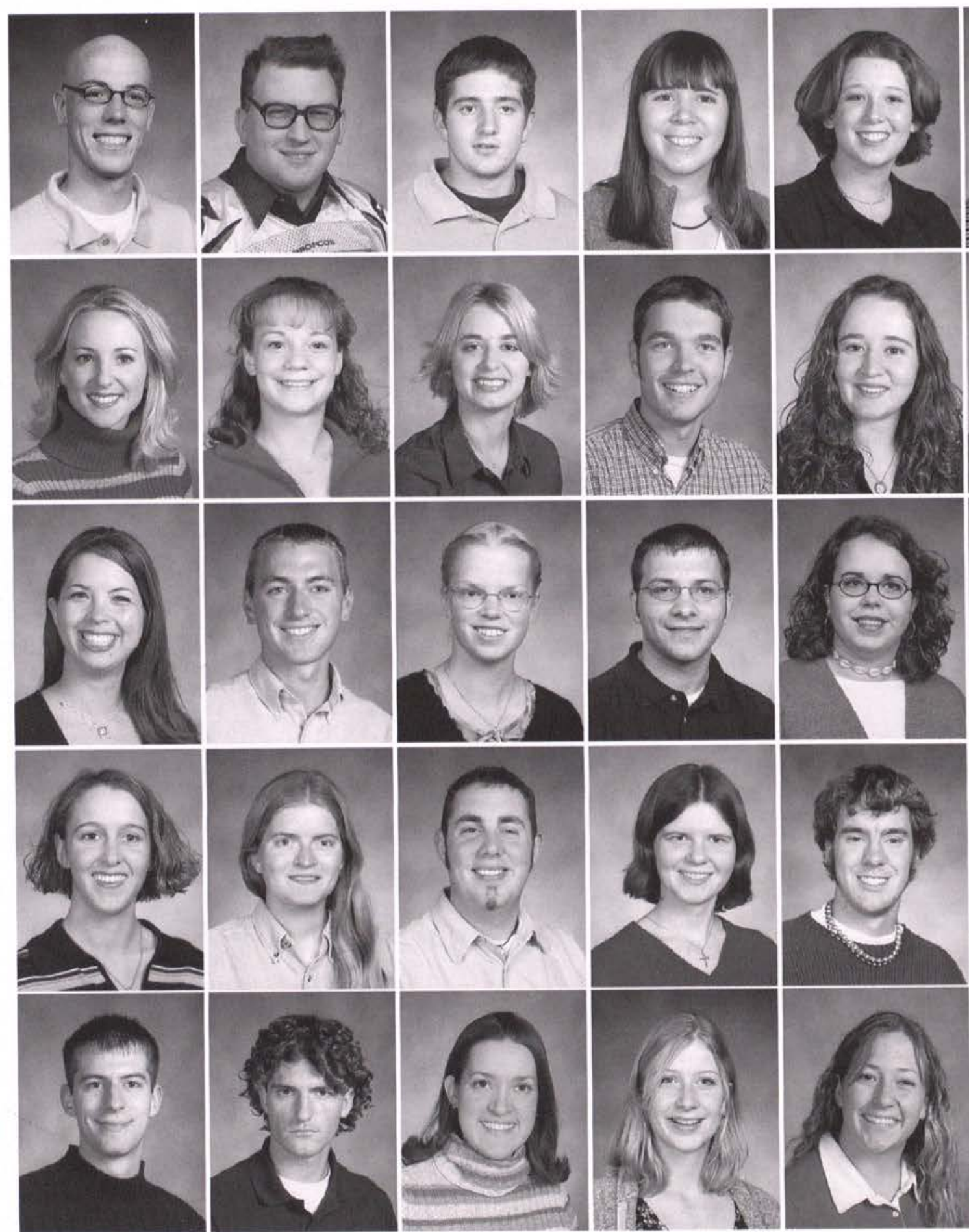
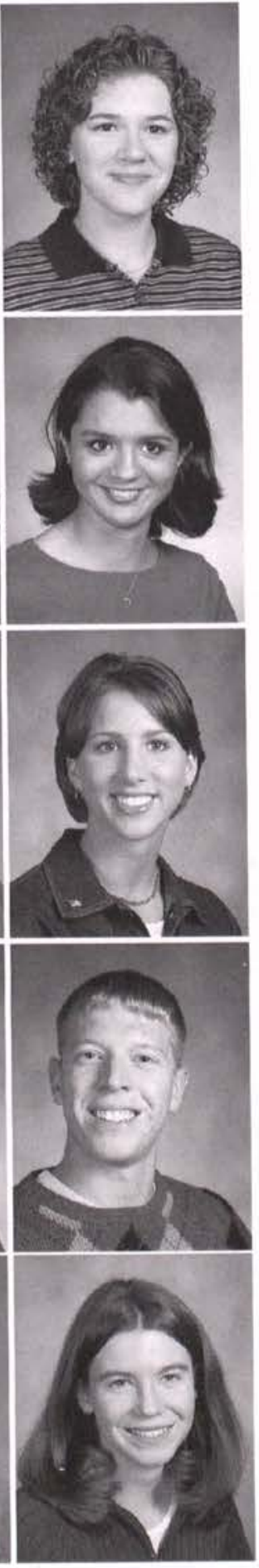

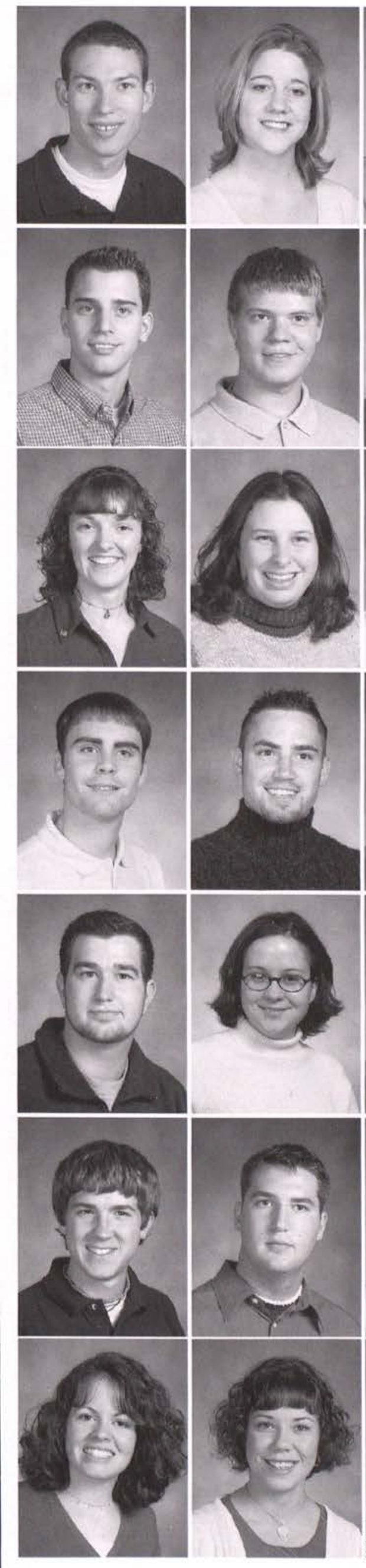
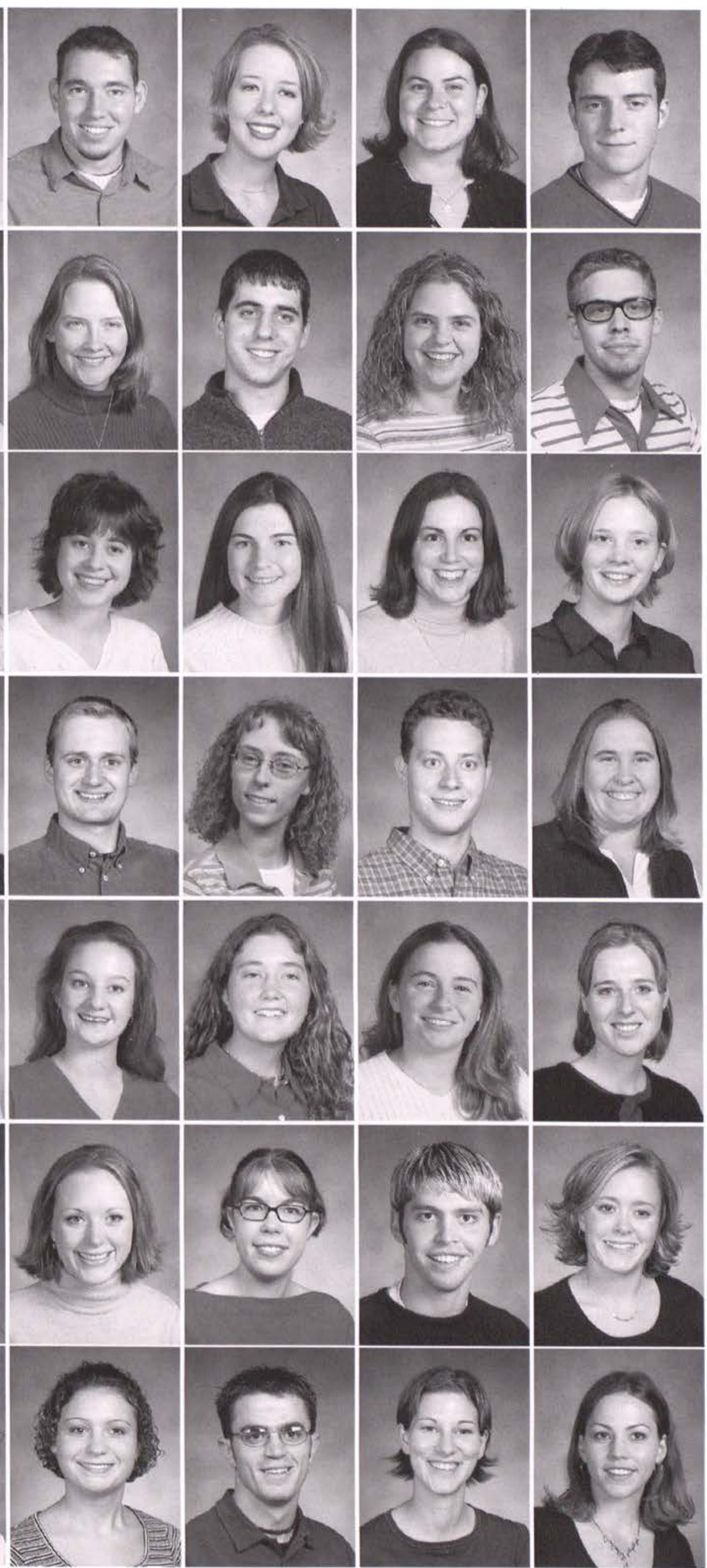

Nathan Bell

Janelle Bender

David Beres

Kelly Bernhard

Deborah Berruti

Douglas Bierer

G. Corey Bigelow

Matt Bigelow

Gretchen Bigley

Chad Billsby

Rebecca Birchfield

David Black

Michele Blalock

Meagan Bledsoe

Allison Blosser

Bethany Bockmann

Sarah Boillat

Jennifer Bonham

Nathan Boone

Benjamin Borich

Kevin Borries

Megan Borton

Henry Bouma

Kimberly Bower

Jack Bowers

Shelley Bowers

Lisa Bowman

Natasha Boyce

Miriah Brammer

Kay Brewer

Richard Brewer

Daniel Brewin

Megan Brewster

Jeanette Brogan

Joshua Bromer

Abigail Brown

Beth Brown

Charlianne Brown

Emily Brown

Jonathan Brown

Susan Brown

Suzanne Brownlee 
Stephen Bruckart

Alan Bruder

Ty Brumback

Matthew Buehler

Beth Bunchkowski

Erika Bunger

Carrie Burke

Joseph Burke

Kara Burks

Thomas Burleigh

Lindsay Burman

Benjamin Burnet

ulie Burt

Stephanie Candler

Joshua Canfield

Becca Carl

Michael Carlo

Ric Carter

ori Carveth

Travis Casper

Robert Chestnut

Genoveva Chipe

Jennifer Chmielewski

Rebecca Christenson

Julia Christner

Kristen Claeys

Jon Clark

Casey Claypool

Michael Coffey

Christina Colarossi

Adria Combs

Debbie Compton

Hannah Cooper

David Corder

Charles Corrick

Michael Cosgrove

Rhoda Coulson

Courtney Cox

Tim Cox

Adam Craig

Barrett Craig

Kevin Craig
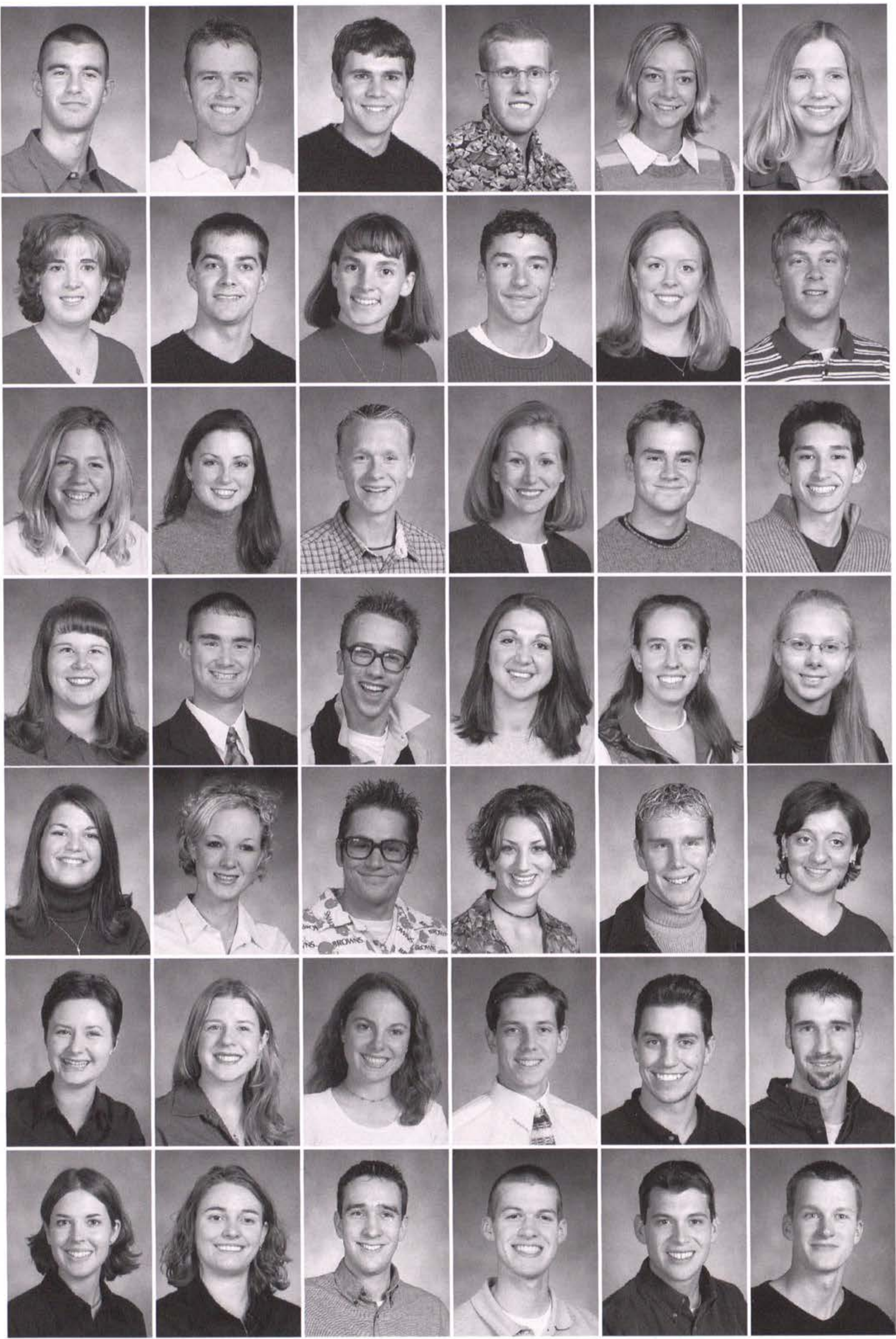

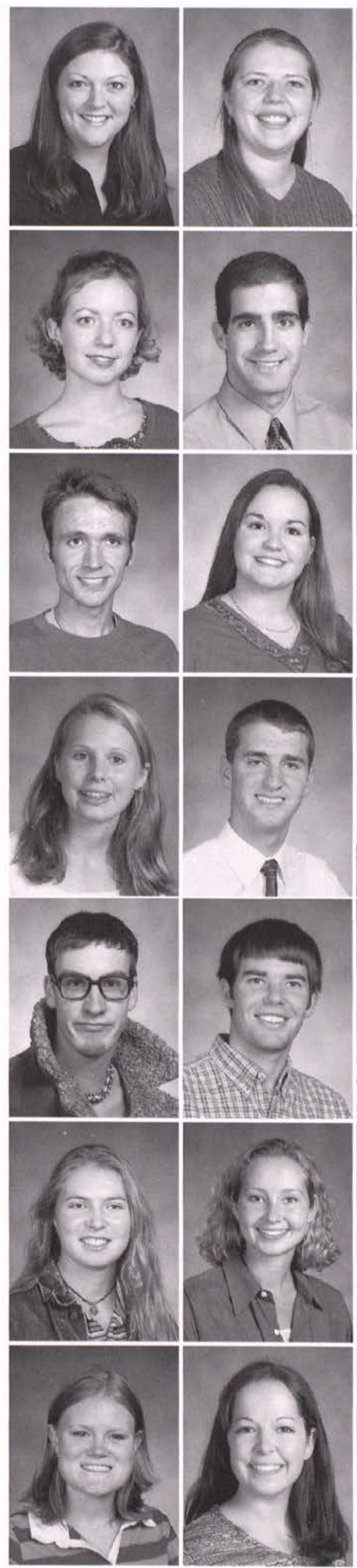
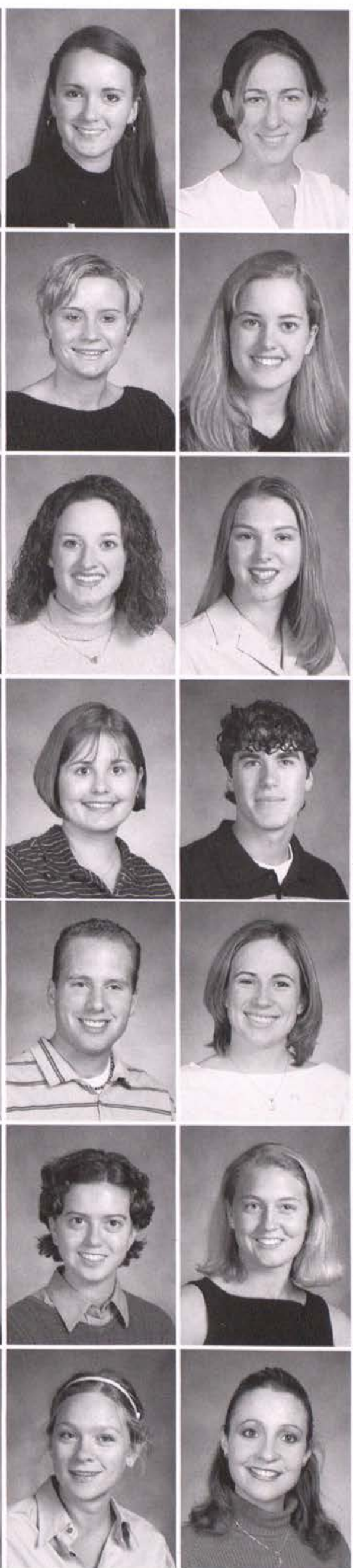
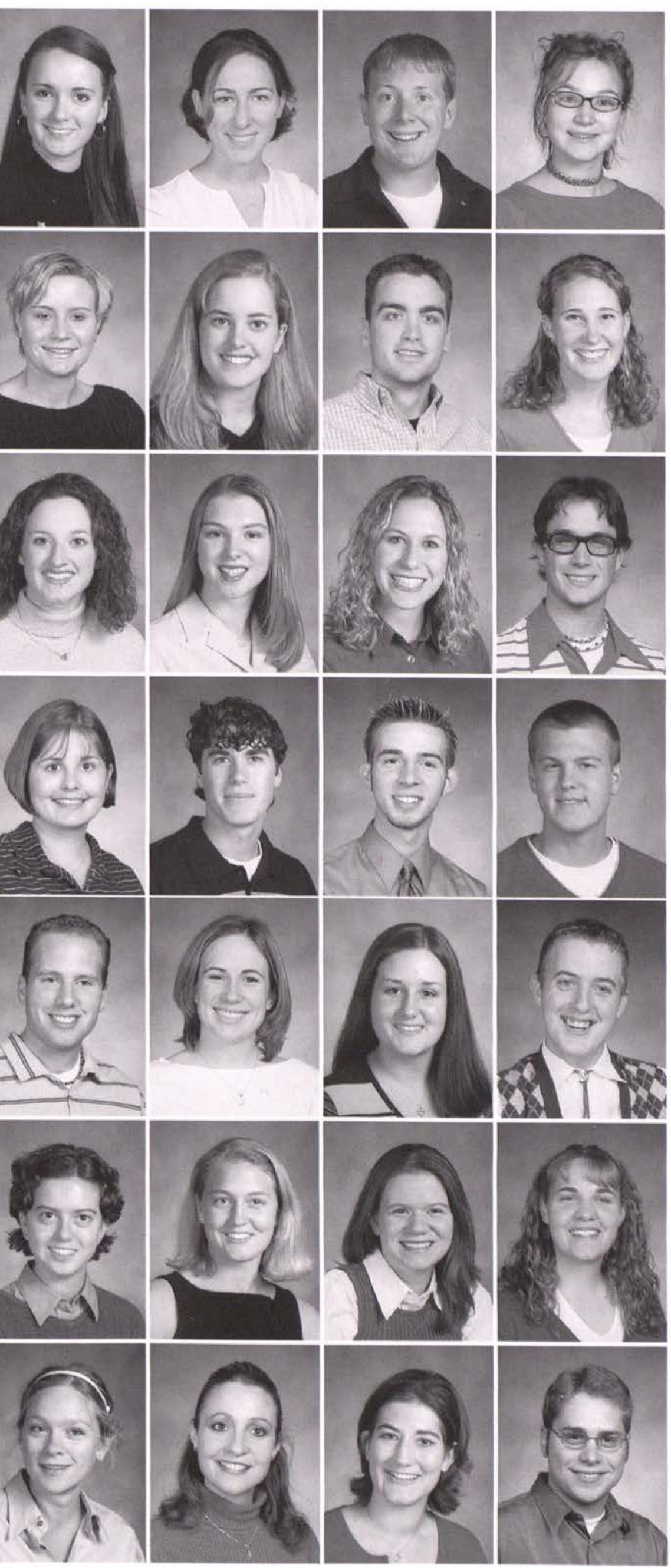

Janelle Criner

Emily Cronbaugh

Casandra Crosby

Theresa Crunelle

Ryan Culpepper

Lisa Culver

Adria Curts

Michael Daiello

Sarah Daniels

Linda Dannemiller

Jonathan Davies

Kate Davies

Aaron Davis

Jennifer Davis

Kara Davis

Elizabeth Debrason

Becky DeGarmo

Daniel DeHaan

Julia DeHart

Brian Dennert

Kristen Detwiler

Jacob Dickinson

Daniel Dieringer

Jeff Diggle

Eric Dolby

Kevin Dougherty

David Dudick

Elizabeth Dudick

Amanda Dunn

Matthew Dunn

Jessica Dunning

Elissa Dvorak

Kari Sue Eaves

Callie Edgington

Kimberly Edlund

Heather Eger

Susan Eggebeen

Katie Eicholz

Shae Elam

Tamara Ellington

Cheryl Elliott

Jason Elwell 
Greg England Amy Estes Joel Estes Joel Estes Jonathan Estes Mary Evans

Heidi Everett Lynsey Fabian Steve Faley Andrew Fallnutz Bethany Farley Jonathan Farrell

Kristin Felts Joshua Fenton April Fincham Kari Finlay Lena Fischer David Fisher

Josh Fisher Beth Flatt Amanda Flenar Gertjan Flikweert Ryan Flunker Jason Forni

Andrew Fortener Aaron Fourman Andrea Franka Aaron Franke Brent Frazier Chris Freeman

Melissa Friesen Sarah Frohmberg Ben Futoran Joellen Galbreath Monica Gallagher William Gardner

Emily Gayer Allen Gehring Josh Geppelt Kyle Gerber Angela Gidley Tim Gilmour
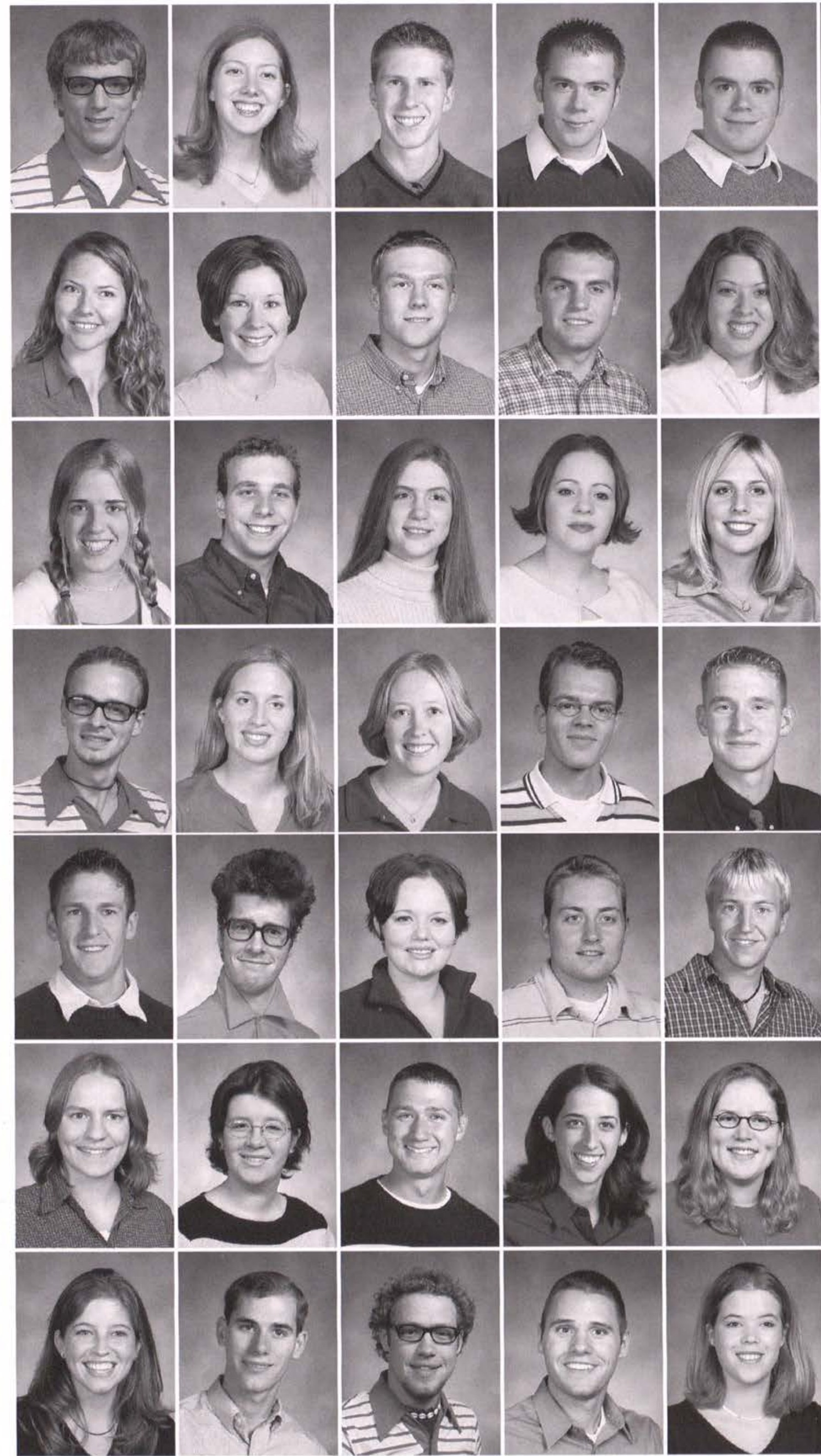
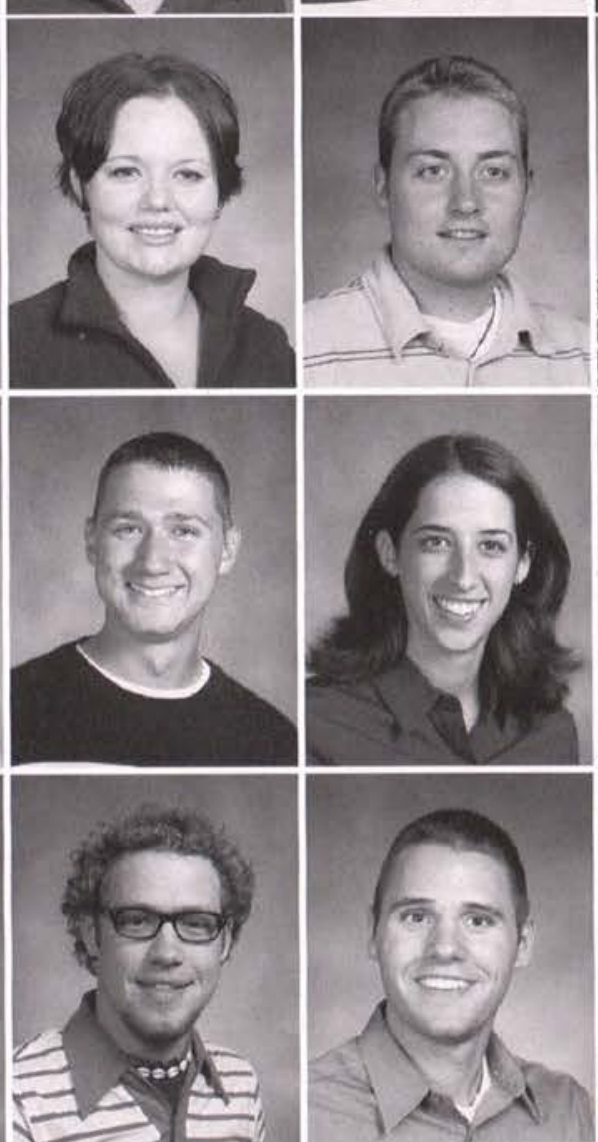

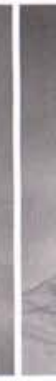

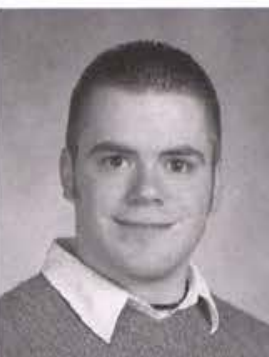
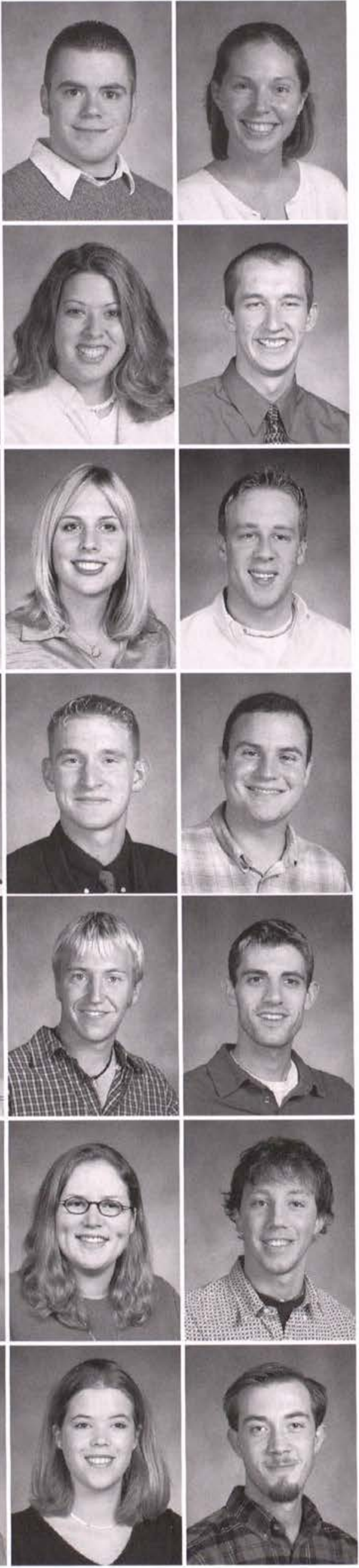


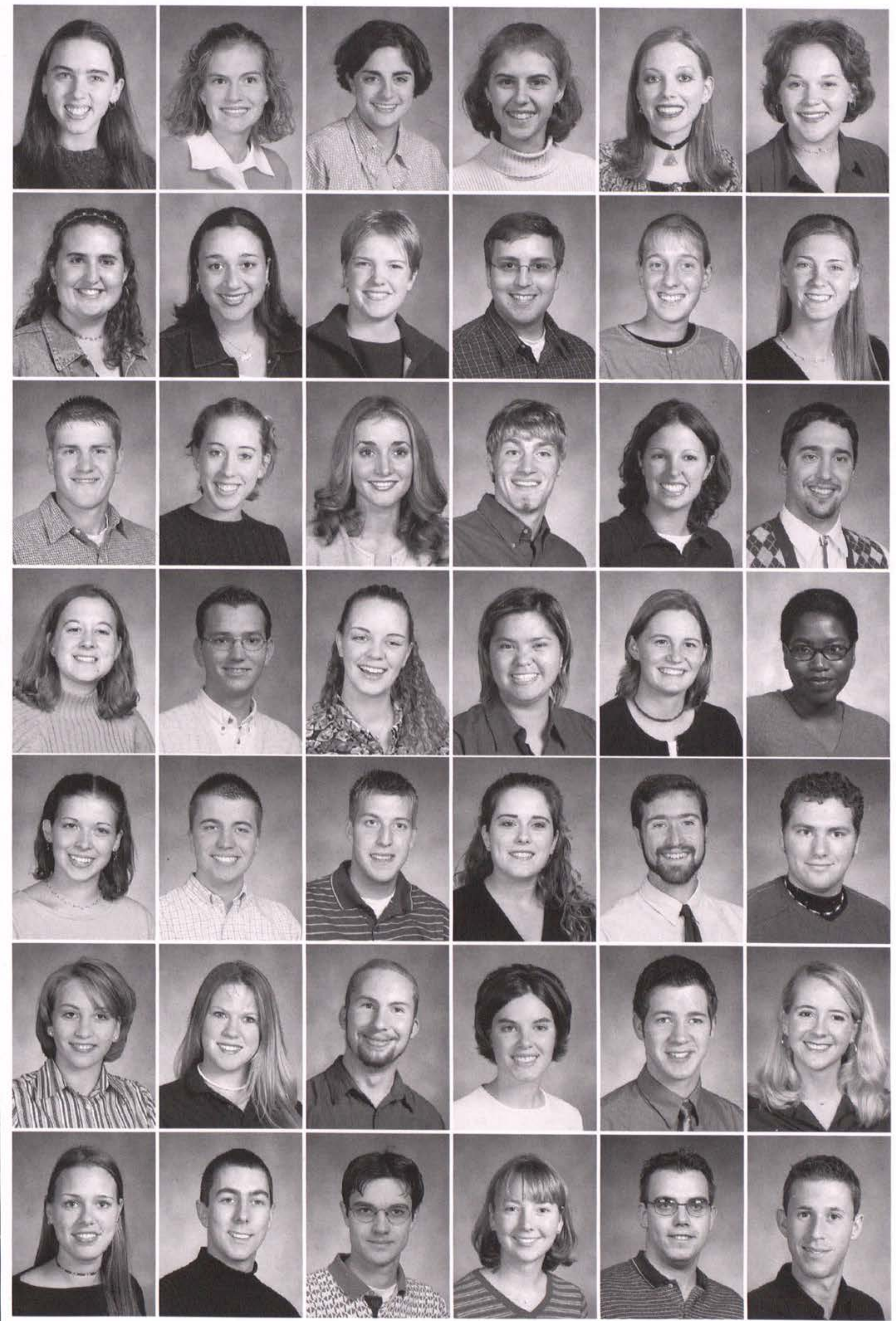

Michalina Gluchowski

Glori Goheen

Leah Gombis

Elizabeth Gowdy

Crystal Gowing

Tiffany Grace

Janna Graham

Melissa Greco

Andrea Greening

Richard Gregory

Andrea Grigorenko

Sarah Grimme

Timothy L. Groff

Megan Grove

Rachel Halleland

Caleb Halulko

Rachel Hamilton

Aaron Handley

Shelley Hansen

Benjamin Harreld

Amy Jo Harris

Diana Harris

Amy Harrison

Marilyn Harrison

Rebecca Hart

Brian Hartsell

Dan Hasty

Victoria Haverlock

Andrew Hayes

Jason Headlee

Cara Hedges

Carrie Heimann

A. Jesse Heinsen

Leah Hendricks

Christopher Hennig

Mandy Herd

Christy Herman

Travis Hermann

Matthew Herring

Julia Hilbish

Michael Hill

Peter Hochstaetter 
Kim Hodge Nathan Hoffman Chad Hofstetter Jason Hohertz Sarah Hoke Carri Holm

Aaron Hoober Jesse Hornback Lara Hourani

David Huber Amber Hughes Katy Hult

Jonathan Hunsberger Jessica Hunt Alia Hunter Alisha Hunter

Brian Huster Samuel Hutchins

Joshua Hynes Abby Iden Amber Isbell David Iverson Katie Jackson Laura Jaeger

Mark Jaskilka Dani Jenks Jessica Jenks Ben Johnson Chad Johnson Jessica Johnson

Joshua Johnson Matthew Johnson Whitney Johnson Laura Jolly Jonathan Kane Paul Karlberg

Dorothy Kee Sean Kelley Naomi Kerns Michael Kibbe Nathan Kibelbek Kevin Kickbusch
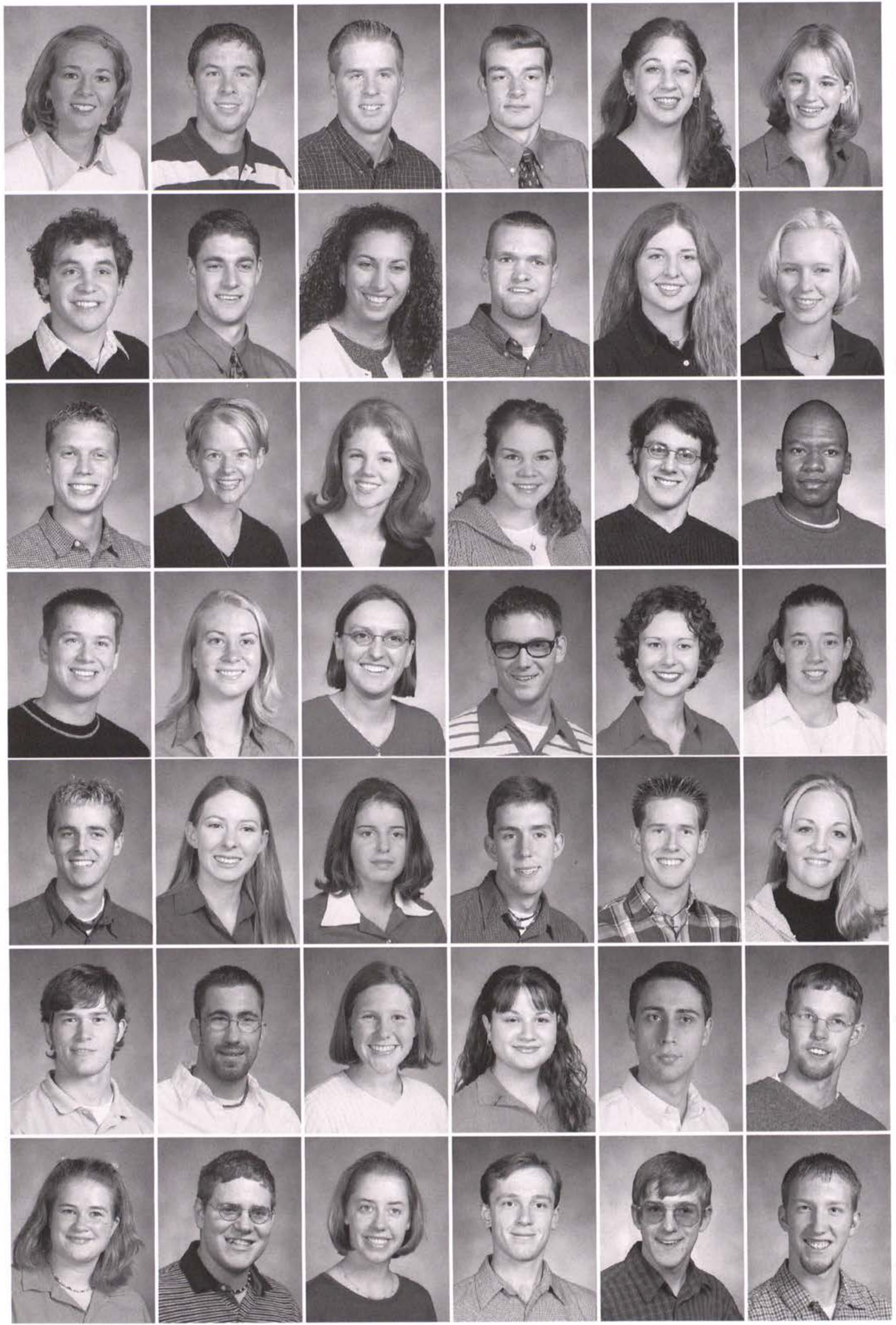

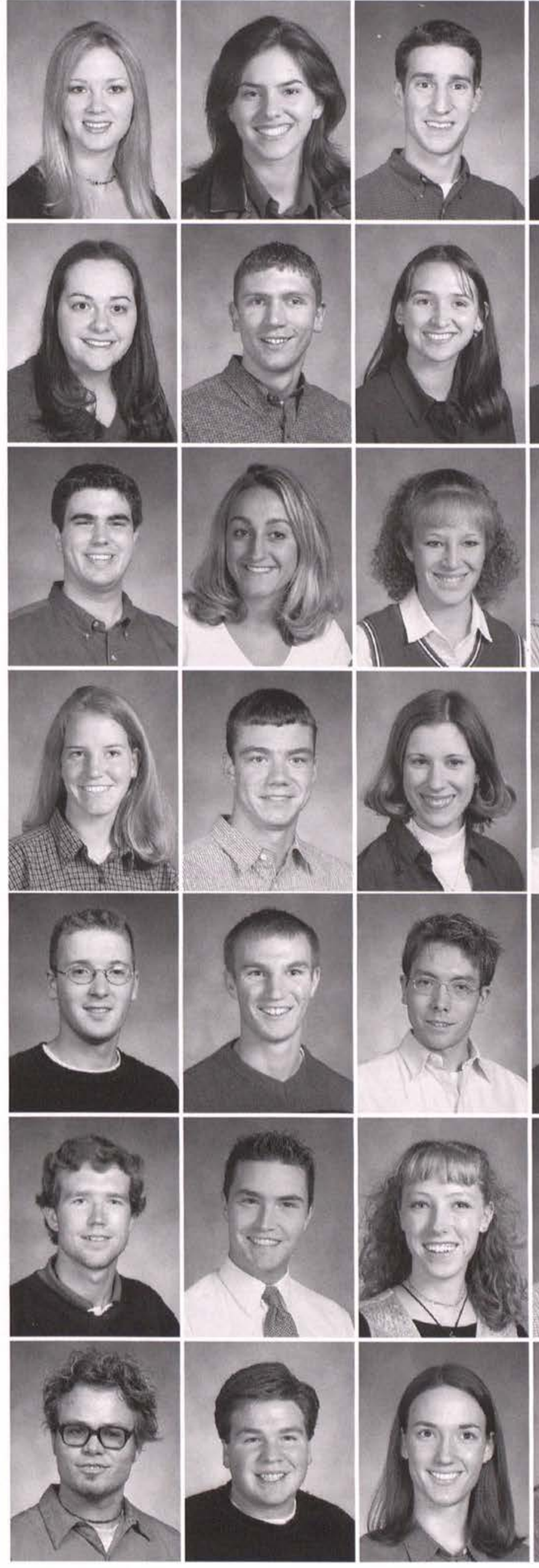
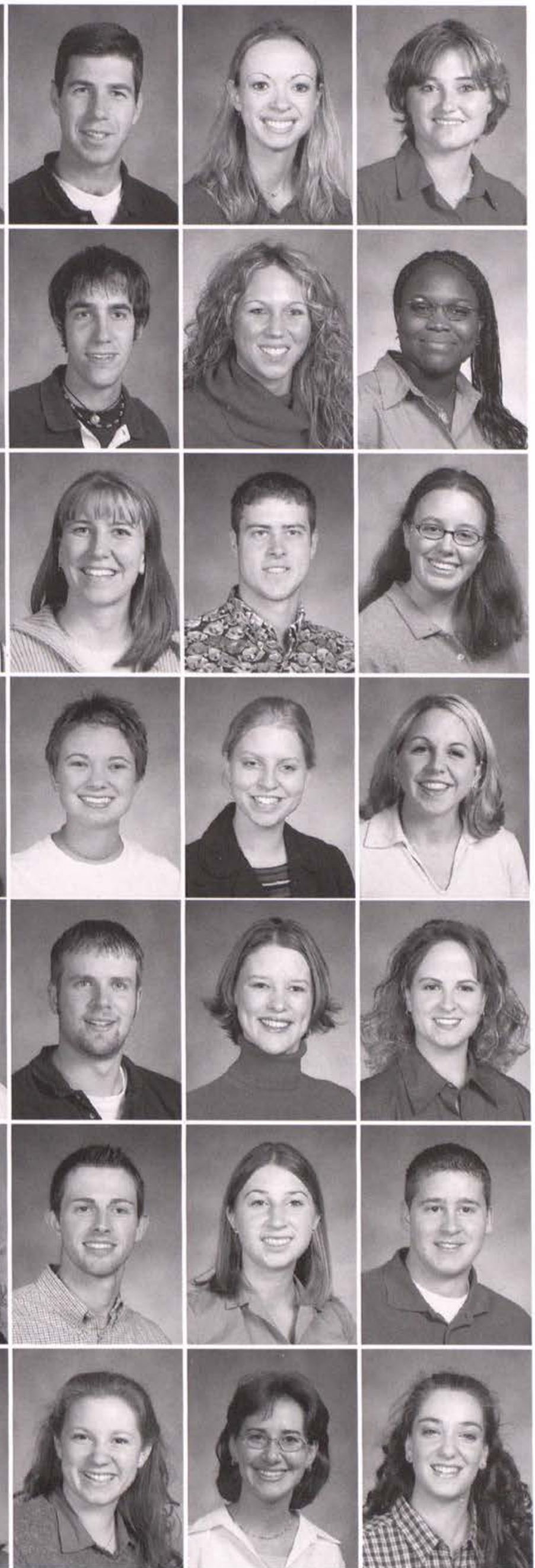

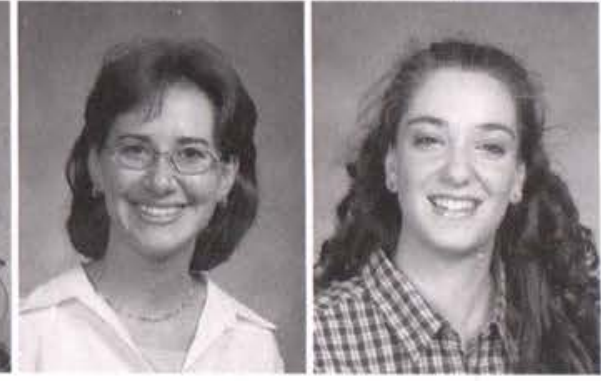

Sara Kilgore

Hannah Kipp

Charles Kirby

Mark Kirby

Amanda Kirchner

Elisabeth Klawer

Stephanie Kline

Joe Knable

Melissa Koch

Todd Kocher

Kelly Kokeny

Kikelomo Kolawole

Daniel Konopasek

Heather Kontras

Juliann Kooy

Stephanie Kreuder-Crowell

Adam Krygowski

Kristi-Lynn Kurczy

Erin Kuyper

Jared Lamb

Julie Landau

Erica Landenberger

Shannon Lauer

Stephanie Ledford

Brian Lee

Jonathan Lefor

Nathaniel Leman

Randy Lewis

Erica Linafelter

Tracie Lincoln

Todd Linden

Ben Lippincott

Dana Litchfield

Jim Lloyd

Diana Locke

David Long

Matthew Lowstetter

Christopher Lucarini

Mary Lyle

Kristin Lynch

Emily Macdonald

Susan Magin 
Jesse Magnuson

Hattie Majka

Kristy Mandigo

Rebekah Manwiller

Jessica Mao

Nathaniel Marsh

Dave Marshall

Susan Martin

Joseph Martinez

Megan Mate

Colby Mathews

Jonathan Mattson

Stephen McClure

Marsha McCulley

Marcella McCumber

Jason McDaniel

Samuel McGuire

Katie McGunnigal

Derek McKinney Josh McKinney

Jessica McManness

David Mead

Doug Messinger

Kimberly Mettler

Benjamin Michael

Cristina Miller

Emily Miller

Erin Miller

James M. Miller

Jenna Miller

Lisa Miller

Megan Miller

Nicholas Miller

Paul Miller

Michael Minahan

Jillian Mistak

Ben Mitchell

Shawnna Moberg

Andrea Modica

Holly Mohler

Sarah Moore

Sara Murphy
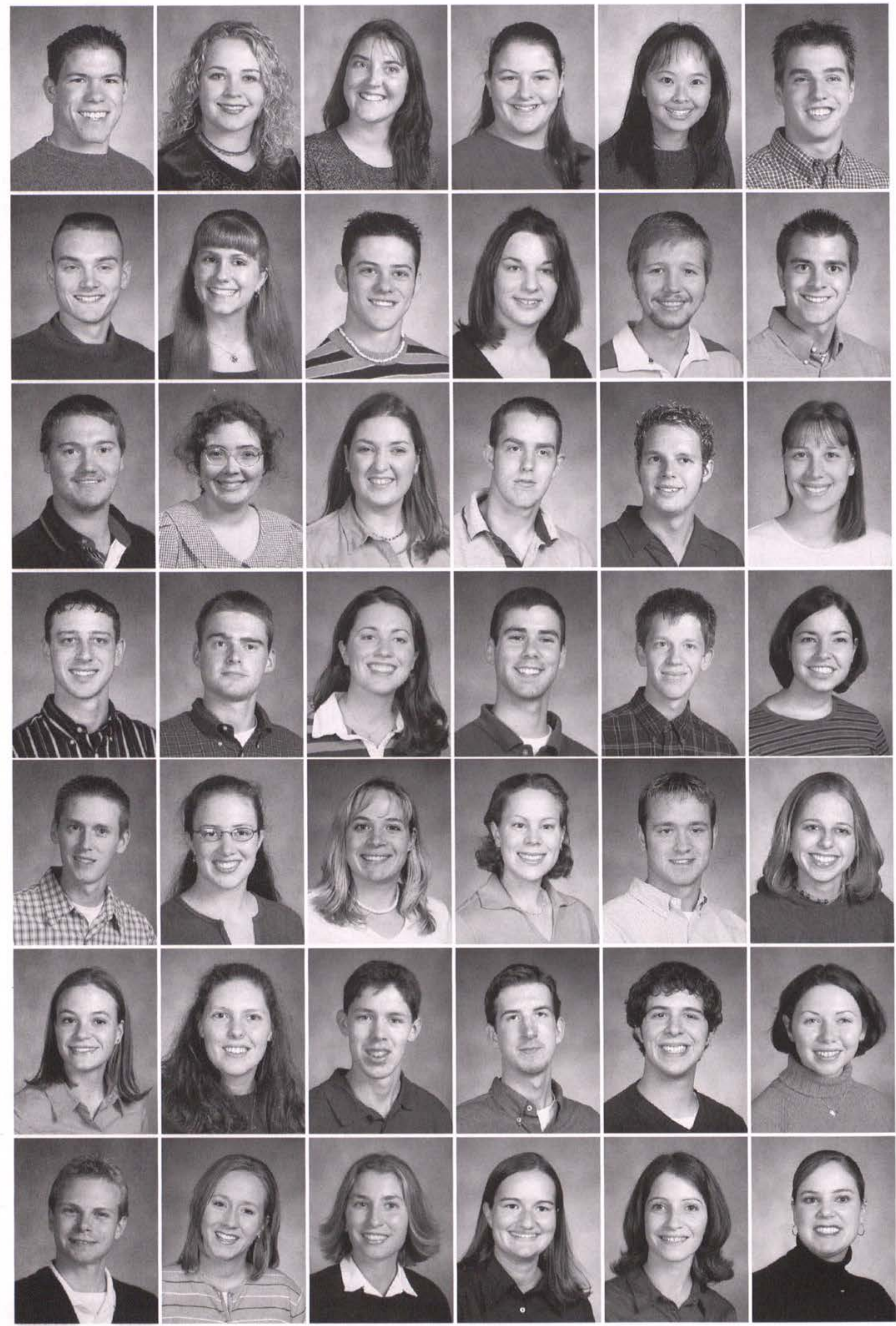


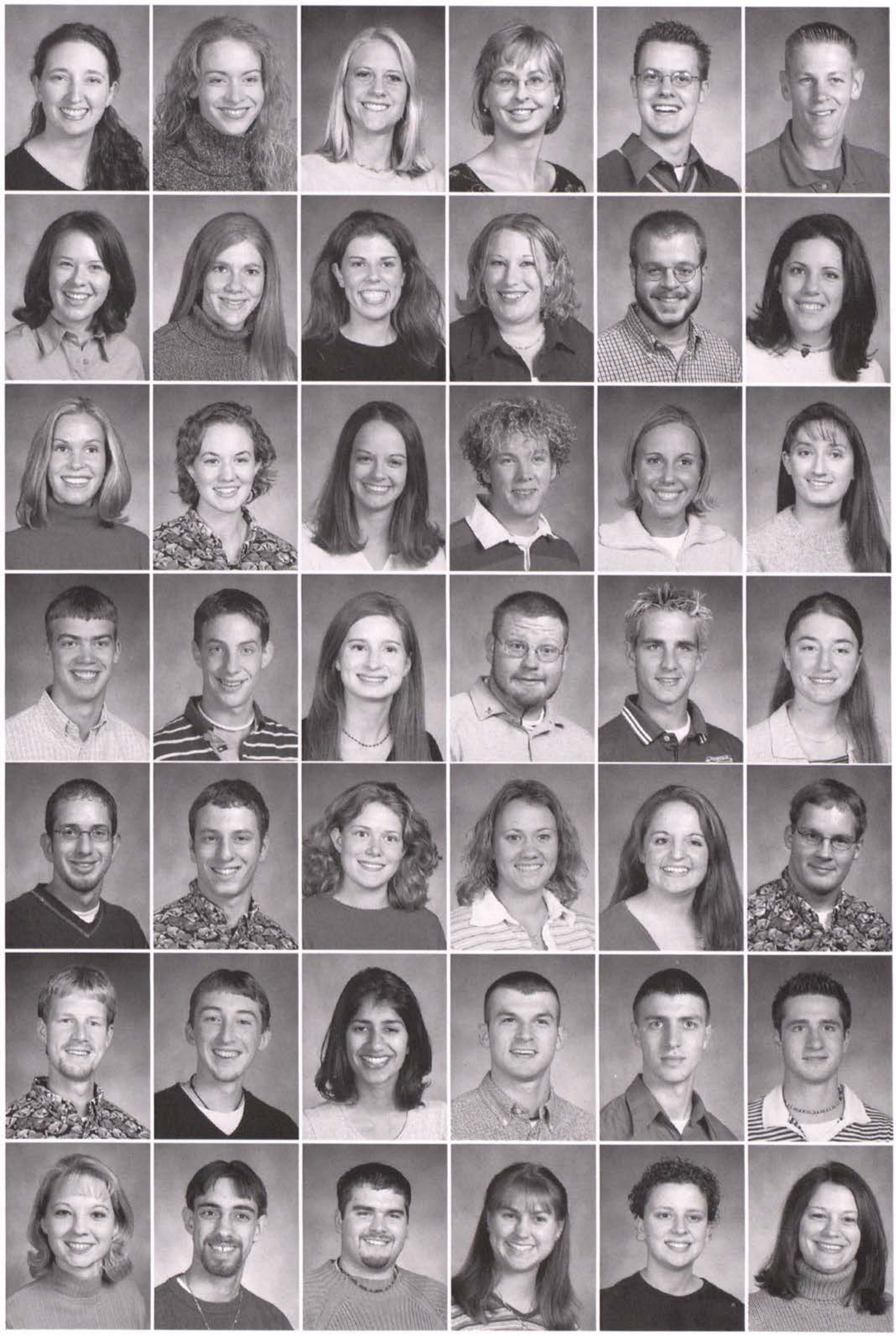

Davina Murray

Kendall Murray

Erin Nehus

Katherine Nelson

Matthew Nelson

Russell Nelson

Melissa Neufeld

Rebekah Nevitt

Natalie Newfield

Natalie Nicholl

L. Emery Nickerson II

Christina Oberdove

Kathryn O'Brien

Karin O'Connell

Julie Offerman

Justin Ohlinger

Sarah Oleszczuk

Amanda Olsen

Lars 0lson

Aaron Osterman

Teresa 0tt

Jeremy Page

Stephen Palmer

Michelle Parrish

Jeremy Patton

Joshua Paulick

Donna Paulsen

Rebekah Pemberton

Debbie Perez

Chancy Persons

Keith Peters

Jeremy Pheasant

Jyoti Philip

Eric Phillips

Tim Phipps

Jessup Pierce

Kristin Pierce

Russell Pierpont

Kelly Plummel

Megan Potter

Kathryn Powalski

Laura Price 
Victor Puhy

Julie Quinn

Stephanie Rankin

Christianna Ransom

Loren Ransom

Andrew Raymond

Brionna Raynor

Melanie Reber

Kellie Redinger

Amy Reed

Matthew Reid

Gregory Reilly

David Rench

Angie Reninger

Joseph Reno

Cara Rex

Christopher Rice

Gregory Richardson

Mark Riddle

Benjamin Ridley

Patty Roach

Kathryn Roberts

Kristin Roberts

Lindsey Roberts

Devin Robinson

Brian Roe

Jennifer Roman

Joshua Root

Sarah Rorrer

Angela Rosseau

Alyssa Rost

Laura Rost

Aaron Roth

Heather Roth

Ellen Ruby

Angela Rudd

Ryan Ruff

Katie Rulapaugh

Kate Russell

Micah Russell

Kent Ruth

Abigail Sanborn
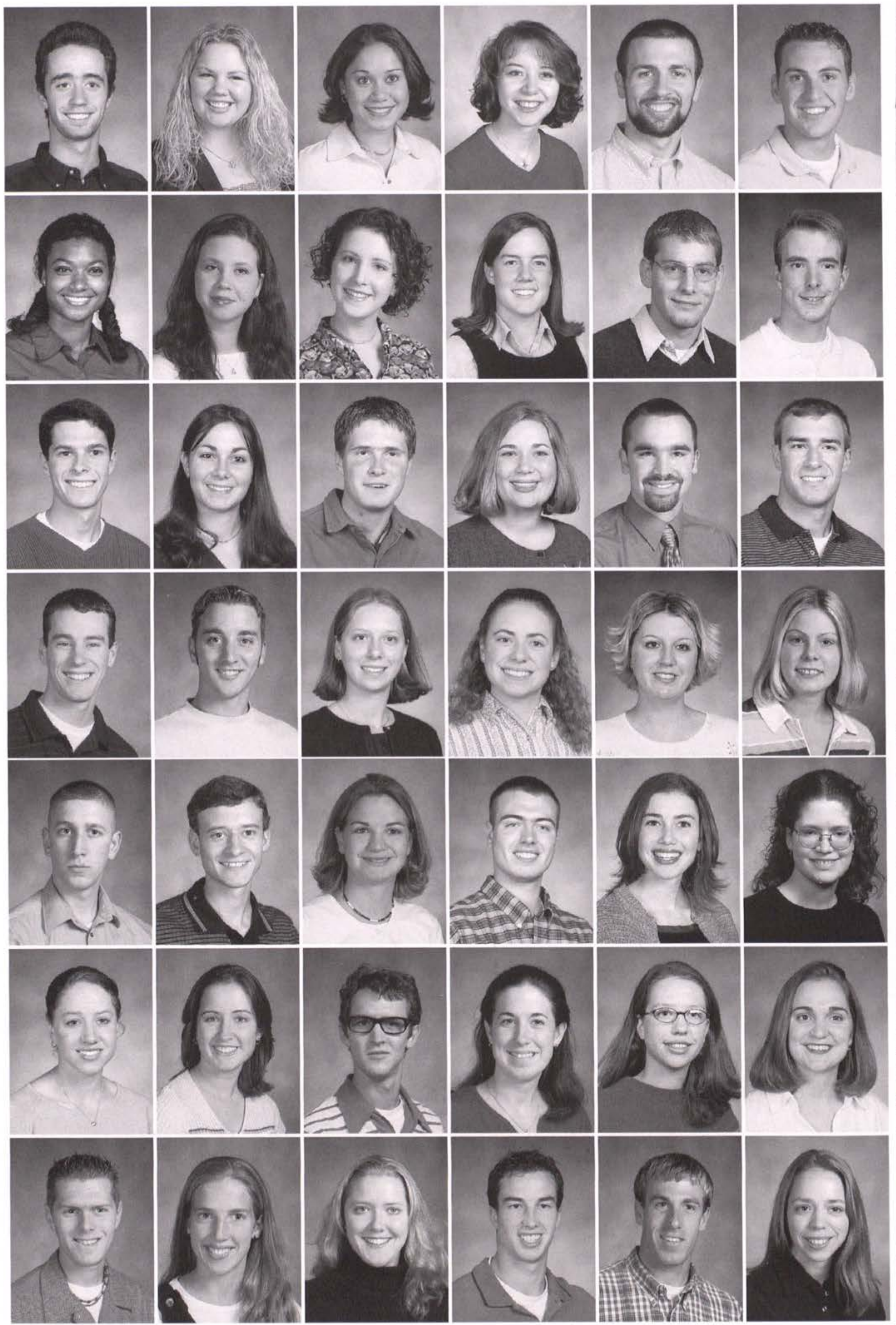
Seth Stevens Becky Stewart Bethany Stone Jesse Stone

Dave Stormont Nisha Strauch

Collin Sutherland Christina Swartzentruber Kara Syversen Jeremy Tencza Jennifer Tetrick Jack Thomas

Monica Thomas Rachel Thompson Matthew Thornburg Catherine Thorne Randy Thurman Lucas Tillett

oel Tomkinson

Elizabeth Topp

Seth Tubbs

Matt Tucker

Keith Tyson Kristie Uminn

Heidi Vander Werf

Michael Van Treese

Stephanie Van Tuyl Jolene Van Wingerden Julie Van Winkle Andrew Vargo

Shauna Verosky Jessica von der Mehden Benjamin Vroman Gretchen Vuurens Brittany Waggoner Karissa Waldron

Dustin Walker Michelle Walker Beth Walters

Nicholas Walton

Sarah Weaver Mark Weeber
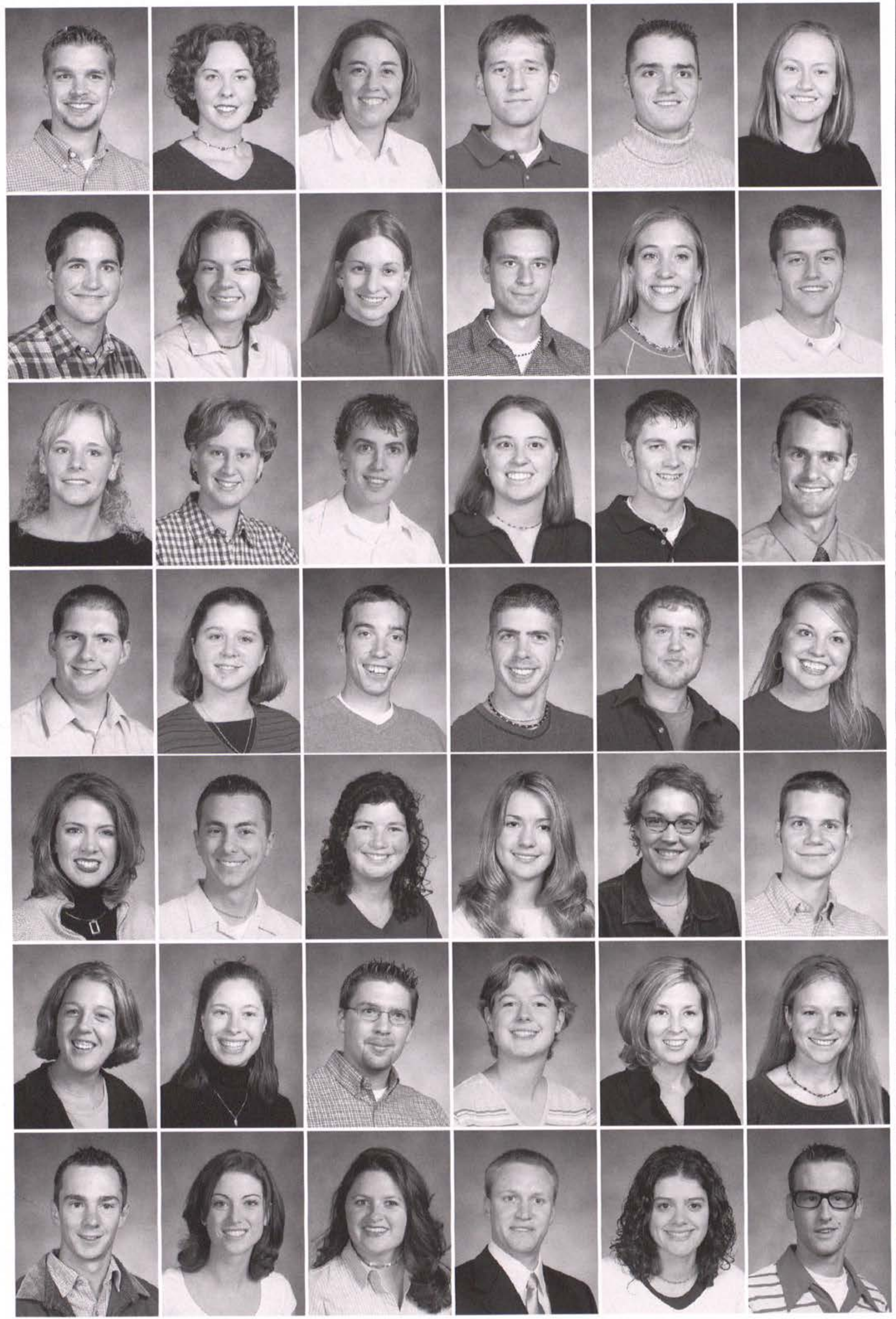


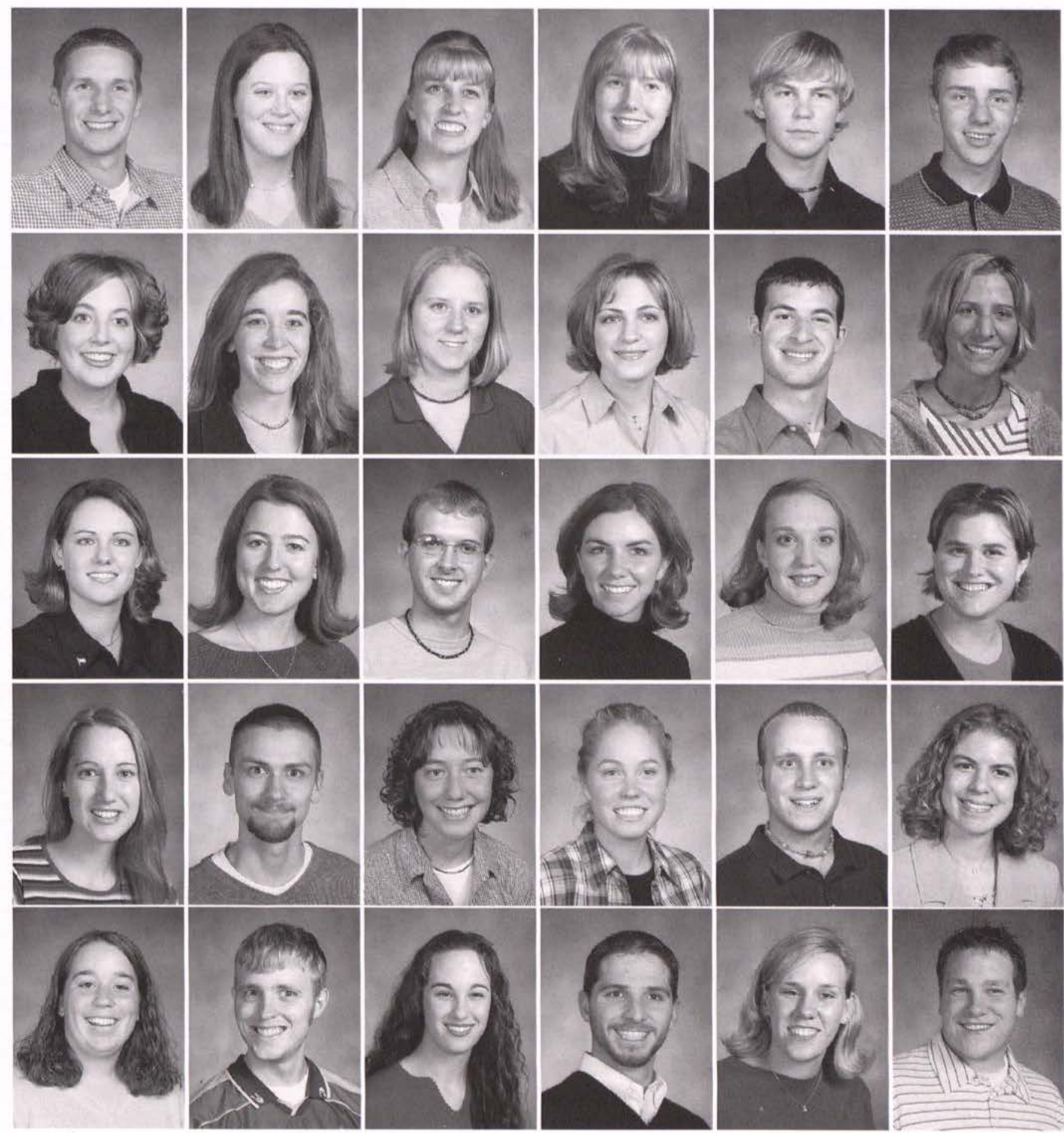

Paul Weimer

Staci Weldon

Rebecca Wells

Kelly Wentzell

David Wenzel

Elijah Werner

Megan Whitman

Emilly Wiedemann

Sandra Wilhelm

Tricia Wilkens

Andrew Williams

Rachel Joy Williams

Charissa Winburg

Andrea Winship

Adam Wirrig

Michal Witt

Sarah Woodstock

Heather Worth

Jennifer Wortley

David Wright

Gillian Wright

Heidi Wright

Rob Yale

Heidi Yehnert

Heidi Yoder

Jonathan Zemmer

Elizabeth Zeron

Timothy Zierenberg

Katherine Zimmerman

Matthew Zimmerman

\section{GLASS OFFIEERS}

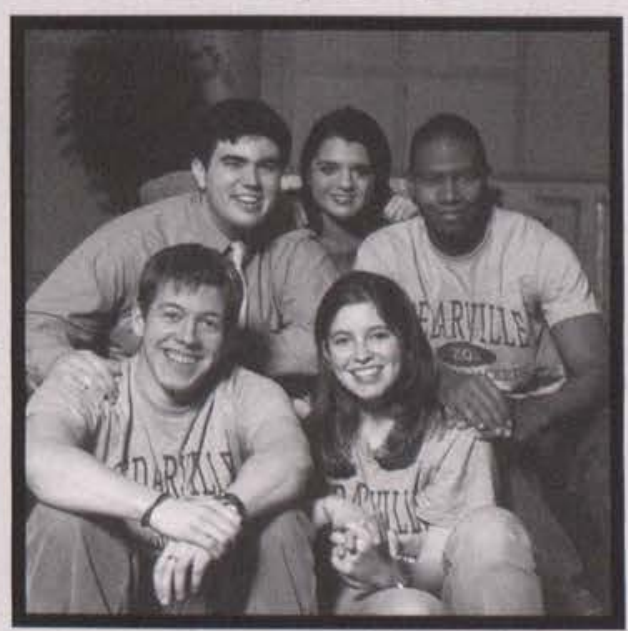

President: Emily Gayer (right-front)

Vice-President: Samuel Hutchins (right-back)

Treasurer: Brian Schildroth (left-front)

Secretary: Sarah Arnstein (center-back)

Chaplain: Dan Konopasek (left-back) 


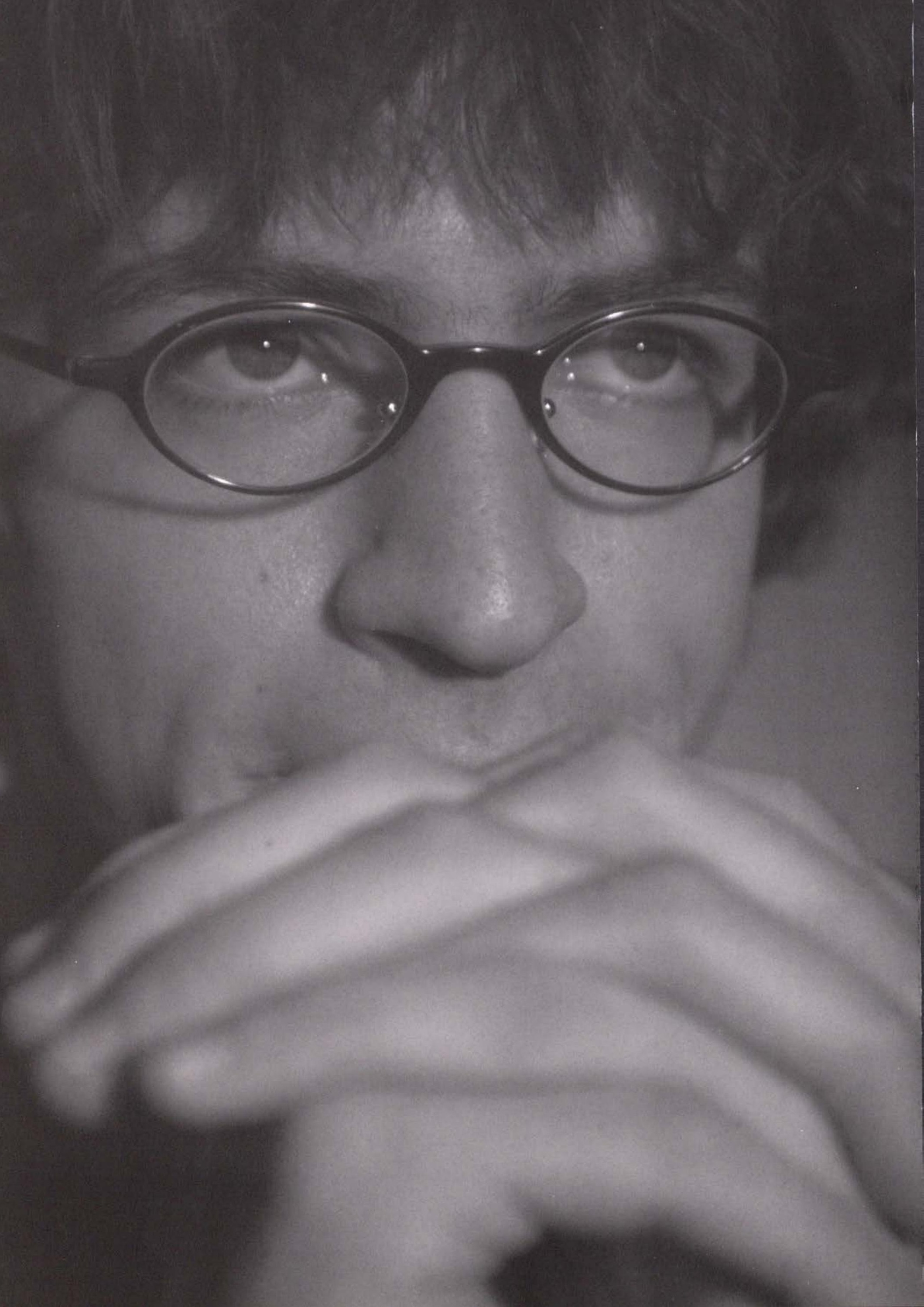



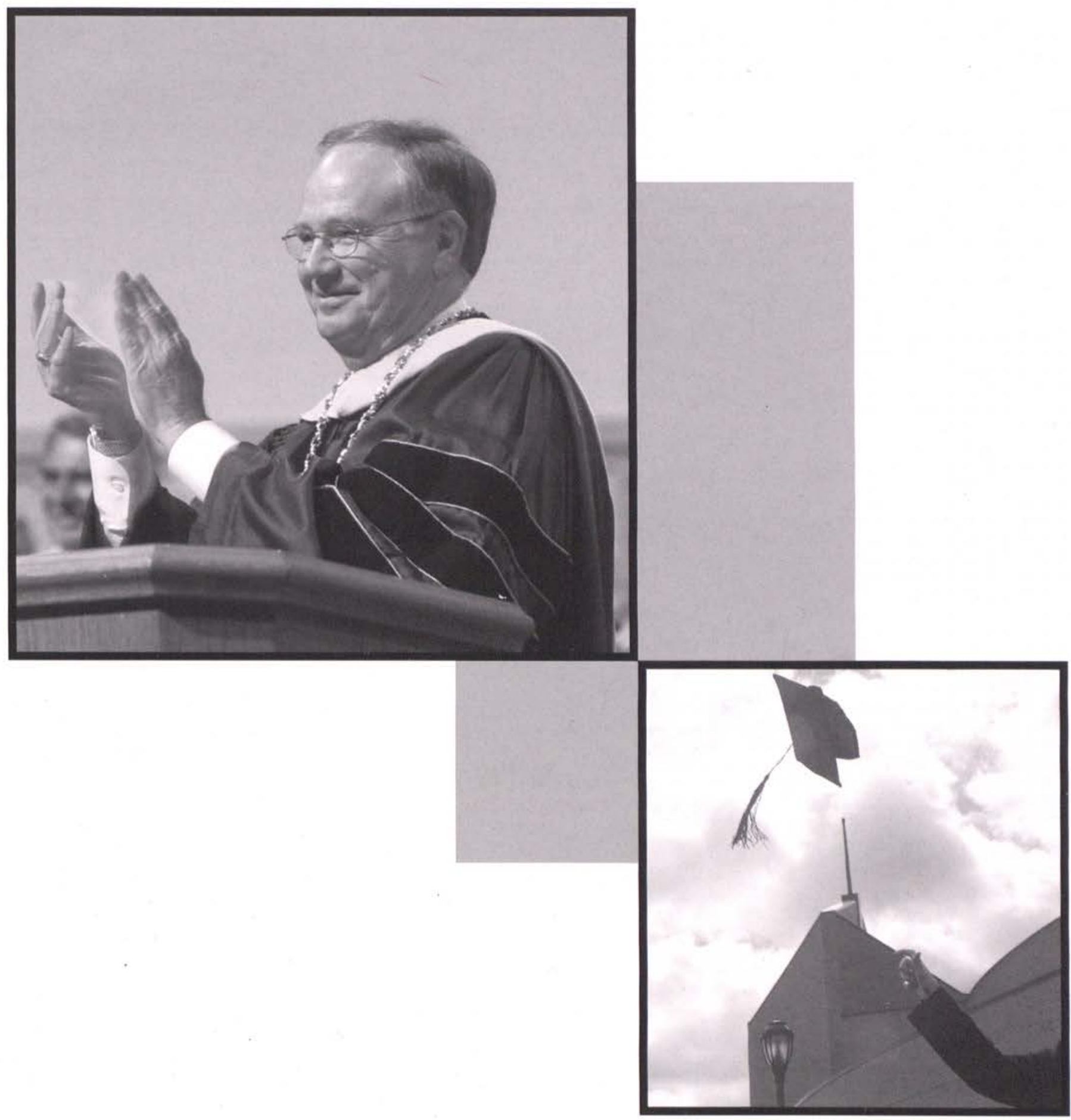

SENIORS 


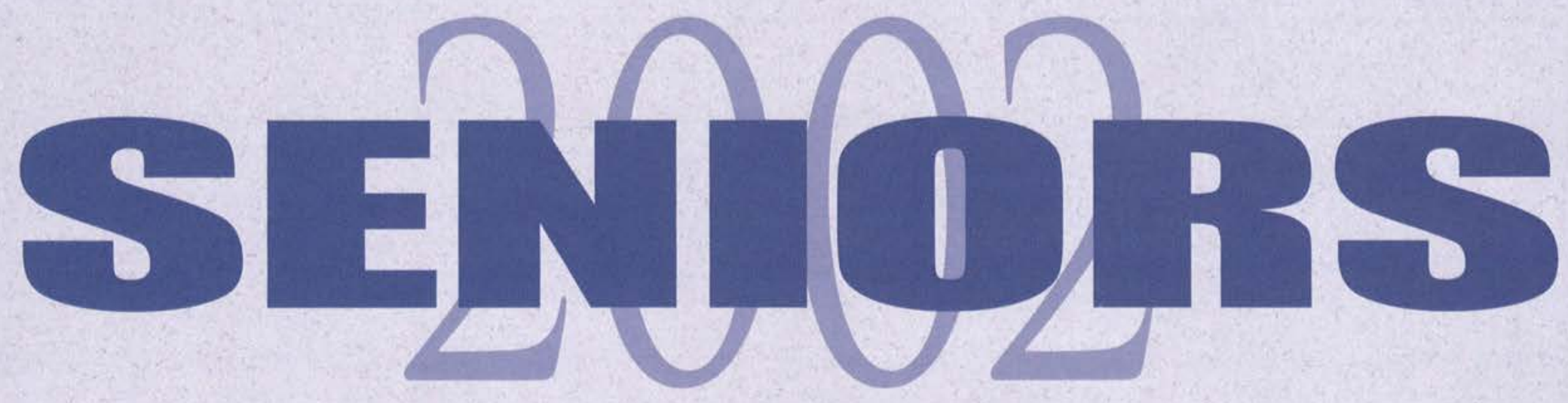

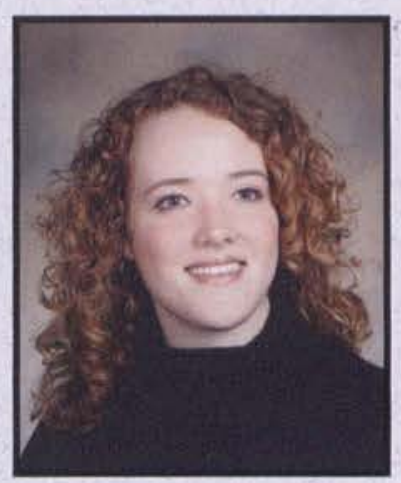

Kristi L. Abildness

Broadcast Sales \& Man.

Hummelstown, PA

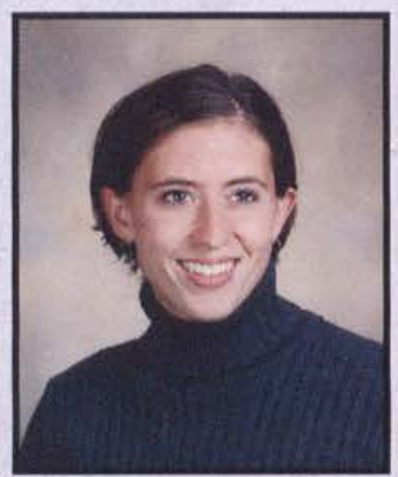

Jessica Alexander

Physical Education

Williamson, NY

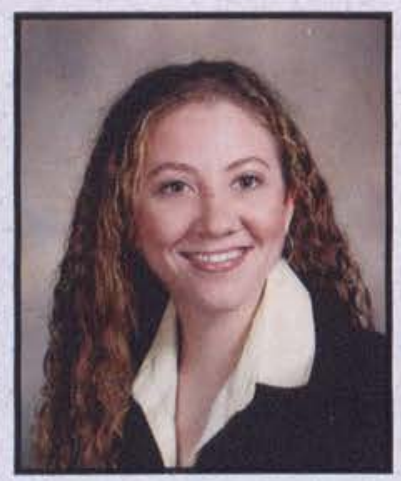

Lisa Alligood

Sociology

Oakwood, GA

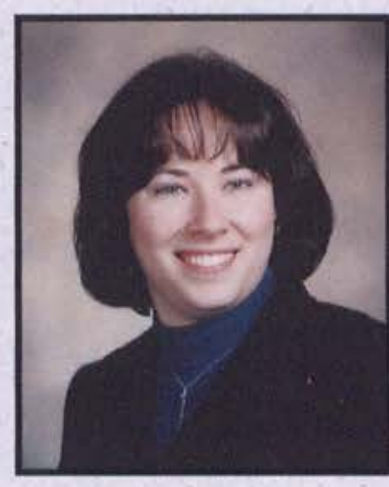

Lisa Marie Ables

Technical \& Professional Comm. Dayton, $\mathrm{OH}$

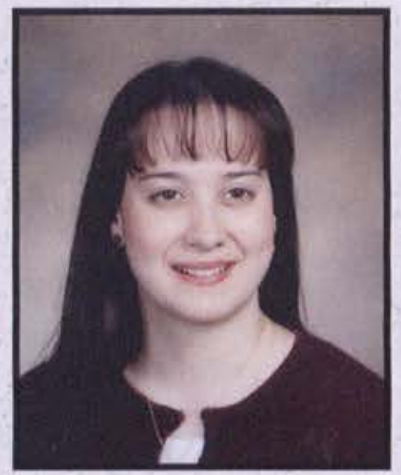

Sara K. Allen

Chemistry

Gahanna, $\mathrm{OH}$

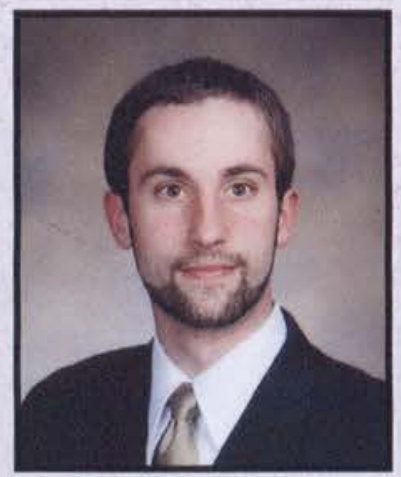

Brian Allport

Business

Beavercreek, $\mathrm{OH}$

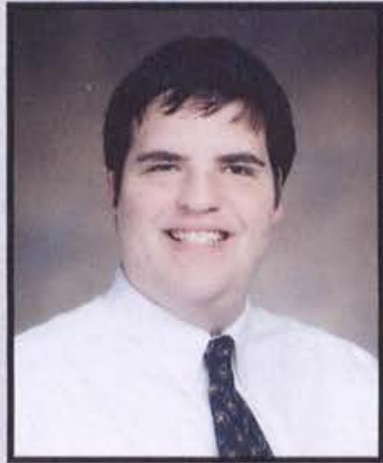

Paul Abraham

Multimedia Technology

New Stanton, PA

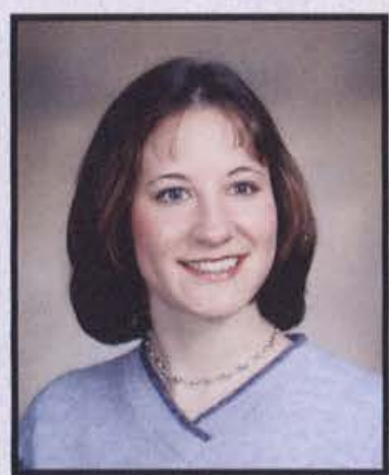

Sarah M. Allen

Early Childhood Education Hamilton, $\mathrm{OH}$

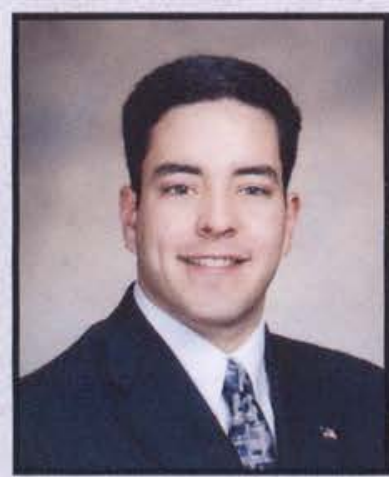

Charles Aman

Mechanical Engineering Wyoming, MI

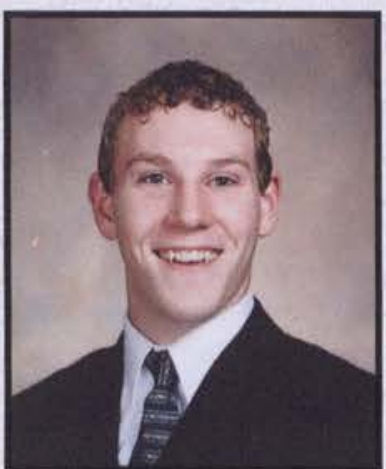

Torrey Adams

Mechanical Engineering Quinnesec, MI

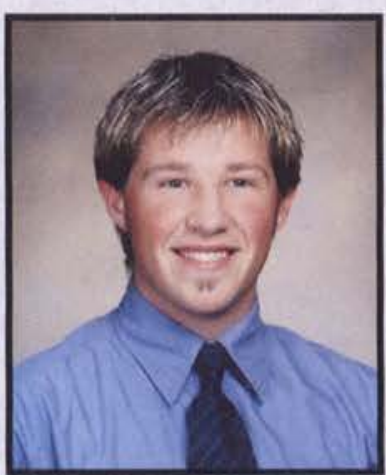

Shawn D. Allen Marketing

Jamestown, NY

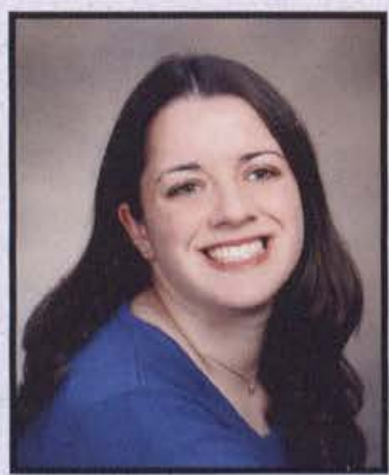

Rebecca Aman Nursing

Union Grove, WI

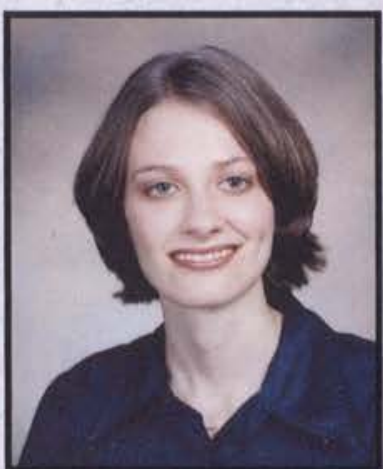

Emily Albanese End-UserInformation Systems Wind Cap, PA

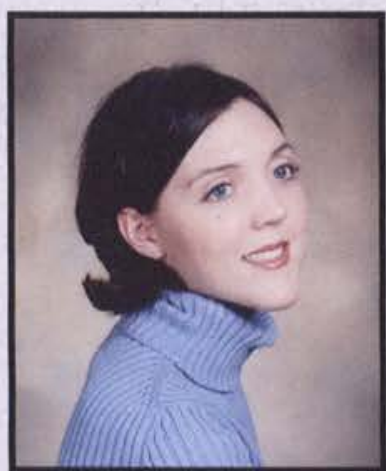

Jewel Alley

Nursing

Hollis, ME

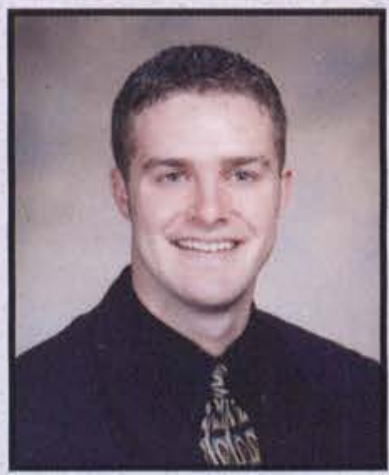

Michael Amann Operations Mang. \& Finance Belmont, MI 


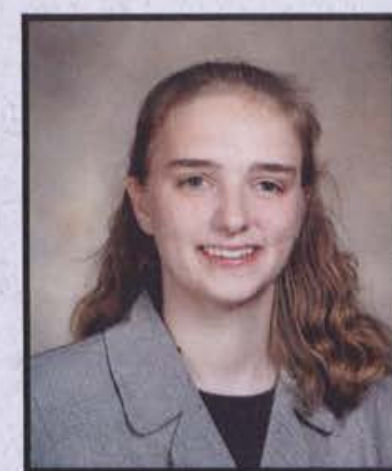

Lindy Anderlini Mechanical Engineering Richland, WA

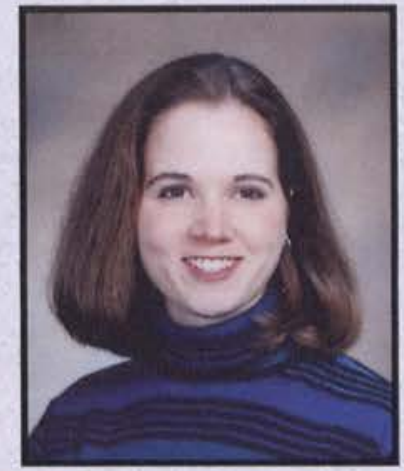

Emily M. Andrews

Marketing

Ephrata, PA

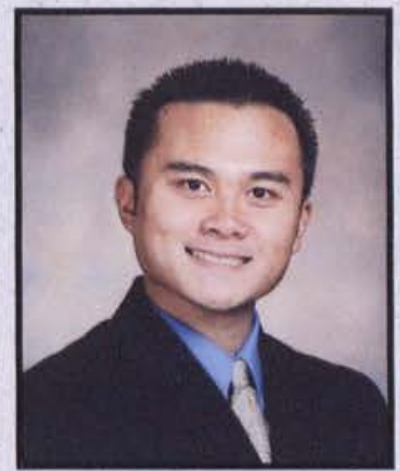

L Bacerra

Multimedia Technology Sound Beach, NY

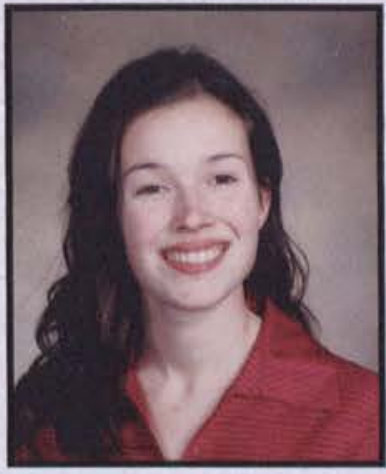

Shana L. Barba

Early Childhood Education Medford, NJ

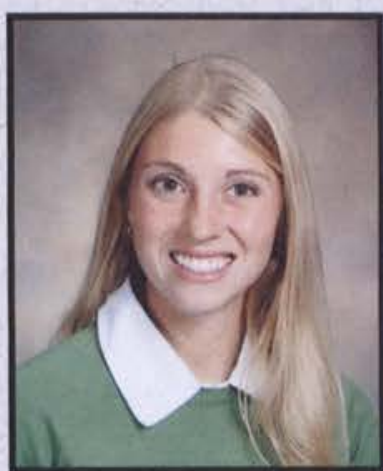

\section{Alicia M. Anderson}

Spanish

Ft. Lupton, CO

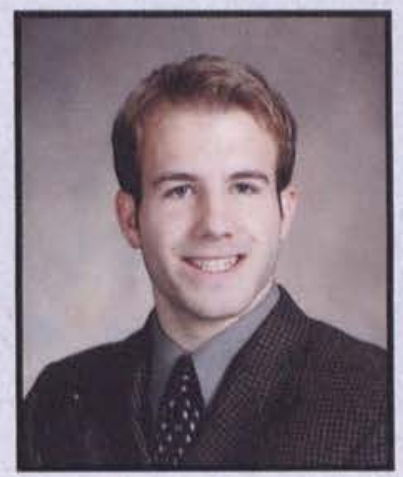

Brian Antes

Christian Education of Youth McKees Rocks, PA

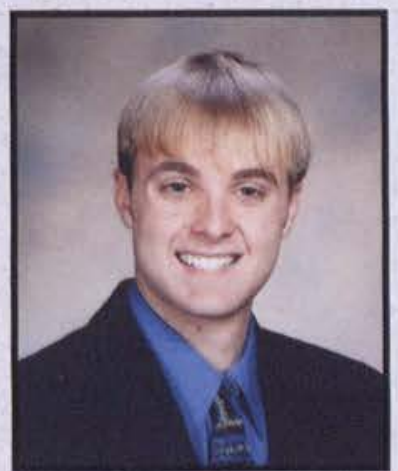

John Bailey

Mechanical Engineering Brownsburg, IN

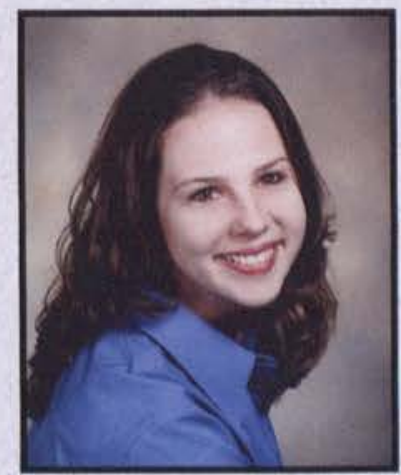

Tami Barlow

Early Childhood Education Oxen Hill, MD

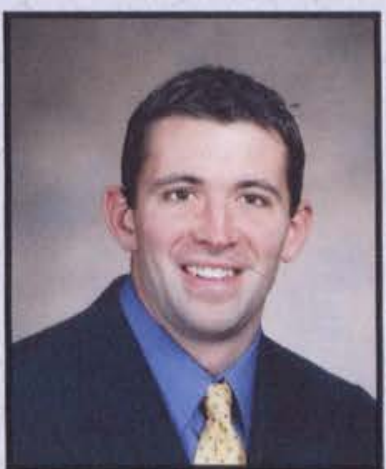

Paul M. Anderson

Electrical Engineering

St Charles, IL

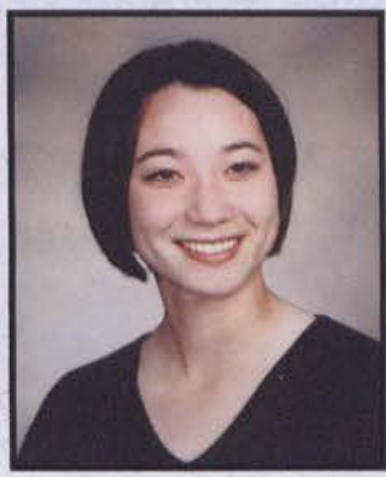

Amiee Arimura

English

Warrenville, IL

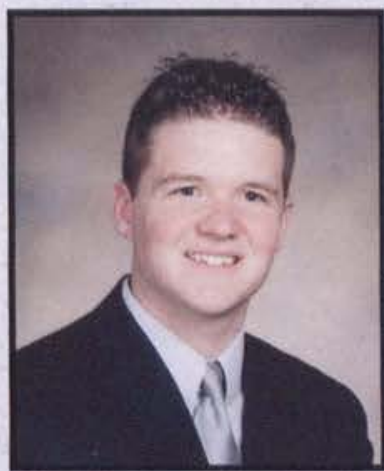

Carl R. Ball

Video \& Media Productions South Elgin, IL.

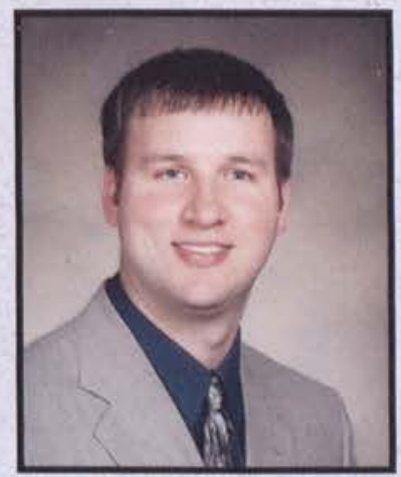

Benjamin M. Barrett

Multimediá Technology Cedarville, $\mathrm{OH}$

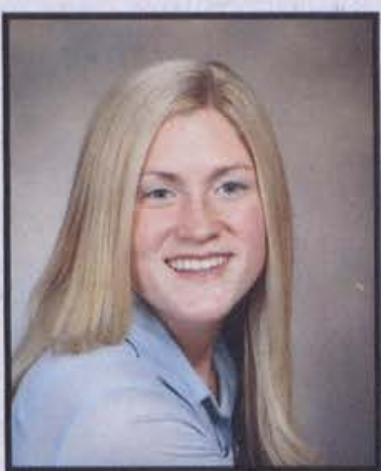

Shiloh Anderson

Nursing

South Berwild, ME

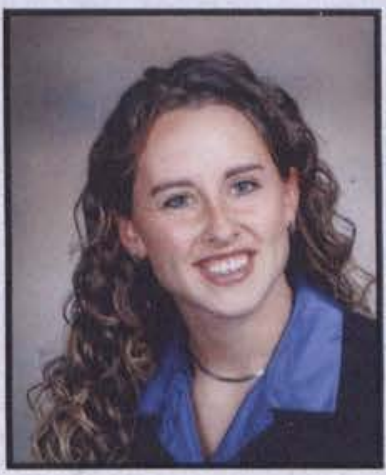

Alicia Ayers

Nursing

Anderson, IN

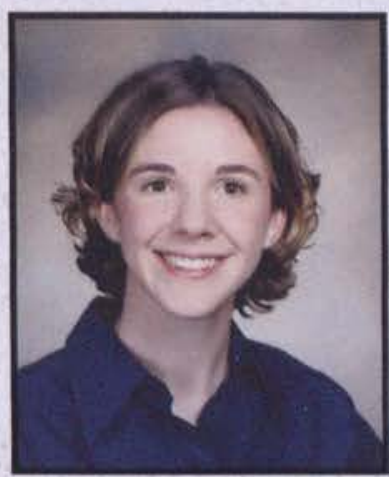

Georgina Band

English

Londonderry, NH

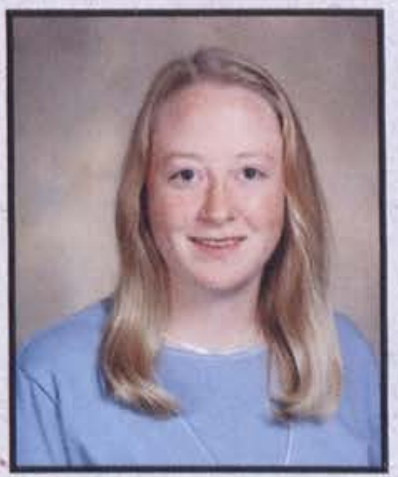

Christina Barrons

Early Childhood Education Caro, MI

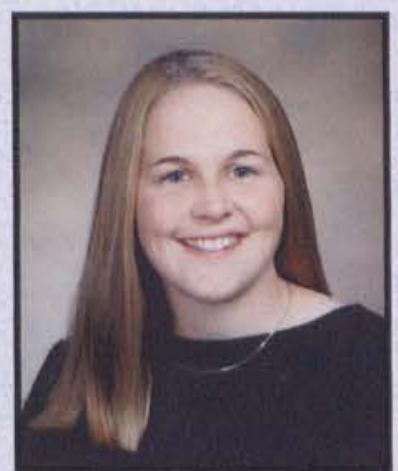

Corrine M. Andrews Early Childhood Education Maddon Heights, NJ

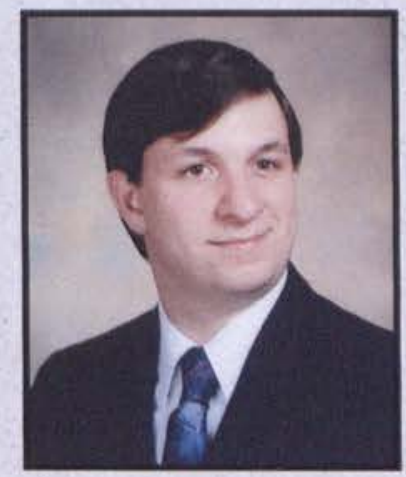

Jonathan F. Ayers English

Westminster, Co

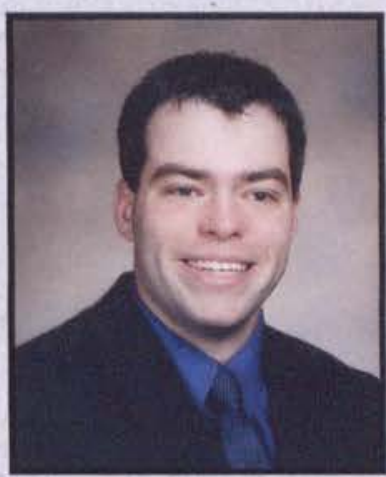

Graig Bantle Finance

Ithaca, NY

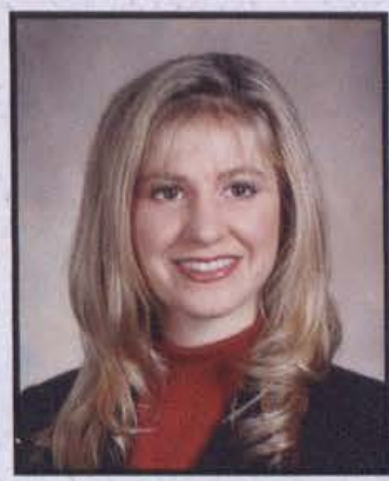

Amanda Bartholomew

Finance \& Accounting Hubbard, $\mathrm{OH}$ 


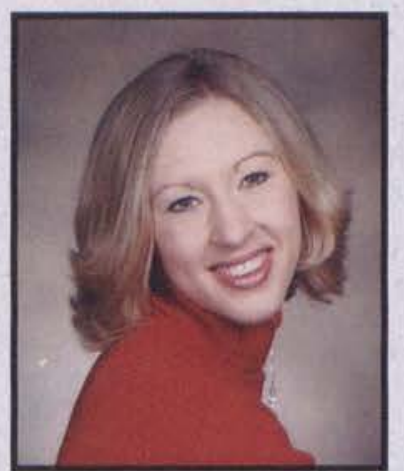

Sarah J. Bartlett

Broadcasting

Cedarville, $\mathrm{OH}$

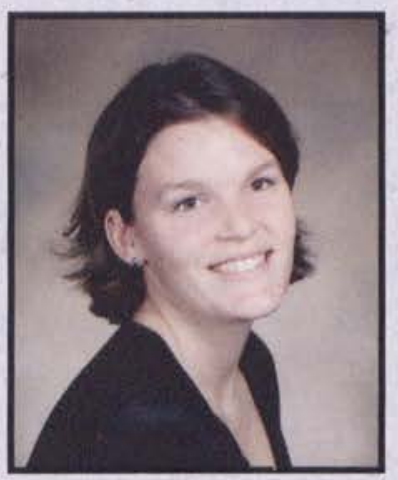

Sandra K. Beatty

Nursing

Shamong, NJ

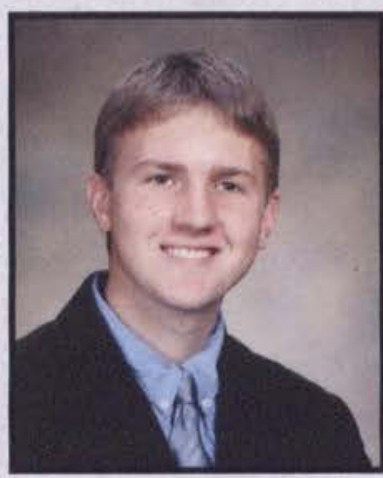

Nate BeVier

Bible \& Pastoral Studies

Pataskala, $\mathrm{OH}$

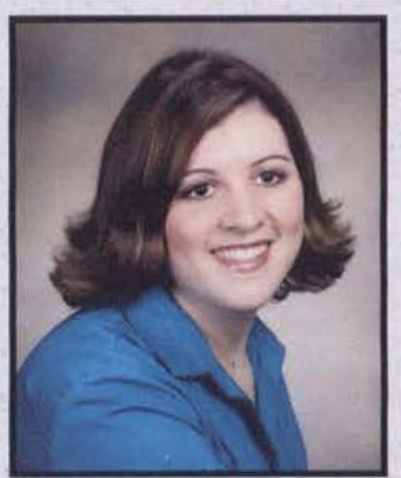

Lauren A. Bizzoco

Communication Arts

Brick, NJ

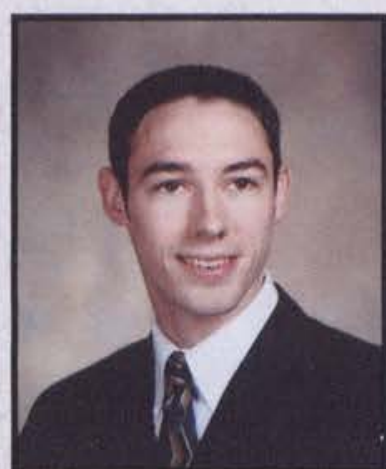

Brian D. Basner

Finance \& Accounting

Voorhees, NJ

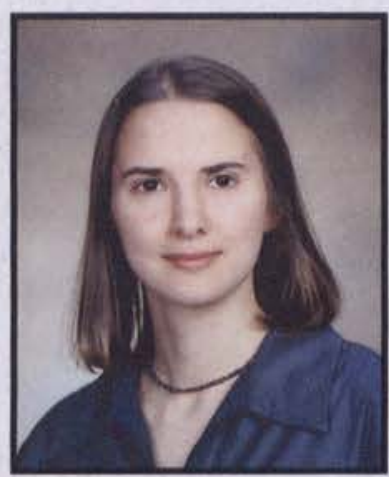

Amy M. Belding

Chemistry

Beckley, WV

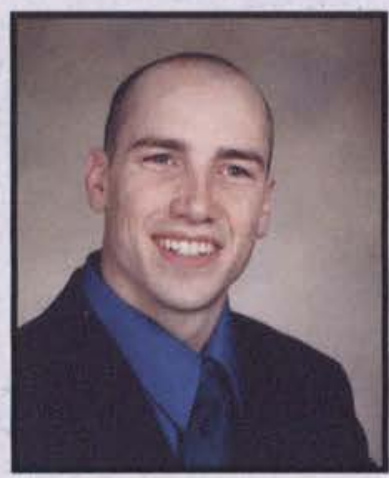

Matthew A. Bicknell

Nursing

Kalispell, MT

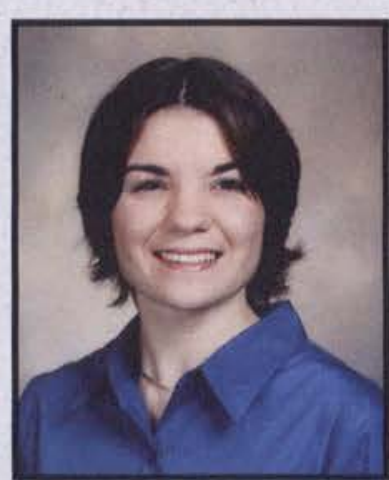

Alissa Black

Technical \& Professional Comm.

Huntington, WV

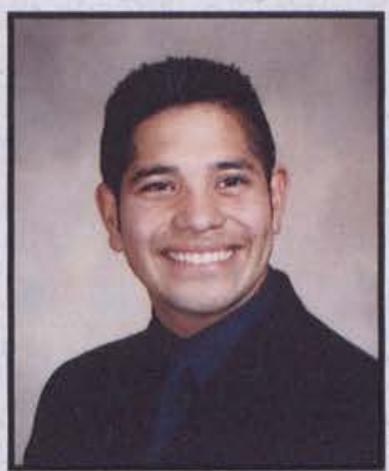

Kevin Batista

Marketing

Cedarville, $\mathrm{OH}$

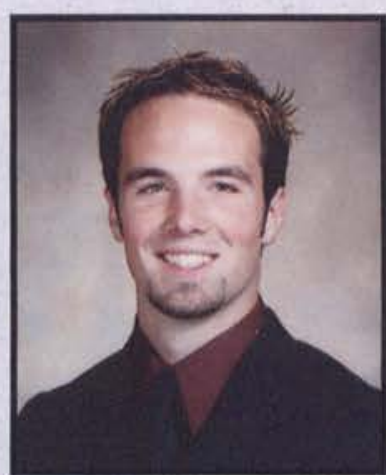

Matthew C. Bell

Christian Education of Youth Somerville, NJ

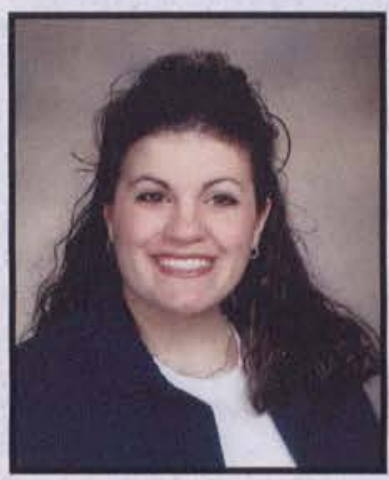

Melissa A. Bielo

Christian Education of Youth

Lakeside Park, KY

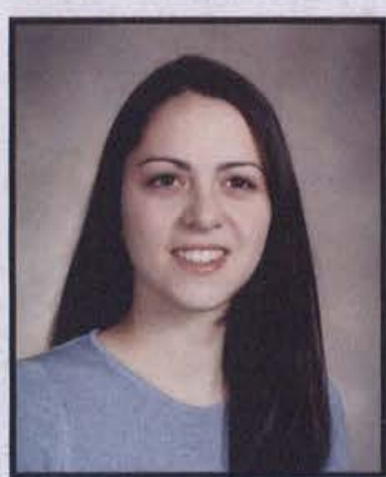

Dorothy Blake

Spanish

Sugar Grove, IL.

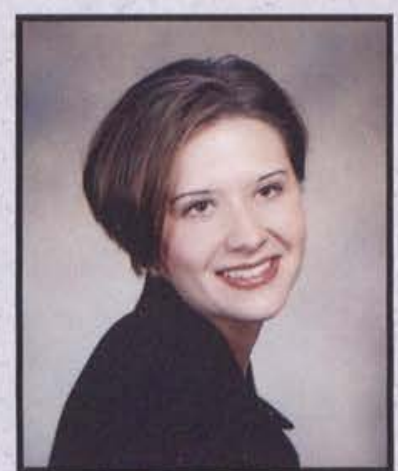

Zipporah Bauman

Music Theory \& Composition Rittman, $\mathrm{OH}$

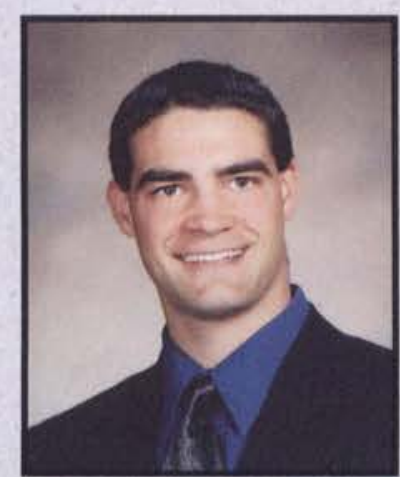

Drew Bennett

Mechanical Engineering Wauseon, $\mathrm{OH}$

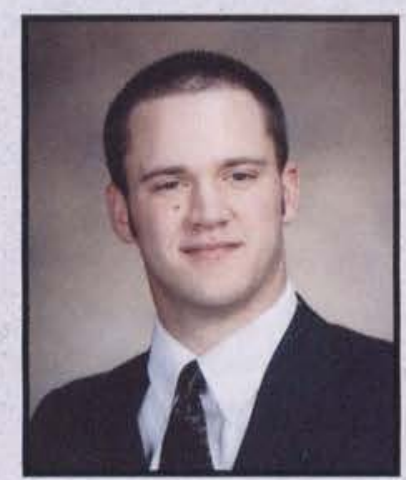

Clint Bieri

Pastoral Studies

Butler, $\mathrm{OH}$

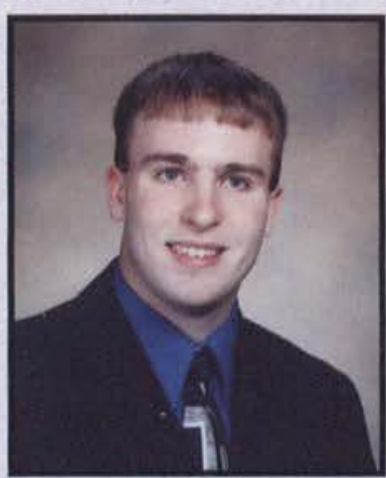

Joseph Blakey

Broadcasting \& Video Prod. Frankfort, IL

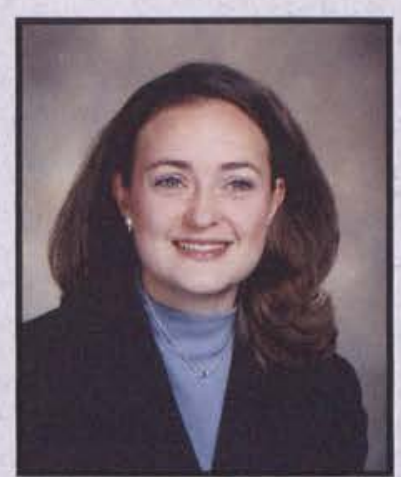

Rebekah Baxter Integrated Math Education Blue Springs, MO

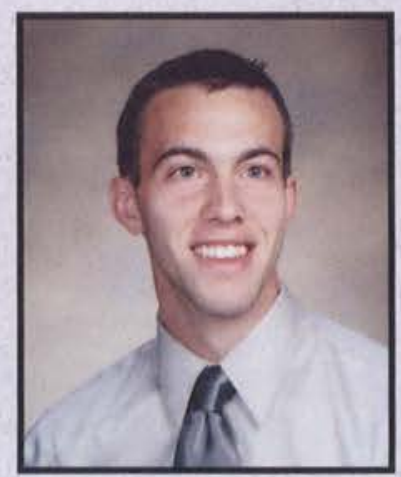

Adam Beres MIS

Tipp City, $\mathrm{OH}$

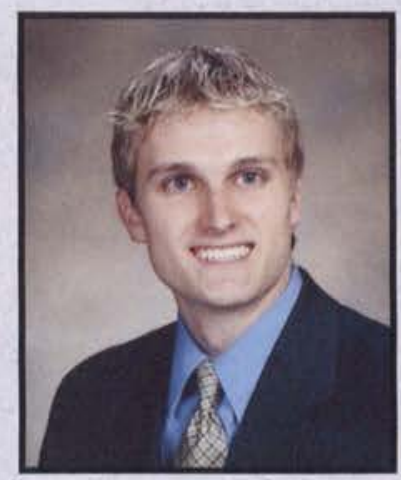

Doug Bitzer

Biology

Charleston, WV

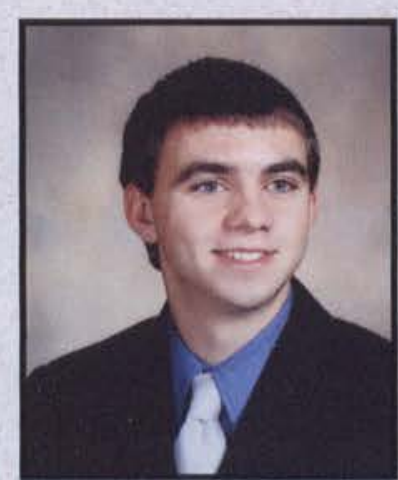

Pete Blodgett

Christian Education of Youth Elkhart, IN 


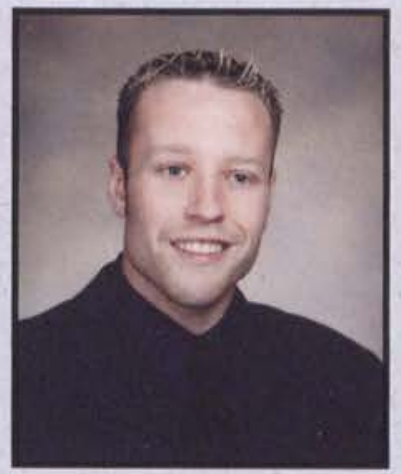

Timothy Blow

Christian Education of Youth Downingtown, PA

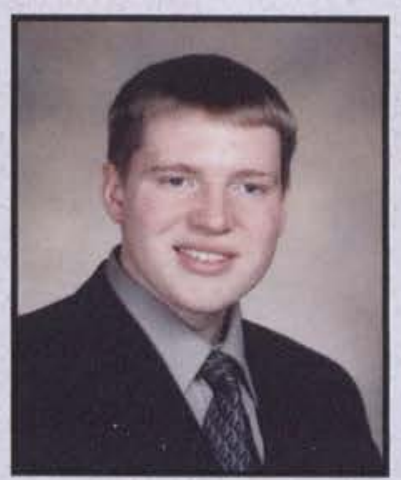

Jeremy A. Bossard Electrical Engineering North East, MD

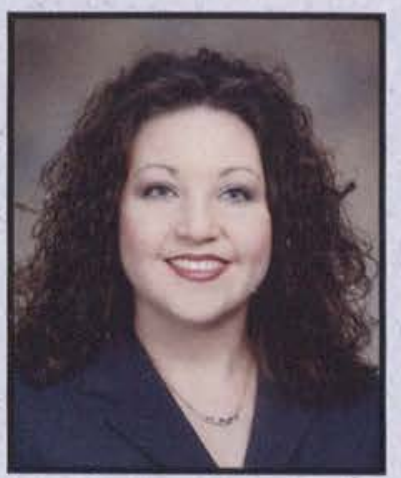

Amanda S. Briggs Marketing

Taylorville, IL

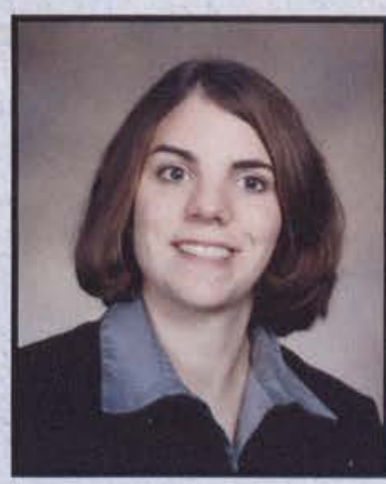

Candice J. Brown

Special Education Van Etten, NY

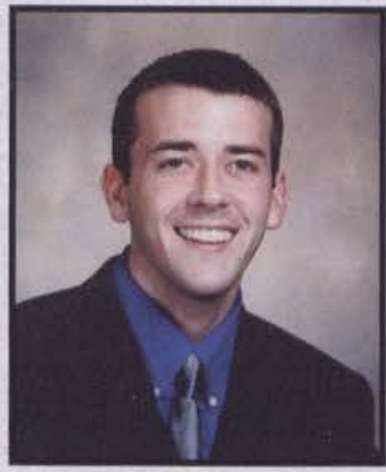

Mark W. Boertje

Elementary Education Lima, $\mathrm{OH}$

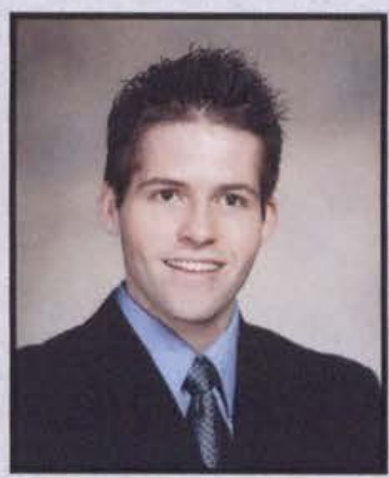

Jeremy A. Bouma Political Science Hudsonville, MI

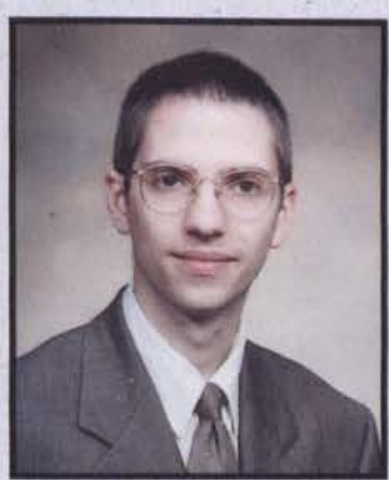

Ehren Brinkmeier Mechanical Engineering Lena, IL

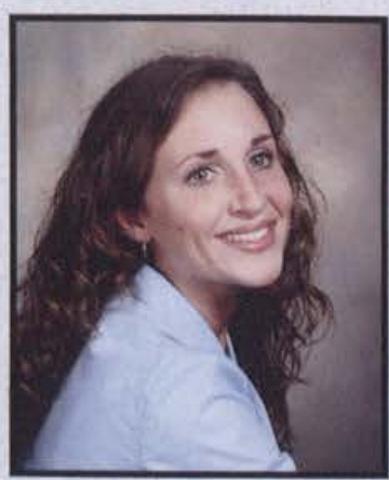

Anne Brumback Finance Hamilton, $\mathrm{OH}$

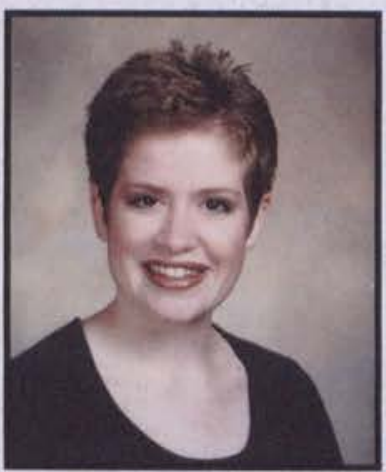

Sarah C. Bolden

American Studies Massillon, $\mathrm{OH}$

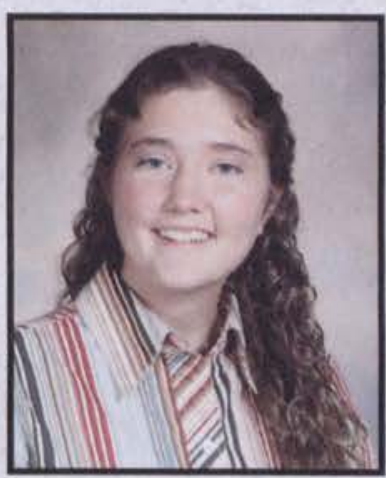

Natasha M. Boyce

Bible Comprehensive Defiance, $\mathrm{OH}$

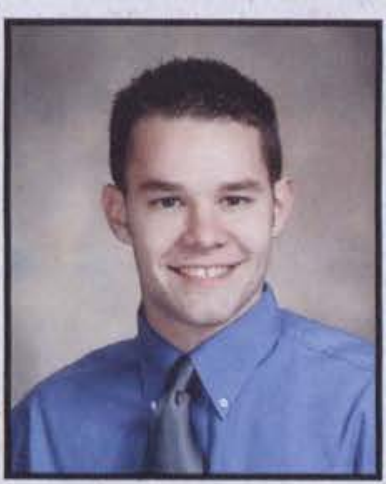

Jonathan S. Brockman

Mechanical Engineering St. Leonard, MD

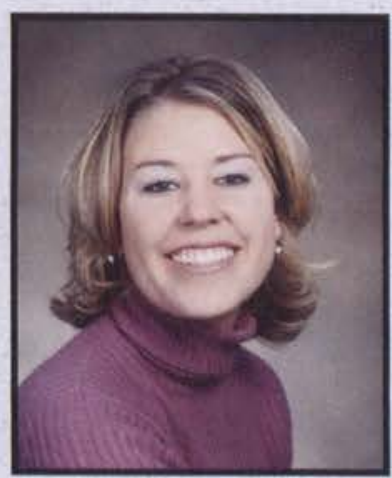

Rebecca Brummel

Org. Communications Allegan, MI

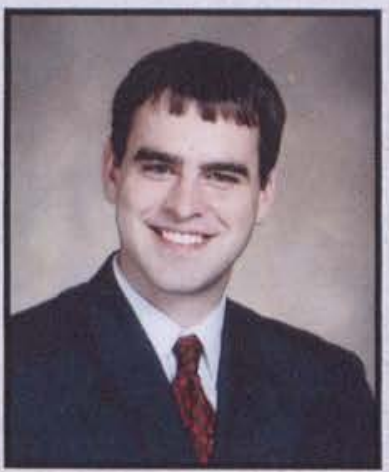

John Bolinger

Finance

Jackson, MI

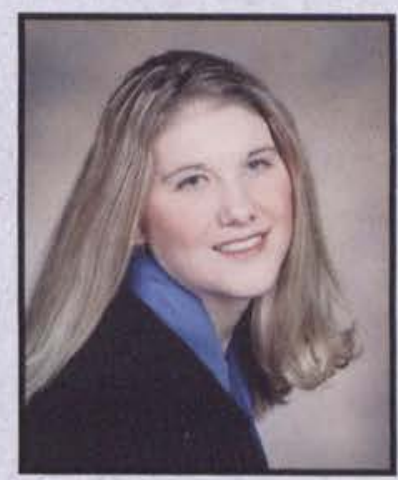

Julie A. Branon

Middle Childhood Education

Grand Rapids, MI

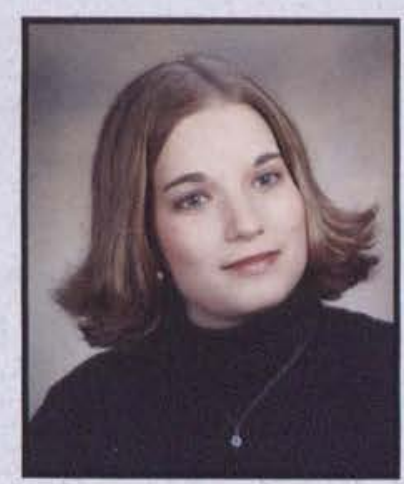

Angela Brooks Accounting \& Finance

Traitville, VA

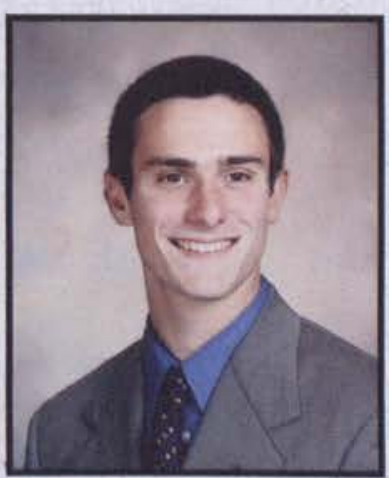

Lael Bryant

Finance \& Marketing Plymouth, MI

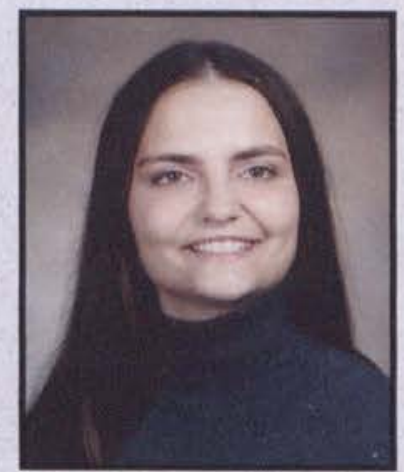

Anna L. Bolser

Special Education Hamilton, $\mathrm{OH}$

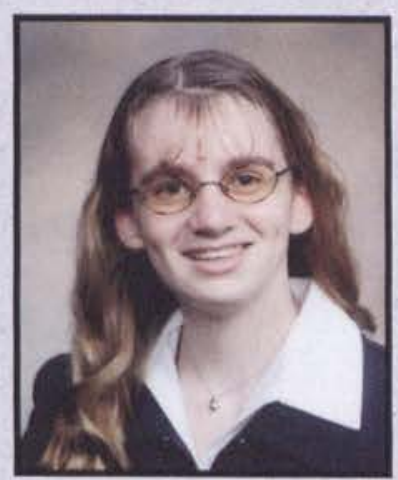

Bethany Brewer Early Childhood Education Lansing, MI

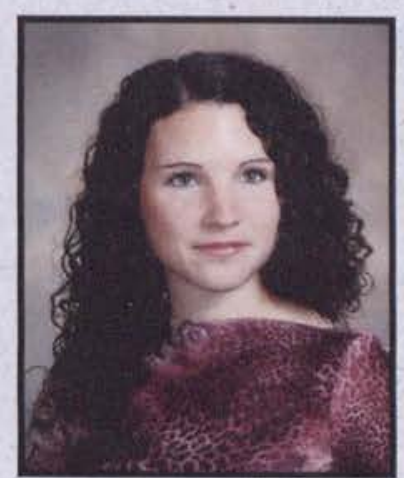

Melanie Brossoit Nursing

Brownstown, MI

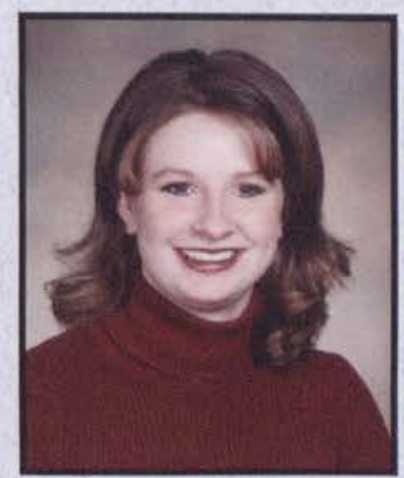

Megan J. Bryant Middle Childhood Education New Carlisle, $\mathrm{OH}$ 


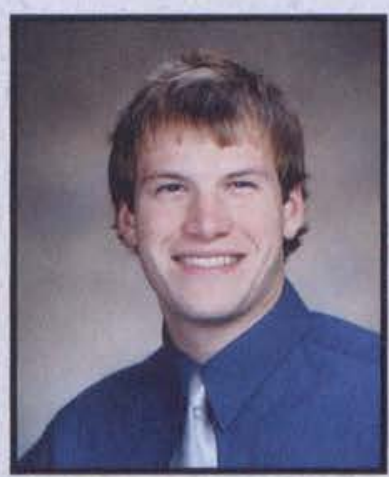

Tim Buchanan

Exercise Science

Columbia Falls, MI

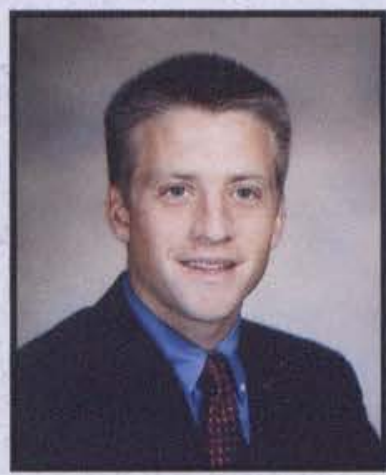

Michael Burgman

Language Arts Education

Pipersville, PA

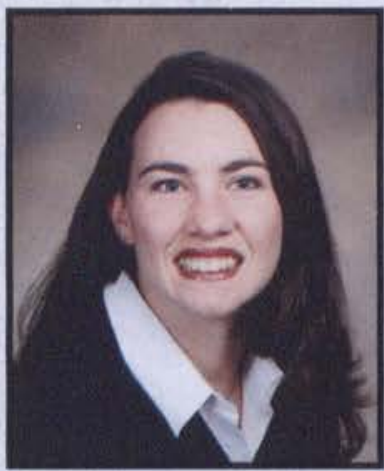

Stephanie J. Carlton Nursing

Washington, DC

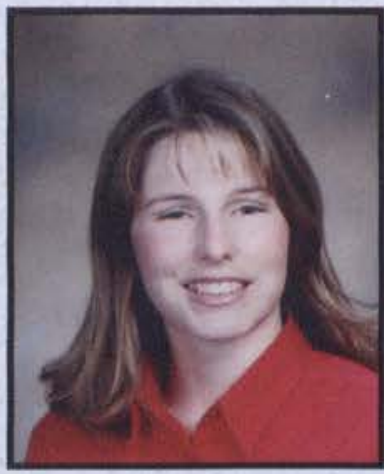

Jennifer Case

Communication Arts

Palmdale, CA

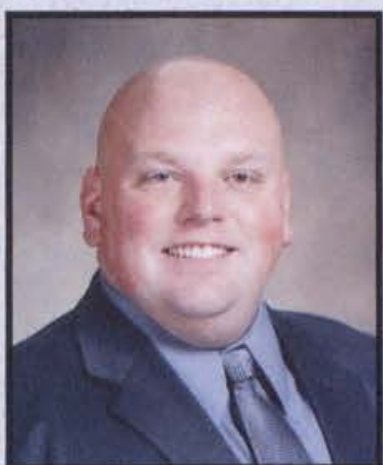

Brett R. Buckingham

Org. Communications

Grand Rapids, MI

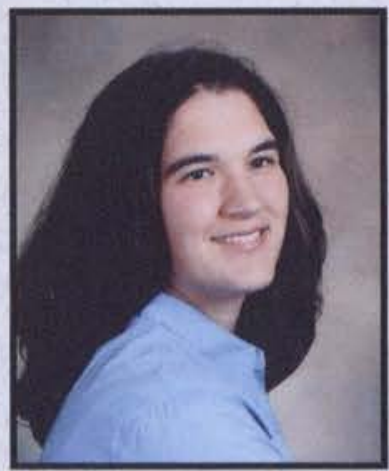

Jena Burns

Early Childhood Education

Lebanon, $\mathrm{OH}$

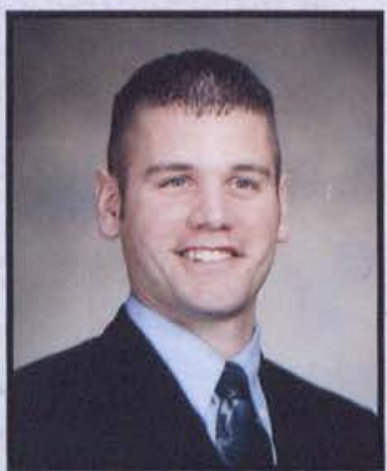

Kevin Carmichael

MIS

Evart, MI

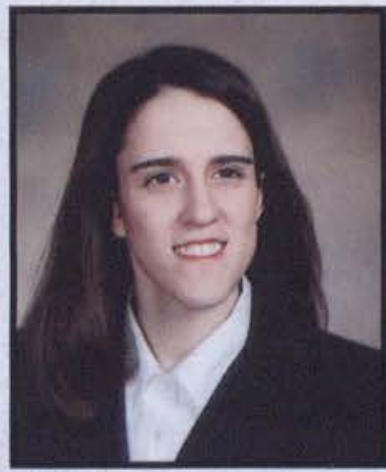

Kendra L. Cassidy

Applied Psychology Camden, MI

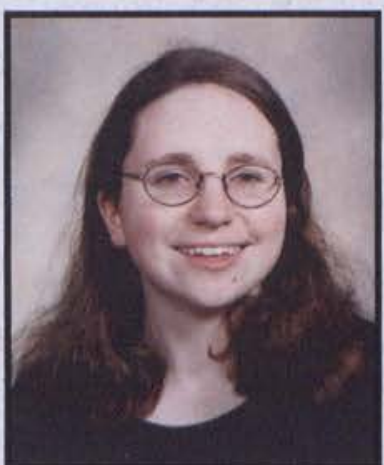

Kate R. Buehner

Music Education

Rochester, NY

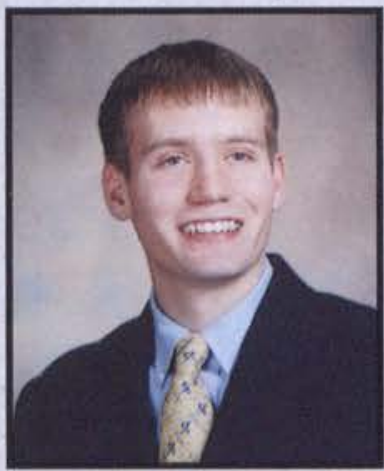

Jeremy Bustle

Pre-Seminary

West Chester, $\mathrm{OH}$

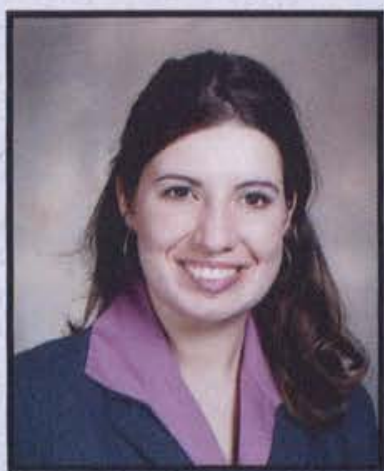

Jennifer Caron

Social Work

Jay, ME

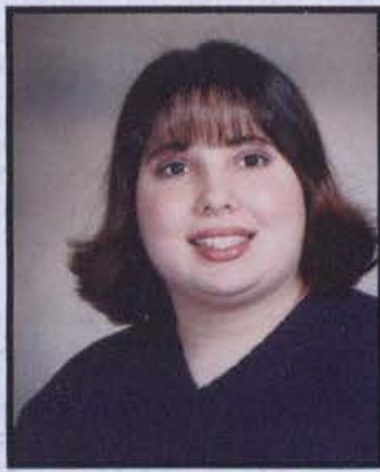

Jennifer Castellani

Technical Communications Sarasota, FL

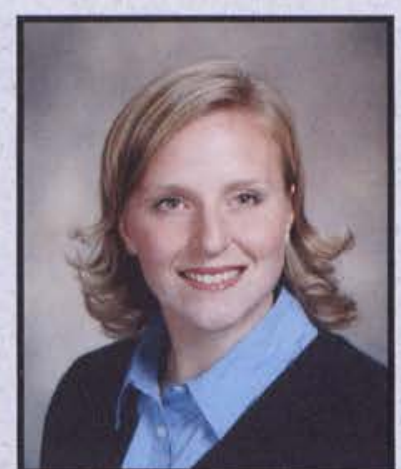

Amber N. Bungart

Biology

Oxford, MI

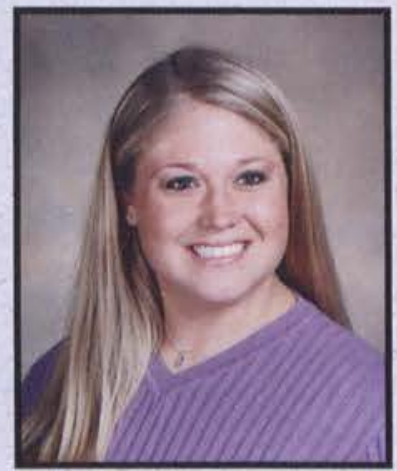

Jill Butz

Physical Education

LaRue, $\mathrm{OH}$

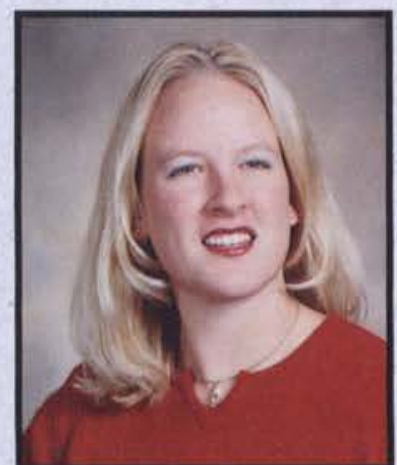

Nicole Carpenter

Language Arts Education Ocala, FL

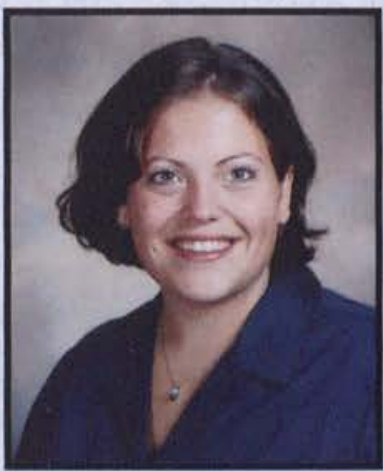

Dawn B. Cazier

Early Childhood Education Hudsonville, MI

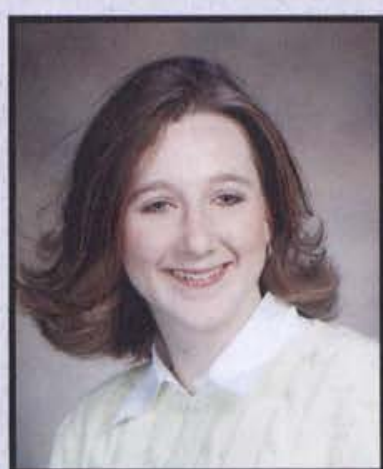

Kristie J. Burch

Biology

Narron, PA

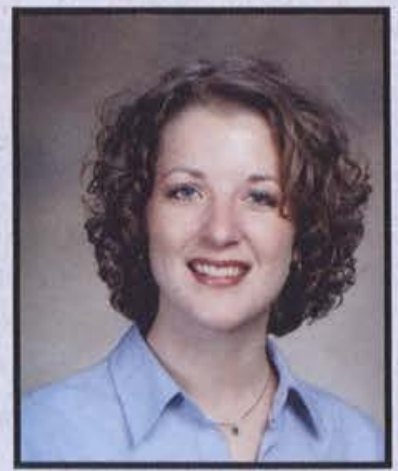

Sarah E. Campbell

Nursing

Mt. Gilead, $\mathrm{OH}$

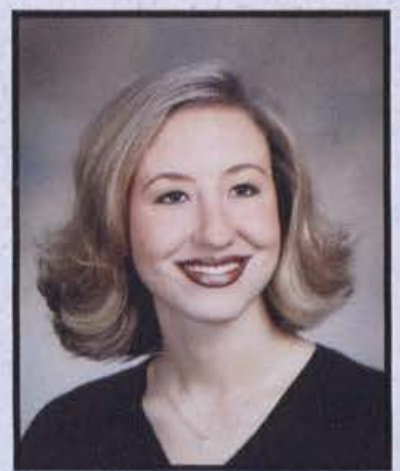

Laurie Carter

Nursing

Pittsboro, IN

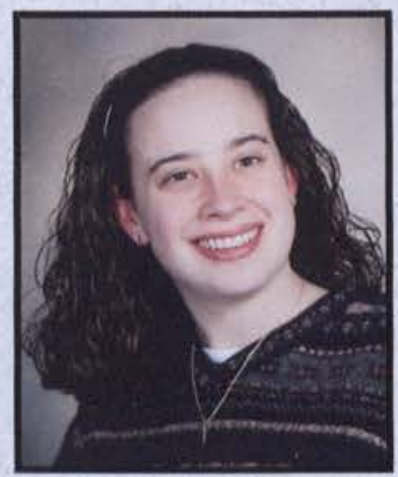

Lindsay Chatfield

Nursing

Tipp City, $\mathrm{OH}$ 


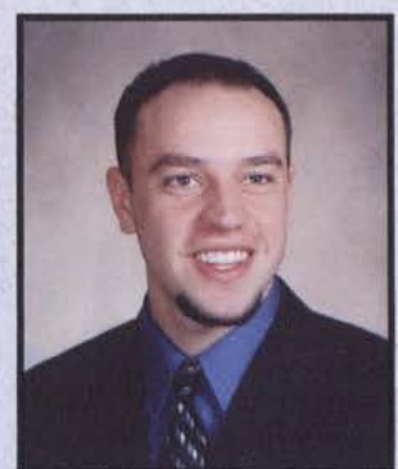

Jonathan Christman

Org. Communications

Philpot, KY

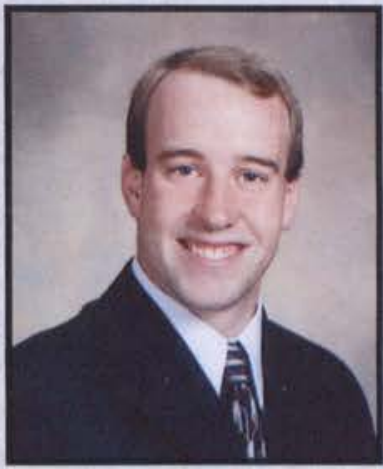

Tim Cochrell

Pre-Seminary

Burbank, $\mathrm{OH}$

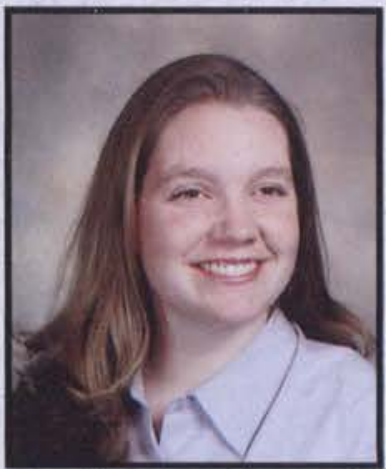

Beth Cooley

Comprehensive Bible

Cedarville, $\mathrm{OH}$

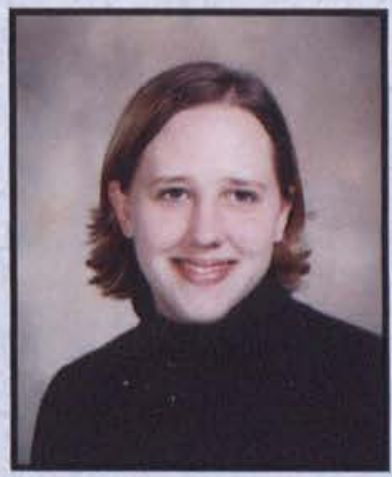

Jodi Crawford

Sociology

Spring Lake, MI

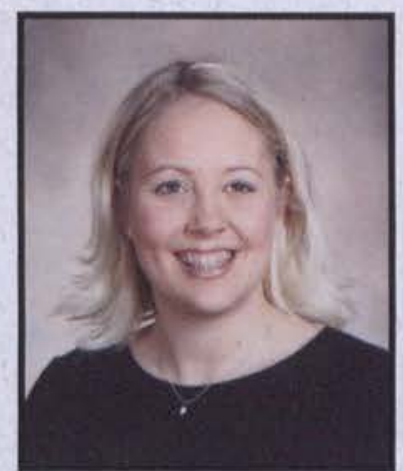

Jennifer Clark

Communication Arts

South Charleston, $\mathrm{OH}$

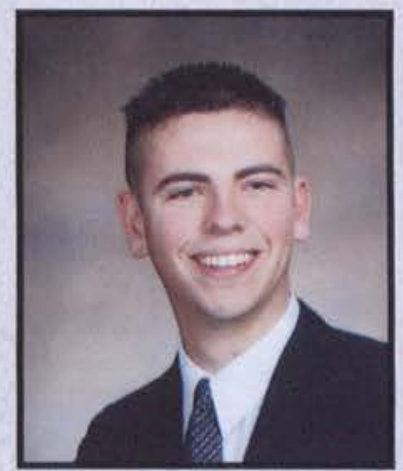

David B. Colao

Political Science

Bel Air, MD

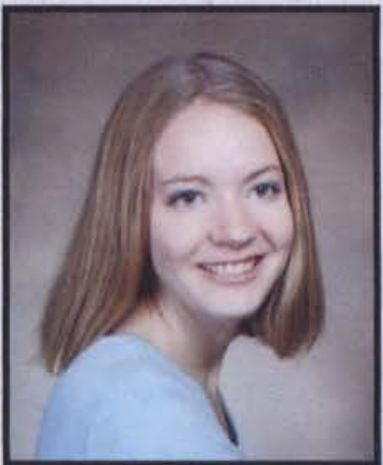

Leah Cooper

Technical Communications Vista, CA

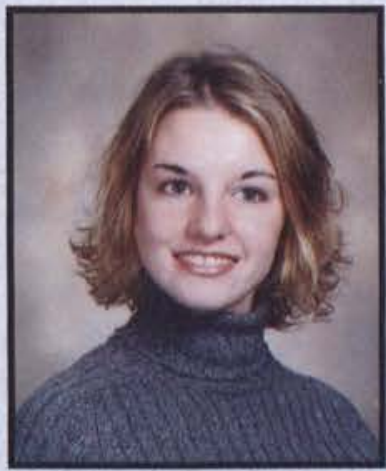

Crystal Cripe

Vocal Performance

Mappane, IN

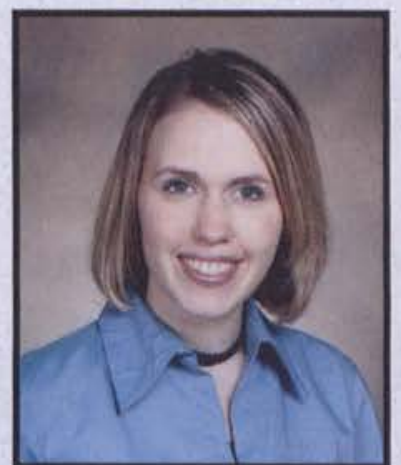

Sarah Clark

Psychology

Perry, IA

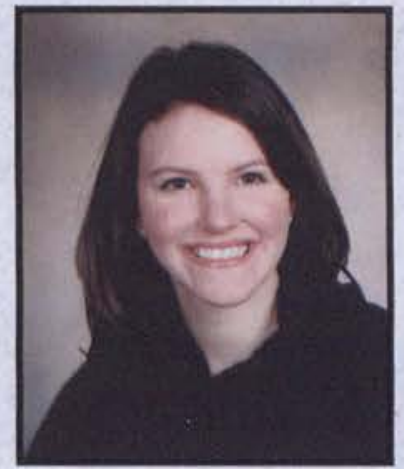

Kimberly Colyer English

Canfield, $\mathrm{OH}$

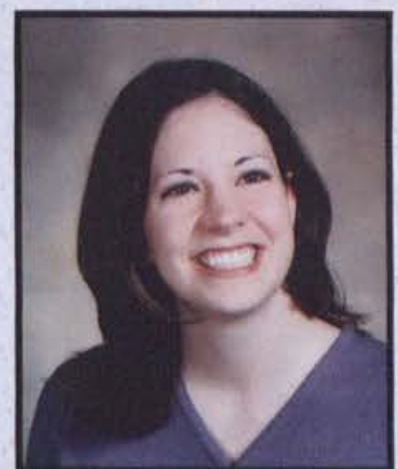

Margaret E. Copella

Psychology

Holland, NY

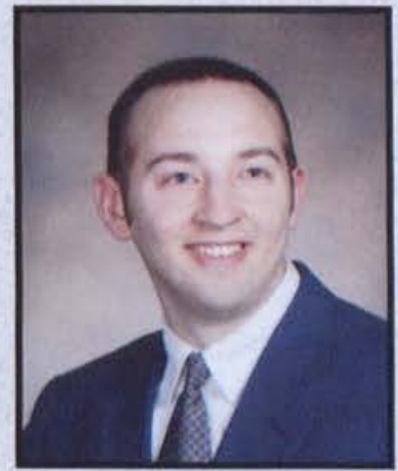

Steven J. Crissman

Broadcasting

Wilmington, DE

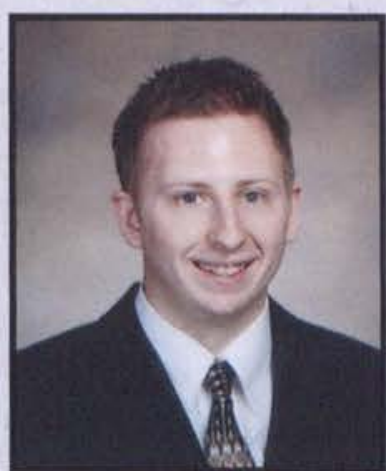

William Cliff

Bible \& CE Youth

Philadelphia, PA

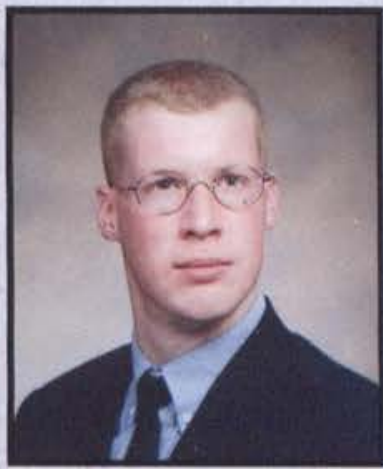

John N. Compton

Electrical Engineering

Winona, MN

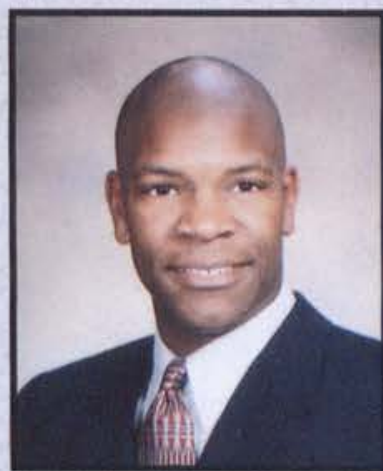

Dan Costin

Integrated Language Arts Sicklerville, NJ

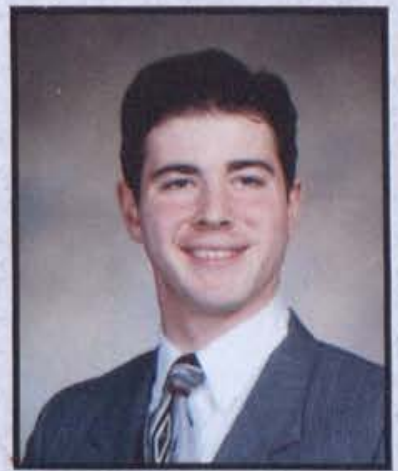

Daniel J. Cross

Physics \& Mathematics West Chester, PA

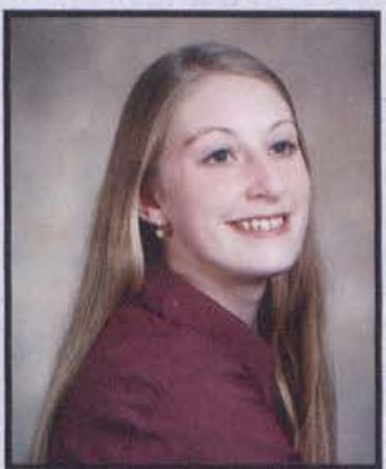

Amy L. Cliffe

Bible Comprehensive

Stow, $\mathrm{OH}$

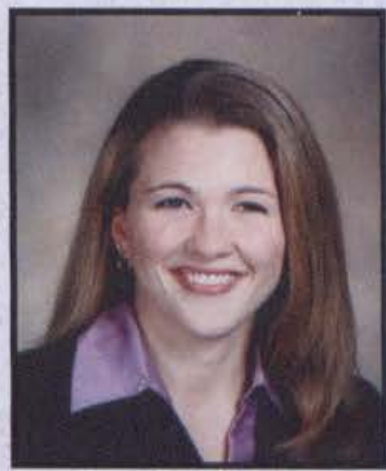

Katherine Conant Nursing

Limington, ME

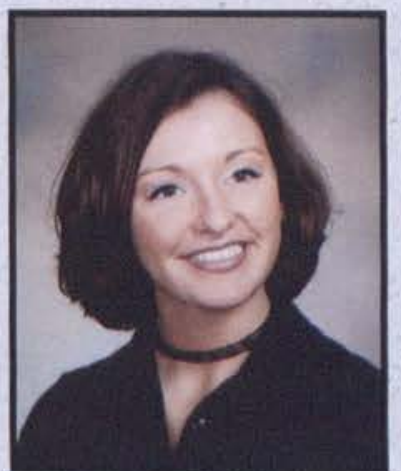

Kellee R. Crady Spanish Education Mr. Rulaski, IL

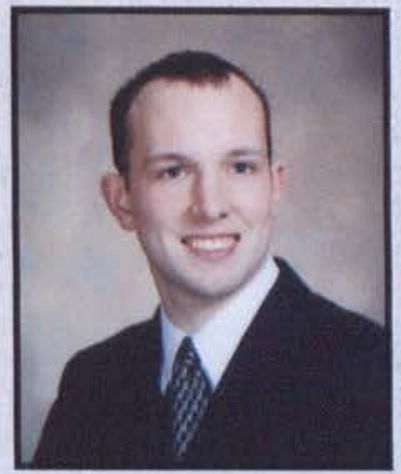

Mark Cross

MIS

Clarks Summit, PA 


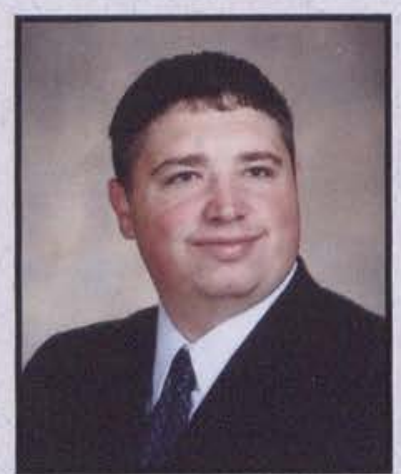

Matt Crowder

Accounting

Brownsburg, IN

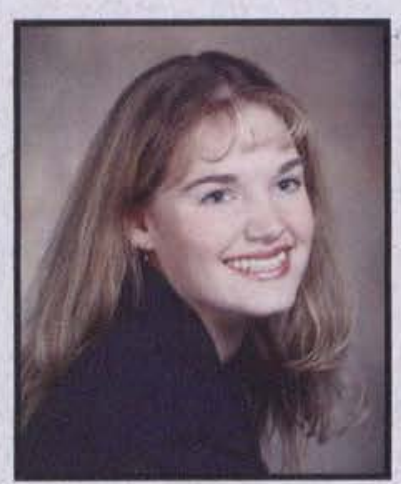

Melissa Dannemiller

Accounting \& Finance

Carroll, $\mathrm{OH}$

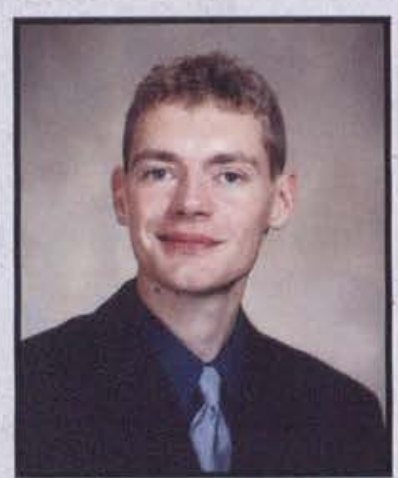

Brian Davis

Management \& Marketing Massillon, $\mathrm{OH}$

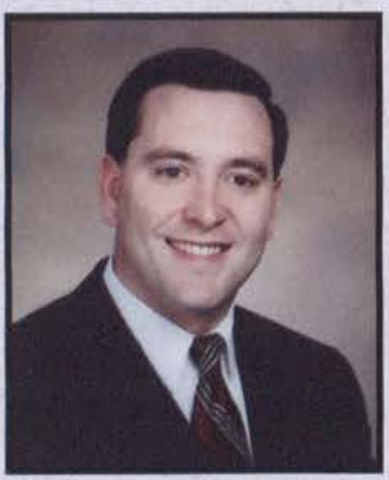

Aaron C. Deal

Bible Comprehensive Cedarville, $\mathrm{OH}$

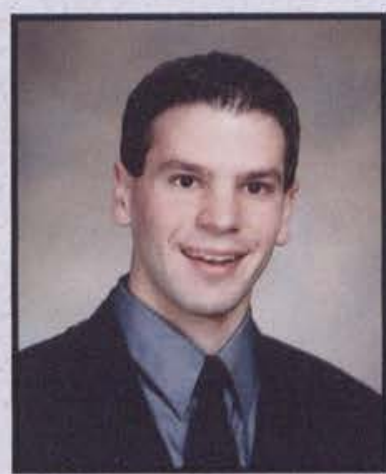

Andrew Cullip

Management Inf. Systems

Goshen, IN

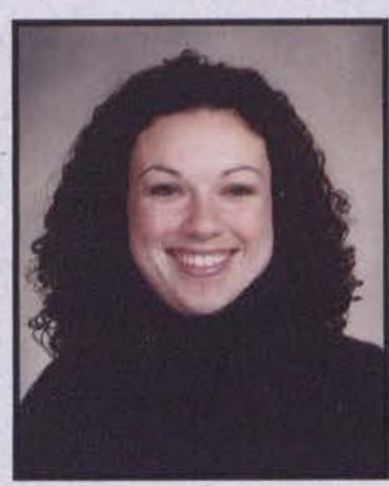

Corban Davies

Applied Psychology

Kapa'a, HI

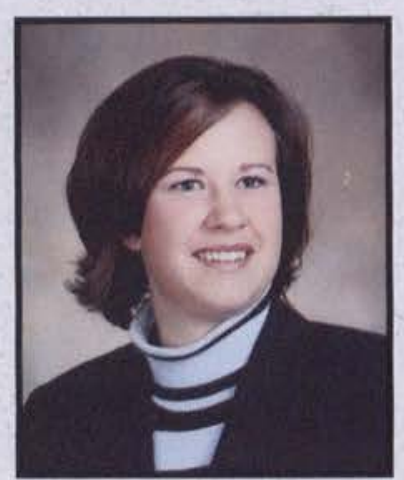

Dana K. Davis

Nursing

LaGrange, NC

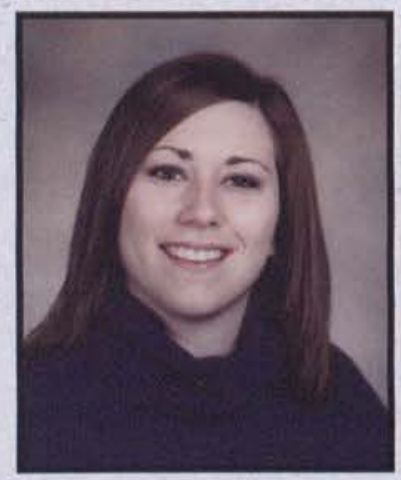

Gina M. DeGuglielmo Christian Education of Youth Elmira, NY

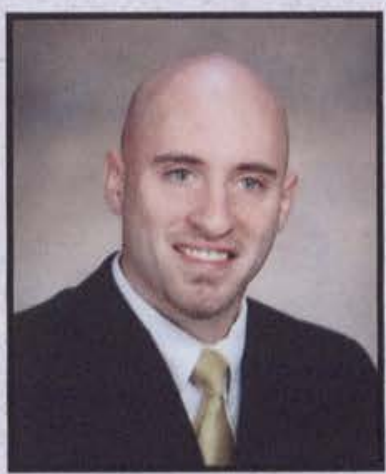

Jonathan Culver

Communication Arts

Clarks Summit, PA

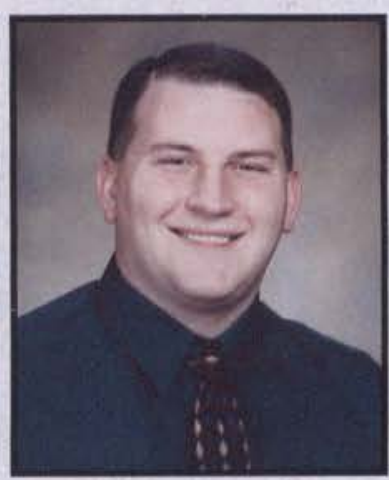

James Davies

AYA Social Studies

Euclid, $\mathrm{OH}$

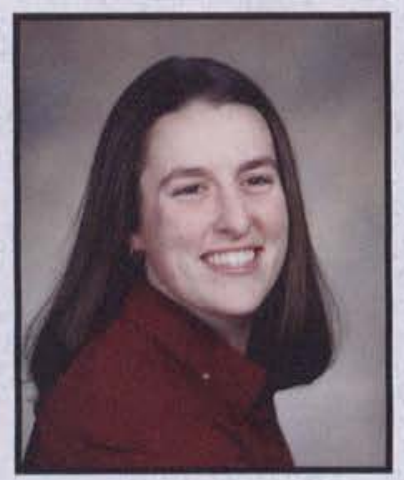

Jennifer R. Davis

Sociology

Cedarville, $\mathrm{OH}$

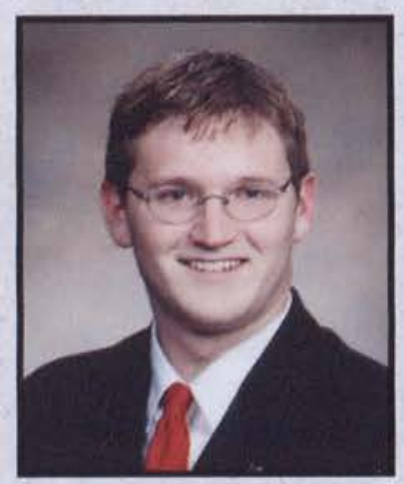

Devin K. DelGrosso

Bible \& CE Youth

Kettering, $\mathrm{OH}$

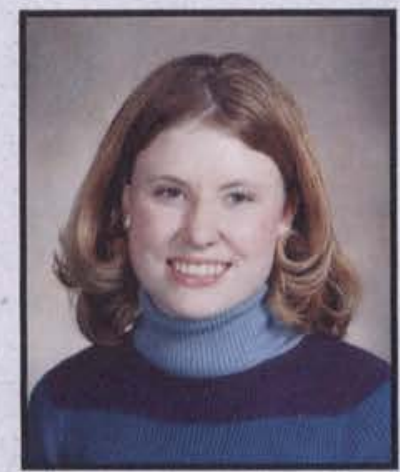

Sarah Cummings

Nursing

Longmont, CO

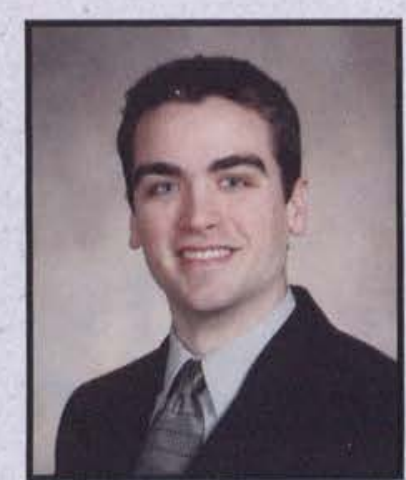

Jonathan R. Davies

Criminal Justice

Mechanicsville, MD

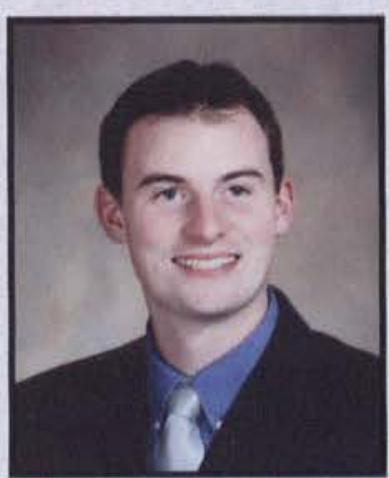

John W. Davis

Public Administration Cedarville, $\mathrm{OH}$

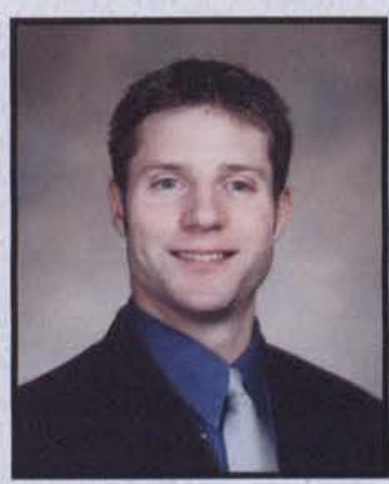

Benjamin DeLong

Church Music

Bellbrook, $\mathrm{OH}$

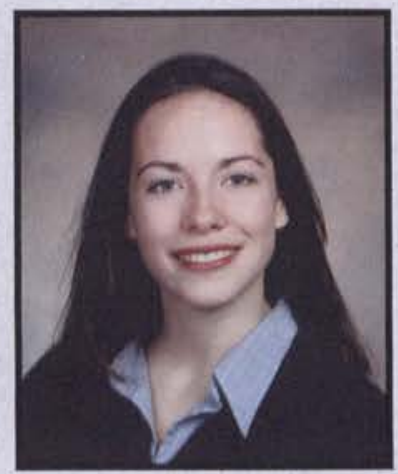

Katherine A. Custer Music

Springfield, $\mathrm{OH}$

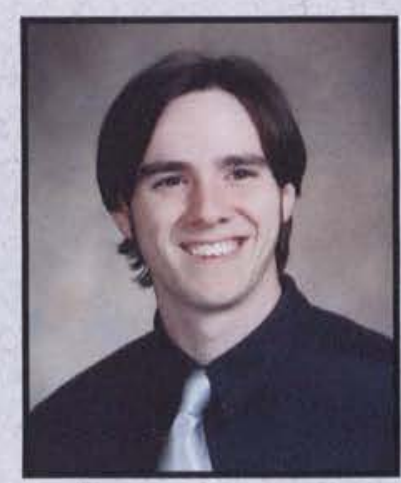

Thomas H. Davies Missions

Havre de Grace, MD

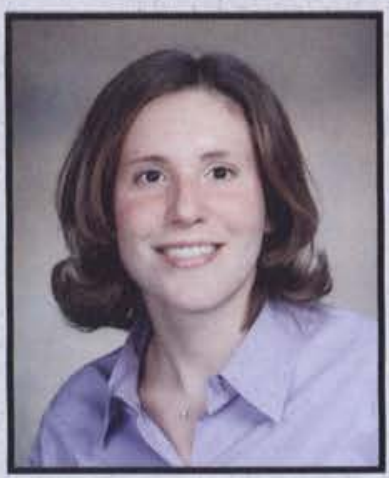

Christine Davlantes

Early Childhood Education Manton, MI

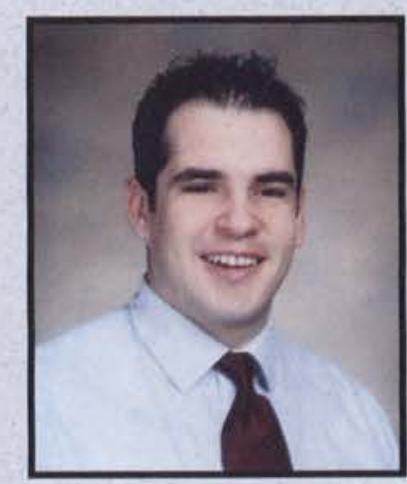

Adam Dennis

Pastoral Studies

Williamsburg, MI 


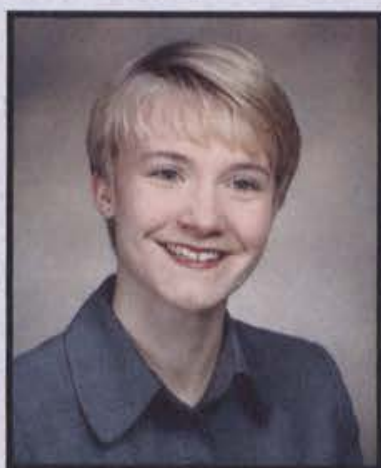

Roberta Jo Denny

Early Childhood Education Caldwell, $\mathrm{OH}$

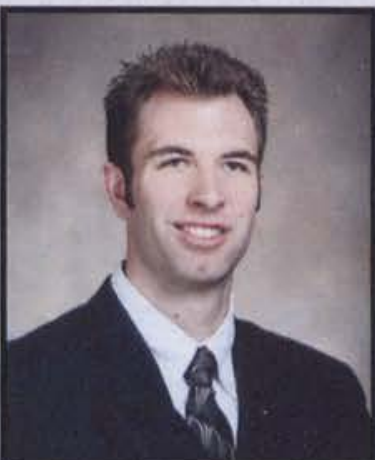

David Dingeman

Business Management Springfield, $\mathrm{OH}$

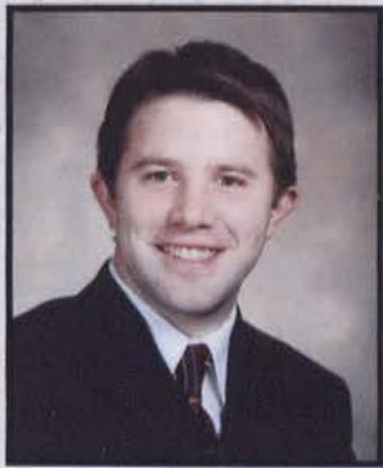

David Drye

Mechanical Engineering Bloomington, IL

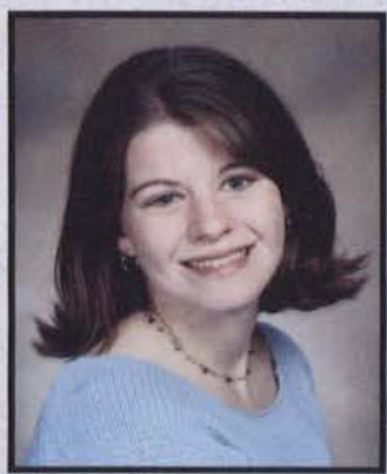

Alison S. Edwards Nursing

Uniontown, PA

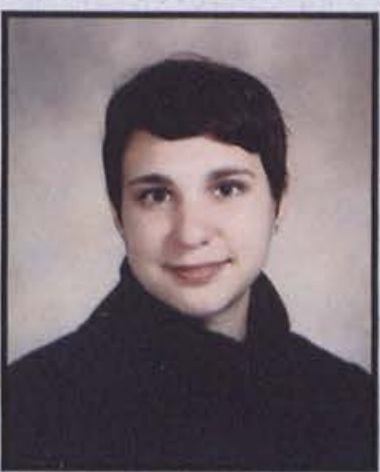

Rebecca DeSantis Broadcast \& Video Prod. West Milton, $\mathrm{OH}$

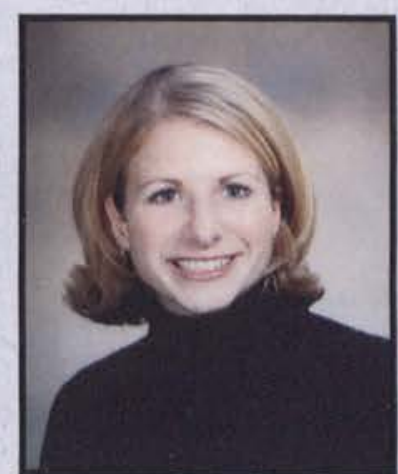

Carolyn M. Dizer Exercise Sports Science Pelham, $\mathrm{NH}$

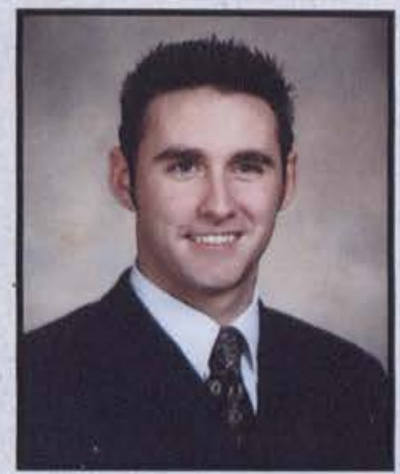

Brian Dugan

Org. Communications Langhorne, PA

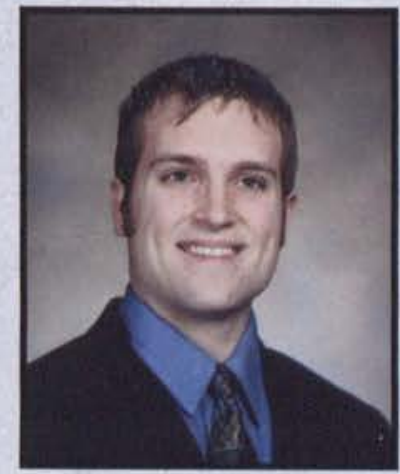

Nathan Eikhoff Social Studies Education Shelby Township, MI

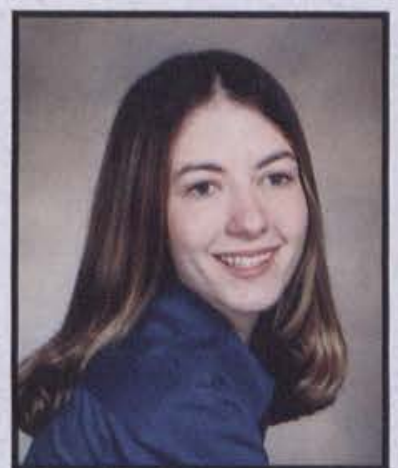

Kathryn DeVoll AYA Life Science

Perkiomenville, PA

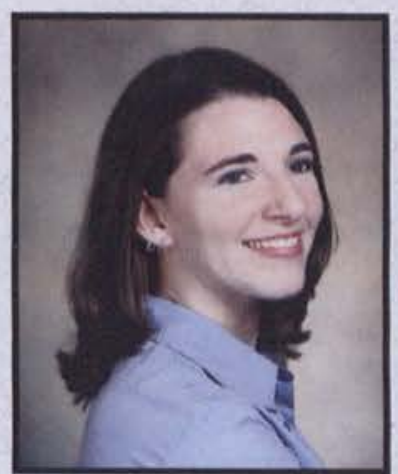

Teri Doleys

Elementary Education Bolingbrook, IL

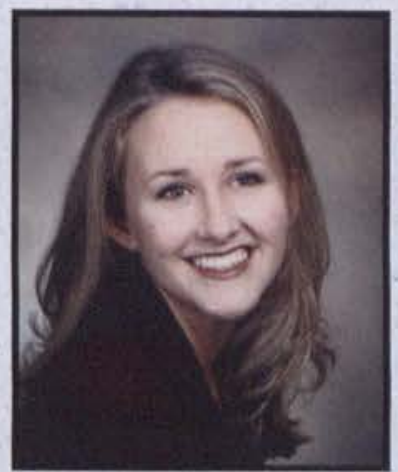

Julie A. Dugan

Org. Communications Langhorne, PA

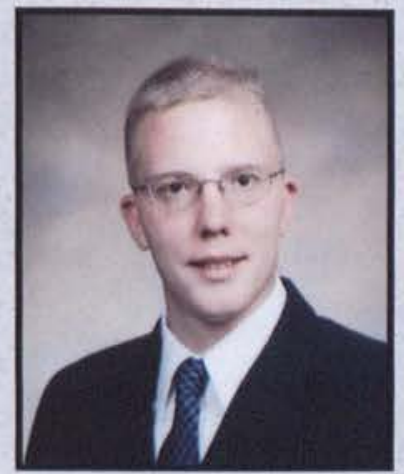

John Erickson

Criminal Justice

Fallston, MD

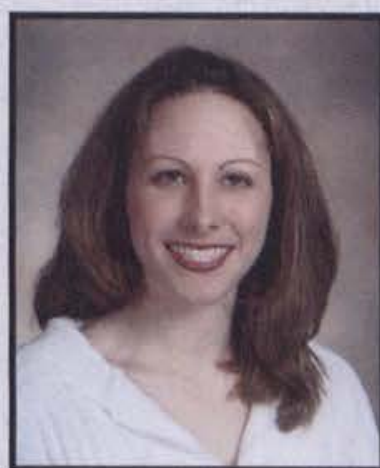

Carrie DiehI

End-User Information Systems Waubegan, IL

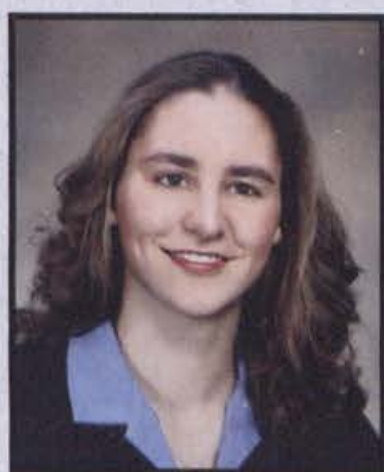

Julie Driessnack Business Management Dunlap, IL

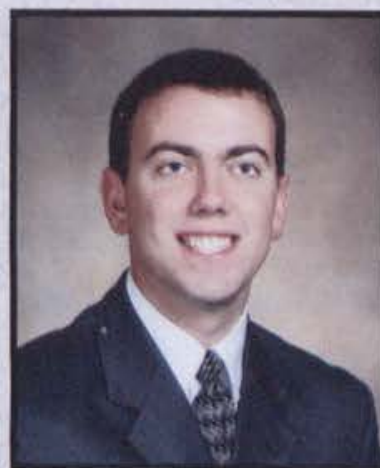

Daniel W. Dunham

End-User Information Systems Peoria, IL

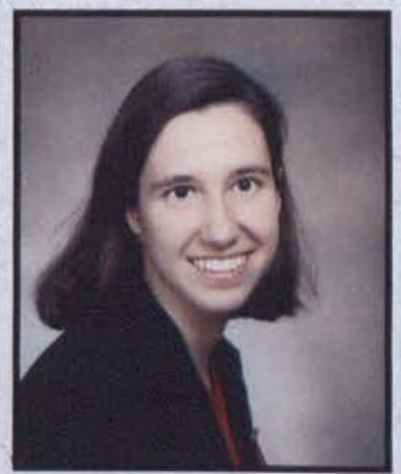

Kimberly Eridon

Technical \& Professional Comm. Bowling Green, $\mathrm{OH}$

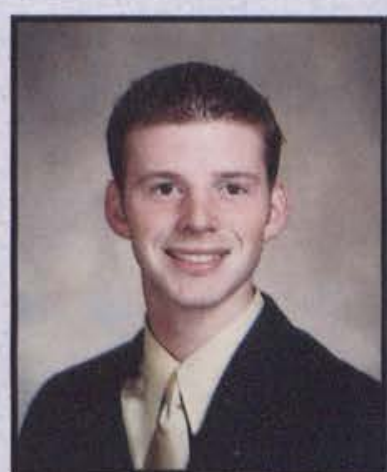

Aaron Dieringer

English

Conyers, GA

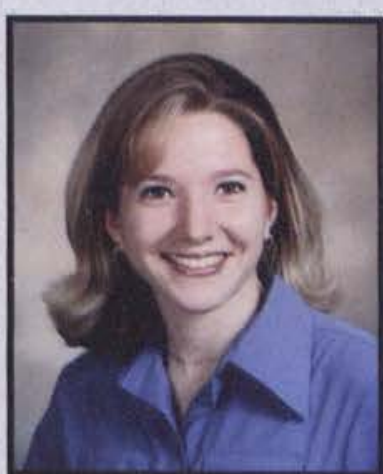

Michelle Drumheller Spanish Education West Milton, $\mathrm{OH}$

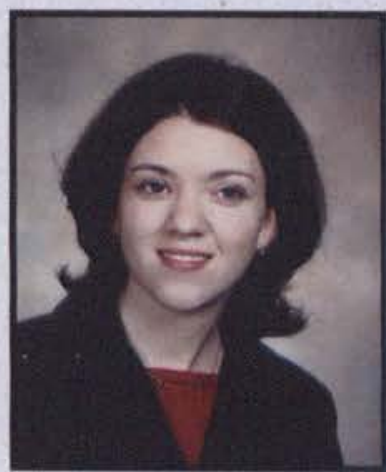

Amber M. Durbin Finance \& Marketing Mount Vernon, $\mathrm{OH}$

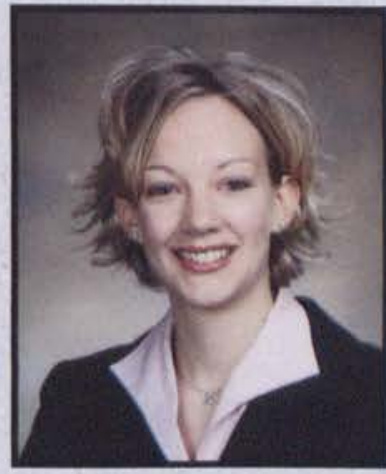

Joanna Estes

Human Resource Mang. Bowie, MD 


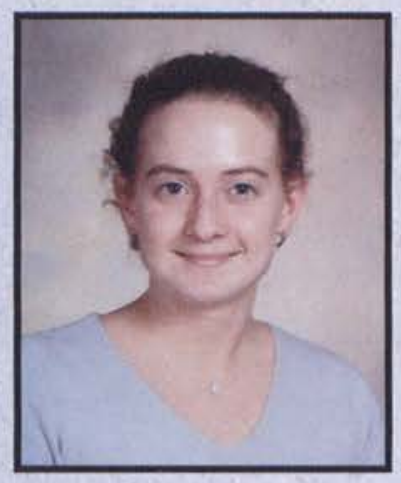

Emily Evans

Nursing

Knoxville, TN

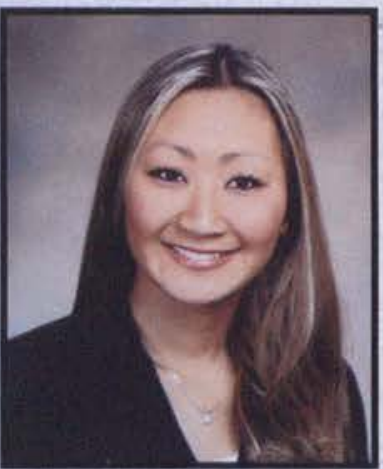

Darcy Fivek

Finance

Peru, IL

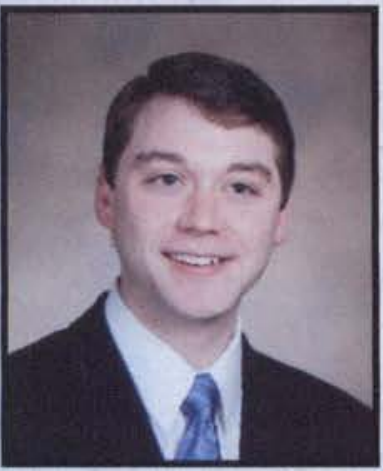

Nicholas Forshee

Mechanical Engineering Caro, MI

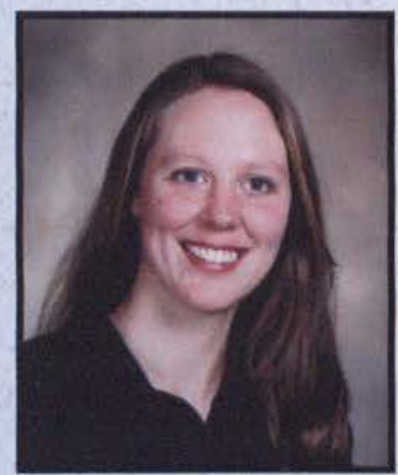

Sheila A. Fraser

Nursing

Tully, NY

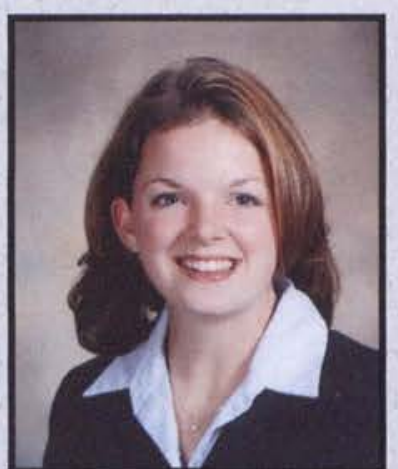

Erin J. Ewig

Nursing

Xenia, $\mathrm{OH}$

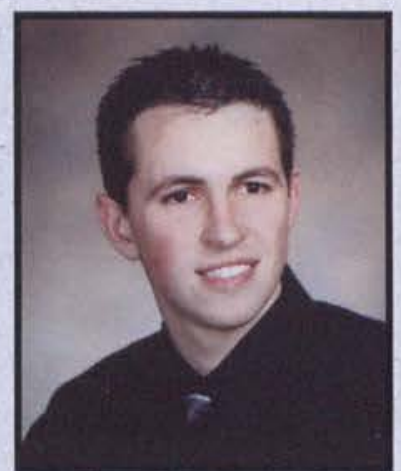

Curtis J. Fleck

Broadcast Production Riverton, IL

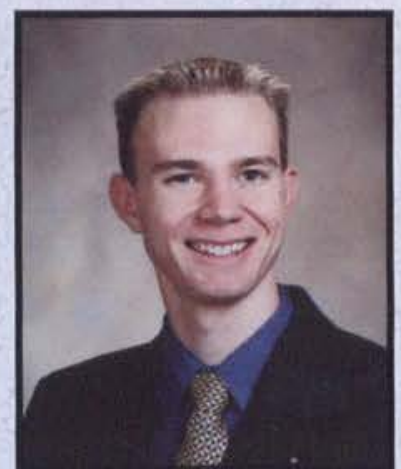

Kenny Foster

Political Science Ceres, CA

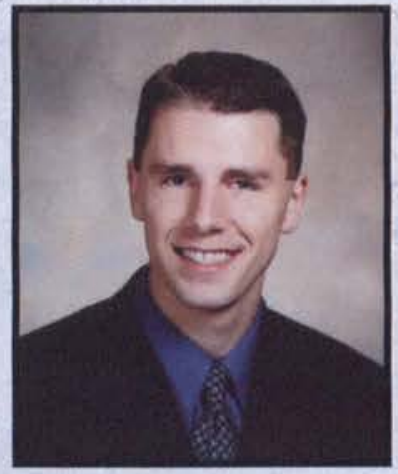

Luke Frederickson MIS

Huntertown, IN

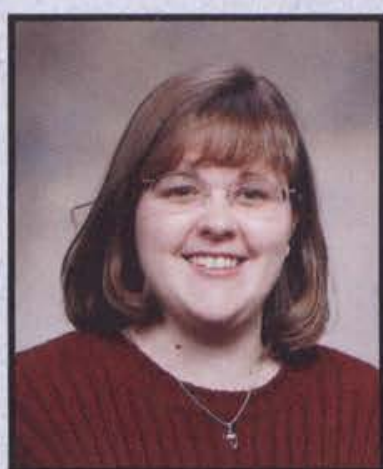

Dawn E. Faugl

Broadcasting

Aiken, SC

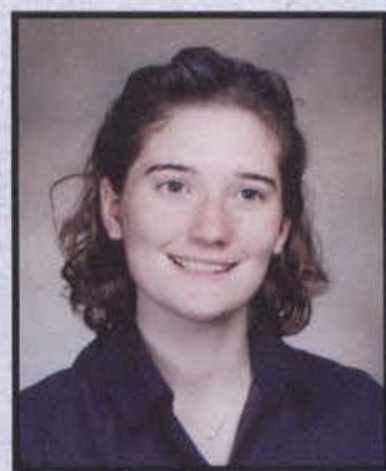

Jenny Flood

Early Childhood Education

Orion, MI

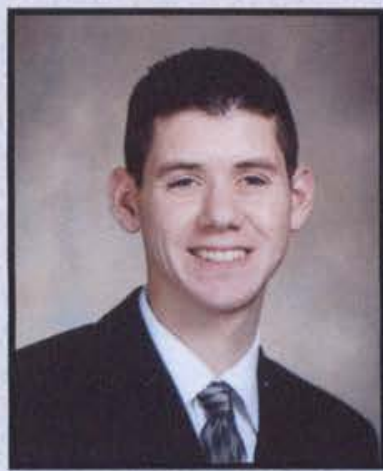

Ryan Foster

Early Childhood Education North East, MA

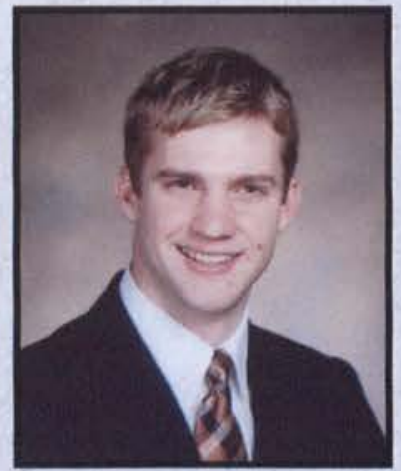

Michael Freeze

Management \& Marketing Punxsutawney, PA

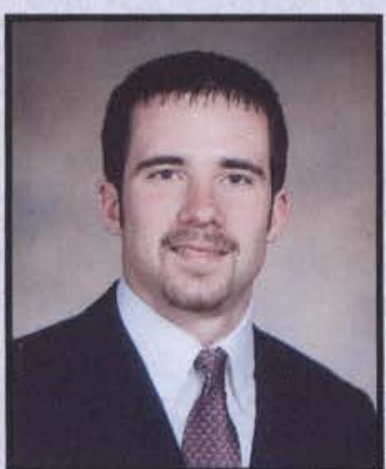

Lance E. Ferguson

Mechanical Engineering

Adrian, MI

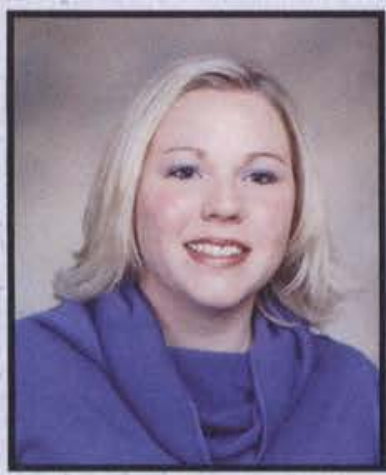

Erin Flora

Early Childhood Education Lynchburg, VA

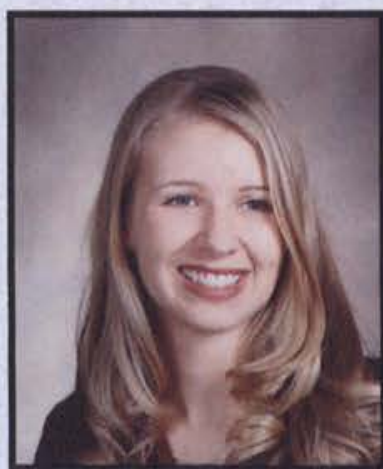

Esther M. Fowler

Pre-Seminary

Oakdale, PA

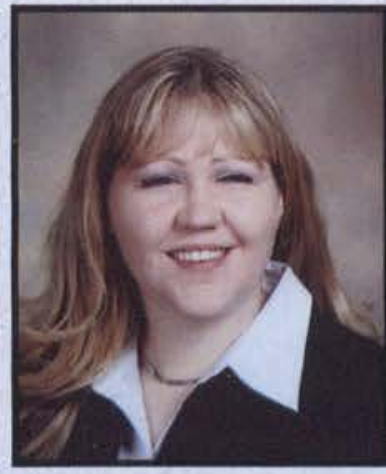

Rachel Frey

Early Childhood Education Dushore, PA

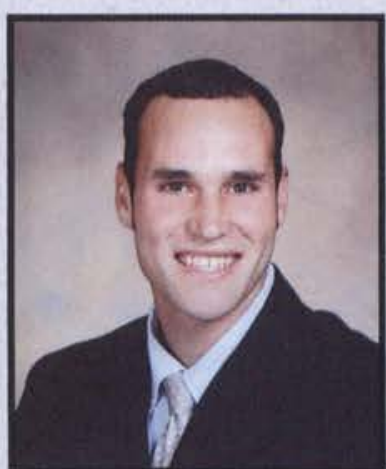

Benjamin J. Fisher Business Management Buellton, CA

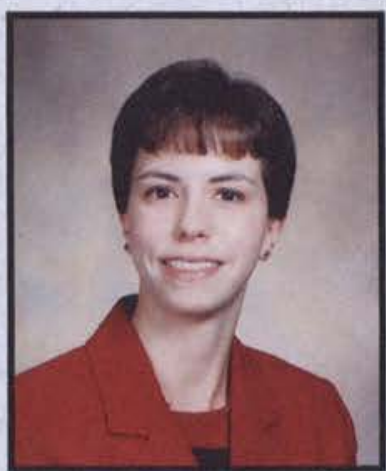

Alyssa Foltz Physical Education Northfield, $\mathrm{OH}$

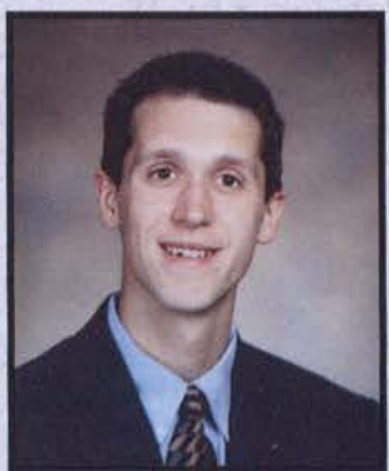

Jody R. Fox

CE Youth \& World Missions Corry, PA

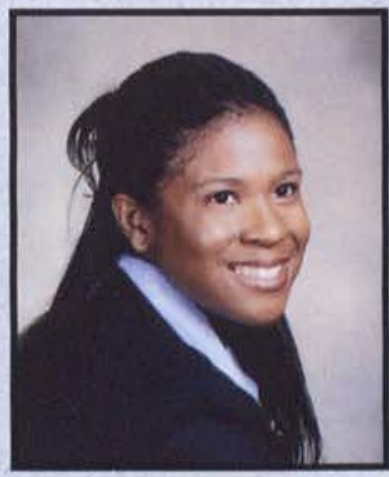

Crystal Frowner

Communication Arts Kansas City, MO 


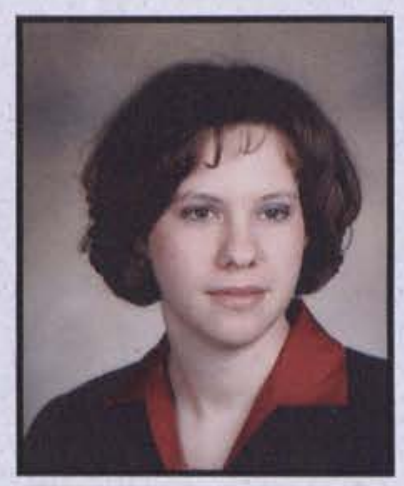

Katie A. Fry

English

Bloomington, IL

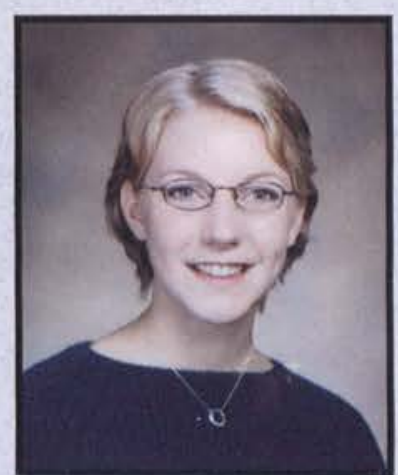

Rebecca L. Gapinski Communications \& Marketing Westfield, IN

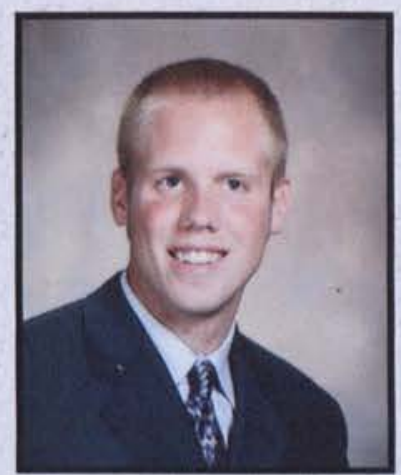

Justin Geer

Pre-Seminary

Batavia, IL

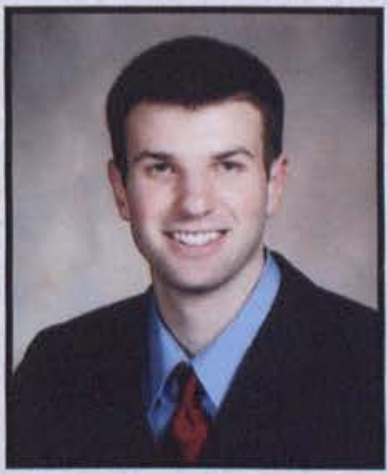

Nathaniel Gilbert

AYA Social Studies

Waterloo, NY

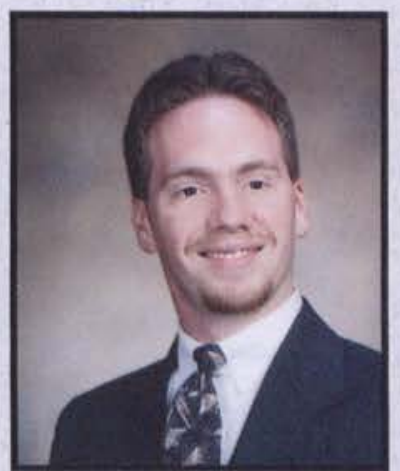

Stephen R. Gaines

Christian Education of Youth Siler City, NC

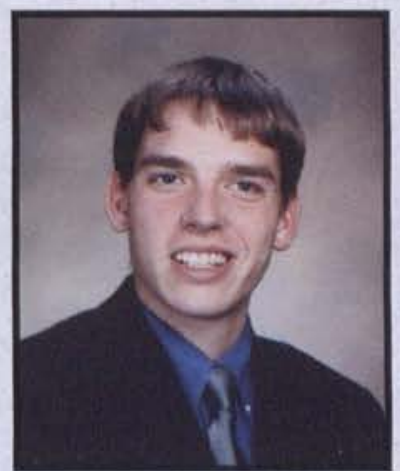

Matthew R. Garrett

Biology

Dayton, $\mathrm{OH}$

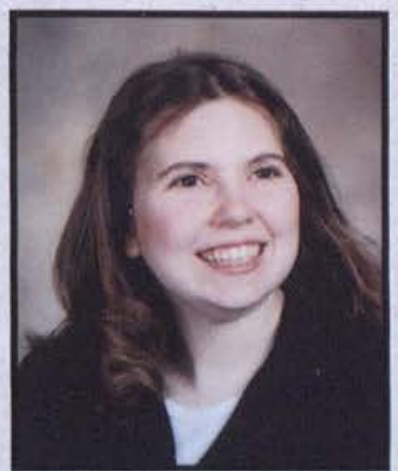

Andrea G. Gensel

End-User Information Systems Manito, IL

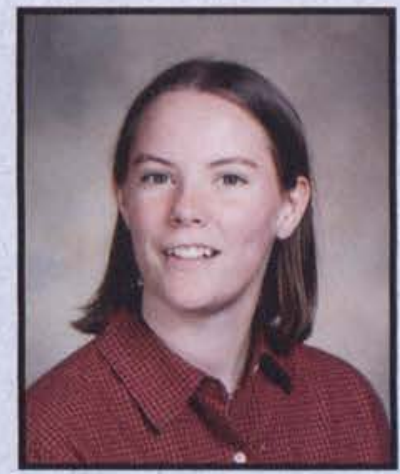

Stephanie R. Gillett Multi Age Physical Education Grand Rapids, MI

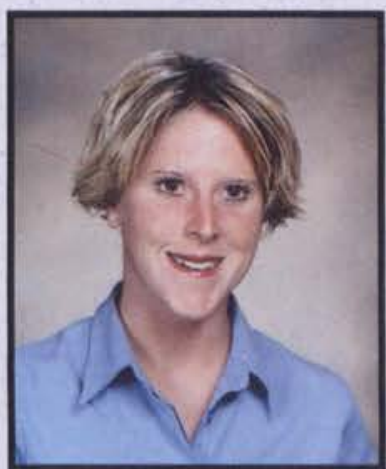

Laurie A. Gallo

Physical Education

Uniontown, PA

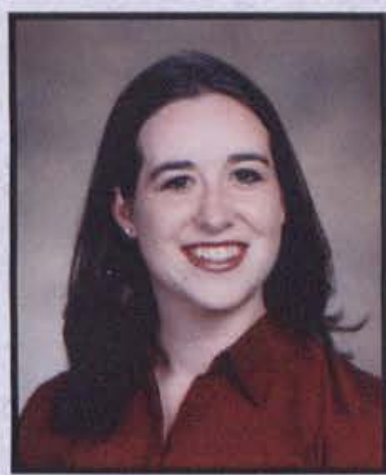

Sarah Gaynier

Early Childhood Education

Beavercreek, $\mathrm{OH}$

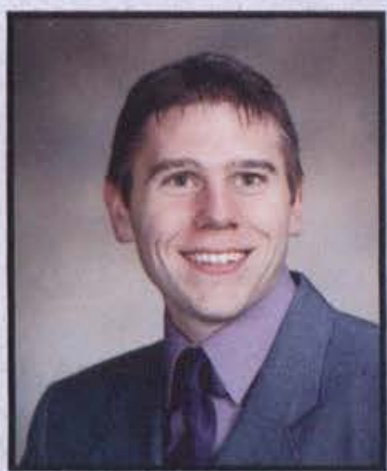

Dana Gerber

Criminal Justice Lander, WY

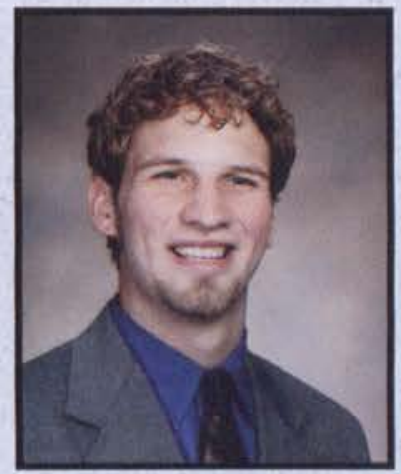

Nathan Goldston

Pastorál Studies

Knoxville, TN

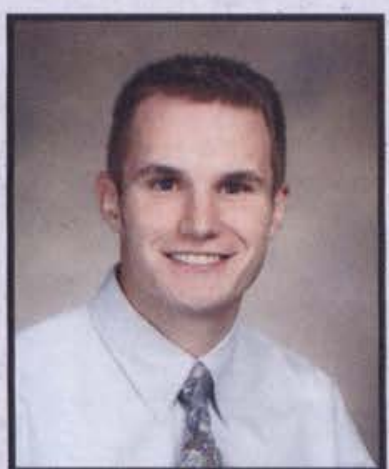

Levi Gangi

English

Livonia, NY

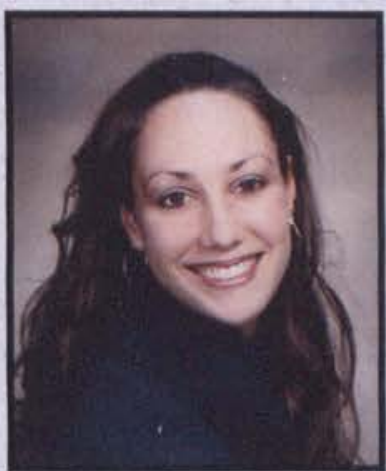

Meredith Gbur Early Childhood Education

Flemington, NJ

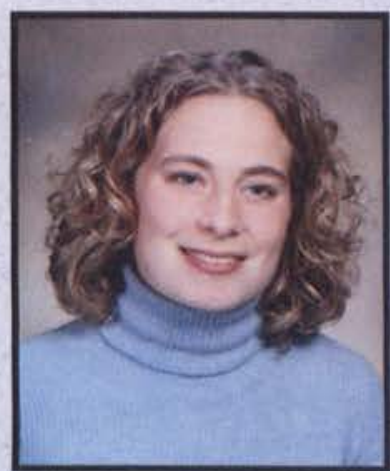

Jennifer Gerber

Middle Childhood Education Dover, $\mathrm{OH}$

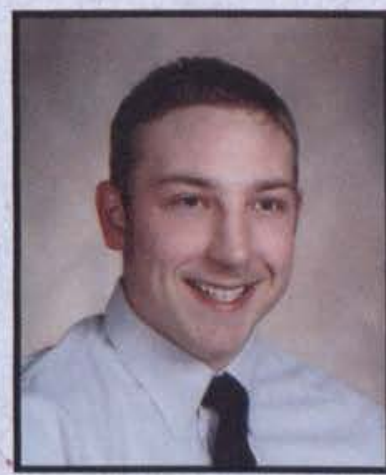

Lee J. Gotthardt

Nursing

Hancock, NY

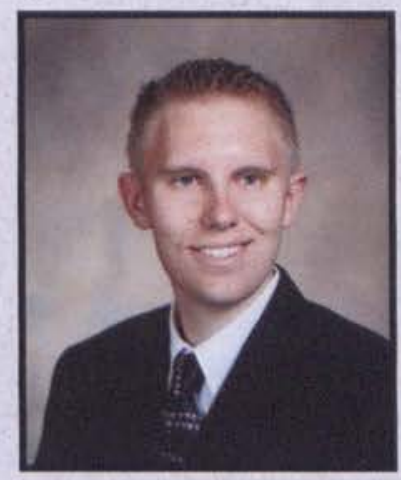

Jeff Ganong

Political Science

Lisbon Falls, ME

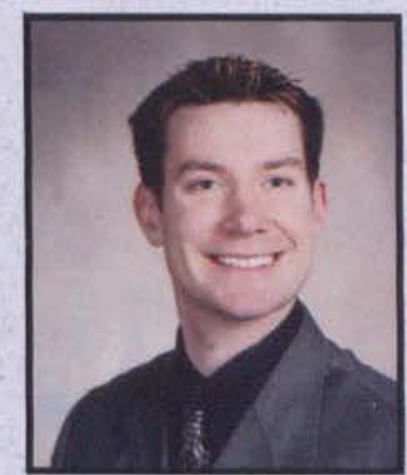

David C. Gedney

Broadcasting

Otego, NY

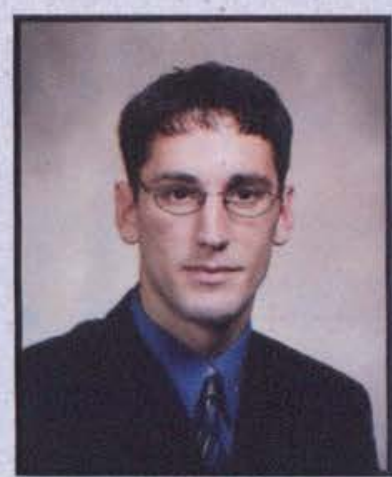

Justin Gerber

Accounting \& Finance

Pella, IA

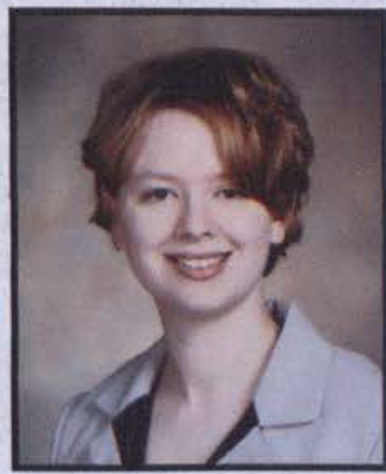

Sarah Graham

Applied Psychology Goshen, $\mathrm{OH}$ 


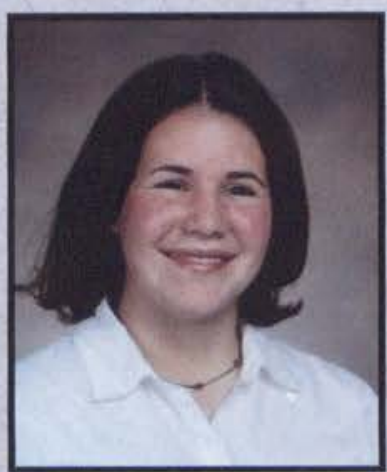

Jennifer Gration

Special Education

Springfield, VA

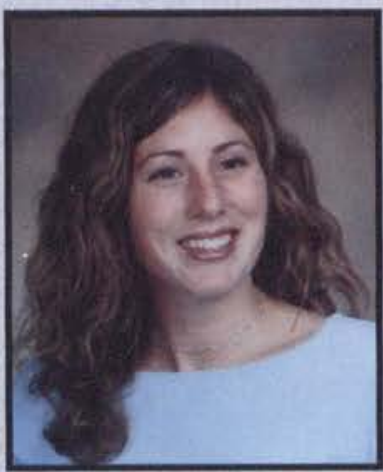

Amy Gregory

Business \& Marketing

Hudsonville, MI

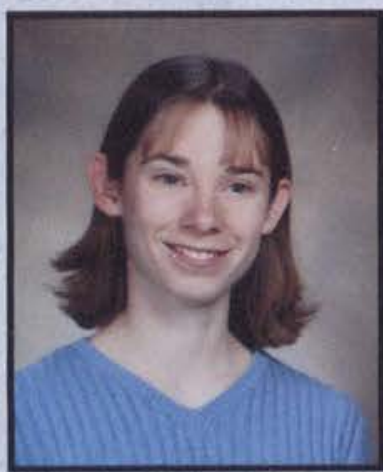

Carla Grossman

Keyboard Pedagogy

Castile, NY

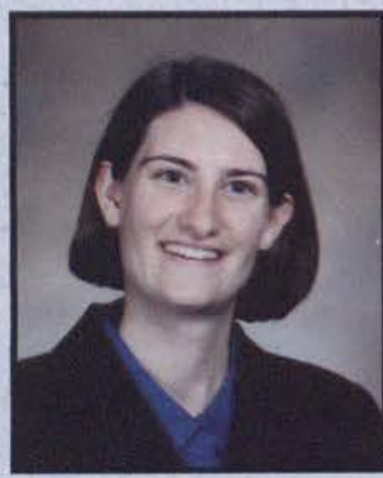

Heather Hall

Business Management Canton, $\mathrm{OH}$

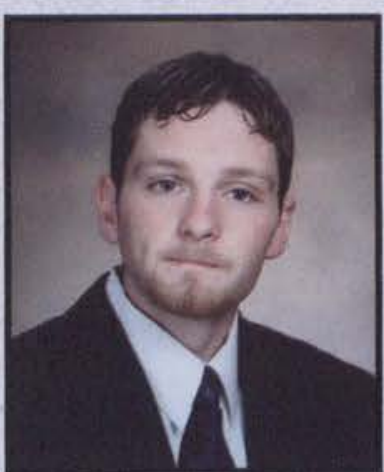

Jason C. Gray

Biology

St. Charles, MO

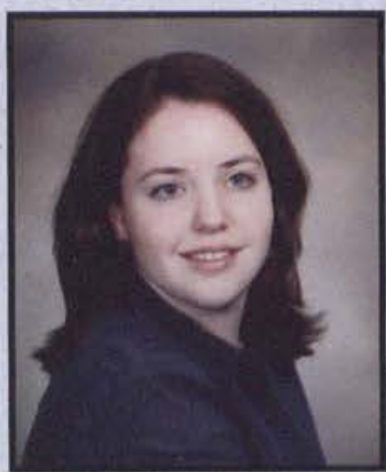

Amy Griffith

Nursing

Lancaster, PA

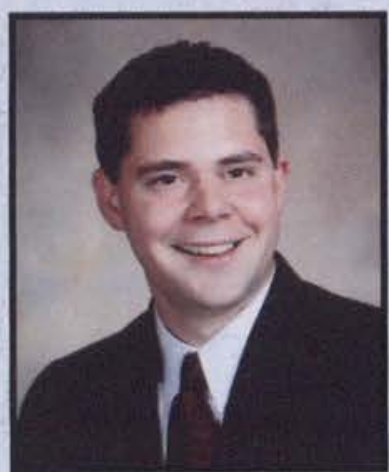

John R. Groth

Political Science

Uniontown, $\mathrm{OH}$

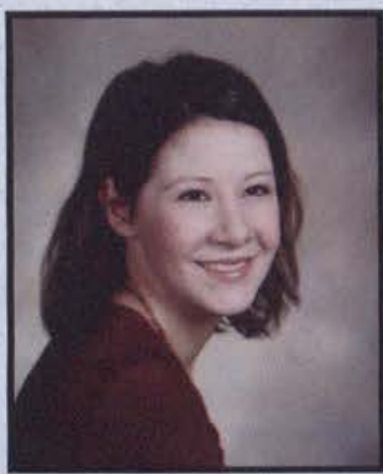

Jessica D. Halsmith

Psychology

Cedarville, $\mathrm{OH}$

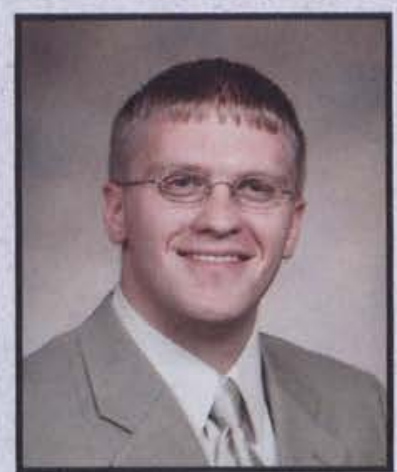

Anthony E. Grebner

Management

Chillicothe, IL

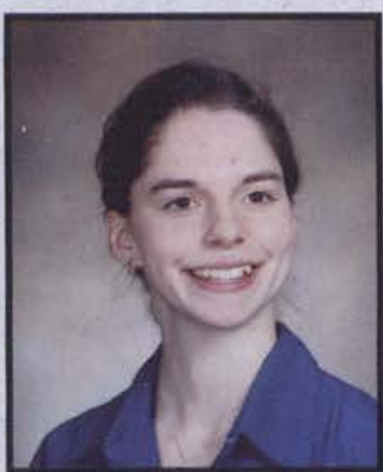

Shannon L. Grimm

Social Work

Streetsboro, $\mathrm{OH}$

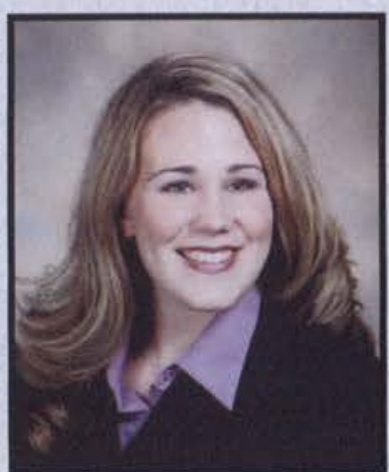

Cheryl J. Gumprecht

Nursing

Colbert, WA

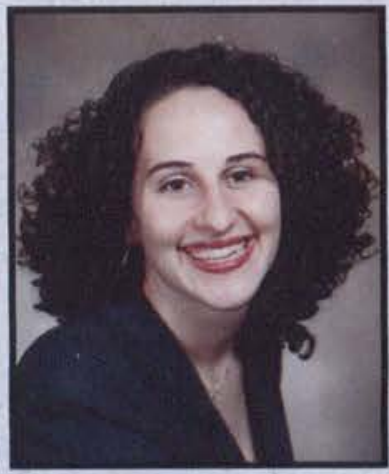

\section{Heidi Hambsch}

Nursing

N. Garden, Utah

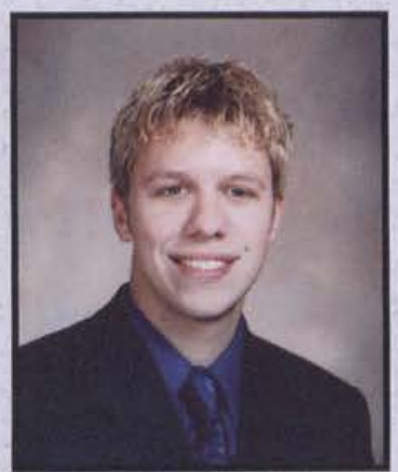

Ray Green

Communication Arts

Newark, $\mathrm{OH}$

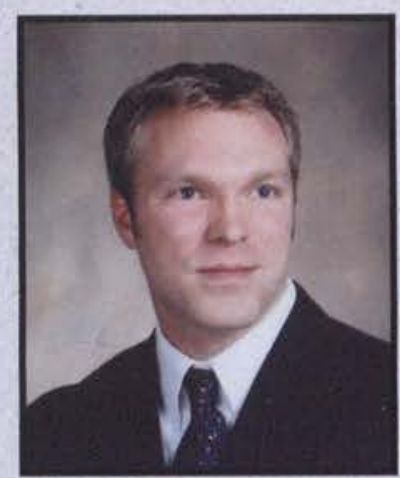

Nicholas Grisco

Mechanical Engineering

Roselle, IL

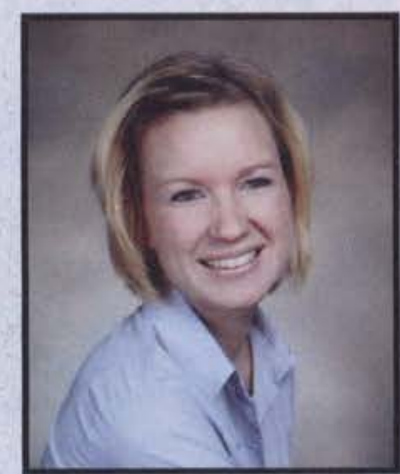

Aamie Guptill

Broadcasting

Berwick, ME

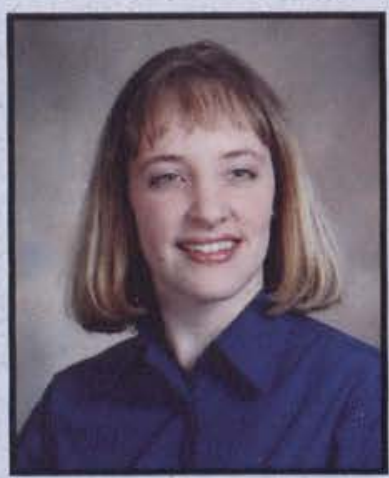

Kristen M. Hamilton

Public Communications Clarks Summit, PA

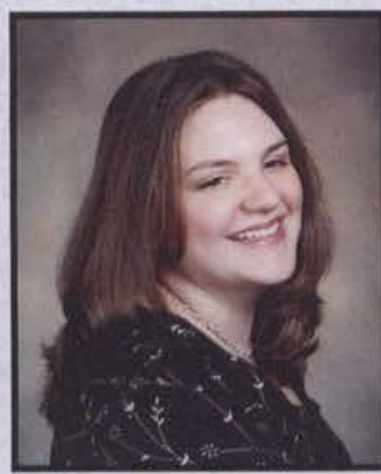

Sarah L. Greene

Language Arts Education

Batavia, $\mathrm{OH}$

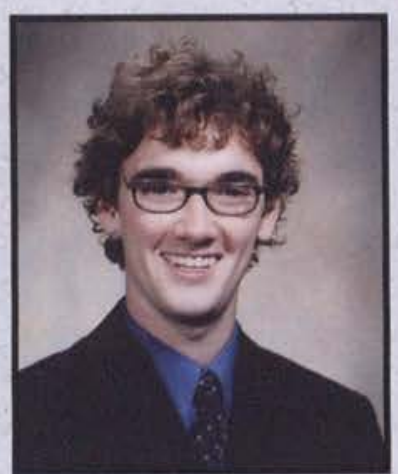

David Gross

Social Work

Elmhurst, IL

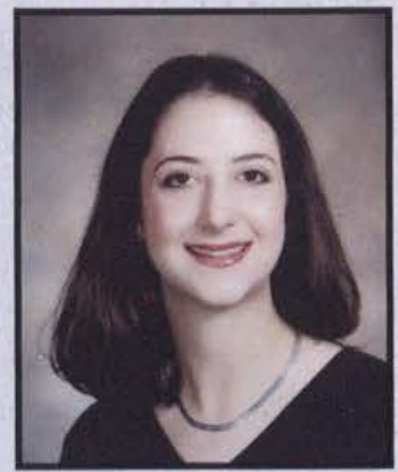

Kimberly Hain

Music Education

Chattanooga, TN

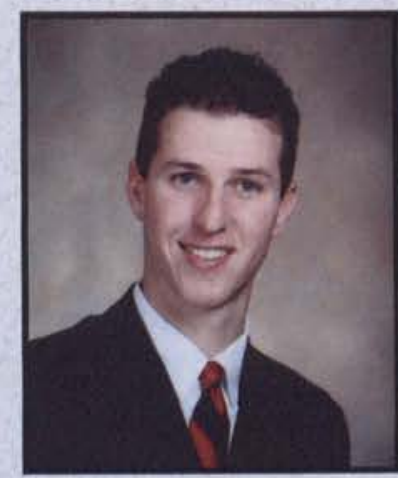

Trenton A. Hamilton

History

Niceville, FL 


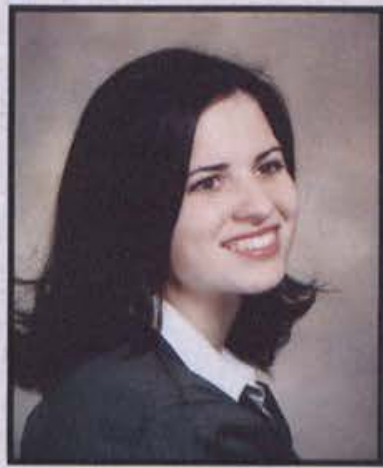

Amanda G. Hancock

Mathematics

Oxford, PA

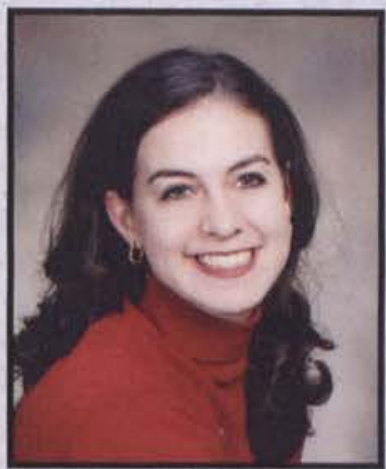

Mary E. Haug

Organizational Comm.

West Chester, $\mathrm{OH}$

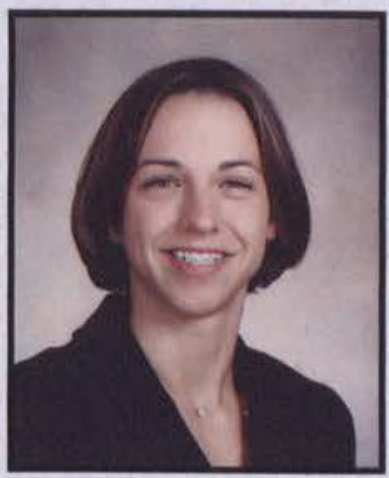

Jenifer A. Heidenreich Nursing

Treasure Island, FL

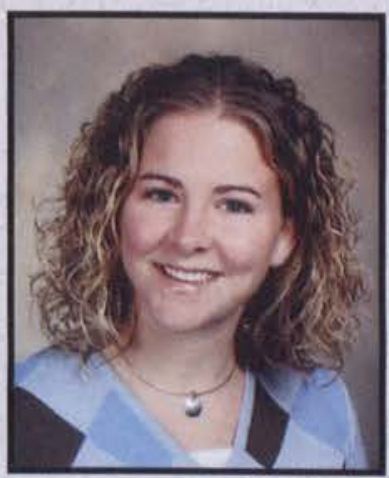

Jessica Hill

English

Grove City, OH

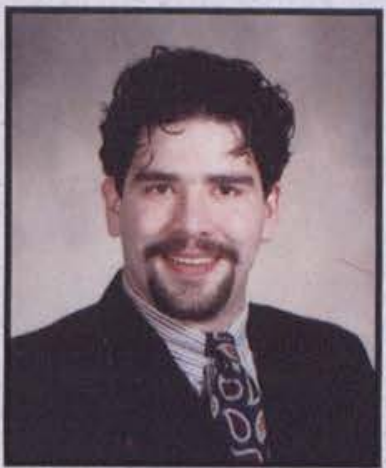

Daniel J. Hankinson

Spanish

Zion, IL

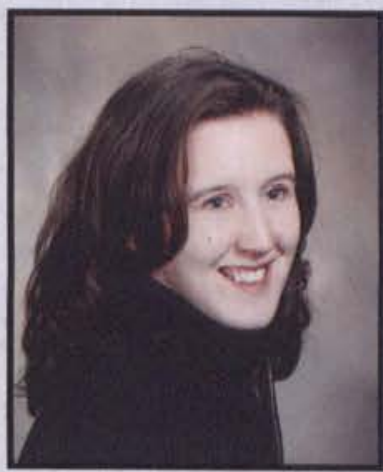

Megan D. Hause

Christian Education of Youth LaRue, $\mathrm{OH}$

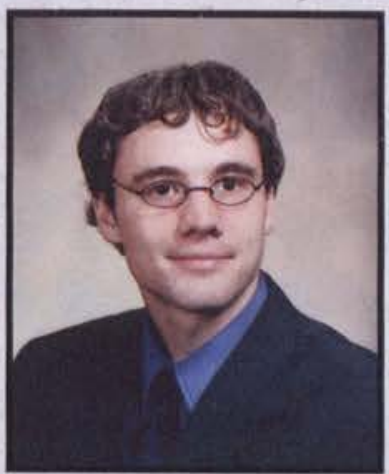

Adam C. Henker Bible \& Pre- Seminary Nekoosa, WI

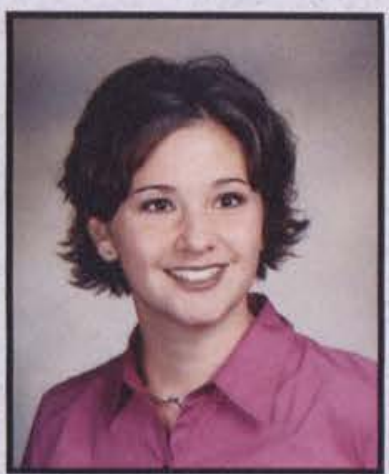

Kristen Hilsher

Special Education

Elizabethtown, PA

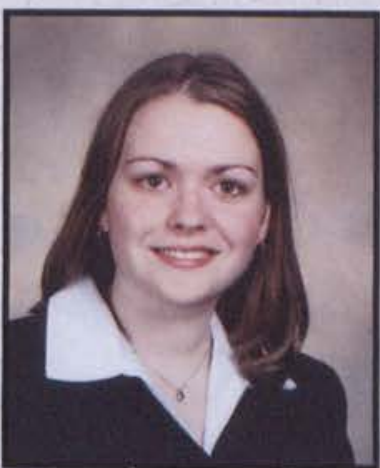

Kimberly Harbison

Middle Childhood Education Mason, $\mathrm{OH}$

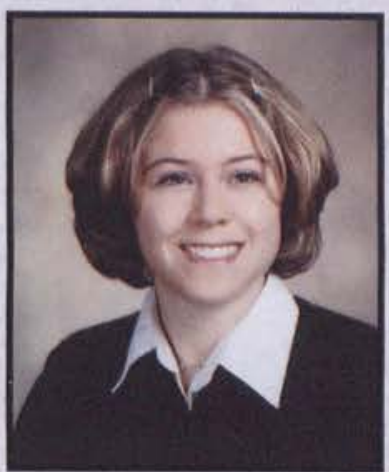

Kacie Hayes

End-User Intemational Studies Swartz Creek, MI

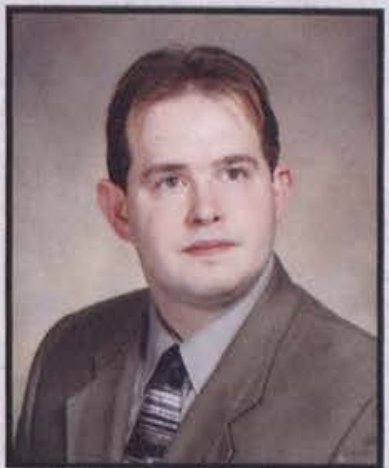

Charles Hicks

Broadcasting

Kettering, $\mathrm{OH}$

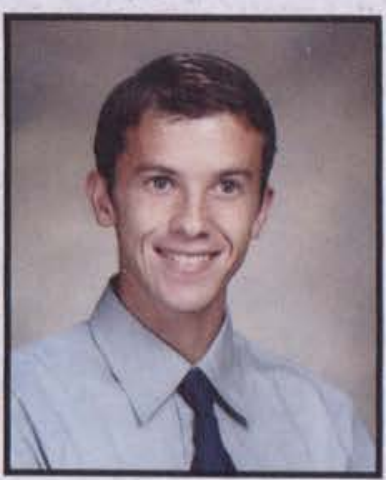

Jeremy Hilty

Biólogy

Bluffton, $\mathrm{OH}$

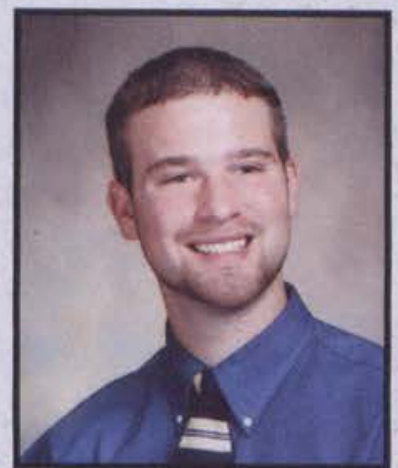

Jason Harvel

Comprehensive Bible Utica, $\mathrm{OH}$

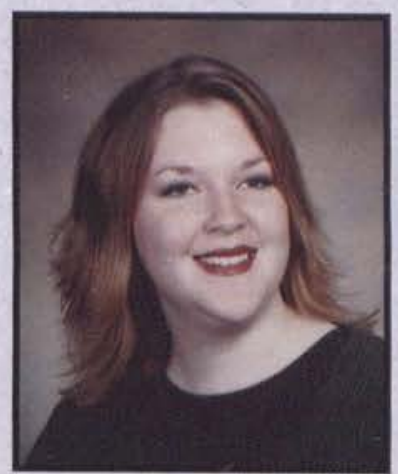

Rebekah Haywood

Multimedia Technology Wellington, CO

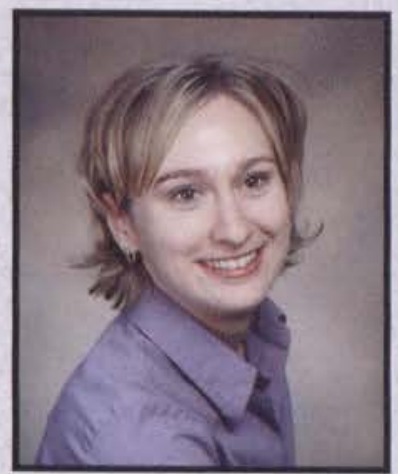

Jodi Hiestand

Nursing

Maytown, PA

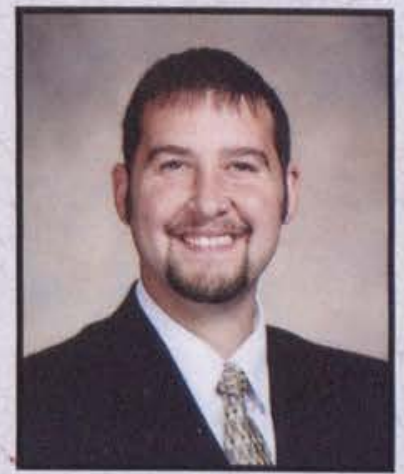

Joel D. Hime

Broadcasting

Denison, KS

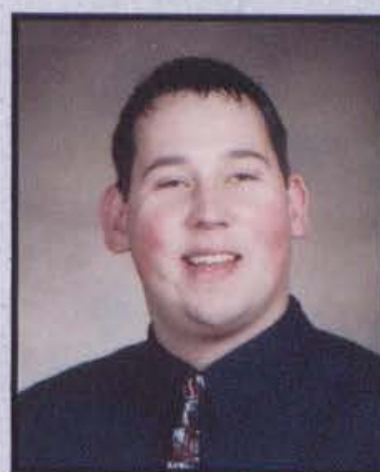

Christopher J. Hatton Middle Childhood Education Cedarville, $\mathrm{OH}$

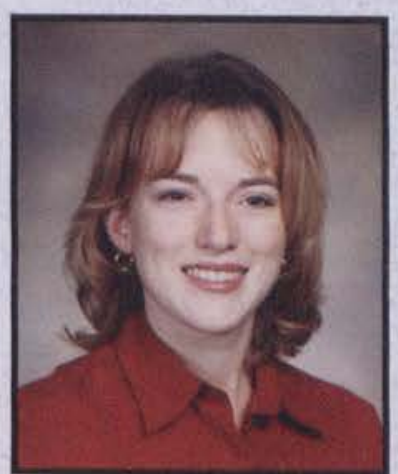

Rachel Heffield

Psychology

Orlando, FL.

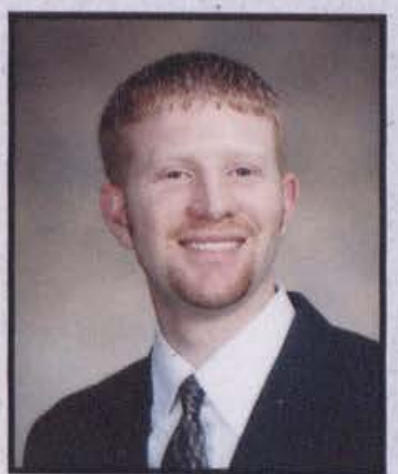

Brian Hill

Applied Psychology

Spotsylvania, VA

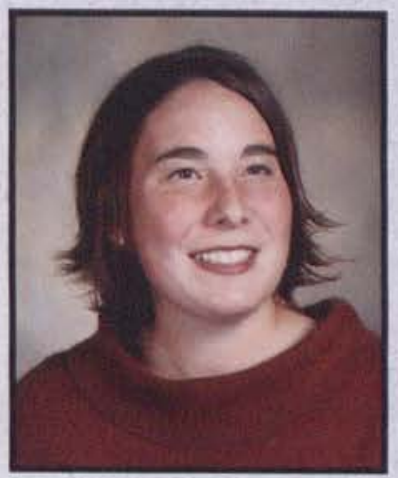

Lisa Hockenberry

Nursing

Orland Park, IL 


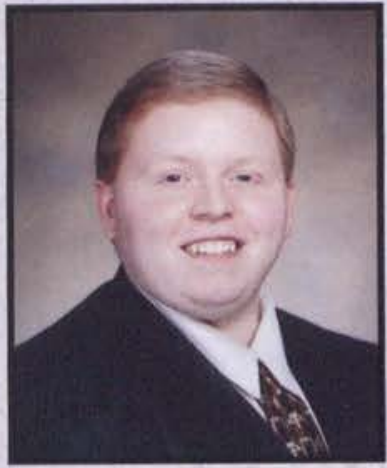

Ethan E. Hodge History \& Political Science Franklin, $\mathrm{OH}$

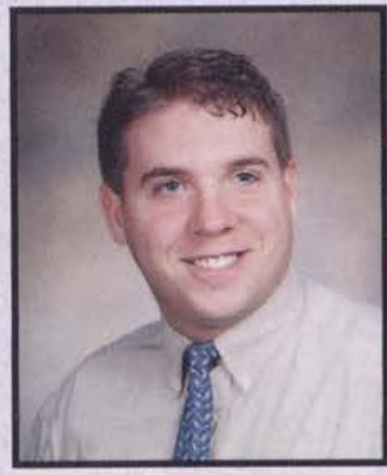

\section{Andrew Hohman}

Music Education

Lima, $\mathrm{OH}$

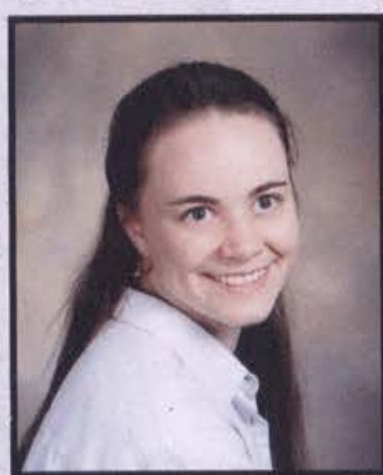

Laura K. Holzmann

Nursing Germany

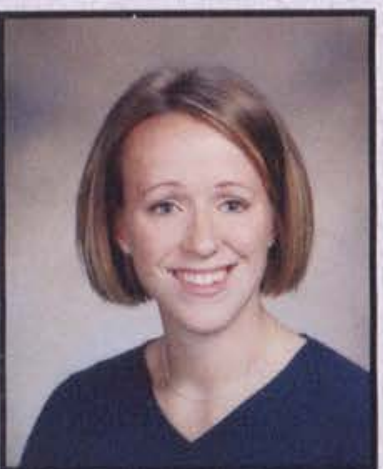

Hannah J. Huggard Nursing

Rochester, NH

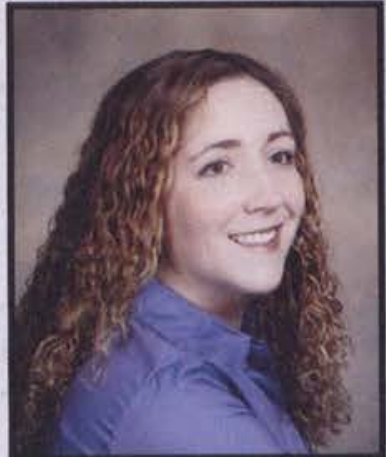

Amber D. Hodkinson Biology

Caldwell, $\mathrm{OH}$

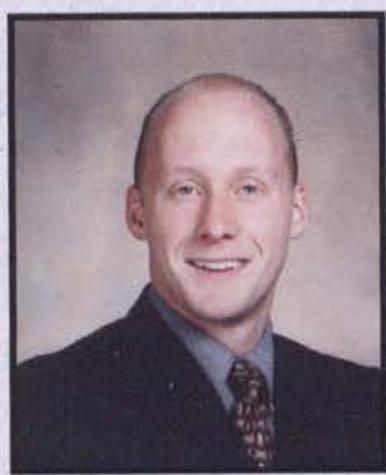

Bronson D. Hokuf

Electrical Engineering

Rising Sun, MD

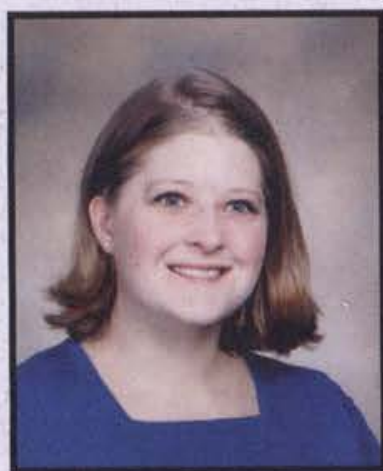

Christen R. Hostetler Business Management Akron, $\mathrm{OH}$

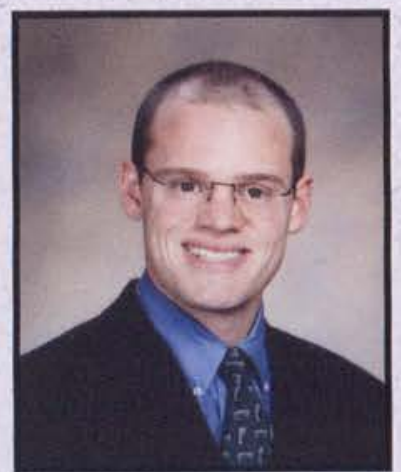

Justin D. Hughen Business Management Little Rock, AR

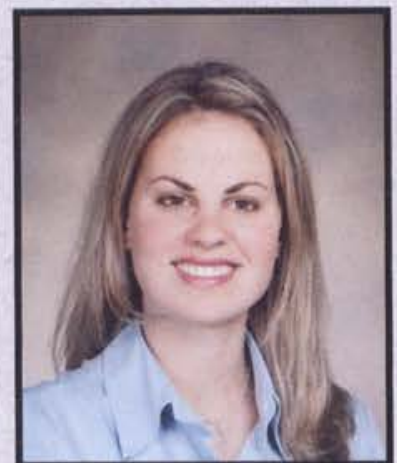

Kathryn E. Hofert

Org. Communications

Apex, NC

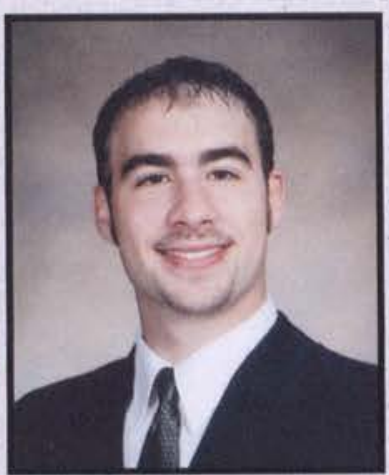

Jason Holland

Philosophy

Lewisberry, PA

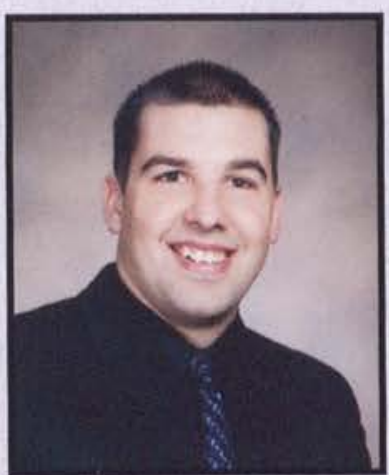

Jeremy Hudson

Spanish

Lima, $\mathrm{OH}$

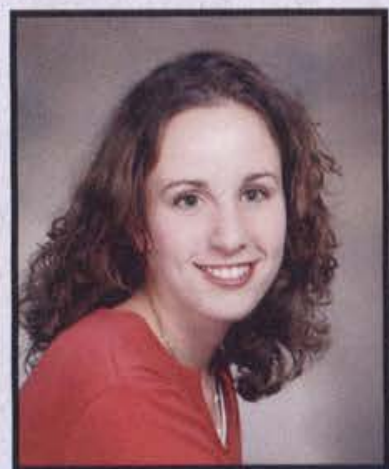

Laura A. Hummitzsch

Criminal Justice \& CE Youth Waukesha, WI

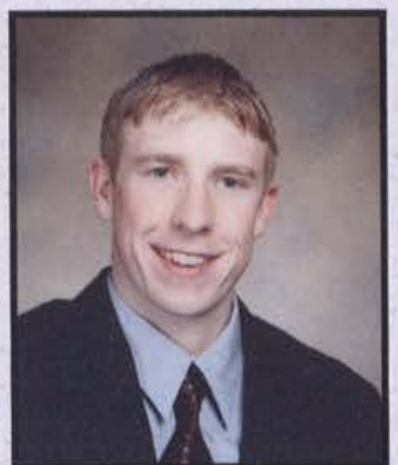

Andrew D. Hoffman Accounting \& Finance

Hillsborough, NJ

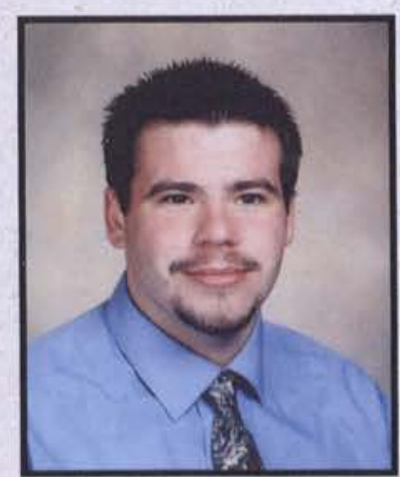

David Hollinger

Chemistry

Cheltenham, PA

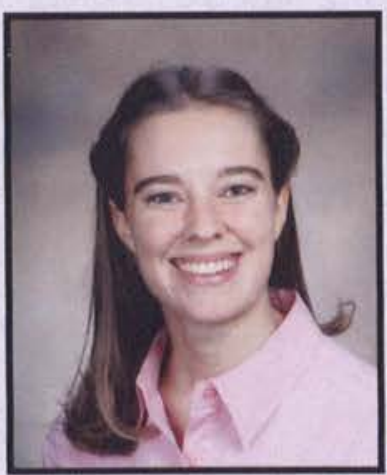

Deborah L. Huff

Early Childhood Education

Jamestown, $\mathrm{OH}$

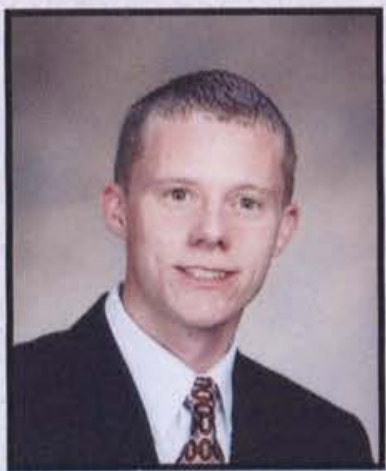

Heath Huskey

Comprehensive Bible Georgetown, $\mathrm{OH}$

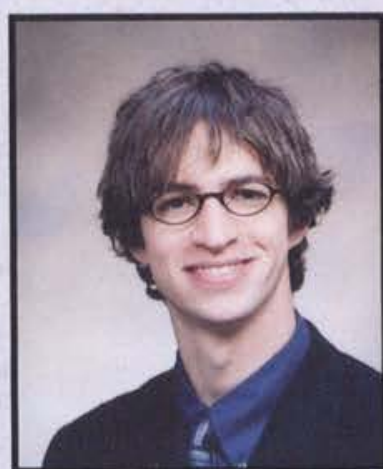

Matthew Hofmann

World Missions

Tabernacle, NJ

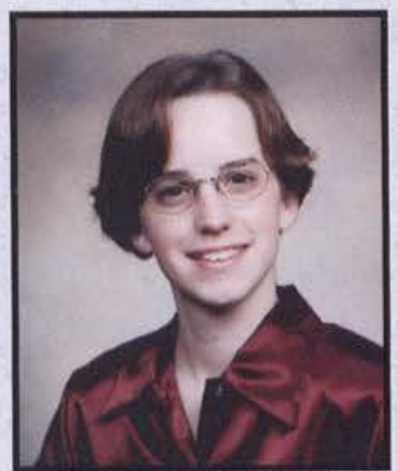

Karen Holloway

Communication Arts

Forest Hill, MD

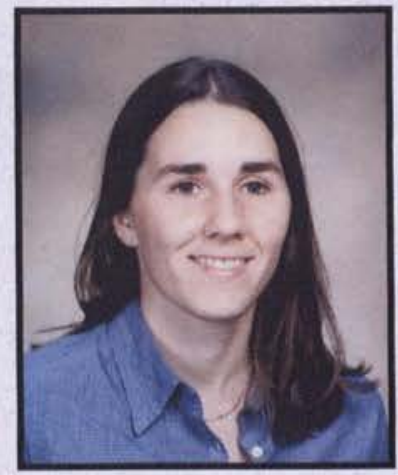

Rebekah Huffman

Missions

Dalton, $\mathrm{OH}$

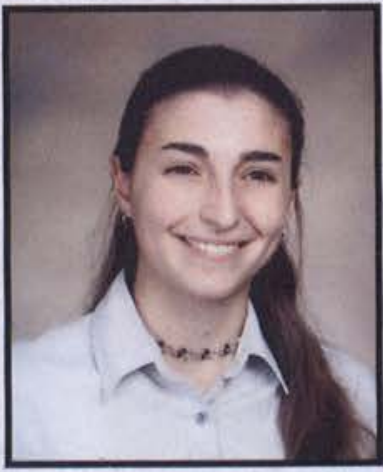

Jennifer A. Ingersoll

Math Education

Spring Hill, FL 


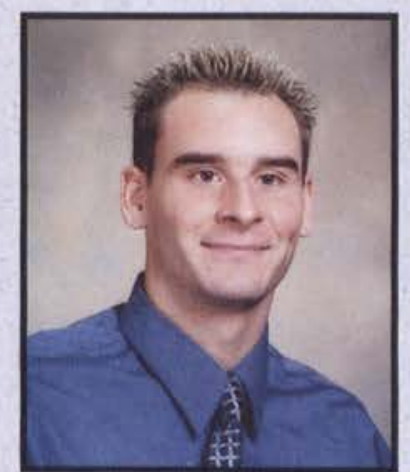

Chad Ireland

Comprehensive Bible

Ocean City, NJ

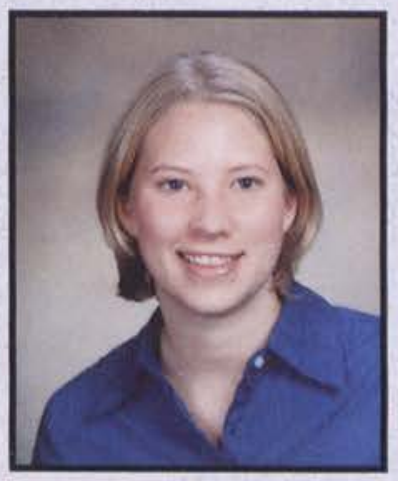

Rebecca Jensen

Early Childhood Education

Bellefontaine, $\mathrm{OH}$

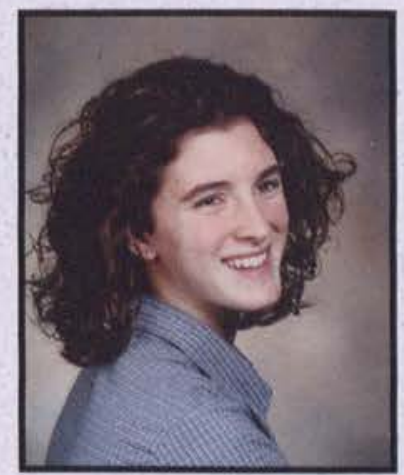

Bethany Keilman

Nursing

Riverview, MI

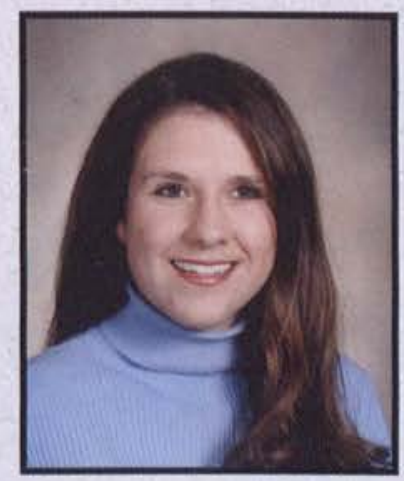

Brooke Kessler

Nursing

Bremerton, WA

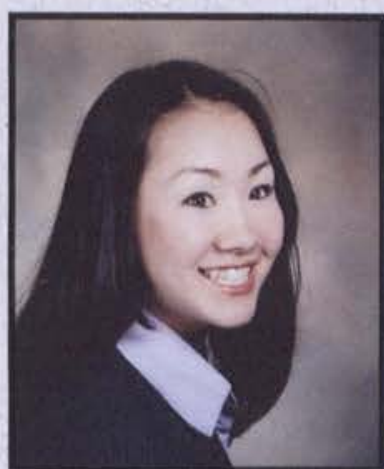

Motoi Ishikawa

Nursing

Akita, Japan

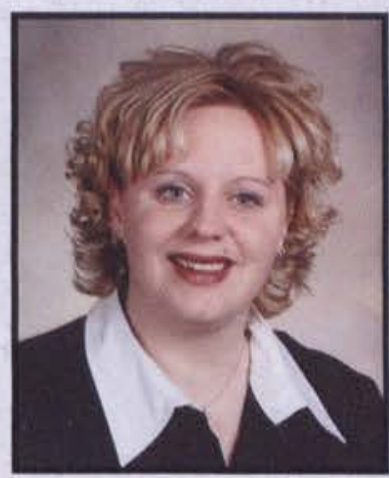

Lindsey M. Johnson

Christian Education of Youth Jamestown, $\mathrm{OH}$

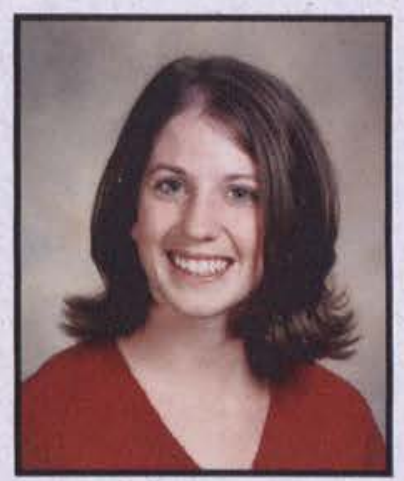

Esther R. Kelly

Multimedia Technology Grand Rapids, MI

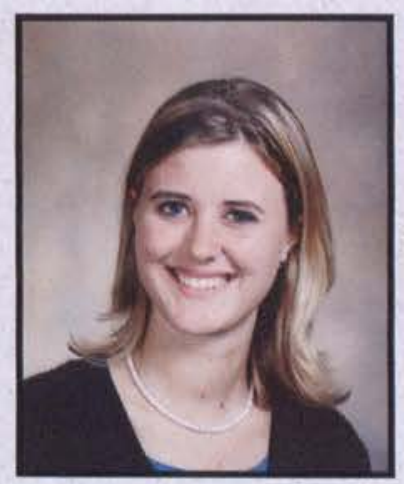

Nicolette E. King

World Missions

Cary, NC

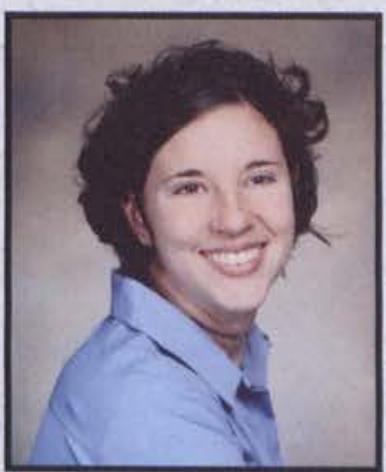

Jessica Jacobowitz English

Lancaster, $\mathrm{OH}$

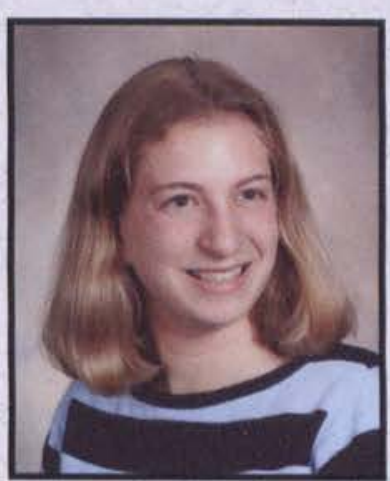

Kristina K. Jonker

Middle Childhood Education

Coatesville, IN

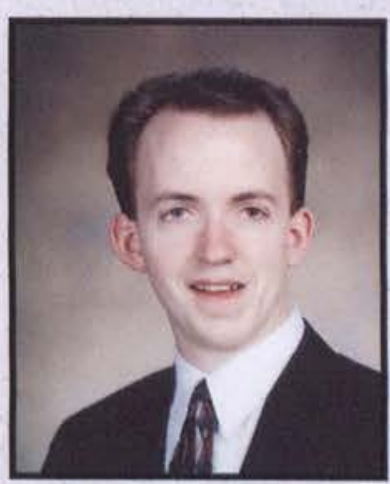

Steven Kenny

Information Systems Racine, WI

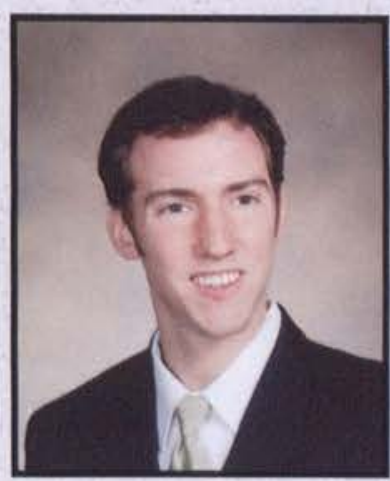

Jonathan D. Kirby

Human Resource Mang Pittston, PA

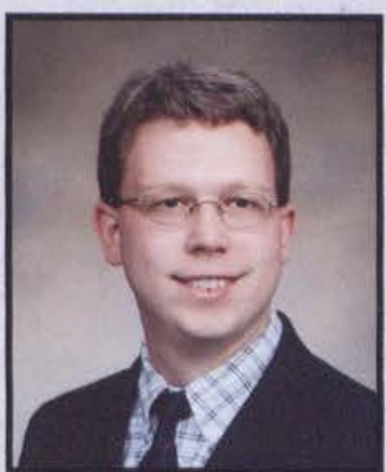

Andrew Jarvis

CE Youth \& Missions Beach Park, IL

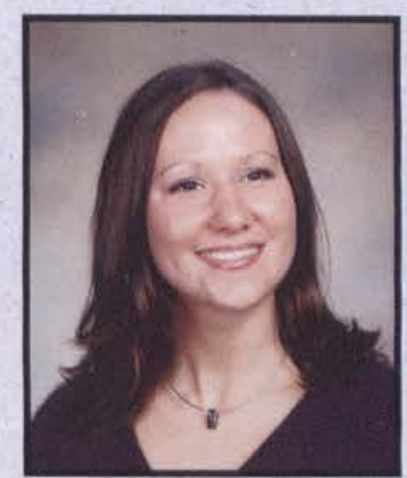

Jessica Kaiser Communication Arts Hamilton Square, NJ

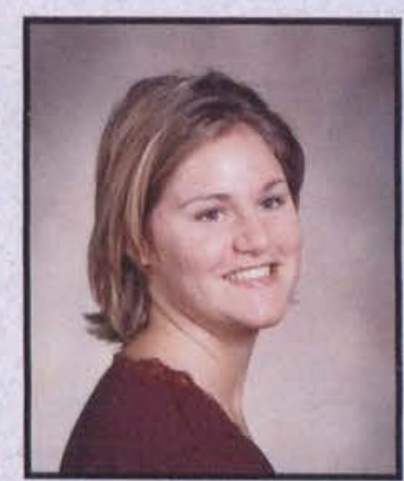

Katie B. Kepner

Psychology

Marlton, NJ

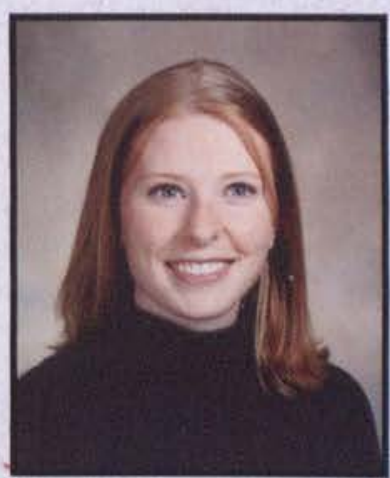

Melissa Knaus

Early Childhood Education Kinnelon, NJ

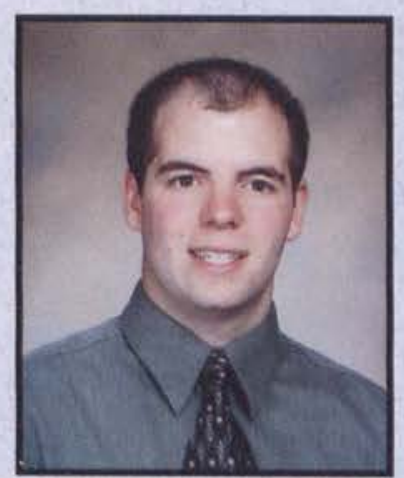

William H. Jenks

Mechanical Engineering Buhl, ID

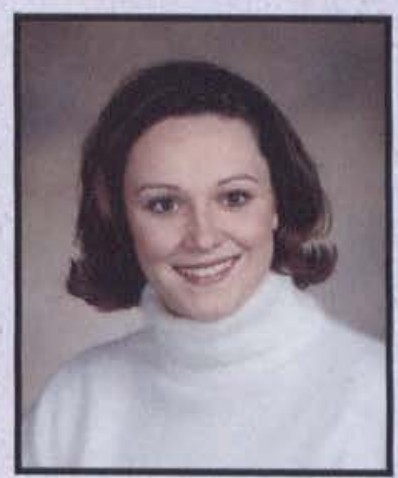

Derika J. Keenan Early Childhood Education Colorado Springs, CO

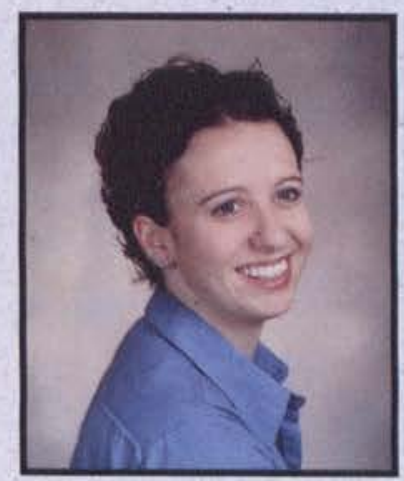

Jacqueline Kernechel Psychology

Coopersburg, PA

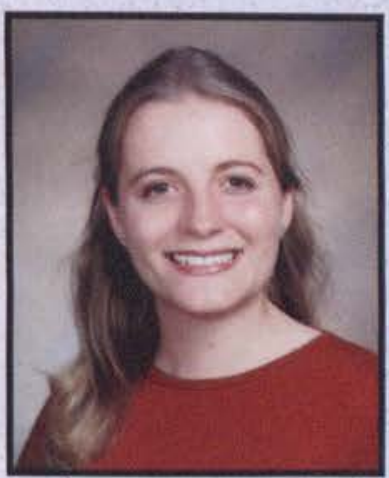

Lynsa Knickerbocker

Nursing \& Psychology Cedarville, $\mathrm{OH}$ 


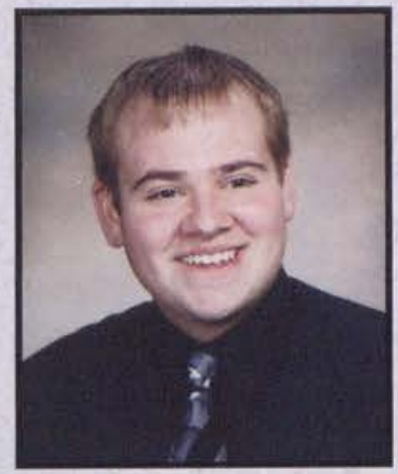

Brian Knouse

Christian Education of Youth Indianapolis, IN

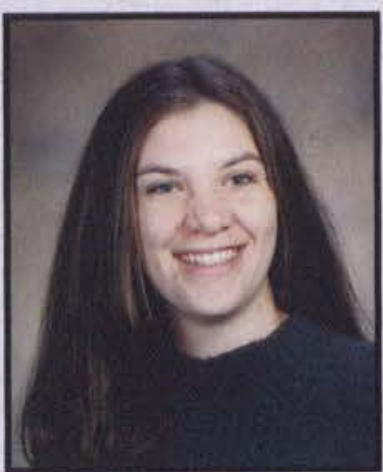

Debra Krick

Early Childhood Education Jersey Shore, PA

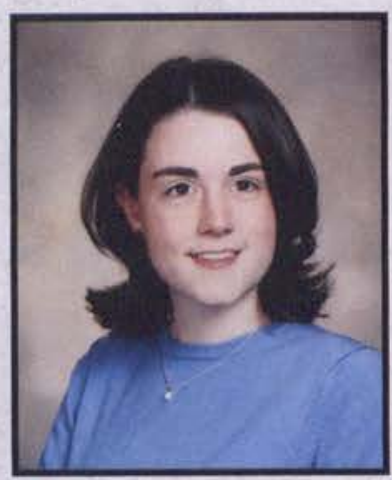

Melissa A. Lasso

Applied Psychology

Bethlehem, PA

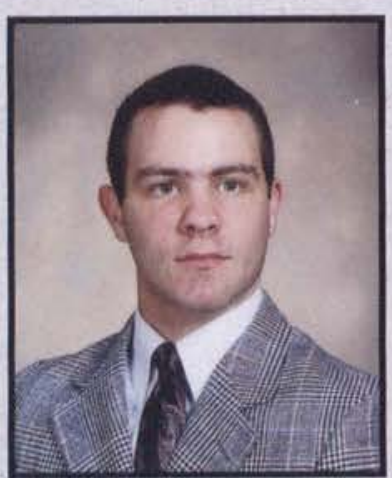

Tom Lee

Business Management Glen Bernie, MD

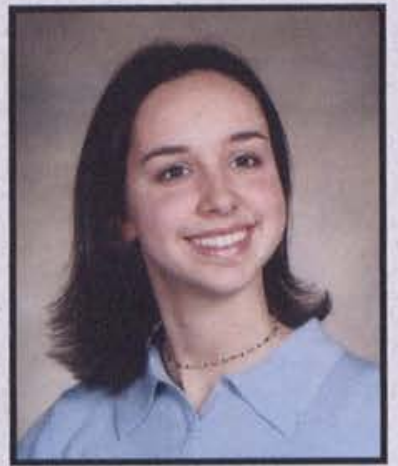

Erin L. Knowles

Social Work

Bourbonnais, IL

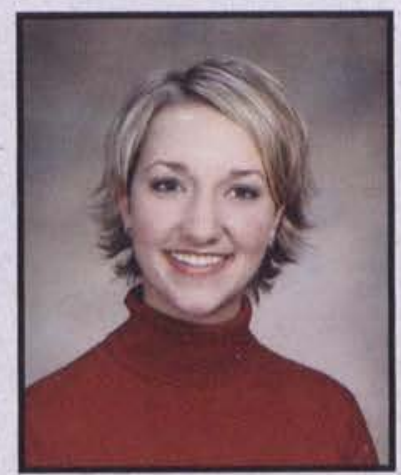

Holly G. Kuhn

Comm. Arts \& Theatre Ada, MI

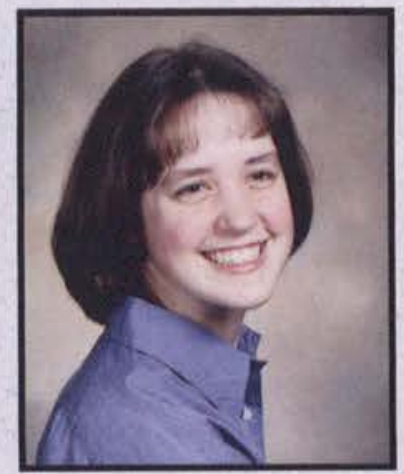

Lisa Lauritzen

Early Childhood Education Fremont, MI

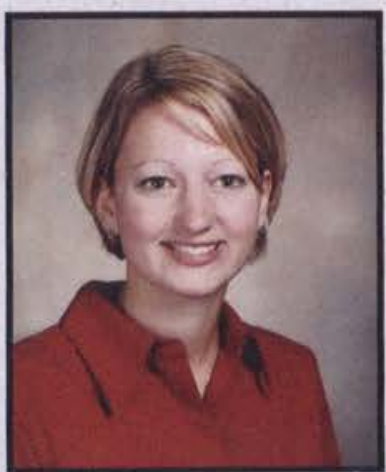

Melissa M. Leingang

Phys. Ed. \& Sports Mang. Tipp City, $\mathrm{OH}$

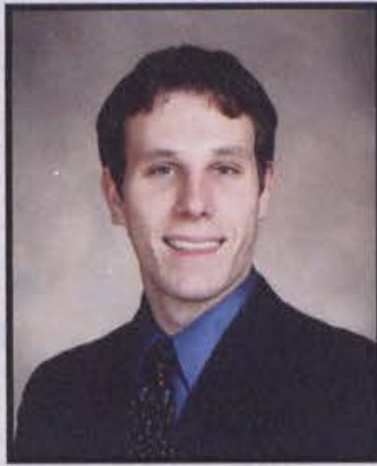

Timothy J. Kopp

Accounting \& Marketing

Clarks Summit, PA

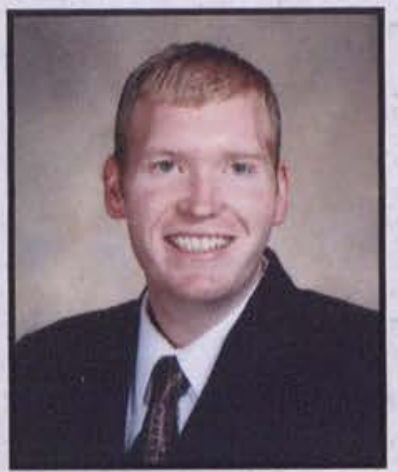

Ryan Kurzen

Finance \& Business Mang. Dalton, $\mathrm{OH}$

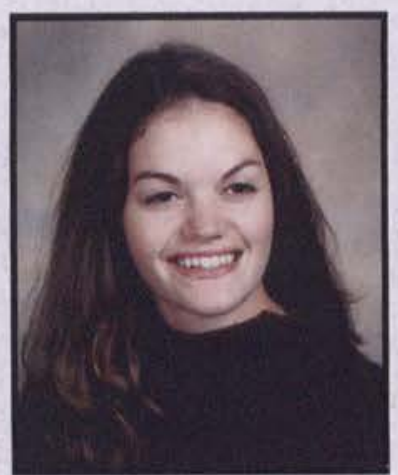

Sarah Lawlor

Social Studies Education

Poughguag, NY

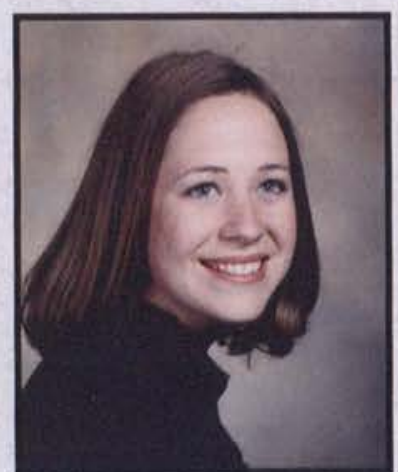

Karie A. Lepp

Middle Childhood Education Galt, CA

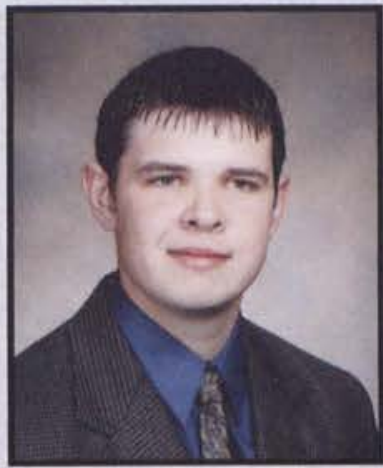

Bradley J. Kormash

Business Management Ypsilanti, MI

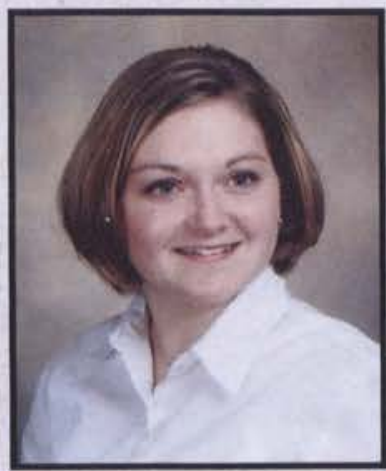

Kelly Lambert

English

North Canton, $\mathrm{OH}$

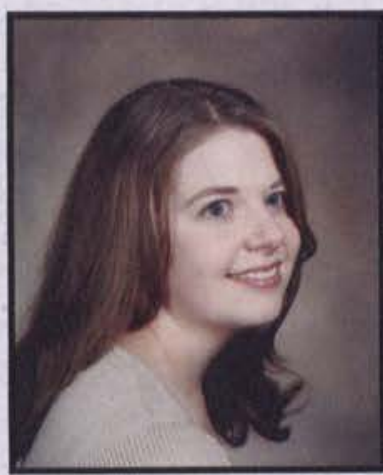

Susan Lawson

Nursing

Langhorne, PA

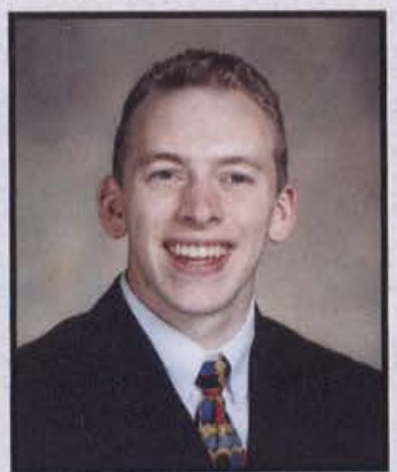

William Leukhardt

Chemistry \& Biology Ashtabula, $\mathrm{OH}$

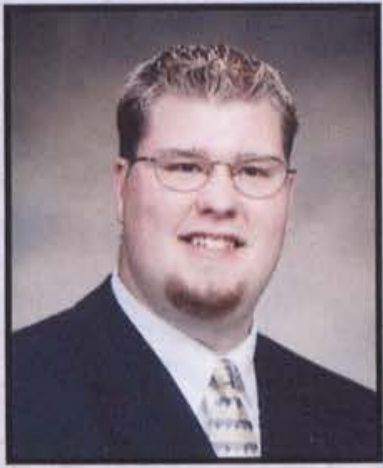

Jared Koverman

Mechanical Engineering Cridersville, $\mathrm{OH}$

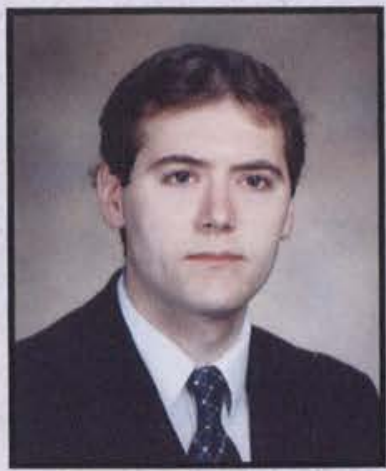

Eric A. Larsen

Accounting \& Finance Burlington, WI

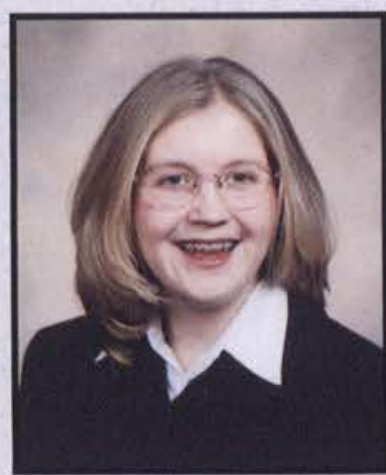

Veronica Lawton Middle Childhood Education Bowie, MD

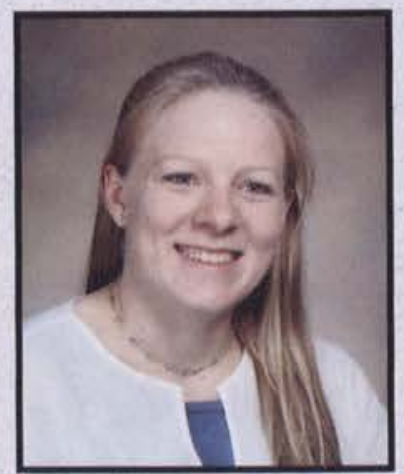

Kimberly Leverson End-User Information Systems Highlands Ranch, CO 


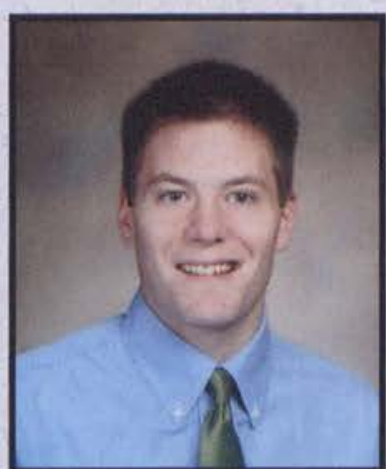

David J. Malwitz

Chemistry

Brookfield, CT

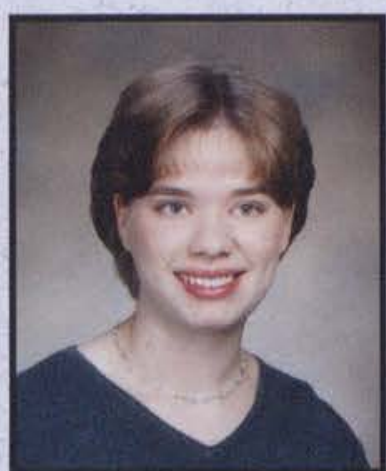

Allison R. Mapes

Nursing

Rochester, NY

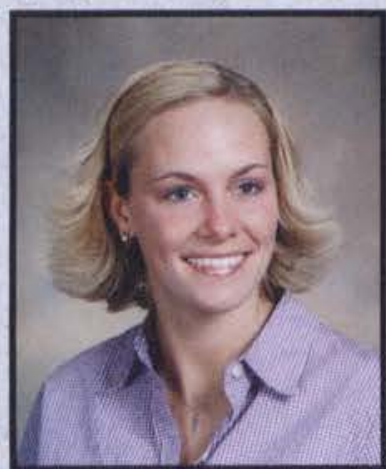

Amy Martin

Early Childhood Education South Charleston, $\mathrm{OH}$

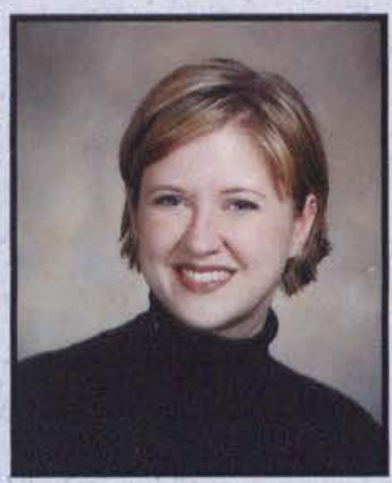

Katie Masterson English \& Theatre

Carmel, IN

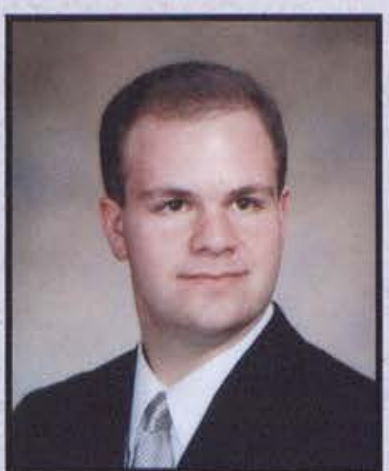

Loris Manaresi

Electrical Engineering

West Creek, NJ

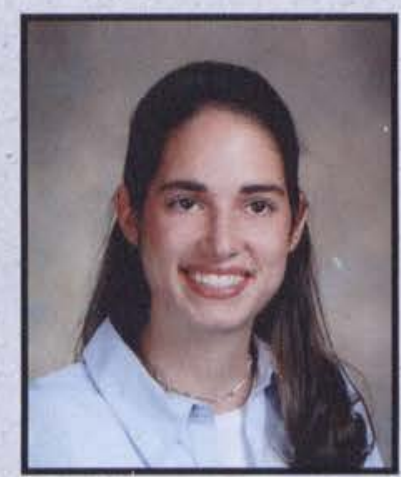

Karen Mapes

Elementary Education

Rochester, NY

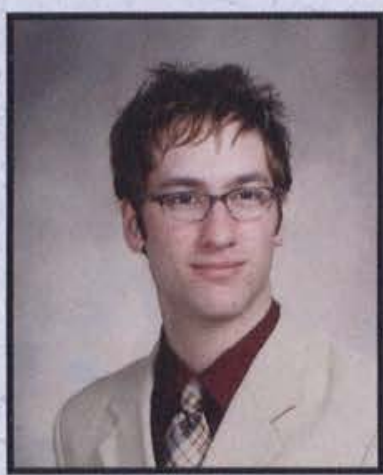

Seth B. Martin

Middle Childhood Education Schroon Lake, NY

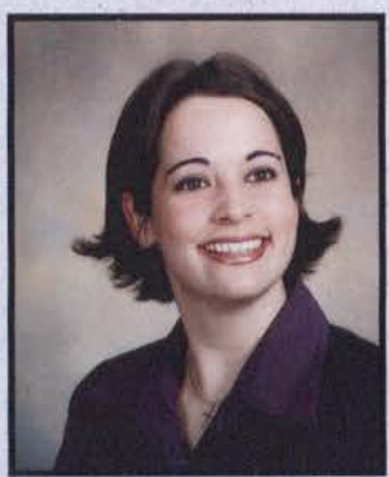

Holly A. Mathews

Org. Communications

Lancaster, $\mathrm{OH}$

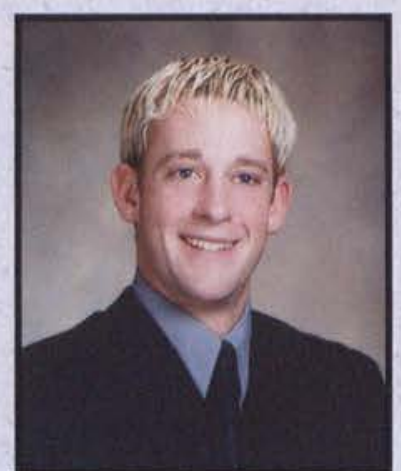

Bryan Mangin

Criminal Justice

Sellersville, PA

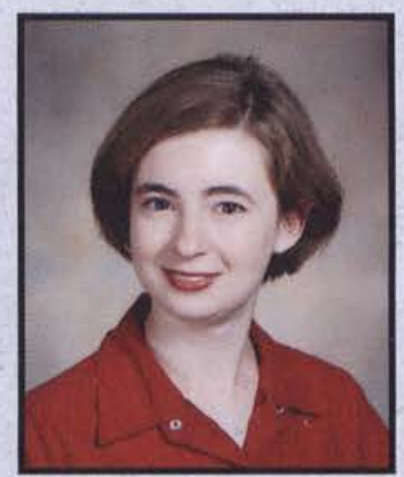

Alicia Marsh

Psychology

Fairfax, VA

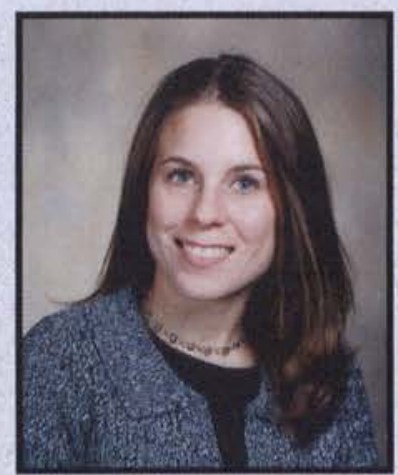

Danielle R. Marzano

Psychology Hilliard, $\mathrm{OH}$

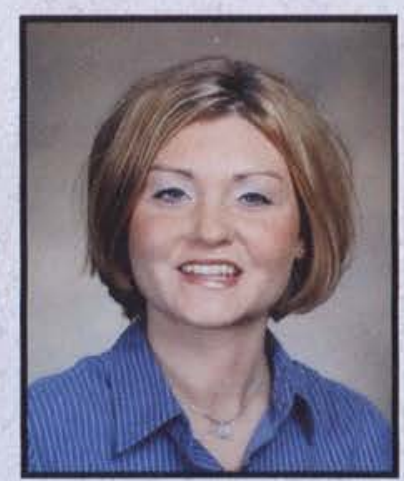

April J. Maurizi

Org. Communications Fort Wayne, IN

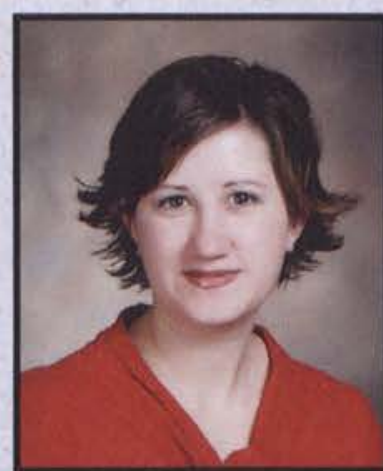

Katie R. Mansfield Nursing

Manns Choice, PA

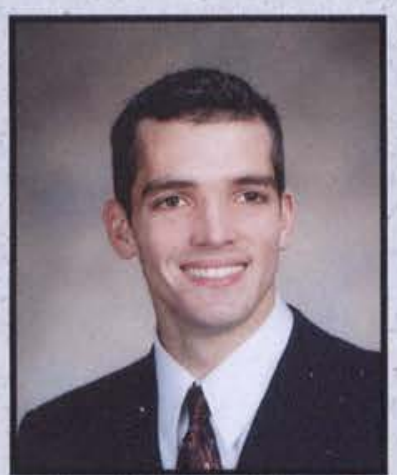

Michael Marsh

Business Management

Madeira Beach, FL

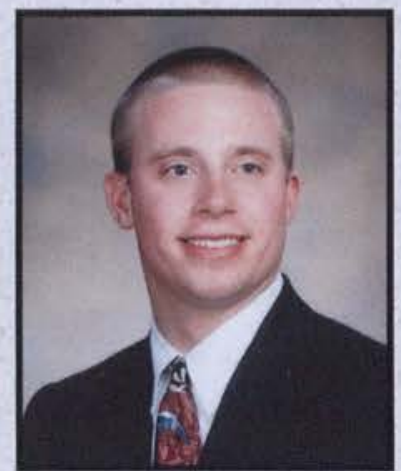

Ron Mason

Mang. Information Systems Clifton Park, NY

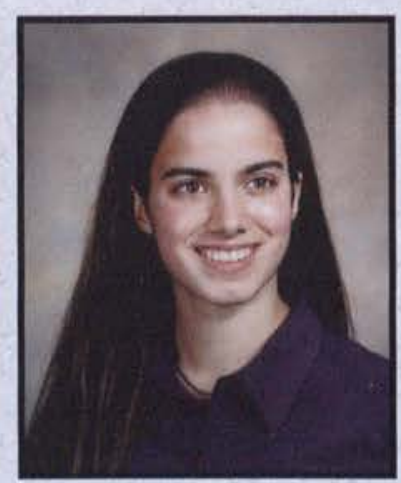

Rubie S. Maybury Biology

North Syracuse, NY

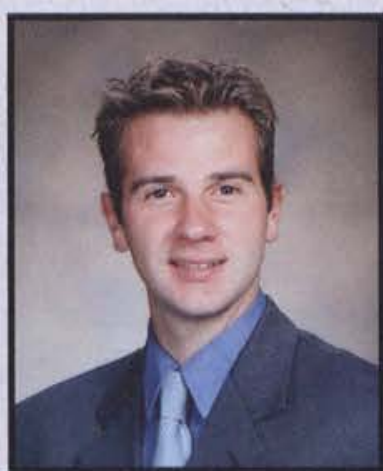

Kenneth Mansfield Mechanical Engineering

Manns Choice, PA

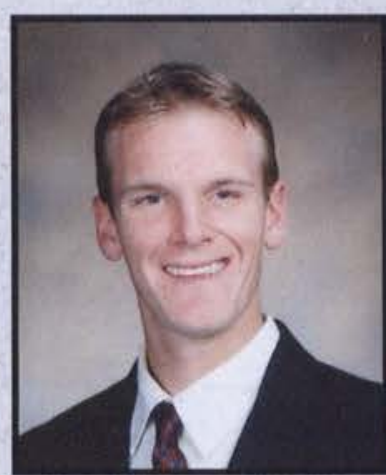

Matthew R. Marshall Biology

Bend, OR

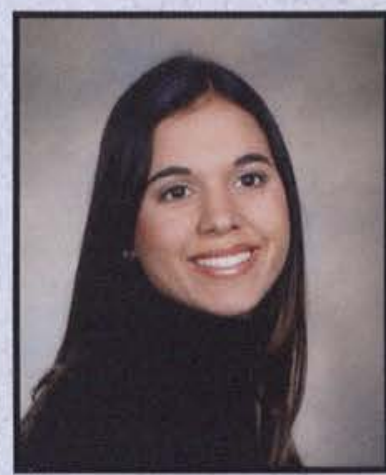

Elizabeth F. Massey

Org. Communications Fayetteville, NY

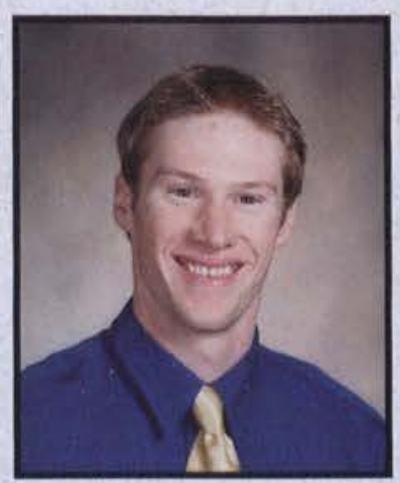

Timothy J. McCorkle Mechanical Engineering Bakersfield, CA 


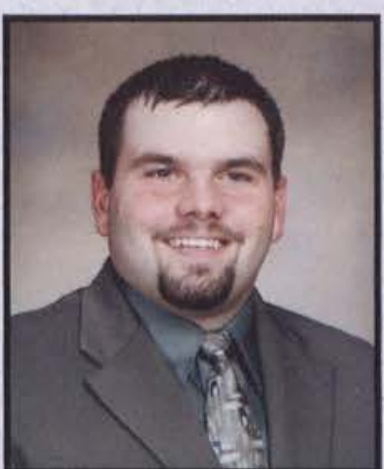

Adam T. McCune

Bible \& Missions

New Lenox, IL

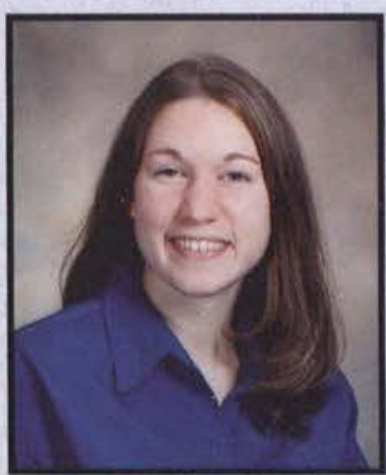

Cheryl L. Meyer

Org. Communications

Elida, $\mathrm{OH}$

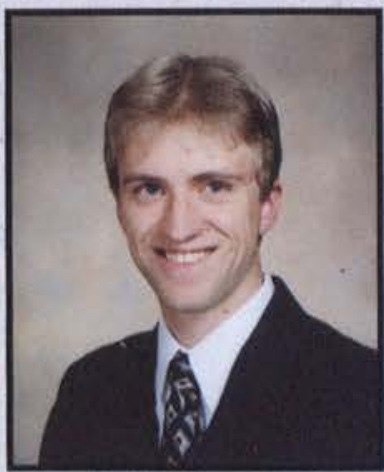

Matthew Miller

Computer Science

Keyport, NJ

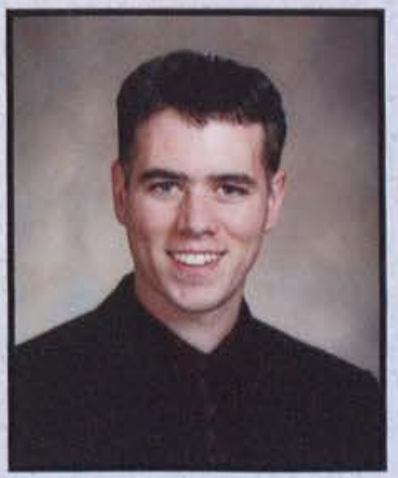

Jonathan Mizer

Pre-Law

Middleburg, PA

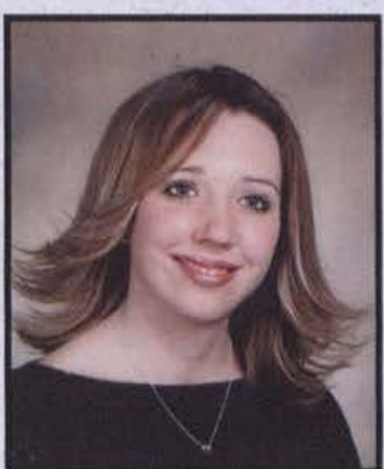

Jenn McKee

Christian Education of Youth

Winfield, IL

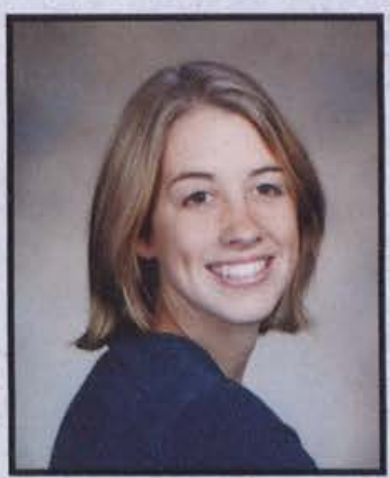

Melissa Meyer

Psychology

Venice, $\mathrm{FL}$

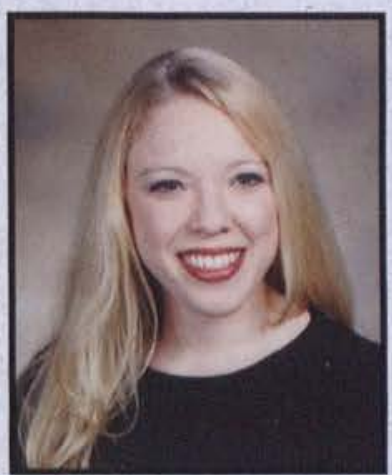

Rochelle M. Miller

Nursing

Clearwater, FL

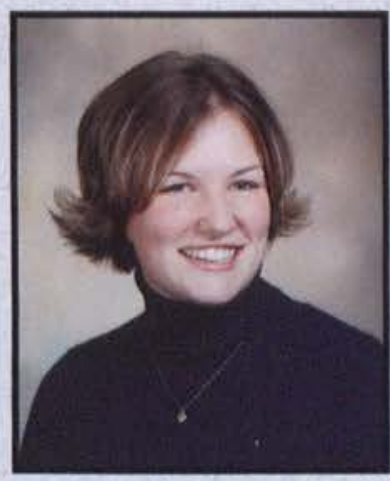

Jamie Mohler

Nursing

Litchfield, $\mathrm{OH}$

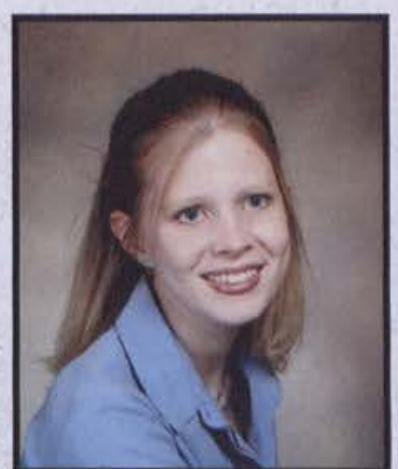

Stephanie McLain

Management \& Marketing

Covington, VA

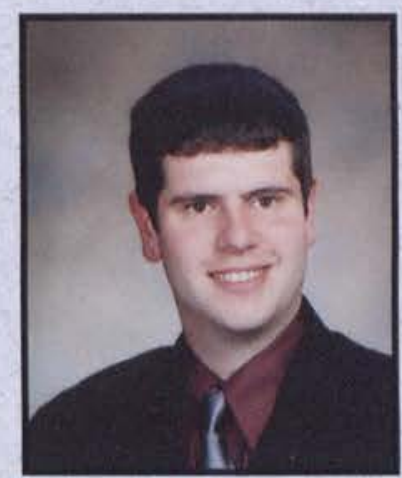

Joseph Mickey

Music Education

Salem, OR

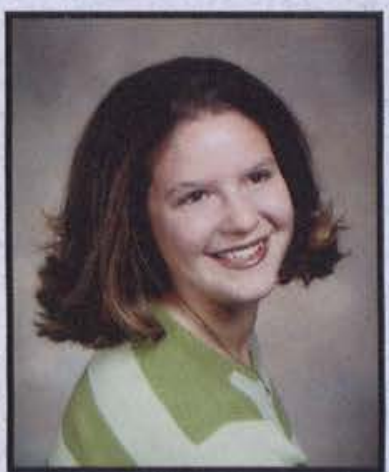

Rebekah R. Millet

Physical Education

Stephenville, TX

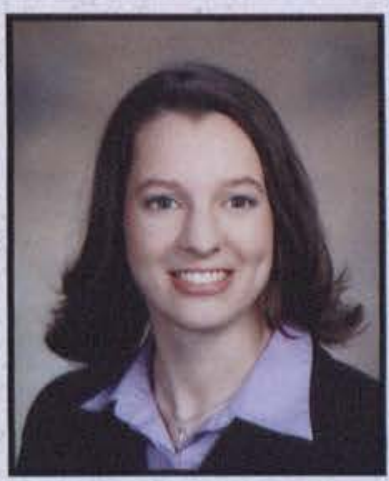

Rachael Mohler

Math Education Austin, TX

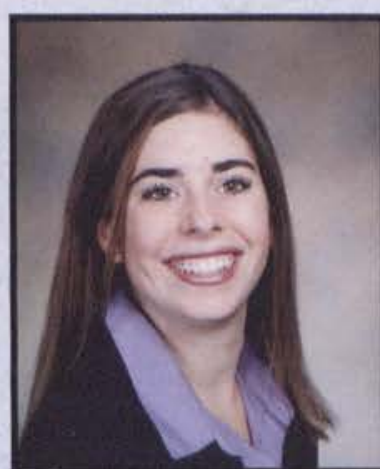

Emily McQuinn

International Studies

Highlands Ranch, CO

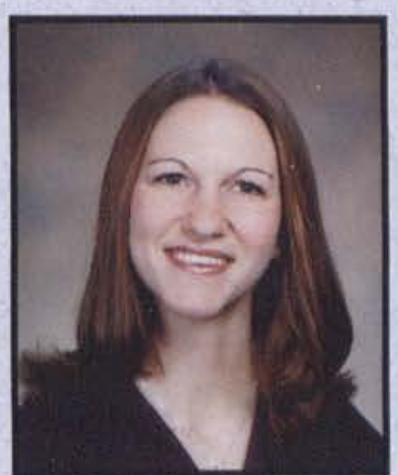

Rebecca M. Mied

Bible \& Missions

Woodbine, MD

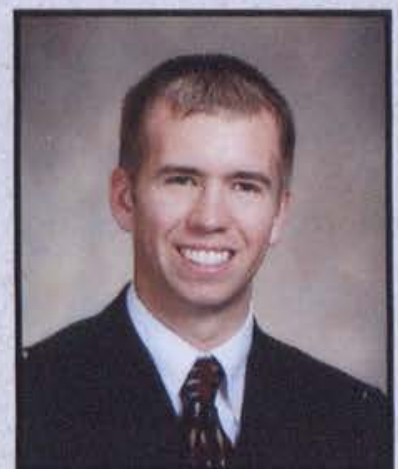

Eric J. Mitchell

Biology

Eaton Rapids, MI

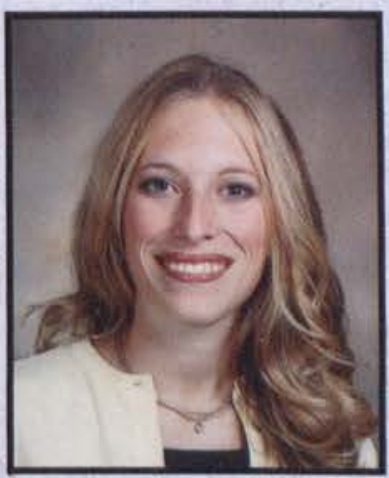

Jena L. Mohr

Early Childhood Education Mt. Joy, PA

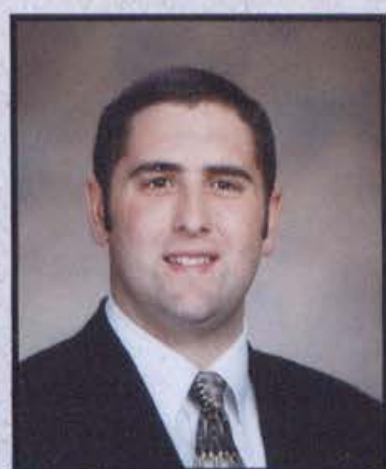

Scott R. MecKley Mang. Information Systems

Clayton, MI

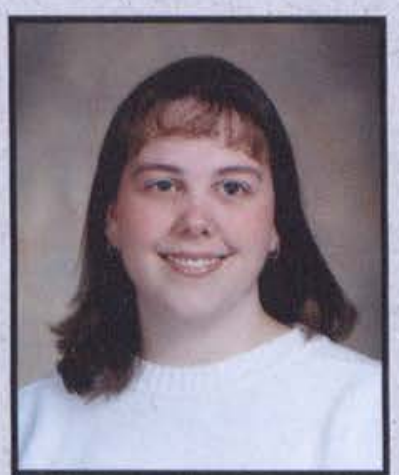

Tammy Mikel

Middle Childhood Education

Farmington Hills, MI

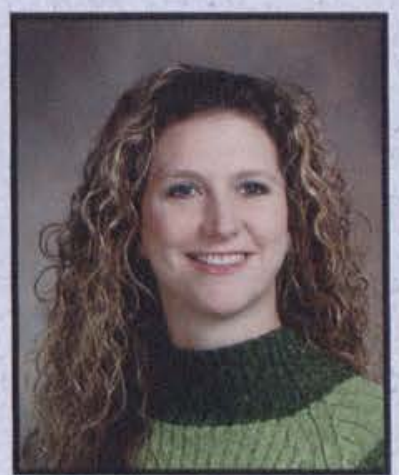

Rachel E. Mitchell

Communications

Cincinnati, $\mathrm{OH}$

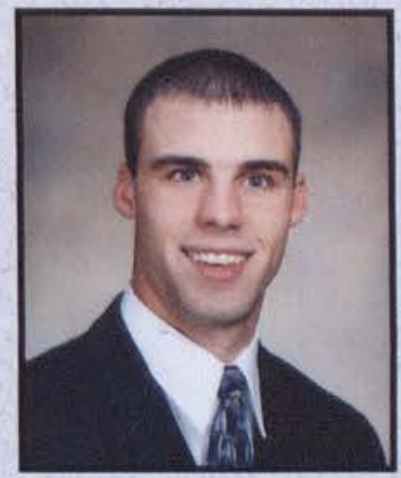

Daniel Montanye

Business Management Milford, NJ 


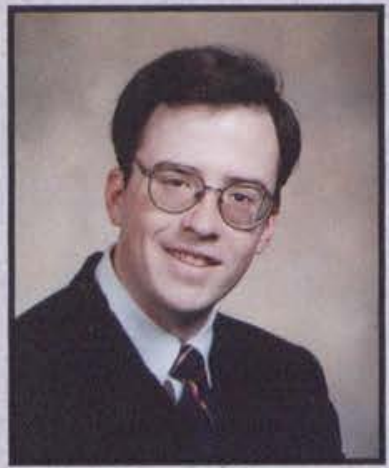

Michael Moon

Biology

Miamisburg, $\mathrm{OH}$

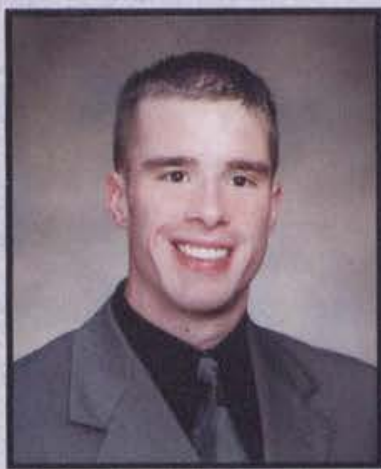

Stephen C. Mosfley

Mechanical Engineering Lima, $\mathrm{OH}$

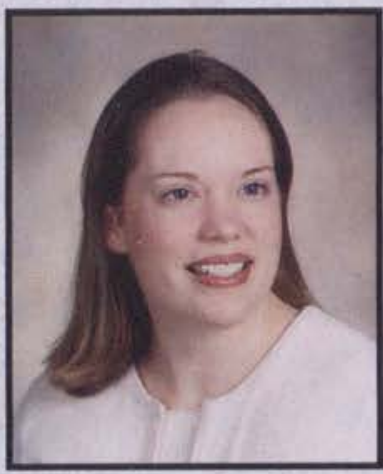

Jennifer Nelson Multi Age Special Education Schoolcraft, MI

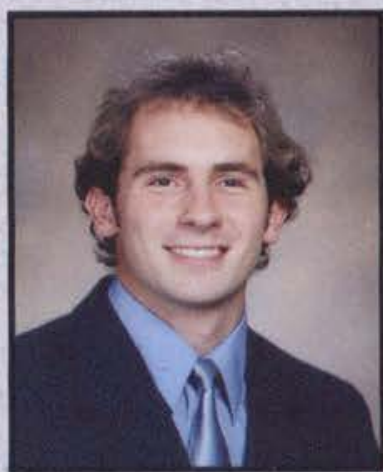

Ryan Newsome

Marketing

Allen Park, MI

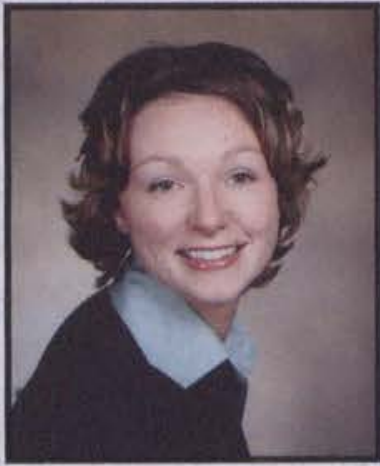

Kara R. Moore

Org. Communications Griffith, IN

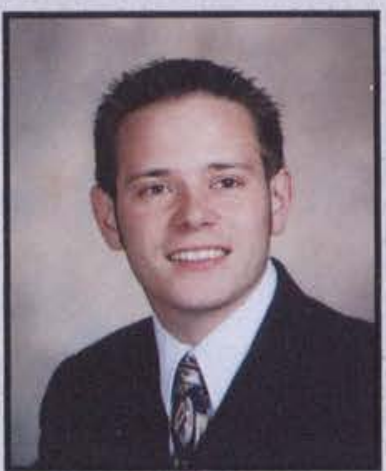

Aaron T. Motta

Mang. Information Systems Assonet, MA

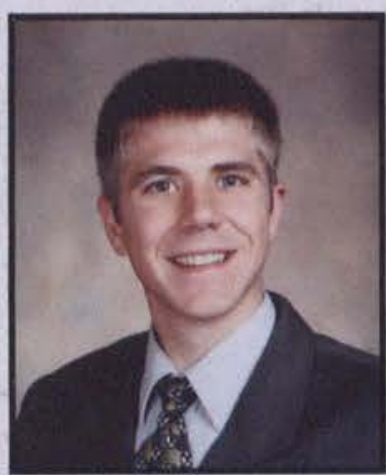

Jonathan L. Nelson

Christian Education of Youth Ithaca, NY

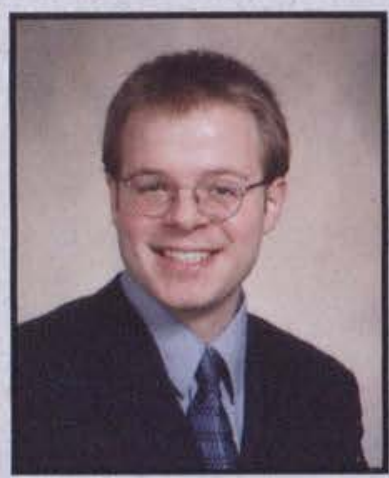

Lloyd E. Nickerson II Biology

Salisbury, NC

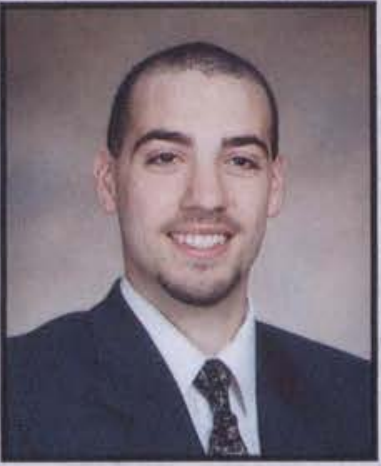

Kenneth J. Moore

Mechanical Engineering Columbus, $\mathrm{OH}$

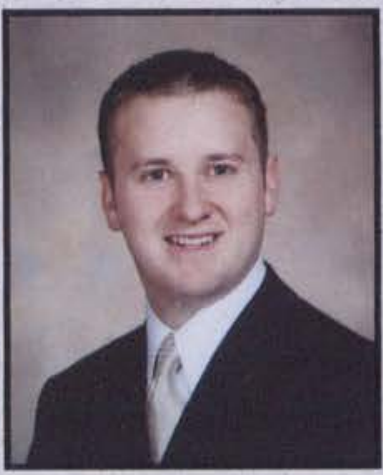

Matthew Nealis

Mechanical Engineering Traverse City, MI

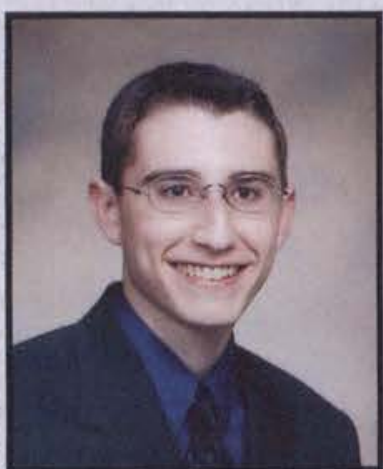

Ben Nesbitt

Social Work

Mechanicsburg, PA

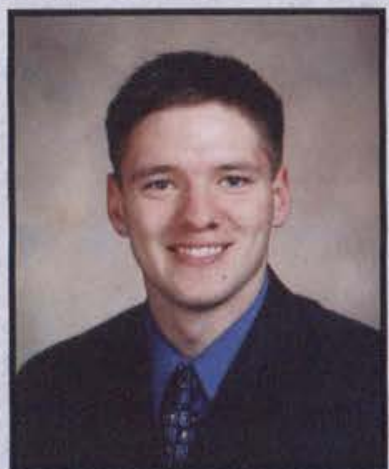

Brad Nicol

Mechanical Engineering Marysville, $\mathrm{OH}$

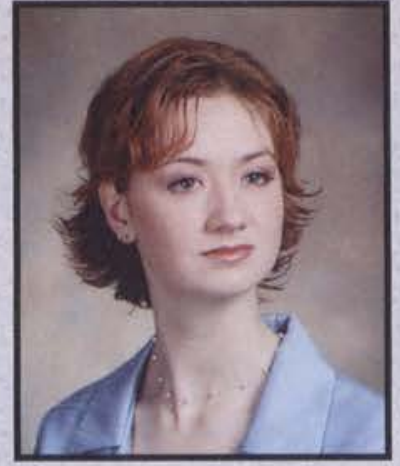

Michelle Moore

Criminal Justice

Ridgefield, WA

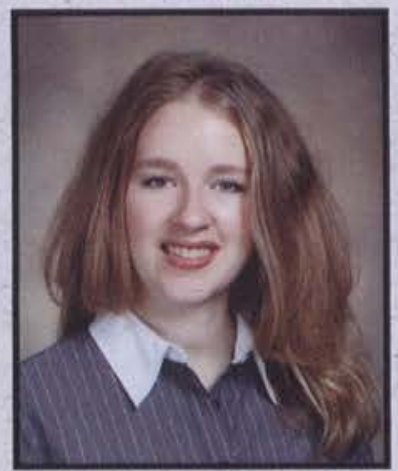

Kelly S. Neer

Social Work

W. Liberty, $\mathrm{OH}$

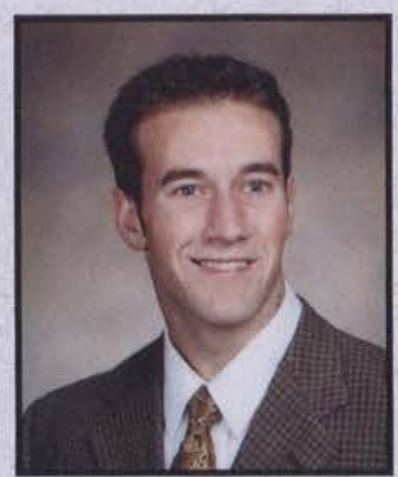

Rob Neuroth

Electrical Engineering

Little Egg Harbor, NJ

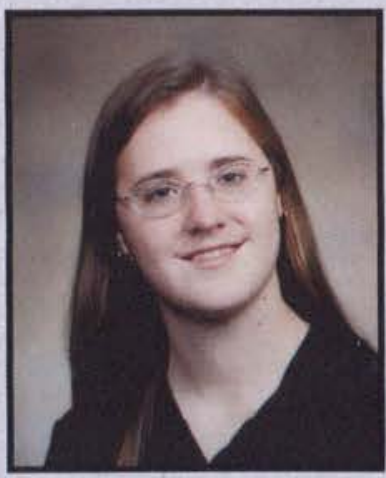

Charis L. Nims

Middle Childhood Education Xenia, $\mathrm{OH}$

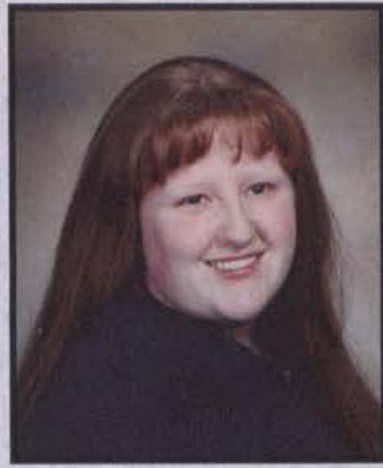

Kimberly D. Morris Accounting

Huber Heights, $\mathrm{OH}$

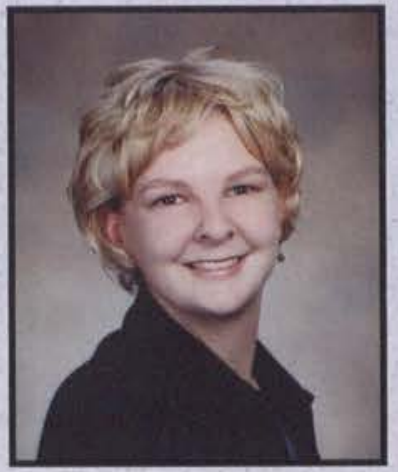

Betsy Nelson

Nursing

Aurora, IL

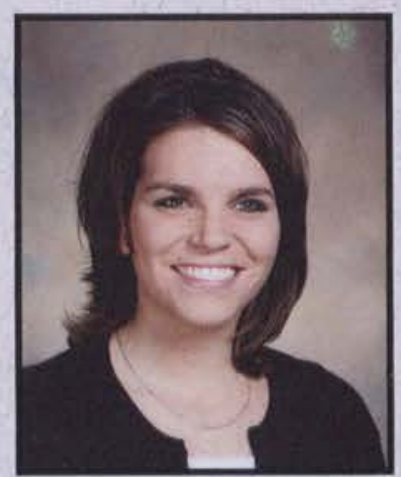

Kristin Newman

Middle Childhood Education Carmel, IN

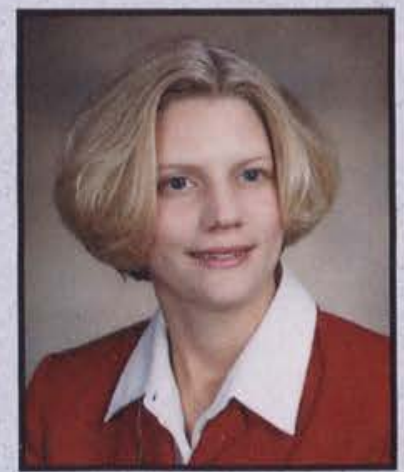

Anne Norman Nursing Jackson, MI 


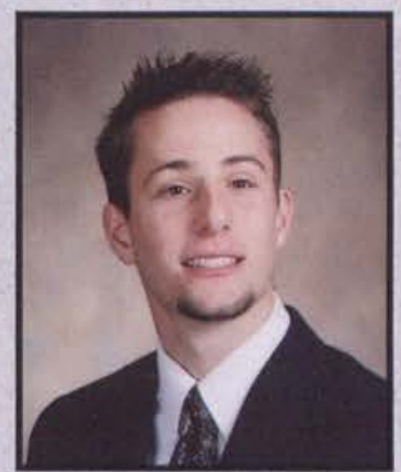

Daren 0. Norris

Applied Psychology

Colorado Springs, CO

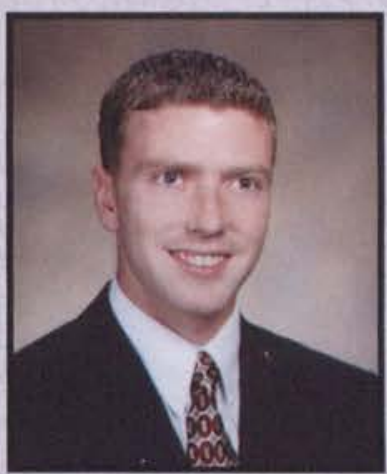

Nate Olin

Business Finance \& Mang. Cedarville, $\mathrm{OH}$

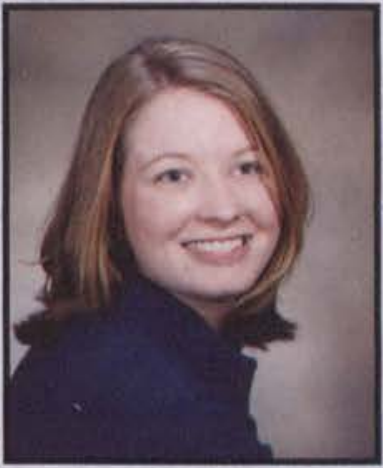

Angela M. Otto

Applied Psychology Accident, MD

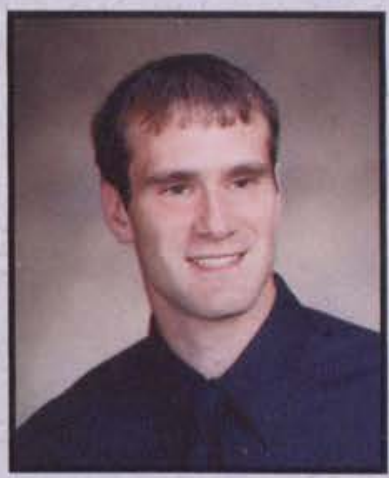

Andrew R. Paugh

Physical Education Cedarville, $\mathrm{OH}$

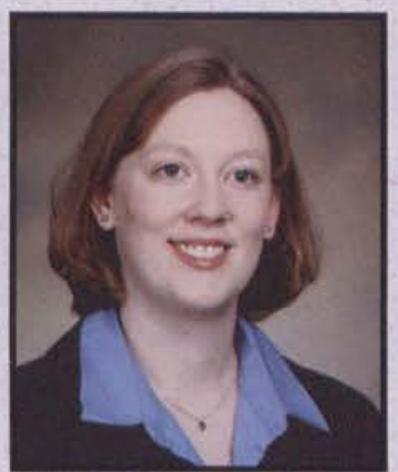

Melissa A. Nuttall

Accounting \& Finance

Charlotte, ME

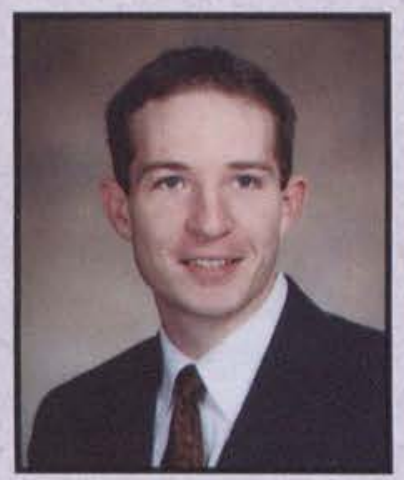

Matt Olson

Theatre

Yuba City, CA

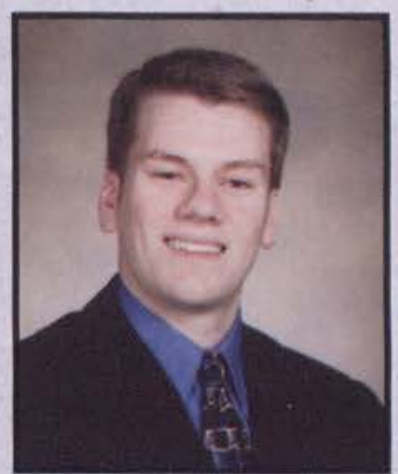

Michael J. Owen

English Education

Tabernacle, NJ

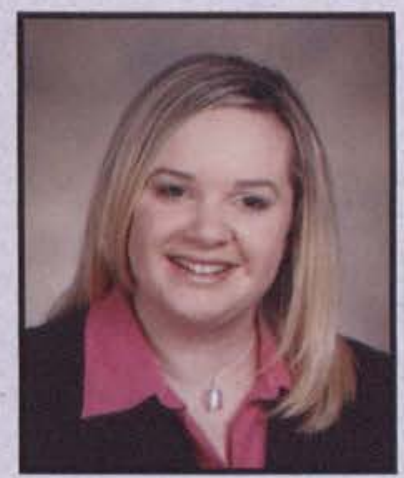

Lisa Pedersen

Org. Communications DesMoines, IA

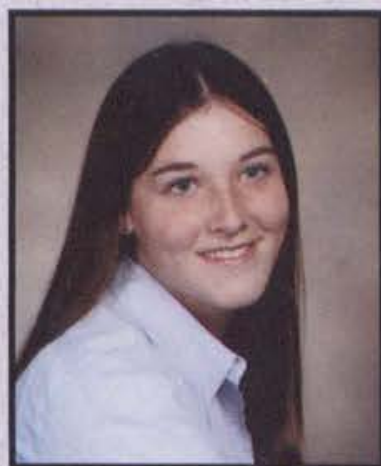

Sheli Oberbeck

English Literature

Meshoppen, PA

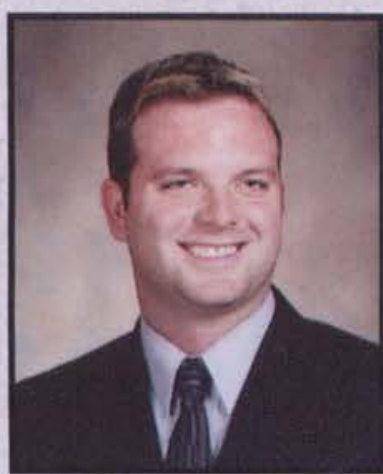

Steven Olson

Broadcasting \& Multimedia

Robbinston, ME

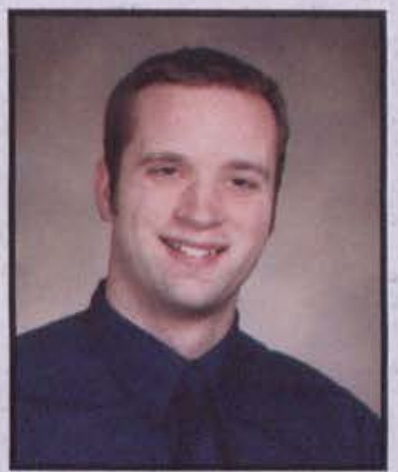

Matthew Ozinga

Bible

Thompson, $\mathrm{OH}$

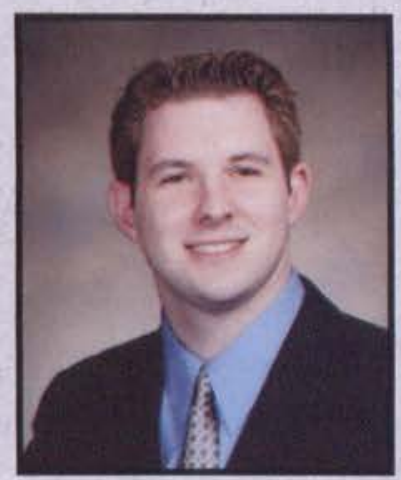

Matthew P. Peeler

Mang. Information Systems Barrington, NJ

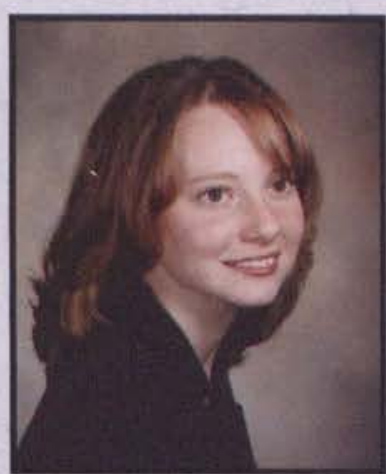

Amanda L. Oeffinger

Accounting \& Finance

Cedarville, $\mathrm{OH}$

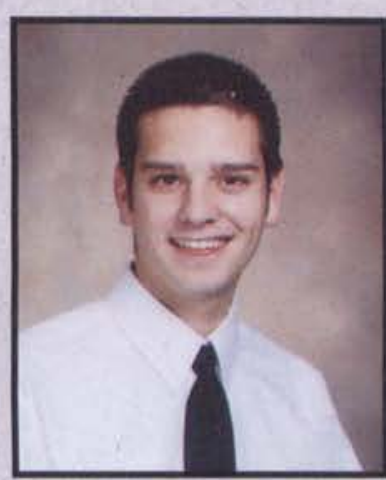

Joseph 0'Neal

Multimedia Technology

Simpsonville, SC

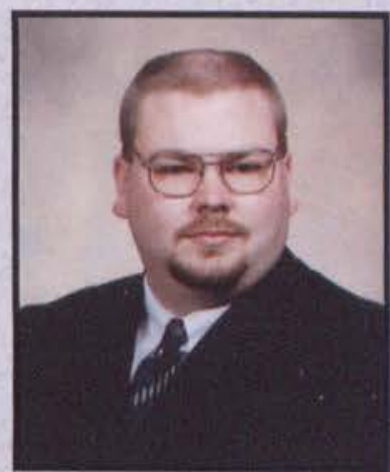

Steven M. Page

Mechanical Engineering

Machesney Park, IL

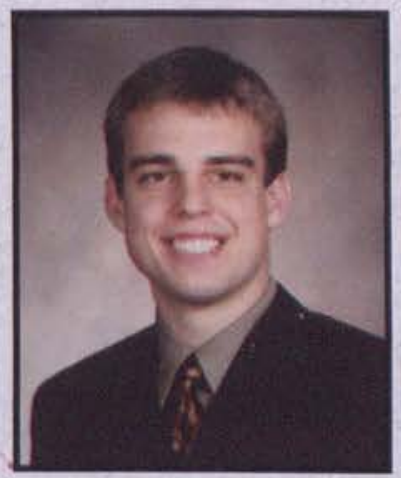

Todd Pellowe

Bible Comprehensive

Kalamazoo, MI

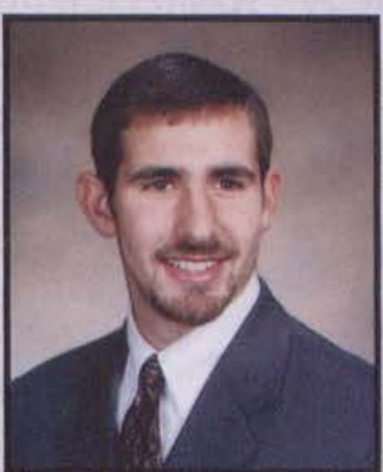

Jeff Olin

Marketing \& Management Loveland, $\mathrm{OH}$

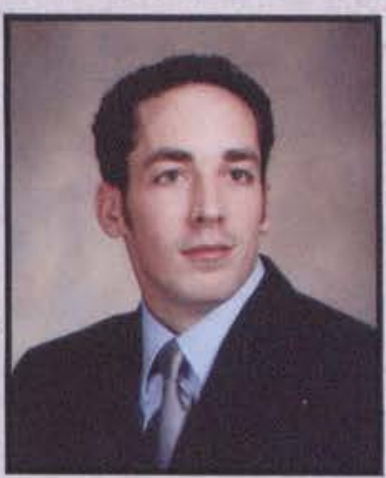

Tom Osypian

Christian Education of Youth

Ransomville, NY

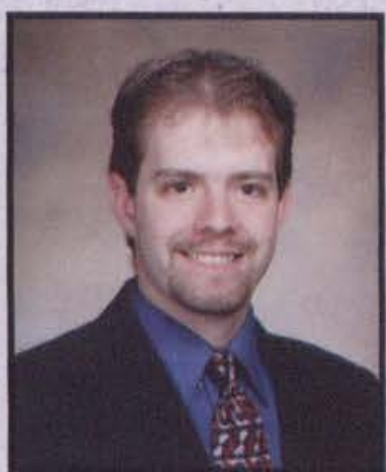

Steve Parker

Mechanical Engineering Mt. Airy, MD

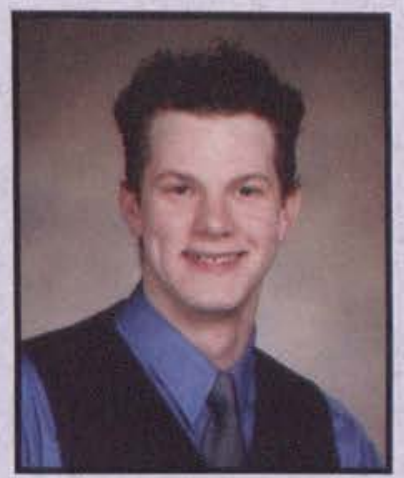

Nathan E. Pennington

Finance

Palmer, AK 


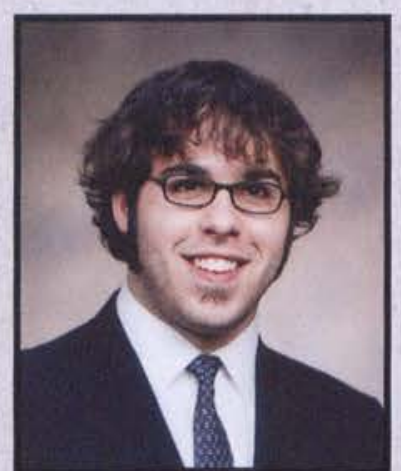

John Pepe

Computer Science

Dracut, MA

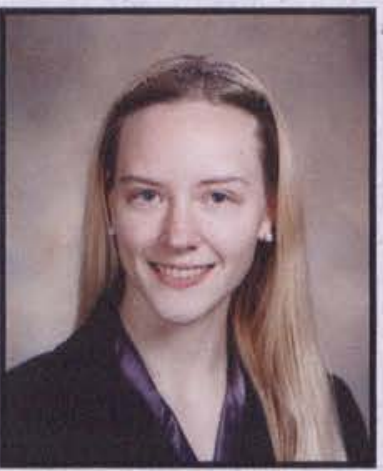

Robyn Pitman

Business Mang. \& Marketing

Taylor, MI

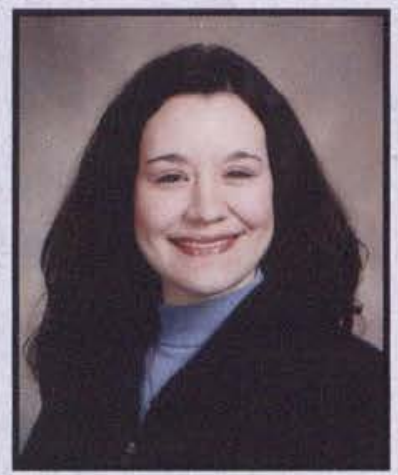

Karie Potter

Nursing

Painesville, $\mathrm{OH}$

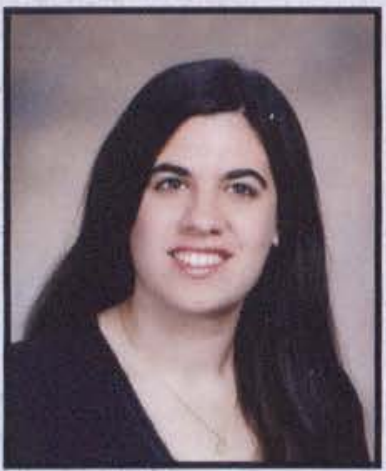

Ariella Price

Broadcasting

Fairfax, VA

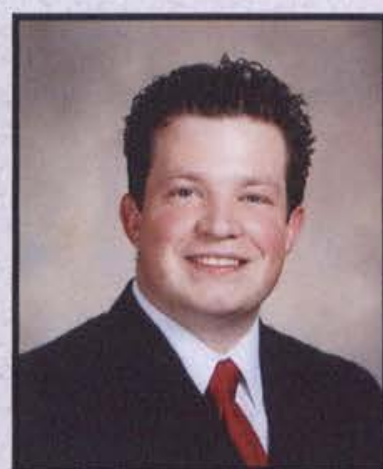

Luke D. Perrine

Bible Comprehensive

Anchorage, AK

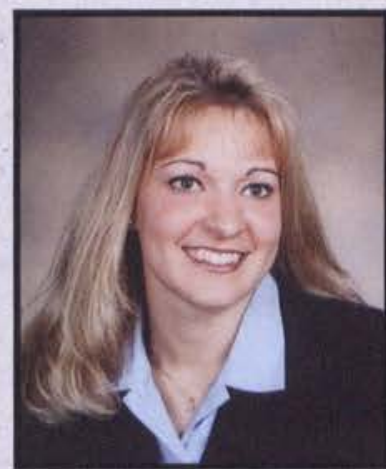

Amie L. Poelman

Nursing

Jenison, MI

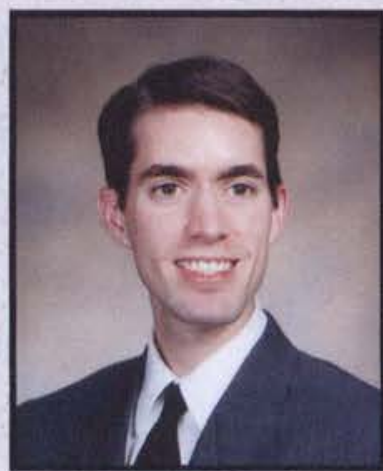

Matthew L. Powell

Math \& Computer Science Cedarville, $\mathrm{OH}$

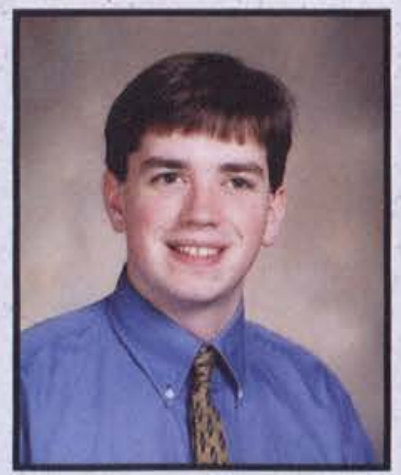

Daniel T. Price

Computer Science

Fruitport, MI

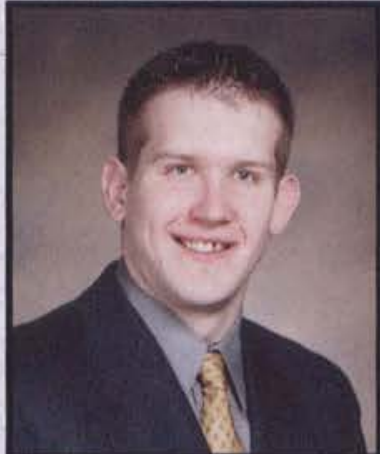

Eric R. Peschell

Physics

Greensboro, NC

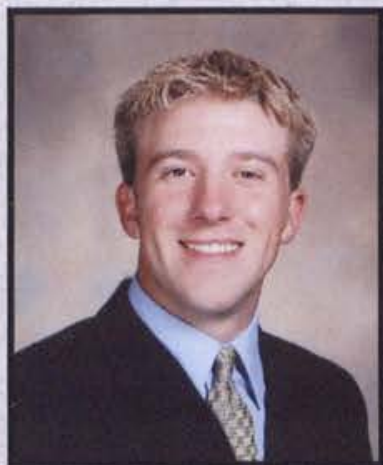

Michael Poelzer

Philosophy \& History

Wauwatosa, WI

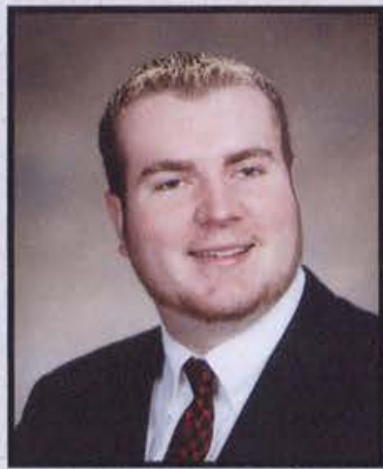

Nicholas A. Powell

Physical Education

West Carrollton, $\mathrm{OH}$

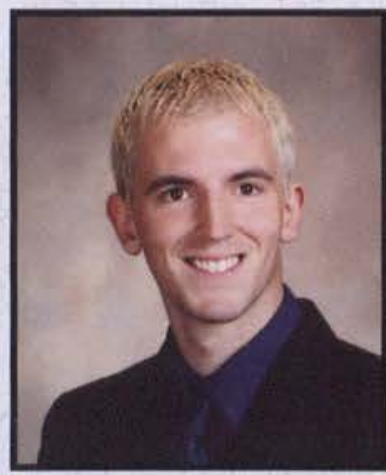

Michael J. Provencher

Computer Science

Epping, $\mathrm{NH}$

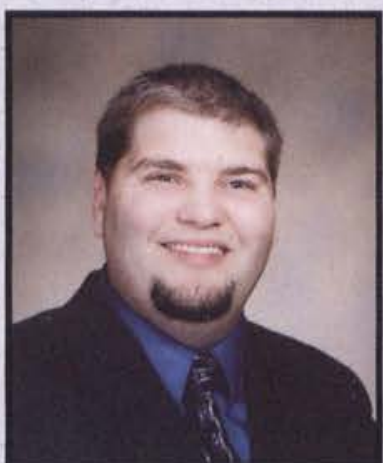

J. Christopher Phillips End-User Information Systems

Fairborn, $\mathrm{OH}$

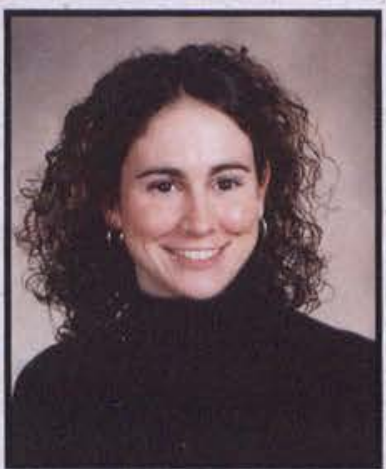

Amanda M. Porter Social Work

Northville, MI

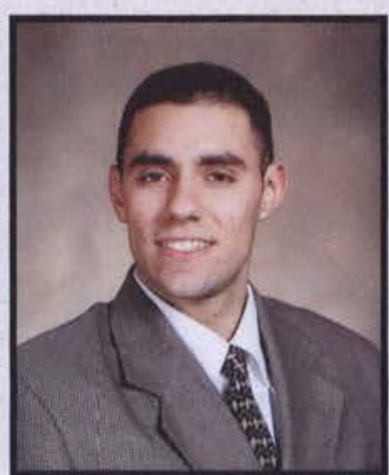

Shaun Power

Computer Science

Beavercreek, $\mathrm{OH}$

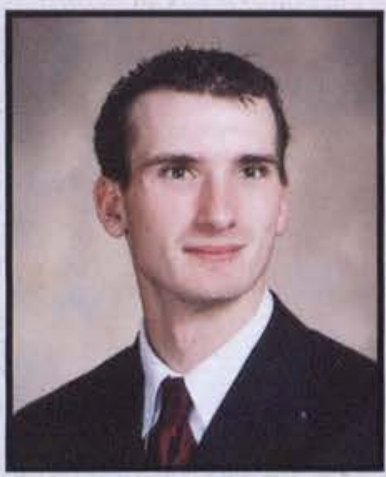

Jonathan S. Purdy

Business Management Irwin, $\mathrm{OH}$

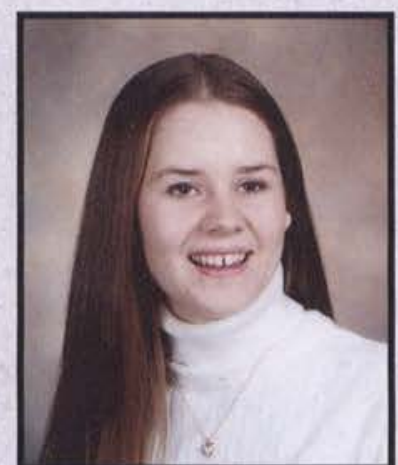

Jill Pinney

Language Arts Education

Jefferson, $\mathrm{OH}$

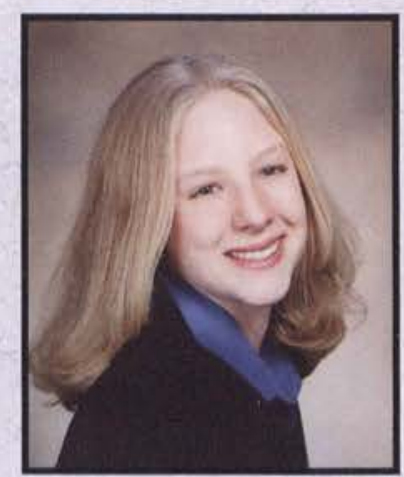

Sarah Posegate Biology

Mt. Arlington, NJ

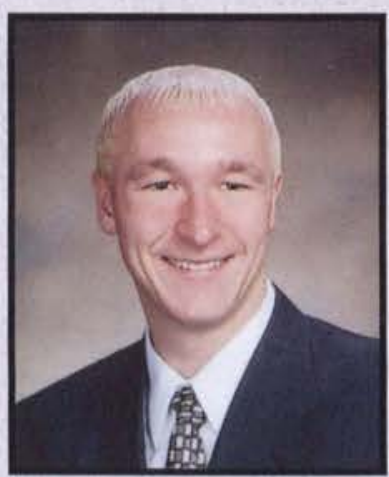

Dave Prahl

Physical Education

Wisconsin Rapids, WI

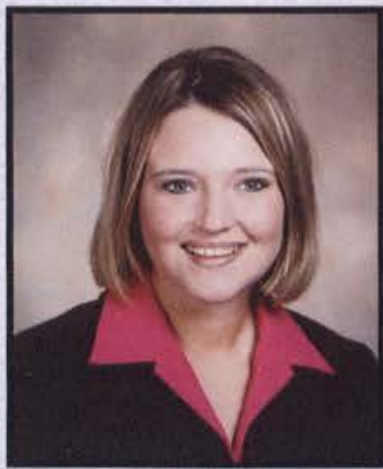

Heather R. Pursley

Nursing

Akron, $\mathrm{OH}$ 


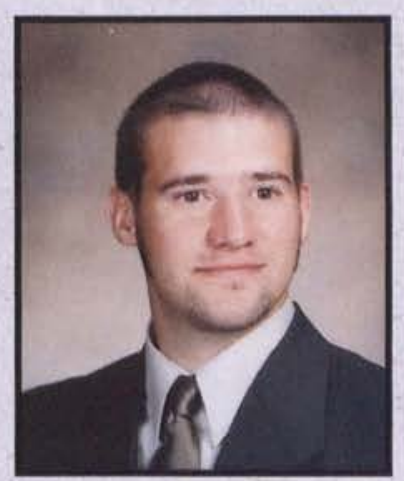

Josh Radcliffe

Electrical Engineering

Dayton, $\mathrm{OH}$

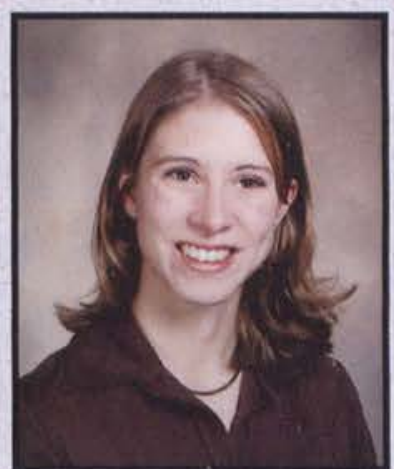

Alison Reemtsma

Org. Communications

Beavercreek, $\mathrm{OH}$

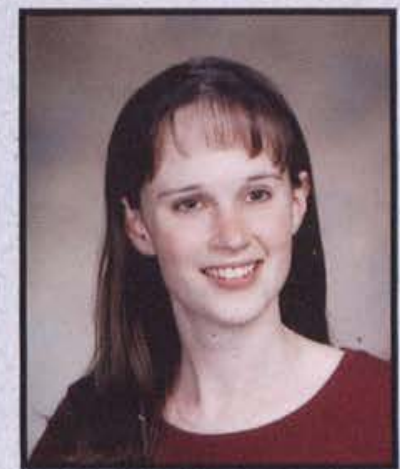

Julia Roberts

Bible

Milton, VT

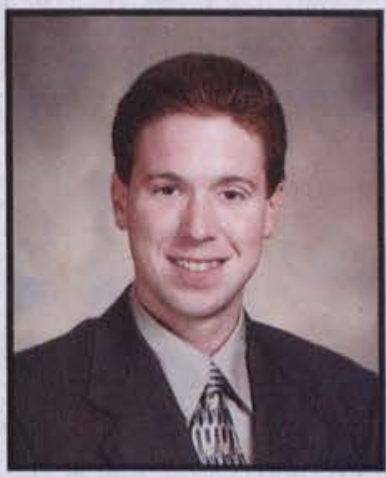

Gregory R. Roth

Electrical Engineering

Waterford, MI

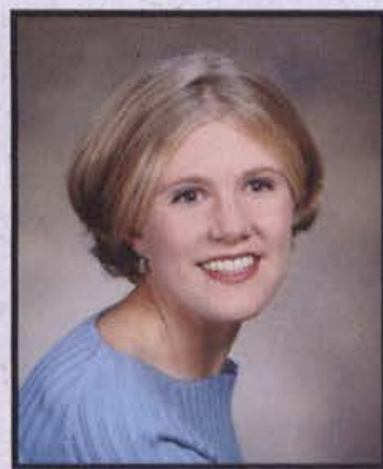

Alicia Rambikur

Spanish Education

Exeter, RI

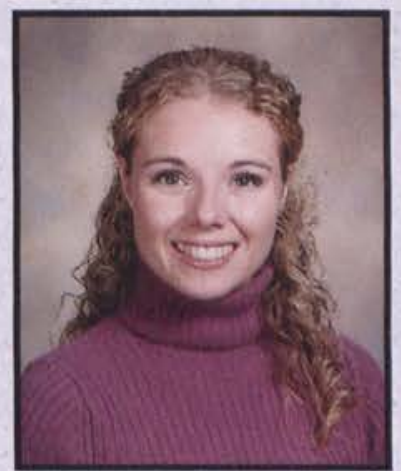

Rebekah L. Reynolds Early Childhood Education

Ravenna, $\mathrm{OH}$

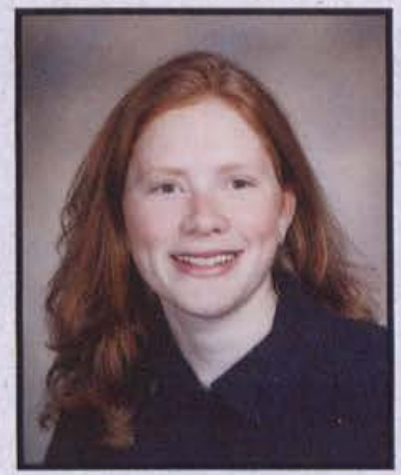

Karen Robinson

Middle Childhood Education Navarre, $\mathrm{OH}$

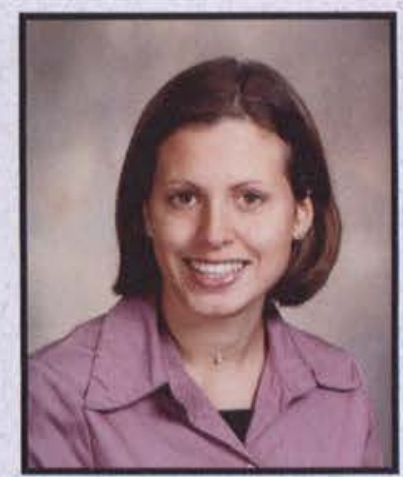

Annette Ruba

Exercise Science

Philadelphia, PA

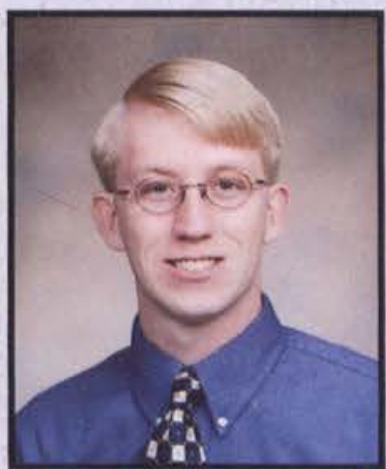

Geoffrey Recktenwald

Mechanical Engineering

White Lake, MI

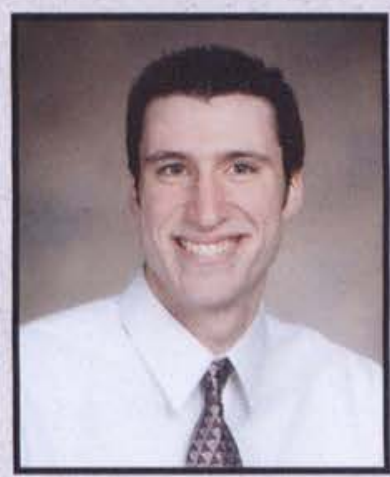

David Rheam

Math Education

Atco, NY

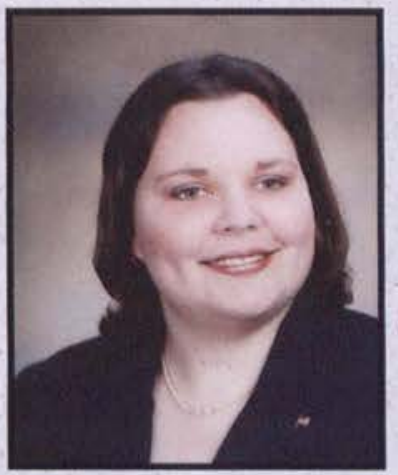

Danielle J. Rogers

Political Science

New Hartford, CT

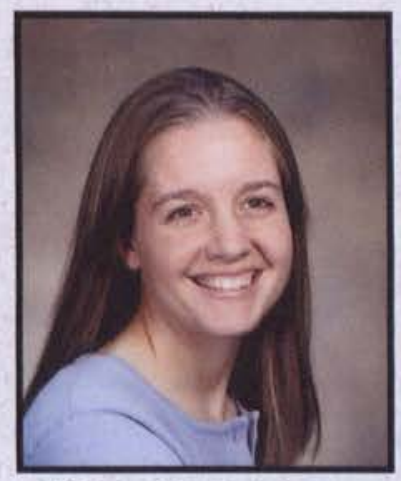

Michelle Ruhlman

Nursing

Seattle, WA

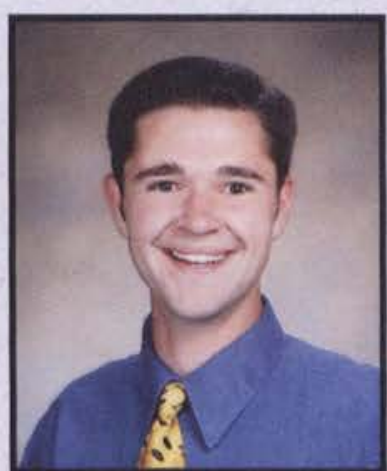

Diamond Redmond

End-User Information Systems

Soldotna, AK

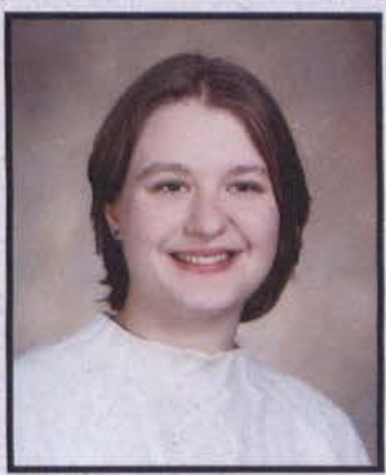

Rachel A. Richardson Nursing

San Antonio, TX

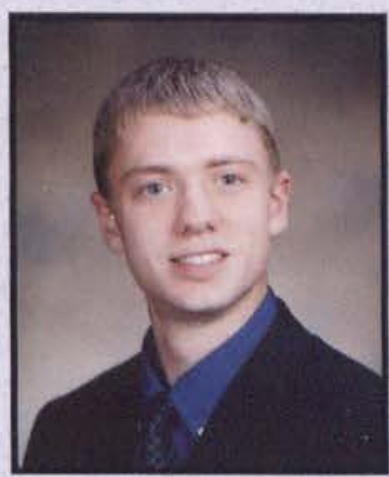

Benjamin Rosner Biology

Oak Hill, VA

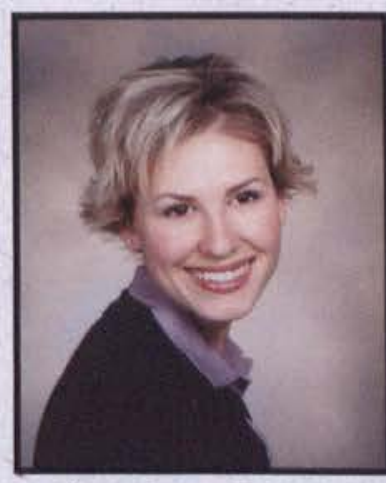

Courtney Salyers

Early Childhood Education Bakersfield, CA

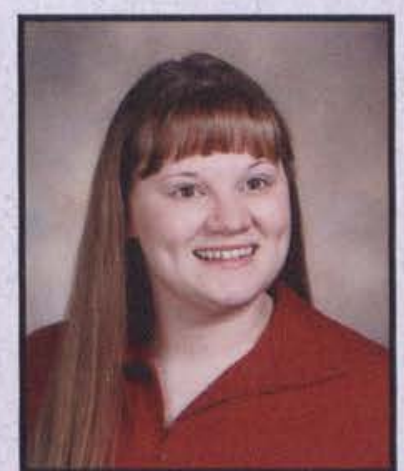

Kymberli Reed

Psychology

Marietta, $\mathrm{OH}$

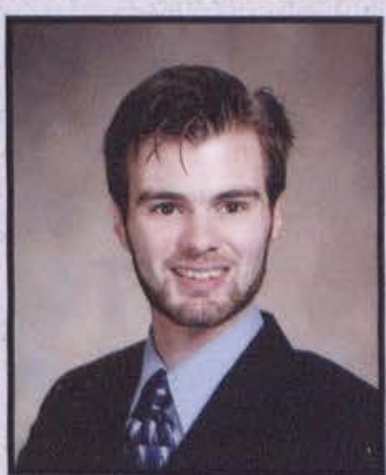

Matthew J. Richmond

Business Management

New Boston, NH

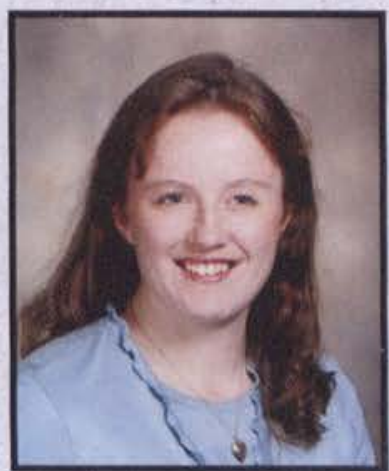

Sarah M. Ross

Nursing

Ulster, PA

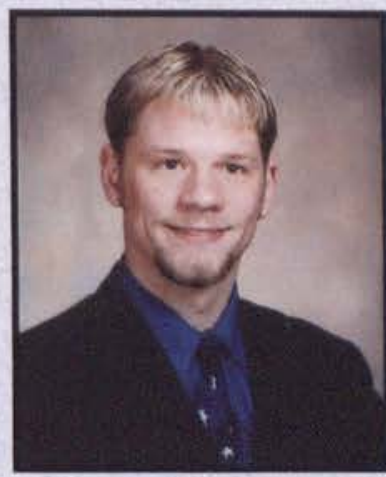

Robert Sampson

Mang. Information Systems Cedarville, $\mathrm{OH}$ 


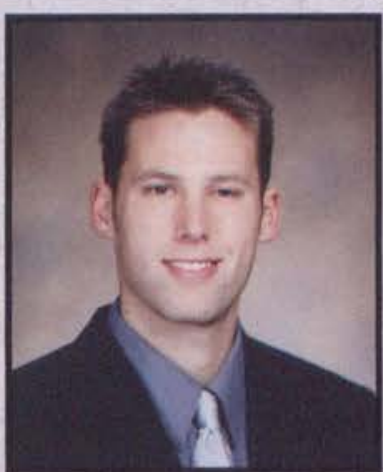

Greg Sanderson Broadcasting Forest, $\mathrm{OH}$

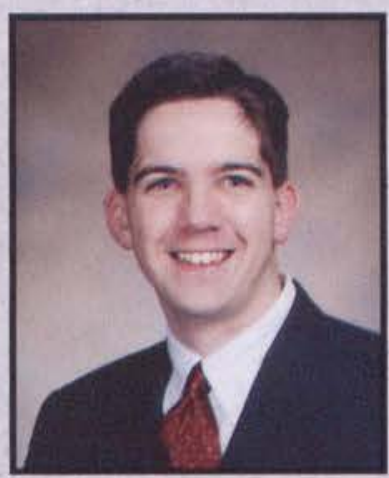

Grayden P. Schafer

English

Basom, NY

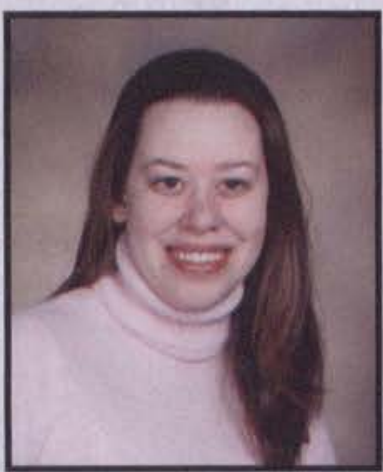

Jessica R. Schmidt

Music Education

Nanty Glo, PA

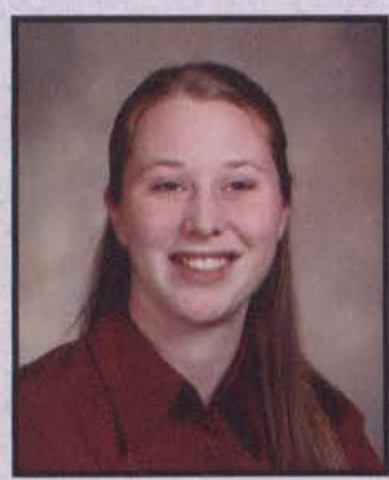

Kristi Schutter

Middle Childhood Education Jackson, MI

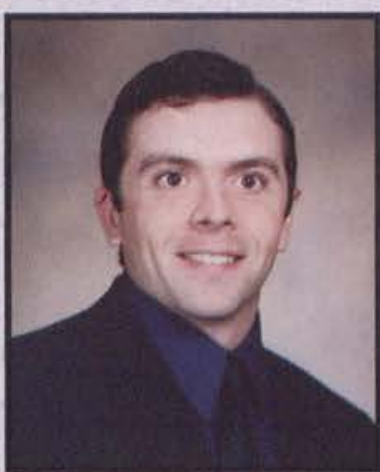

Benjamin Saturley

Business Management Pembroke, NH

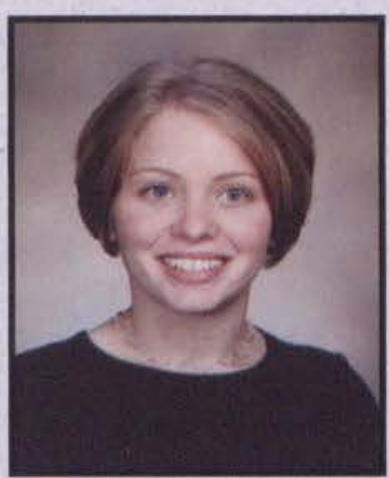

Kimberly Schaffer

Nursing

Prescott, AZ

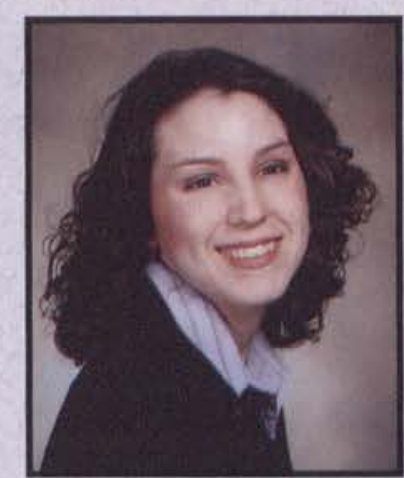

Rebecca A. Schmidt

Communications

Kalamazoo, MI

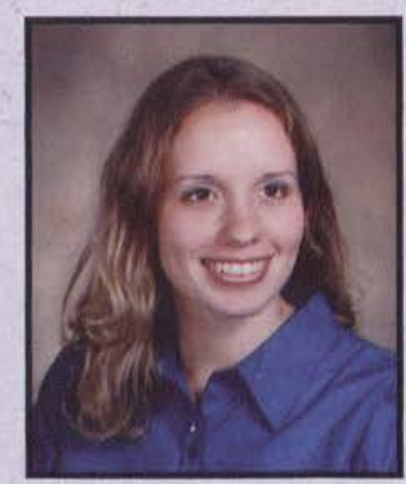

Amber E. Scott

Nursing

Sterling, VA

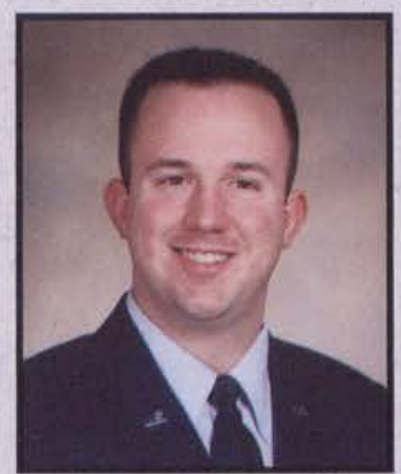

Francis W. Saul

Business Management Cedarville, $\mathrm{OH}$

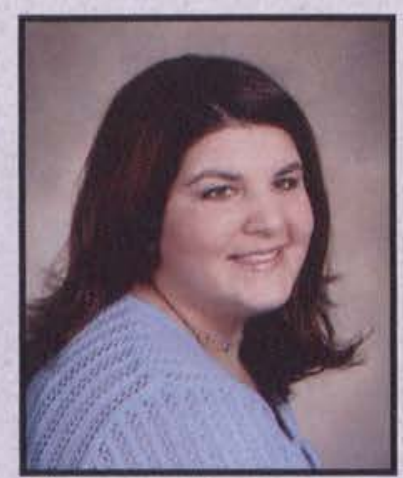

Dana Schiavo

Applied Psychology

Brick, NJ

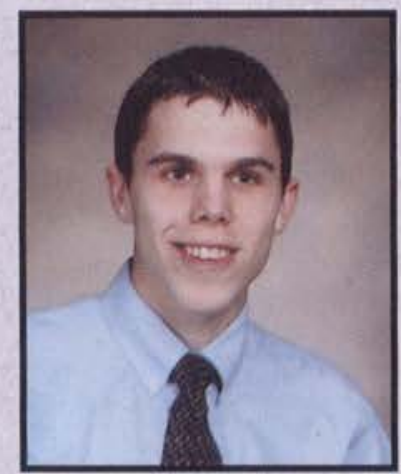

Caleb Schnake

AYA Integrated Math

Williams Bay, WI

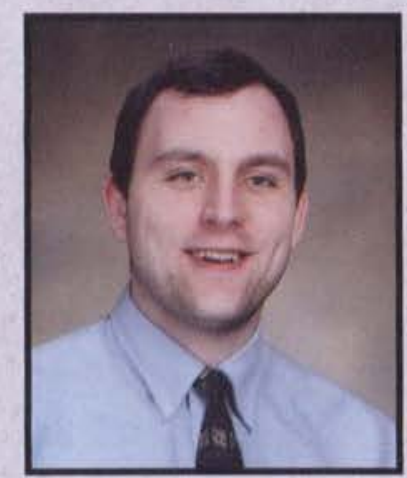

Brett W. Scott

Multimedia Technology West Branch, MI

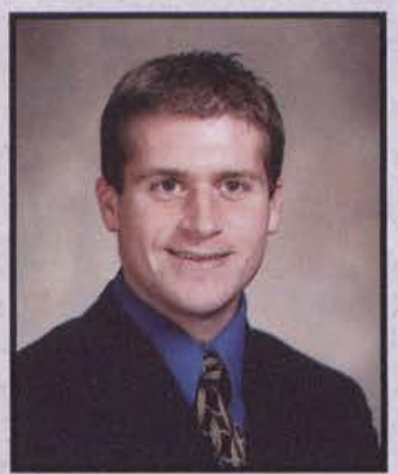

Kurt Savage

Biology

Whitinsville, MA

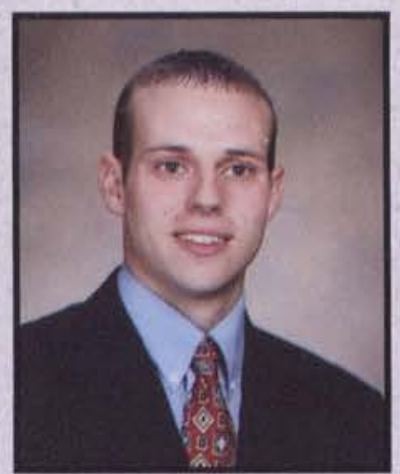

Nick Schlappi

Marketing \& Finance

Cedarville, $\mathrm{OH}$

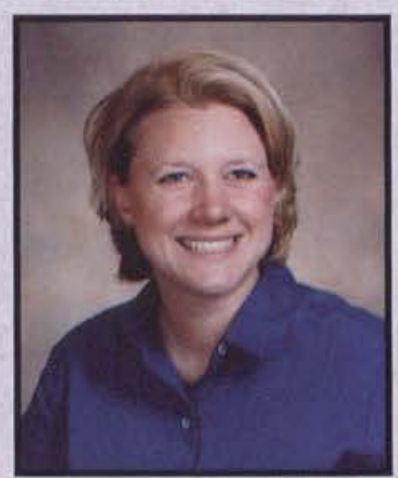

Kate Schriemer

Management \& Marketing Kalamazoo, MI

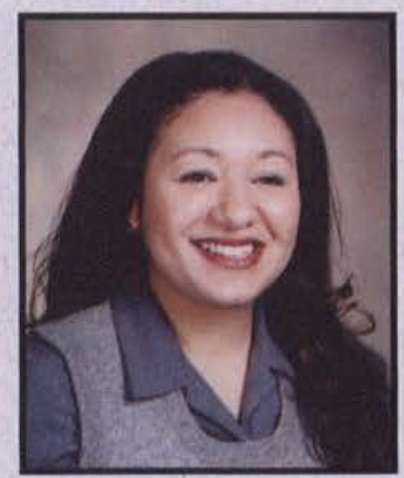

Tesha F. Seabra Nursing Hilliard, $\mathrm{OH}$

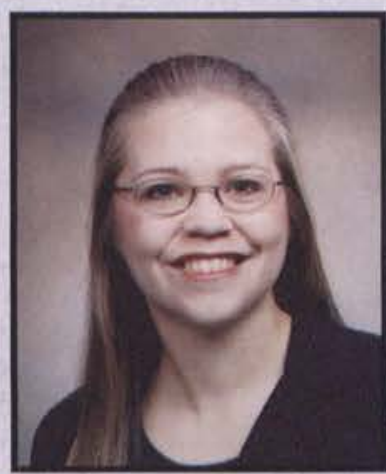

Leslie M. Scadding

Psychology \& Missions Derry, NH

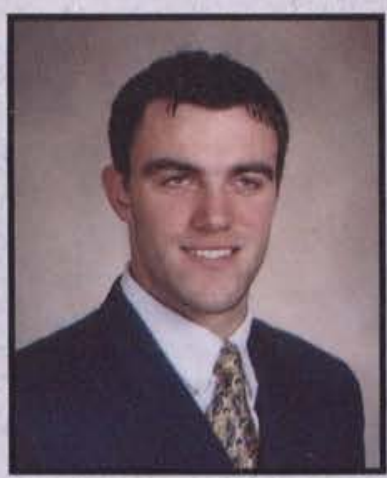

Andrew D. Schmidt Mechanical Engineering Troy, MI

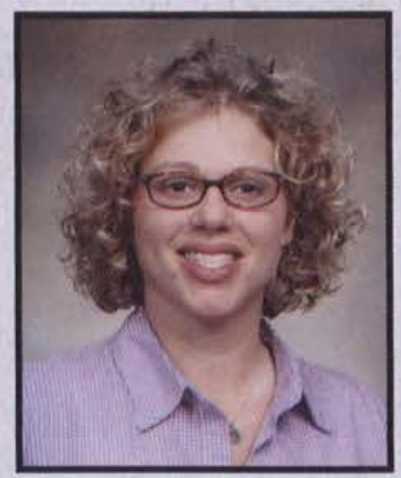

Patricia J. Schryer Physical \& Health Education Jackson, MI

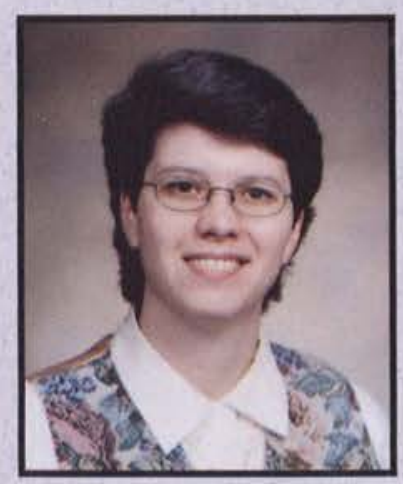

Teresa Sellers Nursing Dayton, $\mathrm{OH}$ 


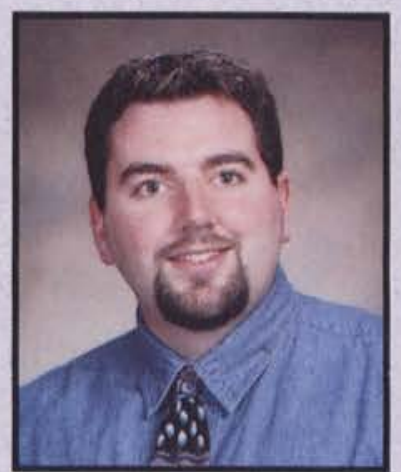

Ryan Sharp

Spanish

Indianapolis, IN

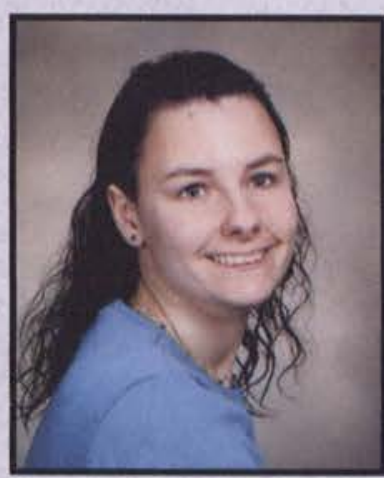

Joy M. Shustack

Early Childhood Education

Perkasie, PA

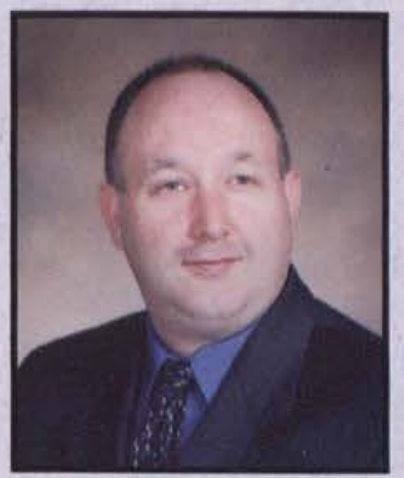

David W. Smith

Org. Communications Cedarville, $\mathrm{OH}$

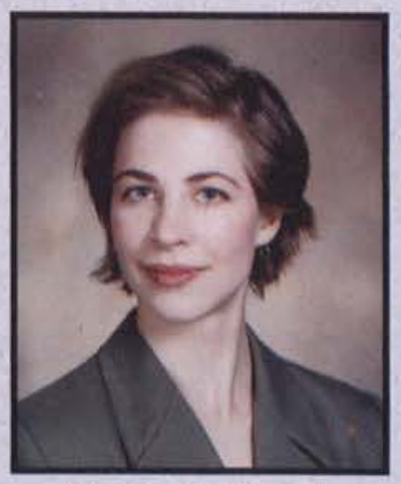

Marisa L. Smith Biology

Cedarville, $\mathrm{OH}$

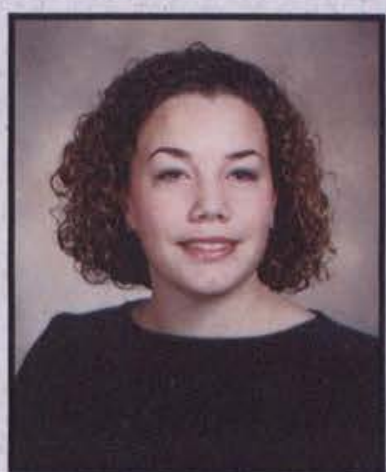

Stacey Shcolnik

English

Chandler, AZ

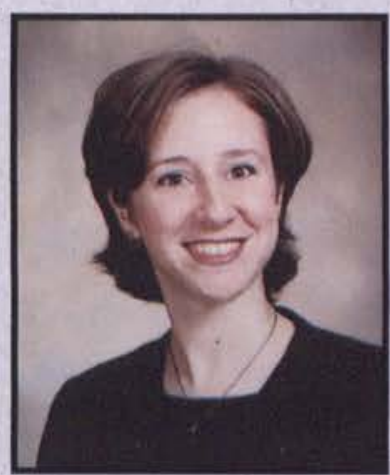

Lisa M. Simpson

Life Science Education

Des Moines, IA

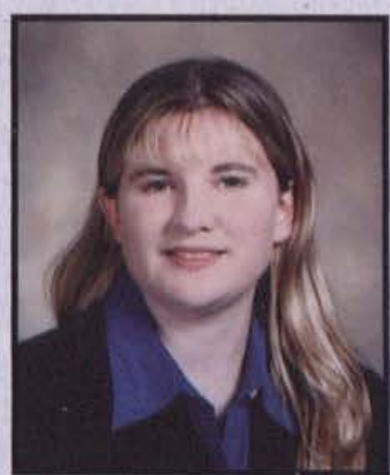

Erin Smith

Broadcasting

Johnstown, $\mathrm{OH}$

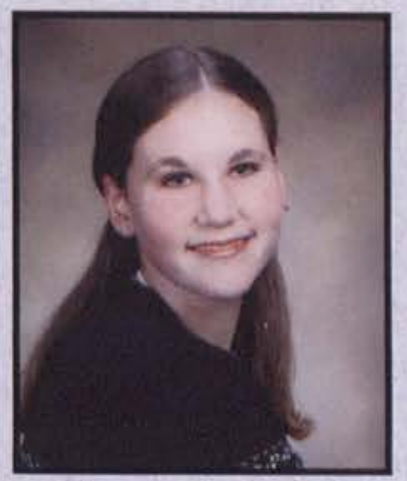

Meagan L. Smith

Psychology

Brockport, NY

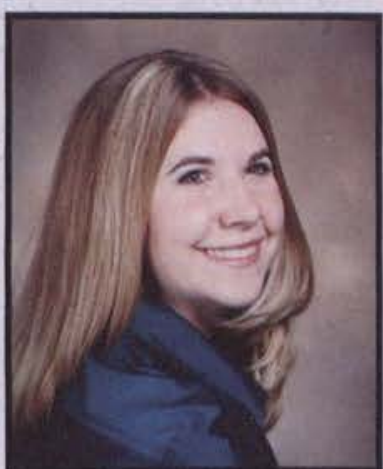

Tammi Sheldon

Early Childhood Education

Columbus, $\mathrm{OH}$

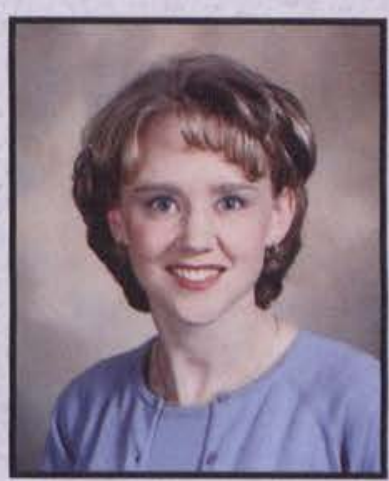

Nicole Sinzinger

Nursing

Columbus, $\mathrm{OH}$

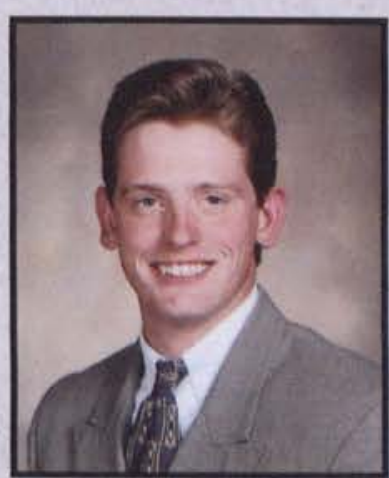

Jamie A. Smith

World Missions

New Holland, $\mathrm{OH}$

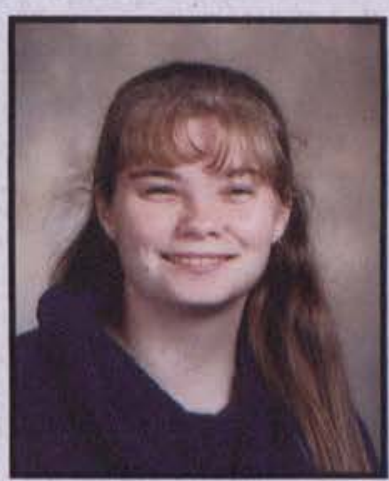

Sarah Snare

Nưrsing

Bluffton, $\mathrm{OH}$

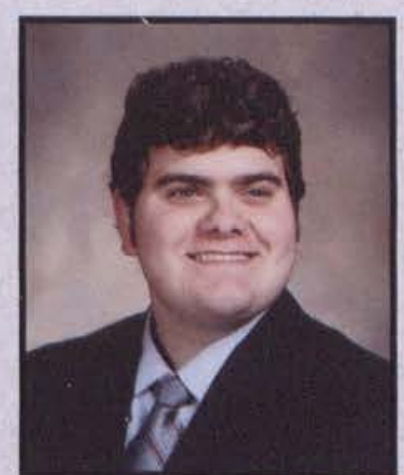

Willy T. Shelton

Music Education

Wasilla, AK

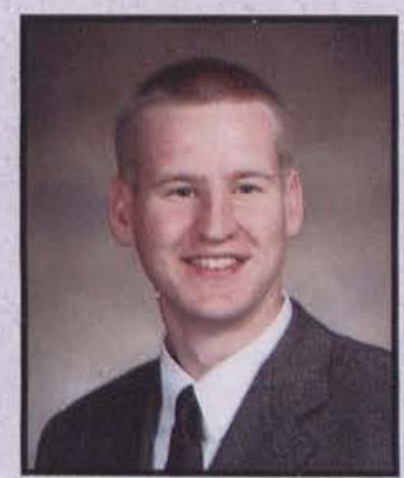

Benjamin Skurdal

Electrical Engineering

Bel Air, MD

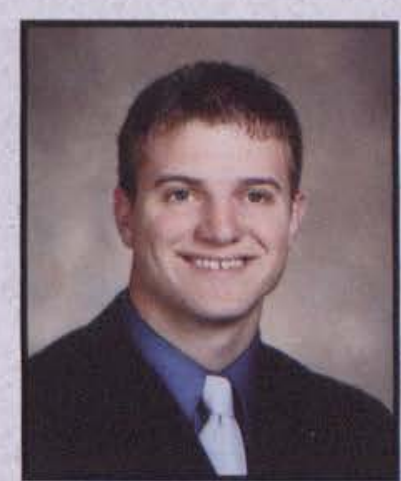

Jason Smith

Communication Arts Decatur, IN

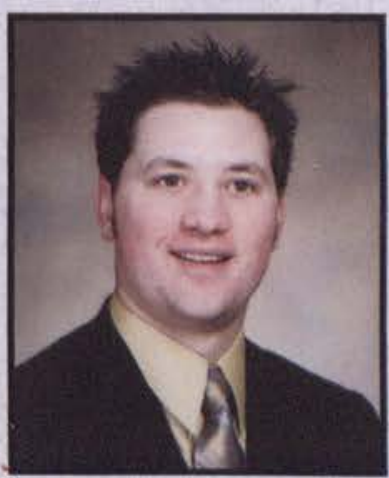

Stephen Snavely

Biology

Elizabethtown, PA

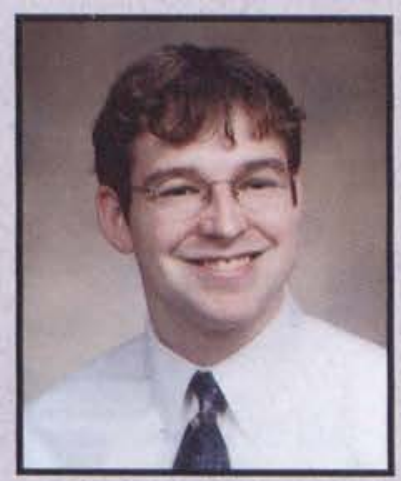

Charlie Shifflett

Bible Comprehensive

Tallahassee, FL

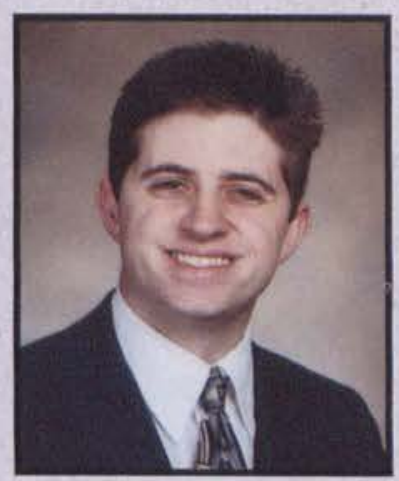

Andrew P. Smith History \& Political Science Sterling Heights, MI

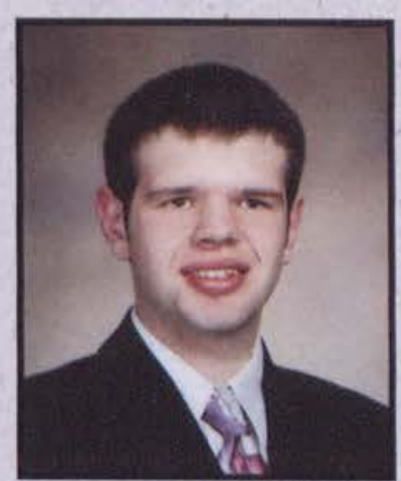

Jeremy Smith

Computer Science Columbia, NC

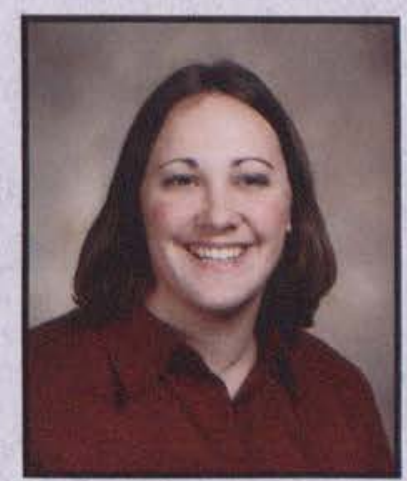

Cara Snider

English

Waynesboro, PA 


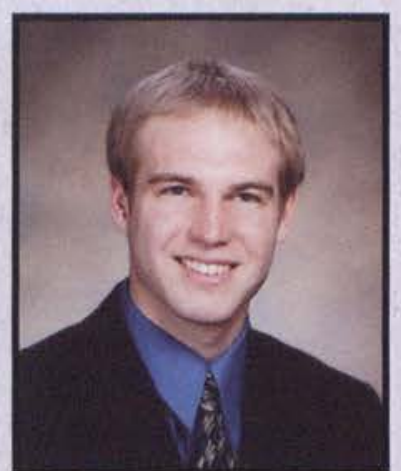

Brian Snyder

Multimedia Technology

Hollidaysburg, PA

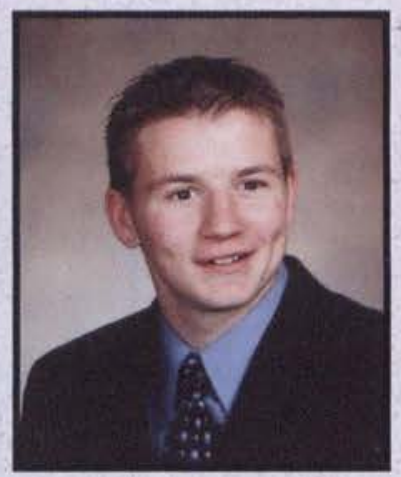

Pete Springirth

Christian Education of Youth Erie, PA

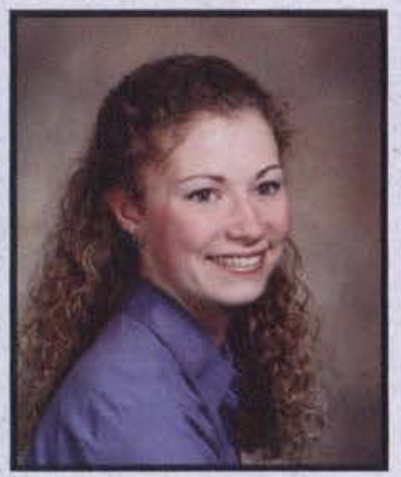

Jennifer N. Steely

Applied Psychology Milford, $\mathrm{OH}$

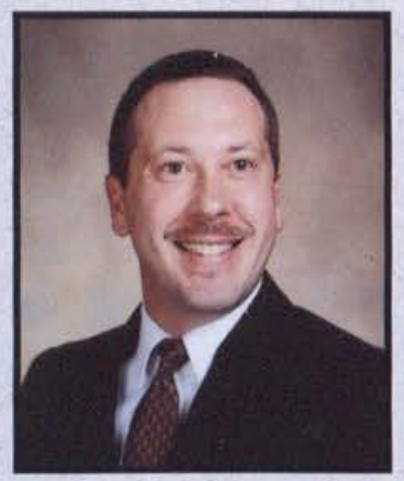

Carl E. Stengel

Bible Certificate

West Liberty, $\mathrm{OH}$

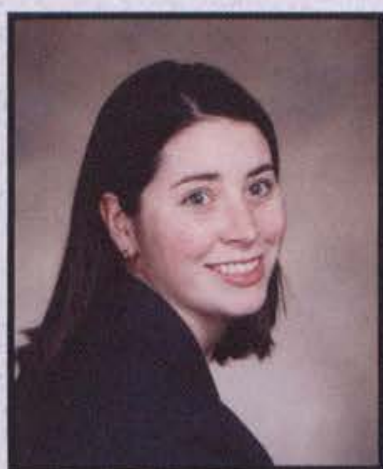

Jessica I. Snyder

AYA Social Studies

Cedarville, $\mathrm{OH}$

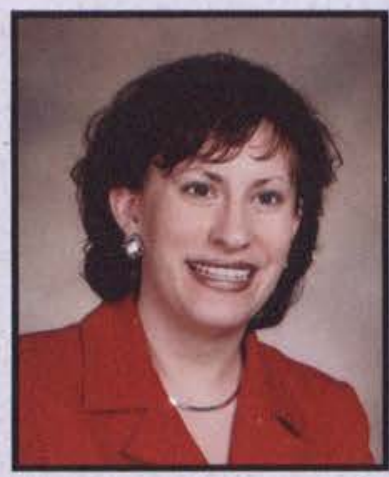

Heidi Sproul

Music Education

Elizabethtown, PA

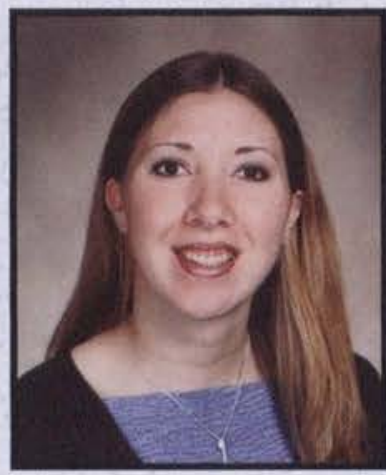

Elizabeth Steenwyk

International Studies Zeeland, MI

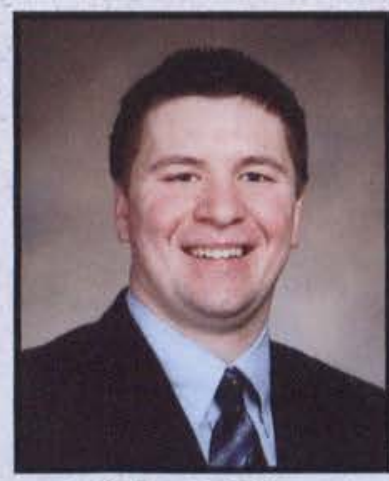

Elisha Stillings

Broadcasting

Forsyth, MO

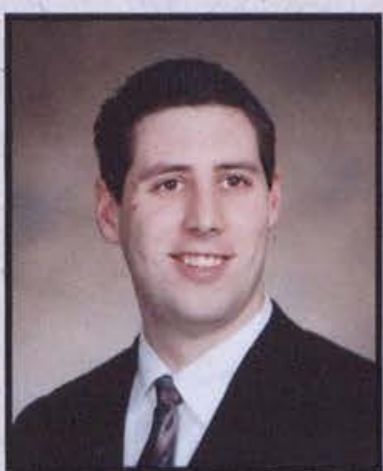

Rob Snyder

Electrical Engineering

Canalwinchester, $\mathrm{OH}$

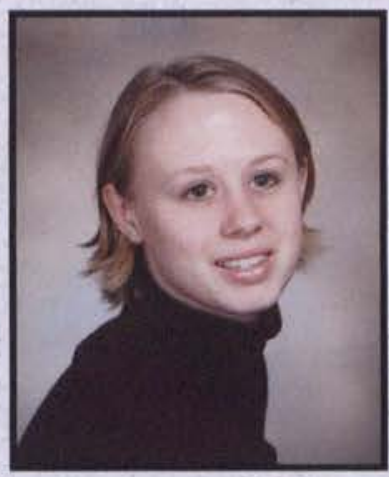

Heather J. Stark Middle Childhood Education Argyle, NY

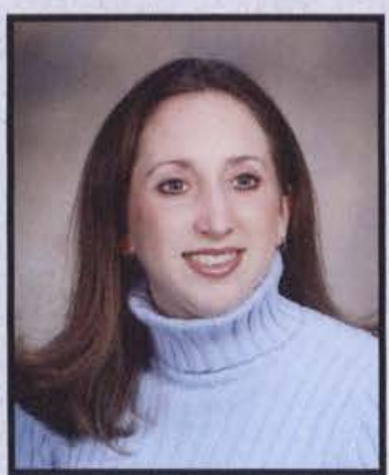

Kelsie L. Steiner

Integrated Social Studies Palatine, IL.

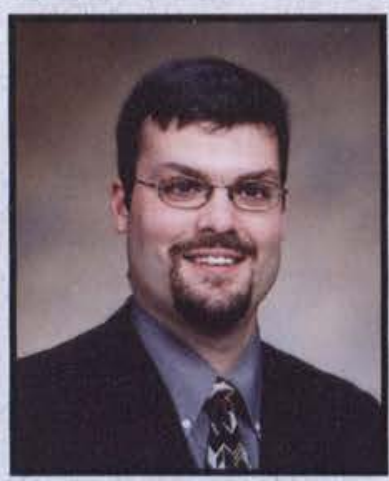

James P. Stitzel

Psychology

Hamlin, NY

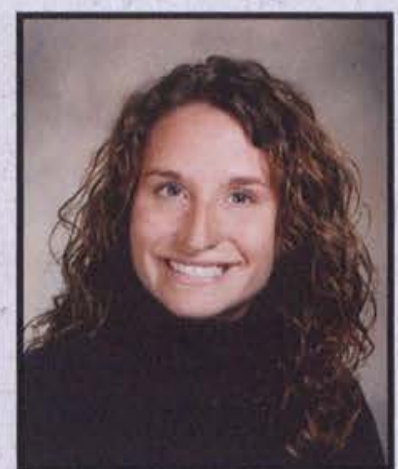

Wendy M. Somers

Athletic Training

Brookville, $\mathrm{OH}$

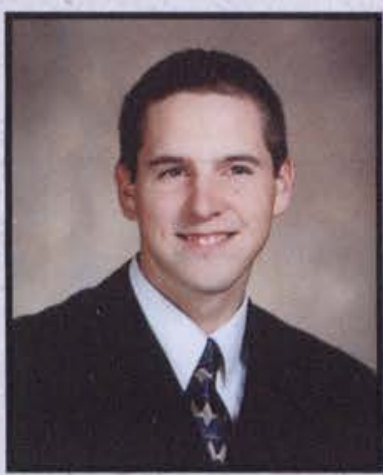

Aaron Statler

Accounting \& Finance

Mount Vernon, $\mathrm{OH}$

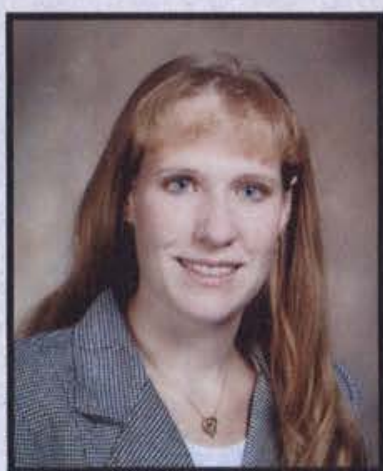

Katherine Steingass

Biology

Defiance, $\mathrm{OH}$

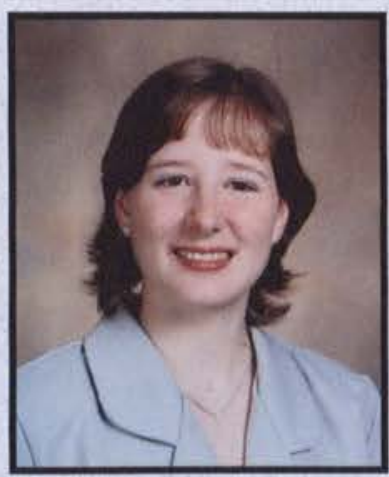

Carla D. Stoltenberg

Biology

Greensburg, PA

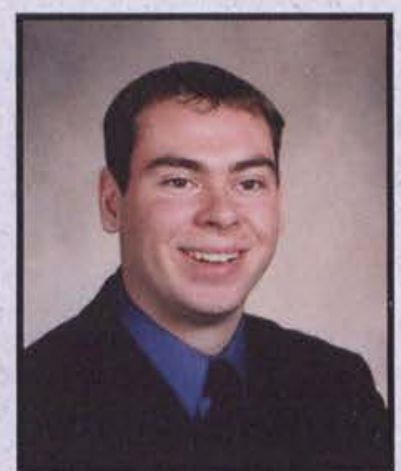

John Sorrell

Christian Education of Youth Franklin, $\mathrm{OH}$

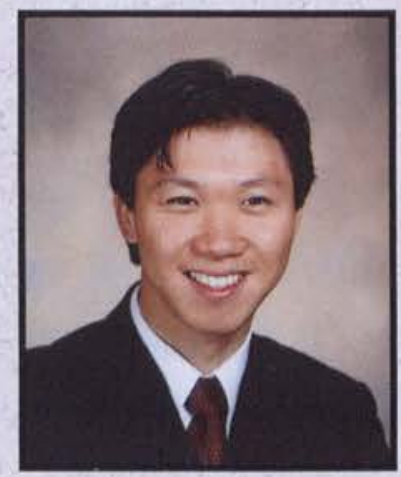

John Stedge Bible

Cedarville, $\mathrm{OH}$

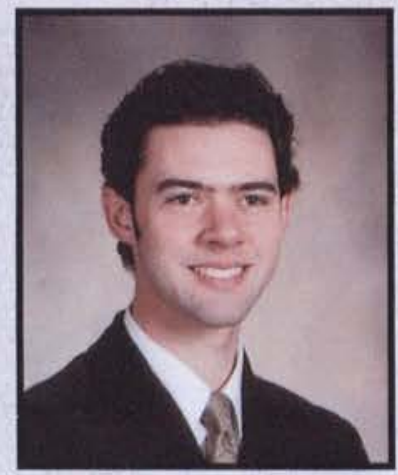

Charles W. Steitler

Bible \& Pre-Seminary Lyons, NY

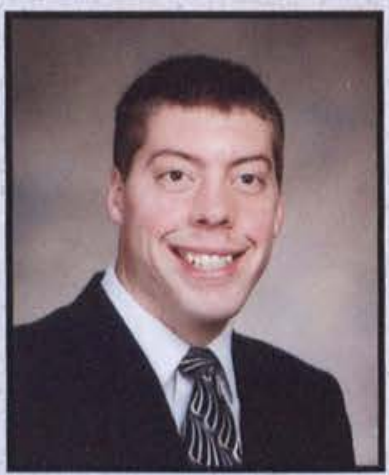

Steven Storer

Accounting

Colman, SD 


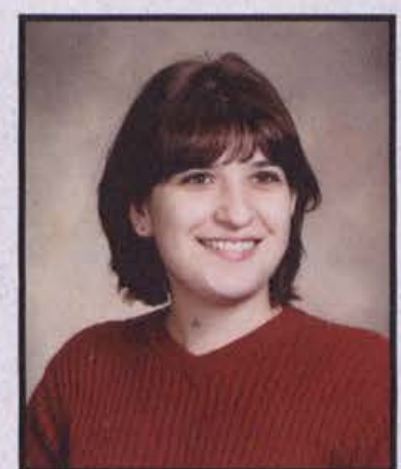

Danielle Stoughton

Social Work

Radcliff, KY

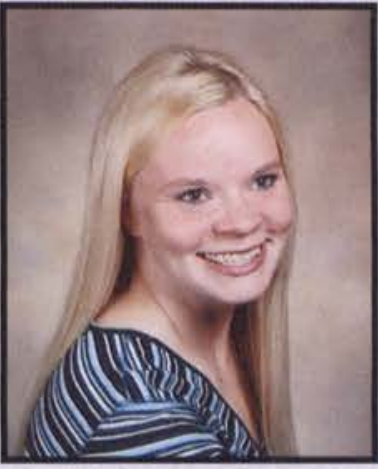

Donna L. Swan

Youth Ministry \& Spanish North East, PA

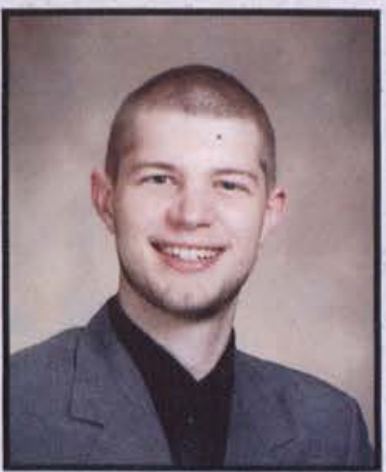

David Tehan

Philosophy

S. Charleston, $\mathrm{OH}$

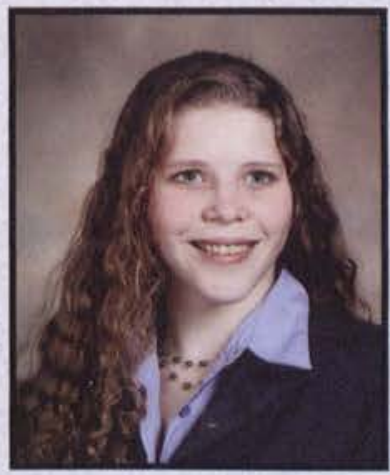

Amey Trimble-Lisch

Nursing

Cedarville, $\mathrm{OH}$

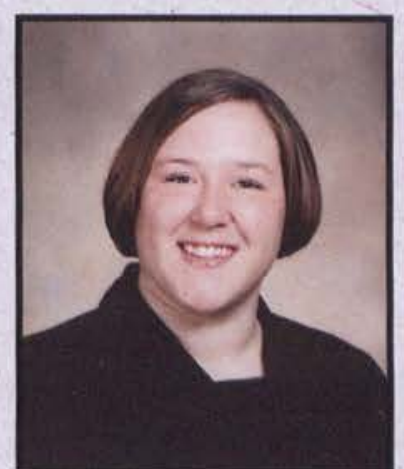

Stephanie L. Strong End-User Information Systems Utica, MI

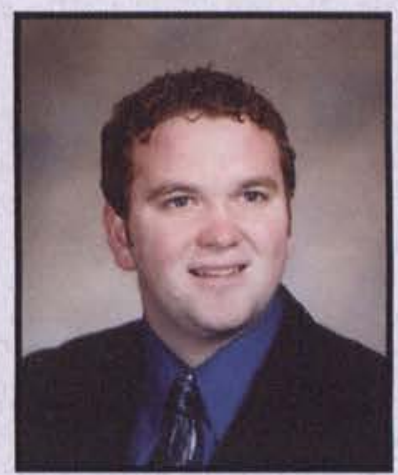

Jonathan Swanson

Accounting

Rockford, IL

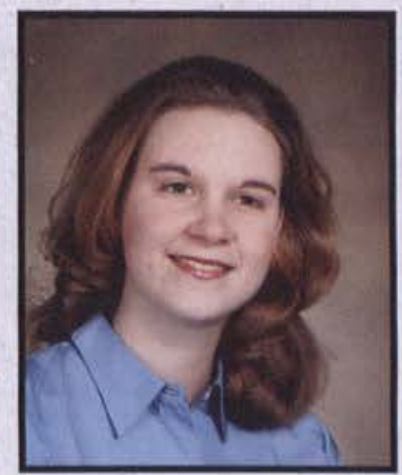

Amy B. ten Brink

Social Work

Grand Rapids, MI

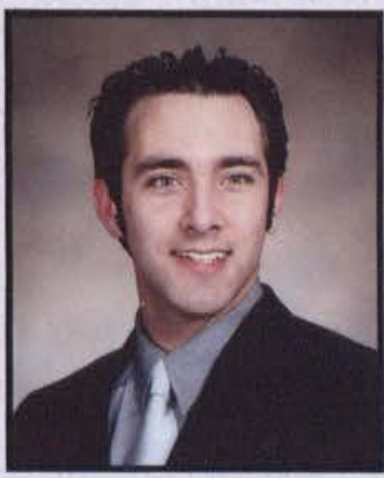

Justin Tubbs

Mang. Information Systems Orchard Park, NY

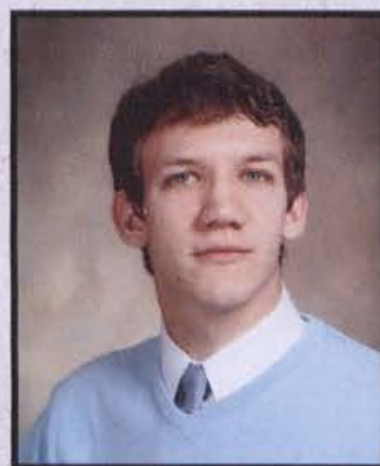

Joseph R. Strychalski

Broadcasting

Lebanon, IN

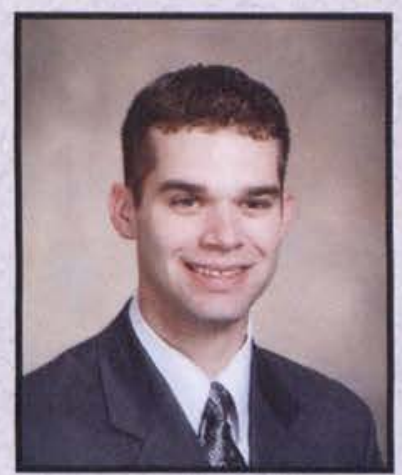

Shaun J. Swingle

World Missions

Morrisville, NC

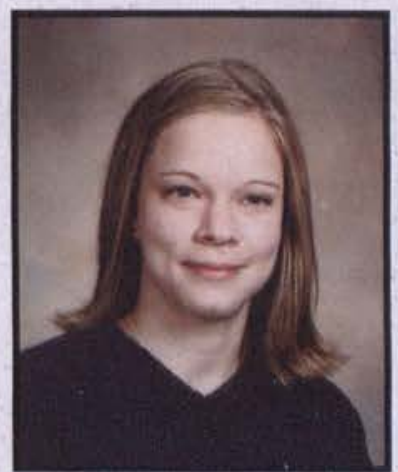

Rebekah Teusink

- Nursing

Sand Lake, MI

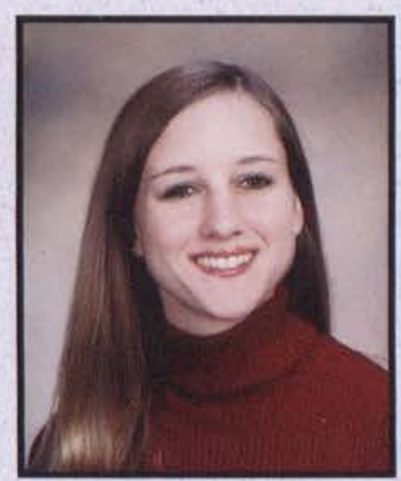

Melissa L. Turnick

Athletic Training

Oberlin, $\mathrm{OH}$

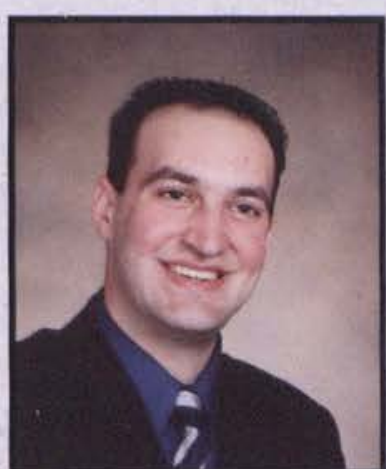

Daniel J. Sudlow

Pre-Seminary

West Chester, $\mathrm{OH}$

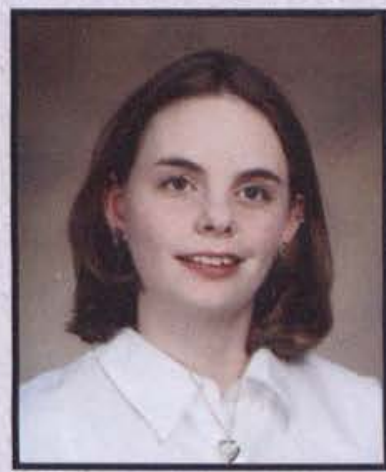

Tiffany Tabor

Social Work

Hillsboro, $\mathrm{OH}$

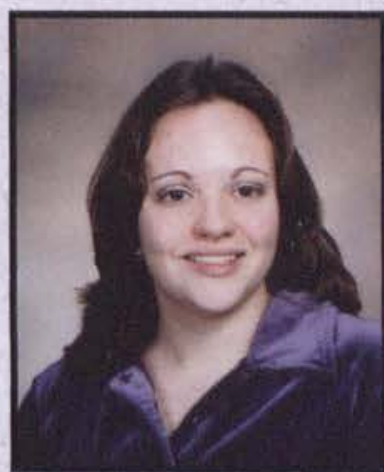

Christine L. Trago

Social Work

Narvon, PA

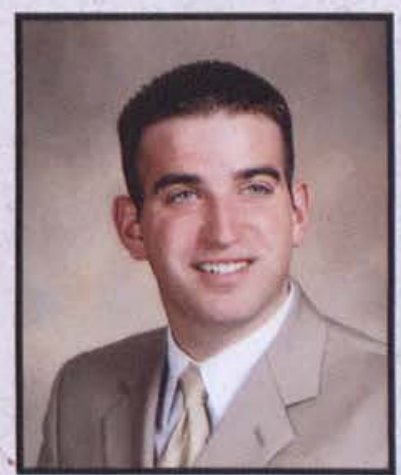

Nick Tynan

Church Music Ministries Maron, IL

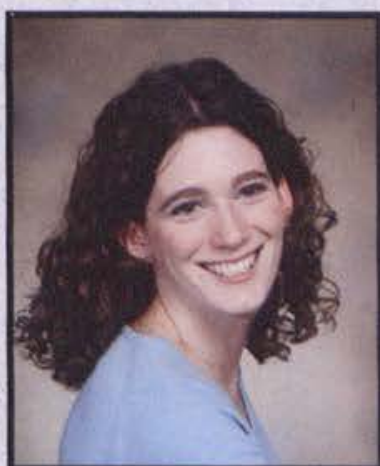

Katherine Summers Middle Childhood Education Rochester, NH

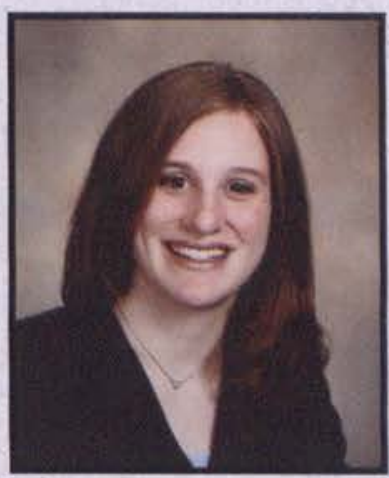

Erica A. Taldo

Human Resource Mang. Archbold, PA

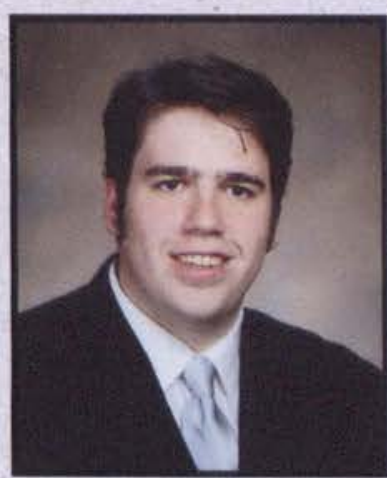

Carl Traub

History

Peach Bottom, PA

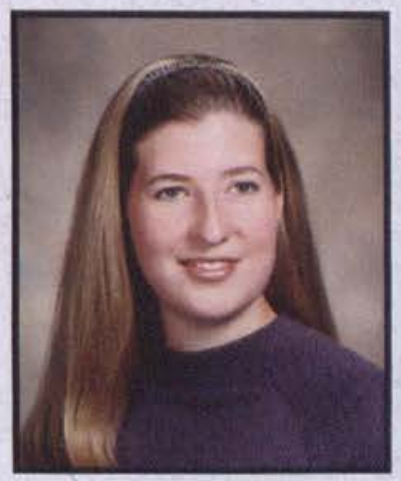

Elizabeth A. Uitti

Biology

Troy, MI 


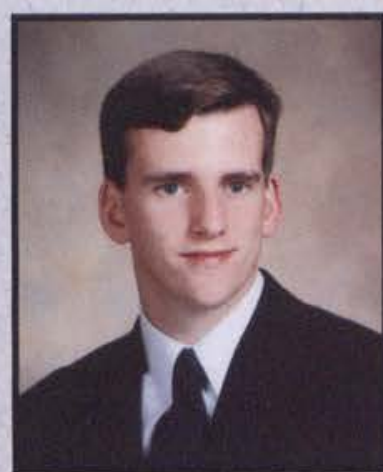

Mark Underkofler

Pre-Seminary

McKurray, PA

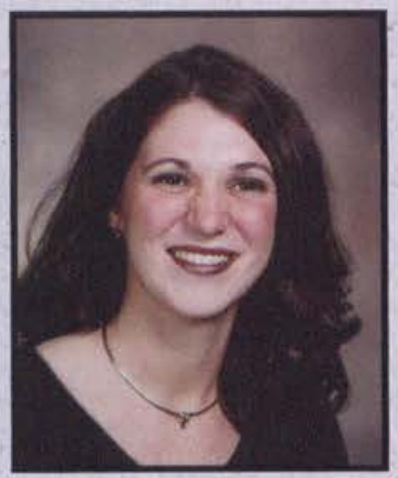

Melissa Van Eerden Nursing Jenison, MI

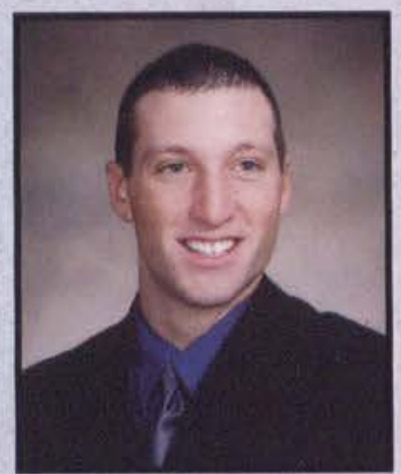

Michael Vanlier

Bible Comprehensive Pittsgrove, NJ

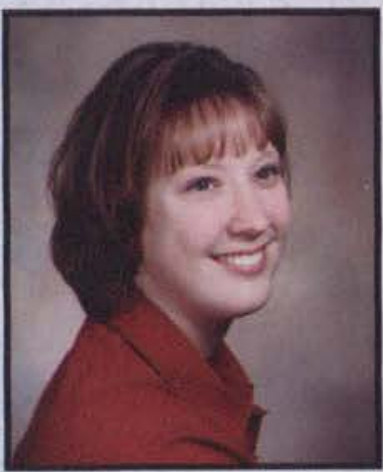

Laura R. Volpe

Early Childhood Education West Seneca, NY

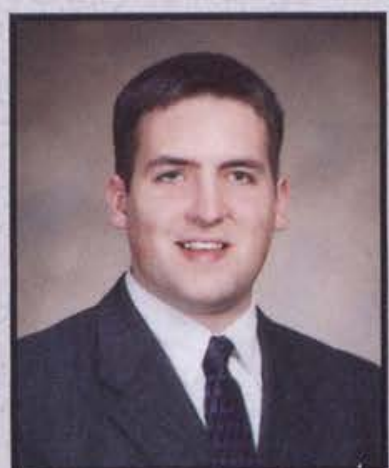

\section{Edward Vander Bush} Marketing \& Management Downingtown, PA

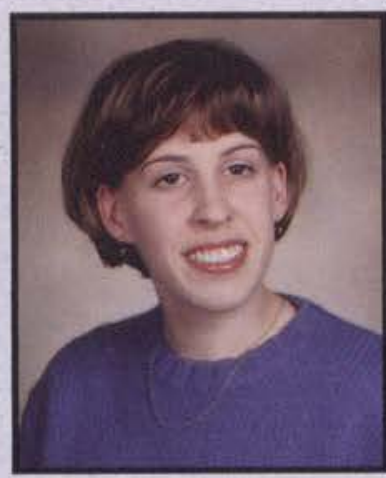

Tiffany N. VanHart Nursing

Bingnamton, NY

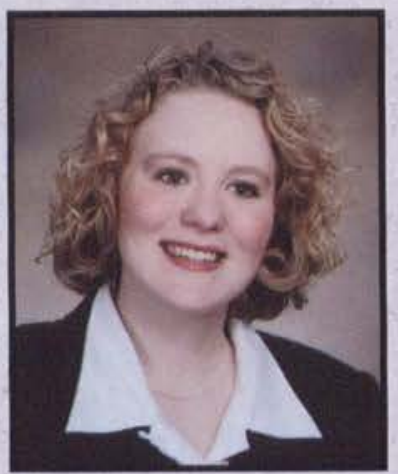

Rebecca J. VanLoon

Communication Arts Jamestown, $\mathrm{OH}$

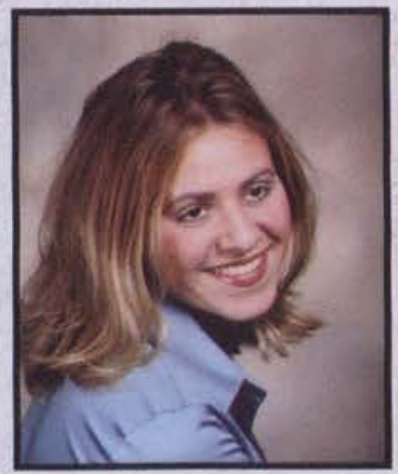

Alissa J. Voltz

Early Childhood Education Ohio City, $\mathrm{OH}$

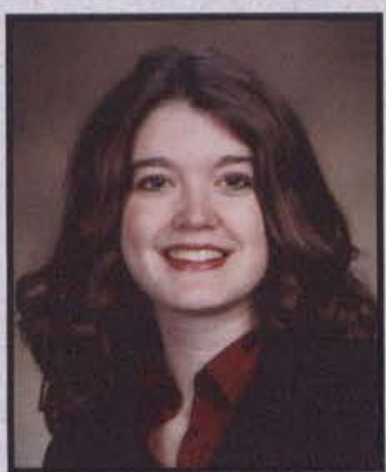

Rebecca VanDeMark Bible Comprehensive

Knoxville, TN

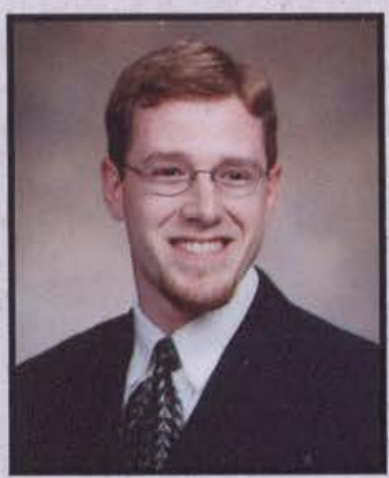

Bradley VanHeukelum Biology

Wataloo, IA

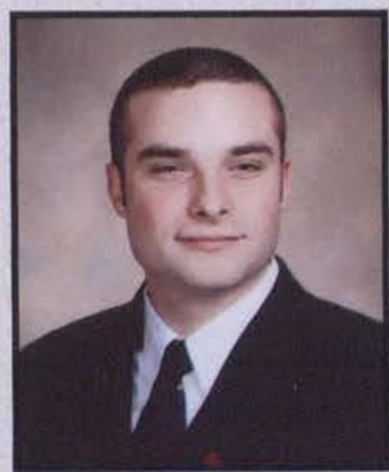

Benjamin Vlug

Multimedia Technologies Wyoming, MI

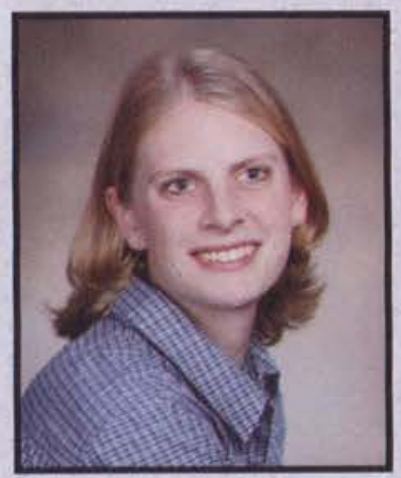

Trisha F. Wabeke

International Studies Wyoming, MI

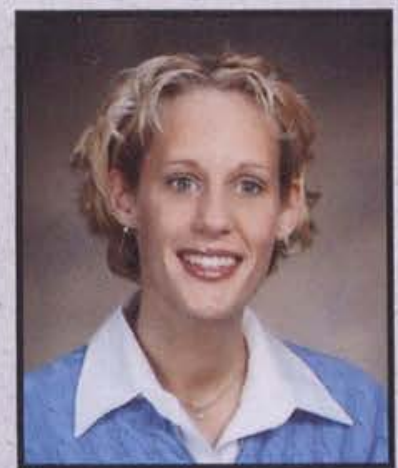

Heather L. VanDerAa

Exercise Science

Bloomington, IL

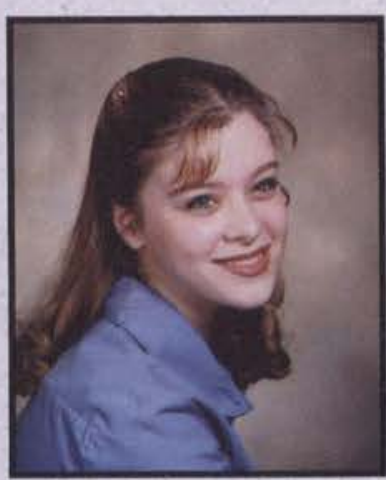

Melissa VanHeukelum Early Childhood Education Rochester, NY

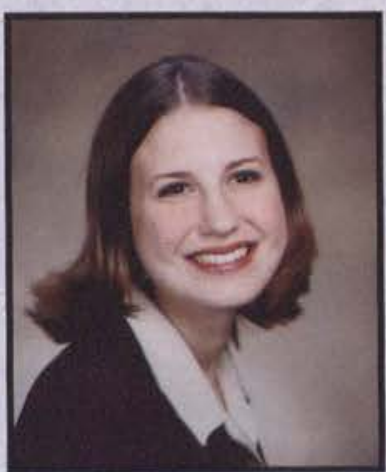

Rachel Vogel

Biology

Springfield, $\mathrm{OH}$

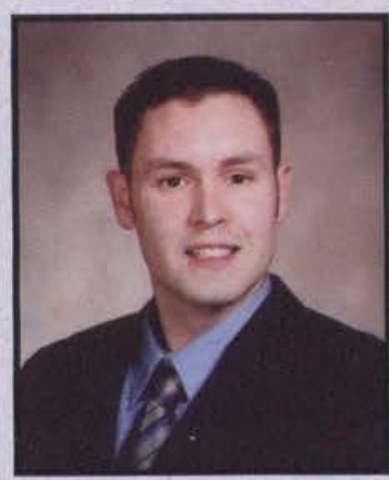

Kent G. Wagner Middle School Education North East, PA

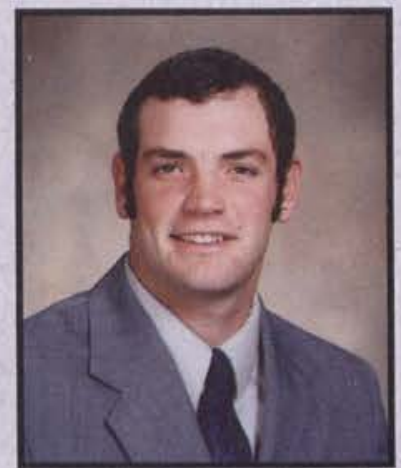

Stephen S. VanDerAa

Spanish Education Winamal, IL

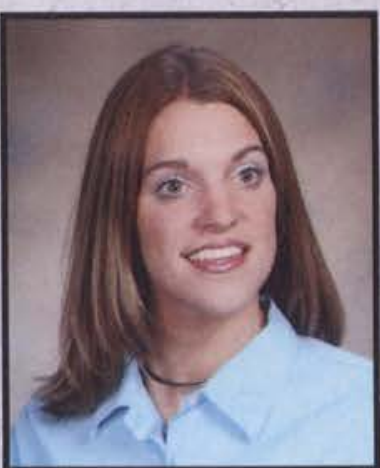

Katie VanKirk Business Mang. \& Marketing Mars, PA

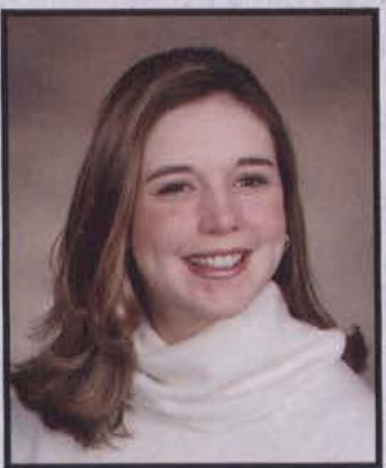

Renae Vogt

Early Childhood Education Bolivar, $\mathrm{OH}$

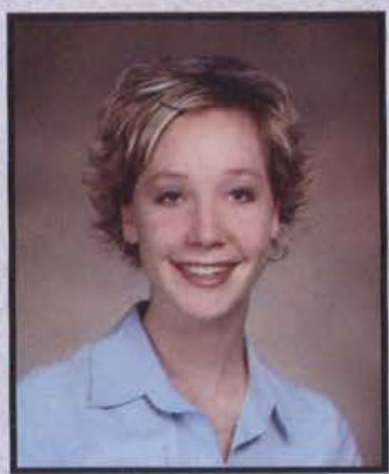

Kimberly Wagner Nursing

Andover, NJ 


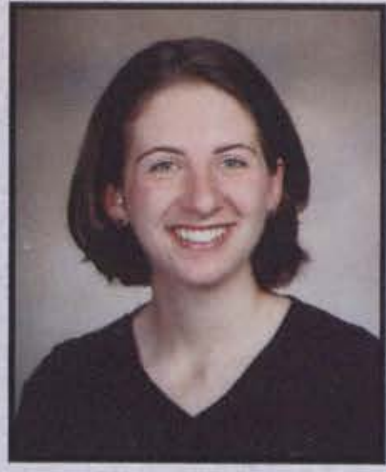

Lynette Wagner

Multi Age Music Education

Fox River Grove, IL

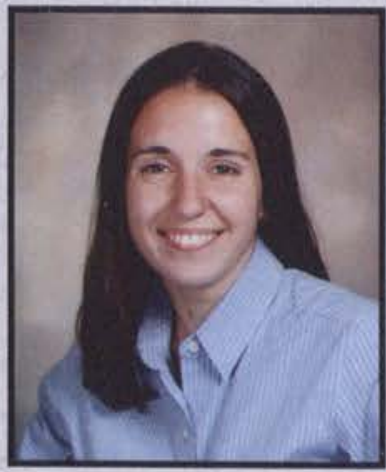

Jennifer Walker

Professional Writing

Brownsburg, IN

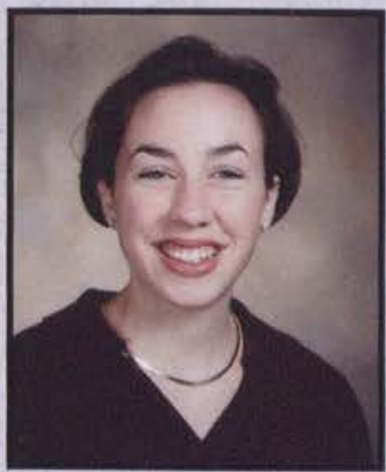

Bethany A. Warner

Nursing

Utica, $\mathrm{OH}$

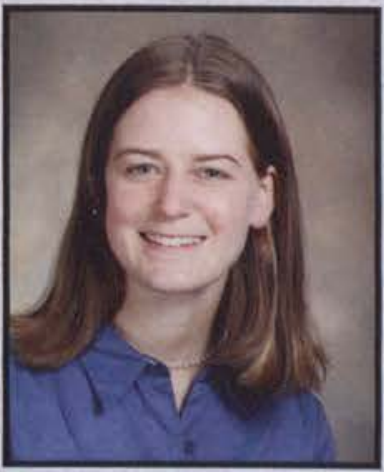

Shaelah D. Weber

Nursing

Millville, CA

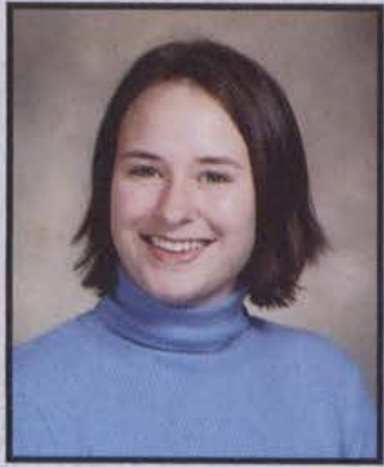

Ruth Wagner

Early Childhood Education Belleville, IL

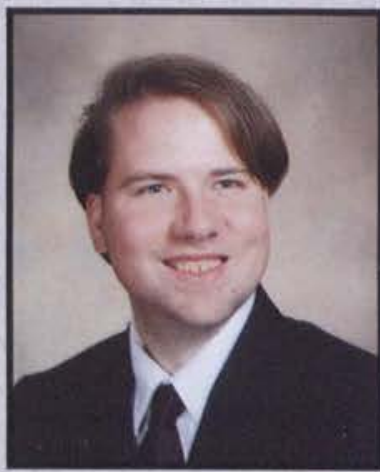

William J. Walker

Mechanical Engineering Galesburg, MI

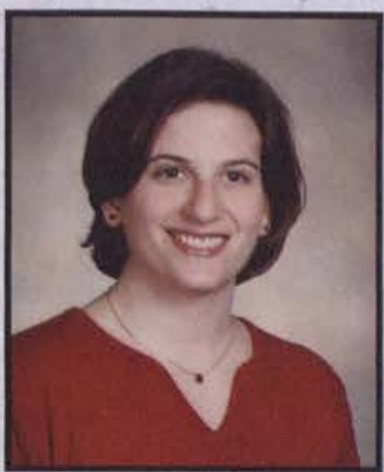

Beth Weakly

Middle Childhood Education Decatur, IL

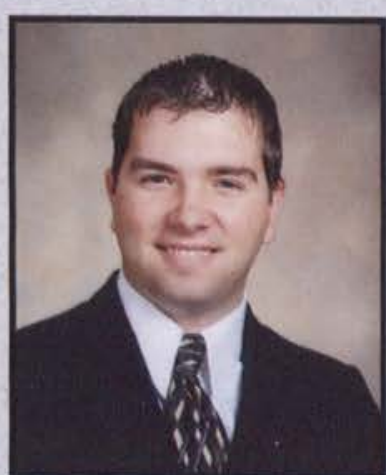

Jason D. Wendzel

Marketing

Richland, MI

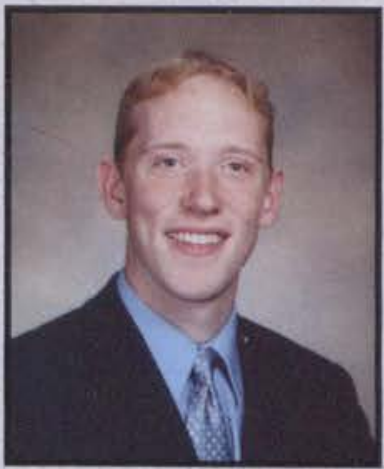

Steven Wakefield

Mechanical Engineering LaViewood, NY

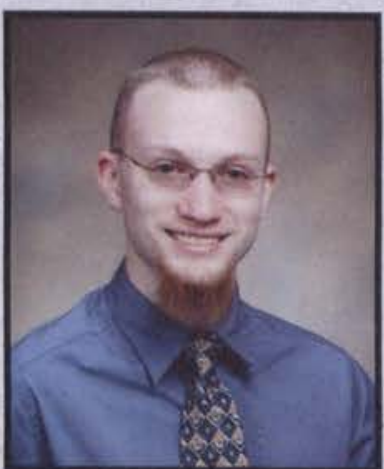

Mark Wallace

Christian Education of Youth Ashtabula, $\mathrm{OH}$

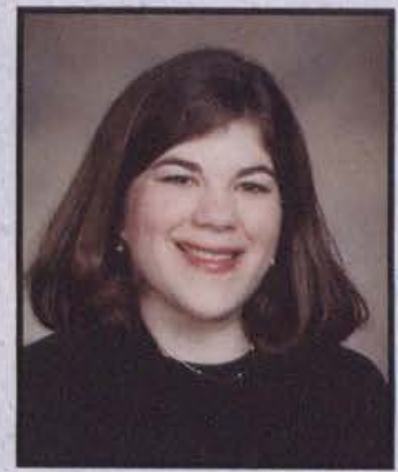

Jennifer L. Weaver

Music Education

Morgantown, PA

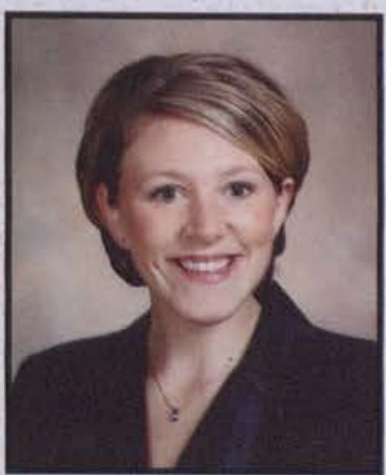

Stephanie L. West Early Childhood Education Springfield, $\mathrm{OH}$

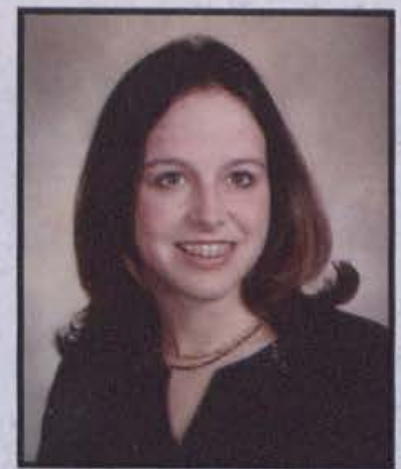

Bethany Walden

Org. Communications Bedford, IN

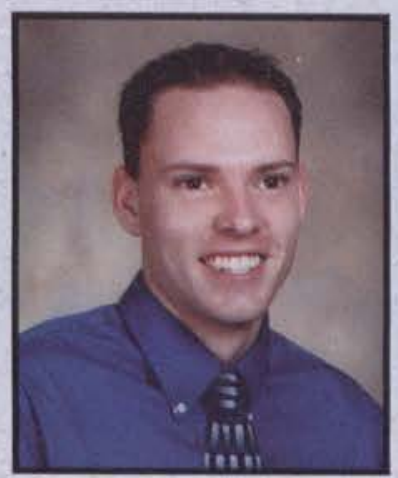

Joel D. Warder

Broadcasting

Stanton, IA

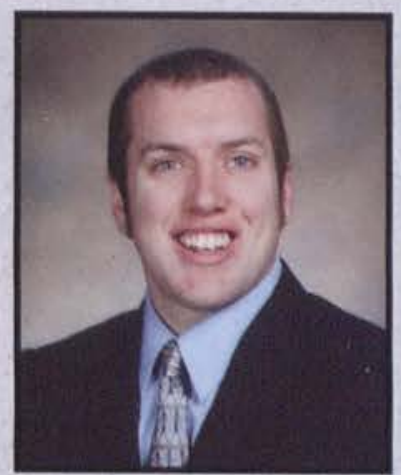

Jason Webb

History

Argos, IN

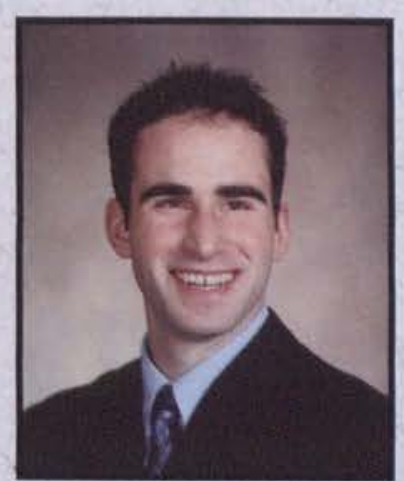

J. Brock Weston

Bible \& Pre-Seminary Morral, $\mathrm{OH}$

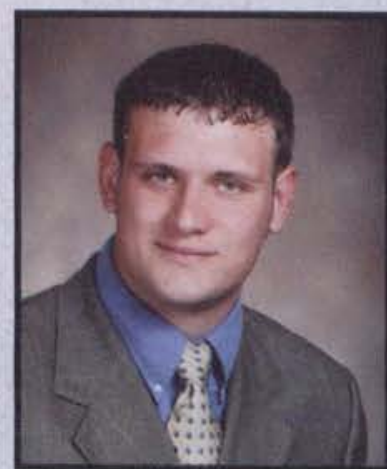

James Waldo

Middle Childhood Education Brookfield, IL

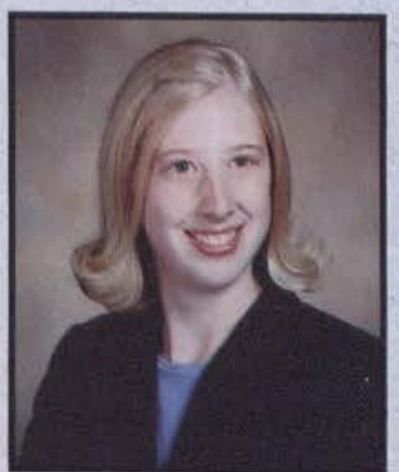

Kristina L. WarndahI Early Childhood Education Rochester, MN

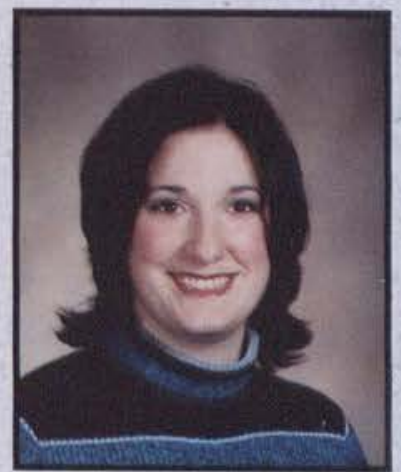

\section{Erin E. Weber}

Spanish Education Archibold, $\mathrm{OH}$

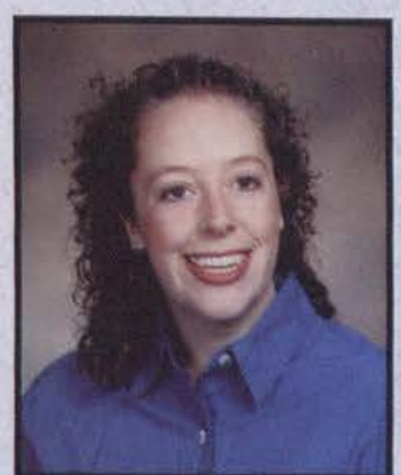

Michelle R. Wheeler Multi Age Spanish Education Cedarville, $\mathrm{OH}$ 


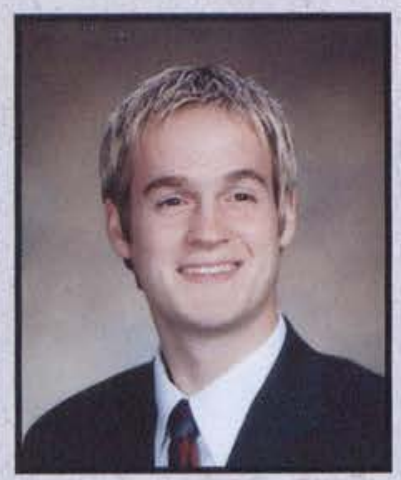

Benjamin Whipple

Church Music

Lafayette, IN

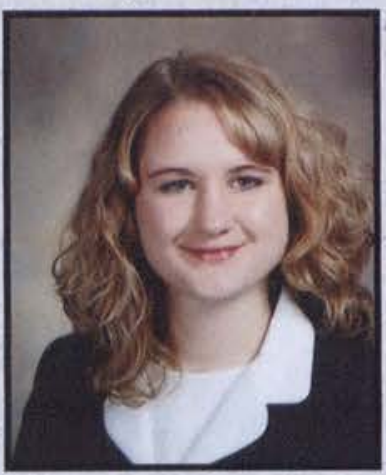

JoAnne Willett

Technical \& Professional Comm. Minerva, $\mathrm{OH}$

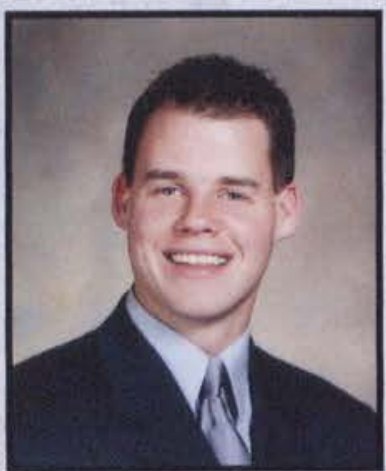

David P. Wolf

Mechanical Engineering

Grand Rapids, MI

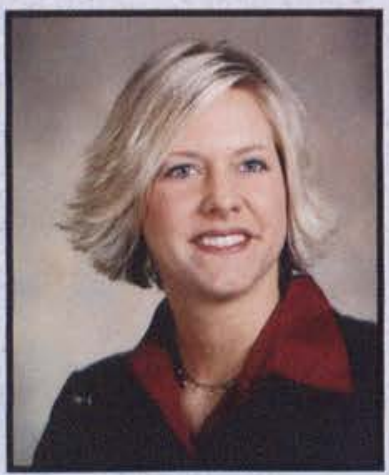

Valerie E. Wubbena

Psychology

Forreston, IL

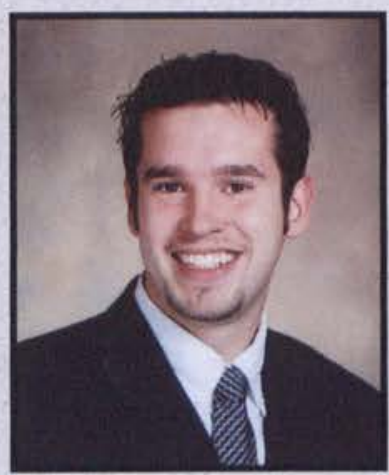

Brian White

Mechanical Engineering

Beavercreek, $\mathrm{OH}$

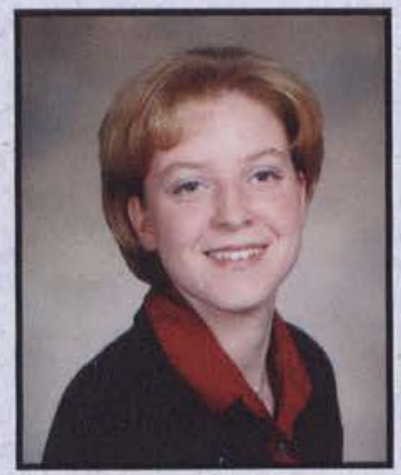

Lynnette Williamson Cross Cultural Nursing

Peoria, IL

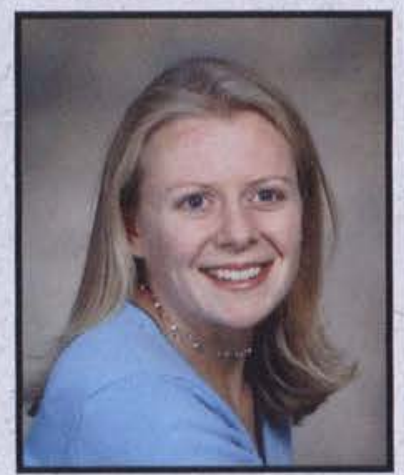

Julia Wolters

Athletic Training \& Phys. Ed. Belmont, WI

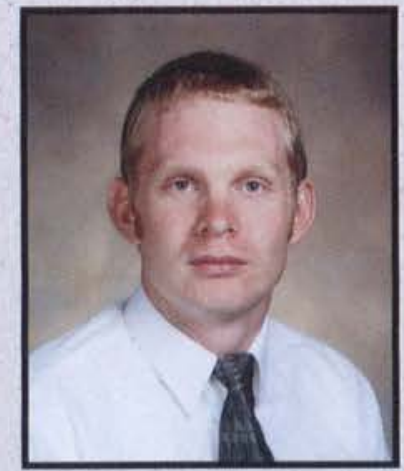

Eric J. Yearley

Chemistry

Amherst, $\mathrm{OH}$

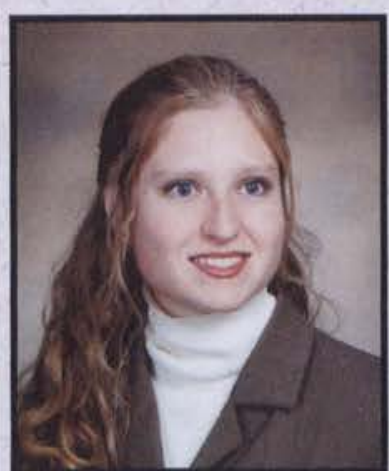

Elizabeth M. Whitley

Applied Psychology

Naperville, IL

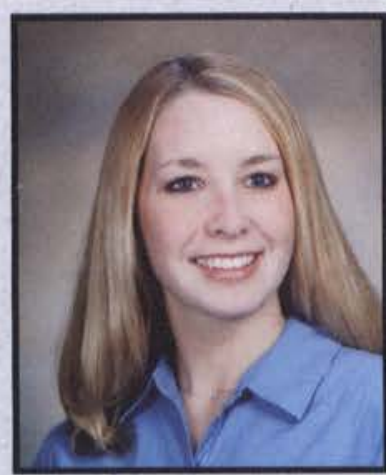

Kimberly L. Wills

Early Childhood Education

Circleville, $\mathrm{OH}$

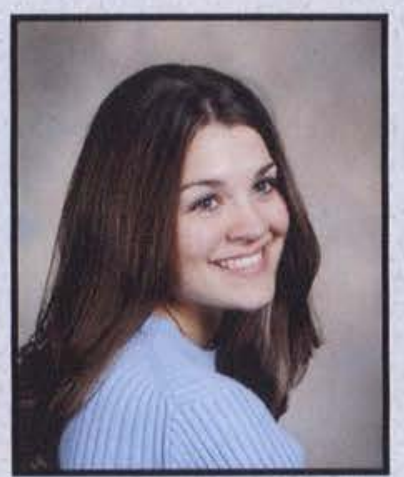

Amy Wood

Social Work

Endwell, NY

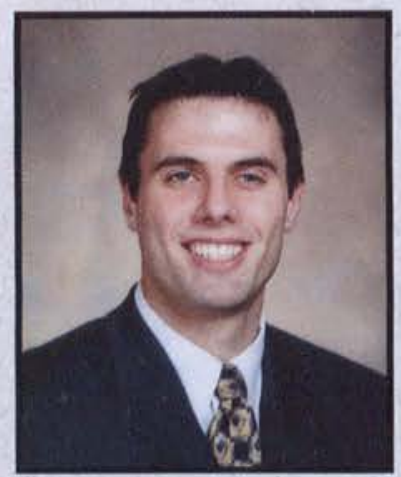

Adam J. Yingling

Mechanical Engineering

N. Canton, $\mathrm{OH}$

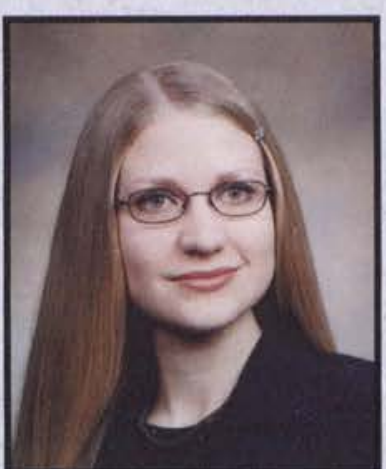

Rebekah J. Wiersma Early Childhood Education Zeeland, MI

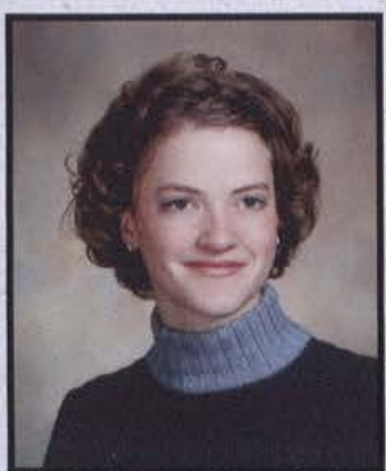

Sherri Winfield Information Systems

Altoona, IA

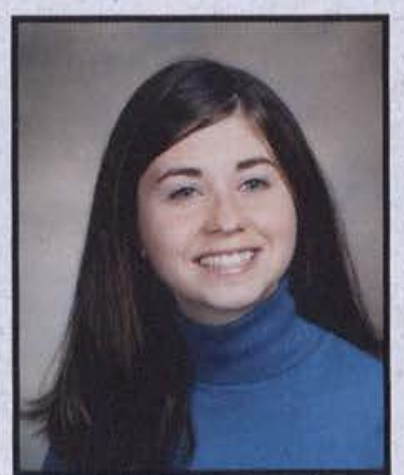

Jennifer J. Wood

Psychology

Swartz Creek, MI

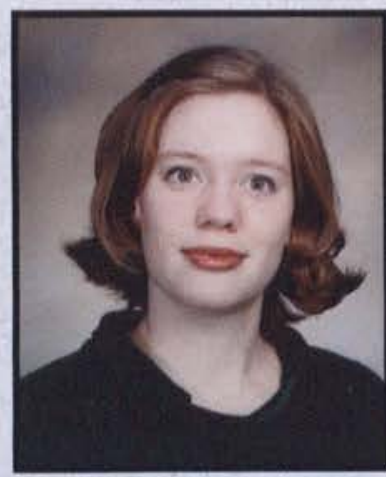

Amber K. Young

Integrated Language Arts Holland, PA

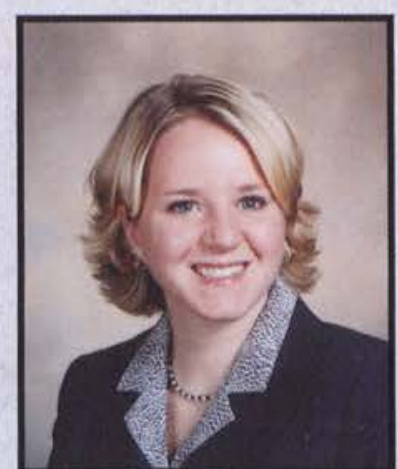

Synthia A. Wilhelm Applied Psychology

Argos, IN

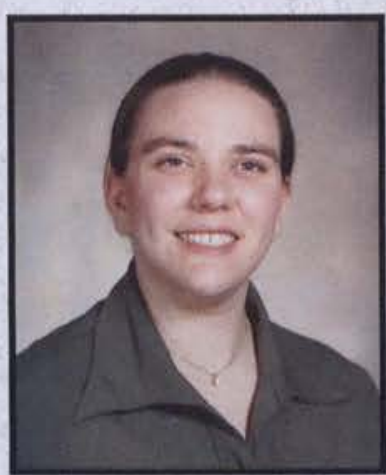

Katherine A. Witmer Integrated Language Arts

Houston, TX

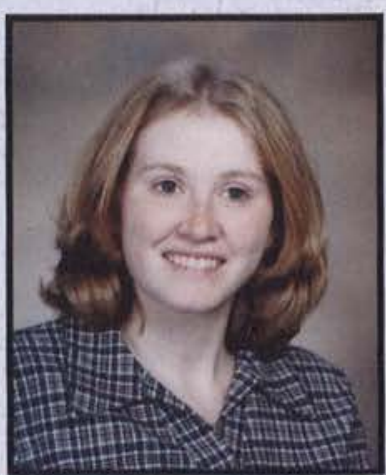

Rachel Wood

Nursing

Newton, IA

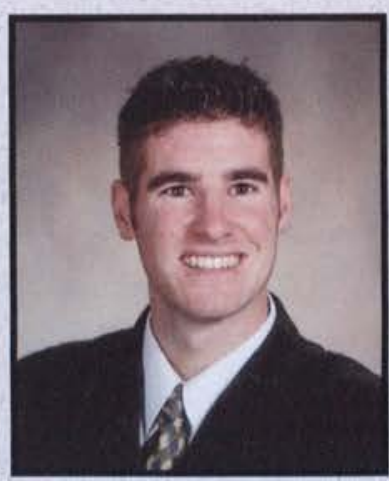

Steve Zarrilli

Biology

Akron, $\mathrm{OH}$ 


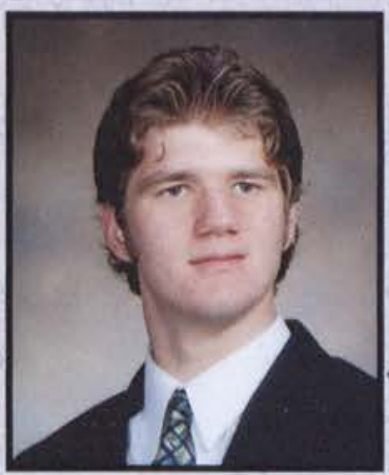

David J. Zelenka

Criminal Justice

Medina, $\mathrm{OH}$

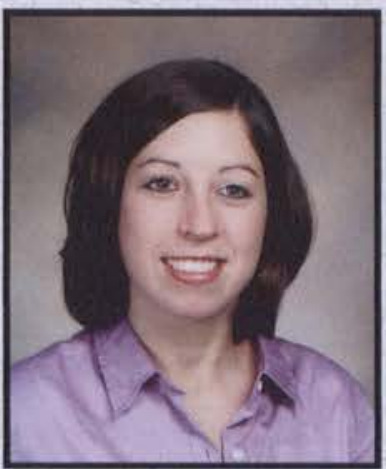

Taira Zgrablich

Piano Pedagogy Doylsetown, PA

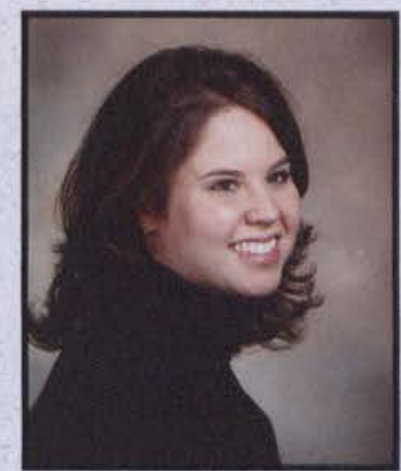

Kristi Zimmerman Bible Comp. \& CE Youth Grayslake, IL

\section{CLASS OFFIGERS}

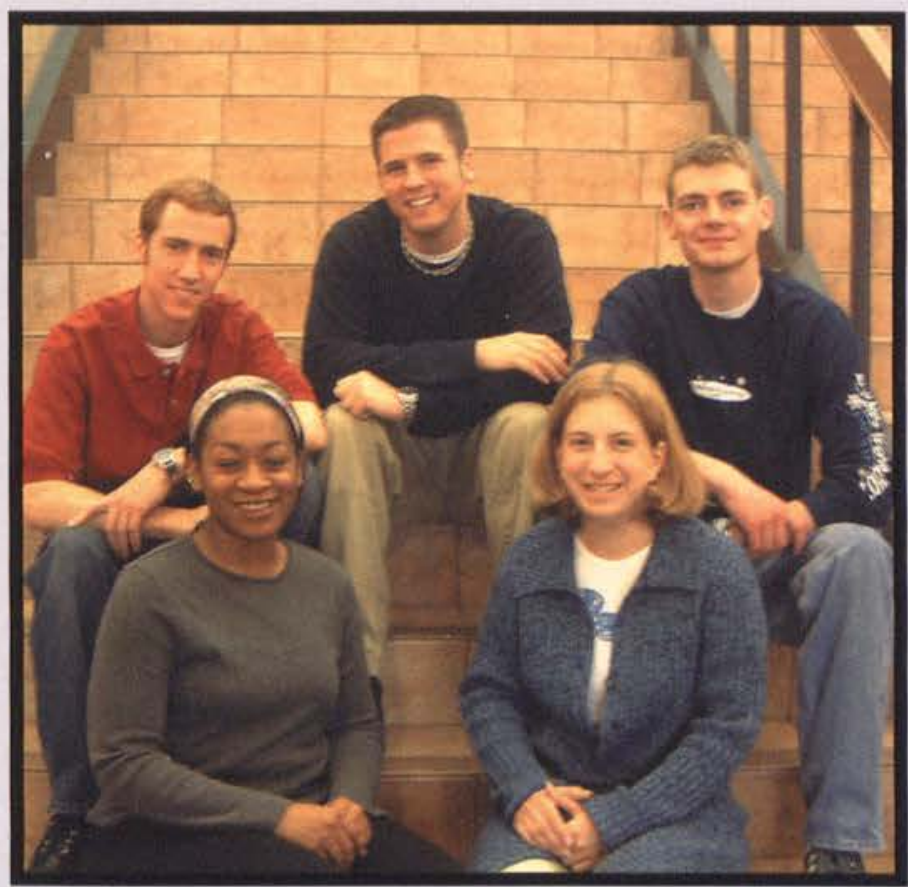

President: Aaron Mahl (center-back)

Vice-President: April Lucas (left-front)

Treasurer: Jonathan Kirby (left-back)

Secretary: Kristi Jonker (right-front)

Chaplain: Brian Davis (right-back)

\section{e will always remember...}

Sometimes it seems like it was forty years and at other times merely minutes. It's hard to believe that it was four years of our lives. Ours was an experience similar to what most would imagine a college experience to be; however, we each lay claim to our own memories of Cedarville.

Who would have thought at the beginnig of freshman year that we would be where we are today? From our very first "There are Giants in the Land" to Allister Begg's reminder that our times are in God's hands, freshman year brought us to a campus of possibility. We actually had time to sit at the meat market, be Velcro couples, and attend basketball games. Who could forget the first time the bagpipes visited chapel? We didn't know then that they would return every year; at the time it was sacred. And the bomb scares? It's true! We actually evacuated our dorms whena cold construction worker refused to continue building the "new dorm." The excuse "my computer was down" was legitimate as our million-dollar yahoo-lauded computer system was defunct for weeks at a time. We were also finally able to move out of Lawlor and Printy, leaving the riots and Fat Guy in Jeans.

We enjoyed the 2nd Floor and could prophesy what was for lunch by the infamous Chuck's odor on friends. We witnessed events such as the Alpha Chi Talent Show featuring "balancing" acts and dueling guitars; Elliv, which whether you loved it or hated it, you talked about it; and the CedarWhat episode that still has us asking "what?"

Our senior year was a time of questions. Where are we headed? Who will we marry? Will we have a White Christmas? We realized that chapels were always a very influential part of our experience. From Dr. Dixon's messages to the praise and worship of SGA, chapels left us discussing how we were challenged and laughing at the latest Cedarville joke. Our friendships became more established as well. As we progressed, the question became "how many hours do I have before class to write that twelve page paper?" just so that we could stay up for the important late night conversations with friends.

Whether we look back and can see it, the person we were when we came is not the person we left as. These four years had an incredible impression on our lives that cannot be erased.

Written by: Seth Martin 

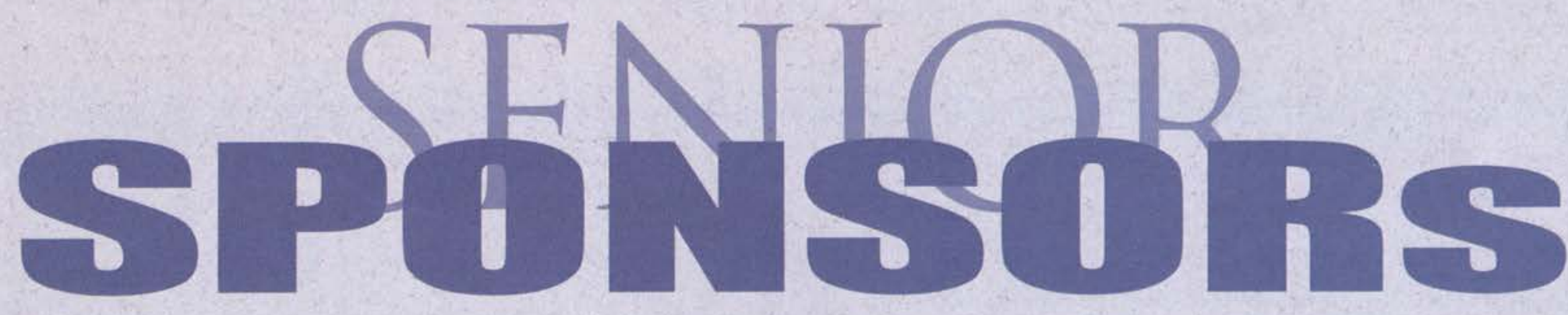

Mark and Amy Button developed lifelong friendships with students while providing leadership in student government at the class level. Both previous Cedarville students, Mark was employed with Production Services and Amy with CDR Radio. Mark, who never technically finished his degree at Cedarville, aimed to complete his education with the graduating class of 2002, and the class enjoyed watching and teasing Mark to success.

Class secretary Kristi Jonker, a middle childhood education major, said, "Mark and Amy were $100 \%$ committed to what they did. They have patiently worked through four years of memorable meetings, chapels, and activities with class officers and members. What I loved the most is that Mark was the ultimate dependable manbehind-the-scenes and that Amy was right with him as the go-getter to get things done and done right."

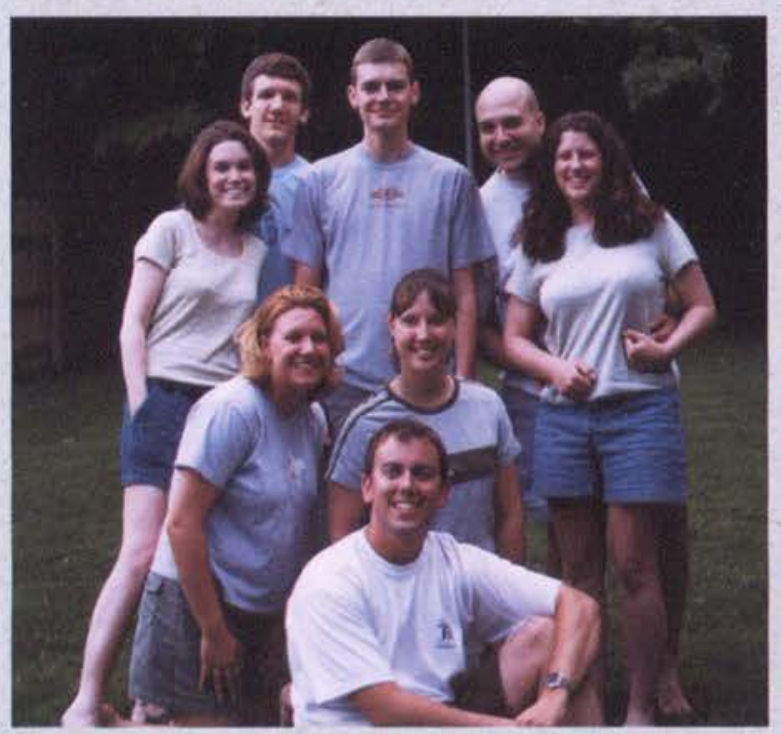

"I love Mark and Amy. They were great as class advisors. They were ALWAYS willing to open their home to us for gettogethers and fun meetings. They were ALWAYS willing to put in extra time, help, and effort! They are like a big brother and sister that you can always turn to for advice and assistance. Plus, I really love the homemade macaroni and cheese that they make!!" said senior Communications major Brett Buckingham, who served the class of 2002 as president during their sophomore year.

Aaron Mahl, senior class president, said, "I have appreciated the self sacrifice and the love that Mark and Amy have shown to us as officers and also to the class - the times they've spent hours with us, listened to our concerns, or just encouraged us with a kind word. Our class would not be complete without them."

\section{The senior class chapel leaders and their sponsers, the Buttons, pose for one last photo.}

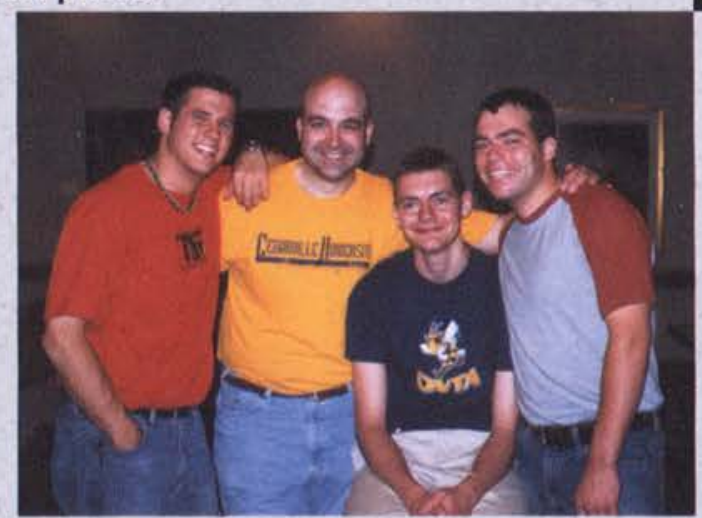

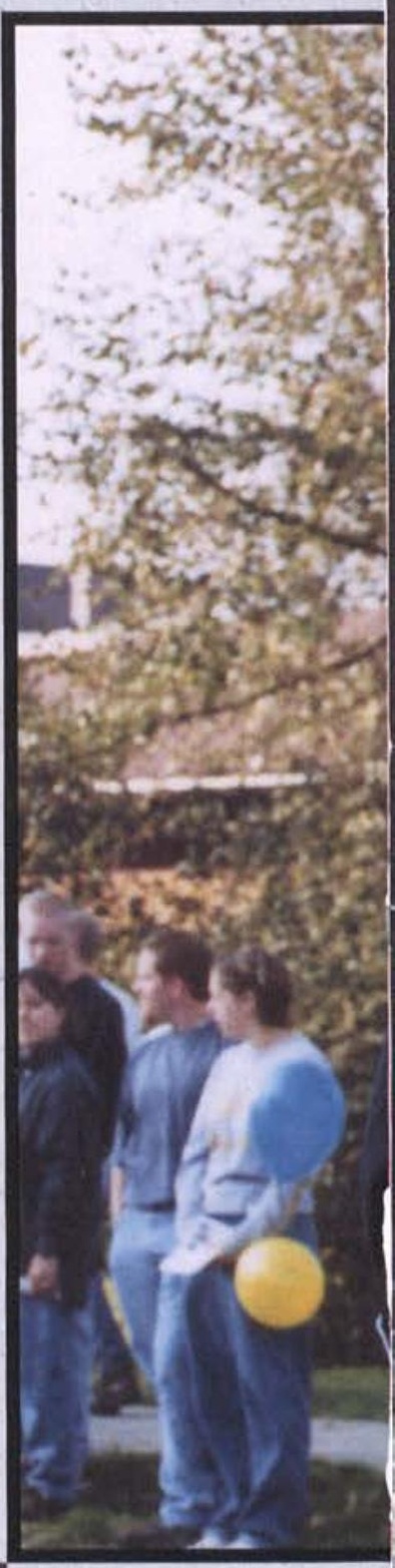

Aaron Mahl, Mark Button, Brian Davis, and Graig Bantle worked hard to make senior chapels and activites fun for their class. 
Amy and Mark

Button became

the senior class

sponsors just two

months after

being married.
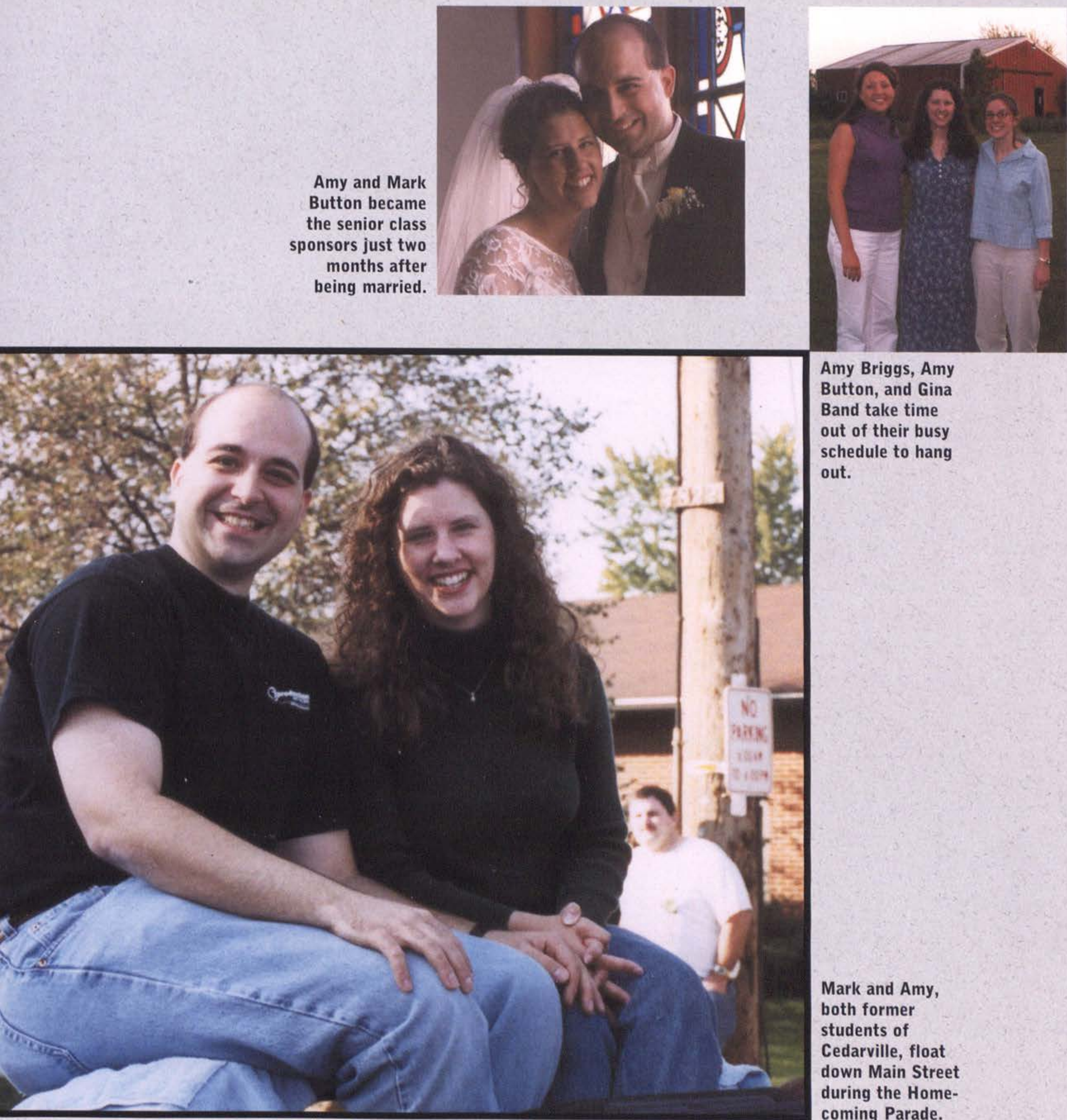

Amy Briggs, Amy

Button, and Gina

Band take time

out of their busy

schedule to hang

out.

Mark and Amy,

both former

students of

Cedarville, float

down Main Street

during the Home-

coming Parade.

The Buttons and Brett Buckingham enjoy a delightful evening in Cincinnati for JS

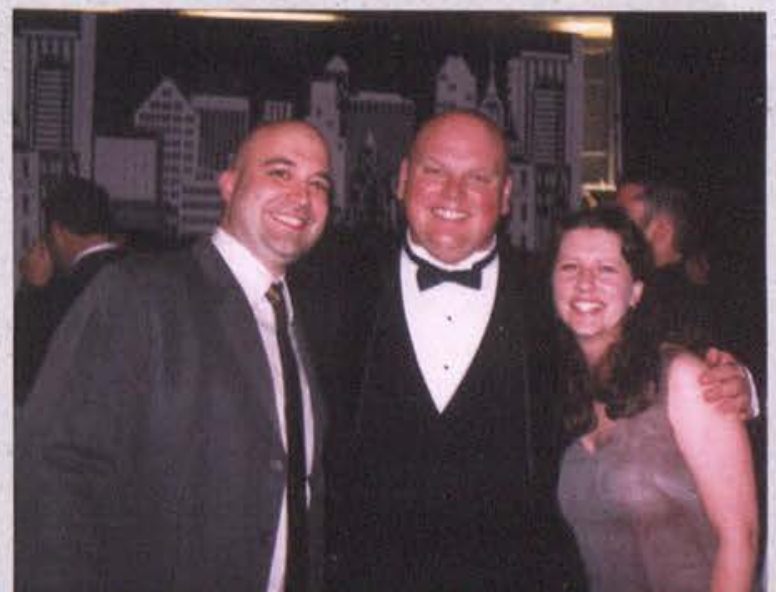



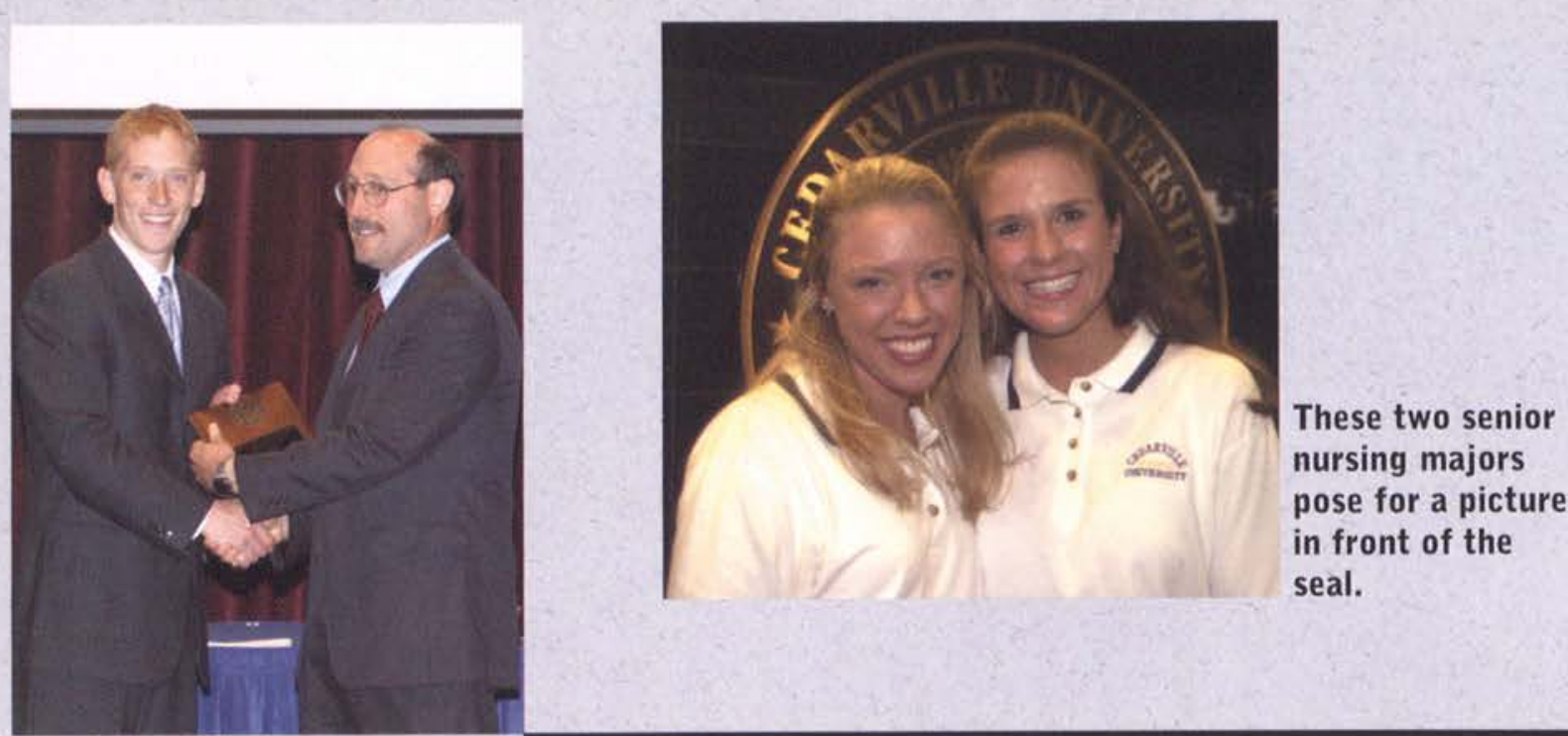

nursing majors

pose for a picture

in front of the

Chester Jenkins

shakes Dr.

Chasnov's hand as

he receives his

award.

Adam Yingling

receives his

certificate from

Dr. Zavodney.

After four years of

hard work,

Bronson Hokuf

appreciates the

recognition from

the Engineering

Department. 

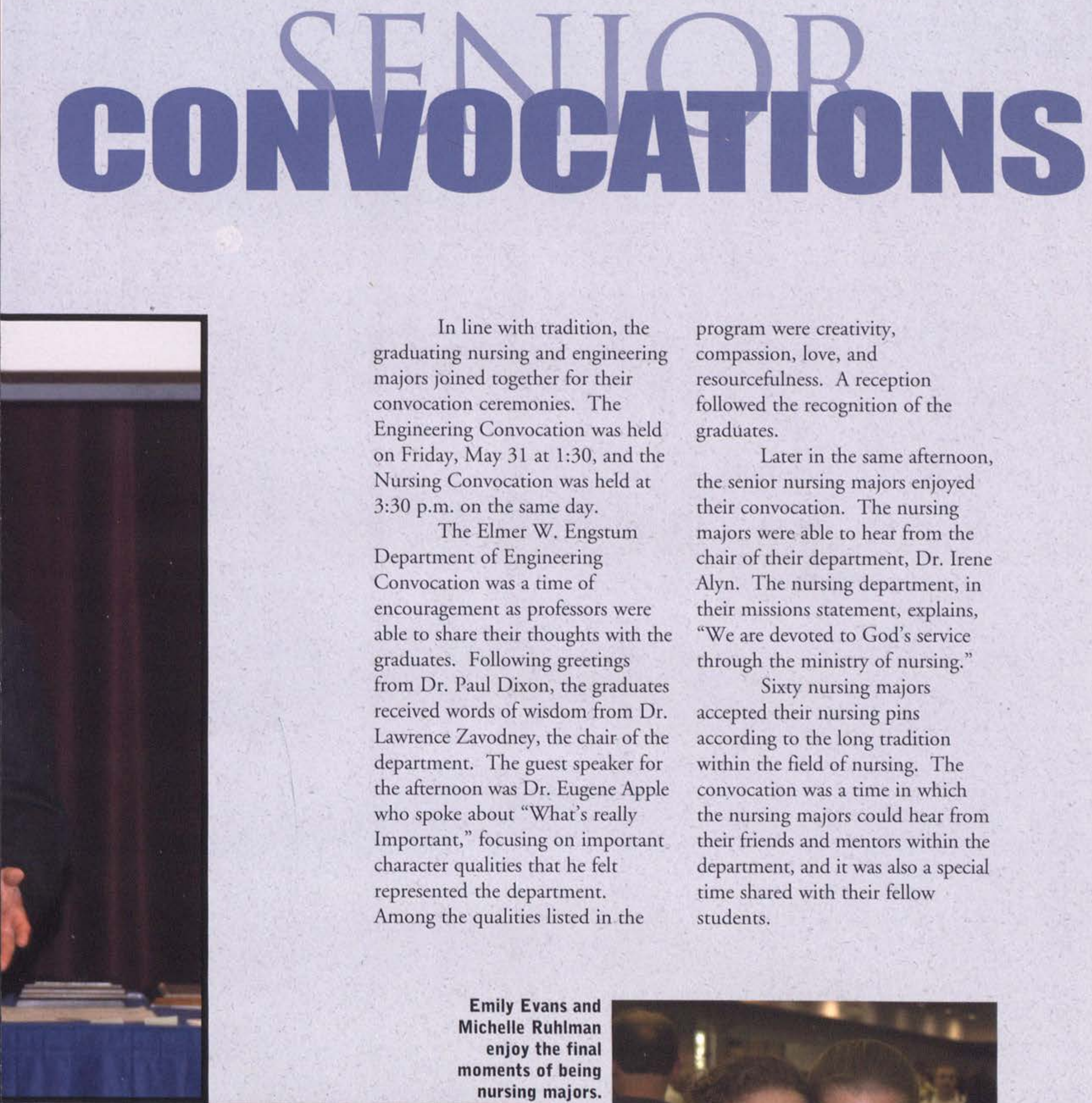

In line with tradition, the graduating nursing and engineering majors joined together for their convocation ceremonies. The Engineering Convocation was held on Friday, May 31 at 1:30, and the Nursing Convocation was held at 3:30 p.m. on the same day.

The Elmer W. Engstum

Department of Engineering

Convocation was a time of

encouragement as professors were able to share their thoughts with the graduates. Following greetings from Dr. Paul Dixon, the graduates received words of wisdom from Dr. Lawrence Zavodney, the chair of the department. The guest speaker for the afternoon was Dr. Eugene Apple who spoke about "What's really Important," focusing on important character qualities that he felt represented the department.

Among the qualities listed in the program were creativity, compassion, love, and resourcefulness. A reception followed the recognition of the graduates.

Later in the same afternoon, the senior nursing majors enjoyed their convocation. The nursing majors were able to hear from the chair of their department, Dr. Irene Alyn. The nursing department, in their missions statement, explains, "We are devoted to God's service through the ministry of nursing."

Sixty nursing majors accepted their nursing pins according to the long tradition within the field of nursing. The convocation was a time in which the nursing majors could hear from their friends and mentors within the department, and it was also a special time shared with their fellow students.
This senior is excited to begin her career as a nurse.
Emily Evans and Michelle Ruhiman enjoy the final moments of being nursing majors.

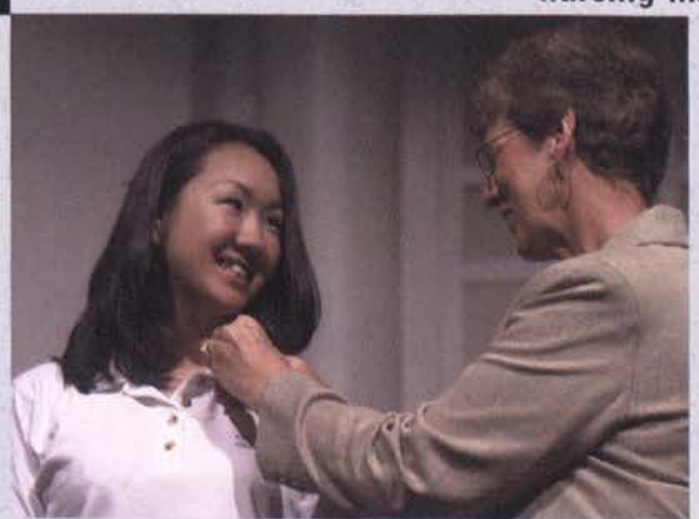

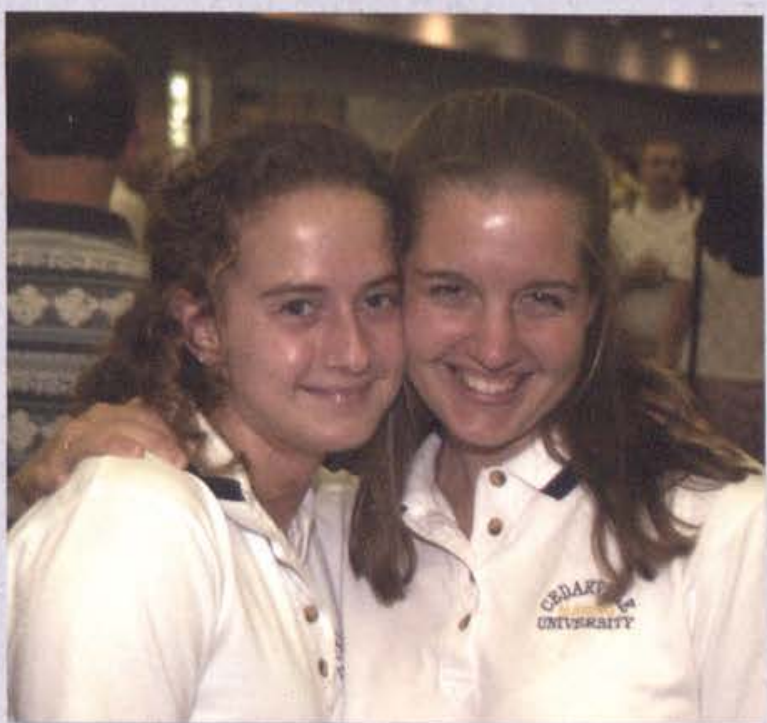




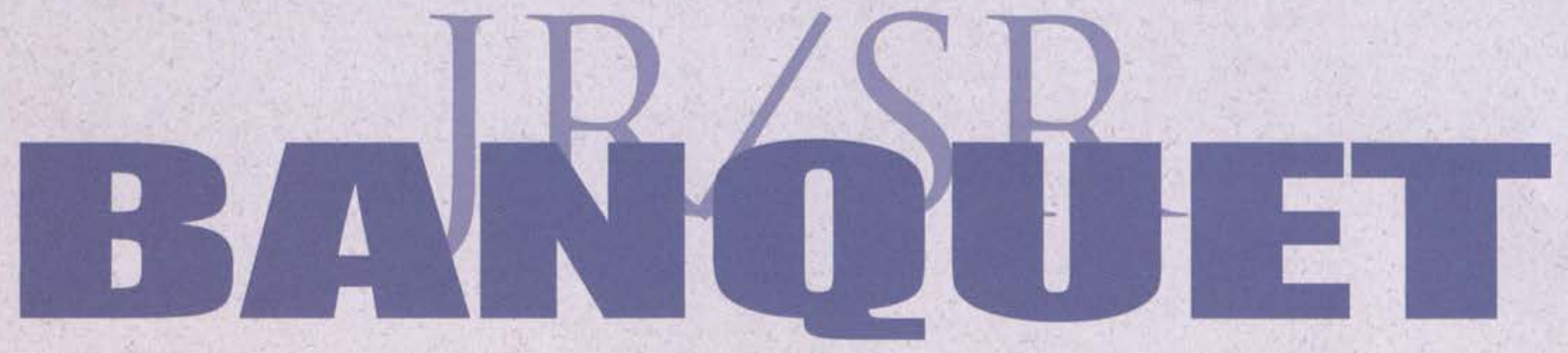

The Junior/Senior Banquet took place on Friday, May $17^{\text {th }}$, at the Museum of Natural History in Cincinnati. The banquet began with a senior reception, exclusively for seniors and their escorts.

Graduating seniors could view the museum's exhibits, take pictures, and converse.

Following the senior reception, the dinner immediately began. Cedarville students, dolled up in snazzy suits and satin finery, gathered in the atrium and found their tables, stopping to chat with friends or listening to the Cincinnati Swing Orchestra play.

Masters of Ceremonies Shae Elam and Rob Chestnut began the banquet with a few humorous remarks and a prayerl.

Between courses, students could walk around and see the sights of the museum, listen to the orchestra's concert, or take pictures in front of the city skyline backdrop.

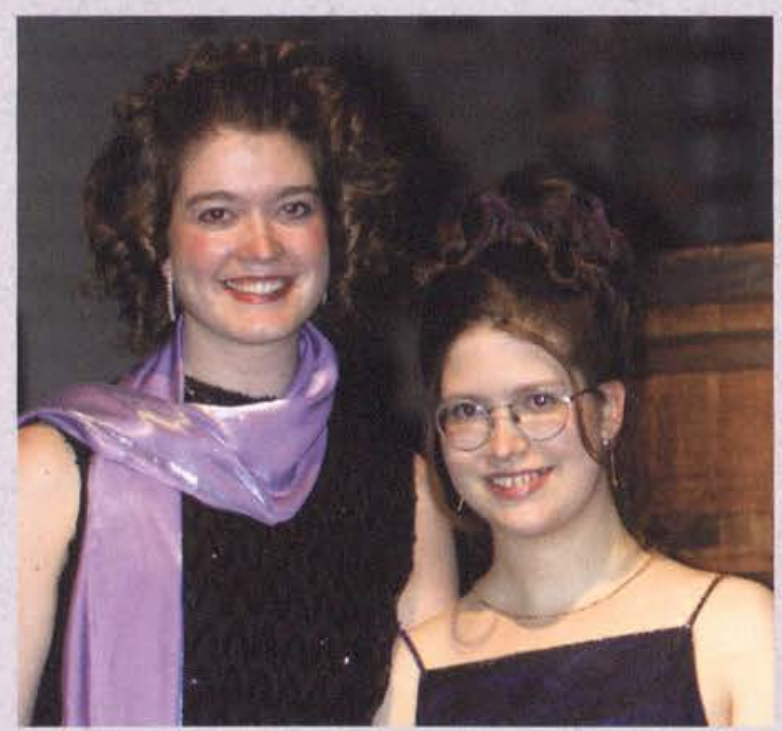

The senior video was shown in two segments - the first one involving music by Enya and candid pictures of seniors through their years at Cedarville. The second segment was a video produced by a student, challenging seniors to live Godly lives.

When the meal was over, Elam and Chestnut resumed the stage to perform a dramatic presentation that they called "Poetry Corner." They proceeded to melodramatically recite lyrics from popular songs about leaving friends. This scene aroused laughter from the audience, particularly when they chose to recite the Michael W. Smith song "Friends," a song they referred to as the "typical youth group goodbye song."

With that, the evening officially ended, and students donned their wraps, coats, and umbrellas to head back into the rainy evening.

\section{Rebecca Vandemark and Angela Rosseau come together to enjoy an exciting night of music and memories.}

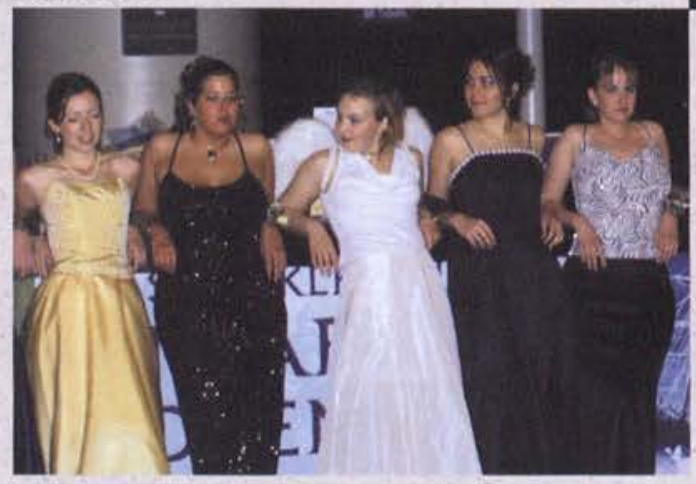

The many beautiful dates decide to strut their stuff and pose for the camera. 

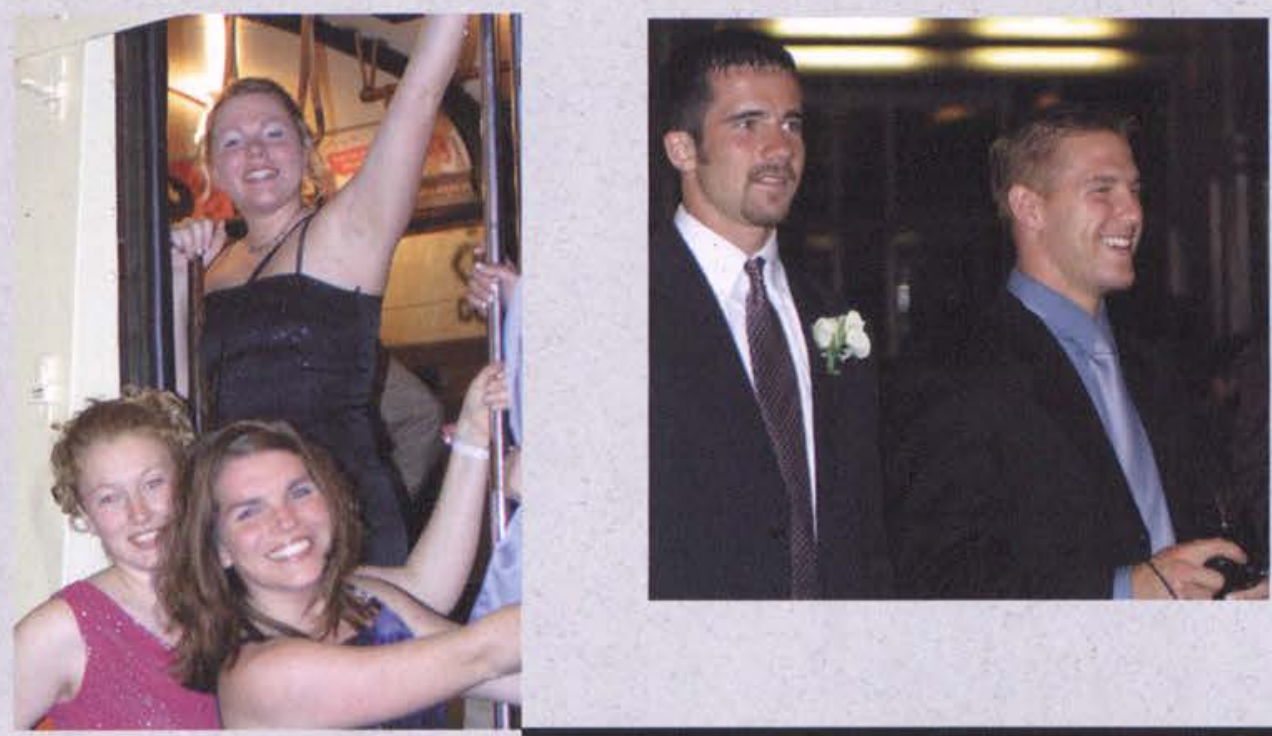

Lance Ferguson and Wes Stephens

give approving glances to their JS dates.

Some girlfriends take advantage of the Cincinnati atmosphere to pose for a couple of pictures.

Eric Philips, Mark Riddle, and Dave

Stormont take time away from the girls for a photo.
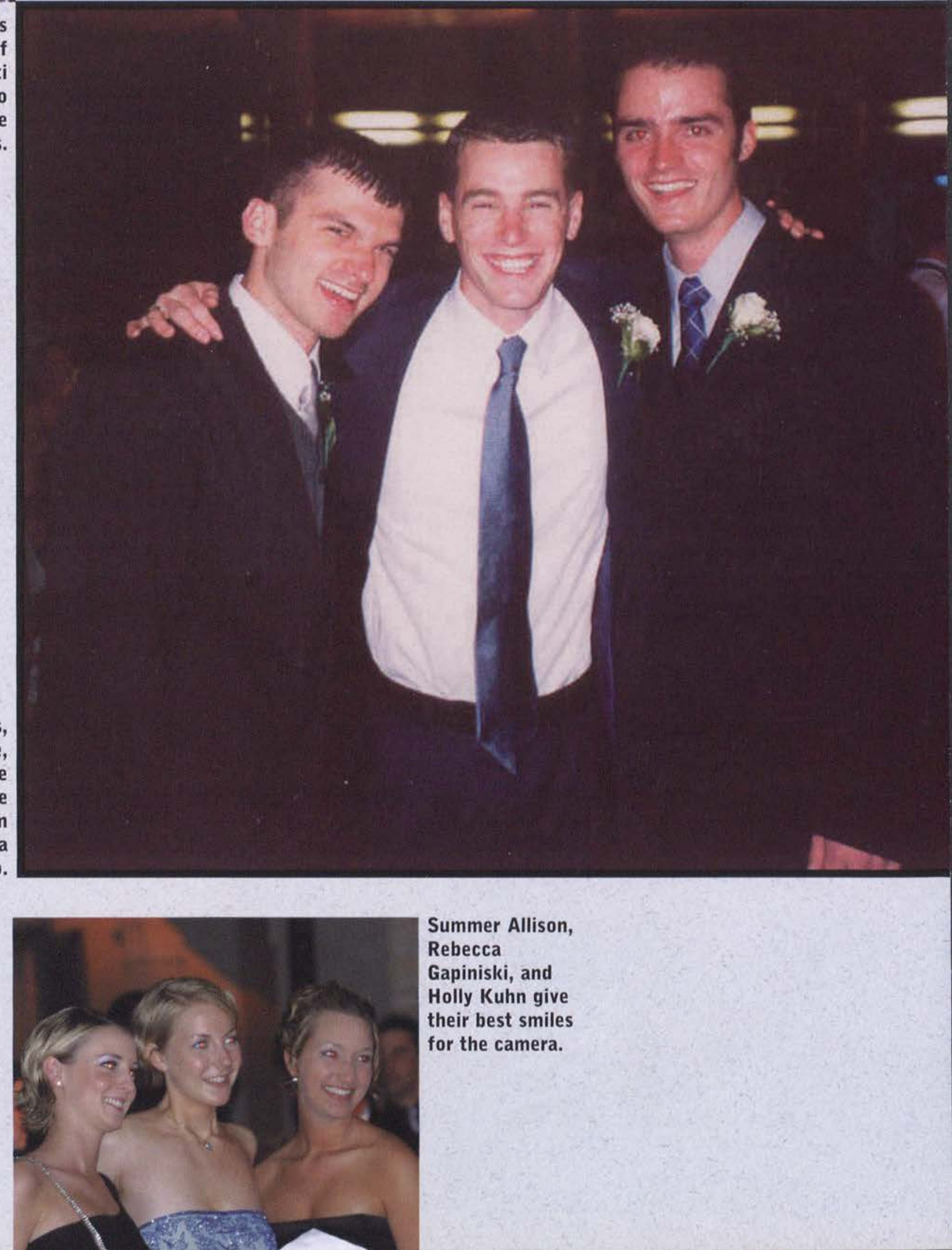

Summer Allison,

Rebecca

Gapiniski, and

Holly Kuhn give

their best smiles

for the camera. 


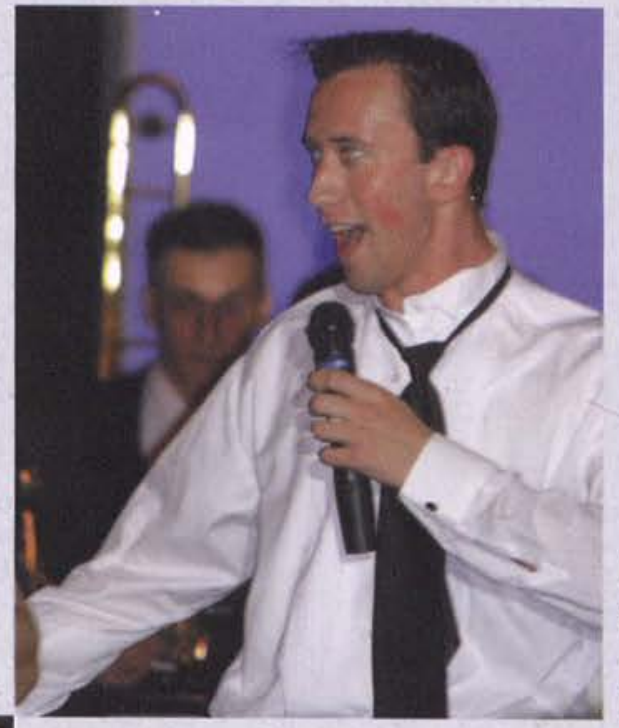

A string quartet plays softly in the background as students eat and talk.

Rob Chestnut makes the crowd laugh with his witty humor.
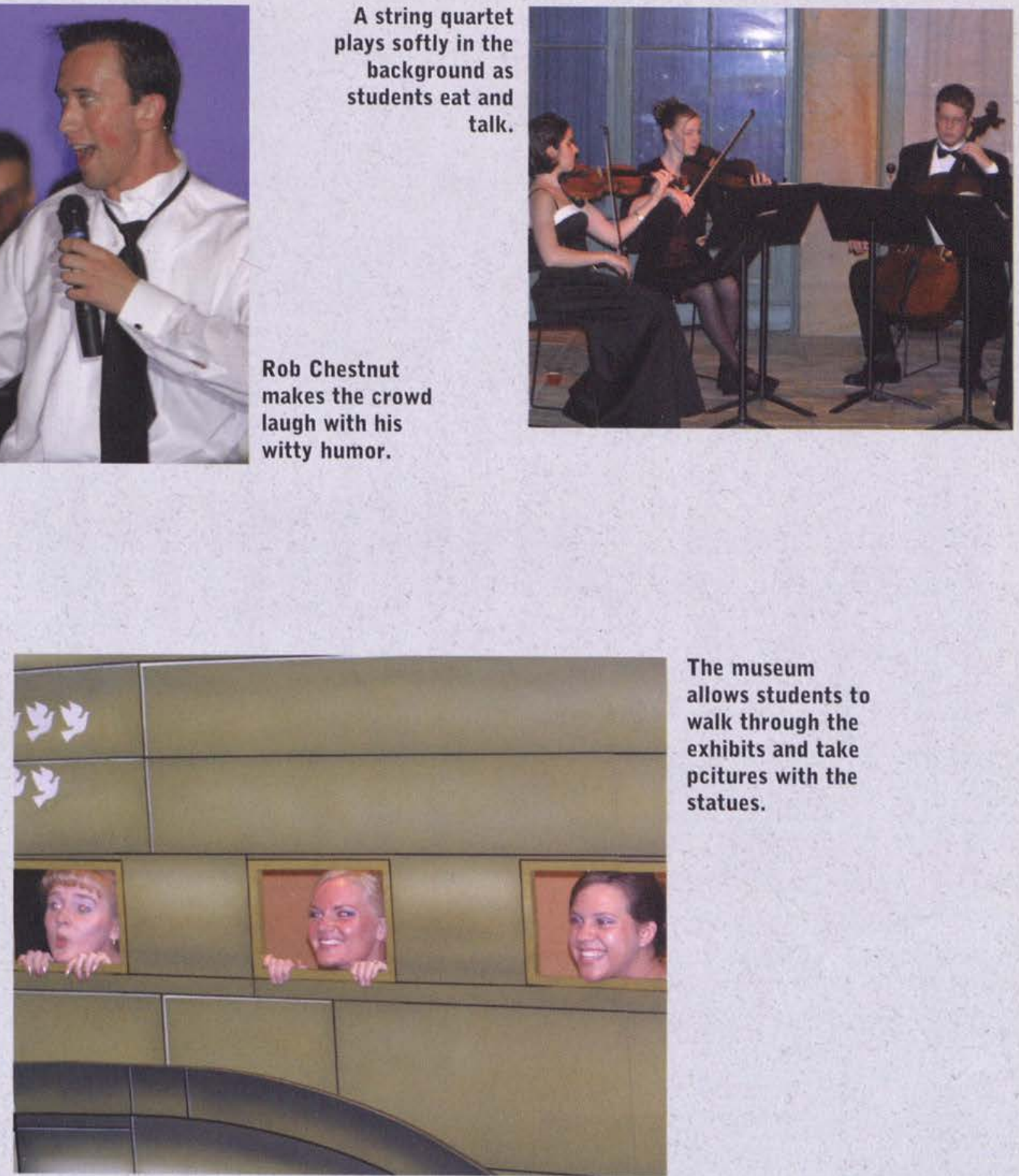

The museum

allows students to walk through the exhibits and take pcitures with the statues.

There is always fun in striking a pose and smiling for the camera.

Friends pair up to take pictures and spend their evening together.
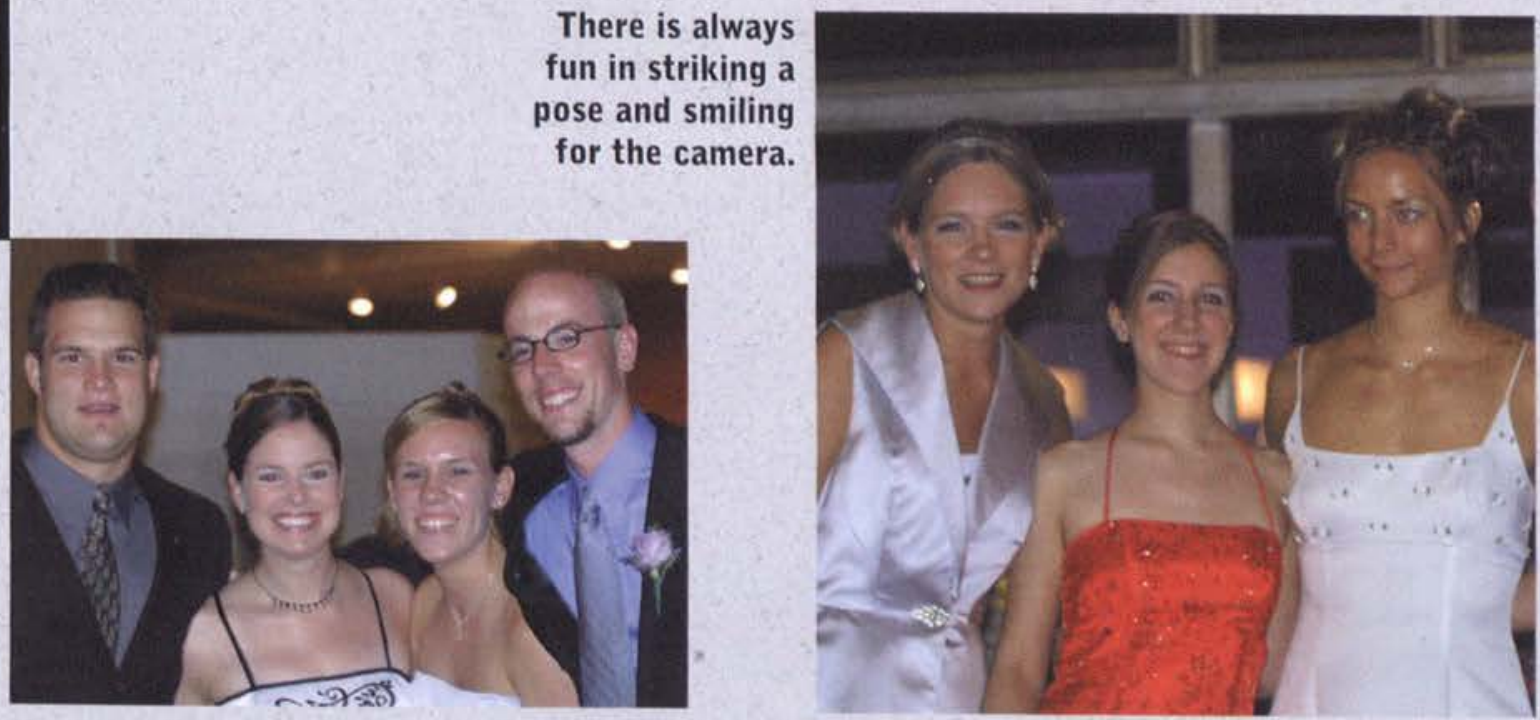


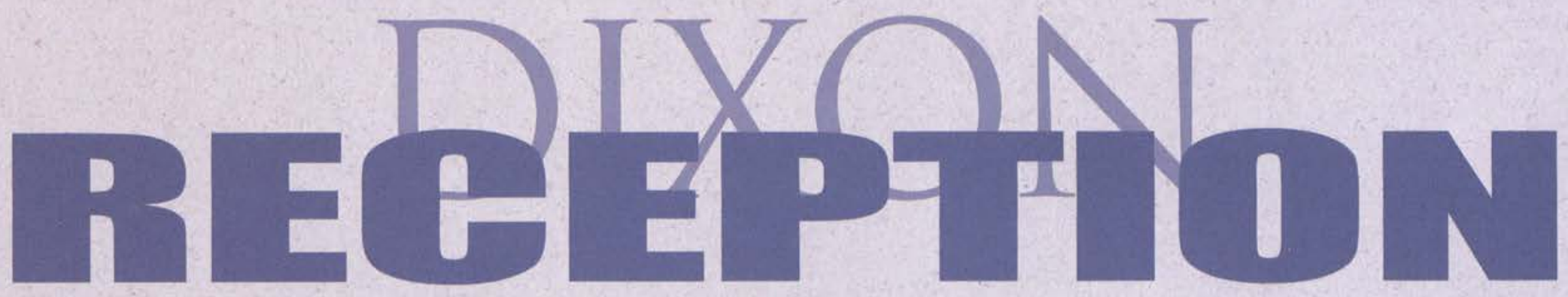

Each year, just before graduation, Dr. and Mrs. Dixon invite the senior class to their house for the senior reception. This year hundreds of graduating seniors attended the Senior Reception that took place on May 26, 2002.

Sunday dress was required for this fairly formal occasion, giving it an air of dignity.

During the one-hour period, students had a chance to partake of some light refreshments and talk with their friends on the vast lawn. They also had the opportunity to take a tour of the Dixons' home, guided by Mrs. Pat Dixon, but only if they took off their shoes first. One of the highlights of the afternoon was having pictures taken with Dr. and Mrs. Dixon.

Esther Kelly had this to say about her visit to the Dixons: "I have seen the Dixons' home from a distance before, but I have never been able to go inside and walk around the yard. It was definitely nice to get an up-close and personal look at where the Dixons have lived for the past few years."

Throughout the reception, the Dixons mingled with the seniors, discussing future plans and past memories. Students enjoyed meeting with the Dixons in their home away from the typical campus setting.

The reception was also one of the last opportunities for seniors to talk with friends, reminiscing about their time at Cedarville. They enjoyed walking around the yard and sampling the assorted snacks. The reception was a great way for these seniors to close out the school year.

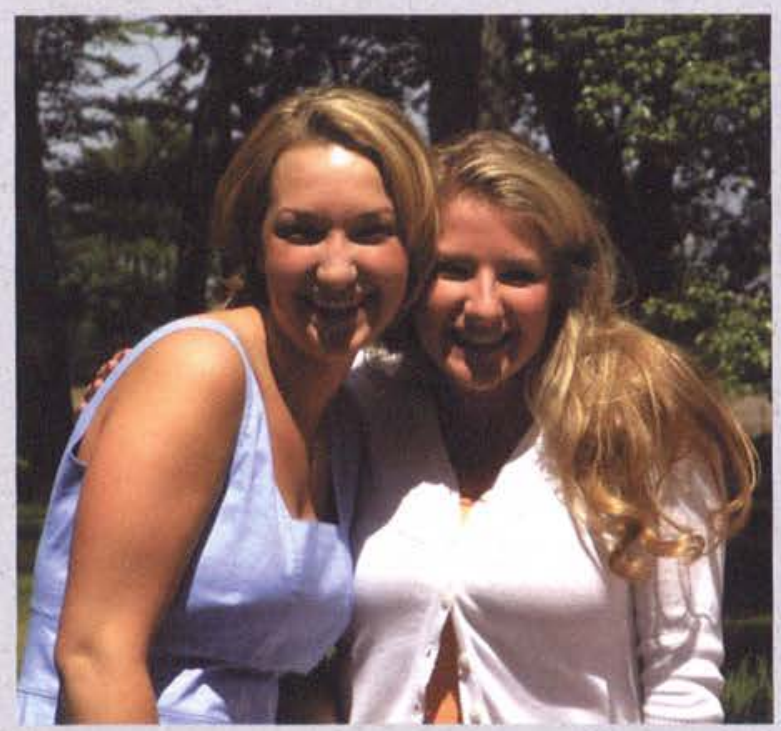

Holly Kuhn and Kristen Maiolo enjoy the afternoon at the Dixons' home.
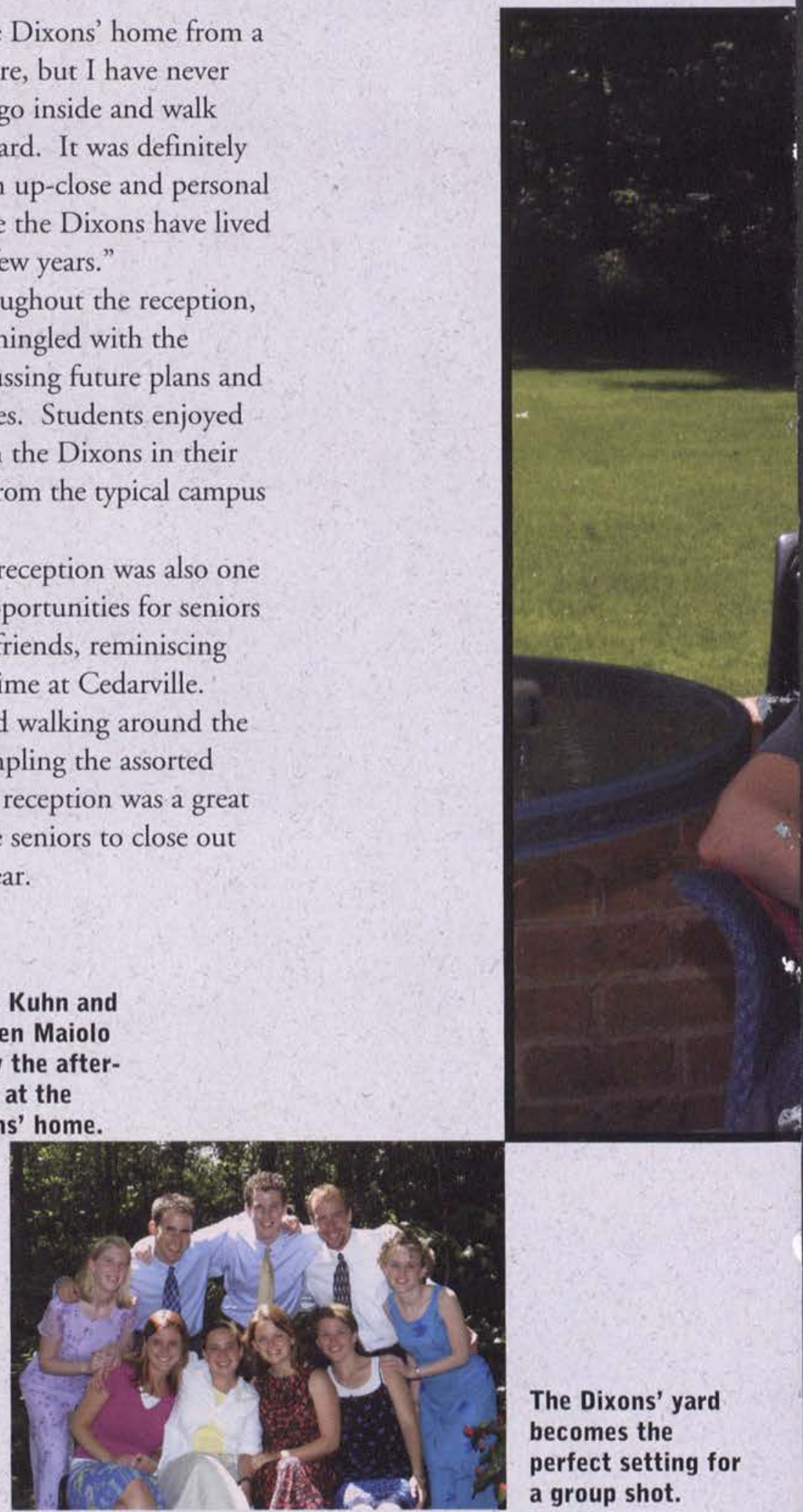

The Dixons' yard becomes the perfect setting for a group shot. 
These two seniors are comfortable lounging in the Dixons' yard.

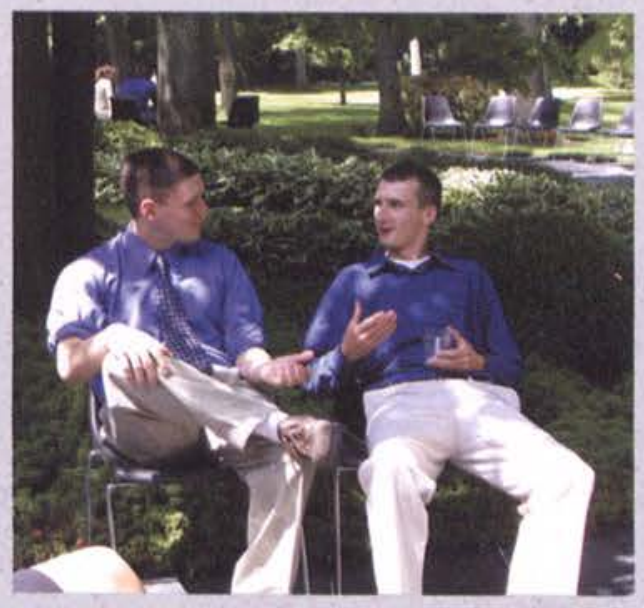

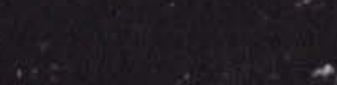

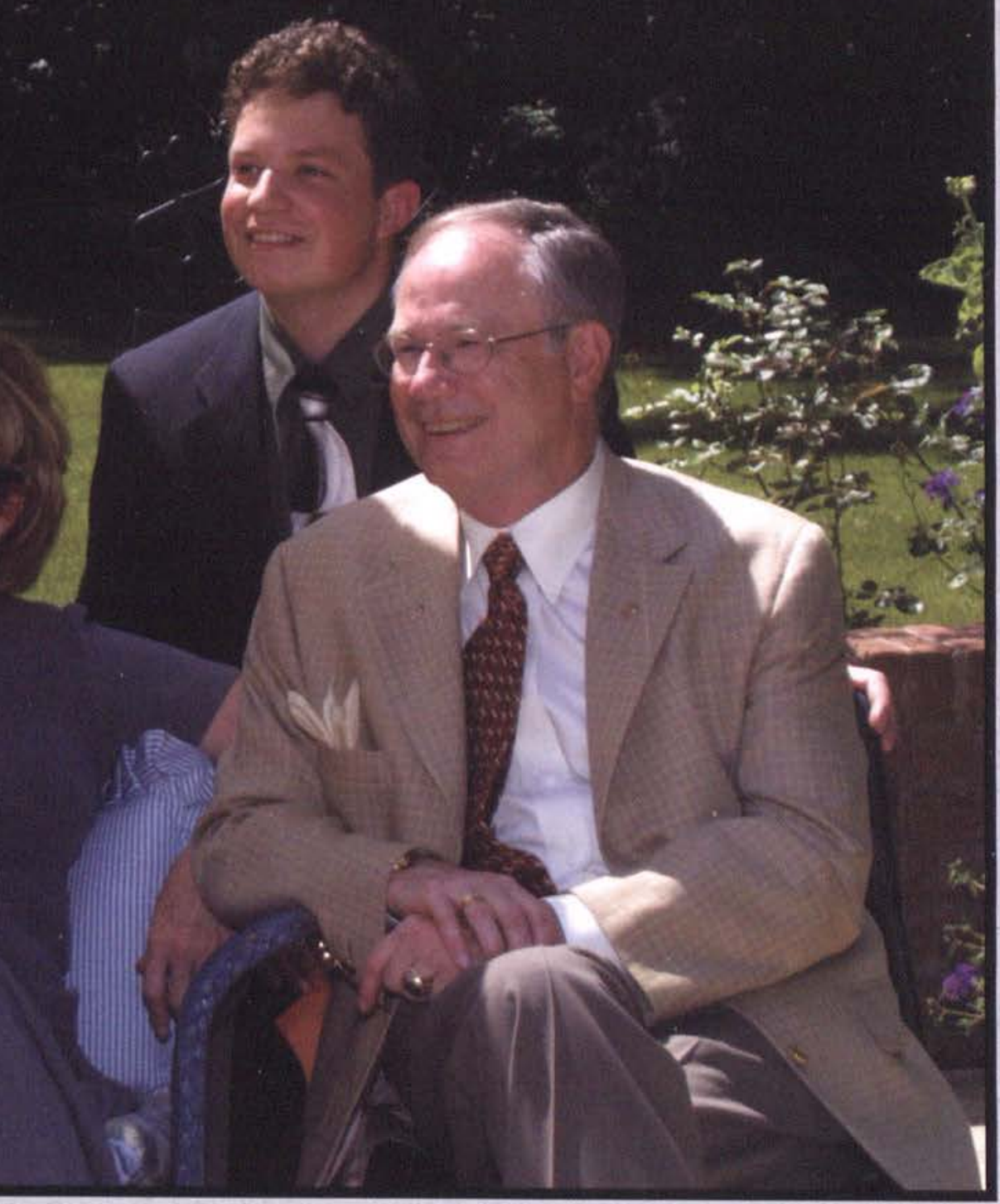

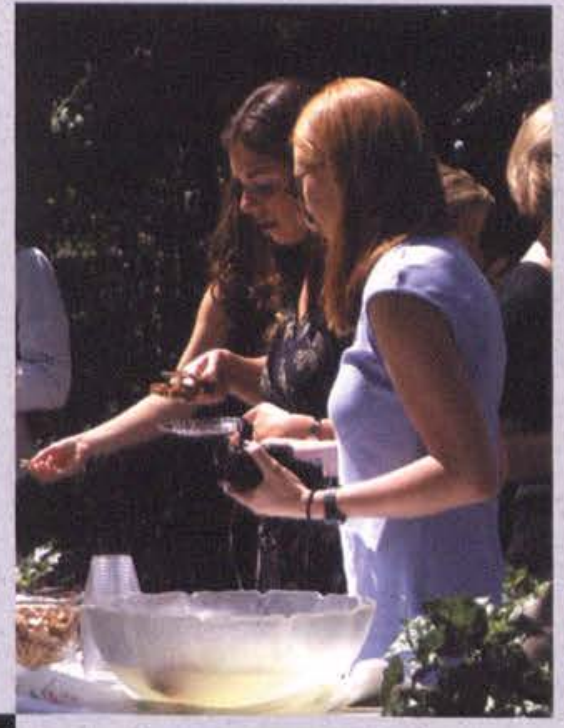

The refreshments are always an important part of the reception.
Everyone takes

time to have a picture taken with Dr. and Mrs.

Dixon.
James Miller and Matthew Garrett appreciate their afternoon at the Dixons'.

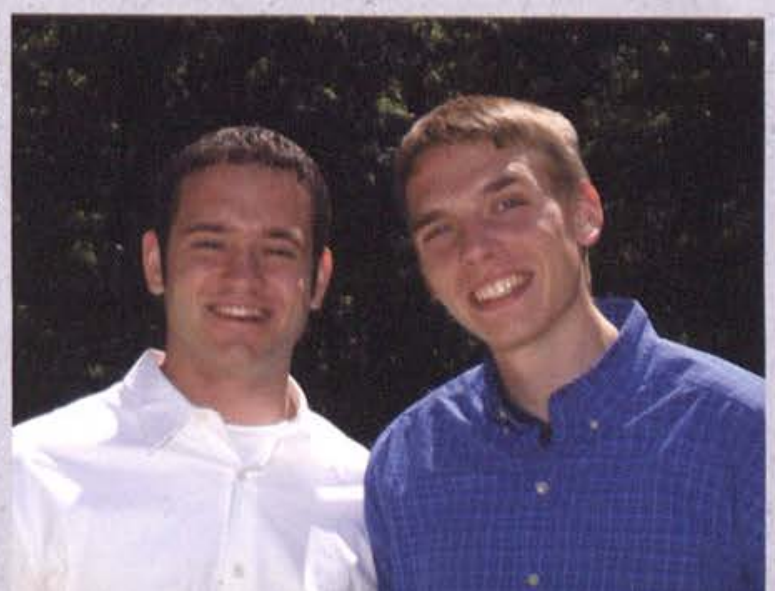




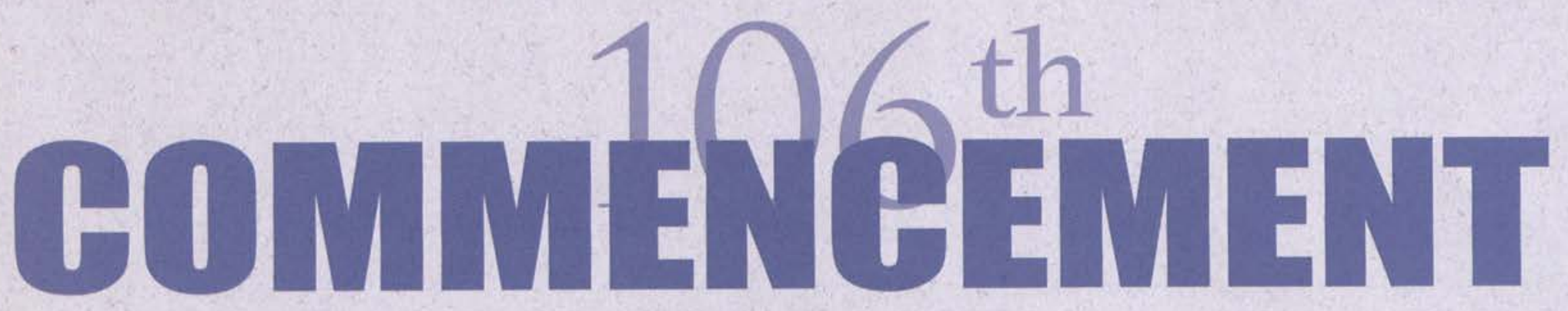

Cedarville University held it's annual commencement on June 1,2002 , at 10:00 a.m. in the Jeremiah Chapel. Decked out in their black robes and hoods, the graduates filed into the chapel followed by the faculty. The chapel was filled to capacity with friends and family of graduates eager to honor the students.

Before the commencement address, Dr. Richard Blumenstock read verses from Psalm 31, which were selected by the class as their class verse. Dr. Paul Dixon gave the commencement address and spoke of the nature of God's hands. He reminded graduates to trust in God's hands because they are strong, compassionate, and guiding. Dixon also urged each student to place themselves in the protection of God's hands.

Aaron Mahl, president of the graduating class, presented the class gift to Dixon. The class of 2002 gave the university a contribution to the funds that were being collected for the addition to the Athletic Center.

The graduates then stood to sing their class song: "The Potter's Hand." The song spoke of the graduates offering their lives to God and asking Him to mold, guide, fill, and use them. The song embodied the graduates' desires to serve God with their lives.

The graduates then marched to the stage and received their diplomas. The 2002 graduation ceremony ended with the singing of the Alma Mater and a benediction.

This was perhaps the most significant two hours of some of the graduates' time at Cedarville. The students said good-bye to their best friends and looked forward to a bright and exciting future. Some left Cedarville with wedding plans, some with plans to go on the mission field, some to go home and find a job, but all went home with wonderful memories of four years as a part of the Cedarville family.

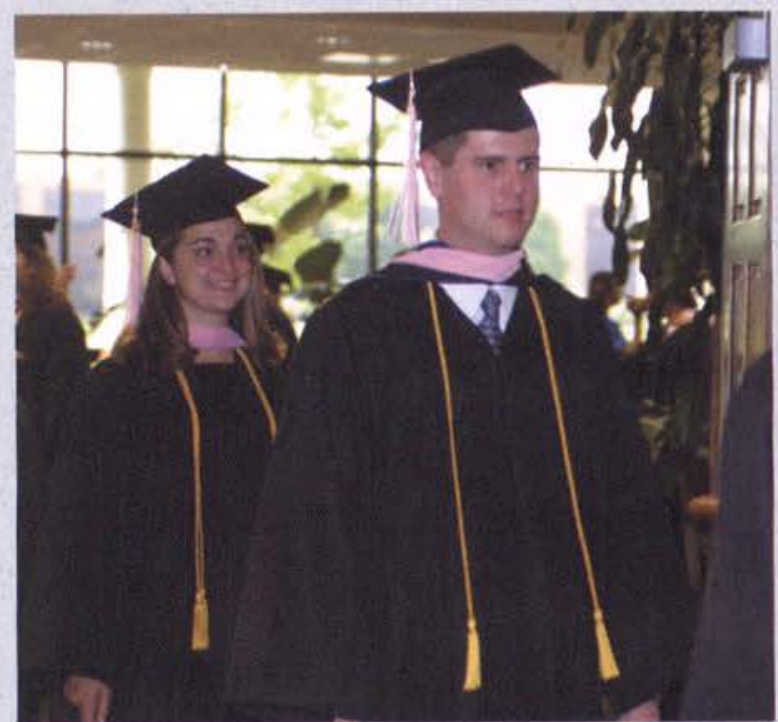

Angela Rudd and Joseph Mickeyprepare for their final ceremony as students.

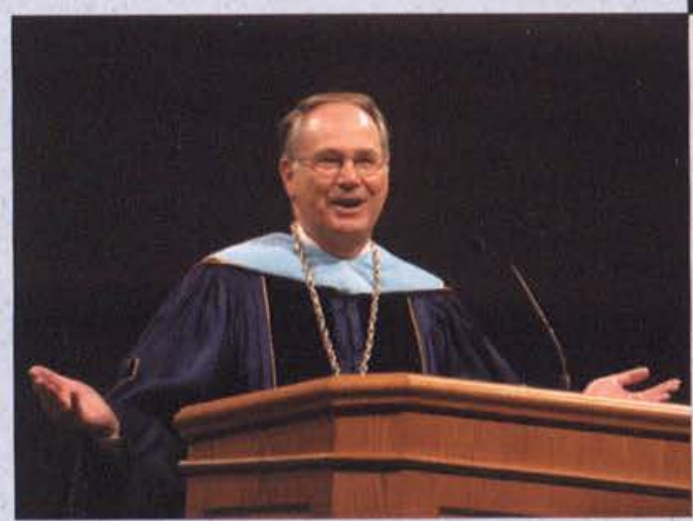




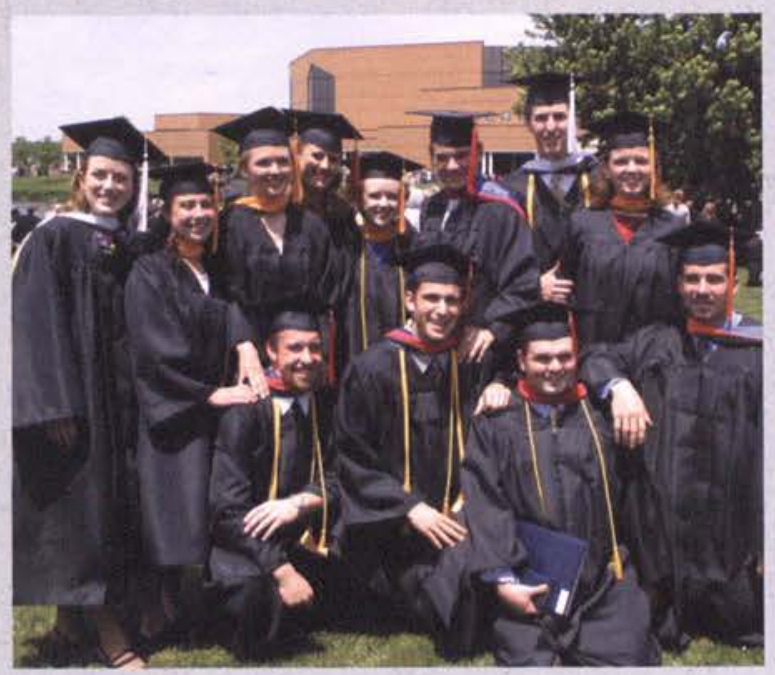

Having flipped

their tassles,

these friends can

now call them-

selves alumni.
Board of Trustee Chairman William

Rudd speaks to

the Class of 2002.

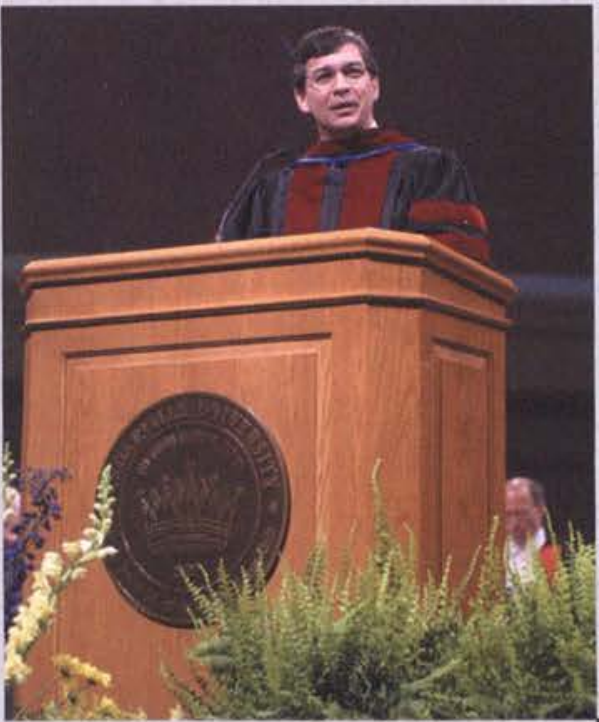

Matt Bell leads the class in their song, "The Potter's Hand."
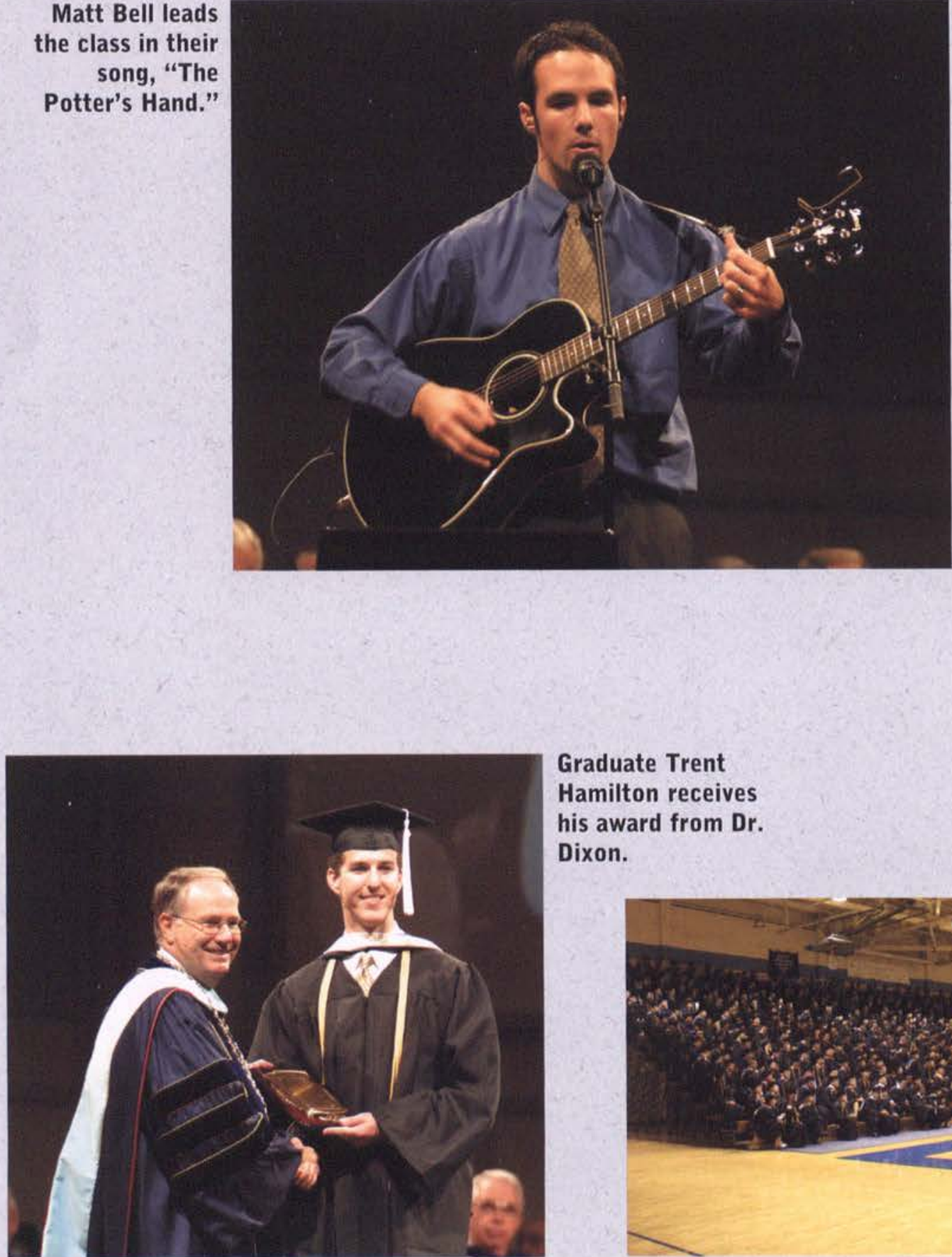

Graduate Trent

Hamilton receives

his award from Dr.

Dixon.

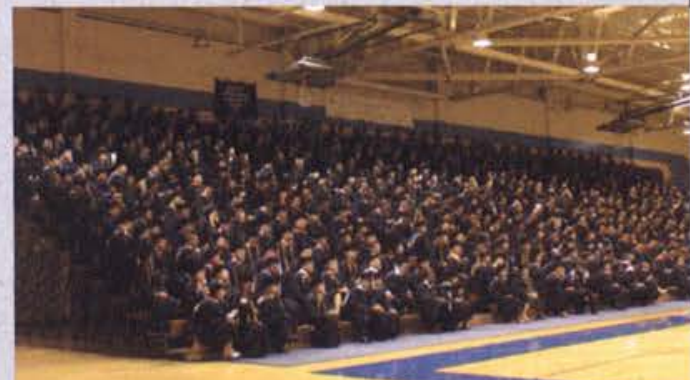

The Class of 2002 eagerly waits in the gym for graduation to begin. 
Adam Yingling and friends pose for yet another graduation picture.
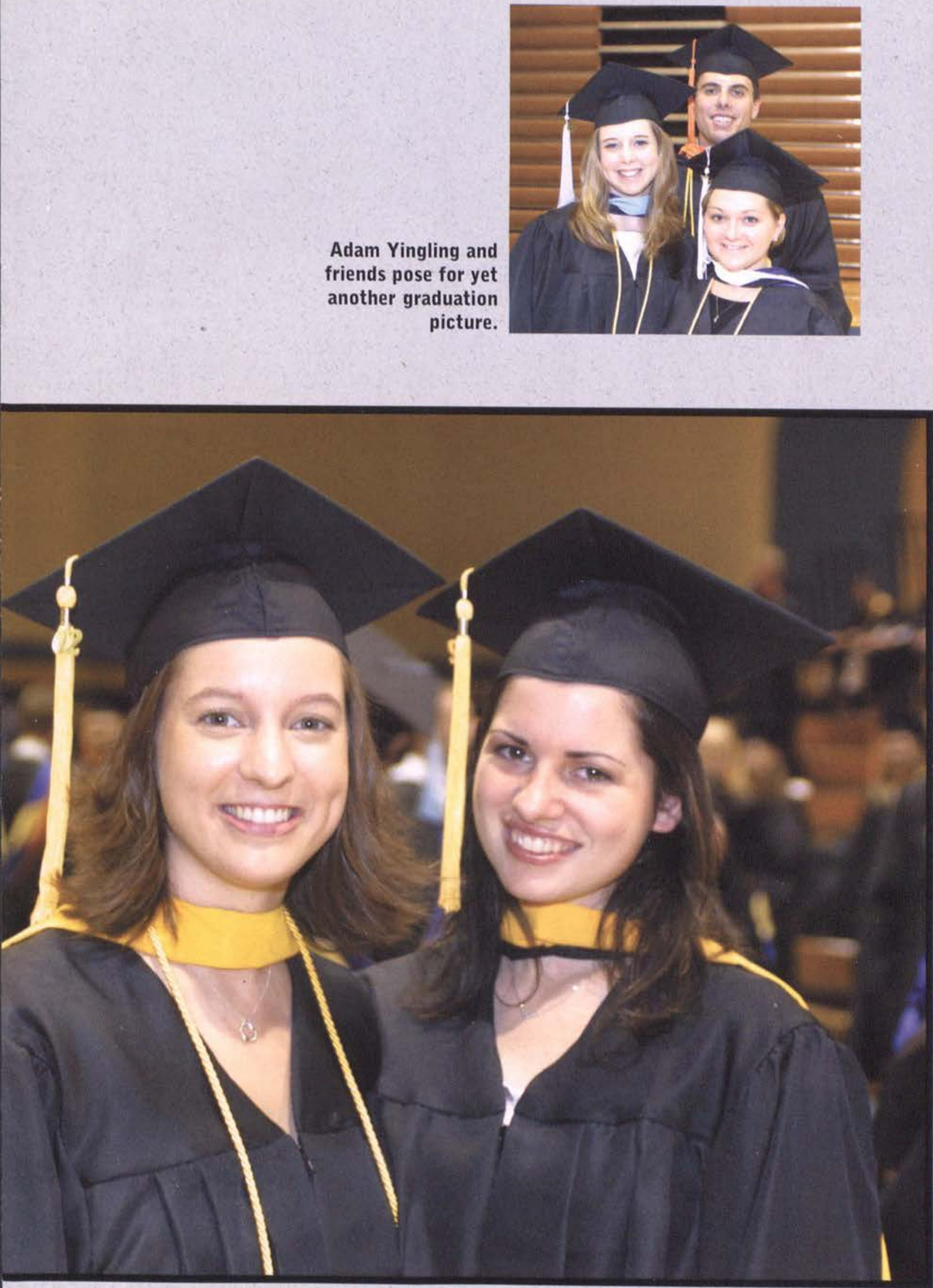

Esther Kelly and her niece Amanda show off their pretty smiles for the camera.

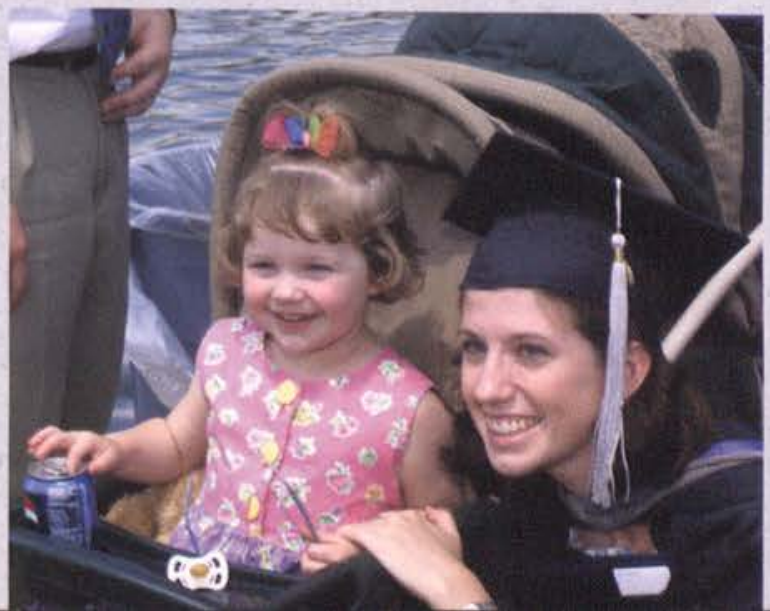

Rachel Mohler and Amanda Hancock kill time before graduation.

This senior is excited to receive her diploma. 


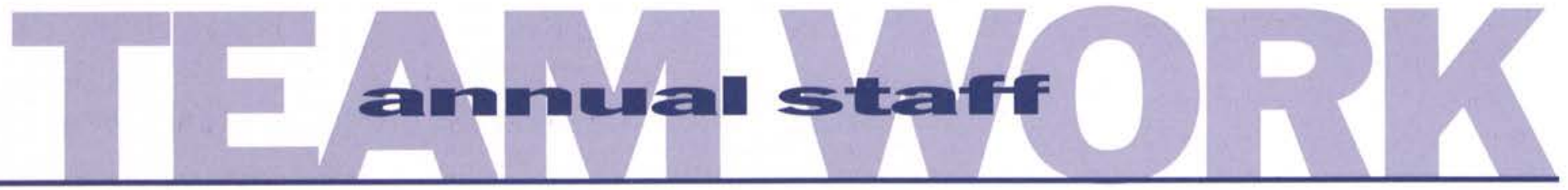

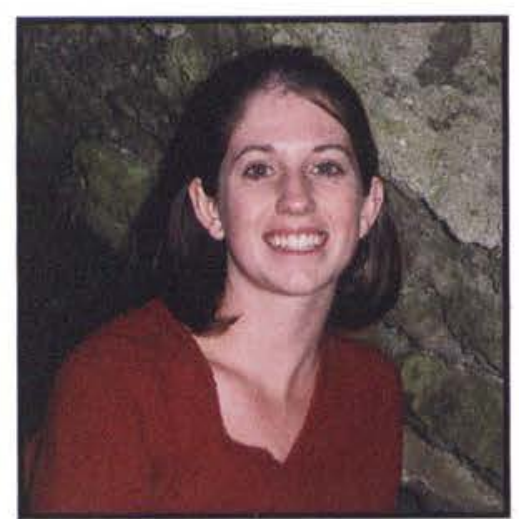

Esther Kelly

Editor-in-Chief

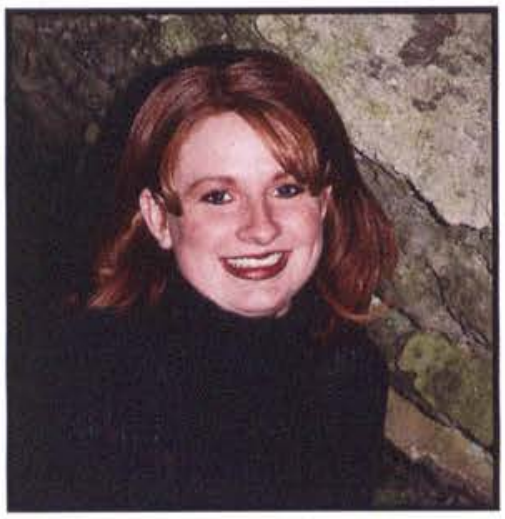

Megan Bryant

Administrative Assistant

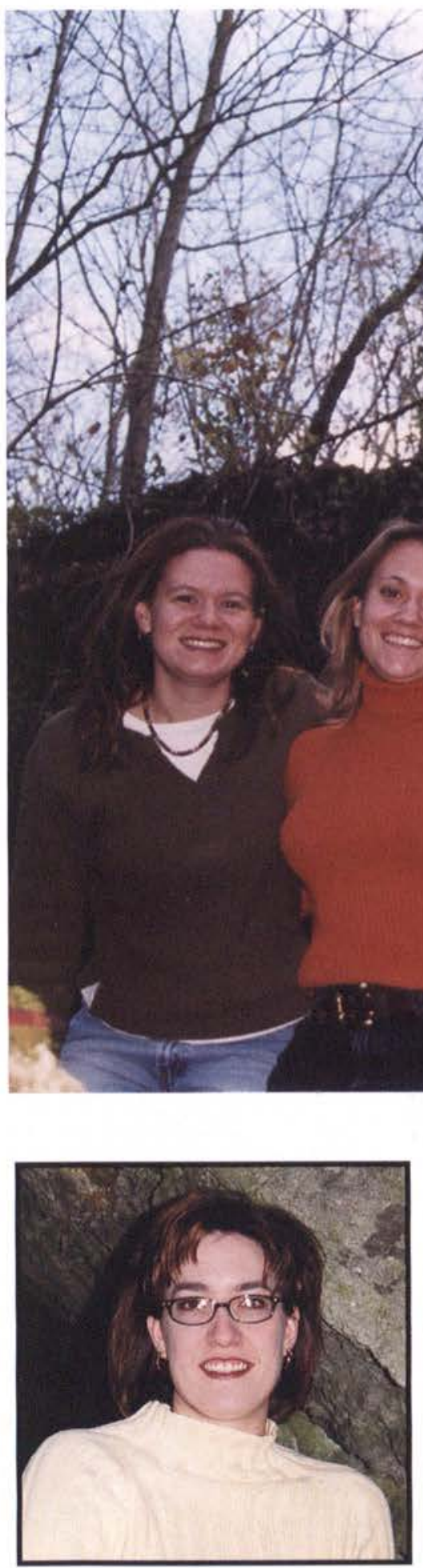

Cyndi Messer

Advisor

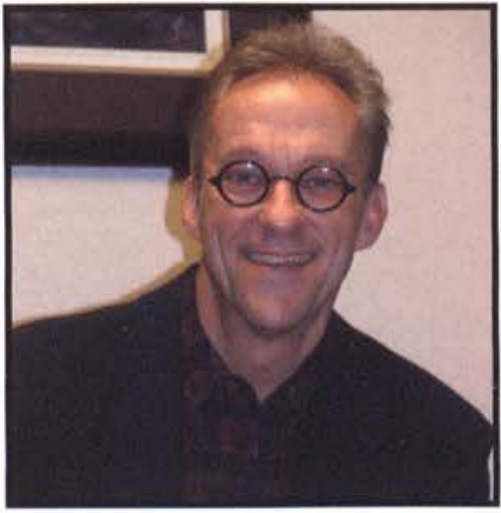

Terry Chamberlain Layout Advisor 


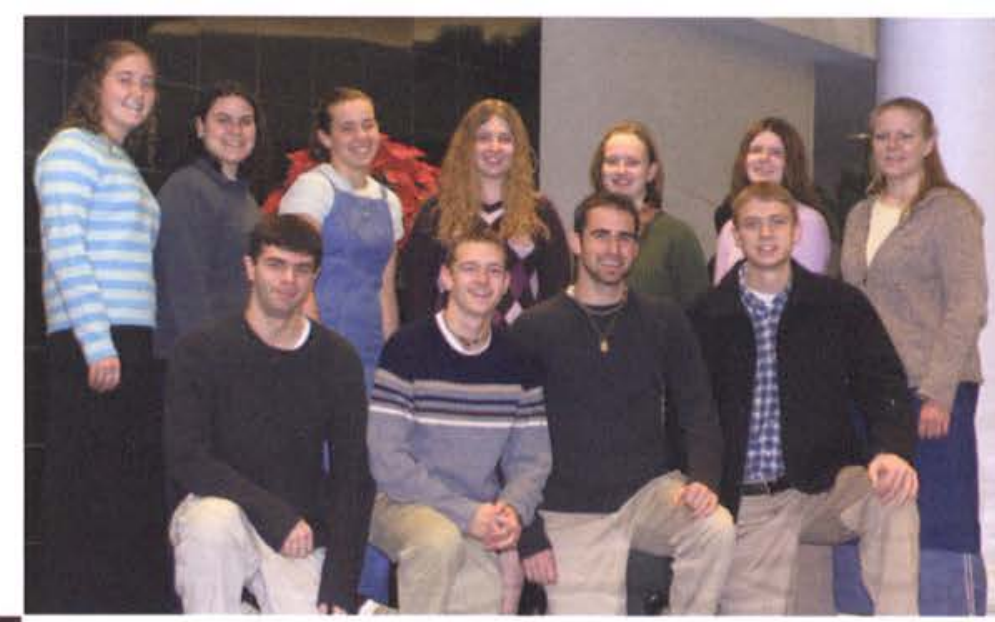

(front row left-to-right) JeffWestlake, Brock Bahler, Brock Weston, Ben Rosner. (back row) Natasha Boyce, Deborah Berruti, Laura Jaeger, Amber Hughes, Joy Daniels, Rebecca Barr, Kim Leverson. (not pictured) Andrea Howell, Kevin Leverson.

\section{photography staff}

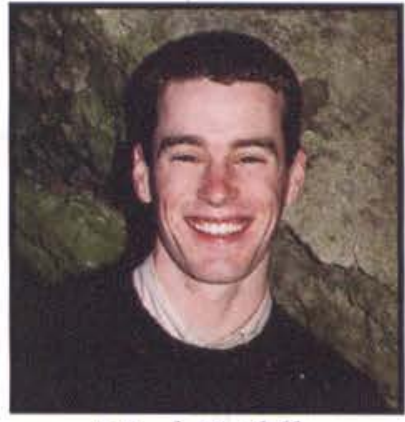

Mark Riddle PhotographyEditor

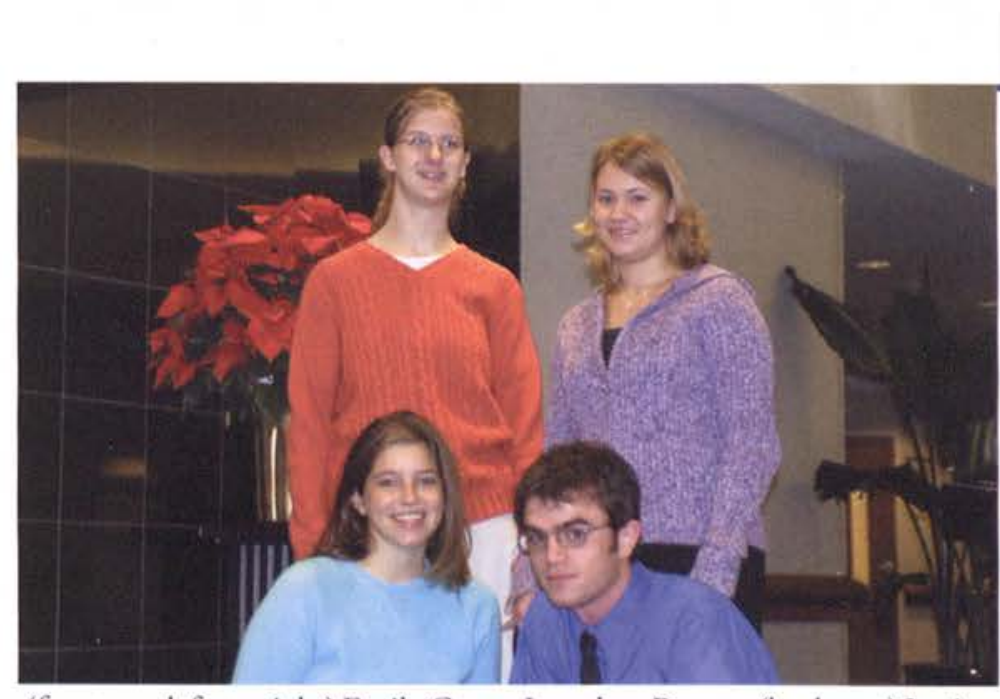

(front row left-to-right) Emily Gayer, Jonathan Brown. (back row) Jessica Busch, Rebekah Pemberton. (not pictured) David Malwitz.

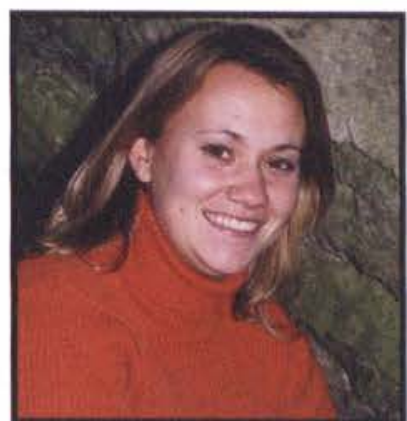

Becki Pemberton Layout Editor

\section{copv staff}

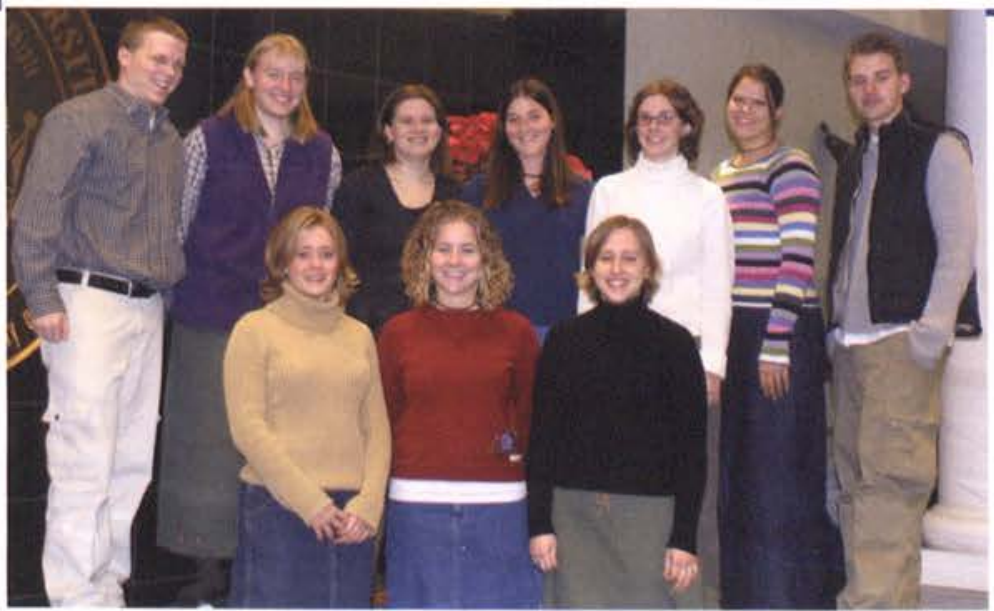

(front row left-to-right) Abby Brown, Jessie Hill, Jodi Crawford. (back row) Aaron Sattler, Bethany Sears, Kimberly Edlund, Sheli Oberbeck, Gina Band, Kristina Hynes, Erik Snell.

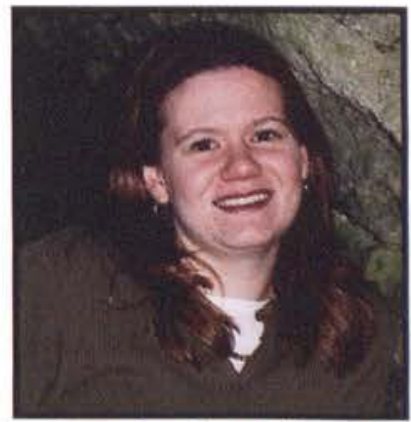

Kimberly Edlund Copy Editor 


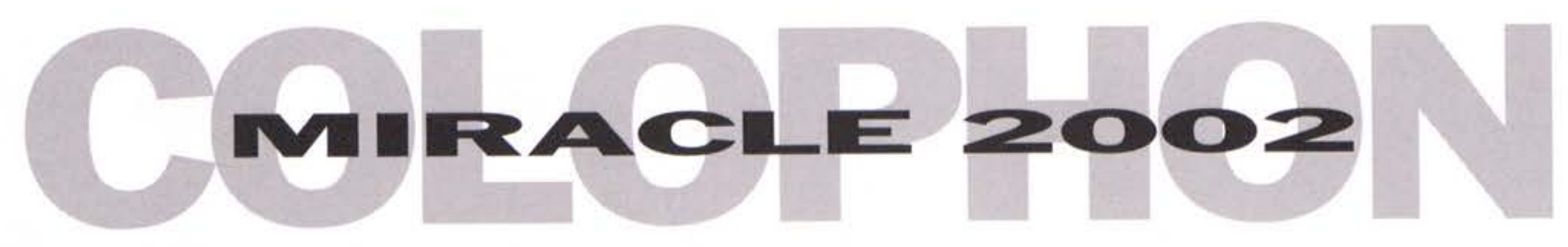

PUMRESEHER

The 2002 Miracle was published by Jostens, Inc. It was printed at their plant located in State College, PA. Our Jostens' representative was Tillie Billheimer. Our plant representative was Tom Yontosh.

\section{CONER}

The 2002 Miracle cover was a Lithocraft Pictorial cover, using photographs provided by our photographer. It was rounded, sewed, and bound. It was printed on High Gloss Litho 478 and had a matte finish. The ink used was Black 395 and Blue 424 . The endsheets were white and also used Black 395 and Blue 424.

\section{PAPER STROCW}

The 2002 Miracle's 300 pages were printed on Glossy 80\# paper.

\section{COR}

The 2002 Miracle contained 76 pages of four color process ink and photos. These pages were located in the opening, Fall Activities, and Senior sections. The Senior section contained a textured background applied with Pantone Blue 424.

\section{DES GN}

The 2002 Miracle cover, opening, dedication, dividers, section layouts, and closing were designed by Esther Kelly.

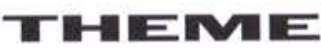

The 2002 Miracle theme "One Body, One Spirit" was selected by the editors of the yearbook at the beginning of the school year. It was chosen to remind the student body of the different aspects of the Body of Christ, while also reminding them of the unity they share in Him. The song "One Body, One Spirit" by Charlie Hall from Hall's "Joel's Window" was implemented with his permission in the introduction of the book. The editors of the book hope that students, alumni, faculty, and staff who view this book would remember the bond they have with other members of the Body, while also recognizing and appreciating the different gifts each member brings to the family of Christ.

\section{PIROE UETION}

The 2002 Miracle was produced on IBM compatible computers. Layouts were produced using Adobe PageMaker 6.5. Photos were scanned using HP Precision Scan. Photos were cropped, resized, and manipulated using Adobe Photoshop 5.5. Text effects were produced using Adobe Photoshop as well. Copy was typed into Microsoft Word and then imported into PageMaker.

\section{TMPOGRARPHM}

The 2002 Miracle contained a variety of fonts throughout the book. The stories are in Agaramond 12 with the captions in BellGothicBlack 10. The cover was in Goudy. The Introduction type was AvantGarde. The section headings of the Fall, Winter, Spring, Activities, Athletics, Chapel Section was printed in Myriad Roman. The Annual Staff section used Franklin Gothic type. The Ministry fonts were GaramondLight Condensed and Veljovic Medium. The Organization fonts were GaramondBook Condensed and Times New Roman. The Academics Section used Kaufmann and Myriad Roman. The Underclassmen and Senior Sections were Impact and Trajan. All of the dividers used Machine.

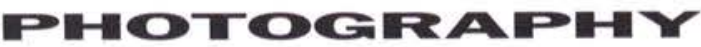

The 2002 Miracle photos, including the cover, introduction, and closing pictures, were taken primarily by Photography Editor Mark Riddle. He also directed a staff of photographers who took many of the pictures. Ministry and organization group photos were taken by photographers from DaVor Photography. Some sports pictures, play pictures, music groups pictures, and concert pictures were taken by Scott Huck, Photographer for Cedarville University, Public Relations.

\section{MNQUERERES}

The 2002 Miracle may be contacted for additional information about its production by writing the staff at Miracle, Cedarville University, 251 North Main Street, Cedarville, OH 45314. They may be reached by phone at (937) 766-4995 or by email at miracle@cedarville.edu. 


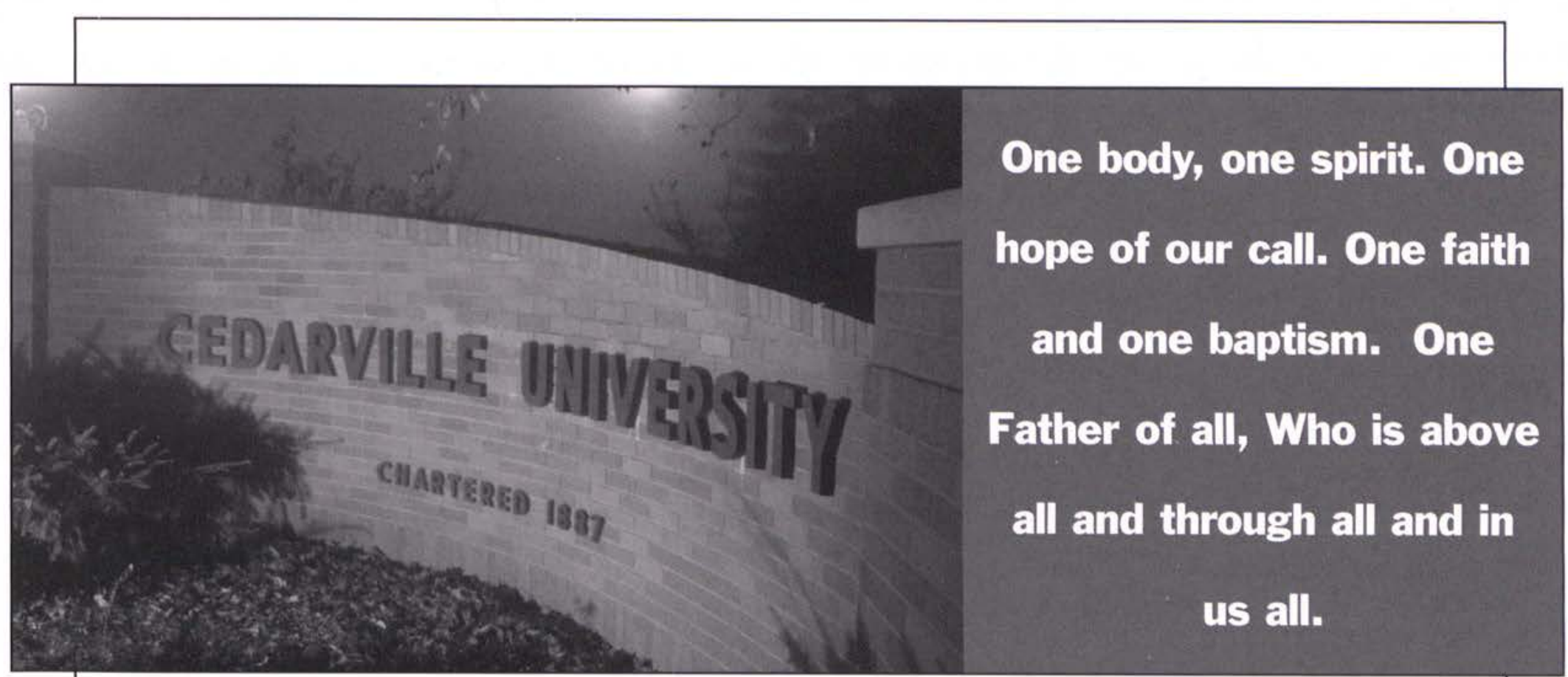

\section{The editor would like to thank everyone who has contributed to the production of this book.}

TO THE 2002 MIRACLE STAFF: WRITERS, PHOTOGRAPHERS, AND LAYOUT MEMBERS, thank you for all your hard work and enthusiasm. This book is full of quality photographs, exceptional stories, and remarkable layouts because of the contribution that each of you made. TO EACH OF THE EDITORS, KIM, MARK, BECKI, AND MEGAN, thank you for doing such an excellent job of overseeing your staff and making sure that your portion of the book was done. This book never would have been completed without the work that each of you put in. I enjoyed working with each of you, and I am so thankful that God gave me the best staff of editors I could ask for. TO KIM, I want to especially thank you for the extra help you gave me many times throughout the year. You seem to know how to do everything and are always willing to be of service. I could never have made it through the year without you, and don't worry about next year; you are going to be an amazing editor-in-chief. TO MARK, I was blessed this year to have you as my photographer. Without you this book would not exist and would not look as amazing as it does. I am so happy with the cover, the dividers, and the many other pictures you took for the book. Aside from yearbook, I really enjoyed getting to know you this year, and I know that you are going to do great things in the future. TO BECKI, thank you so much for working with the layout staff this year. I really appreciated how I could count on you to get pages back to me in time for our deadlines and how you were always willing to help your staff with their pages. TO MEGAN, even though you were not able to finish out the year with us, I am so thankful for the work you put in with the organizing of the 2001 dedication and all those e-mails you had to deal with about students not getting yearbooks. I enjoyed getting to know you better, and by the way, congratulations on graduating! TO CYNDI, thank you for all your support and encouragement throughout the year and for making sure that the book was the best it could be. Also, thank you for checking all those proofs! TO DAVID, thank you for being so supportive of me this past year. I always knew that if I was frustrated or tired with yearbook that you would be there to encourage me and to listen. I know that you did not always want to hear about yearbook, but you were so sweet in pretending that you really wanted to hear every little detail. I love you. TO BECK, JENNY, AND MICHELLE, I want to thank each of you for being such an encouragement to me this year. Each of you always took such an active interest in what I was doing with yearbook and were always willing to listen to me ramble on about things I had to do. TO MY FAMILY AND MRS. MALWITZ, thank you for always asking me about how yearbook was going throughout the year and for always being ready to give advice and creative ideas. TO THE CEDARVILLE UNIVERSITY FAMILY, thank you for sharing in these memories. May you never forget your experiences at Cedarville, and may you never forget that we are one body and one spirit in Jesus Christ. 
A

Abbas, Dr. Robert 16 Abbs, Jacob 91, 226 Abildness, Kristi 129,242 Abildness, Marcy 69, 212 Ables, Lisa Marie 126,242 Abney, Elizabeth 78,198 Abratom, Paul 77,242 Abraham, Rich 212

Acheson, Kailin 55, 81, 198 Acheson, Robin 81, 212 Acker, Mark 226 Ackerman, Julie 84, 90, 198 Acorn, Chris 212 Adamov, Jill 39 Adams, Airynn 70 Adams, Jameson 52 Adams, Jane $38,39,212$ Adams, Jillian 226 Adams, Tana $55,69,212$ Adams, Teressa 121,212 Adams, Torrey 47,242 Adams, Torrey 47,242 Ager, Dr. Merlin Aher, Kuth 174, 125, 212 Albanese, Emily 242 Albanese, Emily 242
Albertson, Heather $121,123,226$ Albertson, Heather 121,123,
Alburger, Daniel $85,94,198$ Alenskis, David 117, 198 Alexander. Jessica $39,83,242$ Alexander, Shawn 91, 198 Allen, Amanda 78, 198 Allen, Brenda 226 Allen, Brian 116, 198 Allen, Sara K. 83, 242 Allen, Sarab M. 242 Allen, Shan M. 242 Allen, Shawn D. 242 Allen, Travis 212 Alligood, Lisa 88,242 Allison. Summer $116,121,226,278$ Allpor, Brian 128, 242

Allport, Chuck 176

Althaus, Rachel 82,212 Altstaetter, Wayne 98 Alyn, Dr. Irene 172 Aman, Charles 242 Aman, Rebecca 242 Amann, Michael 242 Ament, John 198

Anderlini, Lindy 243

Anderson, Alicia M. 38, 39, 243 Anderson, Blair 72, 226 Anderson, Connie 164 Anderson, Desiree 226 Anderson, Dr. Lyle 164 Anderson, Greg 68, 226 Anderson, Jenny 212 Anderson, Lori 117, 174 Anderson, Paul M. 243 Andras, Jill 226 Andras, Michal 117 Andrews, Corrine M. 243 Andrews, Emily M 243 Andrews, Emily M. 243 Andews, Mr. John 15 Antes, Brian 99, 243

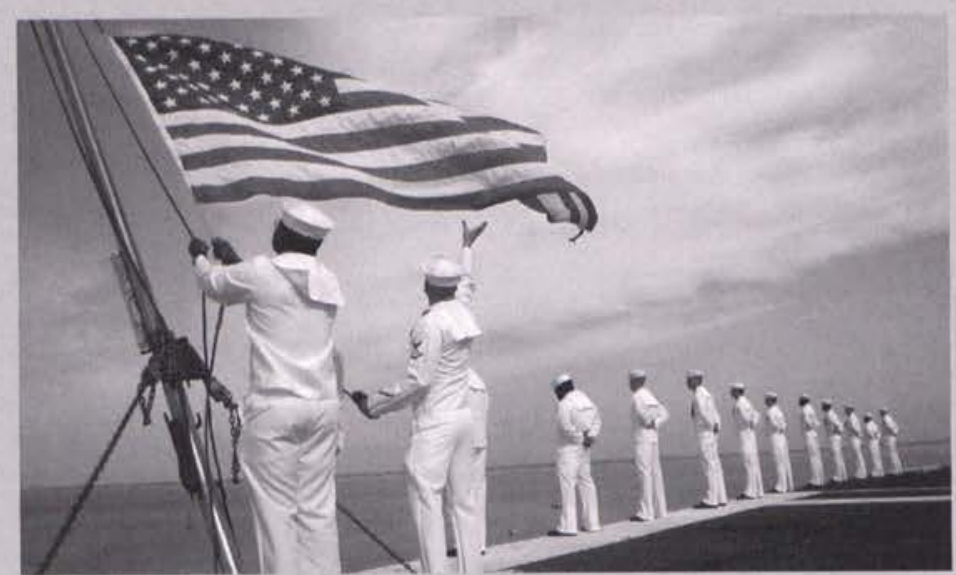

Sailors aboard the aircraft carrier USS Theodore Roosevelt lower the U.S. flag, Wednesday, Sept. 19. 2001, off the coast of Norfolk, Va. The carrier began air operations within hours of leaving the port and heading into the Atlantic Ocean. Navy officials declined to say whether the attacks had changed the battle group's destination.

Antigas, Chris 87

Apple, Eugene 12

Arimura, Amice 243

Arkhipov, Andrey $48,122,128$

Armitage, Kristin 198

Arnold, Nathan 198

Asbury, Jennifer 127,212

Asher, Dee Dee 39,212

Atkins, Doug 176

Atkinson, Ryan 212

Attard, Philip 73, 212

Atwell. Courtney 19, 17

Atwell, Jason 125,178

Augustinc, Krista 24,212

Austin, Deanna 198

Auyer, Jason 36,198
Avery, Anna 116, 125, 212

Avery, Anna 116, 125, 212

Awabdy, Jady 178

Awabdy, Mark 121, 212

Ayers, Alicia $118,119,243$

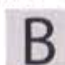

Babcock, Christina 86, 226

Babson, Eric 116,226

Bacerra, L 243
Bahler, Brock 129, 212, 287

Bahorik, Justin 73,128

Bailey, John 60, 61, 120, 125, 243

Bailey, Joshua $120,127,212$

Bailey, Laura 94, 226

Bailcy, Lindsey 59,198

Bailey, Timothy $122,125,226$

Bailey, Tonya 178

Baits, Anelise 226

Baker, Krista 226

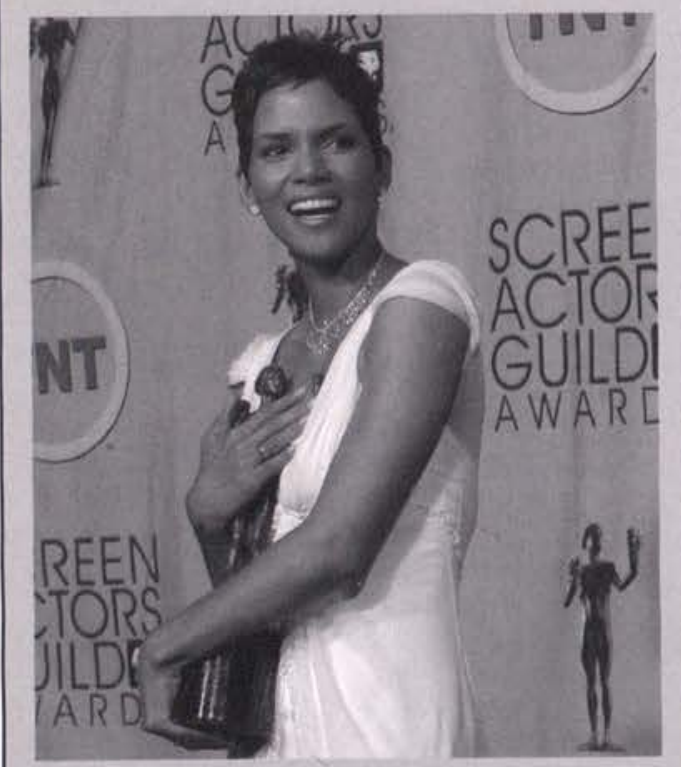

Actress Halle Berry reacts as she holds the award she won for outstanding performance by a female actor in a leading role for her work in the film, "Monster's Ball," at the 8th annual Screen Actors Guild Awards

Sunday, March 10, 2002, in Los Angeles.
Baker, Lydia 74, 122, $198 \quad$ Beres, David 99,227

Baldwin, Dr. Richard 168

Baldwin. Emily 90,212

Bates, LaRissa 98,177

Bales, Rochelle 212

Ball, Carl R. 243

Ball, Kristin 68, 118

Ballard, Ryan 198

Ballou, Hannah 127, 226

Ballou, Ruth 198

Banas, Kristen 195, 198, 211

Band, Georgina $128,243,273,287$

Band, Priscilla 212

Bantle, Graig $127,158,243,272$

Baratta, Jessica 91. 122, 125

Barba, Shana $25,158,243$

Barger, Adam 118, 129, 136, 226

Barham, Jennifer 82, 198

Barr, Rebecea 226, 287

Barrett, Benjamin M. 243

Barron, Stephanie 212

Barrons, Christina 82, 243

Bartholomew, Amanda 122, 128 .

Bartholomew, Dr. Ray 164

Bartholomew, Janine 212

Bartlett, Adam 79, 226

Bartlett, Chris 77, 226

Bartlett, Dave 126

Bartlett, Sarah J. 244

Basner, Brian D. 244

Bates, David 81,226

Batinic, Ivana 122,212

Batista, Kevin 127, 151, 244

Battaglia, Carrin 180

Battaglia, Ryan 226

Bauman, April 74
Bauman, Mary 76,212

Batman, Mary 76, 212

Bauman, Zipporahi 244

Baumann, Dr. Donald 172

Baustian, Marybeth 212

Baxter, Deborah 68, 226

Beach, Rachel 226

Beachy, Althea 72,226

Beagle, Lucas 212

Beall, Todd 125,213

Beatty, Kate 58,59

Beatty, Nathan 213

Beatty, Sandra K. 244

Beck, Tim 56, 198

Beckett, Kristi 86, 119,22

Beckley, Jeffrey 64,213

Begg. Jonathan 73

Belding, Amy M. 244

Bell, Nathan 94, 227

Belleman, Ben 36, 167

Bellows, Albert 213

Ben, Kristen 119, 213

Bender, Janelle 100, 227

Bender, Lindsey 198

Bender, Rachel 213

Bennett, Brandon 198

Bennett, Drew 52, 128, 244

Bennington, Craig 64,65

Bentley, Mark 120, 198

Beres, Adam 118, 244
Basner, Jonathan 17.4

Becker, Andrew 73, 83, 116 (lly 227

Bernhard, William 12

Berruti, Deborah 227. 287

Beste, Jeff $118,129,155,175$

Bethel, Tyler 198

Betts, Amy 198

Bevan, Jim 126, 213

Bicknell, Matthew A. 24.

Biclek, Allison 125

Bielek, Robert 180

Bielo, Melissa A.

Bieniek, Mike 183

Bierer. Douglas

Bieri, Clint 244

Bigelow, G. Corey

Bigelow, Matthew

Bigley, Gretchen

73,227

Billsby, Chad 227

Birchficld,

Rebecea 227

Bird, Rani 198

Biss, Jennifer 199

Bitsko, Mickey

56,59

Bitzer, Doug 244

Bizzoco, Lauren

116.244

Black, David 229,227

Blake, Dorothy

85,24

Blakey, Joseph

129. 244

Blalock, Michele 119,227

Blaquiere, Rachel 199

Bledsoe, Katic 73, 213

Bledsoe, Meagan 123, 227

Bleikamp, Lisa 70, 122, 213

Bliss, Carol 182

Blodgett, John 12

Blodgett, Pete 244

Blosser, Allison 227

Blosser, Matt 82

Blythe, Kellen 90, 116

Bockmann, Bethany 90, 119, 227

Boertic, Mark W. 245

Bogenschutz, Jennifer 119,213

Boillat, Sarah 69,227

Bojczuk, Rachel 119, 123, 213

Boland, Barrak 213

Bolden, Sarah C. 245

Bolender. Jeff $56,59,167$

Bolender, Sharic 40, 43

Bolinger, John 82, 120, 245

Bollenbacher, Brittian 73

Bolser, Anna 78, 245

Botthouse, William 12

Bolton, Andy 89, 199

Boltz, Jonathan 213

Bolvi, Ethan 211

Bondreau, Ryan 90

Bonenberger, Dr, Omer 168

Bonham, Jennifer 94, 125, 126 .

227

Bonhomme, Jesse 213

Boone, Nathan 99, 227
Borich, Benjamin 91.227

Borich, Matt 48, 199

Borland, Seth 213

Borries, Kevin 128, 227

Borud, Danicl 199

Bosma, Jance 171

Bossard, Jeremy 82, 245

Bossman, Erica 199

Bostic, Amber 85, 199

Boucher, Gillian 91, 121, 213

Boudreau, Ryan 213

Boulet, Jessica 199

Bouma, Henry 227

Bouma, Jeremy A. 245

Bouwens, Randall

Bowen, Ryan 64

Bower, Kimberly 227

Bowers, Jack 227

Bowers, Jim 187

Bowers, Johnathon 199

Bowers, Shelley 227

Bowersox, Grafton 213

Bowersox, LT. J. 1

Bowman, Sarah 128,199

Boyce, Natasha $118,227,245,287$

Boyd, Jamie 213

Boyne, Bethany 46.213

Bradds, Connic 180

Bradshaw, Jason 98

Braithwaite, Dr. Edwin 172

Brammer, Miriah 227

Brandon, Carl 171

Brandon, Marjoric 213

Branon, Julie 125, 245
Braun, Matthew 72,199 


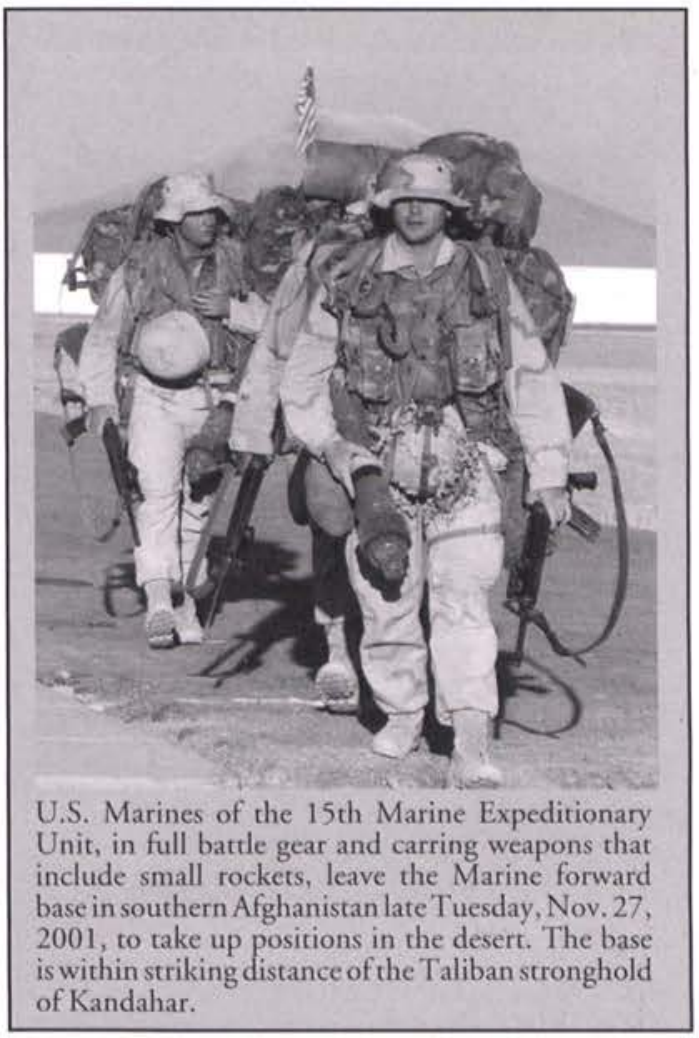

Carlson, Katie 120,122

Carlton, Stephanic J. 246

Carmichael, Kevin 118,246

Caron, Jennifer 124,246

Caron, Michael 214

Carpenter, Kevin 55

Carpenter, Nicole 246

Carpenter, Sue 55

Carr, Alberta 180

Carr. Andrew 199

carroll, Drew 92

Carroll, Eric $\quad 52$

Carter, Braden 36, 199

Carter, Joshua $\quad 116,214$

Carter, Lauric 246

Carter, Ric 228

Carveth, Lori 121, 123, 228

Cary, Tim 98

$\begin{array}{ll}\text { Case, Jennifer } & 246 \\ \text { Casper, Travis } 228\end{array}$

Cassano, Jeffrey 83,21

Cassell, Jonathan 214

Cassidy, Kendra 85, 246

Cassidy, Melissa 88

Cassity, Bob 36

Castellani, Jennifer 88, 126, 246

Castle, Dr. Sally 168

Casto, Chelsea 39, 199

Casto, Samantha 119

Castro, Rachael 59,199

Caterinacci, Mark 199

Cato, Jim 182

Cato, Melody 180

Caudill. Kristen 119,214

Cazier. Dawn 70, 246

Cha, Mary 199

Cha, Mary 199

Chalvners, Sheena 74

Chamberlain, Terry 164, 280

Chamberlin, Barry $48,49,52,125$

Chance, Melanie $2 / 4$

Chandler, Mandy 87,21

Charpie, Kenneth 214

Chasnov, Dr. Robert 172, 274

Chatfield, Lindsay 246

Chestnut, Robert 151, 194, 228,

Chiavetta, Tom 85,214

Chilton, Barbara 168

Chipe, Camy 199

Chipe, Genoveva 77, 228
Chmielewski, Jennifer 82, 228

Chord, Melinda 9

Chouinard, Kathryn 85, 199

Christensen, Lana 118, 123, 199

Christenson, Rebecca 78,118 ,

123,228

Christman, Jonathan 118,125

247, 277

Christner, Julia 82,228

Chrystal, Chris V 180

Churehward, Carrie 199

Ciccanti, Dawn 76

Ciotta, Danielle
Claeys, Kristen
91,228

Clacys, Kristen 91,228
Clark, Andrea 199

Clark, Danicl 164

\section{Clark, Jennifer 121.247 \\ Clark, Jim 44,178}

Clark, Jon 228

Clark, Kay 174

Clark, Rebekah 200

Clark, Sarah 117, 118, 247

Clark, Teresa 44, 167

Clarke, Stefanic 73,214

Clawson, Elizabeth 86, 123, 125

128.214

Claypool, Casey 88.228

Clem, Richelle 44, 55, 200

Clevenger, Dr. Charles 155

Cliffe, Amy 119,247

Clifte, Amy 119,24

Clutz, Michael 123,200

Cochrell, Tim 73, 89, 117, 125 ,

Coffey, Michael 125, 228

Colao, David $116,247,283$
Colarossi, Christina $\quad 119,228$

Cole. Michael 123,214

Coleman, Becky 176

Coleman, Sarah 214

Colgain, Kathy 84,21

Collins, Rachel 117

Colman, Dr. Jam

Colon, Justin 116,200

Colosimo, Nicole 121,277

Colyer, Kimberly 247

Combs, Adria 73, 129, 228

Combs, Angic 200

Commons, Tracy 175

Commons, William 12
Compton, Debbic $78,123,228$

Compton, John 116, 247

Compton, Paul 200

Conant, Katherine 73, 121, 247

Congrove, Daniel 116, 200

Conklin, Jeffrey $90,116,200$

Conway, Dr. Janet 172

Cook, Dr. Jeffrey 164

Cook, Jessica 121, 214

Cook, Michael 214

Cooley, Beth 247

Coon, Brian 116, 194

Coon, Heather 200

Cooper, Hannah 59, 228

Cooper, Leah 89, 126, 247

Copella, Margaret 84,247

Corder, David 228

Corder, Kristi 200

Corrick. Charlie 80. 228

Cosgrove, Michael 78,228

Costin, Dan 247

Couch, T.J. 52,53

Courser, Andrew 82,200

Courtade, Angela $88,119,200$

Cox, Courtney 77, 122, 228

Crady, Kellee R, 247

Cragoe. Dr. Thomas 164

Craig, Adam 90.228

Craig, Barrett 69,228
Craig. Kevin 85, 228

Crawford, Jodi 247.287

Crellin, Mark 51

Crick, Debbic 54
Criner, Janelle 20,229

Cripe, Crystal 247

Crissman, Lauren 82, 90, 126

Crissman, Steven J, 247

Cronbaugh, Emily 125,229

Crosby, Casandra 229

Cross, Daniel 123, 128, 247

Cross, Mark 247

Cross, Rebekah 176

Crowder, Matt 248

Crowder, Seth 82, 122

Crunelle, Theresa 229

Cullip. Amy 92, 214
Cullip. Andrew 248

Culpepper, Jason 200

Culpepper, Ryan 31, 116, 229

Culver, Jonathan 248

Culver, Lisa 72, 229

Cummings, Laura 200

Cummings, Sarah 248

Curlette, Dr. Bruce 164

Curran, Jack 90, 200

Curtis, Wendy 119,200

Curts, Adria 229

Custer, Katherine A, 248

Crechowski, David 76, 129

\section{D}

Daicllo, Michael 120,226

Daigle, Cameron 200

Daniel, Joshua 116,129

Daniels, Joy 287

Dannemiller, Linda 119,229

Dannemiller, Melissa 248

Davidson, Danielle 39,83

Davies, Corban 248

Davies, James 248

Davies. Jonathan 229,248

Davies, Kate 120,229

Davies, Thomas H. 248

Davis, Brian 33.118, 119, 159

$248,271,272$

Davis, Cheryl 121

Davis, Dana $K^{2} 248$

Davis, Ivan 70

Davis, Jennifer 229,248

Davis, John W. 248

Davis, Laura 200

Davis, Matthew 36,84

Davis, Susan 125,214

Davlantes, Christine 74,248

Day, Evan 90,214

de la Rosa, Sam 116

Deal, Aaron C. 248

Deal. Jennifer 179

Dean, Jane 180

Deardorff, Dr. Donald 164

Deardorff. Julic 171

Debrason, Elizabeth 229

DeClark, Scott 137

DeGarme. Becky 220

DeGunglicimo, Ging 124,248

DeHaan, Daniel 60, 229

Deflarn, Jonathan 214

DeHart, Julia $42,43,59,123,129$

Delange, Ann 180

DelGrosso, Devin K. 248

Delk, Jennifer 68,200

Dellicarpini, Kathryn 55, 91, 200

Delong. Benjamin 248

DeLong. Terry 176

, 129,214

Dennert, Brian 90, 129, 220

Dennis, Adam 99, 248

Dennis, Jennifer 74, 200

Dennis, Jeninier 74,200

Denton, Bethany 125,214

DePenning, Desiree 214

DeSantis, Rebecca 249

Detwiler, Kathryn 21.

Detwiler, Kristen 79, 229

DeVoll, Kathryn 249

DeVries, James 12

Dewhurst, Nathanael 36,200

DeYoung, Melissa 200

DiazPons, Rebekah 214

Dice, Dave 60, 61, 214

Dickey. Amy 214

Dickey, LaVerne 176

Dickinson, Jacob 120, 229

DiCuirci, Michael 120, 192, 214

DiCuirci, Mike $140,156,164$

Diehl, Camie 249

Dieringer, Aaron 90, 249

Dieringer, Daniel 229

DiGarmo, Becky 113

Diggle, Jeff 229

Dillon, Carolyn 55

Dimatteo, Karen 90,200

Dingeman, David 48,249

Dirr, Amy 175

Divine, Jesse 116,200

Dixon, Dr. Paul 14, 106, 150

$159,160,186,282,283,284$

Dixon, Dr. Scott 164

Dixon, Kelly 200

Dixon, Mrs. Pat 160

Dobbins, Matthew 214

Doden, Daryle 12

Dolby, Eric 125, 137, 229

Dolby, Valerie 200

Doleys, Teri 76, 121, 249

Dolph. Dr. Chuck 168

Doot, Jeremy $73,86,214$

Dorsey, Michael 109

Doub, Jeffrey R. 200

Dougherty, Keith 74, 200

Dougherty, Kevin 119,229

Douglas, Matthew 200

Doust, Kara 100, 214

Dowd, Jim 200

Doylc, Dustin 200

Drent, Adam 200

Driessnack, Julic 120,249

Drullinger, Dr. David 165

Drumbeller, Michelle 47,249

Drummond, Amber 200

Drye, David $70,72,249$

Duchard, Bob 39

Dudenhofer, Patrick 71, 214

Dudick, Christen 214

Dudick. David 229

Dudick, Flizabeth 70, 123, 229

Duff, Ashley 214

Dugan, Julic A 249

Dulin, Megan 43,200

Dull, Sara 214

Dunham, Daniel 33, 70, 118,128 ,

Dunham, Justin 215

Dunlap, Natalie 215

Bun, A

121,229

Dunn, Matthew 120,229

Dunning, Jessica 229

Durbin, Amber M. 249

Duty, James $94,116,2$

Dye, Amanda $84,120,215$

Dyer, Emily

\section{E}

Earley, Molly 51, 215

Eamhardt, Elizabeth $90,118,215$

Eaves, Kari 73, 94, 229

Eckburg. Meredith 200

ckstein, Sharon 182

Edgington, Callie 59, 79, 229

Edlund, Alan 60

Ellund, Kimberly 123, 134, 229 .

Edlund, Lindsey 200

Edwards Alison 70, 249 
Frazicr, Brent 120, 230 Frederickson, Luke 250 Firecman. Christopher 69, 87, 230 ficcman. 78

I:recman. Thomas $20 \mid$ Fireesc. Kathy 167 Firecz. Michacl 250 French, Adam 215 Frey, Dr. Darrin 172 Frey. Rachel 11\%, 250 Frey. Sieven 129. 215 Friend, Krista 215 Fries, Trisian 116, 129.21 Fricsen, Melissa 230 Frohmberk, Sarah 128,230 Frowner, Crystal 250 Frye, lihan 36 Fulislinge, 13ert 179 Fulor. Neyso 215 Futlcr. Ncysa 215 Funtik. Lynne 170,171 Furlei, Limily 82.201 Finrlong, Aubrey 88,215 G

(atmes, Slephen R, 2SI (ial bre, th. Jocilen 230) (ialchousc, Andrea 84 (iallagher, Dr. Dave 172 Gallagher Junathon 216 (iallagher. Kathy 180 (iallater, Kathy (iallaugher, $\wedge$ shlec Gallaugher. Astice 73, 210 Giallo. Lauric $\Lambda .25$ Gangi. I.cvi 25I Ganong, Jefl 25!
(ianong. Rachel 94, 201 (iapinski, Rebecca 116, 251, 278 (iardner, William 236) (iarrell, Andrew 216 Gurrett, Mathew 69, 120, 251. 281 (issiurowski, Jesiic 39 (iast, Jowh 48

(iathany, Paul 183

(iaycr, Enuly 91. 1 17. 118. 230

239, 287

(iaymier, Anne 69), 2(11

(iaynicr. Sarah 73, 74, 251

(ibur. Meredith 25

(iebert, Anna 216

(iedncy, David 116,251

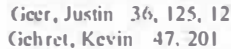

(ichring, Allen 117.230

(iesisel. Kirsten $\quad 68,216$

(iciser. Tracy 73. 201

(icissler limilic 194, 216

Genesi, Dunnil 216

(iensel. Andrea 88, 118,251

(ientry, Angels 92. 201

(icorge, Ndam 201

(ieppeli, Josh 68,231

(icrber. Dann 251

(ierber. Jennifer 43, 251

Gerler. Justin 40, 56. 2

Gerher, Kyle 125, 2.30

(iheen. Tami 51.20

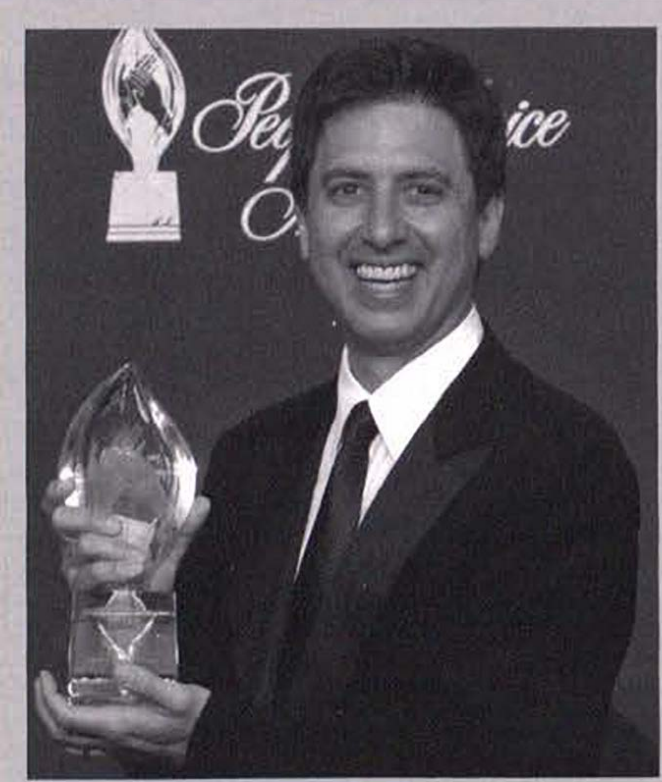

Actor Ray Romano holds his award for favorite male television performer du ring the 28th annual People's Choice Awards show in Pasadena, Calif., Sunday, Jan. 13, 2002. Romano shared the award with Kelscy Grammer of "Frasicr."

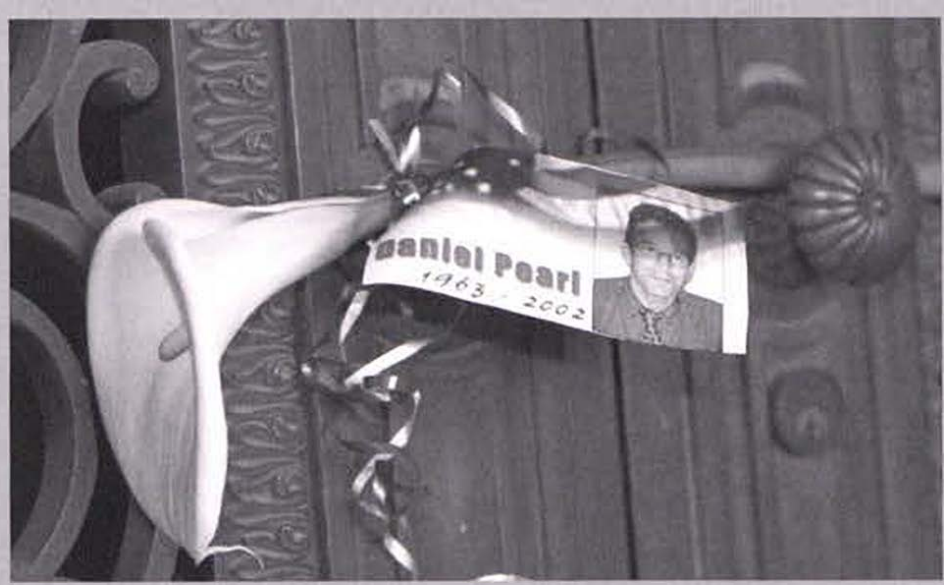

A flower and a photo of slain American journalist Daniel Pearl is placed at the front door of Stanford University Memorial Chapel during a memorial scrivce for Pearl on the Stanford, Calif., campus, Monday, Feb. 25, 2002. Pearl was a student at Stanford in the mid-1980s. President Bush said the United States is "interested in dealing with" the Islamic extremisc implicated in the slaying of Pearl, hut expressed confidence Monday that Pakistan is doing enough to round up Pearl's killers.
Hilywnod, Rehekah 253 Ileadlec. Jasen 117, 231 Hecker, Amanda 124 Hefficld. Rachel 253 Hefficer. Marcic 216 Hegna, De. Harwoxd 173 llciden JC. 120,216 Ileidenreich. Jenifer $\wedge$, 25 Ileinz, Luke 216 Hclmick, Dr, Larry 17.3 Hel nick, Janinc 202 llendricks. L.eah 119.23 llenker, Adam 69. 253 Hennig. Chrisonpher 231 Ifenning. Dr. Nelson 124. 169 llenming. Erika 217 Henry. Eustin 116

I Iensley. Jennifer 93, 217 Henworkl, Cory 116

llerald, Tyson 125, 188, 217, 225 llerd. Amanda 118. 122.23 lierdzak, Karla 202

Herman, Christy $\$ 4,123,125,23$ llermann. Travis 119. 125, 23 Ilerniz. ISannah 202 Ilerreld, Ben 60 Herring. Matthew 231 llerring, Rachel 85, 203 Herter Meredith 92.203 Heslop. Manj 203 Ilewni. Cirol-13eth 76 Ilewitl, Tun 178 Hazcn. Marinus Tox Hedger. Nathan 69.2 Heimann. Carric 119.23 Ilemsen. A. Jesse 231 Heldreth. Sicphanic 216 Ilerman, L.isa 11, 123. 202

Tlokur. Bronson 128, 254, 27.4 Ifoll:tind, Jason 117. 120, 254 Holtand, Mclissa 44 Jlollinger. David 254 Hollingshend, Stephume 50.217 Ilollins. Amy 203

Hollow,1y, Karen 118, 25.4

Ileolm. Carri 232, 233

Ilol mes, Jason 86

Iol Michod 105

Ilolmamann, l.aura K. 25 Tlom zrnann. Trm Kim llooher, Aaron 232. 233 llood. Jonashan \$6, 217 llood wink. Diavid 126 Hook, I)anai 86, 123, 217 llooser, Amanda Vian 210 llop. Sieven 203

llopkins, Fileen 75, 82,217

Hlopkins. Kurt 52

Hopkins. Suphanic 217

Hornhack. Jesse 116, 122, 232.

Horion, Biyan 82, 217 Hoskims. Nocl 203 Therer, Christen 126, 254 $\begin{array}{ll}\text { Houk. Joshuta } & 116 \\ \text { llourani, Lara } 232,233\end{array}$ $\begin{array}{ll}\text { llourani. Lara } & 232,233 \\ \text { lloward, Jason } & 18,19.120 .217\end{array}$ lloward. Mclinda 170 Howder. Scott 176 Howdyshell, Miciah 179 Hlowe, Julianne 112, 127, 203 Howe. Karı 117.217 Howell, Andrea 85. 217. 287 Howland. Melissa 82, 203 lluber. David 232.233 lluck, Scoll 183

Iludson, Jeremy 26, 89, 25 Hamisten Krist 252 Hamention, Rachel 202.23 Itamilion, Timothy (irohan. David 12 Graham, Janniu 231 (iraham, Sarah 251 (irntion, Jennifer 118, 125, 252 Giray. Jack 123. 216 (iray, Jason 40, 252 (irctborer. Anthony l:, 252 Gireco. Mclissa 231 Gireen. Cournney 54, 5s Green, Harold 182 (ireen, Karen 125, 202 (ireen, Margaret 182 Green, Mall 36, 37, 202, 277 Girecn, Raymond (19), 127, 151, 252 (ireenc, Andrew 202 (ireene. Sirath 73, 74, 252 Greening. Andren 125. 23 Greenwood, Jan 183 Greenwood, Paige 216 (ircer. Dr. Clistk I6S (ireer. Georgia 180 (irectham, Forest 52.216 Gregory. Amy 62.252

(ircgury. Richard 23

(irifith, Amy 252

(irigorenko, Andrea 43,59, 231

Grimm. Chris 52.53

Grimm. Shannon 75.121.124, 252

(irimme, Sarah $11 \times .231$

(irimme, William 202

(irisco, Nicholas 89. 252 (iroff. Timmothy $86,117,120,231$ (iros. Mavid 252

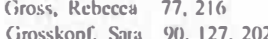
(irossman. Carla 252 (inossman, Miriam 123, 125, 216 (iroth. John $11 \%, 252$

(irove, Megan 231

(iroves, Shawn 140

(iruber, 1), Sleve 16

(iruber, Sara 216

(iuce, Marigrace 122, 216

(iuenin, Roy 12

(imilcr, (ircg 48

(iuntry. Angic 90

(iuphil, Aamic 121, 252

(iuy, Amanda 76, 216

Gwist, kilizabeth 79, 202 (jyurik, Alexandrin 216

\section{H}

IIvas, I3cnjamin 70, 121, 123, 202

|lacker, 13eth 125

Ilacker, lilizabeth 216

Hagnc, Joseph 12

Maguc, Calcb 121
Haguc. Mary Fseth 126

Ilahtko. Cialcb 129

I laim, Kimberly 252

Hakc, Jennifer 202

Tisulc, Jennifer 216

Hall, Jos 71

Ilalladay. I3enjanún 202

Italleland, Rachel 231

Inalsmith, Debra J 176

|lalsmulh, Jcssica D 252

Ilalsmilh, Mr. Morlcy 11
121. 202

Ilamilton. Trenton

19. 69.118 .129 .252 .

284

Hamlin, Lizabcth

Hammond, Bonnic $90,127.216$

Ham mond, Doug 202

llamrick, Erin

26. 127, 202

253. 285

Ilancock, David 87

Uandlev. Aaron 82.

Handley. Justin 210

lankinson, Danicl J.

253

122, 202

llansell. Margucrite

Hansell. Titnothy 168

Mansen, Lisa 92, 202

Jansen. Shelley 86

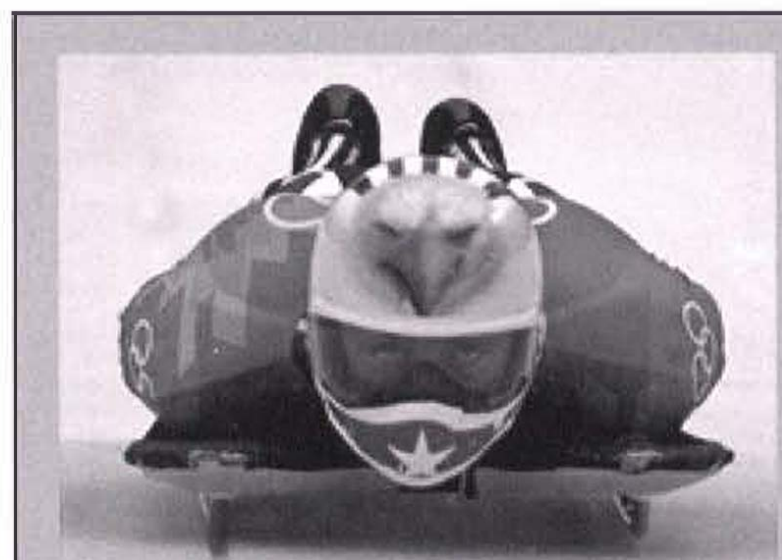

Jim Shea of the United States starts his first run during the men's skeleton final at the 2002 Salt Lake City Winter Olynupics in Park City, Utah, Wednesday, Feb. 20, 2002.
Ilanson, Nieole 210

larbaugh, Mcgann 59, 6\%, 125, Ilickcy, Lucinda 217

202

Ilarbison. Kimberly 7.4. 253

Haring, Kristi 84, 202

Marlan. Amy 202

Harner. Sandra 165

Harrcld, Benjaun in 231

Marris. Diana

Harris, Joel 216

Hamison. Kally 216

Uarrison, Marilyn 231

larshbarger. Amy 210

Itar, Ben 202

Hart, Marrece 84, 202

Hart, Rebeceal 122, 23,

Hartman, Carric 44, 45, 62, 216

Hartuman, Elizabeth 202

Ilartscll, Brian 71.231

Harvel, Jason $253,00,129,202$

Hasity, Dan 120.231

Hatton. Christopher J. 253

llaug. Mary licth 77

Houg, Mary E, 253

Hause Mcean 87, 128, 129, 253

Hausivald, Ross 202

Iavelue Victorin 119.231

Hawkius, is is

Hawkins, Jaime '92

llay, Nitl hain 81, 21 
Ireland, Chad 255 Irish, Cheryl 169 Irving, Mark 18 Irving, Meredith Isbell, Amber 232, 233 Ishikawa, Motoi 86, 122, 25 Issakainen, Kelly 117

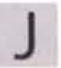

ackson, Chad 99, 203 ackson. Katic 232, 233 acobowitz, Jessica 116, 255 cobs, Jack

cobsen, Tiffany 217 eger, Laura 232, 233, 287 85,122

lanssen, Rachel 203 arvis, Andrew 70, 255 Jaskilka, Mark 125, 232, 23 Jelsma, Elizabeth 73, 203 Ienista, Dr. Frank 169 Jenkins, Andrew 85,203 Jenkins, Chester 274 Jenkins, Heather 117 Jenks, Dani 232, 233 Jenks, Jessica 232, 233 Jenks, William 129, 255 Jensen, Jared 116 Jensen, Rebecea 70, 255 Jeremiah, Dr. David 106, 107 Jewell, Nicole 203 Jingst, Eric 203

Jodry, Kara 203

Jodry, Rachel 80, 217

John, Jesse St. 223

Johnessee, Bethany 59,203

Johns, Nathan 217

Johnson, Andrea 70,203

Johnson, Andrew 124

Jonson, Ariclic 203

132, 233

Johnson, Bethany 203

Johnson, Bethany 203

Johnson, Chad 232, 233

Jehmson, Clifford 176

Johnson, Derek 203

hnson, Dr. Pamela 167

ohnson. Erica 82, 99, 217

Johnson, Jessica 232,233

Johnson, Joshua 91, 232, 23

Johnson, Kaley 78, 128

Johnson, Lindsey $91,98,25$

Johnson, Matthew 232, 233

Johnson, Rachel 74, 203

Johnson, Rebecea 203,217

Johnson, Timothy 180

Johnson, Whitney 129,232, 233

Jolly. Amanda 203

Jolly, Laura 70, 126, 232, 233

Jones, Chris 40

Jones, Jeremy 47

Jones, Keliann 217

Jones, Kristin 72,92,

Jones, Leanne 217

Jones, Lindsay 119,217

Jones, Melissa 203

Jones, William 173

Jonker, Kristina $123,129,255,271$

Joseph, Daniel 217

Joseph, Snema 122

Joubert, Melissa 78, 121, 203

K

Kaercher. Murtha 175

Kaminsky, Timothy 203

Kane, Becea 73

Kane, Jonathan 232, 23,

Kanc, Rebeccal 217

Kaufman, Mauthew 44,217

Kee, Dorothy 119, 232, 233

Kee, Dorothy $119,232,23$

Keilman, Bethany $70,119,255$

Keim, Elisabeth 74, 203

Keith, Steve 217
Keithley, Ginger 55, 217

Keithley, Ginger 55 ,

Keller, Jennifer 218

Keller, Kassondra 20

Kelley, Sean 232,233

Kelly, Esther 255, 283, 285, 286

Kelly, Jamic 204

Kemmerer, Justin 204

Kempe, Jonathan 94,218

Kempton, Ruth 13

Kennard. Amy 85, 90, 204

Kennedy, Daniel 83,218

Kenny, Steven 255

Kepner, Katie B. 255

Kerber, Korie 218

Jacqueline 255

Kerns, Annie 8

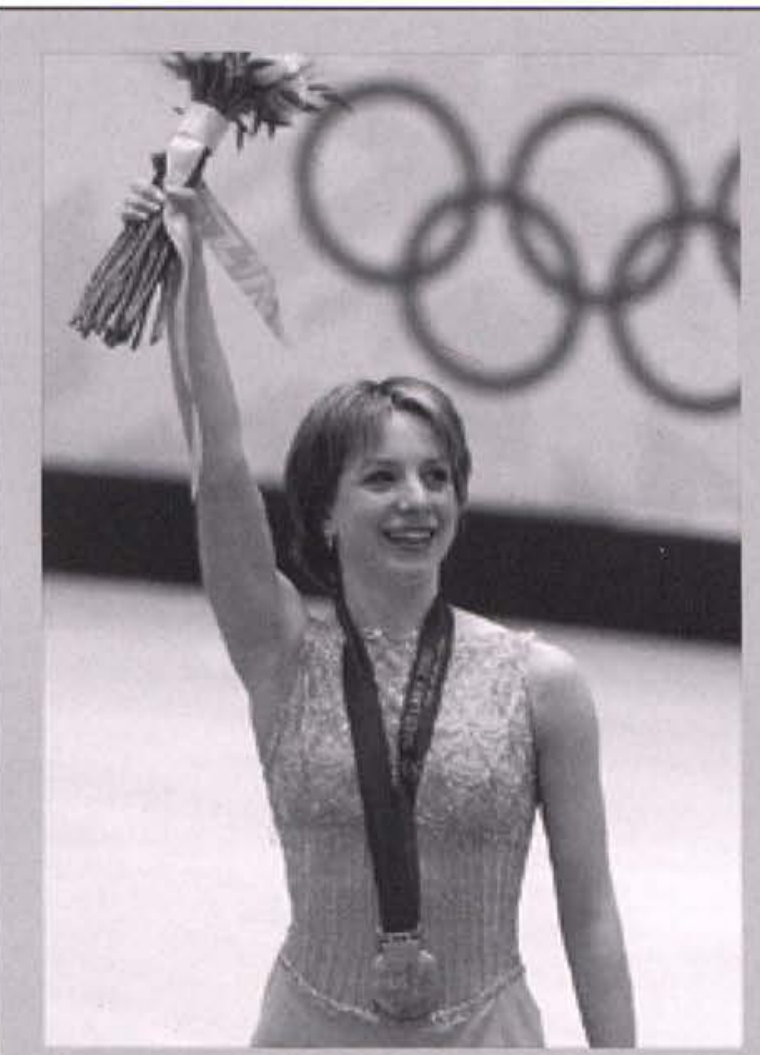

Sarah Hughes of the United States waves to the crowd with her gold medal, after women's skating competiton at the Winter Olympics in Salt Lake City, Thursday, Feb. 21, 2002.

Kems, Naomi 232, 233

Keslar II, Kenneth 218

Kessler, Brooke 255

Keyser, Shannon $76,90,218$

Keyser, Shelby 70, 76, 204

Kibelbek, Jonas 81,218

Kibelbek, Nathan $73,81,232,233$

Kickbusch, Kevin 82, 232, 233

King. Adam 137, 204

King. Nicolete 124, 125, 255

King, Sara 218

King, Stephanic 204

Kinley, Bethany 78

Kinnell. Erin 218
Kinney, Rich 119

Kinniburgh, Scott 60,218

Kinsinger, Jay 173

Kipp, Hannah 129

Kirby. Andrew 85, 204

Kirby, Charles 138

Kirby, Jonathan

Kirby, Mark 89
Kirby, Philip 85,204

Kirby, Philip 85,

Kishpaugh, Janet 98,218

Klein, Andrew $56,90,204$

Klein, Doug 218

Kleis, Noella 175

Klimek, Jennifer 121, 204

Knabic, Joseph 94, 116

Knauff, Gienn 181

Knauff, Nancy 175

Knaus, Melissa 91, 255

Knickerbocker, Lynsa 255

Knoedler, Dustin 218

Knorr, Josh $46,47,218$

Knouse, Brian 256

Knowles, Erin 124, 256

Koch, Melissa 85

Kocher. Tammy 176

Kocher, Todd 118, 120

Kochis, Katharine 218

Koerbel, Kristie 18

Kolawole, Kikelomo 74, 77, 86

Konop, Heather 218

Konopasck, Daniel 100, 116, 123

125, 239

Koons, Megan 113, 204

Kooy, Juliann 70

Kopp, Timothy J. 256

Kordic, Paula 182

Kormash, Bradley J. 48,256

Koury, Andrew 218

Koverman, Jared 256

Koziol, Michelle 79, 204

Kragel, David 48, 125

Kraker, Jeff 204

Kramer, Eric 87, 204

Kreider, Aaron 98, 218

Landenberger. Erica

Lapp, Kristen 90, 218

Lasso, Melissa A. 256

Lawlor, Sarah 256

Leitch, Natalic 125,218
Letor, Jonathan 117
Leukhardt, William 256 Leverson, Kevin 287 256,287

Levesque, Andy 36, 125 Lewellyn, Jennifer 204 Lewis, Clive Staples 90 Lewis, Jutia 94,204 Lewis, Stephanic 122 204

Leykam, Joseph 204 Leykam, Nate 47

Lietzow, Reb
125,257

Lilley, Monica 86,128

Linafelter, Erica 120 Linafelter, Karisa 17

Linamen, Amie 218
Lindeman, Vanessa

257

Linderman, Justin 204

Link, Andrea 218

Little, Shannon 72,218

Littrell, Alison 47, 71 .

218

Livingston, Hannah 72 ,

$90,127,257$

Livingston, Katherine

257

Livingston, Laura 116

Loach, Dr. Barbara 165

LoDico, Stephanie 204

Loescher, Ken 40

Loftis, Nathan 116, 219

Long, Jordan 90, 219

Lookabaugh, Katic 219

Lopez, Dr. Michael 165

Lorence, Jared 125

, Sarah 204

Louden, Gregory 219

257

Loughran, Cheri 204

Kreuder-Crowell, Stephanic

Krick, Debra 55, 256

Krizo, Allison 78, 128

Krizo, Matthew 204

Krupka, Joshus 82, 204

Kubinec. Noelle $123,129,218$

Kuhn, Holly $116,256,278,280$

Kurczy, Kristi-Lynn 94, 120

Kurzen, Melanie 119, 121, 218

Kurzen, Ryan 256

iul 204

rin 70,121

Kwast, Jeremiah 218

Kyle, Becky

Laborde, Paul 83, 116, 218

Lamb, Jared 79,121

Lambers, Sara 218

Lambert, Kelly 256

Landau, Julic 81,120

Landau, Tiffany 70

Lane, Amber 204

Lansford, Joel $93,116,124,126$

Lanz, Richard 204

Lao, Shauna 218

Laramore, Robert 173

Larrabee, Rachel 218

Larsen, Eric A. 256

Larson, Kirsten 88, 218

Larson, Reverend Knute

Laskos, Adam 56, 204

Lauritzen. Lisa 91, 256
Law, Jeremy 122

Lawler, William 218

Lawrence, Chuck 218

Lawson, Susan 256

Lawson, Tasha 218

Lawton, Veronica 90, 256

Leach, Erin 204

Leach, Thomas 84,12

Leasure, Tim 204

Leblanc, Jeanie 18

Leblanc, John 169

Lee, Brandon 48

Leightenheimer, Jesse 120,218

Leightenheimer. Tom 181

Leingang. Melissa M. 256

Lemmel, Elizabeth 129, 204

Lengefeld, Stephanic 74, 218

Lepp, Karie A. 256

Leslie, Jeffrey 128

Lester. Kristy 179

Mandigo, Kristy $89,118,127,234$

Mank, Byan $52,53,258$

Mansfield, Katie R. 258

Mansfield, Kenneth 118, 258

Manwiller, Rebekah 75, 118, 234

Mao, Jessica 87, 127, 234

Mapes, Alison 85,258

Mappes, Dr. David 165

Marely, Rachel 90

Marin, Julia 121

Mark, Josh 40,56,57

Markas, Sarah 205

Marks, Lindsay 219

Marler, Ëric 99

Marley, Rachel 120, 205

Marquardt, Joelle $90,92,219$

Marsh, Alicia $79,93,128,258$

Marsh. Michael 56, 57, 258

Marsh, Nathaniel 234

Marshall, Carol 179

Marshall, Dave 117, M

Marshall, Joseph 82,219

Marshall, Julic $80,129,219$

Marshall, Matthew $36.74,84,258$

Martin. Amy 44,51, 258

Martin, Holly $117,127,219$

Martin, Jared 121,219

Martin, Julia 205

Martin, Kate 205

Martin, Kelly 205

Martin, Kirk 51, 167

Martin, Lisa $44,55,177$

Martin. Neil 117, 21 
Meyer, Brent 127

Meyer, Cheryl 44, 45, 126, 259

Meyer, Katherine 24, 205

Meyer, Melissa 259

Michael, Benjamin 119,234

Michael, Kathryn 121, 219

Michaels, Laura 205

Michonski. Matthew 60, 219

Mickey, Joseph 76, 259

Mied, Anna 69, 205

Mied, Rebecca 92, 118, 129, 259

Miedema, David 205

Mikel, Tammy 70,259

Milby, Paul 69,205

Milich, Jason 71

Miller, Adam 220

Miller, Brent 122, 220

Miller, Cristina 234

Miller, Dr. Chris 164

Miller, Dr. Douglas 173

Miller, Emily 234

Miller, Erin 121. 234

Miller, James 83, 234, 281

Miller, Jason 81

Miller, Jenna 92, 234

Miller, Jonathan 205

Miller, Julic 83,220

Miller, Kate 83, 205

Miller, Kyle 119

Miller, Lisa 94, 234

Miller, Matthew 259

Miller, Melissa 82,205

Miller, Nicholas 234

Miller, Pam 177

Miller, Paul 234

Miller, Philip 220

Miller, Rebekah 220

Miller, Rochelle M. 259

Millet. Rebekah 58, 250

Mills, Catherine 93, 205

Mills, Rebecca 220

Miloch, Amy 85

Minahan, Michael 116, 234

Mings, Carole 220

Miner, Chris 56,220

Mister, Cris 56, 220

Mistak, Jillian 23, 126, 23.

Mistak, Stan 90, 220

Mitchell, Ben 77, 234

Mitchell, Diane 181

Mitchell, Eric 119,259

Mitchell, Jeffrey 90,205

Mitchell, Jenna 124,220

Mitchell, Rachel 126, 259

Mizer, Jonathan $120,127,259$

Moberg, Shawnna 121, 234

Mocas, Gillian 205

Modica, Andrea 23.3

Mohler, Hoily 234

Mohler, Rachael 92, 125, 259. 285

Mohr, Jena L. 259

Mohr, Jonathan 92, 220

Molby, Matt 205

Monroe, Sam 220

$\begin{array}{ll}\text { Montague, Brian } & 82,220 \\ \text { Montanye, Daniel } 259\end{array}$

Moon, Michael 260

Mooney, Sharon 205

Moore, David 220

Moore, Kenneth 128, 260

Moore, Matt 165

Moore, Michelle 260

Moore, Sarah 234

Moore, Tammy 78

Mopkins, Eileen 12

Moran, Donald 13

Moreland, Kurt 126

Moreno, Ruby 18

Moreno-Riano, Gerson 124

Morrell, Mandy 220

Morris, Kevin 220

Morris, Kimberly D. 260

Morris, Leah 220

Morris, Marie 205

Morris, Phyllis 181

Morton, Emily 206

Moseley, Stephen 72,128,
Moses, Brandon 123,220

Moses, Brandon 123,220
Mossop, Michael 206

Mossop, Michael 206

Mowrer, Karen $\quad 80,125,220$

Mowrey, Kathryn $70,74,220$

Moyer, Rachel 72, 90, 125, 220

Mrowca, Tracy 220

Muka, Jennifer 220

Mundy, Chip 70

Munson, Tara 54, 55, 206

Muoio, Janelle 124

Murphy, J. Dale 13

Murphy, Sara 234

Murray, Davina $72,76,235$

Murray, John 90,220

Murray, Kendalt 235

Musselman, Lavern 181

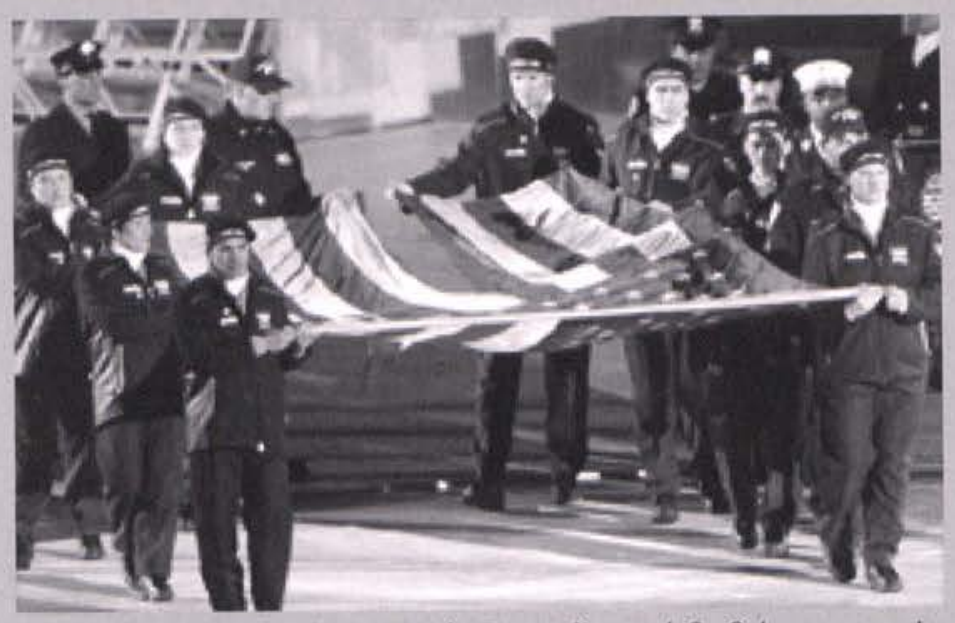

Eight U.S. athletes and New York City police and firefighters carry the tattered American Flag from the World Trade Center into the stadium during the opening ceremonies of the 2002 Winter Olympics in Salt Lake City Friday, Feb. 8, 2002.

Myers, Jennifer 17

Myers, John 52

Myers, K.C. 220

Myers, Matthew 74, 220

Myers, Sigrid 84, 88, 206

Myers, Te

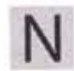

Naik, Sam

Nale, Amanda 220

Napekoski, Karl 220

Nealis, Matthew 260

Neer, Kelly S. 260

Neff. Kasey 206

Neff. Marianna 71, 206

Nehus, Erin 43, 58, 59, 235

Nelson, Amanda 82,206

Nelson, Andrea 70,206

Nelson, Ashli 90, 206

Nelson, Betsy 260

Nelson, Betsy 260

Nelson, Drew 40, 56

Nelson, Jennifer 260
Nelson, Jonathan $75,123,260$

Nelson, Katherine 86, 235

Nelson, Matthew 90, 235

Nelson, Mike 206

Nelson, Russell 235

Nesbitt, Benjamin $79,124,260$

Nester, Brian 183

Nester, Tim 108, 206

Neu, Nicole 179

Neufeld, Melissa 235

Neuhart, Heidi 92, 206

Neuroth, Rob 122,260

Nevitt, Rebekah 235

Newfield, Natalie 88, 127, 235

Newhard, Christine $81,90,220$

Newman, Kristin 119, 260

Newsome, Ryan 125, 260

Nicholl, Andrew 206

Nicholl, Natalie 123, 235

Nichols. Heather $92,129,206$

Nickell, Dave 74, 119, 220

Nickerson, David 85, 128

Nickerson, Lloyd 235,260

Nickum, Benjamin 206

Nicol, Brad 260

Nielsen, Eric 93, 220

Nielson, Leah 77, 116, 124, 220

Nikerie, Jennifer 59

Nikitin, Kimberly 91,220

Nims, Charis 86, 128, 260

Nissley, Josh 220

Nofziger. Christina 69, 220

Noonan, Patrick 82,220

Norman, Anne 260

Norman, Bebo 22, 147

Norris, Daren 87, 261

Norris, Edward 206

Norris, Ted 79

Northcutt, Ruthina 80, 206

Northeimer, Josh 206

Nourse, Jolene 206

Nuttall, Melissa A. 26

Nutter, Shelly 177

Nyhuis, Karin 39,220

Nyquist, Paul 187

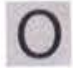

O'Brien, Kathryn 121, 127, 235

O'Brien, Rob 122

O'Connell, Courtney 90, 206

O'Connell, Karin 121, 235

$\mathrm{O}^{\prime}$ Connell, Kelly 93

O'Hara, Stephanie 77, 220

O'Neal, J.D. 88,206
O'Neal, Joseph 261
Oatman, Gwendolyn $\quad 81,206$

Oberbeck, Sheli 261, 287

Oberdove, Christina 235

Oeffinger, Amanda $L$. 235

Ogden, Natalie 206

Ohlinger, Justin 82, 129, 235

Ohman, Kristin 87, 206

Oleszczuk, Sarah 44, 235

Olin, Jeff 118,261

Olin, Julie 181

Olin, Nate 120,261

Olsen, Amanda 122, 126, 235

Olson, Lars 235

Olson, Steven 129,261

Orady, Kellee II

Orchard Paul 56,59,167

Oren, Jonathan $52,73,220$

Ormsbec, Mr. David is

Osborn, Heather 74

Osenni, Laureann 82, 206

Osterman, Aaron 235

Osterman, Rachel 206

Osypian, Tom 26

Otto, Angela M. 72, 26

Overholt, Jodie 76,206

Overturf, Roger 183

Owen, Michael J. 26

Owens, Jeremy 206

Ozinga, Matthew 92, 26।

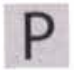

Packard, Morgan 206

Page, Jeremy 235

Page, Steven M. 261

Palmer, Stephen 22, 36, 125, 235

Papke, Christina $72,128,206$

Parker, Justin 221

Parker, Sarah 82,22

Parker, Steve 261

Parobek, Julia 73, 221

Parr, Dr. Robert 169

Parr, Michael 206

Parrish, Michelle 90, 125, 235

Partch, Aimee 206

Pascute, Craig 206

Patibandla, Sneha 221

Patrick, Michelle 51

Patten, Randy 13

Patterson, Rory 171

Patton, Jeremy 235

Patton, Sarah 22

R. 56, 261

Paulick, Joshua 70, 122, 235

Paulsen, Donna 125, 235

Payne, Cherith $83,116,206$

Pearce, Grace Ann 72, 206

Peck, Jenny 221

Pedersen, Lisa 117, 127, 26

Peeler, Matthew P. 261

Pellowe, Todd 91, 158, 261

Pemberton, Rebekah 235, 287

Penning, Desiree De 86

Pennington, Nathan E. 261

Pepe, John 262

Perez, Debbie 235

Perine, Kathryn 68, 206

Perrine, Luke D. 123, 262

Perry, Alyson 128

Perry, Krisin 206

Persons, Chancy 70, 91, 235
Peschell, Eric 116, 262 Peters, Keith 124, 127, 235

Peterson, Caron 221

Peterson, Matthew 121, 221

Petite, William 86, 12.3

Pez, Amanda 206

Pfeister, Emily 73, 221

Pheasant, Jeremy 235

Philip, Jyoti $24,87,235$

Phillips, Annie 121, 22

Phillips, Eric 235, 278

Phillips, J. Christopher 26?

Phipps, Dr. James 164

Phipps, Dr. Terry 173

Pichea, Jason 207

Pierce, Jessup 235

Pierce, Kristin 122, 235

Pierpont, Russell 82,235

Pierre, Alisa 124,221

Pilgrim, Amanda 177

Pinkerton, Melissa 90, 207

Pinney, Jill 262

Pitman, Robyn 77.262

Pitts, Anthony 48

Plaatje, Dan 40

Plate, Emily 81,22

Platt, Kevin 221

Pummel, Kelly 235

Push, Jon $56,59,177$

Poelzer, Michael $64,65,262$

Pollard, Laura 117,221

Pooh, Jeremy B. 128

Porter, Amanda 39,262

Porter, Corinne 72, 207

Porter, Kimber 69, 125, 207

Porter, Matt 207

Powalski, Kathryn 235

Powell, Matthew L. 262 


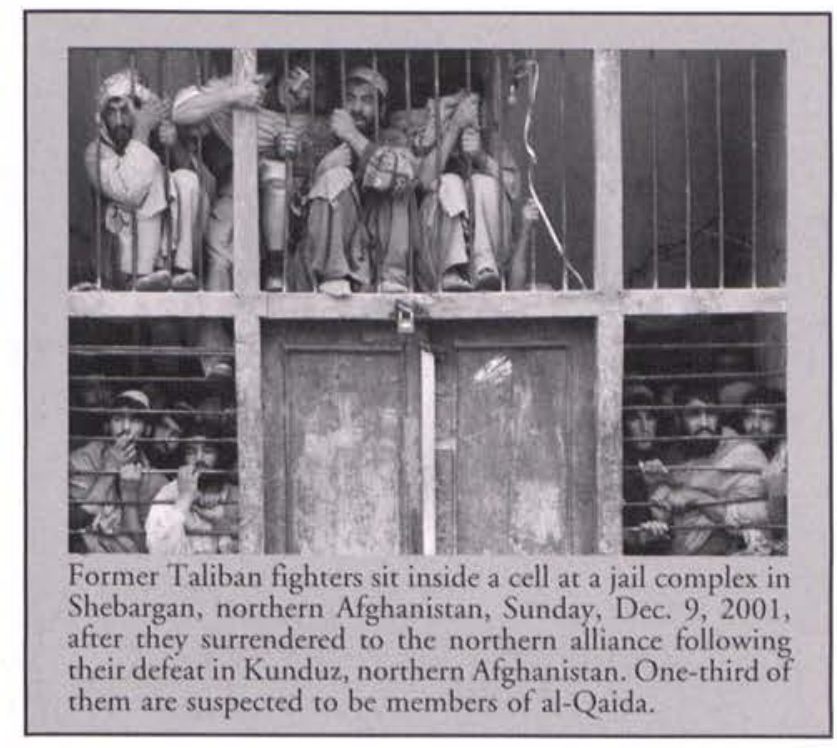

Ruegg, Adrienne 75, 85, 207

Ruff, Ryan 83,236
Ruffin, Courtncy 51,207

Ruhlman, Michelle $39,81,263$.

275

Rulapaugh, Katic 43, 59, 236

Russell, Kate 236

Russell, Micah 120,236

Ruth, Kent 56.236

Rutrough, Leigh Ann 207

Ryan, Christopher 208

\section{S}

Saab, Rachel 129

Sabine, Nichole 84,222

Sagraves, Erin 208

Salmon, Amy 90, 124, 222

Salmons, Joshua 100

Salmons, Pamela 74, 208

Salyers, Courtney 263

Sampson, David 222

Sampson, Robert 263

Sanborn, Abigail 87,236

Sanborn, Joshua 208

Sanders, Sarah 74, 119, 222

Sanderson, Greg 264

Sandlund, Stephen 84,208

Sando, Kristin 19, 188, 222, 225

Sandrof, Jason 208

SanGregory, Dr. Sam

Sartori, Rebekah 208

Sarver, Jessica 222

attertwaite, Stephen 73,208

Sattler, Aaron 128, 287

Saturley, Benjamin

Saul, Francis W. 264

Savage, Kurt 36, 264

Scadding, John 237

Scadding, Leslie 93,264

Schaeffer, Carric 121, 208

Schafer, Grayden 74, 125, 264

Schaffer, Kimberly 264

Schanely, Adelle $81,123,222$

Schamberg, Lorne

Schauer, Katherine 43,59, 208

Scheerschmidt, Melanie 183

Schetter, Dan 5

Schiavo, Dana 89, 264

Schierloh, Timothy 87,237

Schildroth, Brian 92, 99, 193, 237.

239

Schlappi, Nick 120,264

Schlicher, Jesse 208

Schmidt, Andrew 125, 137, 264

Schmidt, Jessica R. 264

Schmidt, Rebecca 90, 26

Schmoyer, Tiffany 208

schmuck, Megan 208

Schnake, Caleb 73, 264

Schneider, Joseph $83,86,116$,

$123,124,208$

Schnittger, Lydia 237

Schoen, Denise 208

Schoonover, Rebecca 237

Schriemer, Kate $72,118,264$

Schriemer, Kelly 78, 222

Schroeder, Eric 222

Schroeder, Lisa 119,237

Schroeder, Matthew 237

Schryer, Patricia J. 51, 264

Schuh, Rachel 237

Schultz, Nathan 94, 222

Schumacher, Brent 90, 118,222

Schumacher, Robert 173

Schut, Christina 119, 237

Schutter, Jon 77, 129, 208

Schutter, Kristi $77,129,264$

Schwab, Gregory 74, 208
Shev, Nathan 99 Shifflett, Krista 268 Shimer, Beth 94, 208 Shirk, Dan 181

Shont, Celia 90, 129

Shortt, Dr. Jeffrey 173

Shortt, Elizabeth 43

59,208

Shuff, Angela 119 ,

222
Shuman, Matthew 36.

Shupe, Cheryl 183

Shustack, Joy 78,265
Siddall, Allison 87,237

Siemer, Jason 89

Silvius, Dr. John 173

Simmons, Bethany $2: 37$

126,208

Simmons, Miranda 222

Simon, Tom 64

Simpson, Lisa 125,265

Sims, Dr. Kevin 169

Sims, Dr. Kevin 169
Sims, Elizabeth 208

Sims, Leanne 208

Sinzinger, Nicole 265

Sipes, Jordan 222

Sisco, Kevin 222

Skaggs, Sara $80,85,208$

Scon, Amber 121, 264

Scott, Brett W. 264

Scott, Dawn 175

Scott, Sarah 2222

Seace, Holly $69,75,122,208$

Seace, Kristina $81,90,127$

Seachrist, Beth 85, 237

Sears, Bethany $118,128,208,287$

Secor, Bethany 73,208

Seeloff, Erin 78, 222

$\begin{array}{ll}\text { Sellars, Krystal } 74 \\ \text { Sellers, Teresa } & 264\end{array}$

Sellers, Teresa 264
Selvey, Daniel 208

Selvey, Daniel 208

Semer, Haley 208

Sensency, LeeAnn 93, 237

Seo, Samuel 122, 208

Seymour, Christopher 237

Shackelford, Lauren 208

Shadle, Eric 222

Shamblin, Leslic 89, 208

Shank, Katic 237

Shank, Merilee 167,177

Sharp, Dr. David 173

Sharp, Dr. Kimberly 173

Sharp, Ryan 87,265

Sharp, Sarah 90, 129,
Sharp, Stephen 208

Sharp, Stephen 208

Shaver, Rachel 121. 125, 126, 222

Skelton. Jennifer 94, 125, 22

Skidmore, Jason 208

Skidmore, Matthew 116, 237

Skiles, O.J. 52,222

Skillings, David 208

Skurdal, Benjamin 128, 265

Slabaugh, Melanic 237

Slade, Rachel 222

Slagle, Amanda 73,222

Slagle, Jodi 98

Slagle, Matis 181

Slagle, Ray 48,167

Slone, Isaac 222

Slone, Tammy 177
Slotterback, Steve 208

Slusher, Mike 208

Smith, Andrew $122,124,126$

Smith, Andrew P. 127,265

Smith, Andrew W, 86, 22

Smith, Andy 76, 120

Smith, Ashley 51, 55

Smith, Benjamin 183

Smith, Bill 13

Smith, Carissa $79,89,119,237$

Smith, David W. 265

Smith, Dr. Galen 169

Smith, Erin 129,265

Smith, Jamie A. 265

Smith, Jason 129, 265

Smith, Jennifer $39,83,208$

Shaw, Rachel 72, 208

Shcolnik, Stacey 265

Sheldon, Kerri 222

Sheldon, Lisa 237

Sheldon, Tammi 119, 125, 265

Shellenbarger, Daniel 116, 222

Shellenbarger, Rachel 70,222

Shelton, Willy 98,265

Sheppard, John-Mark 76, 90, 123 208

Smith, Jeremy 265

Smith, Marisa 123,263

Smith, Matthew 74, 128, 237

smith, Matthew L. 68

Smith, Matthew P. 237

Smith, Meagan L. 265

Smith, Megan 82, 124

Smith, Michelle 122,222

Smith, Nathaniel 209

Sherwood, Jenni 208

Smith, Patrick 125

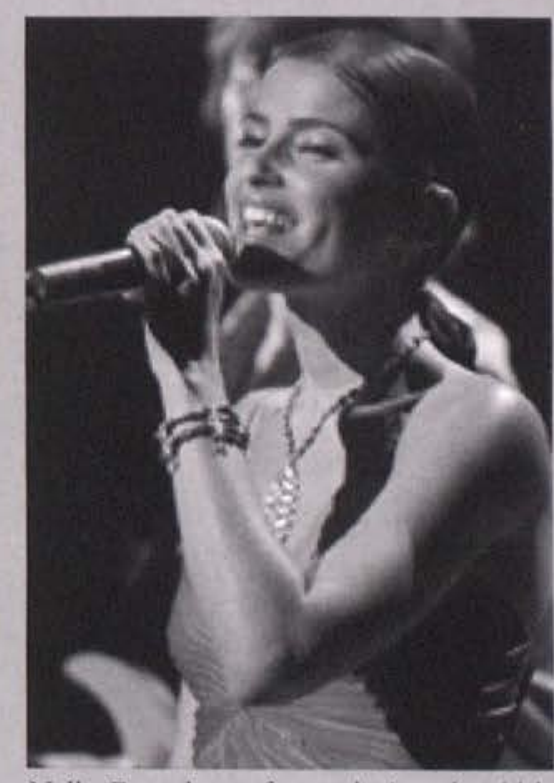

Nelly Furtado performs during the 44 th annual Grammy Awards, Wednesday, Feb. 27, 2002, in Los Angeles.

Smith, Shawna 78,223

Stephens, Debby 13

tephens, Jason 209

Stephens, Matt 125, 237

Smith, Suzanne 71.223

Smithmicr, Amanda 91, 223

Smyth, Megan 223

Snare, Sarah 265

Snavely, Stephen 265

Snedeker, Jessica 125, 237

Snell, Erik 121, 223, 287

Snyder, Aaron 223

Snyder, Ben 209

Snyder, Brian 266

Snyder, Jessica 1. 266

Snyder, Karen 77, 117, 126, 127

Snyder, Melissa 209

Snyder, Rob 266

Soloman, Naomi 121, 237

Somers, Wendy M. 266

Sorensen, Carrie $79,188,223$

Sorrell, John 266

Soules, Matt 237
Spain, Jessica 189

Stephens, William 237,

Stephenson, Wayne 40

Sterner, Matthew

Stevens, Jonathan 200

Stevens. Matthew 70, 209

Stevens, Seth 238

Stevenson, Laura 116, 124, 209

Stewar, Becky $87,122,238$

Stewar, Lauren 87, 223

Stickle, Ben 223

Stiemsher, Daniel 165

Stillings, Elisha 266

Stinings, Ensha 266

Stinson, Melissa 89,128
Stiteher, Peter 68

Stitzel, James 93, 266

Stokes, Chris 87

Stokes, Emily 85, 121, 209

Stoltenberg, Caria D. 266

Taylor, Julie 87,223

Taylor, Laura 223

Taylor, Markis 87,22

Taylor, Mary 209

Stephanic 223

Teboda, Kylee 51, 200

Tedford, Mark 85, 209

Tegge, Elizabeth $43,59,90,209$

Tehan, David 267

tenBrink. Amy 26?

Tencza, Jeremy 238

Terkelsen, Susan 169

Terrill, David $52,92,223$

letrick, Jennifer $42,43,124,238$

Teusink, Rebekah 267

Thengall Sarat 89,223

Themas, Beth 94,209

Themas, Brendan 223

Thomas, Jack 120.23

Thomas, Kelly 209

Thomas, Monica 79, 127, 238

Thomas, Paul 100

Thomas, Robert 13
Thompson, Christina

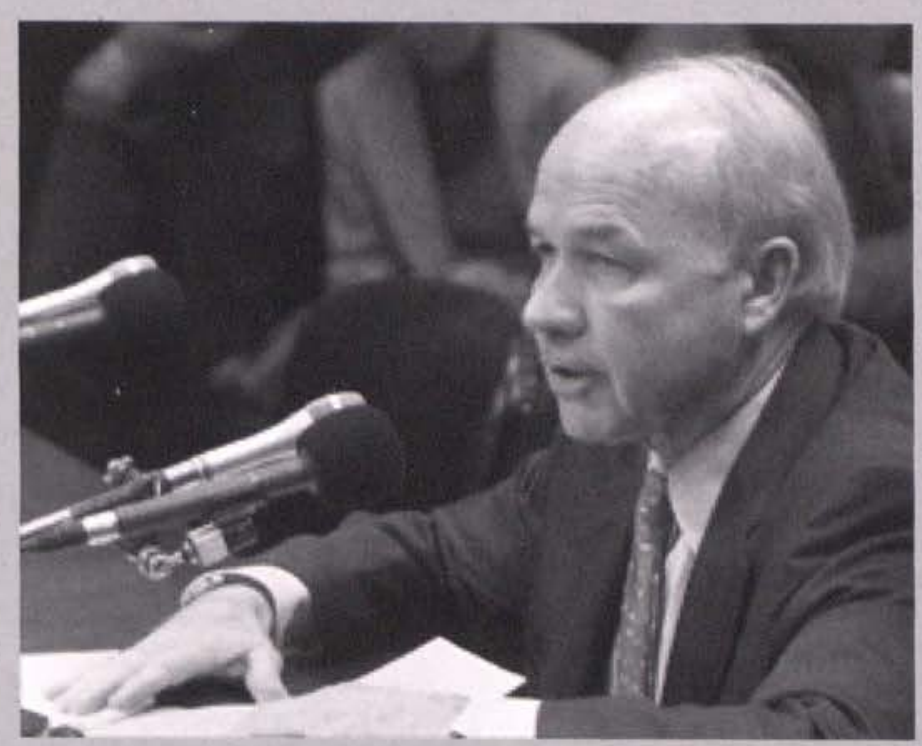

Former Enron CEO Kenneth Lay reads a brief statement before he asserted his Fifth Amendment right and refused to testify before Congress Tuesday, Feb. 12, 2002, in Washington.

Spanagel, Dan 87,237

Sparks, Bruce 13

Sparks, Katic 79, 209

Sparks, Mindi 79, 237

Sparks, Timothy 123

Sparling, Jennifer 72,75

Spears, Jessica 85,209

Spena, Matt 209

Spence, Amanda 223

Spence, Jeremy

Spencer, Charity 125,237

Spencer, Dr. Edward 165

Spencer, Nathanael 209

Spracklin, Sarah 46

Springirth. Pete $60,83,116,124$.

129,266

Sproul, Gretchen 74, 125, 209

Sproul, Heidi 98, 266

Spurlock, Kristen 122

Spurlock, Sarah 119, 223

Staab, Gaelyn 223

Staab, Rachel 92,209
Stafford, Abby 237

Stafford, Abby 237

Stafford, Andrew 237

Stafford, Annie 55,223

Stahl, Elizabeth 92,209

Stanford, Christa 55, 223

Stanton, Kortney 237

Stark, Heather 84,266

Stark, Kenna 77. 723.237

Stark, Kena 77, 123, 237

Statler, Aaron 266

Stauffer, Julie $50,51,223$

Stauffer, Melissa 80, 237

Stauffer, Tim 237 


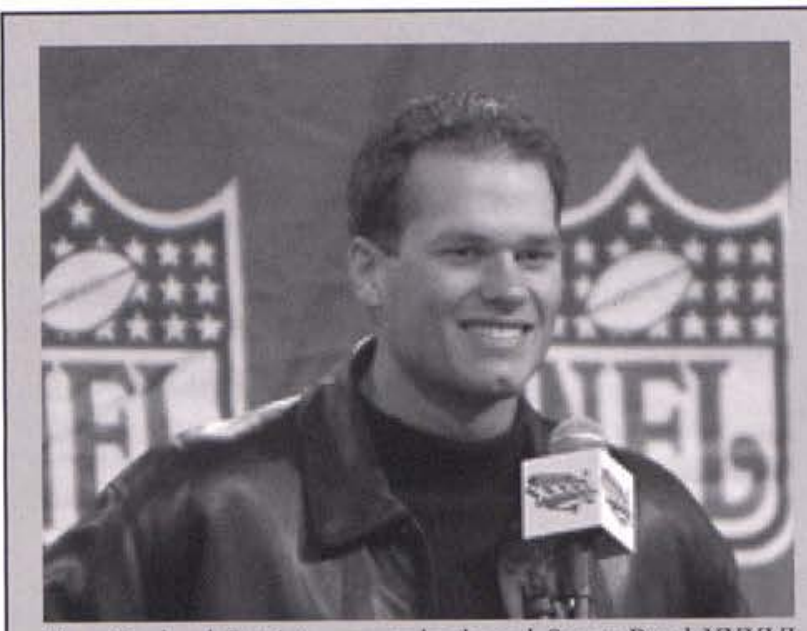

New England Patriots quarterback and Super Bowl XXXVI Most Valuable Player Tom Brady speaks to reporters Monday, Feb. 4, 2002, in New Orleans, one day after the Patriots upset the heavily favored St. Louis Rams 20-17.

\section{Tyson, Keith 238 \\ U \\ Uitti, Elizabeth 72,267 Ullestad, Maren 43,59 Uminn, Kristie 238 \\ Underkofler, Mark 81, 268 \\ Urban, Joshua 2 \\ V}

Valice, Benjamin 90

Valkenburg, Andy Van 224

Van Eerden, Melissa 268

Van Wingerden, Jolene 238

Van Wingerden, Valerie 210

Van Winkle, Julie 31,

Vance, Brian 36, 37

VanDeMark, Rebecca 268, 276

Vander Werf, Heidi 238

vanderAa, Heather 44,268

VanDerAa, Scott 52

VanDerAa, Stephen S. 268

VanderBush, Ed 86, 125

Vanderhoof, Stephanie 72,224

Vanderven, Lavinia $77,85,121$, 210

VanHart, Tiffany N, 268

VanHeukelum, Bradley 268

VanHeukelum, Melissa 268

VanKirk, Katie 268

Vanlier. Michael 268

VanLoo, Scott 118, 120, 175

VanLoon, Rebecca 183,268

Vantuyl, Stephanic 78

Vargo. Andrew 238

Vargo, Andrew 238

Varney, Mikala 224

Vaughn, Aaron 93

Vawser, Amber 224

Vencill, John 125

Verosky. Shauna 238

Viinalass, John $\quad 123,210$

Vine, Bill 51

Vitaliti, Ashley 126

Vitatoe, Nathan 60,224

Vlug, Benjamin $118,129,268$

Vogel, Daniel 210

Vogel, Rachel 268

Vogt, Renae 268

Vogt, Renace 268

Volpe, Laura 90, 125, 268

Voltz, Alissa J. 268

vonderMehden, Jessica 85,87 .

$119,120.238$

Voumard, Bradley 177

Vroman, Benjamin 238

Vruggink, Greg 77, 90

\section{W}

Wabeke, Trisha F, 268

Waggoner, Brittany 76, 238

Waggoner. Jessica 210

Wagner, Bryan 224

Wagner, Kent G 268

Wagner, Kem G. 268

Wagner, Kimberly 268

Wagner, Lynette 269

Wagner, Lynn 123

Wagner, Melissa 83, 90, 224

Wagner, Rebekah 78, 22

Wagner, Ruth 129,269

Wailes, Matthew 224

Wakefield, Steven 269

Walden, Bethany $69,126,269$

Walker, Dr. Ron 169

Weimer. Paul 129,239

Weiss, Adam 189,210

Whitaker, Kaylene 119,210
Wiles, Joseph 210

Wilhelm, Sandra 47 .

Walden, Nathan 224

Waldo, James 269

Waldo, Jonathan $36,37,224$

Waldron, Athan 36, 116, 210

Waldron, Karissa 39,238

Waligorski, Kristin 224

Walker, Dick 118

Walker, Dustin 238

Walker, Jennifer $39,126,269$

Walker, Michael 224

Walker, Wiltian 238

Wallace, Jessica $79,125,224$

$\begin{array}{ll}\text { Wallace, Jessica } & 79,125,224 \\ \text { Wallace, Joshua } 128,210\end{array}$

Wallace, Mark 269

Wallace, Rob 137, 224

Walsh, Ben $91,121,123,224$

Walters, Beth 124, 127, 138, 238

Walters, Steve 210

Walton, Ashley 81,210

Walton, Nicholas $78,118,238$

Waltz, Brandon 183

Wambold, John 183

Wanderi, Sam 122

Ward, Megan 210

Warder, joel D. 269

Warndahl, Kristina 74, 269

Warner, Bethany A. 269

Warner,Susan 169

Warten, David 13

Warten, Daylyn 123.210

Warren. Nathan 224

Warsavage, Charissa 226

Wasson, Tyler 210

Weakley, Jason 48, 49, 224

Weakly, Beth 269

Weaver, Carric 74, 210

Weaver, Cassic 224

Weaver, Cliziche 224

Weaver, Hiliabeth 224

Weaver, Jennifet 123,269

Webb, Jason 269

Webber. Christine 224

Weber, Erin 127, 269

Weber, George 39

Weber, Shaclah D. 269

Webster, Michael $72,90,210$

Wecter, Mark 129, 238

Weir, Nate 224

Weirich, Meliss 75

Weiss, Arat $82,93,224$

Weiss, Traci 82, 93, 224

Weist, Sarah 88, 210

Weldon. Staci 119,239

Wells, Rebecca 23

Welty, Aaron 210

Wendel, David 127

Wendl, Lisa 73, 91, 128, 210

Wendzel, Jason 119, 269

Wentzell, Kelly 239

Wenzel, David 137, 151, 192, 239

Werner, Elijah 90, 239

West, Nellic 181

West, Stephanic L. 269

West, Susan 175

Westlake, Jeff 89, 129, 210, 287

Westake, Jefr 89.129.210, 287

$118,158,191$

269. 287

Westrick, Julic 210

Wetzel, Dr. Daniel 172

Whecler, Jeremy 210

Whecter, Michelle R. 269

Whipple, Benjamin 270

Whitaker, Justin 40, 41, 56

White, Brian 270
117,270

125,239

Whitmore, John 17

Wickert, Elizabeth

Wiedemann, Emily

90.239

Wiegand, Sarah 90.

Wiersma, Rebekah

76,270

Wiggers, Katy 22

Wiggins, Dr, Robert

169

Wikler, Jeremiah

125,224

239,270

Wilkens, Tricia 84.

92,239

Wilkins, Daniel 210

Willaman, Ryan 210

Willett, JoAnne 72 .

126,270

Williams, Andrew

91, 98, 239

Woters, Julia 44. 270

Womack. Glenda 179

Womack, Mark 177

Wood, Amy 121, 27

Wood, Danicl 211

Wood, Dr. Dwayne 15, 157

Wood, Jennifer 117, 125, 270

Wood, Rachal 270

Wood, Sherric 177

Wood. Stephanic 22

Wood, Steve 177

Woodhams, Anna 74, 211

Woodruff, Kelly 211

Woodstock, Sarah 70, 230

Wooldridge, Jennifer 90, 118. 225

Worth. Heather 93.239

Wortley, Jennifer 119, 23:

Wright, Bethany 73, 225

Wright, David 239

Wright, Gillian 239

Wright, Heidi $43,58,59,81,239$

Wright, Sharon 59,79

Wubbena, Valerie 118,27

Wyse, Joshua

\section{Y}

Yackey, Sara 98, 21

Yahara, James 225

Yalc, Rob 239

Yamarino Marcia 225

Yehnert. Heidi 72,239

Yingling, Adam 118, 126, 128, 270.

274, 285

Yoder, Heidi 239

Yonker, Stephanic 21

Yorgey, Mark 83, 22

Young, Amber K. 270

Young, Andrew 73, 21

Young. Jonathan 211

Young, Ruth 225

\section{Z}

Wilson, Ano 75, 90, 121, 127, 224

Wilson, Jennifer 210

Wilson, Kelly 224

Wilson. Patry $55,83,210$

Winturg, Charissa 44.239

Winburn. Abigail 43, 59, 211

Winey, Steven 179

Winfield, Phillip 99

Winfield, Sherri 270

Winn, Susan 171

Winship, Andrea 77, 239

Winslow, Kevin 169

Wires, Steven 224

Wirrig, Adam 239

Wiseman lacey 211

Witumer Katherine A. 270

Witt. Michal 239

Wolf, Brandon 48

Wolf, David 118,270

Wolfe, James 225

Wolgemurh, Leann 73,118

Zarrilli, Joshus 225

Zarrilli, Sreve

Zavodney, Dr. Lawrence 172,27

Zelenka, David 74, 122, 271

Zemmer, fonathan 235

Zenn, Justin 52, 225

Zeppenfeld, Amy 46, 225

Zeron, Elizabeth 82, 128, 239

Zgrablich, Taira 271

Ziegenfuss, Carric 225

Zierenberg. Timothy 239

Zimmerman, Christic 125,21

Zimmerman, Justin 21

Zimmerman, Katherine 68, 125, 239

Zimmerman, Kristi 121, 27

Zimmerman, Mathew 239

Zitzmann. Christopher 122, 211

Zuerner. Joe 36

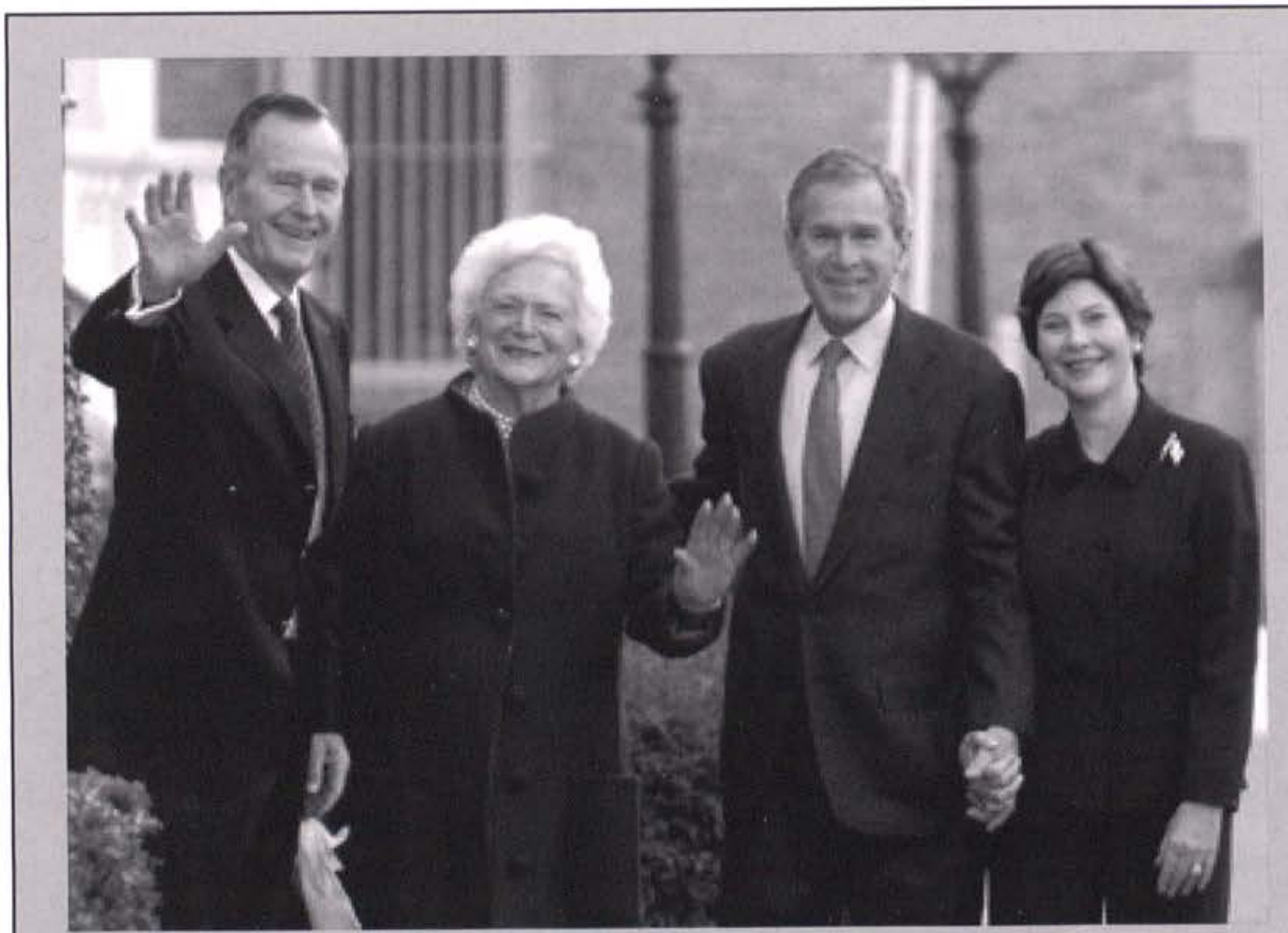

President Bush, second right, and first lady Laura Bush, right, leave Saint John's Church in Washington, Sunday, Jan 27, 2002, with former President George H. W. Bush and former first lady Barbara Bush after attending Sunday service. President Bush will deliver his first State of the Union address on Tuesday. 


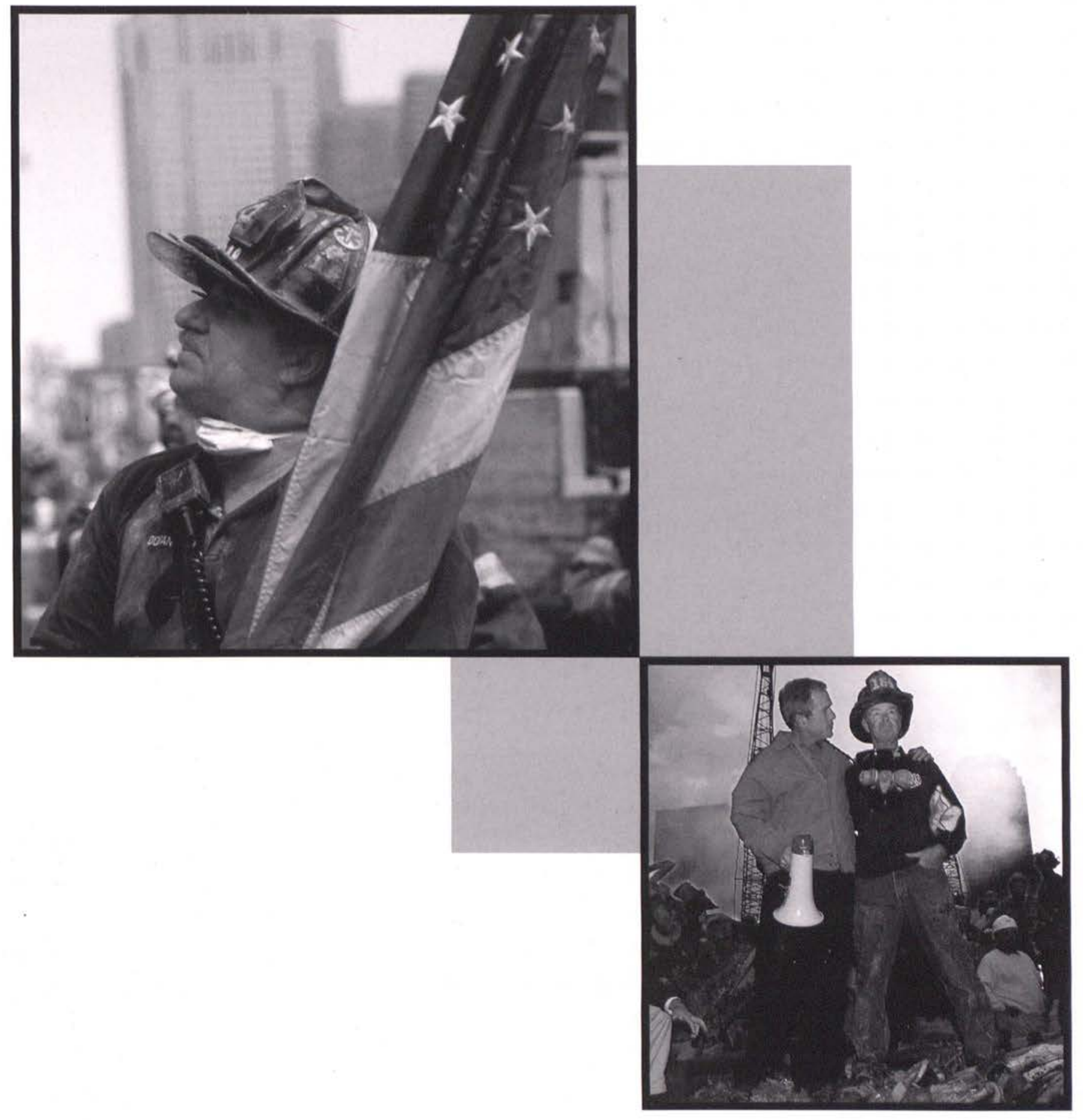

in memorygf 


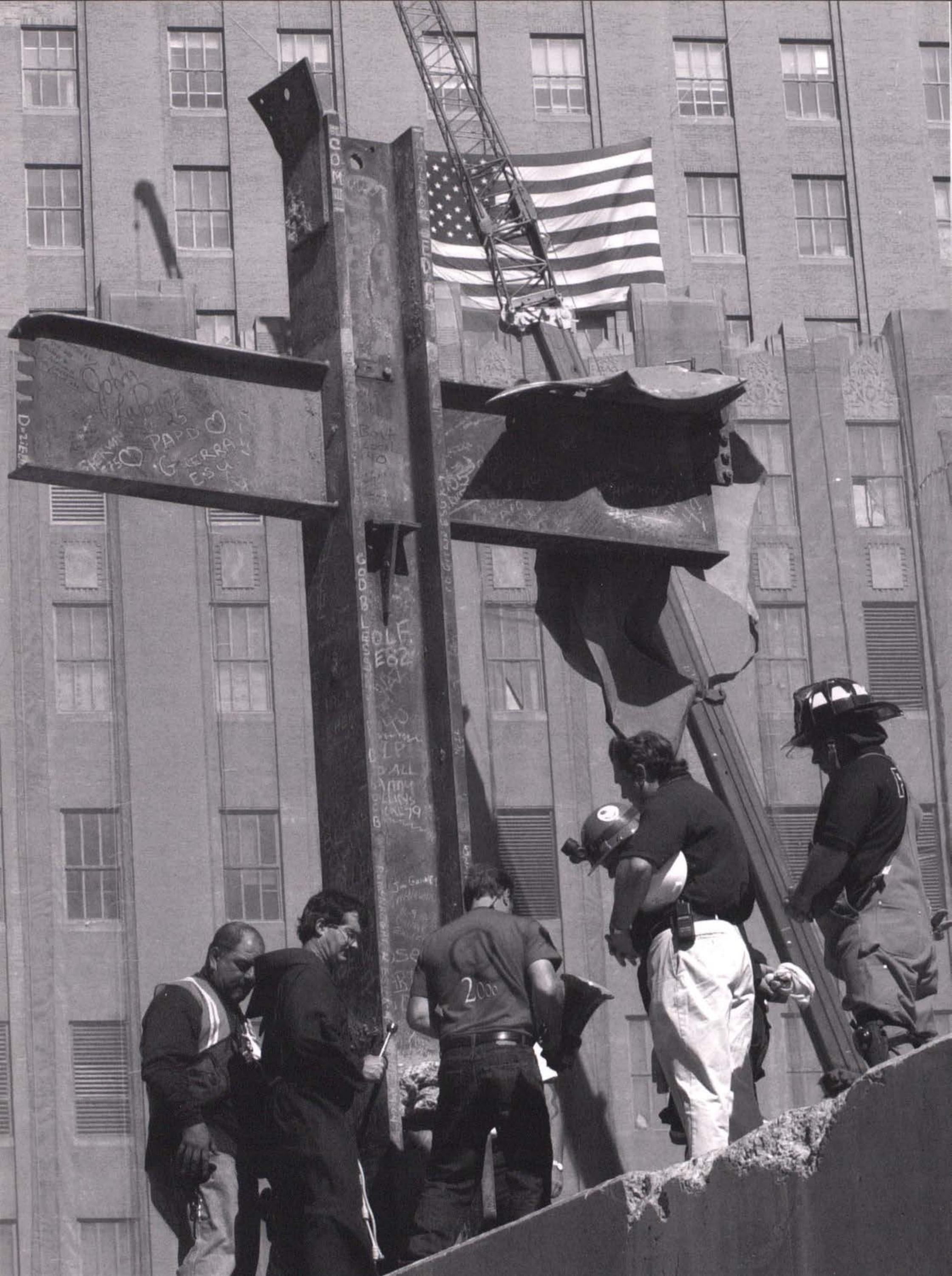




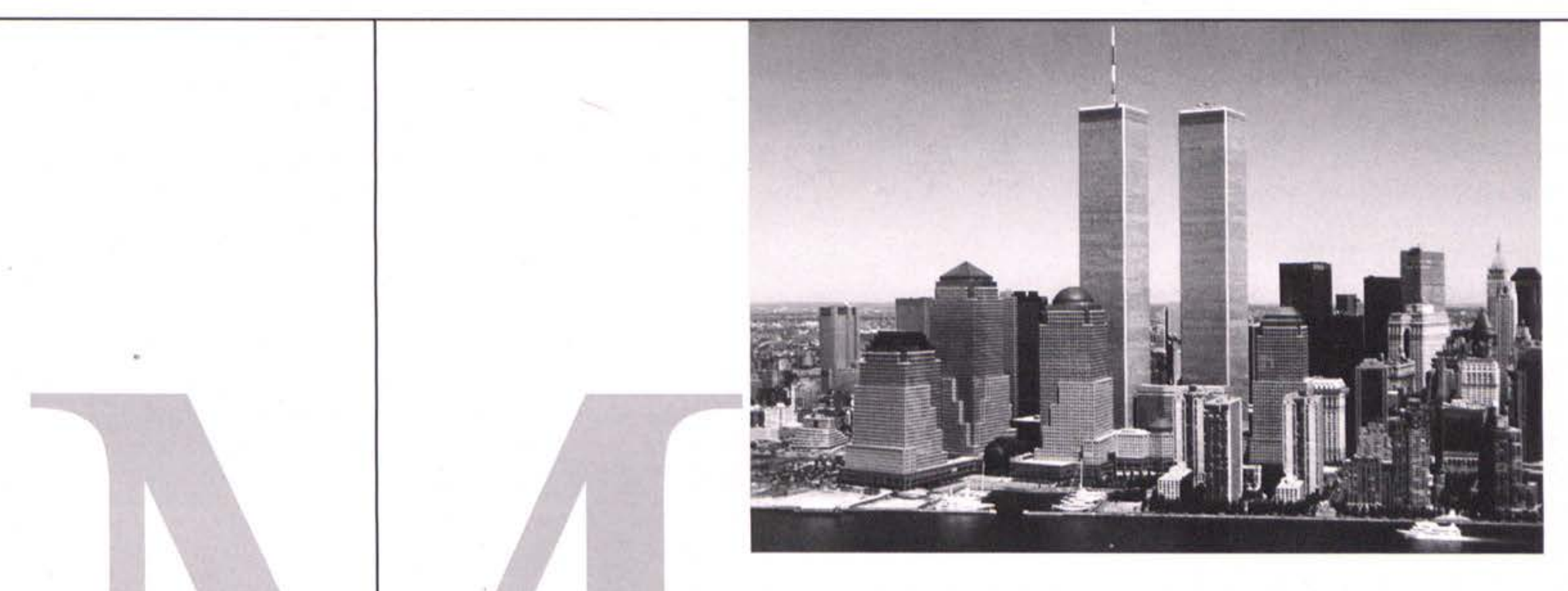

any are calling 2001 "the year when everything changed." In many senses that is true. Never again will Americans feel invulnderable to the attacks of terror and evil. Those of us who can remember December 7 , 1941 can recall the cataclysmic effects the Japanese attack on Pearl Harbor had on our lives and on the relationships we crafted during the war years. Those among us too young for those recollections are experiencing a rebirth of a unified American spirit and, thankfully, a revival of interest in spiritual matters. One must hope and pray that the devastating attacks of September 11 will ultimately result in the same kind of triumph over evil that followed Pearl Harbor and gave rise to the triumph of democracy and freedom over despotism.

We at Cedarville University can point to at least one thing that has not changed since September 11. We steadfastly maintain our focus on the One who is "the same yesterday and today and forever" (Hebrews 13:8). We praise the Lord Jesus Christ for His protection. We praise Him for His love and compassion. And, we praise Him for the good things He has brought our way. 


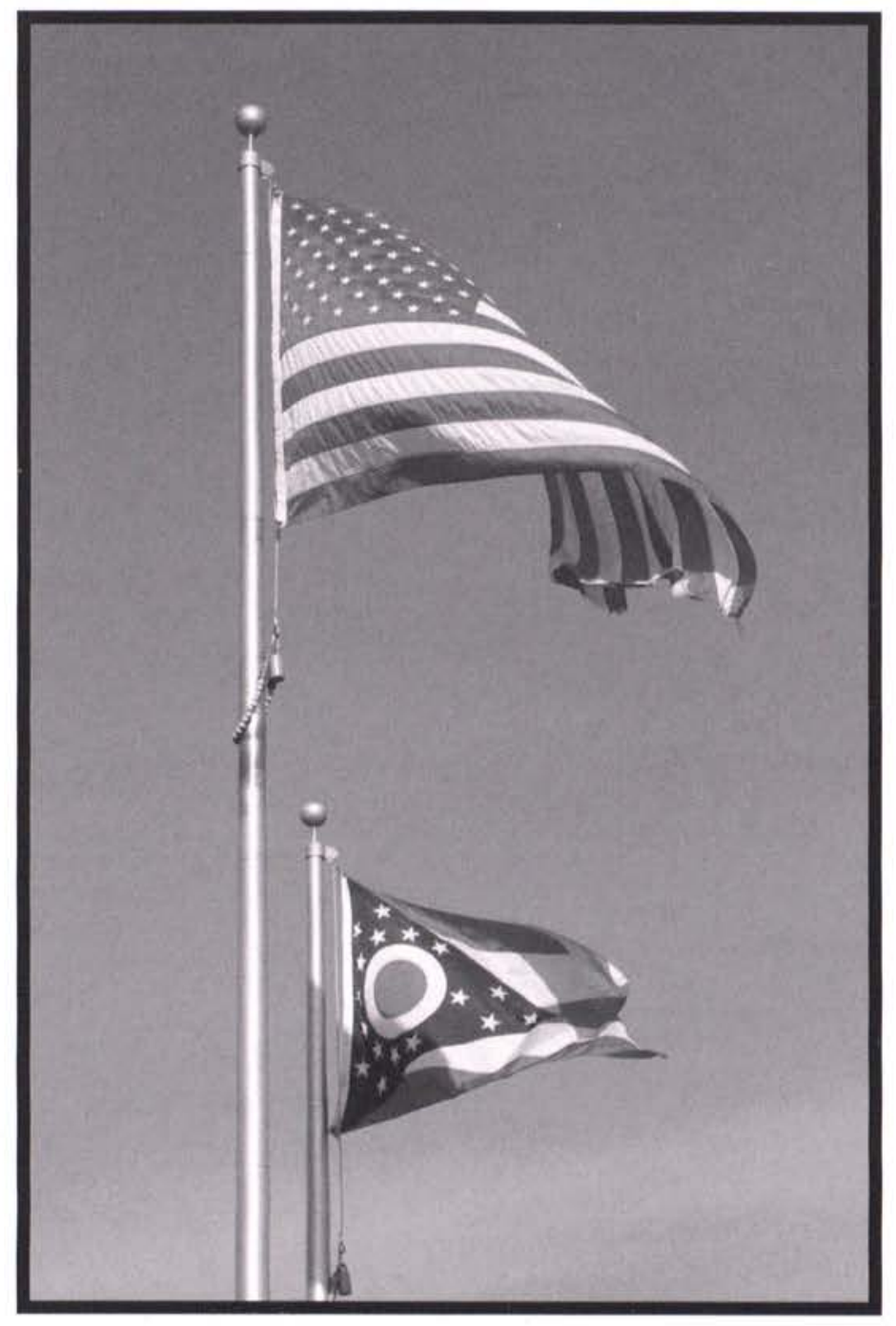







\section{jostens \\ ostens}





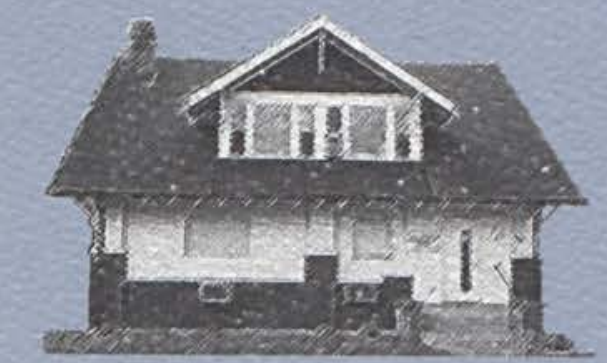

a student publication of Cedarville University Copyright $\odot 2002$ 


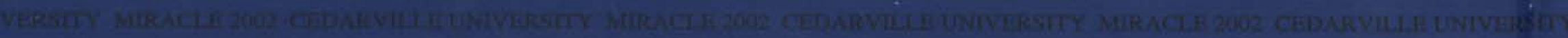

